\title{
Financial Statistics of Major U.S. Publicly Owned Electric Utilities 1992
}

\author{
January 1994
}

\section{Energy Information Administration \\ Office of Coal, Nuclear, Electric and Alternate Fuels \\ U.S. Department of Energy \\ Washington, DC 20585}

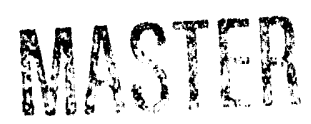

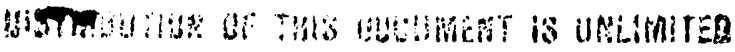




\section{Contacts}

The Financial Statistics of Major U.S. Publicly Owned Electric Utilities is prepared annually by the Survey Management Division; Office of Coal, Nuclear, Elec. tric and Alternate Fuels (CNEAF); Energy Information Administration (EIA); U.S. Department of Energy (DOE).

General information regarding the contents of this publication may be obtained from the National Energy Information Center (202/586-8800). General information about the data appearing in this publication may be obtained from Howard L. Walton (202/254-5500), Director of the Survey Management Division, or Fred Mayes(202/254-5300), Chief of the Renewable and Financial Data Systems and Outreach Branch.

Questions and comments should be referred to Roger L. Sacquety (202/254-5440), Financial Systems Team Leader. Specific information about data contained in the Form ElA-412 may be obtained from Charlene Harris-Russell (202/254-5437). 


\section{Contents}

Page

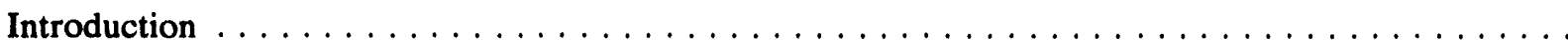

Summary Statistics of Major U.S. Publicly Owned Electric Utilities $\ldots \ldots \ldots \ldots \ldots \ldots \ldots \ldots \ldots$

Detailed Statistics of Major U.S. Publicly Owned Electric Utilities . . . . . . . . . . . . . . . . . . 29

Summary Statistics of U.S. Federal Electric Utilities $\ldots \ldots \ldots \ldots \ldots \ldots \ldots \ldots \ldots \ldots \ldots$

Appendices

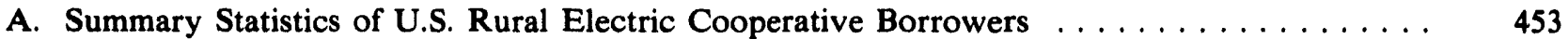

B. Major U.S. Publicly Owned Electric Utility Respondents $\ldots \ldots \ldots \ldots \ldots \ldots \ldots \ldots \ldots$

C. Major U.S. Generator/Nongenerator Respondents by June 30 and December 31 Fiscal Years

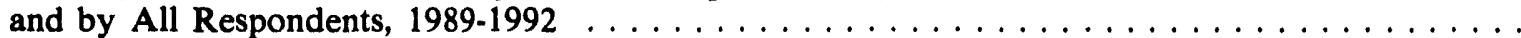

D. Regulation of U.S. Publicly Owned Electric Utilities $\ldots \ldots \ldots \ldots \ldots \ldots \ldots \ldots \ldots$

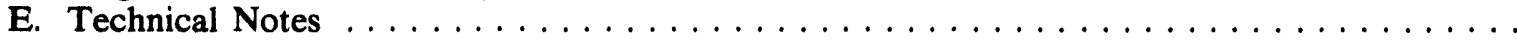




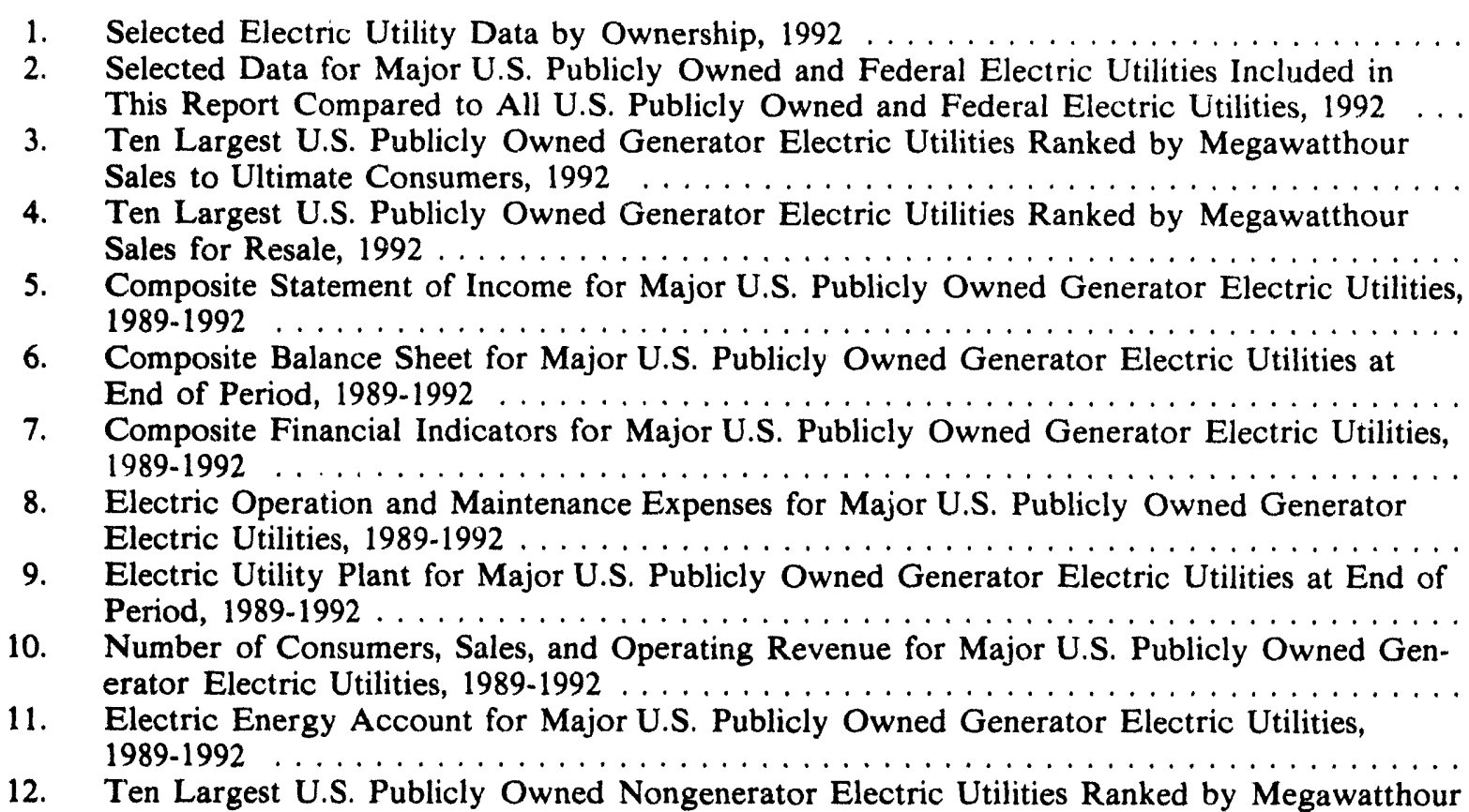

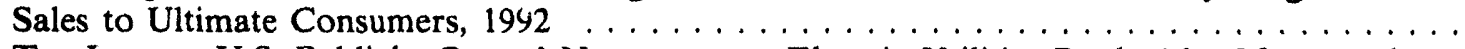

13. Ten Largest U.S. Publicly Owned Nongenerator Electric Utilities Ranked by Megawatthour

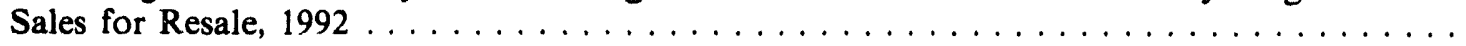

14. Composite Statement of Income for Major U.S. Publicly Owned Nongenerator Electric Util-

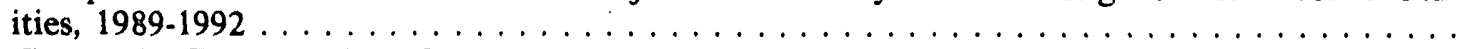

15. Composite Balance Sheet for Major U.S. Publicly Owned Nongenerator Electric Utilities at

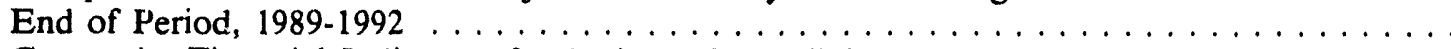

16. Composite Financial Indicators for Major U.S. Publicly Owned Nongenerator Electric Utili-

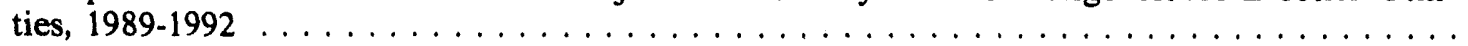

17. Electric Operation and Maintenance Expenses for Major U.S. Publicly Owned Nongenerator

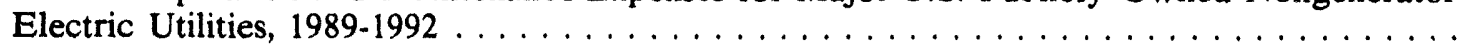

18. Electric Utility Plant for Major U.S. Publicly Owned Nongenerator Electric Utilities at End

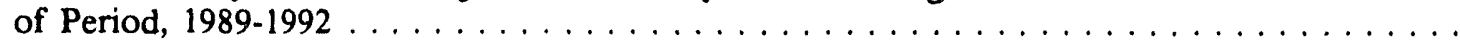

19. Number of Consumers, Sales, and Operating Revenue for Major U.S. Publicly Owned

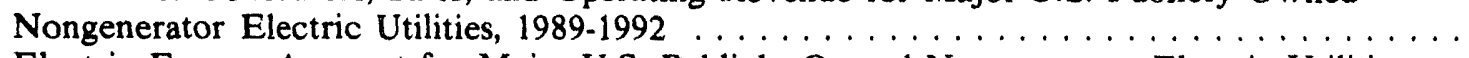

20. Electric Energy Account for Major U.S. Publicly Owned Nongenerator Electric Utilities,

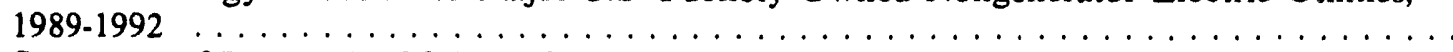

21. Statement of Income by Major U.S. Publicly Owned Electric Utility Within State, $1992 \ldots$

22. Balance Sheet by Major U.S. Publicly Owned Electric Utility Within State at End of Pe-

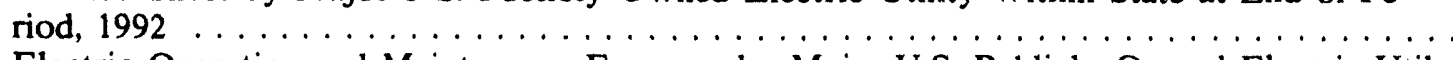

23. Electric Operation and Maintenance Expenses by Major U.S. Publicly Owned Electric Util-

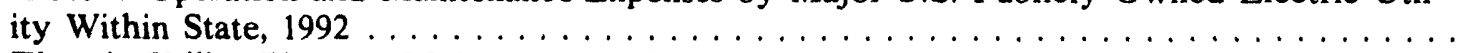

24. Electric Utility Plant by Major U.S. Publicly Owned Electric Utility Within State at End of Period, 1992

25. Number of Consumers, Sales, and Operating Revenue by Major U.S. Publicly Owned Elec-

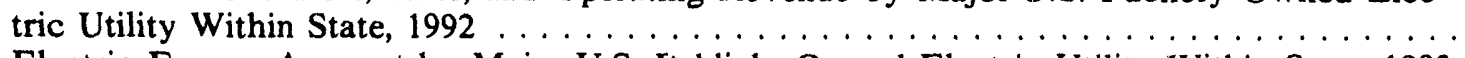

26. Electric Energy Account by Major U.S. P'ublicly Owned Electric Utility Within State, 1992

27. Statement of Income by U.S. Federal Electic Utility, $1992 \ldots \ldots \ldots \ldots \ldots \ldots \ldots \ldots$

28. Balance Sheet by U.S. Federal Electric Utility on September $30,1992 \ldots \ldots \ldots \ldots \ldots$

29. Electric Operation and Maintenance Expenses by U.S. Federal Electric Utility, $1992 \ldots \ldots$

30. Electric Utility Plant by U.S. Federal Electric Utility on September 30, $1992 \ldots \ldots \ldots \ldots$

31. Number of Consumers, Sales, and Operating Revenue by U.S. Federal Electric Utility, 1992

32. Electric Energy Account by U.S. Federal Electric Utility, $1992 \ldots \ldots \ldots \ldots \ldots \ldots \ldots$

A1. Composite Statement of Income for the U.S. Cooperative Borrowers, 1988-1992 . . . . . .

A2. Composite Balance Sheet for the U.S. Cooperative Borrowers on December 31, 1988-1992 
A3. Electric Operation and Maintenance Expenses for the U.S. Cooperative Borrowers, 1988-1992

A4. Number of Consumers, Sales, and Operating Revenue for the U.S. Cooperative Distributor Borrowers, 1988-1992

B1. Major U.S. Publicly Owned Electric Utilities Added to and Deleted from the Form EIA-412, 1989-1992

C1. Ten Largest U.S. Publicly Owned Generator Electric Utilities Ranked by Megawatthour Sales to Ultimate Consumers with Financial Year Ending on June 30, $1992 \ldots \ldots \ldots \ldots \ldots$

C2. Ten Largest U.S. Publicly Owned Generator Electric Utilities Ranked by Megawatthour Sales for Resale with Financial Year Ending on June 30, $1992 \ldots \ldots \ldots \ldots \ldots \ldots \ldots \ldots$

C3. Composite Statement of Income for Major U.S. Publicly Owned Generator Electric Utilities with Financial Year Ending on June 30, 1989-1992 . . . . . . . . . . . . . . . .

C4. Composite Balance Sheet for Major U.S. Publicly Owned Generator Electric Utilities with

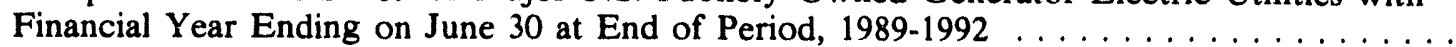

C5. Composite Financial Indicators for Major U.S. Publicly Owned Generator Electric Utilities

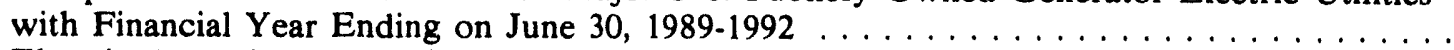

C6. Electric Operation and Maintenance Expenses for Major U.S. Publicly Owned Generator Electric Utilities with Financial Year Ending on June 30, 1989-1992 . . . . . . . . . . . . .

C7. Electric Utility Plant for Major U.S. Publicly Owned Generator Electric Utilities with Financial Year Ending on June 30 at End of Period, 1989-1992

C8. Number of Consumers, Sales, and Operating Revenue for Major U.S. Publicly Owned Generator Electric Utilities with Financial Year Ending on June 30, 1989-1992 . . . . . . . . . .

C9. Electric Energy Account for Major U.S. Publicly Owned Generator Electric Utilities with Financial Year Ending on June $30,1989-1992 \ldots \ldots \ldots \ldots \ldots \ldots \ldots \ldots$

C10. Ten Largest U.S. Publicly Owned Generator Electric Utilities Ranked by Megawatthour Sales to Ultimate Consumers with Financial Year Ending on December 31, 1989-1992 . . . .

C11. Ten Largest U.S. Publicly Owned Generator Electric Utilities Ranked by Megawatthour Sales for Resale with Financial Year Ending on December 31, 1989-1992 . . . . . . . . . . .

C12. Composite Statement of Income for Major U.S. Publicly Owned Generator Electric Utilities with Financial Year Ending on December 31, 1989-1992 . . . . . . . . . . . . . . .

C13. Composite Balance Sheet for Major U.S. Publicly Owned Generator Electric Utilities with Financial Year Ending on December 31 at End of Period, 1989-1992 . . . . . . . . . . .

C14. Composite Financial Indicators for Major U.S. Publicly Owned Generator Electric Utilities with Financial Year Ending on December 31, 1989-1992 . . . . . . . . . . . . . . .

C15. Electric Operation and Maintenance Expenses for Major U.S. Publicly Owned Generator Electric Utilities with Financial Year Ending on December 31, 1989-1992 . . . . . . . . .

C16. Electric Utility Plant for Major U.S. Publicly Owned Generator Electric Utilities with Financial Year Ending on December 31 at End of Period, 1989-1992 . . . . . . . . . . . . .

C17. Number of Consumers, Sales, and Operating Revenue for Major U.S. Publicly Owned Generator Electric Utilities with Financial Year Ending on December 31, 1989-1992 . . . . . . .

C18. Electric Energy Account for Major U.S. Publicly Owned Generator Electric Utilities with

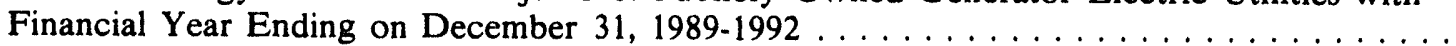

C19. Ten Largest U.S. Publicly Owned Nongenerator Electric Utilities Ranked by Megawatthour Sales to Ultimate Consumers with Financial Year Ending on June 30, $1992 \ldots \ldots \ldots \ldots \ldots$. .

C20. U.S. Publicly Owned Nongenerator Electric Utilities Ranked by Megawatthour Sales for Resale with Financial Year Ending on June 30, $1992 \ldots \ldots \ldots \ldots \ldots \ldots \ldots \ldots \ldots \ldots$

C21. Composite Statement of Income for Major U.S. Publicly Owned Nongenerator Electric Utilities with Financial Year Ending on June 30, 1989-1992 . . . . . . . . . . . . . . . .

C22. Composite Balance Sheet for Major U.S. Publicly Owned Nongenerator Electric Utilities with Financial Year Ending on June 30 at End of Period, 1989-1992 . . . . . . . . . . .

C23. Composite Financial Indicators for Major U.S. Publicly Owned Nongenerator Electric Utilities with Financial Year Ending on June $30,1989-1992 \ldots \ldots \ldots \ldots \ldots \ldots \ldots \ldots$

C24. Electric Operation and Maintenance Expenses for Major U.S. Publicly Owned Nongenerator Electric Utilities with Financial Year Ending on June 30, 1989-1992 . . . . . . . . . . . . .

C25. Electric Utility Plant for Major U.S. Publicly Owned Nongenerator Electric Utilities with

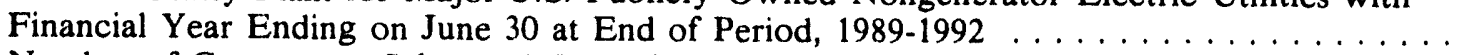

C26. Number of Consumers, Sales, and Operating Revenue for Major U.S. Publicly Owned Nongenerator Electric Utilities with Financial Year Ending on June 30, 1989-1992 . . . . . .

C27. Electric Energy Account for Major U.S. Publicly Owned Nongenerator Electric Utilities with Financial Year Ending on June 30, 1989-1992

C28. Ten Largest U.S. Publicly Owned Nongenerator Electric Utilities Ranked by Megawatthour Sales to Ultimate Consumers with Financial Year Ending on December 31, $1992 \ldots \ldots \ldots$. 
C29. Ten Largest U.S. Publicly Owned Nongenerator Electric Utilities Ranked by Megawatthour Sales for Resale with Financial Year Ending on December 31, 1992 . . . . . . . . . . . .

C30. Composite Statement of Income for Major U.S. Publicly Owned Nongenerator Electric Util-

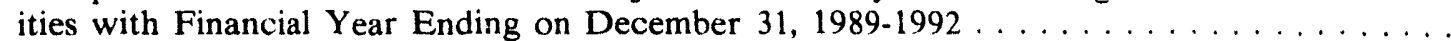

C31. Composite Balance Sheet for Major U.S. Publicly Owned Nongenerator Electric Utilities with Financial Year Ending on December 31 at End of Period, 1989-1992 . . . . . . . . . .

C32. Composite Financial Indicators for Major U.S. Publicly Owned Nongenerator Electric Utili-

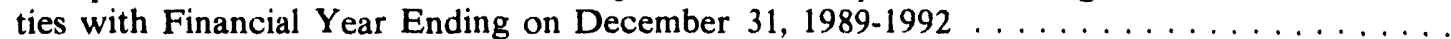

C33. Electric Operation and Maintenance Expenses for Major U.S. Publicly Owned Nongenerator Electric Utilities with Financial Year Ending on December 31, 1992 . . . . . . . . . . . .

C34. Electric Utility Plant for Major U.S. Publicly Owned Nongenerator Electric Utilities with Financial Year Ending on December 31 at End of Period, 1989-1992 . . . . . . . . . . . .

C35. Number of Consumers, Sales, and Operating Revenue for Major U.S. Publicly Owned Nongenerator Electric Utilities with Financial Year Ending on December 31, 1989-1992 ...

C36. Electric Energy Account for Major U.S. Publicly Owned Nongenerator Electric Utilities with Financial Year Ending on December 31, 1989-1992 . . . . . . . . . . . . . .

C37. Twenty Largest U.S. Publicly Owned Electric Utilities Ranked by Megawatthour Sales to Ultimate Consumers for All Respondents, $1992 \ldots \ldots \ldots \ldots \ldots \ldots \ldots \ldots$

C38. Twenty Largest U.S. Publicly Owned Electric Utilities Ranked by Megawatthour Sales for Resale for All Respondents, $1992 \ldots \ldots \ldots \ldots \ldots \ldots \ldots \ldots$

C39. Twenty Largest U.S. Publicly Owned Electric Utilities Ranked by Electric Utility Revenues for All Respondents, $1992 \ldots \ldots \ldots \ldots \ldots \ldots \ldots \ldots \ldots$

C40. Twenty Largest U.S. Publicly Owned Electric Utilities Ranked by Purchase Power Ex-

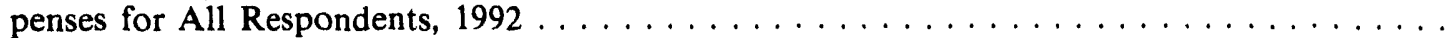

C41. Twenty Largest U.S. Publicly Owned Electric Utilities Ranked by Electric Utility Plant for

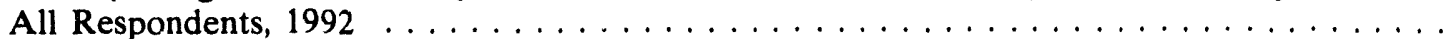

C42. Twenty Largest U.S. Publicly Owned Electric Utilities Ranked by Construction Work in Progress for All Respondents, $1992 \ldots \ldots \ldots \ldots \ldots \ldots \ldots \ldots$

C43. Composite Statement of Income for Major U.S. Publicly Owned Electric Utilities for All

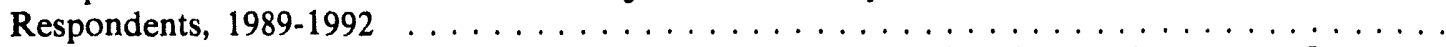

C44. Composite Balance Sheet for Major U.S. Publicly Owned Electric Utilities for All Respon-

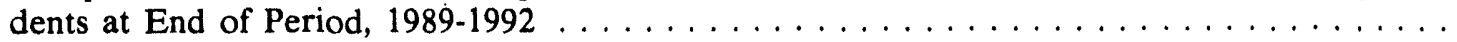

C45. Composite Financia: Indicators for Major U.S. Publicly Owned Electric Utilities for All Re-

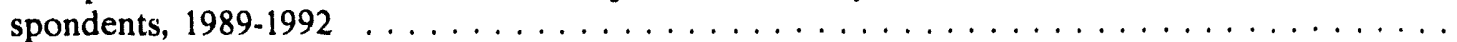

C46. Electric Operation and Maintenance Expenses for Major U.S. Publicly Owned Electric Utilities for All Respondents, $1989-1992 \ldots \ldots \ldots \ldots \ldots \ldots \ldots \ldots \ldots \ldots$

C4.7. Electric Utility Plant for Major U.S. Publicly Owned Electric Utilities for All Respondents

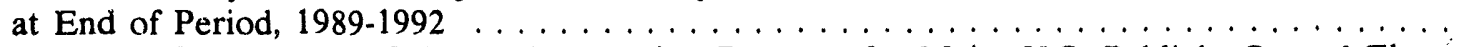

C48. Number of Consumers, Sales, and Operating Revenue for Major U.S. Publicly Owned Electric Utilities for All Respondents, 1989-1992 . . . . . . . . . . . . . . . . . . . .

C49. Electric Energy Account for Major U.S. Publicly Owned Electric Utilities for All Respondents, $1989-1992 \ldots \ldots \ldots \ldots \ldots \ldots \ldots \ldots \ldots \ldots \ldots \ldots \ldots \ldots$

D1. State Agency Authority to Regulate Rate of U.S. Publicly Owned Electric Utilities, 1992 . .

\section{Illustrations}

1. Investment in Electric Utility Plant per Dollar of Revenue, 1989-1992 . . . . . . . . . . . 


\section{Introduction}

\section{About This Publlcation}

The 1992 edition of the Financial Statistics of Major U.S. Publicly Owned Electric Utilities publication presents 4 years (1989 through 1992) of summary financial data and current year detailed financial data on the major publicly owned electric utilities. The objective of the publication is to provide Federal and State governments, industry, and the general public with current and historical data that can be used for policymaking and decisionmaking purposes related to publicly owned electric utility issues.

Generator (Tables 3 through 11) and nongenerator (Tables 12 through 20) summaries are presented in this publication. Four years of summary financial data are provided (Tables 5 through 11 and 14 through 20). Summaries of generators for fiscal years ending June 30 and December 31, nongenerators for fiscal years ending June 30 and December 31, and summaries of all respondents are provided in Appendix C.

The composite tables present aggregates of income statement and balance sheet data, as well as financial indicators. Composite tables also display electric operation and maintenance expenses, electric utility plant, number of consumers, sales of electricity, and operating revenue, and electric energy account data.

The primary source of publicly owned financial data is the Form EIA-412, "Annual Report of Public Electric Utilities." Public electric utilities file this survey on a fiscal year, rather than a calendar year basis, in conformance with their recordkeeping practices. In previous editions of this publication, data were aggregated by the two most commonly reported fiscal years, June 30 and December 31 . This omitted approximately 20 percent of the respondents who operate on fiscal years ending in other months.

Accordingly, the EIA undertook a review of the Form EIA-412 submissions to determine if alternative classifications of publicly owned electric utilities would permit the inclusion of all respondents. The study also focused on understanding the differences in financial characteristics between electric utilities whose fiscal years end June 30 and December 31 . The review indicated that financial indicators differ most according to whether or not a publicly owned electric utility generates electricity. Therefore, the main body of the re- port provides summary information in generator/ nongenerator classifications.

\section{History}

As the result of the Federal Power Act of 1935, the Federal Power Commission (FPC), which was the predecessor to the Federal Energy Regulatory Commission (FERC), began collecting financial statistics for investor-owned electric utilities in 1938. In 1946, the FPC started collecting financial statistics on publicly owned electric utilities. The Energy Information Administration (EIA) upon its establishment in October 1977 took over the responsibility of gathering and publishing the financial statistics from the FERC. In 1982, the EIA combined the contents of two publications containing financial statistics of investor-owned (private) and publicly owned electric utilities into a single volume, the Financial Statistics of Selected Electric Utilities. The 1989 edition reverted to the two separate publications, the Financial Statistics of Selected Investor-Owned Electric Utilities and the Financial Statistics of Selected Publicly Owned Electric Utilities. In 1991, the publication titles were changed to the Financial Statistics of Major Investor-Owned Electric Utilities and the Financial Statistics of Major Publicly Owned Electric Utilities. In 1992, the publication titles were further changed to the Financial Statistics of Major U.S. Investor-Owned Electric Utilities and the Financial Statistics of Major U.S. Publicly Owned Electric Utilities.

Currently, the Financial Statistics of Major U.S. Publicly Owned Electric Utilities publication is prepared by the Renewable and Financial Data Systems and Outreach Branch; Survey Management Division; Office of Coal, Nuclear, Electric and Alternate Fuels; EIA; U.S. Department of Energy. The format was designed to be used by a variety of private, electric power industry, and government users. The publication contents and format have evolved over the years to better serve the needs and requirements of the targeted audience.

\section{About The Industry}

The U.S. electric power industry is a combination of electric utilities (investor-owned, publicly owned, Federal, and cooperatives) and nonutility power producers. Investor-owned electric utilities account for over three-fourths of the sales of electricity and revenue in 
the industry. Historically, the investor-owned electric utilities serve the large consolidated markets and operate in all States except Nebraska. Hawaii is the only State in which all electricity is supplied by investorowned electric utilities.

Publicly owned electric utilities are nonprofit operations that have been established to serve their communities and nearby consumers at cost. The publicly owned electric utilities in this publication include municipals, public power districts, State authorities, irrigation districts, and other State organizations. Publicly owned electric utilities are exempt from taxes and can obtain new financing at lower rates than investorowned electric utilities.

The publicly owned electric utilities are divided into generators and nongenerators (In contrast, virtually all investor-owned electric utilities own and operate generating capacity). Generators are those electric utilities that own/operate generating capacity to supply some or all of their consumer needs. However, some generators supplement their demand by purchasing power. The nongenerators do not produce electric power for end use and rely exclusively on purchasing power. Their primary function is to transmit and distribute electricity to their consumers. The nongenerators comprise over half of the total number of major publicly owned electric utilities.

Federal electric utilities are also presented in this publication and include the five Federal power marketing administrations, the Tennessee Valley Authority, the U.S. Army Corps of Engineers, and the U.S. Bureau of Indian Affairs. The five Federal power marketing administrations are the Alaska Power Administration, the Bonneville Power Administration, the Southeastern Power Administration, the Southwestern Power Administration, and the Western Area Power Administration. Electric power produced by Federal electric utilities is generated primarily by water resources. This power, which is not produced for profit, is primarily wholesaled to other electric utilities rather than being distributed to ultimate consumers. As required by law, publicly owned and cooperative electric utilities are given preference in the purchase of this less expensive power produced by the Federal electric utilities.

Cooperative electric utilities are owned by their members and are established to provide electricity to those members. The Rural Electrification Administration, U.S. Department of Agriculture, was established under the Rural Electrification Act of 1936 with the purpose to extend electric service to small rural communities (usually under 1,500 consumers) and farms where it was more expensive to provide service. The National Rural Utilities Cooperative Finance Corporation, the Federal Financing Bank, and the Bank for Cooperatives are the most important sources of debt financing for cooperatives . Cooperative borrowers (916 of 943 total cooperatives) currently operate in $47 \mathrm{States}$. Financial data for the cooperative borrowers are found in the Statistical Report, Rural Electric Borrowers published by the Rural Electrification Administration of the U.S. Department of Agriculture. Summary tables for the cooperative borrowers are provided in Appen$\operatorname{dix}$ A.

\section{Data Users}

The Financial Statistics of Major U.S. Publicly Owned Electric Utilities pubiication provides information about the financial results from operations of publicly owned electric utilities for use by government, industry, electric utilities, financial organizations and educational institutions in energy planning. In the private sector, the readers of this publication are researchers and analysts associated with the financial markets, the policymaking and decisionmaking members of electric utility companies, and economic development organizations. Other organizations that may be interested in the data presented in this publication include manufacturers of electric power equipment and marketing organizations. In the public sector, the readers of this publication include analysts, researchers, statisticians, and other professionals engaged in regulatory, policy, and program areas. These individuals are generally associated with the Congress, other legislative bodies, State public utility commissions, universities, and national strategic planning organizations.

\section{Coverage of Sources}

Publicly owned electric utilities are required to submit the Form EIA-412 when the generation, transmission, or distribution of electricity, for the two previous years, results in one of the following:

- 120,000 megawatthours of sales to ultimate consumers

- 120,000 megawatthours of sales for resale.

These criteria are based on data reported on the Form EIA-861, "Annual Electric Utility Report." This survey is submitted by all electric utilities in the United States, the U.S. territories, and Puerto Rico. Appendix B contains a list of the major publicly owned electric utilities that submitted Form EIA-412 data for 1992.

Many of the publicly owned electric utilities are selfregulated while some fall under the jurisdiction of State public utility commissions as shown in Appendix D. Because of the absence of required reporting to a specific regulatory body, the accounting practices and policies of publicly owned electric utilities vary considerably. Many use the FERC Uniform System of Accounts or variations of this and other accounting systems. The composite statistics provided in this publication must be viewed with an appropriate degree of caution 
The Form EIA-412 is used to collect detailed annual accounting, financial, and other operating characteristics of publicly owned electric utilities for publication in EIA reports. In 1992, 483 major publicly owned electric utilities submitted data to the EIA. Although calender year reporting of data is preferred, electric utilities are given the option of reporting data on a fiscal year basis. Thị option is permitted in order to minimize respondent burden in preparing the data. When reporting by fiscal year, electric utilities must report operational data for a 12-month period and show consistency in fiscal periods and accounting practices.

\section{Industry Profile}

Selected electric utility data for 1992 are compiled from the Form EIA-861 for the total universe of electric utilities. In 1992, there were 3,232 investor-owned, publicly owned, Federal, and cooperative electric utilities (Table 1).
Key facts concerning sales and revenues in 1992 are as follows:

- The 262 investor-owned electric utilities (8.1 percent of all electric utilities) accounted for 79.1 percent of all revenues from sales of electricity to ultimate consumers and 43.6 percent of all revenues from sales for resale.

- The 2,017 publicly owned electric utilities (62.4 percent of all electric utilities) accounted for 12.6 percent of all revenues from sales to ultimate consumers and 18.1 percent of all revenues from sales for resale.

- The 10 Federal electric utilities accounted for 0.7 percent of all revenues from sales to ultimate consumers and 15.0 percent of all revenues from sales for resale.

- The 943 cooperative electric utilities (29.2 percent of all electric utilities) accounted for 7.7 percent of all revenues from sales to ultimate consumers and 23.3 percent of all revenues from sales for resale.

\section{Table 1. Selected Electric Utility Data by Ownership, 1992}

\begin{tabular}{|c|c|c|c|c|c|}
\hline \multirow[b]{2}{*}{ Item } & \multicolumn{5}{|c|}{ Type of Electric Utility } \\
\hline & Investor-Owned & Publicly Owned & Federal & Cooperative & Total' \\
\hline 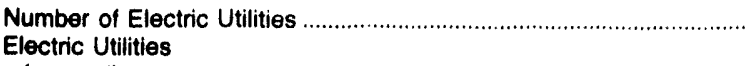 & 262 & 2,017 & 10 & 943 & 3,232 \\
\hline $\begin{array}{l}\text { (percent) } \\
\text { Revenues from Sales to Ultimate Consumers }\end{array}$ & 8.1 & 62.4 & $*$ & 29.2 & 100.0 \\
\hline $\begin{array}{l}\text { (ithousand dollars) } \\
\text { Revenues from Sales to Ultimate Consumers }\end{array}$ & $149,016,317$ & $23,726,654$ & $1,275,948$ & $14,461,665$ & $188,480,584$ \\
\hline $\begin{array}{l}\text { (percent) } \\
\text { Sales of Electricity to Ultimate Consumers }\end{array}$ & 79.1 & 12.6 & .7 & 7.7 & 100.0 \\
\hline $\begin{array}{l}\text { (thousand megawatthours) } \\
\text { Sales of Electricity to Ultimate Consumers }\end{array}$ & $2,112,229$ & 395,387 & 48,768 & 206,939 & $2,763,324$ \\
\hline $\begin{array}{l}\text { (percent) } \\
\text { Revenues from Sales for Resale }\end{array}$ & 76.4 & 14.3 & 1.8 & 7.5 & 100.0 \\
\hline $\begin{array}{l}\text { (thousand dollars) } \\
\text { Revenues from Sales for Resale }\end{array}$ & $18,034,787$ & $7,513,708$ & $6,219,483$ & $9,636,225$ & $41,404,203$ \\
\hline $\begin{array}{l}\text { (percent) } \\
\text { Sales of Electricity Available for Resale }\end{array}$ & 43.6 & 18.1 & 15.0 & 23.3 & 100.0 \\
\hline $\begin{array}{l}\text { (thousand megawatthours) } \\
\text { Sales of Electricity Available for Resale }\end{array}$ & 505,220 & 192,823 & 186,129 & 235,775 & $1,119,948$ \\
\hline 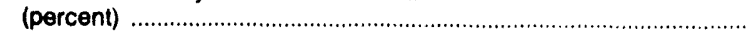 & 45.1 & 17.2 & 16.6 & 21.1 & 100.0 \\
\hline
\end{tabular}

-Value less than 0.5 percent.

Includes only those electric utilities in the United States and the District of Columbia. Note: Totals may not equal sum of components because of independent rounding.

Source: Energy Information Administration, Form ElA-861. "Annual Electric Utility Report." Data are based on calendar year submissions. 
In 1992, the 483 major publicly owned electric utilities in this publication accounted for 87.4 percent of the revenues from sales to ultimate consumers and 99.5 percent of the revenues from sales for resale of all publicly owned electric utilities (Table 2). The eight Federal electric utilities in this publication cover the entire Federal segment.

This publication contains summary and detailed data for 483 major publicly owed electric utilities (Tables 3 through 26). Also, included are summary and detailed data for the eight Federal electric utilities (Tables 27 through 32).

Appendix A tables contain 5 years of summary statistics on U.S. rural electric cooperative borrowers (Tables A1 through A4).

Appendix B contains a list of the major U.S publicly owned electric utility respondents. The major U.S. publicly owned electric utilities added and deleted for
1989 through 1992 are listed (Table B1). The name, State, financial reporting date, and generating status of the respondents are provided (Table B2).

Appendix C contains summary statistics for generating and nongenerating major U.S. publicly owned electric utilities for the fiscal year periods ending June 30 and December 31, as well as for all respondents (Tables C1 through C49).

Appendix D contains a list of the State agencies which have regulatory oversight of publicly owned electric utilities.

Appendix E contains all Technical Notes for the publication. The key sections are Sources of Data, Quality of Data, Formulas and Calculations, and General Information.

The Glossary defines common terms used in the publication.

\section{Table 2. Selected Data for Major U.S. Publicly Owned and Federal Electric Utillties Included in This Report Compared to All U.S. Publicly Owned and Federal Electric Utilities, 1992}

\begin{tabular}{|c|c|c|}
\hline Item & Publicly Owned & Federal' \\
\hline $\begin{array}{l}\text { Number of Electric Utilities in This Report } \\
\text { Share of Electric Utilities Within Ownership Class }\end{array}$ & 483 & 8 \\
\hline $\begin{array}{l}\text { (percent) } \\
\text { Revenues from Sales to Ultimate Consumers }\end{array}$ & 24.0 & 80.0 \\
\hline (thousand dollars) & $20,747,145$ & $1,275,948$ \\
\hline $\begin{array}{l}\text { Share of Pevenues from Sales to Ultimate Consumers } \\
\text { (percent) }\end{array}$ & 87.4 & 100.0 \\
\hline $\begin{array}{l}\text { Sales of Electricity to Uitimate Consumers } \\
\text { (thousand megawatthours) }\end{array}$ & 349,303 & 48,768 \\
\hline $\begin{array}{l}\text { Share of Sales of Electricity to Ultimate Consumers } \\
\text { (percent) }\end{array}$ & 88.3 & 100.0 \\
\hline $\begin{array}{l}\text { Revenues from Sales for Resale } \\
\text { (thousand dollars) }\end{array}$ & $7,479,049$ & $6,219,483$ \\
\hline $\begin{array}{l}\text { Share of Revenues from Sales for Resale } \\
\text { (percent) } \\
\text { Sales of Electricity Available for Resale }\end{array}$ & 99.5 & 100.0 \\
\hline $\begin{array}{l}\text { Sales of Electricity Available for Hesale } \\
\text { (thousand megawatthours) }\end{array}$ & 191,766 & 186,129 \\
\hline $\begin{array}{l}\text { Share of Sales of Electricity Available for Resale } \\
\text { (percent) }\end{array}$ & 99.5 & 100.0 \\
\hline
\end{tabular}

1 The Department of Interior-U.S. Bureau of Reclamation and the Department of State-International Water and Boundary Commission do not file the Form ElA-412; however, their energy is marketed and reported by the Bonneville Power Administration, the Southeastern Power Administration, the South. western Power Administration, and the Western Area Power Administration.

Source: Energy Information Administration, Form ElA-861, "Annual Electric Utility Report." Data are based on calendar year submissions. 


\section{Summary Statistics of Major U.S. Publicly Owned Electric Utilities}

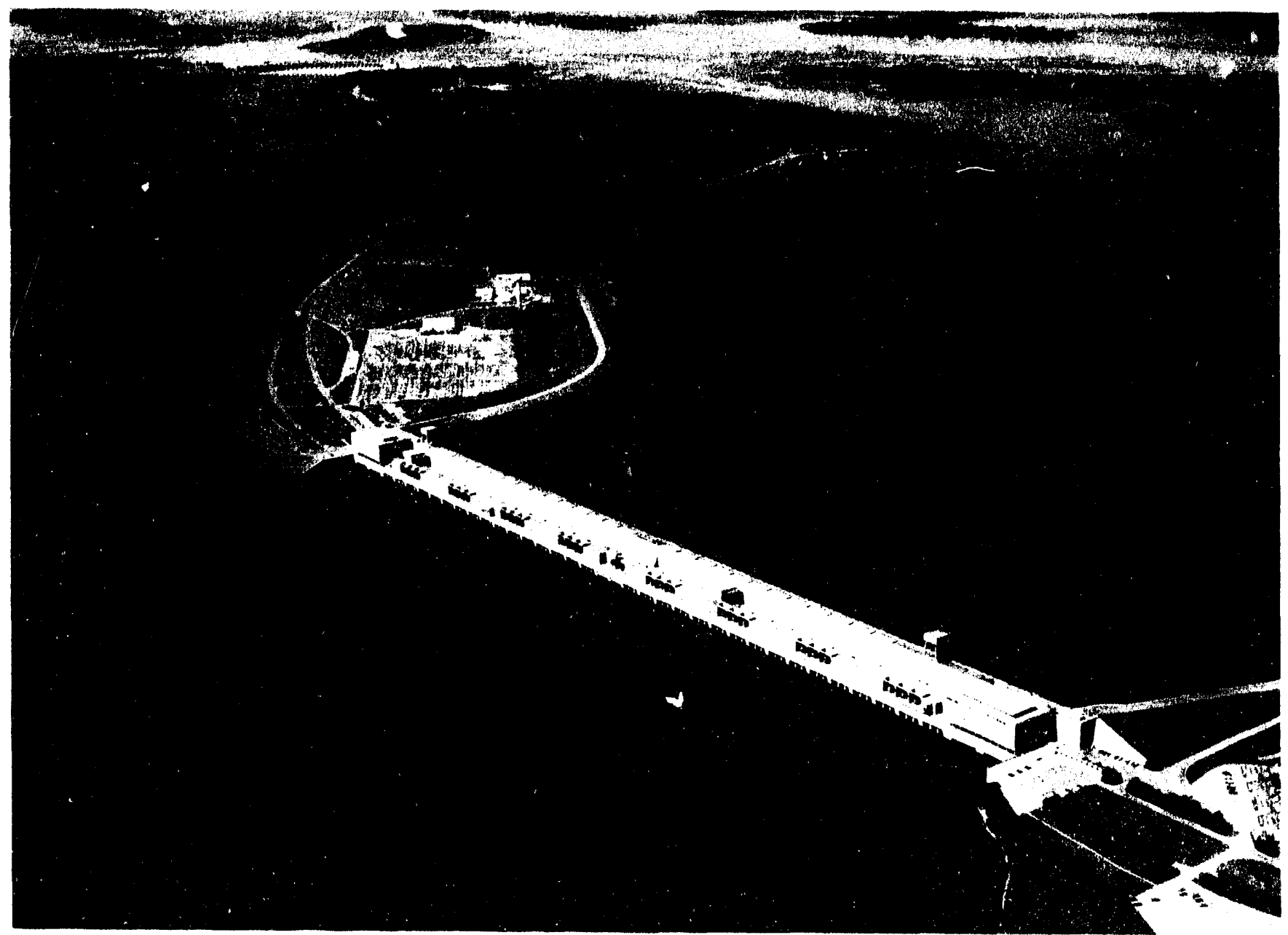

The Moses Power Dam, a hydroelectric plant, is located in St. Lawrence County, New York, and owned by the Power Authority of the State of New York. 


\section{Factors Affecting Major Publicly Owned Electric Utilities During 1992}

\section{Overview}

Summary financial statistics are provided for major publicly owned electric utilities. These statistics include 483 electric utilities for 1992, 470 electric utilities for 1991, 467 electric utilities for 1990, and 454 electric utilities for 1989.

Economic Context. The year 1992 can be characterized as one of very slow recovery from the recession of 1990 through 1991 . While the recession was relatively s..ort and shallow, compared with previous post-war recessions, nonfarm payroll employment remained stagnant for over a year following the trough, and the unemployment rate peaked more than a year after the decline in real gross domestic product (GDP) had ended. Real GDP grew at only 2.1 percent for the year, but the econony did pick up during the second half of 1992, with real GDP growing over 3.2 percent and unemployment falling. The upward trend, although slow, tended to boost electricity sales in 1992.

Weather. Countering the economy's positive influence on electric utility sales, weather worked against the industry in 1992. The year began with heating degree days being lower than normal and lower than first quarter 1991. The summer cooling season, as measured by annual cooling degree days, was almost 25.8 percent lower in 1992 than in 1991; however, during the fourth quarter, the weather turned around for the industry. By year's end, heating degree days were up slightly over last year (3.7 percent) due to a colder fourth quarter than occurred in 1991. In spite of the very mild summer, electric utility sales to ultimate consumers overall were up 1.3 percent over last year's sales. Residential sales, however, declined 0.7 percent in response to the mild weather.

Both the weather and the economic impacts on electric utilities were uneven regionally. Weather by its nature does not impact electric utilities uniformly. State unemployment rates indicated that the 1990 through 1991 recession and slow recovery affected States differently. Illinois and Michigan experienced high unemployment due to restructuring in the automobile industry. California and the New England States were hurt due to defense industry cutbacks. California, the Northeast, and Florida also experienced problems due to overbuilding in commercial real estate and restructuring of the finance and insurance industries. As a result, indi- vidual electric utility and regional electric utility sales results varied considerably from the electric industry aggregate.

Debt Refinancing. The major financial event of the year for the major publicly owned electric utilities was the wave of refinancing brought about by the continuing decline in interest rates. The refinancings were what drove an 84.0-percent increase in electric power bond issues in 1992 over 1991. As summarized by the Bond Buyers 1993 Yearbook:'

- Electric power bond issues in 1992 were 84.0 percent higher than in 1991 ( $\$ 16.5$ billion versus $\$ 9.0$ billion $)^{2}$ and were the highest in the public electric power arena since 1986.

- Advance refinancing was $\$ 13.1$ billion of the $\$ 16.5$ billion total. This has accounted for the majority of electric power bond issues since 1985.

- New money volume actually fell 9.0 percent in 1992 from 1991, going from $\$ 3.8$ billion in 1991 to $\$ 3.5$ in 1992 .

- Five states accounted for half of the volume of electric power bond issues sold in 1992. California ( $\$ 2.4$ billion), Texas ( $\$ 1.9$ billion), Florida ( $\$ 1.3$ billion), Washington ( $\$ 1.3$ billion), and North Carolina ( $\$ 1.2$ billion).

The largest bond issuer was the North Carolina Municipal Power Agency with a single bond issue of $\$ 1.2$ billion in refinancing. This volume was far ahead of the second and third largest bond issuers, the Salt River Agricultural Improvement and Power District (AZ) with two bond issues totaling $\$ 0.8$ billion, and the Massachusetts Municipal Wholesale Electric Company with three bond issues totaling $\$ 0.7$ billion.

\section{Generator Electric Utilities versus Nongenerator Electric Utilities}

The next section of the publication discusses generator and nongenerator electric utilities separately. The two groups are distinct because their financial profiles are significantly different, and aggregating generators and nongenerators obscure fundamental financial and operational differences between the two groups. For example, significant plant production expenses would not exist for nongenerator electric utilities. Existing production plant expenses are mainly maintainance costs for standby plants. It should be noted that both generator and nongenerator electric utilities report according to varying fiscal years.

\footnotetext{
'Bond Buyers 1993 Yearbook, 1993, American Banker Inc., New York, NY, p. 142, 146.

${ }^{2}$ Dollar volumes are for long-term (13 month or greater) bonds. Taxable bonds issued by nonprofit cooperatives are excluded. Bonds issued by State and local government agencies for privately owned electric facilities are included. Bonds are excluded in cases of mixed utilities where a substantial portion of the proceeds are used for nonelectric purposes.
} 
Because nongenerator electric utilities purchase all power needs, they have less plant investment than generator electric utilities per dollar of revenue generated. In 1992, the generator electric utilities showed $\$ 3.94$ of electric utility plant per dollar of electric utility operating revenue, compared with $\$ 1.07$ for nongenerator electric utilities.

Operation and maintenance (O\&M) expenses represent very different costs between the two groups of electric utilities. Purchase power expenses, which comprise the majority of nongenerators' O\&M expenses, contain all the associated costs for the generating plants from which the power was purchased including depreciation. This causes nongenerators' O\&M expenses to appear higher then generators' O\&M expenses on a normalized basis. In 1992, nongenerators' O\&M expenses were 88.8 percent of revenues and depreciation was only 3.4 percent. For generators, depreciation of plant is shown directly, since all or some of their generating needs are met by their own plants. Generators' O\&M expenses only represented 65.0 percent of revenues, but depreciation was 10.5 percent of revenues.

Financing is also different for the two groups. The generator electric utilities, with their larger plant investments per dollar of revenue, have more debt per dollar of revenue than the nongenerator electric utilities. The large amount of debt creates greater interest expense. Interest expense represented 21.9 percent of revenues in 1992 for the generators versus just 1.5 percent of revenues for the nongenerators (Tables 7 and 16).

Figure 1. Investment In Electric UtIllty Plant per Dollar of Revenue, 1989-1992

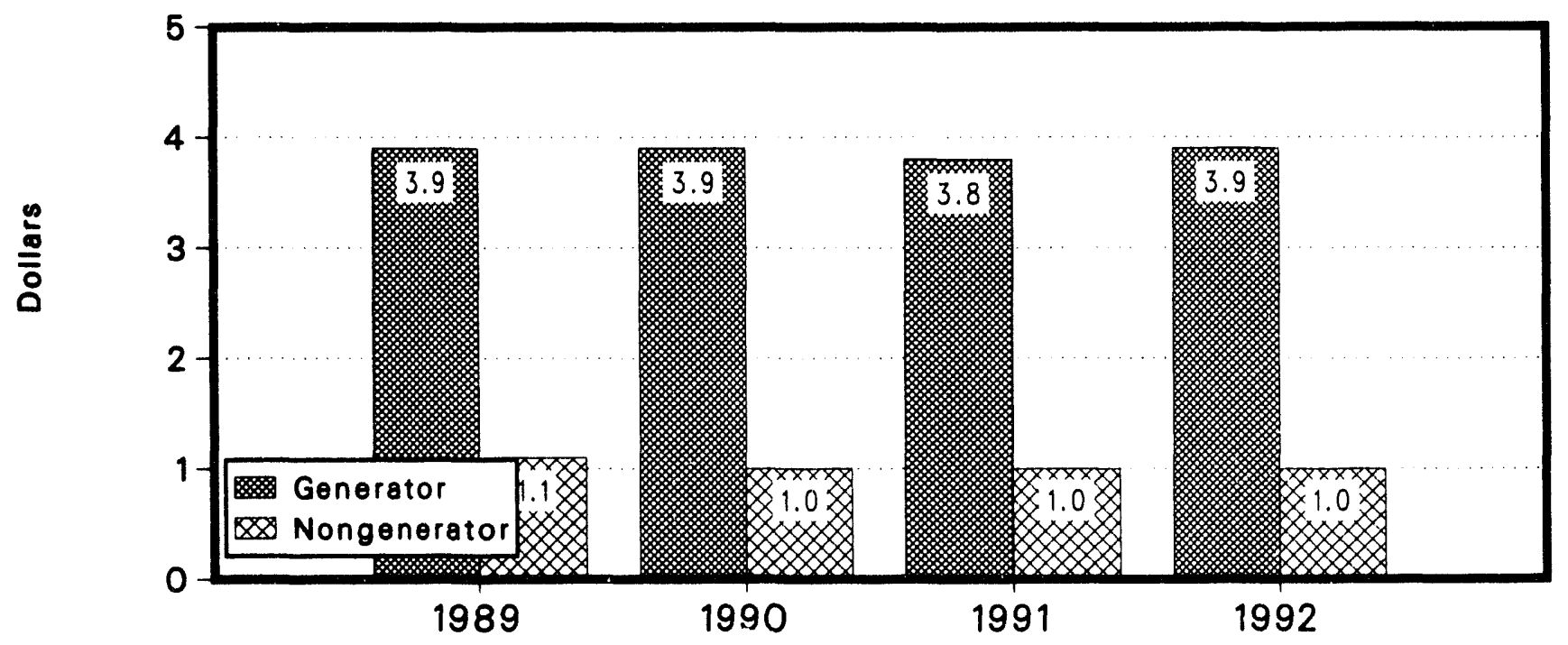

Note: Summery deta are provided in Tables 7 and 16

Source: Energy Information Administration. Form EiA-412, Annual Report of Public Electric Utilities. 
Financial Performance for Generator Electric Utilities

Summary financial statistics are provided for major publicly owned generator electric utilities. These statistics include 225 electric utilites for 1992; 218 electric utilities for 1991; 216 electric utilities for 1990; and 214 electric utilities for 1989 . The new respondents, as well as the electric utilities that are no longer reporting from the previous years, are listed in Appendix B1.

Generator electric utilities require approximately $\$ 4$ of investment to obtain $\$ 1$ in revenue. An average of 65.3 percent of electric utility operating revenues was spent on operation and maintenance expenses during the years 1989 through 1992. Interest on long-term debt as a percent of electric utility operating revenues averaged 22.5 over the same 4 years.

\section{Income Statement}

The Composite Statement of Income for major publicly owned generator electric utilities for the years 1989 through 1992 is presented (Table 5). Net income in 1992 rose a healthy 28.0 percent. Two factors were primarily responsible for this increase:

- Reduced intercst expenses and other income deductions

- Favorable operating conditions. Operating revenues rose just 2.9 percent, while total operating expenses increased only 1.8 percent.

Generator electric utility operating revenues in 1992 were $\$ 21.7$ billion, an increase of 2.9 percent in 1992 over 1991, compared with a 3.0-percent increase in 1991 over 1990. However, the contribution to revenue growth from ultimate consumer sales was stronger from 1991 to 1992 than from 1990 to 1991 . Revenues from ultimate consumers increased 4.4 percent from 1991 to 1992 , compared with 0.8 percent from 1990 to 1991 (Table 10).

Generator electric utility operation and maintenance (O\&M) expenses increased $\$ 0.5$ billion to $\$ 14.1$ billion or 3.6 percent in 1992. These same expenses rose just 1.5 percent from 1990 to 1991 . Total production expenses accounted for 76.6 percent of the generators' total O\&M expenses in 1992. In contrast, purchased power expenses declined between 1990 and $1991(\mathrm{Ta}$ ble 8). On a unit basis, production expenses, including purchased power, averaged 25.0 mills per kilowatthour in 1992 versus 24.2 mills per kilowatthour in 1991. In 1990, production expenses averaged 24.2 mills per kilowatthour. Only steam power production costs declined on a mills per kilowatthour basis between 1991 and 1992. Nuclear power production costs increased by 4.0 mills per kilowatthour to 25.1 mills in 1992; hydropower production costs increased 0.6 mills to 3.7 mills in 1992; purchased power from electric utility and nonelectric utility generators remained unchanged at 37.0 mills; and other power generation costs increased to 59.6 mills in 1992 from 53.3 mills in 1991. Unit fuel costs fell in all cases. Steam generation unit fuel costs went from 16.0 mills in 1991 to 15.2 mills in 1992; nuclear fuel costs declined to 5.5 mills in 1992 from 6.0 mills in 1991; and other power generation declined to 28.1 mills in 1992 from 29.4 mills in 1991.

Generators' total electric utility operating expenses increased 1.8 percent, from $\$ 16.9$ billion in 1991 to $\$ 17.2$ billion in 1992, which was less than the 2.6-percent increase from 1990 to 1991 . The resulting generator electric utility operating income, including income from electric plant leased to others, showed a 7.4-percent increase over 1991 to end the year at $\$ 4.5$ billion.

Interest expense declined, as did other income deductions and allowance for other funds used during construction. The decline in interest expenses was due to lower average interest rates on total debt achieved through recent refinancings. Interest expense as a percent of total long-term debt declined to 6.6 percent in 1992, from 6.9 percent in 1991. Lower interest rates more than offset the effect of a 4.5-percent increase in total long-term debt in 1992 from 1991. Income before extraordinary items increased 31.8 percent over the 1991 value to end the year at $\$ 1.1$ billion versus $\$ 0.8$ billion in 1991. Extraordinary items moderated this growth slightly.

\section{Balance Sheet}

The Composite Balance Sheet for publicly owned generator electric utilities reflected the continuing increases in electric plant in service, deferred debt, and total long-term debt (Table 6). The low interest rates in 1992 encouraged refinancing and the taking on of more debt.

Assets and Other Debits. Generators' total assets and other debits increased $\$ 3.9$ billion, or 3.8 percent, in 1992 over 1991 to end the year at $\$ 106.9$ billion. This growth was slightly smaller than the 3.9-percent increase experienced in 1991 over 1990. Deferred debits contributed the largest amount ( $\$ 1.1$ billion) to the asset increase and accounted for 28.9 percent of the generators' $\$ 3.9$ billion increase in assets. Net plant additions of $\$ 1.0$ billion contributed the next largest amount to the asset growth, followed closely by other property and investments and by current and accrued assets, each of which contributed $\$ 0.9$ billion.

The two largest plant categories contributing to plant in service growth were steam production plant, which increased \$0.9 billion in 1992 over 1991, and distribution plant, which also increased $\$ 0.9$ billion in 1992 over 1991. Together, these two categories accounted for 82.6 percent of the increase to total electric plant in service. The apparent significant decline in nuclear 
plant in service is due to the inclusion of nuclear fuel in production plant prior to the 1992 collection. Nuclear fuel did not have a specific entry under electric utility plant assets for the years 1989 uhrough 1991. Consequently, several electric utilities included it as nuclear production plant. For 1992, however, nuclear fuel is a designated item on the balance sheet.

Liabilities and Other Credits. Proprietary capital for generators increased in 1992 to end of the year at \$22.8 billion, 2.7 percent higher than in 1991. Total long-term debt increased from $\$ 68.9$ billion in 1991 to $\$ 72.0$ billion in 1992, a 4.5-percent increase. Although both debt and proprietary capital increased, the larger debt increase results in a slight leverage increase in 1992 over 1991 for generator electric utilities. Long-term debt as a percent of long-term debt plus total proprietary capital increased to 75.9 percent from 75.6 percent. The lower interest rates in 1992 not only encouraged refinancing but also encouraged issuance of additional debt in the form of bonds. A shift towards bonds occurred as long-term debt without advances from municipalities and others increased to 96.5 percent in 1992 from 95.4 percent in 1991.

\section{Consumers, Sales, and Revenue}

Sales to ultimate consumers of the generator electric utilities grew 1.6 percent from 1991 to 1992 , which was only slightly greater than the 1.4-percent increase experienced from 1990 to 1991 (Table 10). Not all sectors shared in this growth, however. The residential sector declined 0.5 percent and the commercial sector increased 2.3 percent. The industrial sector made up for these declines by growing 3.1 percent during 1992 versus 1.7 percent in 1991, while the other sector increased 1.6 percent. The mild weather experienced in 1992 was the main reason for the residential sector decline. The industrial sector benefitted from the gradual economic recovery experienced during 1992.

The mix of sales to ultimate consumers changed slightly in response to the different sector growth rates. Residential sales lost share of ultimate consumer sales, which dropped to 31.4 percent in 1992 from 32.1 percent in 1991; commercial sales increased to 29.5 percent from 29.3 in 1991; and industrial sales gained share moving to 31.2 percent in 1992 from 30.7 percent in 1991. Other sales remained the same at 7.9 percent of ultimate consumer sales.

Average revenue (mills per kilowatthour) increased in all sectors during 1992. Average revenue for all ultimate consumers increased 1.6 mills from 59.3 mills in 1991 to 60.9 mills in 1992 . By comparison, average revenue from ultimate consumers declined 0.3 mills from 1990 to 1991. Residential consumers saw a 2.1-mill increase during 1992, bringing residential average revenues to 68.5 mills. Commercial consumers averaged 66.4 mills in 1992, which was 1.4 mills higher than in 1991. Industrial consumers experienced a 0.4-mill in- crease, averaging 45.9 mills in 1992. All other ultimate consumers averaged 69.1 mills, which was a 6.5 -mill increase over 1991.

From 1991 to 1992, total revenue from ultimate consumers increased $\$ 0.6$ billion or 4.4 percent, compared with a 0.8-percent increase from 1990 to 1991 . Residential revenue increased by $\$ 0.1$ billion ( 2.6 percent), commercial revenue increased by $\$ 0.2$ billion (4.5 percent), industrial revenue increased by $\$ 0.1$ billion ( 4.1 percent), and other revenue increased by $\$ 0.1$ billion (12.4 percent). The increase in residential revenue was due solely to the increase in average revenue since the volume of residential sales declined. About 62.7 percent of the increase in revenue from ultimate consumers was attributable to industrial sales, while the remaining 37.3 percent was due to the average-revenue increase.

On the average, residential consumers of generator electric utilities paia $\$ 660$ for their electricity during 1992. The residential revenue per consumer was $\$ 10$ or 1.5 percent higher in 1992 than in 1991. Commercial consumers paid $\$ 4,535$ in 1992 , which was 4.4 percent lower than the $\$ 4,744$ paid in 1991 . Industrial consumers on an average paid $\$ 64,281$ in 1992, which was 6.8 percent lower than in 1991.

Operating revenues from sales for resales increased 3.6 percent, reversing the modest decline between 1990 and 1991. The average revenue received from sales for resale was 39.3 mills, a slight increase from 1991.

\section{Generation and Purchased Power}

Total net energy generated and received decreased slightly to 432.0 million megawatthours in 1992 . The biggest change in the source of generation was in conventional hydroelectric, which was down 10.3 percent over the prior year, and represented 22.6 percent of total generation (Table 11). This decline in conventional hydroelectric generation was affected by the 1992 drought experienced by the northwestern portion of th- United States. The second largest decline was in nuclear generation, a decrease of 9.0 percent over the prior year. This decline in nuclear generation was affected by the James A. Fitzpatrick nuclear power plant that was taken out of service on November 27, 1991, to correct performance deficiencies. The Power Authority of the State of New York implemented a renovation program addressing the deficiences and the plant returned to service on January 23, 1993. Steam generation was up 2.8 percent from 1991, representing 58.1 percent of total net generation.

In 1992 , total purchased power continued to play a major role in meeting the power requirements of these generator electric utilities, contributing 32.7 percent of the total net generated and received megawatthours. Total purchased power from electric utilities and nonutilities in 1992 was 141.1 million megawatthours. 
Table 3. Ten Largest U.S. Publicly Owned Generator Electric Utilities Ranked by Megawatthour Sales to Uitimate Consumers, 1992

\begin{tabular}{|c|c|c|c|}
\hline Publlaty Owned Ebetric Uthlites & State & Amount & Percent \\
\hline Los Angeles City of & CA & $21,515,437$ & 9.55 \\
\hline 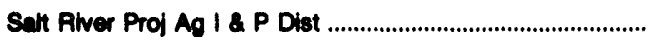 & AZ & $14,678,648$ & 6.52 \\
\hline Power Authority of State of NY & NY & $13,242,116$ & 5.88 \\
\hline San Antonio City of & TX & $11,858,748$ & 5.31 \\
\hline Seattie City of & WA & $8,762,380$ & 3.89 \\
\hline 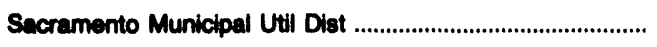 & CA & $8,471,202$ & 3.76 \\
\hline Jeckeonville Electric Auth & FL & $8,199,190$ & 3.64 \\
\hline 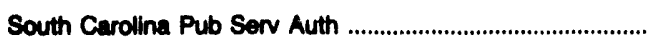 & sc & $7,637,583$ & 3.39 \\
\hline Austin Clty of & $T X$ & $6,582,788$ & 2.92 \\
\hline Omaha Public Power District & NE & $6,452,515$ & 2.86 \\
\hline 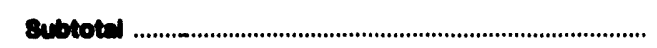 & & $107,500,608$ & 47.72 \\
\hline
\end{tabular}

Note: Percentage calculations are based on total generator electric utilities.

Source: Energy Information Administration, Form ElA-412, "Annual Report of Public Electric Utilities." Individual electric utilities report fiscal year data. Appendix B shows the fiecal year for each electric utility.

\section{Table 4. Ten Largest U.S. Publicly Owned Generator Electric Utilities Ranked by Megawatthour Sales for Resale, 1992}

\begin{tabular}{|c|c|c|c|}
\hline Publlety Owned Electric Uallitices & State & Amount & Percent \\
\hline Power Authority of State of NY & NY & $20,962,342$ & 11.50 \\
\hline 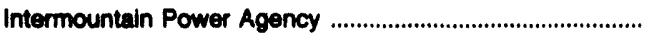 & UT & $11,385,417$ & 6.24 \\
\hline 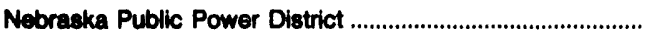 & NE & $11,309,492$ & 6.20 \\
\hline 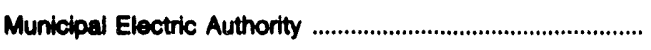 & GA & $9,684,579$ & 5.31 \\
\hline 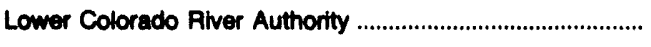 & $T X$ & $8,071,364$ & 4.43 \\
\hline 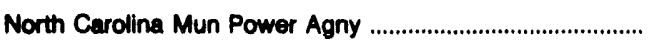 & NC & $7,962,505$ & 4.37 \\
\hline 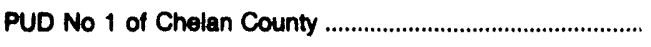 & WA & $7,898,961$ & 4.33 \\
\hline South Carolina Pub Serv Auth & sc & $6,395,055$ & 3.51 \\
\hline PUD No 2 of Grant County & WA & $6,367,661$ & 3.49 \\
\hline 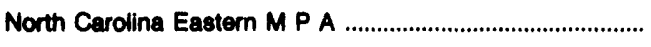 & NC & $5,899,408$ & 3.24 \\
\hline Sublotal & & $95,936,784$ & 52.62 \\
\hline
\end{tabular}

Note: Percentage calculations are based on total generator electric utllities.

Source: Energy Information Administration, Form ElA-412, "Annual Report of Public Electric Utilities." Indlvidual electric utilities report fiscal year data. Appendix $B$ shows the fiscal year for each electric utility. 


\section{Table 5. Composite Statement of Income for Major U.S. Publicly Owned Generator Electric Utillties, 1989-1992 (Thousand Dollars)}

\begin{tabular}{|c|c|c|c|c|}
\hline Item & 1992 & 1991 & 1990 & 1989 \\
\hline Electric Utillity Operating Revenues ...................... & $21,686,349$ & $21,082,870$ & $20,470,371$ & $19,261,832$ \\
\hline 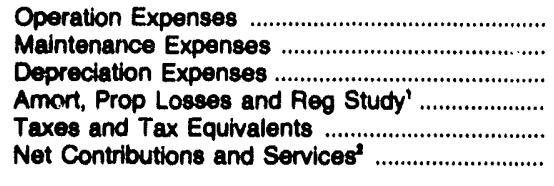 & $\begin{array}{r}12,527,435 \\
1,564,792 \\
2,285,807 \\
131,472 \\
681,140 \\
-\end{array}$ & $\begin{array}{r}12,155,075 \\
1,446,295 \\
2,300,532 \\
- \\
595,719 \\
389,300\end{array}$ & $\begin{array}{r}11,948,084 \\
1,455,786 \\
2,075,595 \\
- \\
550,042 \\
431,193\end{array}$ & $\begin{array}{r}11,310,048 \\
1,486,423 \\
2,051,058 \\
- \\
500,424 \\
373,165\end{array}$ \\
\hline $\begin{array}{l}\text { Total Electrle Utllity Operating } \\
\text { Expenses }\end{array}$ & $17,180,647$ & $16,886,021$ & $16,460,700$ & $15,721,118$ \\
\hline 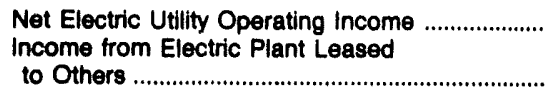 & $\begin{array}{r}4,495,703 \\
15,129\end{array}$ & $\begin{array}{r}4,195,949 \\
5,942\end{array}$ & $\begin{array}{r}4,009,671 \\
11,330\end{array}$ & $\begin{array}{r}3,540,714 \\
5,325\end{array}$ \\
\hline Electric Utility Operating Income ....................... & $4,510,832$ & $4,201,891$ & $4,021,001$ & $3,546,039$ \\
\hline Other Electric Income & $1,839,484$ & $1,890,138$ & $1,735,107$ & $1,790,217$ \\
\hline 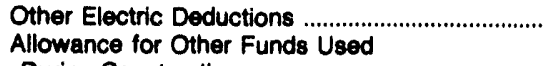 & 225,472 & 123,345 & - & - \\
\hline 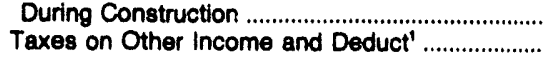 & $\begin{array}{l}24,183 \\
24,380\end{array}$ & $\begin{array}{r}71,025 \\
-\end{array}$ & $\begin{array}{r}123,282 \\
-\end{array}$ & 231,896 \\
\hline 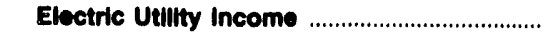 & $6,124,646$ & $6,039,710$ & $5,879,390$ & $5,518,252$ \\
\hline 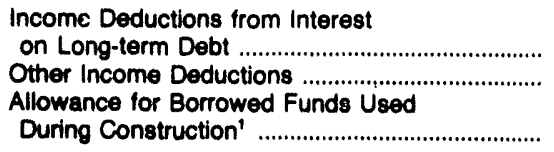 & $\begin{array}{r}4,757,583 \\
313,894 \\
-45,719\end{array}$ & $\begin{array}{r}4,775,003 \\
430,796\end{array}$ & $\begin{array}{r}4,663,114 \\
401,822 \\
-\end{array}$ & $\begin{array}{r}4,337,962 \\
402,229 \\
-\end{array}$ \\
\hline Total Income Deductions ....................................... & $5,025,758$ & $5,205,799$ & $5,064,936$ & $4,740,190$ \\
\hline 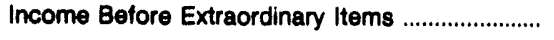 & $1,098,889$ & 833,911 & 814,455 & 778,062 \\
\hline Extraordinary Income & 111,239 & 99,430 & 136,692 & 60,418 \\
\hline 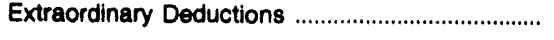 & 226,514 & 164,974 & 245,650 & 714,279 \\
\hline Not Income & 983,613 & 768,367 & 705,497 & ' 124,201 \\
\hline
\end{tabular}

Data reporting initiated in 1992.

2. Data reporting discontinued in 1992.

- Net income reflects $\$ 584$ million of extraordinary deduction associated with the abandonment of the Rancho Seco Nuclear Plant reported by the Sacramento Municipal Utility District.

- Data not available.

Note: Totals may not equal sum of components because of independent rounding. Detailed data are provided in Table 21. The number of publicly owned generating electric utilities for end of period is 225 for 1992,218 for 1991, 216 for 1990, and 214 for 1989 . Emerald Peoples Utility District (OR), City of Bryan (OH), and Northern Wasco County PUD (OR) were nongenerators for 1989 through 1991 , but became generators in 1992. Illinois Municipal Electric Agency (IL) and Wisconsin Public Power Incorporated System (WI) were nongenerators in 1989 and 1990, but became generators in 1991. The Clty of Marchfield (WI) was a generator in 1989 and 1990, but became a nongenerator in 1991.

Source: Energy Information Administration, Form ElA-412, "Annual Report of Public Electric Utilities." Individual electric utilities report fiscal year data. Appendix B shows the fiscal year for each electric utility. 
Table 6. Composite Balance Sheet for Major U.S. Publicly Owned Generator Electric Utilities at End of Period, 1989-1992 (Thousand Dollars)

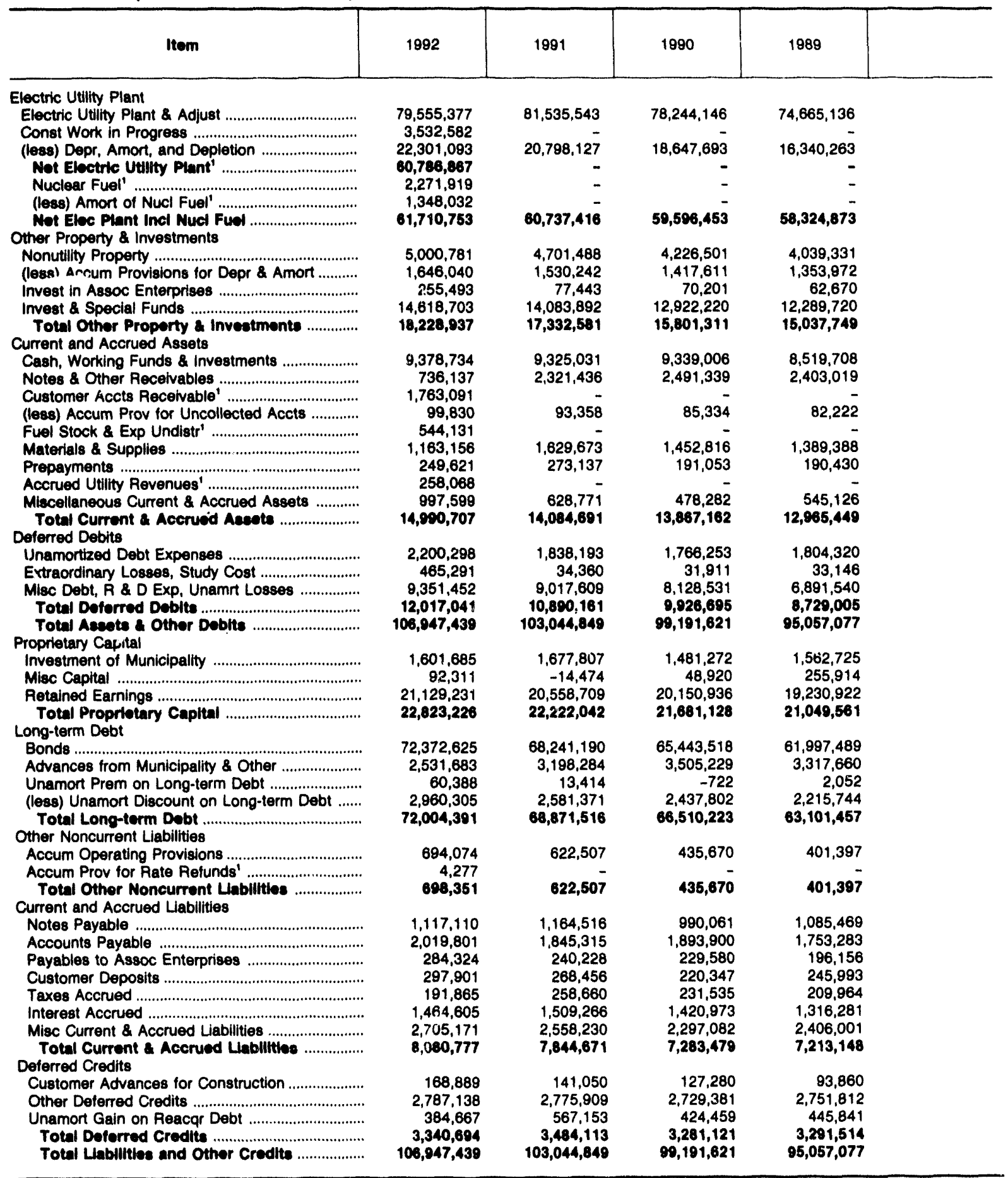

Data reporting initiated in 1992.

Note: Totals may not equal sum of components because of independent rounding. Detailed data are provided in Table 22. The number of publicly owned generating electric utilities for end of period is 225 for 1992, 218 for 1991, 216 for 1990, and 214 for 1989 . Emerald Peoples Utility District (OR), City of Bryan (OH), and Northern Wasco County PUD (OR) were nongenerators for 1989 through 1991, but became generators in 1992. Illinois Municipal Electric Agency (IL) and Wisconsin Public Power Incorporated System (WI) were nongenerators in 1989 and 1990, but became generators in 1991. The City of Marchfleld (WI) was a generator in 1989 and 1990, but became a nongenerator in 1991.

Source: Energy Information Administration, Form ElA-412, "Annual Report of Public Electric Utilities." Individual electric utilities report fiscal year data. Appendix $B$ shows the fiscal year for each electric utility. 
Table 7. Composite Financial Indicators for Major U.S. Publicly Owned Generator Electric Utilities, 1989-1992

\begin{tabular}{|c|c|c|c|c|}
\hline Item & 1982 & 1981 & 1990 & 1989 \\
\hline Total Electric Utility Plant per Dollar of Revenue & 3.9 & 3.8 & 3.8 & 3.9 \\
\hline 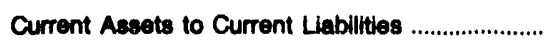 & 1.8 & 1.8 & 1.8 & 1.8 \\
\hline $\begin{array}{l}\text { Totel Electric Utility Plant as a Percent of Total } \\
\text { Assets }\end{array}$ & 79.8 & 78.1 & 78.9 & 78.5 \\
\hline Net Electric Utility Plant as a Percent of Total & 57.7 & 58.9 & 60.1 & 61.4 \\
\hline Debt as a Percent of Total Llabilities ....................... & 74.9 & 74.4 & 74.4 & 74.0 \\
\hline $\begin{array}{l}\text { Depreciation, Amortization and Depletion } \\
\text { as a Percent of Total Electric Uellity Plant .......... }\end{array}$ & 27.7 & 25.5 & 23.8 & 21.9 \\
\hline $\begin{array}{l}\text { Electric Operation and Maintenance Expenses } \\
\text { as a Percent of } \\
\text { Electric Utility Operating Revenues ............................ }\end{array}$ & 65.0 & 64.5 & 65.5 & 66.4 \\
\hline $\begin{array}{l}\text { Electric Depreciation and Amortization } \\
\text { as a Percent of } \\
\text { Electric Utillty Operating Revenues ........................ }\end{array}$ & 10.5 & 10.8 & 10.1 & 10.6 \\
\hline $\begin{array}{l}\text { Taxes and Tax Equivalents } \\
\text { as a Percent of } \\
\text { Electric Utillty Operating Revenues ......................... }\end{array}$ & 3.1 & 2.8 & 2.7 & 2.6 \\
\hline $\begin{array}{l}\text { Interest on Long-term Debt } \\
\text { as a Percent of } \\
\text { Electric Utilly Operating Revenues }\end{array}$ & 21.9 & 22.6 & 22.8 & 22.5 \\
\hline $\begin{array}{l}\text { Net Incoms as a Percent of Electric } \\
\text { Utility Operating Revenues }\end{array}$ & 4.5 & 3.6 & 3.4 & .6 \\
\hline
\end{tabular}

Note: Totals may not equal sum of components because of independent rounding. The number of publicly owned generating electric utilities for end of period is 225 for 1992,218 for 1991,216 for 1990 and 214 for 1989 . Emerald Peoples Utility District (OR), Clity of Bryan (OH), and Northern Wasco County PUD (OR) were nongenerators for 1989 through 1991, but became generators in 1992 . Illinois Municipal Electric Agency (IL) and Wisconsin Public Power incorporated System (WI) were nongenerators in 1989 and 1990 , but became generators in 1891. The City of Marchield (WI) was a generator in 1989 and 1980, but became a nongenerator in 1991.

Source: Energy Information Administration, Form ElA-412, "Annual Report of Public Electric Utilities." Individual electric utilities report fiecal year data. Appendix B shows the fiscal year for each electric utility. 
Table 8. Electric Operation and Maintenance Expenses for Major U.S. Publicly Owned Generator Electric Utilities, 1989-1992 (Thousand Dollars)

\begin{tabular}{l|l|l|l|l|l|l}
\hline Item & 1992 & 1991 & 1990 & 1989 & \\
\hline
\end{tabular}

\section{Production Expensese}

Steam Power Generation

\begin{tabular}{rrrr}
$3,761,983$ & $3,688,328$ & $3,741,339$ & $3,437,703$ \\
$1,318,443$ & $1,217,567$ & $1,133,495$ & $1,179,125$ \\
244,143 & 225,691 & 204,495 & 187,130 \\
175,250 & 167,133 & 196,314 & 170,169 \\
$5,225,943$ & $5,059,469$ & $5,108,259$ & $4,977,616$ \\
72,589 & 88,298 & 105,441 & 61,843 \\
$10,798,351$ & $10,446,486$ & $10,489,344$ & $10,013,586$ \\
\hline 634,583 & 608,062 & 566,408 & 520,387 \\
767,396 & 700,869 & 651,424 & 615,326 \\
289,209 & 290,006 & 273,614 & 248,784 \\
82,731 & 73,913 & 60,587 & 63,978 \\
17,545 & 18,077 & 18,066 & 11,858 \\
$1,492,411$ & $1,463,958$ & $1,344,426$ & $1,322,452$ \\
\hline $14,092,227$ & $13,601,370$ & $13,403,870$ & $12,796,471$
\end{tabular}

Fud Expenees In Operation

Steam Power Generation

$\begin{array}{rrrr}2,562,513 & 2,634,840 & 2,394,569 & 2,142,836 \\ 290,674 & 345,206 & 242,283 & 351,899 \\ 82,753 & 92,111 & 113,038 & 92,268\end{array}$

Other Power Generation

92,268

Number of Elec Dept Employees

Regular Full-time'

60,435

Part-time \& Temporary'

2,812

Total Elec Dept Employees'

63,244

1 Data reporting initiated in 1992.

Note: Totals may not equal sum of components because of independent rounding. Detailed data are provided in Table 23. The number of publicly owned generating electric utilities for end of period is 225 for 1992, 218 for 1991, 216 for 1990 , and 214 for 1989 . Emerald Peoples Utility District (OR), City of Eryan (OH), and Northern Wasco County PUD (OR) were nongenerators for 1989 through 1991 , but be. came generators in 1992. Illinois Municipal Electric Agency (IL) and Wisconsin Public Power Incorporated System (WI) were nongenerators in 1989 and 1990, but became generators in 1991. The City of Marchtield (WI) was a generator in 1989 and 1980, but became a nongenerator in 1991.

Source: Energy Information Administration, Form ElA-412, "Annual Report of Public Electric Utilities." Individual electric utilities report fiscal year data. Appendix $B$ shows the fiscal year for each electric utility. 
Table 9. Electric Utility Plant for Major U.S. Publicly Owned Generator Electric Utilities at End of Period, 1989-1992 (Thousand Dollars)

\begin{tabular}{|c|c|c|c|c|}
\hline Item & 1982 & 1991 & 1990 & 1989 \\
\hline \multicolumn{5}{|l|}{ Electric Plant in Service } \\
\hline Intangible Plant . & 284,166 & 364,819 & 318,464 & 382,790 \\
\hline \multicolumn{5}{|l|}{ Production Plant } \\
\hline Steam & $23,346,099$ & $22,488,350$ & $21,219,432$ & $19,120,267$ \\
\hline Nuclear & $18,743,463$ & $19,440,482$ & $18,992,687$ & $18,313,109$ \\
\hline 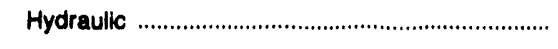 & $7,491,451$ & $6,975,677$ & $6,837,541$ & $6,333,219$ \\
\hline Other & $1,868,084$ & $1,557,135$ & $1,591,090$ & $1,470,073$ \\
\hline 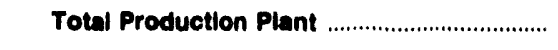 & $51,449,097$ & $50,461,644$ & $48,640,749$ & $45,236,667$ \\
\hline Transmission Plant & $8,743,222$ & $8,490,104$ & $7,847,445$ & $7,476,064$ \\
\hline 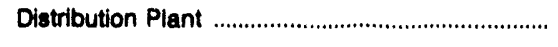 & $13,492,083$ & $12,586,918$ & $11,675,396$ & $11,148,904$ \\
\hline 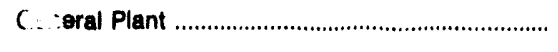 & $4,143,795$ & $4,073,586$ & $3,790,484$ & $3,258,961$ \\
\hline Total Electric Plant in Sorvice ............................ & $78,112,344$ & $75,977,171$ & $72,272,538$ & $67,503,386$ \\
\hline 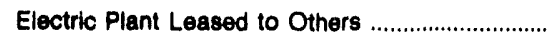 & 67.580 & 565,148 & 482,946 & 478,043 \\
\hline Construction Work in Progress - Electric ................. & $3,532,582$ & $3,900,155$ & $3,938,231$ & $5,371,308$ \\
\hline Electric Plant Held for Future Use ........................... & 305,565 & 626,776 & 819,007 & 743,806 \\
\hline Electric Plant Misc & $1,069,868$ & 456,493 & 731,424 & 568,593 \\
\hline Total Eloctric Utility Plant ................................... & $83,087,959$ & $81,535,543$ & $78,244,146$ & $74,665,136$ \\
\hline $\begin{array}{l}\text { Accumulated Provision for } \\
\text { Depreciation and Amortization ............................... }\end{array}$ & $22,301,093$ & $20,798,127$ & $18,647,693$ & $16,340,263$ \\
\hline Not Electric Utility Piant ..................................... & $60,786,867$ & $60,737,416$ & $59,596,453$ & $58,324,873$ \\
\hline
\end{tabular}

Note: Totals may not equal sum of components because of independent rounding. Detailed data are provided in Table 24. The number of publicly owned generating electric utilities for end of period is 225 for 1992, 218 for 1991, 216 for 1990, and 214 for 1989. Emerald Peoples Utility District (OR), City of Bryan (OH), and Northern Wasco County PUD (OR) were nongenerators for 1989 through 1991, but became generators in 1992. Illinois Municipal Electric Agency (IL) and Wisconsin Public Power Incorporated System (WI) were nongenerators In 1989 and 1990, but became generators in 1991. The City of Marchfield (WI) was a generator in 1989 and 1990, but became a nongenerator in 1991.

Source: Energy Information Administration, Form ElA-412, "Annual Report of Public Electric Utilities." Individual electric utilities report fiscal year data. Appendix $B$ shows the fiscal year for each electric utility. 
Table 10. Number of Consumers, Sales, and Operating Revenue for Major U.S. Publicly Owned Generator Electric Utilities, 1989-1992

\begin{tabular}{|c|c|c|c|c|}
\hline Item & 1982 & 1891 & 1990 & 1989 \\
\hline \multicolumn{5}{|l|}{ Number of Coneumers } \\
\hline Residential & $7,399,653$ & $7,320,039$ & $7,155,754$ & $7,026,529$ \\
\hline Commercial or Small & 977,783 & 894,604 & 893,611 & 929,909 \\
\hline Industrial or Large & 50,465 & 45,202 & 50,829 & 49,864 \\
\hline Other & 158,098 & 162,871 & 164,051 & 137,416 \\
\hline 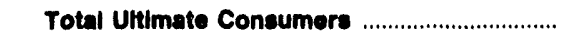 & $8,585,999$ & $8,422,716$ & $8,264,245$ & $8,143,718$ \\
\hline \multicolumn{5}{|l|}{ Sales for the Year (megawatthoura) } \\
\hline 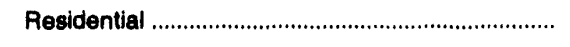 & $71,313,263$ & $71,667,965$ & $70,078,774$ & $68,285,003$ \\
\hline Commercial or Small & $66,801,045$ & $65,283,723$ & $65,302,667$ & $62,908,557$ \\
\hline Industrial or Large & $70,698,216$ & $68,550,382$ & $67,376,604$ & $64,856,200$ \\
\hline Other & $17,977,295$ & $17,643,031$ & $17,378,120$ & $15,418,212$ \\
\hline Total Sales to Ulitimate Consumers .................. & $226,789,819$ & $223,145,101$ & $220,136,165$ & $211,467,972$ \\
\hline Sales for Resale & $184,259,846$ & $183,508,522$ & $184,836,059$ & $181,607,993$ \\
\hline Total Sales & $411,049,685$ & $406,653,623$ & $404,972,224$ & $393,075,965$ \\
\hline \multicolumn{5}{|l|}{$\begin{array}{l}\text { Operating Revenues for the Yoar } \\
\text { (thouseand dollare) }\end{array}$} \\
\hline 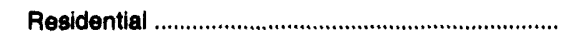 & $4,885,087$ & $4,759,672$ & $4,673,479$ & $4,456,953$ \\
\hline Commercial or Small & $4,434,108$ & $4,244,293$ & $4,296,416$ & $4,015,774$ \\
\hline Industrial or Large & $3,243,937$ & $3,117,161$ & $3,014,459$ & $2,950,948$ \\
\hline Other & $1,242,026$ & $1,105,045$ & $1,142,976$ & $1,008,679$ \\
\hline $\begin{array}{l}\text { Total Revenues from Salos to } \\
\text { Uttimate Consumere }\end{array}$ & $13,805,158$ & $13,226,171$ & $13,127,330$ & $12,432,354$ \\
\hline Sales for Resale & $7,246,170$ & $6,995,157$ & $7,051,730$ & $6,818,991$ \\
\hline $\begin{array}{l}\text { Total Revenues from Sales of } \\
\text { Electrletty }\end{array}$ & $21,051,328$ & $20,221,328$ & $20,178,060$ & $19,251,346$ \\
\hline
\end{tabular}

Note: Totals may not equal sum of components because of independent rounding. Detalled data are provided in Table 25. The number of publicly owned generating electric utilities for end of period is 225 for 1992, 218 for 1991, 216 for 1990, and 214 for 1 1089. Emerald Peoples Utility District (OR), City of Bryan (OH), and Northern Wasco County PUD (OR) were nongenerators for 1989 through 1991, but became generators in 1992. Illinois Municipal Electric Agency (IL) and Wisconsin Public Power Incorporated System (WI) were nongenerators in 1989 and 1990, but became generators in 1991. The City of Marchfield (WI) was a generator in 1989 and 1990, but became a nongenerator in 1991. sions.

Source: Energy Information Administration, Form ElA-861, "Annual Electric Utility Report." Data are based on calendar year submis- 


\section{Table 11. Electric Energy Account for Major U.S. Publicly Owned Generator Electric Utilities, 1989-1992 (Megawatthours)}

\begin{tabular}{|c|c|c|c|c|}
\hline Item & 1992 & 1991 & 1990 & 1989 \\
\hline \multicolumn{5}{|l|}{ Sources of Energy } \\
\hline 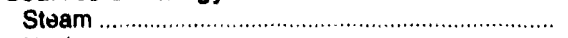 & $169,087,041$ & $164,401,739$ & $168,806,546$ & $177,940,856$ \\
\hline 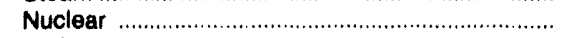 & $52,565,245$ & $57,756,871$ & $50,740,159$ & $53,149,705$ \\
\hline 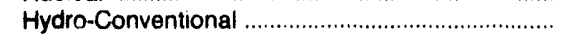 & $65,807,396$ & $73,348,633$ & $75,007,682$ & $68,743,015$ \\
\hline 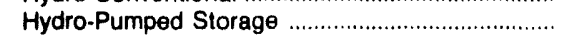 & $4,722,771$ & $3,789,638$ & $4,741,854$ & $4,059,041$ \\
\hline Other & $2,940,656$ & $3,137,344$ & $3,990,503$ & $2,371,953$ \\
\hline 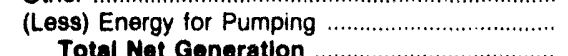 & $\begin{array}{r}4,255,476 \\
290,867,622\end{array}$ & $\begin{array}{r}3,904,547 \\
298,529,666\end{array}$ & $\begin{array}{r}3,551,799 \\
298,734,947\end{array}$ & $\begin{array}{r}3,603,646 \\
302,660,924\end{array}$ \\
\hline & & & & \\
\hline 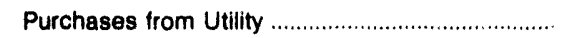 & $140,184,294$ & $135,721,748$ & $134,078,420$ & $117,464,109$ \\
\hline $\begin{array}{l}\text { Purchases from Nonutility ........................................ } \\
\text { Power Exchanges }\end{array}$ & 887,430 & $1,023,894$ & 953,732 & 998,330 \\
\hline 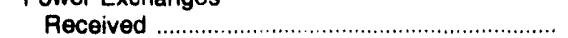 & $18,630,155$ & $19,499,318$ & $35,396,785$ & $20,982,909$ \\
\hline 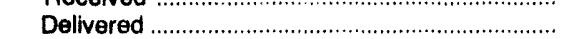 & $18,482,571$ & $22,632,364$ & $37,502,403$ & $21,727,726$ \\
\hline Net Exchanges & 147.591 & $-3,133,045$ & $-2,105,619$ & $-744,818$ \\
\hline \multicolumn{5}{|l|}{ Transmission for Others (Wheeling) } \\
\hline 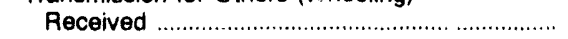 & $22,140,593$ & $27,653,990$ & $30,849,232$ & $30,245,487$ \\
\hline 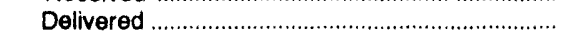 & $21,936,332$ & $27,447,579$ & $30,575,781$ & $29,725,513$ \\
\hline 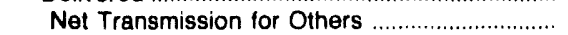 & 204,261 & 206,410 & 273,450 & 519,974 \\
\hline Transmission by Others Losses ............................. & $-242,982$ & $-162,245$ & $-74,580$ & - \\
\hline \multicolumn{5}{|l|}{ Total Net Energy Generated and } \\
\hline 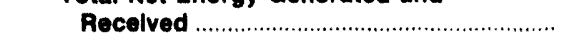 & $432,1748,203$ & $432,186,432$ & $432,860,348$ & $420,898,522$ \\
\hline \multicolumn{5}{|l|}{ Dieposition of Energy } \\
\hline 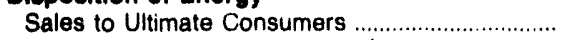 & $225,275,670$ & $222,657,472$ & $218,822,432$ & $211,222,453$ \\
\hline 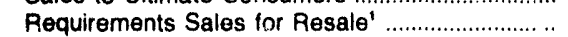 & $145,946,599$ & $154,882,433$ & $150,992,085$ & $180,655,267$ \\
\hline 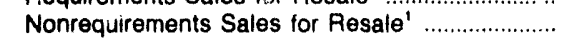 & $36,390,513$ & $30,076,686$ & $33,820,225$ & 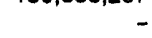 \\
\hline Furnished Without Charge & $1,632,802$ & $1,639,051$ & $1,732,209$ & $1,746,258$ \\
\hline 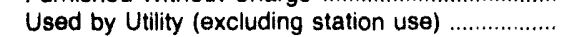 & $6,633.786$ & $7,627,773$ & $11,619,734$ & $11,412,462$ \\
\hline 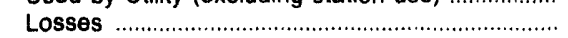 & $16,168,831$ & $15,302,995$ & $15,873,662$ & $15,862,067$ \\
\hline Total Disposition.. & $432,048,203$ & $432,186,432$ & $432,860,348$ & $420,898,522$ \\
\hline
\end{tabular}

- The 1989 data were reported as Sales for Resale (one entry) which is shown as Requirements Sales for Resale.

Note: Totals may not equal sum of components because of independent rounding. Detailed data are provided in Table 26. The number of publicly owned generating electric utilities for end of period is 225 for 1992, 218 for 1991, 216 for 1990 , and 214 for 1989 . Emerald Peoples Utility District (OR), City of Bryan (OH), and Northern Wasco County PUD (OR) were nongenerators for 1989 through 1991 , but became generators in 1992. Illinois Municipal Electric Agency (IL) and Wisconsin Public Power Incorporated System (WI) were nongenerators in 1989 and 1990, but became generators in 1991. The City of Marchfield (WI) was a generator in 1989 and 1990 , but became a nongenerator in 1991. Double counting occurs in components of both sources and disposition of energy and thus neither provides a true total. Purchases from utilities, net exchanges, and net wheeling (except for imports) are included in net generation. Sales for resale is included in sales to ultimate consumers.

Source: Energy Information Administration, Form ElA-412, "Annual Report of Public Electric Utilities." Individual electric utilities report fiscal year data. Appendix $B$ shows the fiscal year for each electric utility. 


\section{Financial Performance for Nongenerator Electric Utilities}

Summary financial statistics are provided for major publicly owned nongenerator electric utilities. These statistics include 258 electric utilities for 1992, 252 electric utilities for 1991, 251 electric utilities for 1990, and 240 electric utilities for 1989 . The new respondents, as well as the electric utilities that are no longer reporting from the previous years, are listed in Appendix B1.

Nongenerator electric utilities require approximately $\$ 1$ of investment to obtain $\$ 1$ in revenue. Electric operation and maintenance expenses averaged 89.0 percent of electric utility operating revenues during the years 1989 through 1992. Interest on long-term debt as a percent of electric utility operating revenues averaged 1.6 over the same 4 years (Table 16).

\section{Income Statement}

The Composite Statement of Income for major publicly owned nongenerator electric utilities for the years 1989 through 1992 is presented (Table 14). Nongenerator electric utility operating revenues in 1992 were: $\$ 7.2$ billion, an increase of 1.8 percent over 1991, which was a slight decline from the 2.0-percent revenue increase experienced from 1990 to 1991 . The residential and industrial sectors made a postive contribution to the revenues in 1992, while revenues from the commercial and other consumer sectors declined. (Table 19).

Nongenerator electric utility operation and maintenance (O\&M) expenses increased 2.1 percent to end the year at $\$ 6.4$ billion (Table 17). Total O\&M expenses increased 1.4 percent from 1990 to 1991 . For the nongenerators, purchased power costs are the major portion of O\&M expenses. In addition, purchased power includes the depreciation from the plants providing the power, so purchased power (and thus O\&M expenses) as a percent of revenues is significant. In 1992, purchased power was 87.1 percent of total O\&M expenses, which was 88.8 percent of total electric utility operating revenues. Transmission, distribution, and customer and sales related expenses also increased. Total purchase power costs increased 1.8 percent from 1991 to 1992, caused almost entirely by an increase in volume of purchases. Unit purchased power costs of 41.1 mills per kilowatthour stayed at almost the same level as in 1991.

Excluding interest expense and other income deductions, total electric utility operating expenses decreased 0.2 percent in 1992. This was less than the 1.8-percent increase experienced from 1990 to 1991 . Nongenerator electric utility income prior to interest and other deductions showed a 20.1-percent increase over 1991 to end the year at $\$ 0.5$ billion.
The decline in interest expense was due to lower average interest rates on total debt achieved through recent refinancings. Interest expense as a percentage of total long-term debt declined to 4.0 percent in 1992 , from 4.4 percent in 1991. Lower interest rates more than offset the effect of a 6.7-percent increase in total long-term debt in 1992 from 1991. Decreased interest expense caused income before extraordinary items to increase 30.6 percent to $\$ 0.3$ billion in 1992 . Net income for the year was $\$ 0.3$ billion, up 34.5 percent from 1991 .

\section{Balance Sheet}

The Composite Balance Sheet for publicly owned nongenerator electric utilities reflected the continuing increase in electric plant in service and total long-term debt (Table 15).

Assets and Other Debits. Nongenerators' total assets and other debts increased $\$ 0.4$ billion, or 4.3 percent, to end the year at $\$ 9.4$ billion. This growth was smaller than the 5.7-percent growth experienced by this electric utility group from 1990 to 1991 . Increases in net electric plant made the largest contribution to asset growth, accounting for 56.6 percent of the increase. The increase in current and accrued assets accounted for 16.8 percent of the total asset and other debit increase, deferred debits contributed 16.0 percent, and other property and investments contributed 10.6 percent.

The largest plant categories contributing to total plant in service growth were distribution and general plant. In 1992, distribution plant comprised 72.5 percent of total electric plant in service and general plant comprised 17.8 percent. Nongenerator electric utilities increased electric plant in service by $\$ 0.3$ billion in 1992 over 1991. Distribution plant accounted for 47.3 percent and general plant accounted for 47.9 percent of the increase in electric plant in service during 1992.

Liabilitic: and Other Credits. Total nongenerator proprietary capital increased 5.3 percent to end the year at $\$ 5.5$ billion. Total long-term debt was $\$ 2.7$ billion, which was a 6.7-percent increase over 1991. As nongenerator electric utilities have smaller asset bases than generator electric utilities to support their sales, they do not use the higher leverage that the generator electric utilities use. Thus, the nongenerator electric utilities stayed about the same leverage level in 1992 as in 1991, ending the year with long-term debt representing 32.9 percent of the sum of long-term debt and proprietary capital.

\section{Consumers, Sales, and Revenue}

Sales to ultimate consumers of the publicly owned nongenerator electric utilities grew 0.7 percent from 1991 to 1992 , much lower than the 3.0-percent growth shown by this group between 1990 and1991 (Table 
19). The industrial sector alone was responsible for this growth, 15.1 percent from 1991 to 1992 , a 1.7 percent increase a year earlier. As with the generator electric utilities, the industrial sector growth for nongenerator electric utilities was mainly due to the improved economic situation in 1992. While residential sales declined only 1.1 percent, the commercial sector dropped 19.2 percent, and the other ultimate consumers' sector declined 6.7 percent.

The mix of sales to ultimate consumers shifted in 1992 so that the industrial sector became the largest of the ultimate consumers sectors at $\mathbf{4 2 . 0}$ percent of total ultimate consumer sales. This was a significant increase over its 36.7 percent of sales share in 1991. The residential sector dropped to 37.8 percent of sales from 38.5 percent, while the commercial sector dropped to 17.8 percent of ultimate consumer sales in 1992 from 22.2 percent in 1991 . The other ultimate consumer sales share of 2.4 percent in 1992 moved very little from its 2.6-percent share in 1991 .

Average revenue (mills per kilowatthour) for all ultimate consumers increased 0.6 mills ( 1.1 percent) to end the year at 56.7 mills. From 1990 to 1991 , average revenue for ultimate consumers only increased 0.2 mills. Residential consumers saw a 1.4-mill increase in 1992, bringing their average revenue to 60.2 mills. Commercial consumers averaged 64.7 mills in 1992, which was 2.5 mills higher than in 1991. Industrial consumers experienced a 0.7 -mill increase, averaging 49.6 mills. All other ultimate consumers averaged 64.6 mills, which was a 1.5-mill increase over 1991

From 1991 to 1992, total revenue frum ultimate consumers increased $\$ 0.1$ billion (1.8 percent) to end the year at \$6.9 billion, compared with \$6.8 billion in 1991 . Ultimate consumer revenue in 1991 was 3.4 percent higher than in 1990. Although total revenue from ul- timate consumers increased, revenue declined in the commercial and other ultimate consumer sectors. The industrial sector revenue increased by $\$ 0.4$ billion in 1992, reaching $\$ 2.6$ billion, 16.7 percent higher than 1991 revenues. The majority of the industrial revenue increase ( 89.5 percent) was due to the increase in sales volume, with the remaining 10.5 percent attributable to the average revenue increase. The residential sector's revenue of $\$ 2.8$ billion increased 1.2 percent from 1991. The commercial sector's revenues of $\$ 1.4$ billion declined 15.9 percent and the other ultimate consumers' revenue of $\$ 0.2$ billion declined 4.5 percent. All of the revenue declines were due to sales volume declines, since average revenue increased in all cases.

Residential consumers of publicly owned nongenerator electric utilities paid $\$ 752$ for power during 1992. This was $\$ 8$ or 1.0 percent less than paid in 1991. Commercial consumers paid an average of $\$ 2,829$ during 1992 , which was $\$ 506$ or 15.2 percent less than in 1991. Industrial consumers on the average paid $\$ 56,085$ for power during 1992, which was a decline of 21.5 percent from 1991. This was due to a 48.7-percent gain in consumers compared with only a 16.7-percent rise in revenues.

\section{Generation and Purchased Power}

In 1992, total purchased power was 136.3 million megawatthours, an increase of 1.5 percent over 1991 (Table 20). The top five nongenerator electric utilities are all Tennessee Valley Authority (TVA) distributors. They are the City of Memphis (TN), the City of Nashville (TN), the City of Chattanooga (TN), the City of Knoxville (TN), and the City of Huntsville (AL) which together totaled 34.2 million megawatthours. These five TVA distributors represented 25.0 percent of total purchases for major nongenerator electric utilities. 
Table 12. Ten Largest U.S. Publicly Owned Nongenerator Electric Utilitles Ranked by Megawatthour Sales to Uitimate Consumers, 1992

\begin{tabular}{|c|c|c|c|}
\hline Publicly Owned Electric Utilitios & State & Amount & Percent \\
\hline 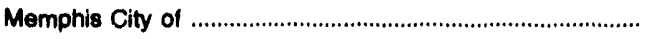 & TN & $11,317,322$ & 9.24 \\
\hline Nashville Electric Service & TN & $9,851,641$ & 8.04 \\
\hline Chattanooga City of & TN & $5,090,333$ & 4.15 \\
\hline 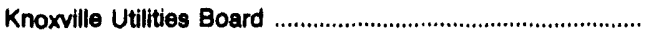 & TN & $4,465,554$ & 3.64 \\
\hline Huntsville City of & AL & $3,474,156$ & 2.84 \\
\hline 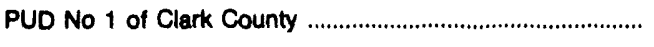 & WA & $3,097,698$ & 2.53 \\
\hline Johnson City City of & TN & $1,415,614$ & 1.16 \\
\hline 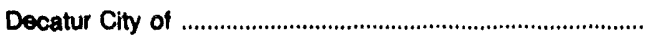 & AL & $1,348,629$ & 1.10 \\
\hline 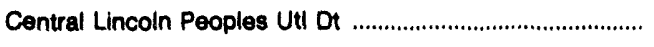 & OA & $1,329,302$ & 1.08 \\
\hline 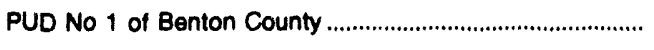 & WA & $1,295,684$ & 1.06 \\
\hline Subtotal & & $42,685,933$ & 34.84 \\
\hline
\end{tabular}

Note: Percentage calculations are based on total nongenerator electric utilities.

Source: Energy Information Administration, Form ElA-412, "Annual Report of Public Electric Utilities." Individual electric utilities report fiscal year data. Appendix $B$ shows the fiscal year for each electric utility.

\section{Table 13. Ten Largest U.S. Publicly Owned Nongenerator Electric Utillties} Ranked by Megawatthour Sales for Resale, 1992

\begin{tabular}{|c|c|c|c|}
\hline Publicly Owned Electric Utilites & State & Amount & Porcent \\
\hline Alabama Municipal Eloc Auth & AL & $2,252,355$ & 29.71 \\
\hline 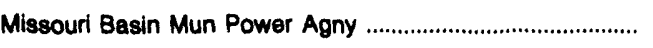 & SD & $2,003,698$ & 26.43 \\
\hline 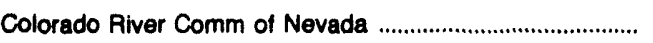 & NV & 826,026 & 10.90 \\
\hline 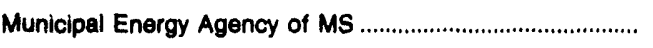 & MS & 772,493 & 10.19 \\
\hline 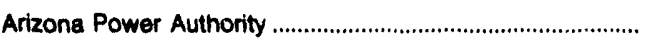 & $A Z$ & 740,505 & 9.77 \\
\hline 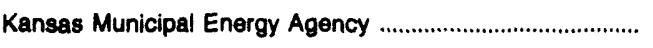 & KS & 311,554 & 4.11 \\
\hline 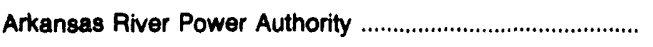 & co & 265,274 & 3.50 \\
\hline 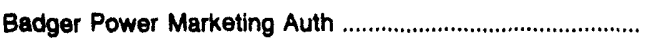 & $W !$ & 238,700 & 3.15 \\
\hline Wilson City of & NC & 56,166 & .74 \\
\hline 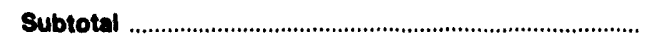 & & $7,490,471$ & 98.81 \\
\hline
\end{tabular}

Note: Percentage calculations are based on total nongenerator electric utilities.

Source: Energy Information Administration, Form EiA-412, "Annual Report of Public Electric Utilities." Individual electric utilities report fiscal year data. Appendix $\mathbf{B}$ shows the fiscal year for each electric utility. 
Table 14. Composite Statement of Income for Major U.S. Publicly Owned Nongenerator Electric Utilities, 1989-1992

(Thousand Dollars)

\begin{tabular}{|c|c|c|c|c|}
\hline Item & 1992 & 1991 & 1990 & 1989 \\
\hline Electrle Utllity Operating Rovenues ................... & $7,247,407$ & $7,119,875$ & $6,978,752$ & $6,552,712$ \\
\hline 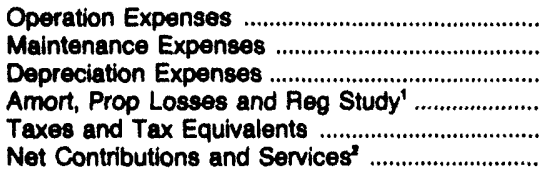 & $\begin{array}{r}6,244,831 \\
192,635 \\
248,040 \\
3,039 \\
154,994 \\
-\end{array}$ & $\begin{array}{r}6,119,385 \\
186,267 \\
246,594 \\
- \\
138,491 \\
168,882\end{array}$ & $\begin{array}{r}6,030,028 \\
191,621 \\
231,197 \\
- \\
133,125 \\
154,956\end{array}$ & $\begin{array}{r}5,693,914 \\
182,509 \\
200,580 \\
- \\
124,160 \\
153,431\end{array}$ \\
\hline $\begin{array}{l}\text { Total Electrlc Utilty Operating } \\
\text { Expenees }\end{array}$ & $6,843,539$ & $6,859,619$ & $6,740,926$ & $6,354,593$ \\
\hline $\begin{array}{l}\text { Net Electric Utility Operating Income ..................... } \\
\text { income from Electric Plant Leased }\end{array}$ & $\begin{array}{r}403,868 \\
1,773\end{array}$ & $\begin{array}{r}260,255 \\
3,264\end{array}$ & $\begin{array}{r}237,826 \\
2,121\end{array}$ & $\begin{array}{r}198,118 \\
1,727\end{array}$ \\
\hline Electrle Utillty Operating Income .................... & 405,642 & 263,520 & 239,948 & 199,845 \\
\hline 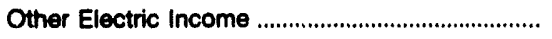 & 172,938 & 147,117 & 154,240 & 169,518 \\
\hline $\begin{array}{l}\text { Other Electric Deductions } \\
\text { Allowance for Other Funds Used.................................. }\end{array}$ & 98,838 & 13,949 & - & - \\
\hline 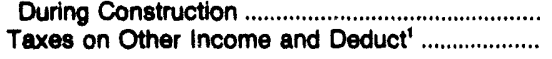 & $\begin{array}{r}39 \\
1,427\end{array}$ & $\begin{array}{r}1,606 \\
-\end{array}$ & -213 & -302 \\
\hline Electric Utillty Income & 478,364 & 398,294 & 393,975 & 369,062 \\
\hline 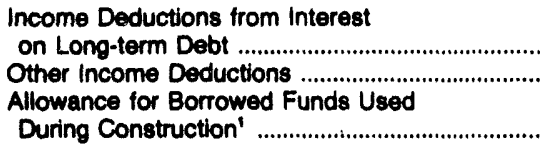 & $\begin{array}{r}109,378 \\
31,560 \\
-78\end{array}$ & $\begin{array}{r}112,031 \\
27,775\end{array}$ & $\begin{array}{r}109,972 \\
27,340\end{array}$ & $\begin{array}{r}101,469 \\
20,934\end{array}$ \\
\hline Total Income Deductions ...................................... & 140,861 & 139,806 & 137,311 & 122,403 \\
\hline Income Before Extraordinary Items ........................... & 337,493 & 258,488 & 256,663 & 246,658 \\
\hline Extraordinary Income & 35,508 & 24,074 & 5,274 & 26,641 \\
\hline 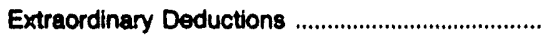 & 37,664 & 33,326 & 16,589 & 11,691 \\
\hline Not income & 335,338 & 249,236 & 245,348 & 261,608 \\
\hline
\end{tabular}

Data reporting initiated in 1992.

- Data reporting discontinued in 1992.

- Data not avallable.

Note: Totals may not equal sum of components because of independent rounding. Detailed data are provided in Table 21. The number of publicly owned nongenerating electric utilities for end of period is 258 for 1992, 252 for 1991, 251 for 1990, and 240 for 1989 . Emerald Peoples Utility District (OR), City of Bryan (OH), and Northern Wasco County PUD (OR) were nongenerators for 1989 through 1991 , but became generators in 1992. Illinois Municipal Electric Agency (IL) and Wisconsin Public Power Incorporated System (WI) were nongenerators in 1989 and 1990, but became generators in 1991. The City of Marchfield (WI) was a generator in 1989 and 1990 , but became a nongenerator in 1991.

Source: Energy Information Administration, Form ElA-412, "Annual Report of Public Electric Utilities." Individual electric utilities report fiscal year data. Appendix B shows the fiscal year for each electric utility. 
Table 15. Composite Balance Sheet for Major U.S. Publicly Owned Nongenerator Electric Utilities at End of Period, 1989-1992 (Thousand Dollars)

\begin{tabular}{|c|c|c|c|c|}
\hline Item & 1992 & 1991 & 1990 & 1989 \\
\hline \multicolumn{5}{|l|}{ Electric Utility Plant } \\
\hline Electric Utility Plant \& Adjust .................................... & $7,474,793$ & $7,318,688$ & $6,861,881$ & $6,344,572$ \\
\hline 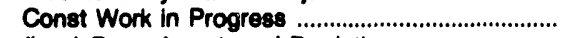 & 258,244 & & - & - \\
\hline 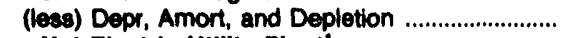 & $2,852,034$ & $2,656,267$ & $2,454,302$ & $2,231,882$ \\
\hline Not Electirc Utilty Plant' ....................................... & $4,881,003$ & - & - & - \\
\hline Nuciear Fuel' & - & - & - & - \\
\hline 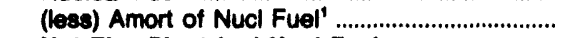 & - & - & - & - \\
\hline \multicolumn{5}{|l|}{ Other Property \& Investments } \\
\hline 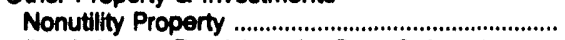 & $1,407,105$ & $1,368,349$ & $1,351,755$ & $1,296,434$ \\
\hline (less) Accum Provisions for Depr \& Amort ........... & 331,064 & 310,379 & 294,492 & 270,584 \\
\hline Imvest in Assoc Enterprises ................................ & 16,768 & 10,274 & 11,269 & 8,120 \\
\hline 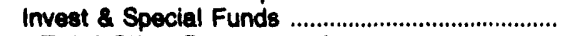 & 797,642 & 781,364 & 702,051 & 676,096 \\
\hline Total Other Property \& Inveatmonts ................. & $1,800,451$ & $1,849,607$ & $1,770,583$ & $1,710,066$ \\
\hline \multicolumn{5}{|l|}{ Current and Accrued Assets } \\
\hline Cesh, Working Funds \& Investments .................... & $1,142,447$ & $1,103,512$ & 976,625 & 959,146 \\
\hline 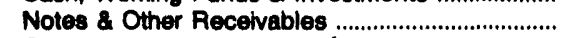 & 311,782 & 743,971 & 762,732 & 710,705 \\
\hline 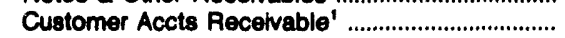 & 377,995 & - & - & - \\
\hline (less) Accum Prov for Uncollected Accts ............ & 21,554 & 20,887 & 18,993 & 17,998 \\
\hline 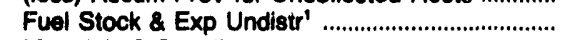 & 1,180 & - & - & 11,000 \\
\hline 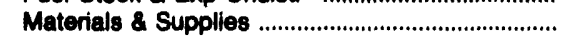 & 168,474 & 167,291 & 167,884 & 166,343 \\
\hline 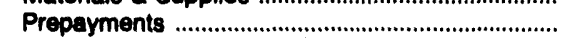 & 155,880 & 104,547 & 130,823 & 50,268 \\
\hline 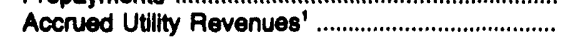 & 29,411 & - & - & - \\
\hline Miscellaneous Current \& Accrued Assets ............ & 61,368 & 63,698 & 44,859 & 65,816 \\
\hline $\begin{array}{l}\text { Total Current a Accrued Aseots ....................... } \\
\text { Deferred Debits }\end{array}$ & $2,227,004$ & $2,162,131$ & $2,083,031$ & $1,934,281$ \\
\hline 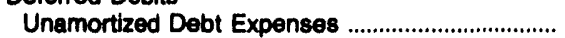 & 91,016 & 70,967 & 64,706 & 52,827 \\
\hline 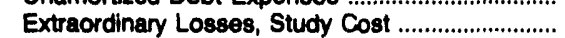 & 4,360 & 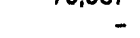 & 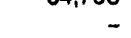 & No, \\
\hline 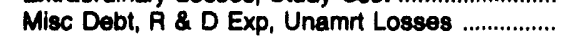 & 290,887 & 253,473 & 206,745 & 197,007 \\
\hline Total Doferred Deblts ..................................... & 386,263 & 324,440 & 271,452 & 249,834 \\
\hline & $9,384,801$ & $8,008,600$ & $6,513,545$ & $8,006,871$ \\
\hline \multicolumn{5}{|l|}{ Proprietary Capital } \\
\hline $\begin{array}{l}\text { Investment of Municipality } \\
\text { Misc Cepital }\end{array}$ & $\begin{array}{l}263,868 \\
429,805\end{array}$ & $\begin{array}{l}411,372 \\
466,780\end{array}$ & $\begin{array}{l}420,570 \\
396,386\end{array}$ & $\begin{array}{l}383,571 \\
401,346\end{array}$ \\
\hline 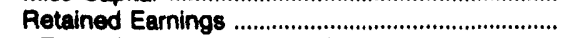 & $4,828,568$ & $4,366,799$ & $4,177,166$ & $3,890,337$ \\
\hline 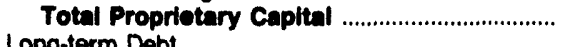 & $5,522,242$ & $5,244,951$ & $4,804,123$ & $4,675,254$ \\
\hline \multicolumn{5}{|l|}{ Long-term Debt } \\
\hline Advances trom Municipality \& Other ............ & $2,277,558$ & $2,174,746$ & $1,989,076$ & $1,854,737$ \\
\hline $\begin{array}{l}\text { Acvances from Municipaliny a Uner .................... } \\
\text { Unamort Prem on Long-term Debt }\end{array}$ & $\begin{array}{r}440,938 \\
906 ?\end{array}$ & $\begin{array}{r}383,340 \\
2,437\end{array}$ & $\begin{array}{r}374,749 \\
2,190\end{array}$ & 383,084 \\
\hline (less) Unamort Discount on Long-term Debt ...... & $\begin{array}{r}8,802 \\
14,736\end{array}$ & $\begin{array}{r}2,437 \\
18,088\end{array}$ & $\begin{array}{r}2,180 \\
17,340\end{array}$ & $\begin{array}{r}1,082 \\
22,004\end{array}$ \\
\hline 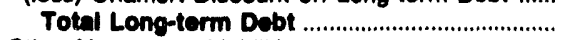 & $2,713,721$ & $2,542,435$ & $2,348,676$ & $2,216,899$ \\
\hline \multicolumn{5}{|l|}{ Other Noncurrent Liabilities } \\
\hline Accum Operating Provisions ..................................... & 10,078 & 55,488 & 38,157 & 40,842 \\
\hline Accum Prov for Rate Refunds' ................................. & 206 & & - & - \\
\hline Total Other Noncurrent Lablittes ................... & 10,284 & 55,488 & 38,157 & 40,842 \\
\hline \multicolumn{5}{|l|}{ Current and Accrued Liabilities } \\
\hline Notes Payable & 50,560 & 69,765 & 51,547 & 46,566 \\
\hline Accounts Payable & 607,825 & 592,275 & 611,501 & 576,639 \\
\hline Payables to Assoc Enterprises ............................... & 16,355 & 29,095 & 22,803 & 28,338 \\
\hline 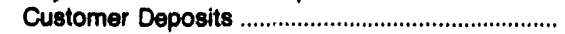 & 125,964 & 116,132 & 106,199 & 96,505 \\
\hline 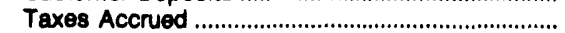 & 21,355 & 36,991 & 17,762 & 17,816 \\
\hline Interest Accrued & 59,637 & 40,611 & 51,094 & 37,435 \\
\hline Misc Current \& Accrued Liabilities .......................... & 102,169 & 84,054 & 88,440 & 83,779 \\
\hline Total Current \& Accrued Liablitities ................. & 983,865 & 988,924 & 949,345 & 887,078 \\
\hline \multicolumn{5}{|l|}{ Deferred Credits } \\
\hline 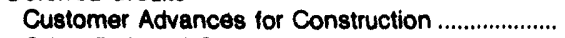 & 48,058 & 48,299 & 43,976 & 38,156 \\
\hline 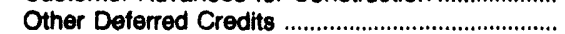 & 101,658 & 136,614 & 139,170 & 143,843 \\
\hline 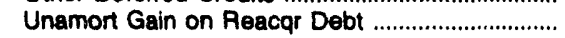 & 4,973 & 1,890 & 88 & 4,800 \\
\hline Total Doferred Credlts ...................................... & 154,689 & 186,803 & 183,244 & 186,799 \\
\hline Total Lablilties and Other Credite ................... & $9,384,801$ & $8,998,600$ & $8,513,545$ & $8,008,871$ \\
\hline
\end{tabular}

Data reporting initiated in 1982.

Note: Totals may not equal sum of components because of independent rounding. Detailed data are provided in Table 22 . The number of publicly owned nongenerating electric utilities for end of period is 258 for 1992, 252 for 1991, 251 for 1990 , and 240 for 1989 . Emerald Peoples Utility District (OR), City of Bryan (OH), and Northern Wasco County PUD (OR) were nongenerators for 1989 through 1991 , but became generators in 1992. Illinois Municipal Electric Agency (IL) and Wisconsin Public Power Incorporated System (WI) were nongenerators in 1989 and 1990, but became generators in 1991. The City of Marchfield (WI) was a generator in 1989 and 1990 , but became a nongenerator in 1991 .

Source: Energy Information Administration, Form EIA-412, "Annual Report of Public Electric Utilities." Individual electric utilities report fiecal year data. Appendix B shows the fiscal year for each electric utility. 
Table 16. Composite Financial Indicators for Major U.S. Publicly Owned Nongenerator Electric Utilities, 1989-1992

\begin{tabular}{|c|c|c|c|c|}
\hline Item & 1992 & 1991 & 1990 & 1989 \\
\hline Total Electric Utility Plant per Dollar of Revenue & 1.1 & 1.0 & 1.0 & 1.0 \\
\hline Curr. Assets to Current Liabilities ........................... & 2.3 & 2.2 & 2.2 & 2.2 \\
\hline $\begin{array}{l}\text { Total Electric Utility Plant as a Percent of Total } \\
\text { Assets }\end{array}$ & 82.4 & 81.3 & 80.6 & 79.2 \\
\hline $\begin{array}{l}\text { Net Electric Utility Plant as a Percent of Total } \\
\text { Assets }\end{array}$ & 52.0 & 51.8 & 51.8 & 51.4 \\
\hline Debt as a Percent of Total Liabilities ..................... & 39.4 & 39.0 & 38.7 & 38.8 \\
\hline $\begin{array}{l}\text { Depreciation, Amortization and Depletion } \\
\text { as a Percent of Total Electric Utility Plant ........... }\end{array}$ & 36.9 & 36.3 & 35.8 & 35.2 \\
\hline $\begin{array}{l}\text { Electric Operation and Maintenance Expenses } \\
\text { as a Percent of } \\
\text { Electric Utility Operating Revenues ...................... }\end{array}$ & 88.8 & 88.6 & 89.2 & 89.7 \\
\hline $\begin{array}{l}\text { Electric Depreciation and Amortization } \\
\text { as a Percent of } \\
\text { Electric Utility Operating Revenues ......................... }\end{array}$ & 3.4 & 3.5 & 3.3 & 3.1 \\
\hline $\begin{array}{l}\text { Taxes and Tax Equivalents } \\
\text { as a Percent of } \\
\text { Electric Utility Operating Revenues }\end{array}$ & 2.1 & 1.9 & 1.9 & 1.9 \\
\hline $\begin{array}{l}\text { Interest on Long-term Debt } \\
\text { as a Percent of } \\
\text { Electric Utility Operating Revenues }\end{array}$ & 1.5 & 1.6 & 1.6 & 1.5 \\
\hline 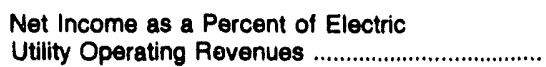 & 4.6 & 3.5 & 3.5 & 4.0 \\
\hline
\end{tabular}

Note: Totals may not equal sum of components because of independent rounding. The number of publicly owned nongenerating elec. tric utilities for end of period is 258 for 1992, 252 for 1991, 251 for 1990, and 240 for 1989. Emerald Peoples Utility District (OR), City of Bryan (OH), and Northern Wasco County PUD (OR) were nongenerators for 1989 through 1991, but became generators in 1892. Ilinois MUnicipal Electric Agency (IL) and Wisconsin Public Power Incorporated System (WI) were nongenerators in 1989 and 1990 , but became generators in 1991. The City of Marchfield (WI) was a generator in 1989 and 1990, but became a nongenerator in 1991

Source: Energy Information Administration, Form EIA-412, "Annual Report of Public Electric Utilities." Individual electric utilities report fiscal year data. Appendix $B$ shows the fiscal year for each electric utility. 
Table 17. Electric Operation and Maintenance Expenses for Major U.S. Publicly Owned Nongenerator Electric Utilities, 1989-1992 (Thousand Dollars)

\begin{tabular}{|c|c|c|c|c|}
\hline Item & 1992 & 1991 & 1990 & 1989 \\
\hline \multicolumn{5}{|l|}{ Production Exponees } \\
\hline 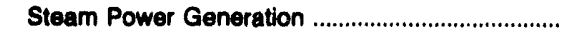 & 416 & 544 & 230 & 263 \\
\hline 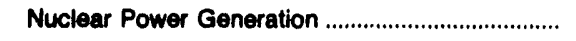 & - & - & - & - \\
\hline 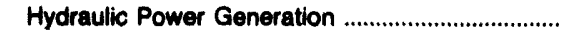 & 15 & 7 & 17 & 52 \\
\hline 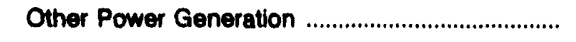 & 622 & 97 & 105 & 1,802 \\
\hline 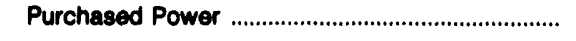 & $5,608,871$ & $5,511,698$ & $5,433,716$ & $5,022,464$ \\
\hline 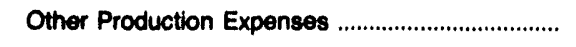 & 7,893 & 14,274 & 49,529 & 37,305 \\
\hline 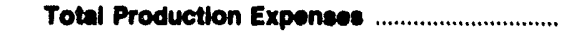 & $5,617,818$ & $5,526,621$ & $5,483,597$ & $5,081,887$ \\
\hline 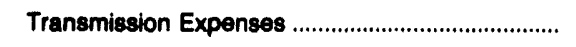 & 43,128 & 37,107 & 37,609 & 31,930 \\
\hline 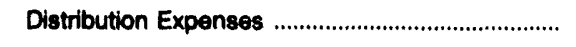 & 357,995 & 326,810 & 298,847 & 373,048 \\
\hline 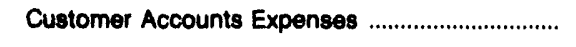 & 109,196 & 103,456 & 101,115 & 95,413 \\
\hline Customer Service and Information Expenses ..... & 15,629 & 15,743 & $14,1 ? 3$ & 13,993 \\
\hline 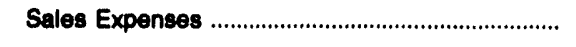 & 11,646 & 11,587 & 11,283 & 5,657 \\
\hline 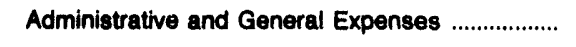 & 281,954 & 284,327 & 275,073 & 294,495 \\
\hline $\begin{array}{l}\text { Total Electrle Operation } \\
\text { and Malntenance Expenses }\end{array}$ & $6,437,466$ & $6,305,652$ & $6,221,849$ & $5,876,423$ \\
\hline \multicolumn{5}{|l|}{ Fual Expenses in Operation } \\
\hline 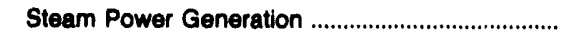 & 13 & 2 & -3 & - \\
\hline 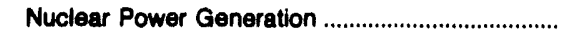 & - & - & - & - \\
\hline 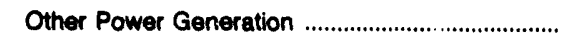 & 5 & 2 & 3 & - \\
\hline \multicolumn{5}{|l|}{ Number of Eloc Dept Employees } \\
\hline 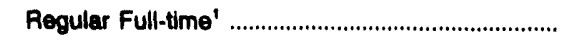 & 14,458 & - & - & - \\
\hline 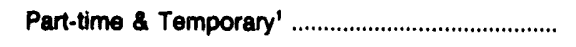 & 1,054 & - & - & - \\
\hline 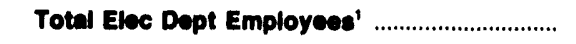 & 15,514 & - & - & - \\
\hline
\end{tabular}

1 Data reporting initiated in 1992.

Note: Totals may not equal sum of components because of independent rounding. Detalled data are provided in Table 23. The number of publicly owned nongenerating electric utilities for end of period is 258 for 1992, 252 for 1991, 251 for 1990, and 240 for 1989 . Emerald Peoples Utility District (OR), City of Bryan (OH), and Northern Wasco County PUD (OR) were nongenerators for 1989 through 1991 , but became generators in 1992. Illinois Municipal Electric Agency (IL) and Wisconsin Public Power Incorporated System (WI) were nongenerators in 1989 and 1990 , but became generators in 1991. The City of Marchfield (WI) was a generator in 1989 and 1990, but became a nongenerator in 1991

Source: Energy Information Administration, Form EIA-412, "Annual Report of Public Electric Utillties." Individual electric utilities report fiscal year data. Appendix B shows the fiscal year for each electric utility. 
Table 18. Electric Utility Plant for Major U.S. Publlcly Owned Nongenerator Electric Utilities at End of Period, 1989-1992 (Thousand Dollars)

\begin{tabular}{|c|c|c|c|c|}
\hline Item & 1992 & 1891 & 1990 & 1989 \\
\hline \multicolumn{5}{|l|}{ Electric Plant In Sorvice } \\
\hline 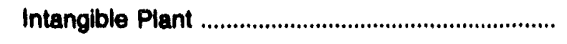 & 10,549 & 8,292 & 7,521 & 8,019 \\
\hline \multicolumn{5}{|l|}{ Production Plant } \\
\hline Steam & 69,727 & 68,062 & 27,215 & 71,049 \\
\hline 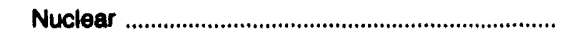 & - & - & - & - \\
\hline 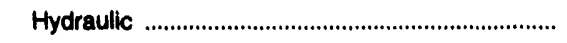 & 15,334 & 15,334 & 15,334 & 14,856 \\
\hline Other & 18,984 & 19,164 & 48,607 & 14,954 \\
\hline Total Production Plant .......................................... & 104,045 & 102,580 & 91,156 & 100,050 \\
\hline 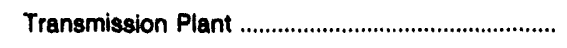 & 602,713 & 589,808 & 501,168 & 460,099 \\
\hline 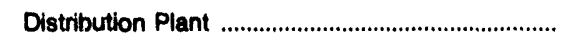 & $5,354,892$ & $5,192,372$ & $4,804,220$ & $4,537,394$ \\
\hline 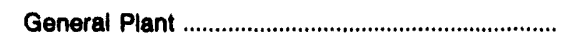 & $1,312,183$ & $1,147,474$ & $1,076,842$ & 968,309 \\
\hline Total Electric Plant in Sorvice ......................... & $7,384,383$ & $7,040,506$ & $6,581,006$ & $6,074,770$ \\
\hline 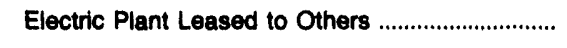 & 615 & 662 & 708 & 640 \\
\hline Construction Work in Progress - Electric .............. & 258,244 & 210,030 & 212,939 & 188,487 \\
\hline Electric Plant Held for Future Use ............................ & 16,074 & 13,860 & 11,391 & 10,638 \\
\hline 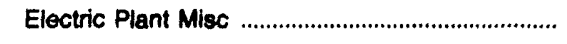 & 73,722 & 53,630 & 55,837 & 70,028 \\
\hline 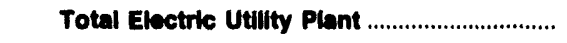 & $7,733,037$ & $7,318,688$ & $6,861,881$ & $6,344,572$ \\
\hline 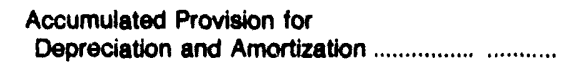 & $2,852,034$ & $2,656,267$ & $2,454,302$ & $2,231,882$ \\
\hline 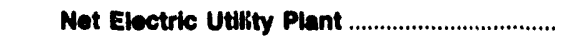 & $4,881,003$ & $4,862,421$ & $4,407,579$ & $4,112,690$ \\
\hline
\end{tabular}

Note: Totals may not equal sum of components because of independent rounding. Detailed data are provided in Table 24. The number of publicly owned nongenerating electric utilities for end of period is 258 for 1992, 252 for 1991, 251 for 1990 , and 240 for 1989 . Emerald Peoples Utility District (OR), City of Bryan (OH), and Northern Wasco County PUD (OR) were nongenerators for 1989 through 1981 , but became generators in 1992 . Illinois Municipal Electric Agency (IL) and Wisconsin Public Power Incorporated System (WI) were nongenerators in 1989 and 1980, but became generators in 1991 . The City of Marchfield (WI) was a generator in 1989 and 1990 , but became a nongenerator in 1891.

Source: Energy Information Administration, Form ElA-412, "Annual Report of Public Electric Utilities." Individual electric utillties report fiscal year data. Appendix B shows the fiscal year for each electric utility. 
Table 19. Number of Consumers, Salee, and Operating Revenue for Major U.S. Publicly Owned Nongenerator Electric Utilities, 1989-1992

\begin{tabular}{|c|c|c|c|c|}
\hline Item & 1992 & 1991 & 1980 & 1989 \\
\hline \multicolumn{5}{|l|}{ Number of Coneumers } \\
\hline 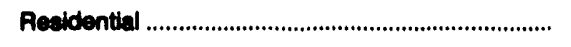 & $3,705,525$ & $3,624,017$ & $3,556,400$ & $3,454,820$ \\
\hline Commercial or Small & 499,250 & 503,917 & 493,348 & 451,840 \\
\hline 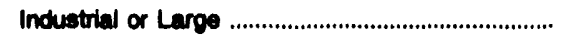 & 45,537 & 30,629 & 31,854 & 35,684 \\
\hline Other & 87,037 & 103,377 & 99,849 & 94,973 \\
\hline 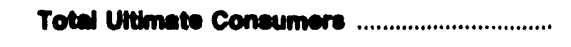 & $4,397,340$ & $4,281,040$ & $4,181,551$ & $4,087,417$ \\
\hline \multicolumn{5}{|l|}{ sales for the Year (megawatthours) } \\
\hline 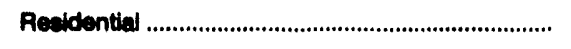 & $46,306,852$ & $46,808,977$ & $45,347,843$ & $44,021,341$ \\
\hline 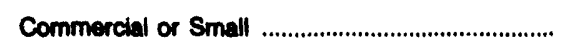 & $21,815,955$ & $26,987,619$ & $25,768,440$ & $23,530,515$ \\
\hline 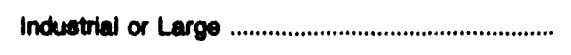 & $51,453,636$ & $44,693,894$ & $43,948,454$ & $42,770,643$ \\
\hline Other & $2,936,880$ & $3,146,885$ & $3,055,644$ & $2,987,372$ \\
\hline Totel save to Uitumate Consumers ................ & $122,513,323$ & $121,637,475$ & $118,120,381$ & $113,300,871$ \\
\hline 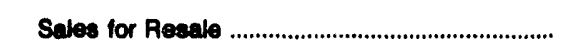 & $7,506,885$ & $7,288,781$ & $10,767,467$ & $8,041,747$ \\
\hline 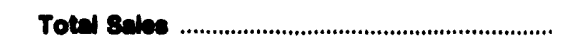 & $130,020,200$ & $128,926,256$ & $128,087,040$ & $121,351,618$ \\
\hline \multicolumn{5}{|l|}{$\begin{array}{l}\text { Operating Rovenues for the Year } \\
\text { (thousend dollare) }\end{array}$} \\
\hline 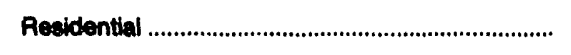 & $2,785,966$ & $2,752,710$ & $2,659,845$ & $2,557,348$ \\
\hline Commercial or Small & $1,412,309$ & $1,680,252$ & $1,596,862$ & $1,453,940$ \\
\hline Industrial or Large & $2,553,829$ & $2,188,095$ & $2,150,794$ & $2,093,283$ \\
\hline Other & 189,783 & 198,756 & 190,987 & 183,333 \\
\hline $\begin{array}{l}\text { Totad Rovenues from Sales to } \\
\text { Uitimate Coneumers }\end{array}$ & $6,941,987$ & $6,819,813$ & $6,590,480$ & $6,207,004$ \\
\hline Sales for Resale & 232,879 & 226,388 & 345,818 & 256,140 \\
\hline $\begin{array}{l}\text { Total Rovenues From Sabe of } \\
\text { Eloctrictly }\end{array}$ & $7,174,866$ & $7,046,201$ & $8,844,306$ & $6,544,044$ \\
\hline
\end{tabular}

Note: Totals may not equal sum of components because of independent rounding. Detailed data are provided in Table 25. The number of publicly owned nongenerating electric utilities for end of period is 258 for 1992, 252 for 1991, 251 for 1990 , and 240 for 1989 . Emerald Peoples Utility District (OR), City of Bryan (OH), and Northern Wasco County PUD (OR) were nongenerators for 1989 through 1991, but became generators in 1992. Illinois Municipal Electric Agency (IL) and Wisconsin Public Power Incorporated System (WI) were nongenerators in 1989 and 1990, but became generators in 1991. The City of Marchfield (WI) was a generator in 1989 and 1990 , but became a nongenerator in 1991.

Source: Energy Information Administration, Form ElA-861, "Annual Electric Utility Report." Data are based on calendar year submissions. 
Table 20. Electric Energy Account for Major U.S. Publicly Owned Nongenerator Electric Utilities, 1989-1992

(Megawatthours)

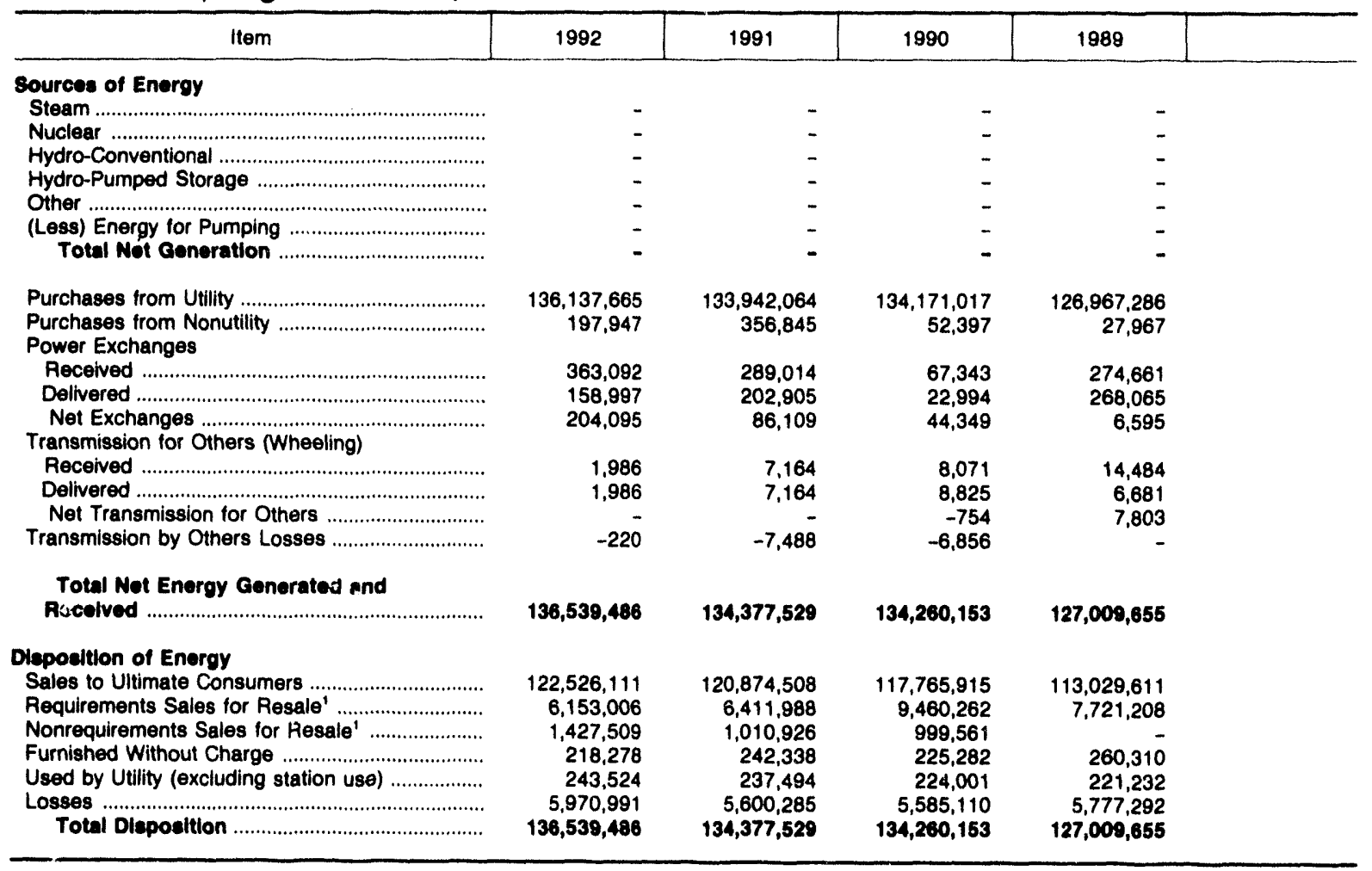

1 The 1989 data were reported as Sales for Resale (one entry) which is shown as Requirements Sales for Resale.

Note: Totals may not equal sum of components because of independent rounding. Detailed data are provided in Table 26. The num. ber of publicly owned nongenerating electric utilities for end of perict is 258 for 1982,252 for 1991,251 for 1990 , and 240 for 1989 . Emerald Peoples Utility District (OR), City of Bryan (OH), and Northern Wasco County PUD (OR) were nongenerators for 1989 through 1991 , but became generators in 1992. Illinois Municipal Electric Agency (IL) and Wisconsin Public Power Incorporated System (WI) were nongenerators in 1989 and 1990, but became generators in 1991. Tho City of Marchfield (WI) was a generator in 1989 and 1990 , but became a nongenerator in 1991. Double counting occurs in components of both sources and disposition of energy and thus neither provides a true total. Purchases from utilities, net exchanges, and net wheeling (except for imports) are included in net generation. Sales for resale is in cluded in sales to ultimate consumers.

Source: Energy Informaion Administration, Form ElA-412, "Annual Report of Public Electric Utilities." Individual electric utilities report fiscal year data. Appendix $B$ shows the fiscal year for each electric utility. 


\section{Detailed Statistics of Major U.S. Publicly Owned Electric Utilities}

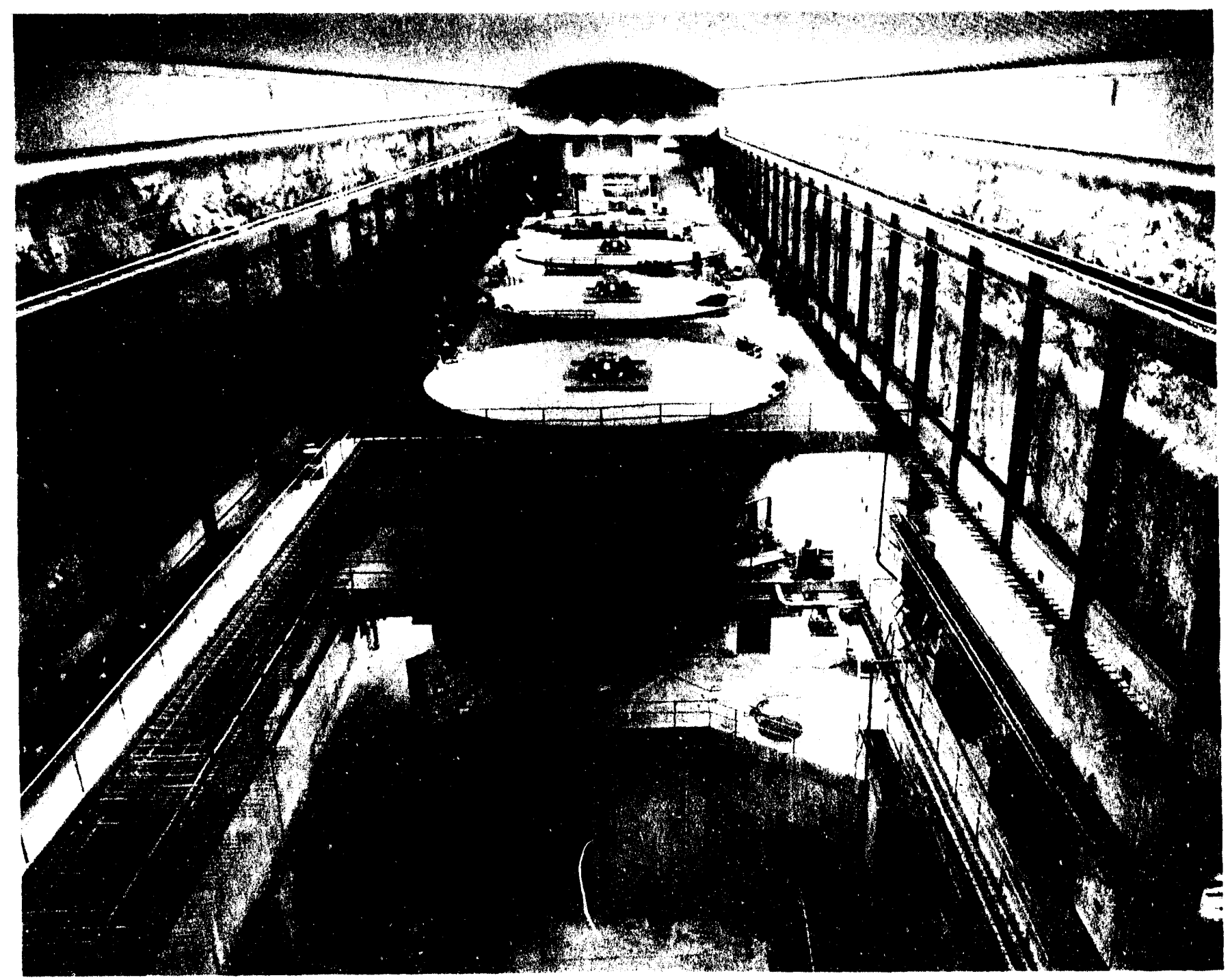

The underground powerhouse of Boundary Dam is located in Pend Oreille County, State of Washington, and owned by the City of Seattle. 
Table 21. Statement of Income by Major U.S. Publicly Owned Electric Utility
Within State, 1992 (Thousand Dollars)

\begin{tabular}{|c|c|c|c|c|c|c|}
\hline Item & $\begin{array}{l}\text { Alabama } \\
\text { Alabama } \\
\text { Municipal } \\
\text { Elec Auth } \\
\text { September } 30\end{array}$ & $\begin{array}{l}\text { Alabama } \\
\text { Albertville } \\
\text { Municipal } \\
\text { Utils Bd } \\
\text { June } 30 \\
\end{array}$ & $\begin{array}{c}\text { Alabama } \\
\text { Andalusia } \\
\text { City of } \\
\text { September } 30\end{array}$ & $\begin{array}{c}\text { Alabama } \\
\text { Athens } \\
\text { City of } \\
\text { December } 31\end{array}$ & $\begin{array}{l}\text { Alabama } \\
\text { Bessemer } \\
\text { City of } \\
\text { June } 30\end{array}$ & $\begin{array}{l}\text { Alabama } \\
\text { Cullman } \\
\text { Power Board } \\
\text { June } 30\end{array}$ \\
\hline Electric Utilty Operating Rovenues ............. & 80,400 & 19,154 & 13,719 & 34,647 & 17,111 & 16,008 \\
\hline 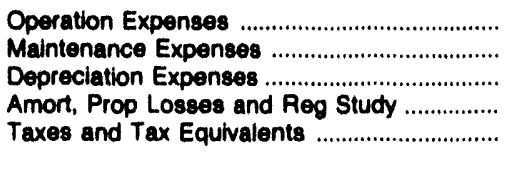 & $\begin{array}{r}69,703 \\
0 \\
13 \\
0 \\
744\end{array}$ & $\begin{array}{r}17.574 \\
437 \\
496 \\
0 \\
354\end{array}$ & $\begin{array}{r}11,998 \\
133 \\
324 \\
0 \\
0\end{array}$ & $\begin{array}{r}31,343 \\
832 \\
874 \\
0 \\
817\end{array}$ & $\begin{array}{r}14,599 \\
551 \\
653 \\
0 \\
795\end{array}$ & $\begin{array}{r}15.132 \\
397 \\
289 \\
0 \\
224\end{array}$ \\
\hline $\begin{array}{l}\text { Total Electric Utility Operating } \\
\text { Expenese }\end{array}$ & 70,460 & 18,801 & 12,465 & 33,867 & 16,698 & 16,051 \\
\hline $\begin{array}{l}\text { Net Electric Utility Operating income } \\
\text { Income from Electric Plant Leased } \\
\text { to Others }\end{array}$ & $\begin{array}{r}17,940 \\
0\end{array}$ & $\begin{array}{r}292 \\
0\end{array}$ & 1,264 & 780 & 513 & 45 \\
\hline Electric Utility Operating income .............. & 17,940 & 292 & 1,264 & 780 & 513 & 46 \\
\hline 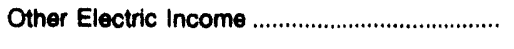 & 6,213 & 270 & 353 & 1,031 & 115 & 206 \\
\hline Other Electric Deductions .......................... & 11,067 & 4 & 1,649 & 0 & 0 & 1 \\
\hline 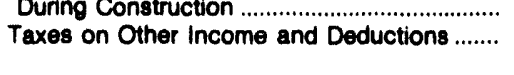 & $\begin{array}{l}0 \\
0\end{array}$ & $\begin{array}{l}0 \\
0\end{array}$ & $\begin{array}{l}0 \\
0\end{array}$ & $\begin{array}{l}0 \\
0\end{array}$ & $\begin{array}{l}0 \\
0\end{array}$ & $\begin{array}{l}0 \\
0\end{array}$ \\
\hline 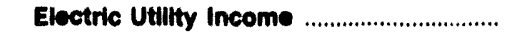 & 13,086 & 558 & -32 & 1,812 & 627 & 280 \\
\hline $\begin{array}{l}\text { Income Deductions from Interest } \\
\text { on Long-term Debt ..................................... } \\
\text { Other Income Deductions .............................. } \\
\text { Allowance for Borrowed Funds Used }\end{array}$ & $\begin{array}{r}13,044 \\
0\end{array}$ & $\begin{array}{l}0 \\
0\end{array}$ & $\begin{array}{l}0 \\
0\end{array}$ & $\begin{array}{r}1,312 \\
36\end{array}$ & $\begin{array}{r}168 \\
0\end{array}$ & $\begin{array}{r}100 \\
3\end{array}$ \\
\hline 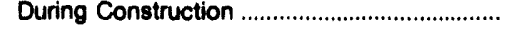 & 0 & 0 & 0 & 0 & 0 & 0 \\
\hline 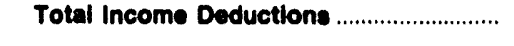 & 13,044 & 0 & 0 & 1,349 & 168 & 103 \\
\hline Income Before Extraordinary Items ................... & 42 & 558 & -32 & 463 & 459 & 147 \\
\hline Extraordinary Income & 0 & 107 & 0 & 0 & 0 & 0 \\
\hline 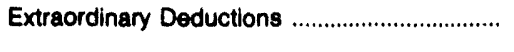 & 0 & 0 & 0 & 0 & 170 & 0 \\
\hline Not Incomø & 42 & 664 & -32 & 463 & 290 & 147 \\
\hline
\end{tabular}

Note: Totals may not equal sum of components because of independent rounding.

Source: Energy Information Administration, Form ElA-412, "Annual Report of Public Electric Utilities." 
Table 21. Statement of Income by Major U.S. Publicly Owned Electric Utility Within State, 1992 (Continued)

(Thousand Dollars)

\begin{tabular}{|c|c|c|c|c|c|c|}
\hline Item & $\begin{array}{l}\text { Alabama } \\
\text { Decatur } \\
\text { Clty of } \\
\text { June } 30\end{array}$ & $\begin{array}{l}\text { Alabama } \\
\text { Dothan } \\
\text { Clty of } \\
\text { Septomber } 30\end{array}$ & $\begin{array}{l}\text { Alabama } \\
\text { Florence } \\
\text { Cthy of } \\
\text { June } 30\end{array}$ & $\begin{array}{c}\text { Alabama } \\
\text { Foley } \\
\text { Clty of } \\
\text { (Riviera Utils) } \\
\text { December } 31\end{array}$ & $\begin{array}{l}\text { Alabama } \\
\text { Fort Payne } \\
\text { Improvement } \\
\text { Auth } \\
\text { June } 30\end{array}$ & $\begin{array}{l}\text { Alabama } \\
\text { Guntersville } \\
\text { Electric } \\
\text { Board } \\
\text { June } 30\end{array}$ \\
\hline Eleotric Utinty Operating Rovenues ............. & 89,420 & 69,041 & 68,909 & 30,473 & 16,317 & 11,303 \\
\hline 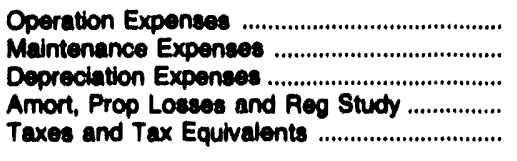 & $\begin{array}{r}56,572 \\
738 \\
1,144 \\
33 \\
249\end{array}$ & $\begin{array}{r}39,200 \\
999 \\
1,889 \\
0 \\
0\end{array}$ & $\begin{array}{r}49,085 \\
1,699 \\
2,017 \\
0 \\
1,876\end{array}$ & $\begin{array}{r}21,913 \\
634 \\
1,754 \\
0 \\
2,413\end{array}$ & $\begin{array}{r}14,267 \\
326 \\
274 \\
0 \\
243\end{array}$ & $\begin{array}{r}10,327 \\
286 \\
255 \\
0 \\
215\end{array}$ \\
\hline $\begin{array}{l}\text { Total Electrle Utuiny Opornting } \\
\text { Expensece }\end{array}$ & 50,496 & 42,000 & 54,678 & 26,714 & 16,111 & 11,003 \\
\hline 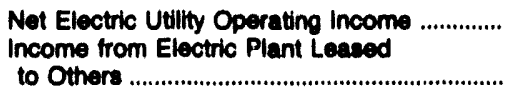 & $\begin{array}{r}-15 \\
0\end{array}$ & $\begin{array}{r}10,953 \\
0\end{array}$ & $\begin{array}{r}1,312 \\
0\end{array}$ & $\begin{array}{r}3,759 \\
5\end{array}$ & $\begin{array}{r}206 \\
0\end{array}$ & $\begin{array}{r}280 \\
0\end{array}$ \\
\hline Electric Utility Operating Inooms .............. & -16 & 10,953 & 1,312 & 3,784 & 206 & 280 \\
\hline 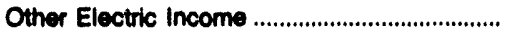 & 529 & 0 & 1,154 & 496 & 276 & 154 \\
\hline 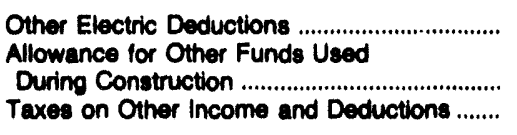 & $\begin{array}{l}0 \\
0\end{array}$ & $\begin{array}{l}0 \\
0\end{array}$ & $\begin{array}{l}0 \\
0\end{array}$ & $\begin{array}{l}0 \\
0\end{array}$ & $\begin{array}{l}0 \\
0\end{array}$ & $\begin{array}{l}0 \\
0 \\
0\end{array}$ \\
\hline 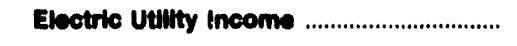 & 513 & 10,063 & 2,467 & 4,261 & 482 & 434 \\
\hline 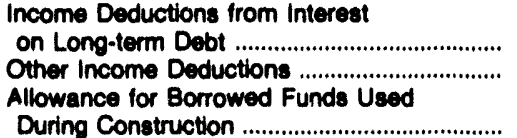 & $\begin{array}{l}0 \\
0\end{array}$ & $\begin{array}{l}0 \\
0\end{array}$ & $\begin{array}{l}391 \\
223\end{array}$ & $\begin{array}{r}849 \\
20 \\
0\end{array}$ & $\begin{array}{r}355 \\
31\end{array}$ & $\begin{array}{l}\theta \\
n\end{array}$ \\
\hline 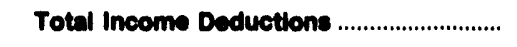 & $\mathbf{0}$ & $\mathbf{0}$ & 614 & 800 & 386 & 9 \\
\hline Income Before Extraordinary Items ...................... & 513 & 10,953 & 1,853 & 3,391 & 96 & 424 \\
\hline 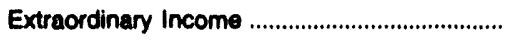 & 0 & 0 & 0 & 0 & 0 & 0 \\
\hline 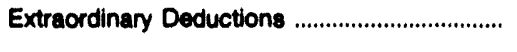 & 0 & 0 & 0 & 0 & 0 & 0 \\
\hline 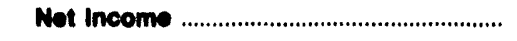 & 513 & 10,063 & 1,853 & 3,391 & $\bullet$ & 424 \\
\hline
\end{tabular}

Note: Totals may not equal sum of components because of independent rounding.

Source: Energy Information Administration, Form ElA-412, "Annual Peport of Public Electric Utilities." 
Table 21. Statement of Income by Major U.S. Publicly Owned Electric Utility Within State, 1992 (Continued)

(Thousand Dollars)

\begin{tabular}{|c|c|c|c|c|c|c|}
\hline Item & $\begin{array}{l}\text { Alabama } \\
\text { Huntsville } \\
\text { City of } \\
\text { September } 30\end{array}$ & $\begin{array}{l}\text { Alabama } \\
\text { Muscle } \\
\text { Shoals } \\
\text { City of } \\
\text { June } 30\end{array}$ & $\begin{array}{c}\text { Alabama } \\
\text { Opelika } \\
\text { Clty of } \\
\text { September } 30\end{array}$ & $\begin{array}{l}\text { Alabama } \\
\text { Scottsboro } \\
\text { City of } \\
\text { June } 30\end{array}$ & $\begin{array}{l}\text { Alabama } \\
\text { Sheffield } \\
\text { Utilities } \\
\text { June } 30\end{array}$ & $\begin{array}{l}\text { Alabama } \\
\text { Sylacauga } \\
\text { Utilities } \\
\text { Board } \\
\text { September } 30\end{array}$ \\
\hline Electrie Utility Operating Rovenues ............ & 184,925 & 10,777 & 17,280 & 16,036 & 23,484 & 10,178 \\
\hline 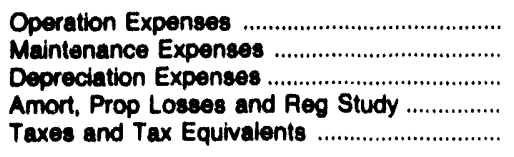 & $\begin{array}{r}170,002 \\
2,829 \\
4,539 \\
0 \\
4,598\end{array}$ & $\begin{array}{r}9,129 \\
221 \\
364 \\
0 \\
333\end{array}$ & $\begin{array}{r}13,422 \\
521 \\
525 \\
0 \\
0\end{array}$ & $\begin{array}{r}14,570 \\
544 \\
429 \\
0 \\
300\end{array}$ & $\begin{array}{r}20,641 \\
917 \\
919 \\
21 \\
641\end{array}$ & $\begin{array}{r}7,162 \\
185 \\
783 \\
0 \\
0\end{array}$ \\
\hline $\begin{array}{l}\text { Total Electrle Utilty Operating } \\
\text { Expenses }\end{array}$ & 181,087 & 10,347 & 14,468 & 15,843 & 23,139 & 8,130 \\
\hline $\begin{array}{l}\text { Net Electric Utility Operating Income ............. } \\
\text { Income from Electric Plant Leased } \\
\text { to Others }\end{array}$ & $\begin{array}{r}2,958 \\
0\end{array}$ & $\begin{array}{r}430 \\
0\end{array}$ & $\begin{array}{r}2,801 \\
0\end{array}$ & $\begin{array}{r}193 \\
0\end{array}$ & $\begin{array}{r}345 \\
0\end{array}$ & $\begin{array}{r}2,048 \\
0\end{array}$ \\
\hline Electric Utility Operating Income .............. & 2,958 & 430 & 2,801 & 193 & 345 & 2,048 \\
\hline 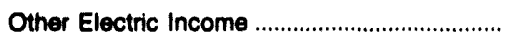 & 4,480 & 152 & 276 & 193 & 566 & 0 \\
\hline $\begin{array}{l}\text { Other Electric Deductions ................................. } \\
\text { Allowance for Other Funds Used }\end{array}$ & 0 & 1 & 124 & 0 & 24 & 955 \\
\hline $\begin{array}{l}\text { During Construction ..................................... } \\
\text { Taxes on Other Income and Deductions ...... }\end{array}$ & $\begin{array}{l}0 \\
0\end{array}$ & $\begin{array}{l}0 \\
0\end{array}$ & $\begin{array}{l}0 \\
0\end{array}$ & $\begin{array}{l}0 \\
0\end{array}$ & $\begin{array}{l}0 \\
0\end{array}$ & $\begin{array}{l}0 \\
0\end{array}$ \\
\hline Electric Utilty Ineome ..................................... & 7,438 & 581 & 2,854 & 387 & 887 & 1,003 \\
\hline 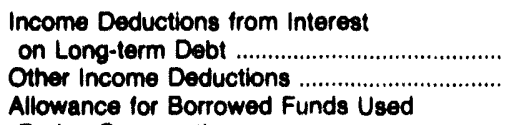 & $\begin{array}{l}572 \\
436\end{array}$ & $\begin{array}{r}71 \\
3\end{array}$ & $\begin{array}{r}166 \\
2,598\end{array}$ & $\begin{array}{r}316 \\
20\end{array}$ & $\begin{array}{r}110 \\
1\end{array}$ & $\begin{array}{r}172 \\
0\end{array}$ \\
\hline 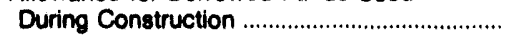 & 0 & 0 & 0 & 0 & 0 & 0 \\
\hline 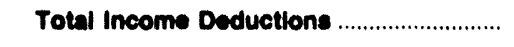 & 1,008 & 75 & 2,764 & 338 & 111 & 172 \\
\hline Income Before Extraordinary Items ................. & 6,430 & 506 & 190 & 51 & 776 & 921 \\
\hline Extraordinary Income & 0 & 0 & 0 & 0 & 0 & 0 \\
\hline 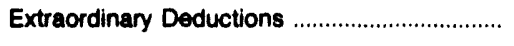 & 0 & 0 & 0 & 0 & 0 & 0 \\
\hline Net Income & 6,430 & 506 & 190 & 51 & 776 & 921 \\
\hline
\end{tabular}

Note: Totals may not equal sum of components because of independent rounding.

Source: Energy Information Administration, Form ElA-412, "Annual Report of Public Electric Utilities." 
Table 21. Statement of Income by Major U.S. Publlcly Owned Electric UtIlity Within State, 1992 (Continued)

(Thousand Dollars)

\begin{tabular}{|c|c|c|c|c|c|c|}
\hline Item & $\begin{array}{c}\text { Alabama } \\
\text { Troy } \\
\text { City of } \\
\text { September } 30\end{array}$ & $\begin{array}{l}\text { Alabama } \\
\begin{array}{c}\text { Tuskegee } \\
\text { City of }\end{array} \\
\text { September } 30\end{array}$ & $\begin{array}{l}\text { Alaska } \\
\text { Alaska } \\
\text { Energy } \\
\text { Authority } \\
\text { June } 30\end{array}$ & $\begin{array}{c}\text { Alaska } \\
\text { Anchorage } \\
\text { City of } \\
\text { December } 31\end{array}$ & $\begin{array}{l}\text { Alaska } \\
\text { Fairbanks } \\
\text { Clty of } \\
\text { December } 31\end{array}$ & $\begin{array}{l}\text { Alaska } \\
\text { Ketchikan } \\
\text { City of } \\
\text { December } 31\end{array}$ \\
\hline Ebotric Utilly Operating Rovonues ............. & 11,204 & 8,289 & 25,632 & 67,633 & 15,389 & 10,584 \\
\hline 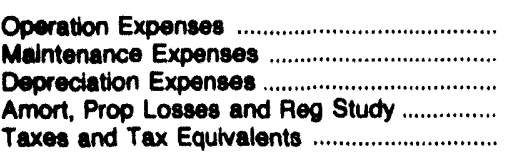 & $\begin{array}{r}8,645 \\
120 \\
0 \\
0 \\
1,823\end{array}$ & $\begin{array}{r}7.289 \\
179 \\
280 \\
0 \\
231\end{array}$ & $\begin{array}{r}4,765 \\
0 \\
22,414 \\
0 \\
0\end{array}$ & $\begin{array}{r}37,534 \\
2,629 \\
11,874 \\
511 \\
1,760\end{array}$ & $\begin{array}{r}11,238 \\
564 \\
1,782 \\
0 \\
938\end{array}$ & $\begin{array}{r}7,595 \\
940 \\
1,148 \\
0 \\
298\end{array}$ \\
\hline $\begin{array}{l}\text { Total Electric Utillty Oporating } \\
\text { Expor }\end{array}$ & 10,689 & 7,979 & 27,178 & 54,300 & 14,520 & 0,002 \\
\hline $\begin{array}{l}\text { Net Electric Utility Operating Income .............. } \\
\text { Income from Electric Plant Leased } \\
\text { to Others }\end{array}$ & $\begin{array}{r}616 \\
0\end{array}$ & $\begin{array}{r}310 \\
0\end{array}$ & $\begin{array}{r}-1,547 \\
0\end{array}$ & $\begin{array}{r}13,225 \\
0\end{array}$ & $\begin{array}{r}869 \\
0\end{array}$ & $\begin{array}{r}612 \\
0\end{array}$ \\
\hline Electrle Utinty Operating Incoms ............. & 616 & 310 & $-1,547$ & 13,225 & 869 & 612 \\
\hline Other Electric Income & 601 & 462 & 40,975 & 3,136 & 152 & 367 \\
\hline $\begin{array}{l}\text { Other Electric Deductions } \\
\text { Allowance for Other Funds Used }\end{array}$ & 0 & 33 & 0 & 0 & 0 & 0 \\
\hline 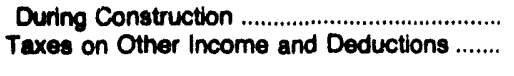 & $\begin{array}{l}0 \\
0\end{array}$ & $\begin{array}{l}0 \\
0\end{array}$ & $\begin{array}{l}0 \\
0\end{array}$ & $\begin{array}{l}0 \\
0\end{array}$ & $\begin{array}{r}24 \\
0\end{array}$ & $\begin{array}{l}0 \\
0\end{array}$ \\
\hline 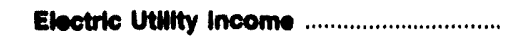 & 1,216 & 730 & 39,428 & 16,361 & 1,045 & 900 \\
\hline $\begin{array}{l}\text { Income Deductions from Interest } \\
\text { on Long-term Debt ....................................... } \\
\text { Other Income Deductions ......................... } \\
\text { Allowance for Borrowed Funds Used }\end{array}$ & $\begin{array}{l}471 \\
785\end{array}$ & $\begin{array}{r}333 \\
0\end{array}$ & $\begin{array}{l}20,882 \\
34,485\end{array}$ & $\begin{array}{r}13,245 \\
2,606\end{array}$ & $\begin{array}{r}1,376 \\
0\end{array}$ & $\begin{array}{r}355 \\
14\end{array}$ \\
\hline 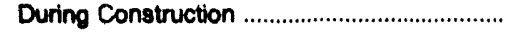 & 0 & 0 & 0 & 0 & 0 & 0 \\
\hline 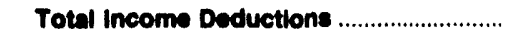 & 1,257 & 333 & 55,367 & 15,850 & 1,376 & 308 \\
\hline 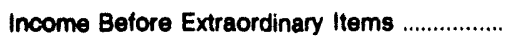 & -41 & 406 & $-15,939$ & 511 & -332 & 610 \\
\hline 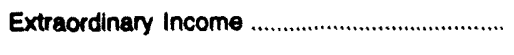 & 0 & 563 & 0 & 0 & 0 & 92 \\
\hline 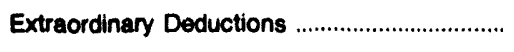 & 0 & 168 & 3,000 & 0 & 0 & 0 \\
\hline Not Income & -41 & 801 & $-18,930$ & 511 & -332 & 702 \\
\hline
\end{tabular}

Note: Totals may not equal sum of components because of independent rounding.

Source: Energy Information Administration, Form ElA-412, "Annual Report of Public Electric Utilities." 
Table 21. Statement of Income by Major U.S. Publicly Owned Electric Utility Within State, 1992 (Continued)

(Thousand Dollars)

\begin{tabular}{|c|c|c|c|c|c|c|}
\hline Item & $\begin{array}{l}\text { Arizona } \\
\text { Arizona } \\
\text { Power } \\
\text { Authority } \\
\\
\text { June } 30\end{array}$ & $\begin{array}{c}\text { Arizona } \\
\text { Electrical } \\
\text { Dist } \\
\text { No2 } \\
\text { Pinal Cnty } \\
\text { December } 31\end{array}$ & $\begin{array}{l}\text { Arizona } \\
\text { Mesa } \\
\text { City of } \\
\text { June } 30\end{array}$ & $\begin{array}{l}\text { Arizona } \\
\text { Navajo } \\
\text { Tribal } \\
\text { Utility } \\
\text { Auth } \\
\text { December } 31\end{array}$ & $\begin{array}{l}\text { Arizona } \\
\text { Salt River } \\
\text { Prol Ag } \\
\text { I \& P Dist } \\
\text { April } 30\end{array}$ & $\begin{array}{l}\text { Arizona } \\
\text { Tohono } \\
\text { OOdham } \\
\text { Utility Auth } \\
\text { December } 31\end{array}$ \\
\hline Eloctro Utinty Operating Rovenuse ............ & 16,669 & 7,202 & 20,657 & 31,687 & $1,176,736$ & 8,705 \\
\hline 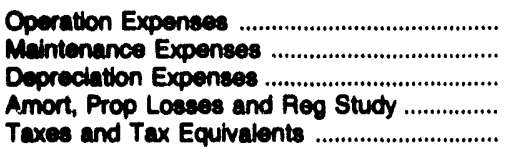 & $\begin{array}{r}17,510 \\
0 \\
75 \\
0 \\
0\end{array}$ & $\begin{array}{r}6,310 \\
347 \\
541 \\
0 \\
0\end{array}$ & $\begin{array}{r}15,351 \\
1,737 \\
1,347 \\
-2,744 \\
0\end{array}$ & $\begin{array}{r}25,976 \\
1,393 \\
3,255 \\
0 \\
0\end{array}$ & $\begin{array}{r}485,389 \\
91,731 \\
156,317 \\
0 \\
162,670\end{array}$ & $\begin{array}{r}7,899 \\
209 \\
268 \\
0 \\
0\end{array}$ \\
\hline 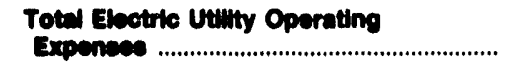 & 17,685 & 7,198 & 15,691 & 30,624 & 896,107 & 8,376 \\
\hline $\begin{array}{l}\text { Net Electric Utility Operating Income .............. } \\
\text { Income from Electric Plant Leased }\end{array}$ & -916 & 3 & 4,966 & 1,063 & 280,629 & 330 \\
\hline 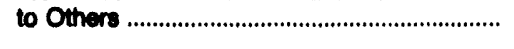 & 0 & 0 & 0 & 0 & 217 & 0 \\
\hline Electrle Utilty Operating Income .............. & -916 & 3 & 4,866 & 1,063 & 280,846 & 330 \\
\hline 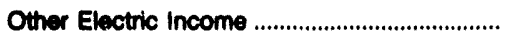 & 4,728 & 684 & 330 & 381 & 33,552 & 65 \\
\hline $\begin{array}{l}\text { Other Electric Deductions ................................. } \\
\text { Allowance for Other Funds Used }\end{array}$ & 0 & 0 & 0 & 369 & 117 & 0 \\
\hline 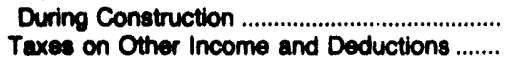 & $\begin{array}{l}0 \\
0\end{array}$ & $\begin{array}{l}0 \\
0\end{array}$ & $\begin{array}{l}0 \\
0\end{array}$ & $\begin{array}{l}0 \\
0\end{array}$ & $\begin{array}{l}4 \\
0\end{array}$ & $\begin{array}{l}0 \\
0\end{array}$ \\
\hline 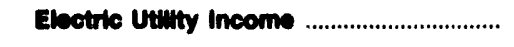 & 3,812 & 687 & 5,296 & 1,075 & 314,284 & 324 \\
\hline $\begin{array}{l}\text { Income Dectuctions from Interest } \\
\text { on Long-term Deht ............................................ } \\
\text { Other Income Deductions ................................. } \\
\text { Alowance for Borrowed Funds Used }\end{array}$ & $\begin{array}{r}3,335 \\
965\end{array}$ & $\begin{array}{l}0 \\
0\end{array}$ & $\begin{array}{r}163 \\
0\end{array}$ & $\begin{array}{r}1,204 \\
0\end{array}$ & $\begin{array}{r}241,913 \\
1,183\end{array}$ & $\begin{array}{r}216 \\
0\end{array}$ \\
\hline 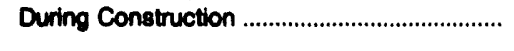 & 0 & 0 & 0 & -83 & 0 & 0 \\
\hline 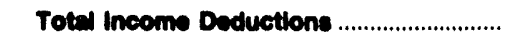 & 4,300 & 0 & 163 & 1,121 & 243,097 & 216 \\
\hline Income Before Extraordinary Items .................. & -488 & 687 & 5,133 & -47 & 71,188 & 178 \\
\hline 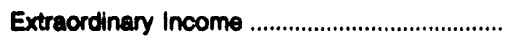 & 0 & 0 & 0 & 0 & 0 & 0 \\
\hline 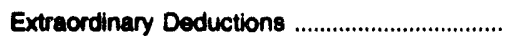 & 0 & 0 & 0 & 0 & 0 & 0 \\
\hline 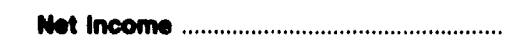 & -488 & 687 & 5,133 & -47 & 71,188 & 178 \\
\hline
\end{tabular}

Note: Totals may not equal sum of components because of independent rounding.

Source: Energy Information Administration, Form ElA-412, "Annual Report of Public Electric Utilities." 
Table 21. Statement of Income by Major U.S. Publicly Owned Electric Utillty Within State, 1992 (Continued)

(Thousand Dollars)

\begin{tabular}{|c|c|c|c|c|c|c|}
\hline Item & $\begin{array}{l}\text { Arkanses } \\
\text { Benton } \\
\text { Clty of } \\
\text { December } 31\end{array}$ & $\begin{array}{l}\text { Arkansas } \\
\text { Bentonville } \\
\text { City of } \\
\text { December } 31\end{array}$ & $\begin{array}{l}\text { Arkansas } \\
\text { Conway } \\
\text { Corp } \\
\text { December } 31\end{array}$ & $\begin{array}{c}\text { Arkansas } \\
\text { Hope } \\
\text { City of } \\
\text { December } 31\end{array}$ & $\begin{array}{c}\text { Arkansas } \\
\text { Jonesboro } \\
\text { City of } \\
\text { December } 31\end{array}$ & $\begin{array}{c}\text { Arkansas } \\
\text { North } \\
\text { Little } \\
\text { Rock } \\
\text { City of } \\
\text { December } 31\end{array}$ \\
\hline Electric Utilly Operating Aovenues ............ & 12,823 & 8,713 & 22,716 & 10,853 & 34,154 & 50,785 \\
\hline 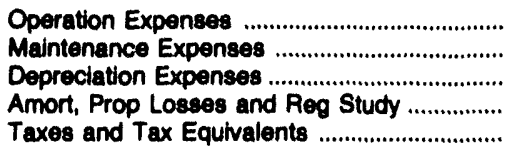 & $\begin{array}{r}8,437 \\
232 \\
235 \\
602 \\
539\end{array}$ & $\begin{array}{r}6,968 \\
152 \\
103 \\
0 \\
456\end{array}$ & $\begin{array}{r}15,725 \\
1,125 \\
2,149 \\
0 \\
532\end{array}$ & $\begin{array}{r}7,744 \\
427 \\
489 \\
0 \\
33\end{array}$ & $\begin{array}{r}21,791 \\
1,307 \\
5,428 \\
0 \\
222\end{array}$ & $\begin{array}{r}33,539 \\
1,433 \\
3,715 \\
0 \\
490\end{array}$ \\
\hline $\begin{array}{l}\text { Total Electrlc Utility Operating } \\
\text { Expenees }\end{array}$ & 10,045 & 7,679 & 19,531 & 8,393 & 28,748 & 30,176 \\
\hline $\begin{array}{l}\text { Net Electric Utility Operating Income .............. } \\
\text { Income from Electric Plant Leased } \\
\text { to Others }\end{array}$ & $\begin{array}{r}2,778 \\
0\end{array}$ & $\begin{array}{r}1,034 \\
0\end{array}$ & $\begin{array}{r}3,184 \\
0\end{array}$ & $\begin{array}{r}2,160 \\
0\end{array}$ & $\begin{array}{r}5,407 \\
0\end{array}$ & $\begin{array}{r}20,588 \\
0\end{array}$ \\
\hline Electrle Utilty Operating Income .............. & 2,778 & 1,034 & 3,184 & 2,160 & 5,407 & 20,580 \\
\hline 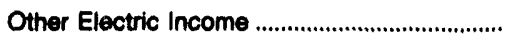 & 663 & 0 & 774 & 0 & 1,372 & 2,083 \\
\hline $\begin{array}{l}\text { Other Electric Deductions } \\
\text { Allowance for Other Funds Used }\end{array}$ & 0 & 0 & 0 & 523 & 0 & 7,266 \\
\hline 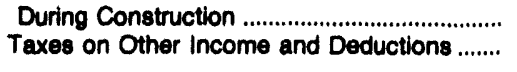 & $\begin{array}{l}0 \\
0\end{array}$ & $\begin{array}{l}0 \\
0\end{array}$ & $\begin{array}{l}0 \\
0\end{array}$ & $\begin{array}{l}0 \\
0\end{array}$ & $\begin{array}{r}108 \\
0\end{array}$ & $\begin{array}{l}0 \\
0\end{array}$ \\
\hline Electric Utility Income & 3,441 & 1,084 & 3,058 & 1,637 & 6,886 & 15,406 \\
\hline $\begin{array}{l}\text { Income Deductions from interest } \\
\text { on Long-term Debt ..................................... } \\
\text { Other Income Deductions ......................... } \\
\text { Allowance for Borrowed Funds Used } \\
\text { During Construction }\end{array}$ & $\begin{array}{l}0 \\
0\end{array}$ & $\begin{array}{r}118 \\
0\end{array}$ & $\begin{array}{r}2,042 \\
17\end{array}$ & $\begin{array}{l}0 \\
0\end{array}$ & $\begin{array}{r}3,925 \\
171\end{array}$ & $\begin{array}{r}11,590 \\
0 \\
0\end{array}$ \\
\hline Total Income Deductiona ............................... & o & 118 & 2,059 & $\mathbf{0}$ & 4,203 & 11,500 \\
\hline 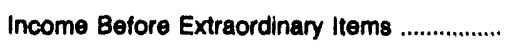 & 3,441 & 816 & 1,899 & 1,637 & 2,683 & 3,815 \\
\hline Extraordinary Income & 0 & 0 & 0 & 0 & 0 & 360 \\
\hline 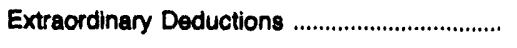 & 0 & 0 & 0 & 0 & 0 & 10,365 \\
\hline Not Income & 3,441 & 916 & 1,899 & 1,637 & 2,693 & $-6,190$ \\
\hline
\end{tabular}

Note: Totals may not equal sum of components because of independent rounding.

Sourcs: Energy Information Administration, Form ElA-412, "Annual Report of Public Electric Utilities." 
Table 21. Statement of Income by Major U.S. Publicly Owned Electric Utility Within State, 1992 (Continued)

(Thousand Dollars)

\begin{tabular}{|c|c|c|c|c|c|c|}
\hline Item & $\begin{array}{l}\text { Artcanases } \\
\text { Osceola } \\
\text { City of } \\
\text { December } 31\end{array}$ & $\begin{array}{c}\text { Arkansas } \\
\text { Paragould } \\
\text { Loht } \\
\text { Water Comm } \\
\text { December } 31\end{array}$ & $\begin{array}{c}\text { Arkanaas } \\
\text { Slloam } \\
\text { Springa } \\
\text { City of } \\
\text { December } 31\end{array}$ & $\begin{array}{c}\text { Arkansas } \\
\text { West } \\
\text { Memphis } \\
\text { City of } \\
\text { Decenber } 31\end{array}$ & $\begin{array}{l}\text { California } \\
\text { Alameda } \\
\text { City of } \\
\text { June } 30\end{array}$ & $\begin{array}{l}\text { California } \\
\text { Anaheim } \\
\text { City of } \\
\text { June } 30\end{array}$ \\
\hline Ebotis Utinty Operating Rovenues ............ & 0,020 & 11,280 & 9,109 & 20,026 & $42, \bullet 28$ & 218,440 \\
\hline 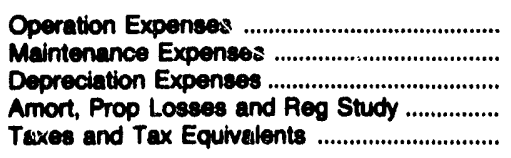 & $\begin{array}{r}7,179 \\
136 \\
41 \\
0 \\
0\end{array}$ & $\begin{array}{r}8,017 \\
0 \\
831 \\
0 \\
0\end{array}$ & $\begin{array}{r}6,179 \\
184 \\
168 \\
0 \\
0\end{array}$ & $\begin{array}{r}12,580 \\
245 \\
5,530 \\
0 \\
731\end{array}$ & $\begin{array}{r}34,585 \\
559 \\
1,480 \\
0 \\
0\end{array}$ & $\begin{array}{r}158,823 \\
19,847 \\
11,106 \\
869 \\
0\end{array}$ \\
\hline Totel Electurc Utilty Operat'ng & 7,746 & 0,849 & 6,630 & 19,098 & 38,604 & 190,745 \\
\hline 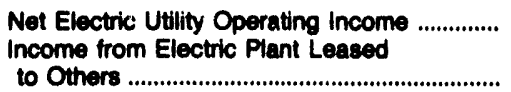 & $\begin{array}{r}1,188 \\
0\end{array}$ & $\begin{array}{r}2,381 \\
0\end{array}$ & $\begin{array}{r}2,649 \\
0\end{array}$ & $\begin{array}{r}839 \\
0\end{array}$ & $\begin{array}{r}6,362 \\
0\end{array}$ & $\begin{array}{r}27,695 \\
0\end{array}$ \\
\hline Electric Utilty Operating Incoms .............. & 1,143 & 2,301 & 2,040 & थs० & 6,382 & 27,605 \\
\hline 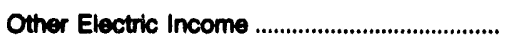 & 0 & 84 & 0 & 1,105 & 1,059 & 6,935 \\
\hline $\begin{array}{l}\text { Other Electric Deductions ................................... } \\
\text { Allowance for Other Funds Used }\end{array}$ & 0 & 0 & 1,638 & 0 & 0 & 0 \\
\hline $\begin{array}{l}\text { During Construction ....................................... } \\
\text { Taxes on Other Income and Deductions ....... }\end{array}$ & $\begin{array}{l}0 \\
0\end{array}$ & $\begin{array}{l}0 \\
0\end{array}$ & $\begin{array}{l}0 \\
0\end{array}$ & $\begin{array}{l}0 \\
0\end{array}$ & $\begin{array}{l}0 \\
0\end{array}$ & $\begin{array}{l}0 \\
0\end{array}$ \\
\hline 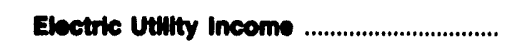 & 1,183 & 2,475 & 1,011 & 2,044 & 7,421 & 34,630 \\
\hline $\begin{array}{l}\text { Income Deductions from Interest } \\
\text { on Long-term Debt ........................................... } \\
\text { Other Income Deductions ............................... } \\
\text { Allowance for Borrowed Funds Used }\end{array}$ & $\begin{array}{r}345 \\
0\end{array}$ & $\begin{array}{r}645 \\
34\end{array}$ & $\begin{array}{l}1 \\
0\end{array}$ & $\begin{array}{r}1,417 \\
152\end{array}$ & $\begin{array}{l}979 \\
899\end{array}$ & $\begin{array}{r}18,098 \\
0\end{array}$ \\
\hline 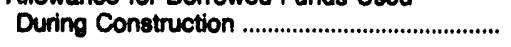 & 0 & 0 & 0 & 0 & 0 & 0 \\
\hline Total income Deductions ............................ & 346 & 679 & 1 & 1,688 & 1,878 & 18,00 \\
\hline Income Betore Extraordinary Items .................. & 838 & 1,786 & 1,011 & 475 & 5,543 & 16,532 \\
\hline 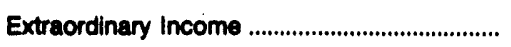 & 0 & 0 & 0 & 128 & 0 & 0 \\
\hline 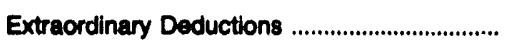 & 0 & 0 & 0 & 0 & 0 & 0 \\
\hline Net Incems & 038 & 1,798 & 1,011 & 603 & 5,543 & 16,632 \\
\hline
\end{tabular}

Note: Totals may not equal sum of components because of independent rounding.

Source: Energy Information Administration, Form ElA-412, "Annual Report of Public Electric Utilities." 
Table 21. Statement of Income by Major U.S. Publicly Owned Electric Utility Within State, 1992 (Continued) (Thousand Dollars)

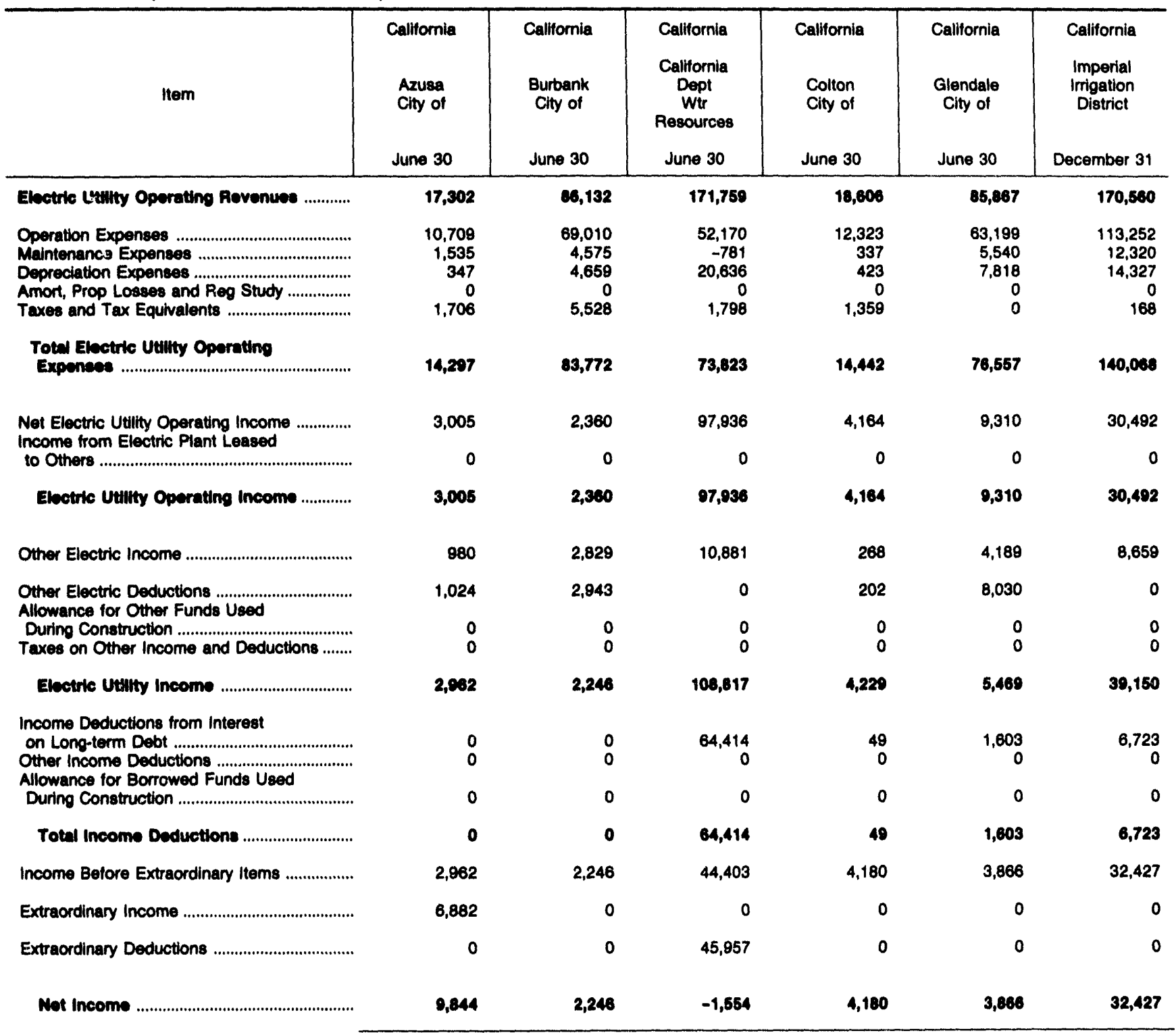

Note: Totals may not equal sum of components because of independent rounding.

Source: Energy Information Administration, Form ElA-412, "Annual Report of Public Electric Utilities." 
Table 21. Statement of Income by Major U.S. Publicly Owned Electric Utility Within State, 1992 (Continued) (Thousand Dollars)

\begin{tabular}{|c|c|c|c|c|c|c|}
\hline Item & $\begin{array}{l}\text { Calfornia } \\
\text { Lodi } \\
\text { City of } \\
\text { June } 30\end{array}$ & $\begin{array}{l}\text { Calfiomia } \\
\text { Los Angeles } \\
\text { City of } \\
\text { June } 30\end{array}$ & $\begin{array}{l}\text { Calliomia } \\
\text { Metropolitan } \\
\text { Water } \\
\text { District } \\
\text { June } 30\end{array}$ & $\begin{array}{l}\text { Calliornia } \\
\text { Modesto } \\
\text { Irigation } \\
\text { District } \\
\text { December } 31\end{array}$ & $\begin{array}{c}\text { California } \\
\text { MSR } \\
\text { Public } \\
\text { Power } \\
\text { Agency } \\
\text { December } 31\end{array}$ & $\begin{array}{l}\text { California } \\
\text { Northern } \\
\text { California } \\
\text { Power Agny } \\
\text { June } 30\end{array}$ \\
\hline Ebetric Utivty Operatho Rovenuse ............. & 34,500 & $1,020,075$ & 13,003 & 127,065 & 44,100 & 168,675 \\
\hline 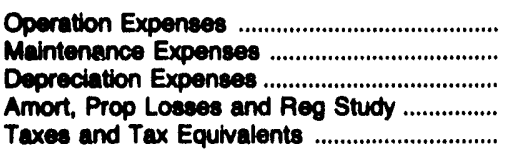 & $\begin{array}{r}29,155 \\
1,434 \\
780 \\
0 \\
0\end{array}$ & $\begin{array}{r}1,304,498 \\
151,945 \\
157,866 \\
0 \\
19,333\end{array}$ & $\begin{array}{r}15,948 \\
0 \\
2,061 \\
0 \\
0\end{array}$ & $\begin{array}{r}83,155 \\
5,089 \\
6,744 \\
0 \\
0\end{array}$ & $\begin{array}{r}18,899 \\
2,699 \\
7,870 \\
460 \\
866\end{array}$ & $\begin{array}{r}81,040 \\
3,099 \\
30,621 \\
0 \\
0\end{array}$ \\
\hline $\begin{array}{l}\text { Totwl Ebetric Utally Operating } \\
\text { Expences }\end{array}$ & 31,370 & $1,633,643$ & 18,000 & 94,090 & 30,003 & 114,700 \\
\hline $\begin{array}{l}\text { Net Electric Utillity Operating Income .............. } \\
\text { Income from Electric Plant Leased } \\
\text { to Others }\end{array}$ & $\begin{array}{r}3,229 \\
0\end{array}$ & $\begin{array}{r}195,433 \\
0\end{array}$ & $\begin{array}{r}-5,006 \\
0\end{array}$ & $\begin{array}{r}32,697 \\
0\end{array}$ & $\begin{array}{r}13,116 \\
0\end{array}$ & $\begin{array}{r}43,815 \\
0\end{array}$ \\
\hline Electric Utilty Operating Income ............. & 3,220 & 195,433 & $-5,008$ & 32,697 & 13,116 & 43,816 \\
\hline 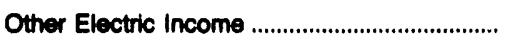 & 399 & 23,578 & 0 & 16,908 & 4,716 & 21,683 \\
\hline 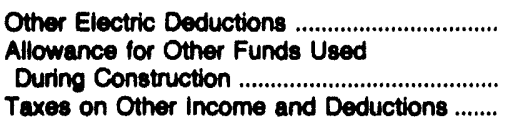 & $\begin{array}{r}2,787 \\
0 \\
0\end{array}$ & $\begin{array}{l}0 \\
0 \\
0\end{array}$ & $\begin{array}{l}0 \\
0 \\
0\end{array}$ & $\begin{array}{r}13,884 \\
0 \\
0\end{array}$ & $\begin{array}{l}0 \\
0\end{array}$ & $\begin{array}{l}0 \\
0 \\
0\end{array}$ \\
\hline Electric Utillty Ineorns ................................... & 840 & 219,011 & $-5,006$ & 35,721 & 17,032 & 66,400 \\
\hline 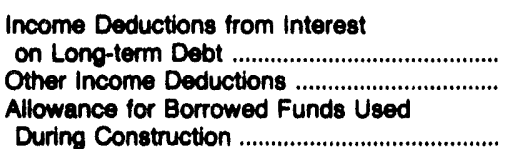 & $\begin{array}{r}0 \\
545 \\
0\end{array}$ & $\begin{array}{r}156,543 \\
0 \\
-11,692\end{array}$ & $\begin{array}{l}0 \\
0 \\
0\end{array}$ & $\begin{array}{r}14,490 \\
576 \\
0\end{array}$ & $\begin{array}{r}38,654 \\
552 \\
0\end{array}$ & $\begin{array}{r}97,142 \\
4,282 \\
0\end{array}$ \\
\hline 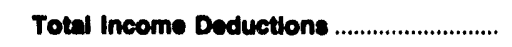 & 545 & 144,851 & o & 15,085 & 39,206 & 101,424 \\
\hline Income Before Extraordinary ltems .................. & 295 & 74,160 & $-5,006$ & 20,656 & $-21,373$ & $-35,826$ \\
\hline Extraordinary Income & 0 & 0 & 0 & 0 & 0 & 0 \\
\hline 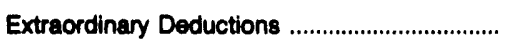 & 0 & 0 & 0 & 0 & 0 & 0 \\
\hline 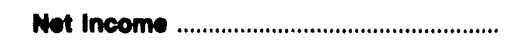 & 205 & 74,160 & $-5,006$ & 20,058 & $-21,373$ & $-36,026$ \\
\hline
\end{tabular}

Note: Totals may not equal sum of components because of independent rounding.

Source: Energy Information Administration, Form ElA-412, "Annual Report of Public Electric Utilities." 
Table 21. Statement of Income by Major U.S. Publicly Owned Electric Utillty Within State, 1992 (Continued)

(Thousand Dollars)

\begin{tabular}{|c|c|c|c|c|c|c|}
\hline Item & $\begin{array}{c}\text { California } \\
\text { Oakdale \& } \\
\text { South } \\
\text { San Joaquin } \\
\text { December } 31\end{array}$ & $\begin{array}{c}\text { California } \\
\text { Oroville } \\
\text { Wyandotte } \\
\text { Irrig Dist }\end{array}$ & $\begin{array}{l}\text { California } \\
\text { Palo Alto } \\
\text { City of } \\
\text { June } 30\end{array}$ & $\begin{array}{l}\text { California } \\
\text { Pasadena } \\
\text { City of } \\
\text { June } 30\end{array}$ & $\begin{array}{l}\text { California } \\
\text { Placer } \\
\text { County } \\
\text { Water } \\
\text { Agency } \\
\text { December } 31\end{array}$ & $\begin{array}{l}\text { California } \\
\text { Redding } \\
\text { City of } \\
\text { June } 30\end{array}$ \\
\hline Electric Utilly Operating Rovonues ............. & 5,275 & 8,732 & 67,111 & 98,415 & 7,668 & 44,477 \\
\hline 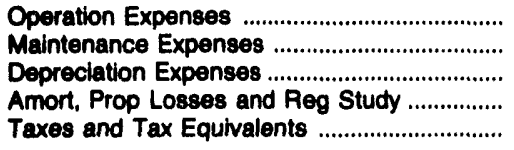 & $\begin{array}{r}1,881 \\
259 \\
825 \\
0 \\
0\end{array}$ & $\begin{array}{r}7,423 \\
880 \\
1,574 \\
0 \\
0\end{array}$ & $\begin{array}{r}33,323 \\
5,009 \\
3,058 \\
0 \\
9,550\end{array}$ & $\begin{array}{r}79,297 \\
5,569 \\
5,543 \\
0 \\
0\end{array}$ & $\begin{array}{r}1,671 \\
1,043 \\
1,628 \\
0 \\
0\end{array}$ & $\begin{array}{r}36,939 \\
759 \\
4,504 \\
0 \\
0\end{array}$ \\
\hline $\begin{array}{l}\text { Total Eloctrlc Utility Operating } \\
\text { Expensese }\end{array}$ & 2,966 & 9,877 & 50,940 & 90,410 & 4,343 & 42,202 \\
\hline 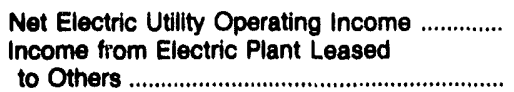 & $\begin{array}{r}2,309 \\
0\end{array}$ & $\begin{array}{r}-1,145 \\
0\end{array}$ & $\begin{array}{r}16,171 \\
0\end{array}$ & $\begin{array}{r}8,005 \\
0\end{array}$ & $\begin{array}{r}3,326 \\
0\end{array}$ & $\begin{array}{r}2,274 \\
0\end{array}$ \\
\hline Electric Utllity Cperating Income .............. & 2,309 & $-1,145$ & 16,171 & 8,005 & 3,326 & 2,274 \\
\hline 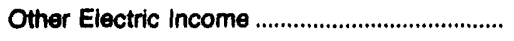 & 1,092 & 221 & 4,379 & 4,429 & 447 & 783 \\
\hline $\begin{array}{l}\text { Other Electric Deductions ............................. } \\
\text { Allowance for Other Funds Used } \\
\text { During Construction .................................... } \\
\text { Taxes on Other Income and Deductions ....... }\end{array}$ & $\begin{array}{r}62 \\
0 \\
0\end{array}$ & $\begin{array}{l}0 \\
0\end{array}$ & $\begin{array}{r}6,986 \\
0 \\
0\end{array}$ & $\begin{array}{r}11 \\
0 \\
10\end{array}$ & $\begin{array}{l}0 \\
0\end{array}$ & $\begin{array}{l}0 \\
0\end{array}$ \\
\hline Electric Utility Income & 3,340 & -924 & 13,564 & 12,413 & 3,772 & 3,058 \\
\hline 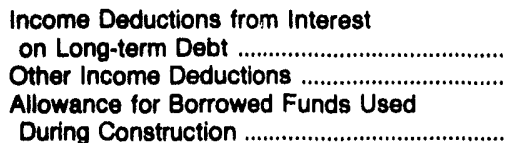 & $\begin{array}{l}0 \\
0\end{array}$ & $\begin{array}{r}3,113 \\
310\end{array}$ & $\begin{array}{l}0 \\
0\end{array}$ & $\begin{array}{r}3,792 \\
0\end{array}$ & $\begin{array}{r}2,598 \\
86\end{array}$ & $\begin{array}{r}4,029 \\
0\end{array}$ \\
\hline 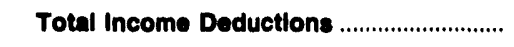 & 0 & 3,423 & 0 & 3,792 & 2,684 & 4,029 \\
\hline Income Before Extraordinary Items ..................... & 3,340 & $-4,348$ & 13,564 & 8,620 & 1,089 & -971 \\
\hline Extraordinary Income & 0 & 5,925 & 0 & 3,442 & 0 & 0 \\
\hline 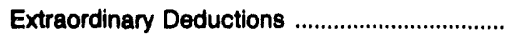 & 1,062 & 0 & 0 & 0 & 0 & 0 \\
\hline Net Income & 2,278 & 1,577 & 13,564 & 12,062 & 1,088 & -971 \\
\hline
\end{tabular}

Note: Totals may not equal sum of components because of independent rounding.

Source: Energy Information Administration, Form EIA-412, "Annual Report of Public Electric Utilities." 
Table 21. Statement of Income by Major U.S. Publicly Owned Electric Utility Within State, 1992 (Continued)

(Thousand Dollars)

\begin{tabular}{|c|c|c|c|c|c|c|}
\hline Item & $\begin{array}{l}\text { California } \\
\text { Riverside } \\
\text { City of } \\
\text { June } 30\end{array}$ & $\begin{array}{l}\text { California } \\
\text { Roseville } \\
\text { City of } \\
\text { June } 30\end{array}$ & $\begin{array}{l}\text { California } \\
\text { Sacramento } \\
\text { Municipal } \\
\text { Util Dist } \\
\text { December } 31\end{array}$ & $\begin{array}{c}\text { California } \\
\text { San Francisco } \\
\text { City } \\
\& \\
\text { County of } \\
\text { June } 30\end{array}$ & $\begin{array}{c}\text { California } \\
\text { Santa } \\
\text { Clara } \\
\text { City of } \\
\text { June } 30\end{array}$ & $\begin{array}{l}\text { California } \\
\text { Southern } \\
\text { California } \\
\text { P P } \\
\text { A } \\
\text { June } 30\end{array}$ \\
\hline Electrle Utullty Operating Rovonues ............. & 180,388 & 42,047 & 648,170 & 63,535 & 162,898 & 217,463 \\
\hline 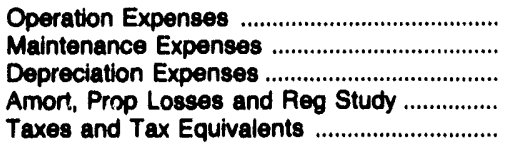 & $\begin{array}{r}116,936 \\
5,712 \\
10,118 \\
0 \\
0\end{array}$ & $\begin{array}{r}28,855 \\
5,273 \\
1,851 \\
0 \\
1,851\end{array}$ & $\begin{array}{r}389,180 \\
24,474 \\
41,387 \\
46,944 \\
128\end{array}$ & $\begin{array}{r}43,027 \\
3,166 \\
8,438 \\
0 \\
879\end{array}$ & $\begin{array}{r}146,811 \\
2,261 \\
5,022 \\
0 \\
8,992\end{array}$ & $\begin{array}{r}51,972 \\
11,153 \\
42,196 \\
0 \\
10,563\end{array}$ \\
\hline $\begin{array}{l}\text { Total Electrle Utility Operating } \\
\text { Expensece }\end{array}$ & 134,766 & 37,829 & 502,113 & 55,510 & 163,086 & 115,884 \\
\hline 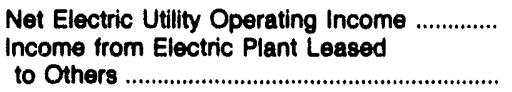 & $\begin{array}{r}45,622 \\
0\end{array}$ & $\begin{array}{r}4,218 \\
0\end{array}$ & $\begin{array}{r}146,057 \\
0\end{array}$ & $\begin{array}{r}8,025 \\
0\end{array}$ & $\begin{array}{r}-188 \\
0\end{array}$ & $\begin{array}{r}101,579 \\
0\end{array}$ \\
\hline Electric Utillty Operating Incom• .............. & 45,622 & 4,218 & 146,057 & 8,025 & -188 & 101,579 \\
\hline 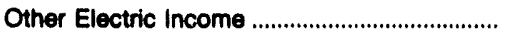 & 7,315 & 1,802 & 35,157 & 14,828 & 20,521 & 27,622 \\
\hline $\begin{array}{l}\text { Other Electric Deductions ............................ } \\
\text { Allowance for Other Funds Used }\end{array}$ & 12,294 & 0 & 0 & 4,965 & 705 & 0 \\
\hline 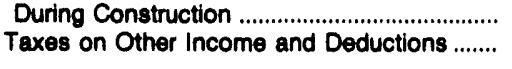 & $\begin{array}{l}0 \\
0\end{array}$ & $\begin{array}{l}0 \\
0\end{array}$ & $\begin{array}{r}79 \\
0\end{array}$ & $\begin{array}{l}0 \\
0\end{array}$ & $\begin{array}{l}0 \\
0\end{array}$ & $\begin{array}{l}0 \\
0\end{array}$ \\
\hline 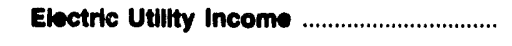 & 40,643 & 6,019 & 181,293 & 17,888 & 19,628 & 129,202 \\
\hline 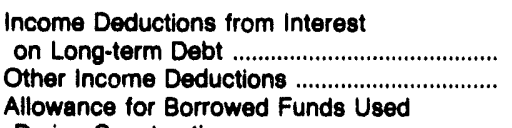 & $\begin{array}{r}13,680 \\
123\end{array}$ & $\begin{array}{r}660 \\
0\end{array}$ & $\begin{array}{r}142,963 \\
1,357\end{array}$ & $\begin{array}{r}29 \\
0\end{array}$ & $\begin{array}{r}8,743 \\
9\end{array}$ & $\begin{array}{r}169,769 \\
0\end{array}$ \\
\hline 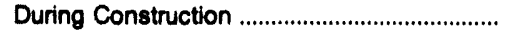 & 0 & 0 & -928 & 0 & 0 & 0 \\
\hline 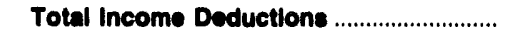 & 13,803 & 660 & 143,392 & 29 & 8,751 & 169,769 \\
\hline Income Before Extraordinary Items .................... & 26,840 & 5,360 & 37,901 & 17,859 & 10,876 & $-40,567$ \\
\hline 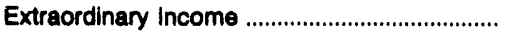 & 0 & 0 & 16,672 & 2,286 & 0 & 0 \\
\hline 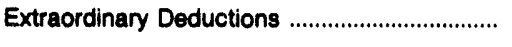 & 0 & 210 & 16,672 & 11,000 & 2,467 & 0 \\
\hline 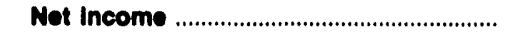 & 26,840 & 5,150 & 37,901 & 9,145 & 8,409 & $-40,567$ \\
\hline
\end{tabular}

Note: Totals may not equal sum of components because of independent rounding.

Source: Energy Information Administration, Form EIA-412, "Annual Report of Public Electric Utilities." 
Table 21. Statement of Income by Major U.S. Publicly Owned Electric Utility Within State, 1992 (Continued)

(Thousand Dollars)

\begin{tabular}{|c|c|c|c|c|c|c|}
\hline Item & $\begin{array}{c}\text { California } \\
\text { Turlock } \\
\text { Imigation } \\
\text { District } \\
\text { December } 31\end{array}$ & $\begin{array}{l}\text { California } \\
\text { Vernon } \\
\text { City of } \\
\text { June } 30\end{array}$ & $\begin{array}{l}\text { Calfornia } \\
\text { Yuba } \\
\text { County } \\
\text { Water } \\
\text { Agency } \\
\text { June } 30\end{array}$ & $\begin{array}{l}\text { Colorado } \\
\text { Arkansas } \\
\text { Rlver } \\
\text { Power } \\
\text { Authority } \\
\text { December } 31\end{array}$ & $\begin{array}{l}\text { Colorado } \\
\text { Colorado } \\
\text { Springs } \\
\text { City of } \\
\text { December } 31\end{array}$ & $\begin{array}{l}\text { Colorado } \\
\text { Fort Collins } \\
\text { City of } \\
\text { December } 31\end{array}$ \\
\hline Eloctric Uuwly Operating Rovenuse ............. & 92,847 & 67,590 & 11,003 & 9,603 & 152,004 & 39,434 \\
\hline 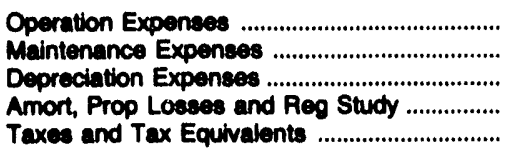 & $\begin{array}{r}68,065 \\
7,144 \\
6,884 \\
0 \\
0\end{array}$ & $\begin{array}{r}45,885 \\
3,315 \\
2,291 \\
0 \\
1,653\end{array}$ & $\begin{array}{r}2,200 \\
516 \\
2,340 \\
107 \\
0\end{array}$ & $\begin{array}{r}9,257 \\
0 \\
84 \\
0 \\
0\end{array}$ & $\begin{array}{r}84,584 \\
12,852 \\
22,253 \\
0 \\
9,784\end{array}$ & $\begin{array}{r}35,695 \\
696 \\
3,564 \\
0 \\
0\end{array}$ \\
\hline $\begin{array}{l}\text { Total Electric Utilly Operating } \\
\text { Expenece }\end{array}$ & 82,093 & 53,144 & 5,164 & 9,341 & 129,473 & 39,955 \\
\hline $\begin{array}{l}\text { Net Electric Utility Operating Income ............. } \\
\text { Income from Electric Plant Leased } \\
\text { to Others }\end{array}$ & $\begin{array}{r}10,754 \\
0\end{array}$ & $\begin{array}{r}14,446 \\
0\end{array}$ & $\begin{array}{r}5,839 \\
1\end{array}$ & $\begin{array}{r}262 \\
0\end{array}$ & $\begin{array}{r}22,622 \\
0\end{array}$ & $\begin{array}{r}-522 \\
0\end{array}$ \\
\hline Ebetrle Utivty Operating incoms .............. & 10,754 & 14,446 & 5,840 & 262 & 22,622 & -522 \\
\hline 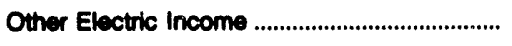 & 3,937 & 27,425 & 103 & 560 & 12,599 & 1,918 \\
\hline $\begin{array}{l}\text { Other Electric Deductions ............................. } \\
\text { Allowance for Other Furids Used }\end{array}$ & 0 & 271 & 0 & 0 & 0 & 2,366 \\
\hline $\begin{array}{l}\text { During Construction .................................. } \\
\text { Texes on Other Income and Deductions ....... }\end{array}$ & $\begin{array}{l}0 \\
0\end{array}$ & $\begin{array}{l}0 \\
0\end{array}$ & $\begin{array}{l}0 \\
0\end{array}$ & $\begin{array}{l}0 \\
0\end{array}$ & $\begin{array}{r}531 \\
0\end{array}$ & $\begin{array}{l}0 \\
0\end{array}$ \\
\hline 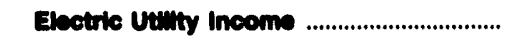 & 14,090 & 41,601 & 5,243 & 822 & 35,752 & -970 \\
\hline 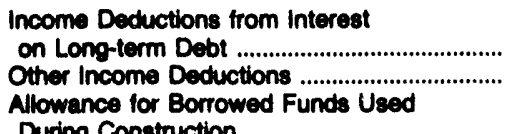 & $\begin{array}{r}2,584 \\
0\end{array}$ & $\begin{array}{r}0 \\
35,738\end{array}$ & $\begin{array}{r}4,517 \\
82\end{array}$ & $\begin{array}{l}0 \\
0\end{array}$ & $\begin{array}{r}27,885 \\
742\end{array}$ & $\begin{array}{l}0 \\
0\end{array}$ \\
\hline 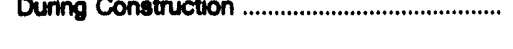 & 0 & 0 & 0 & 0 & -193 & 0 \\
\hline Toted Incoms Deductions ............................. & 2,684 & $\mathbf{3 5 , 7 3 8}$ & 4,599 & $\mathbf{0}$ & 27,835 & $\mathbf{0}$ \\
\hline Income Belore Extraordinary ltems ................... & 12,106 & 5,863 & 1,344 & 822 & 7,817 & -870 \\
\hline Extraordinary Income & 0 & 0 & 15 & 0 & 0 & 0 \\
\hline 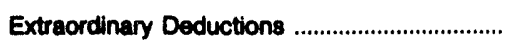 & 4,751 & 0 & 0 & 0 & 12,093 & 0 \\
\hline 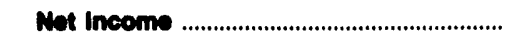 & 7,355 & 5,863 & 1,358 & 822 & $-4,176$ & -970 \\
\hline
\end{tabular}

Note: Totals may not equal sum of components because of independent rounding.

Source: Energy Information Administration, Form EIA-412, "Annual Report of Public Electric Utilities." 
Table 21. Statement of Income by Major U.S. Publicly Owned Electric Utility Within State, 1992 (Continued)

(Thousand Dollars)

\begin{tabular}{|c|c|c|c|c|c|c|}
\hline Item & $\begin{array}{l}\text { Colorado } \\
\begin{array}{c}\text { Longmont } \\
\text { City of }\end{array} \\
\text { December } 31\end{array}$ & $\begin{array}{l}\text { Colorado } \\
\text { Loveland } \\
\text { City of } \\
\text { December } 31\end{array}$ & $\begin{array}{c}\text { Colorado } \\
\text { Platte River } \\
\text { Power } \\
\text { Authority } \\
\text { December } 31\end{array}$ & $\begin{array}{l}\text { Connecticut } \\
\text { Connecticut } \\
\text { Mun } \\
\text { Elec } \\
\text { Engy Coop } \\
\text { December } 31\end{array}$ & $\begin{array}{l}\text { Connecticut } \\
\text { Groton } \\
\text { City of } \\
\text { June } 30\end{array}$ & $\begin{array}{l}\text { Connecticut } \\
\text { Norwich } \\
\text { City of } \\
\text { June } 30\end{array}$ \\
\hline Electric UtAlity Operating Revenues ............. & 21,255 & 19,631 & 135,138 & 59,814 & 43,816 & 25,017 \\
\hline 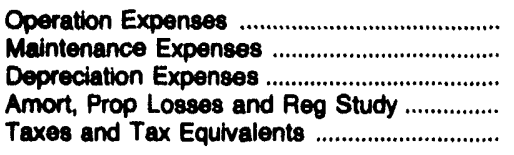 & $\begin{array}{r}18,903 \\
650 \\
1,034 \\
0 \\
1,557\end{array}$ & $\begin{array}{r}13,262 \\
531 \\
1,123 \\
0 \\
1,373\end{array}$ & $\begin{array}{r}57,175 \\
8,469 \\
21,596 \\
0 \\
0\end{array}$ & $\begin{array}{r}54,974 \\
282 \\
1,749 \\
40 \\
75\end{array}$ & $\begin{array}{r}38,580 \\
757 \\
1,169 \\
0 \\
2,199\end{array}$ & $\begin{array}{r}21,987 \\
697 \\
766 \\
0 \\
1,354\end{array}$ \\
\hline $\begin{array}{l}\text { Total Electrlc Utllity Operating } \\
\text { Expeneces }\end{array}$ & 22,144 & 16,289 & 87,239 & 57,120 & 42,705 & 24,803 \\
\hline $\begin{array}{l}\text { Net Electric Utility Operating Income ............. } \\
\text { Income from Electric Plant Leased } \\
\text { to Others }\end{array}$ & $\begin{array}{r}-889 \\
0\end{array}$ & 3,342 & 47,899 & 2,695 & 1,211 & 214 \\
\hline Electrlc Utility Operating income .............. & -800 & 3,342 & 47,890 & 2,695 & 1,211 & 855 \\
\hline 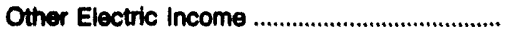 & 617 & 882 & 31,688 & 4,497 & 271 & 101 \\
\hline $\begin{array}{l}\text { Other Electric Deductions } \\
\text { Allowance for Other Funds Used.................. }\end{array}$ & 0 & 1,671 & 0 & 0 & 1,171 & 0 \\
\hline 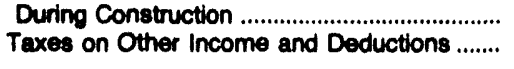 & $\begin{array}{l}0 \\
0\end{array}$ & $\begin{array}{l}0 \\
0\end{array}$ & $\begin{array}{l}0 \\
0\end{array}$ & $\begin{array}{l}0 \\
0\end{array}$ & $\begin{array}{l}0 \\
0\end{array}$ & $\begin{array}{l}0 \\
0\end{array}$ \\
\hline 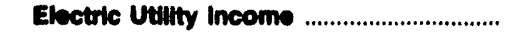 & -272 & 2,654 & 79,687 & 7,191 & 310 & 956 \\
\hline $\begin{array}{l}\text { Income Deductions from Interest } \\
\text { on Long-term Debt ...................................... } \\
\text { Other Income Deductions ........................... } \\
\text { Allowance for Borrowed Funds Used }\end{array}$ & $\begin{array}{l}0 \\
0\end{array}$ & $\begin{array}{r}525 \\
0\end{array}$ & $\begin{array}{r}69,727 \\
6,293\end{array}$ & $\begin{array}{r}9,026 \\
-2,174\end{array}$ & $\begin{array}{r}413 \\
41\end{array}$ & $\begin{array}{r}118 \\
6\end{array}$ \\
\hline 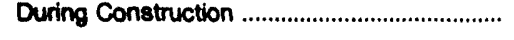 & 0 & 0 & 0 & 0 & 0 & 0 \\
\hline 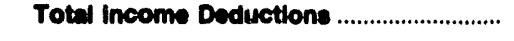 & $\mathbf{0}$ & 525 & 76,021 & 6,852 & 454 & 124 \\
\hline 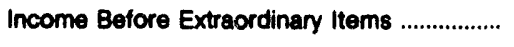 & -272 & 2,028 & 3,567 & 339 & -143 & 832 \\
\hline 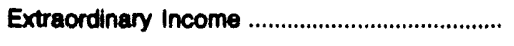 & 0 & 0 & 0 & 0 & 0 & 0 \\
\hline 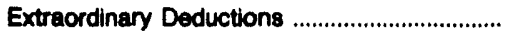 & 0 & 0 & 0 & 0 & 0 & 0 \\
\hline Not Income & -272 & 2,028 & 3,567 & 339 & -143 & 832 \\
\hline
\end{tabular}

Note: Totals may not equal sum of components because of independent rounding.

Source: Energy Information Administration, Form EIA-412, "Annual Report of Public Electric Utilities." 

Table 21. Statement of Income by Major U.S. Publicly Owned Electric UtIlity
Within State, 1992 (Contlnued)

(Thousand Dollars)

\begin{tabular}{|c|c|c|c|c|c|c|}
\hline Item & $\begin{array}{l}\text { Connecticut } \\
\text { Wallingford } \\
\text { Town of } \\
\text { June } 30\end{array}$ & $\begin{array}{l}\text { Delaware } \\
\text { Dover } \\
\text { City of } \\
\text { June } 30\end{array}$ & $\begin{array}{l}\text { Delaware } \\
\text { Mllford } \\
\text { City of } \\
\text { September } 30\end{array}$ & $\begin{array}{l}\text { Delaware } \\
\text { Newark } \\
\text { Clty of } \\
\text { December } 31\end{array}$ & $\begin{array}{l}\text { Florida } \\
\text { Bartow } \\
\text { City of } \\
\text { September } 30\end{array}$ & $\begin{array}{c}\text { Florida } \\
\text { Florida } \\
\text { Municipal } \\
\text { Power Agency } \\
\text { September } 30\end{array}$ \\
\hline Electric Utilty Operating Rovenues ............ & 45,092 & 34,641 & 9,254 & 18,850 & 18,098 & 157,784 \\
\hline 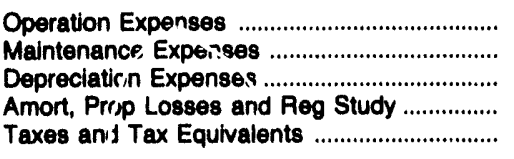 & $\begin{array}{r}38,633 \\
1,278 \\
1,210 \\
0 \\
2,163\end{array}$ & $\begin{array}{r}27,178 \\
0 \\
2,234 \\
0 \\
792\end{array}$ & $\begin{array}{r}6,836 \\
82 \\
290 \\
0 \\
0\end{array}$ & $\begin{array}{r}13,661 \\
516 \\
425 \\
0 \\
0\end{array}$ & $\begin{array}{r}14,020 \\
0 \\
311 \\
0 \\
0\end{array}$ & $\begin{array}{r}111,975 \\
6,117 \\
9,213 \\
0 \\
0\end{array}$ \\
\hline $\begin{array}{l}\text { Total Elastrlc Utility Operating } \\
\text { Expenses }\end{array}$ & 43,285 & 30,204 & 7,308 & 14,602 & 14,331 & 127,305 \\
\hline $\begin{array}{l}\text { Net Electric Utillit) Operating Income } \\
\text { Income from Electric Plant Leased } \\
\text { to Others }\end{array}$ & $\begin{array}{r}1,807 \\
0\end{array}$ & $\begin{array}{r}4,437 \\
0\end{array}$ & $\begin{array}{r}1,946 \\
0\end{array}$ & $\begin{array}{r}4,248 \\
0\end{array}$ & $\begin{array}{r}3,764 \\
0\end{array}$ & $\begin{array}{r}30,479 \\
0\end{array}$ \\
\hline Electric UtIIIty Operating Income ............. & 1,807 & 4,437 & 1,946 & 4,248 & 3,764 & 30,479 \\
\hline 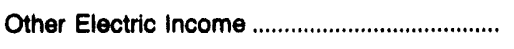 & 928 & 1,335 & 223 & 0 & 120 & 21,344 \\
\hline $\begin{array}{l}\text { Other Electric Deductions .................................. } \\
\text { Allowance for Other Funds Used }\end{array}$ & 0 & 0 & 0 & 0 & 0 & 0 \\
\hline 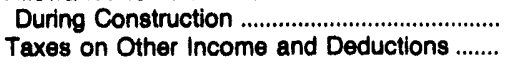 & $\begin{array}{l}0 \\
0\end{array}$ & $\begin{array}{l}0 \\
0\end{array}$ & $\begin{array}{l}0 \\
0\end{array}$ & $\begin{array}{l}0 \\
0\end{array}$ & $\begin{array}{l}0 \\
0\end{array}$ & $\begin{array}{l}0 \\
0\end{array}$ \\
\hline 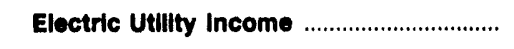 & 2,735 & 5,771 & 2,170 & 4,248 & 3,884 & 51,823 \\
\hline 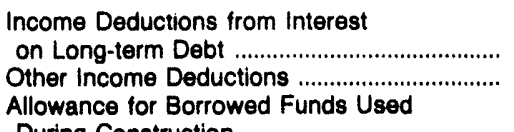 & $\begin{array}{l}47 \\
71\end{array}$ & $\begin{array}{r}2,186 \\
65\end{array}$ & $\begin{array}{r}87 \\
1,443\end{array}$ & $\begin{array}{l}0 \\
0\end{array}$ & $\begin{array}{l}0 \\
0\end{array}$ & $\begin{array}{l}39,101 \\
12,722\end{array}$ \\
\hline During Construction .............................................. & 0 & 0 & 0 & 0 & 0 & 0 \\
\hline 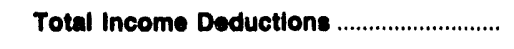 & 118 & 2,251 & 1,530 & 0 & $\mathbf{0}$ & 51,823 \\
\hline Income Before Extraordinary Items .................. & 2,618 & 3,520 & 640 & 4,248 & 3,884 & 0 \\
\hline Extraordinary Income & 0 & 0 & 0 & 0 & 0 & 0 \\
\hline 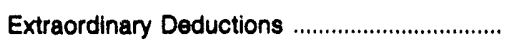 & 0 & 3,000 & 0 & 0 & 3,572 & 0 \\
\hline Not Income & 2,618 & 520 & 640 & 4,248 & 313 & $\mathbf{0}$ \\
\hline
\end{tabular}

Note: Totals may not equal sum of components because of independent rounding.

Source: Energy Information Administration, Form ElA-412, "Annual Report of Public Electric Utilities." 
Table 21. Statement of Income by Major U.S. Publicly Owned Electric Utility Within State, 1992 (Continued) (Thousand Dollars)

\begin{tabular}{|c|c|c|c|c|c|c|}
\hline Item & $\begin{array}{c}\text { Florida } \\
\text { Fort Pierce } \\
\text { Utillies } \\
\text { Auth }\end{array}$ & $\begin{array}{c}\text { Florida } \\
\text { Gainesville } \\
\text { Regional } \\
\text { Utilities } \\
\text { September } 30\end{array}$ & $\begin{array}{l}\text { Florida } \\
\begin{array}{c}\text { Homestead } \\
\text { Clty of }\end{array} \\
\text { September } 30\end{array}$ & $\begin{array}{c}\text { Florida } \\
\text { Jacksonville } \\
\text { Beach } \\
\text { City of } \\
\text { September } 30\end{array}$ & $\begin{array}{c}\text { Florida } \\
\text { Jacksonville } \\
\text { Electric } \\
\text { Auth } \\
\text { September } 30\end{array}$ & $\begin{array}{l}\text { Florida } \\
\text { Key West } \\
\text { City of } \\
\text { September } 30\end{array}$ \\
\hline Enetric Lutity Operating Rovenuse ........... & 40,200 & 112,431 & 28,907 & 37,249 & 682,850 & 44,174 \\
\hline 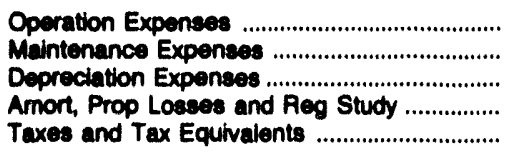 & $\begin{array}{r}29,682 \\
1,839 \\
3,379 \\
0 \\
953\end{array}$ & $\begin{array}{r}58,863 \\
9,164 \\
13,812 \\
0 \\
0\end{array}$ & $\begin{array}{r}19,537 \\
6,044 \\
1,546 \\
0 \\
1,399\end{array}$ & $\begin{array}{r}29,738 \\
334 \\
2,108 \\
0 \\
327\end{array}$ & $\begin{array}{r}368,098 \\
42,382 \\
46,143 \\
0 \\
14,550\end{array}$ & $\begin{array}{r}28,648 \\
3,700 \\
5,473 \\
0 \\
1,022\end{array}$ \\
\hline 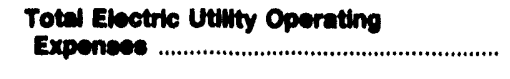 & 35,033 & 81,830 & 28,528 & 32,606 & 471,173 & 38,843 \\
\hline 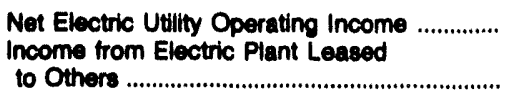 & $\begin{array}{r}4,447 \\
168\end{array}$ & 30,601 & $\begin{array}{r}-1,529 \\
0\end{array}$ & $\begin{array}{r}4,743 \\
0\end{array}$ & $\begin{array}{r}191,677 \\
0\end{array}$ & $\begin{array}{r}5,331 \\
0\end{array}$ \\
\hline Ebetric Uatity Operating Income ............. & 4,615 & 30,601 & $-1,529$ & 4,743 & 191,677 & 5,331 \\
\hline Other Electric Income ........................................ & 1,731 & 10,038 & 656 & 2,350 & 109,697 & 2,047 \\
\hline $\begin{array}{l}\text { Other Electric Deductions ................................. } \\
\text { Allowance for Other Funds Used }\end{array}$ & 0 & 12,852 & 0 & 6,992 & 0 & 0 \\
\hline $\begin{array}{l}\text { During Construction ....................................... } \\
\text { Taxes on Other Income and Deductions ........ }\end{array}$ & $\begin{array}{l}0 \\
0\end{array}$ & $\begin{array}{l}0 \\
0\end{array}$ & $\begin{array}{l}0 \\
0\end{array}$ & $\begin{array}{l}0 \\
0\end{array}$ & $\begin{array}{l}0 \\
0\end{array}$ & $\begin{array}{l}0 \\
0\end{array}$ \\
\hline 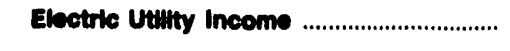 & 6,346 & 27,787 & -873 & 101 & 301,374 & 7,377 \\
\hline $\begin{array}{l}\text { Income Deductions from Interest } \\
\text { on Long-term Debt ........................................... } \\
\text { Other Income Deductions ................................. } \\
\text { Allowance for Borrowed Funds Used }\end{array}$ & $\begin{array}{l}3,568 \\
2,164\end{array}$ & $\begin{array}{r}25,821 \\
0\end{array}$ & $\begin{array}{l}0 \\
0\end{array}$ & $\begin{array}{l}0 \\
0\end{array}$ & $\begin{array}{r}203,447 \\
29,839\end{array}$ & $\begin{array}{r}6,670 \\
0\end{array}$ \\
\hline 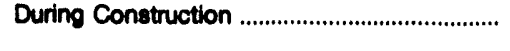 & 0 & 0 & 0 & 0 & $-2,452$ & 0 \\
\hline Total Income Deductions ............................. & 5,731 & 25,821 & $\mathbf{0}$ & $\mathbf{0}$ & 230,833 & 6,670 \\
\hline Income Before Extraordinary Items ................. & 615 & 1,966 & -873 & 101 & 70,540 & 708 \\
\hline 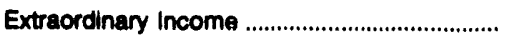 & 0 & 0 & 0 & 0 & 0 & 0 \\
\hline 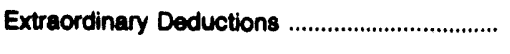 & 23 & 0 & 0 & 0 & 0 & 0 \\
\hline 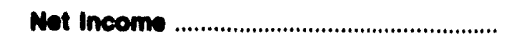 & 591 & 1,966 & -873 & 101 & 70,540 & 708 \\
\hline
\end{tabular}

Note: Totals may not equal sum of components because of independent rounding.

Source: Energy Information Administration, Form ElA-412, "Annual Report of Public Electric Utilities." 
Table 21. Statement of Income by Major U.S. Publicly Owned Electric Utility Within State, 1992 (Continued)

(Thousand Dollars)

\begin{tabular}{|c|c|c|c|c|c|c|}
\hline Item & $\begin{array}{c}\text { Florida } \\
\text { Kissimmee } \\
\text { Utility } \\
\text { Authority } \\
\text { September } 30\end{array}$ & $\begin{array}{l}\text { Hlorida } \\
\text { Lake Worth } \\
\text { Clty of } \\
\text { September } 30\end{array}$ & $\begin{array}{l}\text { Florida } \\
\text { Lakeland } \\
\text { Clty of } \\
\text { September } 30\end{array}$ & $\begin{array}{l}\text { Fiorida } \\
\text { Leesburg } \\
\text { Clty of } \\
\text { September } 30\end{array}$ & $\begin{array}{l}\text { Florida } \\
\text { New Smyrna } \\
\text { Beach } \\
\text { Utils Comm } \\
\text { September } 30\end{array}$ & $\begin{array}{l}\text { Florida } \\
\text { Ocala } \\
\text { City of } \\
\text { September } 30\end{array}$ \\
\hline Electris Utilty Operating Aevenuse ............ & 69,698 & 31,675 & 149,178 & 26,918 & 24,117 & 60,120 \\
\hline 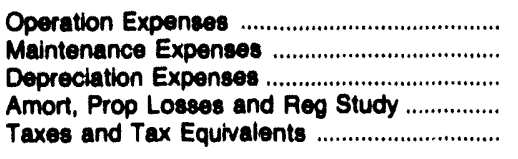 & $\begin{array}{r}36,442 \\
3,891 \\
6,563 \\
-1,946 \\
9\end{array}$ & $\begin{array}{r}21,453 \\
1,468 \\
2,217 \\
0 \\
4,392\end{array}$ & $\begin{array}{r}73,442 \\
15,160 \\
13,658 \\
0 \\
3,363\end{array}$ & $\begin{array}{r}17,049 \\
1,296 \\
1,715 \\
151 \\
608\end{array}$ & $\begin{array}{r}18,460 \\
690 \\
1,551 \\
113 \\
1,451\end{array}$ & $\begin{array}{r}43,659 \\
2,677 \\
2,574 \\
405 \\
1,664\end{array}$ \\
\hline $\begin{array}{l}\text { Total Electrle Utility Oporating } \\
\text { Expenese }\end{array}$ & 44,990 & 20,531 & 108,022 & 20,818 & 22,265 & 80,979 \\
\hline 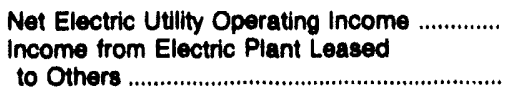 & $\begin{array}{r}14,739 \\
0\end{array}$ & $\begin{array}{r}2,144 \\
0\end{array}$ & $\begin{array}{r}43,555 \\
0\end{array}$ & $\begin{array}{r}5,101 \\
0\end{array}$ & $\begin{array}{r}1,851 \\
0\end{array}$ & $\begin{array}{r}17,141 \\
0\end{array}$ \\
\hline Electrle Utilty Operating Income ............. & 14,739 & 2,144 & 43,655 & 5,101 & 1,851 & 17,141 \\
\hline 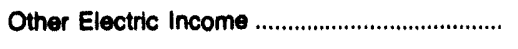 & 3,244 & 1,224 & 8,965 & 892 & 360 & 1,624 \\
\hline $\begin{array}{l}\text { Other Electric Deductions .......................... } \\
\text { Allowance for Other Funds Used } \\
\text { During Construction ................................... } \\
\text { Taxes on Other Income and Deductions ....... }\end{array}$ & $\begin{array}{r}5,053 \\
0 \\
0\end{array}$ & $\begin{array}{l}0 \\
0 \\
0\end{array}$ & $\begin{array}{r}14,706 \\
0 \\
0\end{array}$ & $\begin{array}{r}3,200 \\
0 \\
0\end{array}$ & $\begin{array}{r}55 \\
0 \\
0\end{array}$ & $\begin{array}{l}0 \\
0 \\
0\end{array}$ \\
\hline 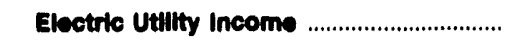 & 12,929 & 3,368 & 37,814 & 2,792 & 2,168 & 18,785 \\
\hline 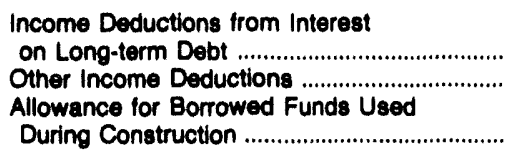 & $\begin{array}{l}6,292 \\
1,171\end{array}$ & $\begin{array}{r}2,089 \\
0\end{array}$ & $\begin{array}{r}22,955 \\
1,187 \\
0\end{array}$ & $\begin{array}{r}1,128 \\
0 \\
0\end{array}$ & $\begin{array}{r}1,475 \\
118\end{array}$ & $\begin{array}{r}1,086 \\
0 \\
0\end{array}$ \\
\hline 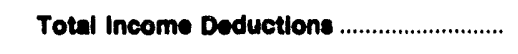 & 7,462 & 2,089 & 24,142 & 1,128 & 1,594 & 1,086 \\
\hline Income Before Extraordinary Items ................. & 5,466 & 1,279 & 13,673 & 1,664 & 562 & 17,678 \\
\hline 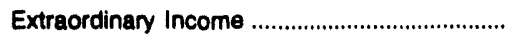 & 26,362 & 0 & 0 & 0 & 0 & 0 \\
\hline 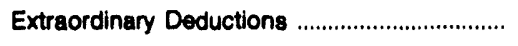 & 0 & 155 & 29 & 0 & 0 & 1,635 \\
\hline 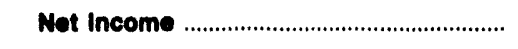 & 31,828 & 1,126 & 13,644 & 1,684 & 562 & 16,044 \\
\hline
\end{tabular}

Note: Totals may not equal sum of components because of independent rounding.

Source: Energy Information Administration, Form EIA-412, "Annual Report of Public Electric Utilities." 
Table 21. Statement of Income by Major U.S. Publlcly Owned Electric Utility Within State, 1992 (Continued)

(Thousand Dollars)

\begin{tabular}{|c|c|c|c|c|c|c|}
\hline Item & $\begin{array}{l}\text { Florida } \\
\text { Oriando } \\
\text { Utillites } \\
\text { Comm } \\
\text { September } 30\end{array}$ & $\begin{array}{l}\text { Florida } \\
\text { Quincy } \\
\text { City of } \\
\text { September } 30\end{array}$ & $\begin{array}{c}\text { Florida } \\
\text { Reedy Creek } \\
\text { Improvement } \\
\text { Dist }\end{array}$ & $\begin{array}{l}\text { Florida } \\
\text { Sebring } \\
\text { Utilities } \\
\text { Comm } \\
\text { September } 30\end{array}$ & $\begin{array}{l}\text { Florida } \\
\text { Si Cloud } \\
\text { City of } \\
\text { September } 30\end{array}$ & $\begin{array}{c}\text { Florida } \\
\text { Tallahasseo } \\
\text { Clty of }\end{array}$ \\
\hline Eleotrio Uttllity Operating Rovenues ............ & 286,781 & 8,810 & 51,673 & 17,004 & 20,190 & 187,244 \\
\hline 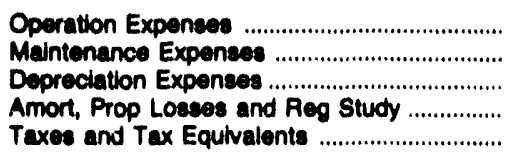 & $\begin{array}{r}141,483 \\
25,026 \\
29,521 \\
16 \\
15,613\end{array}$ & $\begin{array}{r}5,287 \\
334 \\
177 \\
0 \\
137\end{array}$ & $\begin{array}{r}34,288 \\
4,024 \\
0 \\
0 \\
1,846\end{array}$ & $\begin{array}{r}11,527 \\
561 \\
644 \\
0 \\
17\end{array}$ & $\begin{array}{r}13,169 \\
320 \\
2,639 \\
0 \\
1,086\end{array}$ & $\begin{array}{r}85,001 \\
2,995 \\
8,931 \\
80 \\
0\end{array}$ \\
\hline $\begin{array}{l}\text { Total Elootrle Utilty Oporating } \\
\text { Expences }\end{array}$ & 211,600 & 6,036 & 40,160 & 12,740 & 17,214 & 107,008 \\
\hline 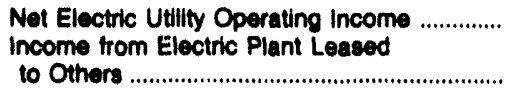 & $\begin{array}{r}75,121 \\
0\end{array}$ & $\begin{array}{r}2,576 \\
0\end{array}$ & $\begin{array}{r}11,515 \\
0\end{array}$ & $\begin{array}{r}5,245 \\
0\end{array}$ & $\begin{array}{r}2,985 \\
0\end{array}$ & $\begin{array}{r}50,237 \\
0\end{array}$ \\
\hline Eleotric Utility Operating Income .............. & 75,121 & 2,576 & 11,516 & 5,246 & 2,985 & 50,237 \\
\hline Other Electric Income & 34,603 & 181 & 0 & 740 & 334 & 12,087 \\
\hline $\begin{array}{l}\text { Other Electric Deductions ....................... } \\
\text { Allowance for Other Funds Used } \\
\text { During Construction ...................................... } \\
\text { Taxes on Other Income and Deductions ....... }\end{array}$ & $\begin{array}{r}14,610 \\
0 \\
0\end{array}$ & $\begin{array}{r}19 \\
0 \\
0\end{array}$ & $\begin{array}{l}0 \\
0\end{array}$ & $\begin{array}{l}0 \\
0 \\
0\end{array}$ & $\begin{array}{l}0 \\
0\end{array}$ & $\begin{array}{r}56 \\
0 \\
0\end{array}$ \\
\hline 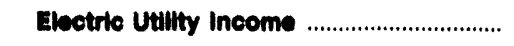 & 98,113 & 2,737 & 11,515 & 5,986 & 3,319 & 62,267 \\
\hline 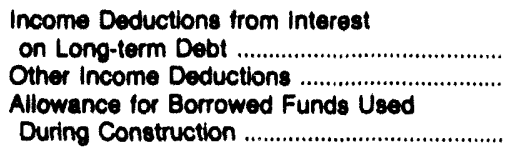 & $\begin{array}{r}81,710 \\
6,689 \\
0\end{array}$ & $\begin{array}{l}0 \\
0\end{array}$ & $\begin{array}{r}8,836 \\
0 \\
0\end{array}$ & $\begin{array}{r}6,509 \\
525 \\
0\end{array}$ & $\begin{array}{r}1,645 \\
0 \\
0\end{array}$ & $\begin{array}{r}8,169 \\
39,841 \\
0\end{array}$ \\
\hline Total Income Deductions .............................. & 88,379 & $\mathbf{0}$ & 8,836 & 7,034 & 1,645 & 48,000 \\
\hline Income Before Extraordinary Items .................. & 6,734 & 2,737 & 2,679 & $-1,048$ & 1,674 & 14,258 \\
\hline Extraordinary Income & 0 & 0 & 0 & 0 & 0 & 0 \\
\hline 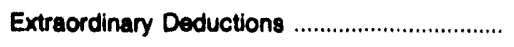 & 0 & 0 & 0 & 67 & 1,897 & 0 \\
\hline Not Income & 6,734 & 2,737 & 2,670 & $-1,116$ & -223 & 14,258 \\
\hline
\end{tabular}

Note: Totels may not equal sum of components because of independent rounding.

Source: Energy Information Administration, Form EIA-412, "Annual Report of Public Electric Utilities." 
Table 21. Statement of Income by Major U.S. Publlcly Owned Electric Utility Within State, 1992 (Continued)

(Thousand Dollars)

\begin{tabular}{|c|c|c|c|c|c|c|}
\hline Item & $\begin{array}{l}\text { Fiorida } \\
\text { Vero } \\
\text { Beach } \\
\text { City of } \\
\text { September } 30\end{array}$ & $\begin{array}{l}\text { Georgla } \\
\text { Abany Water } \\
\text { Gas \& Light } \\
\text { Comm } \\
\text { June } 30\end{array}$ & $\begin{array}{l}\text { Georgla } \\
\text { Calnoun } \\
\text { City of } \\
\text { June } 30\end{array}$ & $\begin{array}{l}\text { Georgia } \\
\text { Cartereville } \\
\text { City of } \\
\text { June } 30\end{array}$ & $\begin{array}{l}\text { Georgla } \\
\text { College } \\
\text { Park City of } \\
\text { June } 30\end{array}$ & $\begin{array}{l}\text { Georgle } \\
\text { Covington } \\
\text { City of } \\
\text { December } 31\end{array}$ \\
\hline Eleotric Uttity Operating Povenues ............ & 30,426 & 64,250 & 10,335 & 21,502 & 14,400 & 14,577 \\
\hline 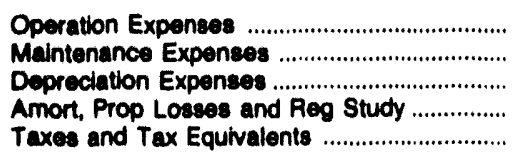 & $\begin{array}{r}25,283 \\
3,649 \\
2,601 \\
0 \\
142\end{array}$ & $\begin{array}{r}47,375 \\
1,424 \\
1,215 \\
0 \\
0\end{array}$ & $\begin{array}{r}14,948 \\
232 \\
231 \\
0 \\
0\end{array}$ & $\begin{array}{r}18,697 \\
167 \\
0 \\
0 \\
1,047\end{array}$ & $\begin{array}{r}14,352 \\
152 \\
260 \\
0 \\
0\end{array}$ & $\begin{array}{r}12,338 \\
185 \\
0 \\
0 \\
712\end{array}$ \\
\hline $\begin{array}{l}\text { Total Ebetric Utility Operating } \\
\text { Expenees }\end{array}$ & 31,075 & 80,013 & 15,410 & 19,911 & 14,784 & 13,234 \\
\hline 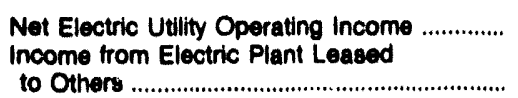 & $\begin{array}{r}7.750 \\
0\end{array}$ & $\begin{array}{r}4,286 \\
0\end{array}$ & $\begin{array}{r}2,824 \\
0\end{array}$ & $\begin{array}{r}1,651 \\
0\end{array}$ & $\begin{array}{r}-358 \\
0\end{array}$ & $\begin{array}{r}1,342 \\
0\end{array}$ \\
\hline Ebotrlc Utility Operating income ............. & 7,750 & 4,240 & 2,924 & 1,051 & -360 & 1,342 \\
\hline Other Electric Income & 2,083 & 1,258 & -12 & 673 & 404 & 378 \\
\hline $\begin{array}{l}\text { Other Electric Deductions } \\
\text { Allowance for Other Funds Used }\end{array}$ & 0 & 0 & 0 & 0 & 2,186 & 0 \\
\hline 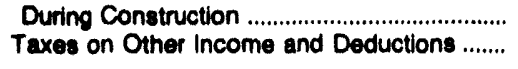 & $\begin{array}{l}0 \\
0\end{array}$ & $\begin{array}{l}0 \\
0\end{array}$ & $\begin{array}{l}0 \\
0\end{array}$ & $\begin{array}{l}0 \\
0\end{array}$ & $\begin{array}{l}0 \\
0\end{array}$ & $\begin{array}{l}0 \\
0\end{array}$ \\
\hline 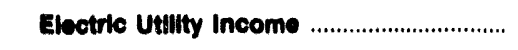 & 9,834 & 5,625 & 2,012 & 2,324 & $-2,140$ & 1,720 \\
\hline 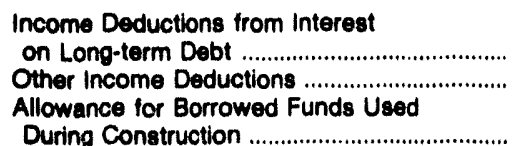 & $\begin{array}{l}3,107 \\
3,152\end{array}$ & $\begin{array}{r}0 \\
57\end{array}$ & $\begin{array}{r}511 \\
2,648\end{array}$ & $\begin{array}{l}0 \\
0\end{array}$ & $\begin{array}{l}0 \\
0\end{array}$ & $\begin{array}{r}23 \\
0\end{array}$ \\
\hline 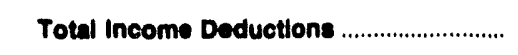 & 6,269 & 67 & 3,160 & 0 & 0 & 23 \\
\hline Income Belore Extraordinary ltems ................... & 3,575 & 5,468 & -247 & 2,324 & $-2,140$ & 1,697 \\
\hline Extraordinary Income & 0 & 0 & 6,970 & 0 & 0 & 0 \\
\hline 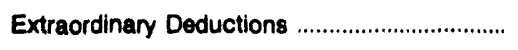 & 0 & 0 & 5,240 & 0 & 0 & 0 \\
\hline 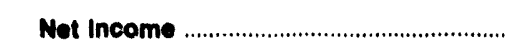 & 3,575 & 5,468 & 1,483 & 2,324 & $-2,140$ & 1,607 \\
\hline
\end{tabular}

Note: Totals may not equal sum of components because of independent rounding.

Source: Energy Information Administration, Form EIA-412, "Annual Report of Public Electric Utilities." 
Table 21. Statement of Income by Major U.S. Publicly Owned Electric Utility Within State, 1992 (Continued)

(Thousand Dollars)

\begin{tabular}{|c|c|c|c|c|c|c|}
\hline Item & $\begin{array}{l}\text { Georgla } \\
\text { Crisp } \\
\text { County } \\
\text { Power } \\
\text { Comm } \\
\text { December } 31\end{array}$ & $\begin{array}{l}\text { Georgia } \\
\text { Dalton } \\
\text { City of } \\
\text { November } 30\end{array}$ & $\begin{array}{l}\text { Georgia } \\
\text { Douglas } \\
\text { Clty of } \\
\text { June } 30\end{array}$ & $\begin{array}{c}\text { Georgia } \\
\text { East } \\
\text { Point } \\
\text { City of } \\
\text { June } 30\end{array}$ & $\begin{array}{c}\text { Georgia } \\
\text { Fitzgerald } \\
\text { Wir Lgt } \\
\text { \& Bond Comm } \\
\text { December } 31\end{array}$ & $\begin{array}{l}\text { Georgia } \\
\text { Griffin } \\
\text { City of } \\
\text { June } 30\end{array}$ \\
\hline Electric Utilty Operating Revenues ............ & 16,015 & 43,952 & 12,690 & 18,864 & 10,369 & 21,771 \\
\hline 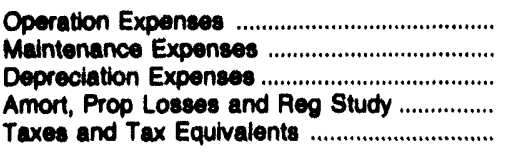 & $\begin{array}{r}12,322 \\
748 \\
1,254 \\
0 \\
754\end{array}$ & $\begin{array}{r}24,405 \\
5,474 \\
5,175 \\
0 \\
279\end{array}$ & $\begin{array}{r}10,223 \\
237 \\
159 \\
0 \\
0\end{array}$ & $\begin{array}{r}16,412 \\
181 \\
383 \\
0 \\
0\end{array}$ & $\begin{array}{r}8,975 \\
599 \\
200 \\
0 \\
0\end{array}$ & $\begin{array}{r}17.188 \\
53 \\
381 \\
0 \\
0\end{array}$ \\
\hline $\begin{array}{l}\text { Total Eleotric Utility Operating } \\
\text { Expenses }\end{array}$ & 15,077 & 35,334 & 10,618 & 16,976 & 9,774 & 17,621 \\
\hline 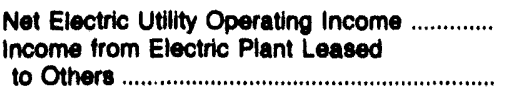 & 1,537 & $\begin{array}{r}8,618 \\
634\end{array}$ & $\begin{array}{r}2,072 \\
0\end{array}$ & $\begin{array}{r}1,888 \\
0\end{array}$ & $\begin{array}{r}595 \\
0\end{array}$ & $\begin{array}{r}4,150 \\
0\end{array}$ \\
\hline Electric Utilty Operating Income ............. & 1,537 & 9,251 & 2,072 & 1,888 & 595 & 4,150 \\
\hline Other Electric Income & 385 & 17,692 & 91 & 0 & 815 & 0 \\
\hline $\begin{array}{l}\text { Other Electric Deductions ............................. } \\
\text { Allowance for Other Funds Used }\end{array}$ & 43 & 0 & 2,258 & 0 & 0 & 287 \\
\hline $\begin{array}{l}\text { During Construction ................................... } \\
\text { Taxes on Other Income and Deductions ....... }\end{array}$ & $\begin{array}{l}0 \\
0\end{array}$ & $\begin{array}{l}0 \\
0\end{array}$ & $\begin{array}{l}0 \\
0\end{array}$ & $\begin{array}{l}0 \\
0\end{array}$ & $\begin{array}{l}0 \\
0\end{array}$ & $\begin{array}{l}0 \\
0\end{array}$ \\
\hline 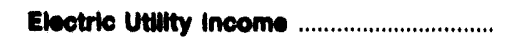 & 1,860 & 28,844 & -95 & 1,888 & 1,411 & 3,882 \\
\hline 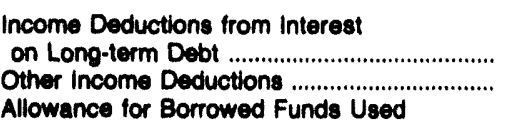 & $\begin{array}{r}0 \\
232\end{array}$ & $\begin{array}{r}8,500 \\
0\end{array}$ & $\begin{array}{l}0 \\
0\end{array}$ & $\begin{array}{l}0 \\
0\end{array}$ & $\begin{array}{r}285 \\
0\end{array}$ & $\begin{array}{l}0 \\
0\end{array}$ \\
\hline 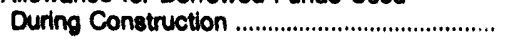 & 0 & 0 & 0 & 0 & 0 & 0 \\
\hline Total Income Deductions ............................. & 232 & 6,800 & $\mathbf{0}$ & 0 & 285 & $\mathbf{0}$ \\
\hline Income Before Extraordinary Items .................. & 1,627 & 20,444 & -95 & 1,888 & 1,126 & 3,862 \\
\hline 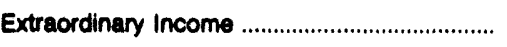 & 0 & 0 & 0 & 0 & 0 & 0 \\
\hline 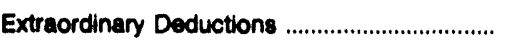 & 0 & 0 & 0 & 0 & 0 & 0 \\
\hline Net Income & 1,627 & 20,444 & -95 & 1,888 & 1,126 & 3,882 \\
\hline
\end{tabular}

Note: Totals may not equal sum of components because of independent rounding.

Source: Energy Information Administration, Form EIA-412, "Annual Report of Public Electric Utilities." 
Table 21. Statement of Income by Major U.S. Publicly Owned Electrlc Utility Within State, 1992 (Continued)

(Thousand Dollars)

\begin{tabular}{|c|c|c|c|c|c|c|}
\hline Item & $\begin{array}{l}\text { Georgia } \\
\text { La Grange } \\
\text { City of } \\
\text { June } 30\end{array}$ & $\begin{array}{l}\text { Georgia } \\
\text { Lawrenceville } \\
\text { City of } \\
\text { August } 30\end{array}$ & $\begin{array}{l}\text { Georgia } \\
\text { Marietta } \\
\text { Clty of } \\
\text { June } 30\end{array}$ & $\begin{array}{l}\text { Georgia } \\
\text { Moultrie } \\
\text { City of } \\
\text { September } 30\end{array}$ & $\begin{array}{l}\text { Georgla } \\
\text { Municipal } \\
\text { Electric } \\
\text { Authority } \\
\text { December } 31\end{array}$ & $\begin{array}{c}\text { Georgla } \\
\text { Thomasville } \\
\text { Clty of }\end{array}$ \\
\hline Electric Utility Operating Revenues ............ & 31,301 & 12,752 & 68,565 & 11,172 & 538,301 & 23,900 \\
\hline 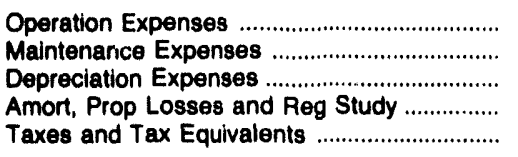 & $\begin{array}{r}25,168 \\
29 \\
196 \\
0 \\
0\end{array}$ & $\begin{array}{r}11,570 \\
10 \\
431 \\
0 \\
0\end{array}$ & $\begin{array}{r}49,264 \\
0 \\
1,346 \\
0 \\
0\end{array}$ & $\begin{array}{r}9,864 \\
0 \\
183 \\
0 \\
0\end{array}$ & $\begin{array}{r}165,557 \\
38,732 \\
83,470 \\
30,697 \\
2,757\end{array}$ & $\begin{array}{r}20,297 \\
476 \\
654 \\
0 \\
941\end{array}$ \\
\hline $\begin{array}{l}\text { Total Electric Utility Operating } \\
\text { Expenses }\end{array}$ & 25,393 & 12,011 & 50,610 & 10,047 & 331,213 & 22,898 \\
\hline $\begin{array}{l}\text { Net Electric Utility Operating Income .............. } \\
\text { Income from Electric Plant Leased }\end{array}$ & 5,909 & 741 & 15,954 & 1,125 & 207,088 & 1,621 \\
\hline 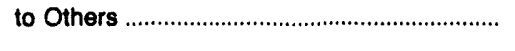 & 0 & 0 & 0 & 0 & 0 & 0 \\
\hline Electrlc Utillty Operating Income .............. & 5,909 & 741 & 15,954 & 1,125 & 207,080 & 1,621 \\
\hline 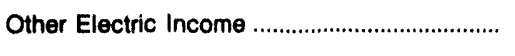 & 85 & 0 & 0 & 107 & 81,300 & 34 \\
\hline $\begin{array}{l}\text { Other Electric Deductions ................................. } \\
\text { Allowance for Other Funds Used }\end{array}$ & 0 & 741 & 0 & 1,458 & 0 & 45 \\
\hline 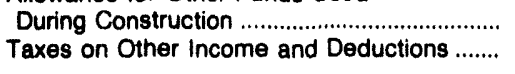 & $\begin{array}{l}0 \\
0\end{array}$ & $\begin{array}{l}0 \\
0\end{array}$ & $\begin{array}{l}0 \\
0\end{array}$ & $\begin{array}{l}0 \\
0\end{array}$ & $\begin{array}{r}0 \\
310\end{array}$ & $\begin{array}{l}0 \\
0\end{array}$ \\
\hline 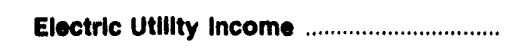 & 5,993 & 0 & 15,054 & -227 & 288,087 & 1,610 \\
\hline 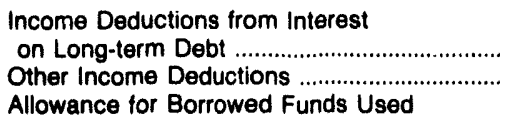 & $\begin{array}{r}0 \\
3,045\end{array}$ & $\begin{array}{l}0 \\
0\end{array}$ & $\begin{array}{l}0 \\
0\end{array}$ & $\begin{array}{l}0 \\
0\end{array}$ & $\begin{array}{l}269,798 \\
-19,343\end{array}$ & $\begin{array}{l}0 \\
6\end{array}$ \\
\hline 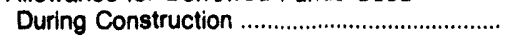 & 0 & 0 & 0 & 0 & 4,345 & 0 \\
\hline Total Income Deductions ........................... & 3,045 & $\mathbf{0}$ & $\mathbf{0}$ & 0 & 264,800 & 6 \\
\hline Income Before Extraordinary Items ................. & 2,949 & 0 & 15,954 & -227 & 33,287 & 1,604 \\
\hline Extraordinary income & 0 & 0 & 0 & 0 & 0 & 0 \\
\hline 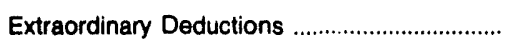 & 0 & 0 & 0 & 0 & 0 & 0 \\
\hline Net Income & 2,949 & $\mathbf{0}$ & 15,954 & -227 & 33,287 & 1,604 \\
\hline
\end{tabular}

Note: Totals may not equal sum of components because of independent rounding.

Source: Energy information Administration, Form EIA-412, "Annual Report of Public Electric Utilities." 
Table 21. Statement of Income by Major U.S. Publicly Owned Electric Utility Within State, 1992 (Continued) (Thousand Dollars)

\begin{tabular}{|c|c|c|c|c|c|c|}
\hline ftem & $\begin{array}{c}\text { Idaho } \\
\text { Idaho } \\
\text { Falls } \\
\text { City of } \\
\text { September } 30\end{array}$ & $\begin{array}{l}\text { Illinois } \\
\text { Batavia } \\
\text { City of } \\
\text { December } 31\end{array}$ & $\begin{array}{l}\text { lllinois } \\
\text { Geneva } \\
\text { City of } \\
\text { April } 30\end{array}$ & $\begin{array}{c}\text { Illinois } \\
\text { Illinois } \\
\text { Municipal } \\
\text { Elec Agency } \\
\text { April } 30\end{array}$ & $\begin{array}{l}\text { Illinois } \\
\text { Naperville } \\
\text { City of } \\
\text { April } 30\end{array}$ & $\begin{array}{l}\text { Illinois } \\
\text { Rochelle } \\
\text { Municipal } \\
\text { Utilities } \\
\text { April } 30\end{array}$ \\
\hline Elective Utity Operating Revenuse ............ & 30,813 & 12,495 & 8,745 & 58,396 & 53,868 & 11,487 \\
\hline 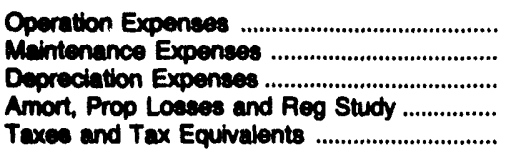 & $\begin{array}{r}16,422 \\
2,269 \\
3,360 \\
0 \\
2,072\end{array}$ & $\begin{array}{r}12,095 \\
0 \\
582 \\
0 \\
0\end{array}$ & $\begin{array}{r}7,627 \\
0 \\
741 \\
0 \\
388\end{array}$ & $\begin{array}{r}48,177 \\
606 \\
2,861 \\
0 \\
0\end{array}$ & $\begin{array}{r}41,470 \\
502 \\
13,721 \\
0 \\
0\end{array}$ & $\begin{array}{r}8,859 \\
889 \\
899 \\
0 \\
577\end{array}$ \\
\hline $\begin{array}{l}\text { Totel Ebctive Uumby Oparating } \\
\text { Expeniese }\end{array}$ & 24,124 & 12,678 & 8,756 & 51,644 & 55,692 & 11,225 \\
\hline 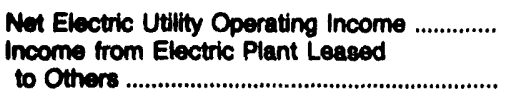 & $\begin{array}{r}6,689 \\
0\end{array}$ & $\begin{array}{r}-183 \\
0\end{array}$ & $\begin{array}{r}-12 \\
0\end{array}$ & $\begin{array}{r}6.753 \\
0\end{array}$ & $\begin{array}{r}-1,825 \\
0\end{array}$ & 262 \\
\hline Eloctile Uuthty Operating Income ............. & 6,680 & -183 & -12 & 6,753 & $-1,825$ & 262 \\
\hline 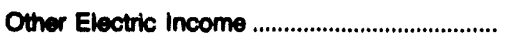 & 1,646 & 459 & 1,149 & 1,690 & 4,070 & 273 \\
\hline $\begin{array}{l}\text { Other Electric Deductions ............................. } \\
\text { Alowance for Other Funds Used } \\
\text { During Construction ........................................ } \\
\text { Taxes on Other Income and Deductions ........ }\end{array}$ & $\begin{array}{r}693 \\
0 \\
0\end{array}$ & $\begin{array}{l}0 \\
0 \\
0\end{array}$ & $\begin{array}{r}108 \\
0 \\
0\end{array}$ & $\begin{array}{l}0 \\
0\end{array}$ & $\begin{array}{r}728 \\
0 \\
0\end{array}$ & $\begin{array}{l}0 \\
0\end{array}$ \\
\hline 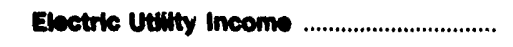 & 7,642 & 276 & 1,030 & 8,442 & 1,518 & 535 \\
\hline 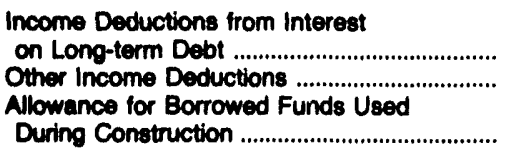 & $\begin{array}{r}7,561 \\
-65 \\
0\end{array}$ & $\begin{array}{l}0 \\
0\end{array}$ & $\begin{array}{r}0 \\
60\end{array}$ & $\begin{array}{r}7,724 \\
646\end{array}$ & $\begin{array}{r}720 \\
0 \\
0\end{array}$ & $\begin{array}{r}491 \\
41\end{array}$ \\
\hline Toted Income Deduetions ............................. & 7,496 & 0 & 60 & 8,370 & 720 & 531 \\
\hline Income Betore Extraordinary Items ................. & 146 & 276 & 970 & 72 & 798 & 3 \\
\hline 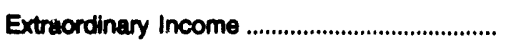 & 0 & 480 & 0 & 366 & 0 & 0 \\
\hline 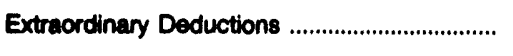 & 0 & 537 & 0 & 0 & 737 & 0 \\
\hline 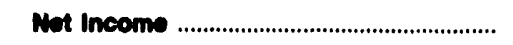 & 146 & 219 & 970 & 438 & 61 & 3 \\
\hline
\end{tabular}

Note: Totals may not equal sum of components because of independent rounding.

Source: Energy Intormation Administration, Form EIA-412, "Annual Report of Public Electric Utilities." 
Table 21. Statement of Income by Major U.S. Publlcly Owned Electric Utility Within State, 1992 (Continued)

(Thousand Dollars)

\begin{tabular}{|c|c|c|c|c|c|c|}
\hline Item & $\begin{array}{l}\text { Illinois } \\
\begin{array}{c}\text { Springfield } \\
\text { City of }\end{array} \\
\text { February } 28\end{array}$ & $\begin{array}{l}\text { Illinois } \\
\text { St Charles } \\
\text { City of } \\
\text { April } 30\end{array}$ & $\begin{array}{c}\text { Indiana } \\
\text { Anderson } \\
\text { City of } \\
\text { December } 31\end{array}$ & $\begin{array}{l}\text { Indiana } \\
\text { Auburn } \\
\text { City of } \\
\text { December } 31\end{array}$ & $\begin{array}{l}\text { Indiana } \\
\text { Bluffton } \\
\text { City of } \\
\text { December } 31\end{array}$ & $\begin{array}{c}\text { Indiana } \\
\text { Crawfordsville } \\
\text { Elec } \\
\text { Lgt\&Pwr Co } \\
\text { December } 31\end{array}$ \\
\hline Electric Utilty Operating Rovenues ............ & 91,056 & 26,165 & 36,290 & 14,441 & 7,433 & 18,368 \\
\hline 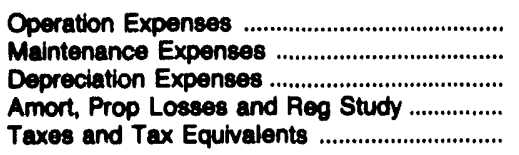 & $\begin{array}{r}48,736 \\
12,638 \\
11,524 \\
87 \\
3,850\end{array}$ & $\begin{array}{r}18,063 \\
3,041 \\
834 \\
0 \\
0\end{array}$ & $\begin{array}{r}32,211 \\
1,130 \\
1,410 \\
0 \\
997\end{array}$ & $\begin{array}{r}12,577 \\
681 \\
358 \\
0 \\
169\end{array}$ & $\begin{array}{r}7,146 \\
511 \\
268 \\
0 \\
140\end{array}$ & $\begin{array}{r}15,230 \\
1,075 \\
922 \\
13 \\
440\end{array}$ \\
\hline 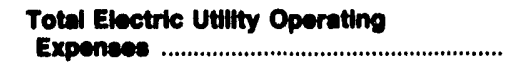 & 76,835 & 21,938 & 36,749 & 13,784 & 8,005 & 17,680 \\
\hline $\begin{array}{l}\text { Net Electric Utility Operating Income } \\
\text { Income from Electric Plant Leased } \\
\text { to Others }\end{array}$ & $\begin{array}{r}14,221 \\
0\end{array}$ & $\begin{array}{r}3,227 \\
0\end{array}$ & $\begin{array}{r}550 \\
0\end{array}$ & 657 & $\begin{array}{r}-632 \\
0\end{array}$ & $\begin{array}{r}678 \\
0\end{array}$ \\
\hline Electrlc Utility Operating Income .............. & 14,221 & 3,227 & 550 & 657 & -632 & 678 \\
\hline Other Electric Income & 2,240 & 1,129 & 269 & 295 & 143 & 172 \\
\hline 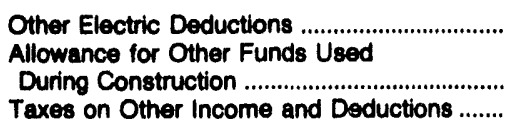 & $\begin{array}{l}0 \\
0 \\
0\end{array}$ & $\begin{array}{l}0 \\
0\end{array}$ & $\begin{array}{l}0 \\
0\end{array}$ & $\begin{array}{l}0 \\
0 \\
0\end{array}$ & $\begin{array}{l}-5 \\
0 \\
0\end{array}$ & $\begin{array}{r}20 \\
2 \\
0\end{array}$ \\
\hline 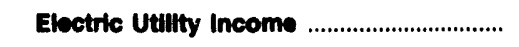 & 16,481 & 4,356 & 819 & 952 & -484 & 833 \\
\hline 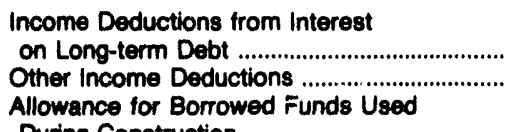 & $\begin{array}{r}6,996 \\
277\end{array}$ & $\begin{array}{r}0 \\
1,215\end{array}$ & $\begin{array}{r}85 \\
5\end{array}$ & $\begin{array}{r}45 \\
0\end{array}$ & $\begin{array}{l}0 \\
0\end{array}$ & $\begin{array}{r}367 \\
259\end{array}$ \\
\hline 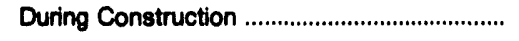 & 0 & 0 & 0 & 0 & 0 & 0 \\
\hline 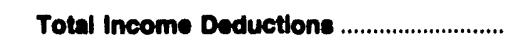 & 7,273 & 1,215 & $\boldsymbol{\infty 0}$ & 45 & 0 & 628 \\
\hline Income Before Extraordinary Items ..................... & 9,188 & 3,142 & 730 & 906 & -484 & 207 \\
\hline Extraordinary Income & 872 & 0 & 0 & 0 & 0 & 0 \\
\hline 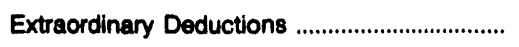 & 0 & 0 & 0 & 0 & 0 & 0 \\
\hline 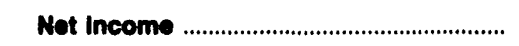 & 10,000 & 3,142 & 730 & 806 & -484 & 207 \\
\hline
\end{tabular}

Note: Totals may not equal sum of components because of independent rounding.

Source: Energy Information Administration, Form EIA-412, "Annual Report of Public Electric Utilities." 
Table 21. Statement of Income by Major U.S. Publicly Owned Electric Utility Within State, 1992 (Continued)

(Thousand Dollars)

\begin{tabular}{|c|c|c|c|c|c|c|}
\hline Item & $\begin{array}{c}\text { Indiana } \\
\text { Frankfort } \\
\text { City of } \\
\text { December } 31\end{array}$ & $\begin{array}{l}\text { Indiana } \\
\text { Greenfield } \\
\text { City of } \\
\text { December } 31\end{array}$ & $\begin{array}{c}\text { Indiana } \\
\text { Indiana } \\
\text { Municipal } \\
\text { Power Agency } \\
\text { Docember } 31\end{array}$ & $\begin{array}{l}\text { Indiana } \\
\text { Jasper } \\
\text { City of } \\
\text { December } 31\end{array}$ & $\begin{array}{c}\text { Indiana } \\
\begin{array}{c}\text { Logansport } \\
\text { City of }\end{array} \\
\text { December } 31\end{array}$ & $\begin{array}{c}\text { Indiana } \\
\text { Mishawaka } \\
\text { City of } \\
\text { December } 31\end{array}$ \\
\hline Eloctrle Utilty Operating Rovenues ............. & 13,231 & 7,826 & 142,305 & 13,378 & 16,552 & 23,411 \\
\hline 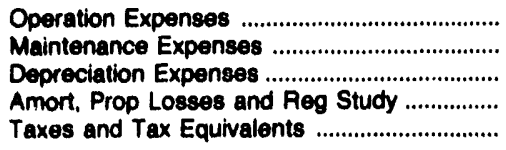 & $\begin{array}{r}12,195 \\
222 \\
500 \\
0 \\
218\end{array}$ & $\begin{array}{r}6,370 \\
570 \\
276 \\
0 \\
0\end{array}$ & $\begin{array}{r}113,840 \\
2,269 \\
6,820 \\
11 \\
858\end{array}$ & $\begin{array}{r}11,968 \\
356 \\
240 \\
0 \\
254\end{array}$ & $\begin{array}{r}12,505 \\
1,616 \\
1,642 \\
0 \\
341\end{array}$ & $\begin{array}{r}21,513 \\
640 \\
1,470 \\
0 \\
398\end{array}$ \\
\hline $\begin{array}{l}\text { Total Electric Utilty Operating } \\
\text { Expenees }\end{array}$ & 13,135 & 7,217 & 123,797 & 12,818 & 16,104 & 24,022 \\
\hline $\begin{array}{l}\text { Not Electric Utility Operating Income ................. } \\
\text { Income from Electric Plant Leased } \\
\text { to Others }\end{array}$ & $\begin{array}{r}96 \\
0\end{array}$ & $\begin{array}{r}608 \\
0\end{array}$ & $\begin{array}{r}18,508 \\
0\end{array}$ & $\begin{array}{r}560 \\
0\end{array}$ & $\begin{array}{r}448 \\
0\end{array}$ & $\begin{array}{r}-611 \\
0\end{array}$ \\
\hline Electric Utility Operating Income .............. & $\boldsymbol{9 6}$ & 608 & 18,508 & 560 & 448 & -611 \\
\hline Other Electric Income & 130 & 130 & 3,339 & 124 & 748 & 548 \\
\hline $\begin{array}{l}\text { Other Electric Deductions } \\
\text { Allowance for Other Funds Used }\end{array}$ & 16 & 0 & $\boldsymbol{9}$ & 16 & 0 & 0 \\
\hline 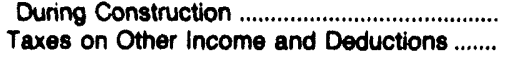 & $\begin{array}{l}0 \\
0\end{array}$ & $\begin{array}{l}0 \\
0\end{array}$ & $\begin{array}{l}0 \\
0\end{array}$ & $\begin{array}{l}0 \\
0\end{array}$ & $\begin{array}{l}0 \\
0\end{array}$ & 0 \\
\hline Electric Utility Income & 210 & 737 & 21,838 & 669 & 1,196 & -62 \\
\hline 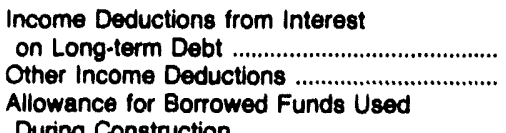 & $\begin{array}{l}0 \\
0\end{array}$ & $\begin{array}{r}140 \\
0\end{array}$ & $\begin{array}{r}20,109 \\
2,141\end{array}$ & $\begin{array}{r}296 \\
4\end{array}$ & $\begin{array}{r}1,203 \\
0\end{array}$ & $\begin{array}{r}104 \\
49\end{array}$ \\
\hline 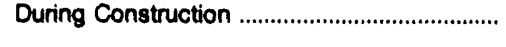 & 0 & 0 & $-2,039$ & 0 & 0 & 0 \\
\hline 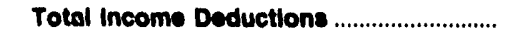 & 0 & 140 & 20,211 & 300 & 1,203 & 153 \\
\hline Income Before Extraordinary Items .................. & 210 & 597 & 1,627 & 369 & -7 & -215 \\
\hline Extraordinary income & 1,221 & 0 & 4,406 & 3 & 0 & 0 \\
\hline 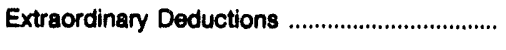 & 0 & 0 & 0 & 117 & 0 & 0 \\
\hline 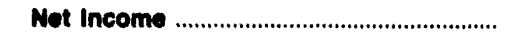 & 1,431 & 597 & 6,033 & 255 & -7 & -216 \\
\hline
\end{tabular}

Note: Totals may not equal sum of components because of independent rounding.

Source: Energy Information Administration, Form ElA-412, "Annual Report of Public Electric Utilities." 
Table 21. Statement of Income by Major U.S. Publicly Owned Electric Utillty Within State, 1992 (Continued) (Thousand Dollars)

\begin{tabular}{|c|c|c|c|c|c|c|}
\hline Item & $\begin{array}{c}\text { Indiana } \\
\text { Peru } \\
\text { Clty of } \\
\text { December } 31\end{array}$ & $\begin{array}{l}\text { Indiana } \\
\text { Richmond } \\
\text { City of } \\
\text { December } 31\end{array}$ & $\begin{array}{c}\text { Indiana } \\
\text { Washington } \\
\text { City of } \\
\text { December } 31\end{array}$ & $\begin{array}{l}\text { lowa } \\
\text { Ames } \\
\text { City of } \\
\text { June } 30\end{array}$ & $\begin{array}{l}\text { lowa } \\
\text { Cedar } \\
\text { Falls } \\
\text { City of } \\
\text { December } 31\end{array}$ & $\begin{array}{l}\text { lowa } \\
\text { Muscatine } \\
\text { City of } \\
\text { December } 31\end{array}$ \\
\hline Electric Utilly Operating Rovenues ............ & 8,968 & 38,180 & 7,528 & 19,944 & 13,035 & 73,115 \\
\hline 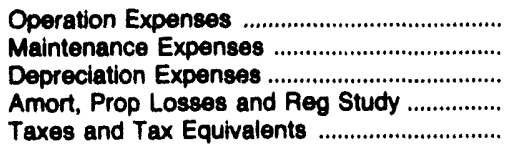 & $\begin{array}{r}7,071 \\
438 \\
812 \\
0 \\
319\end{array}$ & $\begin{array}{r}27,694 \\
3,594 \\
2,705 \\
0 \\
2,092\end{array}$ & $\begin{array}{r}6,932 \\
186 \\
329 \\
172 \\
0\end{array}$ & $\begin{array}{r}12,558 \\
0 \\
3,369 \\
0 \\
0\end{array}$ & $\begin{array}{r}7,435 \\
1,542 \\
2,165 \\
73 \\
648\end{array}$ & $\begin{array}{r}41,563 \\
4,987 \\
9,412 \\
0 \\
112\end{array}$ \\
\hline $\begin{array}{l}\text { Total Electric Utility Operating } \\
\text { Expenses }\end{array}$ & 8,640 & 36,084 & 7,620 & 15,927 & 11,864 & 56,073 \\
\hline $\begin{array}{l}\text { Net Electric Utility Operating Income .............. } \\
\text { Income from Electric Plant Leased }\end{array}$ & 326 & 2,096 & -91 & 4,017 & 1,171 & 17,042 \\
\hline 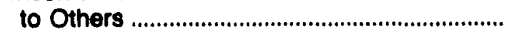 & 0 & 0 & 0 & 0 & 0 & 0 \\
\hline Electric Utility Operating Income .............. & 328 & 2,098 & -91 & 4,017 & 1,171 & 17,042 \\
\hline 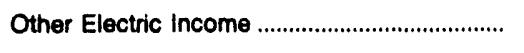 & 116 & 599 & 62 & 1,235 & 1,059 & 13,654 \\
\hline $\begin{array}{l}\text { Other Electric Deductions ................................ } \\
\text { Allowance for Other Funds Used }\end{array}$ & 0 & 72 & 0 & 746 & 41 & 0 \\
\hline $\begin{array}{l}\text { During Construction ...................................... } \\
\text { Taxes on Other Income and Deductions ....... }\end{array}$ & $\begin{array}{r}0 \\
212\end{array}$ & $\begin{array}{r}0 \\
428\end{array}$ & $\begin{array}{l}0 \\
0\end{array}$ & $\begin{array}{l}0 \\
0\end{array}$ & $\begin{array}{l}0 \\
0\end{array}$ & $\begin{array}{l}0 \\
0\end{array}$ \\
\hline 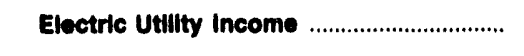 & 230 & 2,195 & -29 & 4,506 & 2,190 & 30,696 \\
\hline $\begin{array}{l}\text { Income Deductions from Interest } \\
\text { on Long-term Debt ......................................... } \\
\text { Other Income Deductions ................................ } \\
\text { Allowance for Borrowed Funds Used }\end{array}$ & $\begin{array}{r}63 \\
4\end{array}$ & $\begin{array}{l}0 \\
0\end{array}$ & $\begin{array}{l}0 \\
0\end{array}$ & $\begin{array}{r}2,227 \\
0\end{array}$ & $\begin{array}{r}380 \\
2\end{array}$ & $\begin{array}{r}17,401 \\
0\end{array}$ \\
\hline 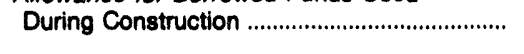 & 0 & 0 & 0 & 0 & 0 & 0 \\
\hline 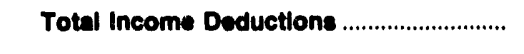 & 67 & $\mathbf{0}$ & 0 & 2,227 & 383 & 17,401 \\
\hline Income Betore Extraordinary Items ................. & 164 & 2,195 & -29 & 2,279 & 1,807 & 13,295 \\
\hline 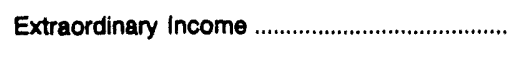 & 0 & 0 & 0 & 0 & 0 & 0 \\
\hline 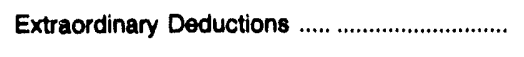 & 0 & 0 & 0 & 0 & 0 & 10,133 \\
\hline 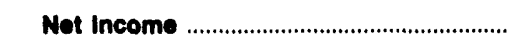 & 164 & 2,195 & -29 & 2,279 & 1,807 & 3,162 \\
\hline
\end{tabular}

Note: Totals may not equal sum of components because of independent rounding.

Source: Energy Information Administration, Form EIA-412, "Annual Report of Public Electric Utilities." 
Table 21. Statement of Income by Major U.S. Publlcly Owned Electric Utility Within State, 1992 (Continued)

(Thousand Dollars)

\begin{tabular}{|c|c|c|c|c|c|c|}
\hline Item & $\begin{array}{l}\text { lowa } \\
\text { Pella } \\
\text { City of } \\
\text { June } 30\end{array}$ & $\begin{array}{c}\text { Kansas } \\
\text { Chanute } \\
\text { Clty of } \\
\text { December } 31\end{array}$ & $\begin{array}{c}\text { Kansas } \\
\text { Coffeyville } \\
\text { City of }\end{array}$ & $\begin{array}{c}\text { Kansas } \\
\text { Garden } \\
\text { City City of } \\
\text { December } 31\end{array}$ & $\begin{array}{c}\text { Kansas } \\
\text { Kansas } \\
\text { City City of } \\
\text { December } 31\end{array}$ & $\begin{array}{c}\text { Kansas } \\
\text { Kansas } \\
\text { Municipal } \\
\text { Energy } \\
\text { Agency } \\
\text { December } 31\end{array}$ \\
\hline Ekotule Utilty Operating Rovenuse ............ & 7,986 & 8,033 & 10,291 & 10,745 & 115,472 & 12,478 \\
\hline 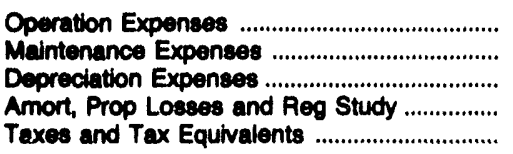 & $\begin{array}{r}5,579 \\
242 \\
0 \\
0 \\
0\end{array}$ & $\begin{array}{r}7,250 \\
132 \\
0 \\
0 \\
0\end{array}$ & $\begin{array}{r}7,590 \\
980 \\
1,224 \\
0 \\
550\end{array}$ & $\begin{array}{r}10,265 \\
0 \\
566 \\
0 \\
0\end{array}$ & $\begin{array}{r}76,248 \\
17,638 \\
15,775 \\
1,215 \\
2,136\end{array}$ & $\begin{array}{r}10,668 \\
0 \\
181 \\
517 \\
17\end{array}$ \\
\hline Total Electric vetilty Operrating & 5,021 & 7,382 & 10,344 & 10,831 & 113,014 & 11,383 \\
\hline $\begin{array}{l}\text { Net Electric Utility Operating Income .............. } \\
\text { Income from Electric Plant Leased }\end{array}$ & $\begin{array}{r}1,865 \\
0\end{array}$ & $\begin{array}{r}651 \\
0\end{array}$ & $\begin{array}{r}-53 \\
0\end{array}$ & $\begin{array}{r}-86 \\
0\end{array}$ & $\begin{array}{r}2,458 \\
0\end{array}$ & $\begin{array}{r}1,095 \\
0\end{array}$ \\
\hline Electrk Utilty Operating Incoms ............. & 1,885 & 851 & -53 & -86 & 2,458 & 1,095 \\
\hline Other Electric Income & 845 & 0 & 271 & 11 & 3,196 & 333 \\
\hline $\begin{array}{l}\text { Other Electric Deductions .............................. } \\
\text { Allowance for Other Funds Used }\end{array}$ & 0 & 0 & 329 & 0 & 0 & 0 \\
\hline $\begin{array}{l}\text { During Construction ...................................... } \\
\text { Taxes on Other Income and Deductions ....... }\end{array}$ & $\begin{array}{l}0 \\
0\end{array}$ & $\begin{array}{l}0 \\
0\end{array}$ & $\begin{array}{l}0 \\
0\end{array}$ & $\begin{array}{l}0 \\
0\end{array}$ & $\begin{array}{l}0 \\
0\end{array}$ & $\begin{array}{l}0 \\
0\end{array}$ \\
\hline 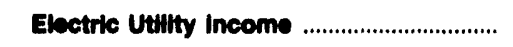 & 2,711 & 651 & -112 & -76 & 5,655 & 1,428 \\
\hline 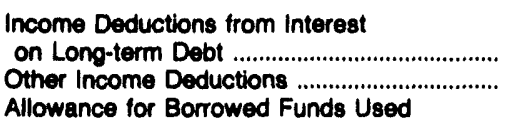 & $\begin{array}{r}200 \\
67\end{array}$ & $\begin{array}{l}0 \\
0\end{array}$ & $\begin{array}{r}65 \\
0\end{array}$ & $\begin{array}{r}0 \\
375\end{array}$ & $\begin{array}{r}10,408 \\
0\end{array}$ & $\begin{array}{r}1,180 \\
63\end{array}$ \\
\hline 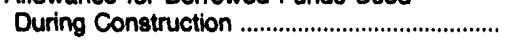 & 0 & 0 & 0 & 0 & 0 & 0 \\
\hline Total income Deductions ........................... & 287 & 0 & 65 & 375 & 10,408 & 1,243 \\
\hline Income Before Extraordinary Items ................. & 2,444 & 651 & -177 & -451 & $-4,754$ & 185 \\
\hline 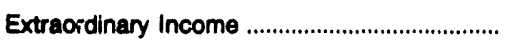 & 0 & 0 & 64 & 0 & 0 & 0 \\
\hline 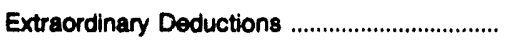 & 0 & 0 & 0 & 0 & 2,022 & 0 \\
\hline Net Income & 2,444 & 651 & -113 & -451 & $-6,775$ & 185 \\
\hline
\end{tabular}

Note: Totals may not equal sum of components because of independent rounding.

Source: Energy Information Administration, Form EIA-412, "Annual Report of Public Electric Utilities." 
Table 21. Statement of Income by Major U.S. Publicly Owned Electric Utility Within State, 1992 (Continued)

(Thousand Dollars)

\begin{tabular}{|c|c|c|c|c|c|c|}
\hline Item & $\begin{array}{c}\text { Kanses } \\
\text { McPherson } \\
\text { City of } \\
\text { December } 31\end{array}$ & $\begin{array}{l}\text { Kansas } \\
\text { Winfield } \\
\text { City of } \\
\text { December } 31\end{array}$ & $\begin{array}{l}\text { Kentucky } \\
\text { Bowling } \\
\text { Green } \\
\text { City of } \\
\text { June } 30\end{array}$ & $\begin{array}{l}\text { Kentucky } \\
\text { Frankfort } \\
\text { City of } \\
\text { June } 30\end{array}$ & $\begin{array}{l}\text { Kentucky } \\
\text { Franklin } \\
\text { City of } \\
\text { June } 30\end{array}$ & $\begin{array}{l}\text { Kentucky } \\
\text { Glasgow } \\
\text { City of } \\
\text { June } 30\end{array}$ \\
\hline Electric Utillty Operating Rovenues ............. & 18,444 & 11,320 & 36,565 & 22,400 & 9,347 & 13,012 \\
\hline 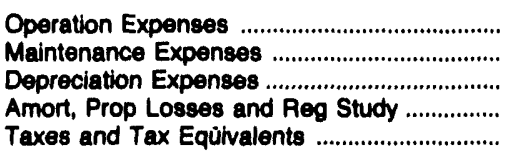 & $\begin{array}{r}14,858 \\
1,566 \\
1,693 \\
0 \\
0\end{array}$ & $\begin{array}{r}9,277 \\
0 \\
590 \\
0 \\
0\end{array}$ & $\begin{array}{r}32,098 \\
979 \\
1,226 \\
0 \\
1,473\end{array}$ & $\begin{array}{r}20,148 \\
1,053 \\
784 \\
0 \\
66\end{array}$ & $\begin{array}{r}8,742 \\
209 \\
130 \\
0 \\
347\end{array}$ & $\begin{array}{r}12,814 \\
266 \\
587 \\
13 \\
308\end{array}$ \\
\hline $\begin{array}{l}\text { Total Eloctric Utillty Operating } \\
\text { Expenese }\end{array}$ & 18,117 & 9,886 & 35,776 & 22,051 & 9,428 & 13,097 \\
\hline 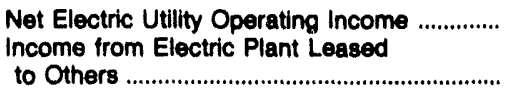 & $\begin{array}{r}327 \\
0\end{array}$ & $\begin{array}{r}1,454 \\
0\end{array}$ & $\begin{array}{r}779 \\
0\end{array}$ & 350 & $\begin{array}{r}-81 \\
0\end{array}$ & $\begin{array}{r}-75 \\
0\end{array}$ \\
\hline Electric Utility Operating Income ............... & 327 & 1,454 & 779 & 350 & -81 & -76 \\
\hline 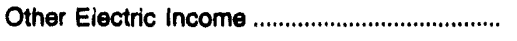 & 1,098 & 185 & 439 & 6,104 & 147 & 197 \\
\hline $\begin{array}{l}\text { Other Electric Deductions } \\
\text { Allowance for Other Funds Used }\end{array}$ & 655 & 4 & 0 & 5,294 & 0 & 2 \\
\hline $\begin{array}{l}\text { During Construction ......................................... } \\
\text { Taxes on Other Income and Deductions ..... }\end{array}$ & $\begin{array}{l}0 \\
0\end{array}$ & $\begin{array}{r}0 \\
799\end{array}$ & $\begin{array}{l}0 \\
0\end{array}$ & $\begin{array}{l}0 \\
0\end{array}$ & $\begin{array}{l}0 \\
0\end{array}$ & $\begin{array}{l}0 \\
0\end{array}$ \\
\hline 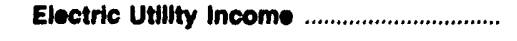 & 771 & 837 & 1,218 & 1,150 & 68 & 120 \\
\hline $\begin{array}{l}\text { Income Deductions from Interest } \\
\text { on Long-term Debt ....................................... } \\
\text { Other Income Deductions ............................... } \\
\text { Allowance for Borrowed Funds Used }\end{array}$ & $\begin{array}{r}750 \\
0\end{array}$ & $\begin{array}{r}347 \\
0\end{array}$ & $\begin{array}{l}401 \\
105\end{array}$ & $\begin{array}{r}207 \\
0\end{array}$ & $\begin{array}{l}0 \\
8\end{array}$ & $\begin{array}{r}276 \\
29\end{array}$ \\
\hline 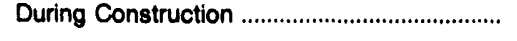 & 0 & 0 & 0 & 0 & 0 & 0 \\
\hline 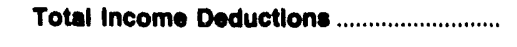 & 750 & 347 & 506 & 207 & • & 305 \\
\hline Income Before Extraordinary Items ................... & 21 & 489 & 712 & 952 & 59 & -184 \\
\hline Extraordinary Income & 0 & 939 & 0 & 0 & 0 & 0 \\
\hline 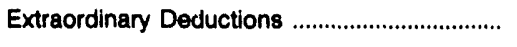 & 0 & 0 & 0 & 0 & 0 & 0 \\
\hline 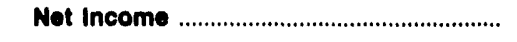 & 21 & 1,428 & 712 & 952 & 59 & -184 \\
\hline
\end{tabular}

Note: Totals may not equal sum of components because of independent rounding.

Source: Energy Information Administration, Form ElA-412, "Annual Report of Public Electric Utilities." 
Table 21. Statement of Income by Major U.S. Publicly Owned Electric Utility Within State, 1992 (Continued)

(Thousand Dollars)

\begin{tabular}{|c|c|c|c|c|c|c|}
\hline Item & $\begin{array}{c}\text { Kentucky } \\
\text { Henderson } \\
\text { City } \\
\text { Utility Comm } \\
\text { May } 31\end{array}$ & $\begin{array}{l}\text { Kentucky } \\
\text { Hopkinsville } \\
\text { City of } \\
\text { June } 30\end{array}$ & $\begin{array}{l}\text { Kentucky } \\
\text { Madisonville } \\
\text { Municipal } \\
\text { Utils } \\
\text { June } 30\end{array}$ & $\begin{array}{l}\text { Kentucky } \\
\text { Maytield } \\
\text { City of } \\
\text { June } 30\end{array}$ & $\begin{array}{l}\text { Kentucky } \\
\text { Murray } \\
\text { City of } \\
\text { June } 30\end{array}$ & $\begin{array}{l}\text { Kentucky } \\
\text { Owensboro } \\
\text { City of } \\
\text { May } 31\end{array}$ \\
\hline Electrle Utility Operating Rovenues ............. & 25,212 & 19,186 & 11,761 & 8,144 & 12,239 & 49,235 \\
\hline 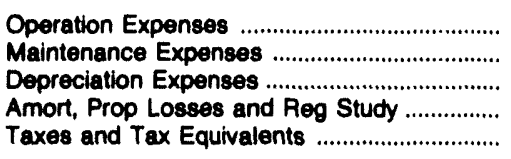 & $\begin{array}{r}12,885 \\
5,340 \\
3,977 \\
0 \\
0\end{array}$ & $\begin{array}{r}17,768 \\
463 \\
456 \\
0 \\
684\end{array}$ & $\begin{array}{r}8,608 \\
672 \\
184 \\
0 \\
0\end{array}$ & $\begin{array}{r}7.244 \\
365 \\
152 \\
0 \\
344\end{array}$ & $\begin{array}{r}11,157 \\
359 \\
292 \\
0 \\
474\end{array}$ & $\begin{array}{r}31,926 \\
7,251 \\
3,726 \\
0 \\
0\end{array}$ \\
\hline $\begin{array}{l}\text { Total Electric UtIlity Operating } \\
\text { Expenese }\end{array}$ & 22,201 & 19,371 & 9,464 & 8,105 & 12,282 & 42,903 \\
\hline $\begin{array}{l}\text { Net Electric Utility Operating Income ............. } \\
\text { Income from Electric Plant Leased }\end{array}$ & 3,011 & -186 & 2,297 & 39 & -43 & 6,331 \\
\hline to Others & 0 & 0 & 0 & 0 & 0 & 0 \\
\hline Electric Utillty Operating Income .............. & 3,011 & -186 & 2,297 & 39 & -43 & 6,331 \\
\hline 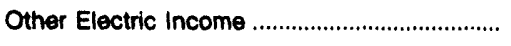 & 1,822 & 642 & 231 & 58 & 128 & 5,592 \\
\hline $\begin{array}{l}\text { Other Electric Deductions ................................. } \\
\text { Allowance for Other Funds Used }\end{array}$ & 0 & 35 & 0 & 0 & 0 & 3,634 \\
\hline 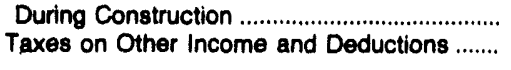 & $\begin{array}{l}0 \\
0\end{array}$ & $\begin{array}{l}0 \\
0\end{array}$ & $\begin{array}{l}0 \\
0\end{array}$ & $\begin{array}{l}0 \\
0\end{array}$ & $\begin{array}{l}0 \\
0\end{array}$ & $\begin{array}{l}0 \\
0\end{array}$ \\
\hline 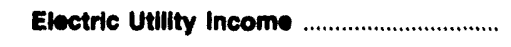 & 4,833 & 421 & 2,529 & 96 & 85 & 8,289 \\
\hline 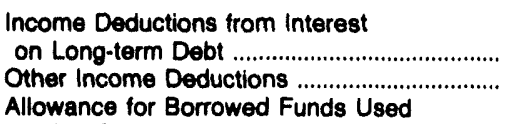 & $\begin{array}{r}2,822 \\
0\end{array}$ & $\begin{array}{r}226 \\
9\end{array}$ & $\begin{array}{r}0 \\
2,800\end{array}$ & $\begin{array}{l}0 \\
7\end{array}$ & $\begin{array}{r}0 \\
15\end{array}$ & $\begin{array}{r}6,506 \\
0\end{array}$ \\
\hline 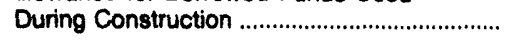 & 0 & 0 & 0 & 0 & 0 & 0 \\
\hline 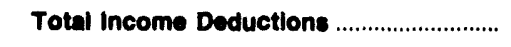 & 2,822 & 235 & 2,800 & 7 & 15 & 6,506 \\
\hline Income Before Extraordinary Items ..................... & 2,011 & 187 & -271 & 89 & 70 & 1,783 \\
\hline Extraordinary Income & 0 & 0 & 0 & 0 & 0 & 0 \\
\hline 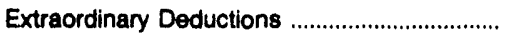 & 0 & 0 & 0 & 0 & 0 & 0 \\
\hline Net Income & 2,011 & 187 & -271 & 89 & 70 & 1,783 \\
\hline
\end{tabular}

Note: Totals may not equal sum of components because of independent rounding.

Source: Energy Information Administration, Form EIA-412, "Annual Report of Public Electric Utilities." 
Table 21. Statement of Income by Major U.S. Publicly Owned Electric Utllity Within State, 1992 (Continued)

(Thousand Dollars)

\begin{tabular}{|c|c|c|c|c|c|c|}
\hline Item & $\begin{array}{l}\text { Kentucky } \\
\text { Paducah } \\
\text { City of } \\
\text { June } 30\end{array}$ & $\begin{array}{l}\text { Louisiana } \\
\text { Alexandria } \\
\text { City of } \\
\text { April } 30\end{array}$ & $\begin{array}{l}\text { Loulsiana } \\
\text { Lafayette } \\
\text { City of } \\
\text { October } 31\end{array}$ & $\begin{array}{l}\text { Loulsiana } \\
\text { Lafayette } \\
\text { Public } \\
\text { Power Auth } \\
\text { Octoher } 31\end{array}$ & $\begin{array}{c}\text { Louisiana } \\
\text { Louisiane } \\
\text { Energy } \\
\& \\
\text { Power Auth } \\
\text { December } 31\end{array}$ & $\begin{array}{l}\text { Louisiana } \\
\text { Morgan } \\
\text { City City of } \\
\text { December } 31\end{array}$ \\
\hline Electric Utility Operating Rovenues ............. & 30,490 & 39,137 & 101,714 & 49,937 & 62,572 & 9,021 \\
\hline 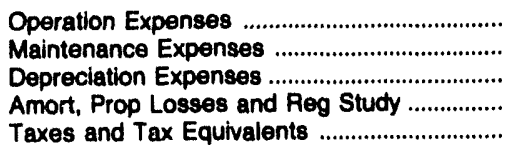 & $\begin{array}{r}26,253 \\
844 \\
1,337 \\
-10 \\
1,449\end{array}$ & $\begin{array}{r}24,611 \\
890 \\
1,785 \\
0 \\
2,027\end{array}$ & $\begin{array}{r}71,630 \\
2,857 \\
3,809 \\
1,965 \\
7,701\end{array}$ & $\begin{array}{r}33,982 \\
1,507 \\
4,318 \\
0 \\
0\end{array}$ & $\begin{array}{r}50,821 \\
1,041 \\
1,808 \\
1,374 \\
0\end{array}$ & $\begin{array}{r}7.714 \\
203 \\
801 \\
0 \\
0\end{array}$ \\
\hline $\begin{array}{l}\text { Total Eloctric Utility Operating } \\
\text { Expenees }\end{array}$ & 29,873 & 20,313 & 80,062 & 39,807 & 55,144 & 8,716 \\
\hline $\begin{array}{l}\text { Net Electric Utility Operating Income } \\
\text { Income from Electric Plant Leased } \\
\text { to Others }\end{array}$ & $\begin{array}{r}626 \\
0\end{array}$ & $\begin{array}{r}9,824 \\
0\end{array}$ & $\begin{array}{r}13,652 \\
26\end{array}$ & $\begin{array}{r}10,131 \\
0\end{array}$ & $\begin{array}{r}7,428 \\
0\end{array}$ & $\begin{array}{r}1,103 \\
0\end{array}$ \\
\hline Electric Utility Operating Income ............. & 626 & 9,824 & 13,678 & 10,131 & 7,428 & 1,103 \\
\hline Other Electric Income & 631 & 831 & 2,861 & 1,443 & 1,479 & 0 \\
\hline $\begin{array}{l}\text { Other Electric Deductions .................................. } \\
\text { Allowance for Other Funds Used }\end{array}$ & 3 & 1,409 & 0 & 0 & 0 & 0 \\
\hline 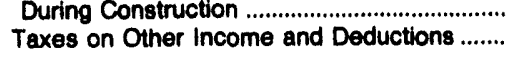 & $\begin{array}{l}0 \\
0\end{array}$ & $\begin{array}{r}0 \\
746\end{array}$ & $\begin{array}{l}0 \\
0\end{array}$ & $\begin{array}{l}0 \\
0\end{array}$ & $\begin{array}{l}0 \\
0\end{array}$ & $\begin{array}{l}0 \\
0\end{array}$ \\
\hline 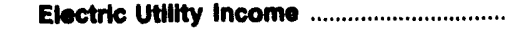 & 1,254 & $\mathbf{8 , 5 0 9}$ & 18,530 & 11,574 & 8,907 & 1,103 \\
\hline 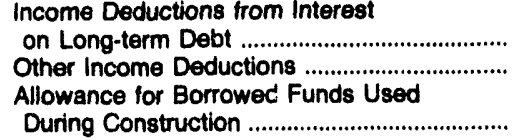 & $\begin{array}{r}241 \\
29\end{array}$ & $\begin{array}{l}3,270 \\
2,086\end{array}$ & $\begin{array}{r}3,073 \\
162\end{array}$ & $\begin{array}{r}11,406 \\
853 \\
0\end{array}$ & $\begin{array}{r}8,705 \\
0 \\
0\end{array}$ & $\begin{array}{r}435 \\
0 \\
0\end{array}$ \\
\hline 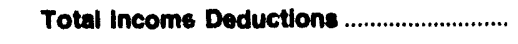 & 270 & 5,366 & 3,234 & 12,258 & 8,705 & 435 \\
\hline 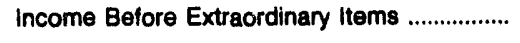 & 984 & 3,243 & 13,304 & -685 & 202 & 668 \\
\hline 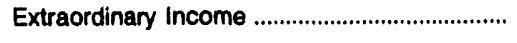 & 0 & 0 & 0 & 0 & 0 & 0 \\
\hline 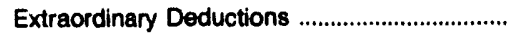 & 0 & 0 & 0 & 0 & 0 & 0 \\
\hline Net Income & $\mathbf{2 8 4}$ & $\mathbf{3 , 2 4 3}$ & 13,304 & -685 & 202 & 688 \\
\hline
\end{tabular}

Note: Totals may not equal sum of components because of independent rounding.

Source: Energy Intormation Administration, Form EIA-412, "Annual Report of Public Electric Utilities." 
Table 21. Statement of Income by Major U.S. Publicly Owned Electric Utility Within State, 1992 (Continued)

(Thousand Dollars)

\begin{tabular}{|c|c|c|c|c|c|c|}
\hline Item & $\begin{array}{l}\text { Louislana } \\
\begin{array}{c}\text { Natchitoches } \\
\text { City of }\end{array} \\
\text { May } 31\end{array}$ & $\begin{array}{l}\text { Louisiana } \\
\text { Ruston } \\
\text { City of } \\
\text { September } 30\end{array}$ & $\begin{array}{c}\text { Louisiana } \\
\text { Terrebonne } \\
\text { Parish } \\
\text { Consol Govt } \\
\text { December } 31\end{array}$ & $\begin{array}{l}\text { Maryland } \\
\text { Easton } \\
\text { Utilities } \\
\text { Comm } \\
\text { June } 30\end{array}$ & $\begin{array}{l}\text { Maryland } \\
\text { Hagerstown } \\
\text { City of } \\
\text { December } 31\end{array}$ & $\begin{array}{c}\text { Massachusetts } \\
\text { Braintree } \\
\text { Town of } \\
\text { December } 31\end{array}$ \\
\hline Evetric Utilly Operating Rovenuse ............ & 13,094 & 9,751 & 17,083 & 12,428 & 15,527 & 31,444 \\
\hline 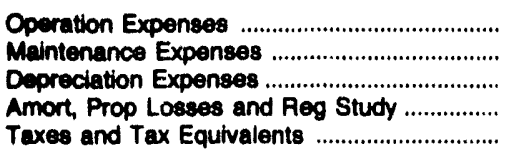 & $\begin{array}{r}10,130 \\
30 \\
813 \\
0 \\
0\end{array}$ & $\begin{array}{r}7,594 \\
381 \\
0 \\
0 \\
0\end{array}$ & $\begin{array}{r}13,340 \\
411 \\
1,656 \\
0 \\
0\end{array}$ & $\begin{array}{r}8,209 \\
726 \\
1,233 \\
0 \\
413\end{array}$ & $\begin{array}{r}12,766 \\
259 \\
792 \\
0 \\
358\end{array}$ & $\begin{array}{r}25,697 \\
1,881 \\
2,451 \\
0 \\
-23\end{array}$ \\
\hline $\begin{array}{l}\text { Total Ewetric Utilty Operating } \\
\text { Expenees }\end{array}$ & 10,972 & 7,975 & 16,407 & 10,680 & 14,175 & 30,006 \\
\hline $\begin{array}{l}\text { Net Electric Utility Operating Income } \\
\text { Income from Electric Plant Leased } \\
\text { to Others }\end{array}$ & $\begin{array}{r}3,022 \\
0\end{array}$ & $\begin{array}{r}1,776 \\
0\end{array}$ & $\begin{array}{r}1,676 \\
0\end{array}$ & $\begin{array}{r}1,848 \\
0\end{array}$ & $\begin{array}{r}1,352 \\
0\end{array}$ & $\begin{array}{r}1,438 \\
0\end{array}$ \\
\hline Ebetric Utility Operating Income .............. & 3,022 & 1,776 & 1,676 & 1,848 & 1,352 & 1,438 \\
\hline Other Electric Income & 92 & 185 & 664 & 160 & 265 & 184 \\
\hline $\begin{array}{l}\text { Other Electric Deductions .............................. } \\
\text { Allowance for Other Funds Used } \\
\text { During Construction ................................ } \\
\text { Taxes on Other Income and Deductions ....... }\end{array}$ & $\begin{array}{r}1,324 \\
0 \\
0\end{array}$ & $\begin{array}{l}0 \\
0 \\
0\end{array}$ & $\begin{array}{l}0 \\
0\end{array}$ & $\begin{array}{l}0 \\
0\end{array}$ & $\begin{array}{r}373 \\
0 \\
0\end{array}$ & $\begin{array}{l}0 \\
0 \\
0\end{array}$ \\
\hline 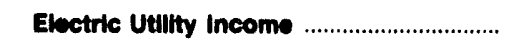 & 1,790 & 1,961 & 2,315 & 2,008 & 1,244 & 1,622 \\
\hline 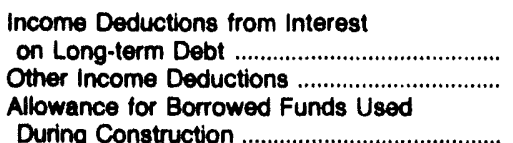 & $\begin{array}{r}350 \\
0 \\
0\end{array}$ & $\begin{array}{r}288 \\
1,009 \\
0\end{array}$ & $\begin{array}{r}647 \\
37\end{array}$ & $\begin{array}{r}927 \\
70 \\
0\end{array}$ & $\begin{array}{r}94 \\
0 \\
0\end{array}$ & $\begin{array}{r}219 \\
1 \\
0\end{array}$ \\
\hline 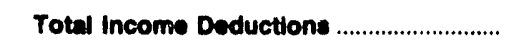 & 350 & 1,298 & 684 & 997 & 94 & 220 \\
\hline Income Before Extraordinary Items .................... & 1,440 & 663 & 1,630 & 1,011 & 1,150 & 1,402 \\
\hline Extraordinary Income & 0 & 0 & 0 & 0 & 0 & 0 \\
\hline 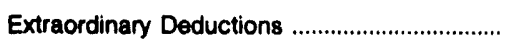 & 0 & 0 & 291 & 0 & 0 & 0 \\
\hline 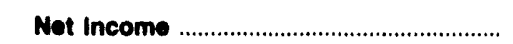 & 1,440 & 663 & 1,340 & 1,011 & 1,150 & 1,402 \\
\hline
\end{tabular}

Note: Totals may not equal sum of components because of independent rounding.

Source: Energy Information Administration, Form ElA-412, "Annual Report of Public Electric Utilities." 
Table 21. Statement of Income by Major U.S. Publlcly Owned Electric Utility Within State, 1992 (Continued)

(Thousand Dollars)

\begin{tabular}{|c|c|c|c|c|c|c|}
\hline Item & $\begin{array}{l}\text { Massachusetts } \\
\text { Chicopee } \\
\text { City of } \\
\text { December } 31\end{array}$ & $\begin{array}{l}\text { Massachusetts } \\
\text { Concord } \\
\text { Town of } \\
\text { December } 31\end{array}$ & $\begin{array}{l}\text { Massachusetts } \\
\text { Danvers } \\
\text { Town of } \\
\text { December } 31\end{array}$ & $\begin{array}{l}\text { Maseachusette } \\
\text { Hingham } \\
\text { Clty of } \\
\text { December } 31\end{array}$ & $\begin{array}{l}\text { Maseachusetts } \\
\text { Holyoke } \\
\text { City of } \\
\text { December } 31\end{array}$ & $\begin{array}{l}\text { Massachusetts } \\
\text { Hudson } \\
\text { Town of } \\
\text { December } 31\end{array}$ \\
\hline Electrio Utilly Operating Rovenues ............ & 30,874 & 12,803 & 32,401 & 13,033 & 26,042 & 28,448 \\
\hline 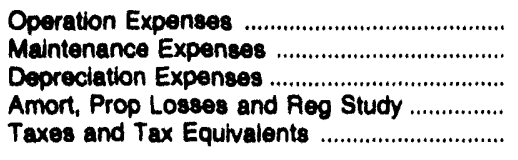 & $\begin{array}{r}23,086 \\
1,431 \\
1,854 \\
0 \\
498\end{array}$ & $\begin{array}{r}11,453 \\
139 \\
710 \\
0 \\
250\end{array}$ & $\begin{array}{r}29,953 \\
521 \\
549 \\
0 \\
0\end{array}$ & $\begin{array}{r}12,450 \\
541 \\
594 \\
0 \\
0\end{array}$ & $\begin{array}{r}22,761 \\
1,379 \\
1,324 \\
0 \\
0\end{array}$ & $\begin{array}{r}28,708 \\
511 \\
521 \\
0 \\
238\end{array}$ \\
\hline $\begin{array}{l}\text { Total Electric Utilty Operating } \\
\text { Expenese }\end{array}$ & 28,848 & 12,551 & 31,023 & 13,686 & 25,484 & 27,979 \\
\hline 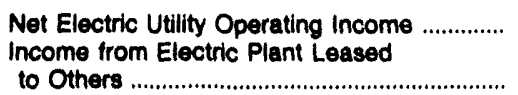 & $\begin{array}{r}4,027 \\
0\end{array}$ & $\begin{array}{r}252 \\
0\end{array}$ & $\begin{array}{r}1,458 \\
0\end{array}$ & $\begin{array}{r}349 \\
0\end{array}$ & $\begin{array}{r}1,478 \\
0\end{array}$ & $\begin{array}{r}469 \\
0\end{array}$ \\
\hline Ebetrle Utiltty Operating Income ............. & 4,027 & 252 & 1,468 & 340 & 1,478 & 469 \\
\hline 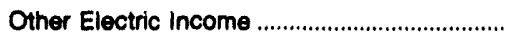 & 1,528 & 360 & 451 & 33 & 278 & 425 \\
\hline $\begin{array}{l}\text { Other Electric Deductions ............................. } \\
\text { Allowance for Other Funds Used }\end{array}$ & 0 & 0 & 0 & 0 & 0 & 0 \\
\hline 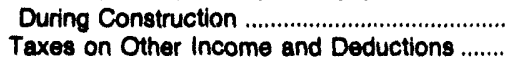 & $\begin{array}{l}0 \\
0\end{array}$ & $\begin{array}{l}0 \\
0\end{array}$ & $\begin{array}{l}0 \\
0\end{array}$ & $\begin{array}{l}0 \\
0\end{array}$ & $\begin{array}{l}0 \\
0\end{array}$ & $\begin{array}{l}0 \\
0\end{array}$ \\
\hline 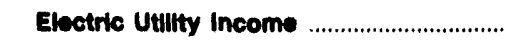 & 5,556 & 612 & 1,000 & 382 & 1,757 & 804 \\
\hline 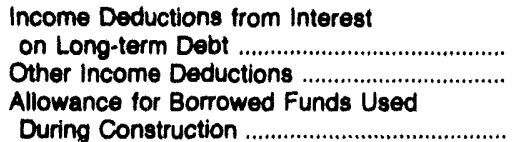 & $\begin{array}{r}2,128 \\
310\end{array}$ & $\begin{array}{r}125 \\
7\end{array}$ & $\begin{array}{r}39 \\
0 \\
0\end{array}$ & $\begin{array}{r}243 \\
18\end{array}$ & $\begin{array}{r}444 \\
127 \\
0\end{array}$ & $\begin{array}{l}0 \\
1 \\
0\end{array}$ \\
\hline 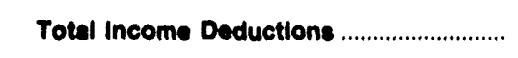 & 2,438 & 132 & 39 & 261 & 571 & 1 \\
\hline Income Before Extraordinary Items ................. & 3,118 & 480 & 1,870 & 121 & 1,186 & 894 \\
\hline Extraordinary Income & 0 & 0 & 0 & 0 & 0 & 0 \\
\hline 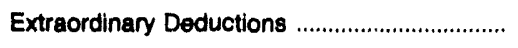 & 300 & 0 & 0 & 0 & 0 & 0 \\
\hline 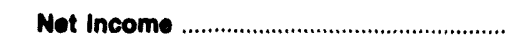 & 2,818 & 480 & 1,870 & 121 & 1,186 & 884 \\
\hline
\end{tabular}

Note: Totals may not equal sum of components because of independent rounding

Source: Energy Information Administration, Form ElA-412, "Annual Report of Public Electric Utilities." 
Table 21. Statement of Income by Major U.S. Publicly Owned Electric Utillty Within State, 1992 (Continued) (Thousand Dollars)

\begin{tabular}{|c|c|c|c|c|c|c|}
\hline Item & $\begin{array}{l}\text { Massachusetts } \\
\text { Littleton } \\
\text { Town of } \\
\text { December } 31\end{array}$ & $\begin{array}{l}\text { Massachusetts } \\
\text { Mansfield } \\
\text { Town of } \\
\text { December } 31\end{array}$ & $\begin{array}{l}\text { Massachusetts } \\
\text { Massachusetts } \\
\text { Mun } \\
\text { Whis } \\
\text { Elec Co } \\
\text { December } 31\end{array}$ & $\begin{array}{l}\text { Massachusetts } \\
\text { Middleborough } \\
\text { Town of } \\
\text { December } 31\end{array}$ & $\begin{array}{l}\text { Massachusetts } \\
\text { North } \\
\text { Attleborough } \\
\text { Town of } \\
\text { December } 31\end{array}$ & $\begin{array}{l}\text { Massachusetts } \\
\text { Norwood } \\
\text { City of } \\
\text { June } 30\end{array}$ \\
\hline Ebotric Utility Operating Rovonues ............. & 16,114 & 20,431 & 275,040 & 16,795 & 17,407 & 27,119 \\
\hline 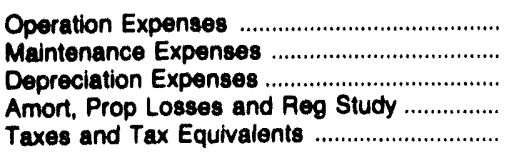 & $\begin{array}{r}13,827 \\
327 \\
538 \\
0 \\
6\end{array}$ & $\begin{array}{r}16,559 \\
433 \\
422 \\
0 \\
180\end{array}$ & $\begin{array}{r}134,075 \\
11,775 \\
45,077 \\
0 \\
8,496\end{array}$ & $\begin{array}{r}15,082 \\
845 \\
422 \\
0 \\
270\end{array}$ & $\begin{array}{r}14,435 \\
624 \\
685 \\
0 \\
25\end{array}$ & $\begin{array}{r}23,924 \\
632 \\
963 \\
0 \\
0\end{array}$ \\
\hline $\begin{array}{l}\text { Total Eloctris Utility Operating } \\
\text { Expenees }\end{array}$ & 14,698 & 17,594 & 199,424 & 16,619 & 15,769 & 25,519 \\
\hline $\begin{array}{l}\text { Net Electric Utility Operating Income } \\
\text { Income from Electric Plant Leased } \\
\text { to Others }\end{array}$ & $\begin{array}{r}1,416 \\
0\end{array}$ & $\begin{array}{r}2,837 \\
0\end{array}$ & $\begin{array}{r}75,617 \\
0\end{array}$ & $\begin{array}{r}176 \\
0\end{array}$ & $\begin{array}{r}1,637 \\
0\end{array}$ & $\begin{array}{r}1,600 \\
0\end{array}$ \\
\hline Electric Utility Operating Income .............. & 1,416 & 2,837 & 75,617 & 176 & 1,637 & 1,600 \\
\hline Other Electric Income & 302 & 123 & 13,435 & 108 & 1,337 & 135 \\
\hline $\begin{array}{l}\text { Other Electric Deductions } \\
\text { Allowance for Other Funds Used }\end{array}$ & 0 & 0 & 0 & 0 & 0 & 0 \\
\hline $\begin{array}{l}\text { During Construction ......................................... } \\
\text { Taxes on Other Income and Deductions ..... }\end{array}$ & $\begin{array}{l}0 \\
0\end{array}$ & $\begin{array}{l}0 \\
0\end{array}$ & $\begin{array}{r}466 \\
0\end{array}$ & $\begin{array}{l}0 \\
0\end{array}$ & $\begin{array}{l}0 \\
0\end{array}$ & $\begin{array}{l}0 \\
0\end{array}$ \\
\hline Electrle Utility Income ... & 1,718 & 2,960 & 89,518 & 284 & 2,974 & 1,736 \\
\hline 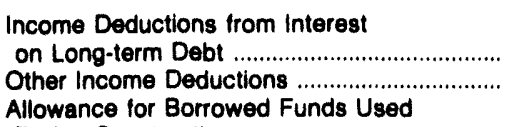 & $\begin{array}{l}23 \\
28\end{array}$ & $\begin{array}{r}16 \\
7\end{array}$ & $\begin{array}{r}111,442 \\
3,081\end{array}$ & $\begin{array}{r}145 \\
0\end{array}$ & $\begin{array}{r}269 \\
71\end{array}$ & $\begin{array}{r}0 \\
67\end{array}$ \\
\hline 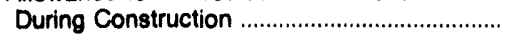 & 0 & 0 & 0 & 0 & 0 & 0 \\
\hline 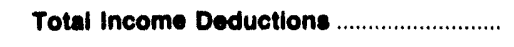 & 51 & 23 & 114,523 & 145 & 340 & 67 \\
\hline Income Before Extraordinary Items ...................... & 1,667 & 2,938 & $-25,005$ & 139 & 2,634 & 1,669 \\
\hline Extraordinary Income & 739 & 0 & 25,005 & 0 & 0 & 0 \\
\hline 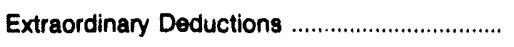 & 485 & 0 & 0 & 0 & 0 & 0 \\
\hline Not Income & 1,921 & 2,938 & $\mathbf{0}$ & 139 & 2,634 & 1,669 \\
\hline
\end{tabular}

Note: Totals may not equal sum of components because of independent rounding.

Source: Energy Information Administration, Form EIA-412, "Annual Report of Public Electric Utilities." 
Table 21. Statement of Income by Major U.S. Publicly Owned Electric Utility Within State, 1992 (Continued)

(Thousand Dollars)

\begin{tabular}{|c|c|c|c|c|c|c|}
\hline Item & $\begin{array}{c}\text { Massachusetts } \\
\text { Peabody } \\
\text { City of } \\
\text { December } 31\end{array}$ & $\begin{array}{l}\text { Massachusetts } \\
\text { Reading } \\
\text { Town of } \\
\text { December } 31\end{array}$ & $\begin{array}{l}\text { Massachusetts } \\
\text { Shrewsbury } \\
\text { Town of } \\
\text { December } 31\end{array}$ & $\begin{array}{c}\text { Massachusetts } \\
\text { Taunton } \\
\text { City of } \\
\text { December } 31\end{array}$ & $\begin{array}{c}\text { Massachusetts } \\
\text { Wakefleld } \\
\text { Town of } \\
\text { December } 31\end{array}$ & $\begin{array}{c}\text { Massachusetts } \\
\text { Wellesley } \\
\text { Town of } \\
\text { December } 31\end{array}$ \\
\hline Electric Utilly Operating Rovenues ............ & 41,908 & 44,646 & 21,134 & 38,028 & 15,043 & 17,747 \\
\hline 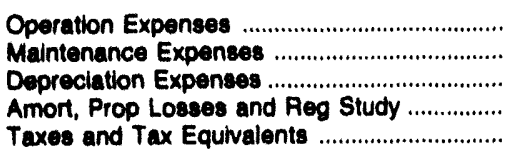 & $\begin{array}{r}35,185 \\
537 \\
1,719 \\
13 \\
0\end{array}$ & $\begin{array}{r}44,521 \\
724 \\
545 \\
0 \\
408\end{array}$ & $\begin{array}{r}18,448 \\
580 \\
621 \\
0 \\
0\end{array}$ & $\begin{array}{r}25,719 \\
4,527 \\
3,343 \\
0 \\
2,360\end{array}$ & $\begin{array}{r}13,416 \\
411 \\
601 \\
0 \\
216\end{array}$ & $\begin{array}{r}15,682 \\
787 \\
615 \\
0 \\
0\end{array}$ \\
\hline $\begin{array}{l}\text { Total Electric Utillty Operating } \\
\text { Expensese }\end{array}$ & 37,484 & 46,108 & 19,649 & 35,950 & 14,643 & 17,064 \\
\hline $\begin{array}{l}\text { Net Electric Utility Operating Income ............. } \\
\text { Income from Electric Plant Leased }\end{array}$ & 4,543 & $-1,553$ & 1,485 & 2,077 & 400 & 683 \\
\hline 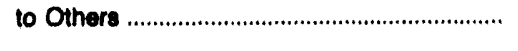 & 0 & 0 & 0 & 0 & 0 & 0 \\
\hline Electric Utilly Operating Income ............. & 4,543 & $-1,553$ & 1,485 & 2,077 & 400 & 683 \\
\hline 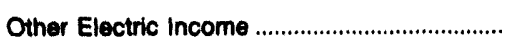 & 710 & 749 & 311 & 483 & 63 & -755 \\
\hline 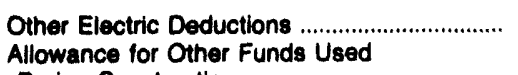 & 0 & 0 & 0 & 0 & 364 & 0 \\
\hline $\begin{array}{l}\text { During Construction ...................................... } \\
\text { Taxes on Other Income and Deductions ....... }\end{array}$ & $\begin{array}{l}0 \\
0\end{array}$ & $\begin{array}{l}0 \\
0\end{array}$ & $\begin{array}{l}0 \\
0\end{array}$ & $\begin{array}{l}0 \\
0\end{array}$ & $\begin{array}{l}0 \\
0\end{array}$ & $\begin{array}{l}0 \\
0\end{array}$ \\
\hline 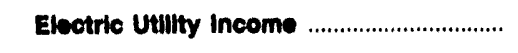 & 5,253 & -805 & 1,796 & 2,560 & 88 & -72 \\
\hline 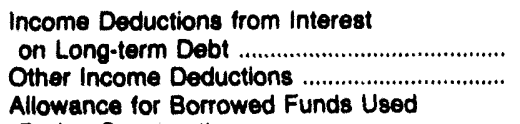 & $\begin{array}{r}1,535 \\
6\end{array}$ & $\begin{array}{r}187 \\
35\end{array}$ & $\begin{array}{l}28 \\
16\end{array}$ & $\begin{array}{r}1,417 \\
19\end{array}$ & $\begin{array}{r}1 \\
14\end{array}$ & $\begin{array}{l}46 \\
17\end{array}$ \\
\hline 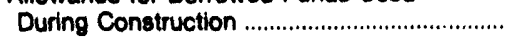 & 0 & 0 & 0 & 0 & 0 & 0 \\
\hline 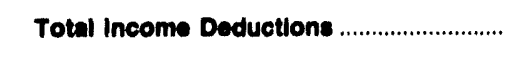 & 1,541 & 222 & 44 & 1,436 & 16 & 64 \\
\hline Income Before Extraordinary Items .................. & 3,712 & $-1,027$ & 1,752 & 1,124 & 82 & -136 \\
\hline Extraordinary Income & 0 & 0 & 0 & 0 & 0 & 0 \\
\hline 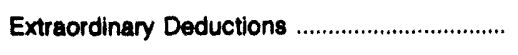 & 0 & 0 & 0 & 0 & 0 & 0 \\
\hline Not Income & 3,712 & $-1,027$ & 1,752 & 1,124 & 82 & -136 \\
\hline
\end{tabular}

Note: Totals may not equal sum of components because of independent rounding.

Source: Energy Information Administration, Form ElA-412. "Annual Report of Public Electric Utilities." 
Table 21. Statement of Income by Major U.S. Publicly Owned Electric Utility Within State, 1992 (Continued)

(Thousand Dollars)

\begin{tabular}{|c|c|c|c|c|c|c|}
\hline Item & $\begin{array}{l}\text { Massachusetts } \\
\text { Westfield } \\
\text { Clty of } \\
\text { December } 31\end{array}$ & $\begin{array}{l}\text { Michigan } \\
\text { Bay } \\
\text { City City of } \\
\text { June } 30\end{array}$ & $\begin{array}{l}\text { Michigan } \\
\text { Coldwater } \\
\text { Board } \\
\text { of } \\
\text { Public Util } \\
\text { June } 30\end{array}$ & $\begin{array}{l}\text { Michigan } \\
\text { Detroit } \\
\text { City of } \\
\text { June } 30\end{array}$ & $\begin{array}{l}\text { Michigan } \\
\text { Grand Haven } \\
\text { City of } \\
\text { June } 30\end{array}$ & $\begin{array}{l}\text { Michigan } \\
\text { Hillsdale } \\
\text { Board } \\
\text { of } \\
\text { Public Wks } \\
\text { June } 30\end{array}$ \\
\hline Electrle Uttlity Operating Rovenues ............ & 31,838 & 15,402 & 10,572 & 81,751 & 20,474 & 9,079 \\
\hline $\begin{array}{l}\text { Operation Expenses } \\
\text { Maintenance Expenses } \\
\text { Depreciation Expenses } \\
\text { Amort, Prop Losees and Reg Study } \\
\text { Taxes and Tax Equivalents }\end{array}$ & $\begin{array}{r}29,650 \\
1,111 \\
611 \\
0 \\
362\end{array}$ & $\begin{array}{r}10,396 \\
564 \\
1,057 \\
0 \\
248\end{array}$ & $\begin{array}{r}9,222 \\
254 \\
415 \\
0 \\
673\end{array}$ & $\begin{array}{r}30,992 \\
13,472 \\
4,826 \\
0 \\
0\end{array}$ & $\begin{array}{r}11,175 \\
1,569 \\
3,216 \\
0 \\
0\end{array}$ & $\begin{array}{r}7,977 \\
309 \\
499 \\
0 \\
267\end{array}$ \\
\hline $\begin{array}{l}\text { Total Electric Utility Oporating } \\
\text { Exponeese }\end{array}$ & 31,734 & 12,265 & 10,565 & 49,290 & 15,960 & $\mathbf{9 , 0 5 2}$ \\
\hline $\begin{array}{l}\text { Net Electric Utility Operating Income } \\
\text { Income from Electric Plant Leased } \\
\text { to Others }\end{array}$ & $\begin{array}{l}104 \\
401\end{array}$ & $\begin{array}{r}3,137 \\
0\end{array}$ & 7 & $\begin{array}{r}32,462 \\
0\end{array}$ & $\begin{array}{r}4,515 \\
0\end{array}$ & 26 \\
\hline Electrlc Utility Operating Income ............. & 505 & 3,137 & 7 & 32,462 & 4,515 & 28 \\
\hline Other Electric Income & 0 & 1,144 & 351 & 0 & 841 & 296 \\
\hline $\begin{array}{l}\text { Other Electric Deductions } \\
\text { Allowance for Other Funds Used............... }\end{array}$ & 0 & 540 & 0 & 12,226 & 24 & 78 \\
\hline 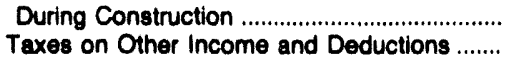 & $\begin{array}{l}0 \\
0\end{array}$ & $\begin{array}{l}0 \\
0\end{array}$ & $\begin{array}{l}0 \\
0\end{array}$ & $\begin{array}{l}0 \\
0\end{array}$ & $\begin{array}{r}0 \\
825\end{array}$ & $\begin{array}{r}0 \\
50\end{array}$ \\
\hline Electric Utility Income .................................... & 505 & 3,741 & 358 & 20,235 & 4,507 & 195 \\
\hline 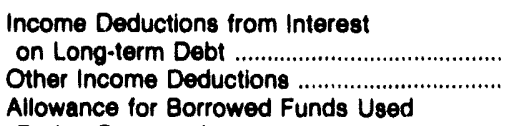 & $\begin{array}{r}133 \\
1\end{array}$ & $\begin{array}{r}1,409 \\
0\end{array}$ & $\begin{array}{r}99 \\
0\end{array}$ & $\begin{array}{r}6,114 \\
0\end{array}$ & $\begin{array}{r}6,752 \\
6\end{array}$ & $\begin{array}{l}0 \\
1\end{array}$ \\
\hline 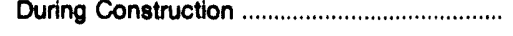 & 0 & 0 & 0 & 0 & 0 & 0 \\
\hline Total Income Deductions ............................. & 135 & 1,409 & 99 & 6,114 & 6,758 & 1 \\
\hline Income Before Extraordinary Items ................... & 370 & 2,333 & 259 & 14,122 & $-2,251$ & 193 \\
\hline Extraordinary Income & 0 & 0 & 0 & 0 & 0 & 0 \\
\hline 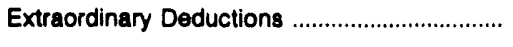 & 0 & 0 & 0 & 0 & 0 & 0 \\
\hline 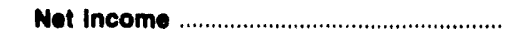 & 370 & 2,333 & 259 & 14,122 & $-2,251$ & 193 \\
\hline
\end{tabular}

Note: Totals may not equal sum of components because of independent rounding.

Source: Energy Information Administration, Form ElA-412, "Annual Report of Public Electric Utilities." 
Table 21. Statement of Income by Major U.S. Publicly Owned Electric Utility Within State, 1992 (Continued) (Thousand Dollars)

\begin{tabular}{|c|c|c|c|c|c|c|}
\hline Item & $\begin{array}{l}\text { Michigan } \\
\text { Holland } \\
\text { City of } \\
\text { June } 30\end{array}$ & $\begin{array}{l}\text { Michigan } \\
\text { Lansing } \\
\text { City of } \\
\text { June } 30\end{array}$ & $\begin{array}{l}\text { Michigan } \\
\text { Marquette } \\
\text { City of } \\
\text { June } 30\end{array}$ & $\begin{array}{c}\text { Michigan } \\
\text { Michigan } \\
\text { Public } \\
\text { Power Agency } \\
\text { Docember } 31\end{array}$ & $\begin{array}{l}\text { Michigan } \\
\text { Michigan } \\
\text { South } \\
\text { Central } \\
\text { Pwr Agy } \\
\text { June } 30\end{array}$ & $\begin{array}{c}\text { Michigan } \\
\text { Sturgis } \\
\text { City of } \\
\text { September } 30\end{array}$ \\
\hline Electric Utility Operating Revenues ............. & 34,918 & 116,330 & 19,013 & 92,228 & 22,476 & 12,189 \\
\hline 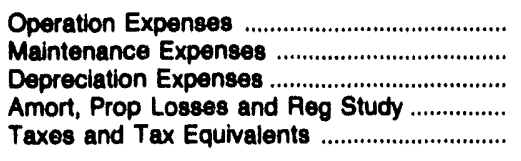 & $\begin{array}{r}24,644 \\
1,855 \\
3,195 \\
0 \\
1,070\end{array}$ & $\begin{array}{r}89,476 \\
8,651 \\
13,007 \\
0 \\
0\end{array}$ & $\begin{array}{r}10,160 \\
1,541 \\
2,992 \\
0 \\
1,470\end{array}$ & $\begin{array}{r}27,228 \\
4,754 \\
12,868 \\
1,176 \\
587\end{array}$ & $\begin{array}{r}14,534 \\
961 \\
2,508 \\
0 \\
40\end{array}$ & $\begin{array}{r}8,352 \\
891 \\
895 \\
0 \\
858\end{array}$ \\
\hline $\begin{array}{l}\text { Total Electrlc UtIlity Operating } \\
\text { Exponeses }\end{array}$ & 30,764 & 111,133 & 16,162 & 46,613 & 18,043 & 11,006 \\
\hline 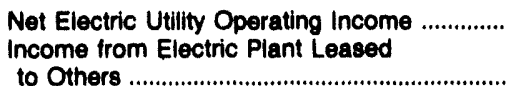 & $\begin{array}{l}4,154 \\
1,758\end{array}$ & $\begin{array}{r}5,206 \\
0\end{array}$ & $\begin{array}{r}2,851 \\
0\end{array}$ & $\begin{array}{r}45,615 \\
0\end{array}$ & $\begin{array}{r}4,433 \\
0\end{array}$ & $\begin{array}{r}1,094 \\
0\end{array}$ \\
\hline Electric Utilty Oporating Income .............. & 5,012 & 5,206 & 2,851 & 45,615 & 4,433 & 1,094 \\
\hline Other Electric Income & 0 & 3,634 & 1,545 & 9,747 & 1,892 & 780 \\
\hline 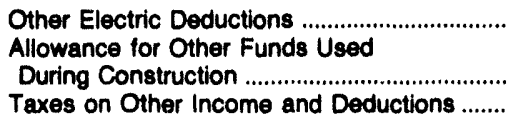 & $\begin{array}{l}0 \\
0 \\
0\end{array}$ & $\begin{array}{l}0 \\
0 \\
0\end{array}$ & $\begin{array}{l}0 \\
0 \\
0\end{array}$ & $\begin{array}{l}0 \\
0 \\
0\end{array}$ & $\begin{array}{l}0 \\
0\end{array}$ & $\begin{array}{l}0 \\
0 \\
0\end{array}$ \\
\hline 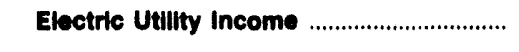 & 5,912 & 8,839 & 4,396 & 55,362 & 6,306 & 1,874 \\
\hline $\begin{array}{l}\text { Income Deductions from Interest } \\
\text { on Long-term Debt .......................................... } \\
\text { Other Income Deductions ............................. } \\
\text { Allowance for Borrowed Funds Used }\end{array}$ & $\begin{array}{r}1,631 \\
0\end{array}$ & $\begin{array}{l}616 \\
177\end{array}$ & $\begin{array}{r}3,359 \\
71\end{array}$ & $\begin{array}{l}34,334 \\
20,981\end{array}$ & $\begin{array}{r}6,476 \\
-1,000\end{array}$ & $\begin{aligned} 320 \\
0\end{aligned}$ \\
\hline During Construction & 0 & 0 & 0 & 0 & 0 & 0 \\
\hline Total Income Deductions ................................ & 1,631 & 793 & 3,430 & 55,316 & 5,476 & 320 \\
\hline Income Before Extraordinary Items ................... & 4,282 & 8,046 & 966 & 47 & 830 & 1,554 \\
\hline 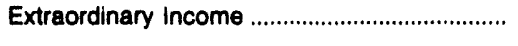 & 0 & 0 & 0 & 0 & 0 & 0 \\
\hline Extraordinary Deductions ...................................... & 0 & 0 & 0 & 0 & 469 & 85 \\
\hline Not Income & 4,282 & 8,046 & 868 & 47 & 361 & 1,469 \\
\hline
\end{tabular}

Note: Totais may not equal sum of components because of independent rounding.

Source: Energy Information Administration, Form EIA-412, "Annual Report of Public Electric Utilities." 
Table 21. Statement of Income by Major U.S. Publicly Owned Electric Utility Within State, 1992 (Continued)

(Thousand Dollars)

\begin{tabular}{|c|c|c|c|c|c|c|}
\hline Item & $\begin{array}{l}\text { Michigan } \\
\text { Traverse } \\
\text { City City of } \\
\text { June } 30\end{array}$ & $\begin{array}{l}\text { Michigan } \\
\text { Wyandotte } \\
\text { Municipal } \\
\text { Serv Comm } \\
\text { September } 30\end{array}$ & $\begin{array}{c}\text { Minnesota } \\
\text { Alexandria } \\
\text { City of }\end{array}$ & $\begin{array}{c}\text { Minnesota } \\
\text { Anoka } \\
\text { City of } \\
\text { December } 31\end{array}$ & $\begin{array}{c}\text { Minnesota } \\
\text { Austin } \\
\text { City of } \\
\text { December } 31\end{array}$ & $\begin{array}{l}\text { Minnesota } \\
\text { Brainerd } \\
\text { City of } \\
\text { December } 31\end{array}$ \\
\hline Electric Utilty Operating Rovenues ............. & 13,940 & 17,881 & 7,170 & 11,273 & 18,533 & 7,026 \\
\hline 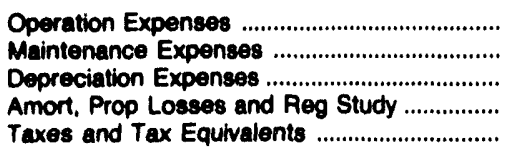 & $\begin{array}{r}9,225 \\
1,968 \\
794 \\
9 \\
708\end{array}$ & $\begin{array}{r}14,172 \\
173 \\
1,970 \\
0 \\
0\end{array}$ & $\begin{array}{r}5,778 \\
297 \\
415 \\
0 \\
359\end{array}$ & $\begin{array}{r}9,575 \\
210 \\
495 \\
0 \\
0\end{array}$ & $\begin{array}{r}16,094 \\
683 \\
739 \\
0 \\
3\end{array}$ & $\begin{array}{r}6,478 \\
84 \\
329 \\
0 \\
0\end{array}$ \\
\hline $\begin{array}{l}\text { Total Electrlc Utlity Oporating } \\
\text { Exponeses }\end{array}$ & 12,704 & 16,315 & 6,850 & 10,280 & 17,519 & 6,890 \\
\hline 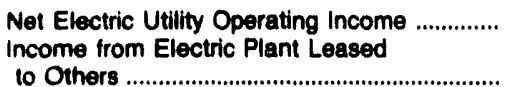 & 1,235 & 1,566 & 330 & 993 & 1,014 & 136 \\
\hline Electric Utilty Operating Incoms .............. & 1,235 & 1,566 & 330 & 1,035 & 1,015 & 136 \\
\hline 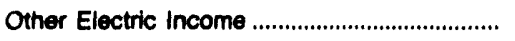 & 357 & 709 & 295 & 0 & 348 & 203 \\
\hline $\begin{array}{l}\text { Other Electric Deductions } \\
\text { Allowance for Other Funds Used........................ }\end{array}$ & 0 & 437 & 0 & 757 & 0 & 0 \\
\hline 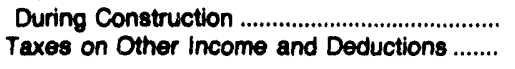 & $\begin{array}{l}0 \\
0\end{array}$ & $\begin{array}{r}701 \\
0\end{array}$ & $\begin{array}{l}0 \\
0\end{array}$ & $\begin{array}{l}0 \\
0\end{array}$ & $\begin{array}{r}0 \\
857\end{array}$ & $\begin{array}{l}0 \\
0\end{array}$ \\
\hline Electric Utilty Income & 1,592 & 2,539 & 624 & 278 & 505 & 338 \\
\hline 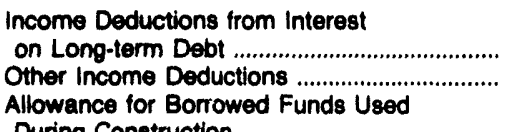 & $\begin{array}{l}0 \\
0\end{array}$ & $\begin{array}{r}1,178 \\
81\end{array}$ & $\begin{array}{l}0 \\
3\end{array}$ & $\begin{array}{l}0 \\
0\end{array}$ & $\begin{array}{l}0 \\
5\end{array}$ & $\begin{array}{l}0 \\
0\end{array}$ \\
\hline 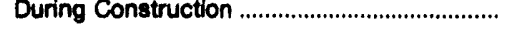 & 0 & 0 & 0 & 0 & 0 & 0 \\
\hline 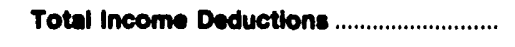 & 0 & 1,259 & 3 & $\mathbf{0}$ & 5 & 0 \\
\hline Income Before Extraordinary Items ..................... & 1,592 & 1,280 & 621 & 278 & 500 & 339 \\
\hline Extraordinary Income & 0 & 0 & 0 & 0 & 0 & 0 \\
\hline 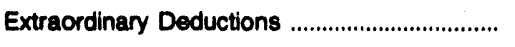 & 0 & 5,145 & 0 & 0 & 0 & 0 \\
\hline Net Income & 1,592 & $-3,865$ & 621 & 278 & 500 & 339 \\
\hline
\end{tabular}

Note: Totals may not equal sum of components because of independent rounding.

Source: Energy Information Administration, Form EIA-412, "Annual Report of Public Electric Utilities." 
Table 21. Statement of Income by Major U.S. Publicly Owned Electric Utility Within State, 1992 (Continued) (Thousand Dollars)

\begin{tabular}{|c|c|c|c|c|c|c|}
\hline Item & $\begin{array}{l}\text { Minnesota } \\
\text { Fairmont } \\
\text { Public } \\
\text { Utilities } \\
\text { Comm } \\
\text { December } 31\end{array}$ & $\begin{array}{l}\text { Minnesota } \\
\text { Hutchinson } \\
\text { Utilities } \\
\text { Comm } \\
\text { December } 31\end{array}$ & $\begin{array}{c}\text { Minnesota } \\
\text { Marshall } \\
\text { City of } \\
\text { December } 31\end{array}$ & $\begin{array}{l}\text { Minnesota } \\
\text { Moorhead } \\
\text { City of } \\
\text { December } 31\end{array}$ & $\begin{array}{l}\text { Minnesota } \\
\text { New Ulm } \\
\text { Public } \\
\text { Utilities } \\
\text { Comm } \\
\text { December } 31\end{array}$ & $\begin{array}{c}\text { Minnesota } \\
\text { Northern } \\
\text { Municipal } \\
\text { Power Agny } \\
\text { December } 31\end{array}$ \\
\hline Electrle Utilty Operating Rovenues ........... & 11,685 & 0,546 & 9,834 & 11,843 & 0,619 & 34,519 \\
\hline 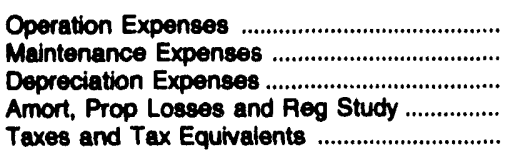 & $\begin{array}{r}9,856 \\
563 \\
519 \\
0 \\
0\end{array}$ & $\begin{array}{r}6,880 \\
520 \\
674 \\
0 \\
0\end{array}$ & $\begin{array}{r}9,700 \\
393 \\
595 \\
0 \\
272\end{array}$ & $\begin{array}{r}8,276 \\
458 \\
683 \\
0 \\
2,623\end{array}$ & $\begin{array}{r}6,947 \\
772 \\
714 \\
0 \\
489\end{array}$ & $\begin{array}{r}8,933 \\
2,105 \\
5,180 \\
0 \\
0\end{array}$ \\
\hline $\begin{array}{l}\text { Total Electric Utility Operating } \\
\text { Expensed }\end{array}$ & 10,038 & 8,074 & 10,961 & 12,030 & 8,923 & 16,218 \\
\hline 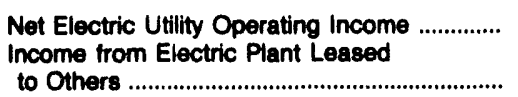 & $\begin{array}{l}697 \\
20\end{array}$ & $\begin{array}{r}1,472 \\
0\end{array}$ & $\begin{array}{r}-1,127 \\
486\end{array}$ & $\begin{array}{r}-96 \\
0\end{array}$ & $\begin{array}{r}696 \\
0\end{array}$ & $\begin{array}{r}18,300 \\
0\end{array}$ \\
\hline Eloctric Utility Operating Income ............. & 717 & 1,472 & -641 & $-\infty$ & $6 \bullet 6$ & 18,300 \\
\hline 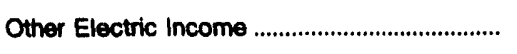 & 1,614 & 436 & 939 & 550 & 181 & 3,491 \\
\hline $\begin{array}{l}\text { Other Electric Deductions ................................ } \\
\text { Allowance for Other Funds Used }\end{array}$ & 529 & 0 & 0 & 0 & 2 & 0 \\
\hline $\begin{array}{l}\text { During Construction ................................... } \\
\text { Taxes on Other Income and Deductions ........ }\end{array}$ & $\begin{array}{l}0 \\
0\end{array}$ & $\begin{array}{l}0 \\
0\end{array}$ & $\begin{array}{r}150 \\
0\end{array}$ & $\begin{array}{l}0 \\
0\end{array}$ & $\begin{array}{l}0 \\
0\end{array}$ & $\begin{array}{l}0 \\
0\end{array}$ \\
\hline 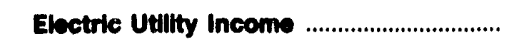 & 1,802 & 1,808 & 447 & 454 & 875 & 21,791 \\
\hline $\begin{array}{l}\text { Income Deductions from Interest } \\
\text { on Long-term Debt ............................................ } \\
\text { Other Income Deductions ............................... } \\
\text { Allowance for Borrowed Funds Used }\end{array}$ & $\begin{array}{l}398 \\
439\end{array}$ & $\begin{array}{r}115 \\
12\end{array}$ & $\begin{array}{l}0 \\
0\end{array}$ & $\begin{array}{r}208 \\
0\end{array}$ & $\begin{array}{r}144 \\
0\end{array}$ & $\begin{array}{r}21,791 \\
0\end{array}$ \\
\hline 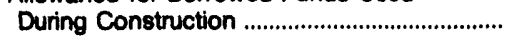 & 0 & 0 & 0 & 0 & 0 & 0 \\
\hline Total Income Deductions ............................. & 837 & 128 & 0 & 208 & 144 & 21,701 \\
\hline 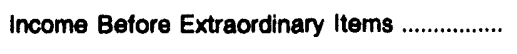 & 965 & 1,780 & 447 & 246 & 731 & 0 \\
\hline Extraordinary Income & 0 & 0 & 0 & 0 & 0 & 0 \\
\hline 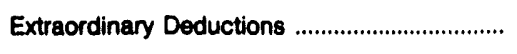 & 0 & 0 & 0 & 0 & 33 & 0 \\
\hline 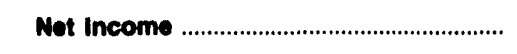 & 985 & 1,780 & 447 & 246 & 688 & 0 \\
\hline
\end{tabular}

Note: Totals may not equal sum of components because of independent rounding.

Source: Energy Information Administration, Form EIA-412, "Annual Report of Public Electric Utilities." 
Table 21. Statement of Income by Major U.S. Publicly Owned Electric Utility Within State, 1992 (Continued)

(Thousand Dollars)

\begin{tabular}{|c|c|c|c|c|c|c|}
\hline Item & $\begin{array}{l}\text { Minnesota } \\
\text { Owatonna } \\
\text { City of } \\
\text { December } 31\end{array}$ & $\begin{array}{c}\text { Minnesota } \\
\text { Pochester } \\
\text { Public } \\
\text { Utilities } \\
\text { December } 31\end{array}$ & $\begin{array}{l}\text { Minnesota } \\
\text { Southern } \\
\text { Minnesota } \\
\text { Mun P } \\
\text { Agny } \\
\text { December } 31\end{array}$ & $\begin{array}{l}\text { Minnesota } \\
\text { Western } \\
\text { Minnesota } \\
\text { Mun } \\
\text { Pwr Agny } \\
\text { December } 31\end{array}$ & $\begin{array}{l}\text { Minnesota } \\
\text { Willmar } \\
\text { Municipal } \\
\text { Utils Comm } \\
\text { December } 31\end{array}$ & $\begin{array}{l}\text { Mississippi } \\
\text { Aberdeen } \\
\text { City of } \\
\text { June } 30\end{array}$ \\
\hline Electric Unity Operating Rovenuce ............. & 17,014 & 68,028 & 120,562 & 42,087 & 10,101 & 7,936 \\
\hline 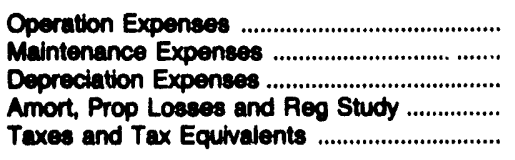 & $\begin{array}{r}14,059 \\
1,049 \\
926 \\
0 \\
0\end{array}$ & $\begin{array}{r}56,604 \\
2,281 \\
2,173 \\
0 \\
5,008\end{array}$ & $\begin{array}{r}51,816 \\
4,367 \\
8,433 \\
0 \\
7,121\end{array}$ & $\begin{array}{r}17,346 \\
4,624 \\
4,215 \\
0 \\
1,148\end{array}$ & $\begin{array}{r}6,870 \\
599 \\
900 \\
0 \\
0\end{array}$ & $\begin{array}{r}7,466 \\
101 \\
125 \\
0 \\
289\end{array}$ \\
\hline $\begin{array}{l}\text { Total Electric Utility Operating } \\
\text { Expences }\end{array}$ & 16,033 & 66,065 & 71,738 & 27,333 & 8,380 & 7,961 \\
\hline 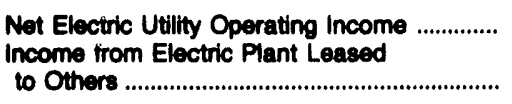 & $\begin{array}{r}981 \\
0\end{array}$ & $\begin{array}{r}863 \\
0\end{array}$ & $\begin{array}{r}48,824 \\
0\end{array}$ & $\begin{array}{r}14,754 \\
0\end{array}$ & $\begin{array}{r}1,731 \\
0\end{array}$ & $\begin{array}{r}-26 \\
0\end{array}$ \\
\hline Electric Vitily Operating Incorrie .............. & 901 & 863 & 48,824 & 14,754 & 1,731 & -26 \\
\hline 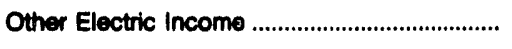 & 399 & 946 & 8,444 & 4,045 & 1,238 & 83 \\
\hline $\begin{array}{l}\text { Other Electric Deductions } \\
\text { Allowance for Other Funds Used............................ }\end{array}$ & 452 & 82 & 0 & 0 & 0 & 13 \\
\hline 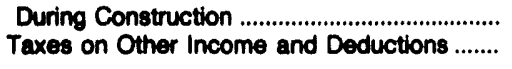 & $\begin{array}{l}0 \\
0\end{array}$ & $\begin{array}{l}0 \\
0\end{array}$ & $\begin{array}{l}0 \\
0\end{array}$ & $\begin{array}{l}0 \\
0\end{array}$ & $\begin{array}{l}0 \\
0\end{array}$ & $\begin{array}{l}0 \\
0\end{array}$ \\
\hline 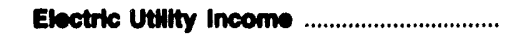 & 928 & 1,727 & 58,268 & 18,790 & 2,869 & 44 \\
\hline $\begin{array}{l}\text { Income Deductions from Interest } \\
\text { on Long-term Debt ........................................... } \\
\text { Other Income Deductions ............................. } \\
\text { Allowance for Borrowed Funds Used }\end{array}$ & $\begin{array}{r}439 \\
0\end{array}$ & $\begin{array}{r}0 \\
49\end{array}$ & $\begin{array}{r}48,285 \\
3,191\end{array}$ & $\begin{array}{r}18,799 \\
0\end{array}$ & $\begin{array}{r}1,014 \\
56\end{array}$ & $\begin{array}{l}0 \\
0\end{array}$ \\
\hline 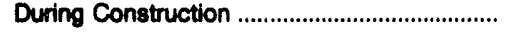 & 0 & 0 & -97 & 0 & 0 & 0 \\
\hline 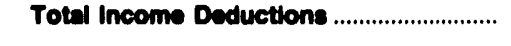 & 439 & 49 & 51,379 & 18,799 & 1,070 & 0 \\
\hline Income Before Extraordinary Items ...................... & 489 & 1,678 & 6,890 & 0 & 1,899 & 44 \\
\hline 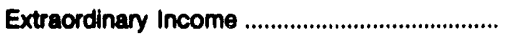 & 0 & 0 & 0 & 0 & 0 & 0 \\
\hline 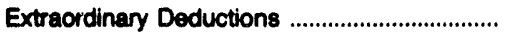 & 0 & 0 & 0 & 0 & 0 & 0 \\
\hline 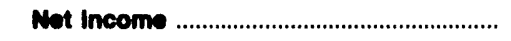 & 489 & 1,678 & 6,890 & o & 1,899 & 44 \\
\hline
\end{tabular}

Note: Totals may not equal sum of components because of independent rounding.

Source: Energy Information Administration, Form ElA-412, "Annual Report of Public Electric Utilities." 
Table 21. Statement of Income by Major U.S. Publicly Owned Electrlc Utillty Within State, 1992 (Continued) (Thousand Dollars)

\begin{tabular}{|c|c|c|c|c|c|c|}
\hline Item & $\begin{array}{l}\text { Missiseippl } \\
\text { Clarkedale } \\
\text { City of } \\
\text { September } 30\end{array}$ & $\begin{array}{l}\text { Mississippi } \\
\text { Columbus } \\
\text { City of } \\
\text { June } 30\end{array}$ & $\begin{array}{l}\text { Mississippi } \\
\text { Greenwood } \\
\text { Uttllties } \\
\text { Comm } \\
\text { September } 30\end{array}$ & $\begin{array}{l}\text { Mississippi } \\
\text { Holly } \\
\text { Springs } \\
\text { City of } \\
\text { June } 30\end{array}$ & $\begin{array}{l}\text { Mississippi } \\
\text { Louisville } \\
\text { Electric } \\
\text { System } \\
\text { June } 30\end{array}$ & $\begin{array}{l}\text { Miediccippi } \\
\text { Municipal } \\
\text { Energy } \\
\text { Agency } \\
\text { of MS } \\
\text { September } 30\end{array}$ \\
\hline Electrle Uttlthy Operatting Rovenuse ............. & 11,702 & 23,108 & 15,003 & 11,226 & 8,292 & 27,027 \\
\hline 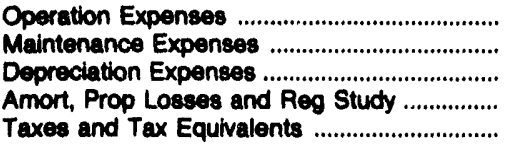 & $\begin{array}{r}8,932 \\
570 \\
862 \\
0 \\
0\end{array}$ & $\begin{array}{r}21,968 \\
640 \\
386 \\
37 \\
902\end{array}$ & $\begin{array}{r}11,735 \\
940 \\
767 \\
0 \\
0\end{array}$ & $\begin{array}{r}9,640 \\
401 \\
278 \\
0 \\
600\end{array}$ & $\begin{array}{r}7,509 \\
117 \\
220 \\
0 \\
214\end{array}$ & $\begin{array}{r}27,873 \\
0 \\
22 \\
65 \\
0\end{array}$ \\
\hline 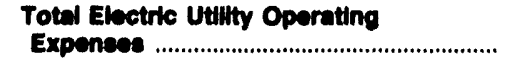 & 10,364 & 23,934 & 13,441 & 10,918 & 8,060 & 27,060 \\
\hline 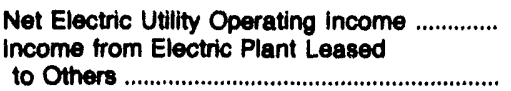 & $\begin{array}{r}1,428 \\
0\end{array}$ & -745 & $\begin{array}{r}1,562 \\
0\end{array}$ & $\begin{array}{r}308 \\
0\end{array}$ & $\begin{array}{r}232 \\
0\end{array}$ & $\begin{array}{r}-133 \\
0\end{array}$ \\
\hline Electric Utility Operating income.............. & 1,428 & -745 & 1,562 & 308 & 232 & -133 \\
\hline 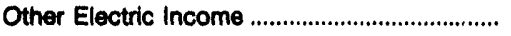 & 333 & 626 & 587 & 299 & 87 & 218 \\
\hline $\begin{array}{l}\text { Other Electric Deductions ............................. } \\
\text { Allowance for Other Funds Used } \\
\text { During Construction ..................................... } \\
\text { Taxes on Other Income and Deductions ........ }\end{array}$ & $\begin{array}{l}0 \\
0\end{array}$ & $\begin{array}{l}0 \\
0\end{array}$ & $\begin{array}{r}1,103 \\
0 \\
0\end{array}$ & $\begin{array}{l}0 \\
0\end{array}$ & $\begin{array}{l}0 \\
0 \\
0\end{array}$ & $\begin{array}{l}0 \\
0\end{array}$ \\
\hline 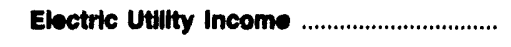 & 1,715 & -124 & 1,045 & 602 & 319 & 84 \\
\hline 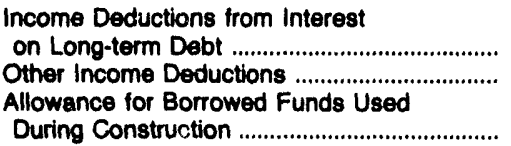 & $\begin{array}{r}186 \\
0\end{array}$ & $\begin{array}{r}0 \\
29\end{array}$ & $\begin{array}{r}21 \\
0\end{array}$ & $\begin{array}{r}0 \\
10\end{array}$ & $\begin{array}{l}0 \\
0\end{array}$ & $\begin{array}{l}0 \\
0\end{array}$ \\
\hline 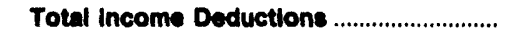 & 186 & 29 & 21 & 10 & $\mathbf{0}$ & o \\
\hline Income Before Extraordinary Items ................... & 1,529 & -153 & 1,024 & 592 & 318 & 84 \\
\hline 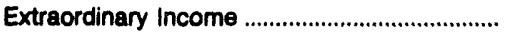 & 0 & 0 & 0 & 0 & 0 & 0 \\
\hline 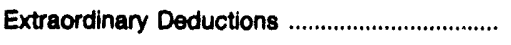 & 0 & 0 & 0 & 0 & 5 & 0 \\
\hline 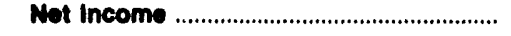 & 1,529 & -153 & 1,024 & 592 & 313 & 84 \\
\hline
\end{tabular}

Note: Totals may not equal sum of components because of independent rounding.

Source: Energy Information Administration, Form EIA-412, "Annual Report of Public Electric Utilities." 
Table 21. Statement of Income by Major U.S. Publicly Owned Electric Utility Within State, 1992 (Continued)

(Thousand Dollars)

\begin{tabular}{|c|c|c|c|c|c|c|}
\hline Item & $\begin{array}{l}\text { Mississippi } \\
\begin{array}{l}\text { New Albany } \\
\text { City of }\end{array} \\
\text { June } 30 \\
\end{array}$ & $\begin{array}{l}\text { Mississippi } \\
\begin{array}{l}\text { Oxford } \\
\text { City of }\end{array} \\
\text { June } 30\end{array}$ & $\begin{array}{c}\text { Mississippi } \\
\text { Starkville } \\
\text { City of } \\
\text { June } 30\end{array}$ & $\begin{array}{l}\text { Mississippi } \\
\text { Tupelo } \\
\text { City of } \\
\text { June } 30\end{array}$ & $\begin{array}{c}\text { Mississippi } \\
\text { West } \\
\text { Point } \\
\text { City of } \\
\text { June } 30\end{array}$ & $\begin{array}{l}\text { Missouri } \\
\text { Carthage } \\
\text { City of } \\
\text { June } 30\end{array}$ \\
\hline Ehetric Utility Operating Revenues .............. & 12,141 & 7,210 & 16,280 & 31,308 & 10,038 & 8,682 \\
\hline 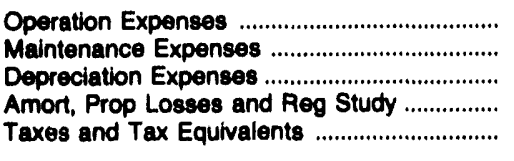 & $\begin{array}{r}10,884 \\
328 \\
270 \\
0 \\
473\end{array}$ & $\begin{array}{r}6,978 \\
136 \\
147 \\
0 \\
453\end{array}$ & $\begin{array}{r}14,370 \\
442 \\
313 \\
11 \\
769\end{array}$ & $\begin{array}{r}28,897 \\
405 \\
608 \\
0 \\
1,742\end{array}$ & $\begin{array}{r}8,783 \\
182 \\
208 \\
0 \\
540\end{array}$ & $\begin{array}{r}7,586 \\
374 \\
459 \\
0 \\
0\end{array}$ \\
\hline 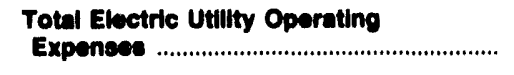 & 11,955 & 7,714 & 15,904 & 31,652 & 9,713 & 8,420 \\
\hline $\begin{array}{l}\text { Net Electric Utility Operating Income .............. } \\
\text { Income from Electric Plant Leased } \\
\text { to Others }\end{array}$ & $\begin{array}{r}186 \\
0\end{array}$ & $\begin{array}{r}-504 \\
0\end{array}$ & $\begin{array}{r}357 \\
0\end{array}$ & $\begin{array}{r}-344 \\
0\end{array}$ & $\begin{array}{r}325 \\
0\end{array}$ & $\begin{array}{r}263 \\
0\end{array}$ \\
\hline Electric Utility Oporating Income .............. & 186 & -504 & 357 & -344 & 325 & 263 \\
\hline Other Electric Income & 321 & 344 & 242 & 636 & 58 & 188 \\
\hline $\begin{array}{l}\text { Other Electric Deductions .............................. } \\
\text { Allowance for Other Funds Used } \\
\text { During Construction ....................................... } \\
\text { Taxes on Other Income and Deductions }\end{array}$ & $\begin{array}{l}21 \\
0 \\
0\end{array}$ & $\begin{array}{r}32 \\
0 \\
0\end{array}$ & $\begin{array}{l}12 \\
0 \\
0\end{array}$ & $\begin{array}{l}0 \\
0\end{array}$ & $\begin{array}{l}1 \\
0 \\
0\end{array}$ & $\begin{array}{l}1 \\
0 \\
0\end{array}$ \\
\hline Electric Utility Income & 486 & -192 & 567 & 292 & 382 & 449 \\
\hline 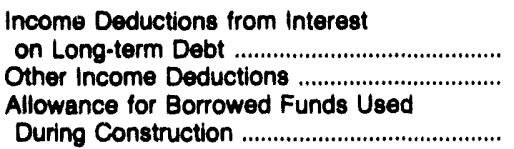 & $\begin{array}{r}18 \\
5\end{array}$ & $\begin{array}{r}0 \\
14 \\
0\end{array}$ & $\begin{array}{r}0 \\
34\end{array}$ & $\begin{array}{l}0 \\
0\end{array}$ & $\begin{array}{r}33 \\
3\end{array}$ & $\begin{array}{l}0 \\
7 \\
0\end{array}$ \\
\hline Total Income Deductions ................................ & 23 & 14 & 34 & $\mathbf{0}$ & 36 & 7 \\
\hline Income Before Extraordinary ltems .................... & 463 & -206 & 553 & 292 & 346 & 442 \\
\hline Extraordinary Income & 0 & 0 & 0 & 0 & 0 & 0 \\
\hline 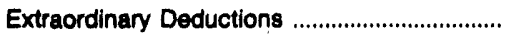 & 0 & 0 & 0 & 0 & 0 & 1,450 \\
\hline Net Income & 463 & -206 & 563 & 292 & 346 & $-1,008$ \\
\hline
\end{tabular}

Note: Totals may not equal sum of components because of independent rounding.

Source: Energy Information Administration, Form EIA-412, "Annual Feport of Public Electric Utilities." 
Table 21. Statement of Income by Major U.S. Publlcly Owned Electric Utility Within State, 1992 (Continued)

(Thousand Dollars)

\begin{tabular}{|c|c|c|c|c|c|c|}
\hline Item & $\begin{array}{l}\text { Missouri } \\
\text { Columbia } \\
\text { City of } \\
\text { September } 30\end{array}$ & $\begin{array}{l}\text { Missouri } \\
\text { Hannibal } \\
\text { City of } \\
\text { June } 30\end{array}$ & $\begin{array}{c}\text { Missouri } \\
\text { Independence } \\
\text { City of } \\
\text { June } 30\end{array}$ & $\begin{array}{l}\text { Missouri } \\
\text { Kennett } \\
\text { City of } \\
\text { June } 30\end{array}$ & $\begin{array}{l}\text { Missouri } \\
\text { Kirkwood } \\
\text { City of } \\
\text { March } 31\end{array}$ & $\begin{array}{l}\text { Missourt } \\
\text { Lebanon } \\
\text { City of } \\
\text { October } 31\end{array}$ \\
\hline Electric Utility Operating Rovenues ............ & 43,376 & 9,490 & 55,152 & 4,507 & 12,410 & 8,635 \\
\hline 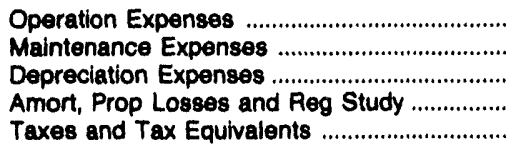 & $\begin{array}{r}32,128 \\
2,106 \\
2,856 \\
0 \\
3,802\end{array}$ & $\begin{array}{r}7,934 \\
579 \\
321 \\
0 \\
407\end{array}$ & $\begin{array}{r}32,721 \\
5,375 \\
4,922 \\
0 \\
6,109\end{array}$ & $\begin{array}{r}3,948 \\
357 \\
504 \\
0 \\
74\end{array}$ & $\begin{array}{r}8,450 \\
605 \\
161 \\
0 \\
0\end{array}$ & $\begin{array}{r}7,472 \\
0 \\
0 \\
0 \\
0\end{array}$ \\
\hline $\begin{array}{l}\text { Total Electric Utility Operating } \\
\text { Expenses }\end{array}$ & 40,893 & 9,241 & 49,127 & 4,882 & 9,216 & 7,472 \\
\hline $\begin{array}{l}\text { Net Electric Utility Operating Income .............. } \\
\text { Income from Electric Plant Leased }\end{array}$ & 2,482 & 249 & 6,025 & -376 & 3,194 & 1,163 \\
\hline 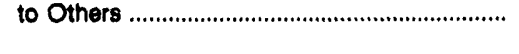 & 0 & 0 & 0 & 0 & 0 & 12 \\
\hline Electrle Utility Oporating Income ............. & 2,482 & 249 & 6,025 & -376 & 3,194 & 1,174 \\
\hline Other Electric Income & 3,459 & 498 & 3,041 & 322 & 427 & 0 \\
\hline 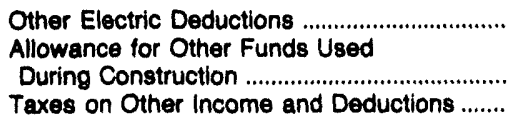 & $\begin{array}{r}210 \\
0 \\
0\end{array}$ & $\begin{array}{r}248 \\
0 \\
0\end{array}$ & $\begin{array}{l}0 \\
0\end{array}$ & $\begin{array}{l}0 \\
0 \\
0\end{array}$ & $\begin{array}{l}0 \\
0\end{array}$ & $\begin{array}{r}1,120 \\
0 \\
0\end{array}$ \\
\hline Electric Utility Income & 5,732 & 499 & 9,066 & -54 & 3,612 & 54 \\
\hline 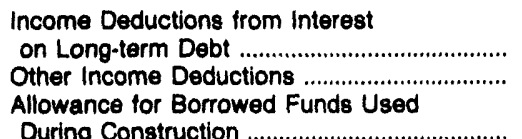 & $\begin{array}{r}2,850 \\
90\end{array}$ & $\begin{array}{l}0 \\
0\end{array}$ & $\begin{array}{r}2,581 \\
103\end{array}$ & $\begin{array}{l}0 \\
0\end{array}$ & $\begin{array}{l}0 \\
0\end{array}$ & $\begin{array}{l}0 \\
0\end{array}$ \\
\hline 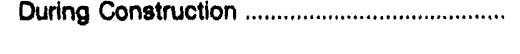 & 0 & 0 & 0 & 0 & 0 & 0 \\
\hline Total Income Deductions .............................. & 2,940 & $\mathbf{0}$ & 2,684 & 0 & 0 & 0 \\
\hline Income Before Extraordinary Items .................... & 2,792 & 499 & 6,382 & -54 & 3,612 & 54 \\
\hline 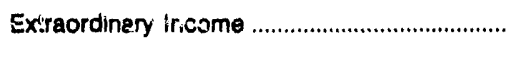 & 0 & 0 & 0 & 0 & 0 & 330 \\
\hline 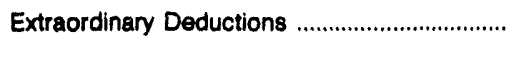 & 2,846 & 0 & 0 & 0 & 4,497 & 0 \\
\hline 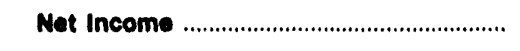 & -54 & 499 & 6,382 & -54 & -885 & 583 \\
\hline
\end{tabular}

Note: Totals may not equal sum of components because of independent rounding.

Source: Energy Information Administration, Form EIA-412, "Annual Report of Public Electric Utilities." 
Table 21. Statement of Income by Major U.S. Publicly Owned Electric Utillty Within State, 1992 (Continued)

(Thousand Dollars)

\begin{tabular}{|c|c|c|c|c|c|c|}
\hline Item & $\begin{array}{c}\text { Missouri } \\
\text { Marshall } \\
\text { City of } \\
\text { September } 30\end{array}$ & $\begin{array}{l}\text { Missouri } \\
\text { Monett } \\
\text { City of } \\
\text { March } 31\end{array}$ & $\begin{array}{c}\text { Missouri } \\
\text { Poplar } \\
\text { Bluff } \\
\text { City of } \\
\text { December } 31\end{array}$ & $\begin{array}{c}\text { Missouri } \\
\text { Rolla } \\
\text { City of } \\
\text { September } 30\end{array}$ & $\begin{array}{l}\text { Missouri } \\
\text { Sikeston } \\
\text { City of } \\
\text { May } 31\end{array}$ & $\begin{array}{c}\text { Missouri } \\
\begin{array}{c}\text { Springfield } \\
\text { City of }\end{array} \\
\text { September } 30\end{array}$ \\
\hline Electric Utillty Operating Rovenues ............. & 8,124 & 7,197 & 8,800 & 9,635 & 66,788 & 93,191 \\
\hline 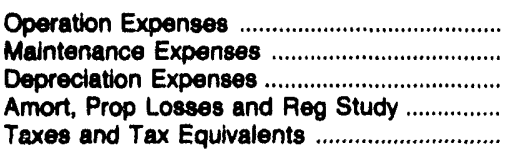 & $\begin{array}{r}4,087 \\
1,039 \\
1,207 \\
0 \\
763\end{array}$ & $\begin{array}{r}4,934 \\
32 \\
140 \\
0 \\
0\end{array}$ & $\begin{array}{r}6,616 \\
612 \\
600 \\
0 \\
0\end{array}$ & $\begin{array}{r}8,132 \\
295 \\
342 \\
0 \\
508\end{array}$ & $\begin{array}{r}29,533 \\
4,423 \\
5,583 \\
667 \\
0\end{array}$ & $\begin{array}{r}49,012 \\
14,293 \\
11,218 \\
0 \\
2,816\end{array}$ \\
\hline $\begin{array}{l}\text { Total Electric UtIlity Operating } \\
\text { Expenees }\end{array}$ & 7,097 & 5,105 & 7,828 & 9,276 & 40,206 & 77,330 \\
\hline $\begin{array}{l}\text { Net Electric Utility Operating Income } \\
\text { Income from Electric Plant Leased } \\
\text { to Others }\end{array}$ & $\begin{array}{r}1,027 \\
0\end{array}$ & $\begin{array}{r}2,091 \\
0\end{array}$ & $\begin{array}{r}972 \\
0\end{array}$ & $\begin{array}{r}358 \\
0\end{array}$ & $\begin{array}{r}16,582 \\
0\end{array}$ & $\begin{array}{r}15,852 \\
8,082\end{array}$ \\
\hline Electric Utility Operating Income ............. & 1,027 & 2,091 & 972 & 358 & 16,582 & 23,934 \\
\hline 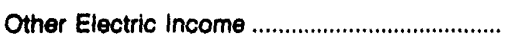 & 550 & 33 & 743 & 266 & 1,681 & 17,459 \\
\hline $\begin{array}{l}\text { Other Electric Deductions ............................. } \\
\text { Allowance for Other Funds Used }\end{array}$ & 0 & 0 & 0 & 59 & 0 & 0 \\
\hline 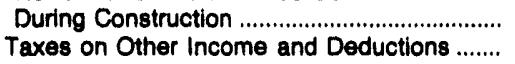 & $\begin{array}{l}0 \\
0\end{array}$ & $\begin{array}{l}0 \\
0\end{array}$ & $\begin{array}{l}0 \\
0\end{array}$ & $\begin{array}{l}0 \\
0\end{array}$ & $\begin{array}{l}0 \\
0\end{array}$ & $\begin{array}{r}247 \\
0\end{array}$ \\
\hline 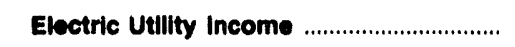 & 1,577 & 2,124 & 1,715 & 586 & 18,263 & 41,640 \\
\hline 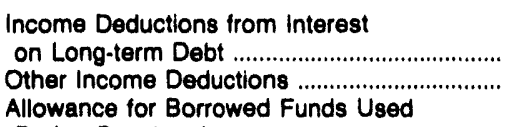 & $\begin{array}{r}143 \\
30\end{array}$ & $\begin{array}{l}0 \\
0\end{array}$ & $\begin{array}{r}16 \\
0\end{array}$ & $\begin{array}{l}0 \\
0\end{array}$ & $\begin{array}{r}14,864 \\
0\end{array}$ & $\begin{array}{r}8,508 \\
901\end{array}$ \\
\hline During Construction ............................................ & 0 & 0 & 0 & 0 & 0 & -782 \\
\hline Total income Deductions ................................ & 173 & 0 & 16 & 0 & 14,864 & 8,627 \\
\hline Income Before Extraordinary Items .................... & 1,404 & 2,124 & 1,699 & 566 & 3,399 & 33,013 \\
\hline Extraordinary Income & 0 & 1 & 0 & 0 & 0 & 0 \\
\hline 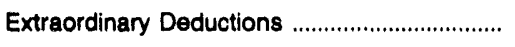 & 0 & 0 & 0 & 0 & 981 & 0 \\
\hline 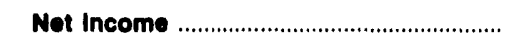 & 1,404 & 2,126 & 1,699 & 566 & 2,419 & 33,013 \\
\hline
\end{tabular}

Note: Totals may not equal sum of components because of independent rounding.

Source: Energy Information Administration, Form ElA.412, "Annual Report of Public Electric Utilities." 
Table 21. Statement of Income by Major U.S. Publicly Owned Electric Utillty Within State, 1992 (Continued)

(Thousand Dollars)

\begin{tabular}{|c|c|c|c|c|c|c|}
\hline Item & $\begin{array}{c}\text { Nebraska } \\
\text { Central } \\
\text { Nebraska } \\
\text { Pub } \\
\text { P\&I Dist } \\
\text { December } 31\end{array}$ & $\begin{array}{l}\text { Nebraska } \\
\text { Cornhusker } \\
\text { Public } \\
\text { Power Dist } \\
\text { December } 31\end{array}$ & $\begin{array}{l}\text { Nebraska } \\
\text { Dawson } \\
\text { County } \\
\text { Public } \\
\text { Pwr Dist } \\
\text { December } 31\end{array}$ & $\begin{array}{l}\text { Nebraska } \\
\text { Fremont } \\
\text { City of } \\
\text { July } 31\end{array}$ & $\begin{array}{l}\text { Nebraska } \\
\text { Grand Island } \\
\text { City of } \\
\text { July } 31\end{array}$ & $\begin{array}{c}\text { Nebraska } \\
\text { Hastings } \\
\text { Clty of } \\
\text { December } 31\end{array}$ \\
\hline Electric Utllity Operating Rovenues ............ & 8,188 & 9,624 & 14,289 & 12,506 & 23,186 & 12,605 \\
\hline 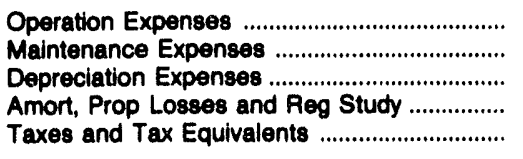 & $\begin{array}{r}4,504 \\
2,625 \\
2,716 \\
0 \\
8\end{array}$ & $\begin{array}{r}7,568 \\
532 \\
880 \\
0 \\
0\end{array}$ & $\begin{array}{r}11,024 \\
479 \\
1,132 \\
96 \\
154\end{array}$ & $\begin{array}{r}7,878 \\
1,215 \\
2,595 \\
0 \\
1,274\end{array}$ & $\begin{array}{r}9,970 \\
1,145 \\
4,835 \\
109 \\
604\end{array}$ & $\begin{array}{r}7,487 \\
1,702 \\
2,481 \\
0 \\
555\end{array}$ \\
\hline $\begin{array}{l}\text { Total Electric Utility Oporating } \\
\text { Expenees }\end{array}$ & 9,853 & 8,980 & 12,885 & 12,962 & 16,663 & 12,226 \\
\hline $\begin{array}{l}\text { Net Electric Utility Operating Income } \\
\text { Income from Electric Plant Leased }\end{array}$ & $-1,665$ & 644 & 1,404 & -456 & 6,523 & 379 \\
\hline 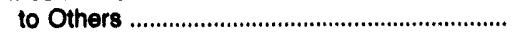 & 13 & 0 & 0 & 0 & 0 & 0 \\
\hline Electric Utility Operating Income ............. & $-1,652$ & 644 & 1,404 & -456 & 6,623 & 379 \\
\hline 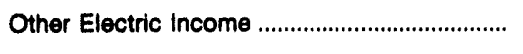 & 733 & 303 & 385 & 1,777 & 1,829 & 2,673 \\
\hline $\begin{array}{l}\text { Other Electric Deductions ................................ } \\
\text { Allowance for Other Funds Used }\end{array}$ & 0 & 23 & 0 & 196 & 0 & 0 \\
\hline 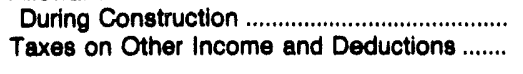 & $\begin{array}{l}0 \\
0\end{array}$ & $\begin{array}{l}0 \\
0\end{array}$ & $\begin{array}{l}0 \\
0\end{array}$ & $\begin{array}{l}0 \\
0\end{array}$ & $\begin{array}{l}0 \\
0\end{array}$ & $\begin{array}{l}0 \\
0\end{array}$ \\
\hline Electric Utility Income ..................................... & -910 & 924 & 1,790 & 1,125 & 8,352 & 3,062 \\
\hline 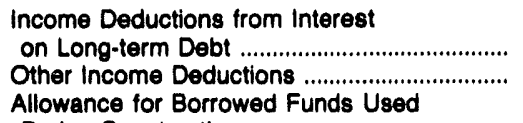 & $\begin{array}{r}101 \\
48\end{array}$ & $\begin{array}{r}613 \\
-235\end{array}$ & $\begin{array}{r}81 \\
0\end{array}$ & $\begin{array}{r}1,110 \\
14\end{array}$ & $\begin{array}{r}4,065 \\
103\end{array}$ & $\begin{array}{r}4,171 \\
0\end{array}$ \\
\hline 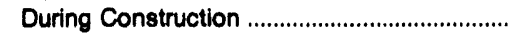 & 0 & 0 & 0 & 0 & 0 & 0 \\
\hline Total Income Deductions ............................. & 149 & 378 & 81 & 1,124 & 4,168 & 4,171 \\
\hline Income Before Extraordinary Items ................. & $-1,068$ & 546 & 1,700 & 0 & 4,184 & $-1,119$ \\
\hline Extraordinary Income & 1,369 & 7 & 0 & 0 & 3,374 & 0 \\
\hline 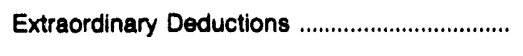 & 0 & 0 & 0 & 0 & 1,062 & 1,222 \\
\hline Not Income ................................................. & 301 & 552 & 1,709 & 0 & 6,496 & $-2,341$ \\
\hline
\end{tabular}

Note: Totals may not equal sum of components because of independent rounding.

Source: Energy Information Administration, Form EIA-412, "Annual Report of Public Electric Utilities." 
Table 21. Statement of Income by Major U.S. Publicly Owned Electric Utility Within State, 1992 (Continued)

(Thousand Dollars)

\begin{tabular}{|c|c|c|c|c|c|c|}
\hline Item & $\begin{array}{l}\text { Nebraska } \\
\text { Lincoln } \\
\text { Electric } \\
\text { System } \\
\text { December } 31\end{array}$ & $\begin{array}{c}\text { Nebraska } \\
\text { Loup } \\
\text { River } \\
\text { Public } \\
\text { Power Dist } \\
\text { December } 31\end{array}$ & $\begin{array}{c}\text { Nebraska } \\
\text { Municipal } \\
\text { Energy } \\
\text { Agency } \\
\text { of NE } \\
\text { March } 31\end{array}$ & $\begin{array}{c}\text { Nebraska } \\
\text { Nebraska } \\
\text { Public } \\
\text { Power } \\
\text { District } \\
\text { December } 31\end{array}$ & $\begin{array}{c}\text { Nebraska } \\
\text { Norris } \\
\text { Public } \\
\text { Power } \\
\text { District } \\
\text { December } 31\end{array}$ & $\begin{array}{c}\text { Nebraska } \\
\text { North } \\
\text { Platte } \\
\text { City of } \\
\text { July } 31\end{array}$ \\
\hline Eloctric Ut:lity Operating Rovenues ............. & 113,702 & 32,617 & 27,640 & 729,399 & 20,085 & 10,286 \\
\hline 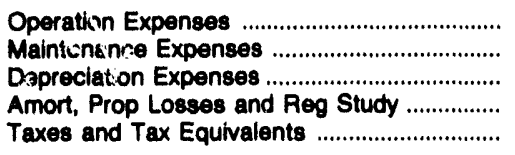 & $\begin{array}{r}73,558 \\
5,506 \\
11,431 \\
568 \\
4,675\end{array}$ & $\begin{array}{r}26,358 \\
1,286 \\
1,123 \\
0 \\
2,027\end{array}$ & $\begin{array}{r}23,768 \\
0 \\
1,430 \\
0 \\
0\end{array}$ & $\begin{array}{r}257,388 \\
45,790 \\
66,641 \\
7,214 \\
5,036\end{array}$ & $\begin{array}{r}14,606 \\
1,090 \\
1,725 \\
0 \\
120\end{array}$ & $\begin{array}{r}8,397 \\
321 \\
392 \\
0 \\
826\end{array}$ \\
\hline $\begin{array}{l}\text { Total Electrle Utility Opornting } \\
\text { Expenees }\end{array}$ & 95,739 & 30,794 & 25,198 & 382,069 & 17,542 & $\mathbf{9 , 9 3 6}$ \\
\hline 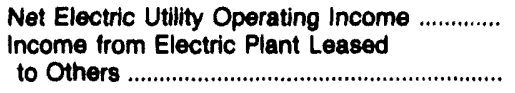 & $\begin{array}{r}17,964 \\
0\end{array}$ & $\begin{array}{r}1,823 \\
0\end{array}$ & $\begin{array}{r}2,442 \\
0\end{array}$ & $\begin{array}{r}347,330 \\
0\end{array}$ & $\begin{array}{r}2,523 \\
0\end{array}$ & $\begin{array}{r}351 \\
0\end{array}$ \\
\hline Electric Utilty Operating incom $z$............... & 17,964 & 1,823 & 2,442 & 347,330 & 2,523 & 351 \\
\hline 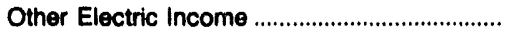 & 3,810 & 1,240 & 372 & 33,003 & 479 & 172 \\
\hline $\begin{array}{l}\text { Other Electric Deductions ............................. } \\
\text { Allowance for Other Funds Used } \\
\text { During Construction ................................... } \\
\text { Taxes on Other Income and Deductions ....... }\end{array}$ & $\begin{array}{l}0 \\
0\end{array}$ & $\begin{array}{l}0 \\
0\end{array}$ & $\begin{array}{l}0 \\
0\end{array}$ & $\begin{array}{r}1,445 \\
0\end{array}$ & $\begin{array}{l}0 \\
0\end{array}$ & $\begin{array}{l}0 \\
0\end{array}$ \\
\hline Electric Utllity Income & 21,773 & 3,063 & 2,814 & 381,778 & 3,002 & 523 \\
\hline 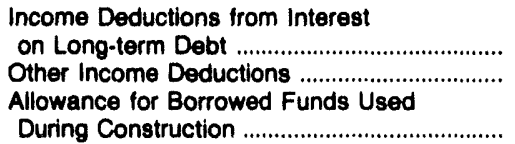 & $\begin{array}{r}16,937 \\
900\end{array}$ & $\begin{array}{r}0 \\
18\end{array}$ & $\begin{array}{r}3,144 \\
0\end{array}$ & $\begin{array}{l}93,151 \\
45,140\end{array}$ & $\begin{array}{r}1,218 \\
52\end{array}$ & $\begin{array}{l}0 \\
0\end{array}$ \\
\hline Total Income Deductions ................................ & 17,837 & 18 & 3,144 & 138,292 & 1,270 & $\mathbf{0}$ \\
\hline Incorne Before Extraordinary Items ................... & 3,836 & 3,045 & -329 & 243,486 & 1,732 & 523 \\
\hline Extraordinary income & 885 & 0 & 0 & 0 & 0 & 0 \\
\hline 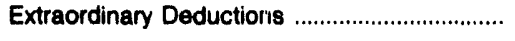 & 0 & 0 & 0 & 0 & 0 & 0 \\
\hline Not Income & 4,821 & 3,045 & -329 & 243,486 & 1,732 & 523 \\
\hline
\end{tabular}

Note: Totals may not equal sum of components because of independent rounding.

Source: Energy Information Administration, Form EIA-412, "Annual Report of Public Electric Utilities." 
Table 21. Statement of Income by Major U.S. Publicly Owned Electric Utillty Within State, 1992 (Continued) (Thousand Dollars)

\begin{tabular}{|c|c|c|c|c|c|c|}
\hline Item & $\begin{array}{l}\text { Nebraska } \\
\text { Omaha Public } \\
\text { Power } \\
\text { District } \\
\text { Decernber } 31\end{array}$ & $\begin{array}{c}\text { Nebraska } \\
\text { Southern } \\
\text { Nebraska Aural } \\
\text { P P D } \\
\text { December } 31\end{array}$ & $\begin{array}{l}\text { Nevada } \\
\text { Colorado } \\
\text { Alver } \\
\text { Comm } \\
\text { of Nevada } \\
\text { June } 30\end{array}$ & $\begin{array}{l}\text { New Jersey } \\
\text { Vineland } \\
\text { City of } \\
\text { June } 30\end{array}$ & $\begin{array}{c}\text { New Mexico } \\
\text { Farmington } \\
\text { City of } \\
\text { June } 30\end{array}$ & $\begin{array}{l}\text { New Mexico } \\
\text { Gallup } \\
\text { City of } \\
\text { June } 30\end{array}$ \\
\hline Electrle Utilly Operating Rovonues ............ & 373,113 & 21,121 & 24,113 & 37,611 & 38,002 & 13,190 \\
\hline 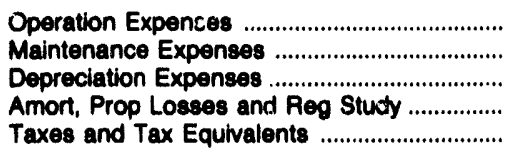 & $\begin{array}{r}184,163 \\
41,900 \\
56,371 \\
0 \\
13,924\end{array}$ & $\begin{array}{r}16,679 \\
831 \\
2,249 \\
0 \\
124\end{array}$ & $\begin{array}{r}24,140 \\
0 \\
0 \\
120 \\
0\end{array}$ & $\begin{array}{r}28,138 \\
2,124 \\
1,397 \\
0 \\
515\end{array}$ & $\begin{array}{r}13,837 \\
2,107 \\
4,231 \\
0 \\
2,844\end{array}$ & $\begin{array}{r}12,488 \\
113 \\
437 \\
0 \\
551\end{array}$ \\
\hline $\begin{array}{l}\text { Total Electric Utility Operating } \\
\text { Expenees }\end{array}$ & 296,358 & 19,892 & 24,260 & 32,174 & 23,110 & 13,680 \\
\hline 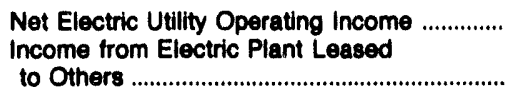 & $\begin{array}{r}76,755 \\
0\end{array}$ & $\begin{array}{r}1,238 \\
0\end{array}$ & $\begin{array}{r}-146 \\
0\end{array}$ & $\begin{array}{r}5,437 \\
0\end{array}$ & $\begin{array}{r}15,783 \\
0\end{array}$ & $\begin{array}{r}-390 \\
0\end{array}$ \\
\hline Electric Utility Operating Income ............. & 76,755 & 1,238 & -146 & 5,437 & 15,783 & -390 \\
\hline Other Electric Income & 16,561 & 0 & 9 & 889 & 1,989 & 167 \\
\hline 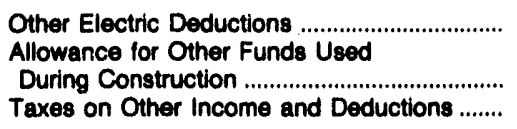 & $\begin{array}{r}0 \\
540 \\
0\end{array}$ & $\begin{array}{l}0 \\
0 \\
0\end{array}$ & $\begin{array}{l}0 \\
0\end{array}$ & $\begin{array}{l}0 \\
0\end{array}$ & $\begin{array}{l}0 \\
0 \\
0\end{array}$ & $\begin{array}{l}0 \\
0 \\
0\end{array}$ \\
\hline 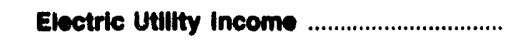 & 93,056 & 1,238 & -137 & 6,426 & 17,771 & -223 \\
\hline 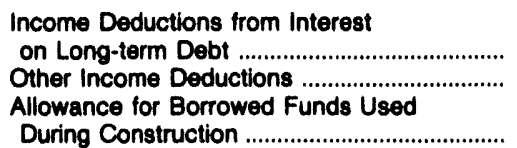 & $\begin{array}{r}60,988 \\
7,218 \\
-4,606\end{array}$ & $\begin{array}{r}425 \\
0\end{array}$ & $\begin{array}{l}0 \\
0 \\
0\end{array}$ & $\begin{array}{r}380 \\
93\end{array}$ & $\begin{array}{r}12,876 \\
273\end{array}$ & $\begin{array}{l}0 \\
0\end{array}$ \\
\hline Total Income Deductions .............................. & 63,601 & 425 & 0 & 473 & 13,150 & $\mathbf{0}$ \\
\hline Income Before Extraordinary Items ................. & 30,255 & 813 & -137 & 5,953 & 4,622 & -223 \\
\hline 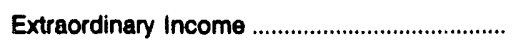 & 0 & 719 & 0 & 0 & 0 & 0 \\
\hline Extraordinary Deductions .................................. & 0 & 0 & 0 & 0 & 0 & 0 \\
\hline Not Income & 30,255 & 1,532 & -137 & 5,953 & 4,622 & -223 \\
\hline
\end{tabular}

Note: Totals may not equal sum of components because of independent rounding.

Source: Energy Information Administration, Form EIA-412, "Annual Report of Public Electric Utilities." 
Table 21. Statement of Income by Major U.S. Publicly Owned Electric Utillty Within State, 1992 (Continued) (Thousand Dollars)

\begin{tabular}{|c|c|c|c|c|c|c|}
\hline Item & $\begin{array}{l}\text { New Mexico } \\
\text { Los Alamos } \\
\text { County } \\
\text { June } 30\end{array}$ & $\begin{array}{c}\text { New York } \\
\text { Fairport } \\
\text { Village of } \\
\text { May } 31\end{array}$ & $\begin{array}{c}\text { New York } \\
\text { Freeport } \\
\text { Village of } \\
\text { Inc }\end{array}$ & $\begin{array}{l}\text { New York } \\
\text { Jamestown } \\
\text { City of } \\
\text { December } 31\end{array}$ & $\begin{array}{l}\text { New York } \\
\text { Massena } \\
\text { Town of } \\
\text { December } 31\end{array}$ & $\begin{array}{c}\text { New York } \\
\text { Plattsburgh } \\
\text { City of } \\
\text { December } 31\end{array}$ \\
\hline Electrio Utilty Operating Rovenues ............ & 26,777 & 10,251 & 14,002 & 21,495 & 6,298 & 10,894 \\
\hline 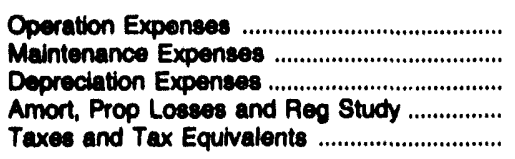 & $\begin{array}{r}12,656 \\
1,067 \\
1,870 \\
686 \\
815\end{array}$ & $\begin{array}{r}7.589 \\
336 \\
623 \\
0 \\
497\end{array}$ & $\begin{array}{r}9,077 \\
1,318 \\
921 \\
0 \\
1,521\end{array}$ & $\begin{array}{r}13,374 \\
1,230 \\
1,898 \\
0 \\
1,285\end{array}$ & $\begin{array}{r}3,545 \\
229 \\
392 \\
287 \\
0\end{array}$ & $\begin{array}{r}7,863 \\
385 \\
802 \\
0 \\
65\end{array}$ \\
\hline 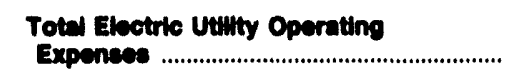 & 17,184 & 9,040 & 12,839 & 17,787 & 4,453 & 9,115 \\
\hline 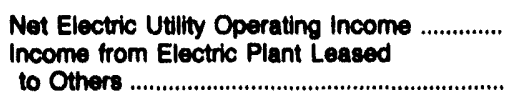 & $\begin{array}{r}8,583 \\
0\end{array}$ & $\begin{array}{r}1,208 \\
14\end{array}$ & $\begin{array}{r}1,165 \\
15\end{array}$ & $\begin{array}{r}3,708 \\
0\end{array}$ & $\begin{array}{r}1,845 \\
0\end{array}$ & $\begin{array}{r}1,779 \\
0\end{array}$ \\
\hline Electric Utulty Operating Income ............. & 8,693 & 1,220 & 1,180 & 3,708 & 1,846 & 1,779 \\
\hline 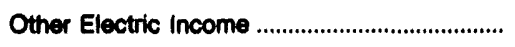 & 1,014 & 74 & 150 & 156 & 61 & 144 \\
\hline $\begin{array}{l}\text { Other Electric Deductions ................................... } \\
\text { Allowance for Other Funds Used }\end{array}$ & 0 & 4 & 0 & 12 & 0 & 0 \\
\hline $\begin{array}{l}\text { During Construction ...................................... } \\
\text { Taxes on Other Income and Deductions ....... }\end{array}$ & $\begin{array}{l}0 \\
0\end{array}$ & $\begin{array}{l}0 \\
0\end{array}$ & $\begin{array}{l}0 \\
0\end{array}$ & $\begin{array}{l}0 \\
0\end{array}$ & $\begin{array}{r}0 \\
266\end{array}$ & $\begin{array}{l}0 \\
0\end{array}$ \\
\hline 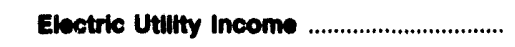 & 9,597 & 1,290 & 1,330 & 3,852 & 1,640 & 1,923 \\
\hline 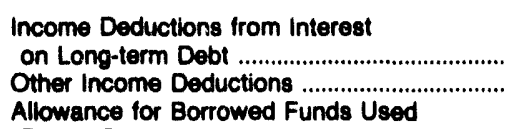 & $\begin{array}{r}7,979 \\
0\end{array}$ & $\begin{array}{l}80 \\
18\end{array}$ & $\begin{array}{r}168 \\
42\end{array}$ & $\begin{array}{r}1,352 \\
0\end{array}$ & $\begin{array}{r}695 \\
4\end{array}$ & $\begin{array}{r}483 \\
57\end{array}$ \\
\hline 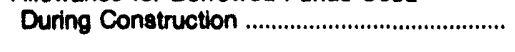 & 0 & 0 & 0 & 0 & 0 & 0 \\
\hline Total Income Deductions .............................. & 7,979 & 100 & 200 & 1,352 & 699 & 539 \\
\hline Income Before Extraordinary Items ................. & 1,618 & 1.180 & 1.120 & 2,500 & 941 & 1,384 \\
\hline 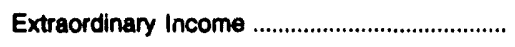 & 401 & 0 & 0 & 0 & 0 & 0 \\
\hline 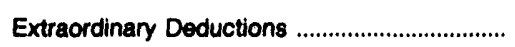 & 0 & 0 & 0 & 0 & 0 & 0 \\
\hline Not Income ............................................. & 2,019 & 1,180 & 1,120 & 2,500 & 841 & 1,384 \\
\hline
\end{tabular}

Note: Totals may not equal sum of components because of independent rounding.

Source: Energy Information Administration, Form EIA-412, "Annual Report of Public Electric Utilities." 
Table 21. Statement of Income by Major U.S. Publlcly Owned Electrlc Utility Within State, 1992 (Continued)

(Thousand Dollars)

\begin{tabular}{|c|c|c|c|c|c|c|}
\hline Item & $\begin{array}{c}\text { New York } \\
\text { Power } \\
\text { Authority } \\
\text { of State of NY } \\
\text { December } 31\end{array}$ & $\begin{array}{l}\text { New York } \\
\text { Rockville } \\
\text { Centre } \\
\text { Village of } \\
\text { May } 31\end{array}$ & $\begin{array}{l}\text { North Carolina } \\
\text { Albemarle } \\
\text { City of } \\
\text { June } 30\end{array}$ & $\begin{array}{l}\text { North Carolina } \\
\text { Concord } \\
\text { Clty of } \\
\text { June } 30\end{array}$ & $\begin{array}{l}\text { North Carolina } \\
\text { Elizabeth } \\
\text { City City of } \\
\text { June } 30\end{array}$ & $\begin{array}{l}\text { North Carnlina } \\
\text { Fayetteville } \\
\text { Public } \\
\text { Works Comm } \\
\text { June } 30\end{array}$ \\
\hline Electrlc Utillity Operating Revenuas ............ & $1,298,616$ & 9,546 & 16,312 & 24,468 & 18,021 & 110,000 \\
\hline 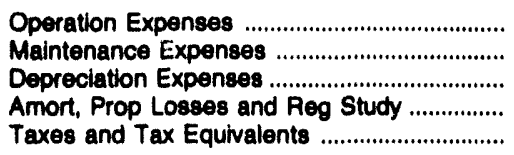 & $\begin{array}{r}930,600 \\
180,446 \\
129,979 \\
0 \\
0\end{array}$ & $\begin{array}{r}7,621 \\
614 \\
679 \\
0 \\
1,053\end{array}$ & $\begin{array}{r}13,965 \\
40 \\
576 \\
0 \\
0\end{array}$ & $\begin{array}{r}17,895 \\
3,256 \\
1,234 \\
0 \\
0\end{array}$ & $\begin{array}{r}16,035 \\
381 \\
735 \\
0 \\
0\end{array}$ & $\begin{array}{r}79,837 \\
4,587 \\
6,164 \\
76 \\
7,785\end{array}$ \\
\hline $\begin{array}{l}\text { Total Electrle Utllity Oparating } \\
\text { Exponees }\end{array}$ & $1,241,026$ & 9,997 & 14,581 & 22,384 & 17,152 & 90,450 \\
\hline $\begin{array}{l}\text { Net Electric Utility Operating Income } \\
\text { Income from Electric Plant Leased } \\
\text { to Others }\end{array}$ & $\begin{array}{r}57,591 \\
918\end{array}$ & $\begin{array}{r}-423 \\
0\end{array}$ & 1,730 & 2,083 & $\begin{array}{r}1,470 \\
0\end{array}$ & $\begin{array}{r}11,646 \\
0\end{array}$ \\
\hline Electric Utility Operating Income ............. & 58,500 & -423 & 1,730 & 2,083 & 1,470 & 11,646 \\
\hline Other Electric Income & 227,576 & 186 & 108 & 363 & 134 & 2,233 \\
\hline 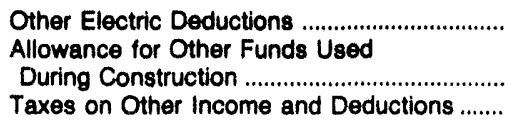 & $\begin{array}{l}0 \\
0\end{array}$ & $\begin{array}{l}0 \\
0\end{array}$ & $\begin{array}{l}0 \\
0\end{array}$ & $\begin{array}{r}801 \\
0 \\
0\end{array}$ & $\begin{array}{r}953 \\
0 \\
0\end{array}$ & $\begin{array}{l}0 \\
0 \\
0\end{array}$ \\
\hline Electric Utility Income & 286,085 & -236 & 1,839 & 1,646 & 650 & 13,879 \\
\hline 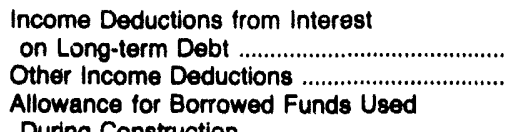 & $\begin{array}{r}232,791 \\
7,621\end{array}$ & $\begin{array}{r}119 \\
30\end{array}$ & $\begin{array}{r}0 \\
1,013\end{array}$ & $\begin{array}{r}158 \\
0\end{array}$ & $\begin{array}{l}0 \\
0\end{array}$ & $\begin{array}{r}2,599 \\
50\end{array}$ \\
\hline 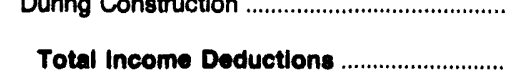 & 240,412 & $\begin{array}{l}-28 \\
121\end{array}$ & $\begin{array}{r}0 \\
1,013\end{array}$ & $\begin{array}{r}0 \\
158\end{array}$ & $\begin{array}{l}0 \\
0\end{array}$ & 2,649 \\
\hline Income Before Extraordinary Items ..................... & 45,673 & -357 & 826 & 1,488 & 650 & 11,230 \\
\hline Extraordinary Income & 0 & 0 & 0 & 0 & 0 & 0 \\
\hline 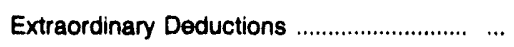 & 9,502 & 0 & 0 & 246 & 0 & 0 \\
\hline 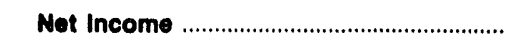 & 36,171 & -357 & 826 & 1,241 & 650 & 11,230 \\
\hline
\end{tabular}

Note: Totals may not equal sum of components because of independent rounding.

Source: Energy Information Administration, Form ElA-412, "Annual Report of Public Electric Utilities." 
Table 21. Statement of Income by Major U.S. Publicly Owned Electric Utility Within State, 1992 (Continued)

(Thousand Dollars)

\begin{tabular}{|c|c|c|c|c|c|c|}
\hline Item & $\begin{array}{l}\text { North Carolina } \\
\text { Gastonia } \\
\text { Clty of } \\
\text { June } 30\end{array}$ & $\begin{array}{c}\text { North Carolina } \\
\text { Greenville } \\
\text { Utilities } \\
\text { Comm } \\
\text { June } 30\end{array}$ & $\begin{array}{c}\text { North Carolina } \\
\text { High } \\
\text { Point } \\
\text { Town } \\
\text { of } \\
\text { June } 30\end{array}$ & $\begin{array}{l}\text { North Carolina } \\
\text { Kinston } \\
\text { City of } \\
\text { June } 30\end{array}$ & $\begin{array}{l}\text { North Carolina } \\
\begin{array}{c}\text { Lexington } \\
\text { City of }\end{array} \\
\text { June } 30\end{array}$ & $\begin{array}{l}\text { North Carolina } \\
\text { Lumberton } \\
\text { City of } \\
\text { June } 30\end{array}$ \\
\hline Eloctric Utility Operating Rovenues ............. & 30,074 & 85,602 & 86,650 & 33,910 & 29,153 & 20,764 \\
\hline 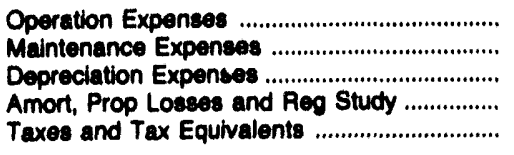 & $\begin{array}{r}27,441 \\
1,012 \\
1,065 \\
0 \\
0\end{array}$ & $\begin{array}{r}74,363 \\
1,785 \\
3,558 \\
0 \\
0\end{array}$ & $\begin{array}{r}42,279 \\
3,593 \\
1,549 \\
0 \\
0\end{array}$ & $\begin{array}{r}30,669 \\
0 \\
817 \\
2 \\
0\end{array}$ & $\begin{array}{r}24,252 \\
108 \\
625 \\
0 \\
653\end{array}$ & $\begin{array}{r}19,262 \\
100 \\
468 \\
0 \\
0\end{array}$ \\
\hline $\begin{array}{l}\text { Total Electric Utility Oporating } \\
\text { Expenees }\end{array}$ & 20,518 & 79,707 & 47,421 & 31,409 & 25,638 & 19,831 \\
\hline 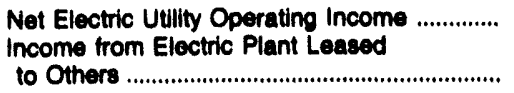 & $\begin{array}{r}9,356 \\
0\end{array}$ & $\begin{array}{r}5,856 \\
0\end{array}$ & $\begin{array}{r}9,138 \\
0\end{array}$ & $\begin{array}{r}2,431 \\
0\end{array}$ & $\begin{array}{r}3,515 \\
0\end{array}$ & 933 \\
\hline Electrle Utility Operating Income ............... & 9,386 & 8,956 & 9,138 & 2,431 & 3,516 & 933 \\
\hline Other Electric Income & 357 & 691 & 455 & 343 & 182 & 924 \\
\hline $\begin{array}{l}\text { Other Electric Deductions ................................. } \\
\text { Allowance for Other Funds Used }\end{array}$ & 0 & 2,235 & 4,000 & 0 & 3,245 & 1,664 \\
\hline 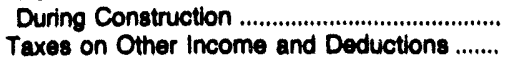 & $\begin{array}{l}0 \\
0\end{array}$ & $\begin{array}{l}0 \\
0\end{array}$ & $\begin{array}{l}0 \\
0\end{array}$ & $\begin{array}{l}0 \\
0\end{array}$ & $\begin{array}{l}0 \\
0\end{array}$ & $\begin{array}{l}0 \\
0\end{array}$ \\
\hline 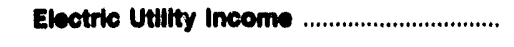 & 0,712 & 4,411 & 5,593 & 2,774 & 463 & 194 \\
\hline 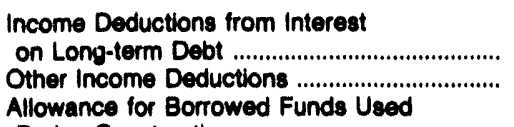 & $\begin{array}{l}0 \\
4\end{array}$ & $\begin{array}{r}289 \\
0\end{array}$ & $\begin{array}{r}89 \\
0\end{array}$ & $\begin{array}{r}97 \\
0\end{array}$ & $\begin{array}{l}26 \\
57\end{array}$ & $\begin{array}{r}4 \\
26\end{array}$ \\
\hline 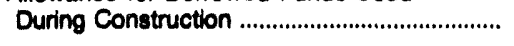 & 0 & 0 & 0 & 0 & 0 & 0 \\
\hline Total Income Deductione ............................... & 4 & 280 & 80 & 97 & 82 & 29 \\
\hline Income Before Extraordinary Items ................... & 9,708 & 4,122 & 5,503 & 2,677 & 370 & 164 \\
\hline 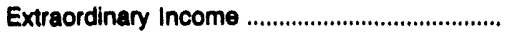 & 0 & 0 & 0 & 0 & 0 & 0 \\
\hline 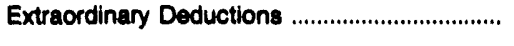 & 0 & 0 & 0 & 0 & 0 & 0 \\
\hline 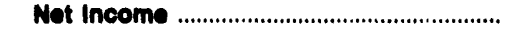 & 0,708 & 4,122 & 5,603 & 2,677 & 370 & 164 \\
\hline
\end{tabular}

Note: Totals may not equal sum of components because of independent rounding.

Source: Energy Information Administration, Form ElA-412, "Annual Report of Public Electric Utilities." 
Table 21. Statement of Income by Major U.S. Publicly Owned Electric UtIlity Within State, 1992 (Continued) (Thousand Dollars)

\begin{tabular}{|c|c|c|c|c|c|c|}
\hline Item & $\begin{array}{c}\text { North Carolina } \\
\text { Monroe } \\
\text { Clty of } \\
\text { June } 30\end{array}$ & $\begin{array}{l}\text { North Carolina } \\
\text { Morganton } \\
\text { Clty of } \\
\text { June } 30\end{array}$ & $\begin{array}{l}\text { North Carolina } \\
\text { Murphy } \\
\text { City of } \\
\text { June } 30\end{array}$ & $\begin{array}{l}\text { North Carolina } \\
\text { New Bern } \\
\text { Clty of } \\
\text { June } 30\end{array}$ & $\begin{array}{c}\text { North Carolina } \\
\text { New River } \\
\text { Light } \\
\& \\
\text { Power Co } \\
\text { December } 31\end{array}$ & $\begin{array}{c}\text { North Carolina } \\
\text { North } \\
\text { Carolina } \\
\text { Eastern M P A } \\
\text { December } 31\end{array}$ \\
\hline Eleotric Utility Operating Rovenues ............ & 24,668 & 16,265 & 8,080 & 28,520 & 11,774 & 398,585 \\
\hline 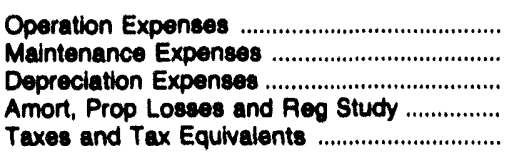 & $\begin{array}{r}20,264 \\
0 \\
553 \\
0 \\
0\end{array}$ & $\begin{array}{r}13,795 \\
0 \\
364 \\
0 \\
0\end{array}$ & $\begin{array}{r}7,338 \\
145 \\
174 \\
0 \\
52\end{array}$ & $\begin{array}{r}26,543 \\
0 \\
659 \\
0 \\
0\end{array}$ & $\begin{array}{r}9,382 \\
386 \\
272 \\
0 \\
378\end{array}$ & $\begin{array}{r}261,831 \\
23,081 \\
48,231 \\
0 \\
15,931\end{array}$ \\
\hline $\begin{array}{l}\text { Total Electrle Utillty Operating } \\
\text { Exponeea }\end{array}$ & 20,817 & 14,159 & 7,700 & 27,202 & 10,419 & 350,074 \\
\hline $\begin{array}{l}\text { Net Electric Utillity Operating Income } \\
\text { Income from Electric Plant Leased } \\
\text { to Others }\end{array}$ & $\begin{array}{r}3,849 \\
0\end{array}$ & $\begin{array}{r}2,106 \\
0\end{array}$ & $\begin{array}{r}371 \\
0\end{array}$ & $\begin{array}{r}1,327 \\
0\end{array}$ & $\begin{array}{r}1,355 \\
0\end{array}$ & $\begin{array}{r}48,511 \\
0\end{array}$ \\
\hline Ebectrle Utility Operating Income .............. & 3,840 & 2,108 & 371 & 1,327 & 1,355 & 48,511 \\
\hline 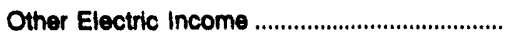 & 1,340 & 399 & 148 & 100 & 136 & 192,480 \\
\hline Other Electric Deductions ..................................... & 1,814 & 2 & 15 & 0 & 0 & 0 \\
\hline 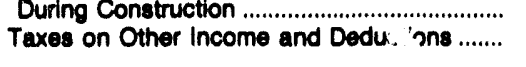 & $\begin{array}{l}0 \\
0\end{array}$ & $\begin{array}{l}0 \\
0\end{array}$ & $\begin{array}{l}0 \\
0\end{array}$ & $\begin{array}{l}0 \\
0\end{array}$ & $\begin{array}{l}0 \\
0\end{array}$ & $\begin{array}{l}0 \\
0\end{array}$ \\
\hline 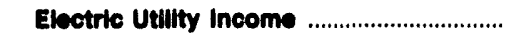 & 3,375 & 2,502 & 504 & 1,427 & 1,490 & 240,901 \\
\hline $\begin{array}{l}\text { Income Deductions from Interest } \\
\text { on Long-term Debt .......................................... } \\
\text { Other Income Deductions ............................. } \\
\text { Allowance for Borrowed Funds Used }\end{array}$ & $\begin{array}{l}0 \\
0\end{array}$ & $\begin{array}{r}0 \\
1,660\end{array}$ & $\begin{array}{l}0 \\
0\end{array}$ & $\begin{array}{r}68 \\
0\end{array}$ & $\begin{array}{l}0 \\
0\end{array}$ & $\begin{array}{r}220,203 \\
24,016\end{array}$ \\
\hline 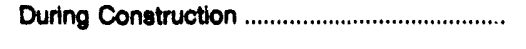 & 0 & 0 & 0 & 0 & 0 & 0 \\
\hline 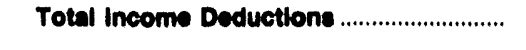 & 0 & 1,660 & 0 & 68 & 0 & 244,219 \\
\hline Income Before Extraordinary ltems ...................... & 3,375 & 841 & 504 & 1,350 & 1,490 & $-3,228$ \\
\hline Extraordinary Income & 0 & 0 & 0 & 0 & 0 & 0 \\
\hline 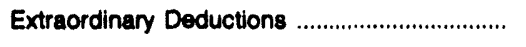 & 0 & 0 & 0 & 0 & 0 & 0 \\
\hline Not Income & 3,375 & 841 & 504 & 1,359 & 1,490 & $-3,228$ \\
\hline
\end{tabular}

Note: Totals may not equal sum of components because of independent rounding.

Source: Energy Information Administration, Form EIA-412, "Annual Report of Public Electric Utilities." 
Table 21. Strent of Income by Major U.S. Publicly Owned Electric Utility Within State, 1992 (Continued) (Thousand Dollars)

\begin{tabular}{|c|c|c|c|c|c|c|}
\hline Hem & $\begin{array}{l}\text { North Carolina } \\
\text { North } \\
\text { Carolina } \\
\text { Mun } \\
\text { Power Agny } \\
\text { December } 31\end{array}$ & $\begin{array}{l}\text { North Carolina } \\
\text { Rocky Mount } \\
\text { City of } \\
\text { June } 30\end{array}$ & $\begin{array}{l}\text { North Carolina } \\
\text { Shelby } \\
\text { City of } \\
\text { June } 30\end{array}$ & $\begin{array}{l}\text { North Carolina } \\
\text { Statesville } \\
\text { City of } \\
\text { June } 30\end{array}$ & $\begin{array}{l}\text { North Carolina } \\
\text { Tarboro } \\
\text { Town of } \\
\text { June } 30\end{array}$ & $\begin{array}{c}\text { North Carolina } \\
\begin{array}{c}\text { Washington } \\
\text { City of }\end{array} \\
\text { June } 30\end{array}$ \\
\hline Electric Utulty Operating Rovenues ............. & 418,234 & 57,121 & 11,450 & 24,080 & 18,773 & 20,721 \\
\hline 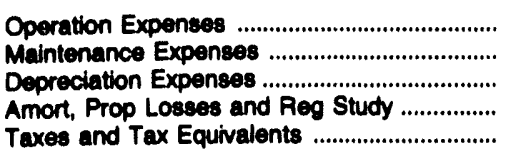 & $\begin{array}{r}226,922 \\
39,239 \\
43,701 \\
0 \\
19,732\end{array}$ & $\begin{array}{r}52,641 \\
0 \\
1,087 \\
0 \\
0\end{array}$ & $\begin{array}{r}8,275 \\
892 \\
259 \\
0 \\
0\end{array}$ & $\begin{array}{r}19,019 \\
0 \\
506 \\
0 \\
0\end{array}$ & $\begin{array}{r}16,979 \\
0 \\
438 \\
0 \\
476\end{array}$ & $\begin{array}{r}16,540 \\
1,379 \\
841 \\
0 \\
0\end{array}$ \\
\hline $\begin{array}{l}\text { Total Electrlc Utilty Operating } \\
\text { Expences }\end{array}$ & 320,504 & 53,728 & 9,427 & 10,525 & 17,893 & 18,761 \\
\hline 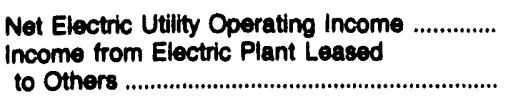 & $\begin{array}{r}88,640 \\
0\end{array}$ & $\begin{array}{r}3,393 \\
0\end{array}$ & $\begin{array}{r}2,023 \\
0\end{array}$ & $\begin{array}{r}4,555 \\
0\end{array}$ & $\begin{array}{r}880 \\
0\end{array}$ & $\begin{array}{r}1,960 \\
0\end{array}$ \\
\hline Electric Utilty Operating Incoms .............. & 88,640 & 3,393 & 2,023 & 4,655 & 880 & 1,960 \\
\hline 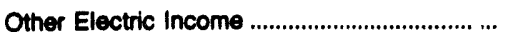 & 97,017 & 187 & 15 & 389 & 369 & 0 \\
\hline 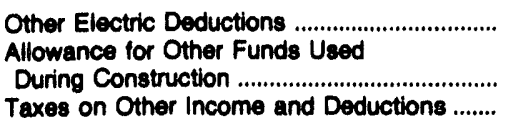 & $\begin{array}{l}0 \\
0\end{array}$ & $\begin{array}{l}0 \\
0\end{array}$ & $\begin{array}{l}0 \\
0\end{array}$ & $\begin{array}{r}269 \\
0 \\
0\end{array}$ & $\begin{array}{l}0 \\
0\end{array}$ & $\begin{array}{l}0 \\
0\end{array}$ \\
\hline 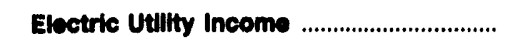 & 185,667 & 3,580 & 2,038 & 4,675 & 1,249 & 1,960 \\
\hline 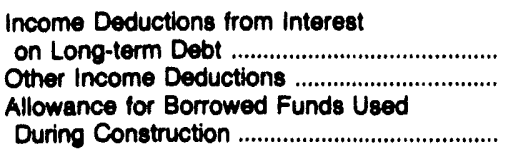 & $\begin{array}{r}176,511 \\
14,945\end{array}$ & $\begin{array}{r}99 \\
803 \\
0\end{array}$ & $\begin{array}{r}14 \\
0 \\
0\end{array}$ & $\begin{array}{l}s \\
0 \\
0\end{array}$ & $\begin{array}{l}0 \\
0\end{array}$ & $\begin{array}{r}355 \\
0 \\
0\end{array}$ \\
\hline 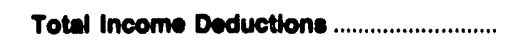 & & $\$ 01$ & 14 & 9 & $\mathbf{0}$ & 355 \\
\hline Income Before Extraordinary Items ..................... & & 2,679 & 2,024 & 4,686 & 1,249 & 1,605 \\
\hline Extraordinary Income & 0 & 0 & 0 & 0 & 0 & 0 \\
\hline 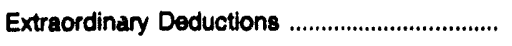 & 0 & 0 & 0 & 0 & 0 & 0 \\
\hline Net Income & $-5,700$ & 2,679 & 2,024 & 4,666 & 1,240 & 1,605 \\
\hline
\end{tabular}

Note: Totals may not equal sum of components because of independent rounding.

Source: Energy Information Administration, Form EIA-412, "Annual Report of Public Electric Utilities." 
Table 21. Statement of Income by Major U.S. Publicly Owned Electric Utility Within State, 1992 (Continued)

(Thousand Dollars)

\begin{tabular}{|c|c|c|c|c|c|c|}
\hline Item & $\begin{array}{l}\text { North Carolina } \\
\text { Wilson } \\
\text { City of } \\
\text { June } 30\end{array}$ & $\begin{array}{c}\text { Ohio } \\
\text { American } \\
\text { Mun } \\
\text { Power } \\
\text { Ohio Inc } \\
\text { December } 31\end{array}$ & $\begin{array}{l}\text { Otio } \\
\text { Bowilng } \\
\text { Green } \\
\text { City of } \\
\text { December } 31\end{array}$ & $\begin{array}{l}\text { Onlo } \\
\text { Bryan } \\
\text { City of } \\
\text { December } 31\end{array}$ & $\begin{array}{l}\text { Onio } \\
\text { Celina } \\
\text { City of } \\
\text { December } 31\end{array}$ & $\begin{array}{l}\text { Onio } \\
\text { Cloveland } \\
\text { Clty of } \\
\text { December } 31\end{array}$ \\
\hline Eloctric Utilty Operating Rovenues ............ & 73,127 & 190,203 & 14,891 & 10,184 & 7,290 & $\mathbf{8 0 , 7 8 4}$ \\
\hline 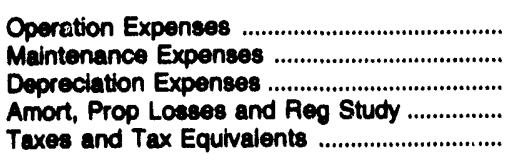 & $\begin{array}{r}65,710 \\
538 \\
1,534 \\
0 \\
0\end{array}$ & $\begin{array}{r}116,443 \\
5,441 \\
3,135 \\
1,255 \\
7,342\end{array}$ & $\begin{array}{r}12,268 \\
888 \\
419 \\
0 \\
0\end{array}$ & $\begin{array}{r}9,607 \\
0 \\
0 \\
0 \\
0\end{array}$ & $\begin{array}{r}6,297 \\
550 \\
0 \\
0 \\
0\end{array}$ & $\begin{array}{r}36,730 \\
11,501 \\
3,445 \\
0 \\
0\end{array}$ \\
\hline 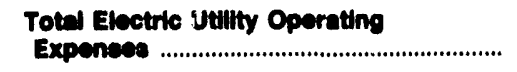 & 67,700 & 133,816 & 13,675 & 9,607 & 6,847 & 51,675 \\
\hline $\begin{array}{l}\text { Net Electric Utility Operating Income } \\
\text { Income from Electric Plant Lease... }\end{array}$ & 5,347 & 5,669 & 1,017 & 576 & 413 & 7,109 \\
\hline 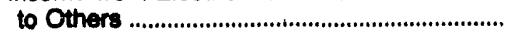 & 0 & 0 & 0 & 0 & 0 & 0 \\
\hline Electric Utulity Operating Income ............... & 5,347 & 5,630 & 1,017 & 576 & 413 & 7,100 \\
\hline 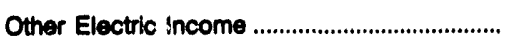 & 1,461 & 1,746 & 728 & 0 & 134 & 1.767 \\
\hline $\begin{array}{l}\text { Other Electric Deductions .................................... } \\
\text { Allowance for Other Funds Used }\end{array}$ & 0 & 1,538 & 0 & 0 & 0 & 0 \\
\hline $\begin{array}{l}\text { During Construction .................................... } \\
\text { Taxes on Other Income and Deductions ........ }\end{array}$ & $\begin{array}{l}0 \\
0\end{array}$ & $\begin{array}{l}0 \\
0\end{array}$ & $\begin{array}{l}0 \\
0\end{array}$ & $\begin{array}{l}0 \\
0\end{array}$ & $\begin{array}{l}0 \\
0\end{array}$ & $\begin{array}{l}0 \\
0\end{array}$ \\
\hline Electric Utilly Income .................................. & 6,005 & 5,876 & 1,746 & 676 & 547 & $\mathbf{8 , 8 7 8}$ \\
\hline $\begin{array}{l}\text { Income Deductions from Interest } \\
\text { on Long-term Debt ............................................ } \\
\text { Other Income Deductions ................................ } \\
\text { Allowance for Borrowed Funds Used }\end{array}$ & $\begin{array}{r}26 \\
344\end{array}$ & $\begin{array}{r}7,563 \\
0\end{array}$ & $\begin{array}{r}48 \\
0\end{array}$ & $\begin{array}{l}0 \\
0\end{array}$ & $\begin{array}{r}0 \\
165\end{array}$ & $\begin{array}{r}173 \\
0\end{array}$ \\
\hline During Construction ............................................... & 0 & 0 & 0 & 0 & 0 & 0 \\
\hline Total Income Deductions ........................... & 370 & 7,663 & 40 & $\mathbf{0}$ & 165 & 173 \\
\hline Income Before Extraordinary Items .................. & 6,438 & $-1,688$ & 1,697 & 576 & 381 & 8,703 \\
\hline Extraordinary Income & 0 & 0 & 0 & 0 & 102 & 0 \\
\hline 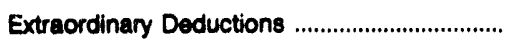 & 0 & 0 & 0 & 0 & 0 & 63 \\
\hline Net Income .................................................... & 6,498 & $-1,4 \mathrm{es}$ & 1,697 & 576 & 403 & 8,640 \\
\hline
\end{tabular}

Note: Totals may not equal sum of components because of independent rounding.

Source: Energy Information Administration, Form EIA-412, "Annual Report of Public Electric Utilities." 
Table 21. Statement of Income by Major U.S. Publicly Owned Electric Utility Within State, 1992 (Continued)

(Thousand Dollars)

\begin{tabular}{|c|c|c|c|c|c|c|}
\hline Item & $\begin{array}{c}\text { Onio } \\
\text { Columbus } \\
\text { City of } \\
\text { December } 31\end{array}$ & $\begin{array}{l}\text { Ohio } \\
\text { Cuyahoga } \\
\text { Falls } \\
\text { City of } \\
\text { December } 31\end{array}$ & $\begin{array}{l}\text { Onio } \\
\text { Dover } \\
\text { Clty of } \\
\text { December } 31\end{array}$ & $\begin{array}{c}\text { Ohio } \\
\text { Hamilton } \\
\text { Clty of } \\
\text { December } 31\end{array}$ & $\begin{array}{c}\text { Onio } \\
\text { Niles } \\
\text { City of } \\
\text { December } 31\end{array}$ & $\begin{array}{c}\text { Ohio } \\
\text { Orrville } \\
\text { City of } \\
\text { December } 31\end{array}$ \\
\hline Electile Utily Operating Rovenues ............ & $4 \mathbf{4 , 0 0 1}$ & 17,202 & 8,761 & 37,570 & 14,398 & 16,768 \\
\hline 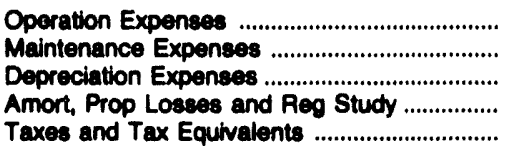 & $\begin{array}{r}18,307 \\
24,112 \\
10,786 \\
0 \\
0\end{array}$ & $\begin{array}{r}16,315 \\
0 \\
560 \\
0 \\
0\end{array}$ & $\begin{array}{r}7,612 \\
0 \\
398 \\
0 \\
0\end{array}$ & $\begin{array}{r}19,377 \\
1,790 \\
6,213 \\
0 \\
0\end{array}$ & $\begin{array}{r}12,438 \\
513 \\
353 \\
0 \\
0\end{array}$ & $\begin{array}{r}11,102 \\
2,267 \\
1,554 \\
33 \\
0\end{array}$ \\
\hline $\begin{array}{l}\text { Total Electric Utilty Operating } \\
\text { Expenece }\end{array}$ & 53,216 & 16,876 & 0,008 & 27,380 & 13,304 & 14,956 \\
\hline 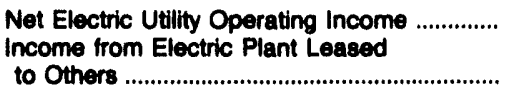 & $\begin{array}{r}-6,324 \\
0\end{array}$ & $\begin{array}{r}407 \\
0\end{array}$ & $\begin{array}{r}752 \\
0\end{array}$ & $\begin{array}{r}10,189 \\
0\end{array}$ & $\begin{array}{r}1,084 \\
0\end{array}$ & $\begin{array}{r}1,804 \\
0\end{array}$ \\
\hline Electrlc Utilly Operating Incoms ............. & $-6,324$ & 407 & 752 & 10,189 & 1,084 & 1,804 \\
\hline 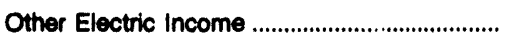 & 6,583 & 0 & 63 & 1,647 & 297 & 391 \\
\hline $\begin{array}{l}\text { Other Electric Deductions ............................ } \\
\text { Allowance for Other Funds Used } \\
\text { During Construction ........................................ } \\
\text { Taxes on Other Income and Deductions ........ }\end{array}$ & $\begin{array}{l}0 \\
0 \\
0\end{array}$ & $\begin{array}{l}0 \\
0 \\
0\end{array}$ & $\begin{array}{l}0 \\
0 \\
0\end{array}$ & $\begin{array}{l}0 \\
0 \\
0\end{array}$ & $\begin{array}{l}0 \\
0 \\
0\end{array}$ & $\begin{array}{r}1,496 \\
0 \\
0\end{array}$ \\
\hline 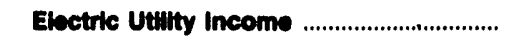 & 250 & 407 & 816 & 11,836 & 1,381 & 698 \\
\hline $\begin{array}{l}\text { Income Deductions from Interest } \\
\text { on Long-term Debt ....................................... } \\
\text { Other Income Deductions ................................. } \\
\text { Allowance for Borrowed Funds Used }\end{array}$ & $\begin{array}{r}11,661 \\
0\end{array}$ & $\begin{array}{l}0 \\
0\end{array}$ & $\begin{array}{l}83 \\
24\end{array}$ & $\begin{array}{r}13,007 \\
0\end{array}$ & $\begin{array}{r}146 \\
0\end{array}$ & $\begin{array}{l}0 \\
0\end{array}$ \\
\hline 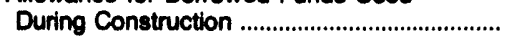 & 0 & 0 & 0 & 0 & 0 & 0 \\
\hline 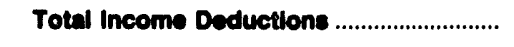 & 11,681 & $\mathbf{0}$ & 87 & 13,007 & 146 & $\mathbf{0}$ \\
\hline Income Before Extraordinary Items ................. & $-11,402$ & 407 & 728 & $-1,171$ & 1,235 & 698 \\
\hline 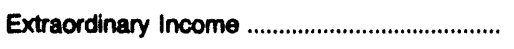 & 0 & 0 & 0 & 0 & 0 & 0 \\
\hline 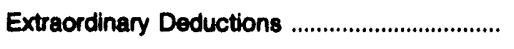 & 6,002 & 0 & 0 & 26,900 & 0 & 0 \\
\hline 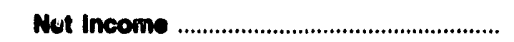 & $-17,404$ & 407 & 720 & $-28,071$ & 1,235 & 609 \\
\hline
\end{tabular}

Note: Totals may not equal sum of components beceuse of independent rounding.

Source: Einergy Information Administration, Form ElA-412, "Annual Report of Public Electric Utilities." 
Table 21. Statement of Income by Major U.S. Publicly Owned Electric Utillty Within State, 1992 (Continued)

(Thousand Dollars)

\begin{tabular}{|c|c|c|c|c|c|c|}
\hline Item & $\begin{array}{c}\text { Onio } \\
\text { Painesville } \\
\text { City of } \\
\text { December } 31\end{array}$ & $\begin{array}{c}\text { Ohio } \\
\text { Piqua } \\
\text { City of } \\
\text { December } 31\end{array}$ & $\begin{array}{l}\text { Ohio } \\
\text { St Marys } \\
\text { City of } \\
\text { December } 31\end{array}$ & $\begin{array}{c}\text { Ohio } \\
\text { Wadsworth } \\
\text { City of }\end{array}$ & $\begin{array}{c}\text { Ohio } \\
\text { Wapakoneta } \\
\text { City of }\end{array}$ & $\begin{array}{c}\text { Onio } \\
\text { Westerville } \\
\text { City of }\end{array}$ \\
\hline Eloctric Utility Operating Revenues ............. & 11,723 & 14,144 & 6,755 & 10,465 & 6,224 & 16,960 \\
\hline 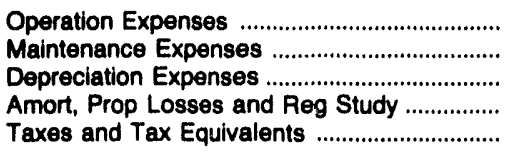 & $\begin{array}{r}9,741 \\
950 \\
1,075 \\
0 \\
0\end{array}$ & $\begin{array}{r}9,876 \\
1,608 \\
971 \\
0 \\
0\end{array}$ & $\begin{array}{r}4,644 \\
1,045 \\
261 \\
0 \\
117\end{array}$ & $\begin{array}{r}9,929 \\
0 \\
0 \\
0 \\
0\end{array}$ & $\begin{array}{r}5,737 \\
191 \\
0 \\
0 \\
0\end{array}$ & $\begin{array}{r}11,476 \\
867 \\
434 \\
0 \\
500\end{array}$ \\
\hline $\begin{array}{l}\text { Total Electric Utility Operating } \\
\text { Expenees }\end{array}$ & 11,766 & 12,455 & 6,068 & 9,929 & 5,928 & 13,278 \\
\hline $\begin{array}{l}\text { Net Electric Utility Operating Income ............. } \\
\text { Income from Electric Plant Leased } \\
\text { to Others }\end{array}$ & $\begin{array}{r}-43 \\
0\end{array}$ & $\begin{array}{r}1,688 \\
0\end{array}$ & $\begin{array}{r}689 \\
0\end{array}$ & $\begin{array}{r}537 \\
0\end{array}$ & $\begin{array}{r}296 \\
0\end{array}$ & $\begin{array}{r}3,682 \\
0\end{array}$ \\
\hline Electric Utility Operating Income .............. & -43 & 1,690 & 689 & 537 & 208 & 3,682 \\
\hline Other Electric Income & -137 & 149 & 155 & 0 & 0 & 3 \\
\hline $\begin{array}{l}\text { Other Electric Deductions } \\
\text { Allowance for Other Funds Used }\end{array}$ & 0 & 238 & 373 & 297 & 0 & 28 \\
\hline 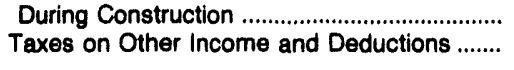 & $\begin{array}{l}0 \\
0\end{array}$ & $\begin{array}{l}0 \\
0\end{array}$ & $\begin{array}{l}0 \\
0\end{array}$ & $\begin{array}{l}0 \\
0\end{array}$ & $\begin{array}{l}0 \\
0\end{array}$ & $\begin{array}{l}0 \\
0\end{array}$ \\
\hline Electric Utility Income & -180 & 1,600 & 470 & 240 & 296 & 3,657 \\
\hline $\begin{array}{l}\text { Income Deductions from Interest } \\
\text { on Long-term Debt .......................................... } \\
\text { Other Income Deductions .......................... } \\
\text { Allowance for Borrowed Funds Used }\end{array}$ & $\begin{array}{r}951 \\
3\end{array}$ & $\begin{array}{r}619 \\
0\end{array}$ & $\begin{array}{l}0 \\
0\end{array}$ & $\begin{array}{l}0 \\
0\end{array}$ & $\begin{array}{l}0 \\
0\end{array}$ & $\begin{array}{r}11 \\
0\end{array}$ \\
\hline Total Income Deductions ................................ & 955 & 619 & 0 & 0 & 0 & 11 \\
\hline Income Before Extraordinary Items ................... & $-1,135$ & 981 & 470 & 240 & 296 & 3,646 \\
\hline 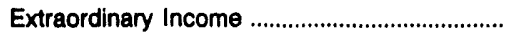 & 5 & 0 & 0 & 0 & 0 & 0 \\
\hline 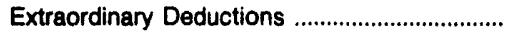 & 567 & 582 & 0 & 0 & 0 & 0 \\
\hline Not Income & $-1,697$ & 390 & 470 & 240 & 296 & 3,646 \\
\hline
\end{tabular}

Note: Totals may not equal sum of components because of independent rounding.

Source: Energy Information Administration, Form ElA-412, "Annual Report of Public Electric Utilities." 
Table 21. Statement of Income by Major U.S. Publicly Owned Electric Utility Within State, 1992 (Continued) (Thousand Dollars)

\begin{tabular}{|c|c|c|c|c|c|c|}
\hline Item & $\begin{array}{l}\text { Oklahoma } \\
\text { Altus } \\
\text { City of } \\
\text { June } 30\end{array}$ & $\begin{array}{c}\text { Oklahoma } \\
\text { Claremore } \\
\text { City of } \\
\text { June } 30\end{array}$ & $\begin{array}{l}\text { Oklahoma } \\
\text { Duncan } \\
\text { City of } \\
\text { June } 30\end{array}$ & $\begin{array}{l}\text { Oklahoma } \\
\text { Edmond } \\
\text { City of } \\
\text { June } 30\end{array}$ & $\begin{array}{c}\text { Oklahoma } \\
\text { Grand River } \\
\text { Dam } \\
\text { Authority } \\
\text { December } 31\end{array}$ & $\begin{array}{c}\text { Oklahoma } \\
\text { Oklahoma } \\
\text { Municipal } \\
\text { Power Auth } \\
\text { December } 31\end{array}$ \\
\hline Ebctric Utilly Opereting Rovenues ............. & 8,570 & 11,531 & 7,027 & 24,564 & 145,863 & 63,579 \\
\hline 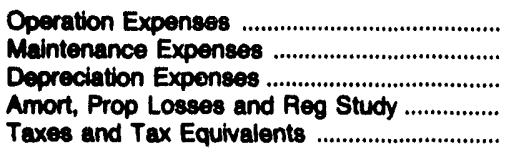 & $\begin{array}{r}6,561 \\
426 \\
0 \\
0 \\
0\end{array}$ & $\begin{array}{r}8,119 \\
965 \\
0 \\
0 \\
0\end{array}$ & $\begin{array}{r}5,630 \\
0 \\
669 \\
0 \\
0\end{array}$ & $\begin{array}{r}20,624 \\
249 \\
1,020 \\
0 \\
0\end{array}$ & $\begin{array}{r}62,813 \\
9,954 \\
25,973 \\
0 \\
0\end{array}$ & $\begin{array}{r}46,691 \\
1,151 \\
4,647 \\
0 \\
1,233\end{array}$ \\
\hline $\begin{array}{l}\text { Total Ebetric Utility Operating } \\
\text { Expenase }\end{array}$ & 6,987 & 9,004 & 6,298 & 21,892 & 98,739 & 53,722 \\
\hline 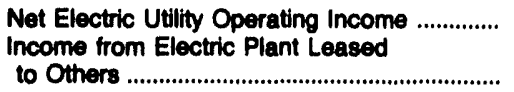 & $\begin{array}{r}1,583 \\
0\end{array}$ & $\begin{array}{r}2,447 \\
0\end{array}$ & $\begin{array}{r}1,628 \\
0\end{array}$ & $\begin{array}{r}2,672 \\
0\end{array}$ & $\begin{array}{r}47,124 \\
0\end{array}$ & $\begin{array}{r}9,858 \\
0\end{array}$ \\
\hline Electric Utility Operating Income ............... & 1,583 & 2,447 & 1,628 & 2,672 & 47,124 & 9,858 \\
\hline 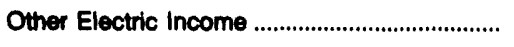 & 206 & 0 & 528 & 1,261 & 17,184 & 4,615 \\
\hline Other Electric Deductions ............................ & 0 & 0 & 0 & 3,753 & 187 & 0 \\
\hline $\begin{array}{l}\text { During Construction ........................... } \\
\text { Taxes on Other Income and Deductions ....... }\end{array}$ & $\begin{array}{l}0 \\
0\end{array}$ & $\begin{array}{l}0 \\
0\end{array}$ & $\begin{array}{l}0 \\
0\end{array}$ & $\begin{array}{l}0 \\
0\end{array}$ & $\begin{array}{l}0 \\
0\end{array}$ & $\begin{array}{l}0 \\
0\end{array}$ \\
\hline 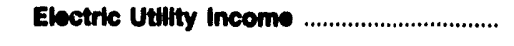 & 1,789 & 2,447 & 2,156 & 180 & 64,121 & 14,473 \\
\hline 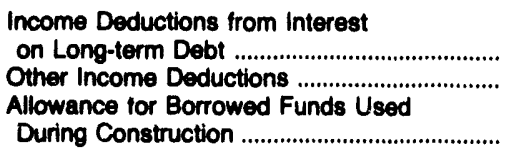 & $\begin{array}{l}0 \\
0\end{array}$ & $\begin{array}{l}0 \\
0\end{array}$ & $\begin{array}{l}0 \\
0\end{array}$ & $\begin{array}{r}36 \\
0\end{array}$ & $\begin{array}{r}70,626 \\
9,224\end{array}$ & $\begin{array}{r}19,713 \\
-111 \\
0\end{array}$ \\
\hline 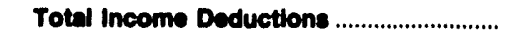 & 0 & $\mathbf{0}$ & $\mathbf{0}$ & 36 & 79,851 & 19,602 \\
\hline Income Before Extraordinary Items ..................... & 1,789 & 2,447 & 2,156 & 144 & $-15,730$ & $-5,130$ \\
\hline 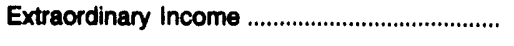 & 0 & 0 & 0 & 0 & 6,082 & 6,909 \\
\hline 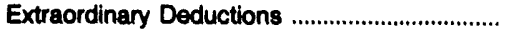 & 2,582 & 0 & 0 & 0 & 0 & 0 \\
\hline Net Income & -793 & 2,447 & 2,156 & 144 & $-9,648$ & 1,780 \\
\hline
\end{tabular}

Note: Totals may not equal sum of components because of independent rounding.

Source: Energy Information Administration, Form ElA-412, "Annual Report of Public Electric Utilities." 
Table 21. Statement of Income by Major U.S. Publlcly Owned Electric Utility Within State, 1992 (Continued) (Thousand Dollars)

\begin{tabular}{|c|c|c|c|c|c|c|}
\hline Item & $\begin{array}{c}\text { Oklahoma } \\
\text { Ponca } \\
\text { City Clty of } \\
\text { June } 30\end{array}$ & $\begin{array}{l}\text { Oklahoma } \\
\text { Stillwater } \\
\text { Utilities } \\
\text { Authority } \\
\text { June } 30\end{array}$ & $\begin{array}{l}\text { Oregon } \\
\text { Ashland } \\
\text { Clty of } \\
\text { June } 30\end{array}$ & $\begin{array}{c}\text { Oregon } \\
\text { Central } \\
\text { Uincoln } \\
\text { Peoples } \\
\text { Utt Dt } \\
\text { December } 31\end{array}$ & $\begin{array}{c}\text { Oregon } \\
\text { Clatskanie } \\
\text { Peoples } \\
\text { Util Dist } \\
\text { December } 31\end{array}$ & $\begin{array}{c}\text { Oregon } \\
\text { Columbia } \\
\text { Alver } \\
\text { Peoples } \\
\text { Ut Dist } \\
\text { December } 31\end{array}$ \\
\hline Eloctric Uttilty Operating Revenuee ............ & 19,630 & 20,743 & 7,000 & 46,601 & 22,784 & 11,133 \\
\hline 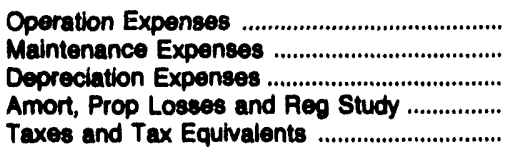 & $\begin{array}{r}13,036 \\
1,164 \\
714 \\
0 \\
0\end{array}$ & $\begin{array}{r}13,105 \\
1,156 \\
802 \\
0 \\
3,553\end{array}$ & $\begin{array}{r}5,417 \\
451 \\
0 \\
97 \\
698\end{array}$ & $\begin{array}{r}36,818 \\
1,513 \\
2,869 \\
0 \\
1,684\end{array}$ & $\begin{array}{r}21,208 \\
391 \\
320 \\
0 \\
133\end{array}$ & $\begin{array}{r}8,617 \\
459 \\
442 \\
228 \\
216\end{array}$ \\
\hline $\begin{array}{l}\text { Total Electric Utility Operating } \\
\text { Expensese }\end{array}$ & 14,915 & 18,716 & 6,604 & 42,094 & 22,053 & 9,981 \\
\hline 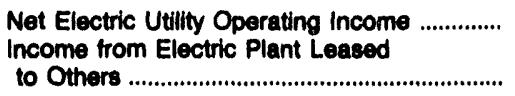 & $\begin{array}{r}4,715 \\
0\end{array}$ & $\begin{array}{r}2,027 \\
0\end{array}$ & $\begin{array}{r}434 \\
0\end{array}$ & $\begin{array}{r}3,677 \\
0\end{array}$ & 731 & $\begin{array}{r}1,171 \\
0\end{array}$ \\
\hline Electric Uillity Operating Income .............. & 4,716 & 2,027 & 434 & 3,677 & 731 & 1,171 \\
\hline Other Electric Income & 167 & 995 & 48 & 502 & 129 & 559 \\
\hline $\begin{array}{l}\text { Other Electric Deductions } \\
\text { Allowance for Other Funds Used }\end{array}$ & 5,346 & $\mathbf{0}$ & 0 & 0 & 0 & 0 \\
\hline 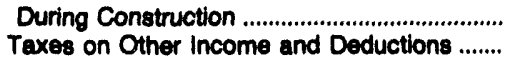 & $\begin{array}{l}0 \\
0\end{array}$ & $\begin{array}{l}0 \\
0\end{array}$ & $\begin{array}{l}0 \\
0\end{array}$ & $\begin{array}{l}0 \\
0\end{array}$ & $\begin{array}{l}0 \\
0\end{array}$ & $\begin{array}{r}0 \\
66\end{array}$ \\
\hline Electric Utility Ineome ................................... & -485 & 3,021 & 482 & 4,179 & 890 & 1,685 \\
\hline 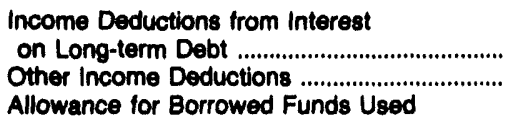 & $\begin{array}{r}386 \\
0\end{array}$ & $\begin{array}{l}2 \\
0\end{array}$ & $\begin{array}{l}0 \\
0\end{array}$ & $\begin{array}{r}1,165 \\
133\end{array}$ & $\begin{array}{l}0 \\
0\end{array}$ & $\begin{array}{r}1,264 \\
189\end{array}$ \\
\hline 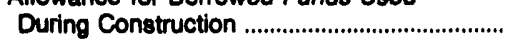 & 0 & 0 & 0 & 0 & 0 & 0 \\
\hline Total Income Deductions .............................. & 396 & 2 & $\mathbf{0}$ & 1,208 & $\mathbf{0}$ & 1,464 \\
\hline Income Before Extraordinary Items .................... & -881 & 3,019 & 482 & 2,881 & 860 & 201 \\
\hline Extraordinary Income & 0 & 0 & 0 & 0 & 0 & 0 \\
\hline 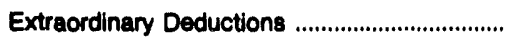 & 0 & 0 & 0 & 4 & 0 & 0 \\
\hline Not Income & -881 & 3,019 & 482 & 2,877 & 890 & 201 \\
\hline
\end{tabular}

Note: Totals may not equal sum of components because of independent rounding.

Source: Energy Information Administration, Form EIA-412, "Annual Report of Public Electric Utilities." 
Table 21. Statement of Income by Major U.S. Publicly Owned Electric Utility Within State, 1992 (Continued)

(Thousand Dollars)

\begin{tabular}{|c|c|c|c|c|c|c|}
\hline Item & $\begin{array}{l}\text { Oregon } \\
\text { Emerald } \\
\text { Peoples } \\
\text { Utility Dist } \\
\text { December } 31\end{array}$ & $\begin{array}{l}\text { Oregon } \\
\text { Eugene } \\
\text { City of } \\
\text { December } 31\end{array}$ & $\begin{array}{c}\text { Oregon } \\
\text { Forest Grove } \\
\text { City of } \\
\text { June } 30\end{array}$ & $\begin{array}{l}\text { Oregon } \\
\begin{array}{c}\text { McMinnville } \\
\text { City of }\end{array} \\
\text { June } 30\end{array}$ & $\begin{array}{c}\text { Oregon } \\
\text { Northern } \\
\text { Wasco County } \\
\text { PU D } \\
\text { December } 31\end{array}$ & $\begin{array}{c}\text { Oregon } \\
\text { Springfield } \\
\text { City of } \\
\text { December } 31\end{array}$ \\
\hline Electric Utility Operating Rovenues ............. & 19,021 & 92,588 & 6,235 & 15,359 & 11,137 & 25,483 \\
\hline 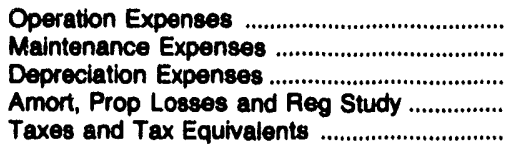 & $\begin{array}{r}10,672 \\
438 \\
1,869 \\
663 \\
519\end{array}$ & $\begin{array}{r}70,564 \\
4,269 \\
7,458 \\
0 \\
6,517\end{array}$ & $\begin{array}{r}5,049 \\
206 \\
360 \\
0 \\
364\end{array}$ & $\begin{array}{r}13,616 \\
0 \\
653 \\
0 \\
793\end{array}$ & $\begin{array}{r}7,330 \\
626 \\
1,022 \\
0 \\
480\end{array}$ & $\begin{array}{r}21,020 \\
1,053 \\
978 \\
182 \\
1,260\end{array}$ \\
\hline $\begin{array}{l}\text { Total Electric Utility Operating } \\
\text { Expensece }\end{array}$ & 14,161 & 88,808 & 5,979 & 15,062 & 9,458 & 24,493 \\
\hline 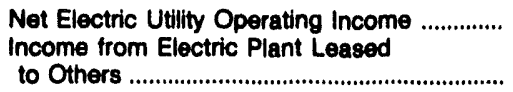 & $\begin{array}{r}4,860 \\
56\end{array}$ & $\begin{array}{r}3,760 \\
371\end{array}$ & $\begin{array}{r}256 \\
0\end{array}$ & 297 & $\begin{array}{r}1,680 \\
0\end{array}$ & $\begin{array}{r}989 \\
0\end{array}$ \\
\hline Electric Utility Oporating Income .............. & 4,017 & 4,132 & 256 & 287 & 1,680 & 988 \\
\hline 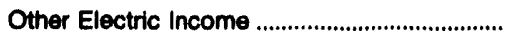 & 1,297 & 1,384 & 34 & 403 & 241 & 191 \\
\hline $\begin{array}{l}\text { Other Electric Deductions ................................ } \\
\text { Allowance for Other Funds Used } \\
\text { During Construction ................................... } \\
\text { Taxes on Other Income and Deductions ....... }\end{array}$ & $\begin{array}{l}25 \\
0 \\
0\end{array}$ & $\begin{array}{r}498 \\
167 \\
0\end{array}$ & $\begin{array}{l}0 \\
0\end{array}$ & $\begin{array}{l}0 \\
0\end{array}$ & $\begin{array}{l}0 \\
0 \\
0\end{array}$ & $\begin{array}{r}0 \\
21 \\
0\end{array}$ \\
\hline Electric Utility income .................................... & 6,189 & 5,185 & 200 & 700 & 1,920 & 1,201 \\
\hline 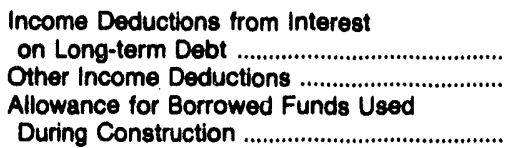 & $\begin{array}{r}4,358 \\
549\end{array}$ & $\begin{array}{r}2,021 \\
333 \\
-56\end{array}$ & $\begin{array}{r}0 \\
54 \\
0\end{array}$ & $\begin{array}{r}0 \\
59\end{array}$ & $\begin{array}{r}1,811 \\
0 \\
0\end{array}$ & $\begin{array}{l}74 \\
10 \\
0\end{array}$ \\
\hline Total Income Deductions .............................. & 4,907 & 2,290 & 54 & 59 & 1,811 & 84 \\
\hline Income Before Extraordinary Items ................... & 1,281 & 2,887 & 236 & 641 & 109 & 1,116 \\
\hline Extraordinary Income & 0 & 0 & 0 & 0 & 0 & 0 \\
\hline 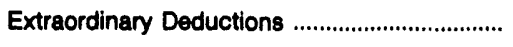 & 0 & 0 & 0 & 0 & 0 & 0 \\
\hline 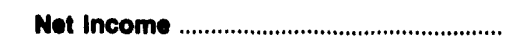 & 1,281 & 2,887 & 236 & 641 & 109 & 1,116 \\
\hline
\end{tabular}

Note: Totals may not equal sum of components because of independent rounding.

Source: Energy Information Administration, Form ElA-412, "Annual Report of Public Electric Utilities." 
Table 21. Statement of Income by Major U.S. Publicly Owned Electric Utility Within State, 1992 (Continued) (Thousand Dollars)

\begin{tabular}{|c|c|c|c|c|c|c|}
\hline Item & $\begin{array}{l}\text { Oregon } \\
\text { Tillamook } \\
\text { Peoples } \\
\text { Utility Dist } \\
\text { December } 31\end{array}$ & $\begin{array}{c}\text { Penneylvania } \\
\text { Chambersburg } \\
\text { Borough of } \\
\text { December } 31\end{array}$ & $\begin{array}{l}\text { South Carolina } \\
\text { Camden } \\
\text { City of } \\
\text { June } 30\end{array}$ & $\begin{array}{l}\text { South Carolina } \\
\text { Easiey } \\
\text { Combined } \\
\text { Utility } \\
\text { System } \\
\text { March } 31\end{array}$ & $\begin{array}{l}\text { South Carolina } \\
\text { Gaffney } \\
\text { City of } \\
\text { March } 31\end{array}$ & $\begin{array}{l}\text { South Carolina } \\
\text { Greenwood } \\
\text { Commissioners } \\
\text { Pub Wk } \\
\text { December } 31\end{array}$ \\
\hline Electric Utilty Operating Rovenues ............ & 14,287 & 10,628 & 11,545 & 12,667 & 11,607 & 12,876 \\
\hline 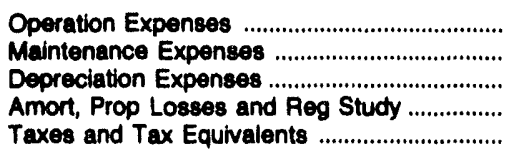 & $\begin{array}{r}11,258 \\
1,037 \\
864 \\
41 \\
543\end{array}$ & $\begin{array}{r}9,257 \\
182 \\
776 \\
0 \\
0\end{array}$ & $\begin{array}{r}9,590 \\
0 \\
336 \\
0 \\
0\end{array}$ & $\begin{array}{r}10,528 \\
568 \\
409 \\
0 \\
0\end{array}$ & $\begin{array}{r}10,430 \\
47 \\
416 \\
0 \\
0\end{array}$ & $\begin{array}{r}11,529 \\
0 \\
354 \\
0 \\
0\end{array}$ \\
\hline Total Ekectric Utilly Oporating & 13,844 & 10,216 & 9,928 & 11,505 & 10,893 & 11,884 \\
\hline $\begin{array}{l}\text { Net Electric Utility Operating Income .............. } \\
\text { Income from Electric Plant Leased }\end{array}$ & 444 & 411 & 1,619 & 1,152 & 804 & 993 \\
\hline 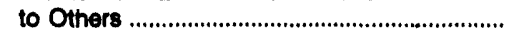 & 0 & 0 & 0 & 0 & 0 & 0 \\
\hline Electrk Utility Operating income ............. & 444 & 411 & 1,610 & 1,152 & 804 & 903 \\
\hline 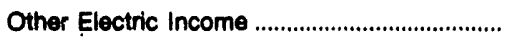 & 455 & 213 & 1,257 & 313 & 198 & 95 \\
\hline $\begin{array}{l}\text { Other Electric Deductions ................................ } \\
\text { Allowance for Other Funds Used }\end{array}$ & 0 & 551 & 0 & 142 & 0 & 0 \\
\hline $\begin{array}{l}\text { During Construction .................................... } \\
\text { Taxes on Other Income and Deductions ....... }\end{array}$ & $\begin{array}{l}0 \\
0\end{array}$ & $\begin{array}{l}0 \\
0\end{array}$ & $\begin{array}{l}0 \\
0\end{array}$ & $\begin{array}{l}0 \\
0\end{array}$ & $\begin{array}{l}0 \\
0\end{array}$ & $\begin{array}{l}0 \\
0\end{array}$ \\
\hline Electric Utilty Income ................................ & 898 & 74 & 2,878 & 1,323 & 1,003 & 1,088 \\
\hline $\begin{array}{l}\text { Income Deductions from Interest } \\
\text { on Long-term Debt .......................................... } \\
\text { Other Income Deductions .................................. } \\
\text { Allowance for Borrowed Funds Used }\end{array}$ & $\begin{array}{r}536 \\
14\end{array}$ & $\begin{array}{l}0 \\
0\end{array}$ & $\begin{array}{r}135 \\
0\end{array}$ & $\begin{array}{r}178 \\
1,091\end{array}$ & $\begin{array}{l}0 \\
0\end{array}$ & $\begin{array}{l}0 \\
0\end{array}$ \\
\hline 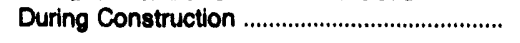 & -10 & 0 & 0 & 0 & 0 & 0 \\
\hline Total Income Deductions ............................. & 540 & $\mathbf{0}$ & 135 & 1,280 & 0 & $\mathbf{0}$ \\
\hline Income Before Extraordinary Items ................. & 358 & 74 & 2,741 & 54 & 1,003 & 1,088 \\
\hline 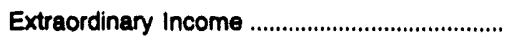 & 0 & 0 & 342 & 0 & 0 & 0 \\
\hline Extraordinary Deductions .................................... & 0 & 0 & 2,307 & 0 & 0 & 0 \\
\hline Not Income & 358 & 74 & 776 & 54 & 1,003 & 1,088 \\
\hline
\end{tabular}

Note: Totals may not equal sum of components because of independent rounding.

Source: Energy Information Administration, Form ElA-412, "Annual Report of Public Electric Utilities." 


\section{Table 21. Statement of Income by Major U.S. Publicly Owned Electric UtIlity Within State, 1992 (Continued) (Thousand Dollars)}

\begin{tabular}{|c|c|c|c|c|c|c|}
\hline Item & $\begin{array}{c}\text { South Carolina } \\
\text { Greer } \\
\text { Comm } \\
\text { of } \\
\text { Public Works } \\
\text { December } 31\end{array}$ & $\begin{array}{l}\text { South Carolina } \\
\text { Newberry } \\
\text { Clty of } \\
\text { June } 30\end{array}$ & $\begin{array}{c}\text { South Carolina } \\
\text { Orangeburg } \\
\text { City of } \\
\text { September } 30\end{array}$ & $\begin{array}{l}\text { South Carolina } \\
\text { Pledmont } \\
\text { Municipal } \\
\text { Power Agny } \\
\text { December } 31\end{array}$ & $\begin{array}{l}\text { South Carolina } \\
\text { Rock Hill } \\
\text { City of } \\
\text { December } 31\end{array}$ & $\begin{array}{c}\text { South Carolina } \\
\text { South } \\
\text { Carolina } \\
\text { Pub } \\
\text { Serv Auth } \\
\text { December } 31\end{array}$ \\
\hline Eleotric Uthly Operating Rovenues ............ & 0,680 & 8,812 & 33,896 & 154,280 & 37,011 & 546,878 \\
\hline 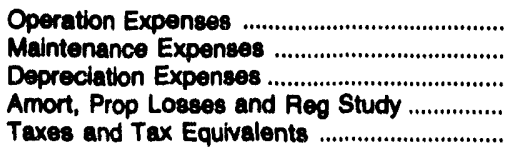 & $\begin{array}{r}8,137 \\
0 \\
530 \\
0 \\
0\end{array}$ & $\begin{array}{r}7,740 \\
0 \\
210 \\
0 \\
0\end{array}$ & $\begin{array}{r}25,286 \\
0 \\
1,182 \\
0 \\
0\end{array}$ & $\begin{array}{r}83,565 \\
18,114 \\
20,403 \\
0 \\
4,114\end{array}$ & $\begin{array}{r}24,511 \\
1,888 \\
908 \\
0 \\
0\end{array}$ & $\begin{array}{r}281,966 \\
50,052 \\
75,025 \\
0 \\
3,643\end{array}$ \\
\hline $\begin{array}{l}\text { Total Elsctric Utulty Operating } \\
\text { Expenses }\end{array}$ & 8,648 & 7,040 & 26,460 & 126,186 & 27,305 & 410,686 \\
\hline 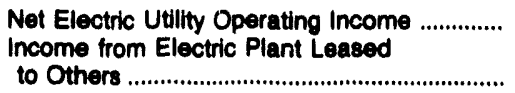 & $\begin{array}{r}898 \\
0\end{array}$ & 863 & $\begin{array}{r}7,427 \\
0\end{array}$ & $\begin{array}{r}28,074 \\
0\end{array}$ & $\begin{array}{r}10,606 \\
0\end{array}$ & $\begin{array}{r}136,192 \\
0\end{array}$ \\
\hline Electric Uttlty Operating Income ............. & 80 & 893 & 7,427 & 28,074 & 10,606 & 136,102 \\
\hline 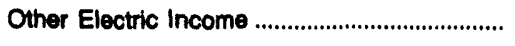 & 1,327 & 287 & 394 & 42,639 & 233 & 22,622 \\
\hline Other Electric Deductions .................................... & 0 & 77 & 0 & 0 & 8,613 & 0 \\
\hline $\begin{array}{l}\text { During Construction ..................................... } \\
\text { Taxes on Other Income and Deductions ........ }\end{array}$ & $\begin{array}{l}0 \\
0\end{array}$ & $\begin{array}{l}0 \\
0\end{array}$ & $\begin{array}{l}0 \\
0\end{array}$ & $\begin{array}{l}0 \\
0\end{array}$ & $\begin{array}{l}0 \\
0\end{array}$ & $\begin{array}{l}0 \\
0\end{array}$ \\
\hline 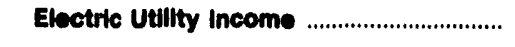 & 2,225 & 1,073 & 7,821 & 70,716 & 2,225 & 158,814 \\
\hline 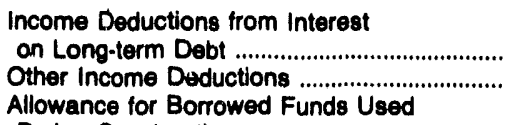 & $\begin{array}{r}33 \\
1,025\end{array}$ & $\begin{array}{r}152 \\
0\end{array}$ & $\begin{array}{r}302 \\
0\end{array}$ & $\begin{array}{r}82,141 \\
-10,697\end{array}$ & $\begin{array}{r}264 \\
0\end{array}$ & $\begin{array}{r}129,894 \\
-797\end{array}$ \\
\hline 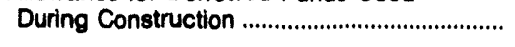 & 0 & 0 & 0 & 0 & 0 & 0 \\
\hline Total Income Deductions ............................. & 1,068 & 152 & 302 & 71,444 & 284 & 129,097 \\
\hline Income Before Extraordinary Items ................. & 1,167 & 921 & 7,520 & -731 & 1,961 & 29,717 \\
\hline 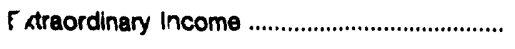 & 0 & 0 & 0 & 0 & 0 & 0 \\
\hline 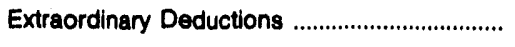 & 0 & 0 & 0 & 0 & 0 & 0 \\
\hline Not Income & 1,167 & 021 & 7,520 & -731 & 1,861 & 29,717 \\
\hline
\end{tabular}

Note: Totals may not equal sum of components because of independent rounding.

Source: Energy Information Administration, Form ElA-412, "Annual Report of Public Electric Utilities." 
Table 21. Statement of Income by Major U.S. Publicly Owned Electric Utillty Within State, 1992 (Continued)

(Thousand Dollars)

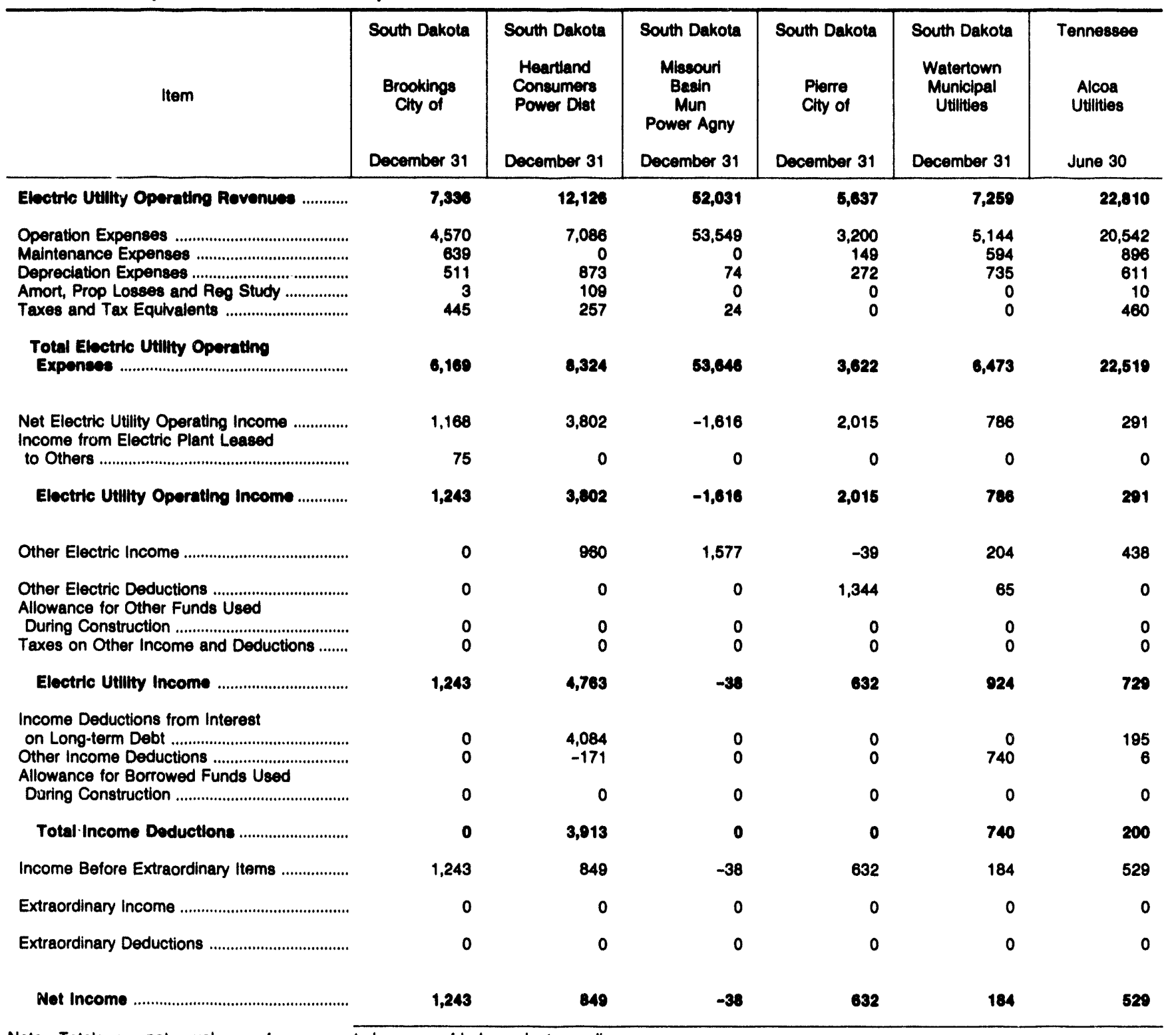

Note: Totals may not equal sum of components because of independent rounding.

Source: Energy Information Administration, Form EIA-412, "Annual Report of Public Electric Utilities." 
Table 21. Statement of Income by Major U.S. Publicly Owned Electric UtIllty Within State, 1992 (Continued) (Thousand Dollars)

\begin{tabular}{|c|c|c|c|c|c|c|}
\hline Item & $\begin{array}{l}\text { Tennesseo } \\
\text { Athens } \\
\text { City of } \\
\text { June } 30\end{array}$ & $\begin{array}{l}\text { Tennessee } \\
\text { Benton } \\
\text { County } \\
\text { June } 30\end{array}$ & $\begin{array}{l}\text { Tennessee } \\
\text { Bolivar } \\
\text { City of } \\
\text { June } 30\end{array}$ & $\begin{array}{l}\text { Tennessee } \\
\text { Bristol } \\
\text { City of } \\
\text { June } 30\end{array}$ & $\begin{array}{c}\text { Tennessee } \\
\begin{array}{c}\text { Brownsville } \\
\text { City of }\end{array} \\
\text { June } 30\end{array}$ & $\begin{array}{l}\text { Tennessee } \\
\text { Carroll } \\
\text { County } \\
\text { June } 30\end{array}$ \\
\hline Electric Uttilty Operating Rovenues ............. & 25,670 & 3,340 & 12,761 & 40,466 & 9,542 & 19,467 \\
\hline 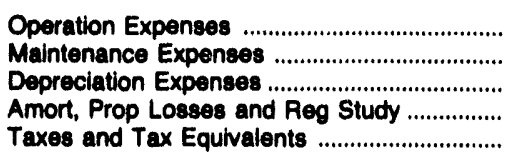 & $\begin{array}{r}23,687 \\
510 \\
528 \\
2 \\
425\end{array}$ & $\begin{array}{r}2,916 \\
117 \\
83 \\
0 \\
110\end{array}$ & $\begin{array}{r}11,599 \\
357 \\
412 \\
0 \\
243\end{array}$ & $\begin{array}{r}35,893 \\
1,481 \\
1,224 \\
0 \\
932\end{array}$ & $\begin{array}{r}9,211 \\
99 \\
185 \\
37 \\
153\end{array}$ & $\begin{array}{r}17,824 \\
561 \\
467 \\
0 \\
352\end{array}$ \\
\hline $\begin{array}{l}\text { Total Electric Utillty Operating } \\
\text { Expeneses }\end{array}$ & 25,153 & 3,226 & 12,612 & 39,530 & 9,685 & 19,204 \\
\hline $\begin{array}{l}\text { Net Electric Utllity Operating Income ............... } \\
\text { Income from Electric Plant Leased } \\
\text { to Others }\end{array}$ & $\begin{array}{r}517 \\
0\end{array}$ & $\begin{array}{r}115 \\
0\end{array}$ & $\begin{array}{r}150 \\
0\end{array}$ & $\begin{array}{r}936 \\
0\end{array}$ & $\begin{array}{r}-143 \\
0\end{array}$ & $\begin{array}{r}263 \\
0\end{array}$ \\
\hline Electric Utility Operating Income .............. & 517 & 115 & 150 & 936 & -143 & 263 \\
\hline Other Electric Income & 182 & 69 & 49 & 1,692 & 151 & 276 \\
\hline $\begin{array}{l}\text { Other Electric Deductions } \\
\text { Allowance for Other Funds Used }\end{array}$ & 3 & 3 & 0 & 0 & 0 & 0 \\
\hline 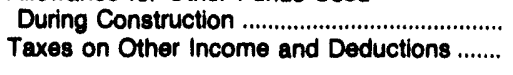 & $\begin{array}{l}0 \\
0\end{array}$ & $\begin{array}{l}0 \\
0\end{array}$ & $\begin{array}{l}0 \\
0\end{array}$ & $\begin{array}{l}0 \\
0\end{array}$ & $\begin{array}{l}0 \\
0\end{array}$ & $\begin{array}{l}0 \\
0\end{array}$ \\
\hline Electrle Utility Income & 696 & 181 & 100 & 2,628 & 8 & 539 \\
\hline 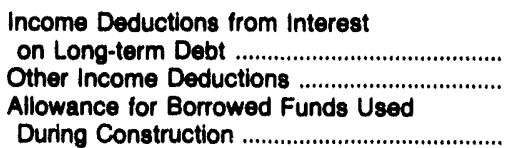 & $\begin{array}{l}0 \\
0\end{array}$ & $\begin{array}{l}0 \\
3\end{array}$ & $\begin{array}{r}56 \\
2\end{array}$ & $\begin{array}{r}0 \\
28\end{array}$ & $\begin{aligned} 19 \\
1\end{aligned}$ & $\begin{array}{r}81 \\
3 \\
0\end{array}$ \\
\hline Total Income Deductione .............................. & 0 & 3 & 58 & 28 & 50 & 84 \\
\hline Income Before Extraordinary Items .................. & 696 & 177 & 140 & 2,600 & -42 & 455 \\
\hline Extraordinary Income & 0 & 0 & 0 & 0 & 0 & 0 \\
\hline 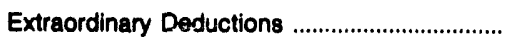 & 0 & 0 & 0 & 0 & 0 & 0 \\
\hline Not Income & 698 & 177 & 140 & 2,600 & -42 & 455 \\
\hline
\end{tabular}

Note: Totals may not equal sum of components because of independent rounding.

Source: Energy Information Administration, Form ElA-412, "Annual Report of Public Electric Utilities." 
Table 21. Statement of Income by Major U.S. Publicly Owned Electric Utility Within State, 1992 (Continued) (Thousand Dollars)

\begin{tabular}{|c|c|c|c|c|c|c|}
\hline Item & $\begin{array}{c}\text { Tennessee } \\
\text { Chattanooga } \\
\text { Clty of } \\
\text { June } 30\end{array}$ & $\begin{array}{l}\text { Tennessee } \\
\text { Clarksville } \\
\text { City of } \\
\text { June } 30\end{array}$ & $\begin{array}{l}\text { Tennessee } \\
\text { Cleveland } \\
\text { Clty of } \\
\text { June } 30\end{array}$ & $\begin{array}{l}\text { Tennessee } \\
\text { Clinton } \\
\text { City of } \\
\text { June } 30\end{array}$ & $\begin{array}{l}\text { Tennessee } \\
\text { Columbia } \\
\text { City of } \\
\text { June } 30\end{array}$ & $\begin{array}{l}\text { Tennessee } \\
\text { Cookeville } \\
\text { City of } \\
\text { June } 30\end{array}$ \\
\hline Electrle Utility Operating Rovenuee ............. & 276,247 & 42,014 & 44,131 & 32,256 & 25,867 & 23,423 \\
\hline 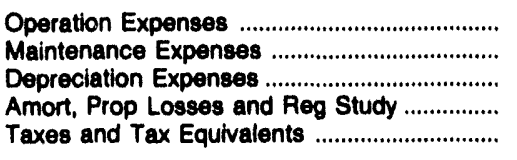 & $\begin{array}{r}251,279 \\
8,160 \\
7,193 \\
0 \\
6,759\end{array}$ & $\begin{array}{r}38,639 \\
984 \\
895 \\
1,583 \\
806\end{array}$ & $\begin{array}{r}40,117 \\
1,171 \\
1,225 \\
136 \\
905\end{array}$ & $\begin{array}{r}29,023 \\
1,012 \\
955 \\
0 \\
753\end{array}$ & $\begin{array}{r}23.930 \\
792 \\
824 \\
0 \\
454\end{array}$ & $\begin{array}{r}21,848 \\
438 \\
474 \\
155 \\
301\end{array}$ \\
\hline $\begin{array}{l}\text { Total Eloctrlc Uttlity Operating } \\
\text { Expenees }\end{array}$ & 273,391 & 42,000 & 43,554 & 31,743 & 28,000 & 23,214 \\
\hline $\begin{array}{l}\text { Net Electric Utility Operating Income ............. } \\
\text { Income from Electric Plant Leased }\end{array}$ & $\begin{array}{r}1,856 \\
0\end{array}$ & -84 & 577 & 513 & -133 & $\begin{array}{r}209 \\
81\end{array}$ \\
\hline Electric Utility Operating Income ............. & 1,858 & -24 & 577 & 513 & -133 & 290 \\
\hline Other Electric Income & 3,052 & 1,488 & 452 & 525 & 436 & 0 \\
\hline Other Electric Deductions .............................. & 0 & 6 & 20 & 0 & 0 & 0 \\
\hline 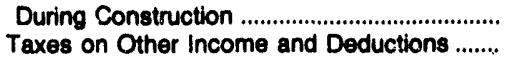 & $\begin{array}{l}0 \\
0\end{array}$ & $\begin{array}{l}0 \\
0\end{array}$ & $\begin{array}{l}0 \\
0\end{array}$ & $\begin{array}{l}0 \\
0\end{array}$ & $\begin{array}{l}0 \\
0\end{array}$ & $\begin{array}{l}0 \\
0\end{array}$ \\
\hline Electric Utility Income ...................................... & 4,007 & 1,388 & 1,000 & 1,038 & 303 & 290 \\
\hline 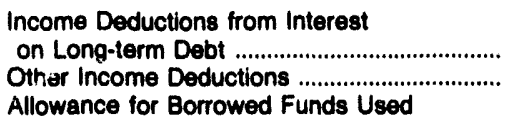 & $\begin{array}{r}31 \\
230\end{array}$ & $\begin{array}{r}495 \\
72\end{array}$ & $\begin{array}{r}0 \\
39\end{array}$ & $\begin{array}{l}0 \\
0\end{array}$ & $\begin{array}{l}0 \\
7\end{array}$ & $\begin{array}{r}95 \\
0\end{array}$ \\
\hline 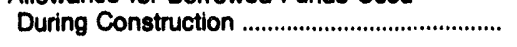 & v & 0 & 0 & 0 & 0 & 0 \\
\hline Total Income Deductions ................................ & 260 & 507 & 39 & $\mathbf{0}$ & 7 & 95 \\
\hline Income Before Extraordinary Items ...................... & 4,647 & 821 & 970 & 1,038 & 297 & 195 \\
\hline 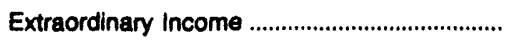 & 0 & 0 & 0 & 0 & 0 & 0 \\
\hline 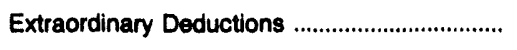 & 0 & 0 & 0 & 0 & 0 & 0 \\
\hline Net Income & 4,647 & 821 & 970 & 1,038 & 297 & 195 \\
\hline
\end{tabular}

Note: Totals may not equal sum of components because of independent rounding.

Source: Energy Information Administration, Form EIA-412, "Annual Report of Public Electric Utilities." 
Table 21. Statement of Income by Major U.S. Publicly Owned Electric Utility Within State, 1992 (Continued)

(Thousand Dollars)

\begin{tabular}{|c|c|c|c|c|c|c|}
\hline Item & $\begin{array}{l}\text { Tennesseo } \\
\text { Covington } \\
\text { Electric } \\
\text { System } \\
\text { June } 30\end{array}$ & $\begin{array}{l}\text { Tennessee } \\
\text { Dayton } \\
\text { Clty of } \\
\text { June } 30\end{array}$ & $\begin{array}{l}\text { Tennessee } \\
\text { Dickson } \\
\text { City of } \\
\text { June } 30\end{array}$ & $\begin{array}{l}\text { Tennessee } \\
\text { Dyersburg } \\
\text { Electric } \\
\text { System } \\
\text { June } 30\end{array}$ & $\begin{array}{l}\text { Tennessee } \\
\text { Elizabethton } \\
\text { City of } \\
\text { June } 30\end{array}$ & $\begin{array}{l}\text { Tennessee } \\
\text { Enwin } \\
\text { Town of } \\
\text { June } 30\end{array}$ \\
\hline Eleotric Utilty Operating Rovenues ............. & 10,605 & 10,161 & 29,776 & 27,100 & 28,426 & 10,389 \\
\hline 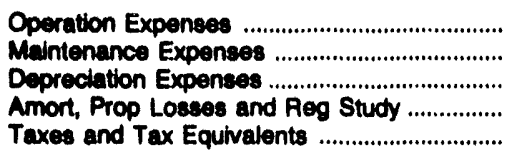 & $\begin{array}{r}9,307 \\
195 \\
194 \\
188 \\
180\end{array}$ & $\begin{array}{r}9,118 \\
211 \\
194 \\
0 \\
186\end{array}$ & $\begin{array}{r}26,154 \\
758 \\
818 \\
0 \\
463\end{array}$ & $\begin{array}{r}24,653 \\
769 \\
770 \\
-37 \\
570\end{array}$ & $\begin{array}{r}24,341 \\
776 \\
619 \\
0 \\
660\end{array}$ & $\begin{array}{r}9,979 \\
208 \\
229 \\
0 \\
192\end{array}$ \\
\hline $\begin{array}{l}\text { Totel Electrlc Utilty Operating } \\
\text { Expenece }\end{array}$ & 10,084 & 9,710 & 28,192 & 28,724 & 28,386 & 10,607 \\
\hline 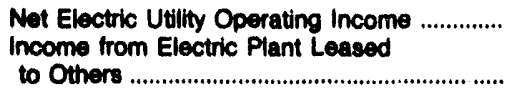 & $\begin{array}{r}501 \\
0\end{array}$ & $\begin{array}{r}441 \\
0\end{array}$ & $\begin{array}{r}1,583 \\
0\end{array}$ & $\begin{array}{r}376 \\
0\end{array}$ & $\begin{array}{r}28 \\
0\end{array}$ & $\begin{array}{r}-218 \\
0\end{array}$ \\
\hline Eloctrle Uttlity Operating Incoms .............. & 501 & 441 & 1,583 & 376 & 28 & -218 \\
\hline Other Electric Income & 269 & 97 & 790 & 571 & 299 & 212 \\
\hline $\begin{array}{l}\text { Other Electric Deductions .............................. } \\
\text { Allowance for Other Funds Used } \\
\text { During Construction .................................. } \\
\text { Taxes on Other Income and Deductions }\end{array}$ & $\begin{array}{l}0 \\
0\end{array}$ & $\begin{array}{l}0 \\
0 \\
0\end{array}$ & $\begin{array}{l}0 \\
0\end{array}$ & $\begin{array}{l}6 \\
0 \\
0\end{array}$ & $\begin{array}{l}0 \\
0 \\
0\end{array}$ & $\begin{array}{l}0 \\
0 \\
0\end{array}$ \\
\hline 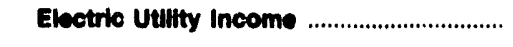 & 767 & 538 & 2,374 & 941 & 327 & -6 \\
\hline 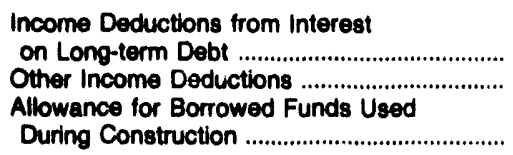 & $\begin{array}{r}45 \\
2\end{array}$ & $\begin{array}{l}0 \\
0\end{array}$ & $\begin{array}{r}770 \\
6\end{array}$ & $\begin{array}{r}538 \\
23\end{array}$ & $\begin{array}{r}0 \\
42\end{array}$ & $\begin{array}{l}0 \\
7\end{array}$ \\
\hline Total Income Deductions ............................. & 47 & 0 & 776 & 561 & 42 & 7 \\
\hline Income Before Extraordinary Items ...................... & 720 & 538 & 1,598 & 380 & 285 & -13 \\
\hline Extraordinary Income & 0 & 0 & 0 & 0 & 0 & 284 \\
\hline 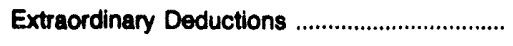 & 0 & 13 & 0 & 0 & 0 & 0 \\
\hline Not Income & 720 & 525 & 1,598 & 380 & 285 & 271 \\
\hline
\end{tabular}

Note: Totals may not equal sum of components because of independent rounding.

Source: Energy Information Administration, Form ElA-412, "Annual Report of Public Electric Utilities." 
Table 21. Statement of Income by Major U.S. Publicly Owned electric Utility Within State, 1992 (Continued) (Thousand Dollars)

\begin{tabular}{|c|c|c|c|c|c|c|}
\hline Item & $\begin{array}{l}\text { Tennessee } \\
\text { Etowah } \\
\text { City of } \\
\text { June } 30\end{array}$ & $\begin{array}{c}\text { Tennessee } \\
\text { Fayetteville } \\
\text { Clty of } \\
\text { June } 30\end{array}$ & $\begin{array}{l}\text { Tennessee } \\
\text { Gallatin } \\
\text { City of } \\
\text { June } 30\end{array}$ & $\begin{array}{c}\text { Tennessee } \\
\text { Greeneville } \\
\text { City of } \\
\text { June } 30\end{array}$ & $\begin{array}{c}\text { Tennessee } \\
\text { Harriman } \\
\text { City of } \\
\text { June } 30\end{array}$ & $\begin{array}{l}\text { Tennessee } \\
\text { Humboldt } \\
\text { City of } \\
\text { June } 30\end{array}$ \\
\hline Electric Utilly Operating Rovenues ............. & 7,226 & 19,791 & 20,639 & 44,274 & 12,743 & 9,859 \\
\hline 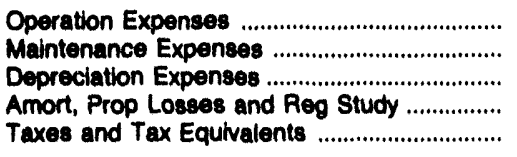 & $\begin{array}{r}6,585 \\
249 \\
156 \\
0 \\
124\end{array}$ & $\begin{array}{r}17,347 \\
492 \\
701 \\
0 \\
518\end{array}$ & $\begin{array}{r}19,536 \\
339 \\
367 \\
41 \\
221\end{array}$ & $\begin{array}{r}40,674 \\
1,246 \\
1,196 \\
0 \\
823\end{array}$ & $\begin{array}{r}11,351 \\
633 \\
566 \\
0 \\
346\end{array}$ & $\begin{array}{r}9,755 \\
186 \\
180 \\
16 \\
127\end{array}$ \\
\hline $\begin{array}{l}\text { Total Electric Utility Operating } \\
\text { Expenses }\end{array}$ & 7,114 & 18,059 & 20,603 & 43,939 & 12,895 & 10,284 \\
\hline 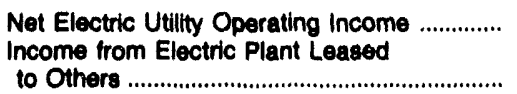 & $\begin{array}{r}111 \\
0\end{array}$ & $\begin{array}{r}733 \\
0\end{array}$ & $\begin{array}{r}135 \\
0\end{array}$ & $\begin{array}{r}334 \\
0\end{array}$ & $\begin{array}{r}-152 \\
0\end{array}$ & $\begin{array}{r}-425 \\
0\end{array}$ \\
\hline Electrlc Utility Operating Income ............. & 111 & 733 & 136 & 334 & -152 & -425 \\
\hline 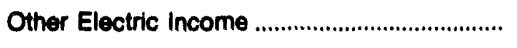 & 105 & 487 & 243 & 1.050 & 289 & 324 \\
\hline $\begin{array}{l}\text { Other Electric Deductions ................................. } \\
\text { Allowance for Other Funds Used }\end{array}$ & 3 & 2 & 0 & 89 & 4 & 8 \\
\hline $\begin{array}{l}\text { During Construction ......................................... } \\
\text { Taxes on Other Income and Deductions ........ }\end{array}$ & $\begin{array}{l}0 \\
0\end{array}$ & $\begin{array}{l}0 \\
0\end{array}$ & $\begin{array}{r}0 \\
53\end{array}$ & $\begin{array}{l}0 \\
0\end{array}$ & $\begin{array}{l}0 \\
0\end{array}$ & $\begin{array}{l}0 \\
0\end{array}$ \\
\hline Electric Utility income & 212 & 1,218 & 326 & 1,296 & 133 & -110 \\
\hline 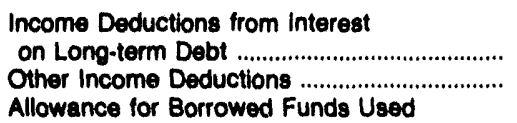 & $\begin{array}{r}10 \\
0\end{array}$ & $\begin{array}{r}400 \\
12\end{array}$ & $\begin{array}{r}3 \\
17\end{array}$ & $\begin{array}{l}0 \\
0\end{array}$ & $\begin{array}{r}44 \\
2\end{array}$ & $\begin{array}{l}0 \\
0\end{array}$ \\
\hline During Construction & 0 & 0 & 0 & 0 & 0 & 0 \\
\hline Total Income Deductions ............................... & 11 & 412 & 20 & o & 46 & $\mathbf{0}$ \\
\hline 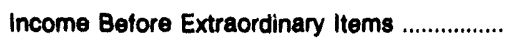 & 201 & 805 & 305 & 1,296 & 86 & -110 \\
\hline 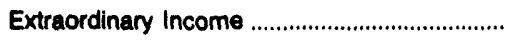 & 0 & 76 & 0 & 0 & 429 & 0 \\
\hline 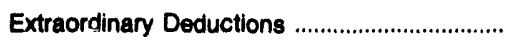 & 0 & 0 & 0 & 325 & 0 & 0 \\
\hline Not Income & 201 & 882 & 305 & 971 & 515 & -110 \\
\hline
\end{tabular}

Note: Totals may not equal sum of components because of independent rounding.

Source: Energy information Administration, Form EiA-412, "Annual Report of Public Electric Utilities." 
Table 21. Statement of Income by Major U.S. Publicly Owned Electric Utility Within State, 1992 (Continued) (Thousand Dollars)

\begin{tabular}{|c|c|c|c|c|c|c|}
\hline Item & $\begin{array}{c}\text { Tennessee } \\
\text { Jackson } \\
\text { City of } \\
\text { June } 30\end{array}$ & $\begin{array}{l}\text { Tennessee } \\
\text { Johnson } \\
\text { City City of } \\
\text { June } 30\end{array}$ & $\begin{array}{c}\text { Tennessee } \\
\text { Knoxville } \\
\text { Utilities } \\
\text { Board } \\
3 \\
\text { June } 30\end{array}$ & $\begin{array}{c}\text { Tennessee } \\
\text { Lawrenceburg } \\
\text { City of } \\
\text { June } 30\end{array}$ & $\begin{array}{c}\text { Tennessee } \\
\text { LaFollette } \\
\text { City of }\end{array}$ & $\begin{array}{c}\text { Tennessee } \\
\text { Lebanon } \\
\text { City of } \\
\text { June } 30\end{array}$ \\
\hline Electric Utilty Operating Revenues .......... . & 56,482 & 75,537 & 252,154 & 22,652 & 18,219 & 16,416 \\
\hline 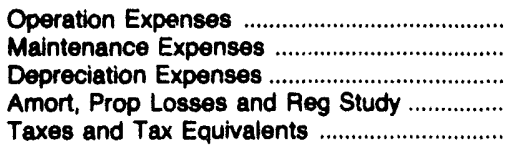 & $\begin{array}{r}51,855 \\
1,079 \\
1,868 \\
65 \\
1,145\end{array}$ & $\begin{array}{r}70,951 \\
2,103 \\
1,302 \\
0 \\
1,098\end{array}$ & $\begin{array}{r}229,156 \\
7,407 \\
8,118 \\
0 \\
6,114\end{array}$ & $\begin{array}{r}21,201 \\
482 \\
677 \\
0 \\
480\end{array}$ & $\begin{array}{r}16,306 \\
734 \\
647 \\
0 \\
348\end{array}$ & $\begin{array}{r}15,552 \\
557 \\
326 \\
1 \\
273\end{array}$ \\
\hline $\begin{array}{l}\text { Total Electric Utility Operating } \\
\text { Expenses }\end{array}$ & 56,013 & 75,454 & 250,795 & 22,840 & 18,035 & 16,708 \\
\hline $\begin{array}{l}\text { Net Electric Utility Operating Income ............. } \\
\text { Income from Electric Plant Leased }\end{array}$ & 468 & 83 & 1,359 & -188 & 184 & -292 \\
\hline Electric Utilty Operating Income ............. & 468 & 83 & 1,359 & -188 & 184 & -292 \\
\hline 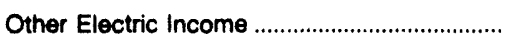 & 719 & 917 & 4,593 & 268 & 507 & 156 \\
\hline $\begin{array}{l}\text { Other Electric Deductions ................................ } \\
\text { Allowance for Other Funds Used }\end{array}$ & 1 & 0 & 0 & 7 & 0 & 38 \\
\hline 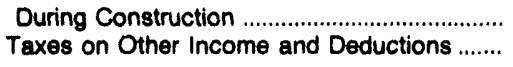 & $\begin{array}{l}0 \\
0\end{array}$ & $\begin{array}{l}0 \\
0\end{array}$ & $\begin{array}{l}0 \\
0\end{array}$ & $\begin{array}{l}0 \\
0\end{array}$ & $\begin{array}{l}0 \\
0\end{array}$ & $\begin{array}{l}0 \\
0\end{array}$ \\
\hline Electric Utility Income .................................. & 1,187 & 1,000 & 5,952 & 72 & 691 & -174 \\
\hline 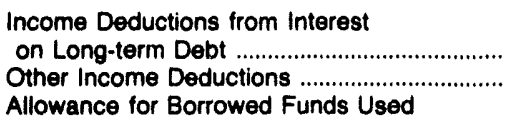 & $\begin{array}{r}554 \\
22\end{array}$ & $\begin{array}{r}0 \\
25\end{array}$ & $\begin{array}{r}2,621 \\
319\end{array}$ & $\begin{array}{r}39 \\
1\end{array}$ & $\begin{array}{r}128 \\
44\end{array}$ & $\begin{array}{l}0 \\
0\end{array}$ \\
\hline 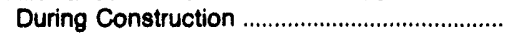 & 0 & 0 & 0 & 0 & 0 & 0 \\
\hline Total Income Deductions ............................... & 576 & 25 & 2,940 & 40 & 172 & $\mathbf{0}$ \\
\hline Income Before Extraordinary Items ................. & 610 & 975 & 3,012 & 33 & 519 & -174 \\
\hline 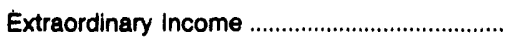 & 0 & 0 & 0 & 82 & 0 & 0 \\
\hline 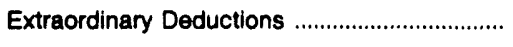 & 0 & 0 & 0 & 0 & 451 & 0 \\
\hline 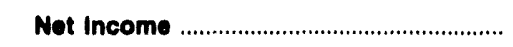 & 610 & 975 & 3,012 & 114 & 68 & -174 \\
\hline
\end{tabular}

Note: Totals may not equal sum of components because of independent rounding

Source: Energy Information Administration, Form EIA-412, "Annual Report of Public Electric Utilities." 
Table 21. Statement of Income by Major U.S. Publicly Owned Electric Utility Within State, 1992 (Continued)

(Thousand Dollars)

\begin{tabular}{|c|c|c|c|c|c|c|}
\hline Item & $\begin{array}{l}\text { Tennessee } \\
\text { Lenoir } \\
\text { City City of } \\
\text { June } 30\end{array}$ & $\begin{array}{l}\text { Tennessee } \\
\text { Lewisburg } \\
\text { City of } \\
\text { June } 30\end{array}$ & $\begin{array}{l}\text { Tennessee } \\
\text { Lexington } \\
\text { City of } \\
\text { June } 30\end{array}$ & $\begin{array}{l}\text { Tennessee } \\
\text { Loudon } \\
\text { City of } \\
\text { June } 30\end{array}$ & $\begin{array}{l}\text { Tennessee } \\
\text { Maryille } \\
\text { Utilities } \\
\text { June } 30\end{array}$ & $\begin{array}{l}\text { Tennessee } \\
\text { MeMinnville } \\
\text { Electric } \\
\text { System } \\
\text { June } 30\end{array}$ \\
\hline Electric Utility Operating Rovenues ............ & 54,807 & 13,718 & 20,119 & 13,128 & 24,855 & 11,210 \\
\hline 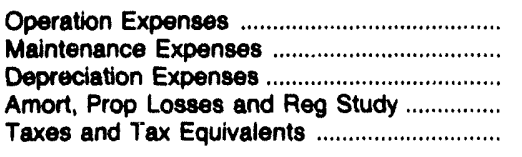 & $\begin{array}{r}48,853 \\
1,249 \\
1,430 \\
0 \\
1,069\end{array}$ & $\begin{array}{r}13,304 \\
182 \\
267 \\
42 \\
255\end{array}$ & $\begin{array}{r}17,843 \\
825 \\
614 \\
0 \\
439\end{array}$ & $\begin{array}{r}11,439 \\
177 \\
313 \\
0 \\
316\end{array}$ & $\begin{array}{r}22,220 \\
594 \\
899 \\
4 \\
478\end{array}$ & $\begin{array}{r}10,288 \\
315 \\
351 \\
47 \\
242\end{array}$ \\
\hline $\begin{array}{l}\text { Total Electric Utility Operating } \\
\text { Expenees }\end{array}$ & 52,600 & 14,051 & 19,721 & 12,246 & 24,195 & 11,243 \\
\hline 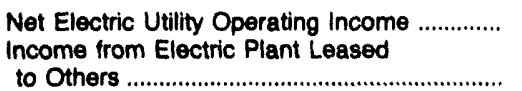 & $\begin{array}{r}2,207 \\
0\end{array}$ & $\begin{array}{r}-333 \\
0\end{array}$ & 398 & $\begin{array}{r}882 \\
0\end{array}$ & 661 & -33 \\
\hline Electric Utility Operating Income .............. & 2,207 & -333 & 398 & 882 & 661 & -33 \\
\hline Other Electric Income & 862 & 174 & 406 & 501 & 188 & 264 \\
\hline $\begin{array}{l}\text { Other Electric Deductions ................................ } \\
\text { Allowance for Other Funds Used }\end{array}$ & 1 & 4 & 0 & 3 & 0 & 6 \\
\hline $\begin{array}{l}\text { During Construction } \\
\text { Taxes on Other Income and Deductions }\end{array}$ & $\begin{array}{l}0 \\
0\end{array}$ & $\begin{array}{l}0 \\
0\end{array}$ & $\begin{array}{l}0 \\
0\end{array}$ & $\begin{array}{l}0 \\
0\end{array}$ & $\begin{array}{l}0 \\
0\end{array}$ & $\begin{array}{l}0 \\
0\end{array}$ \\
\hline 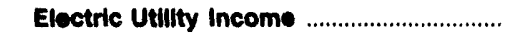 & 3,068 & -163 & 804 & 1,380 & 849 & 225 \\
\hline 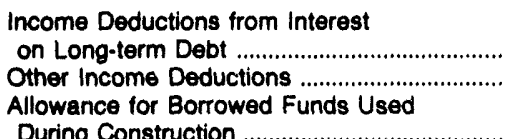 & $\begin{array}{r}1,207 \\
43\end{array}$ & $\begin{array}{r}31 \\
6\end{array}$ & $\begin{array}{l}0 \\
0\end{array}$ & $\begin{array}{r}521 \\
14\end{array}$ & $\begin{array}{r}126 \\
4\end{array}$ & $\begin{array}{r}0 \\
25\end{array}$ \\
\hline 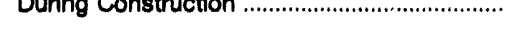 & & & & & & \\
\hline Total Income Deductions ............................ & 1,250 & 37 & 0 & 536 & 130 & 25 \\
\hline Income Before Extraordinary Items ..................... & 1,818 & -200 & 804 & 845 & 719 & 200 \\
\hline Extraordinary Income & 1,544 & 0 & 0 & 0 & 0 & 0 \\
\hline 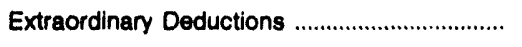 & 0 & 0 & 0 & 0 & 0 & 0 \\
\hline Not Income & 3,363 & -200 & 804 & 845 & 719 & 200 \\
\hline
\end{tabular}

Note: Totals may not equal sum of components because of independent rounding.

Source: Energy Information Administration, Form ElA-412, "Annual Report of Public Electric Utilities." 
Table 21. Statement of Income by Major U.S. Publicly Owned Electric Utility Within State, 1992 (Continued) (Thousand Dollars)

\begin{tabular}{|c|c|c|c|c|c|c|}
\hline Item & $\begin{array}{c}\text { Tennessee } \\
\text { Memphis } \\
\text { City of } \\
\text { December } 31\end{array}$ & $\begin{array}{c}\text { Tennessee } \\
\text { Morrisiown } \\
\text { City of } \\
\text { June } 30\end{array}$ & $\begin{array}{c}\text { Tennessee } \\
\text { Murfreesboro } \\
\text { City of } \\
\text { June } 30\end{array}$ & $\begin{array}{c}\text { Tennessee } \\
\text { Nashville } \\
\text { Electric } \\
\text { Service } \\
\text { June } 30\end{array}$ & $\begin{array}{c}\text { Tennessee } \\
\text { Newport } \\
\text { City of } \\
\text { June } 30\end{array}$ & $\begin{array}{l}\text { Tennessee } \\
\text { Oak Ridge } \\
\text { City of } \\
\text { June } 30\end{array}$ \\
\hline Electric Utility Operating Rovenues ............ & 628,316 & 31,102 & 41,381 & 542,392 & 22,551 & 23,156 \\
\hline 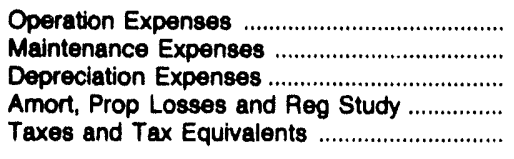 & $\begin{array}{r}558,265 \\
22,628 \\
17,198 \\
641 \\
15,111\end{array}$ & $\begin{array}{r}28,787 \\
720 \\
705 \\
173 \\
539\end{array}$ & $\begin{array}{r}37,750 \\
540 \\
1,016 \\
163 \\
933\end{array}$ & $\begin{array}{r}488,857 \\
13,163 \\
17,210 \\
0 \\
10,423\end{array}$ & $\begin{array}{r}20,222 \\
568 \\
779 \\
0 \\
545\end{array}$ & $\begin{array}{r}21,498 \\
522 \\
662 \\
0 \\
481\end{array}$ \\
\hline $\begin{array}{l}\text { Total Electric Utility Operating } \\
\text { Expentes }\end{array}$ & 613,842 & 30,924 & 40,403 & 529,654 & 22,115 & 23,163 \\
\hline $\begin{array}{l}\text { Net Electric Utility Operating Income ............. } \\
\text { Income from Electric Plant Leased }\end{array}$ & 14,474 & 178 & 978 & 12,738 & 436 & -7 \\
\hline 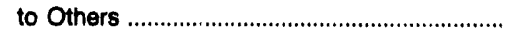 & 0 & 0 & 0 & 0 & 0 & 0 \\
\hline Electric Utility Operating Income .............. & 14,474 & 178 & 978 & 12,738 & 436 & -7 \\
\hline 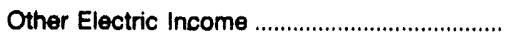 & 30,209 & 479 & 745 & 5,045 & 605 & 83 \\
\hline Other Electric Deductions ................................ & 719 & 7 & 1 & 0 & 6 & 0 \\
\hline 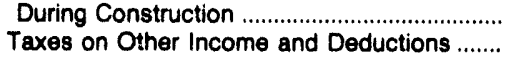 & $\begin{array}{l}0 \\
0\end{array}$ & $\begin{array}{l}0 \\
0\end{array}$ & $\begin{array}{l}0 \\
0\end{array}$ & $\begin{array}{l}0 \\
0\end{array}$ & $\begin{array}{l}0 \\
0\end{array}$ & $\begin{array}{l}0 \\
0\end{array}$ \\
\hline 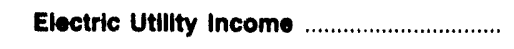 & 43,964 & 650 & 1,722 & 17,783 & 1,035 & 76 \\
\hline 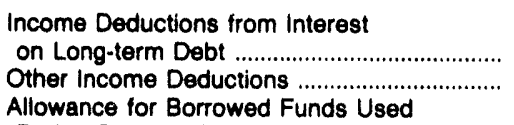 & $\begin{array}{r}16,786 \\
424\end{array}$ & $\begin{array}{r}1 \\
56\end{array}$ & $\begin{array}{l}30 \\
61\end{array}$ & $\begin{array}{r}13,460 \\
768\end{array}$ & $\begin{array}{r}276 \\
23\end{array}$ & $\begin{array}{r}234 \\
0\end{array}$ \\
\hline 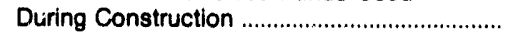 & 0 & 0 & 0 & 0 & 0 & 0 \\
\hline Total Income Deductions ........................... & 17,211 & 56 & 91 & 14,228 & 299 & 234 \\
\hline Income Before Extraordinary Items .................. & 26,753 & 593 & 1,630 & 3,556 & 736 & -158 \\
\hline 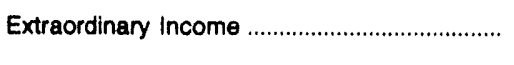 & 0 & 616 & 0 & 0 & 1,007 & 0 \\
\hline 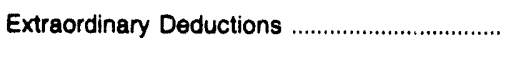 & 11,734 & 0 & 0 & 0 & 0 & 0 \\
\hline Net Income & 15,018 & 1,209 & 1,630 & 3,556 & 1,743 & -158 \\
\hline
\end{tabular}

Note: Totals may not equal sum of components because of independent rounding.

Source: Energy Information Administration, Form E|A.412, "Annual Report of Public Electric Utilities." 
Table 21. Statement of Income by Major U.S. Publicly Owned Electric Utility Within State, 1992 (Continued)

(Thousand Dollars)

\begin{tabular}{|c|c|c|c|c|c|c|}
\hline Item & $\begin{array}{c}\text { Tennessee } \\
\text { Paris } \\
\text { City of } \\
\text { June } 30\end{array}$ & $\begin{array}{l}\text { Tennessee } \\
\text { Pulaski } \\
\text { City of } \\
\text { June } 30\end{array}$ & $\begin{array}{l}\text { Tennessee } \\
\text { Ripley } \\
\text { City of } \\
\text { June } 30\end{array}$ & $\begin{array}{l}\text { Tennessee } \\
\text { Rockwood } \\
\text { City of } \\
\text { June } 30\end{array}$ & $\begin{array}{c}\text { Tennesseo } \\
\text { Sevier } \\
\text { County } \\
\text { Electric } \\
\text { System } \\
\text { June } 30\end{array}$ & $\begin{array}{c}\text { Tennessee } \\
\text { Shelbyville } \\
\text { City of }\end{array}$ \\
\hline Electric Utility Operating Rovenues ............. & 21,176 & 18,656 & 12,689 & 14,758 & 46,464 & 15,825 \\
\hline 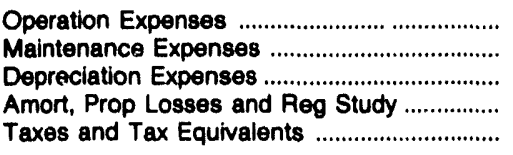 & $\begin{array}{r}19,788 \\
593 \\
736 \\
0 \\
465\end{array}$ & $\begin{array}{r}16,966 \\
578 \\
660 \\
0 \\
415\end{array}$ & $\begin{array}{r}12,170 \\
137 \\
199 \\
29 \\
184\end{array}$ & $\begin{array}{r}13,508 \\
338 \\
400 \\
20 \\
369\end{array}$ & $\begin{array}{r}40,433 \\
1,048 \\
1,707 \\
2.7 \\
790\end{array}$ & $\begin{array}{r}14,995 \\
309 \\
368 \\
18 \\
342\end{array}$ \\
\hline $\begin{array}{l}\text { Total Electrlc Utility Operating } \\
\text { Expenses }\end{array}$ & 21,581 & 18,620 & 12,718 & 14,636 & 44,005 & 16,032 \\
\hline $\begin{array}{l}\text { Net Electric Utility Operating Income ............. } \\
\text { Income from Electric Plant Leased } \\
\text { to Others }\end{array}$ & $\begin{array}{r}-404 \\
0\end{array}$ & 36 & -29 & 123 & 2,459 & $\begin{array}{r}-207 \\
0\end{array}$ \\
\hline Electric Utility Operating Income .............. & -404 & 36 & -29 & 123 & 2,459 & -207 \\
\hline Other Electric Income & 500 & 365 & 407 & 203 & 755 & 252 \\
\hline $\begin{array}{l}\text { Other Electric Deductions } \\
\text { Allowance for Other Funds Used.......................... }\end{array}$ & 1 & 9 & 0 & 12 & 0 & 0 \\
\hline 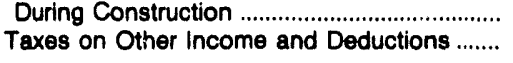 & $\begin{array}{l}0 \\
0\end{array}$ & $\begin{array}{l}0 \\
0\end{array}$ & $\begin{array}{l}0 \\
0\end{array}$ & $\begin{array}{l}0 \\
0\end{array}$ & $\begin{array}{l}0 \\
0\end{array}$ & $\begin{array}{l}0 \\
0\end{array}$ \\
\hline Electric Utility income & 95 & 392 & 378 & 313 & 3,214 & 46 \\
\hline 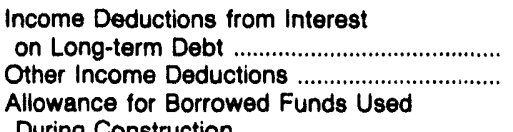 & $\begin{array}{r}217 \\
12\end{array}$ & $\begin{array}{r}207 \\
2\end{array}$ & $\begin{array}{l}0 \\
0\end{array}$ & $\begin{array}{l}0 \\
0\end{array}$ & $\begin{array}{l}278 \\
117\end{array}$ & $\begin{array}{r}0 \\
15\end{array}$ \\
\hline During Construction & 0 & 0 & 0 & 0 & 0 & 0 \\
\hline Total Income Deductions ............................... & 228 & 208 & 0 & o & 395 & 15 \\
\hline Income Before Extraordinary Items ................... & -133 & 184 & 378 & 313 & 2,819 & 31 \\
\hline Extraordinary Income & 0 & 0 & 0 & 0 & 0 & 0 \\
\hline 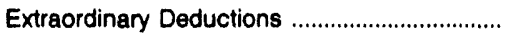 & 37 & 138 & 0 & 0 & 0 & 0 \\
\hline Net Income & -171 & 46 & 378 & 313 & 2,819 & 31 \\
\hline
\end{tabular}

Note: Totals may not equal sum of components because of independent rounding.

Source: Energy Information Administration, Form EIA-412, "Annual Report of Public Electric Utilities." 
Table 21. Statement of Income by Major U.S. Publicly Owned Electric Utility Within State, 1992 (Continued)

(Thousand Dollars)

\begin{tabular}{|c|c|c|c|c|c|c|}
\hline Item & $\begin{array}{l}\text { Tennessee } \\
\text { Springfield } \\
\text { City of } \\
\text { June } 30\end{array}$ & $\begin{array}{l}\text { Tennessee } \\
\text { Sweetwater } \\
\text { City of } \\
\text { June } 30\end{array}$ & $\begin{array}{l}\text { Tennessee } \\
\text { Tullahoma } \\
\text { Board } \\
\text { of } \\
\text { Pub Utils } \\
\text { June } 30\end{array}$ & $\begin{array}{l}\text { Tennessee } \\
\text { Union } \\
\text { City City of } \\
\text { June } 30\end{array}$ & $\begin{array}{c}\text { Tennessee } \\
\text { Weakley } \\
\text { County } \\
\text { Mun } \\
\text { Elec Sys } \\
\text { June } 30\end{array}$ & $\begin{array}{l}\text { Texas } \\
\text { Austin } \\
\text { City of } \\
\text { September } 30\end{array}$ \\
\hline Electric Utility Operating Rovenues ............. & 10,613 & 8,385 & 13,913 & 14,834 & 24,163 & 426,070 \\
\hline 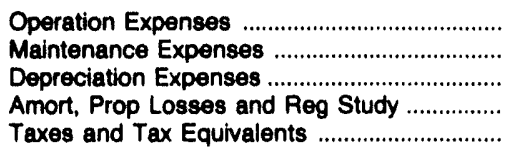 & $\begin{array}{r}9,214 \\
145 \\
359 \\
29 \\
228\end{array}$ & $\begin{array}{r}8,595 \\
290 \\
326 \\
0 \\
192\end{array}$ & $\begin{array}{r}12,928 \\
433 \\
314 \\
12 \\
300\end{array}$ & $\begin{array}{r}13,970 \\
496 \\
313 \\
14 \\
263\end{array}$ & $\begin{array}{r}22,202 \\
454 \\
807 \\
0 \\
470\end{array}$ & $\begin{array}{r}178,435 \\
33,345 \\
56,699 \\
0 \\
0\end{array}$ \\
\hline $\begin{array}{l}\text { Total Eloctrle UtIlity Operating } \\
\text { Expenees }\end{array}$ & 9,976 & 9,403 & 13,987 & 15,056 & 23,933 & 268,479 \\
\hline $\begin{array}{l}\text { Net Electric Utility Operating Income } \\
\text { Income trom Electric Plant Leased } \\
\text { to Others }\end{array}$ & $\begin{array}{r}637 \\
0\end{array}$ & $\begin{array}{r}-18 \\
0\end{array}$ & $\begin{array}{r}-74 \\
0\end{array}$ & $\begin{array}{r}-222 \\
0\end{array}$ & $\begin{array}{r}230 \\
0\end{array}$ & $\begin{array}{r}157,592 \\
0\end{array}$ \\
\hline Electric Utility Operating Income .............. & 637 & -18 & -74 & -222 & 230 & 157,592 \\
\hline Other Electric Income & 191 & 238 & 345 & 342 & 406 & 22,794 \\
\hline 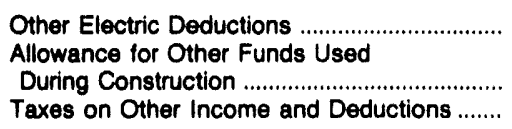 & $\begin{array}{l}0 \\
0\end{array}$ & $\begin{array}{l}0 \\
0\end{array}$ & $\begin{array}{l}0 \\
0\end{array}$ & $\begin{array}{l}0 \\
0\end{array}$ & $\begin{array}{l}0 \\
0\end{array}$ & $\begin{array}{r}1,159 \\
0 \\
0\end{array}$ \\
\hline 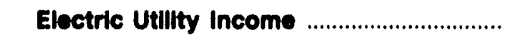 & 828 & 220 & 268 & 88 & 636 & 179,227 \\
\hline 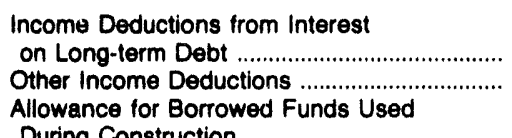 & $\begin{array}{r}143 \\
19\end{array}$ & $\begin{array}{l}0 \\
6\end{array}$ & $\begin{array}{r}120 \\
2\end{array}$ & $\begin{array}{l}0 \\
0\end{array}$ & $\begin{array}{r}0 \\
13\end{array}$ & $\begin{array}{r}145,939 \\
29,565\end{array}$ \\
\hline 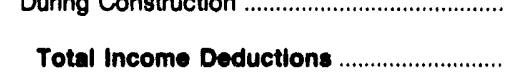 & 161 & 6 & 122 & 0 & 13 & 175,504 \\
\hline 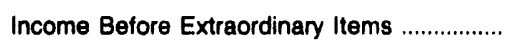 & 667 & 214 & 147 & 88 & 623 & 3,723 \\
\hline Extraordinary Income & 0 & 0 & 0 & 0 & 0 & 986 \\
\hline 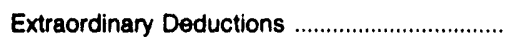 & 0 & 0 & 0 & 0 & 0 & 0 \\
\hline Net Income & 667 & 214 & 147 & 88 & 623 & 4,708 \\
\hline
\end{tabular}

Note: Totals may not equal sum of components because of independent rounding.

Source: Energy Information Administration, Form EIA-412, "Annual Report of Public Electric Utilities." 
Table 2i. Statement of Income by Major U.S. Publicly Owned Electric Utility Within State, 1992 (Continued)

(Thousand Dollars)

\begin{tabular}{|c|c|c|c|c|c|c|}
\hline Item & $\begin{array}{l}\text { Texas } \\
\text { Brenham } \\
\text { City of } \\
\text { September } 30\end{array}$ & $\begin{array}{c}\text { Texas } \\
\text { Brownsville } \\
\text { Public } \\
\text { Utils Board } \\
\text { September } 30\end{array}$ & $\begin{array}{c}\text { Texas } \\
\text { Bryan } \\
\text { City of } \\
\text { September } 30\end{array}$ & $\begin{array}{c}\text { Texas } \\
\text { College } \\
\text { Station } \\
\text { City of } \\
\text { September } 30\end{array}$ & $\begin{array}{c}\text { Texas } \\
\text { Denton } \\
\text { City of } \\
\text { September } 30\end{array}$ & $\begin{array}{c}\text { Texas } \\
\text { Floresville } \\
\text { City of } \\
\text { December } 31\end{array}$ \\
\hline Electric Utility Operating Revenues ............ & 11,732 & 43,851 & 68,766 & 27,860 & 63,727 & 9,071 \\
\hline 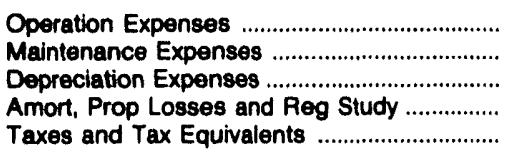 & $\begin{array}{r}10,207 \\
448 \\
244 \\
0 \\
566\end{array}$ & $\begin{array}{r}27,128 \\
1,629 \\
3,437 \\
0 \\
316\end{array}$ & $\begin{array}{r}56,575 \\
1,844 \\
3,624 \\
0 \\
0\end{array}$ & $\begin{array}{r}20,818 \\
341 \\
709 \\
0 \\
0\end{array}$ & $\begin{array}{r}49,519 \\
972 \\
3,248 \\
0 \\
0\end{array}$ & $\begin{array}{r}7,392 \\
237 \\
571 \\
0 \\
0\end{array}$ \\
\hline $\begin{array}{l}\text { Total Electrlc Utility Operating } \\
\text { Expenees }\end{array}$ & 11,465 & 32,510 & 62,043 & 21,868 & 53,739 & 8,200 \\
\hline $\begin{array}{l}\text { Net Electric Utility Operating Income ............. } \\
\text { Income from Electric Plant Leased }\end{array}$ & 267 & 11,341 & 6,722 & 5,992 & 9,988 & 871 \\
\hline 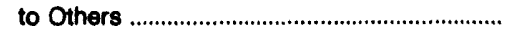 & 0 & 0 & 0 & 0 & 0 & 0 \\
\hline Electric Utilty Operating Income ............. & 267 & 11,341 & 6,722 & 5,992 & 9,988 & 871 \\
\hline Other Electric Income ........................................... & 30 & 21,734 & 2,303 & 903 & 3,723 & 378 \\
\hline $\begin{array}{l}\text { Other Electric Deductions .............................. } \\
\text { Allowance for Other Funds Used } \\
\text { During Construction ...................................... } \\
\text { Taxes on Other Income and Deductions ........ }\end{array}$ & $\begin{array}{l}0 \\
0 \\
0\end{array}$ & $\begin{array}{r}562 \\
0 \\
0\end{array}$ & $\begin{array}{r}2,036 \\
0 \\
0\end{array}$ & $\begin{array}{r}4,025 \\
0 \\
0\end{array}$ & $\begin{array}{r}6,614 \\
0 \\
0\end{array}$ & $\begin{array}{l}0 \\
0 \\
0\end{array}$ \\
\hline 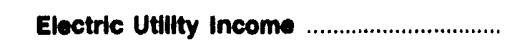 & 297 & 32,513 & 6,980 & 2,871 & 7,097 & 1,250 \\
\hline 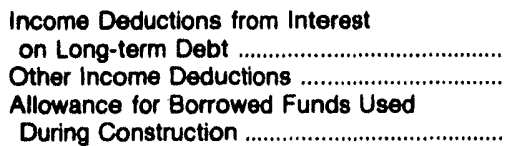 & $\begin{array}{r}81 \\
0 \\
0\end{array}$ & $\begin{array}{r}8,185 \\
23,100 \\
0\end{array}$ & $\begin{array}{r}0 \\
2,951 \\
0\end{array}$ & $\begin{array}{r}485 \\
0 \\
0\end{array}$ & $\begin{array}{r}1,905 \\
0 \\
0\end{array}$ & $\begin{array}{r}320 \\
0 \\
0\end{array}$ \\
\hline 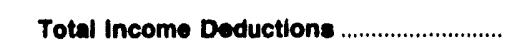 & 81 & 31,285 & 2,951 & 485 & 1,905 & 320 \\
\hline Income Before Extraordinary ltems .................. & 216 & 1,228 & 4,039 & 2,387 & 5,193 & 930 \\
\hline Extraordinary Income & 0 & 0 & 0 & 0 & 0 & 0 \\
\hline 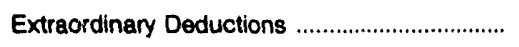 & 0 & 5,587 & 46 & 0 & 0 & 0 \\
\hline Net Income & 216 & $-4,359$ & 3,993 & 2,387 & 5,193 & 930 \\
\hline
\end{tabular}

Note: Totals may not equal sum of components because of independent rounding.

Source: Energy Information Administration, Form EIA-412, "Annual Report of Public Electric Utilities." 
Table 21. Statement of Income by Major U.S. Publicly Owned Electric Utility Within State, 1992 (Continued)

(Thousand Dollars)

\begin{tabular}{|c|c|c|c|c|c|c|}
\hline Item & $\begin{array}{l}\text { Texas } \\
\text { Garland } \\
\text { City of } \\
\text { September } 30\end{array}$ & $\begin{array}{c}\text { Texas } \\
\text { Georgetown } \\
\text { City of } \\
\text { September } 30\end{array}$ & $\begin{array}{c}\text { Texas } \\
\text { Greenville } \\
\text { City of }\end{array}$ & $\begin{array}{c}\text { Texas } \\
\text { Kerrville } \\
\text { Public } \\
\text { Utility } \\
\text { Board } \\
\text { September } 30\end{array}$ & $\begin{array}{c}\text { Texas } \\
\text { Lower } \\
\text { Colorado } \\
\text { River } \\
\text { Authority } \\
\text { June } 30\end{array}$ & $\begin{array}{l}\text { Texas } \\
\text { Lubbock } \\
\text { City of } \\
\text { September } 30\end{array}$ \\
\hline Ebectric Utulty Operating Rovenues ............. & 120,639 & 10,988 & 29,155 & 21,199 & 319,810 & 50,196 \\
\hline 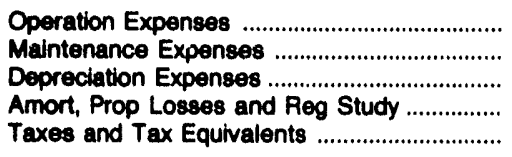 & $\begin{array}{r}98,132 \\
8,254 \\
5,822 \\
0 \\
4,627\end{array}$ & $\begin{array}{r}8,158 \\
33 \\
208 \\
0 \\
222\end{array}$ & $\begin{array}{r}22,720 \\
2,205 \\
1,869 \\
0 \\
1,025\end{array}$ & $\begin{array}{r}16,193 \\
810 \\
865 \\
157 \\
14\end{array}$ & $\begin{array}{r}158,536 \\
28,874 \\
38,214 \\
0 \\
0\end{array}$ & $\begin{array}{r}33,286 \\
614 \\
3,100 \\
0 \\
0\end{array}$ \\
\hline $\begin{array}{l}\text { Total Electrlc Utilty Oporating } \\
\text { Expeneses }\end{array}$ & 116,835 & 8,622 & 27,818 & 18,038 & 225,625 & 37,000 \\
\hline $\begin{array}{l}\text { Net Electric Utility Operating Income .................. } \\
\text { Income from Electric Plant Leased } \\
\text { to Others }\end{array}$ & $\begin{array}{r}12,804 \\
0\end{array}$ & $\begin{array}{r}2,366 \\
0\end{array}$ & $\begin{array}{r}1,337 \\
0\end{array}$ & $\begin{array}{r}3,161 \\
0\end{array}$ & $\begin{array}{r}94,185 \\
0\end{array}$ & $\begin{array}{r}13,196 \\
0\end{array}$ \\
\hline Electric Utility Operating Income .............. & 12,804 & 2,366 & 1,337 & 3,161 & 94,185 & 13,196 \\
\hline Other Electric Income & 2,191 & 487 & 560 & 637 & 45,137 & 4,081 \\
\hline $\begin{array}{l}\text { Other Electric Deductions .............................. } \\
\text { Allowance for Other Funds Used }\end{array}$ & 0 & 0 & 0 & 0 & 64,020 & 0 \\
\hline 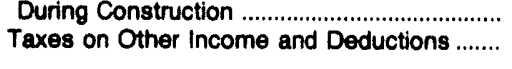 & $\begin{array}{l}0 \\
0\end{array}$ & $\begin{array}{l}0 \\
0\end{array}$ & $\begin{array}{l}0 \\
0\end{array}$ & $\begin{array}{r}18 \\
0\end{array}$ & $\begin{array}{l}0 \\
0\end{array}$ & $\begin{array}{r}0 \\
5,328\end{array}$ \\
\hline 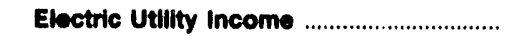 & 14,905 & 2,853 & 1,896 & 3,816 & 75,301 & 11,948 \\
\hline 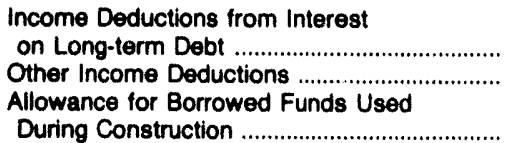 & $\begin{array}{r}1,778 \\
0\end{array}$ & $\begin{array}{r}5 \\
1,082\end{array}$ & $\begin{array}{r}1,119 \\
639\end{array}$ & $\begin{array}{r}2,079 \\
0\end{array}$ & $\begin{array}{r}90,550 \\
-5,877\end{array}$ & $\begin{array}{r}2,724 \\
0\end{array}$ \\
\hline 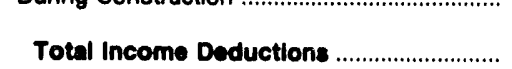 & 1,778 & 1,087 & 1,758 & 2.079 & $\begin{array}{r}2,544 \\
87,218\end{array}$ & 2724 \\
\hline Income Before Extraordinary Items .................... & 13,217 & $1,7 € 6$ & 138 & 1,737 & $-11,916$ & 9,226 \\
\hline Extraordinary Income & 0 & 0 & 0 & 0 & 0 & 0 \\
\hline 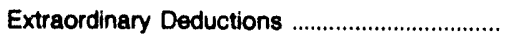 & 264 & 0 & 0 & 0 & 0 & 0 \\
\hline Not Income & 12,953 & 1,766 & 138 & 1,737 & $-11,916$ & 9,226 \\
\hline
\end{tabular}

Note: Totals may not equal sum of components because of independent rounding.

Source: Energy Information Administration, Form EIA-412. "Annual Report of Public Electric Utilities." 
Table 21. Statement of Income by Major U.S. Publicly Owned Electric Utility Within State, 1992 (Continued)

(Thousand Dollars)

\begin{tabular}{|c|c|c|c|c|c|c|}
\hline Item & $\begin{array}{c}\text { Texas } \\
\text { New Braunfels } \\
\text { City of } \\
\text { July } 31\end{array}$ & $\begin{array}{c}\text { Texas } \\
\text { Sam Rayburn } \\
\text { Municipal } \\
\text { Pwr } \\
\text { Agny } \\
\text { September } 30\end{array}$ & $\begin{array}{c}\text { Texas } \\
\text { San Antonio } \\
\text { City of } \\
\text { January } 31\end{array}$ & $\begin{array}{c}\text { Texas } \\
\text { San Marcos } \\
\text { City of } \\
\text { September } 30\end{array}$ & $\begin{array}{c}\text { Texas } \\
\text { Seguin } \\
\text { Clty of } \\
\text { September } 30\end{array}$ & $\begin{array}{c}\text { Texas } \\
\text { Texas } \\
\text { Municipal } \\
\text { Power Agency } \\
\text { September } 30\end{array}$ \\
\hline Electric Utilty Operating Revenues ............ & 36,497 & 32,551 & 708,609 & 18,279 & 11,560 & 168,718 \\
\hline 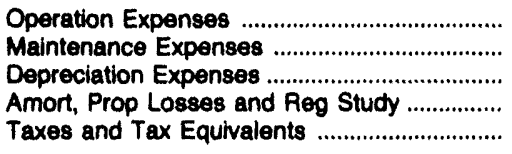 & $\begin{array}{r}30,564 \\
714 \\
1,453 \\
0 \\
1,032\end{array}$ & $\begin{array}{r}13,597 \\
2,665 \\
4,388 \\
0 \\
0\end{array}$ & $\begin{array}{r}264,804 \\
56,630 \\
117,835 \\
0 \\
87,921\end{array}$ & $\begin{array}{r}14,066 \\
721 \\
473 \\
0 \\
1,428\end{array}$ & $\begin{array}{r}8,177 \\
33 \\
260 \\
0 \\
0\end{array}$ & $\begin{array}{r}73,577 \\
9,289 \\
24,599 \\
0 \\
0\end{array}$ \\
\hline $\begin{array}{l}\text { Total Electrlc UtIlty Operating } \\
\text { Expenses }\end{array}$ & 33,764 & 20,650 & 527,189 & 16,688 & 8,470 & 107,485 \\
\hline $\begin{array}{l}\text { Net Electric Utility Operating Income } \\
\text { Income from Electric Plant Leased } \\
\text { to Others }\end{array}$ & $\begin{array}{r}2,733 \\
917\end{array}$ & 11,902 & $\begin{array}{r}179,420 \\
1,648\end{array}$ & $\begin{array}{r}1,592 \\
0\end{array}$ & 3,090 & 61,254 \\
\hline Electric Utillty Operating Income .............. & 3,650 & 11,802 & 181,068 & 1,582 & 3,090 & 61,254 \\
\hline 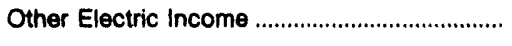 & 563 & 11,262 & 27,567 & 545 & 97 & 15,410 \\
\hline $\begin{array}{l}\text { Other Electric Deductions ................................. } \\
\text { Allowance for Other Funds Used }\end{array}$ & 0 & 0 & 1,059 & 19 & 0 & 0 \\
\hline $\begin{array}{l}\text { During Construction } \\
\text { Taxes on Other Income and Deductions }\end{array}$ & $\begin{array}{l}0 \\
0\end{array}$ & $\begin{array}{l}0 \\
0\end{array}$ & $\begin{array}{r}0 \\
14,665\end{array}$ & $\begin{array}{l}0 \\
0\end{array}$ & $\begin{array}{l}0 \\
0\end{array}$ & $\begin{array}{r}17,080 \\
0\end{array}$ \\
\hline Electric Utillty Income & 4,213 & 23,163 & 192,911 & 2,118 & 3,187 & 93,744 \\
\hline 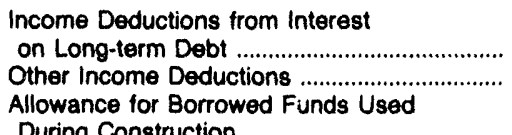 & $\begin{array}{r}458 \\
0\end{array}$ & $\begin{array}{r}15,635 \\
4,481\end{array}$ & $\begin{array}{r}176,785 \\
24,480\end{array}$ & $\begin{array}{r}1,103 \\
42\end{array}$ & $\begin{array}{l}0 \\
0\end{array}$ & $\begin{array}{r}91,561 \\
589\end{array}$ \\
\hline 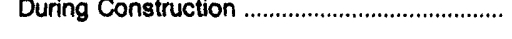 & 0 & 0 & $-29,055$ & 0 & 0 & 0 \\
\hline Total Income Deductions .............................. & 458 & 20,117 & 172,210 & 1,146 & $\mathbf{0}$ & 92,160 \\
\hline Income Before Extraordinary Items .................... & 3,755 & 3,047 & 20,701 & 973 & 3,187 & 1,584 \\
\hline Extraordinary Income & 0 & 0 & 0 & 2,518 & 0 & 0 \\
\hline 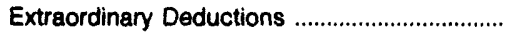 & 2,502 & 0 & 0 & 0 & 1,208 & 0 \\
\hline 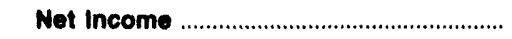 & 1,252 & 3,047 & 20,701 & 3,491 & 1,978 & 1,584 \\
\hline
\end{tabular}

Note: Totals may not equal sum of components because of independent rounding.

Source: Energy Information Administration, Form ElA-412, "Annual Report of Public Electric Utilities." 
Table 21. Statement of Income by Major U.S. Publicly Owned Electric Utility Within State, 1992 (Continued)

(Thousand Dollars)

\begin{tabular}{|c|c|c|c|c|c|c|}
\hline Item & $\begin{array}{l}\text { Texas } \\
\text { Toledo Bend } \\
\text { Project } \\
\text { Joint } \\
\text { Oper } \\
\text { August } 30\end{array}$ & $\begin{array}{c}\text { Texas } \\
\text { Weatherford } \\
\text { Mun } \\
\text { Utility } \\
\text { System } \\
\text { September } 30\end{array}$ & $\begin{array}{c}\text { Utah } \\
\text { Bountiful } \\
\text { City City of } \\
\text { June } 30\end{array}$ & $\begin{array}{c}\text { Utah } \\
\text { Intermountain } \\
\text { Power Agency } \\
\text { June } 30\end{array}$ & $\begin{array}{l}\text { Utah } \\
\text { Logan } \\
\text { City of } \\
\text { June } 30\end{array}$ & $\begin{array}{l}\text { Utah } \\
\text { Murray } \\
\text { City of } \\
\text { June } 30\end{array}$ \\
\hline Electric Utility Operating Revenues ........... & 9,408 & 15,349 & 11,973 & 609,337 & 15,888 & 17,446 \\
\hline 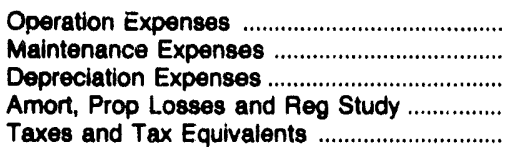 & $\begin{array}{r}6,357 \\
0 \\
704 \\
0 \\
0\end{array}$ & $\begin{array}{r}9,662 \\
0 \\
837 \\
0 \\
602\end{array}$ & $\begin{array}{r}5,900 \\
790 \\
1,017 \\
0 \\
0\end{array}$ & $\begin{array}{r}219,191 \\
25,149 \\
77,404 \\
33,041 \\
21,215\end{array}$ & $\begin{array}{r}10,026 \\
293 \\
884 \\
0 \\
923\end{array}$ & $\begin{array}{r}11,867 \\
664 \\
1,519 \\
0 \\
1,509\end{array}$ \\
\hline $\begin{array}{l}\text { Total Electric Utllity Operating } \\
\text { Expenees }\end{array}$ & 7,080 & 11,102 & 7,707 & 376,000 & 12,126 & 15,559 \\
\hline $\begin{array}{l}\text { Net Electric Utility Operating Income ............. } \\
\text { Income from Electric Plant Leased }\end{array}$ & 2,348 & 4,247 & 4,266 & 233,337 & 3,762 & 1,886 \\
\hline 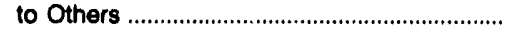 & 0 & 0 & 0 & 0 & 0 & 0 \\
\hline Electric Utility Operating Income ............. & 2,348 & 4,247 & 4,268 & 233,337 & 3,762 & 1,886 \\
\hline 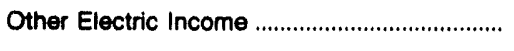 & 0 & 1,473 & 251 & 76,418 & 218 & 732 \\
\hline $\begin{array}{l}\text { Other Electric Deductions ................................... } \\
\text { Allowance for Other Funds Used }\end{array}$ & 0 & 1,626 & 0 & 0 & 69 & 0 \\
\hline $\begin{array}{l}\text { During Construction .......................................... } \\
\text { Taxes on Other Income and Deductions ....... }\end{array}$ & $\begin{array}{l}0 \\
0\end{array}$ & $\begin{array}{l}0 \\
0\end{array}$ & $\begin{array}{l}0 \\
0\end{array}$ & $\begin{array}{l}0 \\
0\end{array}$ & $\begin{array}{l}0 \\
0\end{array}$ & $\begin{array}{l}0 \\
0\end{array}$ \\
\hline 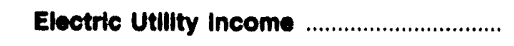 & 2,348 & 4,094 & $4,51:$ & 309,755 & 3,811 & 2,618 \\
\hline 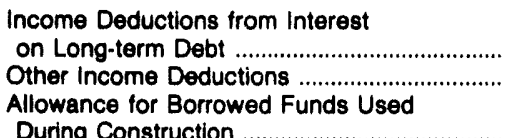 & $\begin{array}{r}2,543 \\
0\end{array}$ & $\begin{array}{r}899 \\
0\end{array}$ & $\begin{array}{l}0 \\
0\end{array}$ & $\begin{array}{l}400,073 \\
-90,318\end{array}$ & $\begin{array}{r}909 \\
0\end{array}$ & $\begin{array}{r}665 \\
0\end{array}$ \\
\hline 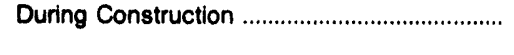 & 0 & 0 & 0 & 0 & 0 & 0 \\
\hline Total Income Deductions ............................. & 2,543 & 899 & 0 & 308,755 & 909 & 665 \\
\hline Income Before Extraordinary Items ................. & -194 & 3,195 & 4,516 & 0 & 3,003 & 1,954 \\
\hline 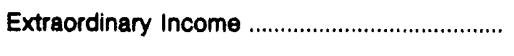 & 0 & 0 & 0 & 0 & 0 & 0 \\
\hline Extraordinary Deductions ....................................... & 0 & 0 & 0 & 0 & 0 & 0 \\
\hline 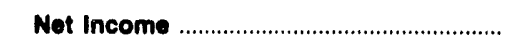 & -194 & 3,195 & 4,516 & $\mathbf{0}$ & 3,003 & 1,954 \\
\hline
\end{tabular}

Note: Totals may not equal sum of components because of independent rounding.

Source: Energy Information Administration. Form EIA-412, "Annual Repori of Public Electric Utilities." 
Table 21. Statement of Income by Major U.S. Publicly Owned Electric Utility Within State, 1992 (Continued)

(Thousand Dollars)

\begin{tabular}{|c|c|c|c|c|c|c|}
\hline Item & $\begin{array}{l}\text { Utah } \\
\text { Provo } \\
\text { City Corp } \\
\text { June } 30\end{array}$ & $\begin{array}{l}\text { Utah } \\
\text { St George } \\
\text { City of } \\
\text { June } 30\end{array}$ & $\begin{array}{c}\text { Utah } \\
\text { Utah } \\
\text { Associated } \\
\text { Mun } \\
\text { Power Sys } \\
\text { March } 31\end{array}$ & $\begin{array}{c}\text { Utah } \\
\text { Utah } \\
\text { Municipal } \\
\text { Power Agency } \\
\text { June } 30\end{array}$ & $\begin{array}{l}\text { Vermont } \\
\text { Burlington } \\
\text { City of } \\
\text { December } 31\end{array}$ & $\begin{array}{l}\text { Vermont } \\
\text { Vermont } \\
\text { Public } \\
\text { Pwr } \\
\text { Supply Auth } \\
\text { December } 31\end{array}$ \\
\hline Electric Utilty Operating Revenues ............. & 31,990 & 15,890 & 35,318 & 28,161 & 36,999 & 9,145 \\
\hline 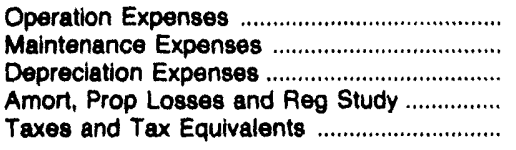 & $\begin{array}{r}22,202 \\
0 \\
3,281 \\
0 \\
0\end{array}$ & $\begin{array}{r}11,586 \\
0 \\
912 \\
0 \\
1,272\end{array}$ & $\begin{array}{r}25,460 \\
982 \\
2,270 \\
295 \\
648\end{array}$ & $\begin{array}{r}24,439 \\
0 \\
942 \\
0 \\
144\end{array}$ & $\begin{array}{r}22,660 \\
1,991 \\
1,623 \\
318 \\
1,890\end{array}$ & $\begin{array}{r}5,555 \\
308 \\
899 \\
0 \\
321\end{array}$ \\
\hline $\begin{array}{l}\text { Total Electric Utility Operating } \\
\text { Expenees }\end{array}$ & 25,483 & 13,771 & 29,655 & 25,525 & 28,481 & 7,084 \\
\hline $\begin{array}{l}\text { Net Electric Utility Operating Income .............. } \\
\text { Income from Electric Plant Leased }\end{array}$ & 6,507 & 2,120 & 5,663 & 2,637 & 8,517 & 2,062 \\
\hline Electric Utility Operating Income ............. & 6,507 & 2,120 & 5,663 & 2,637 & 8,517 & 2,062 \\
\hline Other Electric Income & 822 & 425 & 1,442 & 1,012 & 1,261 & 283 \\
\hline $\begin{array}{l}\text { Other Electric Deductions ............................... } \\
\text { Allowance for Other Funds Used }\end{array}$ & 3,236 & 0 & 0 & 0 & 416 & 20 \\
\hline $\begin{array}{l}\text { During Construction ...................................... } \\
\text { Taxes on Other Income and Deductions ....... }\end{array}$ & $\begin{array}{l}0 \\
0\end{array}$ & $\begin{array}{l}0 \\
0\end{array}$ & $\begin{array}{l}0 \\
0\end{array}$ & $\begin{array}{l}0 \\
0\end{array}$ & $\begin{array}{l}0 \\
0\end{array}$ & $\begin{array}{l}0 \\
0\end{array}$ \\
\hline Electrle Utilty Incom & 4,093 & 2,544 & 7,105 & 3,648 & 9,362 & 2,324 \\
\hline $\begin{array}{l}\text { Income Deductions from Interest } \\
\text { on Long-term Debt ......................................... } \\
\text { Other Income Deductions .............................. } \\
\text { Allowance for Borrowed Funds Ussd }\end{array}$ & $\begin{array}{r}3,866 \\
873\end{array}$ & $\begin{array}{l}0 \\
0\end{array}$ & $\begin{array}{r}-7,013 \\
0\end{array}$ & $\begin{array}{r}3,630 \\
0\end{array}$ & $\begin{array}{r}7,012 \\
474\end{array}$ & $\begin{array}{r}2,237 \\
710\end{array}$ \\
\hline 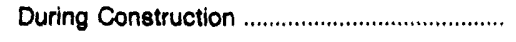 & 0 & 0 & 8,033 & 0 & 0 & 0 \\
\hline 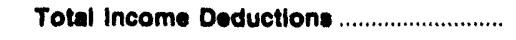 & 4,739 & 0 & 1,020 & 3,630 & 7,486 & 2,948 \\
\hline Income Belore Extraordinary Items ................... & -646 & 2,544 & 6,085 & 18 & 1,876 & $-6: 24$ \\
\hline Extraordinary Income & 0 & 0 & 0 & 450 & 0 & 0 \\
\hline 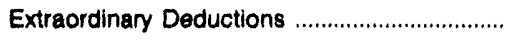 & 0 & 0 & 6,085 & 0 & 0 & 0 \\
\hline Net Income & -646 & 2,544 & 0 & 468 & 1,876 & -624 \\
\hline
\end{tabular}

Note: Totals may not equal sum of components because of independent rounding.

Source: Energy Information Administration, Form ElA-412, "Annual Report of Public Electric Utilities." 
Table 21. Statement of Income by Major U.S. Publicly Owned Electric Utility Within State, 1992 (Continued)

(Thousand Dollars)

\begin{tabular}{|c|c|c|c|c|c|c|}
\hline Item & $\begin{array}{l}\text { Virginia } \\
\text { Bedford } \\
\text { City of } \\
\text { June } 30\end{array}$ & $\begin{array}{l}\text { Virginia } \\
\text { Bristol } \\
\text { Virginia } \\
\text { Utilities Bd } \\
\text { June } 30\end{array}$ & $\begin{array}{l}\text { Virginia } \\
\text { Danville } \\
\text { City of } \\
\text { June } 30\end{array}$ & $\begin{array}{c}\text { Virginia } \\
\begin{array}{c}\text { Harrisonburg } \\
\text { City of }\end{array} \\
\text { Jurie } 30\end{array}$ & $\begin{array}{l}\text { Virginia } \\
\text { Manassas } \\
\text { City of } \\
\text { June } 30\end{array}$ & $\begin{array}{l}\text { Virginia } \\
\begin{array}{c}\text { Martinsville } \\
\text { City of }\end{array} \\
\text { June } 30\end{array}$ \\
\hline Electric UtIIIty Operating Revenues ............. & 10,500 & 27,943 & 39,175 & 29,290 & 17,701 & 10,173 \\
\hline 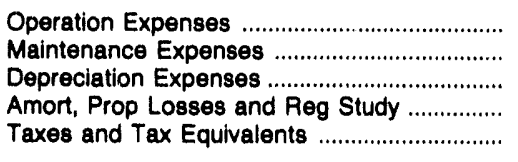 & $\begin{array}{r}7,860 \\
36 \\
502 \\
0 \\
0\end{array}$ & $\begin{array}{r}25,821 \\
401 \\
643 \\
0 \\
486\end{array}$ & $\begin{array}{r}29,011 \\
934 \\
1,251 \\
0 \\
0\end{array}$ & $\begin{array}{r}23,020 \\
452 \\
1,236 \\
182 \\
469\end{array}$ & $\begin{array}{r}14,012 \\
320 \\
1,188 \\
0 \\
385\end{array}$ & $\begin{array}{r}7,487 \\
434 \\
617 \\
0 \\
79\end{array}$ \\
\hline $\begin{array}{l}\text { Total Eloctric Utility Operating } \\
\text { Expeneses }\end{array}$ & 8,398 & 27,351 & 31,196 & 25,059 & 15,906 & 8,616 \\
\hline 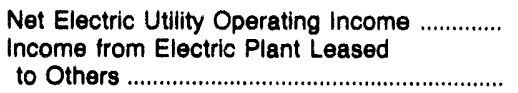 & $\begin{array}{r}2,102 \\
0\end{array}$ & $\begin{array}{r}592 \\
0\end{array}$ & $\begin{array}{r}7,980 \\
75\end{array}$ & $\begin{array}{r}4,231 \\
0\end{array}$ & $\begin{array}{r}1,796 \\
0\end{array}$ & $\begin{array}{r}1,557 \\
0\end{array}$ \\
\hline Electric Utility Operating Income ............... & 2,102 & 592 & 8,054 & 4,231 & 1,796 & 1,557 \\
\hline 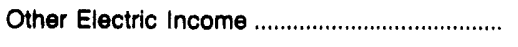 & 88 & 265 & 70 & 35 & 1,051 & 63 \\
\hline $\begin{array}{l}\text { Other Electric Deductions ........................... } \\
\text { Allowance for Other Funds Used }\end{array}$ & 0 & 0 & 6,544 & 0 & 0 & 1,852 \\
\hline 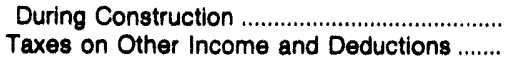 & $\begin{array}{l}0 \\
0\end{array}$ & $\begin{array}{l}0 \\
0\end{array}$ & $\begin{array}{l}0 \\
0\end{array}$ & $\begin{array}{l}0 \\
0\end{array}$ & $\begin{array}{l}0 \\
0\end{array}$ & $\begin{array}{l}0 \\
0\end{array}$ \\
\hline Eloctric Utility Income & 2,190 & 857 & 1,580 & 4,286 & 2,847 & -232 \\
\hline 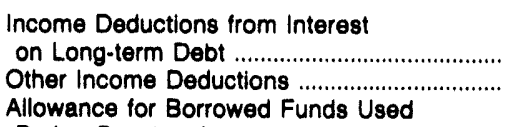 & $\begin{array}{l}1,263 \\
1,615\end{array}$ & $\begin{array}{r}7 \\
16\end{array}$ & $\begin{array}{r}110 \\
0\end{array}$ & $\begin{array}{r}182 \\
14\end{array}$ & $\begin{array}{r}827 \\
0\end{array}$ & $\begin{array}{l}0 \\
0\end{array}$ \\
\hline 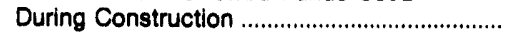 & 0 & 0 & 0 & 0 & 0 & 0 \\
\hline Total Income Deductions ............................... & 2,878 & 23 & 110 & 196 & 827 & $\mathbf{0}$ \\
\hline Income Before Extraordinary Items .................... & -688 & 834 & 1,470 & 4,070 & 2,020 & -232 \\
\hline Extraordinary Income & 0 & 0 & 0 & 0 & 0 & 0 \\
\hline 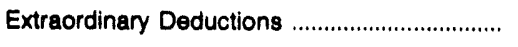 & 0 & 0 & 0 & 0 & 7 & 0 \\
\hline Not Income & -688 & 834 & 1,470 & 4,070 & 2,013 & -232 \\
\hline
\end{tabular}

Note: Totals may not equal sum of components because of independent rounding.

Source: Energy Information Administration, Form EIA-412, "Annual Report of Public Electric Utilities." 
Table 21. Statement of Income by Major U.S. Publicly Owned Electric Utillty Within State, 1992 (Continued)

(Thousand Dollars)

\begin{tabular}{|c|c|c|c|c|c|c|}
\hline Item & $\begin{array}{l}\text { Virginia } \\
\text { Radford } \\
\text { City of } \\
\text { June } 30\end{array}$ & $\begin{array}{l}\text { Virginia } \\
\text { Salem } \\
\text { City of } \\
\text { June } 30\end{array}$ & $\begin{array}{c}\text { Virginia } \\
\text { Virginia } \\
\text { Tech } \\
\text { Electric } \\
\text { Service } \\
\text { June } 30\end{array}$ & $\begin{array}{c}\text { Washington } \\
\text { Centralia } \\
\text { City of } \\
\text { December } 31\end{array}$ & $\begin{array}{c}\text { Washington } \\
\text { Ellensburg } \\
\text { City of }\end{array}$ & $\begin{array}{l}\text { Washington } \\
\begin{array}{c}\text { Port Angeles } \\
\text { City of }\end{array} \\
\text { December } 31\end{array}$ \\
\hline Electric Utility Operating Rovenues ............. & 12,334 & 15,532 & 10,967 & 6,685 & 6,314 & 19,680 \\
\hline $\begin{array}{l}\text { Operation Expenses } \\
\text { Maintenance Expenses } \\
\text { Depreciation Expenses } \\
\text { Amort, Prop Losses and Reg Study } \\
\text { Taxes and Tax Equivalents }\end{array}$ & $\begin{array}{r}9,963 \\
324 \\
827 \\
0 \\
100\end{array}$ & $\begin{array}{r}12,643 \\
190 \\
782 \\
0 \\
635\end{array}$ & $\begin{array}{r}9,535 \\
636 \\
0 \\
0 \\
250\end{array}$ & $\begin{array}{r}6,691 \\
408 \\
428 \\
6 \\
574\end{array}$ & $\begin{array}{r}4,523 \\
288 \\
359 \\
0 \\
222\end{array}$ & $\begin{array}{r}17,192 \\
802 \\
614 \\
0 \\
1,920\end{array}$ \\
\hline $\begin{array}{l}\text { Total Electric Utillty Oporating } \\
\text { Expeneos }\end{array}$ & 11,214 & 14,250 & 10,421 & 8,108 & 5,391 & 20,527 \\
\hline 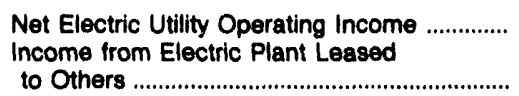 & $\begin{array}{r}1,120 \\
0\end{array}$ & $\begin{array}{r}1,281 \\
0\end{array}$ & $\begin{array}{r}546 \\
0\end{array}$ & $-1,423$ & $\begin{array}{r}923 \\
0\end{array}$ & $\begin{array}{r}-847 \\
0\end{array}$ \\
\hline Electric Utility Operating Income ............. & 1,120 & 1,281 & 546 & $-1,423$ & 923 & -847 \\
\hline Other Electric Income & 313 & 79 & 97 & 971 & 532 & 331 \\
\hline $\begin{array}{l}\text { Other Electric Deductions ............................ } \\
\text { Allowance for Other Funds Used }\end{array}$ & 1,456 & 0 & 0 & 0 & 311 & 0 \\
\hline 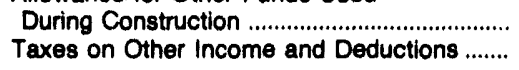 & $\begin{array}{l}0 \\
0\end{array}$ & $\begin{array}{l}0 \\
0\end{array}$ & $\begin{array}{l}0 \\
0\end{array}$ & $\begin{array}{l}0 \\
0\end{array}$ & $\begin{array}{r}0 \\
404\end{array}$ & $\begin{array}{l}0 \\
0\end{array}$ \\
\hline Electric Utility Income & -22 & 1,360 & 643 & -451 & 740 & -516 \\
\hline 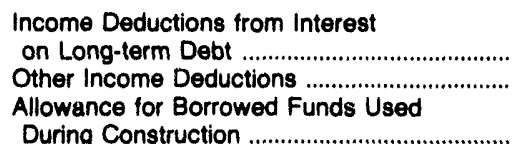 & $\begin{array}{r}194 \\
0\end{array}$ & $\begin{array}{r}802 \\
0\end{array}$ & $\begin{array}{r}193 \\
86\end{array}$ & $\begin{array}{l}77 \\
40\end{array}$ & $\begin{array}{r}79 \\
1\end{array}$ & $\begin{array}{r}54 \\
39 \\
0\end{array}$ \\
\hline 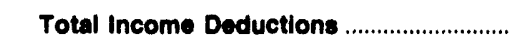 & 194 & 802 & 279 & 117 & 80 & 93 \\
\hline Income Before Extraordinary Items .................... & -216 & 559 & 363 & -569 & 660 & -609 \\
\hline Extraordinary Income & 0 & 0 & 0 & 0 & 0 & 0 \\
\hline 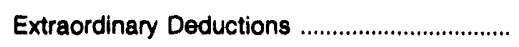 & 0 & 705 & 145 & 0 & 0 & 0 \\
\hline Not Income & -216 & -146 & 218 & -569 & 660 & -609 \\
\hline
\end{tabular}

Note: Totals may not equal sum of components because of independent rounding.

Source: Energy Information Administration, Form EIA-412, "Annual Report of Public Electric Utilities." 
Table 21. Statement of Income by Major U.S. Publicly Owned Electric Utility Within State, 1992 (Continued)

(Thousand Dollars)

\begin{tabular}{|c|c|c|c|c|c|c|}
\hline Item & $\begin{array}{l}\text { Washington } \\
\text { PUD No } 1 \\
\text { of } \\
\text { Benton } \\
\text { County } \\
\text { December } 31\end{array}$ & $\begin{array}{c}\text { Washington } \\
\text { PUD No } 1 \\
\text { of } \\
\text { Chelan } \\
\text { County } \\
\text { December } 31\end{array}$ & $\begin{array}{l}\text { Washington } \\
\text { PUD No } 1 \text { of } \\
\text { Clallam } \\
\text { County } \\
\text { December } 31\end{array}$ & $\begin{array}{l}\text { Washington } \\
\text { PUD No } 1 \\
\text { of } \\
\text { Clark } \\
\text { County } \\
\text { December } 31\end{array}$ & $\begin{array}{l}\text { Washington } \\
\text { PUD No } 1 \text { of } \\
\text { Cowlitz } \\
\text { County } \\
\text { December } 31\end{array}$ & $\begin{array}{l}\text { Washington } \\
\text { PUD No } 1 \text { of } \\
\text { Douglas } \\
\text { County } \\
\text { December } 31\end{array}$ \\
\hline Electric Utilty Operating Revenues .............. & 50,070 & 106,400 & 21,435 & 115,729 & 116,456 & 31,854 \\
\hline 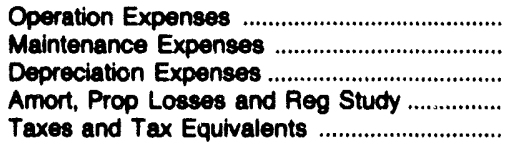 & $\begin{array}{r}37,002 \\
2,015 \\
2,898 \\
0 \\
5,390\end{array}$ & $\begin{array}{r}39,555 \\
11,358 \\
12,607 \\
32 \\
4,646\end{array}$ & $\begin{array}{r}15,681 \\
1,018 \\
1,738 \\
0 \\
660\end{array}$ & $\begin{array}{r}94,534 \\
2,791 \\
7,585 \\
38 \\
6,329\end{array}$ & $\begin{array}{r}101,759 \\
1,663 \\
3,176 \\
72 \\
5,809\end{array}$ & $\begin{array}{r}10,788 \\
2,855 \\
3,438 \\
0 \\
1,462\end{array}$ \\
\hline $\begin{array}{l}\text { Total Eloctric Utility Operating } \\
\text { Expenese }\end{array}$ & 47,305 & 68,198 & 19,097 & 111,278 & 112,479 & 18,543 \\
\hline $\begin{array}{l}\text { Net Electric Utility Operating Inceme } \\
\text { Income from Electric Plant Leased } \\
\text { to Others }\end{array}$ & $\begin{array}{r}2,765 \\
0\end{array}$ & $\begin{array}{r}38,202 \\
0\end{array}$ & $\begin{array}{r}2,338 \\
0\end{array}$ & $\begin{array}{r}4,451 \\
24\end{array}$ & $\begin{array}{r}3,977 \\
0\end{array}$ & $\begin{array}{r}13,312 \\
0\end{array}$ \\
\hline Electric Utility Operating Incomo .............. & 2,765 & 38,202 & 2,338 & 4,475 & 3,977 & 13,312 \\
\hline 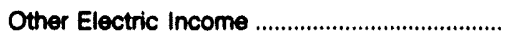 & 5,093 & 9,244 & 389 & 4,404 & 612 & 3,182 \\
\hline $\begin{array}{l}\text { Other Electric Deductions } \\
\text { Aliowance for Cther Funds Used............................. }\end{array}$ & 0 & 0 & 0 & 4,081 & 544 & 36 \\
\hline 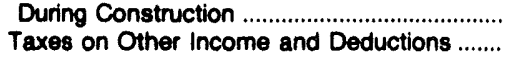 & $\begin{array}{l}0 \\
0\end{array}$ & $\begin{array}{l}0 \\
0\end{array}$ & $\begin{array}{r}0 \\
456\end{array}$ & $\begin{array}{l}0 \\
0\end{array}$ & $\begin{array}{l}0 \\
0\end{array}$ & $\begin{array}{l}0 \\
0\end{array}$ \\
\hline 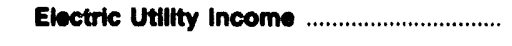 & 7,858 & 47,446 & 2,270 & 4,798 & 4,045 & 16,458 \\
\hline 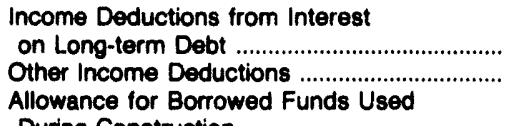 & $\begin{array}{r}2,979 \\
127\end{array}$ & $\begin{array}{r}43,556 \\
1,369\end{array}$ & $\begin{array}{r}469 \\
18\end{array}$ & $\begin{array}{r}4,559 \\
238\end{array}$ & $\begin{array}{r}151 \\
3\end{array}$ & $\begin{array}{r}10,205 \\
634\end{array}$ \\
\hline 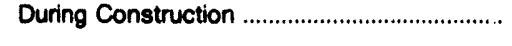 & 0 & 0 & 15 & 0 & 0 & 0 \\
\hline Total Income Deductions ................................ & 3,106 & 44,925 & 502 & 4,797 & 153 & 10,839 \\
\hline Income Before Extraordinary Items ................... & 4,753 & 2,521 & 1,768 & 1 & 3,891 & 5,619 \\
\hline Extraordinary Income & 0 & 0 & 0 & 7,400 & 0 & 0 \\
\hline 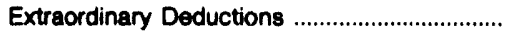 & 0 & 1,276 & 567 & 0 & 0 & 0 \\
\hline Net Income & 4,753 & 1,245 & 1,201 & 7,401 & 3,891 & 5,619 \\
\hline
\end{tabular}

Note: Totals may not equal sum of components because of independent rounding.

Source: Energy Information Administration, Form ElA-412, "Annual Report of Public Electric Utilities." 
Table 21. Statement of Income by Major U.S. Publicly Owned Electric Utility Within State, 1992 (Continued) (Thousand Dollars)

\begin{tabular}{|c|c|c|c|c|c|c|}
\hline Item & $\begin{array}{l}\text { Washington } \\
\text { PUD No } 1 \text { of } \\
\text { Franklin } \\
\text { County } \\
\text { December } 31\end{array}$ & $\begin{array}{c}\text { Washington } \\
\text { PUD No } 1 \\
\text { of } \\
\text { Grays } \\
\text { Harbor Cnty } \\
\text { December } 31\end{array}$ & $\begin{array}{l}\text { Washington } \\
\text { PUD No } 1 \text { of } \\
\text { Klickitat } \\
\text { County } \\
\text { December } 31\end{array}$ & $\begin{array}{c}\text { Washington } \\
\text { PUD No } 1 \\
\text { of } \\
\text { Lewis } \\
\text { County } \\
\text { December } 31\end{array}$ & $\begin{array}{l}\text { Washington } \\
\text { PUD No } 1 \text { of } \\
\text { Okanogan } \\
\text { County }\end{array}$ & $\begin{array}{l}\text { Washington } \\
\text { PUD No } 1 \text { of } \\
\text { Pend Oreille } \\
\text { Cnty } \\
\text { December } 31\end{array}$ \\
\hline Electric Utulty Operating Rovenues ............ & 22,661 & 52,203 & 10,883 & 24,935 & 14,347 & 19,105 \\
\hline 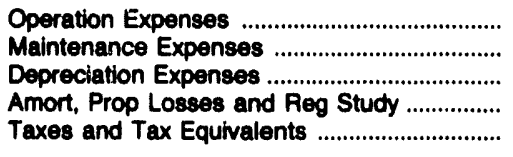 & $\begin{array}{r}17,360 \\
819 \\
1,098 \\
0 \\
1,499\end{array}$ & $\begin{array}{r}38,303 \\
5,350 \\
2,872 \\
0 \\
2,696\end{array}$ & $\begin{array}{r}7,672 \\
553 \\
851 \\
0 \\
748\end{array}$ & $\begin{array}{r}17,739 \\
1,331 \\
1,282 \\
0 \\
1,865\end{array}$ & $\begin{array}{r}9,336 \\
648 \\
1,496 \\
32 \\
1,374\end{array}$ & $\begin{array}{r}13,379 \\
1,137 \\
924 \\
0 \\
1,115\end{array}$ \\
\hline $\begin{array}{l}\text { Total Electric Utility Operating } \\
\text { Expenses }\end{array}$ & 20,776 & 49,221 & 8,824 & 22,217 & 12,886 & 16,556 \\
\hline 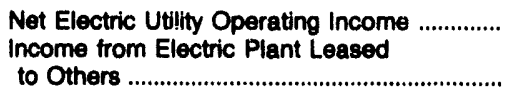 & 1,885 & $\begin{array}{r}2,982 \\
0\end{array}$ & $\begin{array}{r}1,039 \\
0\end{array}$ & $\begin{array}{r}2,718 \\
0\end{array}$ & $\begin{array}{r}1,461 \\
0\end{array}$ & $\begin{array}{r}2,549 \\
0\end{array}$ \\
\hline Electric Utility Operating Income ............. & 1,885 & 2,892 & 1,039 & 2,718 & 1,461 & 2,549 \\
\hline 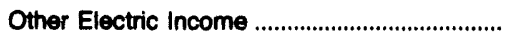 & 747 & 2,260 & 254 & 1,738 & 810 & 687 \\
\hline $\begin{array}{l}\text { Other Electric Deductions .......................................... } \\
\text { Allowance for Other Funds Used }\end{array}$ & 0 & 3 & 0 & 0 & 31 & 275 \\
\hline 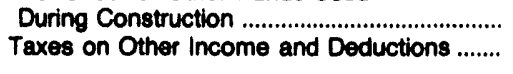 & $\begin{array}{l}0 \\
0\end{array}$ & $\begin{array}{l}0 \\
0\end{array}$ & $\begin{array}{l}0 \\
0\end{array}$ & $\begin{array}{l}0 \\
0\end{array}$ & $\begin{array}{l}0 \\
0\end{array}$ & $\begin{array}{l}0 \\
0\end{array}$ \\
\hline Electric Utilty Income ...................................... & 2,832 & 5,238 & 1,293 & 4,466 & 2,240 & 2,961 \\
\hline $\begin{array}{l}\text { Income Deductions from Interest } \\
\text { nn Long-term Debt ........................................... } \\
\text { Other Income Deductions ................................. } \\
\text { Allowance for Borrowed Funds Used }\end{array}$ & $\begin{array}{r}1,663 \\
92\end{array}$ & $\begin{array}{r}0 \\
3,341\end{array}$ & $\begin{array}{r}640 \\
8\end{array}$ & $\begin{array}{l}0 \\
0\end{array}$ & $\begin{array}{l}0 \\
0\end{array}$ & $\begin{array}{l}260 \\
111\end{array}$ \\
\hline 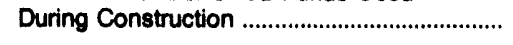 & 0 & 0 & 0 & 0 & 0 & 0 \\
\hline 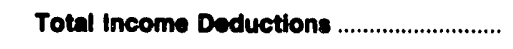 & 1,755 & 3,341 & 648 & 0 & $\mathbf{0}$ & 371 \\
\hline Income Before Extraordinary Items .................. & 877 & 1,897 & 645 & 4,456 & 2,240 & 2,589 \\
\hline 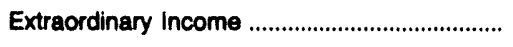 & 377 & 3,099 & 697 & 0 & 871 & 4 \\
\hline 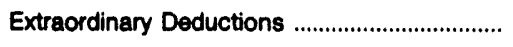 & 0 & 0 & 0 & 0 & 0 & 0 \\
\hline 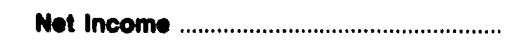 & 1,255 & 4,996 & 1,341 & 4,456 & 3,111 & 2,594 \\
\hline
\end{tabular}

Note: Totals may not equal sum of components because of independent rounding.

Source: Energy Information Administration, Form EIA-412, "Annual Report of Public Electric Utilities." 
Table 21. Statement of Income by Major U.S. Publlcly Owned Electric Utility Within State, 1992 (Continued)

(Thousand Dollars)

\begin{tabular}{|c|c|c|c|c|c|c|}
\hline Item & $\begin{array}{l}\text { Washington } \\
\text { PUD No } 1 \text { of } \\
\text { Snohomish } \\
\text { County } \\
\text { December } 31\end{array}$ & $\begin{array}{l}\text { Washington } \\
\text { PUD No } 1 \text { of } \\
\text { Whatcom } \\
\text { County } \\
\text { December } 31\end{array}$ & $\begin{array}{c}\text { Washington } \\
\text { PUD No } 2 \\
\text { of } \\
\text { Grant } \\
\text { County } \\
\text { December } 31\end{array}$ & $\begin{array}{l}\text { Washington } \\
\text { PUD No } 2 \text { of } \\
\text { Pacific } \\
\text { County } \\
\text { December } 31\end{array}$ & $\begin{array}{c}\text { Washington } \\
\text { PUD No } 3 \\
\text { of } \\
\text { Mason } \\
\text { Couniy } \\
\text { December } 31\end{array}$ & $\begin{array}{l}\text { Washington } \\
\text { Richland } \\
\text { City of } \\
\text { December } 31\end{array}$ \\
\hline Electric Uthlty Operating Rovenues ............ & 244,603 & 3,347 & 85,433 & 10,778 & 20,513 & 22,503 \\
\hline 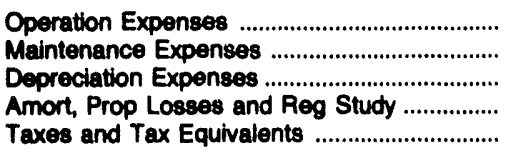 & $\begin{array}{r}184,122 \\
10,094 \\
19,183 \\
0 \\
10,700\end{array}$ & $\begin{array}{r}3,317 \\
20 \\
20 \\
0 \\
212\end{array}$ & $\begin{array}{r}31,629 \\
20,358 \\
13,828 \\
0 \\
3,959\end{array}$ & $\begin{array}{r}8,070 \\
681 \\
1,006 \\
0 \\
690\end{array}$ & $\begin{array}{r}14,851 \\
1,297 \\
1,788 \\
0 \\
626\end{array}$ & $\begin{array}{r}17,533 \\
582 \\
969 \\
0 \\
2,347\end{array}$ \\
\hline $\begin{array}{l}\text { Total Eloctric Utility Operating } \\
\text { Expenses }\end{array}$ & 224,008 & 3,668 & 69,775 & 10,447 & 18,562 & 21,432 \\
\hline $\begin{array}{l}\text { Net Electric Utility Operating Income .............. } \\
\text { Income from Electric Plant Leased }\end{array}$ & 20,405 & -222 & 15,659 & 331 & 1,951 & 1,071 \\
\hline to Others & 0 & 0 & 0 & 0 & 0 & 0 \\
\hline Electric Utility Operating Income ............. & 20,405 & -222 & 15,659 & 331 & 1,951 & 1,071 \\
\hline 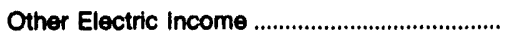 & 8,298 & 140 & 8,801 & 767 & 500 & 665 \\
\hline $\begin{array}{l}\text { Other Electric Deductions ................................. } \\
\text { Allowance for Other Funds Used }\end{array}$ & 0 & 0 & 0 & 476 & 0 & 0 \\
\hline $\begin{array}{l}\text { During Construction ......................................... } \\
\text { Taxes on Other Income and Deductions ........ }\end{array}$ & $\begin{array}{r}1,153 \\
0\end{array}$ & $\begin{array}{l}0 \\
0\end{array}$ & $\begin{array}{l}0 \\
0\end{array}$ & $\begin{array}{l}0 \\
0\end{array}$ & $\begin{array}{l}0 \\
0\end{array}$ & $\begin{array}{l}0 \\
0\end{array}$ \\
\hline 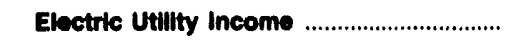 & 29,857 & -81 & 24,460 & 623 & 2,450 & 1,736 \\
\hline 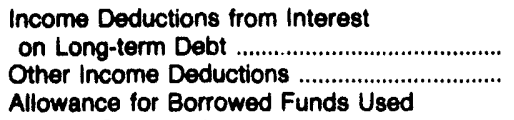 & $\begin{array}{r}33,742 \\
3,847\end{array}$ & $\begin{array}{l}0 \\
0\end{array}$ & $\begin{array}{r}16,962 \\
341\end{array}$ & $\begin{array}{r}242 \\
7\end{array}$ & $\begin{array}{r}556 \\
22\end{array}$ & $\begin{array}{r}1,406 \\
338\end{array}$ \\
\hline 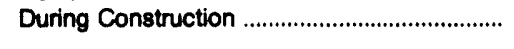 & 0 & 0 & 0 & 0 & 0 & 0 \\
\hline 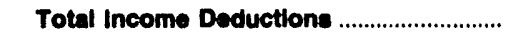 & 37,589 & $\mathbf{0}$ & 17,303 & 249 & 579 & 1,744 \\
\hline Income Before Extraordinary Items .................. & $-7,732$ & -81 & 7,157 & 373 & 1,872 & -8 \\
\hline 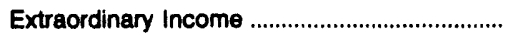 & 0 & 0 & 0 & 870 & 689 & 0 \\
\hline 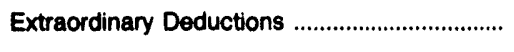 & 0 & 0 & 645 & 692 & 0 & 0 \\
\hline 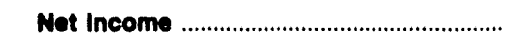 & $-7,732$ & -81 & 6,512 & 551 & 2,561 & -8 \\
\hline
\end{tabular}

Note: Totals may not equal sum of components because of independent rounding.

Source: Energy Information Administration, Form ElA-412, "Annual Report of Public Electric Utilities." 


\section{Table 21. Statement of Income by Major U.S. Publicly Owned Electric Utility Within State, 1992 (Continued) (Thousand Dollars)}

\begin{tabular}{|c|c|c|c|c|c|c|}
\hline Item & $\begin{array}{c}\text { Washington } \\
\text { Seattle } \\
\text { City of } \\
\text { December } 31\end{array}$ & $\begin{array}{c}\text { Washington } \\
\text { Tacoma } \\
\text { City of } \\
\text { December } 31\end{array}$ & $\begin{array}{c}\text { Washington } \\
\text { Vera } \\
\text { Irrigation } \\
\text { District \#15 } \\
\text { December } 31\end{array}$ & $\begin{array}{l}\text { Washington } \\
\text { Washington } \\
\text { Pub } \\
\text { Pwr } \\
\text { Supply Sys } \\
\text { June } 30\end{array}$ & $\begin{array}{l}\text { Wisconsin } \\
\text { Badger Power } \\
\begin{array}{c}\text { Marketing } \\
\text { Auth }\end{array} \\
\text { December } 31\end{array}$ & $\begin{array}{c}\text { Wisconsin } \\
\text { Jefferson } \\
\text { City of } \\
\text { December } 31\end{array}$ \\
\hline Electric Utility Operating Revenues ............ & 294,958 & 192,557 & 6,081 & 439,370 & 9,083 & 5,923 \\
\hline 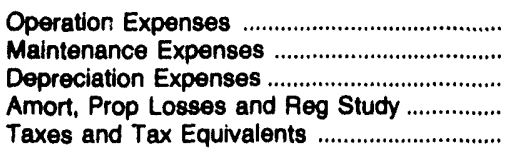 & $\begin{array}{r}201,217 \\
21,409 \\
28,216 \\
0 \\
31,818\end{array}$ & $\begin{array}{r}126,816 \\
18,077 \\
16,200 \\
27 \\
19,246\end{array}$ & $\begin{array}{r}4,805 \\
265 \\
382 \\
0 \\
224\end{array}$ & $\begin{array}{r}131,008 \\
40,898 \\
105,031 \\
109 \\
1,390\end{array}$ & $\begin{array}{r}8,131 \\
7 \\
152 \\
36 \\
141\end{array}$ & $\begin{array}{r}5,309 \\
35 \\
181 \\
0 \\
148\end{array}$ \\
\hline $\begin{array}{l}\text { Total Electric Utility Operating } \\
\text { Expenses }\end{array}$ & 282,660 & 180,388 & 5,676 & 278,436 & 8,467 & 5,672 \\
\hline 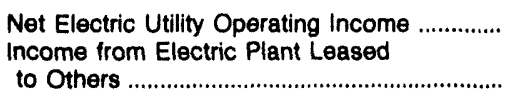 & $\begin{array}{r}12,298 \\
0\end{array}$ & 12,191 & $\begin{array}{r}385 \\
0\end{array}$ & $\begin{array}{r}160,934 \\
0\end{array}$ & $\begin{array}{r}617 \\
9\end{array}$ & $\begin{array}{r}251 \\
0\end{array}$ \\
\hline Electrlc Utility Operating Income .............. & 12,298 & 12,191 & 384 & 160,934 & 626 & 251 \\
\hline 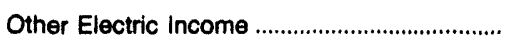 & 8,778 & 2,871 & 182 & 20,505 & 65 & 240 \\
\hline $\begin{array}{l}\text { Other Electric Deductions ................................ } \\
\text { Allowance for Other Funds Used }\end{array}$ & 255 & 332 & 8 & 3 & 0 & 16 \\
\hline $\begin{array}{l}\text { During Construction ....................................... } \\
\text { Taxes on Other Income and Deductions ....... }\end{array}$ & $\begin{array}{r}1,486 \\
0\end{array}$ & $\begin{array}{l}0 \\
0\end{array}$ & $\begin{array}{l}0 \\
0\end{array}$ & $\begin{array}{l}0 \\
0\end{array}$ & $\begin{array}{l}0 \\
0\end{array}$ & $\begin{array}{l}0 \\
0\end{array}$ \\
\hline 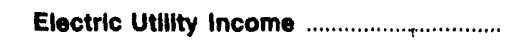 & 22,307 & 14,730 & 559 & 181,436 & 691 & 474 \\
\hline 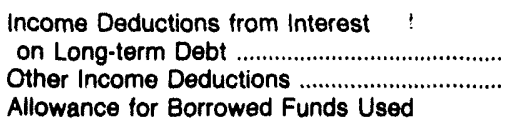 & $\begin{array}{r}32,726 \\
3,644\end{array}$ & $\begin{array}{r}25,396 \\
669\end{array}$ & $\begin{array}{l}85 \\
20\end{array}$ & $\begin{array}{r}170,637 \\
5,266\end{array}$ & $\begin{array}{r}489 \\
29\end{array}$ & $\begin{array}{r}349 \\
-186\end{array}$ \\
\hline 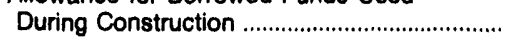 & 0 & $-6,777$ & 0 & 0 & 0 & 0 \\
\hline Total Income Deductions .............................. & 36,370 & 19,288 & 106 & 175,904 & 518 & 164 \\
\hline Income Before Extraordinary Items ................. & $-14,063$ & $-4,557$ & 453 & 5,532 & 173 & 310 \\
\hline 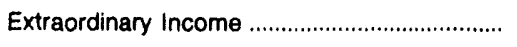 & 0 & 0 & 0 & 0 & 0 & 0 \\
\hline 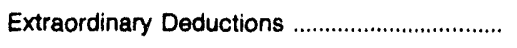 & 0 & 21,291 & 0 & 5,532 & 0 & 0 \\
\hline Net Income & $-14,063$ & $-25,848$ & 453 & $\mathbf{0}$ & 173 & 310 \\
\hline
\end{tabular}

Note: Totals may not equal sum of components because of independent rounding.

Source: Energy Information Administration, Form ElA-412, "Annual Report of Public Electric Utilities." 
Table 21. Statement of Income by Major U.S. Publicly Owned Electric Utllity Within State, 1992 (Continued) (Thousand Dollars)

\begin{tabular}{|c|c|c|c|c|c|c|}
\hline Item & $\begin{array}{c}\text { Wisconsin } \\
\text { Kaukauna } \\
\text { City of } \\
\text { December } 31\end{array}$ & $\begin{array}{c}\text { Wisconsin } \\
\text { Manitowoc } \\
\text { Public } \\
\text { Utilities } \\
\text { December } 31\end{array}$ & $\begin{array}{l}\text { Wisconsin } \\
\text { Marshfield } \\
\text { City of } \\
\text { December } 31\end{array}$ & $\begin{array}{c}\text { Wisconsin } \\
\text { Menasha } \\
\text { City of } \\
\text { Decemter } 31\end{array}$ & $\begin{array}{l}\text { Wisconsin } \\
\text { New London } \\
\text { City of } \\
\text { December } 31\end{array}$ & $\begin{array}{l}\text { Wisconsin } \\
\begin{array}{c}\text { Oconomowoc } \\
\text { City of }\end{array} \\
\text { December } 31\end{array}$ \\
\hline Electric. UtIlity Operating Rovenues ............. & 18,886 & 24,043 & 14,263 & 20,630 & 7,578 & 7,816 \\
\hline 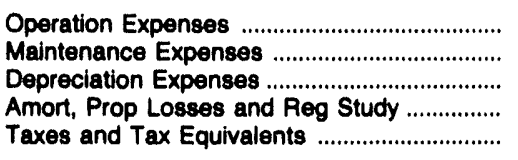 & $\begin{array}{r}15,015 \\
1,025 \\
929 \\
0 \\
904\end{array}$ & $\begin{array}{r}16,608 \\
1,146 \\
1,975 \\
63 \\
1,653\end{array}$ & $\begin{array}{r}11,539 \\
530 \\
536 \\
0 \\
558\end{array}$ & $\begin{array}{r}19,261 \\
712 \\
707 \\
22 \\
629\end{array}$ & $\begin{array}{r}6,579 \\
0 \\
212 \\
0 \\
190\end{array}$ & $\begin{array}{r}6,224 \\
159 \\
418 \\
32 \\
373\end{array}$ \\
\hline $\begin{array}{l}\text { Total Eloctric Utility Operating } \\
\text { Expenees }\end{array}$ & 17,872 & 21,446 & 13,163 & 21,332 & 6,980 & 7,206 \\
\hline $\begin{array}{l}\text { Net Electric Utility Operating Income } \\
\text { Income from Electric Plant Leased } \\
\text { to Others }\end{array}$ & $\begin{array}{r}1,013 \\
0\end{array}$ & $\begin{array}{r}2,597 \\
0\end{array}$ & $\begin{array}{r}1,100 \\
0\end{array}$ & $\begin{array}{r}-702 \\
0\end{array}$ & $\begin{array}{r}597 \\
0\end{array}$ & $\begin{array}{r}610 \\
0\end{array}$ \\
\hline Electric Utility Operating Income ............. & 1,013 & 2,597 & 1,100 & $-70 \%$ & 597 & 610 \\
\hline Other Electric Income & 549 & 527 & 114 & 151 & 0 & 133 \\
\hline $\begin{array}{l}\text { Other Electric Deductions } \\
\text { Allowance for Other Funds Used }\end{array}$ & 0 & 68 & 225 & 130 & 0 & 0 \\
\hline $\begin{array}{l}\text { During Construction ...................................... } \\
\text { Taxes on Other Income and Deductions ........ }\end{array}$ & $\begin{array}{r}0 \\
150\end{array}$ & $\begin{array}{l}0 \\
0\end{array}$ & $\begin{array}{l}0 \\
0\end{array}$ & $\begin{array}{l}0 \\
0\end{array}$ & $\begin{array}{r}0 \\
84\end{array}$ & $\begin{array}{l}0 \\
0\end{array}$ \\
\hline Eloctric Utility Income & 1,412 & 3,056 & 989 & -682 & 513 & 742 \\
\hline 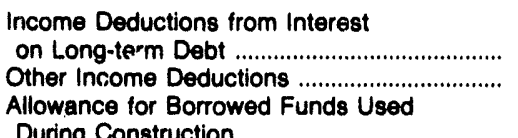 & $\begin{array}{r}1,131 \\
0\end{array}$ & $\begin{array}{r}1,701 \\
64\end{array}$ & $\begin{array}{r}158 \\
28\end{array}$ & $\begin{array}{r}461 \\
46\end{array}$ & $\begin{array}{l}0 \\
0\end{array}$ & $\begin{array}{r}145 \\
4\end{array}$ \\
\hline 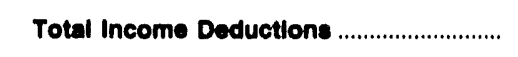 & 1,131 & 1,765 & 187 & 507 & 0 & 150 \\
\hline Income Before Extraordinary Items .................... & 281 & 1,291 & 802 & $-1,189$ & 513 & 593 \\
\hline Extraordinary Income & 0 & 0 & 0 & 0 & 0 & 0 \\
\hline 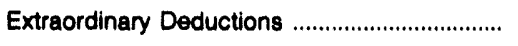 & 0 & 0 & 0 & 0 & 0 & 0 \\
\hline Not Income & 281 & 1,291 & 802 & $-1,189$ & 513 & 593 \\
\hline
\end{tabular}

Note: Totals may not equal sum of components because of independent rounding.

Source: Energy Information Administration, Form ElA-412, "Annual Report of Public Electric Utilities." 
Table 21. Statement of Income by Major U.S. Publicly Owned Electric Utility Within State, 1992 (Continued) (Thousand Dollars)

\begin{tabular}{|c|c|c|c|c|c|c|}
\hline Item & $\begin{array}{l}\text { Wisconsin } \\
\text { Plymouth } \\
\text { City of } \\
\text { December } 31\end{array}$ & $\begin{array}{c}\text { Wisconsin } \\
\text { Reedsburg } \\
\text { Utility Comm } \\
\text { December } 31\end{array}$ & $\begin{array}{c}\text { Wisconsin } \\
\text { Shawano } \\
\text { Municipal } \\
\text { Utilities } \\
\text { December } 31\end{array}$ & $\begin{array}{c}\text { Wisconsin } \\
\text { Sheboygan } \\
\text { Falls } \\
\text { City of } \\
\text { December } 31\end{array}$ & $\begin{array}{c}\text { Wisconsin } \\
\text { Sturgeon Bay } \\
\text { Combined } \\
\text { Utils }\end{array}$ & $\begin{array}{l}\text { Wisconsin } \\
\text { Wisconsin } \\
\text { Public } \\
\text { Power } \\
\text { Inc Sys } \\
\text { June } 30\end{array}$ \\
\hline Electrlc Utility Operating Revenuve ........... & 6,876 & 6,117 & 7,724 & 6,737 & 7,584 & 108,149 \\
\hline 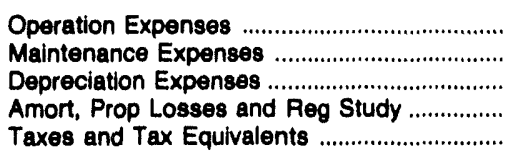 & $\begin{array}{r}5,638 \\
174 \\
363 \\
0 \\
266\end{array}$ & $\begin{array}{r}5,516 \\
56 \\
222 \\
12 \\
170\end{array}$ & $\begin{array}{r}6,589 \\
71 \\
273 \\
0 \\
164\end{array}$ & $\begin{array}{r}6,004 \\
0 \\
250 \\
0 \\
141\end{array}$ & $\begin{array}{r}5,760 \\
283 \\
508 \\
23 \\
410\end{array}$ & $\begin{array}{r}95,599 \\
843 \\
1,846 \\
935 \\
2,077\end{array}$ \\
\hline $\begin{array}{l}\text { Total Electric Utility Operating } \\
\text { Expenese }\end{array}$ & 6,442 & 5,976 & 7,097 & 6,395 & 6,984 & 101,300 \\
\hline 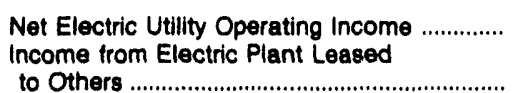 & 434 & 141 & $\begin{array}{l}626 \\
194\end{array}$ & 342 & 600 & 6,848 \\
\hline Electrle Utility Operating income ............. & 434 & 141 & 820 & 342 & 600 & 6,848 \\
\hline 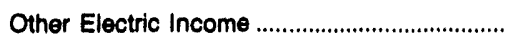 & 58 & 0 & 171 & 0 & 104 & 5,776 \\
\hline $\begin{array}{l}\text { Other Electric Deductions ............................. } \\
\text { Allowance for Other Funds Used } \\
\text { During Construction ........................................ } \\
\text { Taxes on Other income and Deductions ........ }\end{array}$ & $\begin{array}{l}17 \\
0 \\
0\end{array}$ & $\begin{array}{r}23 \\
0 \\
0\end{array}$ & $\begin{array}{r}58 \\
0 \\
98\end{array}$ & $\begin{array}{r}35 \\
0 \\
0\end{array}$ & $\begin{array}{l}0 \\
0\end{array}$ & 189 \\
\hline Electric Utility Income & 475 & 118 & 835 & 308 & 704 & 12,435 \\
\hline $\begin{array}{l}\text { Income Deductions from Interest } \\
\text { on Long-term Debt .......................................... } \\
\text { Other Income Deductions .............................. } \\
\text { Allowance for Borrowed Funds Used }\end{array}$ & $\begin{array}{r}0 \\
25\end{array}$ & $\begin{array}{l}0 \\
0\end{array}$ & $\begin{array}{r}143 \\
83\end{array}$ & $\begin{array}{l}0 \\
0\end{array}$ & $\begin{array}{r}493 \\
23\end{array}$ & $\begin{array}{r}11,013 \\
1,571\end{array}$ \\
\hline 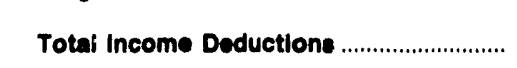 & 25 & $\mathbf{0}$ & 226 & 0 & 516 & 11,140 \\
\hline Income Before Extraordinary Items ................. & 450 & 118 & 609 & 308 & 188 & 1,295 \\
\hline Extraordinary Income & 0 & 0 & 126 & 0 & 0 & 0 \\
\hline 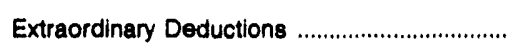 & 0 & 0 & 225 & 0 & 0 & 0 \\
\hline Net Income & 450 & 118 & 510 & 308 & 188 & 1,295 \\
\hline
\end{tabular}

Note: Totals may not equal sum of components because of independent rounding

Source: Energy Information Administration, Form ElA-412, "Annual Report of Public Electric Utilities." 
Table 21. Statement of Income by Major U.S. Publicly Owned Electric Utility Within State, 1992 (Continued)

(Thousand Dollars)

\begin{tabular}{|c|c|c|c|}
\hline Item & $\begin{array}{l}\text { Wisconsin } \\
\text { Wisconsin } \\
\text { Rapids W W } \\
\& \text { L } \\
\text { Comm } \\
\text { December } 31\end{array}$ & $\begin{array}{l}\text { Wyoming } \\
\text { Gillette } \\
\text { City of } \\
\text { June } 30\end{array}$ & $\begin{array}{c}\text { Wyoming } \\
\text { Wyoming } \\
\text { Municipal } \\
\text { Power Agency } \\
\text { December } 31\end{array}$ \\
\hline Electric Utllity Operating Rovenues ............ & 10,300 & 10,088 & 6,307 \\
\hline 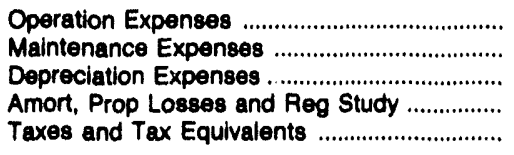 & $\begin{array}{r}8,069 \\
366 \\
567 \\
0 \\
517\end{array}$ & $\begin{array}{r}9,064 \\
0 \\
772 \\
33 \\
69\end{array}$ & $\begin{array}{r}3,036 \\
327 \\
649 \\
0 \\
85\end{array}$ \\
\hline $\begin{array}{l}\text { Total Electric UtIlity Oporating } \\
\text { Expeneee }\end{array}$ & 9,520 & 9,937 & 4,098 \\
\hline 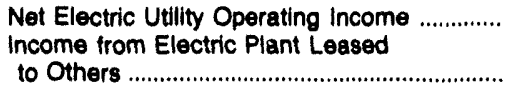 & $\begin{array}{r}781 \\
0\end{array}$ & $\begin{array}{r}150 \\
0\end{array}$ & $\begin{array}{r}1,209 \\
0\end{array}$ \\
\hline Flectric Utility Operating Income .............. & 781 & 150 & 1,209 \\
\hline Other Electric Income & 172 & 685 & 422 \\
\hline 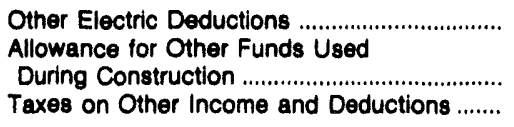 & $\begin{array}{l}43 \\
0 \\
0\end{array}$ & $\begin{array}{l}0 \\
0 \\
0\end{array}$ & $\begin{array}{l}0 \\
0 \\
0\end{array}$ \\
\hline Electric Utility Income & 910 & 835 & 1,031 \\
\hline 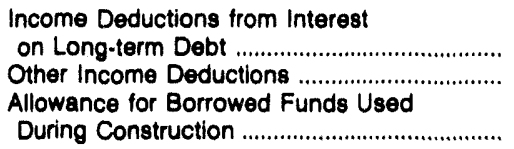 & $\begin{array}{r}38 \\
6 \\
0\end{array}$ & $\begin{array}{r}256 \\
0 \\
0\end{array}$ & $\begin{array}{r}1,317 \\
21 \\
0\end{array}$ \\
\hline Total Income Deductions .............................. & 44 & 256 & 1,338 \\
\hline Income Before Extraordinary Items ..................... & 866 & 579 & 294 \\
\hline Extraordinary Income & 0 & 0 & 0 \\
\hline 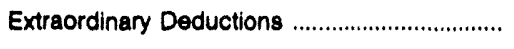 & 0 & 0 & 0 \\
\hline Not Income & 866 & 578 & 294 \\
\hline
\end{tabular}

Note: Totals may not equal sum of components because of independent rounding.

Source: Energy Information Administration, Form EIA-412, "Annual Report of Public Electric Utilities." 
Table 22. Balance Sheet by Major U.S. Publicly Owned Electric Utility Within State at End of Period, 1992 (Thousand Dollars)

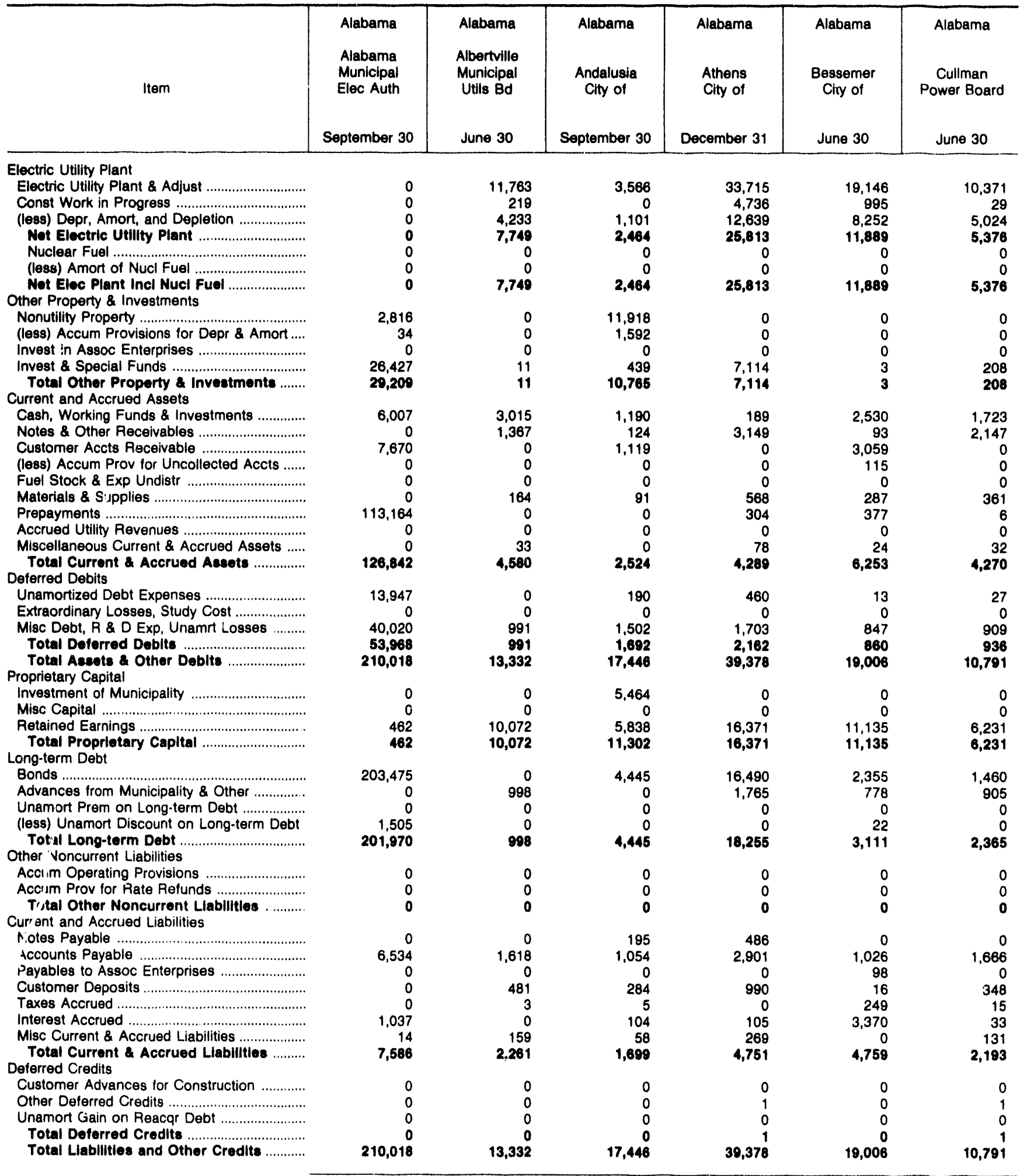

Note: Totals may not equal sum of components because of independent rounding.

Source: Energy Information Administration, Form ElA-412, "Annual Report of Public Electric Utilities." 
Table 22. Balance Sheet by Major U.S. Publicly Owned Electric Utility Within State at End of Perlod, 1992 (Continued) (Thousand Dollars)

\begin{tabular}{|c|c|c|c|c|c|c|}
\hline Item & $\begin{array}{l}\text { Alabama } \\
\text { Decatur } \\
\text { City of } \\
\text { June } 30\end{array}$ & $\begin{array}{l}\text { Alabama } \\
\text { Dothan } \\
\text { City of } \\
\text { September } 30\end{array}$ & $\begin{array}{l}\text { Alabama } \\
\text { Florence } \\
\text { City of } \\
\text { June } 30\end{array}$ & $\begin{array}{c}\text { Alabama } \\
\text { Foley } \\
\text { City of } \\
\text { (Riviera Utils) } \\
\text { December } 31\end{array}$ & $\begin{array}{c}\text { Alabama } \\
\text { Fort Payne } \\
\text { Improvement } \\
\text { Auth } \\
\text { June } 30\end{array}$ & $\begin{array}{l}\text { Alabama } \\
\text { Guntersville } \\
\text { Electric } \\
\text { Board } \\
\text { June } 30\end{array}$ \\
\hline \multicolumn{7}{|l|}{ Eloctric Utility Plant } \\
\hline 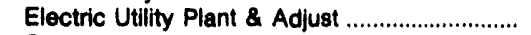 & 36,607 & 50,147 & 67,504 & 49,786 & 10,910 & 8,420 \\
\hline 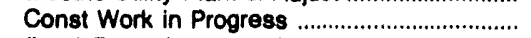 & 3,090 & & 955 & & 508 & 176 \\
\hline (less) Depr, Amort, and Depletion ................... & 15,200 & 17,980 & 27,091 & 15,787 & 3,888 & 3,824 \\
\hline Not Eloctric Utility Plant ................................. & 24,496 & 32,167 & 41,368 & 33,998 & 7,530 & 4,772 \\
\hline 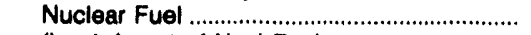 & & 0 & 0 & 0 & 0 & 0 \\
\hline 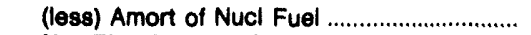 & & 0 & 0 & 0 & 0 & 0 \\
\hline $\begin{array}{l}\text { Not Elec Plant Incl Nucl Fuel .......................... } \\
\text { Other Property \& Investments }\end{array}$ & 24,496 & 32,167 & 41,368 & 33,998 & 7,530 & 4,772 \\
\hline 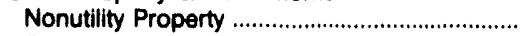 & 3 & 0 & 22 & 0 & 0 & 0 \\
\hline (less) Accum Provisions for Depr \& Amort .... & 0 & 0 & 0 & 0 & 0 & 0 \\
\hline 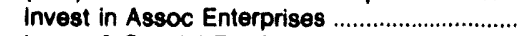 & 0 & 0 & 0 & 0 & 0 & 0 \\
\hline 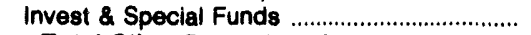 & 0 & 0 & 4,716 & 6,862 & 389 & 393 \\
\hline Total Other Proporty a Investments ........ & 3 & $\mathbf{0}$ & 4,738 & 6,862 & 389 & 393 \\
\hline \multicolumn{7}{|l|}{ Current and Accrued Assets } \\
\hline Cash, Working Funds \& Investments .............. & 4,243 & 6,281 & 2,057 & 6,471 & 2,048 & 762 \\
\hline Notes \& - her Receivables ................................. & 4,427 & 304 & 6,451 & & 1,226 & 826 \\
\hline 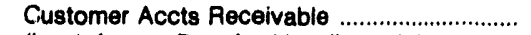 & 0 & 3,248 & 0 & 3,992 & 0 & 0 \\
\hline (less) Accum Prov for Uncollected Accts ...... & 0 & 0 & 0 & 37 & 0 & 0 \\
\hline 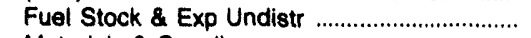 & 0 & 0 & 0 & 27 & 0 & 0 \\
\hline 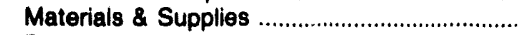 & 686 & 241 & 1,643 & 926 & 153 & 121 \\
\hline Prepayments & 0 & 0 & 38 & 803 & 33 & 50 \\
\hline 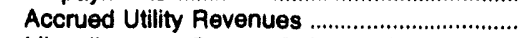 & 0 & 0 & 0 & 0 & 0 & 0 \\
\hline Miscellaneous Current \& Accrued Assets ..... & 0 & 60 & 125 & 69 & 48 & 50 \\
\hline \multicolumn{6}{|l|}{ Deferred Debits } & 1,809 \\
\hline Unamortized Debt Expenses ................................... & 0 & 0 & 163 & 318 & 119 & 20 \\
\hline 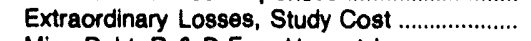 & 0 & 0 & 0 & 0 & 0 & 0 \\
\hline Misc Debt, R \& D Exp, Unamrt Losses .......... & 1,090 & 0 & 2,746 & 0 & 1,916 & 715 \\
\hline Total Doferred Doblis .................................... & 1,090 & & 2,810 & 318 & 2,035 & 735 \\
\hline Total Asects other Deblts ......................... & 34,946 & 42,300 & 59,330 & 53,430 & 13,460 & 7,708 \\
\hline \multicolumn{7}{|l|}{ Proprietary Capital } \\
\hline $\begin{array}{l}\text { Investment of Municipality ..................................... } \\
\text { Misc Capital }\end{array}$ & $\begin{array}{l}0 \\
0\end{array}$ & $\begin{array}{l}0 \\
0\end{array}$ & $\begin{array}{l}0 \\
0\end{array}$ & $\begin{array}{l}0 \\
0\end{array}$ & $\begin{array}{l}0 \\
0\end{array}$ & $\begin{array}{l}0 \\
0\end{array}$ \\
\hline 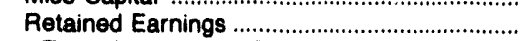 & 29,520 & 36,292 & 41,586 & 37,840 & 5,593 & 5,416 \\
\hline \multicolumn{7}{|l|}{ Long-term Debt } \\
\hline Bonds ..................... & 0 & 0 & 10,274 & 11,120 & 5,021 & 415 \\
\hline Advances from Municipality \& Other ................... & 873 & 0 & 2,817 & 0 & 660 & 745 \\
\hline Unamort Prem on Long-term Debt ..................... & 0 & 0 & $-4,502$ & 0 & -68 & 0 \\
\hline (less) Unamort Discount on Long-term Debt & 0 & 0 & & 0 & 0 & 0 \\
\hline Total Long-term Debt ................................... & 873 & 0 & 8,589 & 11,120 & 5,613 & 1,160 \\
\hline \multicolumn{7}{|l|}{ Other Noncurrent Liabilitios } \\
\hline 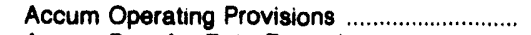 & 0 & 0 & 0 & 271 & 0 & 0 \\
\hline Accum Prov for Rate Refunds ............................ & 0 & 0 & 0 & 0 & 0 & 0 \\
\hline \multicolumn{2}{|l|}{ Current and Accrued Liabilities } & 0 & $\mathbf{0}$ & 271 & 0 & 0 \\
\hline Notes Payable .......................................... & 0 & 0 & 0 & 0 & 0 & 0 \\
\hline Accounts Payable & 4,448 & 3,057 & 5,004 & 1,958 & 1,453 & 829 \\
\hline Payables to Assoc Enterprises .......................... & 0 & 0 & & 0 & 0 & 0 \\
\hline 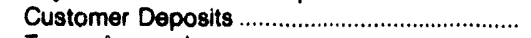 & 0 & 2,537 & 2,927 & 1,274 & 411 & 248 \\
\hline 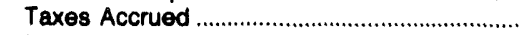 & 0 & -1 & 0 & 387 & 0 & 0 \\
\hline Interest Accrued & 0 & 0 & 112 & 375 & 60 & 6 \\
\hline Misc Current \& Accrued Liabilities .................. & 104 & 415 & 1,022 & 15 & 34 & 48 \\
\hline \multicolumn{7}{|l|}{ Deferred Credits } \\
\hline Customer Advances for Construction ............. & 0 & 0 & 0 & 0 & 0 & 0 \\
\hline Other Deferred Credits & 1 & 0 & 90 & 190 & 296 & 0 \\
\hline Unamort Gain on Reacqr Debt ..................................... & 0 & 0 & 0 & 0 & 0 & 0 \\
\hline Total Deferred Credits ................................... & 1 & 0 & 90 & 190 & 296 & \\
\hline Total Llabilities and Other Credite ............ & 34,946 & 42,300 & 69,330 & $\mathbf{5 3 , 4 3 0}$ & 13,460 & 7,708 \\
\hline
\end{tabular}

Note: Totals may not equal sum of components because of independent rounding.

Source: Energy information Administration, Form EIA-412, "Annual Report of Public Electric Utilities." 
Table 22. Balance Sheet by Major U.S. Publicly Owned Electric Utility Within State at End of Period, 1992 (Continued) (Thousand Dollars)

\begin{tabular}{|c|c|c|c|c|c|c|}
\hline Item & $\begin{array}{l}\text { Alabama } \\
\text { Huntsville } \\
\text { City of } \\
\text { September } 30\end{array}$ & $\begin{array}{l}\text { Alabama } \\
\text { Muscle } \\
\text { Shoals } \\
\text { City of } \\
\text { June } 30\end{array}$ & $\begin{array}{l}\text { Alabama } \\
\text { Opelika } \\
\text { City of } \\
\text { September } 30\end{array}$ & $\begin{array}{l}\text { Alabama } \\
\text { Scottsboro } \\
\text { City of } \\
\text { June } 30\end{array}$ & $\begin{array}{l}\text { Alabama } \\
\text { Shetfield } \\
\text { Utilities } \\
\text { June } 30\end{array}$ & $\begin{array}{c}\text { Alabama } \\
\text { Sylacauga } \\
\text { Utilities } \\
\text { Board } \\
\text { September } 30\end{array}$ \\
\hline Electric Utility Plant & & & & & & \\
\hline Electric Utility Plant \& Adjust .............................. & 147,474 & 11,671 & 16,287 & 13,941 & 30,559 & 10,059 \\
\hline Const Work in Progress & 1,312 & 980 & 159 & 110 & 1,410 & 0 \\
\hline 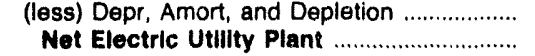 & $\begin{array}{l}54,514 \\
94,272\end{array}$ & $\begin{array}{l}3,702 \\
8,949\end{array}$ & $\begin{array}{l}9,248 \\
7,198\end{array}$ & $\begin{array}{l}4,762 \\
9,289\end{array}$ & $\begin{array}{l}13,343 \\
18,626\end{array}$ & $\begin{array}{l}6,054 \\
4,005\end{array}$ \\
\hline 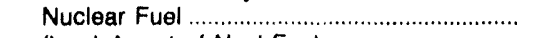 & 0 & 0 & 0 & 0 & 0 & 0 \\
\hline 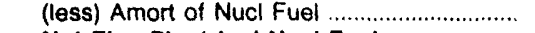 & 0 & 0 & 0 & 0 & 0 & 0 \\
\hline \\
\hline 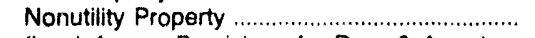 & 0 & 0 & 0 & 0 & 158 & 0 \\
\hline 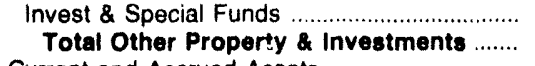 & $\begin{array}{l}9,480 \\
9,480\end{array}$ & $\begin{array}{l}175 \\
175\end{array}$ & $\begin{array}{l}1,148 \\
1,344\end{array}$ & $\begin{array}{l}646 \\
646\end{array}$ & $\begin{array}{l}2,128 \\
2,286\end{array}$ & $\begin{array}{l}3,454 \\
3,454\end{array}$ \\
\hline \multicolumn{7}{|l|}{ Current and Accrued Assets } \\
\hline Cash, Working Funds \& Investments ............... & 31,394 & 1,214 & 3,003 & -81 & 1,630 & 803 \\
\hline Notes \& Other Receivables ............................... & 9,382 & 1,059 & 1,226 & 1,341 & 2,427 & 0 \\
\hline Customer Accts Receivable ............................. & 0 & 0 & 2,386 & 0 & 0 & 909 \\
\hline (less) Accum Prov for Uncollected Accts ...... & 0 & 0 & 0 & 0 & 0 & 0 \\
\hline Fuel Stock \& Exp Undistr .................................. & 0 & 0 & 0 & 0 & 0 & 0 \\
\hline 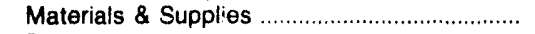 & 2,919 & 205 & 578 & 128 & 693 & 213 \\
\hline 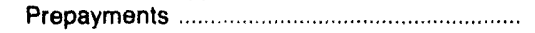 & 37 & 108 & 9 & 6 & 142 & 0 \\
\hline Accrued Utility Revenues .................................. & 0 & 0 & 0 & 0 & 0 & 0 \\
\hline Miscellaneous Current \& Accrued Assets ..... & 597 & 21 & 41 & 49 & 80 & 0 \\
\hline $\begin{array}{l}\text { Total Current \& Accrued Assets ................... } \\
\text { Deferred Debits }\end{array}$ & \multicolumn{5}{|c|}{ Deferred Debits } & 1,925 \\
\hline Unamortized Debt Expenses .............................. & 207 & 35 & 0 & 127 & 18 & 0 \\
\hline Extraordinary Losses, Study Cost ....................... & 0 & 0 & 0 & 0 & 0 & 0 \\
\hline Misc Debt, R \& D Exp, Unamrt Losses .......... & 2,127 & 616 & 0 & 1,101 & 1,671 & 0 \\
\hline $\begin{array}{l}\text { Total Deferred Deblts } \\
\text { Total Assets \& Other Deblts }\end{array}$ & $\begin{array}{r}2,334 \\
150,414\end{array}$ & $\begin{array}{r}651 \\
12,382\end{array}$ & $\begin{array}{r}0 \\
15,784\end{array}$ & $\begin{array}{r}1,228 \\
12,607\end{array}$ & $\begin{array}{r}1,688 \\
27,573\end{array}$ & $\begin{array}{r}0 \\
9,384\end{array}$ \\
\hline 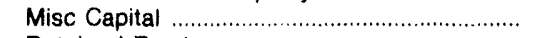 & 0 & 0 & 0 & 0 & 0 & 0 \\
\hline 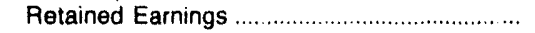 & 113,005 & 9,353 & 10,934 & 6,119 & 20,321 & 6,139 \\
\hline 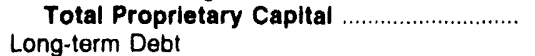 & \multicolumn{5}{|c|}{ Long-term Debt } & 6,139 \\
\hline 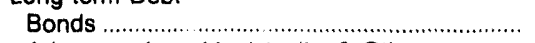 & 8,930 & 965 & 1,590 & 3,485 & 2,200 & 2,445 \\
\hline Advances from Municipality \& Other .............. & 1,460 & 547 & 1,349 & 1,108 & 1,716 & 0 \\
\hline Unamort Prem on Long-term Debt ..................... & 0 & 0 & 0 & 0 & 0 & 0 \\
\hline (less) Unamort Discount on Long-term Debt & 0 & 0 & 0 & 0 & 0 & 0 \\
\hline 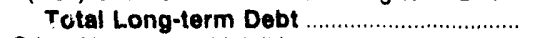 & 10,390 & 1,512 & 2,939 & 4,593 & 3,916 & 2,445 \\
\hline \multicolumn{7}{|l|}{ Other Noncurrent Liabilities } \\
\hline Accum Operating Provisions .............................. & 0 & 0 & 0 & 0 & 0 & 0 \\
\hline 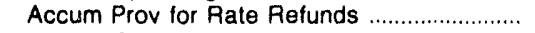 & 0 & 0 & 0 & 0 & 0 & 0 \\
\hline Total Other Noncurrent Llabllities ........... & 0 & $\mathbf{0}$ & 0 & $\mathbf{0}$ & 0 & 0 \\
\hline \multicolumn{7}{|l|}{ Current and Accrued Liabilities } \\
\hline 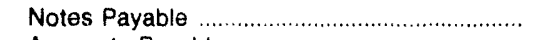 & 0 & 0 & 155 & 0 & 0 & 104 \\
\hline Accounts Payable & 16,434 & 1,041 & 1,162 & 1,081 & 2,302 & 428 \\
\hline Payables to Assoc Enterprises .......................... & 0 & 0 & 75 & 0 & 0 & 0 \\
\hline 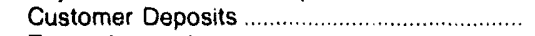 & 8,902 & 363 & 440 & 382 & 609 & 158 \\
\hline 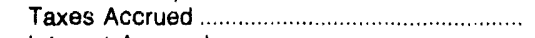 & 0 & 0 & 0 & 21 & 3 & 0 \\
\hline Interest Accruod & 47 & 16 & 10 & 153 & 23 & 88 \\
\hline Misc Current \& Accrued Liabilities .................... & 1,314 & 95 & 68 & 61 & 400 & 0 \\
\hline Total Current \& Accrued Llablilties ......... & 26,697 & 1,515 & 1,911 & 1,697 & 3,336 & 778 \\
\hline \multicolumn{7}{|l|}{ Deferred Credits } \\
\hline Customer Advances for Construction ............ & 0 & 1 & 0 & 0 & 0 & 22 \\
\hline 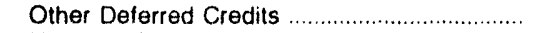 & 322 & 0 & 0 & 198 & 0 & 0 \\
\hline Unamort Gain on Reacar Debt ........................ & 0 & 0 & 0 & 0 & 0 & 0 \\
\hline $\begin{array}{l}\text { Total Deferred Credits } \\
\text { Total Liabllitles and Other Credits }\end{array}$ & $\begin{array}{r}322 \\
150,414\end{array}$ & $\begin{array}{r}1 \\
12,382\end{array}$ & $\begin{array}{r}0 \\
15,784\end{array}$ & $\begin{array}{r}198 \\
12,607\end{array}$ & $\begin{array}{r}0 \\
27,573\end{array}$ & $\begin{array}{r}22 \\
9,384\end{array}$ \\
\hline
\end{tabular}

Note: Totals may not equal sum of components because of independent rounding.

Source: Energy Information Administration. Form ElA-412. "Annual R6port of Public Electric Utilities." 
Table 22. Balance Sheet by Major U.S. Publicly Owned Electric Utility Within State at End of Period, 1992 (Continued) (Thousand Dollars)

\begin{tabular}{|c|c|c|c|c|c|c|}
\hline Item & $\begin{array}{c}\text { Alabama } \\
\text { Troy } \\
\text { City of } \\
\text { September } 30\end{array}$ & $\begin{array}{c}\text { Alabama } \\
\text { Tuskegee } \\
\text { City of } \\
\text { September } 30\end{array}$ & $\begin{array}{l}\text { Alaska } \\
\text { Alaska } \\
\text { Energy } \\
\text { Authority } \\
\text { June } 30\end{array}$ & $\begin{array}{c}\text { Anchorage } \\
\text { City of } \\
\text { December } 31\end{array}$ & $\begin{array}{c}\begin{array}{c}\text { Fairbanks } \\
\text { City of }\end{array} \\
\text { December } 31\end{array}$ & $\begin{array}{c}\text { Ketchikan } \\
\text { City of } \\
\text { December } 31\end{array}$ \\
\hline \multicolumn{7}{|l|}{ Electric Utility Plant } \\
\hline Electric Utility Plant \& Adjust ............................. & 9,451 & 6,810 & $917,42 \mathrm{C}$ & 246,610 & 47,336 & 42,162 \\
\hline 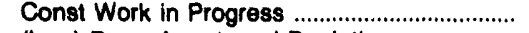 & 0 & 0 & 0 & 3,886 & 511 & 2,712 \\
\hline 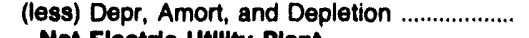 & 5,049 & 2,883 & 127,723 & 105,807 & 25,746 & 18,504 \\
\hline $\begin{array}{l}\text { Net Electrle Utility Plant ............................... } \\
\text { Nuclear Fuel }\end{array}$ & 4,402 & 3,927 & 789,697 & $\lcm{44,689}$ & 22,101 & 26,369 \\
\hline $\begin{array}{l}\text { Nuclear Fuel ........................................... } \\
\text { (less) Amort of Nuel }\end{array}$ & 0 & 0 & 0 & 0 & 0 & 0 \\
\hline 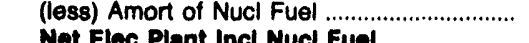 & 0 & 0 & 0 & 0 & 0 & 0 \\
\hline $\begin{array}{l}\text { Net Elec Plant Incl Nucl Fuel ........................... } \\
\text { Other Property \& Investments }\end{array}$ & 4,402 & 3,927 & 789,697 & 144,689 & 22,101 & 26,369 \\
\hline Nonutility Property & 0 & 0 & 4,352 & 0 & 250,107 & 0 \\
\hline (less) Accum Provisions for Depr \& Amort .... & 0 & 0 & 3,150 & 0 & 122,908 & 0 \\
\hline 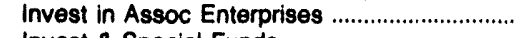 & 0 & 0 & 0 & 0 & 0 & 0 \\
\hline $\begin{array}{l}\text { Invest \& Special Funds } \\
\text { Total Other Property Investmente } \\
\text { Current and Accrued Assets }\end{array}$ & $\begin{array}{l}4,476 \\
4,476\end{array}$ & $\begin{array}{l}0 \\
0\end{array}$ & $\begin{array}{l}28,013 \\
29,214\end{array}$ & $\begin{array}{l}25,470 \\
25,470\end{array}$ & $\begin{array}{r}19,447 \\
146,646\end{array}$ & $\begin{array}{l}10,079 \\
10,079\end{array}$ \\
\hline Cash, Working Funds \& Investments ................. & 135 & 588 & 73,766 & 22,446 & 1,196 & 6,162 \\
\hline 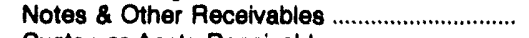 & 1,875 & 0 & 14,118 & 0 & 3,576 & 2,140 \\
\hline Customer Accts Receivable & 0 & 3,449 & 0 & 4,160 & 3,757 & 538 \\
\hline (less) Accum Prov for Uncollected Accts ...... & 0 & 0 & 0 & 275 & 269 & 150 \\
\hline 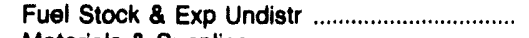 & 0 & 0 & 0 & 699 & 0 & 0 \\
\hline 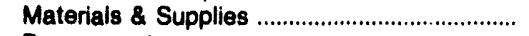 & 0 & 115 & 0 & 2,710 & 3,570 & 1,294 \\
\hline Prepayments & 8 & 0 & 0 & 1,752 & 180 & 312 \\
\hline 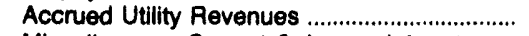 & 0 & 5 & 0 & 0 & 0 & 0 \\
\hline Miscellanoous Current \& Accrued Assets ..... & 221 & 429 & 2,975 & 444 & 0 & 735 \\
\hline $\begin{array}{l}\text { Total Current Accrued Aseets ............... } \\
\text { Deferred Debits }\end{array}$ & Deferred Debits & 4,585 & 90,859 & 31,936 & 12,011 & 11,031 \\
\hline 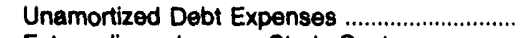 & 190 & 81 & 43 & 2,600 & 1,768 & 765 \\
\hline Extraordinary Losses, Study Cost ........................ & 0 & 0 & 0 & 0 & 0 & 0 \\
\hline Misc Debt, R \& D Exp, Unamrt Losses .......... & 0 & 0 & 2,799 & 29,599 & 156 & 0 \\
\hline $\begin{array}{l}\text { Total Deferred Debits } \\
\text { Total Aseats Other Debits } \\
\text { Proprietary Capital }\end{array}$ & $\begin{array}{r}190 \\
11,307\end{array}$ & $\begin{array}{r}81 \\
8,593\end{array}$ & $\begin{array}{r}2,842 \\
912,613\end{array}$ & $\begin{array}{r}32,199 \\
234,294\end{array}$ & $\begin{array}{r}1,924 \\
182,681\end{array}$ & $\begin{array}{r}765 \\
48,244\end{array}$ \\
\hline 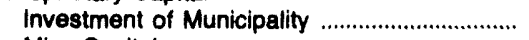 & 0 & 4,515 & 631,706 & 0 & 19,903 & 0 \\
\hline 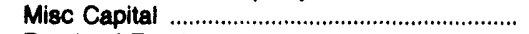 & 0 & 0 & $-120,450$ & 0 & 56,062 & 0 \\
\hline 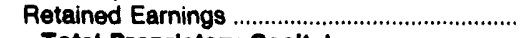 & 2,616 & 1,388 & 0 & 43,433 & 28,862 & 22,065 \\
\hline $\begin{array}{l}\text { Total Proprtatary Capltal ................................ } \\
\text { Long-term Debt }\end{array}$ & \multicolumn{2}{|c|}{ Long-term Debt } & 511,256 & 43,433 & 104,828 & 22,065 \\
\hline Bonds & 7,560 & 311 & 161,220 & 190,520 & 55,640 & 24,536 \\
\hline Advances from Municipality \& Other ............... & 24 & 0 & 214,088 & 0 & 6,431 & 0 \\
\hline Unamort Prem on Long-term Debt .................. & 0 & 0 & 0 & 0 & 0 & 0 \\
\hline (less) Unamort Discount on Long-term Debt & 179 & 0 & 0 & 8,634 & 0 & 0 \\
\hline 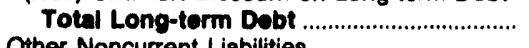 & 7,405 & 311 & 375,308 & 181,886 & 62,071 & 24,536 \\
\hline \multicolumn{7}{|l|}{ Other Noncurrent Liabilities } \\
\hline Accum Operating Provisions ............................. & 0 & 0 & 0 & 350 & 0 & 0 \\
\hline Accum Prov for Rate Refunds .......................... & 0 & 0 & 0 & 0 & 0 & 0 \\
\hline $\begin{array}{l}\text { Total Other Moncurrent Llabllities } \\
\text { Current and Accrued Liabilities }\end{array}$ & $\mathbf{0}$ & Current and Accrued Liabilities & 0 & 350 & 0 & 0 \\
\hline Notes Payable & 22 & 7 & 3,502 & 0 & 4,165 & 0 \\
\hline Accounts Payable & 880 & 1.011 & 4,022 & 3,836 & 2,488 & 1,378 \\
\hline Payables to Assoc Enterprises ........................... & 0 & 0 & 10,094 & 0 & 0 & 0 \\
\hline 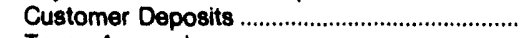 & 206 & 508 & 0 & 1,234 & 777 & 236 \\
\hline 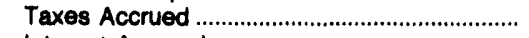 & -1 & 0 & 0 & 0 & 0 & 0 \\
\hline Interest Accrued & 42 & 0 & 5,535 & 1,093 & 2,201 & 29 \\
\hline Misc Current \& Accrued Liabilities ........................ & 137 & 854 & 0 & 1,336 & 6,151 & 0 \\
\hline $\begin{array}{l}\text { Total Current A Accrued Llabliltiee ........... } \\
\text { Deferred Credits }\end{array}$ & \multicolumn{6}{|c|}{ Deferred Credits } \\
\hline Customer Advances for Construction ............. & 0 & 0 & 0 & 71 & 0 & 0 \\
\hline Other Deferred Credits ....................................... & 0 & 0 & 2,896 & 1,056 & 0 & 0 \\
\hline Unamort Gain on Reacar Debt ......................... & 0 & 0 & 0 & 0 & 0 & 0 \\
\hline Total Doferred Credite .............................. & & & 2,896 & 1,126 & 0 & 0 \\
\hline Total Llabllities and Other Credits ............ & 11,307 & 8,593 & 912,613 & 234,294 & 182,681 & 48,244 \\
\hline
\end{tabular}

Note: Totals may not equal sum of components because of independent rounding.

Source: Energy Information Administration, Form ElA-412, "Annual Report of Public Electric Utilities." 
Table 22. Balance Sheet by Major U.S. Publicly Owned Electric Utility Within State at End of Period, 1992 (Continued) (Thousand Dollars)

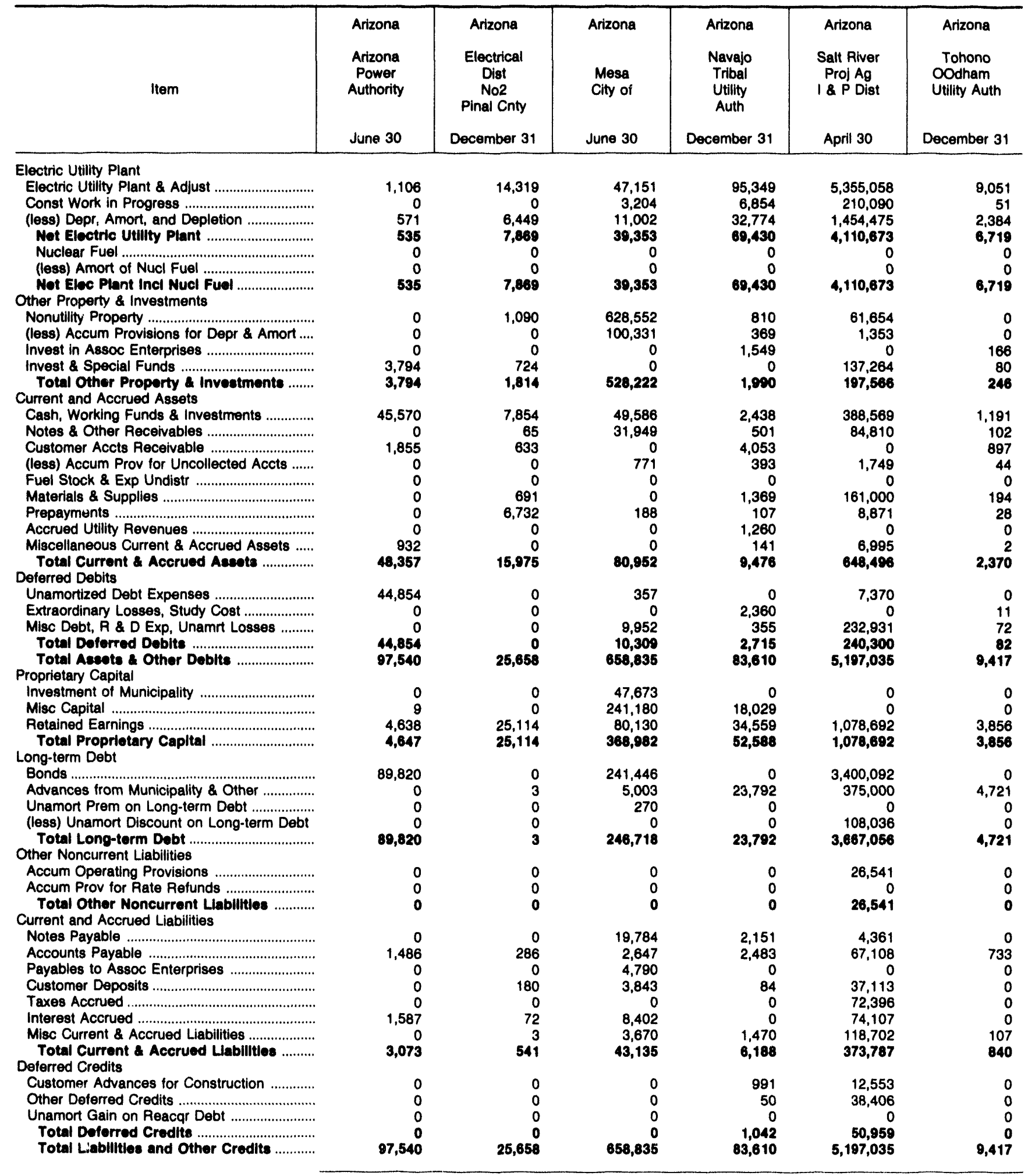

Note: Totals may not equal sum of components because of independent rounding.

Source: Energy Information Administration, Form EIA-412, "Annual Report of Public Electric Utilities." 
Table 22. Balance Sheet by Major U.S. Publicly Owned Electric Utility Within State at End of Period, 1992 (Continued) (Thousand Dollars)

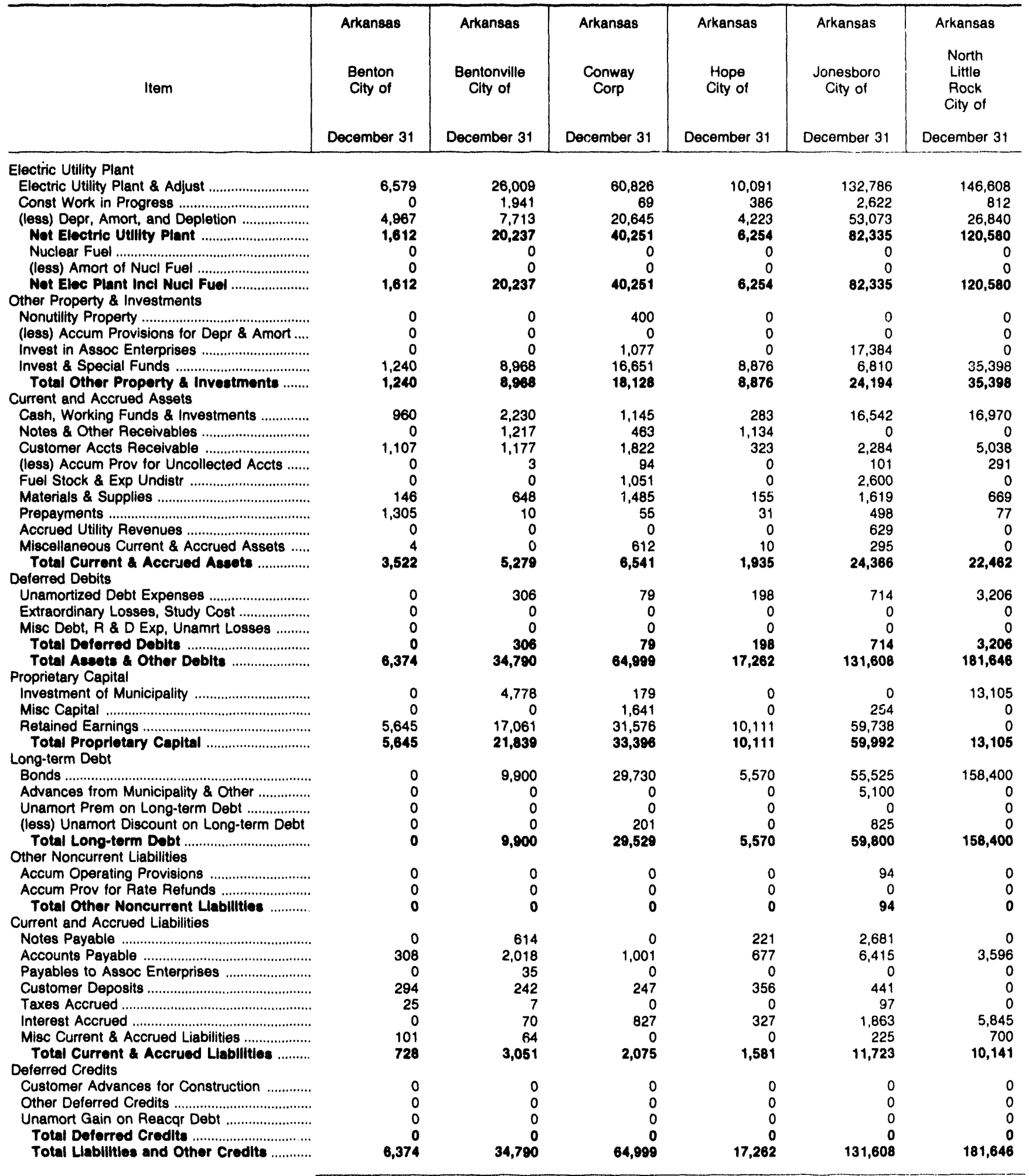

Note: Totals may not equal sum of components because of independent rounding.

Source: Energy Information Administration, Form ElA-412, "Annual Report of Public Electric Utilities." 
Table 22. Balance Sheet by Major U.S. Publicly Owned Electric Utility Within State at End of Period, 1992 (Continued) (Thousand Dollars)

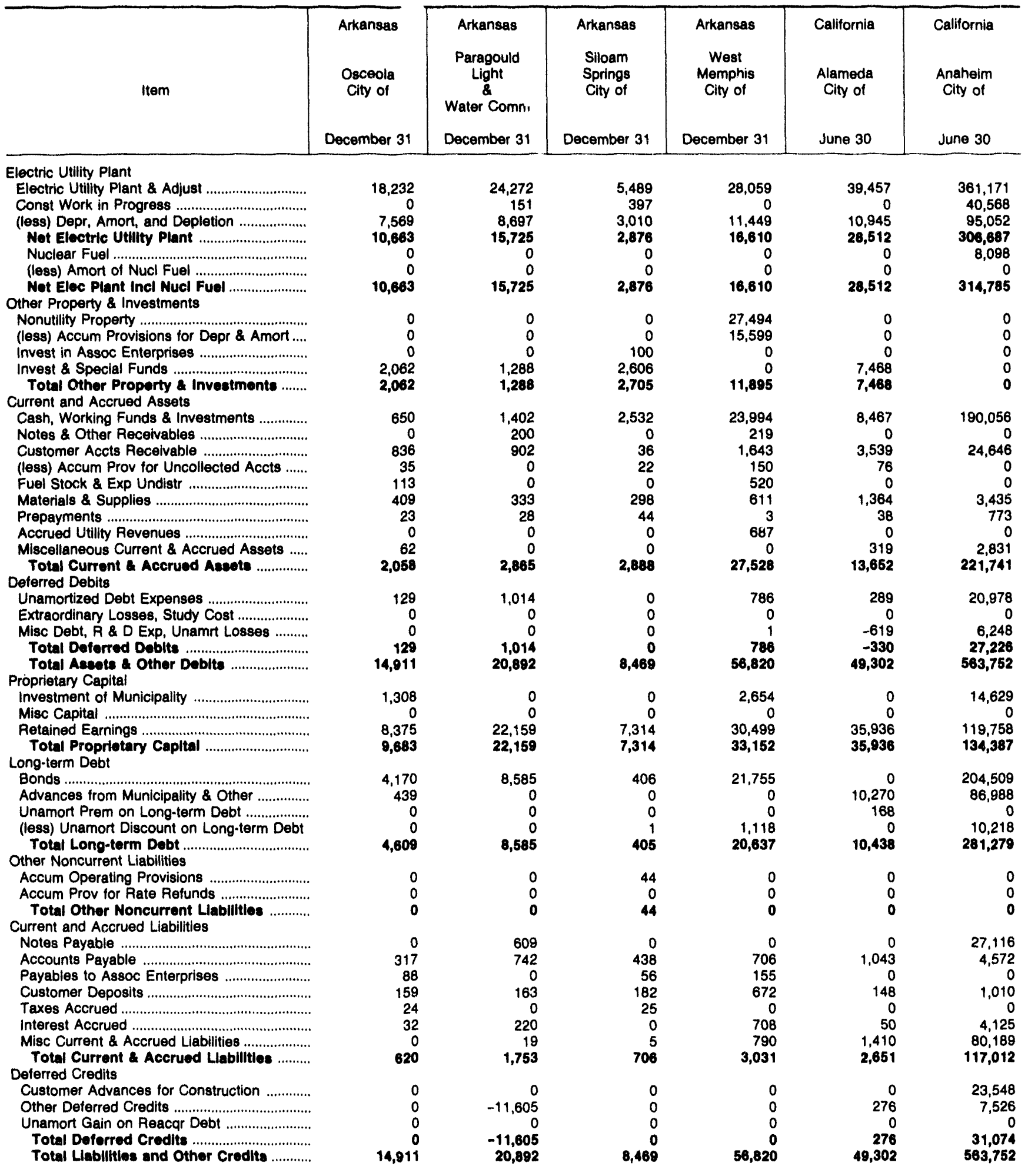

Note: Totals may not equal sum of components because of independent rounding.

Source: Energy Information Administration, Form ElA-412, "Annual Report of Public Electric Utilities." 
Table 22. Balance Sheet by Major U.S. Publicly Owned Electric Utility Within State at End of Period, 1992 (Continued) (Thousand Dollars)

\begin{tabular}{|c|c|c|c|c|c|c|}
\hline Item & $\begin{array}{l}\text { California } \\
\text { Azusa } \\
\text { City of } \\
\text { June } 30\end{array}$ & $\begin{array}{l}\text { California } \\
\text { Burbank } \\
\text { City of } \\
\text { June } 30\end{array}$ & $\begin{array}{l}\text { California } \\
\text { California } \\
\text { Dept } \\
\text { Wtr } \\
\text { Resources } \\
\text { June } 30\end{array}$ & $\begin{array}{l}\text { California } \\
\text { Colton } \\
\text { City of } \\
\text { June } 30\end{array}$ & $\begin{array}{l}\text { California } \\
\text { Glendale } \\
\text { City of } \\
\text { June } 30\end{array}$ & $\begin{array}{l}\text { California } \\
\text { Imperial } \\
\text { Irrigation } \\
\text { District } \\
\text { December } 31\end{array}$ \\
\hline 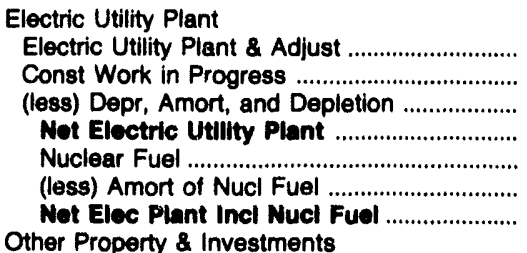 & $\begin{array}{r}11,901 \\
0 \\
4,023 \\
7,878 \\
0 \\
0 \\
7,878\end{array}$ & $\begin{array}{r}153,169 \\
12,038 \\
87,366 \\
77,841 \\
0 \\
0 \\
77,841\end{array}$ & $\begin{array}{r}860,140 \\
0 \\
244,388 \\
615,752 \\
0 \\
0 \\
615,752\end{array}$ & $\begin{array}{r}13,270 \\
0 \\
4,664 \\
8,606 \\
0 \\
0 \\
8,606\end{array}$ & $\begin{array}{r}224,691 \\
27,183 \\
116,910 \\
134,964 \\
0 \\
0 \\
134,964\end{array}$ & $\begin{array}{r}525,941 \\
49,547 \\
162,822 \\
412,687 \\
0 \\
0 \\
412,667\end{array}$ \\
\hline 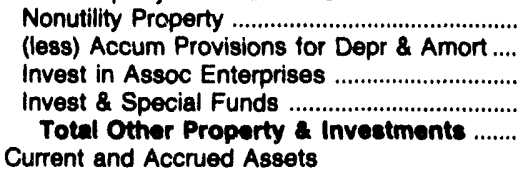 & $\begin{array}{r}0 \\
0 \\
7,954 \\
0 \\
7,954\end{array}$ & $\begin{array}{l}0 \\
0 \\
0 \\
0 \\
0\end{array}$ & $\begin{array}{r}0 \\
0 \\
0 \\
131,460 \\
131,460\end{array}$ & $\begin{array}{l}0 \\
0 \\
0 \\
0 \\
0\end{array}$ & $\begin{array}{l}0 \\
0 \\
0 \\
0 \\
0\end{array}$ & $\begin{array}{r}0 \\
0 \\
0 \\
95,217 \\
95,217\end{array}$ \\
\hline 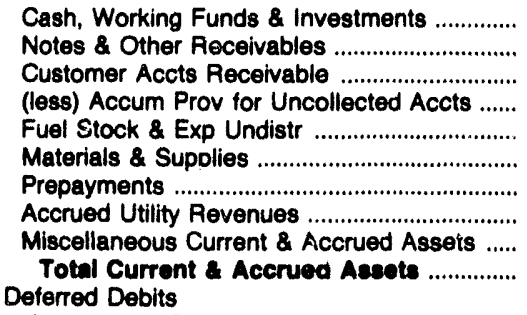 & $\begin{array}{r}14,133 \\
1,559 \\
2,014 \\
0 \\
0 \\
378 \\
0 \\
0 \\
0 \\
18,084\end{array}$ & $\begin{array}{r}11,919 \\
0 \\
12,377 \\
0 \\
0 \\
4,508 \\
4,377 \\
0 \\
0 \\
33,181\end{array}$ & $\begin{array}{r}134,056 \\
21,254 \\
0 \\
0 \\
0 \\
9,041 \\
360 \\
0 \\
0 \\
164,711\end{array}$ & $\begin{array}{r}2,881 \\
4,048 \\
1,802 \\
0 \\
0 \\
1,537 \\
0 \\
0 \\
2,228 \\
12,495\end{array}$ & $\begin{array}{r}30,245 \\
5,000 \\
0 \\
232 \\
151 \\
3,157 \\
1,022 \\
0 \\
0 \\
39,343\end{array}$ & $\begin{array}{r}398 \\
0 \\
17,428 \\
2,231 \\
2,942 \\
8,724 \\
76 \\
0 \\
0 \\
27,336\end{array}$ \\
\hline 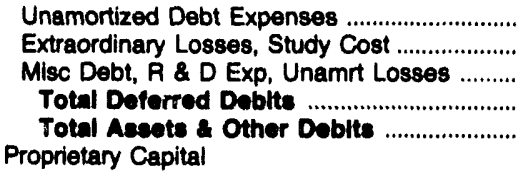 & $\begin{array}{r}0 \\
0 \\
0 \\
0 \\
33,916\end{array}$ & $\begin{array}{r}0 \\
0 \\
0 \\
0 \\
111,022\end{array}$ & $\begin{array}{r}0 \\
0 \\
283,004 \\
283,004 \\
1,194,027\end{array}$ & $\begin{array}{r}0 \\
0 \\
0 \\
0 \\
21,102\end{array}$ & $\begin{array}{r}0 \\
0 \\
0 \\
0 \\
174,307\end{array}$ & $\begin{array}{r}0 \\
0 \\
0 \\
0 \\
535,220\end{array}$ \\
\hline 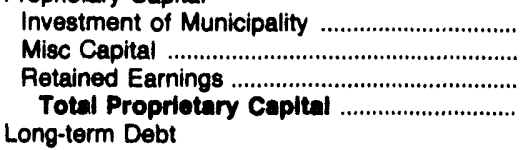 & $\begin{array}{r}0 \\
624 \\
29,922 \\
30,546\end{array}$ & $\begin{array}{r}0 \\
5,040 \\
72,036 \\
77,076\end{array}$ & $\begin{array}{r}34,345 \\
0 \\
-4,184 \\
30,161\end{array}$ & $\begin{array}{r}0 \\
0 \\
18,635 \\
18,635\end{array}$ & $\begin{array}{r}0 \\
20,763 \\
124,670 \\
146,433\end{array}$ & $\begin{array}{r}0 \\
0 \\
368,002 \\
368,002\end{array}$ \\
\hline 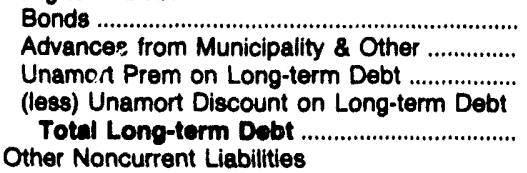 & $\begin{array}{r}0 \\
92 \\
0 \\
0 \\
92\end{array}$ & $\begin{array}{r}22,826 \\
1,596 \\
0 \\
0 \\
24,522\end{array}$ & $\begin{array}{r}952,175 \\
0 \\
0 \\
22,529 \\
929,646\end{array}$ & $\begin{array}{r}755 \\
0 \\
0 \\
0 \\
755\end{array}$ & $\begin{array}{r}20,385 \\
0 \\
0 \\
0 \\
20,395\end{array}$ & $\begin{array}{r}0 \\
123,831 \\
0 \\
2,224 \\
121,607\end{array}$ \\
\hline $\begin{array}{l}\text { Accum Operating Provisions ............................. } \\
\text { Accum Prov for Rate Refunds ....................... } \\
\text { Total Other Noncurrent Llabiltties ............ } \\
\text { Current and Accrued Liabilities }\end{array}$ & $\begin{array}{l}0 \\
0 \\
0\end{array}$ & $\begin{array}{l}0 \\
0 \\
0\end{array}$ & $\begin{array}{r}36,995 \\
0 \\
36,995\end{array}$ & $\begin{array}{l}0 \\
0 \\
0\end{array}$ & $\begin{array}{l}0 \\
0 \\
0\end{array}$ & $\begin{array}{l}0 \\
0 \\
0\end{array}$ \\
\hline 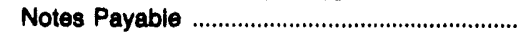 & & 0 & 6,096 & 0 & 2,960 & 0 \\
\hline $\begin{array}{l}\text { Accounts Payable } \\
\text { Payables to Assoc Enterprises }\end{array}$ & & $\begin{array}{l}5,694 \\
2,116\end{array}$ & & $\begin{array}{r}80 \\
0\end{array}$ & $\begin{array}{r}3,647 \\
0\end{array}$ & $\begin{array}{r}12,548 \\
0\end{array}$ \\
\hline 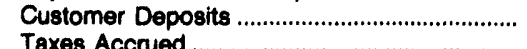 & 952 & 848 & 0 & 570 & 469 & 1,353 \\
\hline $\begin{array}{l}\text { Taxes Accrued } \\
\text { interest Accrued }\end{array}$ & 8 & 0 & 0 & 0 & 566 & 0 \\
\hline 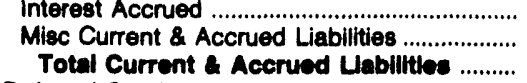 & $\begin{array}{r}0 \\
0 \\
3,278\end{array}$ & $\begin{array}{r}119 \\
647 \\
9,424\end{array}$ & $\begin{array}{r}8,532 \\
27,700 \\
58,107\end{array}$ & $\begin{array}{r}0 \\
1,061 \\
1,711\end{array}$ & $\begin{array}{r}0 \\
36 \\
7,678\end{array}$ & $\begin{array}{r}1,623 \\
23,426 \\
41,050\end{array}$ \\
\hline 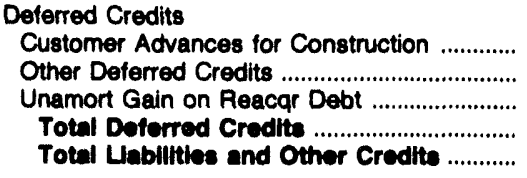 & $\begin{array}{r}0 \\
0 \\
0 \\
0 \\
33,916\end{array}$ & $\begin{array}{r}0 \\
0 \\
0 \\
0 \\
111,022\end{array}$ & $\begin{array}{r}0 \\
140,018 \\
0 \\
140,018 \\
1,194,027\end{array}$ & $\begin{array}{r}0 \\
0 \\
0 \\
0 \\
21,102\end{array}$ & $\begin{array}{r}811 \\
0 \\
0 \\
811 \\
174,307\end{array}$ & $\begin{array}{r}30 \\
3,632 \\
0 \\
3,662 \\
535,220\end{array}$ \\
\hline
\end{tabular}

Note: Totals may not equal sum of components because of independent rounding.

Source: Energy Information Administration, Form ElA-412, "Annual Report of Public Electric Utilities." 
Table 22. Balance Sheet by Major U.S. Publicly Owned Electric Utillty Within State at End of Period, 1992 (Continued) (Thousand Dollars)

\begin{tabular}{|c|c|c|c|c|c|c|}
\hline Item & $\begin{array}{l}\text { California } \\
\text { Lodi } \\
\text { City of } \\
\text { June } 30\end{array}$ & $\begin{array}{l}\text { California } \\
\text { Los Angeles } \\
\text { City of } \\
\text { June } 30\end{array}$ & $\begin{array}{l}\text { California } \\
\text { Metropolitan } \\
\text { Water } \\
\text { District } \\
\text { June } 30\end{array}$ & $\begin{array}{l}\text { California } \\
\text { Modesto } \\
\text { Irrigation } \\
\text { District } \\
\text { December } 31\end{array}$ & $\begin{array}{l}\text { California } \\
\text { MSR } \\
\text { Public } \\
\text { Power } \\
\text { Agency } \\
\text { December } 31\end{array}$ & $\begin{array}{l}\text { California } \\
\text { Northern } \\
\text { California } \\
\text { Power Agny } \\
\text { June } 30\end{array}$ \\
\hline 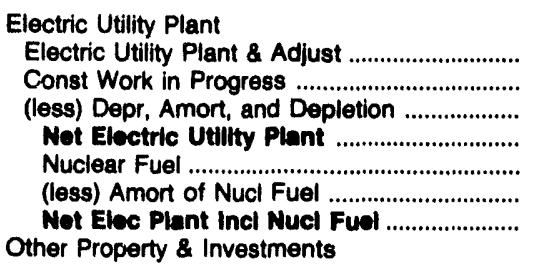 & $\begin{array}{r}20,814 \\
6,553 \\
9,567 \\
17,790 \\
0 \\
0 \\
17,700\end{array}$ & $\begin{array}{r}5,716,181 \\
356,913 \\
1,790,020 \\
4,283,074 \\
54,395 \\
42,007 \\
4,295,461\end{array}$ & $\begin{array}{r}103,038 \\
9,670 \\
17,989 \\
94,719 \\
0 \\
0 \\
94,719\end{array}$ & $\begin{array}{r}202,370 \\
30,694 \\
76,812 \\
156,251 \\
0 \\
0 \\
156,251\end{array}$ & $\begin{array}{r}275,331 \\
5,308 \\
76,505 \\
204,134 \\
0 \\
0 \\
204,134\end{array}$ & $\begin{array}{r}908,372 \\
10,125 \\
170,973 \\
748,524 \\
0 \\
0 \\
748,524\end{array}$ \\
\hline 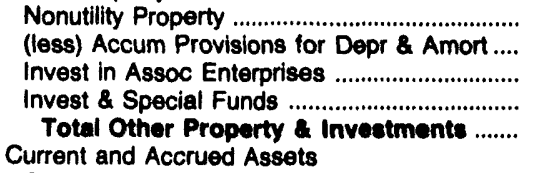 & $\begin{array}{l}0 \\
0 \\
0 \\
0 \\
0\end{array}$ & $\begin{array}{l}0 \\
0 \\
0 \\
0 \\
0\end{array}$ & $\begin{array}{r}4,360,576 \\
1,421,385 \\
0 \\
447,869 \\
3,387,060\end{array}$ & $\begin{array}{r}0 \\
0 \\
0 \\
43,764 \\
43,764\end{array}$ & $\begin{array}{r}15,383 \\
0 \\
0 \\
170,424 \\
185,807\end{array}$ & $\begin{array}{r}0 \\
0 \\
0 \\
262,332 \\
262,332\end{array}$ \\
\hline 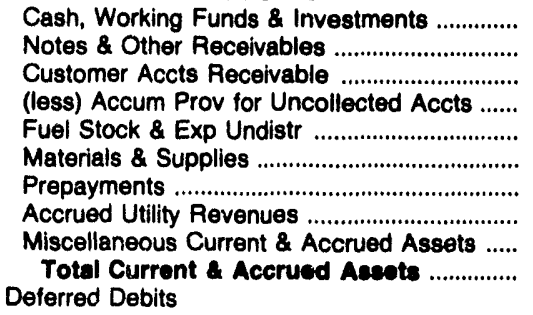 & $\begin{array}{r}6,469 \\
931 \\
1,930 \\
42 \\
0 \\
1,509 \\
0 \\
0 \\
0 \\
10,818\end{array}$ & $\begin{array}{r}226,927 \\
17,345 \\
194,793 \\
7,850 \\
101,645 \\
113,373 \\
13,206 \\
100,280 \\
593 \\
760,313\end{array}$ & $\begin{array}{r}350,247 \\
25,357 \\
82,768 \\
0 \\
231 \\
17,562 \\
0 \\
0 \\
0 \\
476,165\end{array}$ & $\begin{array}{r}183,602 \\
0 \\
9,061 \\
0 \\
470 \\
2,395 \\
4,613 \\
0 \\
7,029 \\
207,170\end{array}$ & $\begin{array}{r}19,308 \\
974 \\
0 \\
0 \\
0 \\
3,169 \\
0 \\
0 \\
97 \\
23,549\end{array}$ & $\begin{array}{r}52,664 \\
453 \\
1,417 \\
0 \\
0 \\
3,142 \\
469 \\
0 \\
0 \\
58,145\end{array}$ \\
\hline 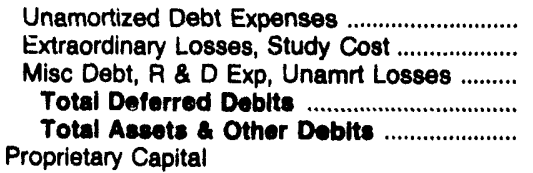 & $\begin{array}{r}0 \\
0 \\
0 \\
0 \\
28,617\end{array}$ & $\begin{array}{r}2,156 \\
0 \\
0 \\
2,156 \\
5,057,930\end{array}$ & $\begin{array}{r}2,101 \\
0 \\
197,236 \\
199,337 \\
4,157,281\end{array}$ & $\begin{array}{r}4,082 \\
0 \\
0 \\
4,082 \\
411,288\end{array}$ & $\begin{array}{r}11,185 \\
0 \\
0 \\
11,185 \\
124,675\end{array}$ & $\begin{array}{r}21,125 \\
2,869 \\
376,558 \\
400,552 \\
1,469,553\end{array}$ \\
\hline 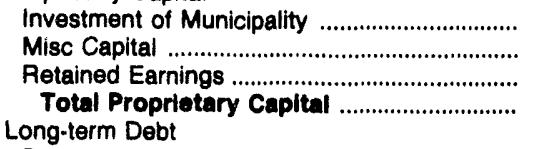 & $\begin{array}{r}0 \\
0 \\
26,311 \\
26,311\end{array}$ & $\begin{array}{r}0 \\
161,272 \\
1,958,270 \\
2,119,543\end{array}$ & $\begin{array}{r}0 \\
0 \\
2,273,959 \\
2,273,959\end{array}$ & $\begin{array}{r}0 \\
0 \\
120,555 \\
120,555\end{array}$ & $\begin{array}{r}0 \\
0 \\
-214,801 \\
-214,801\end{array}$ & $\begin{array}{r}0 \\
0 \\
7,899 \\
7,899\end{array}$ \\
\hline 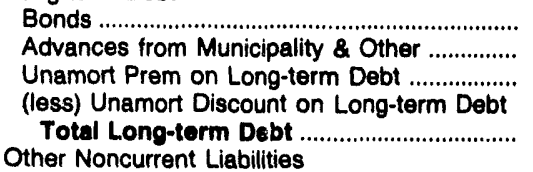 & $\begin{array}{l}0 \\
0 \\
0 \\
0 \\
0\end{array}$ & $\begin{array}{r}2,406,307 \\
0 \\
0 \\
72,504 \\
2,333,803\end{array}$ & $\begin{array}{r}1,307,719 \\
207,289 \\
26 \\
19,460 \\
1,495,574\end{array}$ & $\begin{array}{r}266,877 \\
809 \\
0 \\
10,554 \\
257,131\end{array}$ & $\begin{array}{r}646,325 \\
0 \\
0 \\
33,233 \\
613,092\end{array}$ & $\begin{array}{r}1,409,457 \\
0 \\
3,109 \\
75,409 \\
1,337,157\end{array}$ \\
\hline 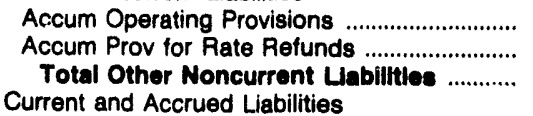 & $\begin{array}{l}0 \\
0 \\
0\end{array}$ & $\begin{array}{l}0 \\
0 \\
0\end{array}$ & $\begin{array}{l}0 \\
0 \\
0\end{array}$ & $\begin{array}{r}4,374 \\
0 \\
4,374\end{array}$ & $\begin{array}{l}0 \\
0 \\
0\end{array}$ & $\begin{array}{l}0 \\
0 \\
0\end{array}$ \\
\hline 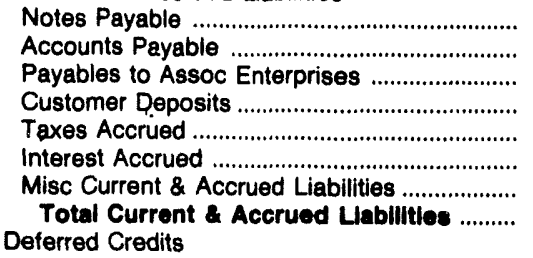 & $\begin{array}{r}0 \\
1,538 \\
0 \\
258 \\
6 \\
0 \\
503 \\
2,308\end{array}$ & $\begin{array}{r}55,655 \\
168,423 \\
90,000 \\
61,465 \\
10,579 \\
49,357 \\
65,137 \\
500,615\end{array}$ & $\begin{array}{r}0 \\
345,850 \\
0 \\
11,975 \\
0 \\
29,923 \\
0 \\
387,748\end{array}$ & $\begin{array}{r}0 \\
21,306 \\
0 \\
218 \\
205 \\
4,198 \\
872 \\
26,799\end{array}$ & $\begin{array}{r}0 \\
1,677 \\
0 \\
0 \\
0 \\
22,837 \\
1,870 \\
26,384\end{array}$ & $\begin{array}{r}0 \\
20,191 \\
145 \\
0 \\
4,068 \\
40,018 \\
87 \\
64,509\end{array}$ \\
\hline 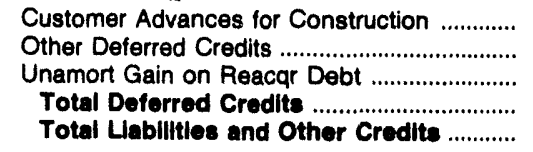 & $\begin{array}{r}0 \\
0 \\
0 \\
0 \\
28,617\end{array}$ & $\begin{array}{r}5,656 \\
2,917 \\
95,397 \\
103,970 \\
5,057,930\end{array}$ & $\begin{array}{r}0 \\
0 \\
0 \\
0 \\
4,157,281\end{array}$ & $\begin{array}{r}2,409 \\
0 \\
0 \\
2,409 \\
411,268\end{array}$ & $\begin{array}{r}0 \\
0 \\
0 \\
0 \\
424,675\end{array}$ & $\begin{array}{r}5,524 \\
54,464 \\
0 \\
59,988 \\
1,469,553\end{array}$ \\
\hline
\end{tabular}

Note: Totals may not equal sum of components because of independent rounding.

Source: Energy Information Administration, Form EIA-412, "Annual Report of Public Electric Utilities." 
Table 22. Balance Sheet by Major U.S. Publicly Owned Electric Utility Within State at End of Period, 1992 (Continued) (Thousand Dollars)

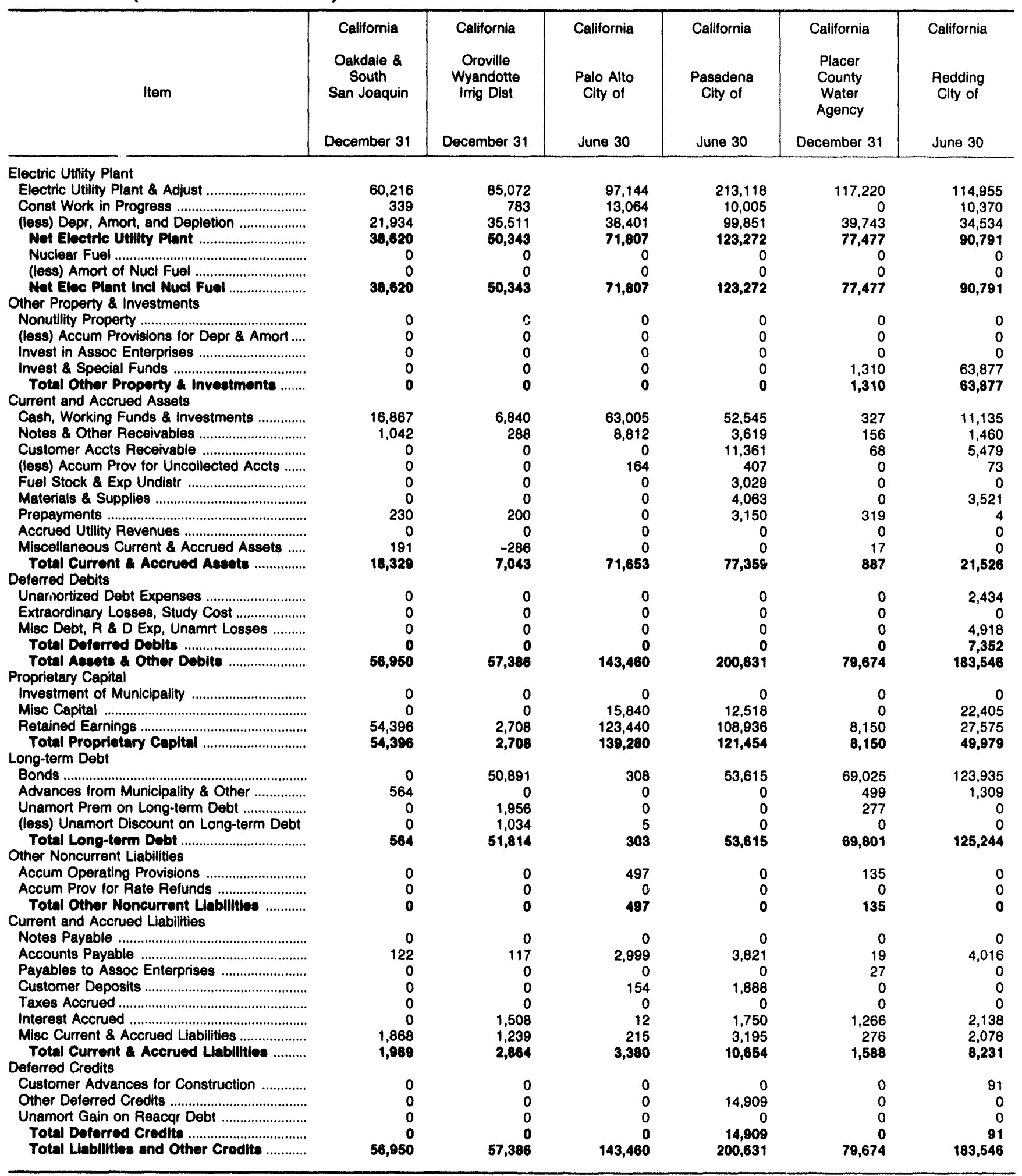

Note: Totals may not equal sum of components because of independent rounding.

Source: Energy Information Administration, Form EIA-412, "Annual Report of Public Electric Utilities." 
Table 22. Balance Sheet by Major U.S. Publicly Owned Electric Utility Within State at End of Period, 1992 (Continued) (Thousand Dollars)

\begin{tabular}{|c|c|c|c|c|c|c|}
\hline Item & $\begin{array}{l}\text { California } \\
\text { Riverside } \\
\text { City of } \\
\text { June } 30\end{array}$ & $\begin{array}{l}\text { California } \\
\text { Rosevilie } \\
\text { City of } \\
\text { June } 30\end{array}$ & $\begin{array}{l}\text { California } \\
\text { Sacramento } \\
\text { Municipal } \\
\text { Util Dist } \\
\text { December } 31\end{array}$ & $\begin{array}{c}\text { California } \\
\text { San Francisco } \\
\text { City } \\
8 \\
\text { County of } \\
\text { June } 30\end{array}$ & $\begin{array}{l}\text { California } \\
\text { Santa } \\
\text { Clara } \\
\text { City of } \\
\\
\text { June } 30\end{array}$ & $\begin{array}{l}\text { California } \\
\text { Southern } \\
\text { California } \\
\text { PP } \\
\text { A } \\
\text { June } 30\end{array}$ \\
\hline 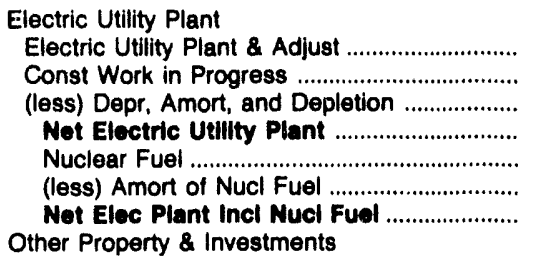 & $\begin{array}{r}261,808 \\
20,543 \\
85,481 \\
188,870 \\
6,133 \\
1,135 \\
201,867\end{array}$ & $\begin{array}{r}67,696 \\
2288 \\
11,074 \\
56,850 \\
0 \\
0 \\
56,850\end{array}$ & $\begin{array}{r}1,339,617 \\
122,893 \\
368,795 \\
1,093,715 \\
0 \\
0 \\
1,093,715\end{array}$ & $\begin{array}{r}436,016 \\
7,254 \\
178,337 \\
264,933 \\
0 \\
0 \\
264,933\end{array}$ & $\begin{array}{r}166,343 \\
43,155 \\
47,738 \\
161,760 \\
0 \\
0 \\
161,760\end{array}$ & $\begin{array}{r}1,305,355 \\
30,786 \\
244,218 \\
1,091,923 \\
35,843 \\
20,616 \\
1,107,150\end{array}$ \\
\hline 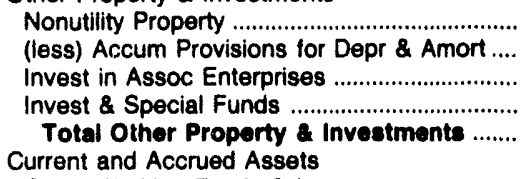 & $\begin{array}{r}0 \\
0 \\
0 \\
46,668 \\
46,688\end{array}$ & $\begin{array}{r}0 \\
0 \\
0 \\
1,450 \\
1,460\end{array}$ & $\begin{array}{r}0 \\
0 \\
130,608 \\
307,900 \\
438,608\end{array}$ & $\begin{array}{r}410 \\
0 \\
0 \\
0 \\
110\end{array}$ & $\begin{array}{r}0 \\
0 \\
37,966 \\
5,000 \\
42,966\end{array}$ & $\begin{array}{l}0 \\
0 \\
0 \\
0 \\
0\end{array}$ \\
\hline 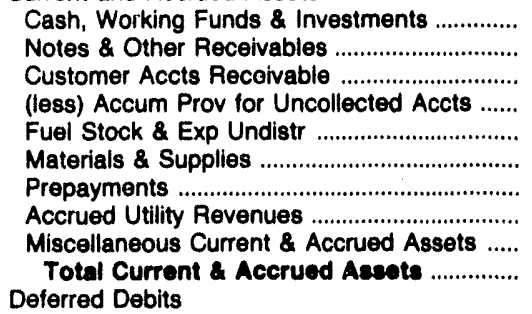 & $\begin{array}{r}63,823 \\
0 \\
22,309 \\
1,096 \\
0 \\
437 \\
3,802 \\
0 \\
843 \\
80,118\end{array}$ & $\begin{array}{r}5,038 \\
2,554 \\
16 \\
0 \\
0 \\
2,086 \\
7,751 \\
6,550 \\
0 \\
23,996\end{array}$ & $\begin{array}{r}263,268 \\
26,565 \\
86,546 \\
3,578 \\
0 \\
20,517 \\
7,940 \\
0 \\
53,698 \\
454,954\end{array}$ & $\begin{array}{r}37,550 \\
977 \\
5,938 \\
0 \\
0 \\
2,156 \\
9 \\
0 \\
16 \\
46,646\end{array}$ & $\begin{array}{r}204,898 \\
5,658 \\
16,967 \\
68 \\
0 \\
3,251 \\
0 \\
0 \\
4,099 \\
234,805\end{array}$ & $\begin{array}{r}1,063,466 \\
0 \\
3,883 \\
0 \\
0 \\
13,009 \\
33,910 \\
0 \\
234,011 \\
1,348,278\end{array}$ \\
\hline 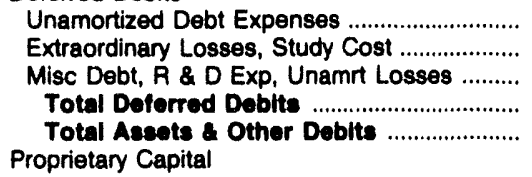 & $\begin{array}{r}1,102 \\
0 \\
5 \\
1,107 \\
339,760\end{array}$ & $\begin{array}{r}269 \\
0 \\
0 \\
269 \\
82,565\end{array}$ & $\begin{array}{r}35,778 \\
0 \\
915,041 \\
950,820 \\
2,937,997\end{array}$ & $\begin{array}{r}0 \\
0 \\
0 \\
0 \\
311,889\end{array}$ & $\begin{array}{r}0 \\
0 \\
0 \\
0 \\
439,531\end{array}$ & $\begin{array}{r}31,126 \\
0 \\
359,323 \\
390,449 \\
2,845,877\end{array}$ \\
\hline 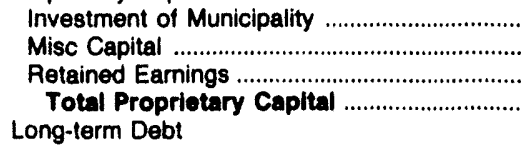 & $\begin{array}{r}0 \\
32,579 \\
59,251 \\
\mathbf{9 1 , 6 3 0}\end{array}$ & $\begin{array}{r}0 \\
0 \\
66,927 \\
68,927\end{array}$ & $\begin{array}{r}0 \\
0 \\
187,787 \\
187,787\end{array}$ & $\begin{array}{r}0 \\
46,431 \\
251,660 \\
298,091\end{array}$ & $\begin{array}{r}644 \\
0 \\
175,765 \\
176,408\end{array}$ & $\begin{array}{l}0 \\
0 \\
0 \\
0\end{array}$ \\
\hline 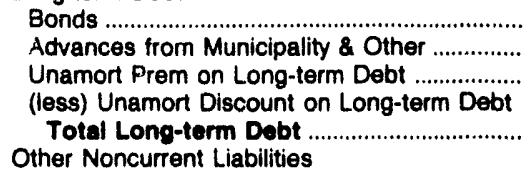 & $\begin{array}{r}188,895 \\
208 \\
0 \\
4,313 \\
184,790\end{array}$ & $\begin{array}{r}10,750 \\
0 \\
0 \\
0 \\
10,750\end{array}$ & $\begin{array}{r}1,909,005 \\
14,048 \\
0 \\
31,617 \\
1,891,436\end{array}$ & $\begin{array}{r}0 \\
2,026 \\
0 \\
0 \\
2,026\end{array}$ & $\begin{array}{r}244,034 \\
0 \\
0 \\
6,466 \\
237,568\end{array}$ & $\begin{array}{r}3,006,201 \\
0 \\
0 \\
310,069 \\
2,696,132\end{array}$ \\
\hline 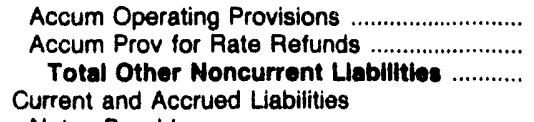 & $\begin{array}{l}0 \\
0 \\
0\end{array}$ & $\begin{array}{r}515 \\
0 \\
515\end{array}$ & $\begin{array}{r}6,781 \\
0 \\
6,781\end{array}$ & $\begin{array}{l}0 \\
0 \\
0\end{array}$ & $\begin{array}{l}0 \\
0 \\
0\end{array}$ & $\begin{array}{l}0 \\
0 \\
0\end{array}$ \\
\hline 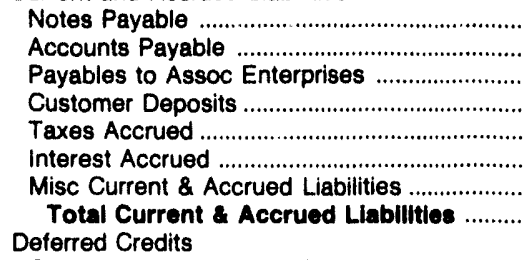 & $\begin{array}{r}0 \\
6,092 \\
0 \\
2,652 \\
0 \\
3,199 \\
29,958 \\
41,901\end{array}$ & $\begin{array}{r}0 \\
1,254 \\
0 \\
289 \\
0 \\
264 \\
191 \\
1,998\end{array}$ & $\begin{array}{r}195,121 \\
77,919 \\
0 \\
9,496 \\
3,596 \\
38,738 \\
68,236 \\
393,106\end{array}$ & $\begin{array}{r}0 \\
8,712 \\
1,382 \\
269 \\
0 \\
0 \\
1,162 \\
11,525\end{array}$ & $\begin{array}{r}2,145 \\
17,451 \\
0 \\
0 \\
0 \\
5,959 \\
0 \\
25,555\end{array}$ & $\begin{array}{r}14,200 \\
8,693 \\
0 \\
0 \\
0 \\
86,202 \\
40,651 \\
149,745\end{array}$ \\
\hline 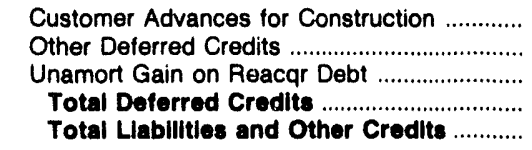 & $\begin{array}{r}0 \\
21,240 \\
0 \\
21,240 \\
339,780\end{array}$ & $\begin{array}{r}0 \\
2,374 \\
0 \\
2,374 \\
82,565\end{array}$ & $\begin{array}{r}2,557 \\
401,636 \\
54,694 \\
458,887 \\
2,937,997\end{array}$ & $\begin{array}{r}251 \\
95 \\
0 \\
347 \\
311,989\end{array}$ & $\begin{array}{r}0 \\
0 \\
0 \\
0 \\
\mathbf{4 3 9 , 5 3 1}\end{array}$ & $\begin{array}{r}0 \\
0 \\
0 \\
0 \\
2,845,877\end{array}$ \\
\hline
\end{tabular}

Note: Totals may not equal sum of components because of independent rounding.

Source: Energy Information Administration, Form EIA-412, "Annual Report of Public Electric Utilities." 
Table 22. Balance Sheet by Major U.S. Publicly Owned Electrlc Utillty Within State at End of Perlod, 1992 (Continued) (Thousand Dollars)

\begin{tabular}{|c|c|c|c|c|c|c|}
\hline Item & $\begin{array}{c}\text { California } \\
\text { Turlock } \\
\text { Imigation } \\
\text { District } \\
\text { December } 31\end{array}$ & $\begin{array}{l}\text { California } \\
\text { Vernon } \\
\text { City of } \\
\text { June } 30\end{array}$ & $\begin{array}{l}\text { California } \\
\text { Yuba } \\
\text { County } \\
\text { Water } \\
\text { Agency } \\
\text { June } 30\end{array}$ & $\begin{array}{l}\text { Colorado } \\
\text { Arkansas } \\
\text { River } \\
\text { Power } \\
\text { Authority } \\
\text { December } 31\end{array}$ & $\begin{array}{l}\text { Colorado } \\
\text { Colorado } \\
\text { Springs } \\
\text { City of } \\
\text { December } 31\end{array}$ & $\begin{array}{l}\text { Colorado } \\
\text { Fort Collins } \\
\text { City of } \\
\text { December } 31\end{array}$ \\
\hline \multicolumn{7}{|l|}{ Electric Utility Plant } \\
\hline 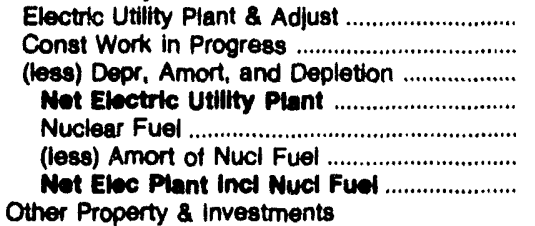 & $\begin{array}{r}213,902 \\
5,412 \\
66,739 \\
152,575 \\
0 \\
0 \\
152,575\end{array}$ & $\begin{array}{r}37,741 \\
26,869 \\
19,729 \\
44,880 \\
0 \\
0 \\
44,880\end{array}$ & $\begin{array}{r}196,241 \\
0 \\
49,878 \\
146,363 \\
0 \\
0 \\
146,363\end{array}$ & $\begin{array}{r}2,710 \\
0 \\
215 \\
2,495 \\
0 \\
0 \\
2,495\end{array}$ & $\begin{array}{r}621,142 \\
15,024 \\
154,561 \\
481,604 \\
0 \\
0 \\
481,604\end{array}$ & $\begin{array}{r}79,388 \\
3,772 \\
31,711 \\
51,450 \\
0 \\
0 \\
51,450\end{array}$ \\
\hline $\begin{array}{l}\text { Nonutility Property } \\
\text { (less) Accum Provisions for Depr \& Amort .... } \\
\text { Invest in Assoc Enterprises ............................ } \\
\text { Invest \& Special Funds .................................. } \\
\text { Total Other Property Investments ........ } \\
\text { Cument and Accrued Assets }\end{array}$ & $\begin{array}{r}0 \\
0 \\
0 \\
40,270 \\
40,270\end{array}$ & $\begin{array}{r}482 \\
0 \\
0 \\
36,387 \\
38,888\end{array}$ & $\begin{array}{r}527 \\
98 \\
0 \\
41,879 \\
42,309\end{array}$ & $\begin{array}{r}201 \\
67 \\
0 \\
1,546 \\
1,680\end{array}$ & $\begin{array}{r}0 \\
0 \\
0 \\
26,342 \\
26,342\end{array}$ & $\begin{array}{l}0 \\
0 \\
0 \\
0 \\
0\end{array}$ \\
\hline 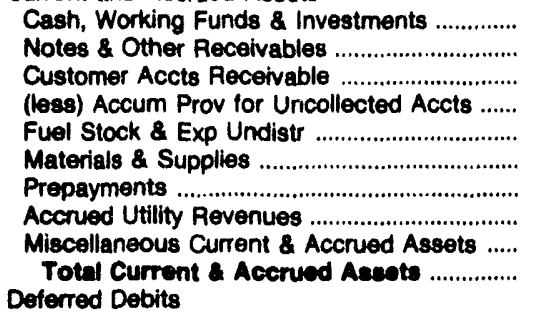 & $\begin{array}{r}16,234 \\
359 \\
7,002 \\
374 \\
0 \\
2,008 \\
391 \\
0 \\
7,083 \\
32,704\end{array}$ & $\begin{array}{r}44,538 \\
3,825 \\
4,805 \\
626 \\
281 \\
782 \\
5,396 \\
2,647 \\
546 \\
62,294\end{array}$ & $\begin{array}{r}192 \\
192 \\
0 \\
0 \\
0 \\
0 \\
89 \\
0 \\
0 \\
172\end{array}$ & $\begin{array}{r}2,417 \\
0 \\
1,056 \\
0 \\
0 \\
33 \\
37 \\
0 \\
0 \\
3,543\end{array}$ & $\begin{array}{r}150,052 \\
21,509 \\
0 \\
850 \\
0 \\
12,404 \\
550 \\
0 \\
967 \\
184,631\end{array}$ & $\begin{array}{r}11,630 \\
0 \\
5,336 \\
150 \\
0 \\
2,445 \\
0 \\
0 \\
153 \\
19,414\end{array}$ \\
\hline 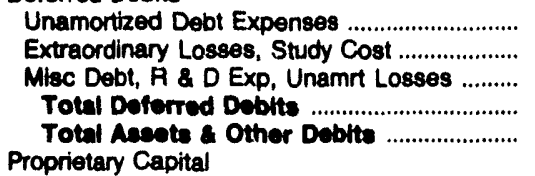 & $\begin{array}{r}57,209 \\
0 \\
0 \\
57,209 \\
282,758\end{array}$ & $\begin{array}{r}0 \\
0 \\
0 \\
0 \\
144,043\end{array}$ & $\begin{array}{r}1,686 \\
0 \\
0 \\
1,688 \\
100,829\end{array}$ & $\begin{array}{r}100 \\
0 \\
0 \\
100 \\
7,819\end{array}$ & $\begin{array}{r}6,433 \\
0 \\
1,282 \\
7,715 \\
700,292\end{array}$ & $\begin{array}{r}0 \\
0 \\
0 \\
0 \\
70,863\end{array}$ \\
\hline 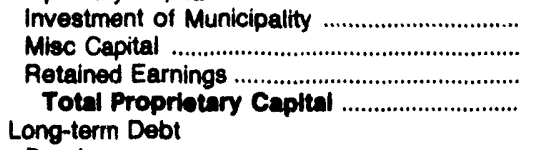 & $\begin{array}{r}0 \\
0 \\
108,149 \\
108,149\end{array}$ & $\begin{array}{r}0 \\
0 \\
132,114 \\
132,114\end{array}$ & $\begin{array}{r}0 \\
0 \\
56,166 \\
56,166\end{array}$ & $\begin{array}{r}0 \\
0 \\
3,581 \\
3,581\end{array}$ & $\begin{array}{r}0 \\
458 \\
216,416 \\
216,874\end{array}$ & $\begin{array}{r}28,731 \\
0 \\
37,502 \\
67,234\end{array}$ \\
\hline $\begin{array}{l}\text { Bonds } \\
\text { Advances from Municipality \& Other .............. } \\
\text { Unamort Prem on Long-term Dobt ............... } \\
\text { (less) Unamort Discount on Long-term Debt } \\
\text { Total Lono-term Debt........................... } \\
\text { Other Noncurrent Liabilities }\end{array}$ & $\begin{array}{r}88,131 \\
66,605 \\
0 \\
4,919 \\
149,817\end{array}$ & $\begin{array}{r}0 \\
3,719 \\
0 \\
0 \\
3,719\end{array}$ & $\begin{array}{r}110,986 \\
2,100 \\
0 \\
0 \\
113,086\end{array}$ & $\begin{array}{r}3,090 \\
0 \\
0 \\
70 \\
3,020\end{array}$ & $\begin{array}{r}297,242 \\
4,878 \\
0 \\
0 \\
302,120\end{array}$ & $\begin{array}{l}0 \\
0 \\
0 \\
0 \\
0\end{array}$ \\
\hline 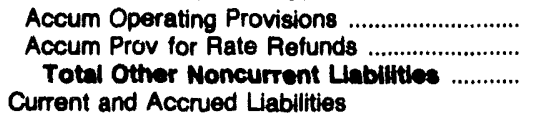 & $\begin{array}{l}0 \\
0 \\
0\end{array}$ & $\begin{array}{l}0 \\
0 \\
0\end{array}$ & $\begin{array}{l}0 \\
0 \\
0\end{array}$ & $\begin{array}{l}0 \\
0 \\
0\end{array}$ & $\begin{array}{r}2,384 \\
398 \\
2,782\end{array}$ & $\begin{array}{l}0 \\
0 \\
0\end{array}$ \\
\hline 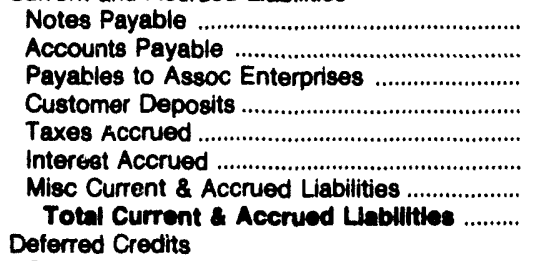 & $\begin{array}{r}3,085 \\
9,640 \\
0 \\
278 \\
0 \\
4,434 \\
5,251 \\
22,688\end{array}$ & $\begin{array}{r}0 \\
6,771 \\
568 \\
142 \\
626 \\
0 \\
104 \\
8,211\end{array}$ & $\begin{array}{r}0 \\
1,065 \\
0 \\
0 \\
0 \\
2,852 \\
0 \\
3,917\end{array}$ & $\begin{array}{r}0 \\
1,148 \\
0 \\
0 \\
0 \\
20 \\
51 \\
1,219\end{array}$ & $\begin{array}{r}0 \\
14,121 \\
0 \\
393 \\
0 \\
1,983 \\
5,345 \\
21,842\end{array}$ & $\begin{array}{r}0 \\
3,430 \\
0 \\
0 \\
0 \\
0 \\
199 \\
3,630\end{array}$ \\
\hline 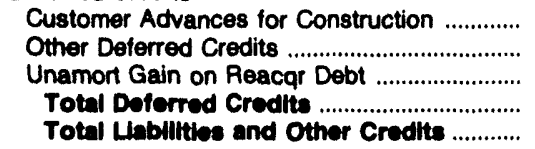 & $\begin{array}{r}1,675 \\
421 \\
0 \\
2,088 \\
282,758\end{array}$ & $\begin{array}{r}0 \\
0 \\
0 \\
0 \\
144,043\end{array}$ & $\begin{array}{r}0 \\
17,680 \\
0 \\
17,860 \\
190,829\end{array}$ & $\begin{array}{r}0 \\
0 \\
0 \\
0 \\
7,819\end{array}$ & $\begin{array}{r}2,099 \\
-12 \\
154,587 \\
158,674 \\
700,292\end{array}$ & $\begin{array}{r}0 \\
0 \\
0 \\
0 \\
70,863\end{array}$ \\
\hline
\end{tabular}

Note: Totals may not equal sum of components because of independent rounding.

Source: Energy information Administration, Form ElA-412, "Annual Report of Public Electric Utilities." 
Table 22. Balance Sheet by Major U.S. Publicly Owned Electric Utility Within State at End of Perlod, 1992 (Continued) (Thousand Dollars)

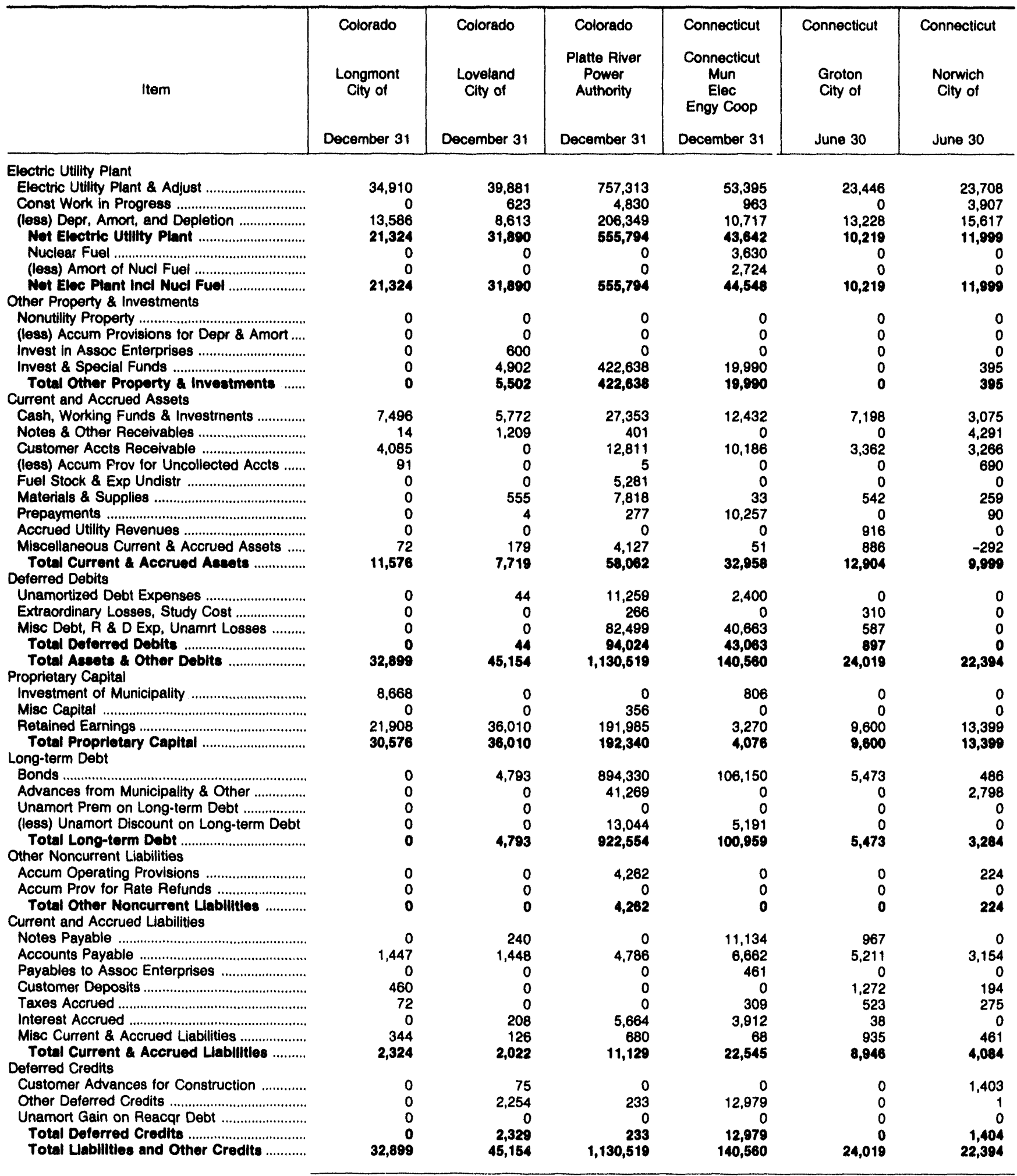

Note: Totals may not equal sum of components because of independent rounding.

Source: Energy Information Administration, Form ElA-412, "Annual Report of Public Electric Utilities." 
Table 22. Balance Sheet by Major U.S. Publicly Owned Electric Utility Within State at End of Period, 1992 (Continued) (Thousand Dollars)

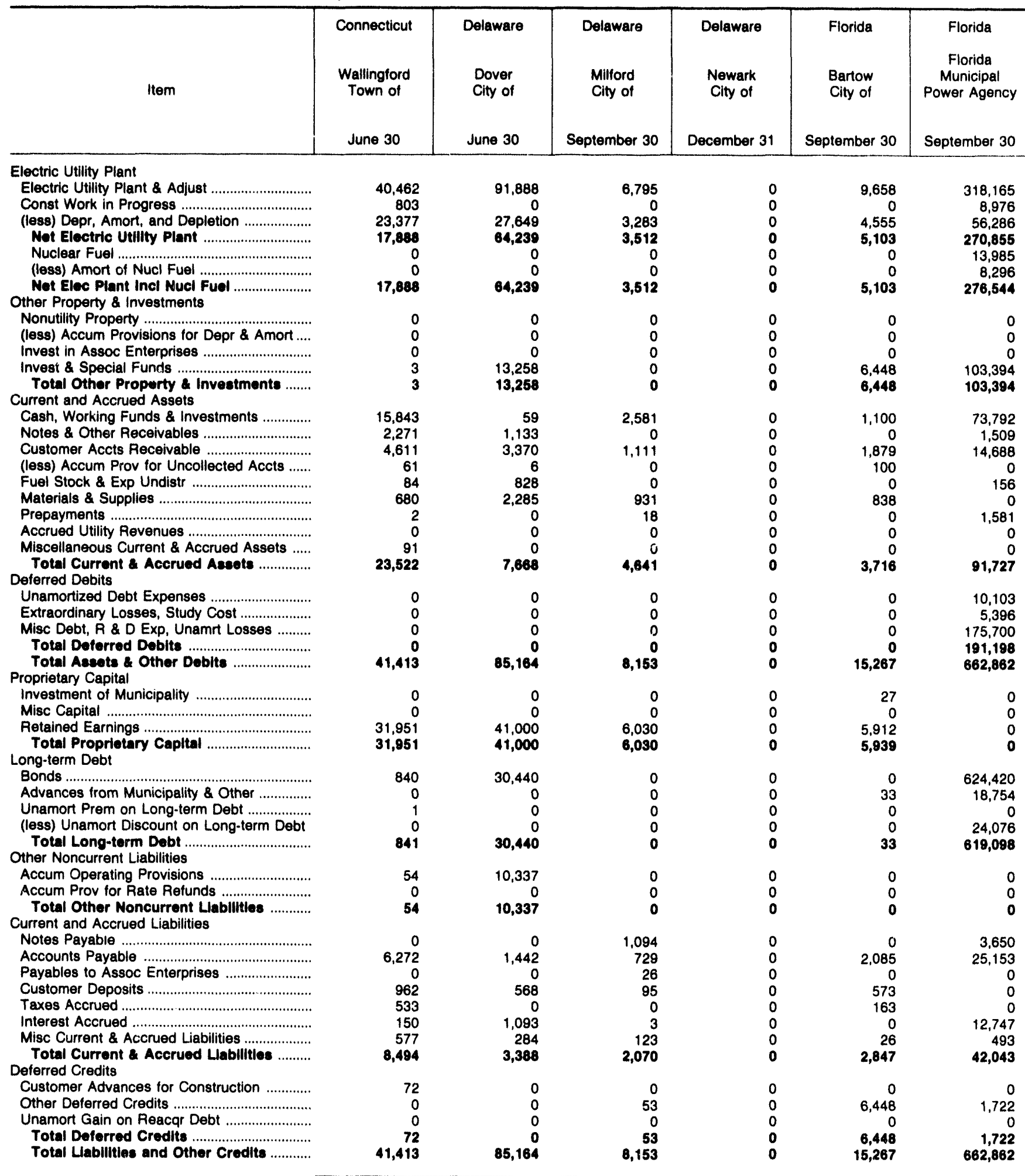

Note: Totals may not equal sum of components because of independent rounding.

Source: Energy Information Administration, Form EIA-412, "Annual Report of Public Electric Utilities." 
Table 22. Balance Sheet by Major U.S. Publicly Owned Electric Utility Within State at End of Perlod, 1992 (Continued) (Thousand Dollars)

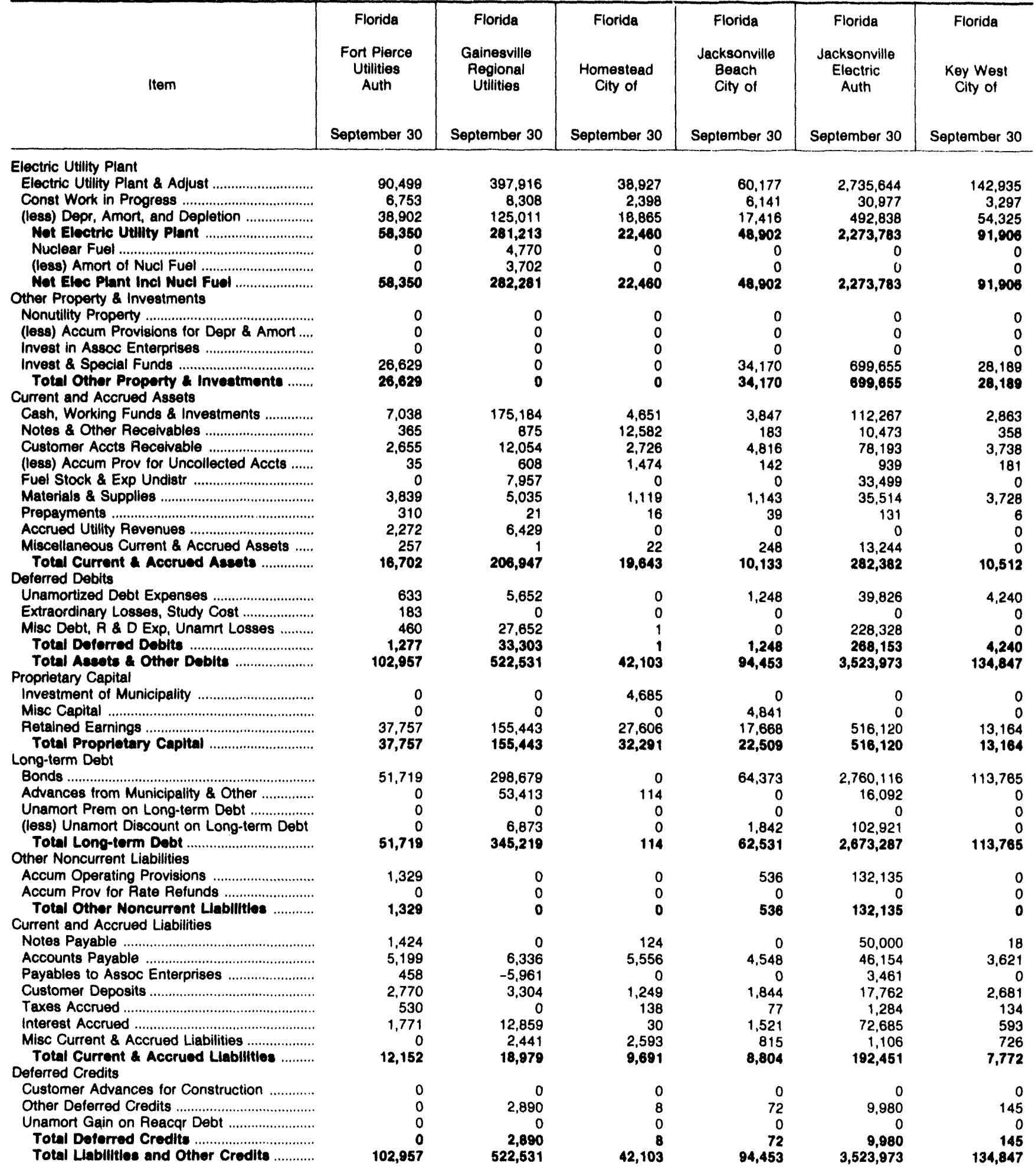

Note: Totals may not equal sum of components because of independent rounding.

Source: Energy Information Adrninistration, Form EIA-412, "Annual Report of Public Electric Utilities." 
Table 22. Balance Sheet by Major U.S. Publicly Owned Electric Utility Within State at End of Period, 1992 (Continued) (Thousand Dollars)

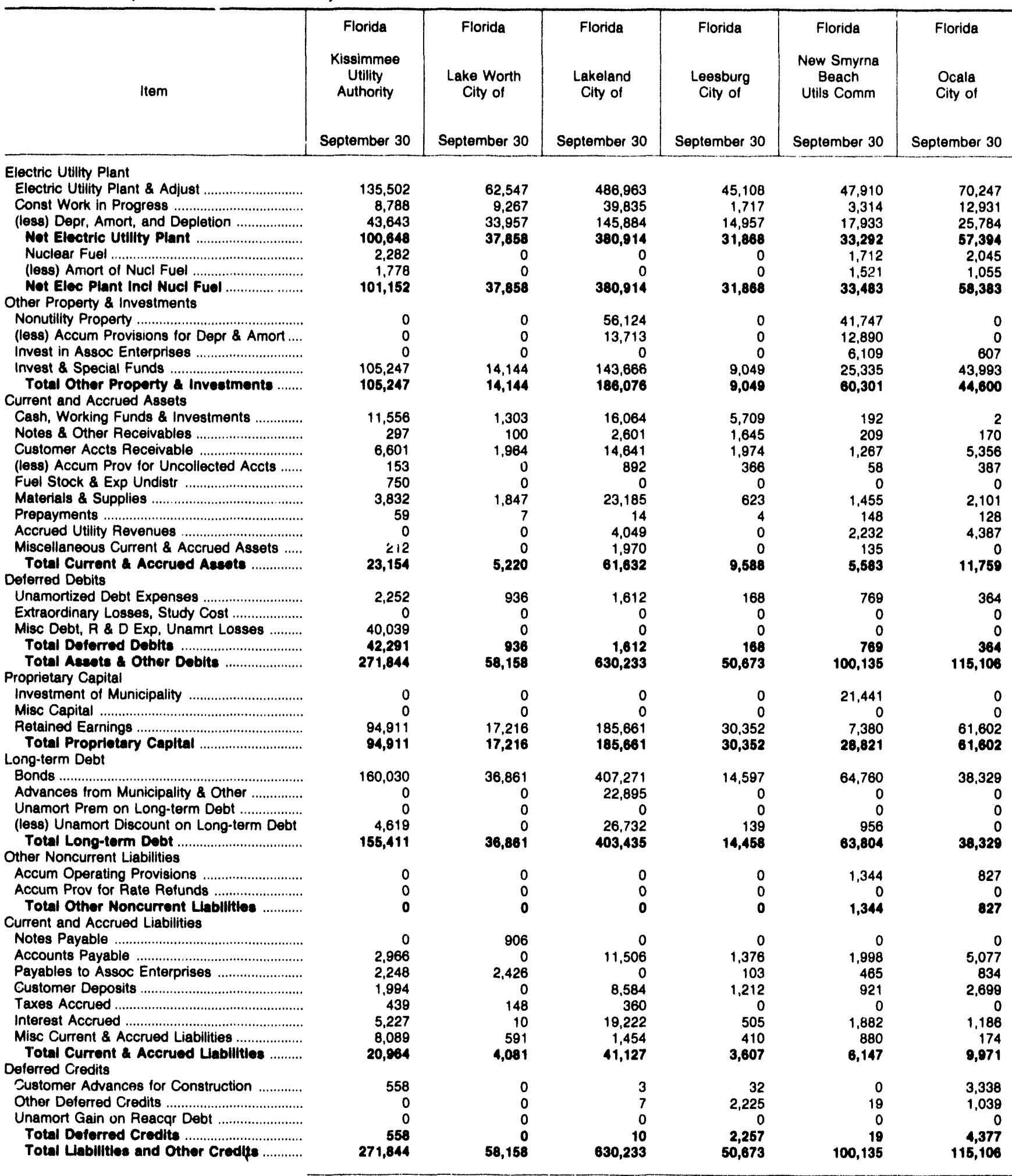

Note: Totals may not equal sum of components because of independent rounding.

Source: Energy Information Administration, Form ElA-412, "Annual Report of Public Electric Utilities." 
Table 22. Balance Sheet by Major U.S. Publlcly Owned Electric Utillty Within State at End of Period, 1992 (Continued) (Thousand Dollars)

\begin{tabular}{|c|c|c|c|c|c|c|}
\hline Item & $\begin{array}{l}\text { Florida } \\
\text { Orlando } \\
\text { Utillties } \\
\text { Comm } \\
\text { September } 30\end{array}$ & $\begin{array}{l}\text { Florida } \\
\text { Quincy } \\
\text { Clty of } \\
\text { September } 30\end{array}$ & $\begin{array}{c}\text { Florida } \\
\text { Reedy Creek } \\
\text { Improvement } \\
\text { Dist } \\
\text { September } 30\end{array}$ & $\begin{array}{l}\text { Florida } \\
\text { Sobring } \\
\text { Utlities } \\
\text { Comm } \\
\text { September } 30\end{array}$ & $\begin{array}{l}\text { Florida } \\
\text { St Cloud } \\
\text { Clty of } \\
\text { September } 30\end{array}$ & $\begin{array}{c}\text { Florida } \\
\text { Tallahassee } \\
\text { City of } \\
\text { September } 30\end{array}$ \\
\hline \multicolumn{7}{|l|}{ Electric Utility Plant } \\
\hline 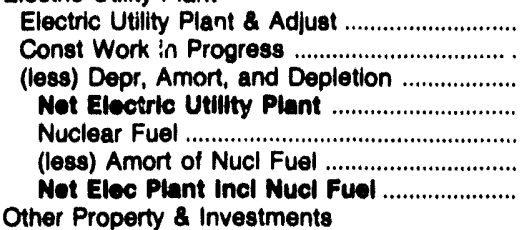 & $\begin{array}{r}1,161,515 \\
76,694 \\
281,573 \\
958,638 \\
20,128 \\
16,978 \\
959,786\end{array}$ & $\begin{array}{r}5,901 \\
0 \\
2,514 \\
3,397 \\
0 \\
0 \\
3,3 a 7\end{array}$ & $\begin{array}{r}85,667 \\
9,187 \\
9,774 \\
85,081 \\
0 \\
0 \\
85,081\end{array}$ & $\begin{array}{r}30,069 \\
41 \\
10,465 \\
19,645 \\
0 \\
0 \\
19,645\end{array}$ & $\begin{array}{r}51,176 \\
1,315 \\
15,191 \\
37,300 \\
0 \\
0 \\
37,300\end{array}$ & $\begin{array}{r}318,623 \\
44,199 \\
137,237 \\
225,586 \\
0 \\
0 \\
225,686\end{array}$ \\
\hline 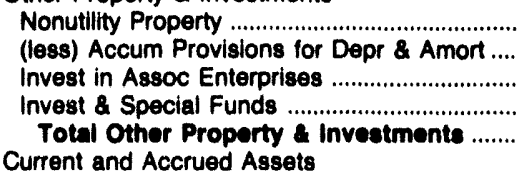 & $\begin{array}{r}414 \\
6 \\
0 \\
355,076 \\
355,483\end{array}$ & $\begin{array}{r}0 \\
0 \\
0 \\
855 \\
865\end{array}$ & $\begin{array}{l}0 \\
0 \\
0 \\
0 \\
0\end{array}$ & $\begin{array}{r}0 \\
0 \\
0 \\
17,959 \\
17,959\end{array}$ & $\begin{array}{l}0 \\
0 \\
0 \\
0 \\
0\end{array}$ & $\begin{array}{r}6,367 \\
3,527 \\
0 \\
90,633 \\
93,473\end{array}$ \\
\hline 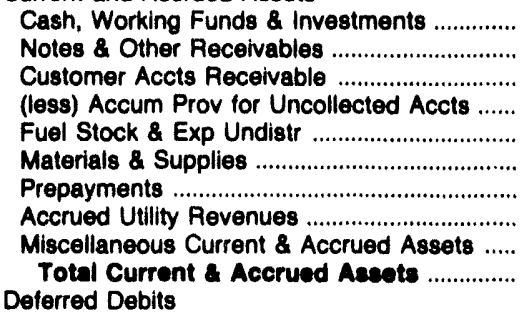 & $\begin{array}{r}185,455 \\
2,367 \\
26,936 \\
750 \\
7,689 \\
24,674 \\
626 \\
14,505 \\
540 \\
262,042\end{array}$ & $\begin{array}{r}120 \\
0 \\
714 \\
190 \\
0 \\
88 \\
36 \\
0 \\
0 \\
778\end{array}$ & $\begin{array}{r}52,446 \\
134 \\
5,684 \\
0 \\
61 \\
2,973 \\
89 \\
820 \\
0 \\
82,218\end{array}$ & $\begin{array}{r}2,741 \\
80 \\
1,418 \\
122 \\
0 \\
592 \\
72 \\
969 \\
0 \\
5,751\end{array}$ & $\begin{array}{r}880 \\
0 \\
1,174 \\
121 \\
0 \\
1,238 \\
36 \\
2,123 \\
0 \\
5,330\end{array}$ & $\begin{array}{r}15,280 \\
216 \\
13,160 \\
2,254 \\
0 \\
4,237 \\
0 \\
0 \\
0 \\
30,638\end{array}$ \\
\hline 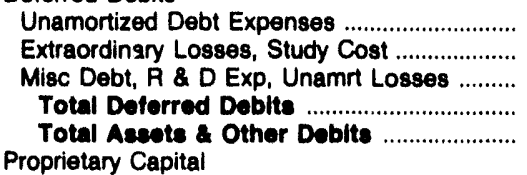 & $\begin{array}{r}2,500 \\
0 \\
4,730 \\
7,230 \\
1,584,541\end{array}$ & $\begin{array}{r}0 \\
0 \\
0 \\
0 \\
\mathbf{5 , 0 1 7}\end{array}$ & $\begin{array}{r}1,355 \\
0 \\
0 \\
1,355 \\
148,654\end{array}$ & $\begin{array}{r}918 \\
0 \\
844 \\
1,762 \\
45,116\end{array}$ & $\begin{array}{r}593 \\
700 \\
4,893 \\
\mathbf{6 , 1 8 8} \\
\mathbf{4 8 , 8 1 6}\end{array}$ & $\begin{array}{r}383 \\
0 \\
0 \\
383 \\
350,079\end{array}$ \\
\hline 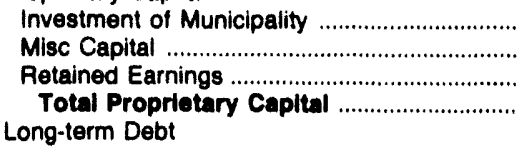 & $\begin{array}{r}0 \\
0 \\
265,431 \\
265,431\end{array}$ & $\begin{array}{r}0 \\
121 \\
3,741 \\
3,882\end{array}$ & $\begin{array}{r}0 \\
0 \\
10,651 \\
10,651\end{array}$ & $\begin{array}{r}0 \\
4,657 \\
-53,868 \\
-49,212\end{array}$ & $\begin{array}{r}0 \\
2,166 \\
17,775 \\
19,941\end{array}$ & $\begin{array}{r}0 \\
0 \\
233,604 \\
233,604\end{array}$ \\
\hline 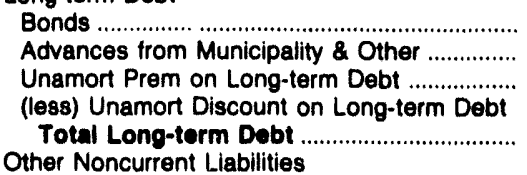 & $\begin{array}{r}1,221,548 \\
0 \\
0 \\
70,502 \\
1,161,046\end{array}$ & $\begin{array}{r}296 \\
0 \\
0 \\
0 \\
298\end{array}$ & $\begin{array}{r}121,215 \\
0 \\
0 \\
1,262 \\
119,953\end{array}$ & $\begin{array}{r}83,598 \\
5,414 \\
0 \\
1,120 \\
87,893\end{array}$ & $\begin{array}{r}26,400 \\
0 \\
0 \\
365 \\
26,035\end{array}$ & $\begin{array}{r}96,160 \\
0 \\
0 \\
1,705 \\
94,455\end{array}$ \\
\hline $\begin{array}{l}\text { Accum Operating Provisions } \\
\text { Accum Prov for Rate Refunds ............................. } \\
\text { Total Other Noncurrent Llabilities ........... } \\
\text { Current and Accrued Liabilities }\end{array}$ & $\begin{array}{l}0 \\
0 \\
0\end{array}$ & $\begin{array}{l}0 \\
0 \\
0\end{array}$ & $\begin{array}{l}0 \\
0 \\
0\end{array}$ & $\begin{array}{l}0 \\
0 \\
0\end{array}$ & $\begin{array}{l}0 \\
0 \\
0\end{array}$ & $\begin{array}{l}0 \\
0 \\
0\end{array}$ \\
\hline 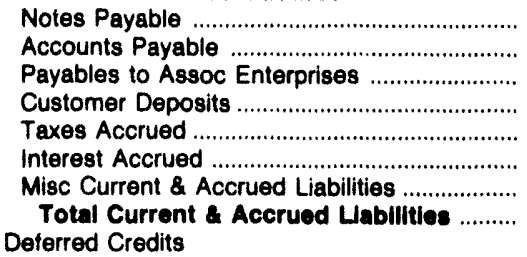 & $\begin{array}{r}5,539 \\
20,855 \\
1,338 \\
10,952 \\
1,202 \\
38,946 \\
6,783 \\
85,616\end{array}$ & $\begin{array}{r}0 \\
501 \\
0 \\
290 \\
0 \\
4 \\
64 \\
859\end{array}$ & $\begin{array}{r}0 \\
8,062 \\
0 \\
0 \\
332 \\
4,505 \\
0 \\
12,899\end{array}$ & $\begin{array}{r}18 \\
2,185 \\
0 \\
1,302 \\
0 \\
2,688 \\
242 \\
6,438\end{array}$ & $\begin{array}{r}570 \\
1,189 \\
0 \\
441 \\
0 \\
320 \\
321 \\
2,840\end{array}$ & $\begin{array}{r}0 \\
15,084 \\
0 \\
6,424 \\
0 \\
0 \\
0 \\
21,508\end{array}$ \\
\hline 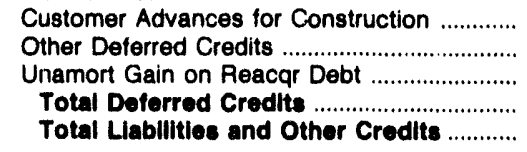 & $\begin{array}{r}33,147 \\
49,303 \\
0 \\
82,449 \\
1,584,541\end{array}$ & $\begin{array}{r}0 \\
0 \\
0 \\
0 \\
5,017\end{array}$ & $\begin{array}{r}0 \\
5,151 \\
0 \\
5,151 \\
148,654\end{array}$ & $\begin{array}{r}0 \\
0 \\
0 \\
0 \\
45,116\end{array}$ & $\begin{array}{r}0 \\
0 \\
0 \\
0 \\
48,816\end{array}$ & $\begin{array}{r}115 \\
398 \\
0 \\
513 \\
350,079\end{array}$ \\
\hline
\end{tabular}

Note: Totals may not equal sum of components because of independent rounding.

Source: Energy Information Administration, Form EIA-412, "Annual Report of Public Electric Utilities." 
Table 22. Balance Sheet by Major U.S. Publicly Owned Electric Utility Within State at End of Period, 1992 (Continued) (Thousand Dollars)

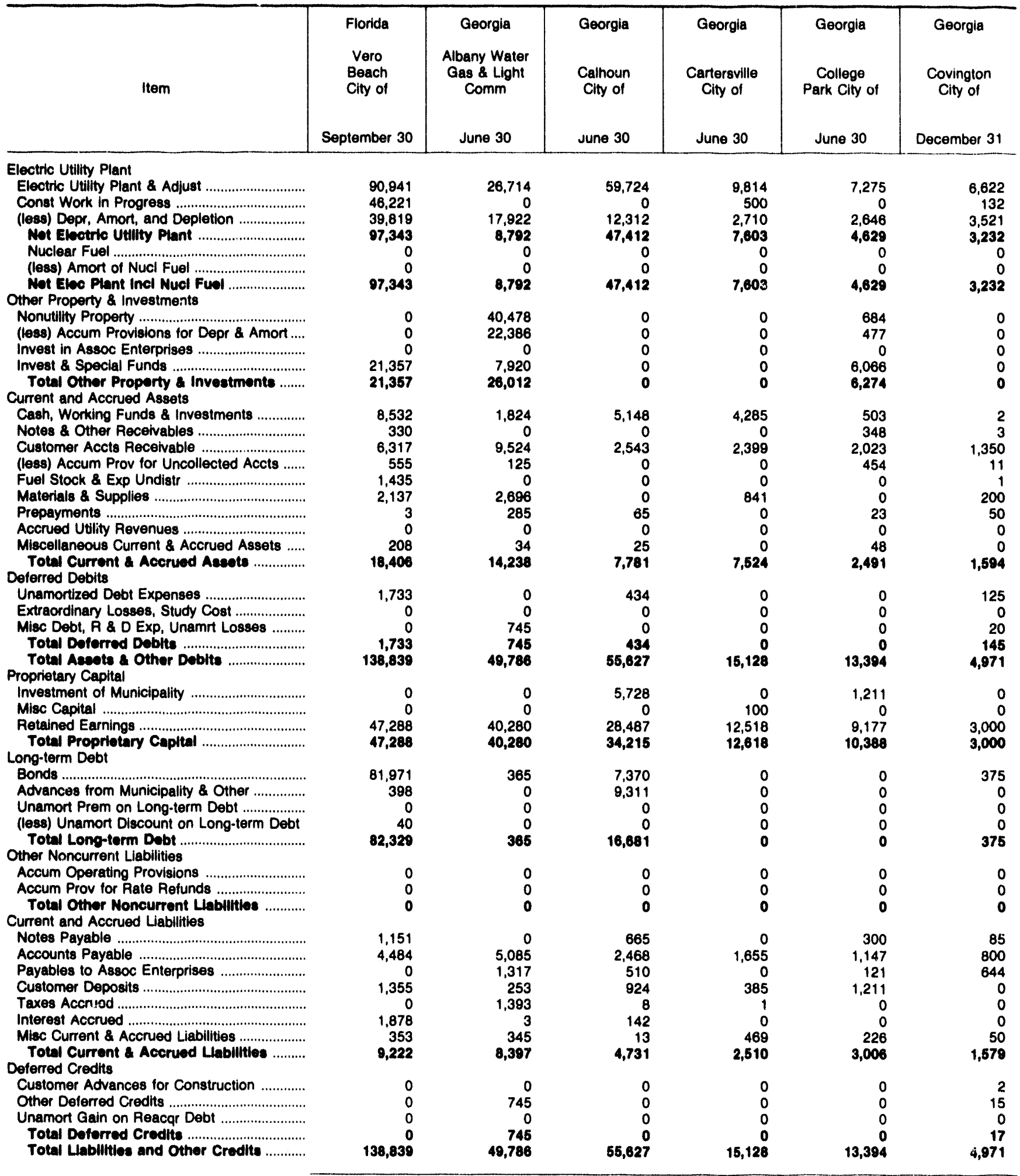

Note: Totals may not equal sum of components because of independent rounding.

Source: Energy Information Administration, Form ElA-412, "Annual Report of Public Electric Utilities." 
Table 22. Balance Sheet by Major U.S. Publlcly Owned Electric Utillty Within State at End of Perlod, 1992 (Continued) (Thousand Dollars)

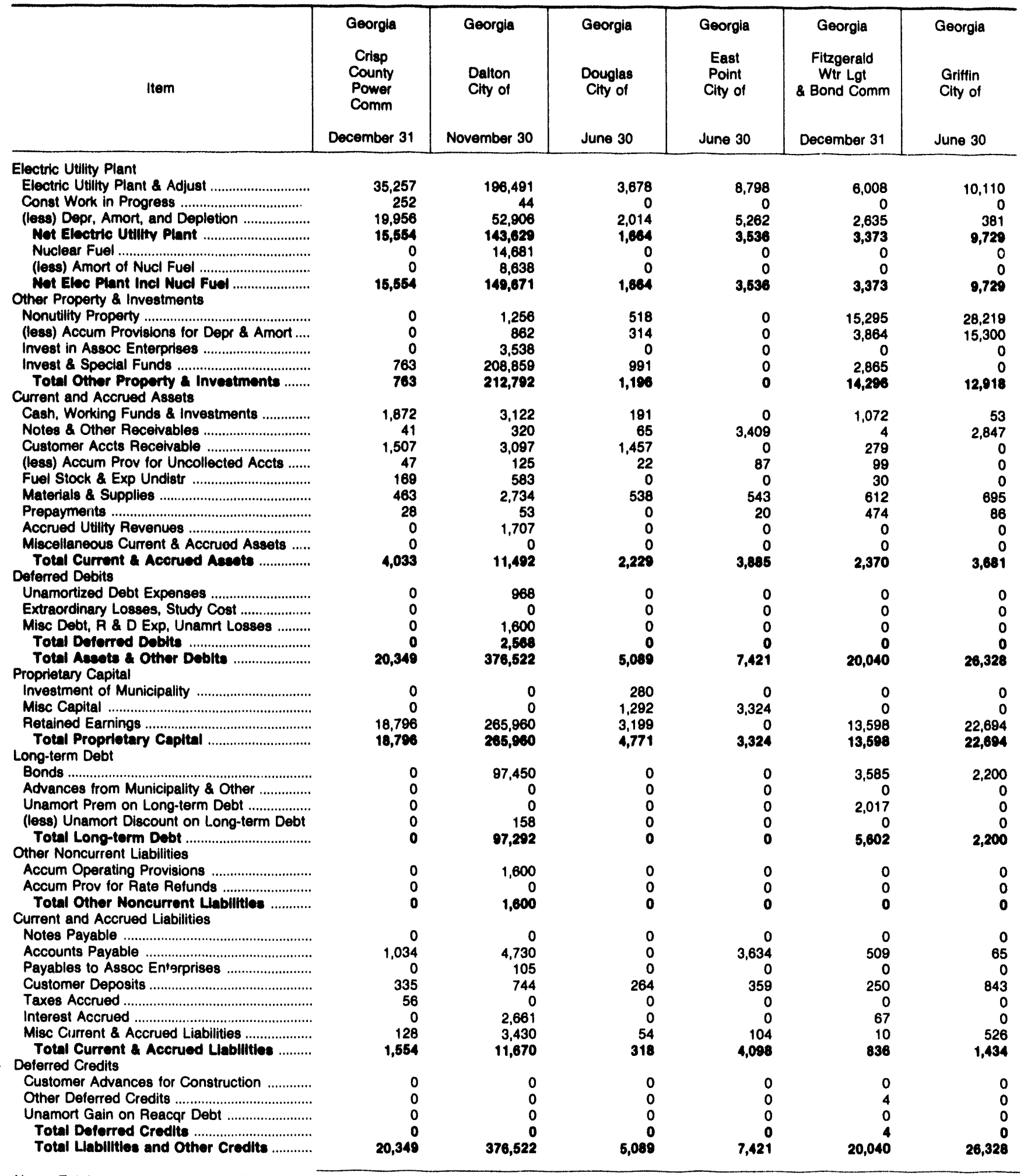

Note: Totals may not equal sum of components because of independent rounding.

Source: Energy Information Administration, Form EIA-412, "Annual Report of Public Electric Utilities." 
Table 22. Balance Sheet by Major U.S. Publicly Owned Electric Utility Within State at End of Period, 1992 (Continued) (Thousand Dollars)

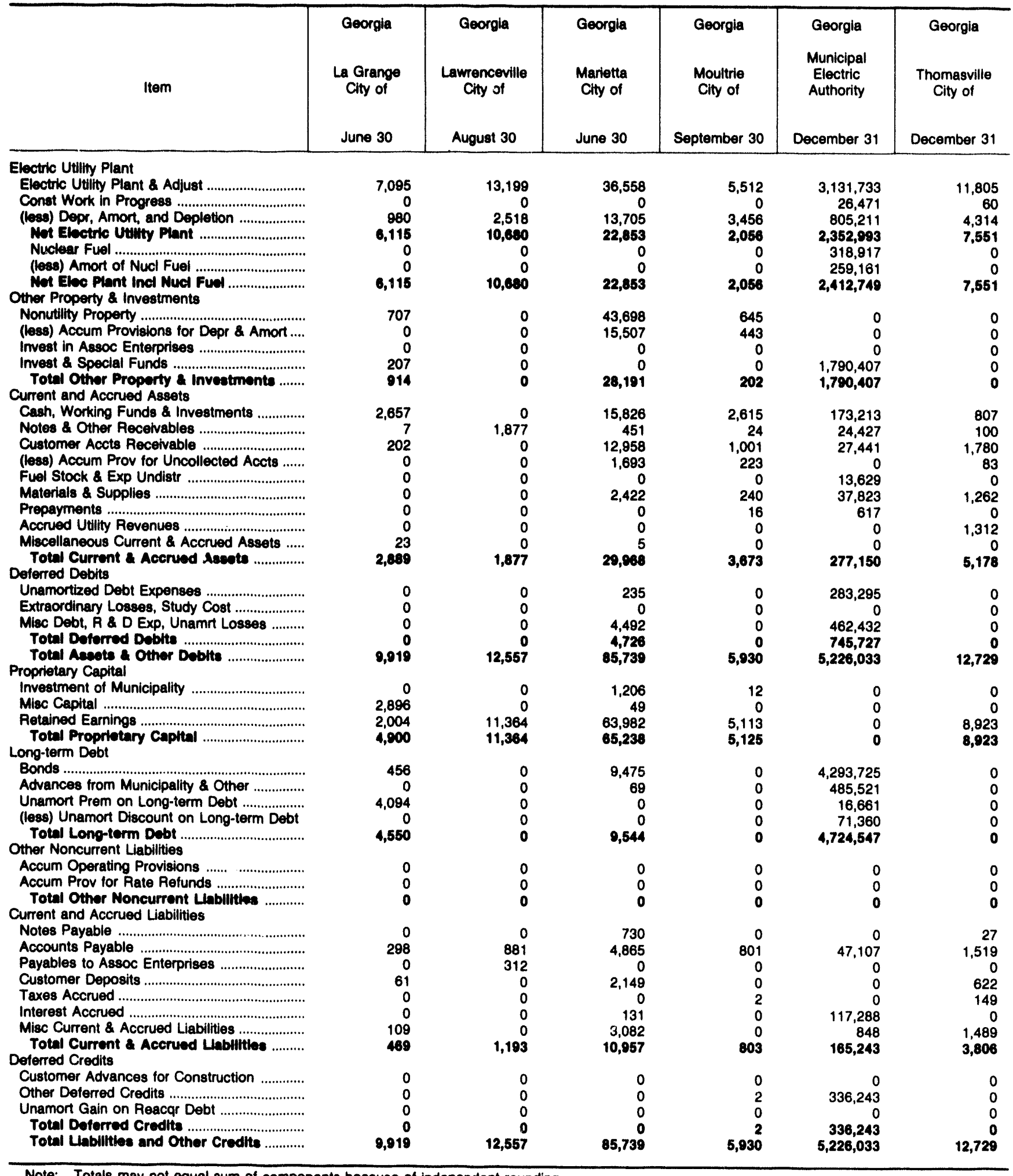

Note: Totals may not equal sum of components because of independent rounding.

Source: Energy Information Administration, Form EIA-412, "Annual Report of Public Electric Utilities." 
Table 22. Balance Sheet by Major U.S. Publicly Owned Electric Utility Within State at End of Period, 1992 (Continued) (Thousand Dollars)

\begin{tabular}{|c|c|c|c|c|c|c|}
\hline Item & $\begin{array}{l}\text { Idaho } \\
\text { Idaho } \\
\text { Falls } \\
\text { City of } \\
\text { September } 30\end{array}$ & $\begin{array}{l}\text { Illinois } \\
\text { Batavia } \\
\text { City of } \\
\text { December } 31\end{array}$ & $\begin{array}{l}\text { Illinois } \\
\begin{array}{c}\text { Geneva } \\
\text { Clty of }\end{array} \\
\text { April } 30\end{array}$ & $\begin{array}{c}\text { Illinois } \\
\text { Ilinols } \\
\text { Municipal } \\
\text { Elec Agency } \\
\text { Aprll } 30\end{array}$ & $\begin{array}{l}\text { Illinois } \\
\begin{array}{c}\text { Naperville } \\
\text { City of }\end{array} \\
\text { April } 30\end{array}$ & $\begin{array}{l}\text { Illinois } \\
\text { Rochelle } \\
\text { Municipal } \\
\text { Utilities } \\
\text { April } 30\end{array}$ \\
\hline 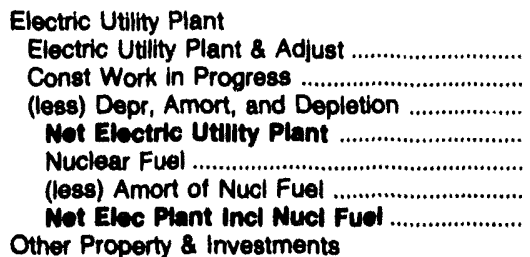 & $\begin{array}{r}126,140 \\
53 \\
27,508 \\
98,688 \\
0 \\
0 \\
98,688\end{array}$ & $\begin{array}{r}14,615 \\
0 \\
5,798 \\
8,817 \\
0 \\
0 \\
8,817\end{array}$ & $\begin{array}{r}18,622 \\
50 \\
7,503 \\
11,169 \\
0 \\
0 \\
11,169\end{array}$ & $\begin{array}{r}95,287 \\
0 \\
3,407 \\
91,880 \\
0 \\
0 \\
91,880\end{array}$ & $\begin{array}{r}101,066 \\
0 \\
67,035 \\
34,031 \\
0 \\
0 \\
34,031\end{array}$ & $\begin{array}{r}23,176 \\
3,815 \\
13,634 \\
13,357 \\
0 \\
0 \\
13,357\end{array}$ \\
\hline 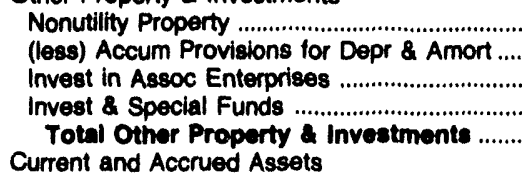 & $\begin{array}{r}0 \\
0 \\
0 \\
20,129 \\
20,129\end{array}$ & $\begin{array}{l}0 \\
0 \\
0 \\
0 \\
0\end{array}$ & $\begin{array}{r}0 \\
0 \\
0 \\
443 \\
443\end{array}$ & $\begin{array}{l}0 \\
0 \\
0 \\
0 \\
0\end{array}$ & $\begin{array}{r}0 \\
0 \\
0 \\
7,755 \\
7,755\end{array}$ & $\begin{array}{r}0 \\
0 \\
0 \\
5,714 \\
5,714\end{array}$ \\
\hline 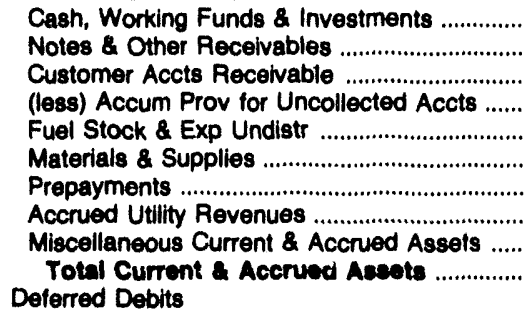 & $\begin{array}{r}1,609 \\
899 \\
2,203 \\
865 \\
0 \\
1,988 \\
0 \\
0 \\
6 \\
5,840\end{array}$ & $\begin{array}{r}3,043 \\
0 \\
4,371 \\
0 \\
0 \\
1,112 \\
0 \\
0 \\
0 \\
8,527\end{array}$ & $\begin{array}{r}645 \\
1,122 \\
0 \\
0 \\
0 \\
462 \\
0 \\
0 \\
0 \\
2,228\end{array}$ & $\begin{array}{r}27,193 \\
0 \\
3,963 \\
0 \\
0 \\
0 \\
155 \\
0 \\
0 \\
31,312\end{array}$ & $\begin{array}{r}15,216 \\
161 \\
6,650 \\
753 \\
0 \\
4,249 \\
0 \\
0 \\
531 \\
26,054\end{array}$ & $\begin{array}{r}380 \\
773 \\
0 \\
10 \\
122 \\
496 \\
69 \\
0 \\
66 \\
1,896\end{array}$ \\
\hline 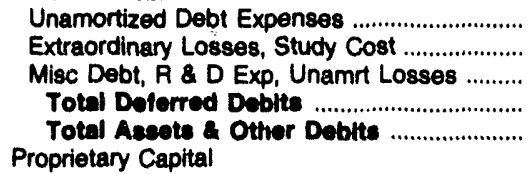 & $\begin{array}{r}2,387 \\
1,771 \\
0 \\
4,158 \\
128,815\end{array}$ & $\begin{array}{r}0 \\
0 \\
0 \\
0 \\
17,343\end{array}$ & $\begin{array}{r}55 \\
0 \\
0 \\
55 \\
13,894\end{array}$ & $\begin{array}{r}3,754 \\
0 \\
2,720 \\
6,474 \\
129,666\end{array}$ & $\begin{array}{r}0 \\
0 \\
0 \\
0 \\
67,840\end{array}$ & $\begin{array}{r}86 \\
0 \\
190 \\
276 \\
21,242\end{array}$ \\
\hline 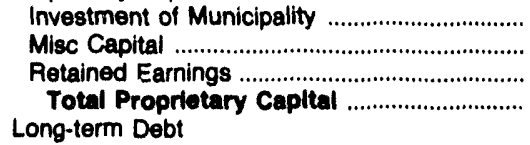 & $\begin{array}{r}0 \\
0 \\
29,058 \\
29,058\end{array}$ & $\begin{array}{r}0 \\
0 \\
13,008 \\
13,008\end{array}$ & $\begin{array}{r}443 \\
662 \\
10,472 \\
11,577\end{array}$ & $\begin{array}{r}0 \\
0 \\
1,095 \\
1,095\end{array}$ & $\begin{array}{r}0 \\
0 \\
52,913 \\
52,913\end{array}$ & $\begin{array}{r}0 \\
0 \\
9,363 \\
9,363\end{array}$ \\
\hline 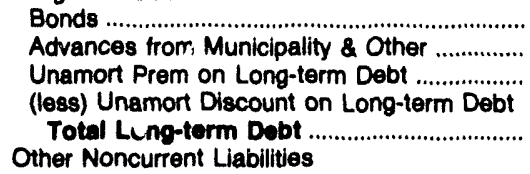 & $\begin{array}{r}84,793 \\
3,298 \\
4,159 \\
1,642 \\
90,608\end{array}$ & $\begin{array}{r}225 \\
0 \\
0 \\
0 \\
225\end{array}$ & $\begin{array}{r}445 \\
19 \\
1,026 \\
0 \\
1,400\end{array}$ & $\begin{array}{r}128,670 \\
0 \\
0 \\
7,321 \\
121,349\end{array}$ & $\begin{array}{r}8,480 \\
371 \\
0 \\
0 \\
8,851\end{array}$ & $\begin{array}{r}9,060 \\
0 \\
0 \\
134 \\
8,926\end{array}$ \\
\hline $\begin{array}{l}\text { Accum Operating Provisions ........................ } \\
\text { Accum Prov for Rate Refunds .................... } \\
\text { Total Other Noncurrent Llabilities .......... } \\
\text { Current and Accrued Liabilities }\end{array}$ & $\begin{array}{l}0 \\
0 \\
0\end{array}$ & $\begin{array}{l}0 \\
0 \\
0\end{array}$ & $\begin{array}{l}0 \\
0 \\
0\end{array}$ & $\begin{array}{l}0 \\
0 \\
0\end{array}$ & $\begin{array}{l}0 \\
0 \\
0\end{array}$ & \\
\hline $\begin{array}{l}\text { Notes Payable } \\
\text { Accounts Payable } \\
\text { Payables to Assoc Enterprises } \\
\text { Customer Deposits } \\
\text { Taxes Accrued } \\
\text { Interest Accrued } \\
\text { Misc Current \& Accrued Liabilities } \\
\text { Total Current \& Accrued Luabilties } \\
\text { Deferred Credits }\end{array}$ & $\begin{array}{r}0 \\
2,278 \\
0 \\
2 \\
0 \\
4,330 \\
2,539 \\
9,146\end{array}$ & $\begin{array}{r}0 \\
3,984 \\
0 \\
109 \\
0 \\
18 \\
0 \\
4,110\end{array}$ & $\begin{array}{r}135 \\
692 \\
0 \\
0 \\
0 \\
0 \\
0 \\
827\end{array}$ & $\begin{array}{r}0 \\
5,299 \\
0 \\
0 \\
0 \\
1,880 \\
0 \\
7,179\end{array}$ & $\begin{array}{r}0 \\
3,022 \\
0 \\
58 \\
0 \\
28 \\
2,720 \\
5,828\end{array}$ & $\begin{array}{r}0 \\
2,560 \\
0 \\
0 \\
0 \\
304 \\
89 \\
2,954\end{array}$ \\
\hline 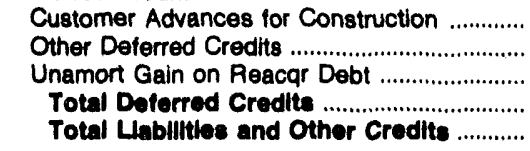 & $\begin{array}{r}0 \\
0 \\
0 \\
0 \\
128,815\end{array}$ & $\begin{array}{r}0 \\
0 \\
0 \\
0 \\
17,343\end{array}$ & $\begin{array}{r}0 \\
0 \\
0 \\
0 \\
13,894\end{array}$ & $\begin{array}{r}0 \\
43 \\
0 \\
43 \\
129,866\end{array}$ & $\begin{array}{r}248 \\
0 \\
0 \\
248 \\
67,840\end{array}$ & $\begin{array}{r}0 \\
0 \\
0 \\
0 \\
21,242\end{array}$ \\
\hline
\end{tabular}

Note: Totals may not equal sum of components bocause of independent rounding.

Source: Energy Information Administration, Form EIA-412, "Annual Report of Public Electric Utilities." 
Table 22. Balance Sheet by Major U.S. Publicly Owned Electric Utility Within State at End of Period, 1992 (Continued) (Thousand Dollars)

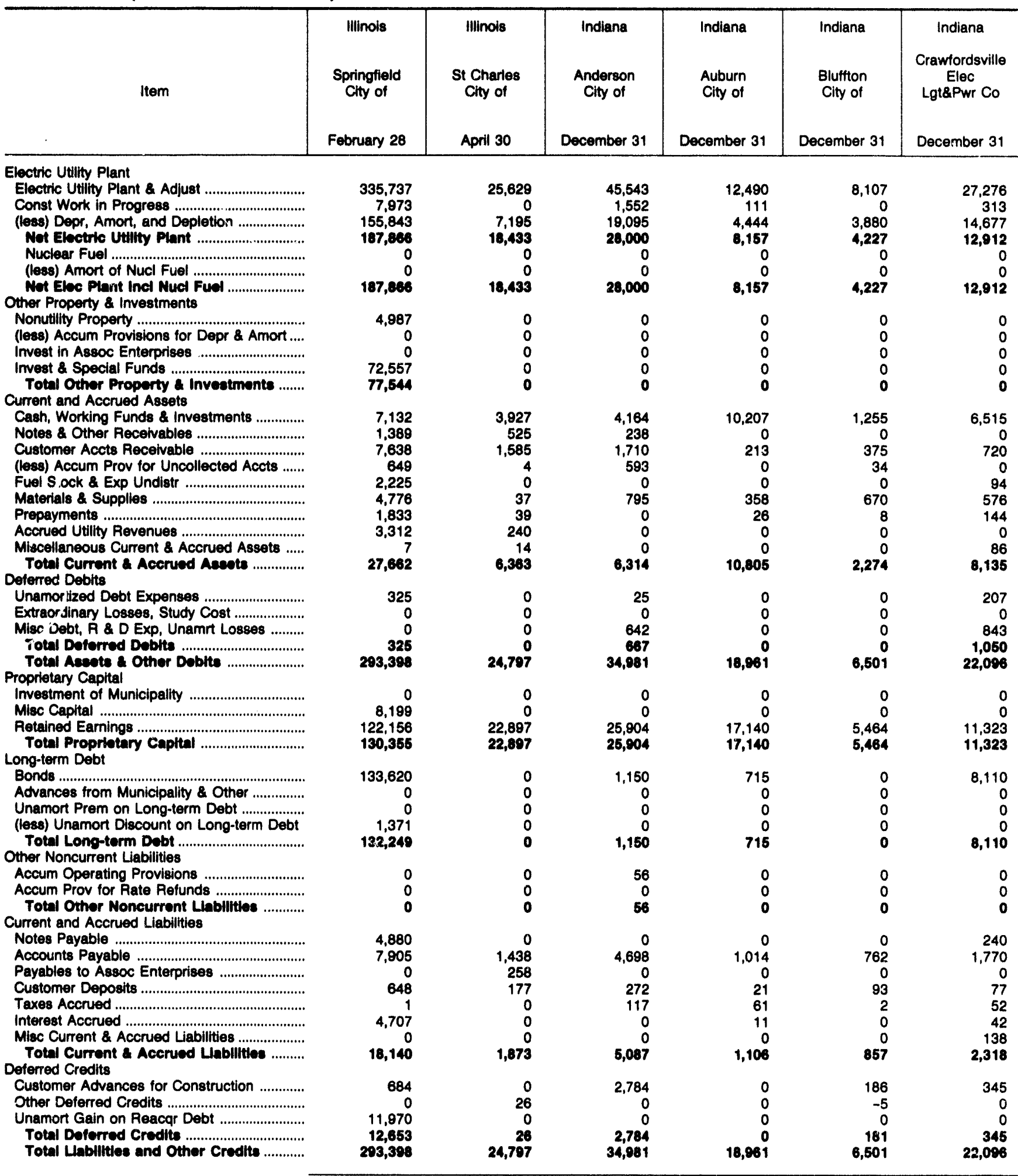

Note: Totals may not equal sum of components because of independent rounding.

Source: Energy Information Administration, Form EIA-412, "Annual Report of Public Electric Utilities." 
Table 22. Balance Sheet by Major U.S. Publicly Owned Electric Utility Within State at End of Period, 1992 (Continued) (Thousand Dollars)

\begin{tabular}{|c|c|c|c|c|c|c|}
\hline Item & $\begin{array}{l}\text { Indiana } \\
\text { Frankfort } \\
\text { City of } \\
\text { December } 31\end{array}$ & $\begin{array}{l}\text { Indiana } \\
\text { Greenfield } \\
\text { City of } \\
\text { December } 31\end{array}$ & $\begin{array}{l}\text { Indiana } \\
\text { Indiana } \\
\text { Municipal } \\
\text { Power Agency } \\
\text { December } 31\end{array}$ & $\begin{array}{l}\text { Indiana } \\
\text { Jasper } \\
\text { City of } \\
\text { December } 31\end{array}$ & $\begin{array}{l}\text { Indiana } \\
\text { Logansport } \\
\text { City of } \\
\text { December } 31\end{array}$ & $\begin{array}{l}\text { Indiana } \\
\text { Mishawaka } \\
\text { City of } \\
\text { December } 31\end{array}$ \\
\hline \multicolumn{7}{|l|}{ Electric Utllity Plant } \\
\hline 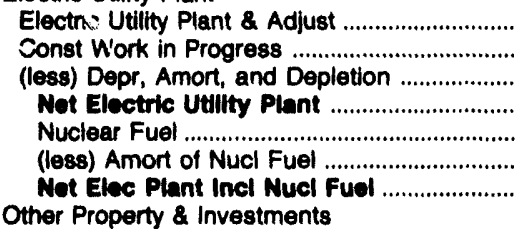 & $\begin{array}{r}17,005 \\
0 \\
5,416 \\
11,588 \\
0 \\
0 \\
11,588\end{array}$ & $\begin{array}{r}6,937 \\
0 \\
1,860 \\
5,077 \\
0 \\
0 \\
5,077\end{array}$ & $\begin{array}{r}213,034 \\
4,842 \\
46,481 \\
171,394 \\
0 \\
0 \\
171,394\end{array}$ & $\begin{array}{r}13,600 \\
1,750 \\
7,358 \\
7,992 \\
0 \\
0 \\
7,992\end{array}$ & $\begin{array}{r}47,519 \\
5,088 \\
25,716 \\
26,891 \\
0 \\
0 \\
26,891\end{array}$ & $\begin{array}{r}29,766 \\
0 \\
14,150 \\
15,616 \\
0 \\
0 \\
15,616\end{array}$ \\
\hline 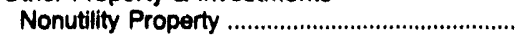 & 0 & 0 & 0 & 0 & 0 & 18 \\
\hline (less) Accum Provisions for Depr \& Amort .... & 0 & 0 & 0 & 0 & 0 & 0 \\
\hline 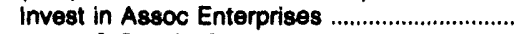 & 0 & 0 & 0 & 0 & 0 & 0 \\
\hline $\begin{array}{l}\text { Invest \& Special Funds } \\
\text { Total Other Property \& Inveatments } \\
\text { Current and Accrued Assets }\end{array}$ & $\begin{array}{l}0 \\
0\end{array}$ & $\begin{array}{l}1,067 \\
1,067\end{array}$ & $\begin{array}{l}0 \\
0\end{array}$ & $\begin{array}{l}7,789 \\
7,789\end{array}$ & $\begin{array}{l}11,365 \\
11,365\end{array}$ & $\begin{array}{l}1,190 \\
1,207\end{array}$ \\
\hline Cash, Working Funds \& Investments .............. & 5,579 & 824 & 65,789 & 248 & 440 & 461 \\
\hline Notes \& Other Recelvables ................................ & 182 & 1,552 & 128 & 0 & 116 & 1 \\
\hline Customer Accts Receivable & 902 & 420 & 18,002 & 1,039 & 1,380 & 2,486 \\
\hline (less) Accum Prov for Uncollected Accts ...... & 0 & 0 & 0 & 15 & 2 & 534 \\
\hline $\begin{array}{l}\text { Fuel Stock \& Exp Undistr } \\
\text { Materials \& Supplies }\end{array}$ & $\begin{array}{r}0 \\
573\end{array}$ & $\begin{array}{r}0 \\
473\end{array}$ & $\begin{array}{l}4,102 \\
1,275\end{array}$ & $\begin{array}{r}0 \\
1,131\end{array}$ & $\begin{array}{r}0 \\
2,043\end{array}$ & $\begin{array}{r}0 \\
1,145\end{array}$ \\
\hline 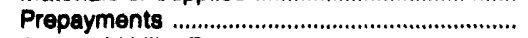 & 34 & 0 & 3,789 & 116 & 38 & 48 \\
\hline 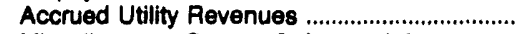 & 0 & 0 & 1,885 & 0 & 0 & 0 \\
\hline $\begin{array}{l}\text { Miscellaneous Current \& Accrued Assets ..... } \\
\text { Total Current a Accrued Aseots .............. } \\
\text { Deferred Debits }\end{array}$ & $\begin{array}{r}10 \\
7,280\end{array}$ & & $\begin{array}{r}326 \\
95,298\end{array}$ & $\begin{array}{r}0 \\
2,518\end{array}$ & $\begin{array}{r}0 \\
4,015\end{array}$ & 3,600 \\
\hline 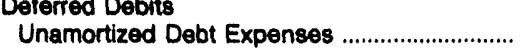 & 0 & 57 & 4,755 & 132 & 572 & \\
\hline 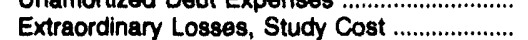 & 0 & 0 & 38,808 & -4 & 0 & $\begin{array}{r}12 \\
0\end{array}$ \\
\hline Misc Debt, A \& D Exp, Unamrt Losses ......... & 0 & 0 & 22,322 & 0 & 0 & 0 \\
\hline 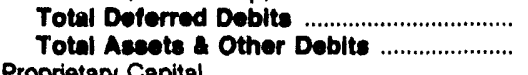 & $\begin{array}{r}0 \\
18,888\end{array}$ & 9,471 & $\begin{array}{r}65,885 \\
332,578\end{array}$ & $\begin{array}{r}128 \\
18,427\end{array}$ & $\begin{array}{r}572 \\
42,842\end{array}$ & $\begin{array}{r}12 \\
20,436\end{array}$ \\
\hline Proprietary Capital & & & & & & \\
\hline Investment of Municipality .................................. & 0 & 0 & 0 & 0 & 0 & 0 \\
\hline 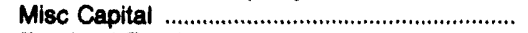 & 0 & 0 & 0 & 0 & 0 & 0 \\
\hline 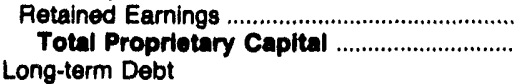 & $\begin{array}{l}14,768 \\
14,768\end{array}$ & $\begin{array}{l}5,691 \\
5,691\end{array}$ & $\begin{array}{l}24,773 \\
24,773\end{array}$ & $\begin{array}{l}7,749 \\
7,749\end{array}$ & $\begin{array}{l}22,024 \\
22,024\end{array}$ & $\begin{array}{l}16,494 \\
16,494\end{array}$ \\
\hline Bonds & 0 & 1,860 & 286,930 & 8,650 & 16,920 & 1,205 \\
\hline Advances from Municipality \& Other ............... & 161 & 0 & 0 & 0 & 0 & 266 \\
\hline Unamort Prem on Long-term Debt ................... & 0 & 0 & 2 & 0 & 0 & 0 \\
\hline 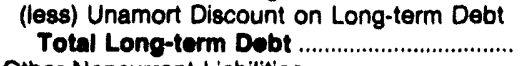 & $\begin{array}{r}0 \\
161\end{array}$ & $\begin{array}{r}0 \\
1,860\end{array}$ & $\begin{array}{r}9,479 \\
277,453\end{array}$ & $\begin{array}{r}0 \\
8,650\end{array}$ & $\begin{array}{r}0 \\
16,820\end{array}$ & $\begin{array}{r}23 \\
1,448\end{array}$ \\
\hline Other Noncurrent Liabilities & & & & & & \\
\hline Accum Operating Provisions ................................ & 0 & 0 & 0 & 0 & 64 & 0 \\
\hline Accum Prov for Rate Relunds ........................... & 0 & 0 & 0 & 0 & 0 & 0 \\
\hline $\begin{array}{l}\text { Total Other Noncurrent Lablilties ............. } \\
\text { Current and Accrued Liabilities }\end{array}$ & 0 & 0 & 0 & $\mathbf{0}$ & 64 & 0 \\
\hline 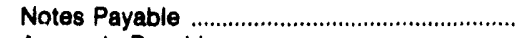 & 0 & 0 & 0 & 0 & 0 & 0 \\
\hline 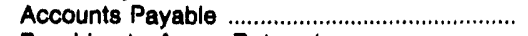 & 932 & 948 & 14,787 & 1,297 & 1,399 & 1,518 \\
\hline Payables to Assoc Enterprises ........................ & 0 & 0 & 4,560 & 0 & 0 & 0 \\
\hline 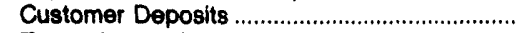 & 228 & 101 & 0 & 174 & 94 & 487 \\
\hline 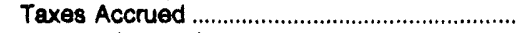 & 68 & 39 & 950 & 0 & 0 & 139 \\
\hline Interest Accrued & 0 & 0 & 10,054 & 0 & 602 & 63 \\
\hline $\begin{array}{l}\text { Misc Current \& Accrued Liabilities ................... } \\
\text { Total Current \& Accrued Llabilitles .......... }\end{array}$ & $\begin{array}{r}231 \\
1,459\end{array}$ & $\begin{array}{r}23 \\
1,111\end{array}$ & $\begin{array}{r}0 \\
30,352\end{array}$ & $\begin{array}{r}0 \\
1,471\end{array}$ & $\begin{array}{l}1,739 \\
3,834\end{array}$ & 2,209 \\
\hline Deferred Credits & & & & & & \\
\hline Customer Advances for Construction ............. & 0 & 810 & 0 & 0 & 0 & 284 \\
\hline Other Deferred Credits ....................................... & 2,479 & 0 & 0 & 556 & 0 & 0 \\
\hline 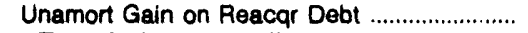 & 0 & 0 & 0 & 0 & 0 & \\
\hline $\begin{array}{l}\text { Total Deferred Credits ............................. } \\
\text { Total Liabllities and Other Credits }\end{array}$ & $\begin{array}{r}2,479 \\
18,868\end{array}$ & $\begin{array}{r}810 \\
9,471\end{array}$ & $\begin{array}{r}0 \\
332,578\end{array}$ & $\begin{array}{r}556 \\
18,427\end{array}$ & $\begin{array}{r}0 \\
42,842\end{array}$ & $\begin{array}{r}284 \\
20,436\end{array}$ \\
\hline
\end{tabular}

Note: Totals may not equal sum of components because of independent rounding.

Source: Energy information Administration, Form ElA-412, "Annual Report of Public Electric Utilities." 
Table 22. Balance Sheet by Major U.S. Publicly Owned Electric Utillty Within State at End of Period, 1992 (Continued) (Thousand Dollars)

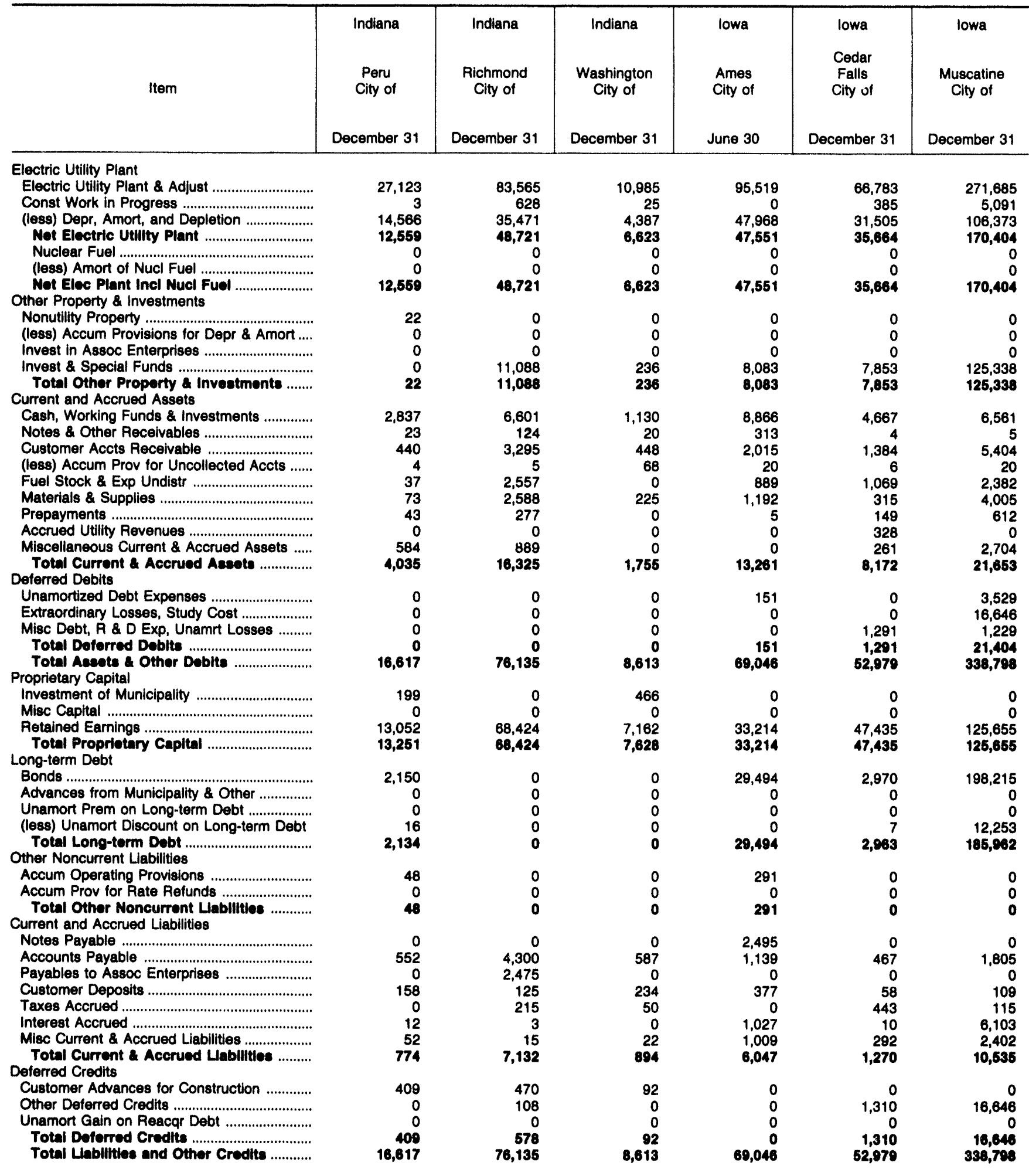

Note: Totals may not equal sum of components because of independent rounding.

Source: Energy Information Administration, Form ElA-412, "Annual Report of Public Electric Utilities." 
Table 22. Balance Sheet by Major U.S. Publicly Owned Electric Utility Within State at End of Period, 1992 (Continued) (Thousand Dollars)

\begin{tabular}{|c|c|c|c|c|c|c|}
\hline Item & $\begin{array}{c}\text { lowa } \\
\text { Pella } \\
\text { City of } \\
\text { June } 30\end{array}$ & $\begin{array}{c}\text { Kansas } \\
\text { Chanute } \\
\text { City of } \\
\text { December } 31\end{array}$ & $\begin{array}{l}\text { Kangas } \\
\text { Coffeyville } \\
\text { Clty of }\end{array}$ & $\begin{array}{c}\text { Kansas } \\
\text { Garden } \\
\text { Clty City of } \\
\text { December } 31\end{array}$ & $\begin{array}{c}\text { Kansas } \\
\text { Kansas } \\
\text { Clty City of } \\
\text { December } 31\end{array}$ & $\begin{array}{c}\text { Kansas } \\
\text { Kansas } \\
\text { Municipal } \\
\text { Energy } \\
\text { Agency } \\
\text { December } 31\end{array}$ \\
\hline 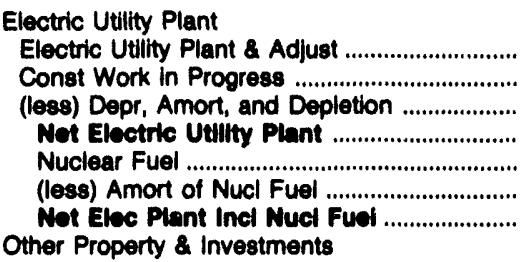 & $\begin{array}{l}0 \\
0 \\
0 \\
0 \\
0 \\
0 \\
0\end{array}$ & $\begin{array}{r}25,870 \\
0 \\
0 \\
25,870 \\
0 \\
0 \\
25,870\end{array}$ & $\begin{array}{r}30,596 \\
0 \\
20,883 \\
9,713 \\
0 \\
0 \\
9,713\end{array}$ & $\begin{array}{r}14,501 \\
0 \\
7,896 \\
6,608 \\
0 \\
0 \\
6,608\end{array}$ & $\begin{array}{r}523,696 \\
51,582 \\
209,776 \\
365,502 \\
0 \\
0 \\
385,502\end{array}$ & $\begin{array}{r}4,847 \\
0 \\
0 \\
1,687 \\
3,160 \\
0 \\
0 \\
0 \\
3,160\end{array}$ \\
\hline 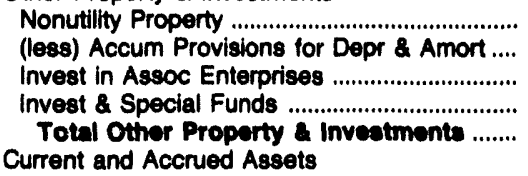 & $\begin{array}{r}0 \\
0 \\
0 \\
589 \\
\mathbf{5 8 0}\end{array}$ & $\begin{array}{l}0 \\
0 \\
0 \\
0 \\
0\end{array}$ & $\begin{array}{r}0 \\
0 \\
0 \\
2,738 \\
2,738\end{array}$ & $\begin{array}{r}27 \\
21 \\
0 \\
0 \\
6\end{array}$ & $\begin{array}{r}0 \\
0 \\
0 \\
26,630 \\
26,630\end{array}$ & $\begin{array}{r}0 \\
0 \\
0 \\
7,827 \\
7,827\end{array}$ \\
\hline 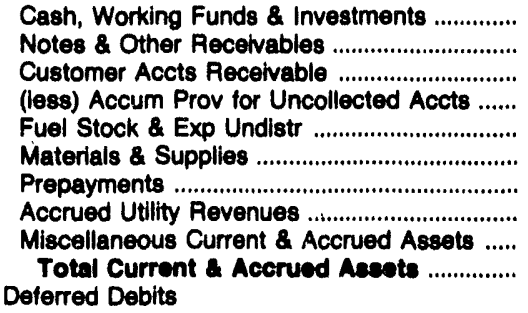 & $\begin{array}{r}14,098 \\
0 \\
401 \\
0 \\
59 \\
352 \\
0 \\
0 \\
152 \\
15,002\end{array}$ & $\begin{array}{r}1,075 \\
0 \\
266 \\
0 \\
0 \\
0 \\
0 \\
0 \\
0 \\
1,340\end{array}$ & $\begin{array}{r}4,807 \\
0 \\
358 \\
0 \\
0 \\
1,578 \\
0 \\
0 \\
234 \\
6,979\end{array}$ & $\begin{array}{r}2,479 \\
0 \\
452 \\
0 \\
0 \\
0 \\
0 \\
0 \\
0 \\
2,931\end{array}$ & $\begin{array}{r}26,389 \\
3,925 \\
11,090 \\
2,391 \\
9,006 \\
13,193 \\
1,106 \\
7,192 \\
1,475 \\
70,985\end{array}$ & $\begin{array}{r}953 \\
1,350 \\
0 \\
0 \\
0 \\
0 \\
950 \\
0 \\
0 \\
3,253\end{array}$ \\
\hline 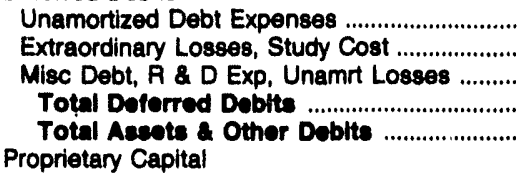 & $\begin{array}{r}31 \\
0 \\
0 \\
31 \\
16,682\end{array}$ & $\begin{array}{r}0 \\
0 \\
0 \\
0 \\
27,210\end{array}$ & $\begin{array}{r}0 \\
0 \\
0 \\
0 \\
19, \mathbf{4 3 0}\end{array}$ & $\begin{array}{r}0 \\
0 \\
0 \\
0 \\
9,543\end{array}$ & $\begin{array}{r}2,966 \\
0 \\
1,299 \\
4,285 \\
467,381\end{array}$ & $\begin{array}{r}310 \\
0 \\
7,638 \\
7,948 \\
22,188\end{array}$ \\
\hline 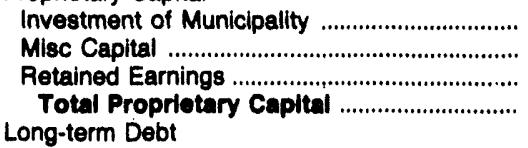 & $\begin{array}{r}0 \\
0 \\
9,280 \\
9,280\end{array}$ & $\begin{array}{r}0 \\
0 \\
10,810 \\
10,810\end{array}$ & $\begin{array}{r}9,159 \\
0 \\
7,044 \\
16,204\end{array}$ & $\begin{array}{r}0 \\
0 \\
8,831 \\
8,831\end{array}$ & $\begin{array}{r}0 \\
0 \\
282,452 \\
282,452\end{array}$ & $\begin{array}{r}0 \\
0 \\
2,092 \\
2,082\end{array}$ \\
\hline $\begin{array}{l}\text { Bdvances from Municipality \& Other ............. } \\
\text { Unamort Prem on Long-term Debt ............... } \\
\text { (less) Unamort Discount on Long-term Debt } \\
\text { Total Long-term Debt.............................. } \\
\text { Other Noncurrent Liabilities }\end{array}$ & $\begin{array}{r}5,725 \\
0 \\
0 \\
104 \\
5,621\end{array}$ & $\begin{array}{r}16,400 \\
0 \\
0 \\
0 \\
16,400\end{array}$ & $\begin{array}{r}875 \\
0 \\
0 \\
0 \\
875\end{array}$ & $\begin{array}{l}0 \\
0 \\
0 \\
0 \\
0\end{array}$ & $\begin{array}{r}162,755 \\
0 \\
0 \\
0 \\
162,755\end{array}$ & $\begin{array}{r}15,070 \\
0 \\
0 \\
200 \\
14,870\end{array}$ \\
\hline 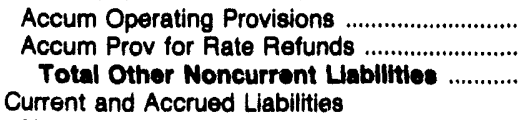 & $\begin{array}{l}0 \\
0 \\
0\end{array}$ & $\begin{array}{l}0 \\
0 \\
0\end{array}$ & $\begin{array}{r}1,937 \\
0 \\
1,937\end{array}$ & $\begin{array}{l}0 \\
0 \\
0\end{array}$ & $\begin{array}{r}1,504 \\
0 \\
1,504\end{array}$ & $\begin{array}{l}0 \\
0 \\
0\end{array}$ \\
\hline 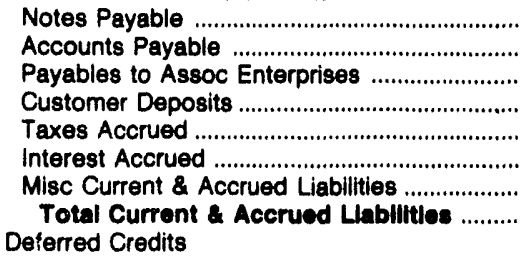 & $\begin{array}{r}275 \\
414 \\
0 \\
0 \\
0 \\
0 \\
91 \\
781\end{array}$ & $\begin{array}{l}0 \\
0 \\
0 \\
0 \\
0 \\
0 \\
0 \\
0\end{array}$ & $\begin{array}{r}0 \\
180 \\
0 \\
234 \\
0 \\
0 \\
0 \\
415\end{array}$ & $\begin{array}{r}0 \\
653 \\
0 \\
59 \\
0 \\
0 \\
0 \\
712\end{array}$ & $\begin{array}{r}0 \\
13,231 \\
0 \\
2,899 \\
650 \\
1,673 \\
2,116 \\
20,569\end{array}$ & $\begin{array}{r}0 \\
1,326 \\
0 \\
0 \\
0 \\
157 \\
1,575 \\
3,058\end{array}$ \\
\hline 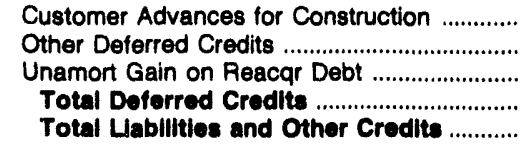 & $\begin{array}{r}0 \\
0 \\
0 \\
0 \\
15,682\end{array}$ & $\begin{array}{r}0 \\
0 \\
0 \\
0 \\
27,210\end{array}$ & $\begin{array}{r}0 \\
0 \\
0 \\
0 \\
19,430\end{array}$ & $\begin{array}{r}0 \\
0 \\
0 \\
0 \\
9,543\end{array}$ & $\begin{array}{r}0 \\
102 \\
0 \\
102 \\
467,381\end{array}$ & $\begin{array}{r}0 \\
2,168 \\
0 \\
2,168 \\
22,188\end{array}$ \\
\hline
\end{tabular}

Note: Totals may not equal sum of components because of independent rounding.

Source: Energy Information Administration, Form EIA-412, "Annual Report of Public Electric Utilities." 
Table 22. Balance Sheet by Major U.S. Publlcly Owned Electric Utility Within State at End of Perlod, 1992 (Continued) (Thousand Dollars)

\begin{tabular}{|c|c|c|c|c|c|c|}
\hline Item & $\begin{array}{c}\text { Kansas } \\
\text { McPherson } \\
\text { Clty of } \\
\text { December } 31\end{array}$ & $\begin{array}{l}\text { Kansas } \\
\text { Winfield } \\
\text { City of } \\
\text { December } 31\end{array}$ & $\begin{array}{l}\text { Kentucky } \\
\text { Bowling } \\
\text { Green } \\
\text { City of } \\
\text { June } 30\end{array}$ & $\begin{array}{l}\text { Kentucky } \\
\text { Frankfort } \\
\text { City of } \\
\text { June } 30\end{array}$ & $\begin{array}{l}\text { Kentucky } \\
\text { Franklin } \\
\text { City of } \\
\text { June } 30\end{array}$ & $\begin{array}{l}\text { Kentucky } \\
\text { Glasgow } \\
\text { City of } \\
\text { June } 30\end{array}$ \\
\hline \multicolumn{7}{|l|}{ Electric Utility Plant } \\
\hline Electric Utility Plant \& Adjust .................................. & 46.457 & 22,211 & 33,885 & 21,226 & 4,803 & 13,388 \\
\hline Const Work in Progress & & 7,684 & 1,254 & & 179 & 165 \\
\hline (less) Depr, Amori, and Depletion ................... & 23,777 & 13,445 & 10,870 & 11,013 & 1,682 & 4,579 \\
\hline Not Eloctric Utility Plant ................................... & 22,747 & 16,450 & 24,268 & 10,213 & 3,301 & 8,975 \\
\hline 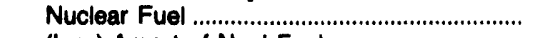 & 0 & 0 & 0 & 0 & 0 & 0 \\
\hline 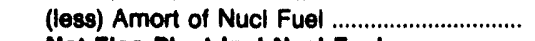 & 0 & 0 & 0 & 0 & 0 & 0 \\
\hline $\begin{array}{l}\text { Not Elec Plant Incl Mucl Fuel .......................... } \\
\text { Other Property \& Investments }\end{array}$ & 22,747 & 16,450 & 24,268 & 10,213 & 3,301 & 8,975 \\
\hline Nonutility Property ................................................ & 200 & 0 & 0 & 24,253 & 0 & 0 \\
\hline (less) Accum Provisions for Depr \& Amort.... & 0 & 0 & 0 & 7,800 & 0 & 0 \\
\hline 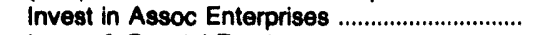 & & 0 & 0 & & 0 & 0 \\
\hline 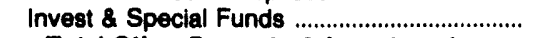 & 10,963 & 839 & 707 & 4,342 & 464 & 1,263 \\
\hline $\begin{array}{l}\text { Total Other Property a Inveotments ........ } \\
\text { Current and Accrued Assets }\end{array}$ & 11,164 & 839 & 707 & 20,795 & 464 & 1,263 \\
\hline Cash, Working Funds \& Investments ................. & 4,265 & 1,344 & 3,250 & 596 & 904 & 391 \\
\hline Notes \& Other Receivables ................................. & & 0 & 2,140 & 36 & 800 & 1,128 \\
\hline Customer Accts Receivable ................................... & 1,592 & 87 & 0 & 3,487 & 0 & 0 \\
\hline (less) Accum Prov for Uncollected Accts ...... & 0 & 0 & 0 & 2 & 0 & 0 \\
\hline 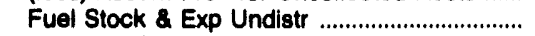 & 343 & 95 & 0 & 0 & 0 & 0 \\
\hline 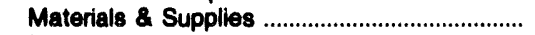 & 353 & 0 & 844 & 1,956 & 111 & 277 \\
\hline 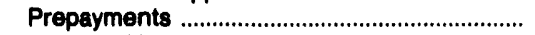 & 22 & 1,238 & 150 & 197 & 15 & 90 \\
\hline 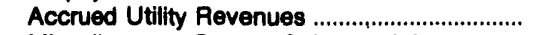 & 227 & 0 & 0 & 0 & 0 & 0 \\
\hline Miscellaneous Current \& Accrued Assets ..... & & & 25 & 9 & 26 & \\
\hline $\begin{array}{l}\text { Total Current \& Accrued Aseets ................. } \\
\text { Deferred Debits }\end{array}$ & 6,804 & 2,765 & 6,408 & 6,279 & 1,856 & 1,888 \\
\hline Unamortized Debt Expenses .................................. & 705 & 0 & 29 & 0 & 0 & 54 \\
\hline Extraordinary Losses, Study Cost ......................... & 0 & 0 & 0 & 0 & 0 & 20 \\
\hline Misc Debt, R \& D Exp, Unamrt Losses ........... & 0 & 0 & 447 & 0 & 199 & 136 \\
\hline Total Deforred Debite ........................................ & 705 & & 476 & & 199 & 210 \\
\hline Total Aceots \& Other Debits ............................ & 41,420 & 20,053 & 31,859 & 37,287 & 5,819 & 12,335 \\
\hline \multirow{2}{*}{\multicolumn{7}{|c|}{$\begin{array}{l}\text { Proprietary Capital } \\
\text { Investment of Municipality ................................. }\end{array}$}} \\
\hline & 0 & 0 & 0 & 0 & 0 & 0 \\
\hline 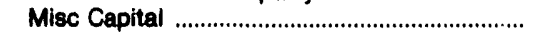 & 0 & 0 & 0 & 0 & 0 & 0 \\
\hline 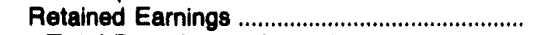 & 27,505 & 14,725 & 19,191 & 27,841 & 4,655 & 7,047 \\
\hline $\begin{array}{l}\text { Total Propriotary Capttal ................................... } \\
\text { Lono.term Debt }\end{array}$ & 27,505 & 14,725 & 19,191 & 27,841 & 4,655 & 7,047 \\
\hline \multicolumn{7}{|l|}{ Long-term Debt } \\
\hline & $\begin{array}{r}12,282 \\
0\end{array}$ & $\begin{array}{r}5,050 \\
0\end{array}$ & 5,595 & 5,309 & 0 & 3,714 \\
\hline 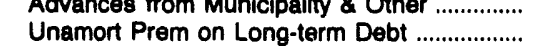 & $\begin{array}{l}0 \\
0\end{array}$ & $\begin{array}{l}0 \\
0\end{array}$ & $\begin{array}{l}461 \\
-66\end{array}$ & $\begin{array}{l}0 \\
0\end{array}$ & 189 & 34 \\
\hline (less) Unamort Discount on Long-term Debt & & & & 0 & 0 & 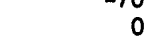 \\
\hline Total Long-term Debt .................................... & 12,282 & 5,050 & 5,990 & 5,309 & 189 & 3,678 \\
\hline \multicolumn{7}{|l|}{ Other Noncurrent Liabilities } \\
\hline 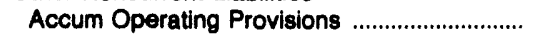 & 0 & 38 & 0 & 0 & 0 & 0 \\
\hline Accum Prov for Rate Refunds ........................... & 0 & 47 & 0 & 0 & 0 & 0 \\
\hline Total Other Noncurrent Llabilitiee ............. & 0 & 85 & 0 & 0 & 0 & $\mathbf{0}$ \\
\hline \multicolumn{7}{|l|}{ Current and Accrued Liabilities } \\
\hline 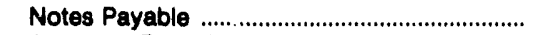 & 0 & 8 & 600 & 0 & 0 & 0 \\
\hline Accounts Payable & 1,224 & 73 & 2,973 & 2,828 & 671 & 1,051 \\
\hline 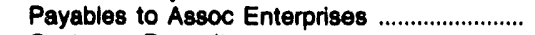 & 0 & 0 & 0 & 0 & 0 & 0 \\
\hline 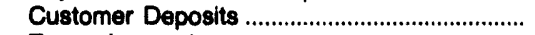 & 91 & 0 & 2,251 & 489 & 192 & 134 \\
\hline 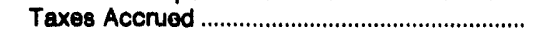 & 0 & 0 & 137 & 194 & 22 & 45 \\
\hline Interest Accrued & 79 & 112 & 278 & 151 & 0 & 24 \\
\hline Misc Current \& Accrued Liabilities .................. & 239 & 0 & 430 & 220 & 19 & 136 \\
\hline Total Current a Accrued Llabilitles .......... & 1,633 & 193 & 6,669 & 3,891 & 804 & 1,390 \\
\hline \multicolumn{7}{|l|}{ Deferred Credits } \\
\hline Customer Advances for Construction .............. & 0 & 0 & $\boldsymbol{\theta}$ & 0 & 0 & 1 \\
\hline Other Deferred Gredits .................................... & 0 & 0 & 0 & 246 & 71 & 219 \\
\hline Unamort Gain on Reacqr Debt ........................... & 0 & 0 & 0 & 0 & 0 & \\
\hline 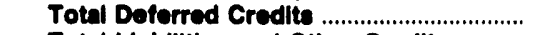 & & & & 246 & 71 & 220 \\
\hline Total Labilitiee and Other Credite............. & 41,420 & 20,053 & 31,869 & 37,287 & 5,810 & 12,336 \\
\hline
\end{tabular}

Note: Totals may not equal sum of components because of independent rounding.

Source: Energy Information Administration, Form EIA-412, "Annual Report of Public Electric Utilities." 
Table 22. Balance Sheet by Major U.S. Publicly Owned Electric Utillty Within State at End of Perlod, 1992 (Continued) (Thousand Dollars)

\begin{tabular}{|c|c|c|c|c|c|c|}
\hline Item & $\begin{array}{c}\text { Kentucky } \\
\text { Henderson } \\
\text { City } \\
\text { Utility Comm } \\
\text { May } 31\end{array}$ & $\begin{array}{l}\text { Kentucky } \\
\text { Hopkinsville } \\
\text { City of } \\
\text { June } 30\end{array}$ & $\begin{array}{c}\text { Kentucky } \\
\begin{array}{c}\text { Madisonville } \\
\text { Municipal } \\
\text { Utils }\end{array} \\
\text { June } 30\end{array}$ & $\begin{array}{c}\text { Kentucky } \\
\text { Maytield } \\
\text { City of } \\
\text { June } 30\end{array}$ & $\begin{array}{l}\text { Kentucky } \\
\text { Murray } \\
\text { City of } \\
\text { June } 30\end{array}$ & $\begin{array}{c}\text { Kentucky } \\
\text { Owensboro } \\
\text { City of } \\
\text { May } 31\end{array}$ \\
\hline \multicolumn{7}{|l|}{ Electric Utility Plant } \\
\hline 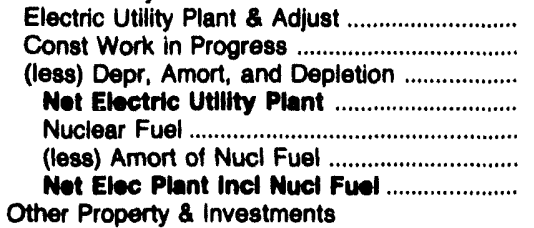 & $\begin{array}{r}101,286 \\
0 \\
53,740 \\
47,546 \\
0 \\
0 \\
47,546\end{array}$ & $\begin{array}{r}14,781 \\
106 \\
6,001 \\
8,886 \\
0 \\
0 \\
8,886\end{array}$ & $\begin{array}{r}6,497 \\
0 \\
2,863 \\
3,634 \\
0 \\
0 \\
3,634\end{array}$ & $\begin{array}{r}5,509 \\
86 \\
2,333 \\
3,282 \\
0 \\
0 \\
3,282\end{array}$ & $\begin{array}{r}8,050 \\
31 \\
3,548 \\
4,534 \\
0 \\
0 \\
4,534\end{array}$ & $\begin{array}{r}123,314 \\
20,458 \\
68,235 \\
75,537 \\
0 \\
0 \\
75,537\end{array}$ \\
\hline 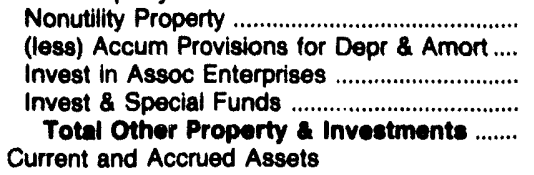 & $\begin{array}{r}0 \\
0 \\
0 \\
23,040 \\
23,040\end{array}$ & $\begin{array}{r}265 \\
0 \\
0 \\
4,083 \\
4,348\end{array}$ & $\begin{array}{l}0 \\
0 \\
0 \\
0 \\
0\end{array}$ & $\begin{array}{l}0 \\
0 \\
0 \\
3 \\
3\end{array}$ & $\begin{array}{r}0 \\
0 \\
0 \\
683 \\
683\end{array}$ & $\begin{array}{r}0 \\
0 \\
0 \\
212,349 \\
212,349\end{array}$ \\
\hline Cash, Working Funds \& Investments .............. & 8,016 & 1,223 & 3,395 & 277 & 822 & 2,730 \\
\hline 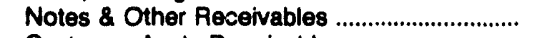 & 0 & 1,442 & 1,372 & 925 & 972 & 209 \\
\hline Customer Accts Receivable ................................ & 179 & 0 & 1,479 & 0 & 0 & 1,957 \\
\hline (less) Accum Prov for Uncollected Accts ...... & 3 & 0 & 0 & 0 & 0 & 301 \\
\hline 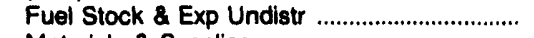 & 908 & 0 & 0 & 0 & 0 & \\
\hline 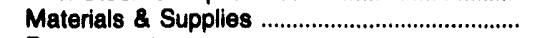 & 2,373 & 196 & 0 & 96 & 148 & 1,045 \\
\hline 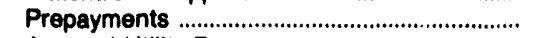 & 327 & 214 & 24 & 9 & 0 & 9 \\
\hline 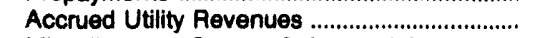 & 640 & 0 & 0 & 0 & 0 & 0 \\
\hline $\begin{array}{l}\text { Miscellaneous Current \& Accrued Assets ..... } \\
\text { Total Current A Accrued Aseats .............. } \\
\text { Deferred Debits }\end{array}$ & $\begin{array}{r}0 \\
12,441\end{array}$ & $\begin{array}{r}133 \\
3,208\end{array}$ & $\begin{array}{r}450 \\
6,720\end{array}$ & $\begin{array}{r}5 \\
1,312\end{array}$ & $\begin{array}{r}16 \\
1,859\end{array}$ & $\begin{array}{r}0 \\
5,648\end{array}$ \\
\hline 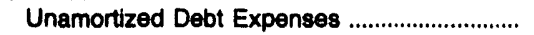 & 641 & 19 & 0 & 0 & 0 & 1,789 \\
\hline 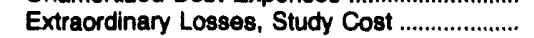 & 0 & 0 & 0 & 0 & 0 & 0 \\
\hline Misc Debt, R \& D Exp, Unamrt Losses .......... & 0 & 230 & 0 & 16 & 17 & 2,333 \\
\hline $\begin{array}{l}\text { Total Deforred Deblts ................................ } \\
\text { Total Aseote \& Other Deblts }\end{array}$ & $\begin{array}{r}641 \\
83,688\end{array}$ & $\begin{array}{r}249 \\
16,691\end{array}$ & $\begin{array}{r}0 \\
10,354\end{array}$ & $\begin{array}{r}16 \\
4,594\end{array}$ & $\begin{array}{r}17 \\
7,193\end{array}$ & $\begin{array}{r}4,122 \\
297,856\end{array}$ \\
\hline & & & & & & \\
\hline 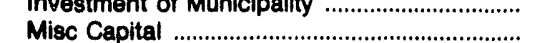 & $\begin{array}{l}0 \\
0\end{array}$ & 0 & $\begin{array}{r}0 \\
120\end{array}$ & 0 & 0 & 1,773 \\
\hline & $\begin{array}{r}0 \\
3 \cap 026\end{array}$ & $\begin{array}{r}0 \\
075\end{array}$ & 130 & 0 & 0 & 0 \\
\hline 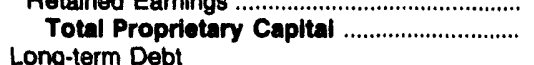 & $\begin{array}{l}30,636 \\
30,636\end{array}$ & $\begin{array}{l}10,875 \\
10,875\end{array}$ & $\begin{array}{l}8,891 \\
9,021\end{array}$ & $\begin{array}{l}3,342 \\
3,342\end{array}$ & $\begin{array}{l}5,868 \\
5,868\end{array}$ & $\begin{array}{l}48,363 \\
50,135\end{array}$ \\
\hline $\begin{array}{l}\text { Long-term Debt } \\
\text { Bonds ................ }\end{array}$ & & & & & & \\
\hline 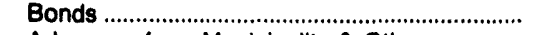 & 44,540 & 3,433 & 0 & 0 & 0 & 216,951 \\
\hline Advances from Municipality \& Other .................. & 0 & 239 & 0 & 12 & 11 & 5,731 \\
\hline Unamort Prem on Long-term Debt .................. & 0 & -21 & 0 & 0 & 0 & 0 \\
\hline (less) Unamort Discount on Long-term Debt & 0 & 0 & 0 & 0 & 0 & 0 \\
\hline $\begin{array}{l}\text { Total Long-term Debt ....................................... } \\
\text { Other Noncurrent Liabilities }\end{array}$ & 44,540 & 3,652 & 0 & 12 & 11 & 222,682 \\
\hline $\begin{array}{l}\text { Other Noncurrent Liabilities } \\
\text { Accum Operating Provisions }\end{array}$ & & & & & & \\
\hline 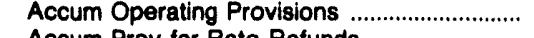 & 0 & 0 & 0 & 0 & 0 & 0 \\
\hline Accum Prov for Rate Refunds ........................ & 0 & 0 & 0 & 0 & 0 & 0 \\
\hline $\begin{array}{l}\text { Total Other Noncurrent Liabilities } \\
\text { Current and Accrued Liabilities }\end{array}$ & $\mathbf{0}$ & $\mathbf{0}$ & 0 & $\mathbf{0}$ & $\mathbf{0}$ & $\mathbf{0}$ \\
\hline 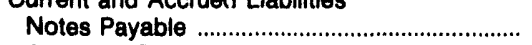 & 0 & & 0 & & 0 & 0 \\
\hline 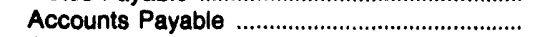 & 1,929 & 1,651 & 998 & 656 & 841 & 3.013 \\
\hline Payables to Assoc Enterprises ........................ & 0 & 0 & 68 & 0 & 0 & 0,0 \\
\hline 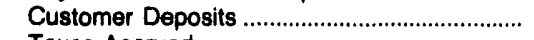 & 274 & 287 & 208 & 179 & 323 & 0 \\
\hline 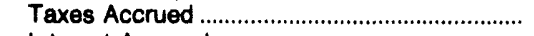 & 0 & 98 & 0 & 51 & 64 & 0 \\
\hline Interest Accrued & 688 & 51 & 58 & 0 & 0 & 3,220 \\
\hline $\begin{array}{l}\text { Misc Current \& Accrued Liabilities ................... } \\
\text { Total Current \& Accrued Llabillties ......... }\end{array}$ & $\begin{array}{l}5,601 \\
8,492\end{array}$ & $\begin{array}{r}62 \\
2,149\end{array}$ & $\begin{array}{r}0 \\
1,332\end{array}$ & $\begin{array}{r}150 \\
1,236\end{array}$ & $\begin{array}{r}86 \\
1,314\end{array}$ & $\begin{array}{r}954 \\
7,188\end{array}$ \\
\hline Deferred Credits & & & & & & \\
\hline Customer Advances for Construction .............. & 0 & 0 & 0 & 0 & 0 & 0 \\
\hline 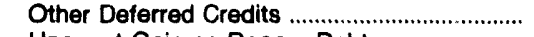 & 0 & 15 & 0 & 4 & 0 & 17,651 \\
\hline 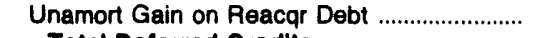 & 0 & 0 & 0 & 0 & 0 & 0 \\
\hline $\begin{array}{l}\text { Total Deferred Credite } \\
\text { Total Liablititee and Other Credits }\end{array}$ & $\begin{array}{r}0 \\
83,688\end{array}$ & $\begin{array}{r}15 \\
16,691\end{array}$ & $\begin{array}{r}0 \\
10,354\end{array}$ & 4,594 & $\begin{array}{r}0 \\
7,193\end{array}$ & $\begin{array}{r}17,651 \\
297,656\end{array}$ \\
\hline
\end{tabular}

Note: Totals may not equal sum of somponents because of independent rounding.

Source: Energy Information Administration, Form ElA-412, "Annual Report of Public Electric Utilities." 
Table 22. Balance Sheet by Major U.S. Publicly Owned Electric Utility Within State at End of Period, 1992 (Continued) (Thousand Dollars)

\begin{tabular}{|c|c|c|c|c|c|c|}
\hline Item & $\begin{array}{l}\text { Kentucky } \\
\text { Paducah } \\
\text { City of } \\
\text { June } 30\end{array}$ & $\begin{array}{l}\text { Loulsiana } \\
\text { Alexandria } \\
\text { City of } \\
\text { April } 30\end{array}$ & $\begin{array}{l}\text { Louisiana } \\
\text { Lafayette } \\
\text { City of } \\
\text { October } 31\end{array}$ & $\begin{array}{l}\text { Loulsiana } \\
\text { Lafayette } \\
\text { Public } \\
\text { Power Auth } \\
\text { October } 31\end{array}$ & $\begin{array}{c}\text { Louisiana } \\
\text { Louisiana } \\
\text { Energy } \\
\& \\
\text { Power Auth } \\
\text { December } 31\end{array}$ & $\begin{array}{l}\text { Louisiana } \\
\text { Morgan } \\
\text { City City of } \\
\text { December } 31\end{array}$ \\
\hline \multicolumn{7}{|l|}{ Electric Utility Plant } \\
\hline 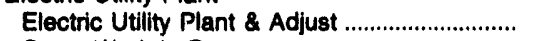 & 39,842 & 137.134 & 205,716 & 150,264 & 87,124 & 23,246 \\
\hline Const Work in Progress .................................... & & & & 1,168 & & \\
\hline 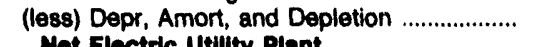 & 11,621 & 55,358 & 78,979 & 48,605 & 14,181 & 3,757 \\
\hline Not Electric Utility Piant ................................ & $\begin{array}{r}29,146 \\
0\end{array}$ & $\begin{array}{r}81,779 \\
0\end{array}$ & $\begin{array}{r}127,285 \\
0\end{array}$ & $\begin{array}{r}102,827 \\
0\end{array}$ & $\begin{array}{r}72,943 \\
0\end{array}$ & $\begin{array}{r}19,490 \\
0\end{array}$ \\
\hline (less) Amort of Nucl Fuel & & & & & & \\
\hline & 29,146 & 81,779 & 127,265 & 102,827 & 72,943 & 19,490 \\
\hline \multicolumn{2}{|l|}{ Other Property \& Investments } & 2,576 & 0 & 0 & 80 & \\
\hline (less) Accum Provisions for Depr \& Amort.... & 0 & & 0 & 0 & 61 & 0 \\
\hline 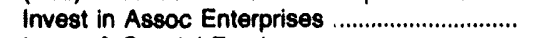 & 0 & 0 & 0 & 0 & 0 & 2,693 \\
\hline 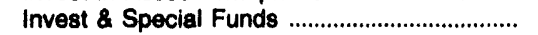 & 4,332 & 24,286 & 73,761 & 18,678 & 18,260 & 701 \\
\hline \multirow{2}{*}{\multicolumn{2}{|c|}{$\begin{array}{l}\text { Current and Accrued Assets } \\
\text { Cash, Working Funds \& Investments ............. }\end{array}$}} & 26,862 & 73,761 & 18,678 & 18,279 & 3,394 \\
\hline & 3,992 & 9,274 & 4,531 & 21,702 & 10,516 & 0 \\
\hline Notes \& Other Receivables ................................... & 1,580 & 5,506 & 1,411 & 6 & & 686 \\
\hline 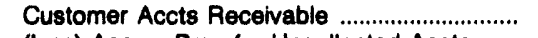 & 0 & & 14,224 & 1,783 & 4,662 & 1,070 \\
\hline (less) Accum Prov for Uncollected Accts ...... & 0 & 599 & 344 & 0 & 0 & 0 \\
\hline Fuel Stock \& Exp Undistr ..................................... & 0 & & 1,496 & 7,226 & 3,776 & 0 \\
\hline 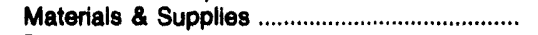 & 801 & 1,585 & 1,214 & 50 & 0 & 213 \\
\hline 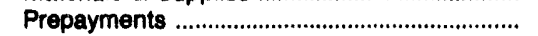 & 37 & 0 & 3 & 6 & 1 & 440 \\
\hline 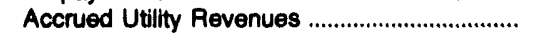 & 0 & 0 & 0 & 392 & 0 & 589 \\
\hline Miscellaneous Current \& Accrued Assets ..... & 48 & 951 & 1,270 & & 76 & 55 \\
\hline \multicolumn{7}{|l|}{ Deferred Debits } \\
\hline Unamortized Debt Expenses ................................... & 87 & 0 & 332 & 1,208 & 3,649 & 0 \\
\hline Extraordinary Losses, Study Cost .......................... & 0 & 0 & 0 & 20,521 & 0 & 0 \\
\hline & 589 & 0 & 498 & 15,051 & 31,924 & 0 \\
\hline 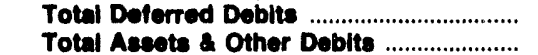 & 687 & 0 & 831 & 36,780 & 35,573 & 0 \\
\hline \multirow{2}{*}{\multicolumn{7}{|c|}{$\begin{array}{l}\text { Proprietary Capital } \\
\text { Investment of Municipality ................................... }\end{array}$}} \\
\hline & 0 & 37,129 & 5,318 & 0 & 0 & 2,874 \\
\hline 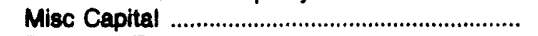 & & & & 0 & 0 & 0 \\
\hline 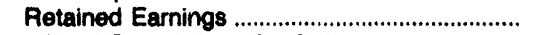 & 31,564 & 35,968 & 112,431 & 2,081 & 8,590 & 8,097 \\
\hline \multirow{2}{*}{\multicolumn{7}{|c|}{ Long-term Debt }} \\
\hline & 4,830 & 43,605 & 64,460 & 180,975 & 128,220 & 10,751 \\
\hline Advances from Municipality \& Other .................. & 522 & 96 & & & & 0 \\
\hline Unamort Prem on Long-term Debt ................... & -82 & 0 & 0 & 0 & 0 & 0 \\
\hline (less) Unamort Discount on Long-term Debt & & & & 1,269 & 5,922 & 0 \\
\hline Total Long-term Dobt .................................... & 5,270 & 43,701 & 64,460 & 179,706 & 122,298 & 10,751 \\
\hline \multicolumn{7}{|l|}{ Other Noncurrent Liabilities } \\
\hline Accum Operating Provisions .................................. & 0 & 0 & 0 & 0 & 0 & 1,389 \\
\hline Accum Prov for Rate Refunds ............................. & 0 & & & 0 & 0 & \\
\hline Total Other Noncurrent Llablittios .............. & 0 & 0 & $\mathbf{0}$ & $\mathbf{0}$ & 0 & 1,389 \\
\hline \multicolumn{7}{|l|}{ Current and Accrued Liabilities } \\
\hline 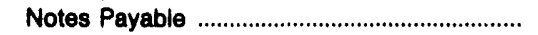 & 0 & 535 & 0 & 0 & 0 & 749 \\
\hline 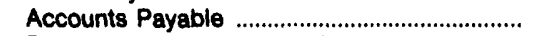 & 2,403 & 467 & 6,706 & 1,399 & 4,549 & 434 \\
\hline 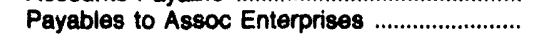 & 0 & 212 & 0 & 185 & 0 & 537 \\
\hline 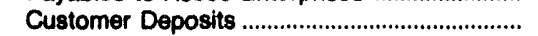 & 394 & 4,697 & 3,188 & 0 & 0 & 669 \\
\hline Taxes Accrued ................................................. & 269 & 0 & 0 & 0 & 0 & 0 \\
\hline 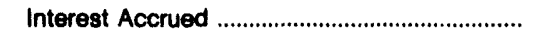 & 150 & 1,579 & 2,716 & 6,078 & 4,249 & 280 \\
\hline Misc Current \& Accrued Liabillties ......................... & 443 & 1,069 & 515 & & 4,310 & 177 \\
\hline Total Current a Accrued Luabilitibe ........... & 3,659 & 8,580 & 13,125 & 7,661 & 13,107 & 2,826 \\
\hline \multicolumn{7}{|l|}{ Deferred Credits } \\
\hline Customer Advances for Construction .............. & 0 & 0 & 30,328 & 0 & 0 & 0 \\
\hline Other Deferred Credits .......................................... & 129 & 0 & 0 & 0 & 1,831 & 0 \\
\hline 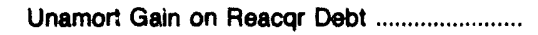 & 0 & 0 & 0 & 0 & 0 & 0 \\
\hline Total Deferred Credlis ........................... & 120 & & 30,328 & & 1,831 & \\
\hline & & & 62 & & 327 & \\
\hline
\end{tabular}

Note: Totals may not equal sum of components because of independent rounding.

Source: Energy Information Administration, Form EIA-412, "Annual Report of Public Electric Utilities." 
Table 22. Balance Sheet by Major U.S. Publlcly Owned Electric Utillty Within State at End of Period, 1992 (Continued) (Thousand Dollars)

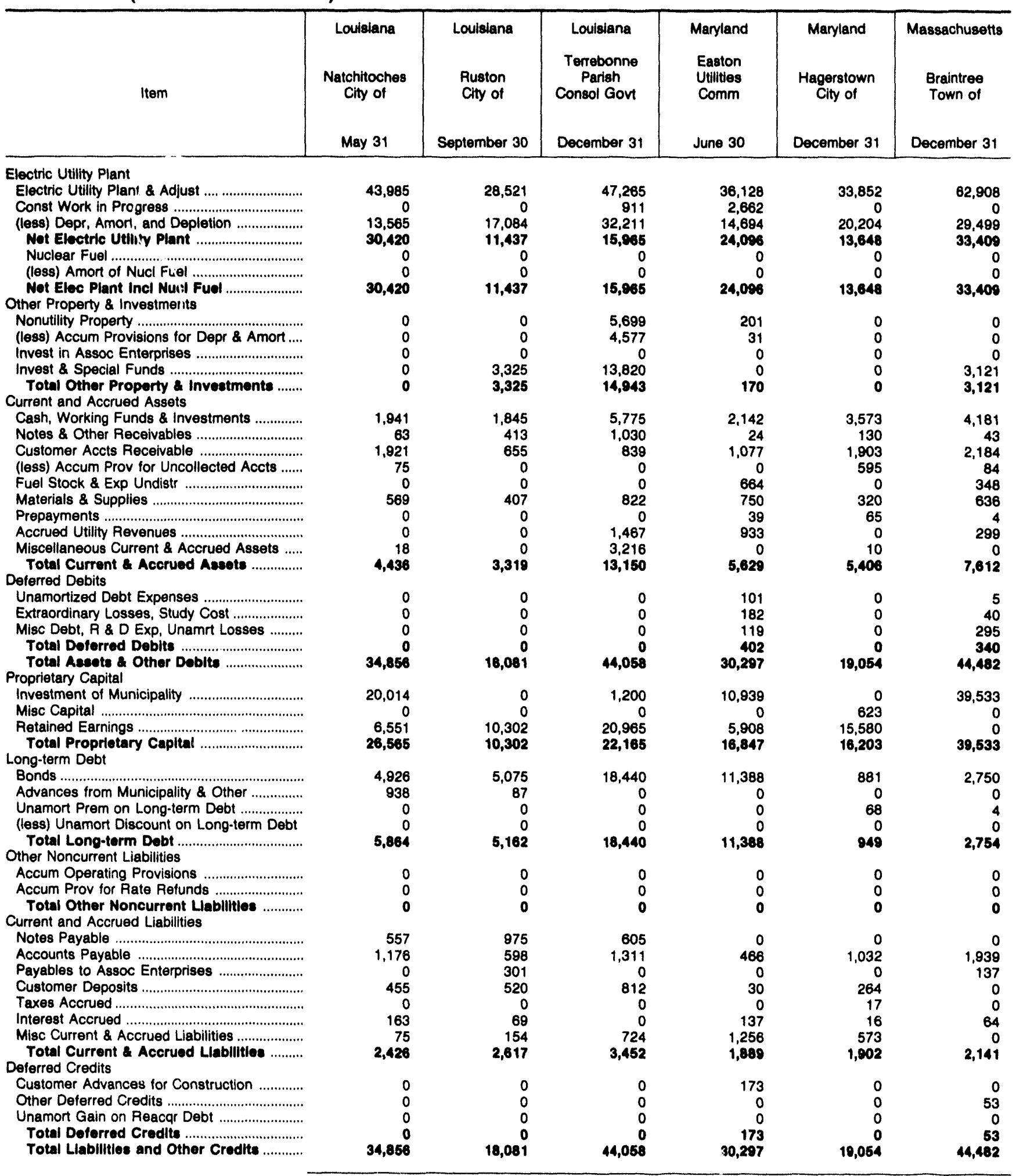

Note: Totals may not equal sum of components because of independent rounding.

Source: Energy Information Administration, Form ElA-412, "Annual Report of Public Electric Utilities." 
Table 22. Balance Sheet by Major U.S. Publicly Owned Electric Utility Within State at End of Period, 1992 (Continued) (Thousand Dollars)

\begin{tabular}{|c|c|c|c|c|c|c|}
\hline Item & $\begin{array}{l}\text { Massachusetts } \\
\text { Chicopee } \\
\text { Clty of } \\
\text { December } 31\end{array}$ & $\begin{array}{l}\text { Massachusetts } \\
\text { Concord } \\
\text { Town of } \\
\text { December } 31\end{array}$ & $\begin{array}{l}\text { Massachusetts } \\
\text { Danvers } \\
\text { Town of } \\
\text { December } 31\end{array}$ & $\begin{array}{l}\text { Massachusetts } \\
\text { Hingham } \\
\text { City of } \\
\text { December } 31\end{array}$ & $\begin{array}{l}\text { Massachusetts } \\
\text { Holyoke } \\
\text { City of } \\
\text { December } 31\end{array}$ & $\begin{array}{l}\text { Massachusetts } \\
\text { Hudson } \\
\text { Town of } \\
\text { December } 31\end{array}$ \\
\hline 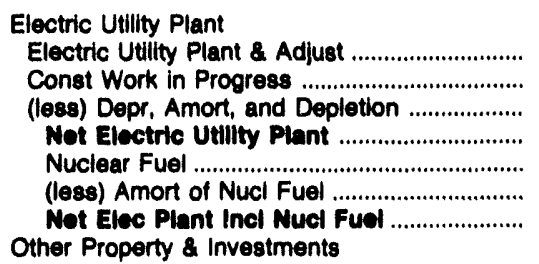 & $\begin{array}{r}64,210 \\
672 \\
21,597 \\
43,284 \\
3,318 \\
2,360 \\
44,242\end{array}$ & $\begin{array}{r}15,935 \\
2,020 \\
8,021 \\
0,933 \\
0 \\
0 \\
0,033\end{array}$ & $\begin{array}{r}18,736 \\
2,173 \\
9,286 \\
11,623 \\
0 \\
0 \\
11,623\end{array}$ & $\begin{array}{r}20,185 \\
0 \\
4,970 \\
15,215 \\
0 \\
0 \\
15,216\end{array}$ & $\begin{array}{r}51,123 \\
674 \\
28,392 \\
23,405 \\
0 \\
0 \\
23,405\end{array}$ & $\begin{array}{r}17,283 \\
0 \\
11,522 \\
5,761 \\
168 \\
93 \\
5,836\end{array}$ \\
\hline 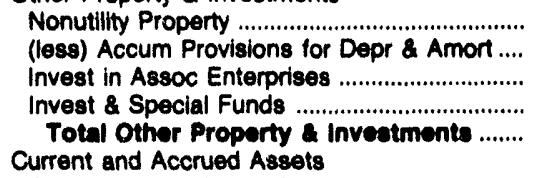 & $\begin{array}{r}0 \\
0 \\
0 \\
21,434 \\
21,434\end{array}$ & $\begin{array}{r}0 \\
0 \\
0 \\
2,215 \\
2,216\end{array}$ & $\begin{array}{r}0 \\
0 \\
0 \\
6,737 \\
6,737\end{array}$ & $\begin{array}{r}0 \\
0 \\
0 \\
498 \\
498\end{array}$ & $\begin{array}{r}18,702 \\
10,129 \\
0 \\
1,693 \\
10,267\end{array}$ & $\begin{array}{r}0 \\
0 \\
146 \\
6,182 \\
6,328\end{array}$ \\
\hline 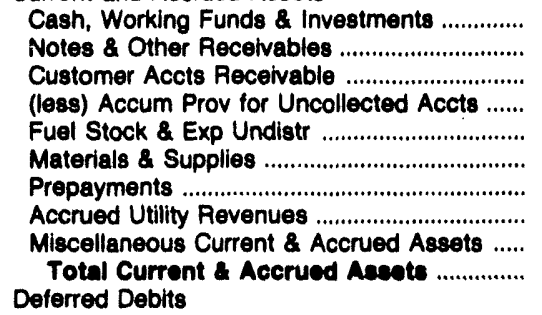 & $\begin{array}{r}3,220 \\
507 \\
2,288 \\
153 \\
35 \\
1,980 \\
836 \\
0 \\
97 \\
8,808\end{array}$ & $\begin{array}{r}7,586 \\
0 \\
1,497 \\
30 \\
0 \\
490 \\
47 \\
0 \\
632 \\
10,224\end{array}$ & $\begin{array}{r}4,198 \\
218 \\
3,561 \\
276 \\
0 \\
814 \\
249 \\
0 \\
238 \\
9,001\end{array}$ & $\begin{array}{r}967 \\
5 \\
1,252 \\
0 \\
0 \\
180 \\
678 \\
0 \\
0 \\
3,082\end{array}$ & $\begin{array}{r}4,827 \\
561 \\
6,729 \\
500 \\
973 \\
1,267 \\
924 \\
0 \\
99 \\
14,880\end{array}$ & $\begin{array}{r}2,741 \\
114 \\
2,840 \\
0 \\
271 \\
293 \\
425 \\
0 \\
31 \\
6,715\end{array}$ \\
\hline 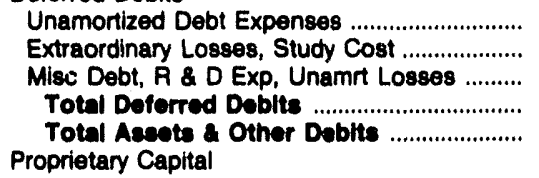 & $\begin{array}{r}433 \\
10 \\
645 \\
1,089 \\
75,573\end{array}$ & $\begin{array}{r}32 \\
0 \\
0 \\
32 \\
22,404\end{array}$ & $\begin{array}{r}0 \\
0 \\
14 \\
14 \\
27,374\end{array}$ & $\begin{array}{r}0 \\
0 \\
135 \\
135 \\
18,931\end{array}$ & $\begin{array}{r}118 \\
0 \\
1,775 \\
1,893 \\
50,444\end{array}$ & $\begin{array}{r}0 \\
0 \\
369 \\
369 \\
19,248\end{array}$ \\
\hline 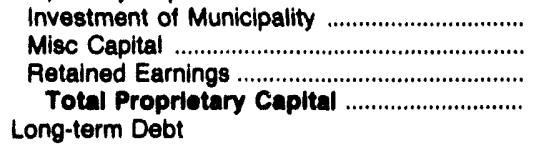 & $\begin{array}{r}43,253 \\
0 \\
0 \\
43,253\end{array}$ & $\begin{array}{r}2,342 \\
0 \\
13,574 \\
15,916\end{array}$ & $\begin{array}{r}1,934 \\
0 \\
20,849 \\
22,782\end{array}$ & $\begin{array}{r}0 \\
0 \\
12,827 \\
12,827\end{array}$ & $\begin{array}{r}0 \\
0 \\
36,306 \\
36,306\end{array}$ & $\begin{array}{r}20 \\
0 \\
16,829 \\
16,849\end{array}$ \\
\hline 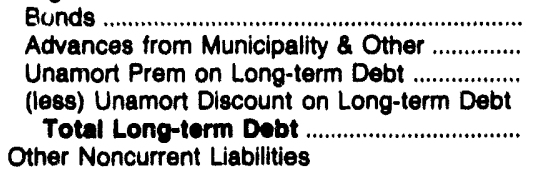 & $\begin{array}{r}23,445 \\
0 \\
0 \\
0 \\
23,445\end{array}$ & $\begin{array}{r}3,912 \\
0 \\
0 \\
0 \\
3,912\end{array}$ & $\begin{array}{r}600 \\
0 \\
0 \\
0 \\
600\end{array}$ & $\begin{array}{r}3,345 \\
0 \\
0 \\
0 \\
3,345\end{array}$ & $\begin{array}{r}6,055 \\
0 \\
0 \\
0 \\
6,055\end{array}$ & $\begin{array}{l}0 \\
0 \\
0 \\
0 \\
0\end{array}$ \\
\hline 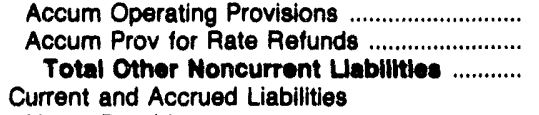 & $\begin{array}{l}0 \\
0 \\
0\end{array}$ & $\begin{array}{r}103 \\
0 \\
103\end{array}$ & $\begin{array}{l}0 \\
0 \\
0\end{array}$ & $\begin{array}{l}0 \\
0 \\
0\end{array}$ & $\begin{array}{l}0 \\
0 \\
0\end{array}$ & $\begin{array}{r}605 \\
0 \\
605\end{array}$ \\
\hline $\begin{array}{l}\text { Notes Payable } \\
\text { Accounts Payable }\end{array}$ & $\begin{array}{r}0 \\
2,678\end{array}$ & $\begin{array}{r}0 \\
1,863\end{array}$ & $\begin{array}{r}0 \\
940\end{array}$ & $\begin{array}{r}0 \\
1,142\end{array}$ & $\begin{array}{r}0 \\
7,001\end{array}$ & $\begin{array}{r}0 \\
601\end{array}$ \\
\hline $\begin{array}{l}\text { Payables to Assoc Enterprises } \\
\text { Customer Deposits }\end{array}$ & & $\begin{array}{r}0 \\
106\end{array}$ & $\begin{array}{r}0 \\
560\end{array}$ & $\begin{array}{l}287 \\
417\end{array}$ & $\begin{array}{r}0 \\
690\end{array}$ & $\begin{array}{r}0 \\
336\end{array}$ \\
\hline $\begin{array}{l}\text { Taxes Accrued } \\
\text { Interest Accrued }\end{array}$ & $\begin{array}{r}283 \\
1,139\end{array}$ & $\begin{array}{l}10 \\
55\end{array}$ & $\begin{array}{l}0 \\
6\end{array}$ & $\begin{array}{l}16 \\
99\end{array}$ & $\begin{array}{r}0 \\
107\end{array}$ & $\begin{array}{r}20 \\
0\end{array}$ \\
\hline $\begin{array}{l}\text { Misc Current \& Accrued Liabilities ................. } \\
\text { Total Current \& Accrued Labilities ......... } \\
\text { Deferred Credits }\end{array}$ & $\begin{array}{r}73 \\
4,685\end{array}$ & 2,047 & $\begin{array}{r}91 \\
1,597\end{array}$ & $\begin{array}{r}101 \\
2,062\end{array}$ & $\begin{array}{r}0 \\
7,798\end{array}$ & $\begin{array}{r}86 \\
1,042\end{array}$ \\
\hline 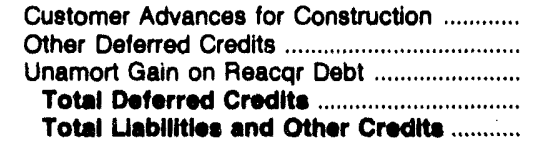 & $\begin{array}{r}1,949 \\
1,645 \\
616 \\
4,210 \\
75,573\end{array}$ & $\begin{array}{r}68 \\
359 \\
0 \\
428 \\
22,404\end{array}$ & $\begin{array}{r}21 \\
2,373 \\
0 \\
2,395 \\
27,374\end{array}$ & $\begin{array}{r}462 \\
234 \\
0 \\
698 \\
18,931\end{array}$ & $\begin{array}{r}0 \\
286 \\
0 \\
286 \\
50,444\end{array}$ & $\begin{array}{r}3 \\
749 \\
0 \\
752 \\
19,248\end{array}$ \\
\hline
\end{tabular}

Note: Totals may not equal sum of components because of independent rounding.

Source: Energy Intormation Administration, Form EIA-412, "Annual Report of Public Electric Utilities." 
Table 22. Balance Sheet by Major U.S. Publisly Owned Electric Utility Within State at End of Perlod, 1982 (Continued) (Thousand Dollars)

\begin{tabular}{|c|c|c|c|c|c|c|}
\hline Item & $\begin{array}{l}\text { Massachusetts } \\
\text { Littieton } \\
\text { Town of } \\
\text { December } 31\end{array}$ & $\begin{array}{l}\text { Massechusetts } \\
\text { Mansfield } \\
\text { Town of } \\
\text { December } 31\end{array}$ & $\begin{array}{l}\text { Massachusetts } \\
\text { Massachusetts } \\
\text { Mun } \\
\text { Whis } \\
\text { Elec Co } \\
\text { December } 31\end{array}$ & $\begin{array}{l}\text { Massachusetts } \\
\text { Middleborough } \\
\text { Town of } \\
\text { December } 31\end{array}$ & $\begin{array}{c}\text { Massachusetts } \\
\text { North } \\
\text { Attleborough } \\
\text { Town of } \\
\text { December } 31\end{array}$ & $\begin{array}{l}\text { Massachusetts } \\
\text { Norwood } \\
\text { City of } \\
\text { June } 30\end{array}$ \\
\hline 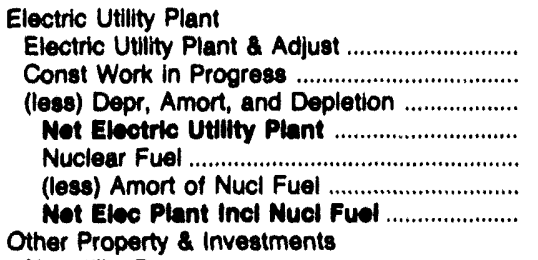 & $\begin{array}{r}13,945 \\
155 \\
5,388 \\
8,711 \\
0 \\
0 \\
8,711\end{array}$ & $\begin{array}{r}9,016 \\
0 \\
5,276 \\
3,739 \\
0 \\
0 \\
3,730\end{array}$ & $\begin{array}{r}1,229,845 \\
1,414 \\
201,172 \\
1,030,187 \\
64,655 \\
40,029 \\
1,054,813\end{array}$ & $\begin{array}{r}14,801 \\
9 \\
6,017 \\
8,793 \\
0 \\
0 \\
8,703\end{array}$ & $\begin{array}{r}14,885 \\
2,538 \\
5,166 \\
12,257 \\
0 \\
0 \\
12,267\end{array}$ & $\begin{array}{r}20,439 \\
0 \\
13,131 \\
7,308 \\
0 \\
0 \\
7,308\end{array}$ \\
\hline $\begin{array}{l}\text { Nonutility Property } \\
\text { (less) Accum Provisions for Depr \& Amort.... } \\
\text { Invest in Assoc Enterprises ........................... } \\
\text { invest \& Special Funds ................................... } \\
\text { Total Other Property \& Inveatmente ........ } \\
\text { Current and Accrued Assets }\end{array}$ & $\begin{array}{r}0 \\
0 \\
0 \\
6,889 \\
6,880\end{array}$ & $\begin{array}{r}0 \\
0 \\
0 \\
422 \\
422\end{array}$ & $\begin{array}{l}0 \\
0 \\
0 \\
0 \\
0\end{array}$ & $\begin{array}{r}0 \\
0 \\
106 \\
709 \\
816\end{array}$ & $\begin{array}{r}0 \\
0 \\
0 \\
2,653 \\
2,653\end{array}$ & $\begin{array}{r}0 \\
0 \\
0 \\
2,704 \\
2,704\end{array}$ \\
\hline 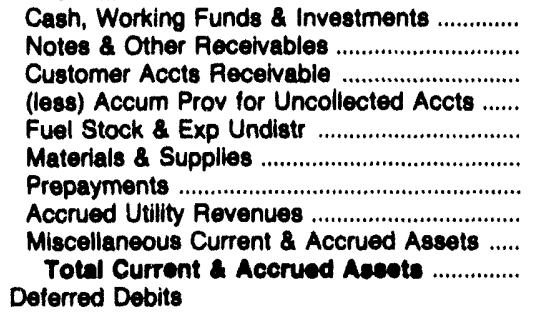 & $\begin{array}{r}57 \\
0 \\
1,218 \\
100 \\
0 \\
392 \\
1,963 \\
0 \\
0 \\
3,531\end{array}$ & $\begin{array}{r}1,644 \\
192 \\
1,655 \\
0 \\
0 \\
417 \\
1,350 \\
0 \\
0 \\
5,257\end{array}$ & $\begin{array}{r}189,878 \\
5,714 \\
442 \\
0 \\
3,346 \\
11,915 \\
6,652 \\
8,491 \\
7 \\
238,446\end{array}$ & $\begin{array}{r}1,637 \\
230 \\
2,229 \\
0 \\
11 \\
840 \\
1,545 \\
0 \\
0 \\
6,492\end{array}$ & $\begin{array}{r}4,009 \\
46 \\
1,585 \\
88 \\
6 \\
342 \\
141 \\
0 \\
0 \\
6,042\end{array}$ & $\begin{array}{r}1,865 \\
44 \\
1,721 \\
471 \\
0 \\
0 \\
0 \\
0 \\
0 \\
3,159\end{array}$ \\
\hline 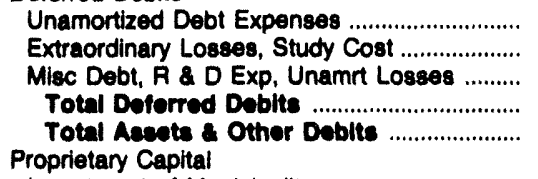 & $\begin{array}{r}0 \\
0 \\
0 \\
0 \\
19,131\end{array}$ & $\begin{array}{r}0 \\
0 \\
3 \\
3 \\
9,421\end{array}$ & $\begin{array}{r}40,272 \\
1,726 \\
136,507 \\
178,606 \\
1,469,784\end{array}$ & $\begin{array}{r}0 \\
0 \\
683 \\
663 \\
16,763\end{array}$ & $\begin{array}{r}0 \\
71 \\
0 \\
71 \\
21,023\end{array}$ & $\begin{array}{r}0 \\
0 \\
0 \\
0 \\
13,171\end{array}$ \\
\hline 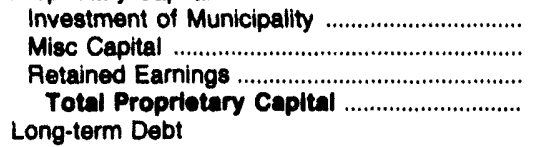 & $\begin{array}{r}15,583 \\
0 \\
0 \\
15,583\end{array}$ & $\begin{array}{r}0 \\
13 \\
8,380 \\
8,393\end{array}$ & $\begin{array}{l}0 \\
0 \\
0 \\
0\end{array}$ & $\begin{array}{r}1,762 \\
0 \\
11,025 \\
12,787\end{array}$ & $\begin{array}{r}12,881 \\
3,162 \\
0 \\
16,043\end{array}$ & $\begin{array}{r}8,367 \\
0 \\
2,160 \\
10,526\end{array}$ \\
\hline $\begin{array}{l}\text { Bdvances from Municipality \& Other ................ } \\
\text { Unamort Prem on Long-term Debt ................. } \\
\text { (less) Unamort Discount on Long-term Debt } \\
\text { Total Long-term Debt ................................... } \\
\text { Other Noncurrent Liabilities }\end{array}$ & $\begin{array}{r}150 \\
0 \\
0 \\
0 \\
150\end{array}$ & $\begin{array}{l}0 \\
0 \\
0 \\
0 \\
0\end{array}$ & $\begin{array}{r}1,376,700 \\
0 \\
0 \\
0 \\
1,378,700\end{array}$ & $\begin{array}{r}1,885 \\
340 \\
0 \\
0 \\
2,225\end{array}$ & $\begin{array}{r}3,400 \\
0 \\
0 \\
0 \\
3,400\end{array}$ & $\begin{array}{l}0 \\
0 \\
0 \\
0 \\
0\end{array}$ \\
\hline $\begin{array}{l}\text { Accum Operating Provisions ......................... } \\
\text { Accum Prov for Rate Refunds ......................... } \\
\text { Total Other Moncurrent Llabilities ........... } \\
\text { Current and Accrued Llabilities }\end{array}$ & $\begin{array}{r}0 \\
2,345 \\
2,345\end{array}$ & $\begin{array}{r}43 \\
0 \\
43\end{array}$ & $\begin{array}{r}5,897 \\
0 \\
5,897\end{array}$ & $\begin{array}{r}396 \\
0 \\
396\end{array}$ & $\begin{array}{l}0 \\
0 \\
0\end{array}$ & $\begin{array}{l}0 \\
0 \\
0\end{array}$ \\
\hline 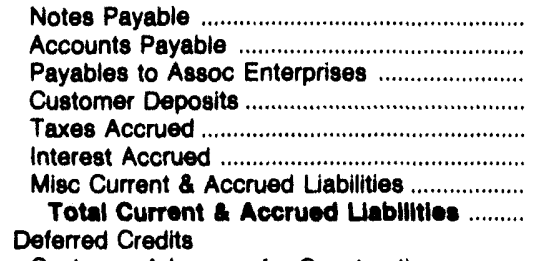 & $\begin{array}{r}0 \\
735 \\
0 \\
56 \\
0 \\
0 \\
0 \\
792\end{array}$ & $\begin{array}{r}0 \\
475 \\
300 \\
182 \\
16 \\
0 \\
11 \\
985\end{array}$ & $\begin{array}{r}113 \\
30,583 \\
0 \\
0 \\
1,062 \\
0 \\
34,682 \\
66,441\end{array}$ & $\begin{array}{r}0 \\
964 \\
0 \\
35 \\
0 \\
88 \\
0 \\
1,087\end{array}$ & $\begin{array}{r}0 \\
971 \\
0 \\
320 \\
8 \\
165 \\
116 \\
1,580\end{array}$ & $\begin{array}{r}0 \\
1,951 \\
0 \\
358 \\
99 \\
0 \\
102 \\
2,509\end{array}$ \\
\hline 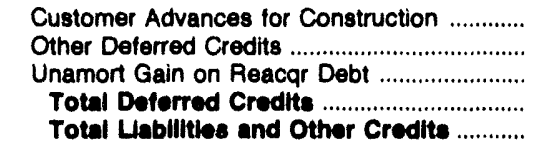 & $\begin{array}{r}0 \\
261 \\
0 \\
281 \\
19,131\end{array}$ & $\begin{array}{r}0 \\
0 \\
0 \\
0 \\
9,421\end{array}$ & $\begin{array}{r}-3 \\
20,729 \\
0 \\
20,726 \\
1,469,784\end{array}$ & $\begin{array}{r}0 \\
268 \\
0 \\
268 \\
16,763\end{array}$ & $\begin{array}{r}0 \\
0 \\
0 \\
0 \\
21,023\end{array}$ & $\begin{array}{r}1,35 \\
0 \\
0 \\
135 \\
13,171\end{array}$ \\
\hline
\end{tabular}

Note: Totals may not equal sum of components because of independent rounding.

Source: Energy Iniorrnation Administration, Form ElA-412, "Annual Report of Public Electric Utilities." 
Table 22. Balance Sheet by Major U.S. Publicly Owned Electrlc Utllity Within State at End of Perlod, 1992 (Continued) (Thousand Dollars)

\begin{tabular}{|c|c|c|c|c|c|c|}
\hline Item & $\begin{array}{l}\text { Maseachusetts } \\
\text { Peabody } \\
\text { City of } \\
\text { December } 31\end{array}$ & $\begin{array}{l}\text { Massachusetts } \\
\text { Reading } \\
\text { Town of } \\
\text { December } 31\end{array}$ & $\begin{array}{c}\text { Masaachusetts } \\
\text { Shrewsbury } \\
\text { Town of } \\
\text { December } 31\end{array}$ & $\begin{array}{l}\text { Masachusetts } \\
\text { Taunton } \\
\text { Clty of } \\
\text { December } 31\end{array}$ & $\begin{array}{l}\text { Massachusetts } \\
\text { Wakefield } \\
\text { Town of } \\
\text { December } 31\end{array}$ & $\begin{array}{c}\text { Massachusetts } \\
\text { Wellesley } \\
\text { Town of } \\
\text { December } 31\end{array}$ \\
\hline 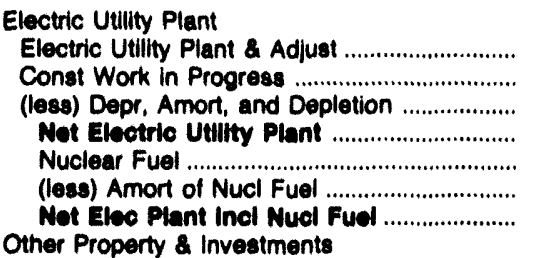 & $\begin{array}{r}58,105 \\
0 \\
20,229 \\
38,876 \\
0 \\
0 \\
38,870\end{array}$ & $\begin{array}{r}40,121 \\
0 \\
18,204 \\
21,917 \\
0 \\
0 \\
21,017\end{array}$ & $\begin{array}{r}21,954 \\
0 \\
10,335 \\
11,619 \\
0 \\
0 \\
11,810\end{array}$ & $\begin{array}{r}87,921 \\
3,754 \\
49,081 \\
42,694 \\
217 \\
119 \\
42,692\end{array}$ & $\begin{array}{r}12,707 \\
0 \\
10,331 \\
2,376 \\
0 \\
0 \\
2,375\end{array}$ & $\begin{array}{r}23,190 \\
1,086 \\
11,160 \\
13,117 \\
0 \\
0 \\
13,117\end{array}$ \\
\hline 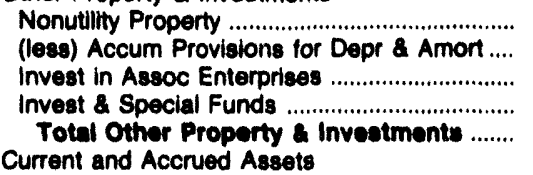 & $\begin{array}{r}0 \\
0 \\
0 \\
4,712 \\
4,712\end{array}$ & $\begin{array}{r}0 \\
0 \\
0 \\
804 \\
804\end{array}$ & $\begin{array}{r}0 \\
0 \\
160 \\
2,994 \\
3,184\end{array}$ & $\begin{array}{r}0 \\
0 \\
0 \\
12,000 \\
12,000\end{array}$ & $\begin{array}{r}0 \\
0 \\
0 \\
1,244 \\
1,244\end{array}$ & $\begin{array}{r}0 \\
0 \\
0 \\
3,478 \\
3,478\end{array}$ \\
\hline 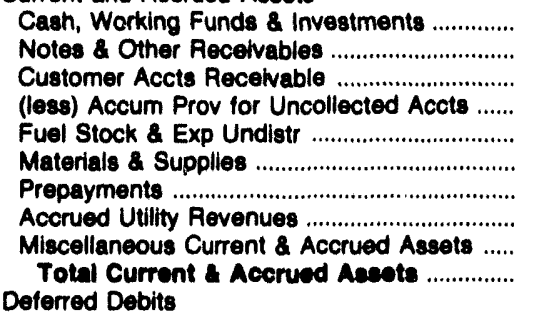 & $\begin{array}{r}3,784 \\
307 \\
4,645 \\
100 \\
768 \\
0 \\
1,023 \\
0 \\
80 \\
10,488\end{array}$ & $\begin{array}{r}12,883 \\
365 \\
2,899 \\
300 \\
0 \\
815 \\
1,280 \\
0 \\
0 \\
17,043\end{array}$ & $\begin{array}{r}3,770 \\
371 \\
1,324 \\
0 \\
0 \\
141 \\
1,438 \\
0 \\
0 \\
7,045\end{array}$ & $\begin{array}{r}1,635 \\
123 \\
2,242 \\
0 \\
930 \\
972 \\
1,420 \\
0 \\
796 \\
8,110\end{array}$ & $\begin{array}{r}1,334 \\
145 \\
1,838 \\
145 \\
0 \\
321 \\
537 \\
0 \\
0 \\
4,030\end{array}$ & $\begin{array}{r}-584 \\
0 \\
933 \\
75 \\
0 \\
623 \\
-124 \\
0 \\
52 \\
825\end{array}$ \\
\hline 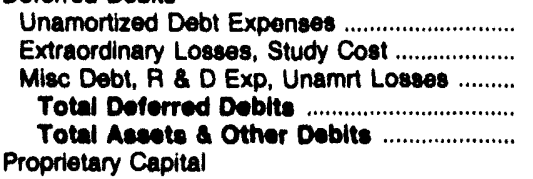 & $\begin{array}{r}113 \\
0 \\
0 \\
113 \\
64,180\end{array}$ & $\begin{array}{r}0 \\
0 \\
18 \\
18 \\
40,681\end{array}$ & $\begin{array}{r}0 \\
0 \\
2 \\
21,820\end{array}$ & $\begin{array}{r}0 \\
0 \\
336 \\
338 \\
63,147\end{array}$ & $\begin{array}{r}0 \\
0 \\
3 \\
3 \\
7,652\end{array}$ & $\begin{array}{r}0 \\
0 \\
0 \\
0 \\
17,420\end{array}$ \\
\hline 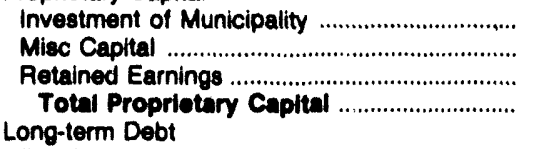 & $\begin{array}{r}2,920 \\
0 \\
22,531 \\
26,461\end{array}$ & $\begin{array}{r}25,884 \\
0 \\
0 \\
25,884\end{array}$ & $\begin{array}{r}0 \\
0 \\
18,321 \\
18,321\end{array}$ & $\begin{array}{r}39,953 \\
0 \\
0 \\
39,953\end{array}$ & $\begin{array}{r}0 \\
0 \\
5,255 \\
5,255\end{array}$ & $\begin{array}{r}1,580 \\
0 \\
12,520 \\
14,100\end{array}$ \\
\hline $\begin{array}{l}\text { Bonds } \\
\text { Advances from Municipality \& Other .............. } \\
\text { Unamort Prem on Long-term Debt ............... } \\
\text { (less) Unamort Discount on Long-term Debt } \\
\text { Totul Long-term Debt ................................ } \\
\text { Other Noncurrent Liabilities }\end{array}$ & $\begin{array}{r}21,480 \\
0 \\
0 \\
0 \\
21,400\end{array}$ & $\begin{array}{r}4,596 \\
0 \\
0 \\
0 \\
4,596\end{array}$ & $\begin{array}{r}215 \\
170 \\
0 \\
0 \\
386\end{array}$ & $\begin{array}{r}17,770 \\
0 \\
0 \\
0 \\
17,770\end{array}$ & $\begin{array}{l}0 \\
0 \\
0 \\
0 \\
0\end{array}$ & $\begin{array}{r}600 \\
0 \\
0 \\
0 \\
600\end{array}$ \\
\hline 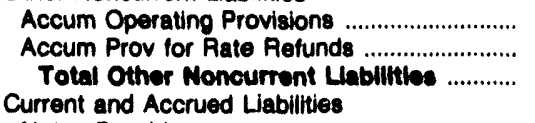 & $\begin{array}{r}3,731 \\
0 \\
3,731\end{array}$ & $\begin{array}{l}0 \\
0 \\
0\end{array}$ & $\begin{array}{l}0 \\
0 \\
0\end{array}$ & $\begin{array}{l}0 \\
0 \\
0\end{array}$ & $\begin{array}{l}0 \\
0 \\
0\end{array}$ & $\begin{array}{l}0 \\
0 \\
0\end{array}$ \\
\hline 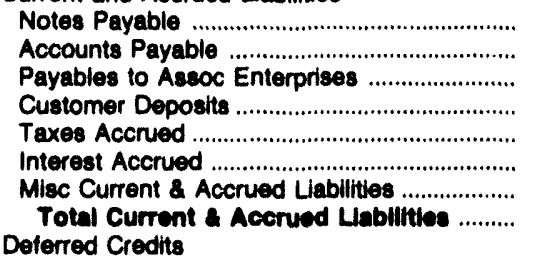 & $\begin{array}{r}0 \\
1,418 \\
174 \\
1,435 \\
0 \\
500 \\
0 \\
3,626\end{array}$ & $\begin{array}{r}680 \\
4,001 \\
0 \\
603 \\
0 \\
17 \\
541 \\
6,842\end{array}$ & $\begin{array}{r}0 \\
1,412 \\
0 \\
355 \\
16 \\
4 \\
0 \\
1,786\end{array}$ & $\begin{array}{r}0 \\
2,028 \\
0 \\
303 \\
0 \\
602 \\
97 \\
3,030\end{array}$ & $\begin{array}{r}0 \\
1,299 \\
0 \\
493 \\
0 \\
0 \\
605 \\
2,397\end{array}$ & $\begin{array}{r}0 \\
2,231 \\
0 \\
282 \\
0 \\
0 \\
104 \\
2,617\end{array}$ \\
\hline 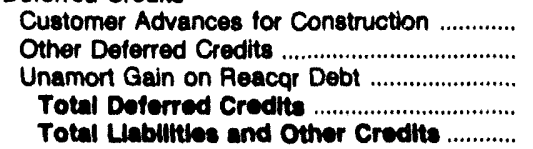 & $\begin{array}{r}0 \\
0 \\
0 \\
0 \\
54,189\end{array}$ & $\begin{array}{r}2,794 \\
1,565 \\
0 \\
4,360 \\
40,881\end{array}$ & $\begin{array}{r}0 \\
328 \\
0 \\
328 \\
21,820\end{array}$ & $\begin{array}{r}2,394 \\
0 \\
0 \\
2,394 \\
83,147\end{array}$ & $\begin{array}{r}0 \\
0 \\
0 \\
0 \\
7,852\end{array}$ & $\begin{array}{r}103 \\
0 \\
0 \\
103 \\
17,120\end{array}$ \\
\hline
\end{tabular}

Note: Totals may not equal sum of components because of independent rounding.

Source: Energy Information Administration, Form EIA-412, "Annual Report of Public Electric Utilities." 
Table 22. Balance Sheet by Major U.S. Publicly Owned Electric UtIlity Within State at End of Perlod, 1992 (Continued) (Thousand Dollars)

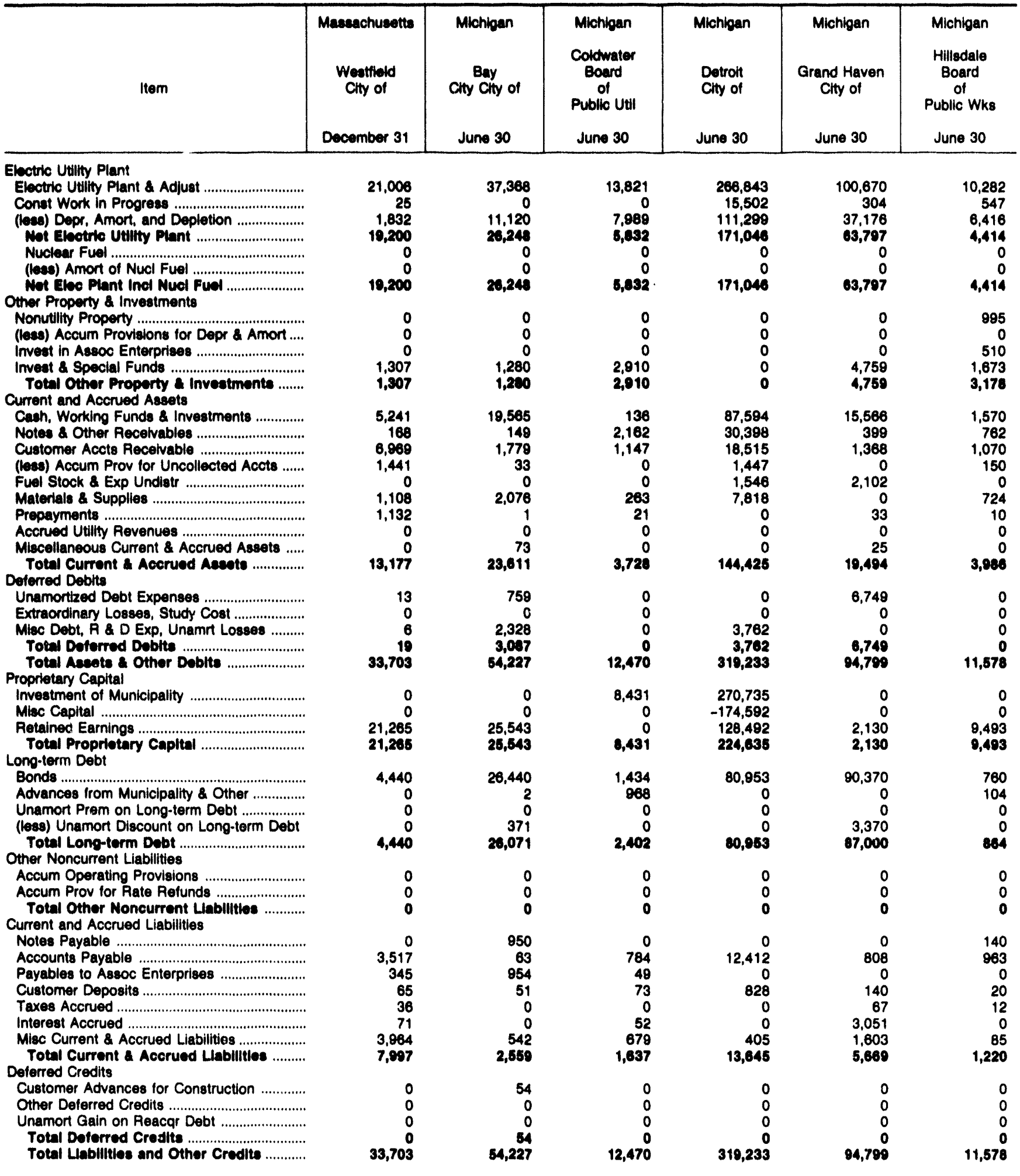

Note: Totals may not equal sum of components because of independent rounding.

Source: Energy Information Administration, Form EIA-412, "Annual Report of Public Electric Utilities." 
Table 22. Balance Sheet by Major U.S. Publicly Owned Electric Utility Within State at End of Period, 1992 (Continued) (Thousand Dollars)

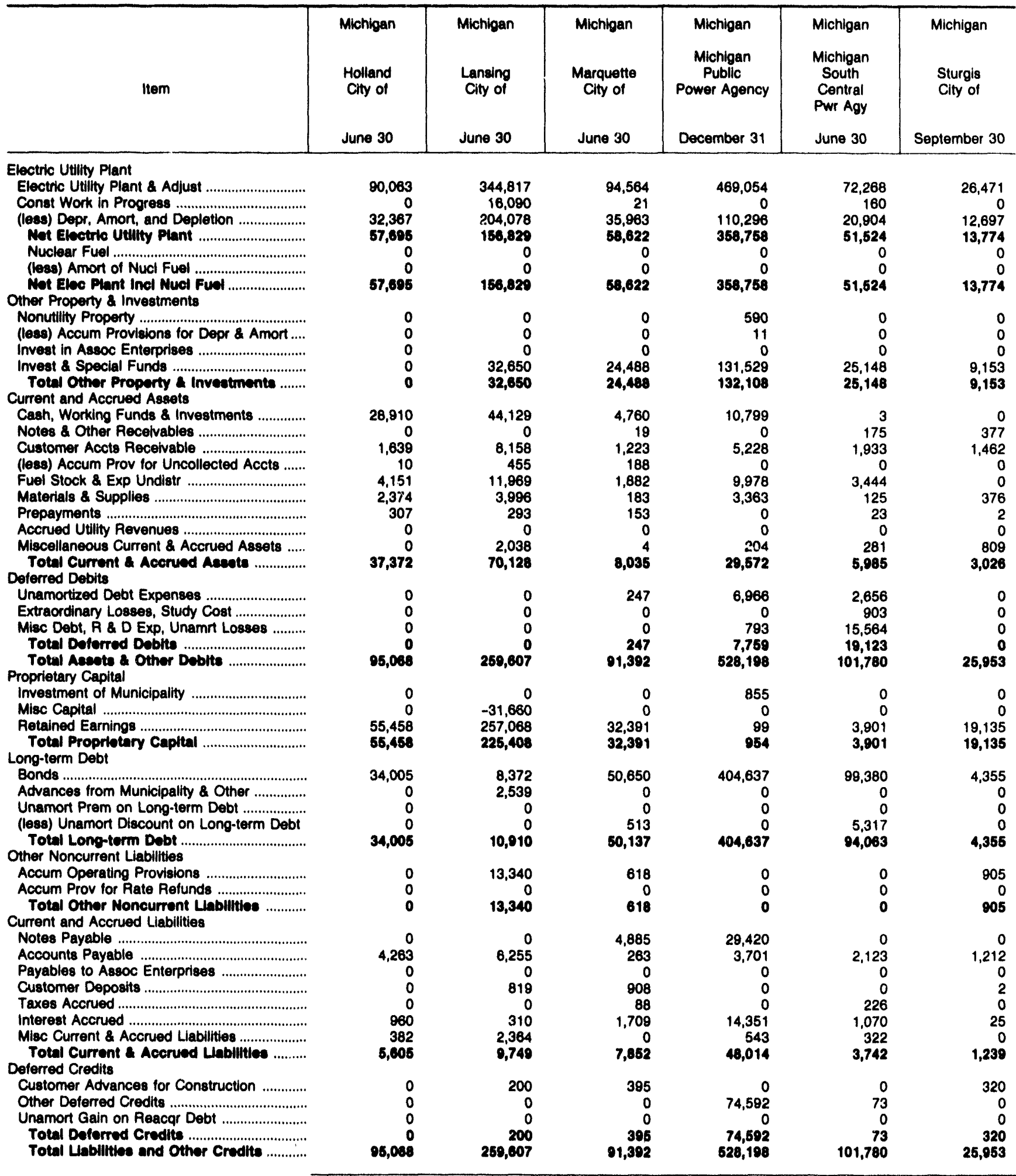

Note: Totals may not equal sum of components because of independent rounding.

Source: Energy Information Administration, Form EIA-412, "Annual Report of Public Electric Utilities." 
Table 22. Balance Sheet by Major U.S. Publicly Owned Electric Utility Within State at End of Perlod, 1992 (Continued) (Thousand Dollars)

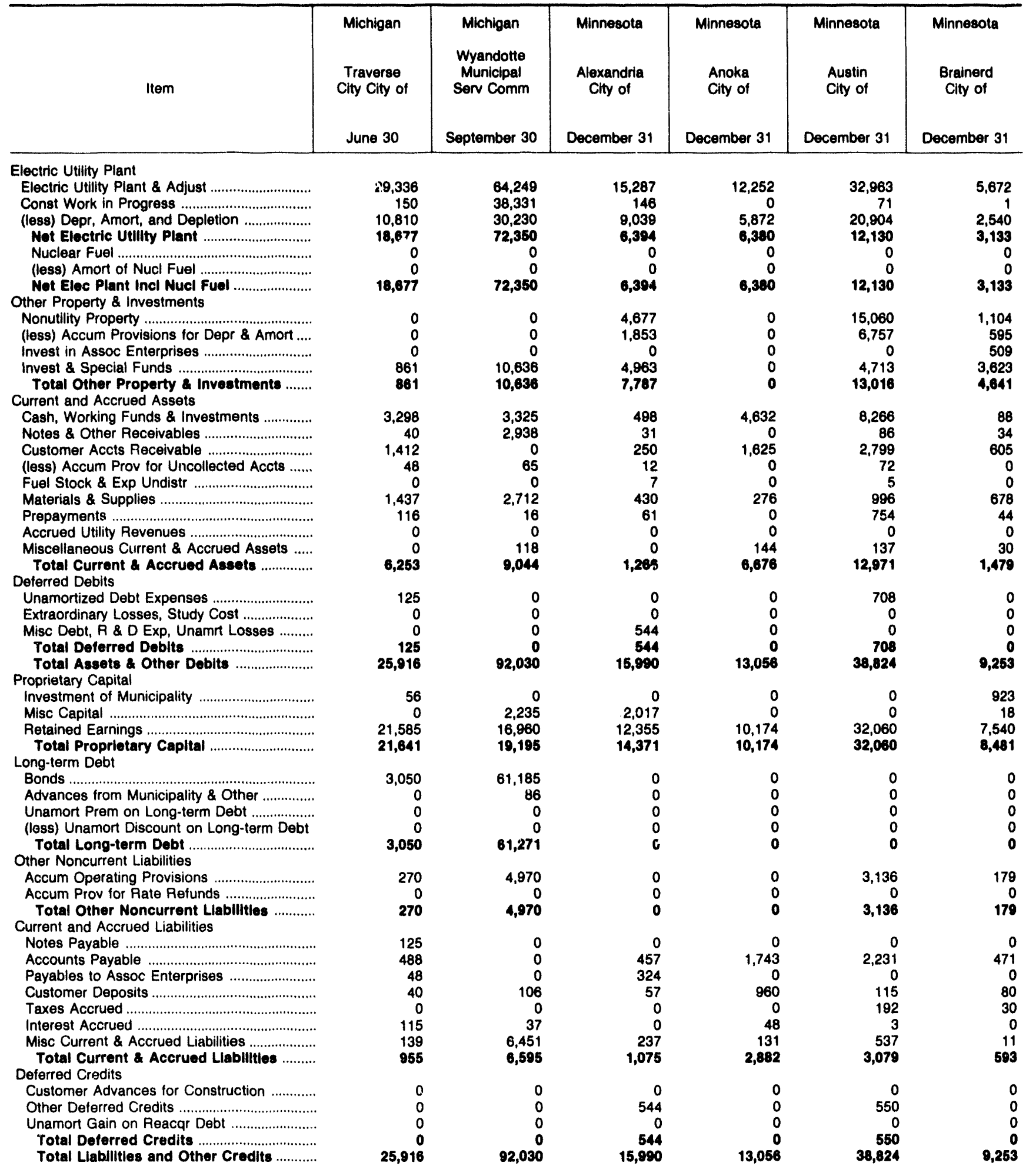

Note: Totals may not equal sum of components because of independent rounding.

Source: Energy Information Administration, Form EIA-412, "Annual Report of Public Electric Utilities." 
Table 22. Balance Sheet by Major U.S. Publicly Owned Electric Utility Within State at End of Period, 1992 (Continued) (Thousand Dollars)

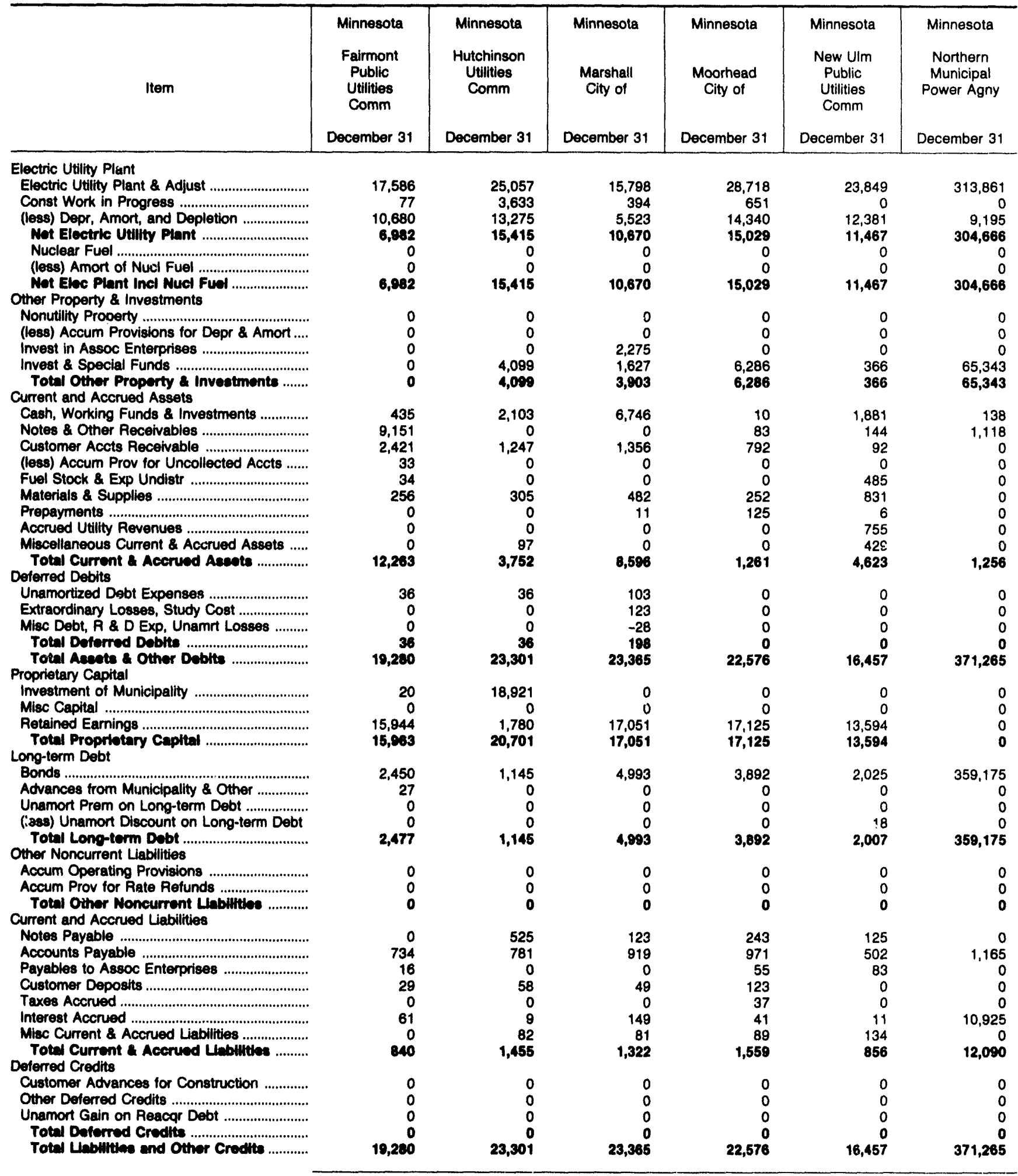

Note: Totals may not equal sum of components because of independent rounding.

Source: Energy Information Administration, Form EIA-412, "Annual Report of Public Electric Utilities." 
Table 22. Balance Sheet by Major U.S. Publicly Owned Electric Utility Within State at End of Perlod, 1992 (Continued) (Thousand Dollars)

\begin{tabular}{|c|c|c|c|c|c|c|}
\hline Item & $\begin{array}{l}\text { Minnesota } \\
\text { Owatonna } \\
\text { City of } \\
\text { December } 31\end{array}$ & $\begin{array}{c}\text { Minnesota } \\
\text { Rochester } \\
\text { Public } \\
\text { Utilities } \\
\text { December } 31\end{array}$ & $\begin{array}{l}\text { Minnsista } \\
\text { Southern } \\
\text { Minnesota } \\
\text { Mun P } \\
\text { Agny } \\
\text { December } 31\end{array}$ & $\begin{array}{c}\text { Minnesota } \\
\text { Western } \\
\text { Minnesota } \\
\text { Mun } \\
\text { Pwr Agny } \\
\text { December } 31\end{array}$ & $\begin{array}{l}\text { Minnesota } \\
\text { Willmar } \\
\text { Municipal } \\
\text { Utils Comm } \\
\text { December } 31\end{array}$ & $\begin{array}{l}\text { Mississippi } \\
\text { Aberdeen } \\
\text { City of } \\
\text { June } 30\end{array}$ \\
\hline 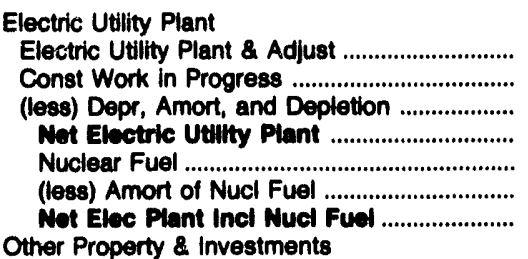 & $\begin{array}{r}26,136 \\
414 \\
11,709 \\
14,841 \\
0 \\
0 \\
14,841\end{array}$ & $\begin{array}{r}92,044 \\
6,469 \\
49,639 \\
48,874 \\
0 \\
0 \\
48,874\end{array}$ & $\begin{array}{r}512,141 \\
4,261 \\
85,068 \\
431,334 \\
0 \\
0 \\
431,334\end{array}$ & $\begin{array}{r}237,241 \\
608 \\
41,795 \\
196,054 \\
0 \\
0 \\
196,054\end{array}$ & $\begin{array}{r}28,444 \\
1,286 \\
14,333 \\
15,397 \\
0 \\
0 \\
15,307\end{array}$ & $\begin{array}{r}4,153 \\
35 \\
1,807 \\
2,381 \\
0 \\
0 \\
2,381\end{array}$ \\
\hline $\begin{array}{l}\text { Nonutility Property } \\
\text { (less) Accum Provisions for Depr \& Amort .... } \\
\text { Invest in Assoc Enterprises ......................... } \\
\text { Invest \& Special Funds ................................. } \\
\text { Total Other Property \& Inveatmente ....... } \\
\text { Current and Accrued Assets }\end{array}$ & $\begin{array}{r}0 \\
0 \\
0 \\
2,560 \\
2,580\end{array}$ & $\begin{array}{r}0 \\
0 \\
0 \\
195 \\
195\end{array}$ & $\begin{array}{r}43 \\
0 \\
0 \\
53,233 \\
58,276\end{array}$ & $\begin{array}{r}0 \\
0 \\
0 \\
51,344 \\
51,344\end{array}$ & $\begin{array}{r}10,823 \\
2,709 \\
0 \\
13,180 \\
21,295\end{array}$ & $\begin{array}{l}0 \\
0 \\
0 \\
2 \\
2\end{array}$ \\
\hline 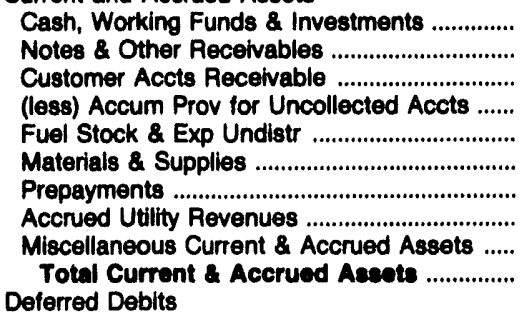 & $\begin{array}{r}4,085 \\
121 \\
1,267 \\
86 \\
0 \\
496 \\
79 \\
406 \\
625 \\
6,992\end{array}$ & $\begin{array}{r}12,621 \\
800 \\
4,273 \\
20 \\
843 \\
2,041 \\
237 \\
1,878 \\
194 \\
22,897\end{array}$ & $\begin{array}{r}97,082 \\
12 \\
10,764 \\
0 \\
4,108 \\
2,718 \\
4,644 \\
0 \\
8,831 \\
128,161\end{array}$ & $\begin{array}{r}0 \\
0 \\
5,654 \\
0 \\
1,349 \\
3,130 \\
266 \\
0 \\
3,807 \\
14,208\end{array}$ & $\begin{array}{r}2,325 \\
0 \\
1,447 \\
0 \\
405 \\
332 \\
121 \\
0 \\
161 \\
4,791\end{array}$ & $\begin{array}{r}227 \\
882 \\
0 \\
0 \\
0 \\
130 \\
12 \\
0 \\
25 \\
1,277\end{array}$ \\
\hline $\begin{array}{l}\text { Unamortized Debt Expenses ........................ } \\
\text { Extraordinary Losses, Study Cost ................... } \\
\text { Misc Debt, R \& D Exp, Unamrt Losses .......... } \\
\text { Total Deferred Deblts ................................... } \\
\text { Total Aseots \& Other Debits ...................... } \\
\text { Proprietary Capltal }\end{array}$ & $\begin{array}{r}111 \\
0 \\
28 \\
130 \\
24,633\end{array}$ & $\begin{array}{r}0 \\
67 \\
-1 \\
66 \\
72,103\end{array}$ & $\begin{array}{r}137,346 \\
439 \\
70,337 \\
.208,123 \\
820,808\end{array}$ & $\begin{array}{r}7,682 \\
0 \\
8,299 \\
15,081 \\
277,585\end{array}$ & $\begin{array}{r}295 \\
0 \\
253 \\
548 \\
42,030\end{array}$ & $\begin{array}{r}0 \\
0 \\
396 \\
398 \\
4,058\end{array}$ \\
\hline 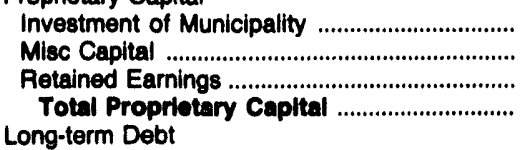 & $\begin{array}{r}0 \\
0 \\
16,039 \\
18,039\end{array}$ & $\begin{array}{r}0 \\
0 \\
\mathbf{5 7 , 5 4 9} \\
\mathbf{5 7 , 5 4 9}\end{array}$ & $\begin{array}{r}0 \\
0 \\
18,843 \\
18,843\end{array}$ & $\begin{array}{l}0 \\
0 \\
0 \\
0\end{array}$ & $\begin{array}{r}0 \\
0 \\
18,904 \\
18,904\end{array}$ & $\begin{array}{r}0 \\
0 \\
2,755 \\
2,756\end{array}$ \\
\hline $\begin{array}{l}\text { Bonds . } \\
\text { Advances from Municipality \& Other .............. } \\
\text { Unamort Prem on Long-term Debt ................ } \\
\text { (less) Unamort Discount on Long-term Debt } \\
\text { Total Long-term Debt ................................. } \\
\text { Other Noncurrent Liabilities }\end{array}$ & $\begin{array}{r}6,468 \\
0 \\
0 \\
127 \\
6,341\end{array}$ & $\begin{array}{r}0 \\
168 \\
0 \\
0 \\
168\end{array}$ & $\begin{array}{r}782,215 \\
0 \\
0 \\
55,087 \\
727,128\end{array}$ & $\begin{array}{r}267,790 \\
0 \\
0 \\
11,207 \\
266,583\end{array}$ & $\begin{array}{r}19,880 \\
0 \\
0 \\
0 \\
19,880\end{array}$ & $\begin{array}{r}0 \\
405 \\
0 \\
0 \\
405\end{array}$ \\
\hline 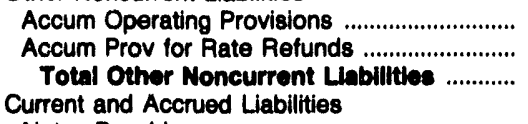 & $\begin{array}{l}0 \\
0 \\
0\end{array}$ & $\begin{array}{r}4,920 \\
0 \\
4,920\end{array}$ & $\begin{array}{l}0 \\
0 \\
0\end{array}$ & $\begin{array}{r}8,673 \\
0 \\
8,673\end{array}$ & $\begin{array}{l}0 \\
0 \\
0\end{array}$ & $\begin{array}{l}0 \\
0 \\
0\end{array}$ \\
\hline 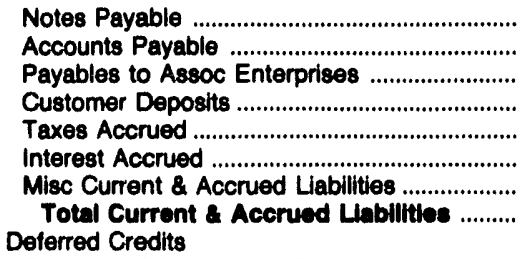 & $\begin{array}{r}0 \\
1,346 \\
0 \\
18 \\
0 \\
219 \\
570 \\
2,154\end{array}$ & $\begin{array}{r}0 \\
5,311 \\
625 \\
535 \\
407 \\
0 \\
1,224 \\
8,103\end{array}$ & $\begin{array}{r}0 \\
5,530 \\
934 \\
0 \\
7,155 \\
23,789 \\
26,693 \\
64,100\end{array}$ & $\begin{array}{r}0 \\
2,175 \\
0 \\
0 \\
754 \\
9,399 \\
0 \\
12,329\end{array}$ & $\begin{array}{r}1,200 \\
621 \\
121 \\
111 \\
38 \\
493 \\
661 \\
3,246\end{array}$ & $\begin{array}{r}0 \\
713 \\
0 \\
160 \\
1 \\
0 \\
22 \\
898\end{array}$ \\
\hline $\begin{array}{l}\text { Customer Advances for Construction ............ } \\
\text { Other Deferred Credits ..................................... } \\
\text { Unamort Gain on Reacqr Debt ..................... } \\
\text { Total Deferred Credits ................................. } \\
\text { Total Llabillties and Other Credits ............ }\end{array}$ & $\begin{array}{r}0 \\
0 \\
0 \\
0 \\
24,683\end{array}$ & $\begin{array}{r}0 \\
1,364 \\
0 \\
1,364 \\
72,103\end{array}$ & $\begin{array}{r}0 \\
10,822 \\
0 \\
10,822 \\
820,893\end{array}$ & $\begin{array}{r}0 \\
0 \\
0 \\
0 \\
277,585\end{array}$ & $\begin{array}{r}0 \\
0 \\
0 \\
0 \\
42,030\end{array}$ & $\begin{array}{r}0 \\
0 \\
0 \\
0 \\
4,058\end{array}$ \\
\hline
\end{tabular}

Note: Totals may not equal sum of components because of independent rounding.

Source: Energy Information Administration, Form ElA-412, "Annual Report of Public Electric Utilities." 
Table 22. Balance Sheet by Major U.S. Publicly Owned Electric Utility Within State at End of Period, 1992 (Continued) (Thousand Dollars)

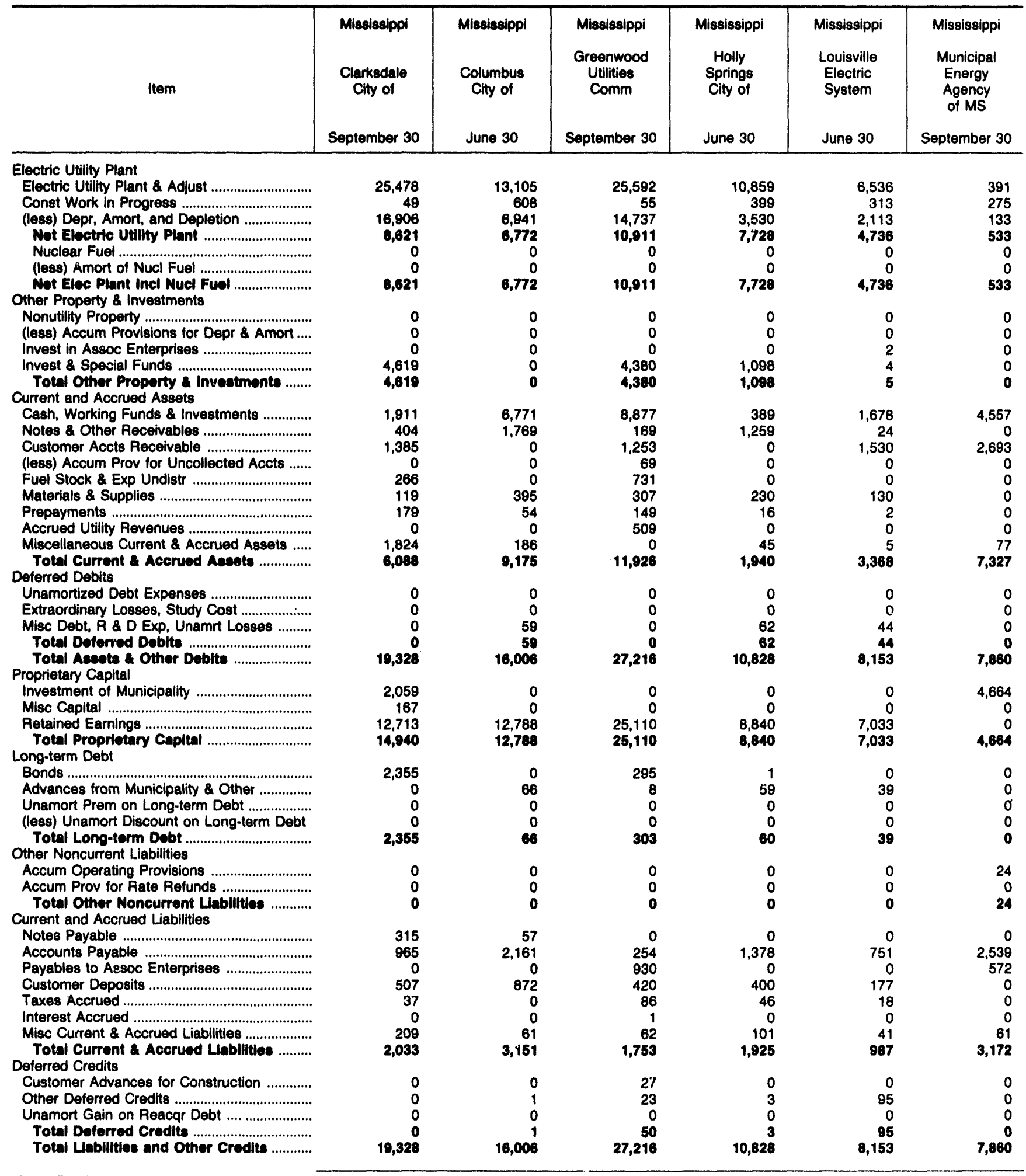

Note: Totals may not equal sum of components because of independent rounding.

Source: Energy Information Administration, Form EIA-412, "Annual Report of Public Electric Utilities." 
Table 22. Balance Sheet by Major U.S. Publlcly Owned Electric Utillty Within State at End of Period, 1992 (Continued) (Thousand Dollars)

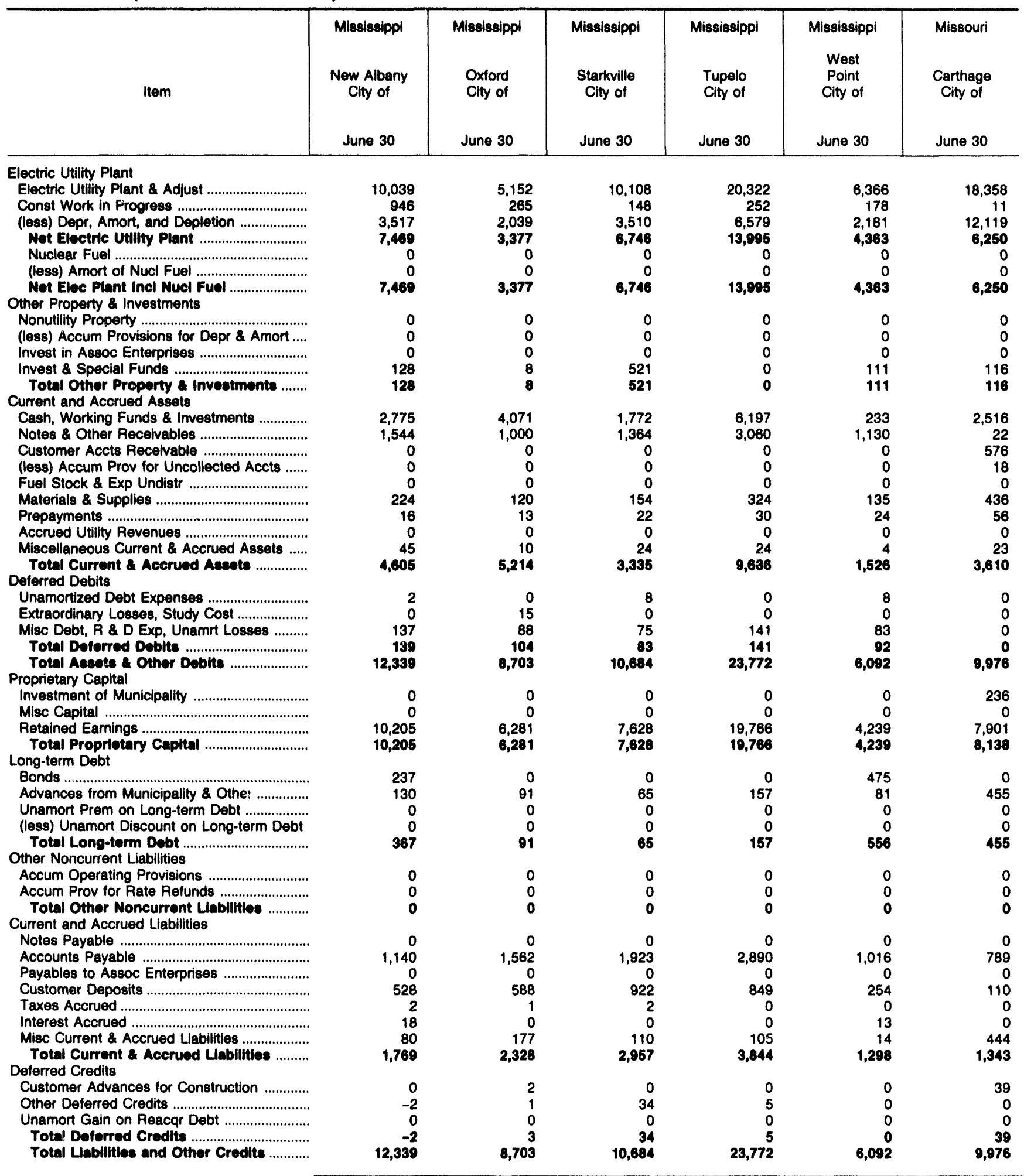

Note: Totals may not equal sum of components because of independent rounding.

Source: Energy Information Administration, Form EIA-412, "Annual Report of Public Electric Utilities." 
Table 22. Balance Sheet by Major U.S. Publicly Owned Electric Utility Within State at End of Period, 1992 (Continued) (Thousand Dollars)

\begin{tabular}{|c|c|c|c|c|c|c|}
\hline Item & $\begin{array}{l}\text { Missouri } \\
\text { Columbia } \\
\text { City of } \\
\text { September } 30\end{array}$ & $\begin{array}{l}\text { Missouri } \\
\text { Hannibal } \\
\text { City of } \\
\text { June } 30\end{array}$ & $\begin{array}{c}\text { Missouri } \\
\text { Independence } \\
\text { City of } \\
\text { June } 30\end{array}$ & $\begin{array}{l}\text { Missouri } \\
\text { Kennett } \\
\text { City of } \\
\text { June } 30\end{array}$ & $\begin{array}{l}\text { Missouri } \\
\text { Kirkwood } \\
\text { City of } \\
\text { March } 31\end{array}$ & $\begin{array}{l}\text { Missouri } \\
\text { Lebanon } \\
\text { City of } \\
\text { October } 31\end{array}$ \\
\hline \multicolumn{7}{|l|}{ Electric Utility Plant } \\
\hline 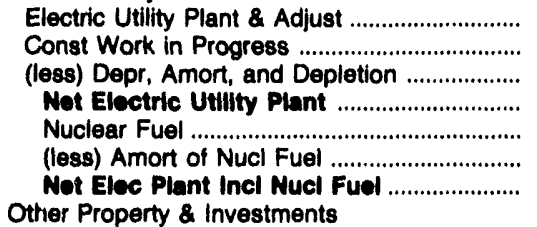 & $\begin{array}{r}72,258 \\
1,578 \\
30,496 \\
43,340 \\
0 \\
0 \\
43,340\end{array}$ & $\begin{array}{r}9,224 \\
560 \\
6,395 \\
3,389 \\
0 \\
0 \\
3,389\end{array}$ & $\begin{array}{r}147,092 \\
8,048 \\
79,042 \\
76,099 \\
0 \\
0 \\
76,099\end{array}$ & $\begin{array}{r}13,302 \\
0 \\
9,220 \\
4,083 \\
0 \\
0 \\
4,083\end{array}$ & $\begin{array}{r}5,189 \\
0 \\
3,084 \\
2,104 \\
0 \\
0 \\
2,104\end{array}$ & $\begin{array}{l}0 \\
0 \\
0 \\
0 \\
0 \\
0 \\
0\end{array}$ \\
\hline 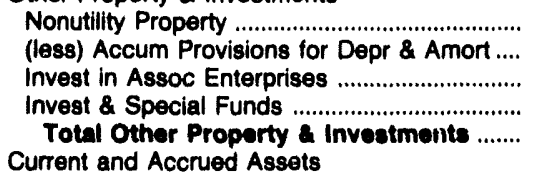 & $\begin{array}{r}31,466 \\
9,080 \\
0 \\
28,723 \\
51,109\end{array}$ & $\begin{array}{r}0 \\
0 \\
727 \\
5,421 \\
6,148\end{array}$ & $\begin{array}{r}0 \\
0 \\
0 \\
12,621 \\
12,621\end{array}$ & $\begin{array}{l}0 \\
0 \\
0 \\
0 \\
0\end{array}$ & $\begin{array}{l}0 \\
0 \\
0 \\
0 \\
0\end{array}$ & $\begin{array}{l}0 \\
0 \\
0 \\
0 \\
0\end{array}$ \\
\hline 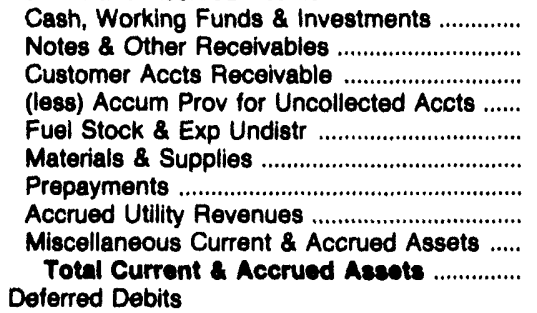 & $\begin{array}{r}12,543 \\
151 \\
5,341 \\
38 \\
420 \\
2,920 \\
32 \\
1,122 \\
342 \\
22,833\end{array}$ & $\begin{array}{r}2,090 \\
347 \\
681 \\
25 \\
0 \\
303 \\
52 \\
0 \\
0 \\
3,448\end{array}$ & $\begin{array}{r}32,462 \\
347 \\
2,720 \\
62 \\
2,001 \\
4,149 \\
9 \\
4,006 \\
855 \\
46,489\end{array}$ & $\begin{array}{r}2,348 \\
0 \\
150 \\
1 \\
150 \\
0 \\
266 \\
0 \\
0 \\
2,913\end{array}$ & $\begin{array}{r}9,135 \\
0 \\
62 \\
18 \\
0 \\
114 \\
5 \\
411 \\
11 \\
9,719\end{array}$ & $\begin{array}{l}0 \\
0 \\
0 \\
0 \\
0 \\
0 \\
0 \\
0 \\
0 \\
0\end{array}$ \\
\hline 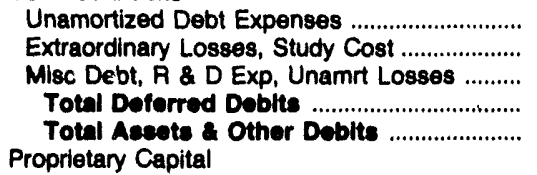 & $\begin{array}{r}435 \\
0 \\
0 \\
435 \\
117,718\end{array}$ & $\begin{array}{r}0 \\
0 \\
0 \\
0 \\
12,888\end{array}$ & $\begin{array}{r}2,633 \\
0 \\
0 \\
2,633 \\
137,842\end{array}$ & $\begin{array}{r}0 \\
0 \\
0 \\
0 \\
6,988\end{array}$ & $\begin{array}{r}89 \\
0 \\
0 \\
89 \\
11,912\end{array}$ & $\begin{array}{l}0 \\
0 \\
0 \\
0 \\
0\end{array}$ \\
\hline 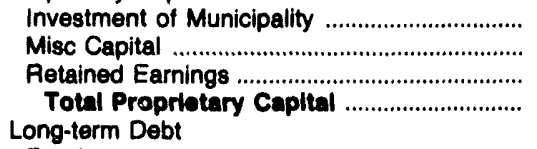 & $\begin{array}{r}426 \\
0 \\
53,432 \\
53,857\end{array}$ & $\begin{array}{r}0 \\
0 \\
11,792 \\
11,792\end{array}$ & $\begin{array}{r}0 \\
0 \\
95,136 \\
95,136\end{array}$ & $\begin{array}{r}191 \\
12 \\
5,672 \\
5,875\end{array}$ & $\begin{array}{r}0 \\
268 \\
9,569 \\
9,837\end{array}$ & $\begin{array}{l}0 \\
0 \\
0 \\
0\end{array}$ \\
\hline 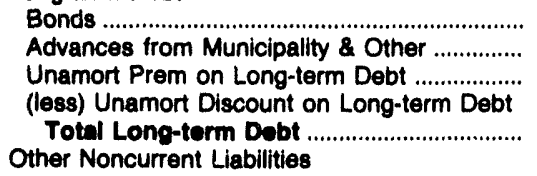 & $\begin{array}{r}56,020 \\
21 \\
0 \\
460 \\
55,682\end{array}$ & $\begin{array}{l}0 \\
0 \\
0 \\
0 \\
0\end{array}$ & $\begin{array}{r}35,670 \\
0 \\
0 \\
0 \\
35,670\end{array}$ & $\begin{array}{r}0 \\
300 \\
0 \\
0 \\
300\end{array}$ & $\begin{array}{l}0 \\
0 \\
0 \\
0 \\
0\end{array}$ & $\begin{array}{l}0 \\
0 \\
0 \\
0 \\
0\end{array}$ \\
\hline 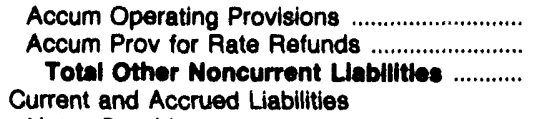 & $\begin{array}{l}0 \\
0 \\
0\end{array}$ & $\begin{array}{r}0 \\
206 \\
206\end{array}$ & $\begin{array}{r}1,429 \\
0 \\
1,429\end{array}$ & $\begin{array}{l}0 \\
0 \\
0\end{array}$ & $\begin{array}{l}0 \\
0 \\
0\end{array}$ & $\begin{array}{l}0 \\
0 \\
0\end{array}$ \\
\hline 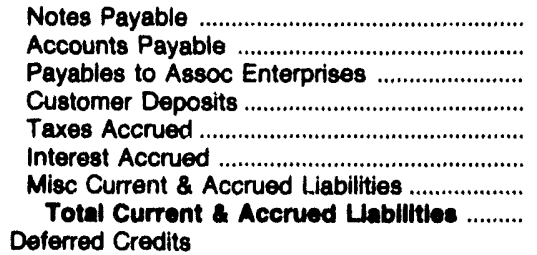 & $\begin{array}{r}28 \\
2,746 \\
0 \\
1,291 \\
478 \\
822 \\
2,913 \\
8,270\end{array}$ & $\begin{array}{r}0 \\
770 \\
0 \\
124 \\
0 \\
0 \\
84 \\
898\end{array}$ & $\begin{array}{r}0 \\
2,468 \\
0 \\
929 \\
0 \\
212 \\
1,052 \\
4,661\end{array}$ & $\begin{array}{r}120 \\
386 \\
0 \\
240 \\
3 \\
6 \\
66 \\
821\end{array}$ & $\begin{array}{r}80 \\
414 \\
1,446 \\
77 \\
0 \\
13 \\
46 \\
2,075\end{array}$ & $\begin{array}{l}0 \\
0 \\
0 \\
0 \\
0 \\
0 \\
0 \\
0\end{array}$ \\
\hline $\begin{array}{l}\text { Customer Advarces for Construction ............ } \\
\text { Other Deferred Credits ....................................... } \\
\text { Unamort Gain on Reacqr Debt ..................... } \\
\text { Total Deferred Credlts ............................... } \\
\text { Total Labllities and Other Credits ........... }\end{array}$ & $\begin{array}{r}0 \\
0 \\
0 \\
0 \\
117,718\end{array}$ & $\begin{array}{r}0 \\
0 \\
0 \\
0 \\
12,498\end{array}$ & $\begin{array}{r}946 \\
0 \\
0 \\
946 \\
137,842\end{array}$ & $\begin{array}{r}0 \\
0 \\
0 \\
0 \\
6,996\end{array}$ & $\begin{array}{r}0 \\
0 \\
0 \\
0 \\
11,912\end{array}$ & $\begin{array}{l}0 \\
0 \\
0 \\
0 \\
0\end{array}$ \\
\hline
\end{tabular}

Note: Totals may not equal sum of components because of independent rounding.

Source: Energy Information Administration, Form ElA-412, "Annual Report of Public Electric Utilities." 
Table 22. Balance Sheet by Major U.S. Publicly Owned Electric Utillty Within State at End of Period, 1992 (Continued) (Thousand Dollars)

\begin{tabular}{|c|c|c|c|c|c|c|}
\hline Item & $\begin{array}{l}\text { Mlasour } \\
\text { Marshall } \\
\text { City of } \\
\text { September } 30\end{array}$ & $\begin{array}{l}\text { Missouri } \\
\text { Monett } \\
\text { City of } \\
\text { March } 31\end{array}$ & $\begin{array}{c}\text { Missoun } \\
\text { Poplar } \\
\text { Bluff } \\
\text { City of } \\
\text { December } 31\end{array}$ & $\begin{array}{l}\text { Missouri } \\
\text { Rolla } \\
\text { City of } \\
\text { September } 30\end{array}$ & $\begin{array}{l}\text { Missouri } \\
\text { Sikeston } \\
\text { City of } \\
\text { May } 31\end{array}$ & $\begin{array}{l}\text { Missouri } \\
\text { Springfield } \\
\text { City of } \\
\text { September } 30\end{array}$ \\
\hline 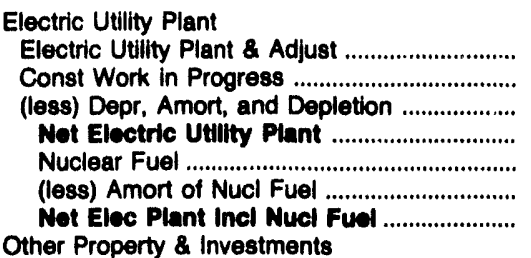 & $\begin{array}{r}30,182 \\
1,714 \\
15,450 \\
16,446 \\
0 \\
0 \\
16,446\end{array}$ & $\begin{array}{r}1,164 \\
0 \\
0 \\
1,184 \\
0 \\
0 \\
1,164\end{array}$ & $\begin{array}{r}17,851 \\
0 \\
7,447 \\
10,404 \\
0 \\
0 \\
10,404\end{array}$ & $\begin{array}{r}8,285 \\
0 \\
5,469 \\
2,816 \\
0 \\
0 \\
2,816\end{array}$ & $\begin{array}{r}218,913 \\
712 \\
61,228 \\
158,396 \\
0 \\
0 \\
158,396\end{array}$ & $\begin{array}{r}360,284 \\
3,901 \\
116,089 \\
248,096 \\
0 \\
0 \\
248,096\end{array}$ \\
\hline 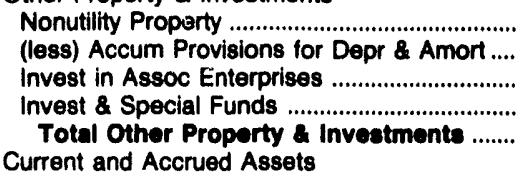 & $\begin{array}{l}0 \\
0 \\
0 \\
0 \\
0\end{array}$ & $\begin{array}{r}0 \\
0 \\
0 \\
582 \\
\mathbf{5 8 2}\end{array}$ & $\begin{array}{r}0 \\
0 \\
0 \\
12,584 \\
12,584\end{array}$ & $\begin{array}{r}5,260 \\
2,434 \\
0 \\
3,364 \\
6,190\end{array}$ & $\begin{array}{r}0 \\
0 \\
0 \\
23,521 \\
23,521\end{array}$ & $\begin{array}{r}0 \\
0 \\
0 \\
117,515 \\
117,515\end{array}$ \\
\hline 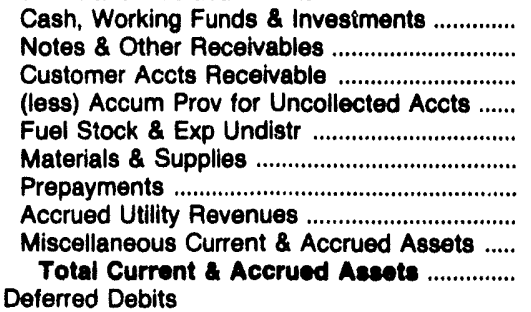 & $\begin{array}{r}9,459 \\
186 \\
634 \\
0 \\
117 \\
604 \\
106 \\
223 \\
0 \\
11,330\end{array}$ & $\begin{array}{r}12,512 \\
0 \\
0 \\
0 \\
0 \\
0 \\
0 \\
0 \\
0 \\
12,512\end{array}$ & $\begin{array}{r}718 \\
12 \\
452 \\
109 \\
110 \\
268 \\
74 \\
1,000 \\
1,009 \\
3,583\end{array}$ & $\begin{array}{r}1,230 \\
0 \\
535 \\
5 \\
0 \\
276 \\
25 \\
0 \\
39 \\
2,099\end{array}$ & $\begin{array}{r}3,323 \\
168 \\
6,062 \\
135 \\
8,983 \\
1,795 \\
162 \\
0 \\
0 \\
20,356\end{array}$ & $\begin{array}{r}9,104 \\
1,027 \\
9,514 \\
100 \\
3,223 \\
7,236 \\
297 \\
0 \\
0 \\
30,301\end{array}$ \\
\hline $\begin{array}{l}\text { Unamortized Debt Expenses ......................... } \\
\text { Extraordinary Losses, Study Cost .................... } \\
\text { Misc Debt, R \& D Exp, Unamrt Losses ......... } \\
\text { Total Deferred Deblts .................................... } \\
\text { Total Aseete \& Other Debits ....................... }\end{array}$ & $\begin{array}{r}0 \\
0 \\
0 \\
0 \\
27,776\end{array}$ & $\begin{array}{r}0 \\
0 \\
0 \\
0 \\
14,258\end{array}$ & $\begin{array}{r}0 \\
0 \\
0 \\
0 \\
\mathbf{2 6 , 5 2 1}\end{array}$ & $\begin{array}{r}0 \\
0 \\
0 \\
0 \\
11,105\end{array}$ & $\begin{array}{r}4,355 \\
0 \\
1,295 \\
5,850 \\
207,924\end{array}$ & $\begin{array}{r}533 \\
0 \\
6,247 \\
6,780 \\
402,692\end{array}$ \\
\hline 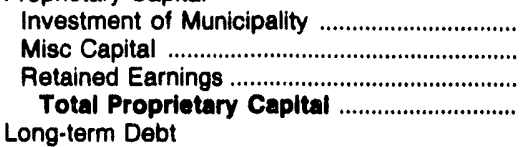 & $\begin{array}{r}180 \\
0 \\
23,868 \\
24,048\end{array}$ & $\begin{array}{r}0 \\
0 \\
13,793 \\
13,793\end{array}$ & $\begin{array}{r}0 \\
0 \\
25,577 \\
25,577\end{array}$ & $\begin{array}{r}28 \\
0 \\
9,667 \\
9,695\end{array}$ & $\begin{array}{r}0 \\
0 \\
-9,335 \\
-8,335\end{array}$ & $\begin{array}{r}0 \\
0 \\
286,877 \\
286,877\end{array}$ \\
\hline 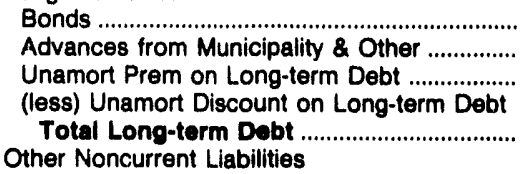 & $\begin{array}{r}2,030 \\
0 \\
0 \\
0 \\
2,030\end{array}$ & $\begin{array}{l}0 \\
0 \\
0 \\
0 \\
0\end{array}$ & $\begin{array}{r}44 \\
0 \\
0 \\
0 \\
4\end{array}$ & $\begin{array}{l}0 \\
0 \\
0 \\
0 \\
0\end{array}$ & $\begin{array}{r}207,375 \\
0 \\
0 \\
2,099 \\
205,278\end{array}$ & $\begin{array}{r}63,952 \\
26,736 \\
0 \\
13,524 \\
77,164\end{array}$ \\
\hline $\begin{array}{l}\text { Accum Operating Provisions } \\
\text { Accum Prov for Rate Refunds .............................. } \\
\text { Total Other Noncurrent Lلbablities ............ } \\
\text { Current and Accrued Liabilities }\end{array}$ & $\begin{array}{l}0 \\
0 \\
0\end{array}$ & $\begin{array}{l}0 \\
0 \\
0\end{array}$ & $\begin{array}{l}0 \\
0 \\
0\end{array}$ & $\begin{array}{l}0 \\
0 \\
0\end{array}$ & $\begin{array}{l}0 \\
0 \\
0\end{array}$ & $\begin{array}{r}6,720 \\
0 \\
6,720\end{array}$ \\
\hline 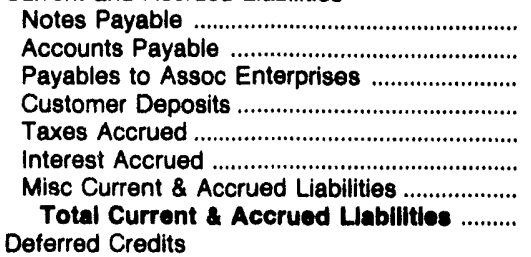 & $\begin{array}{r}0 \\
1,003 \\
0 \\
317 \\
179 \\
35 \\
164 \\
1,698\end{array}$ & $\begin{array}{r}0 \\
351 \\
0 \\
112 \\
0 \\
0 \\
2 \\
465\end{array}$ & $\begin{array}{r}0 \\
404 \\
0 \\
194 \\
25 \\
226 \\
0 \\
848\end{array}$ & $\begin{array}{r}0 \\
933 \\
144 \\
261 \\
0 \\
0 \\
72 \\
1,410\end{array}$ & $\begin{array}{r}0 \\
501 \\
5 \\
247 \\
0 \\
7,432 \\
826 \\
8,010\end{array}$ & $\begin{array}{r}0 \\
6,851 \\
807 \\
880 \\
0 \\
905 \\
17,269 \\
26,712\end{array}$ \\
\hline 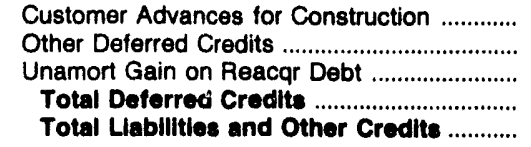 & $\begin{array}{r}0 \\
0 \\
0 \\
0 \\
27,776\end{array}$ & $\begin{array}{r}0 \\
0 \\
0 \\
0 \\
14,258\end{array}$ & $\begin{array}{r}51 \\
0 \\
0 \\
51 \\
28,521\end{array}$ & $\begin{array}{r}0 \\
0 \\
0 \\
0 \\
11,105\end{array}$ & $\begin{array}{r}0 \\
2,972 \\
0 \\
2,972 \\
207,924\end{array}$ & $\begin{array}{r}1 \\
5,218 \\
0 \\
5,219 \\
402,692\end{array}$ \\
\hline
\end{tabular}

Note: Totals may not equal sum of components because of independent rounding.

Source: Energy Information Administration, Form EIA-412, "Annual Peport of Public Electric Utilities." 
Table 22. Balance Sheet by Major U.S. Publicly Owned Electric Utillty Within State at End of Period, 1992 (Continued) (Thousand Dollars)

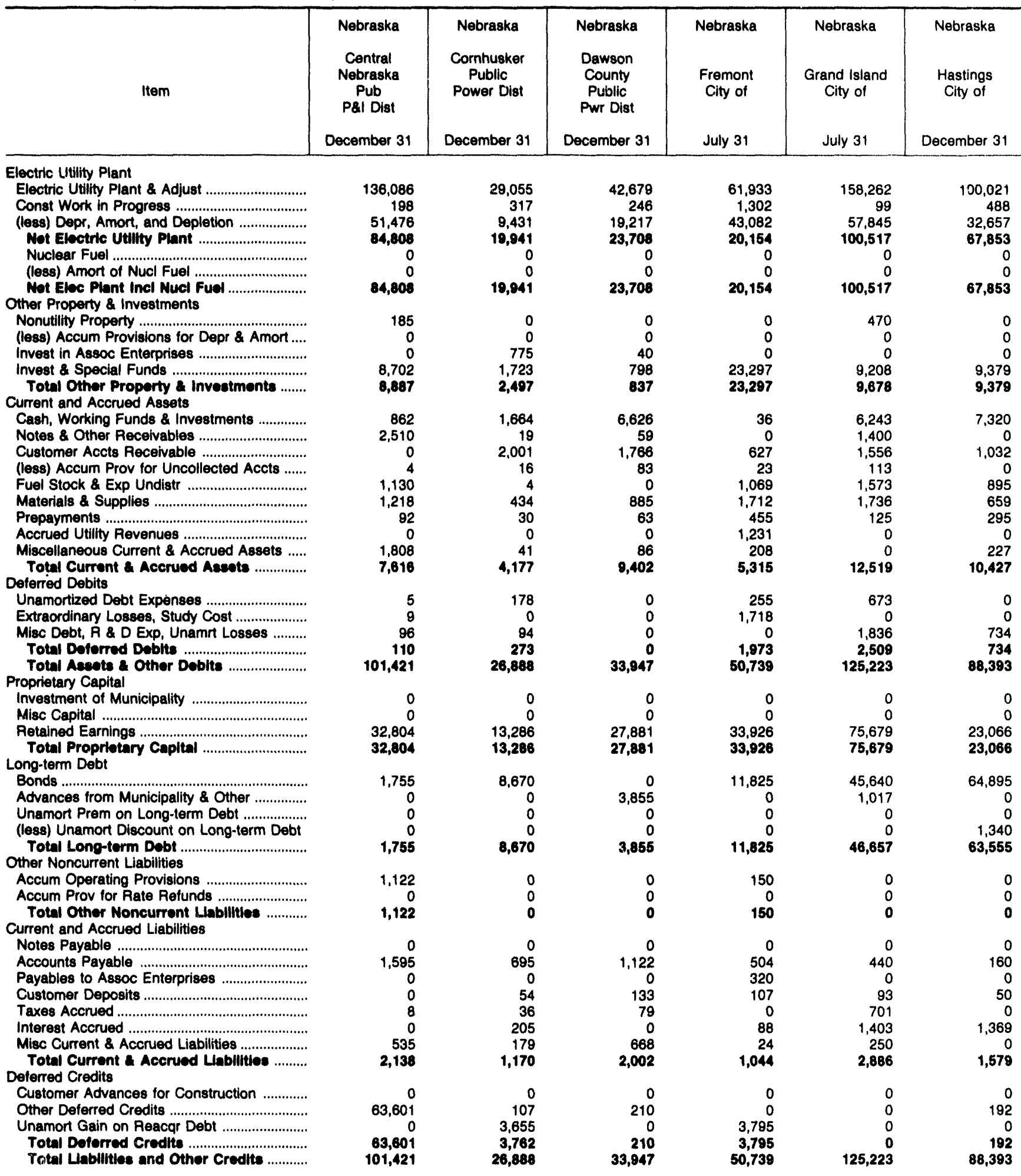

Note: Totals may not equal sum of components because of independent rounding.

Source: Energy Information Administration, Form ElA-412, "Annual Report of Public Electric Utilities." 
Table 22. Balance Sheet by Major U.S. Publicly Owned Electric Utility Within State at End of Period, 1992 (Continued) (Thousand Dollars)

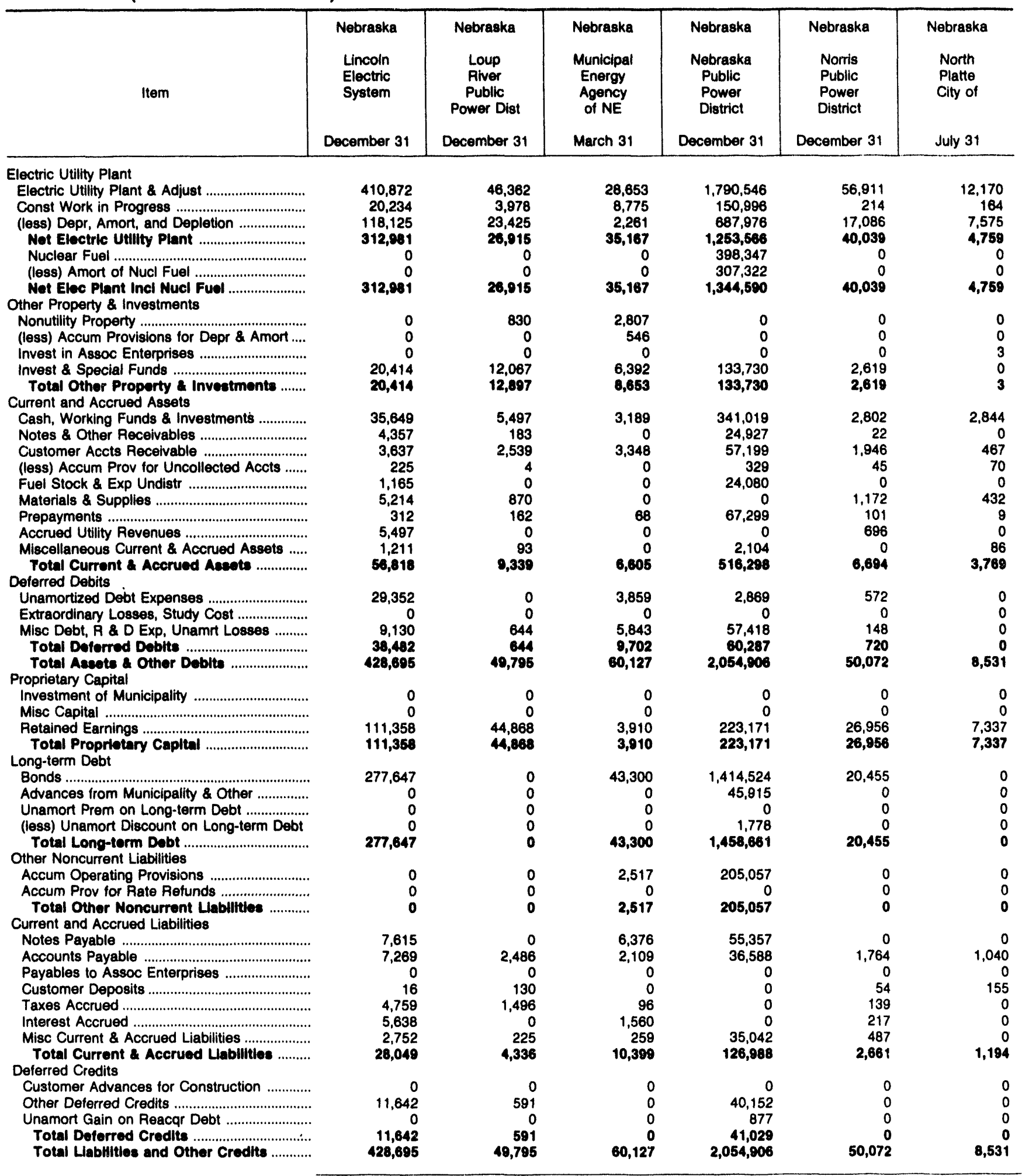

Note: Totals may not equal sum of components because of independent rounding.

Source: Energy Information Administration, Form EIA-412, "Annual Report of Public Electric Utilities." 
Table 22. Balance Sheet by Major U.S. Publicly Owned Electric Utility Within State at End of Perlod, 1992 (Continued) (Thousand Dollars)

\begin{tabular}{|c|c|c|c|c|c|c|}
\hline Item & $\begin{array}{c}\text { Nebraska } \\
\text { Omaha Public } \\
\text { Power } \\
\text { District } \\
\text { December } 31\end{array}$ & $\begin{array}{c}\text { Nebraska } \\
\text { Southern } \\
\text { Nebraska Aural } \\
\text { P P D } \\
\text { December } 31\end{array}$ & $\begin{array}{l}\text { Nevada } \\
\text { Colorado } \\
\text { River } \\
\text { Comm } \\
\text { of Nevada } \\
\text { June } 30\end{array}$ & $\begin{array}{l}\text { New Jersey } \\
\text { Vineland } \\
\text { City of } \\
\text { June } 30\end{array}$ & $\begin{array}{l}\text { New Mexico } \\
\text { Farmington } \\
\text { City of } \\
\text { June } 30\end{array}$ & $\begin{array}{l}\text { New Mexico } \\
\text { Gallup } \\
\text { City of } \\
\text { June } 30\end{array}$ \\
\hline \multicolumn{7}{|l|}{ Electric Utility Plant } \\
\hline 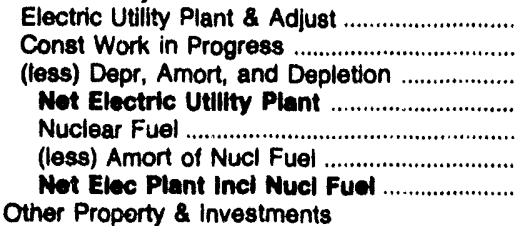 & $\begin{array}{r}1,837,126 \\
92,376 \\
656,420 \\
1,273,082 \\
176,099 \\
55,265 \\
1,393,016\end{array}$ & $\begin{array}{r}68,524 \\
137 \\
29,545 \\
39,116 \\
0 \\
0 \\
39,116\end{array}$ & $\begin{array}{l}0 \\
0 \\
0 \\
0 \\
0 \\
0 \\
0\end{array}$ & $\begin{array}{r}65,041 \\
2,928 \\
31,767 \\
36,201 \\
0 \\
0 \\
36,201\end{array}$ & $\begin{array}{r}166,136 \\
3,831 \\
49,618 \\
120,349 \\
0 \\
0 \\
120,349\end{array}$ & $\begin{array}{r}10,609 \\
0 \\
5,411 \\
5,198 \\
0 \\
0 \\
5,198\end{array}$ \\
\hline 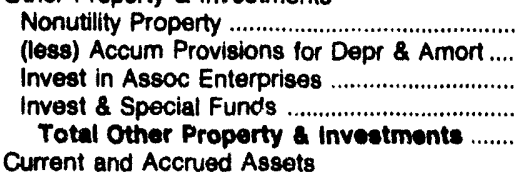 & $\begin{array}{r}0 \\
0 \\
0 \\
299,868 \\
299,898\end{array}$ & $\begin{array}{r}0 \\
0 \\
0 \\
2,004 \\
2,004\end{array}$ & $\begin{array}{r}258,946 \\
65,978 \\
0 \\
51,843 \\
244,811\end{array}$ & $\begin{array}{r}0 \\
0 \\
0 \\
3,449 \\
3,449\end{array}$ & $\begin{array}{l}0 \\
0 \\
0 \\
0 \\
0\end{array}$ & $\begin{array}{r}22,868 \\
10,025 \\
0 \\
0 \\
12,844\end{array}$ \\
\hline 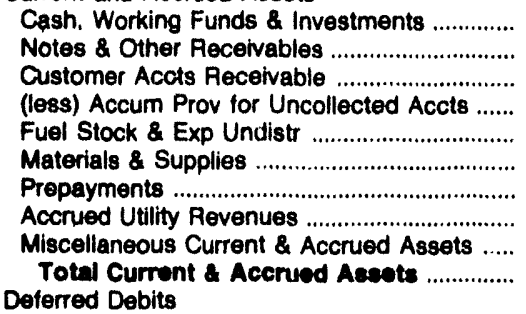 & $\begin{array}{r}16,161 \\
44,840 \\
28,078 \\
805 \\
9,410 \\
36,272 \\
311 \\
16,075 \\
3,868 \\
154,211\end{array}$ & $\begin{array}{r}10,153 \\
0 \\
1,633 \\
0 \\
0 \\
1,694 \\
46 \\
0 \\
168 \\
13,694\end{array}$ & $\begin{array}{r}6,467 \\
948 \\
5,341 \\
0 \\
0 \\
139 \\
6,514 \\
0 \\
0 \\
19,408\end{array}$ & $\begin{array}{r}17,868 \\
0 \\
2,828 \\
0 \\
0 \\
1,394 \\
0 \\
0 \\
0 \\
22,000\end{array}$ & $\begin{array}{r}22,745 \\
0 \\
2,223 \\
13 \\
592 \\
1,372 \\
180 \\
1,829 \\
10,086 \\
39,014\end{array}$ & $\begin{array}{r}2,325 \\
475 \\
1,623 \\
136 \\
0 \\
1,001 \\
0 \\
0 \\
1,950 \\
7,238\end{array}$ \\
\hline 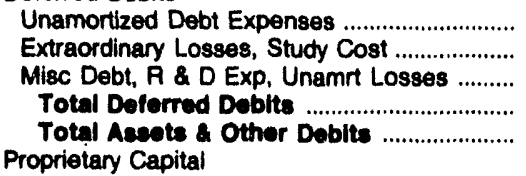 & $\begin{array}{r}1,260 \\
0 \\
98,570 \\
99,830 \\
1,947,826\end{array}$ & $\begin{array}{r}0 \\
0 \\
932 \\
\mathbf{9 3 2} \\
\mathbf{5 5 , 7 4 5}\end{array}$ & $\begin{array}{r}1,065 \\
0 \\
49,495 \\
50,560 \\
\mathbf{3 1 4 , 7 7 9}\end{array}$ & $\begin{array}{r}0 \\
0 \\
0 \\
0 \\
81,739\end{array}$ & $\begin{array}{r}5,718 \\
0 \\
0 \\
5,711 \\
165,081\end{array}$ & $\begin{array}{r}87 \\
0 \\
0 \\
87 \\
25,366\end{array}$ \\
\hline 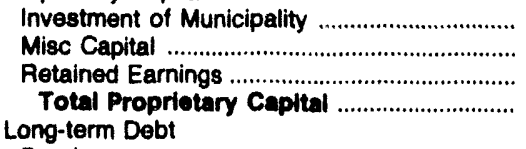 & $\begin{array}{r}0 \\
0 \\
665,950 \\
665,950\end{array}$ & $\begin{array}{r}0 \\
0 \\
49,394 \\
49,394\end{array}$ & $\begin{array}{r}1,526 \\
0 \\
-50,038 \\
-48,511\end{array}$ & $\begin{array}{r}0 \\
0 \\
46,719 \\
46,719\end{array}$ & $\begin{array}{r}0 \\
12,962 \\
10,210 \\
23,172\end{array}$ & $\begin{array}{r}13,370 \\
7,353 \\
0 \\
20,723\end{array}$ \\
\hline 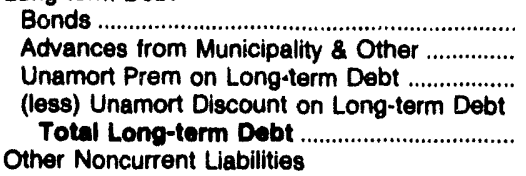 & $\begin{array}{r}980,040 \\
64,477 \\
0 \\
8,493 \\
1,036,025\end{array}$ & $\begin{array}{r}3,844 \\
0 \\
0 \\
0 \\
3,844\end{array}$ & $\begin{array}{r}154,920 \\
188,188 \\
5 \\
0 \\
343,112\end{array}$ & $\begin{array}{r}5,190 \\
0 \\
0 \\
0 \\
5,190\end{array}$ & $\begin{array}{r}132,987 \\
0 \\
0 \\
0 \\
132,987\end{array}$ & $\begin{array}{r}2,760 \\
76 \\
0 \\
0 \\
2,836\end{array}$ \\
\hline 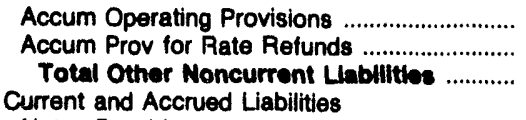 & $\begin{array}{r}4,603 \\
0 \\
4,603\end{array}$ & $\begin{array}{l}0 \\
0 \\
0\end{array}$ & $\begin{array}{l}0 \\
0 \\
0\end{array}$ & $\begin{array}{r}3,449 \\
0 \\
3,449\end{array}$ & $\begin{array}{l}0 \\
0 \\
0\end{array}$ & $\begin{array}{l}0 \\
0 \\
0\end{array}$ \\
\hline 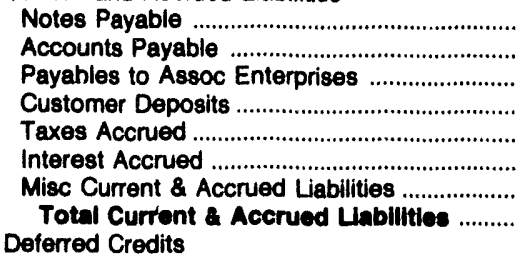 & $\begin{array}{r}18,982 \\
33,387 \\
0 \\
4,775 \\
12,988 \\
24,375 \\
18,566 \\
113,073\end{array}$ & $\begin{array}{r}0 \\
1,331 \\
0 \\
57 \\
0 \\
0 \\
1,118 \\
2,507\end{array}$ & $\begin{array}{r}0 \\
4,872 \\
0 \\
0 \\
0 \\
5,903 \\
5,950 \\
16,725\end{array}$ & $\begin{array}{r}0 \\
3,850 \\
0 \\
571 \\
0 \\
356 \\
1,562 \\
6,339\end{array}$ & $\begin{array}{r}0 \\
1,256 \\
0 \\
522 \\
555 \\
1,585 \\
665 \\
4,584\end{array}$ & $\begin{array}{r}0 \\
918 \\
0 \\
678 \\
70 \\
0 \\
98 \\
1,763\end{array}$ \\
\hline 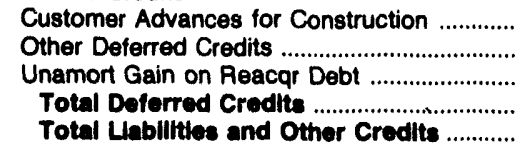 & $\begin{array}{r}523 \\
127,652 \\
0 \\
128,174 \\
1,947,826\end{array}$ & $\begin{array}{r}0 \\
0 \\
0 \\
0 \\
\mathbf{5 5 , 7 4 5}\end{array}$ & $\begin{array}{r}0 \\
3,453 \\
0 \\
3,453 \\
314,779\end{array}$ & $\begin{array}{r}43 \\
0 \\
0 \\
43 \\
61,739\end{array}$ & $\begin{array}{r}2,114 \\
2,224 \\
0 \\
4,338 \\
165,081\end{array}$ & $\begin{array}{r}0 \\
44 \\
0 \\
44 \\
25,368\end{array}$ \\
\hline
\end{tabular}

Note: Totals may not equal sum of components because of independent rounding.

Source: Energy Information Administration, Form ElA-412, "Annual Report of Public Electric Utilities." 
Table 22. Balance Sheet by Major U.S. Publlcly Owned Electric Utility Within State at End of Perlod, 1992 (Continued) (Thousand Dollars)

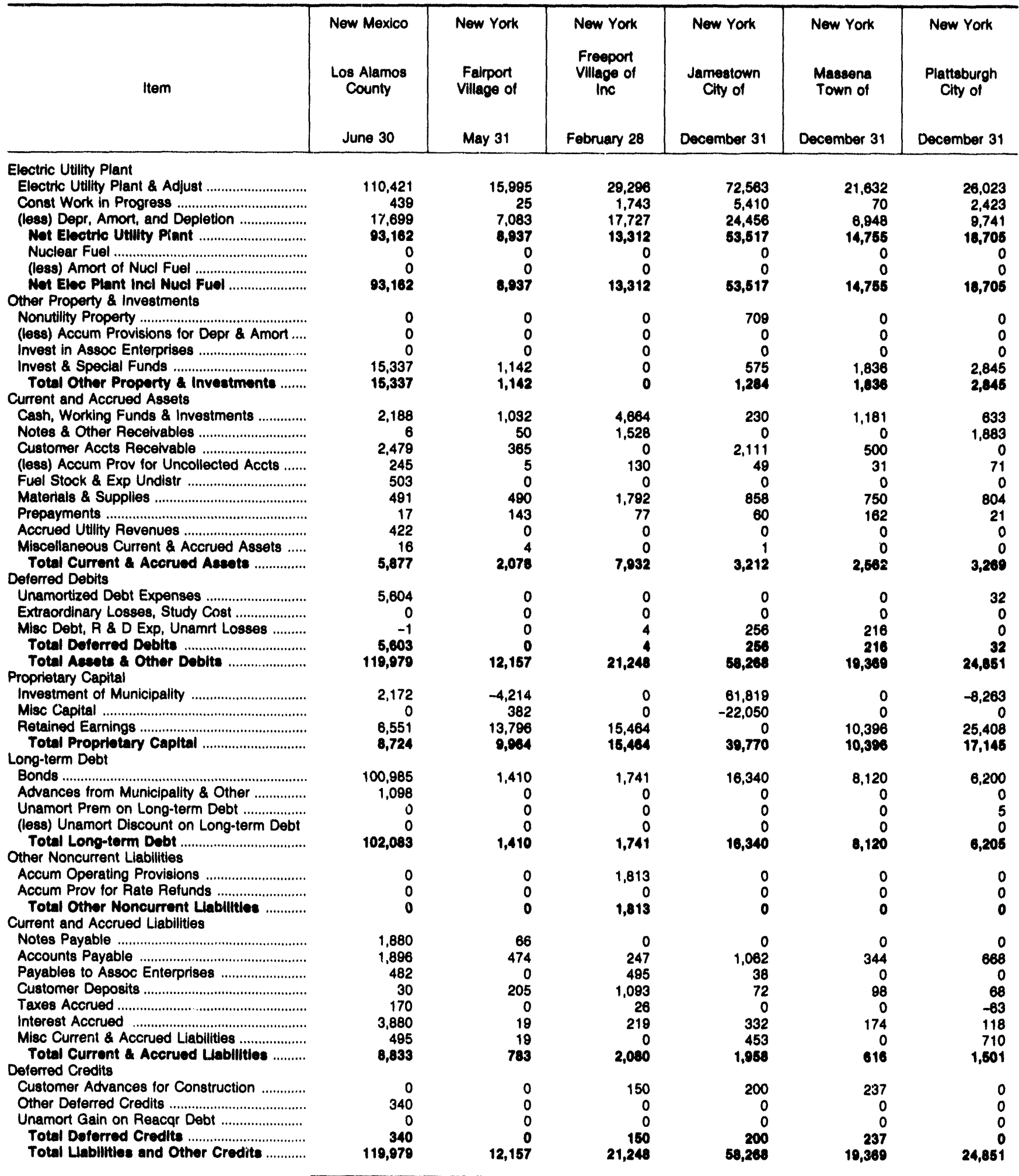

Note: Totals may not equal sum of components because of independent rounding.

Source: Energy Information Administration, Form ElA-412, "Annual Report of Public Electric Utilities." 
Table 22. Balance Sheet by Major U.S. Publlcly Owned Electric Utillty Within State at End of Perlod, 1992 (Continued) (Thousand Dollars)

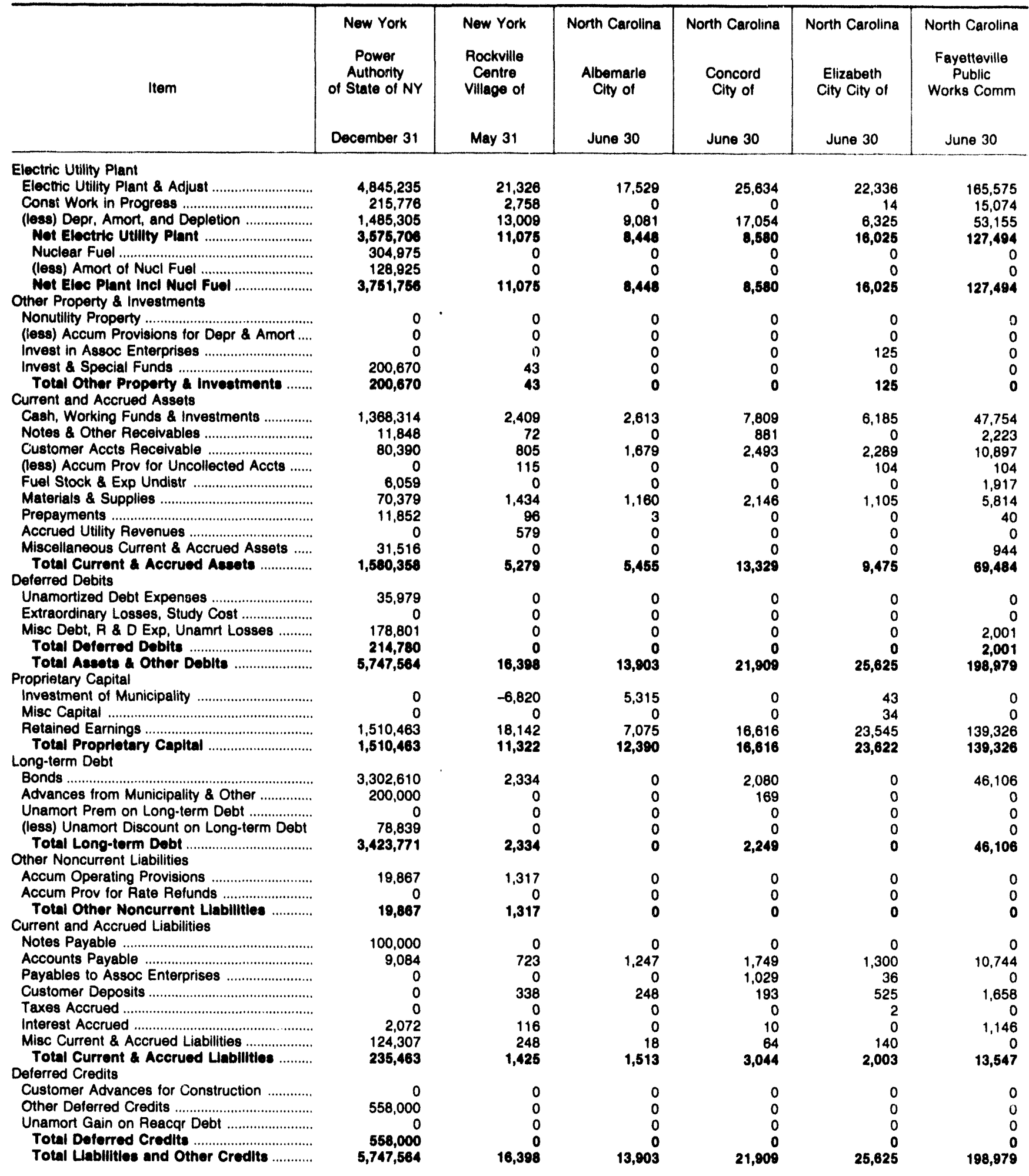

Note: Totals may not equal sum of components because of independent rounding.

Source: Energy Information Administration, Form EIA-412, "Annual Report of Public Electric Utilities." 
Table 22. Balance Sheet by Major U.S. Publicly Owned Electric Utillty Within State at End of Perlod, 1992 (Continued) (Thousand Dollars)

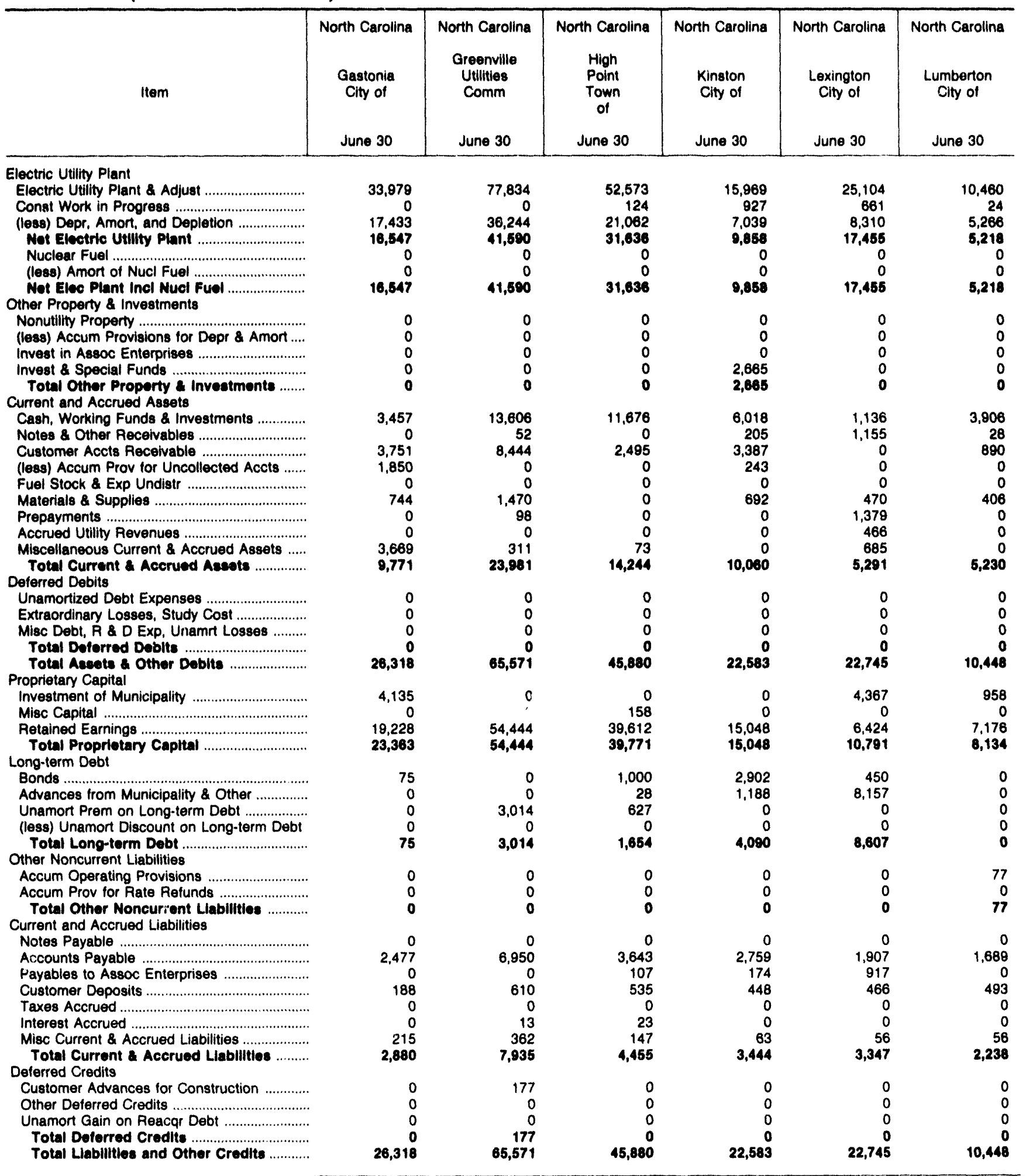

Note: Totals may nol equal sum of components because of independent rounding.

Source: Energy Information Administration, Form ElA-412, "Annual Report of Public Electric Utilities." 
Table 22. Balance Sheet by Major U.S. Publlcly Owned Electric Utillty Within State at End of Perlod, 1992 (Continued) (Thousand Dollars)

\begin{tabular}{|c|c|c|c|c|c|c|}
\hline Item & $\begin{array}{l}\text { North Carolina } \\
\text { Monroe } \\
\text { City of } \\
\text { June } 30\end{array}$ & $\begin{array}{l}\text { North Carolina } \\
\begin{array}{c}\text { Morganton } \\
\text { City of }\end{array} \\
\text { June } 30\end{array}$ & $\begin{array}{l}\text { North Carolina } \\
\text { Murphy } \\
\text { City of } \\
\text { June } 30\end{array}$ & $\begin{array}{l}\text { North Carolina } \\
\text { New Bern } \\
\text { City of } \\
\text { June } 30\end{array}$ & $\begin{array}{c}\text { North Carolina } \\
\text { New River } \\
\text { Light } \\
\& \\
\text { Power Co } \\
\text { December } 31\end{array}$ & $\begin{array}{c}\text { North Carolina } \\
\text { North } \\
\text { Carolina } \\
\text { Eastern M P A } \\
\text { December } 31\end{array}$ \\
\hline \multicolumn{7}{|l|}{ Electric Utility Plant } \\
\hline Electric Utility Plant \& Adjust ............................ & 18,157 & 8,666 & 6.597 & 17.880 & 9,464 & $1,372,153$ \\
\hline Const Work in Progress & 1,490 & & 145 & & & 16,730 \\
\hline 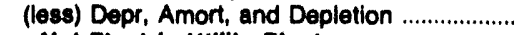 & 5,965 & 4,227 & 1,814 & 7,486 & 2,487 & 320,940 \\
\hline Not Eloctric Utility Plant ................................ & 13,682 & 5,448 & 4,928 & 10,384 & 7,012 & $1,087,943$ \\
\hline 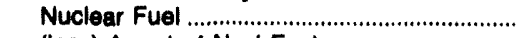 & & 0 & & 0 & 0 & 69,341 \\
\hline 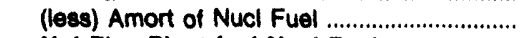 & & & & & 0 & 33,146 \\
\hline $\begin{array}{l}\text { Not Elec Plant Incl Nucl Fuvl ........................ } \\
\text { Other Property \& Investments }\end{array}$ & 13,682 & 5,448 & 4,928 & 10,394 & 7,012 & $1,104,138$ \\
\hline $\begin{array}{l}\text { Other Property \& Investments } \\
\text { Nonutility Property }\end{array}$ & 0 & 0 & 0 & 0 & 0 & 3,131 \\
\hline (less) Accum Provisions for Depr \& Amort .... & 0 & 0 & 0 & 0 & 0 & 980 \\
\hline 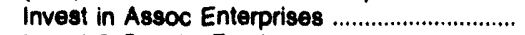 & 0 & 0 & 0 & 0 & 4,475 & 0 \\
\hline 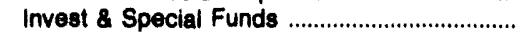 & 0 & 0 & 1,555 & 0 & 2,000 & 450,284 \\
\hline Current and Accrued Assets & 0 & 0 & 1,555 & 0 & 6,475 & 462,435 \\
\hline Cash, Working Funds \& investments .................. & 16,123 & 7,641 & 271 & 614 & 274 & 199,010 \\
\hline 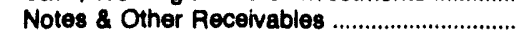 & 1,968 & 763 & 589 & 0 & 40 & \\
\hline 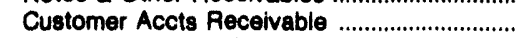 & 0 & 1,502 & 0 & 3,784 & 1,192 & 31,584 \\
\hline (less) Accum Prov for Uncollected Accts ...... & 0 & 0 & 0 & 0 & 35 & \\
\hline 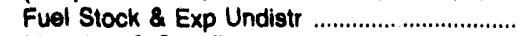 & 0 & 0 & 0 & 0 & 0 & 3,789 \\
\hline & 1,081 & 6 & 126 & 1,345 & 261 & 7,216 \\
\hline 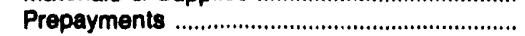 & 0 & 0 & 75 & 0 & 11 & 391 \\
\hline 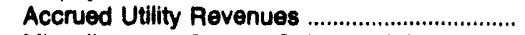 & 0 & 0 & 0 & 0 & 0 & 0 \\
\hline Miscellaneous Current \& Accrued Assets ..... & 0 & 74 & 25 & 0 & 0 & \\
\hline $\begin{array}{l}\text { Total Current \& Accrued Aseats ................. } \\
\text { Deferred Debits }\end{array}$ & \multicolumn{5}{|c|}{ Deferred Debits } & 241,990 \\
\hline 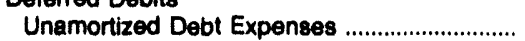 & 0 & 0 & 0 & 0 & 0 & 42,522 \\
\hline Extraordinary Losses, Study Cost ..................... & 0 & 0 & 0 & 0 & 0 & \\
\hline Misc Debt, R \& D Exp, Unamrt Losses .......... & 0 & 0 & 10 & 0 & 0 & $1,458,358$ \\
\hline Total Doforred Debits ................................. & & & 10 & & & $1,500,880$ \\
\hline Total Aasets \& Other Debits & 32,865 & 15,435 & 7,577 & 16,137 & 15,230 & $3,299,443$ \\
\hline \multirow{2}{*}{\multicolumn{7}{|c|}{$\begin{array}{l}\text { Proprietary Capital } \\
\text { Investment of Municipality }\end{array}$}} \\
\hline & 0 & 3,143 & 0 & 5,074 & 0 & 0 \\
\hline 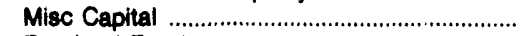 & 0 & & 0 & 0 & 0 & 0 \\
\hline Retained Earnings & 30,488 & 10,949 & 6,903 & 7,171 & 13,250 & 5,170 \\
\hline \multirow{2}{*}{\multicolumn{7}{|c|}{ Long-term Debt }} \\
\hline & 0 & 0 & 0 & 0 & 0 & $3,203,750$ \\
\hline Advances from Municipality \& Other ................... & 0 & 0 & 2 & 836 & 0 & 19,786 \\
\hline Unamort Prem on Long-term Debt ..................... & 0 & 0 & 0 & 0 & 710 & 1,548 \\
\hline (less) Unamort Discount on Long-term Debt & 0 & 0 & 0 & 0 & 0 & 215,874 \\
\hline 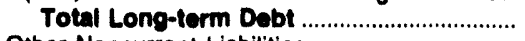 & 0 & 0 & 2 & 836 & 710 & $3,009,210$ \\
\hline \multicolumn{7}{|l|}{ Other Noncurrent Liabilities } \\
\hline Accum Operating Provisions .................................. & 0 & 0 & 0 & 0 & 0 & 0 \\
\hline 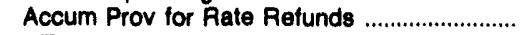 & 0 & 0 & 0 & 0 & 0 & 0 \\
\hline Total Other Noncurrent Llabilitios ................. & o & 0 & 0 & 0 & 0 & 0 \\
\hline \multicolumn{7}{|l|}{ Current and Accrued Liabilities } \\
\hline Notes Payable .............................. & 95 & 0 & 0 & 238 & 130 & 146,073 \\
\hline Accounts Payablo & 1,959 & 1,122 & 490 & 1,887 & 936 & 26,307 \\
\hline Payables to Assoc Enterprises ............................. & 0 & 0 & 0 & 0 & 0 & 0 \\
\hline 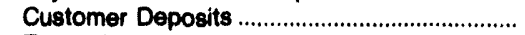 & 299 & 193 & 182 & 875 & 187 & 0 \\
\hline 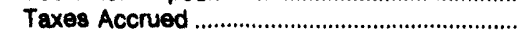 & 0 & 0 & 0 & 0 & 0 & 6,381 \\
\hline Interest Accrued .............................................. & 0 & 0 & 0 & 0 & 12 & 106,302 \\
\hline 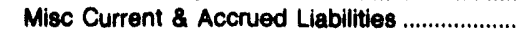 & 13 & 28 & 0 & 55 & & \\
\hline Total Current a Accrued Uablities ........... & 2,367 & 1,343 & 672 & 3,056 & 1,270 & 285,063 \\
\hline \multicolumn{7}{|l|}{ Deferred Credits } \\
\hline Customer Advances for Construction ................ & 0 & 0 & 0 & 0 & 0 & 0 \\
\hline 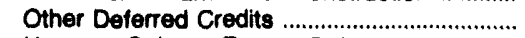 & 0 & 0 & 0 & 0 & 0 & 0 \\
\hline Unamort Gain on Reacqr Debt ........................... & 0 & 0 & 0 & 0 & 0 & 0 \\
\hline Total Doferred Credite & 0 & 0 & 0 & 0 & 0 & 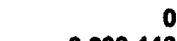 \\
\hline lor Credite ................. & 32,865 & 15,436 & 7,577 & 16,137 & 15,230 & $3,299,443$ \\
\hline
\end{tabular}

Note: Totals may not equal sum of components because of independent rounding.

Source: Energy Information Administration, Form ElA-412, "Annual Report of Public Electric Utilities." 
Table 22. Balance Sheet by Major U.S. Publlcly Owned Electric UtIlity Within State at End of Perlod, 1992 (Continued) (Thousand Dollars)

\begin{tabular}{|c|c|c|c|c|c|c|}
\hline Item & $\begin{array}{c}\text { North Carolina } \\
\text { North } \\
\text { Carolina } \\
\text { Mun } \\
\text { Power Agny } \\
\text { December } 31\end{array}$ & $\begin{array}{l}\text { North Carolina } \\
\text { Rocky Mount } \\
\text { City of } \\
\text { June } 30\end{array}$ & $\begin{array}{l}\text { North Carolina } \\
\text { Shelby } \\
\text { City of } \\
\text { June } 30\end{array}$ & $\begin{array}{l}\text { North Carolina } \\
\text { Statesville } \\
\text { City of } \\
\text { June } 30\end{array}$ & $\begin{array}{l}\text { North Carolina } \\
\text { Tarboro } \\
\text { Town of } \\
\text { June } 30\end{array}$ & $\begin{array}{l}\text { North Carolina } \\
\text { Washington } \\
\text { City of } \\
\text { June } 30\end{array}$ \\
\hline \multicolumn{7}{|l|}{ Electric Utility Plant } \\
\hline 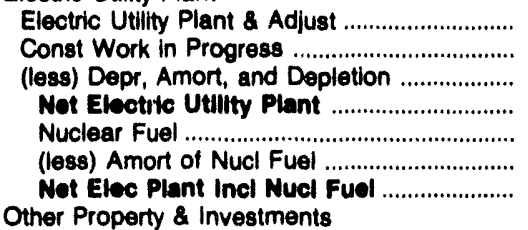 & $\begin{array}{r}1,413,516 \\
7,049 \\
275,239 \\
1,145,320 \\
255,234 \\
195,068 \\
1,205,492\end{array}$ & $\begin{array}{r}29,682 \\
3,825 \\
12,135 \\
21,373 \\
0 \\
0 \\
21,373\end{array}$ & $\begin{array}{r}6,111 \\
33 \\
4,112 \\
2,031 \\
0 \\
0 \\
2,031\end{array}$ & $\begin{array}{r}14,679 \\
0 \\
5,760 \\
8,910 \\
0 \\
0 \\
8,919\end{array}$ & $\begin{array}{r}14,716 \\
0 \\
5,072 \\
9,644 \\
0 \\
0 \\
9,644\end{array}$ & $\begin{array}{r}23,986 \\
102 \\
9,916 \\
14,172 \\
0 \\
0 \\
14,172\end{array}$ \\
\hline 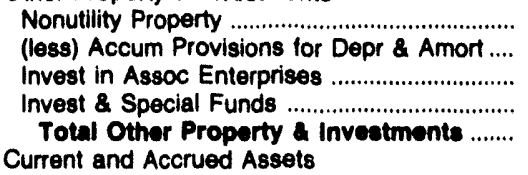 & $\begin{array}{r}3,131 \\
980 \\
0 \\
345,643 \\
347,794\end{array}$ & $\begin{array}{l}0 \\
0 \\
0 \\
0 \\
0\end{array}$ & $\begin{array}{l}0 \\
0 \\
0 \\
0 \\
0\end{array}$ & $\begin{array}{r}856 \\
342 \\
0 \\
0 \\
514\end{array}$ & $\begin{array}{l}0 \\
0 \\
0 \\
0 \\
0\end{array}$ & $\begin{array}{l}0 \\
0 \\
0 \\
0 \\
0\end{array}$ \\
\hline 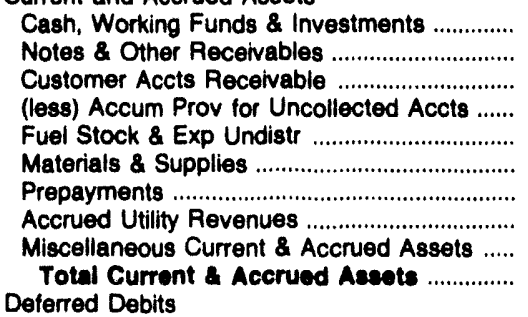 & $\begin{array}{r}24,120 \\
0 \\
15,512 \\
0 \\
0 \\
18,037 \\
0 \\
0 \\
446,773 \\
504,442\end{array}$ & $\begin{array}{r}3,282 \\
90 \\
5,991 \\
0 \\
0 \\
619 \\
0 \\
0 \\
0 \\
9,992\end{array}$ & $\begin{array}{r}1,130 \\
28 \\
1,055 \\
161 \\
0 \\
274 \\
0 \\
0 \\
0 \\
2,328\end{array}$ & $\begin{array}{r}7,259 \\
35 \\
2,957 \\
234 \\
0 \\
984 \\
18 \\
0 \\
0 \\
11,019\end{array}$ & $\begin{array}{r}7,760 \\
1,867 \\
0 \\
31 \\
0 \\
661 \\
0 \\
0 \\
0 \\
10,258\end{array}$ & $\begin{array}{r}7,588 \\
2 \\
2,118 \\
0 \\
0 \\
620 \\
0 \\
0 \\
0 \\
10,328\end{array}$ \\
\hline 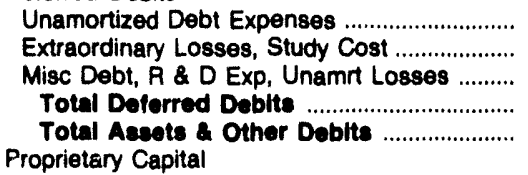 & $\begin{array}{r}40,845 \\
319,874 \\
89,642 \\
450,361 \\
2,508,089\end{array}$ & $\begin{array}{r}0 \\
0 \\
0 \\
0 \\
31,355\end{array}$ & $\begin{array}{r}0 \\
0 \\
2 \\
2 \\
4,350\end{array}$ & $\begin{array}{r}0 \\
0 \\
0 \\
0 \\
20,452\end{array}$ & $\begin{array}{r}0 \\
0 \\
0 \\
0 \\
19,802\end{array}$ & $\begin{array}{r}0 \\
0 \\
0 \\
0 \\
24,500\end{array}$ \\
\hline 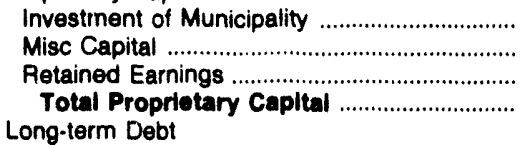 & $\begin{array}{r}0 \\
0 \\
4,279 \\
4,279\end{array}$ & $\begin{array}{r}0 \\
811 \\
23,575 \\
24,388\end{array}$ & $\begin{array}{r}0 \\
88 \\
2,945 \\
3,033\end{array}$ & $\begin{array}{r}21 \\
0 \\
17,789 \\
17,811\end{array}$ & $\begin{array}{r}906 \\
17,258 \\
0 \\
18,163\end{array}$ & $\begin{array}{r}317 \\
0 \\
18,280 \\
18,598\end{array}$ \\
\hline 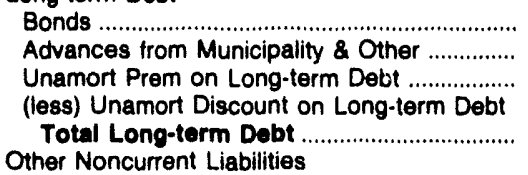 & $\begin{array}{r}2,591,031 \\
31,409 \\
12,613 \\
207,919 \\
2,427,134\end{array}$ & $\begin{array}{r}1,336 \\
0 \\
0 \\
0 \\
1,636\end{array}$ & $\begin{array}{r}188 \\
0 \\
0 \\
0 \\
188\end{array}$ & $\begin{array}{r}784 \\
0 \\
0 \\
0 \\
784\end{array}$ & $\begin{array}{l}0 \\
0 \\
0 \\
0 \\
0\end{array}$ & $\begin{array}{r}3,671 \\
416 \\
0 \\
0 \\
4,087\end{array}$ \\
\hline 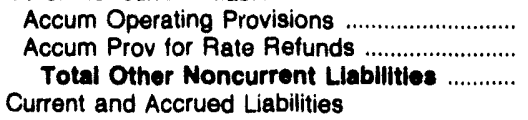 & $\begin{array}{l}0 \\
0 \\
0\end{array}$ & $\begin{array}{l}0 \\
0 \\
0\end{array}$ & $\begin{array}{l}0 \\
0 \\
0\end{array}$ & $\begin{array}{r}78 \\
0 \\
78\end{array}$ & $\begin{array}{l}0 \\
0 \\
0\end{array}$ & $\begin{array}{l}0 \\
0 \\
0\end{array}$ \\
\hline 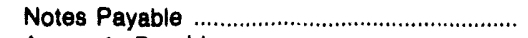 & 0 & 0 & 13 & 0 & 0 & 0 \\
\hline 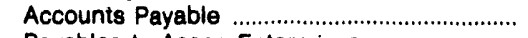 & 10,394 & 4,533 & 768 & 1,588 & 1,613 & 1.522 \\
\hline 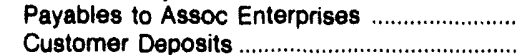 & $\begin{array}{l}0 \\
0\end{array}$ & $\begin{array}{r}0 \\
625\end{array}$ & $\begin{array}{r}0 \\
328\end{array}$ & $\begin{array}{r}0 \\
182\end{array}$ & $\begin{array}{r}0 \\
98\end{array}$ & $\begin{array}{r}0 \\
197\end{array}$ \\
\hline 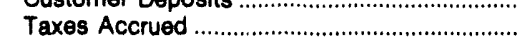 & 13,674 & $\begin{array}{r}0<0 \\
0\end{array}$ & $\begin{array}{r}3<0 \\
0\end{array}$ & $\begin{array}{r}102 \\
0\end{array}$ & $\begin{array}{r}90 \\
0\end{array}$ & $\begin{array}{r}191 \\
0\end{array}$ \\
\hline Interest Accrued & 52,608 & 7 & 3 & 9 & 0 & 0 \\
\hline $\begin{array}{l}\text { Misc Current \& Accrued Liabilities ................... } \\
\text { Total Current \& Accrued Liabilities .......... } \\
\text { Deferred Credits }\end{array}$ & 78,676 & $\begin{array}{r}168 \\
5,333\end{array}$ & $\begin{array}{r}27 \\
1,139\end{array}$ & $\begin{array}{r}0 \\
1,779\end{array}$ & $\begin{array}{r}27 \\
1,738\end{array}$ & $\begin{array}{r}97 \\
1,815\end{array}$ \\
\hline Customer Advances for Construction .............. & 0 & 0 & 0 & 0 & 0 & 0 \\
\hline 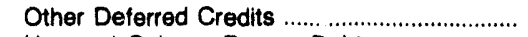 & 0 & 0 & 0 & 0 & 0 & 0 \\
\hline 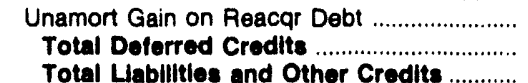 & $\begin{array}{r}0 \\
0 \\
2.508 .089\end{array}$ & $\begin{array}{r}0 \\
0 \\
31,355\end{array}$ & $\begin{array}{r}0 \\
0 \\
359\end{array}$ & $\begin{array}{r}0 \\
0 \\
20,452\end{array}$ & $\begin{array}{r}0 \\
0 \\
19.902\end{array}$ & $\begin{array}{r}0 \\
0 \\
24.500\end{array}$ \\
\hline
\end{tabular}

Note: Totals may not equal sum of components because of independent rounding.

Source: Energy Information Administration, Form EIA-412, "Annual Report of Public Electric Utilities." 
Table 22. Balance Sheet by Major U.S. Publicly Owned Electric Utillty Within State at End of Period, 1992 (Continued) (Thousand Dollars)

\begin{tabular}{|c|c|c|c|c|c|c|}
\hline Item & $\begin{array}{l}\text { North Carolina } \\
\text { Wilson } \\
\text { City of } \\
\text { June } 30\end{array}$ & $\begin{array}{l}\text { Ohio } \\
\text { American } \\
\text { Mun } \\
\text { Power } \\
\text { Ohio Inc } \\
\text { December } 31\end{array}$ & $\begin{array}{l}\text { Ohio } \\
\text { Bowling } \\
\text { Green } \\
\text { City of } \\
\text { December } 31\end{array}$ & $\begin{array}{l}\text { Ohio } \\
\text { Bryan } \\
\text { City of } \\
\text { December } 31\end{array}$ & $\begin{array}{l}\text { Ohio } \\
\text { Celina } \\
\text { City of } \\
\text { December } 31\end{array}$ & $\begin{array}{l}\text { Ohio } \\
\text { Cleveland } \\
\text { City of } \\
\text { December } 31\end{array}$ \\
\hline 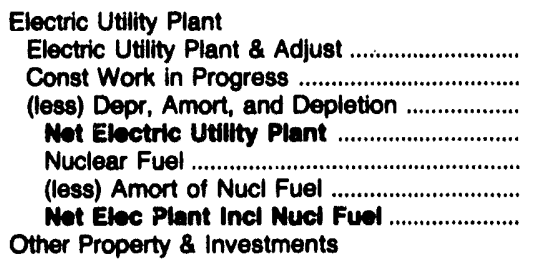 & $\begin{array}{r}46,567 \\
742 \\
23,378 \\
23,931 \\
0 \\
0 \\
23,931\end{array}$ & $\begin{array}{r}62,851 \\
1,346 \\
12,643 \\
51,554 \\
0 \\
0 \\
51,554\end{array}$ & $\begin{array}{r}12,113 \\
3,064 \\
8,031 \\
7,145 \\
0 \\
0 \\
7,145\end{array}$ & $\begin{array}{l}0 \\
0 \\
0 \\
0 \\
0 \\
0 \\
0\end{array}$ & $\begin{array}{r}17,415 \\
0 \\
0 \\
17,415 \\
0 \\
0 \\
17,415\end{array}$ & $\begin{array}{r}174,420 \\
37,870 \\
86,413 \\
125,877 \\
0 \\
0 \\
125,877\end{array}$ \\
\hline 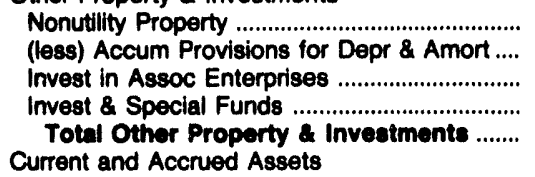 & $\begin{array}{l}0 \\
0 \\
0 \\
0 \\
0\end{array}$ & $\begin{array}{r}1,800 \\
710 \\
0 \\
16,709 \\
17,800\end{array}$ & $\begin{array}{r}0 \\
0 \\
0 \\
3,033 \\
3,033\end{array}$ & $\begin{array}{l}0 \\
0 \\
0 \\
0 \\
0\end{array}$ & $\begin{array}{l}0 \\
0 \\
0 \\
0 \\
0\end{array}$ & $\begin{array}{r}0 \\
0 \\
0 \\
26,387 \\
28,387\end{array}$ \\
\hline 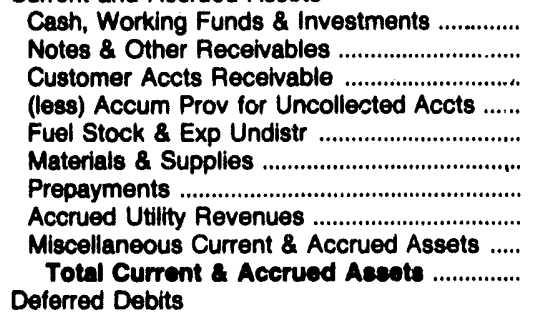 & $\begin{array}{r}24,510 \\
902 \\
1,826 \\
94 \\
0 \\
1,583 \\
34 \\
4,986 \\
0 \\
33,747\end{array}$ & $\begin{array}{r}9,375 \\
308 \\
11,780 \\
0 \\
379 \\
963 \\
181 \\
0 \\
427 \\
23,413\end{array}$ & $\begin{array}{r}1,654 \\
232 \\
601 \\
0 \\
0 \\
1,146 \\
23 \\
644 \\
0 \\
4,290\end{array}$ & $\begin{array}{l}0 \\
0 \\
0 \\
0 \\
0 \\
0 \\
0 \\
0 \\
0 \\
0\end{array}$ & $\begin{array}{r}2,065 \\
0 \\
624 \\
121 \\
0 \\
584 \\
9 \\
0 \\
2 \\
3,164\end{array}$ & $\begin{array}{r}9,246 \\
0 \\
7,337 \\
205 \\
0 \\
6,915 \\
115 \\
992 \\
293 \\
24,694\end{array}$ \\
\hline 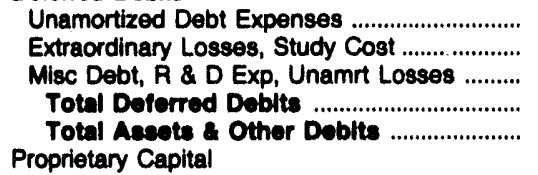 & $\begin{array}{r}0 \\
0 \\
0 \\
0 \\
57,678\end{array}$ & $\begin{array}{r}0 \\
0 \\
0 \\
0 \\
92,766\end{array}$ & $\begin{array}{r}0 \\
0 \\
0 \\
0 \\
14,477\end{array}$ & $\begin{array}{l}0 \\
0 \\
0 \\
0 \\
0\end{array}$ & $\begin{array}{r}0 \\
0 \\
0 \\
0 \\
20,579\end{array}$ & $\begin{array}{r}500 \\
0 \\
0 \\
500 \\
177,458\end{array}$ \\
\hline 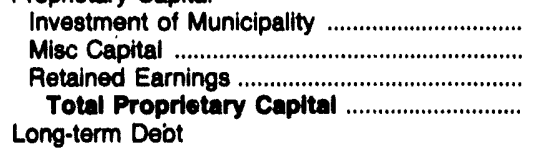 & $\begin{array}{r}74 \\
10 \\
50,955 \\
51,039\end{array}$ & $\begin{array}{r}566 \\
0 \\
2,366 \\
2,982\end{array}$ & $\begin{array}{r}0 \\
10,417 \\
1,697 \\
12,114\end{array}$ & $\begin{array}{l}0 \\
0 \\
0 \\
0\end{array}$ & $\begin{array}{r}17,999 \\
0 \\
1,892 \\
19,992\end{array}$ & $\begin{array}{r}28,636 \\
0 \\
65,336 \\
93,972\end{array}$ \\
\hline 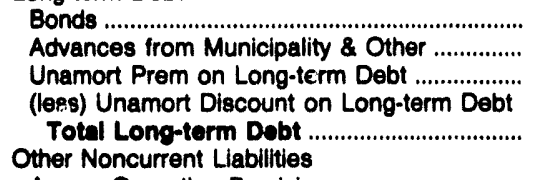 & $\begin{array}{r}200 \\
0 \\
0 \\
0 \\
200\end{array}$ & $\begin{array}{r}68,157 \\
0 \\
0 \\
0 \\
68,157\end{array}$ & $\begin{array}{l}0 \\
0 \\
0 \\
0 \\
0\end{array}$ & $\begin{array}{l}0 \\
0 \\
0 \\
0 \\
0\end{array}$ & $\begin{array}{l}0 \\
0 \\
0 \\
0 \\
0\end{array}$ & $\begin{array}{r}64,304 \\
0 \\
0 \\
0 \\
64,304\end{array}$ \\
\hline 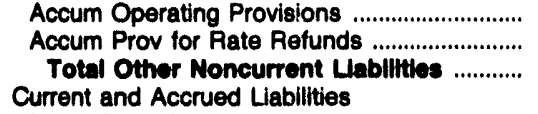 & $\begin{array}{l}0 \\
0 \\
0\end{array}$ & $\begin{array}{l}0 \\
0 \\
0\end{array}$ & $\begin{array}{l}0 \\
0 \\
0\end{array}$ & $\begin{array}{l}0 \\
0 \\
0\end{array}$ & $\begin{array}{r}413 \\
0 \\
413\end{array}$ & $\begin{array}{l}0 \\
0 \\
0\end{array}$ \\
\hline 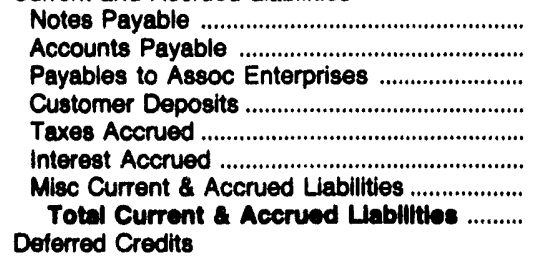 & $\begin{array}{r}0 \\
5,498 \\
0 \\
616 \\
0 \\
3 \\
322 \\
6,430\end{array}$ & $\begin{array}{r}0 \\
8,562 \\
1,553 \\
0 \\
4,677 \\
1,898 \\
2,408 \\
19,008\end{array}$ & $\begin{array}{r}595 \\
1,038 \\
0 \\
224 \\
0 \\
10 \\
324 \\
2,191\end{array}$ & $\begin{array}{l}0 \\
0 \\
0 \\
0 \\
0 \\
0 \\
0 \\
0\end{array}$ & $\begin{array}{r}0 \\
73 \\
0 \\
101 \\
0 \\
0 \\
0 \\
174\end{array}$ & $\begin{array}{r}7,545 \\
7,049 \\
0 \\
0 \\
0 \\
726 \\
3,862 \\
19,182\end{array}$ \\
\hline 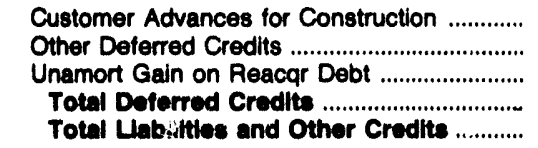 & $\begin{array}{r}0 \\
0 \\
0 \\
0 \\
57,678\end{array}$ & $\begin{array}{r}0 \\
2,579 \\
0 \\
2,579 \\
92,766\end{array}$ & $\begin{array}{r}0 \\
172 \\
0 \\
172 \\
14,477\end{array}$ & $\begin{array}{l}0 \\
0 \\
0 \\
0 \\
0\end{array}$ & $\begin{array}{r}0 \\
0 \\
0 \\
0 \\
20,579\end{array}$ & $\begin{array}{r}0 \\
0 \\
0 \\
0 \\
177,458\end{array}$ \\
\hline
\end{tabular}

Note: Totals may not equal sum of components because of independent rounding.

Source: Energy Information Administration, Form EIA-412, "Annual Report of Public Electric Utilities." 
Table 22. Balance Sheet by Major U.S. Publicly Owned Electric Utility Within State at End of Period, 1992 (Continued) (Thousand Dollars)

\begin{tabular}{|c|c|c|c|c|c|c|}
\hline Item & $\begin{array}{l}\text { Onio } \\
\text { Columbus } \\
\text { City of } \\
\text { December } 31\end{array}$ & $\begin{array}{c}\text { Ohio } \\
\text { Cuyahoga } \\
\text { Falls } \\
\text { City of } \\
\text { December } 31\end{array}$ & $\begin{array}{l}\text { Ohio } \\
\text { Dover } \\
\text { City of } \\
\text { December } 31\end{array}$ & $\begin{array}{c}\text { Onio } \\
\text { Hamilton } \\
\text { City of } \\
\text { December } 31\end{array}$ & $\begin{array}{c}\text { Ohio } \\
\text { Niles } \\
\text { City of } \\
\text { December } 31\end{array}$ & $\begin{array}{c}\text { Ohio } \\
\text { Orrville } \\
\text { City of } \\
\text { December } 31\end{array}$ \\
\hline \multicolumn{7}{|l|}{ Electric Utility Plant } \\
\hline 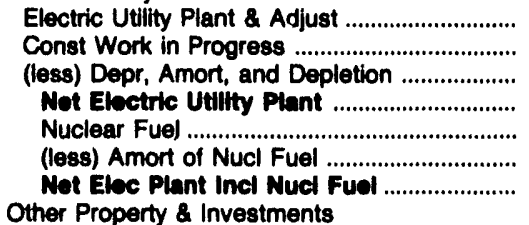 & $\begin{array}{r}276,378 \\
0 \\
100,798 \\
175,579 \\
0 \\
0 \\
175,579\end{array}$ & $\begin{array}{r}18,333 \\
419 \\
9,876 \\
8,877 \\
0 \\
0 \\
8,877\end{array}$ & $\begin{array}{r}10,094 \\
0 \\
0 \\
10,004 \\
0 \\
0 \\
10,094\end{array}$ & $\begin{array}{r}221,885 \\
0 \\
66,954 \\
154,931 \\
0 \\
0 \\
154,981\end{array}$ & $\begin{array}{r}11,993 \\
0 \\
6,586 \\
5,407 \\
0 \\
0 \\
5,407\end{array}$ & $\begin{array}{r}50,137 \\
120 \\
24,054 \\
26,202 \\
0 \\
0 \\
26,202\end{array}$ \\
\hline 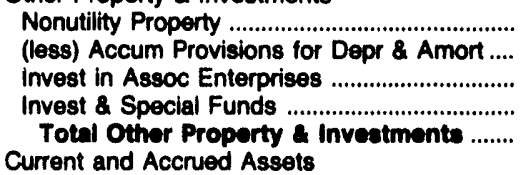 & $\begin{array}{r}0 \\
0 \\
0 \\
13,847 \\
13,847\end{array}$ & $\begin{array}{l}0 \\
0 \\
0 \\
0 \\
0\end{array}$ & $\begin{array}{r}0 \\
0 \\
0 \\
1,188 \\
1,188\end{array}$ & $\begin{array}{r}0 \\
0 \\
0 \\
42,147 \\
42,147\end{array}$ & $\begin{array}{l}0 \\
0 \\
0 \\
0 \\
0\end{array}$ & $\begin{array}{l}0 \\
0 \\
0 \\
0 \\
0\end{array}$ \\
\hline 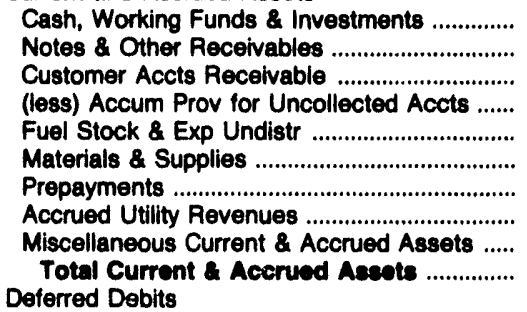 & $\begin{array}{r}837 \\
498 \\
4,573 \\
0 \\
0 \\
5,331 \\
0 \\
0 \\
0 \\
11,288\end{array}$ & $\begin{array}{r}7,176 \\
934 \\
2,211 \\
0 \\
0 \\
1,819 \\
45 \\
0 \\
0 \\
12,184\end{array}$ & $\begin{array}{r}1,046 \\
0 \\
1,343 \\
0 \\
0 \\
746 \\
50 \\
0 \\
11 \\
3,196\end{array}$ & $\begin{array}{r}3,506 \\
4,210 \\
0 \\
0 \\
0 \\
2,447 \\
0 \\
0 \\
6,354 \\
16,517\end{array}$ & $\begin{array}{r}5,265 \\
0 \\
2,133 \\
250 \\
0 \\
557 \\
0 \\
0 \\
164 \\
7,868\end{array}$ & $\begin{array}{r}6,073 \\
25 \\
1,885 \\
102 \\
0 \\
1,621 \\
31 \\
0 \\
160 \\
9,693\end{array}$ \\
\hline 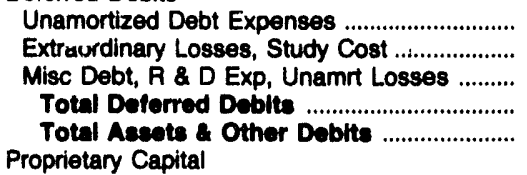 & $\begin{array}{r}0 \\
0 \\
666 \\
686 \\
201,330\end{array}$ & $\begin{array}{r}0 \\
0 \\
0 \\
0 \\
21,081\end{array}$ & $\begin{array}{r}0 \\
0 \\
0 \\
0 \\
14,477\end{array}$ & $\begin{array}{r}3,174 \\
0 \\
0 \\
3,174 \\
216,788\end{array}$ & $\begin{array}{r}0 \\
0 \\
420 \\
420 \\
13,695\end{array}$ & $\begin{array}{r}563 \\
0 \\
0 \\
563 \\
36,458\end{array}$ \\
\hline 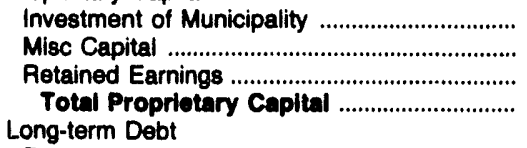 & $\begin{array}{r}18,833 \\
0 \\
-30,610 \\
-19,777\end{array}$ & $\begin{array}{r}0 \\
0 \\
15,237 \\
15,237\end{array}$ & $\begin{array}{r}0 \\
135 \\
6,544 \\
6,678\end{array}$ & $\begin{array}{r}0 \\
0 \\
-6,700 \\
-6,700\end{array}$ & $\begin{array}{r}0 \\
0 \\
9,956 \\
9,956\end{array}$ & $\begin{array}{r}0 \\
0 \\
16,076 \\
16,076\end{array}$ \\
\hline 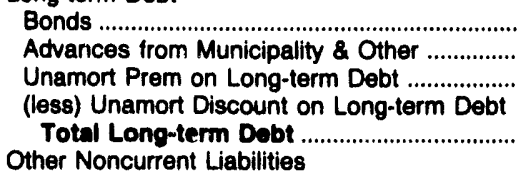 & $\begin{array}{r}210,827 \\
0 \\
0 \\
0 \\
210,827\end{array}$ & $\begin{array}{r}3,880 \\
0 \\
0 \\
0 \\
3,880\end{array}$ & $\begin{array}{r}1,600 \\
59 \\
0 \\
0 \\
1,659\end{array}$ & $\begin{array}{r}213,292 \\
0 \\
0 \\
0 \\
213,292\end{array}$ & $\begin{array}{r}2,570 \\
0 \\
0 \\
0 \\
2,570\end{array}$ & $\begin{array}{r}19,140 \\
0 \\
0 \\
0 \\
19,140\end{array}$ \\
\hline $\begin{array}{l}\text { Accum Operating Provisions } \\
\text { Accum Prov for Rate Refunds ........................... } \\
\text { Total Other Noncurrent Llabillties } \\
\text { Current and Accrued Liabilities }\end{array}$ & $\begin{array}{l}0 \\
0 \\
0\end{array}$ & $\begin{array}{l}0 \\
0 \\
0\end{array}$ & $\begin{array}{l}0 \\
0 \\
\mathbf{0}\end{array}$ & $\begin{array}{l}\mathbf{0} \\
\mathbf{0} \\
\mathbf{0}\end{array}$ & $\begin{array}{l}0 \\
0 \\
0\end{array}$ & $\begin{array}{l}0 \\
0 \\
0\end{array}$ \\
\hline 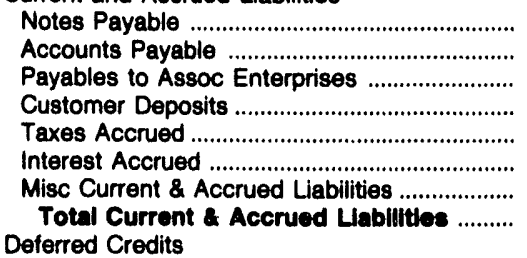 & $\begin{array}{r}0 \\
1,816 \\
475 \\
460 \\
0 \\
5,382 \\
2,062 \\
10,104\end{array}$ & $\begin{array}{r}0 \\
1,194 \\
153 \\
152 \\
0 \\
22 \\
423 \\
1,944\end{array}$ & $\begin{array}{r}5,250 \\
327 \\
0 \\
0 \\
0 \\
28 \\
535 \\
6,140\end{array}$ & $\begin{array}{r}2,505 \\
2,089 \\
0 \\
346 \\
0 \\
3,849 \\
1,388 \\
10,177\end{array}$ & $\begin{array}{r}0 \\
941 \\
0 \\
0 \\
0 \\
21 \\
206 \\
1,168\end{array}$ & $\begin{array}{r}0 \\
485 \\
0 \\
0 \\
0 \\
118 \\
639 \\
1,242\end{array}$ \\
\hline 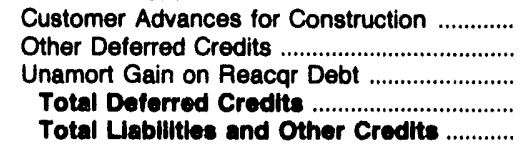 & $\begin{array}{r}0 \\
86 \\
0 \\
86 \\
201,330\end{array}$ & $\begin{array}{r}0 \\
0 \\
0 \\
0 \\
21,081\end{array}$ & $\begin{array}{r}0 \\
0 \\
0 \\
0 \\
14,477\end{array}$ & $\begin{array}{r}0 \\
0 \\
0 \\
0 \\
216,788\end{array}$ & $\begin{array}{r}0 \\
0 \\
0 \\
0 \\
13,695\end{array}$ & $\begin{array}{r}0 \\
0 \\
0 \\
0 \\
36,458\end{array}$ \\
\hline
\end{tabular}

Note: Totals may not equal sum of components because of independent rounding.

Source: Energy Intormation Administration, Form ElA-412, "Annual Report of Public Electric Utilities." 
Table 22. Balance Sheet by Major U.S. Publlcly Owned Electric Utility Within State at End of Period, 1992 (Continued) (Thousand Dollars)

\begin{tabular}{|c|c|c|c|c|c|c|}
\hline Item & $\begin{array}{c}\text { Ohio } \\
\text { Painesville } \\
\text { City of } \\
\text { December } 31\end{array}$ & $\begin{array}{c}\text { Ohio } \\
\text { Piqua } \\
\text { City of } \\
\text { December } 31\end{array}$ & $\begin{array}{c}\text { Ohio } \\
\text { St Marys } \\
\text { City of } \\
\text { December } 31\end{array}$ & $\begin{array}{c}\text { Onio } \\
\text { Wadsworth } \\
\text { City of } \\
\text { Deceniber } 31\end{array}$ & $\begin{array}{c}\text { Ohio } \\
\text { Wapakoneta } \\
\text { City of } \\
\text { December } 31\end{array}$ & $\begin{array}{c}\text { Ohio } \\
\text { Westerville } \\
\text { City of } \\
\text { December } 31\end{array}$ \\
\hline 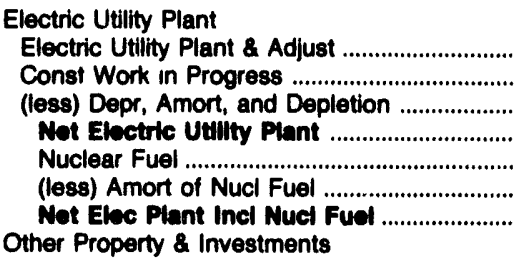 & $\begin{array}{r}35,777 \\
2,159 \\
20,542 \\
17,305 \\
0 \\
0 \\
17,305\end{array}$ & $\begin{array}{r}41,606 \\
692 \\
18,523 \\
28,775 \\
0 \\
0 \\
28,775\end{array}$ & $\begin{array}{r}13,789 \\
1,314 \\
9,941 \\
5,161 \\
0 \\
0 \\
5,161\end{array}$ & $\begin{array}{r}9,630 \\
0 \\
5,909 \\
3,720 \\
0 \\
0 \\
3,720\end{array}$ & $\begin{array}{l}0 \\
0 \\
0 \\
0 \\
0 \\
0 \\
0\end{array}$ & $\begin{array}{r}9,786 \\
0 \\
4,907 \\
4,879 \\
0 \\
0 \\
4,879\end{array}$ \\
\hline $\begin{array}{l}\text { Nonutility Property ..................................... } \\
\text { (less) Accum Provisions for Depr \& Amort .... } \\
\text { Invest in Assoc Enterprises ............................ } \\
\text { Invest \& Special Funds ................................. } \\
\text { Total Other Property \& Investments ....... } \\
\text { Current and Accrued Assets }\end{array}$ & $\begin{array}{r}0 \\
0 \\
0 \\
5,836 \\
5,836\end{array}$ & $\begin{array}{r}0 \\
0 \\
0 \\
1,018 \\
1,018\end{array}$ & $\begin{array}{r}0 \\
0 \\
0 \\
1,909 \\
1,900\end{array}$ & $\begin{array}{l}0 \\
0 \\
0 \\
0 \\
0\end{array}$ & $\begin{array}{l}0 \\
0 \\
0 \\
0 \\
0\end{array}$ & $\begin{array}{l}0 \\
0 \\
0 \\
0 \\
0\end{array}$ \\
\hline 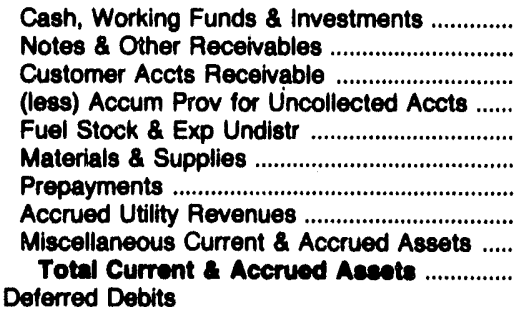 & $\begin{array}{r}115 \\
31 \\
1,428 \\
0 \\
0 \\
573 \\
26 \\
0 \\
0 \\
2,172\end{array}$ & $\begin{array}{r}671 \\
4 \\
971 \\
57 \\
0 \\
532 \\
194 \\
626 \\
151 \\
3,002\end{array}$ & $\begin{array}{r}2,516 \\
0 \\
327 \\
0 \\
0 \\
193 \\
55 \\
9 \\
0 \\
3,100\end{array}$ & $\begin{array}{r}3,250 \\
0 \\
901 \\
0 \\
0 \\
300 \\
0 \\
0 \\
0 \\
4,452\end{array}$ & $\begin{array}{r}2,828 \\
0 \\
0 \\
0 \\
0 \\
0 \\
0 \\
0 \\
0 \\
2,828\end{array}$ & $\begin{array}{r}21,438 \\
0 \\
1,665 \\
71 \\
0 \\
1,190 \\
0 \\
1,166 \\
0 \\
25,380\end{array}$ \\
\hline 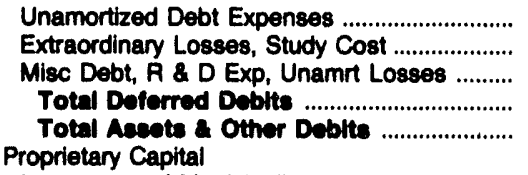 & $\begin{array}{r}0 \\
0 \\
0 \\
0 \\
25,402\end{array}$ & $\begin{array}{r}0 \\
0 \\
0 \\
0 \\
27,885\end{array}$ & $\begin{array}{r}205 \\
0 \\
0 \\
205 \\
10,375\end{array}$ & $\begin{array}{r}0 \\
0 \\
0 \\
0 \\
8,172\end{array}$ & $\begin{array}{r}0 \\
0 \\
0 \\
0 \\
2,828\end{array}$ & $\begin{array}{r}0 \\
0 \\
0 \\
0 \\
30,260\end{array}$ \\
\hline 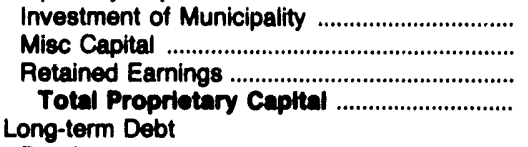 & $\begin{array}{r}57 \\
0 \\
16,366 \\
16,423\end{array}$ & $\begin{array}{r}0 \\
0 \\
16,408 \\
16,408\end{array}$ & $\begin{array}{r}0 \\
0 \\
4,153 \\
4,163\end{array}$ & $\begin{array}{r}0 \\
0 \\
6,894 \\
6,894\end{array}$ & $\begin{array}{r}388 \\
0 \\
2,440 \\
2,828\end{array}$ & $\begin{array}{r}0 \\
27 \\
28,695 \\
28,722\end{array}$ \\
\hline 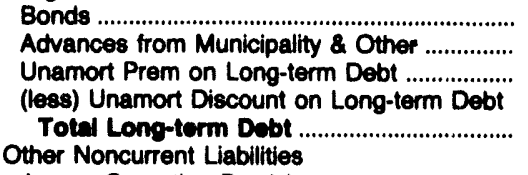 & $\begin{array}{r}6,945 \\
0 \\
0 \\
0 \\
6,945\end{array}$ & $\begin{array}{r}10,152 \\
0 \\
0 \\
0 \\
10,152\end{array}$ & $\begin{array}{r}5,510 \\
0 \\
0 \\
0 \\
5,510\end{array}$ & $\begin{array}{l}0 \\
0 \\
0 \\
0 \\
0\end{array}$ & $\begin{array}{l}0 \\
0 \\
0 \\
0 \\
0\end{array}$ & $\begin{array}{l}0 \\
0 \\
0 \\
0 \\
0\end{array}$ \\
\hline $\begin{array}{l}\text { Accum Operating Provisions } \\
\text { Accum Prov for Rate Refunds ............................................. } \\
\text { Total Other Moncurrent Labilities ........... } \\
\text { Current and Accrued Liabilities }\end{array}$ & $\begin{array}{r}487 \\
0 \\
487\end{array}$ & $\begin{array}{r}278 \\
0 \\
278\end{array}$ & $\begin{array}{l}0 \\
0 \\
0\end{array}$ & $\begin{array}{l}0 \\
0 \\
0\end{array}$ & $\begin{array}{l}0 \\
0 \\
0\end{array}$ & $\begin{array}{r}258 \\
0 \\
258\end{array}$ \\
\hline 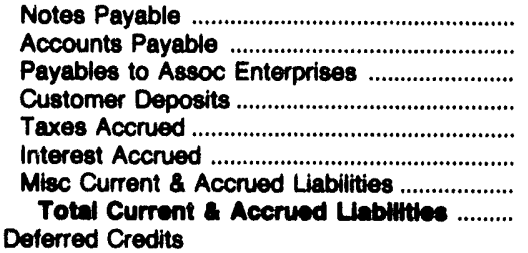 & $\begin{array}{r}0 \\
918 \\
0 \\
244 \\
0 \\
0 \\
385 \\
1,547\end{array}$ & $\begin{array}{r}0 \\
698 \\
0 \\
0 \\
0 \\
0 \\
348 \\
1,046\end{array}$ & $\begin{array}{r}0 \\
290 \\
86 \\
202 \\
0 \\
31 \\
103 \\
712\end{array}$ & $\begin{array}{r}170 \\
608 \\
0 \\
0 \\
0 \\
0 \\
500 \\
1,278\end{array}$ & $\begin{array}{l}0 \\
0 \\
0 \\
0 \\
0 \\
0 \\
0 \\
0\end{array}$ & $\begin{array}{r}250 \\
914 \\
0 \\
57 \\
0 \\
5 \\
43 \\
1,280\end{array}$ \\
\hline $\begin{array}{l}\text { Customer Advances for Construction ............ } \\
\text { Other Deferred Credits ................................... } \\
\text { Unamort Gain on Reacqr Debt ...................... } \\
\text { Total Deferred Credits ................................ } \\
\text { Total Uabillties and Other Crodits ............ }\end{array}$ & $\begin{array}{r}0 \\
0 \\
0 \\
0 \\
26,402\end{array}$ & $\begin{array}{r}0 \\
0 \\
0 \\
0 \\
27,285\end{array}$ & $\begin{array}{r}0 \\
0 \\
0 \\
0 \\
10,375\end{array}$ & $\begin{array}{r}0 \\
0 \\
0 \\
0 \\
\mathbf{9}, 172\end{array}$ & $\begin{array}{r}0 \\
0 \\
0 \\
0 \\
2,828\end{array}$ & $\begin{array}{r}0 \\
20 \\
0 \\
20 \\
30,260\end{array}$ \\
\hline
\end{tabular}

Note: Totals may not equal sum of components because of independent rounding.

Source: Energy Information Administration, Form ElA-412, "Annual Report of Public Electric Utilities." 
Table 22. Balance Sheet by Major U.S. Publicly Owned Electric Utility Within State at End of Perlod, 1992 (Continued) (Thousand Dollars)

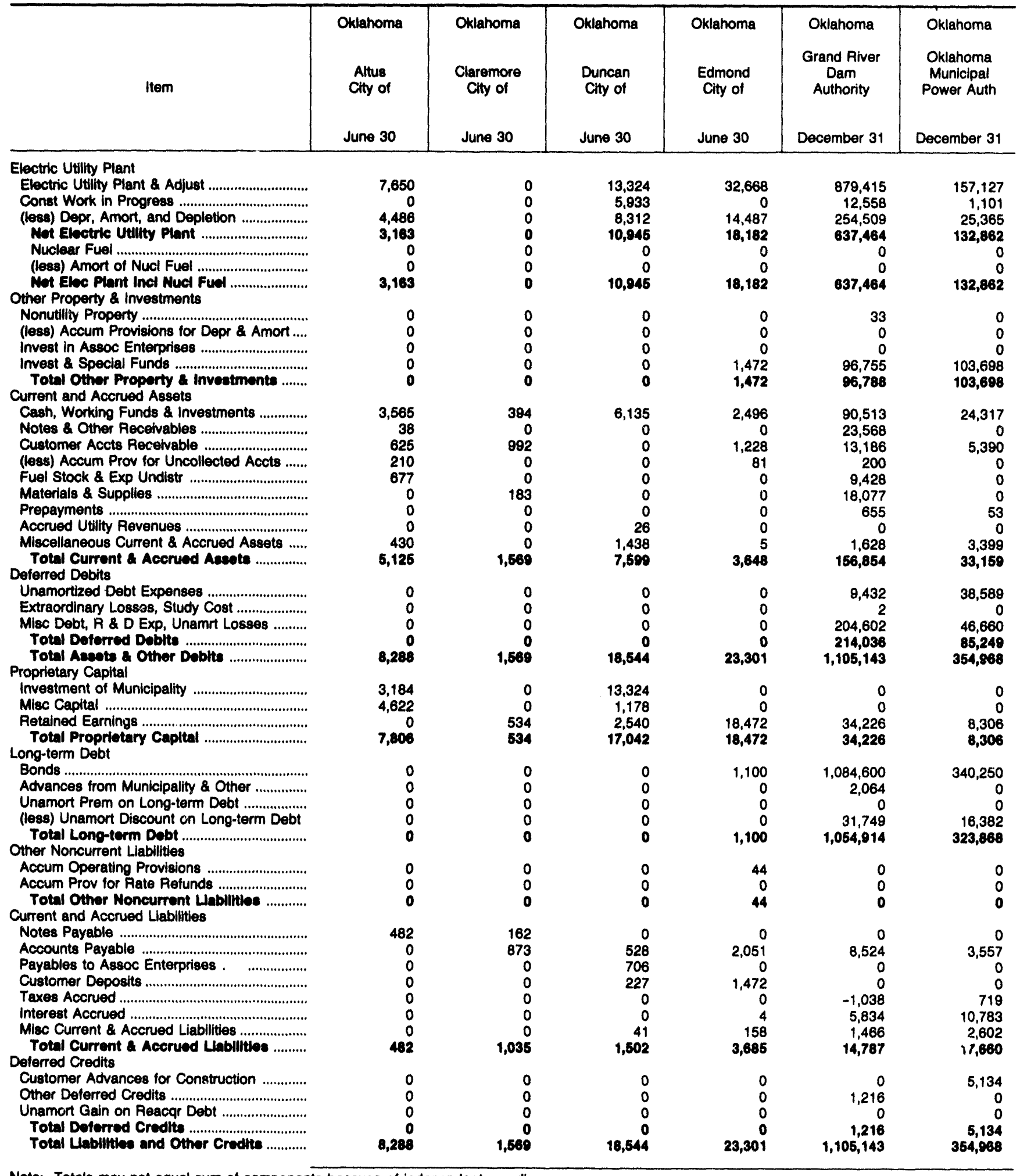

Note: Totals may not equal sum of components because of independent rounding.

Source: Energy information Administration, Form ElA-412, "Annual Report of Public Electric Utilities." 
Table 22. Balance Sheet by Major U.S. Publicly Owned Electric Utility Within State at End of Period, 1992 (Continued) (Thousand Dollars)

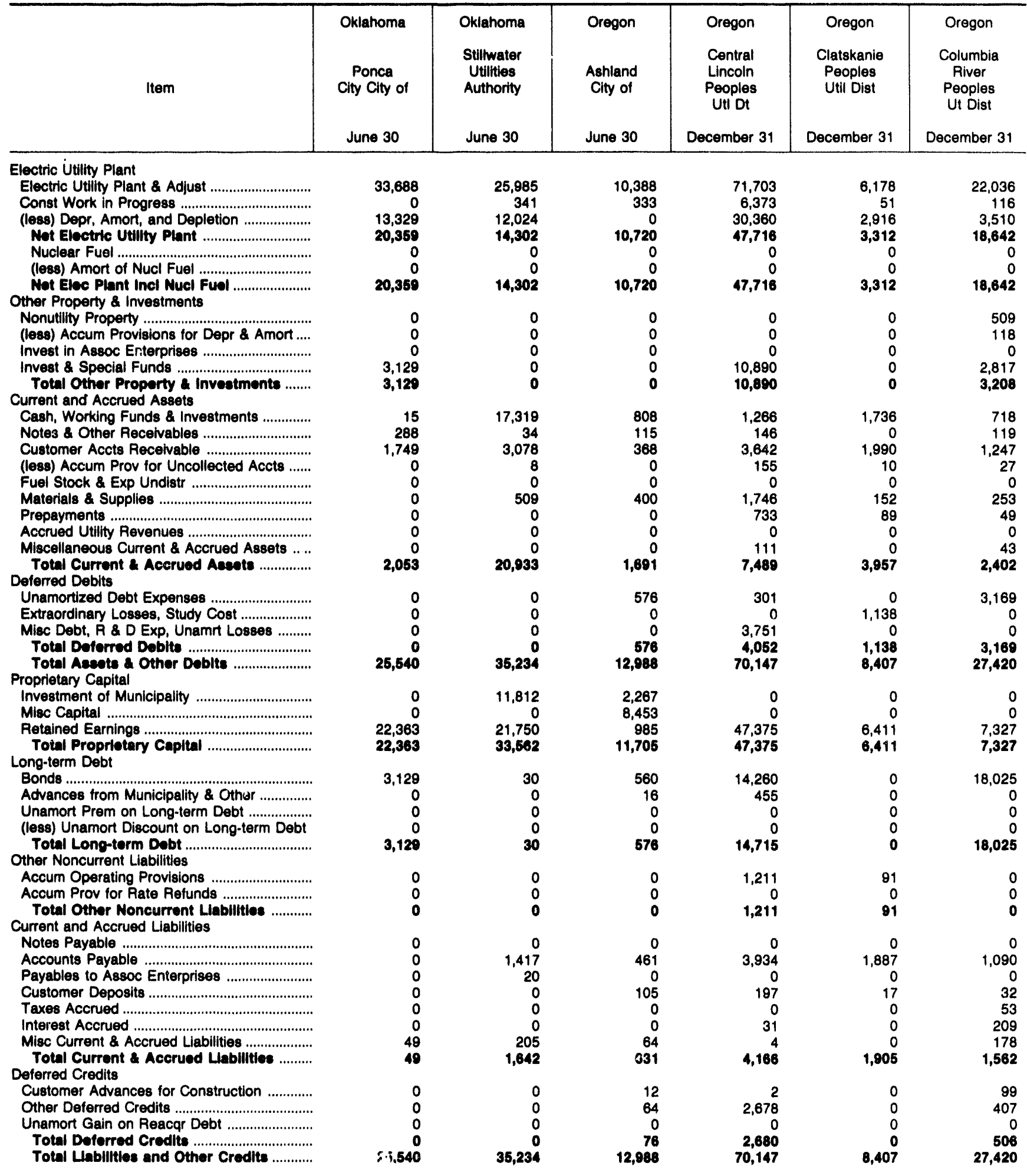

Note: Totals may not equal sum of componente because of independent rounding.

Source: Energy Information Administration, Form EIA-412, "Annual Report of Public Electric Utilities." 
Table 22. Balance Sheet by Major U.S. Publlcly Owned Electric Utillty Within State at End of Period, 1992 (Continued) (Thousand Dollars)

\begin{tabular}{|c|c|c|c|c|c|c|}
\hline Item & $\begin{array}{c}\text { Oregon } \\
\text { Emerald } \\
\text { Peoples } \\
\text { Utility Dist } \\
\text { December } 31\end{array}$ & $\begin{array}{l}\text { Oregon } \\
\text { Eugene } \\
\text { City of } \\
\text { December } 31\end{array}$ & $\begin{array}{l}\text { Oregon } \\
\text { Forest Grove } \\
\text { City of } \\
\text { June } 30\end{array}$ & $\begin{array}{l}\text { Oregon } \\
\begin{array}{l}\text { McMinnville } \\
\text { City of }\end{array} \\
\text { June } 30\end{array}$ & $\begin{array}{c}\text { Oregon } \\
\text { Northern } \\
\text { Wasco County } \\
\text { PU D } \\
\text { December } 31\end{array}$ & $\begin{array}{c}\text { Oregon } \\
\text { Springtield } \\
\text { City of } \\
\text { December } 31\end{array}$ \\
\hline \multicolumn{7}{|l|}{ Electric Utility Plant } \\
\hline Electric Utility Plant \& Adjust ....... & 66,070 & 234,997 & 10,381 & 19,789 & 30,365 & 39,915 \\
\hline Const Work in Progress & 2,219 & 3,876 & & 160 & & \\
\hline (less) Depr, Amort, and Depletion ........................ & 22,432 & 106,907 & 3,308 & 4,732 & 7,079 & 11,122 \\
\hline $\begin{array}{l}\text { Not Eloctric Utility Plant ................................... } \\
\text { Nuclear Fuel . }\end{array}$ & $\begin{array}{r}45,857 \\
0\end{array}$ & $\begin{array}{r}131,966 \\
0\end{array}$ & $\begin{array}{r}7,318 \\
0\end{array}$ & 15,216 & 23,296 & 29,387 \\
\hline $\begin{array}{l}\text { Nuclear Fuel } \\
\text { (less) Amort of Nucl Fuel ... }\end{array}$ & $\begin{array}{l}0 \\
0\end{array}$ & $\begin{array}{l}0 \\
0\end{array}$ & 0 & $\begin{array}{l}0 \\
0\end{array}$ & $\begin{array}{l}0 \\
0\end{array}$ & $\begin{array}{l}0 \\
0\end{array}$ \\
\hline Not Eloc Plant Inct Nuct Fuel .......................... & 45,857 & 131,968 & 7,318 & 15,216 & 23,296 & 29,367 \\
\hline \multicolumn{7}{|l|}{ Other Property \& investments } \\
\hline Nonutility Property ..................................... & 0 & 0 & 0 & 0 & 0 & 0 \\
\hline $\begin{array}{l}\text { (less) Accum Provisions for Depr \& Amort.... } \\
\text { Invest in Assoc Enterprises }\end{array}$ & $\begin{array}{l}0 \\
0\end{array}$ & $\begin{array}{l}0 \\
0\end{array}$ & $\begin{array}{l}0 \\
0\end{array}$ & $\begin{array}{l}0 \\
0\end{array}$ & $\begin{array}{l}0 \\
0\end{array}$ & 0 \\
\hline 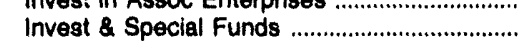 & 5,852 & 9,623 & 0 & 0 & 2,373 & 4,615 \\
\hline \multicolumn{7}{|l|}{ Current and Accrued Assets } \\
\hline Cash, Working Funds \& Investments .............. & 3,579 & 9,270 & 895 & 3,252 & 4,196 & 3,437 \\
\hline Notes \& Other Receivabies .................................. & 860 & 10,356 & 4 & 354 & 38 & 603 \\
\hline 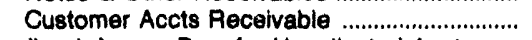 & 1,525 & 5,015 & 355 & 1,102 & 1,055 & 2,927 \\
\hline (less) Accum Prov for Uncollected Accts ...... & 35 & 217 & 117 & 10 & 93 & 44 \\
\hline Fuel Stock \& Exp Undistr ................................. & 0 & 0 & 0 & 0 & 0 & \\
\hline Materials \& Supplies .................................. & 328 & 2,846 & 228 & 230 & 243 & 1,144 \\
\hline 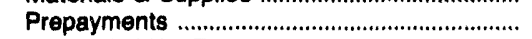 & 286 & 519 & 0 & 0 & 146 & 0 \\
\hline Accrued Utility Revenues ......................................... & 853 & 0 & 0 & 0 & 0 & \\
\hline Miscellaneous Current \& Accrued Assets ..... & & 6,598 & 108 & 0 & 0 & 66 \\
\hline \multicolumn{7}{|l|}{ Deferred Debits } \\
\hline Unamortized Debt Expenses .................................. & 1,282 & 307 & 0 & 0 & 632 & 127 \\
\hline Extraordinary Losses, Study Cost ...................... & 27 & 1,987 & 0 & 0 & 1,340 & \\
\hline Misc Debt, A \& D Exp, Unamrt Losses .......... & 9,997 & 16,360 & 0 & 617 & 0 & 800 \\
\hline Total Doforred Debits ............................... & 11,306 & 18,653 & & 617 & 1,972 & $\mathbf{9 2 7}$ \\
\hline \multirow{2}{*}{\multicolumn{7}{|c|}{ Proprietary Capital }} \\
\hline & & & & & & \\
\hline $\begin{array}{l}\text { Investment of Municipality } \\
\text { Misc Capital }\end{array}$ & $\begin{array}{l}0 \\
0\end{array}$ & $\begin{array}{l}0 \\
0\end{array}$ & $\begin{array}{r}8,294 \\
0\end{array}$ & $\begin{array}{r}440 \\
2.201\end{array}$ & $\begin{array}{l}76 \\
90\end{array}$ & $\begin{array}{r}0 \\
1.813\end{array}$ \\
\hline 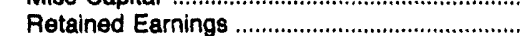 & $-1,363$ & 128,769 & 236 & $\begin{array}{r}2,2014 \\
15,214\end{array}$ & 9,674 & 28,529 \\
\hline 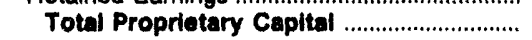 & $-1,363$ & 128,769 & 8,530 & 17,855 & 9,840 & 30,341 \\
\hline \multirow{2}{*}{\multicolumn{7}{|c|}{ Long-term Debt }} \\
\hline & 68,570 & 43,607 & 0 & 0 & 21,232 & 5,147 \\
\hline Advances from Municipality \& Other ............... & 189 & & 0 & 617 & 0 & \\
\hline Unamort Prem on Long-term Debt ...................... & 0 & 0 & 0 & 0 & 0 & \\
\hline (less) Unamort Discount on Long-term Debt & 902 & 345 & 0 & 0 & 0 & $\sigma$ \\
\hline \multirow{2}{*}{\multicolumn{7}{|c|}{ Other Noncurrent Liabilities }} \\
\hline & & & & & & \\
\hline Accum Operating Provisions .............................. & 0 & 0 & 0 & 0 & 0 & 0 \\
\hline Accum Prov for Rate Refunds ......................... & 0 & 0 & 0 & 0 & 0 & 0 \\
\hline Total Other Noncurrent Llabillties ............... & 0 & $\mathbf{0}$ & 0 & 0 & 0 & 0 \\
\hline \multicolumn{7}{|l|}{ Current and Accrued Liabilities } \\
\hline Notes Payable ............................ & 0 & 0 & 97 & 0 & 0 & \\
\hline Accounts Payable & 1,139 & 7,711 & 0 & 2,063 & 868 & 5,567 \\
\hline Payables to Assoc Enterprises ..................... & 0 & 0 & 0 & 0 & 0 & \\
\hline Customer Deposits ............................................... & 9 & 183 & 0 & 17 & 60 & 429 \\
\hline 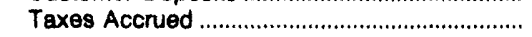 & 6 & 647 & 0 & 0 & 0 & 13 \\
\hline 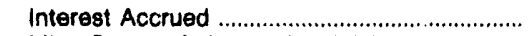 & 722 & 2,233 & 0 & 0 & 612 & 166 \\
\hline Misc Current \& Accrued Liabilities ....................... & 2,139 & 8,378 & 0 & 209 & 281 & 576 \\
\hline Total Current \& Accrued Llabilities .......... & 4,016 & 19,152 & 97 & 2,290 & 1,821 & 6,751 \\
\hline \multicolumn{7}{|l|}{ Deferred Credits } \\
\hline Customer Advances for Construction ................ & 0 & 61 & 123 & 0 & 30 & 52 \\
\hline Other Deferred Credits .................................... & 2 & 774 & 41 & 0 & 304 & 750 \\
\hline Unamort Gain on Reacqr Debt ...................... & 0 & 2,612 & 0 & 0 & 0 & 0 \\
\hline Total Doferred Credits ............................... & & 3,447 & 165 & & 333 & 802 \\
\hline Total Liabilities and Other Credits ............ & 70,512 & 184,631 & 8,792 & 20,761 & 33,227 & 43,042 \\
\hline
\end{tabular}

Note: Totals may not equal sum of components because of independent rounding

Source: Energy Information Administration, Form EIA-412, "Annual Report of Public Electric Utilities." 
Table 22. Balance Sheet by Major U.S. Publicly Owned Electric Utility Within State at End of Perlod, 1992 (Continued) (Thousand Dollars)

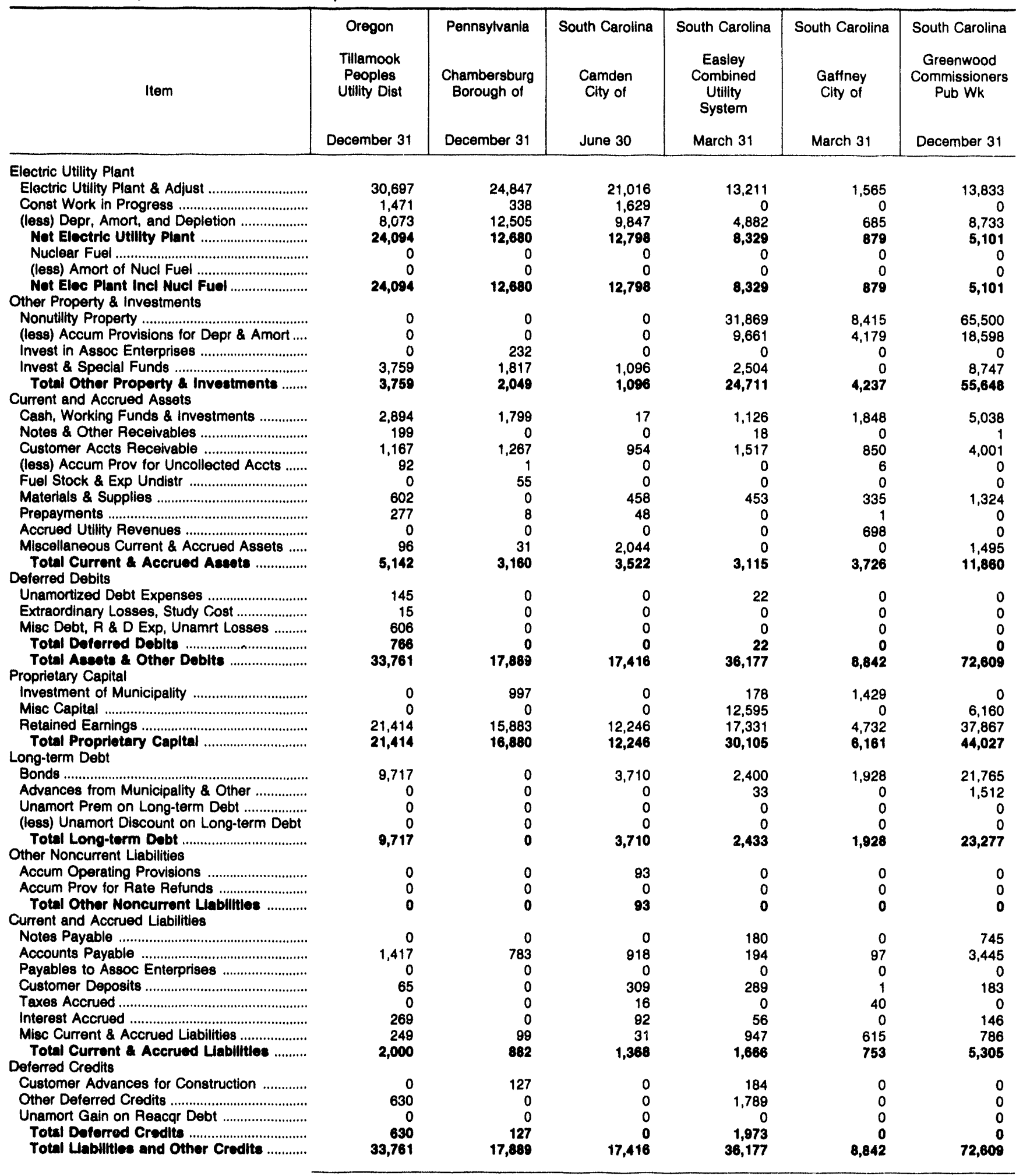

Note: Totals may not equal sum of components because of independent rounding.

Source: Energy Information Administration, Form EIA-412, "Annual Repori of Public Electric Utilities." 
Table 22. Balance Sheet by Major U.S. Publicly Owned Electrlc Utillty Within State at End of Period, 1992 (Continued) (Thousand Dollars)

\begin{tabular}{|c|c|c|c|c|c|c|}
\hline Item & $\begin{array}{c}\text { South Carolina } \\
\text { Greer } \\
\text { Comm } \\
\text { of } \\
\text { Public Works } \\
\text { December } 31\end{array}$ & $\begin{array}{l}\text { South Carolina } \\
\text { Newberry } \\
\text { City of } \\
\text { June } 30\end{array}$ & $\begin{array}{l}\text { South Carolina } \\
\text { Orangeburg } \\
\text { City of }\end{array}$ & $\begin{array}{l}\text { South Carolina } \\
\text { Piedmont } \\
\text { Municipal } \\
\text { Power Agny } \\
\text { December } 31\end{array}$ & $\begin{array}{l}\text { South Carolina } \\
\text { Rock Hill } \\
\text { City of } \\
\text { December } 31\end{array}$ & $\begin{array}{c}\text { South Carolina } \\
\text { South } \\
\text { Carolina } \\
\text { Pub } \\
\text { Serv Auth } \\
\text { December } 31\end{array}$ \\
\hline 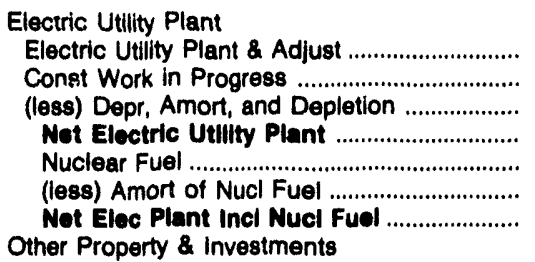 & $\begin{array}{r}68,721 \\
205 \\
18,764 \\
50,162 \\
0 \\
0 \\
50,162\end{array}$ & $\begin{array}{r}7,425 \\
0 \\
3,801 \\
3,624 \\
0 \\
0 \\
3,624\end{array}$ & $\begin{array}{r}44,246 \\
1,159 \\
10,479 \\
34,027 \\
0 \\
0 \\
34,927\end{array}$ & $\begin{array}{r}546,493 \\
3,952 \\
123,540 \\
426,805 \\
39,318 \\
18,480 \\
447,743\end{array}$ & $\begin{array}{r}28,138 \\
1,065 \\
10,326 \\
18,876 \\
0 \\
0 \\
18,876\end{array}$ & $\begin{array}{r}2,475,764 \\
267,411 \\
746,749 \\
1,996,426 \\
19,100 \\
0 \\
2,015,526\end{array}$ \\
\hline $\begin{array}{l}\text { Nonutility Property } \\
\text { (less) Accum Provisions for Depr \& Amort .... } \\
\text { Invest in Assoc Enterprises .......................... } \\
\text { Invest \& Special Funds ................................... } \\
\text { Total Other Property \& Investments ....... } \\
\text { Current and Accrued Assets }\end{array}$ & $\begin{array}{r}0 \\
0 \\
0 \\
4,809 \\
4,800\end{array}$ & $\begin{array}{r}23,357 \\
8,350 \\
0 \\
5,650 \\
20,657\end{array}$ & $\begin{array}{r}0 \\
0 \\
0 \\
15,442 \\
15,442\end{array}$ & $\begin{array}{r}0 \\
0 \\
0 \\
171,839 \\
171,839\end{array}$ & $\begin{array}{r}104,357 \\
19,064 \\
0 \\
0 \\
85,293\end{array}$ & $\begin{array}{r}1,694 \\
197 \\
0 \\
607,112 \\
608,609\end{array}$ \\
\hline 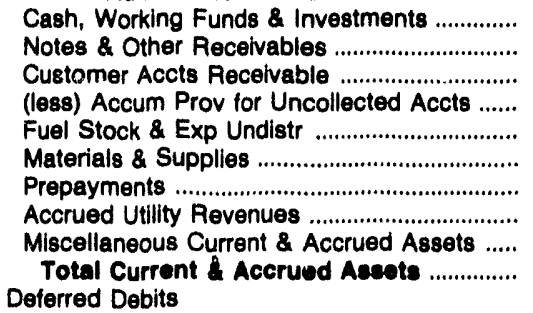 & $\begin{array}{r}1,401 \\
152 \\
939 \\
0 \\
0 \\
621 \\
0 \\
0 \\
0 \\
3,112\end{array}$ & $\begin{array}{r}1,669 \\
15 \\
878 \\
139 \\
0 \\
612 \\
0 \\
0 \\
121 \\
3,157\end{array}$ & $\begin{array}{r}826 \\
0 \\
1,564 \\
20 \\
93 \\
2,756 \\
241 \\
27 \\
51,801 \\
57,288\end{array}$ & $\begin{array}{r}284,617 \\
3,308 \\
5,482 \\
0 \\
0 \\
2,603 \\
8 \\
0 \\
19,840 \\
316,858\end{array}$ & $\begin{array}{r}4,513 \\
2,597 \\
6,476 \\
0 \\
0 \\
1,117 \\
0 \\
0 \\
0 \\
14,703\end{array}$ & $\begin{array}{r}145,741 \\
0 \\
51,858 \\
1,570 \\
46,506 \\
30,600 \\
986 \\
0 \\
3,329 \\
277,450\end{array}$ \\
\hline 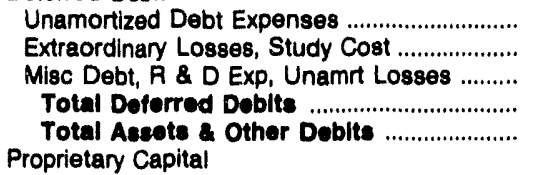 & $\begin{array}{r}0 \\
0 \\
0 \\
0 \\
58,083\end{array}$ & $\begin{array}{r}0 \\
0 \\
0 \\
0 \\
27,438\end{array}$ & $\begin{array}{r}0 \\
0 \\
0 \\
0 \\
107,657\end{array}$ & $\begin{array}{r}23,547 \\
0 \\
377,000 \\
400,547 \\
1,335,987\end{array}$ & $\begin{array}{r}2,636 \\
0 \\
0 \\
2,636 \\
121,608\end{array}$ & $\begin{array}{r}21,518 \\
0 \\
592,358 \\
613,876 \\
3,515,461\end{array}$ \\
\hline 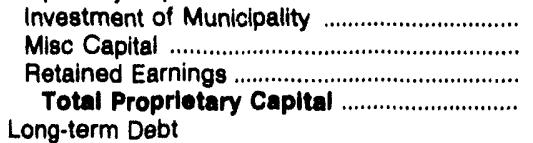 & $\begin{array}{r}0 \\
10,124 \\
45,654 \\
56,778\end{array}$ & $\begin{array}{r}0 \\
320 \\
14,960 \\
15,280\end{array}$ & $\begin{array}{r}0 \\
0 \\
94,137 \\
94,137\end{array}$ & $\begin{array}{r}0 \\
0 \\
12,181 \\
12,181\end{array}$ & $\begin{array}{r}0 \\
37,346 \\
24,492 \\
61,837\end{array}$ & $\begin{array}{r}34,438 \\
0 \\
590,098 \\
624,536\end{array}$ \\
\hline $\begin{array}{l}\text { Bdvances from Municipality \& Other ............. } \\
\text { Unamort Prem on Long-term Debt ................ } \\
\text { (less) Unamort Discount on Long-term Debt } \\
\text { Total Long-term Debt ............................. } \\
\text { Other Noncurrent Llabilities }\end{array}$ & $\begin{array}{l}0 \\
0 \\
0 \\
0 \\
0\end{array}$ & $\begin{array}{r}10,895 \\
0 \\
0 \\
0 \\
10,995\end{array}$ & $\begin{array}{r}7,800 \\
595 \\
0 \\
0 \\
8,395\end{array}$ & $\begin{array}{r}1,358,701 \\
0 \\
0 \\
93,425 \\
1,265,276\end{array}$ & $\begin{array}{r}55,020 \\
0 \\
0 \\
0 \\
55,020\end{array}$ & $\begin{array}{r}2,439,869 \\
55,820 \\
0 \\
42,537 \\
2,453,152\end{array}$ \\
\hline $\begin{array}{l}\text { Accum Operating Provisions } \\
\text { Accum Prov for Rate Refunds ........................... } \\
\text { Total Other Noncurrent Llablities .......... } \\
\text { Current and Accrued Liabilities }\end{array}$ & $\begin{array}{l}0 \\
0 \\
0\end{array}$ & $\begin{array}{l}0 \\
0 \\
0\end{array}$ & $\begin{array}{r}461 \\
0 \\
461\end{array}$ & $\begin{array}{r}8,168 \\
0 \\
8,168\end{array}$ & $\begin{array}{l}0 \\
0 \\
0\end{array}$ & $\begin{array}{l}0 \\
0 \\
0\end{array}$ \\
\hline 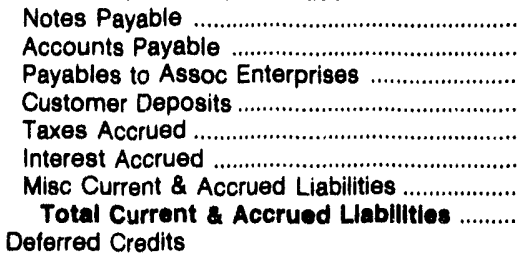 & $\begin{array}{r}0 \\
2,112 \\
0 \\
193 \\
0 \\
0 \\
0 \\
2,305\end{array}$ & $\begin{array}{r}0 \\
894 \\
0 \\
0 \\
0 \\
194 \\
76 \\
1,164\end{array}$ & $\begin{array}{r}0 \\
3,111 \\
0 \\
722 \\
0 \\
0 \\
831 \\
4,664\end{array}$ & $\begin{array}{r}0 \\
4,778 \\
0 \\
0 \\
0 \\
45,584 \\
0 \\
50,362\end{array}$ & $\begin{array}{r}0 \\
2,324 \\
0 \\
1,146 \\
0 \\
95 \\
1,085 \\
4,650\end{array}$ & $\begin{array}{r}245,545 \\
53,705 \\
0 \\
5,463 \\
1,816 \\
80,506 \\
46,264 \\
433,299\end{array}$ \\
\hline 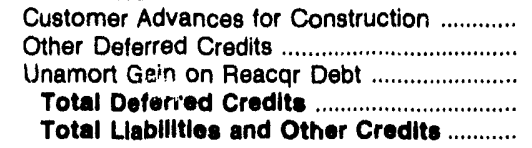 & $\begin{array}{r}0 \\
0 \\
0 \\
0 \\
58,083\end{array}$ & $\begin{array}{r}0 \\
0 \\
0 \\
0 \\
27,438\end{array}$ & $\begin{array}{r}0 \\
0 \\
0 \\
0 \\
107,657\end{array}$ & $\begin{array}{r}0 \\
0 \\
0 \\
0 \\
1,335,987\end{array}$ & $\begin{array}{r}0 \\
0 \\
0 \\
0 \\
121,508\end{array}$ & $\begin{array}{r}0 \\
3,908 \\
566 \\
\mathbf{4 , 4 7 4} \\
\mathbf{3 , 5 1 5 , 4 6 1}\end{array}$ \\
\hline
\end{tabular}

Note: Totals may not equal sum of components because of independent rounding.

Source: Energy Information Administration, Form ElA-412, "Annual Report of Public Electric Utilities." 
Table 22. Balance Sheet by Major U.S. Publicly Owned Electric Utility Within State at End of Period, 1992 (Continued) (Thousand Dollars)

\begin{tabular}{|c|c|c|c|c|c|c|}
\hline Item & $\begin{array}{l}\text { South Dakota } \\
\text { Brookings } \\
\text { City of } \\
\text { December } 31\end{array}$ & $\begin{array}{l}\text { South Dakota } \\
\text { Heartland } \\
\text { Consumers } \\
\text { Power Dist } \\
\text { December } 31\end{array}$ & $\begin{array}{l}\text { South Dakota } \\
\text { Missouri } \\
\text { Basin } \\
\text { Mun } \\
\text { Power Agny } \\
\text { December } 31\end{array}$ & $\begin{array}{c}\text { South Dakota } \\
\text { Pierre } \\
\text { City of } \\
\text { December } 31\end{array}$ & $\begin{array}{c}\text { South Dakota } \\
\text { Watertown } \\
\text { Municipal } \\
\text { Utilities } \\
\text { December } 31\end{array}$ & $\begin{array}{c}\text { Tennessee } \\
\text { Alcoa } \\
\text { Utilities } \\
\text { June } 30\end{array}$ \\
\hline 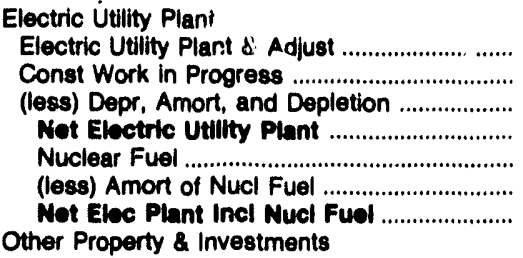 & $\begin{array}{r}15,844 \\
638 \\
4,572 \\
11,010 \\
0 \\
0 \\
11,910\end{array}$ & $\begin{array}{r}57,267 \\
111 \\
6,183 \\
51,195 \\
0 \\
0 \\
51,195\end{array}$ & $\begin{array}{r}2,582 \\
0 \\
618 \\
1,964 \\
0 \\
0 \\
1,964\end{array}$ & $\begin{array}{r}7,096 \\
584 \\
2,065 \\
5,615 \\
0 \\
0 \\
5,615\end{array}$ & $\begin{array}{r}14,912 \\
20 \\
8,658 \\
6,273 \\
0 \\
0 \\
6,273\end{array}$ & $\begin{array}{r}17,875 \\
354 \\
5,658 \\
12,571 \\
0 \\
0 \\
12,571\end{array}$ \\
\hline 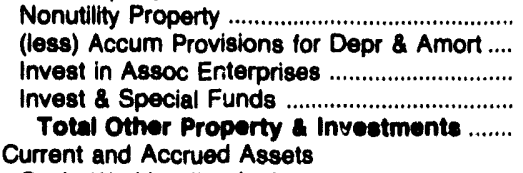 & $\begin{array}{l}0 \\
0 \\
0 \\
0 \\
0\end{array}$ & $\begin{array}{r}0 \\
0 \\
0 \\
8,882 \\
8,882\end{array}$ & $\begin{array}{r}0 \\
0 \\
0 \\
13,672 \\
13,672\end{array}$ & $\begin{array}{l}0 \\
0 \\
0 \\
0 \\
0\end{array}$ & $\begin{array}{l}0 \\
0 \\
0 \\
0 \\
0\end{array}$ & $\begin{array}{r}0 \\
0 \\
0 \\
1,253 \\
1,253\end{array}$ \\
\hline 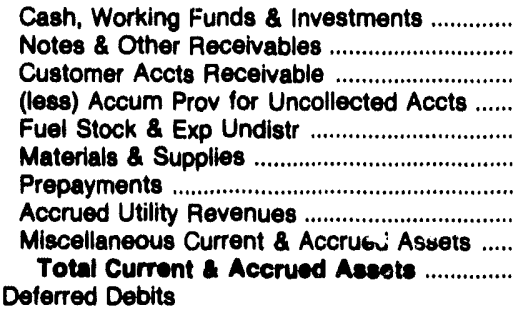 & $\begin{array}{r}1,461 \\
19 \\
1,187 \\
6 \\
0 \\
230 \\
5 \\
0 \\
0 \\
2,896\end{array}$ & $\begin{array}{r}4,563 \\
389 \\
749 \\
0 \\
17 \\
2,158 \\
17 \\
374 \\
63 \\
8,330\end{array}$ & $\begin{array}{r}4,823 \\
0 \\
6,404 \\
0 \\
51 \\
0 \\
1,600 \\
0 \\
754 \\
13,632\end{array}$ & $\begin{array}{r}1,092 \\
0 \\
375 \\
57 \\
0 \\
559 \\
0 \\
1,270 \\
16 \\
3,255\end{array}$ & $\begin{array}{r}2,620 \\
0 \\
1,089 \\
2 \\
0 \\
278 \\
26 \\
0 \\
6 \\
4,018\end{array}$ & $\begin{array}{r}1,835 \\
1,321 \\
0 \\
0 \\
0 \\
254 \\
11 \\
0 \\
69 \\
3,491\end{array}$ \\
\hline 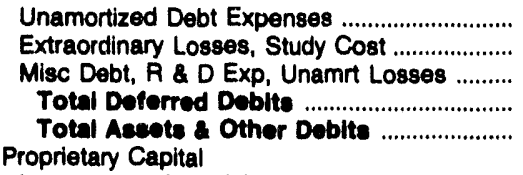 & $\begin{array}{r}0 \\
0 \\
0 \\
0 \\
14,808\end{array}$ & $\begin{array}{r}4,125 \\
0 \\
991 \\
5,116 \\
73,522\end{array}$ & $\begin{array}{r}0 \\
0 \\
53 \\
53 \\
29,320\end{array}$ & $\begin{array}{r}0 \\
0 \\
0 \\
0 \\
\mathbf{8 , 8 7 1}\end{array}$ & $\begin{array}{r}0 \\
0 \\
0 \\
0 \\
10,291\end{array}$ & $\begin{array}{r}31 \\
0 \\
1,082 \\
1,113 \\
18,429\end{array}$ \\
\hline 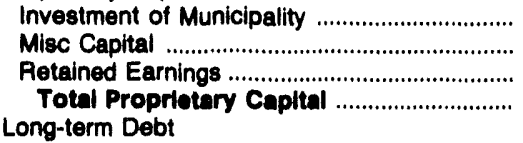 & $\begin{array}{r}0 \\
0 \\
14,262 \\
14,262\end{array}$ & $\begin{array}{r}0 \\
0 \\
1,715 \\
1,715\end{array}$ & $\begin{array}{r}0 \\
0 \\
22,624 \\
22,624\end{array}$ & $\begin{array}{r}62 \\
0 \\
8,196 \\
8,257\end{array}$ & $\begin{array}{r}0 \\
16 \\
8,898 \\
8,914\end{array}$ & $\begin{array}{r}0 \\
0 \\
10,987 \\
10,967\end{array}$ \\
\hline 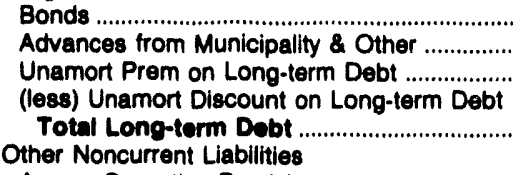 & $\begin{array}{l}0 \\
0 \\
0 \\
0 \\
0\end{array}$ & $\begin{array}{r}66,835 \\
0 \\
0 \\
0 \\
68,835\end{array}$ & $\begin{array}{l}0 \\
0 \\
0 \\
0 \\
0\end{array}$ & $\begin{array}{l}0 \\
0 \\
0 \\
0 \\
0\end{array}$ & $\begin{array}{l}0 \\
0 \\
0 \\
0 \\
0\end{array}$ & $\begin{array}{r}2,948 \\
931 \\
-34 \\
0 \\
3,845\end{array}$ \\
\hline $\begin{array}{l}\text { Accum Operating Provisions ........................... } \\
\text { Accum Prov for Rate Refunds ....................... } \\
\text { Total Other Noncurrent Llabilities ........... } \\
\text { Current and Accrued Liabilities }\end{array}$ & $\begin{array}{l}0 \\
0 \\
0\end{array}$ & $\begin{array}{l}0 \\
0 \\
0\end{array}$ & $\begin{array}{l}0 \\
0 \\
0\end{array}$ & $\begin{array}{r}41 \\
0 \\
41\end{array}$ & $\begin{array}{l}0 \\
0 \\
\mathbf{0}\end{array}$ & $\begin{array}{l}0 \\
0 \\
0\end{array}$ \\
\hline 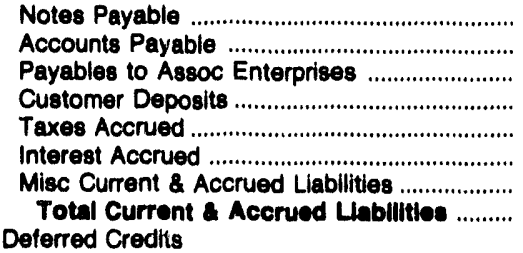 & $\begin{array}{r}0 \\
442 \\
43 \\
0 \\
28 \\
0 \\
31 \\
645\end{array}$ & $\begin{array}{r}0 \\
793 \\
0 \\
0 \\
3 \\
256 \\
985 \\
2,037\end{array}$ & $\begin{array}{r}0 \\
6,672 \\
0 \\
0 \\
24 \\
0 \\
0 \\
6,696\end{array}$ & $\begin{array}{r}0 \\
324 \\
0 \\
222 \\
21 \\
0 \\
0 \\
567\end{array}$ & $\begin{array}{r}0 \\
489 \\
8 \\
116 \\
56 \\
0 \\
709 \\
1,377\end{array}$ & $\begin{array}{r}0 \\
1,946 \\
0 \\
1,259 \\
0 \\
37 \\
299 \\
3,541\end{array}$ \\
\hline 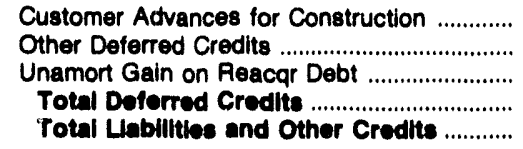 & $\begin{array}{r}0 \\
0 \\
0 \\
0 \\
14,800\end{array}$ & $\begin{array}{r}0 \\
70 \\
2,865 \\
2,935 \\
\mathbf{7 3 , 5 2 2}\end{array}$ & $\begin{array}{r}0 \\
0 \\
0 \\
0 \\
29,320\end{array}$ & $\begin{array}{r}5 \\
0 \\
0 \\
5 \\
8,871\end{array}$ & $\begin{array}{r}0 \\
0 \\
0 \\
0 \\
10,291\end{array}$ & $\begin{array}{r}76 \\
0 \\
0 \\
76 \\
18,429\end{array}$ \\
\hline
\end{tabular}

Note: Totals may not equal sum of components because of independent rounding.

Source: Energy Information Administration, Form EIA-412, "Annual Report of Public Electric Utilities." 
Table 22. Balance Sheet by Major U.S. Publicly Owned Electric Utility Within State at End of Period, 1992 (Continued) (Thousand Dollars)

\begin{tabular}{|c|c|c|c|c|c|c|}
\hline Item & $\begin{array}{l}\text { Tennessee } \\
\text { Athens } \\
\text { City of } \\
\text { June } 30\end{array}$ & $\begin{array}{l}\text { Tennessee } \\
\text { Bentcr } \\
\text { County } \\
\text { June } 30\end{array}$ & $\begin{array}{l}\text { Tennessee } \\
\text { Bolivar } \\
\text { City of } \\
\text { June } 30\end{array}$ & $\begin{array}{l}\text { Tennessee } \\
\text { Bristol } \\
\text { City of } \\
\text { June } 30\end{array}$ & $\begin{array}{c}\text { Tennessee } \\
\text { Brownsville } \\
\text { City of } \\
\text { June } 30\end{array}$ & $\begin{array}{l}\text { Tennessee } \\
\text { Carroll } \\
\text { County } \\
\text { June } 30\end{array}$ \\
\hline \multicolumn{7}{|l|}{ Electric Utility Plant } \\
\hline 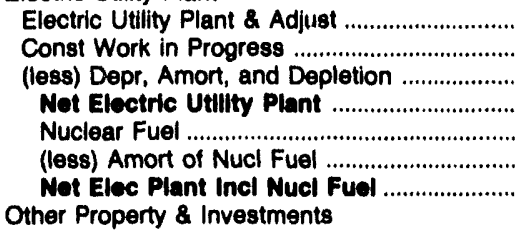 & $\begin{array}{r}16,565 \\
526 \\
6,271 \\
10,820 \\
0 \\
0 \\
10,820\end{array}$ & $\begin{array}{r}2,935 \\
163 \\
1,133 \\
1,965 \\
0 \\
0 \\
1,965\end{array}$ & $\begin{array}{r}12,556 \\
1,581 \\
4,762 \\
9,374 \\
0 \\
0 \\
9,374\end{array}$ & $\begin{array}{r}37,523 \\
1,773 \\
19,981 \\
19,314 \\
0 \\
0 \\
19,314\end{array}$ & $\begin{array}{r}6,100 \\
569 \\
1,829 \\
4,840 \\
0 \\
0 \\
4,840\end{array}$ & $\begin{array}{r}16,636 \\
134 \\
5,499 \\
11,272 \\
0 \\
0 \\
11,272\end{array}$ \\
\hline 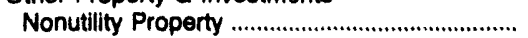 & 0 & 0 & 0 & 190 & 0 & 0 \\
\hline (less) Accum Provisions for Depr \& Amort .... & 0 & 0 & 0 & 0 & 0 & 0 \\
\hline 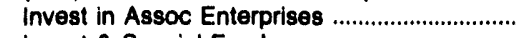 & 0 & 0 & 0 & 0 & 0 & 0 \\
\hline $\begin{array}{l}\text { Invest \& Special Funds } \\
\text { Total Other Property Investments } \\
\text { Current and Accrued Assets }\end{array}$ & $\begin{array}{l}20 \\
20\end{array}$ & $\begin{array}{l}26 \\
26\end{array}$ & $\begin{array}{l}131 \\
131\end{array}$ & $\begin{array}{l}10,200 \\
10,380\end{array}$ & $\begin{array}{l}727 \\
727\end{array}$ & $\begin{array}{l}1,196 \\
1,186\end{array}$ \\
\hline Cash, Working Funds \& Investments ............. & 637 & 899 & -113 & 5,309 & 1,052 & 792 \\
\hline Notes \& Other Receivables ................................... & 2,110 & 349 & 222 & 2,633 & 603 & 1,518 \\
\hline 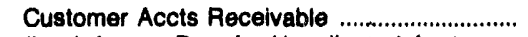 & 0 & 0 & 1,281 & 0 & 0 & 0 \\
\hline (less) Accum Prov for Uncollected Accts ....... & 0 & 0 & 2 & 0 & 0 & 0 \\
\hline 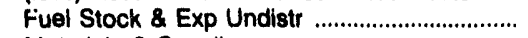 & 0 & 0 & 0 & 0 & 0 & 0 \\
\hline 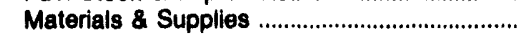 & 235 & 47 & 284 & 570 & 164 & 328 \\
\hline 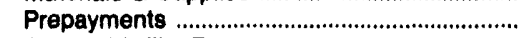 & 10 & 10 & 13 & 112 & 53 & 80 \\
\hline Accrued Utility Revenues ................................... & 0 & 0 & 0 & 0 & 0 & 0 \\
\hline Miscellaneous Current \& Accrued Assets ..... & 63 & 10 & 3 & 76 & 6 & 41 \\
\hline $\begin{array}{l}\text { Total Current \& Accrued Asests ................ } \\
\text { Deferred Debits }\end{array}$ & \multicolumn{5}{|c|}{ Deferred Debits } & 2,760 \\
\hline 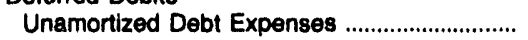 & 0 & 0 & 49 & 0 & 5 & 16 \\
\hline Extraordinary Losses, Study Cost ........................ & 0 & 0 & 0 & 0 & 0 & 0 \\
\hline Misc Debt, A \& D Exp, Unamrt Losses .......... & 959 & 20 & 994 & 4,739 & 48 & 305 \\
\hline Total Doferred Deblte ................................. & 959 & 20 & 1,043 & 4,739 & 53 & 322 \\
\hline $\begin{array}{l}\text { Total Aseats Other Deblts } \\
\text { Proprietary Capital }\end{array}$ & 14,855 & 3,326 & 12,237 & 43,143 & 7,497 & 15,560 \\
\hline 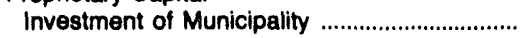 & 0 & 0 & 0 & 0 & 0 & 0 \\
\hline 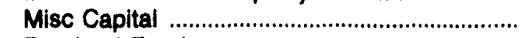 & 0 & 0 & 0 & 0 & 0 & 0 \\
\hline $\begin{array}{l}\text { Retained Earnings } \\
\text { Total Propritary Capital }\end{array}$ & $\begin{array}{l}11,908 \\
11,908\end{array}$ & $\begin{array}{l}2,967 \\
2,967\end{array}$ & $\begin{array}{l}7,408 \\
7,408\end{array}$ & $\begin{array}{l}34,826 \\
34,828\end{array}$ & $\begin{array}{l}5,012 \\
5,012\end{array}$ & $\begin{array}{l}11,361 \\
11,361\end{array}$ \\
\hline \multicolumn{7}{|l|}{ Long-term Debt } \\
\hline Bonds & 0 & 0 & 1,295 & 0 & 750 & 1,155 \\
\hline Advances from Municipality \& Other ................ & 976 & 20 & 440 & 4,464 & 12 & 253 \\
\hline Unamort Prem on Long-term Debt ................... & 0 & 0 & 0 & 0 & 0 & -9 \\
\hline (less) Unamort Discount on Long-term Debt & 0 & 0 & 0 & 0 & 0 & \\
\hline $\begin{array}{l}\text { Total Long-term Debt .................................... } \\
\text { Other Noncurrent Liabilities }\end{array}$ & 976 & 20 & 1,735 & 4,464 & 762 & 1,390 \\
\hline Accum Operating Provisions .............................. & 0 & 0 & 0 & 0 & 0 & 0 \\
\hline 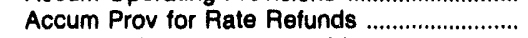 & 0 & 0 & 0 & 0 & 0 & 0 \\
\hline Total Other Noncurrent Liablilties ............ & $\mathbf{0}$ & $\mathbf{0}$ & $\mathbf{0}$ & $\mathbf{0}$ & $\mathbf{0}$ & 0 \\
\hline \multicolumn{7}{|l|}{ Current and Accrued Liabilities } \\
\hline Notes Payable & 0 & 0 & 0 & 0 & 0 & 0 \\
\hline Accounts Payable & 1,819 & 233 & 1,179 & 2,567 & 1,089 & 1,383 \\
\hline Payables to Assoc Enterprises ........................ & 0 & 0 & 75 & 0 & 0 & 0 \\
\hline Customer Deposits .............................................. & 0 & 74 & 405 & 613 & 182 & 354 \\
\hline Taxes Accrued & 0 & 19 & 0 & 181 & 0 & 269 \\
\hline Interest Accrued & 0 & 0 & 9 & 0 & 4 & 20 \\
\hline $\begin{array}{l}\text { Misc Current \& Accrued Liabilities .................. } \\
\text { Total Current \& Accrued Liabilitios ......... }\end{array}$ & $\begin{array}{r}129 \\
1,949\end{array}$ & $\begin{array}{r}12 \\
339\end{array}$ & $\begin{array}{r}196 \\
1,864\end{array}$ & $\begin{array}{r}468 \\
3,830\end{array}$ & $\begin{array}{r}93 \\
1,368\end{array}$ & $\begin{array}{r}512 \\
2,536\end{array}$ \\
\hline \multicolumn{7}{|l|}{ Deferred Credits } \\
\hline Customer Advances for Construction .............. & 0 & 0 & 0 & 0 & 0 & 8 \\
\hline 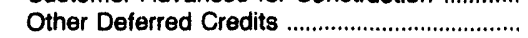 & 22 & 0 & 1,230 & 24 & 355 & 246 \\
\hline Unamort Gain on Reacqr Debt ........................... & 0 & 0 & 0 & 0 & 0 & 0 \\
\hline $\begin{array}{l}\text { Total Deferred Credits ............................... } \\
\text { Total Liabilitles and Other Credits }\end{array}$ & $\begin{array}{r}22 \\
14,855\end{array}$ & $\begin{array}{r}0 \\
3,326\end{array}$ & $\begin{array}{r}1,230 \\
12,237\end{array}$ & $\begin{array}{r}24 \\
43,143\end{array}$ & $\begin{array}{r}355 \\
7,497\end{array}$ & $\begin{array}{r}254 \\
15,550\end{array}$ \\
\hline
\end{tabular}

Note: Totals may not equal sum of romponents because of independent rounding.

Source: Energy Information Administiation, Form ElA-412, "Annual Report of Public Electric Utilities." 
Table 22. Balance Sheet by Major U.S. Publlcly Owned Electric Utillty Within State at End of Perlod, 1992 (Continued) (Thousand Dollars)

\begin{tabular}{|c|c|c|c|c|c|c|}
\hline Item & $\begin{array}{c}\text { Tennessee } \\
\begin{array}{c}\text { Chattanooga } \\
\text { City of }\end{array} \\
\text { June } 30\end{array}$ & $\begin{array}{l}\text { Tennessee } \\
\text { Clarksville } \\
\text { City of } \\
\text { June } 30\end{array}$ & $\begin{array}{l}\text { Tennessee } \\
\text { Cleveland } \\
\text { City of } \\
\text { June } 30\end{array}$ & $\begin{array}{l}\text { Tennessee } \\
\text { Clinton } \\
\text { Clty of } \\
\text { June } 30\end{array}$ & $\begin{array}{l}\text { Tennessee } \\
\text { Columbia } \\
\text { City of } \\
\text { June } 30\end{array}$ & $\begin{array}{l}\text { Tennessee } \\
\text { Cookeville } \\
\text { City of } \\
\text { June } 30\end{array}$ \\
\hline 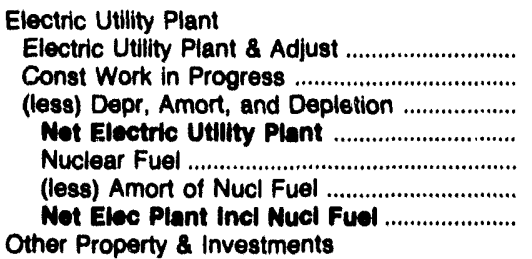 & $\begin{array}{r}226,761 \\
4,958 \\
88,950 \\
142,769 \\
0 \\
0 \\
142,760\end{array}$ & $\begin{array}{r}38,818 \\
841 \\
8,437 \\
31,221 \\
0 \\
0 \\
31,221\end{array}$ & $\begin{array}{r}42,606 \\
607 \\
12,248 \\
30,898 \\
0 \\
0 \\
30,898\end{array}$ & $\begin{array}{r}32,560 \\
391 \\
11,213 \\
21,738 \\
0 \\
0 \\
21,738\end{array}$ & $\begin{array}{r}23,347 \\
276 \\
9,119 \\
14,504 \\
0 \\
0 \\
14,604\end{array}$ & $\begin{array}{r}15,415 \\
1,953 \\
4,473 \\
12,895 \\
0 \\
0 \\
12,895\end{array}$ \\
\hline 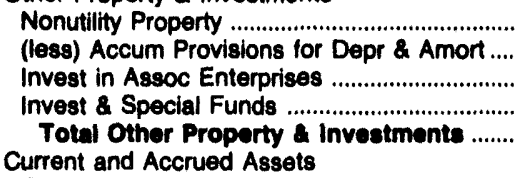 & $\begin{array}{r}0 \\
0 \\
0 \\
11,320 \\
11,320\end{array}$ & $\begin{array}{r}509 \\
2 \\
0 \\
5,860 \\
6,387\end{array}$ & $\begin{array}{r}0 \\
0 \\
0 \\
15 \\
15\end{array}$ & $\begin{array}{r}0 \\
0 \\
0 \\
722 \\
722\end{array}$ & $\begin{array}{r}0 \\
0 \\
0 \\
528 \\
528\end{array}$ & $\begin{array}{r}0 \\
0 \\
0 \\
101 \\
101\end{array}$ \\
\hline 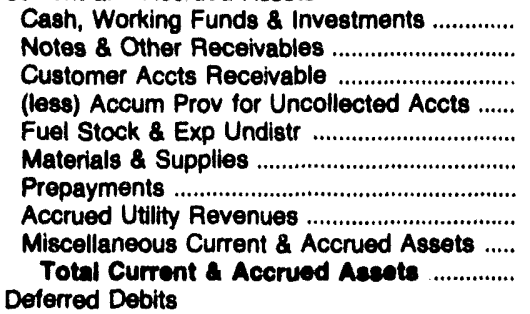 & $\begin{array}{r}30,715 \\
17,604 \\
0 \\
0 \\
0 \\
3,547 \\
550 \\
0 \\
13,683 \\
68,008\end{array}$ & $\begin{array}{r}2,682 \\
171 \\
2,248 \\
0 \\
0 \\
602 \\
1 \\
0 \\
136 \\
5,840\end{array}$ & $\begin{array}{r}2,398 \\
3,896 \\
0 \\
0 \\
0 \\
758 \\
0 \\
0 \\
52 \\
7,105\end{array}$ & $\begin{array}{r}1,430 \\
2,967 \\
0 \\
0 \\
0 \\
436 \\
3 \\
0 \\
102 \\
4,988\end{array}$ & $\begin{array}{r}2,425 \\
1,571 \\
0 \\
0 \\
0 \\
571 \\
28 \\
0 \\
49 \\
4,644\end{array}$ & $\begin{array}{r}1,340 \\
141 \\
1,542 \\
0 \\
3 \\
534 \\
2 \\
0 \\
31 \\
3,593\end{array}$ \\
\hline $\begin{array}{l}\text { Unamortized Debt Expenses ....................... } \\
\text { Extraordinary Losses, Study Cost ................... } \\
\text { Misc Debt, R \& D Exp, Unamrt Losses ......... } \\
\text { Total Deferred Debits .................................... } \\
\text { Total Assets \& Other Debits ...................... }\end{array}$ & $\begin{array}{r}0 \\
0 \\
14,317 \\
14,317 \\
234,504\end{array}$ & $\begin{array}{r}52 \\
0 \\
5,700 \\
5,752 \\
49,180\end{array}$ & $\begin{array}{r}0 \\
0 \\
1,704 \\
1,704 \\
39,792\end{array}$ & $\begin{array}{r}0 \\
0 \\
1,885 \\
1,885 \\
29,284\end{array}$ & $\begin{array}{r}0 \\
0 \\
1,361 \\
1,361 \\
21,037\end{array}$ & $\begin{array}{r}10 \\
0 \\
444 \\
454 \\
17,044\end{array}$ \\
\hline 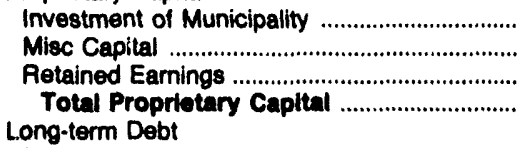 & $\begin{array}{r}0 \\
0 \\
154,876 \\
154,876\end{array}$ & $\begin{array}{r}0 \\
0 \\
25,153 \\
25,153\end{array}$ & $\begin{array}{r}0 \\
0 \\
30,862 \\
30,882\end{array}$ & $\begin{array}{r}0 \\
0 \\
23,611 \\
23,611\end{array}$ & $\begin{array}{r}0 \\
0 \\
17,234 \\
17,234\end{array}$ & $\begin{array}{r}0 \\
0 \\
12,567 \\
12,587\end{array}$ \\
\hline $\begin{array}{l}\text { Bonds } \\
\text { Advances from Municipality \& Other .............. } \\
\text { Unamort Prem on Long-term Debt ............... } \\
\text { (less) Unamort Discount on Long-term Debt } \\
\text { Total Long-term Debt ............................... } \\
\text { Other Noncurrent Liabilities }\end{array}$ & $\begin{array}{r}12,854 \\
15,988 \\
0 \\
0 \\
28,842\end{array}$ & $\begin{array}{r}7,260 \\
2,793 \\
0 \\
36 \\
10,017\end{array}$ & $\begin{array}{r}0 \\
1,631 \\
0 \\
0 \\
1,631\end{array}$ & $\begin{array}{r}0 \\
1,785 \\
0 \\
0 \\
1,785\end{array}$ & $\begin{array}{r}0 \\
1,164 \\
0 \\
0 \\
1,164\end{array}$ & $\begin{array}{r}1,320 \\
453 \\
0 \\
0 \\
1,773\end{array}$ \\
\hline $\begin{array}{l}\text { Accum Operating Provisions } \\
\text { Accum Prov for Rate Refunds ................................. } \\
\text { Total Other Noncurrent Llabillities ............. } \\
\text { Current and Accrued Liabilities }\end{array}$ & $\begin{array}{l}0 \\
0 \\
0\end{array}$ & $\begin{array}{l}0 \\
0 \\
0\end{array}$ & $\begin{array}{l}0 \\
0 \\
0\end{array}$ & $\begin{array}{l}0 \\
0 \\
0\end{array}$ & $\begin{array}{l}0 \\
0 \\
0\end{array}$ & $\begin{array}{l}0 \\
0 \\
0\end{array}$ \\
\hline 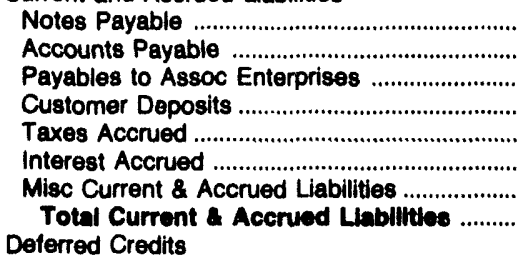 & $\begin{array}{r}0 \\
37,164 \\
0 \\
4,000 \\
5,669 \\
953 \\
1,370 \\
49,168\end{array}$ & $\begin{array}{r}0 \\
2,910 \\
0 \\
1,438 \\
0 \\
164 \\
964 \\
5,475\end{array}$ & $\begin{array}{r}0 \\
3,937 \\
0 \\
900 \\
0 \\
0 \\
258 \\
5,094\end{array}$ & $\begin{array}{r}0 \\
2,330 \\
0 \\
995 \\
0 \\
0 \\
551 \\
3,875\end{array}$ & $\begin{array}{r}0 \\
1,371 \\
0 \\
858 \\
0 \\
0 \\
409 \\
2,638\end{array}$ & $\begin{array}{r}0 \\
1,765 \\
0 \\
395 \\
0 \\
28 \\
54 \\
2,241\end{array}$ \\
\hline 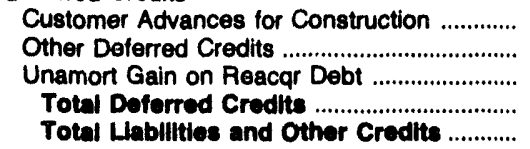 & $\begin{array}{r}0 \\
1,630 \\
0 \\
1,630 \\
234,604\end{array}$ & $\begin{array}{r}0 \\
8,535 \\
0 \\
8,585 \\
49,180\end{array}$ & $\begin{array}{r}0 \\
2,204 \\
0 \\
2,204 \\
30,702\end{array}$ & $\begin{array}{r}0 \\
12 \\
0 \\
12 \\
29,284\end{array}$ & $\begin{array}{r}0 \\
0 \\
0 \\
0 \\
21,037\end{array}$ & $\begin{array}{r}0 \\
463 \\
0 \\
463 \\
17,044\end{array}$ \\
\hline
\end{tabular}

Note: Totals may not equal sum of components because of independent rounding.

Source: Energy Intormation Administration, Form ElA-412, "Annual Report of Public Electric Utilities." 
Table 22. Balance Sheet by Major U.S. Publlcly Owned Electrlc Utility Within State at End of Perlod, 1992 (Continued) (Thousand Dollars)

\begin{tabular}{|c|c|c|c|c|c|c|}
\hline llem & $\begin{array}{l}\text { Tennesese } \\
\text { Covington } \\
\text { Electric } \\
\text { System } \\
\text { June } 30\end{array}$ & $\begin{array}{l}\text { Tennesees } \\
\text { Dayton } \\
\text { City of } \\
\text { June } 30\end{array}$ & $\begin{array}{l}\text { Tennessee } \\
\text { Dickson } \\
\text { City of } \\
\text { June } 30\end{array}$ & $\begin{array}{l}\text { Tennessee } \\
\text { Dyeraburg } \\
\text { Electric } \\
\text { System } \\
\text { June } 30\end{array}$ & $\begin{array}{c}\text { Tennessee } \\
\text { Elizabethton } \\
\text { Clty of } \\
\text { June } 30\end{array}$ & $\begin{array}{l}\text { Tennessee } \\
\text { Enwin } \\
\text { Town of } \\
\text { June } 30\end{array}$ \\
\hline 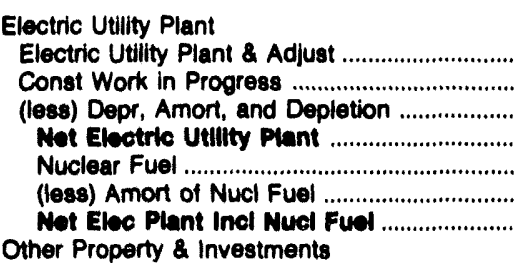 & $\begin{array}{r}7,828 \\
55 \\
1,894 \\
8,090 \\
0 \\
0 \\
8,009\end{array}$ & $\begin{array}{r}9,127 \\
59 \\
2,884 \\
6,302 \\
0 \\
0 \\
6,302\end{array}$ & $\begin{array}{r}30,868 \\
1,844 \\
9,915 \\
22,804 \\
0 \\
0 \\
22,804\end{array}$ & $\begin{array}{r}22,589 \\
2,175 \\
6,727 \\
18,037 \\
0 \\
0 \\
18,037\end{array}$ & $\begin{array}{r}22,884 \\
237 \\
7,984 \\
16,227 \\
0 \\
0 \\
16,227\end{array}$ & $\begin{array}{r}7,335 \\
238 \\
3,034 \\
4,630 \\
0 \\
0 \\
4,630\end{array}$ \\
\hline 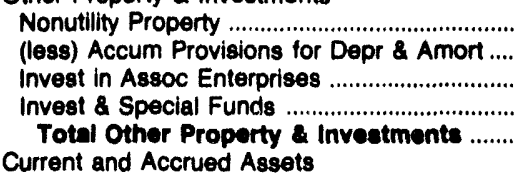 & $\begin{array}{r}0 \\
0 \\
1 \\
681 \\
682\end{array}$ & $\begin{array}{l}0 \\
0 \\
0 \\
0 \\
0\end{array}$ & $\begin{array}{r}0 \\
0 \\
0 \\
4,529 \\
\mathbf{4 , 5 2 0}\end{array}$ & $\begin{array}{r}0 \\
0 \\
0 \\
4,939 \\
4,930\end{array}$ & $\begin{array}{r}0 \\
0 \\
0 \\
689 \\
689\end{array}$ & $\begin{array}{l}0 \\
0 \\
0 \\
4 \\
4\end{array}$ \\
\hline 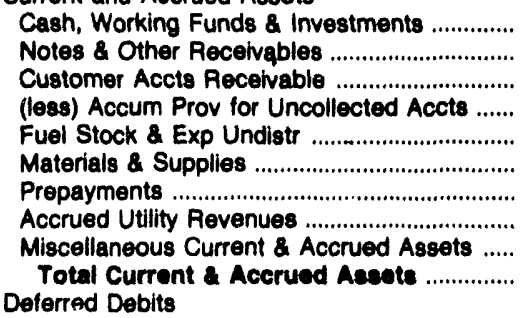 & $\begin{array}{r}3,772 \\
33 \\
934 \\
0 \\
0 \\
110 \\
47 \\
0 \\
5 \\
4,001\end{array}$ & $\begin{array}{r}1,135 \\
841 \\
0 \\
0 \\
0 \\
84 \\
5 \\
0 \\
33 \\
2,007\end{array}$ & $\begin{array}{r}1,708 \\
2,182 \\
0 \\
0 \\
0 \\
524 \\
164 \\
0 \\
119 \\
4,697\end{array}$ & $\begin{array}{r}910 \\
2,063 \\
0 \\
0 \\
0 \\
465 \\
71 \\
0 \\
43 \\
3,552\end{array}$ & $\begin{array}{r}908 \\
1,509 \\
0 \\
0 \\
0 \\
413 \\
0 \\
0 \\
97 \\
2,928\end{array}$ & $\begin{array}{r}687 \\
922 \\
0 \\
0 \\
0 \\
183 \\
0 \\
0 \\
377 \\
2,189\end{array}$ \\
\hline $\begin{array}{l}\text { Unamortized Debt Expenses ........................ } \\
\text { Extraordinary Losses, Study Cost .................... } \\
\text { Misc Debt, \& \& D Exp, Unamrt Losses ......... } \\
\text { Total Doferred Debits .................................. } \\
\text { Total Aseote \& Other Debits ..................... }\end{array}$ & $\begin{array}{r}14 \\
0 \\
393 \\
407 \\
12,070\end{array}$ & $\begin{array}{r}0 \\
0 \\
94 \\
84 \\
8,493\end{array}$ & $\begin{array}{r}97 \\
0 \\
55 \\
162 \\
32,272\end{array}$ & $\begin{array}{r}74 \\
0 \\
1,185 \\
1,260 \\
27,787\end{array}$ & $\begin{array}{r}0 \\
0 \\
2,060 \\
2,000 \\
20,903\end{array}$ & $\begin{array}{r}0 \\
0 \\
581 \\
581 \\
7,294\end{array}$ \\
\hline 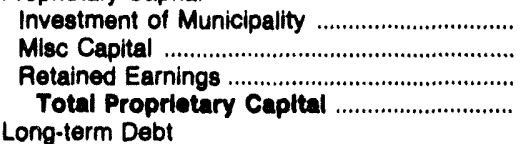 & $\begin{array}{r}0 \\
0 \\
8,783 \\
8,783\end{array}$ & $\begin{array}{r}0 \\
0 \\
7,268 \\
7,268\end{array}$ & $\begin{array}{r}0 \\
0 \\
14,486 \\
14,488\end{array}$ & $\begin{array}{r}0 \\
0 \\
13,102 \\
13,102\end{array}$ & $\begin{array}{r}0 \\
0 \\
15,296 \\
15,298\end{array}$ & $\begin{array}{r}0 \\
0 \\
5,428 \\
5,428\end{array}$ \\
\hline 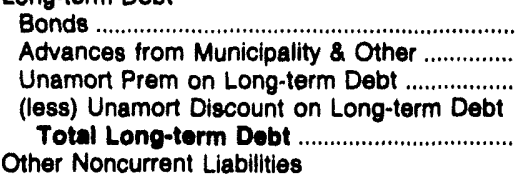 & $\begin{array}{r}665 \\
126 \\
0 \\
9 \\
782\end{array}$ & $\begin{array}{r}0 \\
113 \\
0 \\
0 \\
113\end{array}$ & $\begin{array}{r}5,855 \\
8,251 \\
0 \\
0 \\
14,108\end{array}$ & $\begin{array}{r}9,825 \\
1,155 \\
-92 \\
0 \\
10,988\end{array}$ & $\begin{array}{r}0 \\
1,646 \\
0 \\
0 \\
1,646\end{array}$ & $\begin{array}{r}0 \\
553 \\
0 \\
0 \\
553\end{array}$ \\
\hline 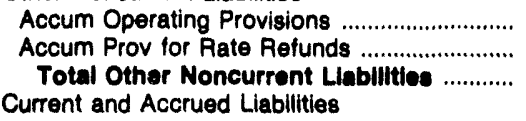 & $\begin{array}{l}0 \\
0 \\
0\end{array}$ & $\begin{array}{l}0 \\
0 \\
0\end{array}$ & $\begin{array}{l}0 \\
0 \\
0\end{array}$ & $\begin{array}{l}1 \\
0 \\
0\end{array}$ & $\begin{array}{l}0 \\
0 \\
0\end{array}$ & $\begin{array}{l}0 \\
0 \\
0\end{array}$ \\
\hline 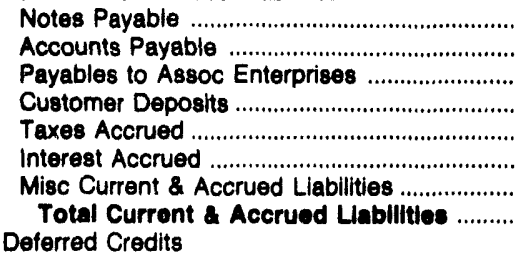 & $\begin{array}{r}0 \\
798 \\
0 \\
246 \\
0 \\
11 \\
58 \\
1,114\end{array}$ & $\begin{array}{r}0 \\
919 \\
0 \\
163 \\
1 \\
0 \\
29 \\
1,112\end{array}$ & $\begin{array}{r}0 \\
2,330 \\
0 \\
983 \\
0 \\
237 \\
118 \\
3,688\end{array}$ & $\begin{array}{r}0 \\
2,737 \\
0 \\
282 \\
1 \\
263 \\
368 \\
3,860\end{array}$ & $\begin{array}{r}0 \\
1,715 \\
0 \\
775 \\
0 \\
0 \\
1,472 \\
3, \bullet 82\end{array}$ & $\begin{array}{r}0 \\
818 \\
0 \\
158 \\
0 \\
0 \\
42 \\
1,018\end{array}$ \\
\hline 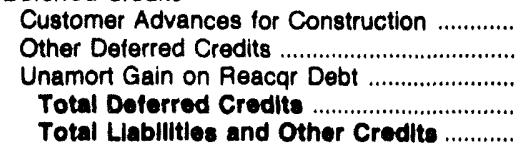 & $\begin{array}{r}0 \\
1,400 \\
0 \\
1,400 \\
12,079\end{array}$ & $\begin{array}{r}0 \\
0 \\
0 \\
0 \\
8,493\end{array}$ & $\begin{array}{r}0 \\
13 \\
0 \\
13 \\
32,272\end{array}$ & $\begin{array}{r}0 \\
48 \\
0 \\
48 \\
27,787\end{array}$ & $\begin{array}{r}0 \\
0 \\
0 \\
0 \\
20, \infty 03\end{array}$ & $\begin{array}{r}2 \\
292 \\
0 \\
294 \\
7,204\end{array}$ \\
\hline
\end{tabular}

Note: Totals may not equal sum of components because of independent rounding.

Source: Energy Information Administration, Form ElA-412, "Annual Report of Public Electric Utilities." 
Table 22. Balance Sheet by Major U.S. Publicly Owned Electric Utillty Within State at End of Perlod, 1992 (Continued) (Thousand Dollars)

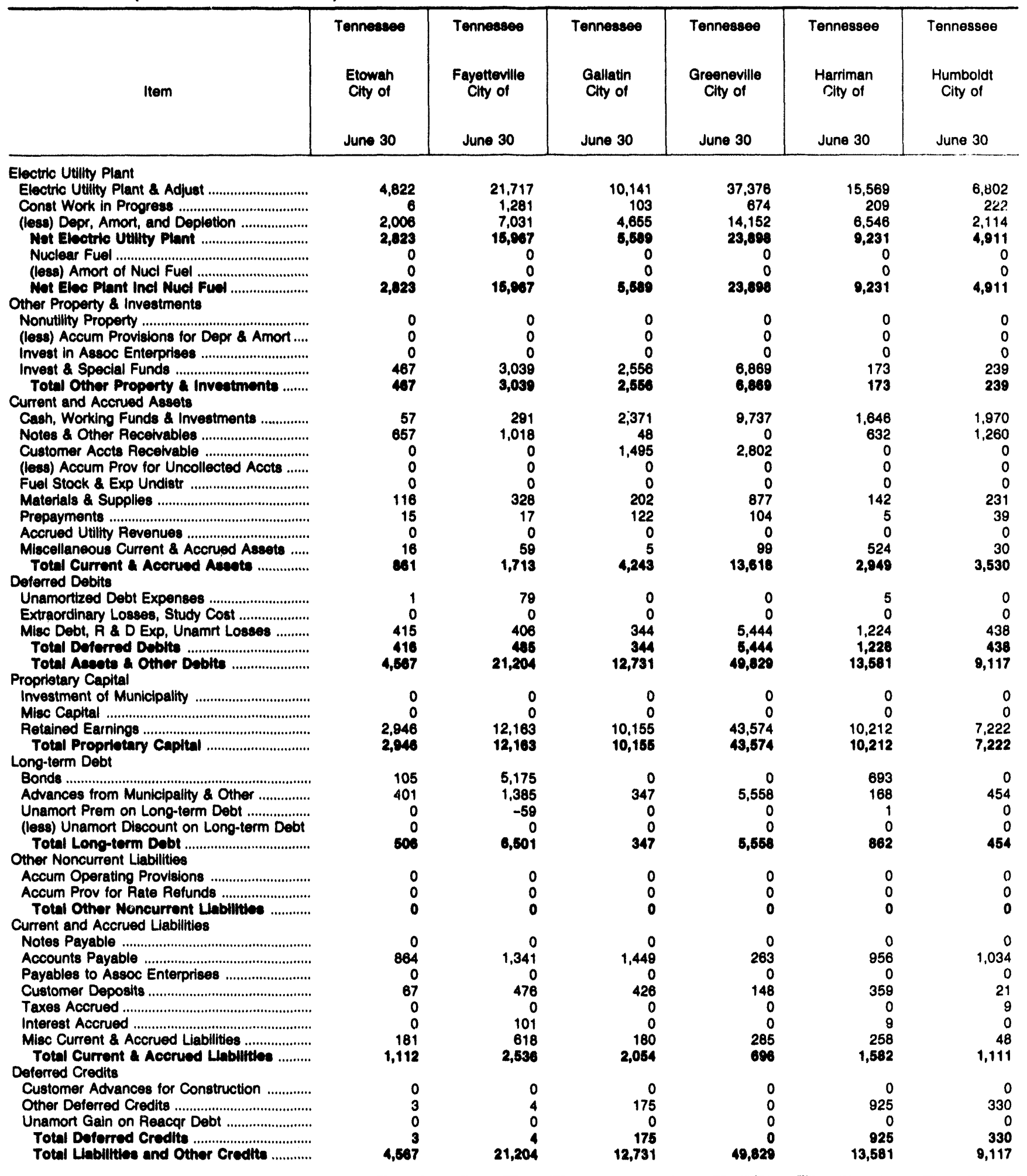

Note: Totals may not equal sum of components because of independent rounding.

Source: Energy Information Administration, Form EIA-412, "Annual Report of Publlc Electric Utilities." 
Table 22. Balance Sheet by Major U.S. Publicly Owned Electric Utility Within State at End of Perlod, 1992 (Continued) (Thousand Dollars)

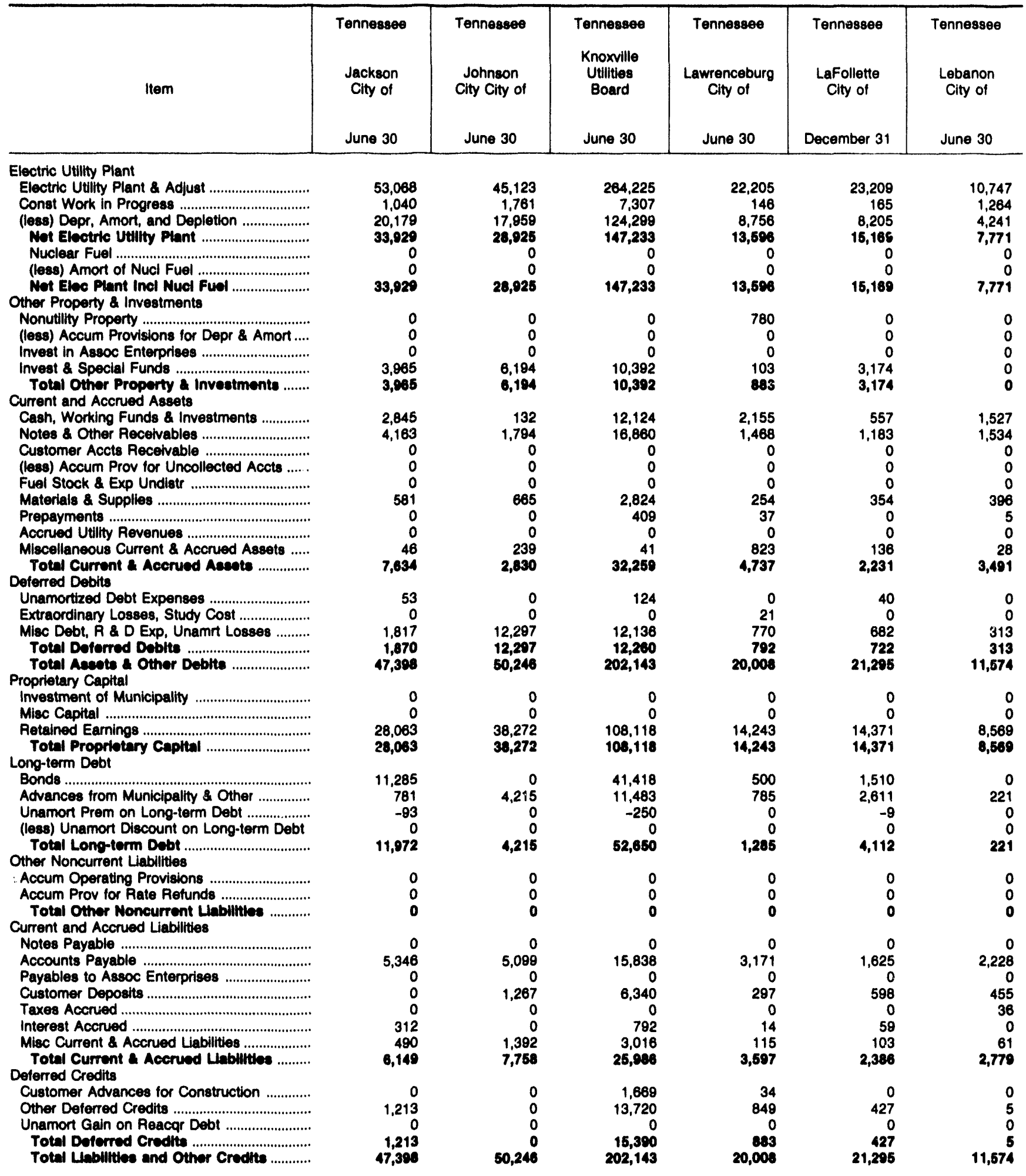

Note: Totals may not equal sum of components because of independent rounding.

Source: Energy Information Administration, Form ElA-412, "Annual Report of Public Electric Utilities." 
Table 22. Balance St by Major U.S. Publicly Owned Electric Utility Within State ai End of Porlod, 1992 (Continued) (Thousand Dollars)

\begin{tabular}{|c|c|c|c|c|c|c|}
\hline Item & $\begin{array}{c}\text { Tennessee } \\
\text { Lenoir } \\
\text { City City of } \\
\text { June } 30\end{array}$ & $\begin{array}{l}\text { Tennessee } \\
\text { Lewisburg } \\
\text { Clty of } \\
\text { June } 30\end{array}$ & $\begin{array}{l}\text { Tennesees } \\
\text { Lexington } \\
\text { Clty of } \\
\text { June } 30\end{array}$ & $\begin{array}{l}\text { Tennessee } \\
\text { Loudon } \\
\text { City of } \\
\text { June } 30\end{array}$ & $\begin{array}{c}\text { Tennessee } \\
\text { Maryville } \\
\text { Utilities } \\
\text { June } \mathbf{3 0}\end{array}$ & $\begin{array}{l}\text { Tennessee } \\
\text { McMinnville } \\
\text { Electric } \\
\text { System } \\
\text { June } 30\end{array}$ \\
\hline 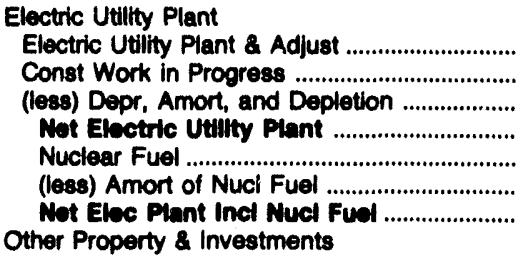 & $\begin{array}{r}53,877 \\
687 \\
13,395 \\
41,169 \\
0 \\
0 \\
41,169\end{array}$ & $\begin{array}{r}8,938 \\
315 \\
3,283 \\
5,971 \\
0 \\
0 \\
5,971\end{array}$ & $\begin{array}{r}18,885 \\
164 \\
5,715 \\
13,334 \\
0 \\
0 \\
13,384\end{array}$ & $\begin{array}{r}13,454 \\
2,466 \\
3,206 \\
12,714 \\
0 \\
0 \\
12,714\end{array}$ & $\begin{array}{r}22,188 \\
160 \\
6,639 \\
15,700 \\
0 \\
0 \\
15,700\end{array}$ & $\begin{array}{r}10,221 \\
30 \\
3,913 \\
6,338 \\
0 \\
0 \\
6,338\end{array}$ \\
\hline $\begin{array}{l}\text { Nonutility Property ................................... } \\
\text { (less) Accum Provisions for Depr \& Amort .... } \\
\text { Invest in Assoc Enterprises ............................... } \\
\text { Invest \& Special Funds ................................. } \\
\text { Totat Other Property \& Inveetments ....... } \\
\text { Current and Accrued Assets }\end{array}$ & $\begin{array}{r}0 \\
0 \\
0 \\
5,565 \\
\mathbf{5 , 5 8 5}\end{array}$ & $\begin{array}{r}0 \\
0 \\
0 \\
148 \\
148\end{array}$ & $\begin{array}{r}0 \\
0 \\
0 \\
2,128 \\
2,128\end{array}$ & $\begin{array}{r}0 \\
0 \\
0 \\
1,256 \\
1,256\end{array}$ & $\begin{array}{r}143 \\
27 \\
0 \\
1,499 \\
1,615\end{array}$ & $\begin{array}{r}0 \\
0 \\
0 \\
489 \\
489\end{array}$ \\
\hline 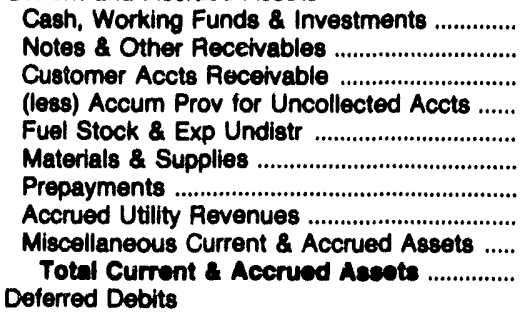 & $\begin{array}{r}203 \\
3,387 \\
0 \\
0 \\
0 \\
763 \\
35 \\
0 \\
1,380 \\
5,769\end{array}$ & $\begin{array}{r}2,630 \\
642 \\
0 \\
0 \\
0 \\
230 \\
6 \\
0 \\
11 \\
3,518\end{array}$ & $\begin{array}{r}577 \\
1,251 \\
0 \\
0 \\
0 \\
391 \\
41 \\
0 \\
95 \\
2,355\end{array}$ & $\begin{array}{r}336 \\
1,715 \\
0 \\
0 \\
0 \\
248 \\
2 \\
0 \\
18 \\
2,320\end{array}$ & $\begin{array}{r}1,807 \\
125 \\
1,323 \\
67 \\
0 \\
353 \\
22 \\
0 \\
6 \\
3,689\end{array}$ & $\begin{array}{r}1,032 \\
713 \\
0 \\
0 \\
0 \\
143 \\
7 \\
0 \\
18 \\
1,013\end{array}$ \\
\hline 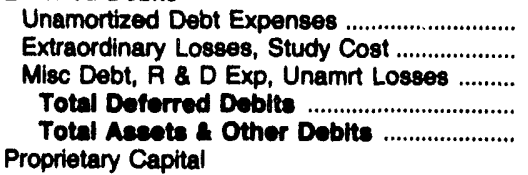 & $\begin{array}{r}357 \\
0 \\
2,378 \\
2,736 \\
55,238\end{array}$ & $\begin{array}{r}0 \\
0 \\
212 \\
212 \\
9,849\end{array}$ & $\begin{array}{r}0 \\
0 \\
984 \\
18,811\end{array}$ & $\begin{array}{r}65 \\
0 \\
345 \\
410 \\
16,700\end{array}$ & $\begin{array}{r}23 \\
0 \\
635 \\
65 t \\
21,551\end{array}$ & $\begin{array}{r}0 \\
0 \\
456 \\
458 \\
9,198\end{array}$ \\
\hline 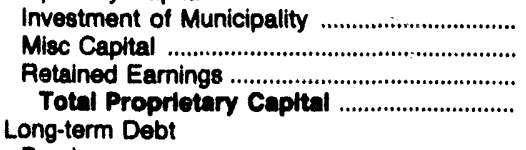 & $\begin{array}{r}0 \\
0 \\
25,241 \\
25,241\end{array}$ & $\begin{array}{l}0 \\
0 \\
\end{array}$ & $\begin{array}{r}0 \\
0 \\
15,518 \\
15,518\end{array}$ & $\begin{array}{r}0 \\
0 \\
6,950 \\
6,950\end{array}$ & $\begin{array}{r}0 \\
0 \\
15,563 \\
15,563\end{array}$ & $\begin{array}{r}0 \\
0 \\
7,994 \\
7,994\end{array}$ \\
\hline 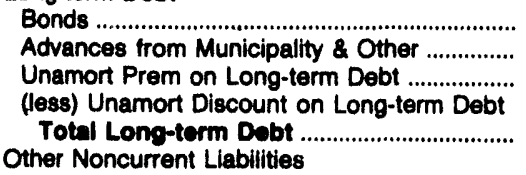 & $\begin{array}{r}17,065 \\
2,436 \\
0 \\
0 \\
19,501\end{array}$ & $\begin{array}{r}37 \\
0 \\
0 \\
761\end{array}$ & $\begin{array}{r}0 \\
845 \\
0 \\
0 \\
845\end{array}$ & $\begin{array}{r}7,885 \\
15 \\
-67 \\
0 \\
7,832\end{array}$ & $\begin{array}{r}2,600 \\
0 \\
483 \\
17 \\
3,086\end{array}$ & $\begin{array}{r}0 \\
462 \\
0 \\
0 \\
462\end{array}$ \\
\hline 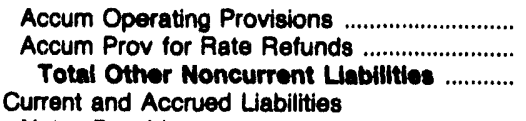 & $\begin{array}{l}0 \\
0 \\
0\end{array}$ & $\begin{array}{l}0 \\
0 \\
0\end{array}$ & $\begin{array}{l}0 \\
0 \\
0\end{array}$ & $\begin{array}{l}0 \\
0 \\
0\end{array}$ & $\begin{array}{l}0 \\
0 \\
0\end{array}$ & $\begin{array}{l}0 \\
0 \\
0\end{array}$ \\
\hline 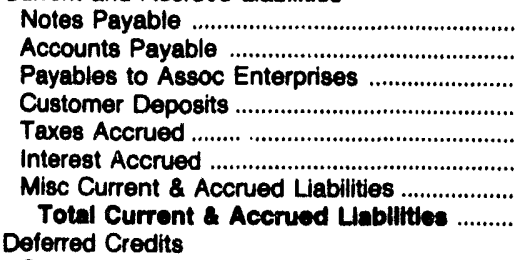 & $\begin{array}{r}0 \\
7,132 \\
0 \\
1,514 \\
0 \\
96 \\
1,293 \\
10,036\end{array}$ & $\begin{array}{r}0 \\
1,097 \\
0 \\
182 \\
0 \\
0 \\
149 \\
1,428\end{array}$ & $\begin{array}{r}0 \\
1,465 \\
0 \\
102 \\
0 \\
0 \\
880 \\
2,447\end{array}$ & $\begin{array}{r}0 \\
1,451 \\
0 \\
2 \\
0 \\
261 \\
177 \\
1,891\end{array}$ & $\begin{array}{r}0 \\
2,249 \\
0 \\
261 \\
0 \\
43 \\
368 \\
2,922\end{array}$ & $\begin{array}{r}0 \\
83 \\
0 \\
457 \\
0 \\
0 \\
135 \\
675\end{array}$ \\
\hline 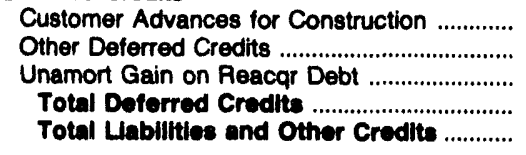 & $\begin{array}{r}423 \\
38 \\
0 \\
461 \\
55,238\end{array}$ & $\begin{array}{r}0 \\
325 \\
0 \\
325 \\
9,849\end{array}$ & $\begin{array}{r}1 \\
0 \\
0 \\
1 \\
18,811\end{array}$ & $\begin{array}{r}27 \\
0 \\
0 \\
27 \\
16,700\end{array}$ & $\begin{array}{r}0 \\
0 \\
0 \\
0 \\
21,551\end{array}$ & $\begin{array}{r}0 \\
65 \\
0 \\
65 \\
9,198\end{array}$ \\
\hline
\end{tabular}

Note: Totals may not equal sum of components because of independent rounding.

Source: Energy Information Administration, Form EIA-412, "Annual Report of Public Electric Utilities." 
Table 22. Balance Sheet by Major U.S. Publicly Owned Electric Utility Within State at End of Period, 1992 (Continued) (Thousand Dollars)

\begin{tabular}{|c|c|c|c|c|c|c|}
\hline Item & $\begin{array}{l}\text { Tennessee } \\
\text { Meinphis } \\
\text { City of } \\
\text { December } 31\end{array}$ & $\begin{array}{l}\text { Tennessee } \\
\text { Morristown } \\
\text { Clty of } \\
\text { June } 30\end{array}$ & $\begin{array}{l}\text { Tennessee } \\
\text { Murtreesboro } \\
\text { City of } \\
\text { June } 30\end{array}$ & $\begin{array}{c}\text { Tennessee } \\
\text { Nashville } \\
\text { Electric } \\
\text { Service } \\
\text { June } 30\end{array}$ & $\begin{array}{l}\text { Tennessee } \\
\text { Newport } \\
\text { City of } \\
\text { June } 30\end{array}$ & $\begin{array}{c}\text { Tennessee } \\
\text { Oak Ridge } \\
\text { City of } \\
\text { June } 30\end{array}$ \\
\hline 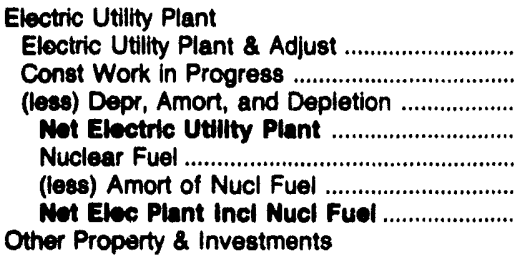 & $\begin{array}{r}674,748 \\
33,784 \\
233,774 \\
474,768 \\
0 \\
0 \\
474,768\end{array}$ & $\begin{array}{r}25,082 \\
116 \\
7,902 \\
17,208 \\
0 \\
0 \\
17,206\end{array}$ & $\begin{array}{r}30,717 \\
1,742 \\
9,438 \\
23,021 \\
0 \\
0 \\
23,021\end{array}$ & $\begin{array}{r}508,037 \\
15,254 \\
175,242 \\
349,040 \\
0 \\
0 \\
348,040\end{array}$ & $\begin{array}{r}22,689 \\
2,142 \\
7,344 \\
17,486 \\
0 \\
0 \\
17,488\end{array}$ & $\begin{array}{r}21,384 \\
1,119 \\
8,379 \\
14,124 \\
0 \\
0 \\
14,124\end{array}$ \\
\hline 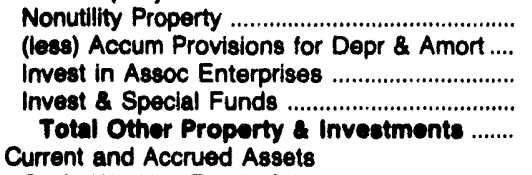 & $\begin{array}{r}0 \\
0 \\
0 \\
76,928 \\
76,928\end{array}$ & $\begin{array}{l}0 \\
0 \\
0 \\
6 \\
6\end{array}$ & $\begin{array}{r}0 \\
0 \\
0 \\
6,230 \\
6,230\end{array}$ & $\begin{array}{r}0 \\
0 \\
0 \\
68,752 \\
\mathbf{6 9 , 7 5 2}\end{array}$ & $\begin{array}{r}0 \\
0 \\
0 \\
3,536 \\
\mathbf{3 , 5 3 6}\end{array}$ & $\begin{array}{r}0 \\
0 \\
0 \\
434 \\
434\end{array}$ \\
\hline 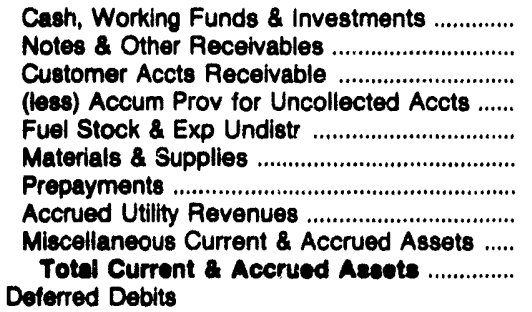 & $\begin{array}{r}46,139 \\
46,368 \\
0 \\
0 \\
0 \\
10,457 \\
0 \\
0 \\
4,437 \\
107,402\end{array}$ & $\begin{array}{r}4,958 \\
2,580 \\
0 \\
0 \\
0 \\
536 \\
8 \\
0 \\
635 \\
8,717\end{array}$ & $\begin{array}{r}3,181 \\
1,789 \\
0 \\
0 \\
0 \\
564 \\
23 \\
0 \\
51 \\
5,608\end{array}$ & $\begin{array}{r}31,723 \\
3,077 \\
32,515 \\
2,287 \\
0 \\
6,327 \\
247 \\
0 \\
297 \\
71,000\end{array}$ & $\begin{array}{r}602 \\
857 \\
0 \\
0 \\
0 \\
316 \\
11 \\
0 \\
1,345 \\
3,131\end{array}$ & $\begin{array}{r}1,446 \\
60 \\
2,306 \\
278 \\
0 \\
355 \\
0 \\
0 \\
24 \\
3,013\end{array}$ \\
\hline 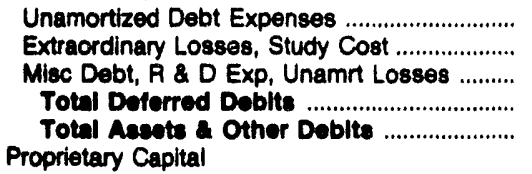 & $\begin{array}{r}4,320 \\
0 \\
17,144 \\
21,464 \\
680,652\end{array}$ & $\begin{array}{r}0 \\
0 \\
1,570 \\
1,570 \\
27,569\end{array}$ & $\begin{array}{r}29 \\
0 \\
1,356 \\
1,395 \\
38,243\end{array}$ & $\begin{array}{r}1,962 \\
4 \\
26,616 \\
28,682 \\
517,283\end{array}$ & $\begin{array}{r}110 \\
0 \\
2,116 \\
2,226 \\
28,380\end{array}$ & $\begin{array}{r}30 \\
5 \\
273 \\
308 \\
18,770\end{array}$ \\
\hline 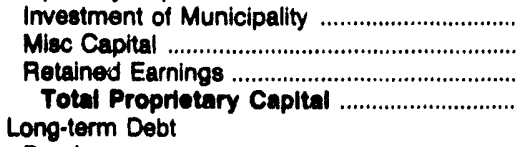 & $\begin{array}{r}0 \\
0 \\
321,748 \\
321,749\end{array}$ & $\begin{array}{r}0 \\
0 \\
20,177 \\
20,177\end{array}$ & $\begin{array}{r}0 \\
0 \\
25,403 \\
25,403\end{array}$ & $\begin{array}{r}0 \\
0 \\
252,570 \\
252,670\end{array}$ & $\begin{array}{r}0 \\
0 \\
16,925 \\
16,925\end{array}$ & $\begin{array}{r}0 \\
0 \\
11,082 \\
11,082\end{array}$ \\
\hline 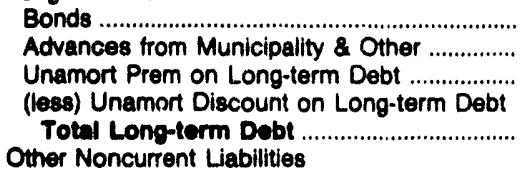 & $\begin{array}{r}266,865 \\
9,268 \\
0 \\
0 \\
276,133\end{array}$ & $\begin{array}{r}2 \\
1,523 \\
0 \\
0 \\
1,525\end{array}$ & $\begin{array}{r}4,080 \\
1,187 \\
0 \\
0 \\
5,287\end{array}$ & $\begin{array}{r}162,340 \\
25,415 \\
0 \\
1,679 \\
186,076\end{array}$ & $\begin{array}{r}4,475 \\
1,189 \\
-64 \\
0 \\
5,601\end{array}$ & $\begin{array}{r}3,215 \\
0 \\
0 \\
34 \\
3,181\end{array}$ \\
\hline $\begin{array}{l}\text { Accum Operating Provisions .......................... } \\
\text { Accum Prov for Rate Refunds ........................ } \\
\text { Total Other Noncurrent Liablities .......... } \\
\text { Current and Accrued Liabilities }\end{array}$ & $\begin{array}{l}0 \\
0 \\
0\end{array}$ & $\begin{array}{l}0 \\
0 \\
0\end{array}$ & $\begin{array}{l}0 \\
0 \\
0\end{array}$ & $\begin{array}{r}2,134 \\
0 \\
2,134\end{array}$ & $\begin{array}{l}0 \\
0 \\
0\end{array}$ & $\begin{array}{l}0 \\
0 \\
0\end{array}$ \\
\hline 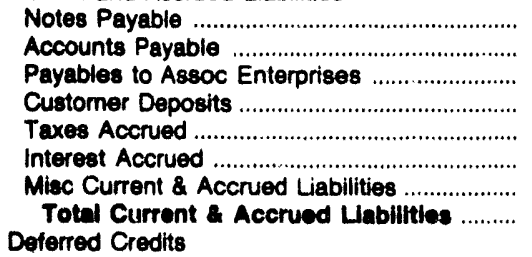 & $\begin{array}{r}0 \\
52,866 \\
0 \\
0 \\
-412 \\
0 \\
3,897 \\
56,552\end{array}$ & $\begin{array}{r}0 \\
2,579 \\
0 \\
1,155 \\
0 \\
0 \\
852 \\
4,586\end{array}$ & $\begin{array}{r}0 \\
3,003 \\
0 \\
1,422 \\
0 \\
59 \\
388 \\
4,882\end{array}$ & $\begin{array}{r}0 \\
43,881 \\
0 \\
9,862 \\
0 \\
18,913 \\
151 \\
72,007\end{array}$ & $\begin{array}{r}0 \\
3,106 \\
0 \\
551 \\
0 \\
95 \\
88 \\
3,840\end{array}$ & $\begin{array}{r}0 \\
3,432 \\
304 \\
266 \\
0 \\
77 \\
71 \\
4,150\end{array}$ \\
\hline 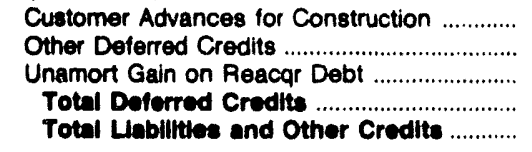 & $\begin{array}{r}1,982 \\
24,136 \\
0 \\
26,118 \\
\mathbf{6 8 0 , 5 5 2}\end{array}$ & $\begin{array}{r}0 \\
1,300 \\
0 \\
1,300 \\
27,680\end{array}$ & $\begin{array}{r}0 \\
691 \\
0 \\
691 \\
38,243\end{array}$ & $\begin{array}{r}821 \\
2,876 \\
0 \\
3,097 \\
517,283\end{array}$ & $\begin{array}{r}12 \\
1 \\
0 \\
13 \\
28,380\end{array}$ & $\begin{array}{r}0 \\
367 \\
0 \\
367 \\
18,779\end{array}$ \\
\hline
\end{tabular}

Note: Totals may not equal sum of components because of independent rounding.

Source: Engrgy Information Administration, Form EIA-412, "Annual Report of Public Electric Utilities." 
Table 22. Balance Sheet by Major U.S. Publicly Owned Electric Utility Within State at End of Perlod, 1992 (Continued) (Thousand Dollars)

\begin{tabular}{|c|c|c|c|c|c|c|}
\hline Item & $\begin{array}{c}\text { Tennessee } \\
\text { Paris } \\
\text { City of } \\
\text { June } 30\end{array}$ & $\begin{array}{l}\text { Tennessee } \\
\text { Pulaskl } \\
\text { Clty of } \\
\text { June } 30\end{array}$ & $\begin{array}{l}\text { Tennessee } \\
\text { Ripley } \\
\text { Clity of } \\
\text { June } 30\end{array}$ & $\begin{array}{l}\text { Tennessee } \\
\text { Rockwood } \\
\text { City of } \\
\text { June } 30\end{array}$ & $\begin{array}{c}\text { Tennessee } \\
\text { Sevier } \\
\text { County } \\
\text { Electric } \\
\text { System } \\
\text { June } 30\end{array}$ & $\begin{array}{c}\text { Tennessee } \\
\text { Shelbyville } \\
\text { City of } \\
\text { June } 30\end{array}$ \\
\hline 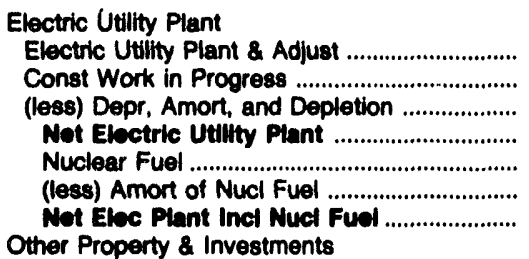 & $\begin{array}{r}23,572 \\
724 \\
9,776 \\
14,620 \\
0 \\
0 \\
14,520\end{array}$ & $\begin{array}{r}18,715 \\
2,898 \\
7,860 \\
13,758 \\
0 \\
0 \\
13,753\end{array}$ & $\begin{array}{r}7,137 \\
27 \\
2,234 \\
4,930 \\
0 \\
0 \\
4,930\end{array}$ & $\begin{array}{r}15,304 \\
141 \\
4,984 \\
10,461 \\
0 \\
0 \\
10,461\end{array}$ & $\begin{array}{r}55,643 \\
404 \\
13,790 \\
42,258 \\
0 \\
0 \\
42,258\end{array}$ & $\begin{array}{r}10,930 \\
85 \\
4,174 \\
6,841 \\
0 \\
0 \\
6,841\end{array}$ \\
\hline 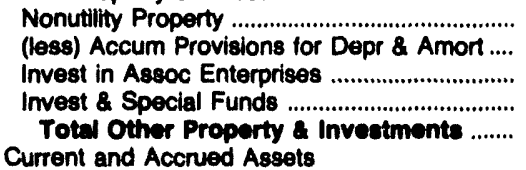 & $\begin{array}{r}0 \\
0 \\
0 \\
2,267 \\
2,267\end{array}$ & $\begin{array}{r}0 \\
0 \\
0 \\
1,608 \\
1,608\end{array}$ & $\begin{array}{r}0 \\
0 \\
0 \\
5,163 \\
\mathbf{5 , 1 6 3}\end{array}$ & $\begin{array}{l}0 \\
0 \\
0 \\
4 \\
4\end{array}$ & $\begin{array}{r}0 \\
0 \\
0 \\
823 \\
823\end{array}$ & $\begin{array}{l}0 \\
0 \\
0 \\
0 \\
0\end{array}$ \\
\hline 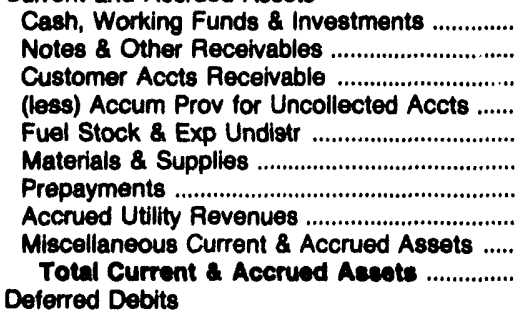 & $\begin{array}{r}1,978 \\
1,032 \\
0 \\
0 \\
0 \\
225 \\
23 \\
0 \\
30 \\
3,288\end{array}$ & $\begin{array}{r}531 \\
1,436 \\
0 \\
0 \\
0 \\
203 \\
89 \\
0 \\
859 \\
3,118\end{array}$ & $\begin{array}{r}377 \\
1,120 \\
0 \\
0 \\
0 \\
162 \\
51 \\
0 \\
15 \\
1,725\end{array}$ & $\begin{array}{r}82 \\
536 \\
0 \\
0 \\
0 \\
164 \\
0 \\
0 \\
52 \\
834\end{array}$ & $\begin{array}{r}3,274 \\
2,400 \\
0 \\
0 \\
0 \\
719 \\
0 \\
0 \\
1,933 \\
8,327\end{array}$ & $\begin{array}{r}3,320 \\
1,612 \\
0 \\
0 \\
0 \\
167 \\
34 \\
0 \\
75 \\
5,207\end{array}$ \\
\hline $\begin{array}{l}\text { Unamortized Debt Expenses .......................... } \\
\text { Extraordinary Losses, Study Cost ..................... } \\
\text { Hilsc Debt, R \& D Exp, Unamrt Loseses ......... } \\
\text { Total Deferred Debits ..................................... } \\
\text { Total Aasets \& Other Debite ...................... } \\
\text { Proprietary Capital }\end{array}$ & $\begin{array}{r}50 \\
0 \\
1,561 \\
1,811 \\
21,689\end{array}$ & $\begin{array}{r}22 \\
0 \\
371 \\
392 \\
18,872\end{array}$ & $\begin{array}{r}0 \\
0 \\
748 \\
748 \\
12,568\end{array}$ & $\begin{array}{r}0 \\
0 \\
16 \\
16 \\
11,315\end{array}$ & $\begin{array}{r}32 \\
0 \\
1,801 \\
1,832 \\
53,240\end{array}$ & $\begin{array}{r}0 \\
0 \\
586 \\
588 \\
12,635\end{array}$ \\
\hline 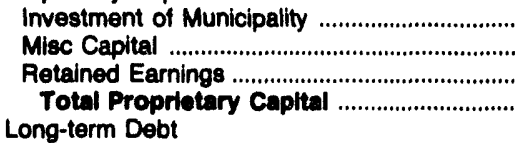 & $\begin{array}{r}0 \\
0 \\
14,460 \\
14,460\end{array}$ & $\begin{array}{r}0 \\
0 \\
13,486 \\
13,488\end{array}$ & $\begin{array}{r}0 \\
0 \\
10,120 \\
10,120\end{array}$ & $\begin{array}{r}0 \\
0 \\
9,617 \\
9,617\end{array}$ & $\begin{array}{r}0 \\
0 \\
40,346 \\
40,348\end{array}$ & $\begin{array}{r}0 \\
0 \\
9,993 \\
9,993\end{array}$ \\
\hline $\begin{array}{l}\text { Bdvances from Municipality \& Other ............... } \\
\text { Unamort Prem on Long-term Debt ............... } \\
\text { (less) Unamort Discount on Long-term Debt } \\
\text { Total Long-term Debt................................. } \\
\text { Other Noncurrent Liabilities }\end{array}$ & $\begin{array}{r}3,320 \\
1,564 \\
0 \\
0 \\
4,884\end{array}$ & $\begin{array}{r}2,835 \\
383 \\
0 \\
0 \\
3,318\end{array}$ & $\begin{array}{r}0 \\
743 \\
0 \\
0 \\
743\end{array}$ & $\begin{array}{r}0 \\
18 \\
0 \\
0 \\
18\end{array}$ & $\begin{array}{r}4,423 \\
1,618 \\
-27 \\
0 \\
6,014\end{array}$ & $\begin{array}{r}0 \\
603 \\
0 \\
0 \\
603\end{array}$ \\
\hline 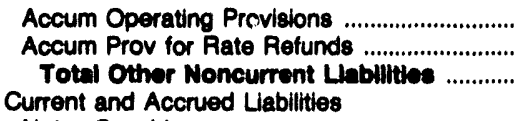 & $\begin{array}{l}0 \\
0 \\
0\end{array}$ & $\begin{array}{l}0 \\
0 \\
0\end{array}$ & $\begin{array}{l}0 \\
0 \\
0\end{array}$ & $\begin{array}{l}0 \\
0 \\
0\end{array}$ & $\begin{array}{l}0 \\
0 \\
0\end{array}$ & $\begin{array}{l}0 \\
0 \\
0\end{array}$ \\
\hline 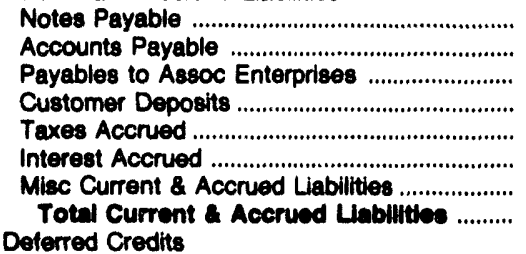 & $\begin{array}{r}0 \\
1,562 \\
0 \\
451 \\
0 \\
59 \\
238 \\
2,310\end{array}$ & $\begin{array}{r}0 \\
1,621 \\
0 \\
307 \\
28 \\
17 \\
91 \\
2,083\end{array}$ & $\begin{array}{r}0 \\
912 \\
0 \\
376 \\
0 \\
0 \\
117 \\
1,405\end{array}$ & $\begin{array}{r}0 \\
913 \\
0 \\
361 \\
0 \\
0 \\
262 \\
1,636\end{array}$ & $\begin{array}{r}0 \\
3,238 \\
0 \\
2,849 \\
0 \\
139 \\
636 \\
6,863\end{array}$ & $\begin{array}{r}0 \\
1,451 \\
0 \\
431 \\
0 \\
0 \\
61 \\
1,043\end{array}$ \\
\hline 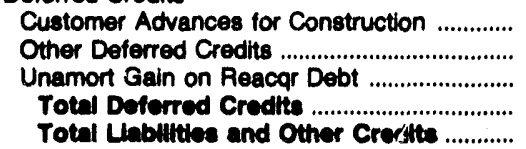 & $\begin{array}{r}0 \\
32 \\
0 \\
32 \\
21,696\end{array}$ & $\begin{array}{r}0 \\
6 \\
0 \\
18,872\end{array}$ & $\begin{array}{r}0 \\
298 \\
0 \\
298 \\
12,688\end{array}$ & $\begin{array}{r}0 \\
144 \\
0 \\
144 \\
11,315\end{array}$ & $\begin{array}{r}0 \\
18 \\
0 \\
18 \\
53,240\end{array}$ & $\begin{array}{r}0 \\
86 \\
0 \\
86 \\
12,635\end{array}$ \\
\hline
\end{tabular}

Note: Totals may not equal sum of components because of independent rounding.

Source: Energy Information Administration, Form EIA-412, "Annual Feport of Public Electric Utilities." 
Table 22. Balance Sheet by Major U.S. Publicly Owned Electric Utility Within State at End of Period, 1992 (Continued) (Thousand Dollars)

\begin{tabular}{|c|c|c|c|c|c|c|}
\hline Item & $\begin{array}{l}\text { Tennessee } \\
\text { Springfield } \\
\text { City of } \\
\text { June } 30\end{array}$ & $\begin{array}{c}\text { Tennessee } \\
\text { Sweetwater } \\
\text { City of } \\
\text { June } 30\end{array}$ & $\begin{array}{c}\text { Tennessee } \\
\text { Tullahoma } \\
\text { Board } \\
\text { of } \\
\text { Pub Utils } \\
\text { June } 30\end{array}$ & $\begin{array}{c}\text { Tennessee } \\
\text { Union } \\
\text { City City of } \\
\text { June } 30\end{array}$ & $\begin{array}{l}\text { Tennessee } \\
\text { Weakley } \\
\text { County } \\
\text { Mun } \\
\text { Elec Sys } \\
\text { June } 30\end{array}$ & $\begin{array}{l}\text { Texas } \\
\text { Austin } \\
\text { City of } \\
\text { September } 30\end{array}$ \\
\hline \multicolumn{7}{|l|}{ Electric Utility Plant } \\
\hline 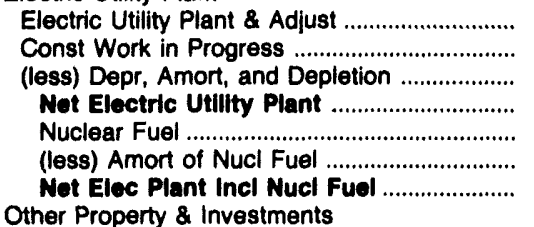 & $\begin{array}{r}8,977 \\
627 \\
3,603 \\
6,001 \\
0 \\
0 \\
6,001\end{array}$ & $\begin{array}{r}8,563 \\
1,247 \\
3,180 \\
7,630 \\
0 \\
0 \\
7,630\end{array}$ & $\begin{array}{r}10,076 \\
178 \\
3,636 \\
6,619 \\
0 \\
0 \\
6,619\end{array}$ & $\begin{array}{r}9,155 \\
182 \\
3,188 \\
6,150 \\
0 \\
0 \\
6,150\end{array}$ & $\begin{array}{r}25,552 \\
971 \\
11,965 \\
14,558 \\
0 \\
0 \\
14,558\end{array}$ & $\begin{array}{r}2,017,484 \\
106,502 \\
498,858 \\
1,625,128 \\
88,390 \\
51,093 \\
1,662,425\end{array}$ \\
\hline 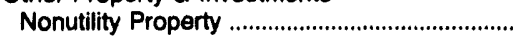 & 0 & 0 & 0 & 37 & 0 & 0 \\
\hline (less) Accum Provisions for Depr \& Amort .... & 0 & 0 & 0 & 0 & 0 & 0 \\
\hline 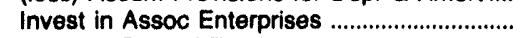 & 0 & 0 & 0 & 0 & 0 & 0 \\
\hline $\begin{array}{l}\text { Invest \& Special Funds } \\
\text { Total Other Property \& Investments ........ } \\
\text { Current and Accrued Assets }\end{array}$ & $\begin{array}{l}920 \\
920\end{array}$ & $\begin{array}{l}717 \\
717\end{array}$ & $\begin{array}{l}321 \\
321\end{array}$ & $\begin{array}{l}353 \\
390\end{array}$ & $\begin{array}{l}1,580 \\
1,580\end{array}$ & $\begin{array}{l}310,679 \\
310,679\end{array}$ \\
\hline Cash, Working Funds \& Investments .............. & 92 & 2,301 & 3,004 & 3,376 & 851 & 23,199 \\
\hline 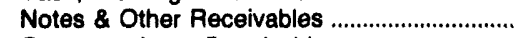 & 839 & 274 & 735 & 1,097 & 1,519 & 16 \\
\hline Customer Accts Fieceivable ................................ & 0 & 0 & 0 & 0 & 0 & 81,507 \\
\hline (less) Accum Prov for Uncollected Accts ...... & 0 & 0 & 0 & 0 & 0 & 41,330 \\
\hline 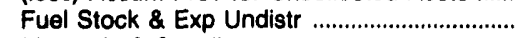 & 0 & 0 & 0 & 0 & 0 & 16,495 \\
\hline 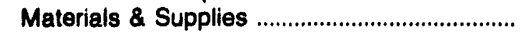 & 177 & 190 & 342 & 188 & 360 & 27,646 \\
\hline 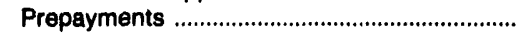 & 0 & 58 & 47 & 2 & 48 & 2,439 \\
\hline 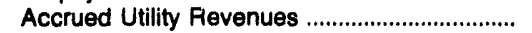 & 0 & 0 & 0 & 0 & 0 & 0 \\
\hline Miscellaneous Current \& Accrued Assets ..... & $\begin{array}{r}12 \\
120\end{array}$ & 26 & 32 & $\begin{array}{r}65 \\
728\end{array}$ & 53 & $\begin{array}{r}0 \\
10092\end{array}$ \\
\hline \multicolumn{6}{|l|}{ Deferred Debits } & 109,973 \\
\hline 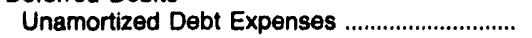 & 12 & 0 & 16 & 0 & 0 & 8,862 \\
\hline 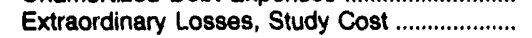 & 0 & 0 & 0 & 4 & 0 & 0 \\
\hline Misc Debt, R \& D Exp, Unamrt Losses .......... & 485 & 741 & 1,114 & 177 & 1,863 & 152,362 \\
\hline $\begin{array}{l}\text { Total Deferred Debits ................................. } \\
\text { Total Assets \& Other Debits .................... } \\
\text { Proprietary Capital }\end{array}$ & $\begin{array}{r}497 \\
8,538\end{array}$ & $\begin{array}{r}741 \\
11,939\end{array}$ & $\begin{array}{r}1,130 \\
12,231\end{array}$ & $\begin{array}{r}181 \\
11,449\end{array}$ & $\begin{array}{r}1,863 \\
20,832\end{array}$ & $\begin{array}{r}161,224 \\
2,244,302\end{array}$ \\
\hline 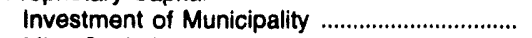 & 0 & 0 & 0 & 0 & 0 & 33,522 \\
\hline 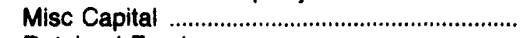 & 0 & 0 & 0 & 0 & 0 & 0 \\
\hline 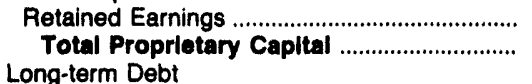 & $\begin{array}{l}4,853 \\
4,853\end{array}$ & $\begin{array}{l}8,599 \\
8,599\end{array}$ & $\begin{array}{l}7,271 \\
7,271\end{array}$ & $\begin{array}{l}9,806 \\
9,808\end{array}$ & $\begin{array}{l}16,399 \\
16,399\end{array}$ & $\begin{array}{l}396,004 \\
429,528\end{array}$ \\
\hline $\begin{array}{l}\text { Long-term Debt } \\
\text { Bonds }\end{array}$ & 1,600 & 0 & 2,100 & \multicolumn{3}{|c|}{ Long-term Debt } \\
\hline Advances from Municipality \& Other ................ & 503 & 753 & 721 & $\begin{array}{r}0 \\
145\end{array}$ & $\begin{array}{r}0 \\
1,876\end{array}$ & $\begin{array}{r}1,678,637 \\
18,850\end{array}$ \\
\hline Unamort Prem on Long-term Debt ................... & -28 & 0 & -9 & 0 & $\begin{array}{r}1,0 \\
0\end{array}$ & 17,164 \\
\hline (less) Unamort Discount on Long-term Debt & 0 & 0 & 0 & 0 & 0 & 63,572 \\
\hline 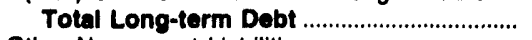 & 2,075 & 753 & 2,811 & 145 & 1,876 & $1,651,079$ \\
\hline \multicolumn{7}{|l|}{ Other Noncurrent Liabilities } \\
\hline Accum Operating Provisions .............................. & 0 & 0 & 0 & 0 & 0 & 10,973 \\
\hline Accum Prov for Rate Refunds ............................. & 0 & 0 & 0 & 0 & 0 & 0 \\
\hline \multirow{2}{*}{\multicolumn{5}{|c|}{ Current and Accrued Liabilities }} & & 10,973 \\
\hline & & & 0 & 0 & & \\
\hline $\begin{array}{l}\text { Notes Payable } \\
\text { Accounts Payable }\end{array}$ & 1,146 & 2,357 & 1,266 & 1,164 & 1613 & $\begin{array}{r}0 \\
57928\end{array}$ \\
\hline $\begin{array}{l}\text { Accounts Payable } \\
\text { Payables to Assoc Enterprises }\end{array}$ & $\begin{array}{r}1,140 \\
0\end{array}$ & 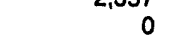 & $\begin{array}{r}1,200 \\
0\end{array}$ & 1,104 & $\begin{array}{r}1,010 \\
0\end{array}$ & $\begin{array}{r}57,928 \\
0\end{array}$ \\
\hline $\begin{array}{l}\text { Payables to Assoc Enterprises } \\
\text { Customer Deposits }\end{array}$ & 82 & 136 & 501 & 80 & 418 & $\begin{array}{r}0 \\
5370\end{array}$ \\
\hline Customer Deposits & $\begin{array}{r}02 \\
0\end{array}$ & $\begin{array}{r}100 \\
0\end{array}$ & 0 & 0 & $\begin{array}{r}410 \\
0\end{array}$ & 5,370 \\
\hline 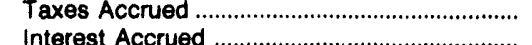 & 11 & 0 & 32 & 0 & & 891 \\
\hline Interest Accrued ..................................... & $\begin{array}{l}11 \\
88\end{array}$ & 93 & 139 & 205 & $\begin{array}{r}0 \\
517\end{array}$ & 66,595 \\
\hline $\begin{array}{l}\text { Misc Current \& Accrued Liabilities ................... } \\
\text { Total Current Accrued Llabilities ......... } \\
\text { Deferred Credits }\end{array}$ & $\begin{array}{r}88 \\
1,327\end{array}$ & 2,586 & $\begin{array}{r}139 \\
1,939\end{array}$ & $\begin{array}{r}205 \\
1,449\end{array}$ & $\begin{array}{r}517 \\
2,548\end{array}$ & $\begin{array}{r}8,245 \\
139,029\end{array}$ \\
\hline Customer Advances for Construction .............. & 0 & 0 & 0 & 0 & 0 & 0 \\
\hline 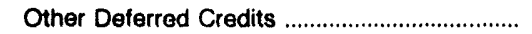 & 283 & 0 & 210 & 48 & 10 & 4,181 \\
\hline Unamort Gain on Reacar Debt ........................... & 0 & 0 & 0 & 0 & 0 & 9,513 \\
\hline $\begin{array}{l}\text { Total Deferred Credits } \\
\text { Total Llabilities and Other Credite }\end{array}$ & $\begin{array}{r}283 \\
8,538\end{array}$ & $\begin{array}{r}0 \\
11,939\end{array}$ & $\begin{array}{r}210 \\
12,231\end{array}$ & $\begin{array}{r}48 \\
11,449\end{array}$ & $\begin{array}{r}10 \\
20,832\end{array}$ & $\begin{array}{r}13,695 \\
2,244,302\end{array}$ \\
\hline
\end{tabular}

Note: Totals may not equal sum of components because of independent rounding.

Source: Energy Information Administration, Form EIA-412, "Annual Report of Public Electric Utilities." 
Table 22. Balance Sheet by Major U.S. Publicly Owned Electric Utility Within State at End of Perlod, 1992 (Continued) (Thousand Dollars)

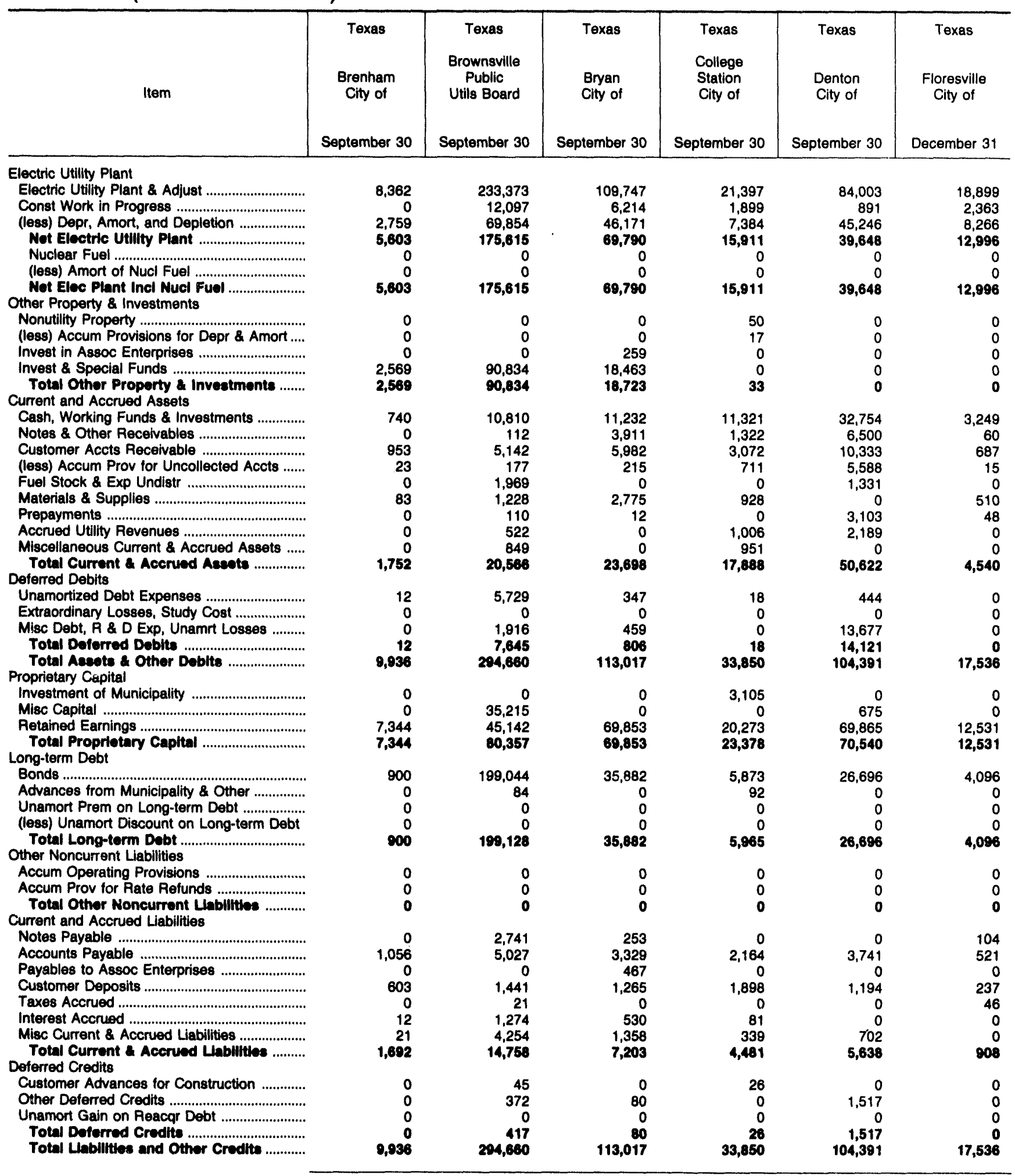

Note: Totals may not equal sum of components because of independent rounding.

Source: Energy Information Administration, Form EIA-412, "Annual Report of Public Electric Utilities." 
Table 22. Balance Sheet by Major U.S. Publlcly Owned Electric UtIlity Within State at End of Period, 1992 (Continued) (Thousand Dollars)

\begin{tabular}{|c|c|c|c|c|c|c|}
\hline Item & $\begin{array}{c}\text { Texas } \\
\text { Garland } \\
\text { City of } \\
\text { September } 30\end{array}$ & $\begin{array}{c}\text { Texas } \\
\text { Georgetown } \\
\text { City of } \\
\text { September } 30\end{array}$ & $\begin{array}{c}\text { Texas } \\
\text { Greenville } \\
\text { City of } \\
\text { September } 30\end{array}$ & $\begin{array}{l}\text { Texas } \\
\text { Kerrville } \\
\text { Public } \\
\text { Utility } \\
\text { Board } \\
\text { September } 30\end{array}$ & $\begin{array}{l}\text { Texas } \\
\text { Lower } \\
\text { Colorado } \\
\text { Rlver } \\
\text { Authority } \\
\text { June } 30\end{array}$ & $\begin{array}{l}\text { Texas } \\
\text { Lubbock } \\
\text { City of } \\
\text { September } 30\end{array}$ \\
\hline 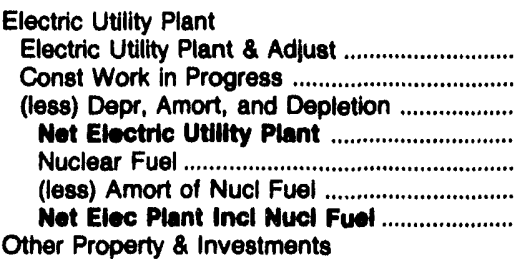 & $\begin{array}{r}182,841 \\
0 \\
78,799 \\
114,042 \\
0 \\
0 \\
114,042\end{array}$ & $\begin{array}{r}4,536 \\
0 \\
1,779 \\
2,757 \\
0 \\
0 \\
2,757\end{array}$ & $\begin{array}{r}46,393 \\
0 \\
26,134 \\
20,260 \\
0 \\
0 \\
20,280\end{array}$ & $\begin{array}{r}25,863 \\
408 \\
7,727 \\
18,544 \\
0 \\
0 \\
18,544\end{array}$ & $\begin{array}{r}1,336,514 \\
153,398 \\
354,737 \\
1,135,175 \\
0 \\
0 \\
1,135,175\end{array}$ & $\begin{array}{r}97,105 \\
35,254 \\
47,978 \\
84,381 \\
0 \\
0 \\
84,381\end{array}$ \\
\hline 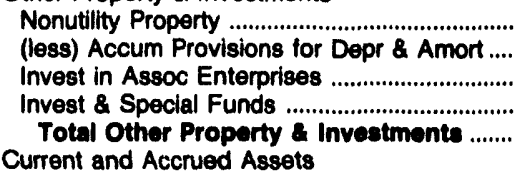 & $\begin{array}{r}0 \\
0 \\
0 \\
\mathbf{5 , 5 8 9} \\
\mathbf{5 , 5 8 9}\end{array}$ & $\begin{array}{r}447 \\
65 \\
0 \\
809 \\
1,291\end{array}$ & $\begin{array}{r}0 \\
0 \\
0 \\
3,102 \\
3,102\end{array}$ & $\begin{array}{r}0 \\
0 \\
0 \\
6,347 \\
\mathbf{6 , 3 4 7}\end{array}$ & $\begin{array}{r}3,413 \\
1,263 \\
0 \\
124,735 \\
126,884\end{array}$ & $\begin{array}{l}0 \\
0 \\
0 \\
0 \\
0\end{array}$ \\
\hline 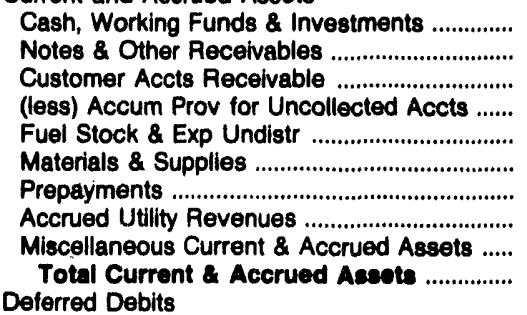 & $\begin{array}{r}38,556 \\
2,595 \\
16,402 \\
0 \\
0 \\
7,230 \\
14 \\
0 \\
287 \\
65,084\end{array}$ & $\begin{array}{r}5,112 \\
374 \\
1,176 \\
71 \\
0 \\
0 \\
0 \\
0 \\
0 \\
6,501\end{array}$ & $\begin{array}{r}7,967 \\
198 \\
4,183 \\
0 \\
303 \\
951 \\
0 \\
0 \\
0 \\
13,601\end{array}$ & $\begin{array}{r}6,025 \\
60 \\
918 \\
72 \\
0 \\
425 \\
0 \\
1,473 \\
5 \\
8,833\end{array}$ & $\begin{array}{r}30,063 \\
5,473 \\
29,532 \\
451 \\
38,202 \\
25,487 \\
3,845 \\
8,603 \\
3,010 \\
143,764\end{array}$ & $\begin{array}{r}8,907 \\
3,602 \\
0 \\
0 \\
0 \\
200 \\
0 \\
0 \\
262 \\
12,971\end{array}$ \\
\hline 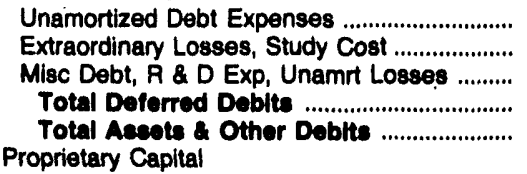 & $\begin{array}{r}0 \\
0 \\
35 \\
35 \\
184,750\end{array}$ & $\begin{array}{r}0 \\
0 \\
0 \\
0 \\
10,639\end{array}$ & $\begin{array}{r}486 \\
0 \\
0 \\
486 \\
37,449\end{array}$ & $\begin{array}{r}764 \\
0 \\
130 \\
894 \\
34,818\end{array}$ & $\begin{array}{r}17,755 \\
0 \\
439,610 \\
457,365 \\
1,863,188\end{array}$ & $\begin{array}{r}0 \\
1,766 \\
32,340 \\
34,105 \\
131,468\end{array}$ \\
\hline 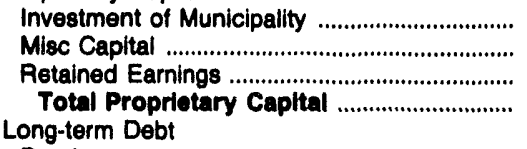 & $\begin{array}{r}0 \\
0 \\
147,928 \\
147,028\end{array}$ & $\begin{array}{r}3,654 \\
0 \\
5,633 \\
9,287\end{array}$ & $\begin{array}{r}200 \\
0 \\
14,515 \\
14,715\end{array}$ & $\begin{array}{r}0 \\
0 \\
884 \\
884\end{array}$ & $\begin{array}{r}0 \\
10,510 \\
395,965 \\
408,475\end{array}$ & $\begin{array}{r}7,918 \\
0 \\
78,548 \\
86,465\end{array}$ \\
\hline $\begin{array}{l}\text { Bonds } \\
\text { Advances from Municipality \& Other ............... } \\
\text { Unamort Prem on Long-term Debt ................ } \\
\text { (less) Unamort Discount on Long-term Debt } \\
\text { Total Long-term Debt ................................ } \\
\text { Other Noncurrent Liabilities }\end{array}$ & $\begin{array}{r}26,921 \\
0 \\
0 \\
0 \\
24,921\end{array}$ & $\begin{array}{r}49 \\
22 \\
0 \\
0 \\
70\end{array}$ & $\begin{array}{r}18,448 \\
0 \\
0 \\
0 \\
18,448\end{array}$ & $\begin{array}{r}32,115 \\
0 \\
0 \\
1,304 \\
30,811\end{array}$ & $\begin{array}{r}1,460,500 \\
5,616 \\
0 \\
122,036 \\
1,344,080\end{array}$ & $\begin{array}{r}35,327 \\
1,210 \\
0 \\
0 \\
36,537\end{array}$ \\
\hline 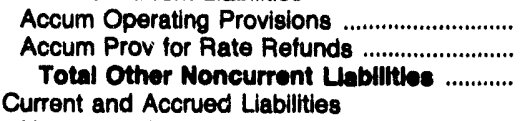 & $\begin{array}{l}0 \\
0 \\
0\end{array}$ & $\begin{array}{l}0 \\
0 \\
0\end{array}$ & $\begin{array}{l}0 \\
0 \\
0\end{array}$ & $\begin{array}{l}0 \\
0 \\
0\end{array}$ & $\begin{array}{l}0 \\
0 \\
0\end{array}$ & $\begin{array}{l}0 \\
0 \\
0\end{array}$ \\
\hline 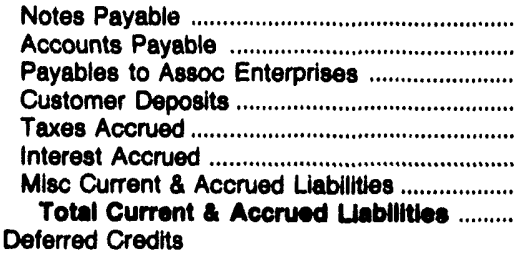 & $\begin{array}{r}168 \\
4,508 \\
34 \\
3,508 \\
0 \\
187 \\
1,451 \\
0,867\end{array}$ & $\begin{array}{r}0 \\
986 \\
0 \\
314 \\
0 \\
2 \\
0 \\
1,282\end{array}$ & $\begin{array}{r}1,328 \\
1,477 \\
36 \\
576 \\
0 \\
136 \\
220 \\
3,773\end{array}$ & $\begin{array}{r}0 \\
1,863 \\
0 \\
195 \\
0 \\
865 \\
0 \\
2,023\end{array}$ & $\begin{array}{r}0 \\
21,817 \\
0 \\
25 \\
883 \\
27,417 \\
13,683 \\
63,834\end{array}$ & $\begin{array}{r}0 \\
6,275 \\
0 \\
37 \\
138 \\
1,229 \\
776 \\
8,456\end{array}$ \\
\hline 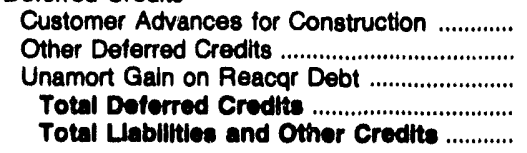 & $\begin{array}{r}0 \\
44 \\
0 \\
44 \\
184,780\end{array}$ & $\begin{array}{r}0 \\
0 \\
0 \\
0 \\
10,680\end{array}$ & $\begin{array}{r}513 \\
0 \\
0 \\
513 \\
37,449\end{array}$ & $\begin{array}{r}0 \\
0 \\
0 \\
0 \\
34,818\end{array}$ & $\begin{array}{r}1,099 \\
857 \\
46,842 \\
48,788 \\
1,863,188\end{array}$ & $\begin{array}{r}0 \\
0 \\
0 \\
0 \\
131,458\end{array}$ \\
\hline
\end{tabular}

Note: Totals may not equal sum of components because of independent rounding.

Source: Energy Information Administration, Form ElA-412, "Annual Report of Public Electric Utillties." 
Table 22. Balance Sheet by Major U.S. Publicly Owned Electric Utillty Within State at End of Perlod, 1992 (Continued) (Thousand Dollars)

\begin{tabular}{|c|c|c|c|c|c|c|}
\hline Item & $\begin{array}{l}\text { Texas } \\
\text { New Braunfels } \\
\text { City of } \\
\text { July } 31\end{array}$ & $\begin{array}{l}\text { Texas } \\
\text { Sam Rayburn } \\
\text { Municipal } \\
\text { Pwr } \\
\text { Agny } \\
\text { September } 30\end{array}$ & $\begin{array}{l}\text { Texas } \\
\text { San Antonio } \\
\text { City of } \\
\text { January } 31\end{array}$ & $\begin{array}{l}\text { Texas } \\
\text { San Marcos } \\
\text { City of } \\
\text { September } 30\end{array}$ & $\begin{array}{l}\text { Texas } \\
\text { Seguin } \\
\text { City of } \\
\text { September } 30\end{array}$ & $\begin{array}{c}\text { Texas } \\
\text { Texas } \\
\text { Municipal } \\
\text { Power Agency } \\
\text { September } 30\end{array}$ \\
\hline \multicolumn{7}{|l|}{ Electric Utility Plant } \\
\hline 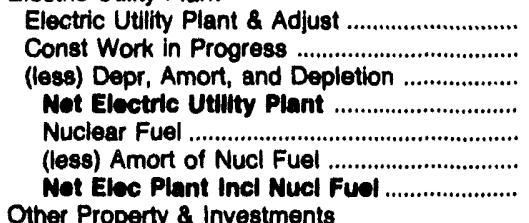 & $\begin{array}{r}49,147 \\
437 \\
17,808 \\
31,776 \\
0 \\
0 \\
31,776\end{array}$ & $\begin{array}{r}138,168 \\
1,184 \\
35,281 \\
104,082 \\
0 \\
0 \\
104,082\end{array}$ & $\begin{array}{r}4,323,282 \\
98,333 \\
633,919 \\
3,787,698 \\
162,629 \\
74,131 \\
3,876,194\end{array}$ & $\begin{array}{r}15,076 \\
597 \\
4,884 \\
10,789 \\
0 \\
0 \\
10,789\end{array}$ & $\begin{array}{r}6,194 \\
0 \\
3,442 \\
2,752 \\
0 \\
0 \\
2,752\end{array}$ & $\begin{array}{r}757,144 \\
113,192 \\
219,946 \\
650,390 \\
0 \\
0 \\
650,380\end{array}$ \\
\hline 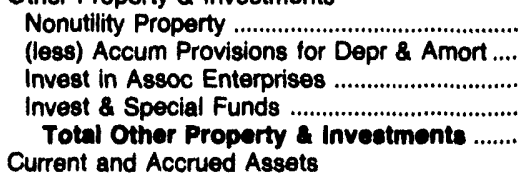 & $\begin{array}{r}60,126 \\
17,454 \\
0 \\
7,629 \\
50,301\end{array}$ & $\begin{array}{r}0 \\
0 \\
0 \\
33,008 \\
33,008\end{array}$ & $\begin{array}{r}0 \\
0 \\
0 \\
250,655 \\
250,655\end{array}$ & $\begin{array}{l}0 \\
0 \\
0 \\
0 \\
0\end{array}$ & $\begin{array}{r}0 \\
0 \\
0 \\
1,464 \\
1,494\end{array}$ & $\begin{array}{r}0 \\
0 \\
0 \\
205,306 \\
205,306\end{array}$ \\
\hline 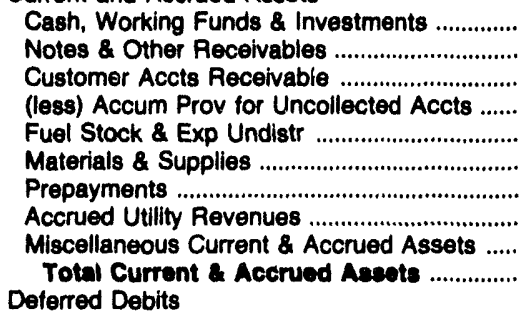 & $\begin{array}{r}5,813 \\
1,258 \\
3,566 \\
0 \\
0 \\
814 \\
95 \\
0 \\
0 \\
11,546\end{array}$ & $\begin{array}{r}23,735 \\
2,810 \\
1,816 \\
0 \\
1,763 \\
200 \\
55 \\
0 \\
257 \\
30,635\end{array}$ & $\begin{array}{r}200,870 \\
11,210 \\
65,515 \\
2,593 \\
25,941 \\
53,513 \\
2,918 \\
0 \\
4,800 \\
362,174\end{array}$ & $\begin{array}{r}12,830 \\
281 \\
2,576 \\
688 \\
0 \\
369 \\
0 \\
0 \\
217 \\
15,585\end{array}$ & $\begin{array}{r}413 \\
-38 \\
1,133 \\
0 \\
0 \\
593 \\
0 \\
450 \\
0 \\
2,551\end{array}$ & $\begin{array}{r}56,164 \\
8,518 \\
0 \\
0 \\
1,203 \\
3,699 \\
0 \\
0 \\
1,823 \\
71,407\end{array}$ \\
\hline 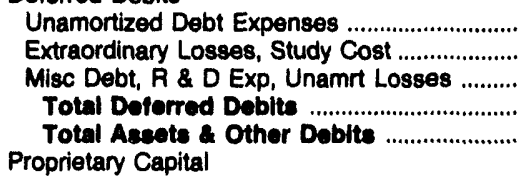 & $\begin{array}{r}0 \\
0 \\
0 \\
0 \\
\mathbf{e 3 , 6 2 3}\end{array}$ & $\begin{array}{r}5,125 \\
0 \\
68,483 \\
73,608 \\
241,312\end{array}$ & $\begin{array}{r}7,125 \\
0 \\
189,536 \\
196,661 \\
4,685,683\end{array}$ & $\begin{array}{r}1,008 \\
0 \\
-76 \\
933 \\
27,306\end{array}$ & $\begin{array}{r}47 \\
0 \\
0 \\
47 \\
6,815\end{array}$ & $\begin{array}{r}199,512 \\
721 \\
312,680 \\
512,913 \\
1,440,016\end{array}$ \\
\hline 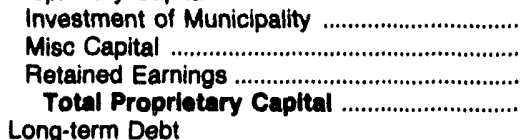 & $\begin{array}{r}2,426 \\
0 \\
32,175 \\
34,600\end{array}$ & $\begin{array}{r}0 \\
0 \\
37,512 \\
\mathbf{3 7 , 5 1 2}\end{array}$ & $\begin{array}{r}0 \\
0 \\
1,778,842 \\
1,778,842\end{array}$ & $\begin{array}{r}0 \\
318 \\
8,197 \\
8,514\end{array}$ & $\begin{array}{r}0 \\
3,112 \\
2,071 \\
5,183\end{array}$ & $\begin{array}{r}0 \\
0 \\
23,495 \\
23,495\end{array}$ \\
\hline 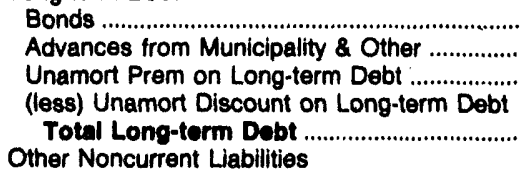 & $\begin{array}{r}28,565 \\
15,585 \\
0 \\
170 \\
43,970\end{array}$ & $\begin{array}{r}202,135 \\
0 \\
0 \\
0 \\
202,135\end{array}$ & $\begin{array}{r}3,016,750 \\
30,000 \\
0 \\
394,847 \\
2,651,903\end{array}$ & $\begin{array}{r}15,290 \\
0 \\
0 \\
0 \\
15,290\end{array}$ & $\begin{array}{l}0 \\
0 \\
0 \\
0 \\
0\end{array}$ & $\begin{array}{r}1,217,820 \\
175,192 \\
0 \\
39,887 \\
1,353,125\end{array}$ \\
\hline $\begin{array}{l}\text { Accum Operating Provisions } \\
\text { Accum Prov for Rate Refunds ............................. } \\
\text { Total Other Noncurrent Llabilitios ............ } \\
\text { Current and Accrued Liabilities }\end{array}$ & $\begin{array}{l}0 \\
0 \\
0\end{array}$ & $\begin{array}{l}0 \\
0 \\
0\end{array}$ & $\begin{array}{r}21,396 \\
0 \\
21,398\end{array}$ & $\begin{array}{r}45 \\
0 \\
45\end{array}$ & $\begin{array}{l}0 \\
0 \\
0\end{array}$ & $\begin{array}{l}0 \\
0 \\
0\end{array}$ \\
\hline 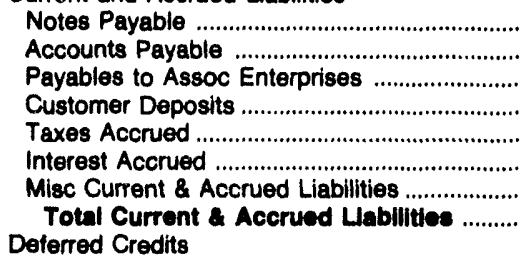 & $\begin{array}{r}950 \\
3,489 \\
0 \\
418 \\
0 \\
308 \\
1,726 \\
6,891\end{array}$ & $\begin{array}{r}0 \\
315 \\
0 \\
0 \\
0 \\
1,351 \\
0 \\
1,686\end{array}$ & $\begin{array}{r}8,800 \\
94,546 \\
86,455 \\
23,509 \\
832 \\
772 \\
2,940 \\
217,854\end{array}$ & $\begin{array}{r}240 \\
1,539 \\
272 \\
845 \\
56 \\
0 \\
505 \\
3,457\end{array}$ & $\begin{array}{r}0 \\
1,053 \\
0 \\
212 \\
0 \\
0 \\
367 \\
1,632\end{array}$ & $\begin{array}{r}36,000 \\
19,097 \\
5,436 \\
0 \\
0 \\
0 \\
2,863 \\
63,386\end{array}$ \\
\hline $\begin{array}{l}\text { Customer Advances for Construction } \\
\text { Other Deferred Credits ............................................ } \\
\text { Unamort Gain on Reacqr Debt ..................... } \\
\text { Total Deferred Credlits ............................... } \\
\text { Total Lublities and Other Credite ........... }\end{array}$ & $\begin{array}{r}8,152 \\
0 \\
0 \\
8,152 \\
93,623\end{array}$ & $\begin{array}{r}0 \\
0 \\
0 \\
0 \\
241,312\end{array}$ & $\begin{array}{r}7,203 \\
8,484 \\
0 \\
15,687 \\
4,685,683\end{array}$ & $\begin{array}{r}0 \\
0 \\
0 \\
0 \\
27,306\end{array}$ & $\begin{array}{r}0 \\
0 \\
0 \\
0 \\
6,815\end{array}$ & $\begin{array}{r}0 \\
0 \\
0 \\
0 \\
1,440,018\end{array}$ \\
\hline
\end{tabular}

Note: Totals may not equal sum of components because of independent rounding.

Source: Energy Information Administration, Form ElA-412, "Annual Report of Public Electric Utilities." 
Table 22. Balance Sheet by Major U.S. Publlcly Owned Electric Utility Within State at End of Period, 1992 (Continued) (Thousand Dollars)

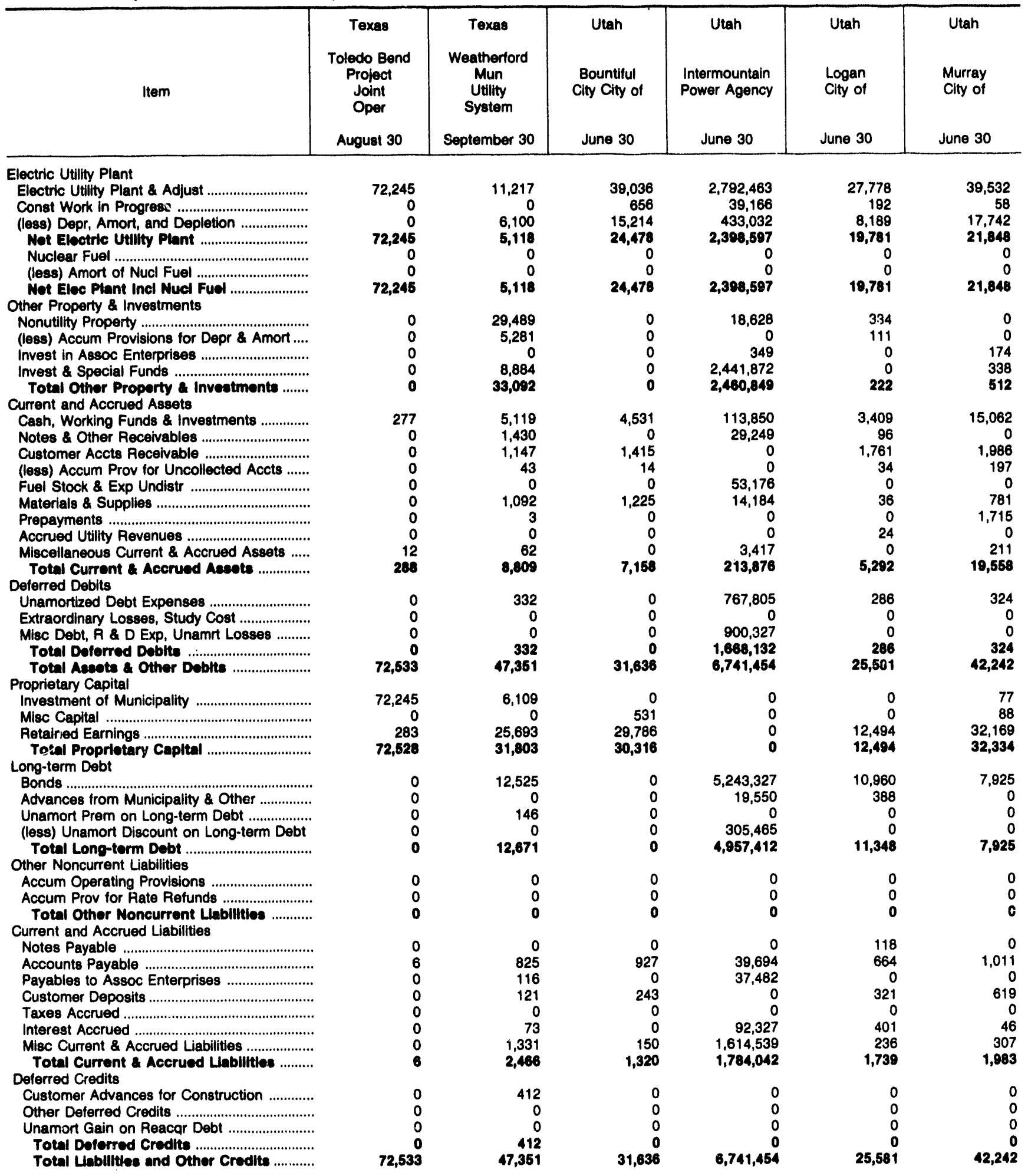

Note: Totals may not equal sum of components because of independent rounding.

Source: Energy Information Administration, Form ElA-412, "Annual Report of Public Electric Utilities." 
Table 22. Balance Sheet by Major U.S. Publicly Owned Electric Utillty Within State at End of Period, 1992 (Continued) (Thousand Dollars)

\begin{tabular}{|c|c|c|c|c|c|c|}
\hline Item & $\begin{array}{l}\text { Utah } \\
\text { Provo } \\
\text { City Corp } \\
\text { June } 30\end{array}$ & $\begin{array}{c}\text { Utah } \\
\text { St George } \\
\text { City of } \\
\text { June } 30\end{array}$ & $\begin{array}{c}\text { Utah } \\
\text { Utah } \\
\text { Associated } \\
\text { Mun } \\
\text { Power Sys } \\
\text { March } 31\end{array}$ & $\begin{array}{c}\text { Utah } \\
\text { Utah } \\
\text { Municipal } \\
\text { Power Agency } \\
\text { June } 30\end{array}$ & $\begin{array}{c}\text { Vermont } \\
\text { Burlington } \\
\text { City of } \\
\text { December } 31\end{array}$ & $\begin{array}{c}\text { Vermont } \\
\text { Vermont } \\
\text { Public } \\
\text { Pwr } \\
\text { Supply Auth } \\
\text { December } 31\end{array}$ \\
\hline 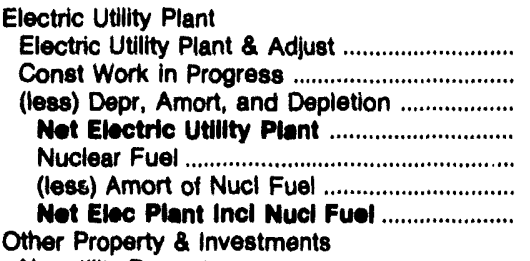 & $\begin{array}{r}82,044 \\
0 \\
29,238 \\
52,808 \\
0 \\
0 \\
52,800\end{array}$ & $\begin{array}{r}24,474 \\
0 \\
7,236 \\
17,239 \\
0 \\
0 \\
17,239\end{array}$ & $\begin{array}{r}66,349 \\
8,148 \\
14,540 \\
59,957 \\
0 \\
0 \\
59,957\end{array}$ & $\begin{array}{r}33,734 \\
0 \\
5,515 \\
28,218 \\
0 \\
0 \\
28,218\end{array}$ & $\begin{array}{r}71,841 \\
51 \\
16,499 \\
55,393 \\
0 \\
0 \\
55,393\end{array}$ & $\begin{array}{r}20,507 \\
0 \\
7,160 \\
13,347 \\
0 \\
0 \\
13,347\end{array}$ \\
\hline 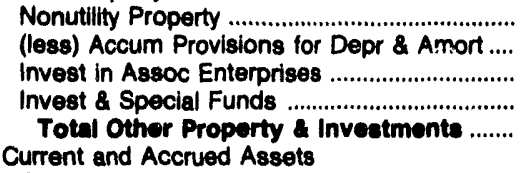 & $\begin{array}{r}6,107 \\
0 \\
0 \\
0 \\
6,107\end{array}$ & $\begin{array}{l}0 \\
0 \\
0 \\
0 \\
0\end{array}$ & $\begin{array}{r}624 \\
526 \\
0 \\
0 \\
98\end{array}$ & $\begin{array}{r}278 \\
0 \\
0 \\
14,452 \\
14,730\end{array}$ & $\begin{array}{r}776 \\
0 \\
2,325 \\
9,158 \\
12,250\end{array}$ & $\begin{array}{r}0 \\
0 \\
0 \\
6,874 \\
8,874\end{array}$ \\
\hline 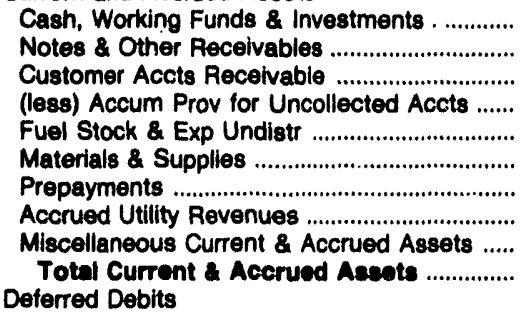 & $\begin{array}{r}7,564 \\
5,496 \\
2,400 \\
88 \\
0 \\
1,106 \\
0 \\
0 \\
0 \\
16,478\end{array}$ & $\begin{array}{r}8,923 \\
0 \\
2,094 \\
307 \\
0 \\
2,926 \\
0 \\
0 \\
66 \\
13,704\end{array}$ & $\begin{array}{r}26,291 \\
0 \\
8,681 \\
0 \\
0 \\
0 \\
1,277 \\
0 \\
181 \\
36,430\end{array}$ & $\begin{array}{r}608 \\
2,835 \\
3,011 \\
0 \\
0 \\
1,881 \\
28 \\
0 \\
0 \\
8,363\end{array}$ & $\begin{array}{r}14,323 \\
1,023 \\
2,727 \\
34 \\
340 \\
1,284 \\
29 \\
2,519 \\
0 \\
22,211\end{array}$ & $\begin{array}{r}242 \\
1,180 \\
0 \\
0 \\
292 \\
0 \\
0 \\
0 \\
0 \\
1,713\end{array}$ \\
\hline 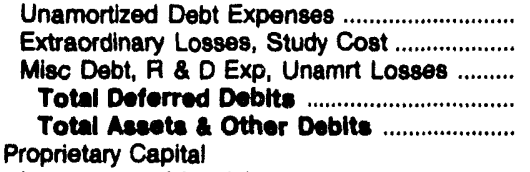 & $\begin{array}{r}0 \\
0 \\
0 \\
0 \\
75,391\end{array}$ & $\begin{array}{r}0 \\
0 \\
0 \\
0 \\
30,843\end{array}$ & $\begin{array}{r}6,175 \\
35,404 \\
0 \\
41,578 \\
138,084\end{array}$ & $\begin{array}{r}2,121 \\
0 \\
2,358 \\
4,479 \\
55,790\end{array}$ & $\begin{array}{r}3,046 \\
16 \\
42,389 \\
45,451 \\
135,314\end{array}$ & $\begin{array}{r}1,407 \\
0 \\
10,812 \\
12,219 \\
34,153\end{array}$ \\
\hline 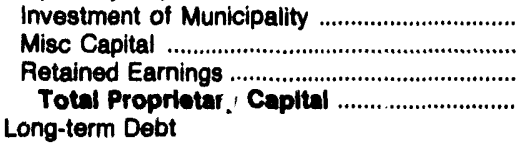 & $\begin{array}{r}0 \\
0 \\
18,455 \\
18,455\end{array}$ & $\begin{array}{r}0 \\
0 \\
29,148 \\
29,148\end{array}$ & $\begin{array}{r}127 \\
0 \\
0 \\
127\end{array}$ & $\begin{array}{l}3 \\
0 \\
0 \\
3\end{array}$ & $\begin{array}{r}0 \\
0 \\
18,449 \\
18,449\end{array}$ & $\begin{array}{r}0 \\
0 \\
-1,434 \\
-1,434\end{array}$ \\
\hline $\begin{array}{l}\text { Advances from Municipality \& Other .............. } \\
\text { Unamort Prem on Long-term Debt ................ } \\
\text { (less) Unamort Discount on Long-term Debt } \\
\text { Total Long-term Debt .................................. } \\
\text { Other Noncurrent Liabilities }\end{array}$ & $\begin{array}{r}58,525 \\
627 \\
0 \\
6,350 \\
52,802\end{array}$ & $\begin{array}{l}0 \\
0 \\
0 \\
0 \\
0\end{array}$ & $\begin{array}{r}116,184 \\
0 \\
0 \\
0 \\
116,184\end{array}$ & $\begin{array}{r}52,215 \\
0 \\
0 \\
0 \\
52,215\end{array}$ & $\begin{array}{r}105,228 \\
5,012 \\
2 \\
635 \\
109,607\end{array}$ & $\begin{array}{r}36,590 \\
0 \\
0 \\
3,680 \\
32,910\end{array}$ \\
\hline $\begin{array}{l}\text { Accum Operating Provisions ......................... } \\
\text { Accum Prov for Rate Refunds ......................... } \\
\text { Total Other Noncurrent Llabilities ........... } \\
\text { Current and Accrued Liabilities }\end{array}$ & $\begin{array}{l}0 \\
0 \\
0\end{array}$ & $\begin{array}{l}0 \\
0 \\
0\end{array}$ & $\begin{array}{l}0 \\
0 \\
0\end{array}$ & $\begin{array}{l}0 \\
0 \\
0\end{array}$ & $\begin{array}{r}10 \\
1,487 \\
1,497\end{array}$ & $\begin{array}{l}0 \\
0 \\
0\end{array}$ \\
\hline 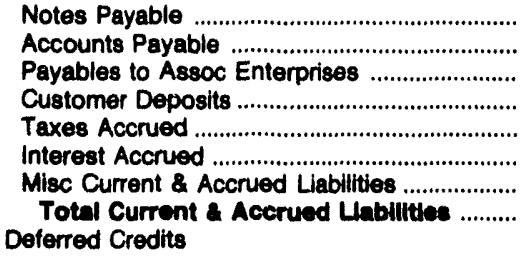 & $\begin{array}{r}126 \\
2,248 \\
0 \\
974 \\
76 \\
147 \\
563 \\
4,134\end{array}$ & $\begin{array}{r}0 \\
1,331 \\
0 \\
464 \\
0 \\
0 \\
0 \\
1,795\end{array}$ & $\begin{array}{r}0 \\
2,845 \\
0 \\
6,317 \\
0 \\
1,781 \\
711 \\
11,864\end{array}$ & $\begin{array}{r}1,321 \\
0 \\
0 \\
0 \\
0 \\
1,815 \\
435 \\
3,571\end{array}$ & $\begin{array}{r}0 \\
1,700 \\
0 \\
8 \\
212 \\
2,940 \\
682 \\
5,623\end{array}$ & $\begin{array}{r}230 \\
472 \\
0 \\
825 \\
0 \\
1,113 \\
37 \\
2,677\end{array}$ \\
\hline $\begin{array}{l}\text { Customer Advances for Construction ............ } \\
\text { Other Deferred Credits .................................. } \\
\text { Unamort Gain on Reacqr Debt ..................... } \\
\text { Total Deterred Credlts ............................... } \\
\text { Total Llabilties and Other Credits ............ }\end{array}$ & $\begin{array}{r}0 \\
0 \\
0 \\
0 \\
75,391\end{array}$ & $\begin{array}{r}0 \\
0 \\
0 \\
0 \\
30,843\end{array}$ & $\begin{array}{r}0 \\
10,098 \\
0 \\
10,008 \\
138,084\end{array}$ & $\begin{array}{r}0 \\
0 \\
0 \\
0 \\
56,790\end{array}$ & $\begin{array}{r}0 \\
238 \\
0 \\
238 \\
135,314\end{array}$ & $\begin{array}{r}0 \\
0 \\
0 \\
0 \\
34,153\end{array}$ \\
\hline
\end{tabular}

Note: Totais may not equal sum of components because of independent rounding.

Source: Energy Information Administration, Form EIA-412, "Annual Report of Public Electric Utilities." 
Table 22. Balance Sheet by Major U.S. Publicly Owned Electric Utility Within State at End of Perlod, 1992 (Continued) (Thousand Dollars)

\begin{tabular}{|c|c|c|c|c|c|c|}
\hline Item & $\begin{array}{l}\text { Virginia } \\
\text { Bedford } \\
\text { City of } \\
\text { June } 30\end{array}$ & $\begin{array}{c}\text { Virginia } \\
\text { Bristol } \\
\text { Virginia } \\
\text { Utillites Bd } \\
\text { June } 30\end{array}$ & $\begin{array}{l}\text { Virginia } \\
\text { Damille } \\
\text { Clty of } \\
\text { June } 30\end{array}$ & $\begin{array}{l}\text { Virginia } \\
\text { Harrisonburg } \\
\text { City of } \\
\text { June } 30\end{array}$ & $\begin{array}{c}\text { Virginia } \\
\text { Manassas } \\
\text { City of } \\
\text { June } 30\end{array}$ & $\begin{array}{l}\text { Virginia } \\
\text { Martinsville } \\
\text { Clty of } \\
\text { June } 30\end{array}$ \\
\hline 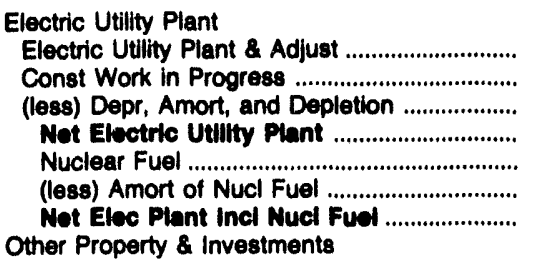 & $\begin{array}{r}17,264 \\
0 \\
4,457 \\
12,007 \\
0 \\
0 \\
12,007\end{array}$ & $\begin{array}{r}20,867 \\
1,042 \\
10,047 \\
11,092 \\
0 \\
0 \\
11,802\end{array}$ & $\begin{array}{r}50,010 \\
1,392 \\
21,336 \\
30,035 \\
0 \\
0 \\
30,035\end{array}$ & $\begin{array}{r}39,369 \\
1,287 \\
12,299 \\
28,357 \\
0 \\
0 \\
28,357\end{array}$ & $\begin{array}{r}35,057 \\
72 \\
9,896 \\
25,233 \\
0 \\
0 \\
25,233\end{array}$ & $\begin{array}{r}16,042 \\
0 \\
5,408 \\
10,684 \\
0 \\
0 \\
10,834\end{array}$ \\
\hline 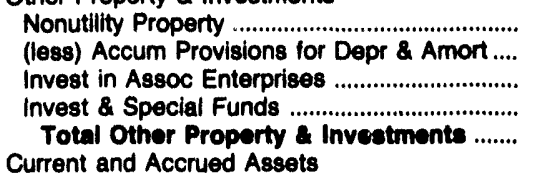 & $\begin{array}{l}0 \\
0 \\
0 \\
0 \\
0\end{array}$ & $\begin{array}{r}591 \\
0 \\
0 \\
1,500 \\
2,001\end{array}$ & $\begin{array}{l}0 \\
0 \\
0 \\
0 \\
0\end{array}$ & $\begin{array}{l}0 \\
0 \\
0 \\
1 \\
1\end{array}$ & $\begin{array}{l}0 \\
0 \\
0 \\
0 \\
0\end{array}$ & $\begin{array}{l}0 \\
0 \\
0 \\
0 \\
0\end{array}$ \\
\hline 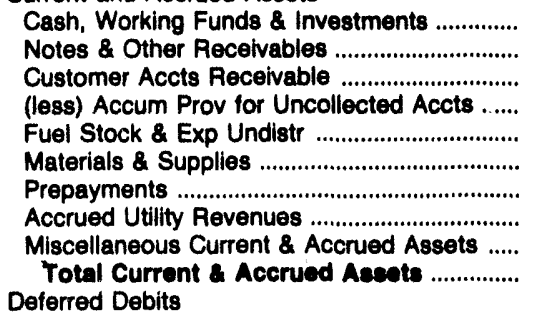 & $\begin{array}{r}4,186 \\
0 \\
1,157 \\
0 \\
0 \\
0 \\
0 \\
0 \\
69 \\
5,411\end{array}$ & $\begin{array}{r}3,286 \\
707 \\
0 \\
0 \\
0 \\
352 \\
0 \\
0 \\
1,486 \\
\mathbf{5 , 8 3 1}\end{array}$ & $\begin{array}{r}3,541 \\
404 \\
5,271 \\
0 \\
0 \\
477 \\
0 \\
0 \\
0 \\
9,693\end{array}$ & $\begin{array}{r}970 \\
122 \\
2,170 \\
0 \\
0 \\
1,177 \\
62 \\
378 \\
0 \\
4,880\end{array}$ & $\begin{array}{r}1,212 \\
126 \\
1,891 \\
9 \\
0 \\
0 \\
0 \\
0 \\
0 \\
3,219\end{array}$ & $\begin{array}{r}2,332 \\
997 \\
1,289 \\
37 \\
0 \\
0 \\
0 \\
0 \\
4 \\
4,584\end{array}$ \\
\hline 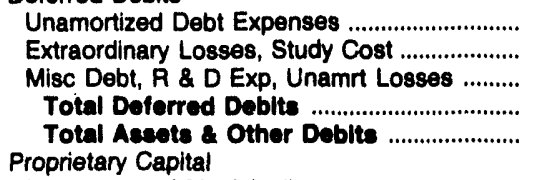 & $\begin{array}{r}288 \\
0 \\
0 \\
288 \\
18,508\end{array}$ & $\begin{array}{r}0 \\
0 \\
2,493 \\
2,493 \\
22,377\end{array}$ & $\begin{array}{r}0 \\
0 \\
0 \\
0 \\
39,758\end{array}$ & $\begin{array}{r}17 \\
0 \\
0 \\
17 \\
33,254\end{array}$ & $\begin{array}{r}0 \\
0 \\
0 \\
0 \\
28,453\end{array}$ & $\begin{array}{r}0 \\
0 \\
0 \\
0 \\
15,219\end{array}$ \\
\hline 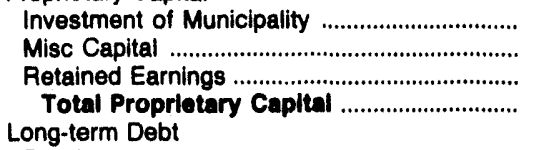 & $\begin{array}{r}4,265 \\
0 \\
-1,877 \\
2,398\end{array}$ & $\begin{array}{r}0 \\
0 \\
16,468 \\
16,468\end{array}$ & $\begin{array}{r}27,911 \\
0 \\
2,606 \\
30,517\end{array}$ & $\begin{array}{r}1,199 \\
0 \\
26,168 \\
27,398\end{array}$ & $\begin{array}{r}437 \\
0 \\
14,397 \\
14,834\end{array}$ & $\begin{array}{r}0 \\
1,167 \\
12,951 \\
14,118\end{array}$ \\
\hline $\begin{array}{l}\text { Bdvances from Municipality \& Other ............... } \\
\text { Unamort Prem on Long-term Debt ................. } \\
\text { (less) Unamort Discount on Long-term Debt } \\
\text { Total Long-term Debt .................................... } \\
\text { Other Noncurrent Liabilities }\end{array}$ & $\begin{array}{r}15,065 \\
85 \\
0 \\
0 \\
15,160\end{array}$ & $\begin{array}{l}0 \\
0 \\
0 \\
0 \\
0\end{array}$ & $\begin{array}{r}5,536 \\
130 \\
0 \\
0 \\
5,686\end{array}$ & $\begin{array}{r}0 \\
0 \\
3,024 \\
0 \\
3,024\end{array}$ & $\begin{array}{r}10,188 \\
1,350 \\
0 \\
0 \\
11,538\end{array}$ & $\begin{array}{l}0 \\
0 \\
0 \\
0 \\
0\end{array}$ \\
\hline 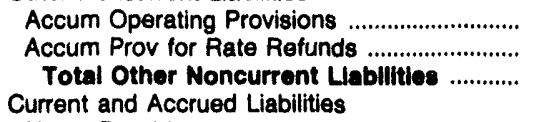 & $\begin{array}{l}0 \\
0 \\
0\end{array}$ & $\begin{array}{l}0 \\
0 \\
0\end{array}$ & $\begin{array}{l}0 \\
0 \\
0\end{array}$ & $\begin{array}{l}0 \\
0 \\
0\end{array}$ & $\begin{array}{l}0 \\
0 \\
0\end{array}$ & $\begin{array}{r}17 \\
0 \\
17\end{array}$ \\
\hline 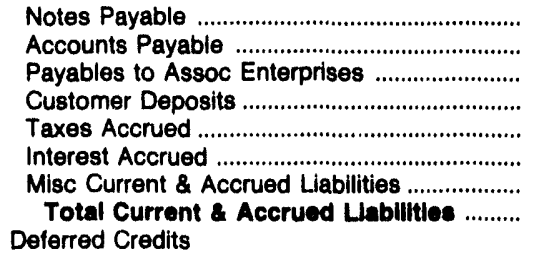 & $\begin{array}{r}0 \\
501 \\
0 \\
69 \\
0 \\
100 \\
298 \\
988\end{array}$ & $\begin{array}{r}0 \\
3,511 \\
0 \\
319 \\
203 \\
0 \\
988 \\
5,021\end{array}$ & $\begin{array}{r}180 \\
2,405 \\
0 \\
911 \\
0 \\
80 \\
0 \\
3,576\end{array}$ & $\begin{array}{r}220 \\
2,214 \\
0 \\
264 \\
0 \\
15 \\
149 \\
2,862\end{array}$ & $\begin{array}{r}0 \\
1,140 \\
0 \\
235 \\
0 \\
206 \\
500 \\
2,081\end{array}$ & $\begin{array}{r}0 \\
651 \\
0 \\
220 \\
0 \\
0 \\
212 \\
1,084\end{array}$ \\
\hline 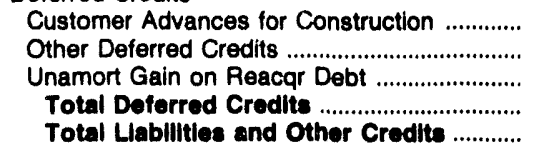 & $\begin{array}{r}0 \\
0 \\
0 \\
0 \\
18,500\end{array}$ & $\begin{array}{r}0 \\
888 \\
0 \\
888 \\
22,377\end{array}$ & $\begin{array}{r}0 \\
0 \\
0 \\
0 \\
39,758\end{array}$ & $\begin{array}{r}0 \\
0 \\
0 \\
0 \\
33,254\end{array}$ & $\begin{array}{r}0 \\
0 \\
0 \\
0 \\
28,453\end{array}$ & $\begin{array}{r}0 \\
0 \\
0 \\
0 \\
15,219\end{array}$ \\
\hline
\end{tabular}

Note: Totals may $\mathrm{m}^{-\cdot}$ qual sum of components because of independent rounding

Source: Energy Intornation Administration, Form EIA-412, "Annual Report of Public Electric Utilities." 
Table 22. Balance Sheet by Major U.S. Publicly Owned Electric Utility Within State at End of Period, 1992 (Continued) (Thousand Dollars)

\begin{tabular}{|c|c|c|c|c|c|c|}
\hline Item & $\begin{array}{l}\text { Virginia } \\
\text { Radford } \\
\text { City of } \\
\text { June } 30\end{array}$ & $\begin{array}{l}\text { Virginia } \\
\text { Salem } \\
\text { City of } \\
\text { June } 30\end{array}$ & $\begin{array}{l}\text { Virginia } \\
\text { Virginia } \\
\text { Tech } \\
\text { Electric } \\
\text { Service } \\
\text { June } 30\end{array}$ & $\begin{array}{l}\text { Washington } \\
\text { Centralia } \\
\text { City of } \\
\text { December } 31\end{array}$ & $\begin{array}{c}\text { Washington } \\
\text { Ellensburg } \\
\text { City of }\end{array}$ & $\begin{array}{c}\text { Washington } \\
\text { Port Angeles } \\
\text { City of } \\
\text { December } 31\end{array}$ \\
\hline 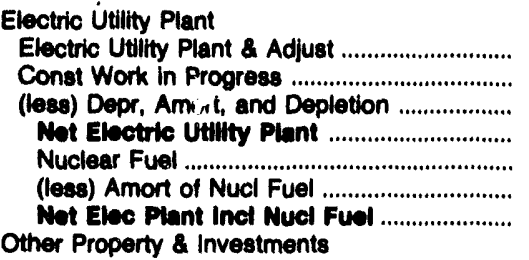 & $\begin{array}{r}12,393 \\
0 \\
6,233 \\
6,160 \\
0 \\
0 \\
6,160\end{array}$ & $\begin{array}{r}19,669 \\
0 \\
8,722 \\
0,947 \\
0 \\
0 \\
10,947\end{array}$ & $\begin{array}{l}0 \\
0 \\
0 \\
0 \\
0 \\
0 \\
0\end{array}$ & $\begin{array}{r}14,632 \\
491 \\
7,445 \\
7,678 \\
0 \\
0 \\
7,678\end{array}$ & $\begin{array}{r}11,842 \\
0 \\
5,108 \\
6,734 \\
0 \\
0 \\
6,734\end{array}$ & $\begin{array}{r}20,175 \\
802 \\
7,934 \\
13,043 \\
0 \\
0 \\
13,043\end{array}$ \\
\hline $\begin{array}{l}\text { Nonutility Property .................................... } \\
\text { (less) Accum Provisions for Depr \& Amort.... } \\
\text { Invest in Assoc Enterprises ............................... } \\
\text { Invest \& Special Funds .................................. } \\
\text { Total Other Property \& Investments ....... } \\
\text { Current and Accrued Assets }\end{array}$ & $\begin{array}{l}0 \\
0 \\
0 \\
0 \\
0\end{array}$ & $\begin{array}{r}0 \\
0 \\
0 \\
613 \\
613\end{array}$ & $\begin{array}{l}0 \\
0 \\
0 \\
0 \\
0\end{array}$ & $\begin{array}{r}57 \\
0 \\
0 \\
786 \\
843\end{array}$ & $\begin{array}{r}204 \\
103 \\
0 \\
311 \\
412\end{array}$ & $\begin{array}{r}88 \\
131 \\
569 \\
0 \\
526\end{array}$ \\
\hline 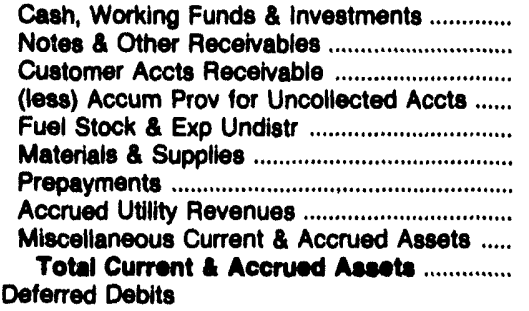 & $\begin{array}{r}4,360 \\
4,194 \\
1,113 \\
75 \\
0 \\
215 \\
0 \\
0 \\
0 \\
9,808\end{array}$ & $\begin{array}{r}2,547 \\
25 \\
995 \\
52 \\
0 \\
541 \\
2 \\
738 \\
0 \\
4,798\end{array}$ & $\begin{array}{r}2,843 \\
175 \\
385 \\
0 \\
0 \\
303 \\
1 \\
0 \\
0 \\
3,707\end{array}$ & $\begin{array}{r}1,430 \\
118 \\
657 \\
9 \\
0 \\
139 \\
0 \\
0 \\
8 \\
2,343\end{array}$ & $\begin{array}{r}830 \\
0 \\
566 \\
9 \\
0 \\
386 \\
0 \\
99 \\
0 \\
1,872\end{array}$ & $\begin{array}{r}4,423 \\
499 \\
2,648 \\
0 \\
0 \\
214 \\
0 \\
0 \\
1 \\
7,785\end{array}$ \\
\hline 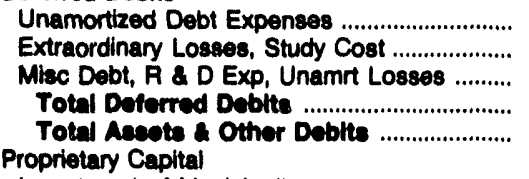 & $\begin{array}{r}0 \\
0 \\
0 \\
0 \\
15,987\end{array}$ & $\begin{array}{r}0 \\
0 \\
0 \\
0 \\
16,365\end{array}$ & $\begin{array}{r}2,760 \\
0 \\
0 \\
2,760 \\
6,487\end{array}$ & $\begin{array}{r}0 \\
0 \\
0 \\
0 \\
10,885\end{array}$ & $\begin{array}{r}2 \\
0 \\
0 \\
2 \\
9,019\end{array}$ & $\begin{array}{r}0 \\
0 \\
0 \\
0 \\
21,354\end{array}$ \\
\hline 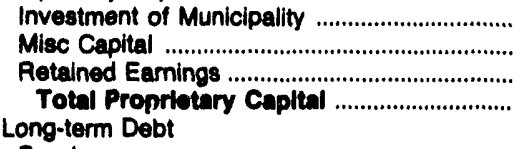 & $\begin{array}{r}0 \\
0 \\
10,647 \\
10,647\end{array}$ & $\begin{array}{r}0 \\
0 \\
4,685 \\
4,685\end{array}$ & $\begin{array}{r}0 \\
0 \\
2,869 \\
2,909\end{array}$ & $\begin{array}{r}672 \\
0 \\
7,840 \\
8,612\end{array}$ & $\begin{array}{r}0 \\
0 \\
7,325 \\
7,325\end{array}$ & $\begin{array}{r}987 \\
0 \\
13,590 \\
14,576\end{array}$ \\
\hline 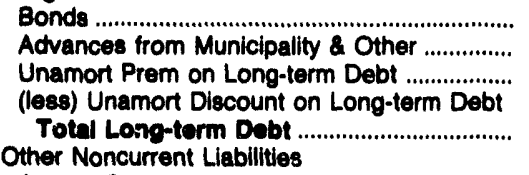 & $\begin{array}{r}4,200 \\
0 \\
0 \\
0 \\
4,200\end{array}$ & $\begin{array}{r}10,220 \\
0 \\
0 \\
102 \\
10,118\end{array}$ & $\begin{array}{r}2,760 \\
0 \\
0 \\
0 \\
2,760\end{array}$ & $\begin{array}{r}985 \\
0 \\
0 \\
22 \\
983\end{array}$ & $\begin{array}{r}425 \\
563 \\
0 \\
0 \\
988\end{array}$ & $\begin{array}{r}2,880 \\
349 \\
0 \\
0 \\
3,229\end{array}$ \\
\hline $\begin{array}{l}\text { Accum Operating Provisions ........................... } \\
\text { Accum Prov for Rate Pefunds ........................ } \\
\text { Total Other Noncurrent Llabilities ............ } \\
\text { Current and Accrued Liabilities }\end{array}$ & $\begin{array}{l}0 \\
0 \\
0\end{array}$ & $\begin{array}{l}0 \\
0 \\
0\end{array}$ & $\begin{array}{l}0 \\
0 \\
0\end{array}$ & $\begin{array}{r}197 \\
0 \\
197\end{array}$ & $\begin{array}{l}0 \\
0 \\
0\end{array}$ & $\begin{array}{r}90 \\
0 \\
90\end{array}$ \\
\hline 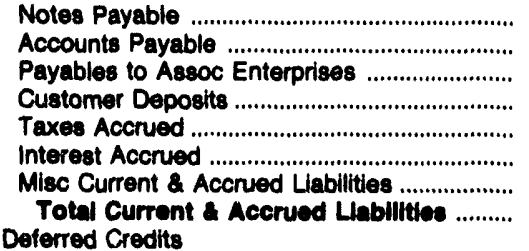 & $\begin{array}{r}797 \\
0 \\
0 \\
187 \\
0 \\
0 \\
137 \\
1,120\end{array}$ & $\begin{array}{r}0 \\
994 \\
0 \\
371 \\
0 \\
106 \\
83 \\
1,563\end{array}$ & $\begin{array}{r}0 \\
616 \\
0 \\
0 \\
0 \\
16 \\
106 \\
738\end{array}$ & $\begin{array}{r}0 \\
906 \\
0 \\
289 \\
0 \\
6 \\
0 \\
1,181\end{array}$ & $\begin{array}{r}0 \\
547 \\
47 \\
0 \\
0 \\
10 \\
101 \\
706\end{array}$ & $\begin{array}{r}0 \\
1,637 \\
55 \\
0 \\
134 \\
80 \\
163 \\
2,068\end{array}$ \\
\hline 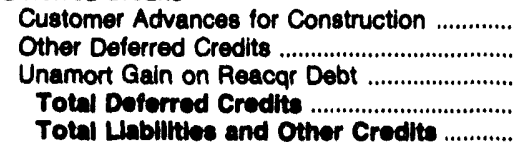 & $\begin{array}{r}0 \\
0 \\
0 \\
0 \\
16,987\end{array}$ & $\begin{array}{r}0 \\
0 \\
0 \\
0 \\
16,355\end{array}$ & $\begin{array}{r}0 \\
0 \\
0 \\
0 \\
6,467\end{array}$ & $\begin{array}{r}0 \\
12 \\
0 \\
12 \\
10,885\end{array}$ & $\begin{array}{r}0 \\
0 \\
0 \\
0 \\
9,019\end{array}$ & $\begin{array}{r}1,391 \\
0 \\
0 \\
1,391 \\
21,354\end{array}$ \\
\hline
\end{tabular}

Note: Totals may not equal sum of components because of independent rounding.

Source: Energy Information Administration, Form EIA-412, "Annual Report of Public Electric Utilities." 
Table 22. Balance Sheet by Major U.S. Publicly Owned Electric Utility Within State at End of Period, 1992 (Continued) (Thousand Dollars)

\begin{tabular}{|c|c|c|c|c|c|c|}
\hline Item & $\begin{array}{l}\text { Washington } \\
\text { PUD No } 1 \\
\text { of } \\
\text { Benton } \\
\text { County } \\
\text { December } 31\end{array}$ & $\begin{array}{c}\text { Washington } \\
\text { PUD No } 1 \\
\text { of } \\
\text { Chelan } \\
\text { County } \\
\text { December } 31\end{array}$ & $\begin{array}{l}\text { Washington } \\
\text { PUD No } 1 \text { of } \\
\text { Clallam } \\
\text { County } \\
\text { December } 31\end{array}$ & $\begin{array}{l}\text { Washington } \\
\text { PUD No } 1 \\
\text { of } \\
\text { Clark } \\
\text { County } \\
\text { December } 31\end{array}$ & $\begin{array}{l}\text { Washington } \\
\text { PUD No } 1 \text { of } \\
\text { Cowlitz } \\
\text { County } \\
\text { December } 31\end{array}$ & $\begin{array}{l}\text { Washington } \\
\text { PUD No } 1 \text { of } \\
\text { Douglas } \\
\text { County } \\
\text { December } 31\end{array}$ \\
\hline 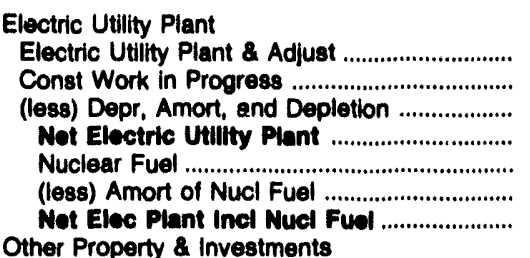 & $\begin{array}{r}76,469 \\
1,788 \\
31,012 \\
47,246 \\
0 \\
0 \\
47,245\end{array}$ & $\begin{array}{r}841,150 \\
18,985 \\
143,508 \\
718,627 \\
0 \\
0 \\
716,627\end{array}$ & $\begin{array}{r}53,963 \\
2,025 \\
26,723 \\
29,286 \\
0 \\
0 \\
29,296\end{array}$ & $\begin{array}{r}199,820 \\
4,988 \\
77,503 \\
127,305 \\
0 \\
0 \\
127,305\end{array}$ & $\begin{array}{r}107,288 \\
352 \\
45,933 \\
61,707 \\
0 \\
0 \\
61,707\end{array}$ & $\begin{array}{r}266,048 \\
5,018 \\
41,914 \\
229,154 \\
0 \\
0 \\
229,154\end{array}$ \\
\hline 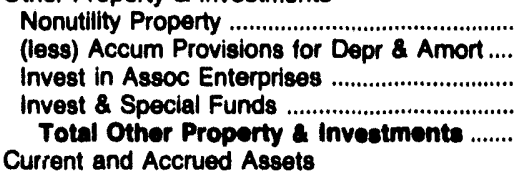 & $\begin{array}{r}0 \\
0 \\
0 \\
21,209 \\
21,200\end{array}$ & $\begin{array}{r}0 \\
0 \\
8,947 \\
118,222 \\
127,169\end{array}$ & $\begin{array}{r}0 \\
0 \\
0 \\
3,323 \\
3,323\end{array}$ & $\begin{array}{r}116 \\
8 \\
0 \\
6,639 \\
6,747\end{array}$ & $\begin{array}{r}1 \\
0 \\
1,282 \\
1,869 \\
3,152\end{array}$ & $\begin{array}{r}0 \\
0 \\
0 \\
23,714 \\
23,714\end{array}$ \\
\hline 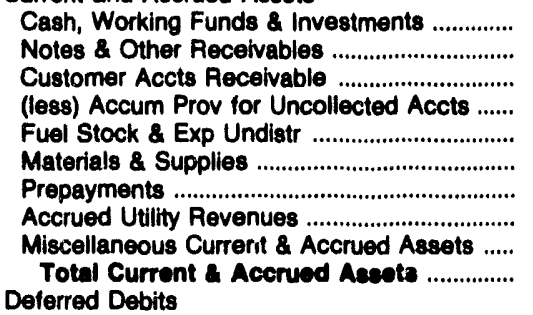 & $\begin{array}{r}2,301 \\
135 \\
4,004 \\
12 \\
0 \\
1,540 \\
55 \\
0 \\
589 \\
8,621\end{array}$ & $\begin{array}{r}27,913 \\
1,014 \\
3,349 \\
30 \\
0 \\
3,350 \\
927 \\
0 \\
1,303 \\
\mathbf{3 7 , 0 2 6}\end{array}$ & $\begin{array}{r}3,734 \\
387 \\
1,301 \\
26 \\
0 \\
1,512 \\
247 \\
0 \\
57 \\
7,221\end{array}$ & $\begin{array}{r}19,105 \\
852 \\
11,660 \\
1,368 \\
0 \\
2,623 \\
92 \\
4,152 \\
0 \\
37,115\end{array}$ & $\begin{array}{r}11,573 \\
145 \\
9,101 \\
153 \\
0 \\
1,675 \\
497 \\
0 \\
230 \\
23,067\end{array}$ & $\begin{array}{r}20,489 \\
783 \\
612 \\
38 \\
0 \\
1,517 \\
718 \\
0 \\
1,151 \\
25,233\end{array}$ \\
\hline 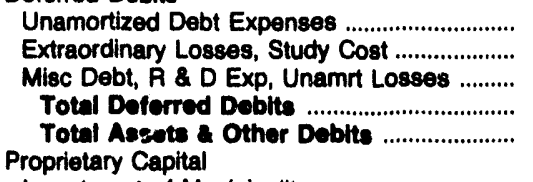 & $\begin{array}{r}1,387 \\
0 \\
331 \\
1,718 \\
78,793\end{array}$ & $\begin{array}{r}14,569 \\
0 \\
27,650 \\
42,219 \\
928,841\end{array}$ & $\begin{array}{r}236 \\
0 \\
0 \\
236 \\
40,047\end{array}$ & $\begin{array}{r}1,486 \\
0 \\
1,211 \\
2,687 \\
173,864\end{array}$ & $\begin{array}{r}5 \\
355 \\
47 \\
408 \\
88,334\end{array}$ & $\begin{array}{r}2,338 \\
85 \\
28,451 \\
30,874 \\
308,975\end{array}$ \\
\hline 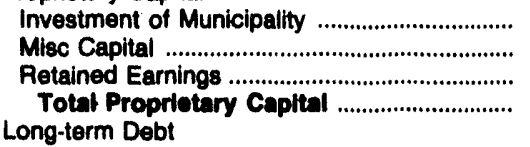 & $\begin{array}{r}0 \\
0 \\
25,410 \\
25,410\end{array}$ & $\begin{array}{r}14,374 \\
0 \\
209,977 \\
224,351\end{array}$ & $\begin{array}{r}0 \\
0 \\
23,631 \\
23,631\end{array}$ & $\begin{array}{r}0 \\
0 \\
71,988 \\
71,988\end{array}$ & $\begin{array}{r}0 \\
0 \\
53,546 \\
53,546\end{array}$ & $\begin{array}{r}0 \\
0 \\
93,244 \\
93,244\end{array}$ \\
\hline $\begin{array}{l}\text { Bonds } \\
\text { Advances from Municipality \& Other ............... } \\
\text { Unamort Prem on Long-term Debt ................ } \\
\text { (less) Unamort Discount on Long-term Debt } \\
\text { Total Lono-term Debt ................................. } \\
\text { Other Noncurrent Llabilities }\end{array}$ & $\begin{array}{r}40,475 \\
969 \\
0 \\
0 \\
41,444\end{array}$ & $\begin{array}{r}680,658 \\
0 \\
0 \\
0 \\
690,658\end{array}$ & $\begin{array}{r}9,884 \\
378 \\
0 \\
0 \\
10,282\end{array}$ & $\begin{array}{r}58,580 \\
5,015 \\
0 \\
24 \\
63,571\end{array}$ & $\begin{array}{r}3,795 \\
6,950 \\
0 \\
4 \\
10,741\end{array}$ & $\begin{array}{r}198,270 \\
4,760 \\
0 \\
0 \\
203,030\end{array}$ \\
\hline 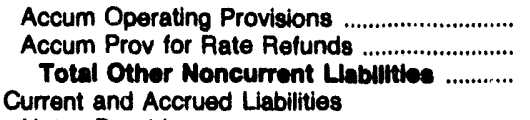 & $\begin{array}{l}0 \\
0 \\
0\end{array}$ & $\begin{array}{l}0 \\
0 \\
0\end{array}$ & $\begin{array}{l}0 \\
0 \\
0\end{array}$ & $\begin{array}{r}2,417 \\
0 \\
2,417\end{array}$ & $\begin{array}{r}1,576 \\
0 \\
1,576\end{array}$ & $\begin{array}{l}0 \\
0 \\
0\end{array}$ \\
\hline 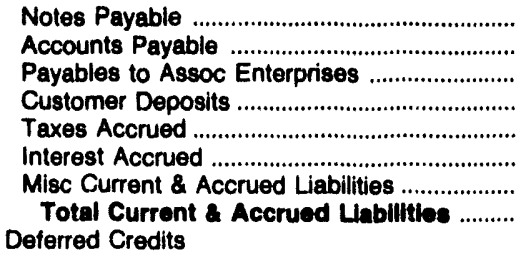 & $\begin{array}{r}364 \\
3,533 \\
0 \\
632 \\
1,464 \\
480 \\
788 \\
7,261\end{array}$ & $\begin{array}{r}0 \\
4,407 \\
916 \\
160 \\
2,285 \\
7,249 \\
2,868 \\
17,885\end{array}$ & $\begin{array}{r}0 \\
3,267 \\
0 \\
206 \\
597 \\
194 \\
351 \\
4,615\end{array}$ & $\begin{array}{r}8,582 \\
11,275 \\
0 \\
6 \\
2,796 \\
2,199 \\
9,785 \\
34,643\end{array}$ & $\begin{array}{r}639 \\
10,124 \\
76 \\
246 \\
2,115 \\
69 \\
783 \\
14,052\end{array}$ & $\begin{array}{r}1,501 \\
1,168 \\
0 \\
116 \\
965 \\
3,340 \\
1,697 \\
8,787\end{array}$ \\
\hline 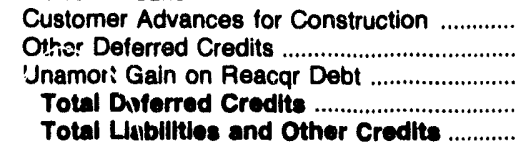 & $\begin{array}{r}4,539 \\
139 \\
0 \\
4,678 \\
78,793\end{array}$ & $\begin{array}{r}0 \\
947 \\
0 \\
947 \\
923,841\end{array}$ & $\begin{array}{r}361 \\
1,177 \\
0 \\
1.538 \\
4 \sim, v 47\end{array}$ & $\begin{array}{r}32 \\
1,213 \\
0 \\
1,246 \\
173,864\end{array}$ & $\begin{array}{r}8,378 \\
42 \\
0 \\
8,419 \\
88,334\end{array}$ & $\begin{array}{r}0 \\
3,914 \\
0 \\
3,914 \\
308,975\end{array}$ \\
\hline
\end{tabular}

Note: Totals may not equal sum of components because of independent rounding.

Source: Energy Information Administration, Form EIA-412, "Annual Peport of Public Electric Utilities." 
Table 22. Balance Sheet by Major U.S. Publicly Owned Electric Utility Within State at End of Period, 1992 (Continued) (Thousand Dollars)

\begin{tabular}{|c|c|c|c|c|c|c|}
\hline Item & $\begin{array}{l}\text { Washington } \\
\text { PUD No } 1 \text { of } \\
\text { Franklin } \\
\text { County } \\
\text { December } 31\end{array}$ & $\begin{array}{c}\text { Washington } \\
\text { PUD No } 1 \\
\text { of } \\
\text { Grays } \\
\text { Harbor Cnty } \\
\text { December } 31\end{array}$ & $\begin{array}{l}\text { Washington } \\
\text { PUD No } 1 \text { of } \\
\text { Klickitat } \\
\text { County } \\
\text { December } 31\end{array}$ & $\begin{array}{c}\text { Washington } \\
\text { PUD No } 1 \\
\text { of } \\
\text { Lewis } \\
\text { County } \\
\text { December } 31\end{array}$ & $\begin{array}{l}\text { Washington } \\
\text { PUD No } 1 \text { of } \\
\text { Okanogan } \\
\text { County }\end{array}$ & $\begin{array}{l}\text { Washington } \\
\text { PUD No } 1 \text { of } \\
\text { Pend Oreille } \\
\text { Cnty } \\
\text { December } 31\end{array}$ \\
\hline 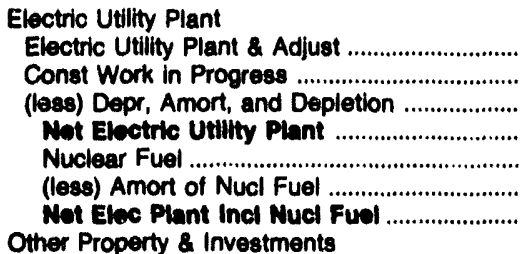 & $\begin{array}{r}36,581 \\
1,963 \\
14,288 \\
24,245 \\
0 \\
0 \\
24,245\end{array}$ & $\begin{array}{r}96,743 \\
1,861 \\
34,647 \\
63,957 \\
0 \\
0 \\
63,957\end{array}$ & $\begin{array}{r}29,947 \\
6,162 \\
12,370 \\
23,730 \\
0 \\
0 \\
23,730\end{array}$ & $\begin{array}{r}52,372 \\
76,219 \\
13,729 \\
114,862 \\
0 \\
0 \\
114,862\end{array}$ & $\begin{array}{r}46,572 \\
1,668 \\
23,311 \\
24,928 \\
0 \\
0 \\
24,828\end{array}$ & $\begin{array}{r}42,216 \\
407 \\
13,776 \\
28,847 \\
0 \\
0 \\
28,847\end{array}$ \\
\hline 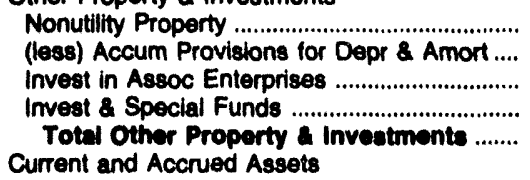 & $\begin{array}{r}0 \\
0 \\
0 \\
8,448 \\
\mathbf{8 , 4 4 9}\end{array}$ & $\begin{array}{r}19 \\
0 \\
0 \\
3,300 \\
3,320\end{array}$ & $\begin{array}{r}0 \\
0 \\
0 \\
1,290 \\
1,290\end{array}$ & $\begin{array}{r}0 \\
0 \\
0 \\
116,953 \\
116,953\end{array}$ & $\begin{array}{r}0 \\
0 \\
0 \\
3,591 \\
3,591\end{array}$ & $\begin{array}{r}36 \\
0 \\
0 \\
3,480 \\
3,516\end{array}$ \\
\hline 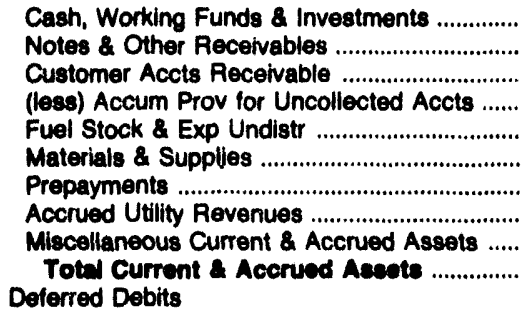 & $\begin{array}{r}3,913 \\
0 \\
3,084 \\
4 \\
0 \\
1,251 \\
38 \\
0 \\
744 \\
9,028\end{array}$ & $\begin{array}{r}9,587 \\
736 \\
3,835 \\
25 \\
236 \\
2,871 \\
94 \\
0 \\
45 \\
17,390\end{array}$ & $\begin{array}{r}4,142 \\
0 \\
999 \\
172 \\
0 \\
628 \\
4 \\
287 \\
0 \\
5,888\end{array}$ & $\begin{array}{r}9,989 \\
1,738 \\
1,785 \\
102 \\
0 \\
1,399 \\
15 \\
0 \\
97 \\
14,922\end{array}$ & $\begin{array}{r}14,560 \\
102 \\
742 \\
3 \\
0 \\
1,195 \\
25 \\
0 \\
0 \\
18,620\end{array}$ & $\begin{array}{r}9,081 \\
215 \\
250 \\
7 \\
0 \\
494 \\
127 \\
0 \\
163 \\
10,322\end{array}$ \\
\hline 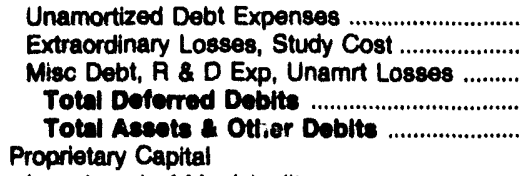 & $\begin{array}{r}500 \\
0 \\
-68 \\
432 \\
42,152\end{array}$ & $\begin{array}{r}449 \\
0 \\
281 \\
730 \\
85,387\end{array}$ & $\begin{array}{r}51 \\
0 \\
32 \\
83 \\
30,900\end{array}$ & $\begin{array}{r}1,983 \\
0 \\
223 \\
2,186 \\
248,923\end{array}$ & $\begin{array}{r}0 \\
102 \\
56 \\
159 \\
45,290\end{array}$ & $\begin{array}{r}77 \\
0 \\
-18 \\
58 \\
42,744\end{array}$ \\
\hline 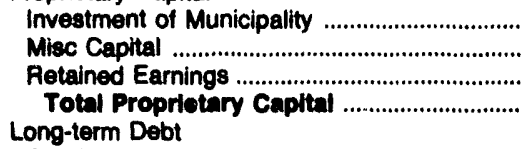 & $\begin{array}{r}901 \\
0 \\
11,787 \\
12,898\end{array}$ & $\begin{array}{r}0 \\
0 \\
58,430 \\
58,430\end{array}$ & $\begin{array}{r}4,020 \\
0 \\
12,986 \\
17,006\end{array}$ & $\begin{array}{r}0 \\
0 \\
57,256 \\
57,256\end{array}$ & $\begin{array}{r}0 \\
0 \\
41,908 \\
41,908\end{array}$ & $\begin{array}{r}0 \\
0 \\
32,670 \\
32,670\end{array}$ \\
\hline $\begin{array}{l}\text { Advances from Municipality \& Other ............. } \\
\text { Unamort Prem on Long-term Debt ............... } \\
\text { (less) Unamort Discount on Long-term Debt } \\
\text { Total Long-term Debt ................................. } \\
\text { Other Noncurrent Liabilities }\end{array}$ & $\begin{array}{r}23,760 \\
0 \\
0 \\
365 \\
23,395\end{array}$ & $\begin{array}{r}12,945 \\
168 \\
0 \\
0 \\
13,113\end{array}$ & $\begin{array}{r}3,205 \\
8,528 \\
0 \\
0 \\
11,733\end{array}$ & $\begin{array}{r}180,643 \\
379 \\
540 \\
4,266 \\
177,297\end{array}$ & $\begin{array}{r}0 \\
499 \\
0 \\
0 \\
499\end{array}$ & $\begin{array}{r}5,229 \\
0 \\
0 \\
0 \\
5,220\end{array}$ \\
\hline 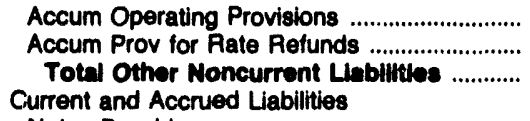 & $\begin{array}{r}503 \\
0 \\
503\end{array}$ & $\begin{array}{l}0 \\
0 \\
0\end{array}$ & $\begin{array}{l}0 \\
0 \\
0\end{array}$ & $\begin{array}{l}0 \\
0 \\
0\end{array}$ & $\begin{array}{l}0 \\
0 \\
0\end{array}$ & $\begin{array}{l}0 \\
0 \\
\mathbf{0}\end{array}$ \\
\hline 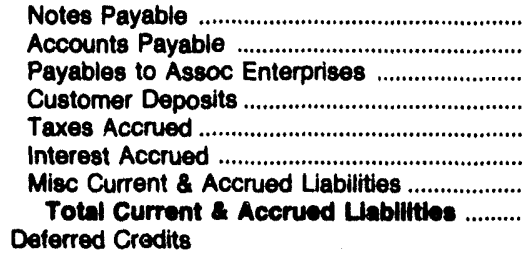 & $\begin{array}{r}74 \\
1,817 \\
0 \\
383 \\
716 \\
593 \\
1,813 \\
5,398\end{array}$ & $\begin{array}{r}3,212 \\
4,189 \\
0 \\
535 \\
1,215 \\
0 \\
2,521 \\
11,671\end{array}$ & $\begin{array}{r}0 \\
913 \\
0 \\
125 \\
263 \\
150 \\
263 \\
1,714\end{array}$ & $\begin{array}{r}0 \\
4,581 \\
264 \\
288 \\
1,509 \\
2,875 \\
378 \\
9,898\end{array}$ & $\begin{array}{r}584 \\
1,355 \\
0 \\
179 \\
392 \\
0 \\
377 \\
2,887\end{array}$ & $\begin{array}{r}1,681 \\
1,830 \\
0 \\
60 \\
580 \\
51 \\
236 \\
4,447\end{array}$ \\
\hline $\begin{array}{l}\text { Customer Advances for Construction } \\
\text { Other Deferred Credits ............................................ } \\
\text { Unamort Gain on Reacqr Debt ..................... } \\
\text { Total Deferred Gredits ................................ } \\
\text { Total Labillties and Other Credite }\end{array}$ & $\begin{array}{r}0 \\
171 \\
0 \\
171 \\
42,152\end{array}$ & $\begin{array}{r}31 \\
2,141 \\
0 \\
2,172 \\
85,387\end{array}$ & $\begin{array}{r}14 \\
532 \\
0 \\
546 \\
30,990\end{array}$ & $\begin{array}{r}1,310 \\
3,165 \\
0 \\
4,475 \\
248,923\end{array}$ & $\begin{array}{r}3 \\
1 \\
0 \\
4 \\
45,299\end{array}$ & $\begin{array}{r}0 \\
398 \\
0 \\
398 \\
42,744\end{array}$ \\
\hline
\end{tabular}

Note: Totals may not equal sum of components because of independent rounding.

Source: Energy Information Administration, Form ElA-412, "Annual Report of Public Electric Utilities." 
Table 22. Balance Sheet by Major U.S. Publicly Owned Electric Utillty Within State at End of Period, 1992 (Continued) (Thousand Dollars)

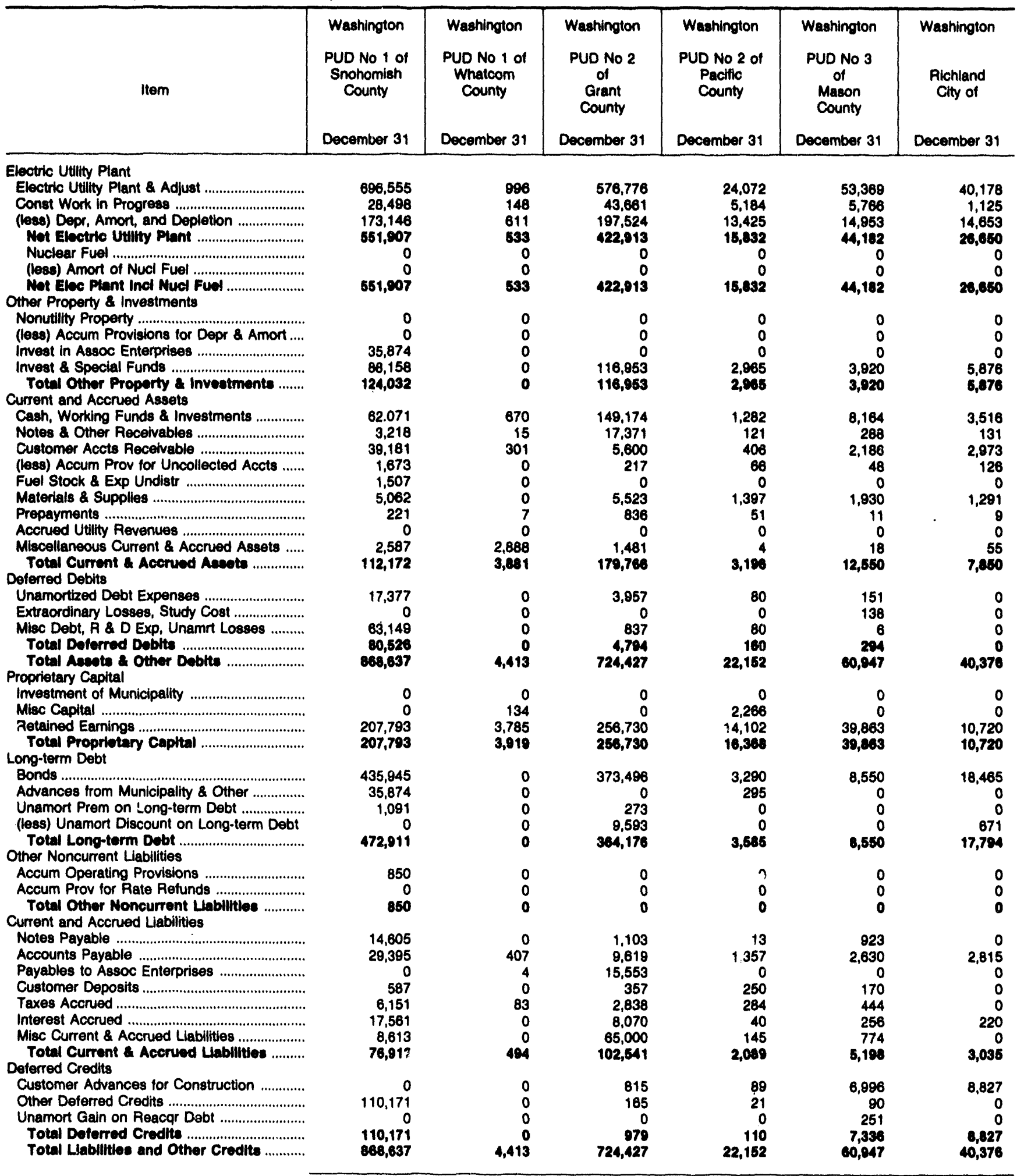

Note: Totals may not equal sum of components because of independent rounding.

Source: Energy Information Administration, Form ElA-412, "Annual Report of Public Electric Utilities." 
Table 22. Balance Sheet by Major U.S. Publicly Owned Electric Utility Within State at End of Period, 1992 (Continued) (Thousand Dollars)

\begin{tabular}{|c|c|c|c|c|c|c|}
\hline Item & $\begin{array}{l}\text { Washington } \\
\text { Seattle } \\
\text { City of } \\
\text { December } 31\end{array}$ & $\begin{array}{l}\text { Washington } \\
\text { Tacoma } \\
\text { City of } \\
\text { December } 31\end{array}$ & $\begin{array}{c}\text { Washington } \\
\text { Vera } \\
\text { Irrigation } \\
\text { District \#15 } \\
\text { December } 31\end{array}$ & $\begin{array}{l}\text { Washington } \\
\text { Washington } \\
\text { Pub } \\
\text { Pwr } \\
\text { Supply Sys } \\
\text { June } 30\end{array}$ & $\begin{array}{l}\text { Wisconsin } \\
\text { Badger Power } \\
\begin{array}{c}\text { Marketing } \\
\text { Auth }\end{array} \\
\text { December } 31\end{array}$ & $\begin{array}{c}\text { Wisconsin } \\
\text { Jefferson } \\
\text { City of } \\
\text { December } 31\end{array}$ \\
\hline \multicolumn{7}{|l|}{ Electric Utillty Plant } \\
\hline Eloctric Utility Plant \& Adjust .................................. & $1,068,586$ & 609,007 & 10,945 & $3,320,661$ & 5,914 & 4,193 \\
\hline 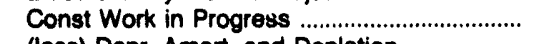 & 54,866 & 55,368 & & 119,709 & & 2,586 \\
\hline 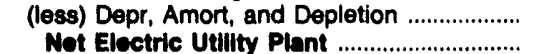 & $\begin{array}{l}485,936 \\
637,516\end{array}$ & $\begin{array}{l}212,237 \\
452,138\end{array}$ & $\begin{array}{l}3,554 \\
7,491\end{array}$ & $\begin{array}{r}868,993 \\
2,571,377\end{array}$ & $\begin{array}{r}870 \\
5,045\end{array}$ & $\begin{array}{l}1,889 \\
4,890\end{array}$ \\
\hline 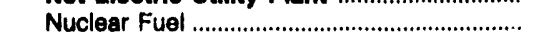 & & & 0 & 203,513 & 0 & 0 \\
\hline 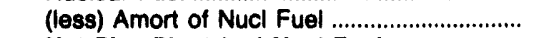 & & & & 74,392 & & \\
\hline Not Elec Plant Incl Nucl Fuel ........................ & 637,516 & 452,136 & 7,491 & $2,700,498$ & 5,045 & 4,890 \\
\hline \multicolumn{7}{|l|}{ Other Property \& Investments } \\
\hline 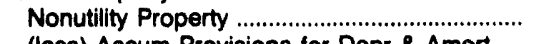 & 7,834 & 179 & 0 & 0 & 0 & 0 \\
\hline (less) Accum Provisions for Depr \& Amort .... & 4,439 & 8 & 0 & 0 & 0 & 0 \\
\hline 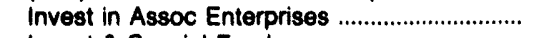 & 1,736 & 0 & 0 & 0 & 0 & 0 \\
\hline 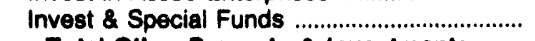 & 159,991 & 42,534 & 135 & 195,110 & 1,663 & 0 \\
\hline \multicolumn{7}{|l|}{ Current and Accrued Assets } \\
\hline Cash, Working Funds \& Investments .............. & 60,353 & 64,423 & 1,041 & 25,957 & 112 & 3,292 \\
\hline 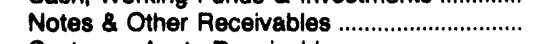 & 4,941 & 6,524 & 526 & 88,166 & 762 & 31 \\
\hline 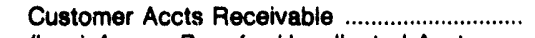 & 32,586 & 14,826 & 518 & 0 & 0 & 531 \\
\hline (less) Accum Prov for Uncollected Acets ...... & 1,549 & 555 & 0 & 0 & 0 & 0 \\
\hline 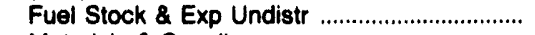 & 1,566 & 2,163 & 0 & 0 & 0 & 0 \\
\hline 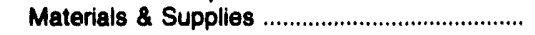 & 18,897 & 3,454 & 285 & 41,016 & 0 & 79 \\
\hline Prepayments & 1,812 & 68 & 95 & 554 & 13 & 0 \\
\hline 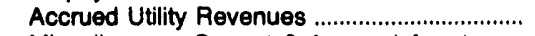 & 25,413 & 10,348 & 0 & 0 & 0 & 0 \\
\hline Miscellaneous Current \& Accrued Assets ..... & 1,657 & 744 & 0 & 273 & 7 & 0 \\
\hline $\begin{array}{l}\text { Total Current a Accrued Assets ................... } \\
\text { Deferred Debits }\end{array}$ & 145,674 & 101,995 & 2,464 & 155,966 & 893 & 3,934 \\
\hline 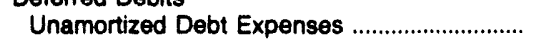 & 1,210 & 4,606 & 121 & 19,279 & 282 & 126 \\
\hline Extraordinary Losses, Study Cost ...................... & & 1,746 & 0 & 8,965 & 5 & 0 \\
\hline Misc Debt, R \& D Exp, Unamrt Losses ......... & 96,636 & 3,172 & 0 & 3,367 & 0 & 0 \\
\hline Total Deforred Debite .................................. & 97,846 & 9,523 & 121 & 31,611 & 287 & 126 \\
\hline \multirow{2}{*}{\multicolumn{7}{|c|}{ Proprietary Capital }} \\
\hline & 0 & 0 & 0 & 0 & 0 & 154 \\
\hline 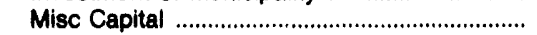 & 0 & 0 & 0 & 0 & 0 & 228 \\
\hline 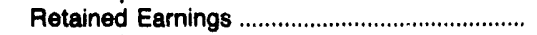 & 281,740 & 221,210 & 7,624 & 0 & 239 & 2,779 \\
\hline $\begin{array}{l}\text { Total Propriotary Capltal ..................................... } \\
\text { Long-term Debt }\end{array}$ & 281,740 & 221,210 & 7,624 & 0 & 239 & 3,161 \\
\hline 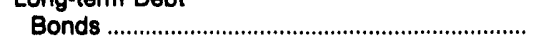 & 608,850 & 351,186 & 1,875 & $2,526,566$ & 6,650 & 0 \\
\hline Advances from Municipality \& Other ............... & & & 0 & 0 & 0 & 0 \\
\hline Unamort Prem on Long-term Debt .................. & & 206 & 0 & 607 & 0 & 0 \\
\hline (less) Unamort Discount on Long-term Debt & 10,538 & 5,999 & & 111,736 & 0 & 0 \\
\hline 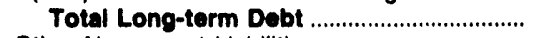 & 598,314 & 345,394 & 1,875 & $2,415,437$ & 6,650 & 0 \\
\hline \multicolumn{7}{|l|}{ Other Noncurrent Liabilities } \\
\hline 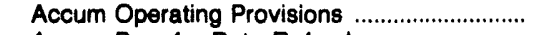 & 116,518 & 0 & 0 & 2,252 & 0 & 0 \\
\hline Accum Prov for Rate Refunds .......................... & & 0 & 0 & 0 & 0 & 0 \\
\hline & 116,518 & \multicolumn{3}{|c|}{ Current and Accrued Liabilities } & $\mathbf{0}$ & 0 \\
\hline 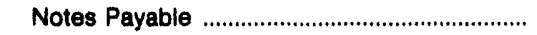 & 2 & 0 & 0 & 0 & 0 & 5,000 \\
\hline Accounts Payable & 22,141 & 19,041 & 665 & 70,947 & 795 & 190 \\
\hline 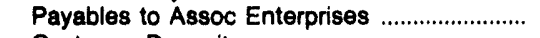 & 7,468 & 909 & 0 & 1,685 & 0 & 113 \\
\hline 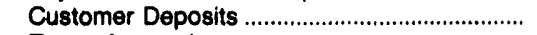 & 88 & 1,285 & 0 & & 0 & 0 \\
\hline 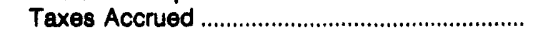 & 3,394 & 2,804 & 0 & 1,173 & 0 & 0 \\
\hline Interest Accrued & 10,112 & 8,188 & 0 & 179 & 120 & 0 \\
\hline Misc Current \& Accrued Liabilities ........................ & 6,021 & 4,468 & 48 & 44,961 & 0 & 472 \\
\hline Total Current a Accrued Llabilitios ........... & 49,225 & 36,694 & 712 & 118,945 & 915 & 5,775 \\
\hline \multicolumn{7}{|l|}{ Doferred Credits } \\
\hline Customer Advances for Construction ............. & 0 & 1,712 & 0 & 0 & 2 & 14 \\
\hline 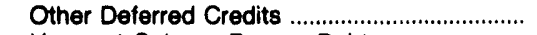 & 362 & 1,350 & 0 & 546,220 & 81 & 0 \\
\hline Unamort Gain on Reacqr Debt ............................ & 0 & 0 & 0 & 332 & 0 & 0 \\
\hline $\begin{array}{l}\text { Total Doferred Credits } \\
\text { Total Labilities and Other Credits }\end{array}$ & $\begin{array}{r}362 \\
1,046,158\end{array}$ & $\begin{array}{r}3,062 \\
608,361\end{array}$ & $\begin{array}{r}0 \\
10,211\end{array}$ & $\begin{array}{r}546,552 \\
3,083,186\end{array}$ & $\begin{array}{r}84 \\
7,888\end{array}$ & 8,950 \\
\hline
\end{tabular}

Note: Totals may not equal sum of components because of independent rounding.

Source: Energy Information Administration, Form ElA-412, "Annual Report of Public Electric Utilities." 
Table 22. Balance Sheet by Major U.S. Publicly Owned Electric Utility Within State at End of Perlod, 1992 (Continued) (Thousand Dollars)

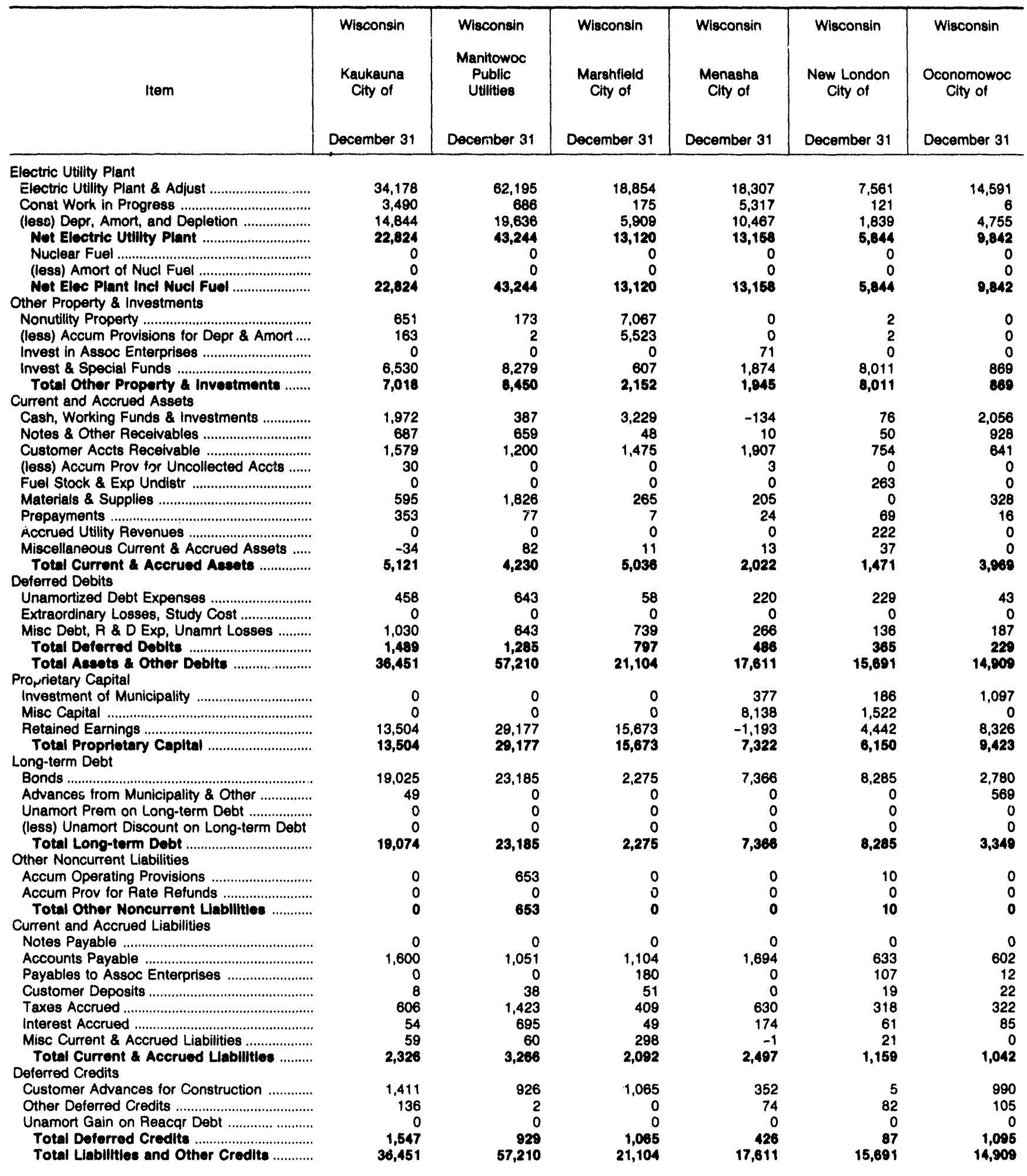

Note: Totals may not equal sum of components because of independent rounding.

Source: Energy Information Administration, Form EIA-412, "Annual Report of Public Electric Utilities." 
Table 22. Balance Sheet by Major U.S. Publlcly Owned Electric Utility Within State at End of Period, 1992 (Continued) (Thousand Dollars)

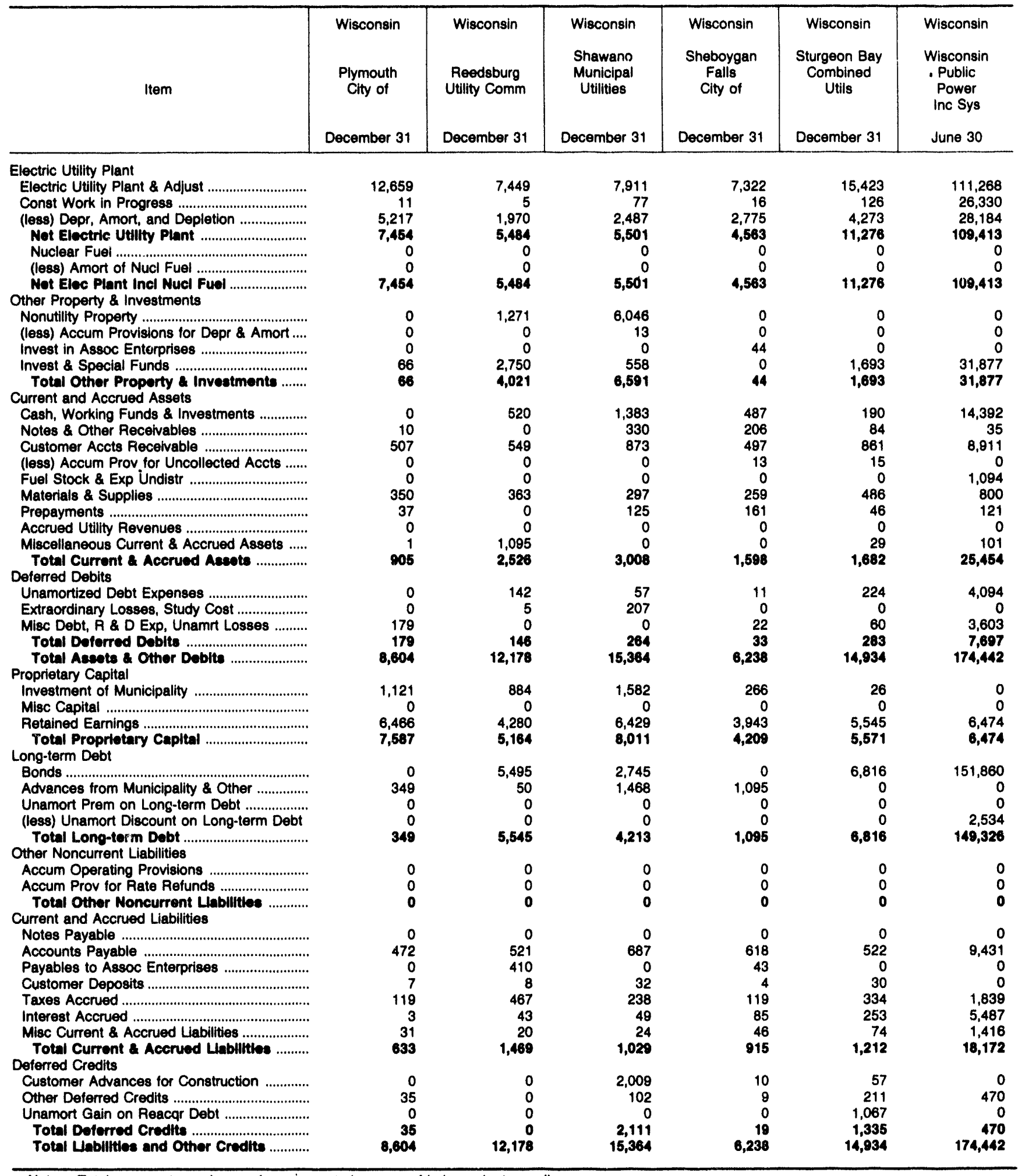

Note: Totals may not equal sum of components because of independent rounding.

Source: Energy Information Administration, Form ElA-412, "Annual Report of Public Electric Utilities." 
Table 22. Balance Sheet by Major U.S. Publicly Owned Electric Utility Within State at End of Perlod, 1992 (Continued) (Thousand Dollars)

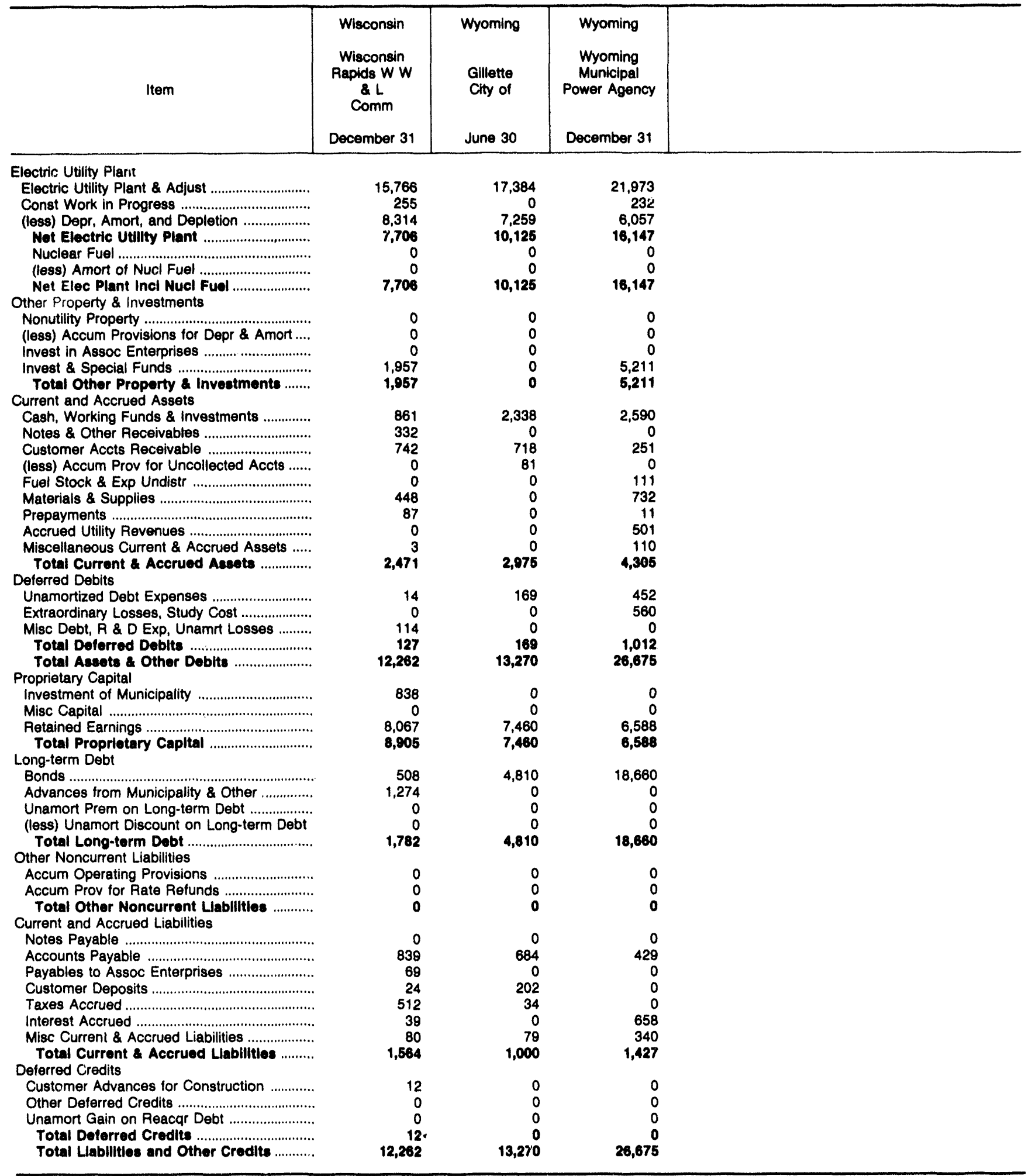

Note: Toials may not equal sum of components because of independent rounding.

Source: Energy Information Administration, Form ElA-412, "Annual Report of Public Electric Utilities." 
Table 23. Electric Operation and Maintenance Expenses by Major U.S. Publicly Owned Electric Utility Within State, 1992

(Thousand Dollars)

\begin{tabular}{|c|c|c|c|c|c|c|}
\hline Item & $\begin{array}{l}\text { Alabama } \\
\text { Alabama } \\
\text { Municipal } \\
\text { Elec Auth } \\
\text { September } 30\end{array}$ & $\begin{array}{l}\text { Alabama } \\
\text { Albertville } \\
\text { Municipal } \\
\text { Utils Bd } \\
\text { June } 30\end{array}$ & $\begin{array}{c}\text { Alabama } \\
\text { Andalusia } \\
\text { City of }\end{array}$ & $\begin{array}{l}\text { Alabama } \\
\text { Athens } \\
\text { City of } \\
\text { December } 31\end{array}$ & $\begin{array}{l}\text { Alabama } \\
\text { Bessemer } \\
\text { City of } \\
\text { June } 30\end{array}$ & $\begin{array}{c}\text { Alabama } \\
\text { Cullman } \\
\text { Power Board } \\
\text { June } 30\end{array}$ \\
\hline 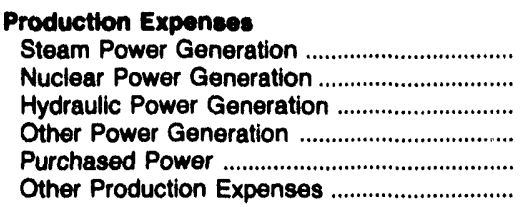 & $\begin{array}{r}0 \\
0 \\
0 \\
0 \\
68,979 \\
0\end{array}$ & $\begin{array}{r}0 \\
0 \\
0 \\
0 \\
16,628 \\
0\end{array}$ & $\begin{array}{r}0 \\
0 \\
0 \\
0 \\
11,330 \\
0\end{array}$ & $\begin{array}{r}0 \\
0 \\
0 \\
0 \\
29,352 \\
0\end{array}$ & $\begin{array}{r}0 \\
0 \\
0 \\
0 \\
12,871 \\
0\end{array}$ & $\begin{array}{r}0 \\
0 \\
0 \\
0 \\
13,946 \\
0\end{array}$ \\
\hline Total Production Expenses ........................... & 68,979 & 16,628 & 11,330 & 29,352 & 12,871 & 13,941 \\
\hline 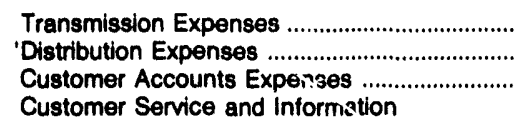 & $\begin{array}{l}0 \\
0 \\
0\end{array}$ & $\begin{array}{r}0 \\
713 \\
272\end{array}$ & $\begin{array}{r}0 \\
133 \\
21\end{array}$ & $\begin{array}{r}186 \\
1,413 \\
484\end{array}$ & $\begin{array}{r}0 \\
669 \\
563\end{array}$ & $\begin{array}{r}0 \\
779 \\
231\end{array}$ \\
\hline $\begin{array}{l}\text { Expenses } \\
\text { Sales Expenses } \\
\text { Administrative and General }\end{array}$ & $\begin{array}{l}0 \\
0\end{array}$ & $\begin{array}{r}23 \\
9\end{array}$ & $\begin{array}{r}32 \\
0\end{array}$ & $\begin{array}{l}31 \\
26\end{array}$ & $\begin{array}{r}20 \\
0\end{array}$ & $\begin{array}{r}15 \\
1\end{array}$ \\
\hline 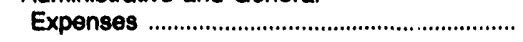 & 724 & 366 & 615 & 682 & 1,027 & 555 \\
\hline $\begin{array}{l}\text { Total Electric Operation and } \\
\text { Malntenance Expenses }\end{array}$ & 69,703 & 18,011 & 12,131 & 32,175 & 15,150 & 15,529 \\
\hline
\end{tabular}

\section{Fuel Expenses in Operation}

Steam Power Generation .....

0

\section{0}

0

Nuclear Power Generation 0

0

0

Other Power Generation

0

o

0

0

0

0

0

Number of Elec Dept Employees

\begin{tabular}{|c|c|c|c|c|c|c|}
\hline Regular Full-time & 5 & 35 & 12 & 66 & 55 & 22 \\
\hline 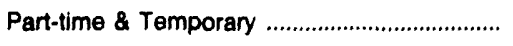 & 0 & 0 & 0 & 0 & 0 & 0 \\
\hline Total Elec Dept Employees ................................ & 5 & 35 & 12 & 66 & 55 & 22 \\
\hline
\end{tabular}

Note: Totals may not equal sum of components because of independent rounding.

Source: Energy Information Administration, Form ElA-412, "Annual Report of Public Electric Utilities." 
Table 23. Electric Operation and Maintenance Expenses by Major U.S. Publicly Owned Electric Utility Within State, 1992 (Continued) (Thousand Dollars)

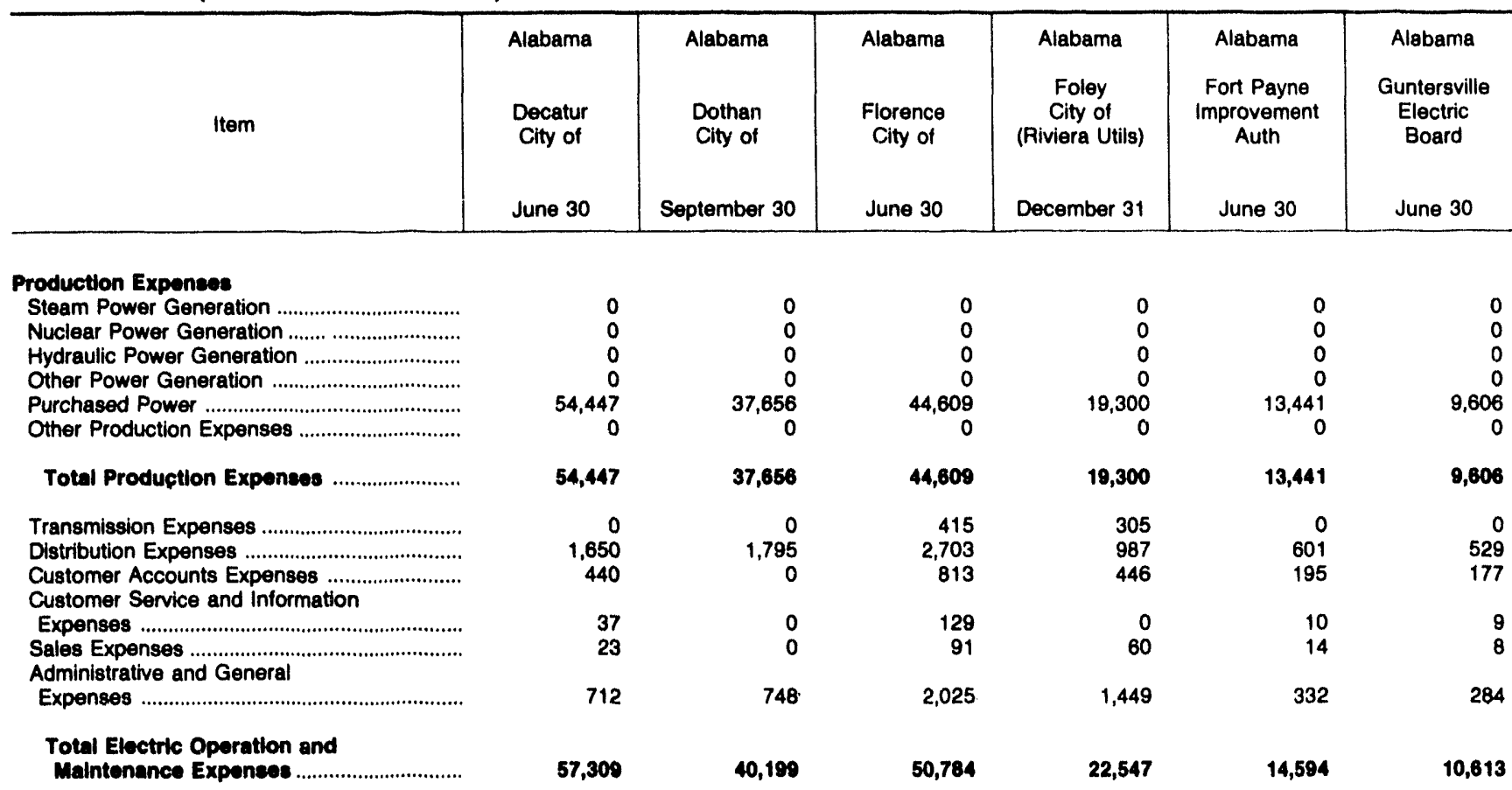

\section{Fuel Expenees in Operation}

Steam Power Generation

Nuclear Power Generation

0

0

Other Power Generation

Number of Elec Dept Employees

Regular Full-time

Part-time \& Temporary

Total Elec Dept Employees
65

0

85
73

163

113

24

24

1

74

163

2

115

0

0

24

Note: Totals may not equal sum of components because of independent rounding.

Source: Energy information Administration, Form ElA-412, "Annual Report of Public Electric Utilities." 
Table 23. Electric Operation and Maintenance Expenses by Major U.S. Publicly Owned Electric Utility Within State, 1992 (Continued) (Thousand Dollars)

\begin{tabular}{|c|c|c|c|c|c|c|}
\hline Item & $\begin{array}{c}\text { Alabama } \\
\text { Huntsville } \\
\text { City of }\end{array}$ & $\begin{array}{l}\text { Alabama } \\
\text { Muscle } \\
\text { Shoals } \\
\text { City of }\end{array}$ & $\begin{array}{l}\text { Alabama } \\
\text { Opelika } \\
\text { City of }\end{array}$ & $\begin{array}{c}\text { Alabama } \\
\text { Scottsboro } \\
\text { City of }\end{array}$ & $\begin{array}{c}\text { Alabama } \\
\text { Sheffield } \\
\text { Utilities }\end{array}$ & $\begin{array}{l}\text { Alabama } \\
\text { Sylacauga } \\
\text { Utilities } \\
\text { Board }\end{array}$ \\
\hline & September 30 & June 30 & September 30 & June 30 & June 30 & September 30 \\
\hline
\end{tabular}

\section{Production Expenses}

Steam Power Generation

Nuclear Power Generation....

Hydraulic Power Generation

Other Power Generation

Purchased Power

Other Production Expenses

Total Production Expenses

Transmission Expenses

Distribution Expenses

Customer Accounts Expenses .........

Expenses

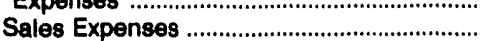

Administrative and General

Expenses

Total Electric Operation and

Maintenance Expences.

0
0
0
0
163,873
0

163,873

92

4,500

1,801

129

82

2,374

172,830
0
0
0
0
8,739
0

0
0
0
0
12,471

2,471
0

12,471

8,739

0

415
118

45

0

334

9,850

13,943

0
0
0
0
13,521
0

0
0
0
0
18,269

13,521

18,269

39

1,620

455

19

1,104

435

21,568

15,115

(n)

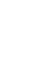

Fuel Expenses in Operation

Steam Power Generation

Nuclear Power Generation .

0

0

0

0

0

0

0

Other Power Generation

0

0

0

0

0

0

o

0

0

Number of Elec Dept Employees

Regular Full-time

245

32

31

64

21

Part-time \& Temporary

0

0

245

19

33

31

0

1

Total Elec Dept Employees

ts because of independent rounding.

Note: Totals may not equal sum of components because of independent rounding.
Source: Energy Information Administration, Form EIA-412, "Annual Report of Public Electric Utilities." 
Table 23. Electric Operation and Maintenance Expenses by Major U.S. Publicly Owned Electric Utllity Within State, 1992 (Continued) (Thousand Dollars)

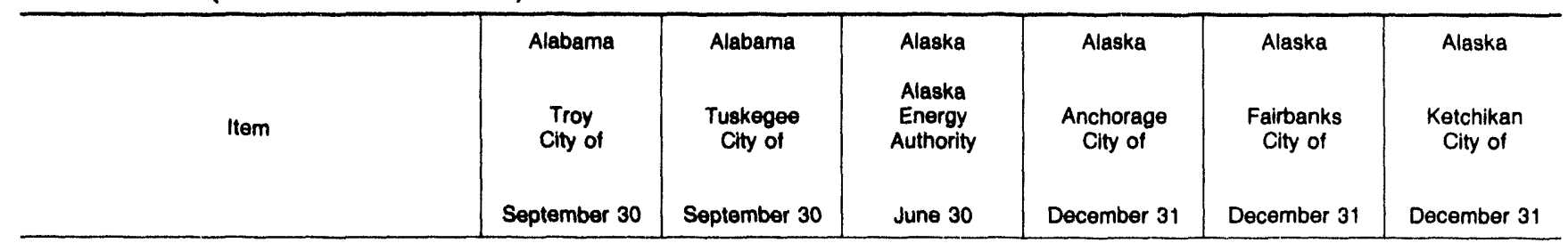

Production Expones:

Steam Power Generation ....

lic Power Generation

Other Power Generation

Purchased Power

Other Production Expenses

Total Production Expenses

Transmission Expenses .

Distribution Expenses ......................................

Customer Accounts Expenses .........................

Customer Service and Information

Expenses ..........

Sales Expenses

Administrative and General

Expenses

Total Electric Operation and

Maintenance Expenses

Fuel Expenses in Operation

Steam Power Generation

Nuclear Power Generation ................................

Other Power Generation

.............

Number of Elec Dept Employees

Regular Full-time

Part-time \& Temporary

Total Elec Dept Employese

Note: Totals may not equal sum of components because of independent rounding

Source: Energy Information Auministration, Form ElA-112, "Annual Report of Public Electric Utilities."
15

0

$\begin{array}{rrrr}0 & 1,654 & 8,707 & 0 \\ 0 & 0 & 0 & 0 \\ 3,985 & 0 & 0 & 1,111 \\ 0 & 20,376 & 0 & 312 \\ 0 & 4,791 & 1,349 & 4,235 \\ 0 & 657 & 0 & 0 \\ 3,985 & 27,478 & 10,056 & 5,858 \\ 0 & 543 & 0 & 6 \\ 0 & 5,462 & 726 & 1,128 \\ 0 & 2,693 & 0 & 0 \\ 0 & 106 & 0 & 199 \\ 0 & 48 & 0 & 0 \\ 779 & 3,834 & 1,020 & 1,544 \\ & & & 8,535\end{array}$

0

0

359

0

0

0

17,954

$\begin{array}{rrrrrr}65 & 36 & 209 & 46 & 41 \\ 0 & 0 & 18 & 0 & 4 \\ 65 & 36 & 227 & 46 & 45\end{array}$


Table 23. Electric Operation and Maintenance Expenses by Major U.S. Publicly Owned Electric Utility Within State, 1992 (Continued) (Thousand Dollars)

\begin{tabular}{|c|c|c|c|c|c|c|}
\hline Item & $\begin{array}{l}\text { Arizona } \\
\text { Arizona } \\
\text { Power } \\
\text { Authority } \\
\\
\text { June } 30\end{array}$ & $\begin{array}{c}\text { Arizona } \\
\text { Electrical } \\
\text { Dist } \\
\text { No2 } \\
\text { Pinal Cnty } \\
\text { December } 31\end{array}$ & $\begin{array}{l}\text { Arizona } \\
\text { Mesa } \\
\text { City of } \\
\text { June } 30\end{array}$ & $\begin{array}{l}\text { Arizona } \\
\text { Navajo } \\
\text { Tribal } \\
\text { Utility } \\
\text { Auth } \\
\text { December } 31\end{array}$ & $\begin{array}{l}\text { Arizona } \\
\text { Salt River } \\
\text { Proj Ag } \\
\text { I \& P Dist } \\
\text { April } 30\end{array}$ & $\begin{array}{l}\text { Arizona } \\
\text { Tohono } \\
\text { OOdham } \\
\text { Utility Auth } \\
\text { December } 31\end{array}$ \\
\hline
\end{tabular}

Production Expenese

Steam Power Generetion

Nuclear Power Generation

Hydraullc Power Generation

Other Power Generation

Purchased Power

Other Production Expenses

Total Production Expenses

Transmission Expenses

Distribution Expenses

Customer Accounts Expenses

Customer Service and Intormation

Expenses

Sales Expenses

Administrative and General

Expenses

0
0
0
0
13,808
0

0
0
0
0
5,216
0

13,808

2,852

11
0

(1)

0
0

839

Total Electric Operation and

Maintenance Expenses

\section{and}

Fuel Expenese in Operation

Steam Power Generation

0

0

Nuclear Power Generation

Other Power Generation

Number of Elec Dept Employees

Regular Full-time

Part-time \& Temporary

Total Elec Dept Employees

0
0
0
0
13,264
0

0

0

19,116

0

13,264

19,116

5,216

0
2,410

2,410
0

456

104

854

524

6,657

17,088

$$
\begin{array}{r}
698 \\
2,499
\end{array}
$$$$
\begin{array}{r}
2,499 \\
1,714
\end{array}
$$

1,714

$$
\begin{aligned}
& 0 \\
& 0
\end{aligned}
$$

3,342

27,369

265,879

92,074

12,461

$\begin{array}{r}8,199 \\ \hline\end{array}$

55,445

$\begin{array}{r}3,639 \\ \hline\end{array}$

437,696

11,356

34,399

20,067

5,269

5,021

63,312

577,120

Note: Totals may not equal sum of components because of independent rounding.

Source: Energy Intormation Administration, Form EIA-412, "Annual Report of Public Electric Utilities." 
Table 23. Electric Operation and Maintenance Expenses by Major U.S. Publicly Owned Electric Utility Within State, 1992 (Continued) (Thousand Dollars)

\begin{tabular}{|c|c|c|c|c|c|c|}
\hline Item & $\begin{array}{l}\text { Arkansas } \\
\text { Benton } \\
\text { City of } \\
\text { December } 31\end{array}$ & $\begin{array}{l}\text { Arkansas } \\
\text { Bentonville } \\
\text { City of }\end{array}$ & $\begin{array}{l}\text { Arkansas } \\
\text { Conway } \\
\text { Corp }\end{array}$ & $\begin{array}{c}\text { Arkansas } \\
\text { Hope } \\
\text { City of } \\
\text { December } 31\end{array}$ & $\begin{array}{c}\text { Arkansas } \\
\text { Jonesboro } \\
\text { City of }\end{array}$ & $\begin{array}{c}\text { Arkansas } \\
\text { North } \\
\text { Little } \\
\text { Rock } \\
\text { City of } \\
\text { December } 31\end{array}$ \\
\hline
\end{tabular}

Production Expences

Steam Power Generation

Nuclear Power Generation

Hydraulic Power Generation

Other Power Generation

Purchased f

Other Production Exponses

Total Production Expenses

Transmission Expenses

Distribution Expenses

Customer Accounts Expenses

Customer Service and Information

Expeng

Sales Expenses

Administrative and General

Expenses

Total Electric Operation and

Malntenance Expenses

0
0
0
138
6,953
0

7,091

0
1,086
0

0

0
85

407

8,669

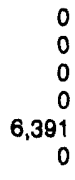

6,391

0
152
0

0

$$
\begin{aligned}
& 0 \\
& 0
\end{aligned}
$$

578

7,120

0
0
0
$5,7 \begin{array}{r}5 \\ 0\end{array}$
15,229

15,222

0
877$$
297
$$

0
0

454

16,850

183
0
0

9,421

0
0
0

10,048
0

19,469

6,994

138

427

0

0
0

612

8,171

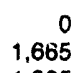

1,005
0

607

29,110

0

29,718

0
1,950

1,428

0

1,876

34,972

\section{Fuel Expenses In Operation}

Steam Power Generation

Nuclear Power Generation .

Other Power Generation

Part-time \& Temporary

Note: Totals may not equal sum of components because of independent rounding.

. Tource: Energy Information Administration, Form EIA-412, "Annual Report of Public Electric Utilities." 
Table 23. Electric Operation and Maintenance Expenses by Major U.S. Publicly Owned Electric UtIllty Within State, 1992 (Continued) (Thousand Dollars)

\begin{tabular}{|c|c|c|c|c|c|c|}
\hline Item & $\begin{array}{c}\text { Arkansas } \\
\text { Osceola } \\
\text { City of } \\
\text { December } 31\end{array}$ & $\begin{array}{l}\text { Arkansar } \\
\text { Paragould } \\
\text { Light } \\
\& \\
\text { Water Comm } \\
\text { December } 31\end{array}$ & $\begin{array}{c}\text { Arkansas } \\
\text { Siloam } \\
\text { Springs } \\
\text { City of } \\
\text { December } 31\end{array}$ & $\begin{array}{c}\text { Arkansas } \\
\text { West } \\
\text { Memphis } \\
\text { City of } \\
\text { December } 31\end{array}$ & $\begin{array}{l}\text { California } \\
\text { Alameda } \\
\text { City of } \\
\text { June } 30\end{array}$ & $\begin{array}{l}\text { California } \\
\text { Anaheim } \\
\text { City of } \\
\text { June } 30\end{array}$ \\
\hline 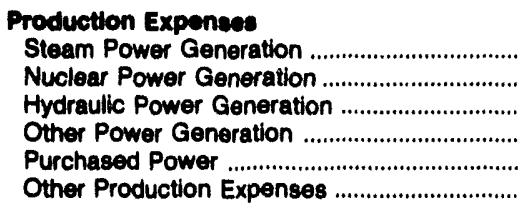 & $\begin{array}{r}0 \\
0 \\
0 \\
0 \\
6,270 \\
116\end{array}$ & $\begin{array}{r}0 \\
0 \\
0 \\
87 \\
6,003 \\
0\end{array}$ & $\begin{array}{r}0 \\
0 \\
0 \\
0 \\
5,395 \\
0\end{array}$ & $\begin{array}{r}367 \\
0 \\
0 \\
0 \\
11,817 \\
0\end{array}$ & $\begin{array}{r}0 \\
0 \\
0 \\
0 \\
28,585 \\
0\end{array}$ & $\begin{array}{r}0 \\
12,708 \\
0 \\
0 \\
132,962 \\
97\end{array}$ \\
\hline Total Production Expenese .......................... & 6,386 & 6,091 & 5,395 & 12,184 & 28,585 & 145,767 \\
\hline 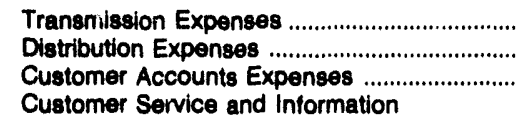 & $\begin{array}{r}0 \\
654 \\
0\end{array}$ & $\begin{array}{r}0 \\
526 \\
304\end{array}$ & $\begin{array}{r}40 \\
881 \\
0\end{array}$ & $\begin{array}{r}0 \\
591 \\
0\end{array}$ & $\begin{array}{r}45 \\
1,459 \\
977\end{array}$ & $\begin{array}{r}284 \\
22,854 \\
3,607\end{array}$ \\
\hline $\begin{array}{l}\text { Expenses } \\
\text { Sales Expenses } \\
\text { Administrative and General }\end{array}$ & $\begin{array}{l}0 \\
0\end{array}$ & $\begin{array}{l}0 \\
0\end{array}$ & $\begin{array}{l}1 \\
0\end{array}$ & $\begin{array}{l}0 \\
0\end{array}$ & $\begin{array}{r}176 \\
25\end{array}$ & $\begin{array}{r}28 \\
0\end{array}$ \\
\hline 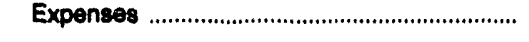 & 275 & 1,095 & 56 & 50 & 3,857 & 6,130 \\
\hline $\begin{array}{l}\text { Total Electric Operation and } \\
\text { Maintenance Expenses }\end{array}$ & 7,314 & 8,017 & 6,373 & 12,825 & 35,124 & 178,670 \\
\hline \multicolumn{7}{|l|}{ Fuel Expenses in Operation } \\
\hline 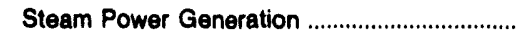 & 0 & 0 & 0 & 178 & 0 & 0 \\
\hline Nuclear Power Generation ................................... & 0 & 0 & 0 & 0 & 0 & 3,343 \\
\hline Other Power Generation .................................... & 0 & 25 & 0 & 0 & 0 & 0 \\
\hline \multicolumn{7}{|l|}{ Number of Elec Dept Employees } \\
\hline Regular Full-time & 35 & 85 & 18 & 15 & 94 & 250 \\
\hline 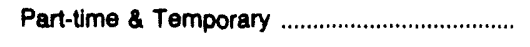 & 0 & 2 & 0 & 0 & 12 & 23 \\
\hline 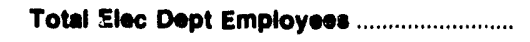 & 35 & 87 & 18 & 15 & 106 & 273 \\
\hline
\end{tabular}

Note: Totals may not equal sum of components because of independent rounding.

Source: Energy Information Administration, Form EIA-412, "Annual Report of Public Electric Utilities." 
Table 23. Electric Operation and Maintenance Expenses by Major U.S. Publicly Owned Electric Utility Within State, 1992 (Continued) (Thousand Dollars)

\begin{tabular}{|c|c|c|c|c|c|c|}
\hline Item & $\begin{array}{l}\text { California } \\
\text { Azusa } \\
\text { City of } \\
\text { June } 30\end{array}$ & $\begin{array}{l}\text { California } \\
\text { Burbank } \\
\text { City of } \\
\text { June } 30\end{array}$ & $\begin{array}{l}\text { California } \\
\text { California } \\
\text { Dept } \\
\text { Wtr } \\
\text { Resources } \\
\text { June } 30\end{array}$ & $\begin{array}{l}\text { California } \\
\text { Colton } \\
\text { City of } \\
\text { June } 30\end{array}$ & $\begin{array}{l}\text { California } \\
\text { Giendale } \\
\text { City of } \\
\text { June } 30\end{array}$ & $\begin{array}{c}\text { California } \\
\text { Imperial } \\
\text { Irrigation } \\
\text { District } \\
\text { December } 31\end{array}$ \\
\hline 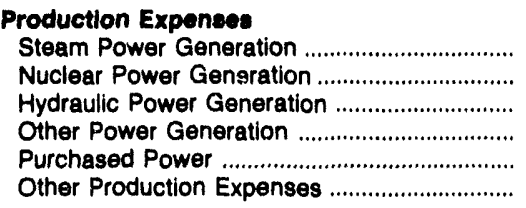 & $\begin{array}{r}0 \\
0 \\
0 \\
0 \\
9,661 \\
0\end{array}$ & $\begin{array}{r}13,010 \\
0 \\
0 \\
0 \\
45,027 \\
1,374\end{array}$ & $\begin{array}{r}7,038 \\
0 \\
9,880 \\
0 \\
34,471 \\
0\end{array}$ & $\begin{array}{r}0 \\
0 \\
0 \\
0 \\
8,904 \\
0\end{array}$ & $\begin{array}{r}9,188 \\
0 \\
0 \\
2,314 \\
34,228 \\
4,678\end{array}$ & $\begin{array}{r}17,202 \\
0 \\
1,954 \\
848 \\
76,145 \\
744\end{array}$ \\
\hline Total Production Expenees ............................ & 9,661 & 59,411 & 51,389 & 8,804 & 50,408 & 96,893 \\
\hline 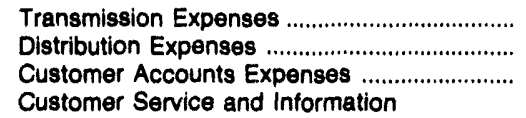 & $\begin{array}{r}0 \\
1,535 \\
774\end{array}$ & $\begin{array}{l}1,717 \\
4,884 \\
1,122\end{array}$ & $\begin{array}{l}0 \\
0 \\
0\end{array}$ & $\begin{array}{r}0 \\
450 \\
0\end{array}$ & $\begin{array}{r}854 \\
5,197 \\
3,142\end{array}$ & $\begin{array}{l}3,193 \\
9,826 \\
3,995\end{array}$ \\
\hline 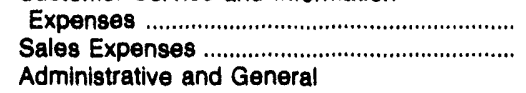 & $\begin{array}{l}0 \\
0\end{array}$ & $\begin{array}{l}0 \\
0\end{array}$ & $\begin{array}{l}0 \\
0\end{array}$ & $\begin{array}{l}0 \\
0\end{array}$ & $\begin{array}{l}0 \\
0\end{array}$ & $\begin{array}{l}0 \\
0\end{array}$ \\
\hline 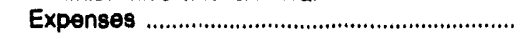 & 274 & 6,451 & 0 & 3,306 & 9,138 & 11,666 \\
\hline 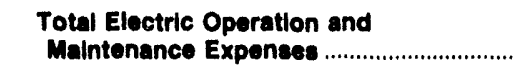 & 12,244 & 73,585 & 51,389 & 12,660 & 68,739 & 125,573 \\
\hline \multicolumn{7}{|l|}{ Fuel Expenses In Operation } \\
\hline 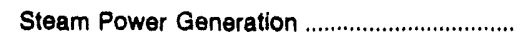 & 0 & 6,631 & 1,692 & 0 & 6,929 & 13,929 \\
\hline Nuclear Power Generation ............................... & 0 & 0 & 0 & 0 & 0 & 0 \\
\hline Other Power Generation ..................................... & 0 & 0 & 0 & 0 & 26 & 335 \\
\hline \multicolumn{7}{|l|}{ Number of Elec Dept Employees } \\
\hline 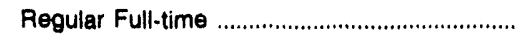 & 14 & 270 & 96 & 37 & 275 & 429 \\
\hline 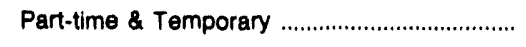 & 0 & 0 & 0 & 0 & 0 & 2 \\
\hline Total Elec Dept Employees ............................. & 14 & 270 & 96 & 37 & 275 & 431 \\
\hline
\end{tabular}

Source: Energy Information Administration, Form EIA-412, "Annual Report of Public Electric Utilities." 
Table 23. Electric Operation and Maintenance Expenses by Major U.S. Publicly Owned Electric Utillty Within State, 1992 (Continued) (Thousand Dollars)

\begin{tabular}{|c|c|c|c|c|c|c|}
\hline Item & $\begin{array}{l}\text { California } \\
\text { Lodi } \\
\text { City of } \\
\text { June } 30\end{array}$ & $\begin{array}{l}\text { California } \\
\text { Los Angeles } \\
\text { City of } \\
\text { June } 30\end{array}$ & $\begin{array}{l}\text { California } \\
\text { Metropolitan } \\
\text { Water } \\
\text { District } \\
\text { June } 30\end{array}$ & $\begin{array}{c}\text { California } \\
\text { Modesto } \\
\text { Irrigation } \\
\text { District } \\
\text { December } 31\end{array}$ & $\begin{array}{c}\text { California } \\
\text { MSR } \\
\text { Public } \\
\text { Power } \\
\text { Agency } \\
\text { December } 31\end{array}$ & $\begin{array}{l}\text { California } \\
\text { Northern } \\
\text { California } \\
\text { Power Agny } \\
\text { June } 30\end{array}$ \\
\hline 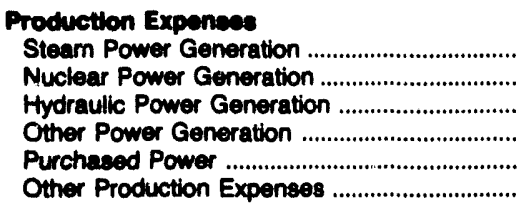 & $\begin{array}{r}0 \\
0 \\
0 \\
0 \\
25,778 \\
0\end{array}$ & $\begin{array}{r}291,814 \\
28,768 \\
21,623 \\
170 \\
660,345 \\
0\end{array}$ & $\begin{array}{r}0 \\
0 \\
1,606 \\
0 \\
14,342 \\
0\end{array}$ & $\begin{array}{r}0 \\
0 \\
644 \\
448 \\
68,402 \\
158\end{array}$ & $\begin{array}{r}19,999 \\
0 \\
0 \\
0 \\
62 \\
50\end{array}$ & $\begin{array}{r}57,864 \\
0 \\
1,596 \\
1,142 \\
10,120 \\
2,053\end{array}$ \\
\hline Total Production Expensese .......................... & 25,778 & $1,002,720$ & 15,848 & 69,652 & 20,111 & 72,775 \\
\hline 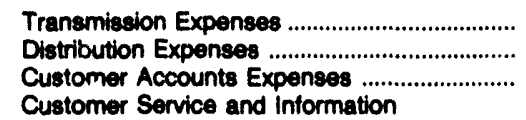 & $\begin{array}{r}0 \\
1,434 \\
1,359\end{array}$ & $\begin{array}{r}29,197 \\
146,306 \\
60,496\end{array}$ & $\begin{array}{l}0 \\
0 \\
0\end{array}$ & $\begin{array}{r}213 \\
6,022 \\
2,792\end{array}$ & $\begin{array}{r}202 \\
0 \\
0\end{array}$ & $\begin{array}{r}6,213 \\
0 \\
0\end{array}$ \\
\hline 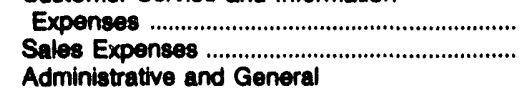 & $\begin{array}{l}0 \\
0\end{array}$ & $\begin{array}{r}18,344 \\
0\end{array}$ & $\begin{array}{l}0 \\
0\end{array}$ & $\begin{array}{r}1,290 \\
49\end{array}$ & $\begin{array}{l}0 \\
0\end{array}$ & $\begin{array}{l}0 \\
0\end{array}$ \\
\hline 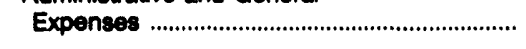 & 2,019 & 199,381 & 0 & 8,225 & 1,386 & 5,151 \\
\hline Totel Ebetric Operation and & 30,589 & $1,466,444$ & 15,948 & 88,244 & 21,698 & 84,139 \\
\hline \multicolumn{7}{|l|}{ Fuel Expenses in Operation } \\
\hline Steam Power Generation .................................... & 0 & 206,422 & 0 & 0 & 15,783 & 50,961 \\
\hline Nuclear Power Generation .................................. & 0 & 9,609 & 0 & 0 & 0 & 0 \\
\hline 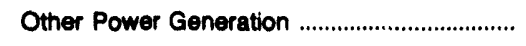 & 0 & 17 & 0 & 51 & 0 & 264 \\
\hline \multicolumn{7}{|l|}{ Number of Elec Dept Employees } \\
\hline 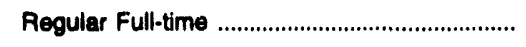 & 39 & 7,781 & 292 & 298 & 177 & 182 \\
\hline Part-time \& Temporary .................................... & 1 & 877 & 0 & 13 & 0 & 12 \\
\hline Total Elec Dept Employees .......................... & 40 & 8,658 & 292 & 311 & 177 & 184 \\
\hline
\end{tabular}

Note: Totals may not equal sum of components because of independent rounding.

Source: Energy Information Administration, Form ElA-412, "Annual Report of Public Electric Utilities." 
Table 23. Electric Operation and Maintenance Expenses by Major U.S. Publicly Owned Electric Utility Within State, 1992 (Continued) (Thousand Dollars)

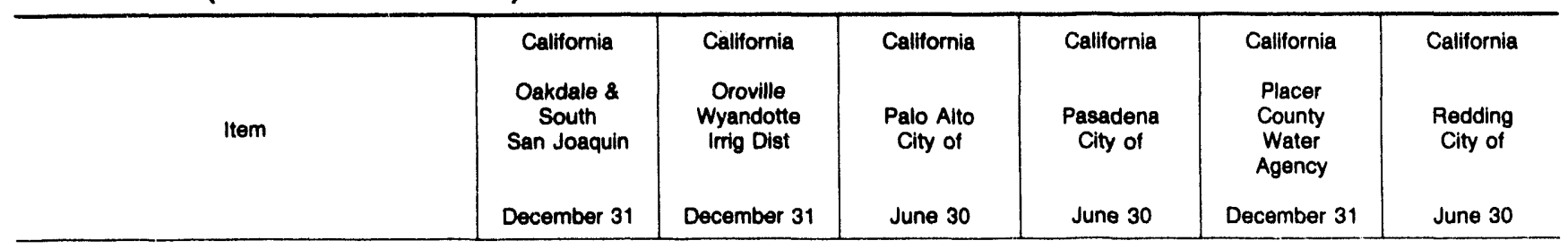

Production Expensees

Steam Power Generation

Nuclear Power Generation

Hydraulic Power Generation

Other Power Generation

Purchased Power

Other Production Expenses

Total Production Expenses

Transmission Expenses

Distribution Expenses

Customer Accounts Expenses .

Customer Service and Information

Expenses

Sales Expenses ..................

Administrative and General

Expenses

Total Electric Operation and

Maintenance Expenses

Fuel Exponses in Oporation

Steam Power Generation

Nuclear Power Generation

Other Power Generation

Number of Elec Dept Employees

Regular Full-time

Part-time \& Temporary

Total Elec Dept Employees
0
0
828
0
0
0

828

0
0
0

0
0
0

0

0

1,313

2,140

0

0

0

22

0

22

0
0
8,303
0
0
0

8,303
0
0
0
0
28,397
0

17,073

0
45

52,550

52,559
373

28,397

70,051

0
5,009

1,312

4,287

1,031

923

0
2,468

2,458

7,085

38,332

10.708

0

0

0

95

0

95

0

0

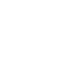

20

4
Note: Totals may not equal sum of components because of independent rounding.

Source: Energy Information Administration, Form EIA-412, "Annual Report of Public Electric Utilities." 
Table 23. Electric Operation and Maintenance Expenses by Major U.S. Publicly Owned Electric Utility Within State, 1992 (Continued)

(Thousand Dollars)

\begin{tabular}{|c|c|c|c|c|c|c|}
\hline Item & $\begin{array}{l}\text { California } \\
\text { Piverside } \\
\text { City of } \\
\text { June } 30\end{array}$ & $\begin{array}{l}\text { California } \\
\text { Roseville } \\
\text { City of } \\
\text { June } 30\end{array}$ & $\begin{array}{l}\text { California } \\
\text { Sacramento } \\
\text { Municipal } \\
\text { Util Dist } \\
\text { December } 31\end{array}$ & $\begin{array}{l}\text { California } \\
\text { San Francisco } \\
\text { City } \\
\mathbf{8} \\
\text { County of } \\
\text { June } 30\end{array}$ & $\begin{array}{l}\text { California } \\
\text { Santa } \\
\text { Clara } \\
\text { City of } \\
\text { June } 30\end{array}$ & $\begin{array}{c}\text { California } \\
\text { Southern } \\
\text { California } \\
\text { P P } \\
\text { A } \\
\text { June } 30\end{array}$ \\
\hline 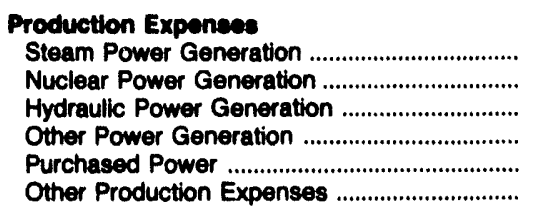 & $\begin{array}{r}0 \\
8,759 \\
0 \\
0 \\
79,660 \\
761\end{array}$ & $\begin{array}{r}0 \\
0 \\
0 \\
0 \\
26,134 \\
623\end{array}$ & $\begin{array}{r}16,326 \\
3,981 \\
7,397 \\
1,045 \\
292,963 \\
4,112\end{array}$ & $\begin{array}{r}0 \\
0 \\
3,214 \\
0 \\
20,081 \\
8,193\end{array}$ & $\begin{array}{r}0 \\
0 \\
69 \\
1,910 \\
115,210 \\
489\end{array}$ & $\begin{array}{r}0 \\
28,489 \\
0 \\
0 \\
1,769 \\
130\end{array}$ \\
\hline Total Production Expenses ............................ & 80,170 & 26,768 & 325,824 & 31,488 & 117,677 & 30,387 \\
\hline 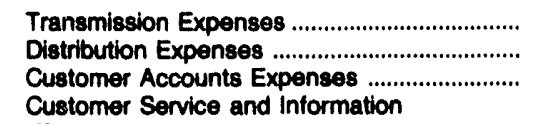 & $\begin{array}{r}15,110 \\
5,686 \\
2,807\end{array}$ & $\begin{array}{r}0 \\
5,273 \\
932\end{array}$ & $\begin{array}{l}15,463 \\
24,027 \\
20,601\end{array}$ & $\begin{array}{r}1,941 \\
0 \\
0\end{array}$ & $\begin{array}{r}108 \\
3,540 \\
8\end{array}$ & $\begin{array}{r}16,146 \\
0 \\
0\end{array}$ \\
\hline $\begin{array}{l}\text { Expenses } \\
\text { Sales Expenses } \\
\text { Administrative and General }\end{array}$ & $\begin{array}{r}776 \\
2\end{array}$ & $\begin{array}{l}0 \\
0\end{array}$ & $\begin{array}{r}4,247 \\
368\end{array}$ & $\begin{array}{l}0 \\
0\end{array}$ & $\begin{array}{r}0 \\
65\end{array}$ & $\begin{array}{l}0 \\
0\end{array}$ \\
\hline 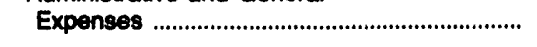 & 11,079 & 1,166 & 23,124 & 12,765 & 27,673 & 16,592 \\
\hline $\begin{array}{l}\text { Total Ebetric Operation and } \\
\text { Malntenance Expenece }\end{array}$ & 124,648 & 34,127 & 413,654 & 46,193 & 149,072 & 63,125 \\
\hline \multicolumn{7}{|l|}{ Fuel Expensese In Operation } \\
\hline 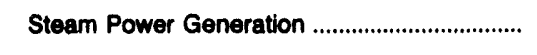 & 0 & 0 & 0 & 0 & 0 & 0 \\
\hline 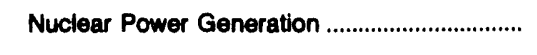 & 1,466 & 0 & 0 & 0 & 0 & 8,639 \\
\hline 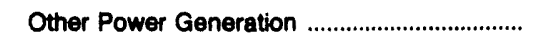 & 0 & 0 & 329 & 0 & 1,379 & 0 \\
\hline \multicolumn{7}{|l|}{ Number of Elec Dept Employees } \\
\hline Regular Full-time & 261 & 68 & 2,380 & 33 & 102 & 16 \\
\hline 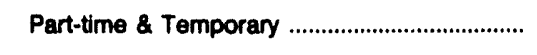 & 11 & 5 & 29 & 0 & 7 & 0 \\
\hline Total Elec Dopt Employees ............................ & 272 & 73 & 2,400 & 33 & 109 & 16 \\
\hline
\end{tabular}

Note: Totals may not equal sum of components because of independent rounding.

Source: Energy Information Administration, Form EIA-412, "Annual Report of Public Electric Utilities." 
Table 23. Electric Operation and Maintenance Expenses by Major U.S. Publicly Owned Electric Utility Within State, 1992 (Continued)

(Thousand Dollars)

\begin{tabular}{|c|c|c|c|c|c|c|}
\hline Item & $\begin{array}{c}\text { California } \\
\text { Turlock } \\
\text { Imization } \\
\text { District } \\
\text { December } 31\end{array}$ & $\begin{array}{l}\text { Callfornia } \\
\text { Vernon } \\
\text { City of } \\
\text { June } 30\end{array}$ & $\begin{array}{l}\text { California } \\
\text { Yuba } \\
\text { County } \\
\text { Water } \\
\text { Agency } \\
\text { June } 30\end{array}$ & $\begin{array}{l}\text { Colorado } \\
\text { Arkansas } \\
\text { River } \\
\text { Power } \\
\text { Authority } \\
\text { December } 31\end{array}$ & $\begin{array}{l}\text { Colorado } \\
\text { Colorado } \\
\text { Springs } \\
\text { City of } \\
\text { December } 31\end{array}$ & $\begin{array}{l}\text { Colorado } \\
\begin{array}{c}\text { Fort Collins } \\
\text { Clty of }\end{array} \\
\text { December } 31\end{array}$ \\
\hline 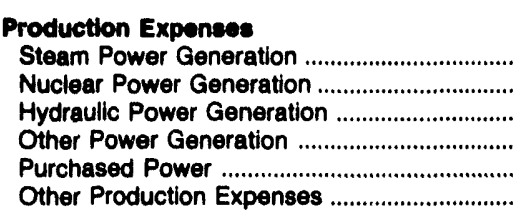 & $\begin{array}{r}0 \\
0 \\
3,331 \\
1,363 \\
48,626 \\
360\end{array}$ & $\begin{array}{r}0 \\
0 \\
0 \\
2,962 \\
39,243 \\
0\end{array}$ & $\begin{array}{r}0 \\
0 \\
1,668 \\
0 \\
0 \\
0\end{array}$ & $\begin{array}{r}0 \\
0 \\
0 \\
0 \\
8,708 \\
0\end{array}$ & $\begin{array}{r}61,153 \\
0 \\
390 \\
0 \\
8,977 \\
0\end{array}$ & $\begin{array}{r}0 \\
0 \\
0 \\
0 \\
29,162 \\
0\end{array}$ \\
\hline Total Production Expenses ............................ & 53,680 & 42,205 & 1,668 & 8,708 & 70,620 & 29,162 \\
\hline 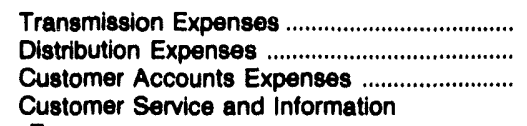 & $\begin{array}{r}1,081 \\
7,044 \\
0\end{array}$ & $\begin{array}{r}2,253 \\
2,148 \\
0\end{array}$ & $\begin{array}{l}0 \\
0 \\
0\end{array}$ & $\begin{array}{l}0 \\
0 \\
0\end{array}$ & $\begin{array}{r}1,723 \\
11,592 \\
4,251\end{array}$ & $\begin{array}{r}0 \\
3,676 \\
1,210\end{array}$ \\
\hline $\begin{array}{l}\text { Expenses } \\
\text { Sales Expenses } \\
\text { Administrative and General }\end{array}$ & $\begin{array}{l}0 \\
0\end{array}$ & $\begin{array}{l}352 \\
705\end{array}$ & $\begin{array}{l}0 \\
0\end{array}$ & $\begin{array}{l}0 \\
0\end{array}$ & $\begin{array}{r}196 \\
0\end{array}$ & $\begin{array}{r}283 \\
0\end{array}$ \\
\hline 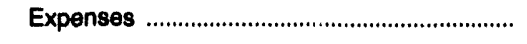 & 13,404 & 1,537 & 1,048 & 549 & 9,154 & 2,060 \\
\hline $\begin{array}{l}\text { Total Electric Operation and } \\
\text { Maintenance Expenees }\end{array}$ & 75,209 & 49,200 & 2,716 & 9,257 & 97,436 & 36,391 \\
\hline \multicolumn{7}{|l|}{ Fuel Expenees in Operation } \\
\hline 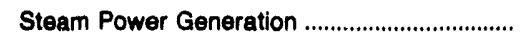 & 0 & 0 & 0 & 0 & 46,780 & 0 \\
\hline 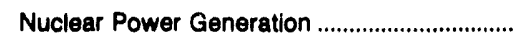 & 0 & 0 & 0 & 0 & 0 & 0 \\
\hline 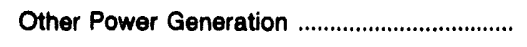 & 133 & 759 & 0 & 0 & 0 & 0 \\
\hline \multicolumn{7}{|l|}{ Number of Elec Dept Employees } \\
\hline Regular Full-time & 3 & 44 & 15 & 3 & 507 & 104 \\
\hline 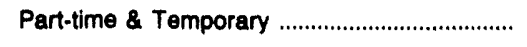 & 0 & 1 & 10 & 0 & 18 & 28 \\
\hline Total Eloc Dopt Employees ............................... & 3 & 45 & 26 & 3 & 625 & 134 \\
\hline
\end{tabular}

Note: Totals may not equal sum of components because of independent rounding.

Source: Energy Information Administration, Form EIA-412, "Annual Report of Public Electric Utilities." 
Table 23. Electric Operation and Maintenance Expenses by Major U.S. Publicly
Owned Electric Utility Within State, 1992 (Continued) (Thousand Dollars)

\begin{tabular}{|c|c|c|c|c|c|c|}
\hline Item & $\begin{array}{l}\text { Colorado } \\
\text { Longmont } \\
\text { Clty of } \\
\text { December } 31\end{array}$ & $\begin{array}{l}\text { Colorado } \\
\text { Loveland } \\
\text { City of } \\
\text { December } 31\end{array}$ & $\begin{array}{l}\text { Colorado } \\
\text { Platte River } \\
\text { Power } \\
\text { Authority } \\
\text { December } 31\end{array}$ & $\begin{array}{l}\text { Connecticut } \\
\text { Connecticut } \\
\text { Mun } \\
\text { Elec } \\
\text { Engy Coop } \\
\text { December } 31\end{array}$ & $\begin{array}{l}\text { Connecticut } \\
\text { Groton } \\
\text { City of } \\
\text { June } 30\end{array}$ & $\begin{array}{l}\text { Connecticut } \\
\text { Norwich } \\
\text { City of } \\
\text { June } 30\end{array}$ \\
\hline
\end{tabular}

Production Expenses

Steam Power Generation

Nuclear Power Generation

Hydraulic Power Generation

Other Power Generation

Purchased Power

Other Production Expenses

Total Production Expenses

Transmiscion Expenses

Distribution Expenses

Customer Accounts Expenses

Customer Service and Information

Expenses

Sales Expenses

Administrattve and General

Expenses

0
0
247
0
15,089
0

0
0
76
0
12,206
0
12,281

16,316

0
1,650
0

0
960

109

1,128

1,128
0

1,459

Total Electrlc Operation and

Maintenance Expenses

19,663

13,708

45,036
0
0
0
12,291
631

57,959

2,153

0

0

0

137
0

306

5,532

65,844

0
2,073
0
0
48,418
0

0
, 073
0
0
418
0

50,491

2,419

0
0

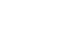

35,6

0
0
0
0
35,658
0

0

0
255

0

15,709

6,964

110

110
792
797

797

0

0

2,346

35,658

139
1,103

361

4
0

5,017

55,250

22,684

Fuel Expenees in Operation

Steam Powse Saneration

Nuclear Power Generation:

Other Power Generation

$\begin{array}{ll}0 & 0 \\ 0 & 0 \\ 0 & 0\end{array}$

27,081

0
379

30,337

Number of Elec Dept Employees

Regular Full-time

55

Part-time \& Temporany

0

52

203

5

6

57

200

65

Total Elec Dopt Employees

Note: Totals may not equal sum of components because of independent rounding.

Source: Energy Information Administration, Form EIA-412, "Annual Report of Public Electric Utilities." 
Table 23. Electric Operation and Maintenance Expenses by Major U.S. Publicly Owned Electric Utility Within State, 1992 (Continued) (Thousand Dollars)

\begin{tabular}{|c|c|c|c|c|c|c|}
\hline Item & $\begin{array}{l}\text { Connecticut } \\
\text { Wallingtord } \\
\text { Town of } \\
\text { June } 30\end{array}$ & $\begin{array}{l}\text { Delaware } \\
\text { Dover } \\
\text { City of } \\
\text { June } 30\end{array}$ & $\begin{array}{l}\text { Delaware } \\
\text { Milford } \\
\text { City of } \\
\text { September } 30\end{array}$ & $\begin{array}{l}\text { Delaware } \\
\text { Newark } \\
\text { City of } \\
\text { December } 31\end{array}$ & $\begin{array}{l}\text { Florida } \\
\text { Bartow } \\
\text { City of } \\
\text { September } 30\end{array}$ & $\begin{array}{c}\text { Florida } \\
\text { Florida } \\
\text { Municipal } \\
\text { Power Agency } \\
\text { September } 30\end{array}$ \\
\hline 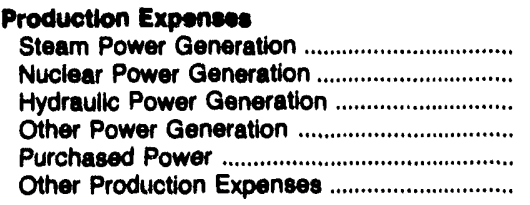 & $\begin{array}{r}862 \\
0 \\
0 \\
0 \\
33,455 \\
0\end{array}$ & $\begin{array}{r}13,122 \\
0 \\
0 \\
0 \\
8,092 \\
328\end{array}$ & $\begin{array}{r}0 \\
0 \\
0 \\
0 \\
6,044 \\
0\end{array}$ & $\begin{array}{r}0 \\
0 \\
0 \\
0 \\
12,751 \\
0\end{array}$ & $\begin{array}{r}0 \\
0 \\
0 \\
0 \\
10,893 \\
0\end{array}$ & $\begin{array}{r}20,354 \\
11,548 \\
0 \\
353 \\
68,785 \\
447\end{array}$ \\
\hline Total Production Expenses ......................... & 34,317 & 21,543 & 6,044 & 12,751 & 10,893 & 101,487 \\
\hline 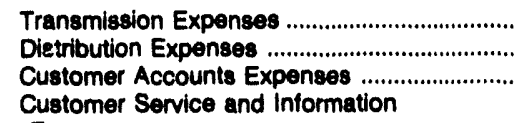 & $\begin{array}{r}9 \\
1,564 \\
803\end{array}$ & $\begin{array}{r}3,127 \\
0 \\
0\end{array}$ & $\begin{array}{r}0 \\
923 \\
0\end{array}$ & $\begin{array}{r}0 \\
1,427 \\
0\end{array}$ & $\begin{array}{l}276 \\
982 \\
131\end{array}$ & $\begin{array}{r}11,319 \\
0 \\
0\end{array}$ \\
\hline 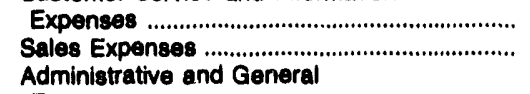 & $\begin{array}{r}51 \\
0\end{array}$ & 0 & $\begin{array}{l}0 \\
0\end{array}$ & $\begin{array}{l}0 \\
0\end{array}$ & $\begin{array}{l}0 \\
0\end{array}$ & $\begin{array}{l}0 \\
0\end{array}$ \\
\hline 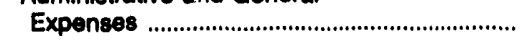 & 3,1613 & 2,508 & 52 & 0 & 1,738 & 5,286 \\
\hline $\begin{array}{l}\text { Total Electric Operation and } \\
\text { Maintenance Expenses }\end{array}$ & 39,911 & 27,178 & 7,018 & 14,177 & 14,020 & 118,092 \\
\hline \multicolumn{7}{|l|}{ Fual Exponese in Operation } \\
\hline Steam Power Generation ........................................ & 28 & 8,545 & 0 & 0 & 0 & 10,447 \\
\hline Nuclear Power Generation ................................ & 0 & 0 & 0 & 0 & 0 & 2,501 \\
\hline 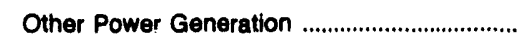 & 0 & 0 & 0 & 0 & 0 & 176 \\
\hline \multicolumn{7}{|l|}{ Number of Elec Dept Employees } \\
\hline 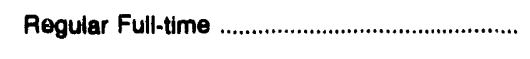 & 78 & 118 & 9 & 21 & 25 & 30 \\
\hline Part-time \& Temporary ..................................... & 1 & 1 & 1 & 0 & 0 & 0 \\
\hline 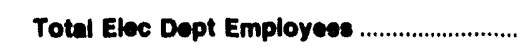 & 79 & 118 & 10 & 21 & 25 & 30 \\
\hline
\end{tabular}

Note: Totals may not equal sum of components because of independent rounding.

Source: Energy Information Administration, Form ElA-412, "Annual Report of Public Electric Utilities." 
Table 23. Electric Operation and Maintenance Expenses by Major U.S. Publicly Owned Electric Utility Within State, 1992 (Continued) (Thousand Dollars)

\begin{tabular}{|c|c|c|c|c|c|c|}
\hline Item & $\begin{array}{l}\text { Florida } \\
\text { Fort Pierce } \\
\text { Utilities } \\
\text { Auth } \\
\text { September } 30\end{array}$ & $\begin{array}{c}\text { Florida } \\
\text { Gainesville } \\
\text { Reglonal } \\
\text { Utilities } \\
\text { September } 30\end{array}$ & $\begin{array}{c}\text { Florida } \\
\text { Homestead } \\
\text { City of } \\
\text { September } 30\end{array}$ & $\begin{array}{c}\text { Florida } \\
\text { Jacksonville } \\
\text { Beach } \\
\text { Clty of } \\
\text { September } 30\end{array}$ & $\begin{array}{l}\text { Florida } \\
\text { Jacksonville } \\
\text { Electric } \\
\text { Auth }\end{array}$ & $\begin{array}{l}\text { Florida } \\
\text { Key West } \\
\text { City of } \\
\text { September } 30\end{array}$ \\
\hline 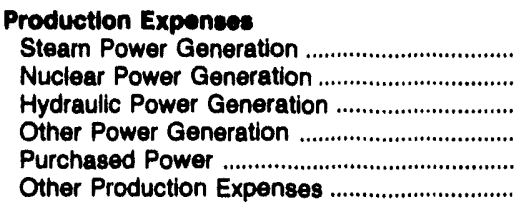 & $\begin{array}{r}12,114 \\
0 \\
0 \\
26 \\
12,796 \\
0\end{array}$ & $\begin{array}{r}47,450 \\
1,768 \\
0 \\
052 \\
1,008 \\
532\end{array}$ & $\begin{array}{r}0 \\
0 \\
0 \\
4,328 \\
9,253 \\
363\end{array}$ & $\begin{array}{r}0 \\
0 \\
0 \\
0 \\
24,201 \\
0\end{array}$ & $\begin{array}{r}266,167 \\
0 \\
0 \\
976 \\
69,878 \\
11\end{array}$ & $\begin{array}{r}5,544 \\
0 \\
0 \\
0,163 \\
15,183 \\
159\end{array}$ \\
\hline Total Production Expenses ............................. & 24,936 & 51,710 & 13,944 & 24,201 & 337,032 & 24,049 \\
\hline 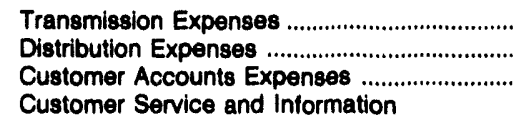 & $\begin{array}{r}663 \\
1,230 \\
701\end{array}$ & $\begin{array}{r}564 \\
4,938 \\
2,071\end{array}$ & $\begin{array}{r}210 \\
4,917 \\
1,513\end{array}$ & $\begin{array}{r}18 \\
1,082 \\
163\end{array}$ & $\begin{array}{r}8,336 \\
19,434 \\
12,255\end{array}$ & $\begin{array}{r}225 \\
1,909 \\
609\end{array}$ \\
\hline 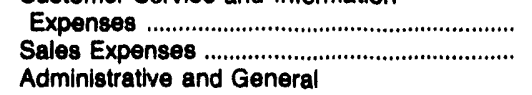 & $\begin{array}{l}0 \\
0\end{array}$ & $\begin{array}{r}20 \\
343\end{array}$ & $\begin{array}{l}0 \\
0\end{array}$ & $\begin{array}{l}0 \\
0\end{array}$ & $\begin{array}{r}811 \\
0\end{array}$ & $\begin{array}{r}171 \\
0\end{array}$ \\
\hline 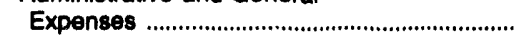 & 3,971 & 8,372 & 4,997 & 4,607 & 32,512 & 5,384 \\
\hline $\begin{array}{l}\text { Total Electric Operattori and } \\
\text { Maintenance Exponses }\end{array}$ & 31,501 & 68,017 & 25,881 & 30,071 & 410,490 & 32,348 \\
\hline \multicolumn{7}{|l|}{ Fuel Exponese in Operation } \\
\hline 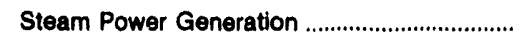 & 9,670 & 37,711 & 0 & 0 & 187,983 & 3,325 \\
\hline Nuclear Power Generation .................................. & 0 & 354 & 0 & 0 & 0 & 0 \\
\hline Other Power Generation ....................................... & 8 & 523 & 2,036 & 0 & 552 & 2,313 \\
\hline \multicolumn{7}{|l|}{ Number of Elec Dept Employees } \\
\hline Regular Full-time & 48 & 687 & 112 & 76 & 1,886 & 200 \\
\hline 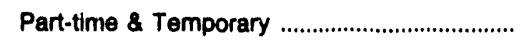 & 0 & 32 & 0 & 1 & 43 & 6 \\
\hline Total Elec Dept Employees .............................. & 48 & 718 & 112 & 77 & 2,029 & 200 \\
\hline
\end{tabular}

Note: Totals may not equal sum of components because of independent rounding.

Source: Energy Information Administration, Form EIA-412, "Annual Report of Public Electric Utilities." 
Table 23. Electric Operation and Maintenance Expenses by Major U.S. Publicly Owned Electric Utility Within State, 1992 (Continued)

(Thousand Dollars)

\begin{tabular}{|c|c|c|c|c|c|c|}
\hline Item & $\begin{array}{c}\text { Florida } \\
\text { Klsaimmee } \\
\text { Utilty } \\
\text { Authority } \\
\text { September } 30\end{array}$ & $\begin{array}{l}\text { Florida } \\
\text { Lake Worth } \\
\text { City of } \\
\text { September } 30\end{array}$ & $\begin{array}{l}\text { Floride } \\
\text { Lakeland } \\
\text { City of } \\
\text { September } 30\end{array}$ & $\begin{array}{c}\text { Florida } \\
\text { Leesburg } \\
\text { City of }\end{array}$ & $\begin{array}{c}\text { Florida } \\
\text { New Smyrna } \\
\text { Beach } \\
\text { Utils Comm } \\
\text { September } 30\end{array}$ & $\begin{array}{l}\text { Florida } \\
\text { Ocala } \\
\text { City of } \\
\text { September } 30\end{array}$ \\
\hline 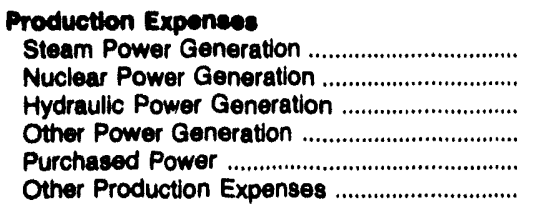 & $\begin{array}{r}4,220 \\
1,323 \\
0 \\
9,968 \\
17,171 \\
0\end{array}$ & $\begin{array}{r}7,826 \\
0 \\
0 \\
490 \\
11,817 \\
0\end{array}$ & $\begin{array}{r}55,243 \\
0 \\
0 \\
1,497 \\
8,877 \\
0\end{array}$ & $\begin{array}{r}0 \\
570 \\
0 \\
0 \\
14,458 \\
0\end{array}$ & $\begin{array}{r}0 \\
918 \\
0 \\
806 \\
12,916 \\
367\end{array}$ & $\begin{array}{r}0 \\
3,777 \\
0 \\
0 \\
36,043 \\
0\end{array}$ \\
\hline 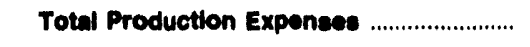 & 32,600 & 20,233 & 65,616 & 15,027 & 15,006 & 39,820 \\
\hline 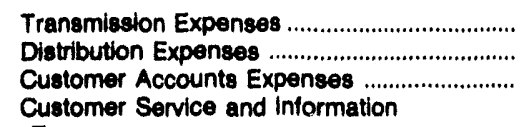 & $\begin{array}{r}362 \\
2,498 \\
1,389\end{array}$ & $\begin{array}{r}604 \\
1,269 \\
461\end{array}$ & $\begin{array}{l}1,291 \\
6,022 \\
2,997\end{array}$ & $\begin{array}{r}0 \\
2,128 \\
732\end{array}$ & $\begin{array}{r}143 \\
1,179 \\
480\end{array}$ & $\begin{array}{r}364 \\
4,101 \\
512\end{array}$ \\
\hline $\begin{array}{l}\text { Expenses } \\
\text { Sales Expenses } \\
\text { Administrattve and General }\end{array}$ & $\begin{array}{r}660 \\
0\end{array}$ & $\begin{array}{l}0 \\
0\end{array}$ & $\begin{array}{r}576 \\
0\end{array}$ & $\begin{array}{l}0 \\
0\end{array}$ & $\begin{array}{l}0 \\
0\end{array}$ & $\begin{array}{l}184 \\
183\end{array}$ \\
\hline 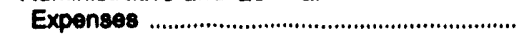 & 2,733 & 356 & 12,100 & 458 & 2,332 & 1,163 \\
\hline $\begin{array}{l}\text { Total Electrle Oporation and } \\
\text { Melmentenance Exponses }\end{array}$ & 40,333 & 22,922 & $\mathbf{0 0 , 6 0 2}$ & 18,346 & 19,160 & 46,335 \\
\hline \multicolumn{7}{|l|}{ Fuel Expenees in Operation } \\
\hline 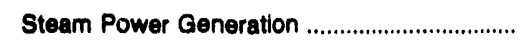 & 362 & 4,962 & 39,482 & 0 & 0 & 0 \\
\hline Nuclear Power Generation .................................. & 74 & 0 & 0 & 385 & 140 & 798 \\
\hline 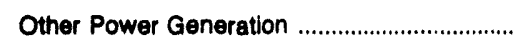 & 5.101 & 163 & 621 & 0 & 258 & 0 \\
\hline \multicolumn{7}{|l|}{ Number of Eloc Dept Employeses } \\
\hline 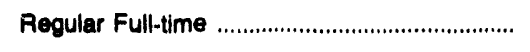 & 48 & 103 & 754 & 48 & 99 & 142 \\
\hline 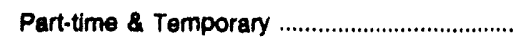 & 0 & 2 & 38 & 1 & 2 & 1 \\
\hline Total Eloc Dept Employees & 49 & 105 & 792 & 40 & 101 & 143 \\
\hline
\end{tabular}

Note: Totals may not equal sum of components because of independent rounding.

Source: Energy Intormation Administration, Form ElA-412, "Annual Report of Public Electric Utilities." 
Table 23. Electric Operation and Maintenance Expenses by Major U.S. Publicly Owned Electric UtIllty Within State, 1992 (Continued) (Thousand Dollars)

\begin{tabular}{|c|c|c|c|c|c|c|}
\hline Item & $\begin{array}{l}\text { Florida } \\
\text { Orlando } \\
\text { Utilities } \\
\text { Comm }\end{array}$ & $\begin{array}{l}\text { Florida } \\
\text { Quincy } \\
\text { Clty of }\end{array}$ & $\begin{array}{c}\text { Florida } \\
\text { Reedy Creek } \\
\text { Improvement } \\
\text { Dist }\end{array}$ & $\begin{array}{l}\text { Florida } \\
\text { Sebring } \\
\text { Utilities } \\
\text { Comm }\end{array}$ & $\begin{array}{l}\text { Florida } \\
\text { St Cloud } \\
\text { Clty of }\end{array}$ & $\begin{array}{c}\text { Florida } \\
\text { Tallahassee } \\
\text { City of }\end{array}$ \\
\hline & September 30 & September 30 & September 30 & September 30 & September 30 & September 30 \\
\hline
\end{tabular}

\section{Production Expenees}

Steam Power Generation

Nuclear Power Generation.....

Hydraulic Power Generation

Other Power Generation

Purchased Power

Other Production Expenses

Total Production Exponses

Transmission Expenses

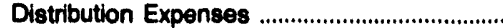

Customer Accounts Expenses .........................

Customer Service and Intormation

Expenses

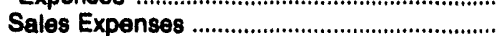

Administrative and General

Expenses

Total Electric Operation and

Malntenance Expenses

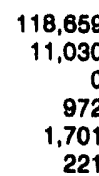

118,659
11,030
0
972
1,701
221

132,584

5,162

4,911

5,481

964
57

17,351

166,500

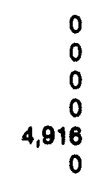

0
0
0
0
16
0

4,916

0

334

198

0

173

5,621
1,184

0
5,827

21,749

349

20,100

0
8,460

8,460
0

0

744

38,312

12,088

0
0
0
2,381

2,381
7,912

0

10,292

0

2,254

034

1,034
0

$-92$

13,489

Fuel Expenese in Operation

Steam Power Generation

Nuclear Power Generation

94,366

2,694

684

Oiher Power Generation

Number of Elec Dept Employees

Regular Full-time

514

Part-time \& Temporary

Total Elec Dept Employees

10

524

$$
871
$$

3,648

0

66

108

0

108
46,747

1,459

225

30,423

1,654

80,509

565

4,966

6,983

0

4,973

97,996

Note: Totals may not equal sum of components because of independent rounding.

Source: Energy information Administration, Form EIA-412, "Annual Report of Public Electric Utillies." 
Table 23. Electric Operation and Maintenance Expenses by Major U.S. Publicly Owned Electric Utility Within State, 1992 (Continued) (Thousand Dollars)

\begin{tabular}{|c|c|c|c|c|c|c|}
\hline Item & $\begin{array}{l}\text { Florida } \\
\text { Vero } \\
\text { Beach } \\
\text { City of } \\
\text { September } 30\end{array}$ & $\begin{array}{l}\text { Georgia } \\
\text { Albany Water } \\
\text { Gas \& Light } \\
\text { Comm } \\
\text { June } 30\end{array}$ & $\begin{array}{l}\text { Georgia } \\
\text { Calhoun } \\
\text { City of } \\
\text { June } 30\end{array}$ & $\begin{array}{l}\text { Georgia } \\
\text { Cartersville } \\
\text { City of } \\
\text { June } 30\end{array}$ & $\begin{array}{l}\text { Georgia } \\
\text { College } \\
\text { Park City of } \\
\text { June } 30\end{array}$ & $\begin{array}{l}\text { Georgia } \\
\text { Covington } \\
\text { City of } \\
\text { December } 31\end{array}$ \\
\hline 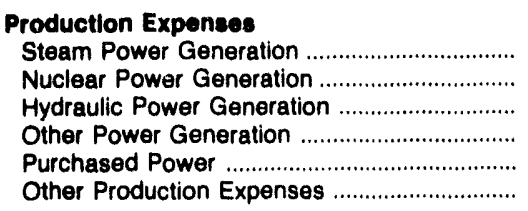 & $\begin{array}{r}9,908 \\
0 \\
0 \\
0 \\
12,828 \\
172\end{array}$ & $\begin{array}{r}0 \\
0 \\
0 \\
0 \\
42,401 \\
0\end{array}$ & $\begin{array}{r}0 \\
0 \\
0 \\
0 \\
14,262 \\
0\end{array}$ & $\begin{array}{r}0 \\
0 \\
0 \\
0 \\
16,817 \\
0\end{array}$ & $\begin{array}{r}0 \\
0 \\
0 \\
0 \\
13,457 \\
0\end{array}$ & $\begin{array}{r}0 \\
0 \\
0 \\
0 \\
10,324 \\
0\end{array}$ \\
\hline Total Production Expenses .......................... & 22,909 & 42,401 & 14,262 & 16,817 & 13,457 & 10,324 \\
\hline 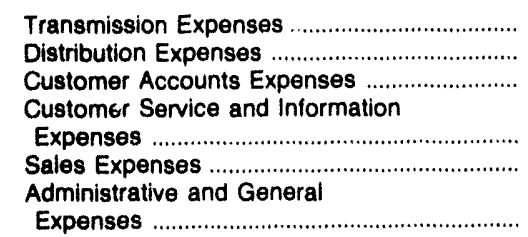 & $\begin{array}{r}960 \\
960 \\
506 \\
674 \\
0 \\
2,924\end{array}$ & $\begin{array}{r}2,875 \\
0 \\
0 \\
0 \\
0 \\
3,522\end{array}$ & $\begin{array}{r}0 \\
917 \\
0 \\
\\
0 \\
0 \\
0\end{array}$ & $\begin{array}{r}0 \\
1,004 \\
119 \\
324 \\
0 \\
599\end{array}$ & $\begin{array}{r}0 \\
1,048 \\
0 \\
0 \\
0 \\
0\end{array}$ & $\begin{array}{r}0 \\
1,932 \\
138 \\
0 \\
0 \\
128\end{array}$ \\
\hline $\begin{array}{l}\text { Total Electric Operation and } \\
\text { Malntenance Expenses ..................................... }\end{array}$ & 28,932 & 48,799 & 15,179 & 18,864 & 14,505 & 12,523 \\
\hline \multicolumn{7}{|l|}{ Fuel Expenses in Operation } \\
\hline 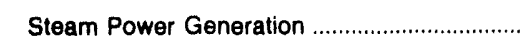 & 5,540 & 0 & 0 & 0 & 0 & 0 \\
\hline 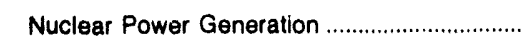 & 0 & 0 & 0 & 0 & 0 & 0 \\
\hline Other Power Generation & 0 & 0 & 0 & 0 & 0 & 0 \\
\hline \multicolumn{7}{|l|}{ Number of Elec Dept Employees } \\
\hline 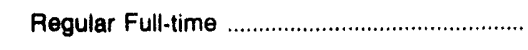 & 140 & 53 & 17 & 20 & 250 & 18 \\
\hline 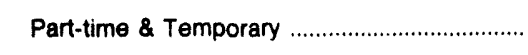 & 0 & 0 & 0 & 0 & 50 & 0 \\
\hline 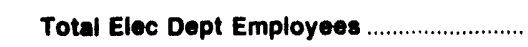 & 140 & 53 & 17 & 20 & 300 & 18 \\
\hline
\end{tabular}

Note: Totals may not equal sum of components because of independent rounding.

Source: Energy Information Administration, Form EIA-412, "Annual Report of Public Electric Utilities." 
Table 23. Electric Operation and Maintenance Expenses by Major U.S. Publicly Owned Electric Utility Within State, 1992 (Continued) (Thousand Dollars)

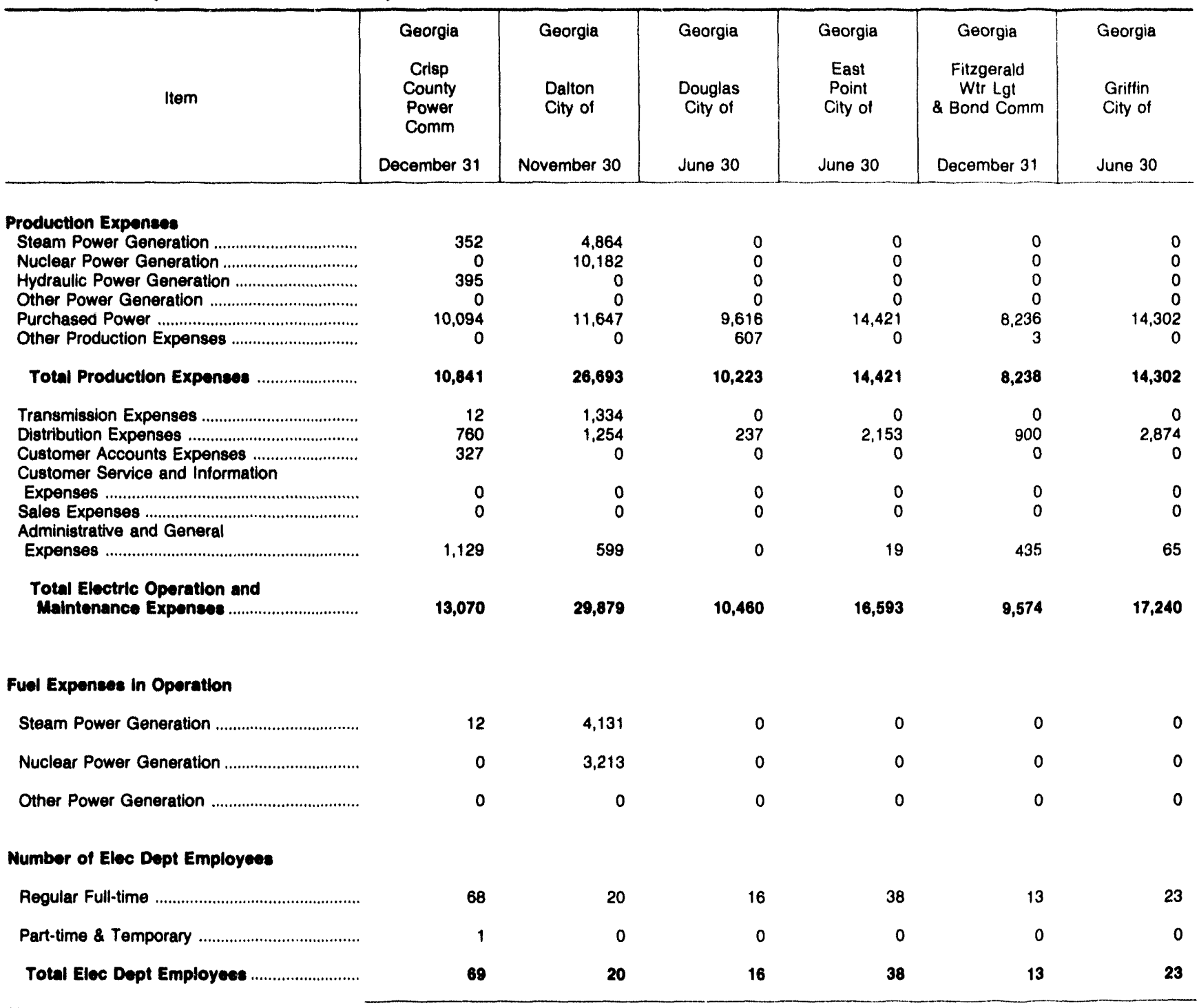

Note: Totals may not equal sum of components because of independent rounding.

Source: Energy Information Administration, Form ElA-412, "Annual Report of Public Electric Utilities." 
Table 23. Electric Operation and Maintenance Expenses by Major U.S. Publicly Owned Electric Utility Within State, 1992 (Continued)

(Thousand Dollars)

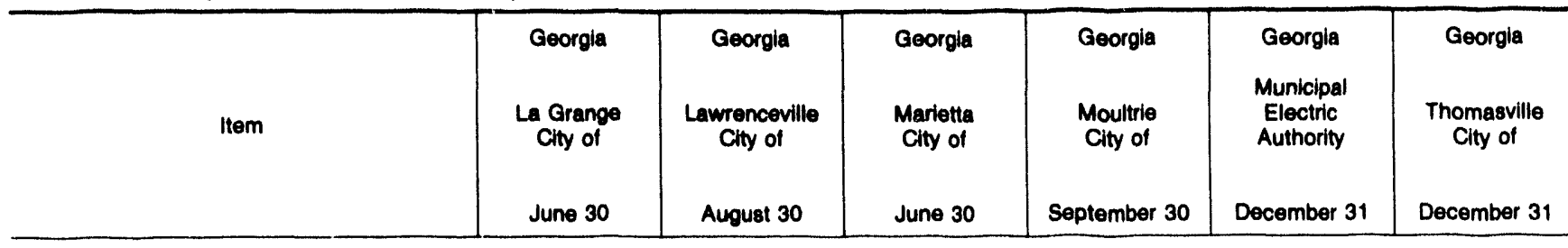

\section{Production Expenses}

Steam Power Generation

Nuclear Power Generation

Hydraullc Power Generation ...

Other Power Generation

Purchased Power

Other Production Expenses

Total Production Expenses

Transmission Expenses

Distribution Expenses

Customer Accounts Expensos

Customer Service and Information

Expenses ......

Sales Expenses

Administrative and General

Expenses

Total Electric Operation and

Maintenance Expenses

0
0
0
0
23,536
0

23,639

529

0
0

0

1,131

25,197

0
0
0
0
9,873
0

0
0
0
0
43,891
0

9,873

1,697

11,690
43,091

0
5,373

0
0

0

.

0
0
0
0
8,425
0

8,425

0
536

536
0

0

902

9,864

49,284
66,585
79,338
0
0
41,006
0

186,929

4,325

3,624

0

8,411

204,280

Fuel Expences in Operation

Steam Power Generation .

0

0

0

55,194

0

Nuclear Power Generation

Other Power Generation

0

0

0

0

0

0

93

0

83

16

13

16

0

.

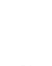

Note: Totals may not equal sum of components because of independent rounding.

Source: Energy Information Administration, Form EIA-412, "Annual Report of Public Electric Utilities." 
Table 23. Electric Operation and Maintenance Expenses by Major U.S. Publicly Owned Electric Utillity Within State, 1992 (Continued) (Thousand Dollars)

\begin{tabular}{|c|c|c|c|c|c|c|}
\hline Item & $\begin{array}{l}\text { Idaho } \\
\text { Idaho } \\
\text { Falls } \\
\text { City of }\end{array}$ & $\begin{array}{l}\text { Illinois } \\
\text { Batavia } \\
\text { Clty of }\end{array}$ & $\begin{array}{l}\text { Illinois } \\
\text { Geneva } \\
\text { City of }\end{array}$ & $\begin{array}{c}\text { Illinois } \\
\text { Illinois } \\
\text { Municipal } \\
\text { Elec Agency }\end{array}$ & $\begin{array}{l}\text { Illinois } \\
\text { Naperville } \\
\text { City of }\end{array}$ & $\begin{array}{c}\text { Illinois } \\
\text { Rochelle } \\
\text { Municipal } \\
\text { Utilities }\end{array}$ \\
\hline & September 30 & December 31 & April 30 & April 30 & April 30 & April 30 \\
\hline
\end{tabular}

\section{Production Exponese}

Steam Power Generation

Nuclear Power Generation

Hydraulic Power Generation

Other Power Generation

Other Production Expenses

Total Production Expenses

Transmission Expenses

Distribution Expenses

Customer Accounts Expenses ..........................

Customer Service and Information

Expenses ........

Sales Expenses

Administrative and General

Expenses

Total Electric Operation and

Maintenance Expenses

0
0
885
0
13,331
0

0
0
0
0
10,549
0

14,316

100

1,873

830

4

1,568

18,892

10,549

1,015

280

0

251

12,095

0
0
0
0
6,601
0

6,601

0
644

5,820
0
0
0
37,102
0

42,921

4,414

0
0

0

, 447

48,783

7,627

0
0
0
0
35,280
0

3,021

0

623

4,129

35,280

7,773

20

602

83

$\begin{array}{ll}998 & 0 \\ 461 & 0\end{array}$

2,122

1,270

41,972

9,748

\section{Fual Expenses in Operation}

Steam Power Generation

0

Nuclear Power Generation

0

0

3,627

0

2,012

Other Power Generation

0

0

0

0

0

0

0

157

Number of Elec Dept Employees

Regular Full-time

55

17

15

10

82

48

Part-time \& Temporary

1

1

58

18

1

0

10

0

82

40

Note: Totals may not equal sum of components because of independent rounding.

Source: Energy information Administration, Form EIA-412, "Annual Report of Public Electric Utilities." 
Table 23. Electric Operation and Maintenance Expenses by Major U.S. Publicly Owned Electric Utility Within State, 1992 (Continued) (Thousand Dollars)

\begin{tabular}{|c|c|c|c|c|c|c|}
\hline Item & $\begin{array}{c}\text { Illinois } \\
\text { Springtield } \\
\text { City of } \\
\text { Fobruary } 28 \\
\end{array}$ & $\begin{array}{l}\text { Illinois } \\
\text { St Charles } \\
\text { City of } \\
\text { Aprll } 30\end{array}$ & $\begin{array}{c}\text { Indiana } \\
\text { Anderson } \\
\text { City of } \\
\text { December } 31\end{array}$ & $\begin{array}{l}\text { Indiana } \\
\text { Auburn } \\
\text { City of } \\
\text { December } 31\end{array}$ & $\begin{array}{l}\text { Indiana } \\
\text { Bluftton } \\
\text { City of } \\
\text { December } 31\end{array}$ & $\begin{array}{c}\text { Indiana } \\
\text { Crawtordsville } \\
\text { Elec } \\
\text { Lgt\&Pwr Co } \\
\text { December } 31\end{array}$ \\
\hline 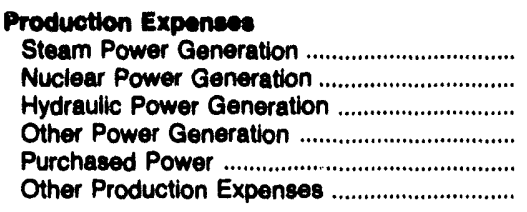 & $\begin{array}{r}42,813 \\
0 \\
0 \\
87 \\
136 \\
0\end{array}$ & $\begin{array}{r}0 \\
0 \\
0 \\
0 \\
18,063 \\
0\end{array}$ & $\begin{array}{r}0 \\
0 \\
0 \\
0 \\
27,804 \\
0\end{array}$ & $\begin{array}{r}0 \\
0 \\
0 \\
0 \\
12,208 \\
0\end{array}$ & $\begin{array}{r}0 \\
0 \\
0 \\
698 \\
6,019 \\
0\end{array}$ & $\begin{array}{r}1,961 \\
0 \\
0 \\
0 \\
12,393 \\
0\end{array}$ \\
\hline Total Production Expeneses ............................ & 43,036 & 18,063 & 27,804 & 12,208 & 6,718 & 14,354 \\
\hline 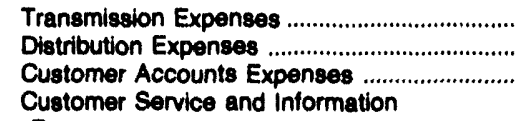 & $\begin{array}{r}889 \\
5,453 \\
3,539\end{array}$ & $\begin{array}{r}0 \\
3,041 \\
0\end{array}$ & $\begin{array}{r}17 \\
2,633 \\
361\end{array}$ & $\begin{array}{r}0 \\
681 \\
28\end{array}$ & $\begin{array}{r}0 \\
510 \\
0\end{array}$ & $\begin{array}{r}5 \\
739 \\
204\end{array}$ \\
\hline $\begin{array}{l}\text { Expenses } \\
\text { Sales Expenses } \\
\text { Administrative and General }\end{array}$ & $\begin{array}{r}565 \\
0\end{array}$ & $\begin{array}{l}0 \\
0\end{array}$ & $\begin{array}{l}0 \\
0\end{array}$ & $\begin{array}{l}0 \\
0\end{array}$ & $\begin{array}{r}33 \\
0\end{array}$ & $\begin{array}{l}0 \\
0\end{array}$ \\
\hline 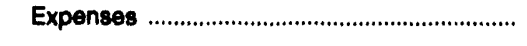 & 7,892 & 0 & 2,526 & 341 & 396 & 1,005 \\
\hline $\begin{array}{l}\text { Total Electric Operation and } \\
\text { Maintenance Expanese }\end{array}$ & 61,374 & 21,104 & 33,342 & 13,258 & 7,657 & 16,306 \\
\hline \multicolumn{7}{|l|}{ Fuel Expenese in Operation } \\
\hline 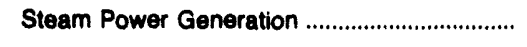 & 27,036 & 0 & 0 & 0 & 0 & 803 \\
\hline 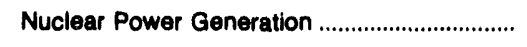 & 0 & 0 & 0 & 0 & 0 & 0 \\
\hline 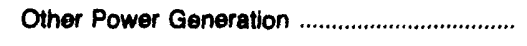 & 64 & 0 & 0 & 0 & 170 & 0 \\
\hline \multicolumn{7}{|l|}{ Number of Elec Dept Employees } \\
\hline 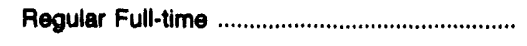 & 605 & 24 & 87 & 14 & 17 & 52 \\
\hline 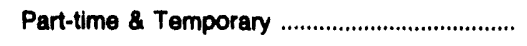 & 0 & 4 & 0 & 0 & 0 & 0 \\
\hline Total Elec Dept Employees ................................ & 605 & 28 & 87 & 14 & 17 & 52 \\
\hline
\end{tabular}

Note: Totals may not equal sum of components because of independent rounding.

Source: Energy Information Administration, Form EIA-412, "Annual Report of Public Electric Utilities." 
Table 23. Electric Operation and Maintenance Expenses by Major U.S. Publicly Owned Electric Utility Within State, 1992 (Continued) (Thousand Dollars)

\begin{tabular}{|c|c|c|c|c|c|c|}
\hline Item & $\begin{array}{l}\text { Indiana } \\
\text { Frankfort } \\
\text { City of } \\
\text { December } 31\end{array}$ & $\begin{array}{c}\text { Indiana } \\
\text { Greenfield } \\
\text { City of } \\
\text { December } 31\end{array}$ & $\begin{array}{c}\text { Indiana } \\
\text { Indlana } \\
\text { Municipal } \\
\text { Power Agency } \\
\text { December } 31\end{array}$ & $\begin{array}{l}\text { Indiana } \\
\text { Jasper } \\
\text { City of } \\
\text { December } 31\end{array}$ & $\begin{array}{l}\text { Indiana } \\
\text { Logansport } \\
\text { City of } \\
\text { December } 31\end{array}$ & $\begin{array}{l}\text { Indiana } \\
\text { Mishawaka } \\
\text { City of } \\
\text { December } 31\end{array}$ \\
\hline 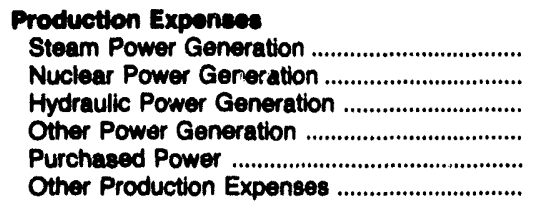 & $\begin{array}{r}0 \\
0 \\
0 \\
0 \\
10,278 \\
0\end{array}$ & $\begin{array}{r}0 \\
0 \\
0 \\
0 \\
5,903 \\
0\end{array}$ & $\begin{array}{r}22,819 \\
0 \\
0 \\
705 \\
87,049 \\
187\end{array}$ & $\begin{array}{r}1,816 \\
0 \\
0 \\
0 \\
8,869 \\
0\end{array}$ & $\begin{array}{r}4,611 \\
0 \\
0 \\
376 \\
6,623 \\
0\end{array}$ & $\begin{array}{r}0 \\
0 \\
0 \\
0 \\
18,852 \\
0\end{array}$ \\
\hline Total Production Expenses ............................ & 10,278 & 8,003 & 110,760 & 10,885 & 11,810 & 18,852 \\
\hline 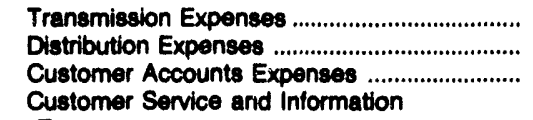 & $\begin{array}{r}0 \\
599 \\
190\end{array}$ & $\begin{array}{r}0 \\
570 \\
123\end{array}$ & $\begin{array}{r}3,192 \\
503 \\
0\end{array}$ & $\begin{array}{r}0 \\
742 \\
73\end{array}$ & $\begin{array}{r}0 \\
1,342 \\
105\end{array}$ & $\begin{array}{r}0 \\
1,805 \\
570\end{array}$ \\
\hline 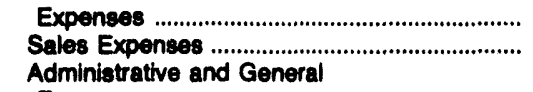 & $\begin{array}{l}0 \\
0\end{array}$ & $\begin{array}{l}0 \\
0\end{array}$ & $\begin{array}{l}0 \\
0\end{array}$ & $\begin{array}{l}0 \\
0\end{array}$ & $\begin{array}{r}25 \\
0\end{array}$ & $\begin{array}{l}0 \\
0\end{array}$ \\
\hline 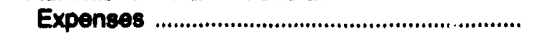 & 1,351 & 344 & 1,653 & 824 & 1,039 & 827 \\
\hline $\begin{array}{l}\text { Total Electric Operation and } \\
\text { Maintenance Expenese ................................ }\end{array}$ & 12,418 & 6,941 & 116,108 & 12,324 & 14,121 & 22,153 \\
\hline \multicolumn{7}{|l|}{ Fuel Expenses in Operation } \\
\hline 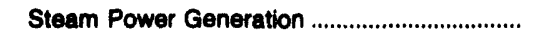 & 0 & 0 & 16,904 & 1,012 & 2,072 & 0 \\
\hline 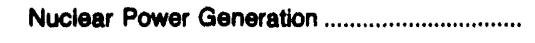 & 0 & 0 & 0 & 0 & 0 & 0 \\
\hline 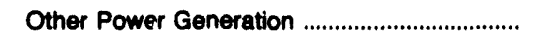 & 0 & 0 & 514 & 0 & 376 & 0 \\
\hline \multicolumn{7}{|l|}{ Number of Elec Deps Employees } \\
\hline 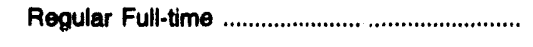 & 26 & 26 & 15 & 43 & 75 & 65 \\
\hline 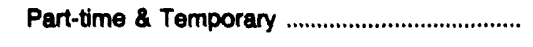 & 0 & 4 & 0 & 1 & 2 & 10 \\
\hline 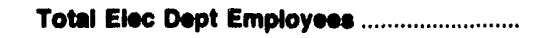 & 28 & 30 & 15 & 44 & 77 & 75 \\
\hline
\end{tabular}

Note: Totals may not equal sum of components because of independent rounding.

Source: Energy Information Administration, Form EIA-412, "Annual Report of Public Electric Utilities." 
Table 23. Electric Operation and Maintenance Expenses by Major U.S. Publicly Owned Electric Utility Within State, 1992 (Continued) (Thousand Dollars)

\begin{tabular}{|c|c|c|c|c|c|c|}
\hline Item & $\begin{array}{l}\text { Indiana } \\
\text { Peru } \\
\text { City of } \\
\text { December } 31\end{array}$ & $\begin{array}{l}\text { Indiana } \\
\text { Richmond } \\
\text { City of } \\
\text { December } 31\end{array}$ & $\begin{array}{l}\text { Indiana } \\
\text { Washington } \\
\text { City of } \\
\text { December } 31\end{array}$ & $\begin{array}{l}\text { lowa } \\
\text { Ames } \\
\text { City of } \\
\text { June } 30\end{array}$ & $\begin{array}{l}\text { lowa } \\
\text { Cedar } \\
\text { Falls } \\
\text { City of } \\
\text { December } 31\end{array}$ & $\begin{array}{c}\text { lowa } \\
\text { Muscatine } \\
\text { Clty of } \\
\text { December } 31\end{array}$ \\
\hline 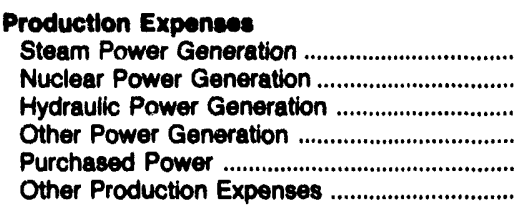 & $\begin{array}{r}651 \\
0 \\
0 \\
0 \\
5,028 \\
0\end{array}$ & $\begin{array}{r}14,045 \\
0 \\
0 \\
0 \\
10,778 \\
0\end{array}$ & $\begin{array}{r}0 \\
0 \\
0 \\
0 \\
6,089 \\
0\end{array}$ & $\begin{array}{r}7,516 \\
0 \\
0 \\
0 \\
1,323 \\
707\end{array}$ & $\begin{array}{r}4,753 \\
0 \\
0 \\
32 \\
919 \\
121\end{array}$ & $\begin{array}{r}37,264 \\
0 \\
0 \\
0 \\
1,675 \\
949\end{array}$ \\
\hline Total Preduction Expenees ............................ & 5,679 & 24,023 & 6,000 & 9,546 & 5,825 & 39,888 \\
\hline 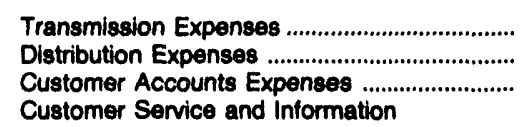 & $\begin{array}{r}27 \\
591 \\
142\end{array}$ & $\begin{array}{r}32 \\
1,827 \\
488\end{array}$ & $\begin{array}{r}0 \\
595 \\
185\end{array}$ & $\begin{array}{r}0 \\
1,933 \\
214\end{array}$ & $\begin{array}{r}385 \\
1,021 \\
310\end{array}$ & $\begin{array}{r}1,920 \\
0 \\
350\end{array}$ \\
\hline 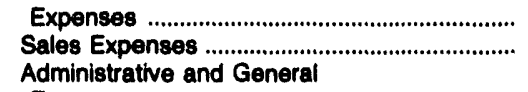 & $\begin{array}{l}0 \\
0\end{array}$ & $\begin{array}{r}15 \\
0\end{array}$ & $\begin{array}{l}0 \\
0\end{array}$ & $\begin{array}{l}9 \\
0\end{array}$ & $\begin{array}{r}152 \\
0\end{array}$ & $\begin{array}{l}0 \\
0\end{array}$ \\
\hline Expenses & 1,070 & 4,103 & 249 & 856 & 1,284 & 4,392 \\
\hline 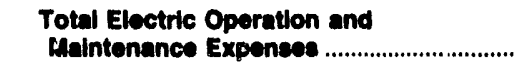 & 7,500 & 31,280 & 7,110 & 12,658 & 8,977 & 46,650 \\
\hline \multicolumn{7}{|l|}{ Fuel Expenses in Operation } \\
\hline 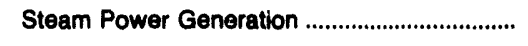 & 155 & 10,411 & 0 & 5,014 & 2,914 & 29,367 \\
\hline Nuclear Power Generation ...................................... & 0 & 0 & 0 & 0 & 0 & 0 \\
\hline 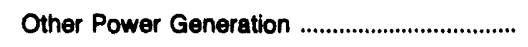 & 0 & 0 & 0 & 0 & 15 & 0 \\
\hline \multicolumn{7}{|l|}{ Number of Elec Dept Employees } \\
\hline Regular Full-time & 44 & 160 & 28 & 83 & 88 & 176 \\
\hline 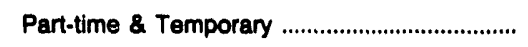 & 1 & $\boldsymbol{\theta}$ & 0 & 1 & 3 & 0 \\
\hline Total Eloc Dept Employece ................................ & 45 & 160 & 28 & 84 & 91 & 178 \\
\hline
\end{tabular}

Note: Totals may not equal sum of components because of independent rounding.

Source: Energy Information Administration, Form EIA-412, "Annual Report of Public Electric Utilities." 
Table 23. Electric Operation and Maintenance Expenses by Major U.S. Publicly Owned Electric UtIlity Within State, 1992 (Continued) (Thousand Dollars)

\begin{tabular}{|c|c|c|c|c|c|c|}
\hline Item & $\begin{array}{l}\text { lowa } \\
\text { Pella } \\
\text { City of } \\
\text { June } 30\end{array}$ & $\begin{array}{c}\text { Kansas } \\
\text { Chanute } \\
\text { City of } \\
\text { December } 31\end{array}$ & $\begin{array}{c}\text { Kansas } \\
\text { Coffeyville } \\
\text { City of }\end{array}$ & $\begin{array}{l}\text { Kansas } \\
\text { Garden } \\
\text { City City of } \\
\text { December } 31\end{array}$ & $\begin{array}{c}\text { Kansas } \\
\text { Kansas } \\
\text { City City of } \\
\text { December } 31\end{array}$ & $\begin{array}{c}\text { Kansas } \\
\text { Kansas } \\
\text { Municipal } \\
\text { Energy } \\
\text { Agency } \\
\text { December } 31\end{array}$ \\
\hline 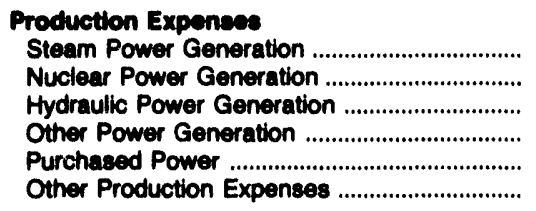 & $\begin{array}{r}2,637 \\
0 \\
0 \\
0 \\
1,600 \\
0\end{array}$ & $\begin{array}{r}0 \\
0 \\
0 \\
279 \\
3,216 \\
872\end{array}$ & $\begin{array}{r}3,866 \\
0 \\
0 \\
0 \\
3,121 \\
0\end{array}$ & $\begin{array}{r}0 \\
0 \\
0 \\
0 \\
8,523 \\
97\end{array}$ & $\begin{array}{r}58,822 \\
0 \\
0 \\
128 \\
4,970 \\
1,063\end{array}$ & $\begin{array}{r}0 \\
0 \\
0 \\
0 \\
9,770 \\
0\end{array}$ \\
\hline Total Production Expenses .......................... & 4,237 & 4,366 & 6,987 & 8,620 & 64,984 & 9,770 \\
\hline 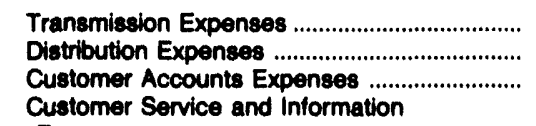 & $\begin{array}{r}0 \\
476 \\
42\end{array}$ & $\begin{array}{r}668 \\
182 \\
0\end{array}$ & $\begin{array}{r}0 \\
892 \\
20\end{array}$ & $\begin{array}{r}0 \\
624 \\
9\end{array}$ & $\begin{array}{r}505 \\
9,831 \\
3,869\end{array}$ & $\begin{array}{r}185 \\
0 \\
0\end{array}$ \\
\hline $\begin{array}{l}\text { Expenses } \\
\text { Sales Expenses } \\
\text { Administrative and General }\end{array}$ & $\begin{array}{l}0 \\
5\end{array}$ & $\begin{array}{r}182 \\
0\end{array}$ & $\begin{array}{r}187 \\
1\end{array}$ & $\begin{array}{r}0 \\
319\end{array}$ & $\begin{array}{l}0 \\
0\end{array}$ & $\begin{array}{l}0 \\
0\end{array}$ \\
\hline 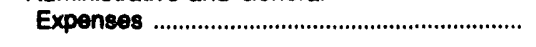 & 1,062 & 1,983 & 483 & 693 & 14,698 & 713 \\
\hline 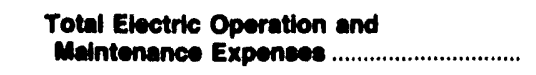 & 5,821 & 7,382 & 8,570 & 10,265 & 93,887 & 10,668 \\
\hline \multicolumn{7}{|l|}{ Fual Expensese in Operation } \\
\hline 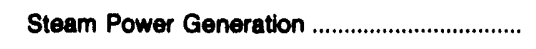 & 1,816 & 0 & 1,681 & 0 & 36,032 & 0 \\
\hline 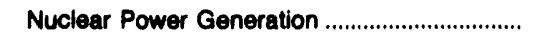 & 0 & 0 & 0 & 0 & 0 & 0 \\
\hline 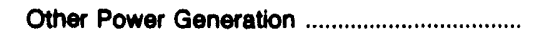 & 0 & 118 & 0 & 0 & 24 & 0 \\
\hline \multicolumn{7}{|l|}{ Number of Elec Dept Employees } \\
\hline Regular Full-time & 27 & 25 & 39 & 14 & 676 & 5 \\
\hline 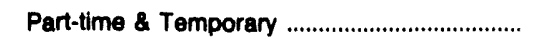 & 0 & 0 & 3 & 0 & 0 & 1 \\
\hline 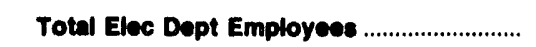 & 27 & 25 & 42 & 14 & 676 & 6 \\
\hline
\end{tabular}

Note: Totals may not equal sum of components because of independent rounding.

Source: Energy Information Administration, Form EIA-412, "Annual Report of Public Electric Utilities." 
Table 23. Electric Operation and Maintenance Expenses by Major U.S. Publicly Owned Electric Utility Within State, 1992 (Continued) (Thousand Dollars)

\begin{tabular}{|c|c|c|c|c|c|c|}
\hline Item & $\begin{array}{c}\text { Kansas } \\
\text { McPherson } \\
\text { City of } \\
\text { December } 31\end{array}$ & $\begin{array}{l}\text { Kansas } \\
\text { Winfield } \\
\text { City of } \\
\text { December } 31\end{array}$ & $\begin{array}{l}\text { Kentucky } \\
\text { Bowling } \\
\text { Green } \\
\text { City of } \\
\text { June } 30\end{array}$ & $\begin{array}{l}\text { Kentucky } \\
\text { Frankfort } \\
\text { City of } \\
\text { June } 30\end{array}$ & $\begin{array}{l}\text { Kentucky } \\
\text { Franklin } \\
\text { City of } \\
\text { June } 30\end{array}$ & $\begin{array}{l}\text { Kentucky } \\
\text { Glasgow } \\
\text { City of } \\
\text { June } 30\end{array}$ \\
\hline 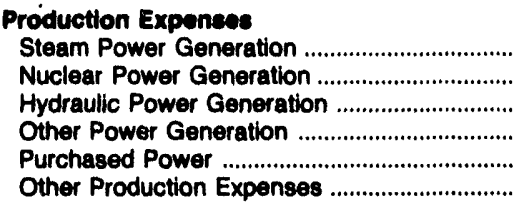 & $\begin{array}{r}919 \\
0 \\
0 \\
548 \\
12,247 \\
459\end{array}$ & $\begin{array}{r}1,462 \\
0 \\
0 \\
0 \\
6,262 \\
271\end{array}$ & $\begin{array}{r}0 \\
0 \\
0 \\
0 \\
29,498 \\
0\end{array}$ & $\begin{array}{r}0 \\
0 \\
0 \\
0 \\
18,135 \\
0\end{array}$ & $\begin{array}{r}0 \\
0 \\
0 \\
0 \\
7,928 \\
0\end{array}$ & $\begin{array}{r}0 \\
0 \\
0 \\
0 \\
11,858 \\
0\end{array}$ \\
\hline Total Production Expensee ........................... & 14,174 & 7,005 & 20,498 & 18,135 & 7,928 & 11,858 \\
\hline 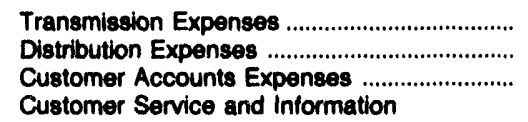 & $\begin{array}{r}28 \\
1,622 \\
116\end{array}$ & $\begin{array}{r}0 \\
55 \\
166\end{array}$ & $\begin{array}{r}0 \\
1,926 \\
383\end{array}$ & $\begin{array}{r}52 \\
1,001 \\
353\end{array}$ & $\begin{array}{r}0 \\
460 \\
132\end{array}$ & $\begin{array}{r}0 \\
521 \\
175\end{array}$ \\
\hline 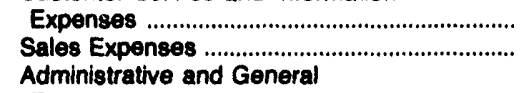 & $\begin{array}{l}1 \\
0\end{array}$ & $\begin{array}{l}0 \\
0\end{array}$ & $\begin{array}{r}183 \\
29\end{array}$ & 0 & $\begin{array}{l}31 \\
19\end{array}$ & $\begin{array}{r}108 \\
0\end{array}$ \\
\hline 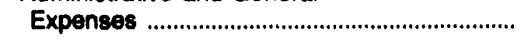 & 483 & 1,061 & 1,058 & 1,659 & 382 & 418 \\
\hline $\begin{array}{l}\text { Total Electric Operation and } \\
\text { Maintenance Expenees }\end{array}$ & 16,424 & 9,277 & 33,077 & 21,200 & 8,951 & 13,080 \\
\hline \multicolumn{7}{|l|}{ Fuel Expenses in Operation } \\
\hline 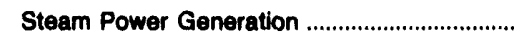 & 151 & 823 & 0 & 0 & 0 & 0 \\
\hline 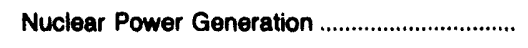 & 0 & 0 & 0 & 0 & 0 & 0 \\
\hline 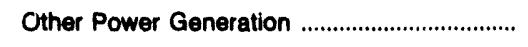 & 110 & 0 & 0 & 0 & 0 & 0 \\
\hline \multicolumn{7}{|l|}{ Number of Elec Dept Employess } \\
\hline Regular Full-time & 60 & 29 & 73 & 105 & 14 & 32 \\
\hline 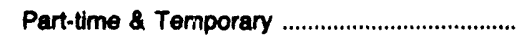 & 1 & 2 & 0 & 0 & 0 & $\mathbf{0}$ \\
\hline 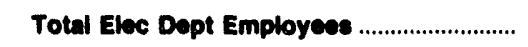 & 61 & 31 & 73 & 105 & 14 & 32 \\
\hline
\end{tabular}

Note: Totals may not equal sum of components because of independent rounding.

Source: Energy Information Administration, Form ElA-412, "Annual Report of Public Electric Utilities." 
Table 23. Electric Operation and Maintenance Expenses by Major U.S. Publicly
Owned Electric Utility Within State, 1992 (Continued) (Thousand Dollars)

\begin{tabular}{|c|c|c|c|c|c|c|}
\hline Item & $\begin{array}{l}\text { Kentucky } \\
\text { Henderson } \\
\text { City } \\
\text { Utility Comm } \\
\text { May } 31\end{array}$ & $\begin{array}{l}\text { Kentucky } \\
\text { Hopkinsville } \\
\text { City of } \\
\text { June } 30\end{array}$ & $\begin{array}{c}\text { Kentucky } \\
\text { Madisonville } \\
\text { Municipal } \\
\text { Utils }\end{array}$ & $\begin{array}{l}\text { Kentucky } \\
\text { Maytield } \\
\text { City of } \\
\text { June } 30\end{array}$ & $\begin{array}{l}\text { Kentucky } \\
\text { Murray } \\
\text { City of } \\
\text { June } 30\end{array}$ & $\begin{array}{c}\text { Kentucky } \\
\text { Owensboro } \\
\text { City of } \\
\text { May } 31\end{array}$ \\
\hline 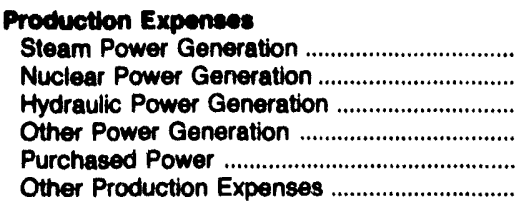 & $\begin{array}{r}12,513 \\
0 \\
0 \\
0 \\
483 \\
0\end{array}$ & $\begin{array}{r}0 \\
0 \\
0 \\
0 \\
16,296 \\
0\end{array}$ & $\begin{array}{r}0 \\
0 \\
0 \\
0 \\
8,268 \\
0\end{array}$ & $\begin{array}{r}0 \\
0 \\
0 \\
0 \\
6,341 \\
0\end{array}$ & $\begin{array}{r}0 \\
0 \\
0 \\
0 \\
10,386 \\
0\end{array}$ & $\begin{array}{r}32,593 \\
0 \\
0 \\
0 \\
450 \\
0\end{array}$ \\
\hline Total Production Expenses .......................... & 13,006 & 16,290 & $\mathbf{8 , 2 6 8}$ & 6,341 & 10,386 & 33,043 \\
\hline 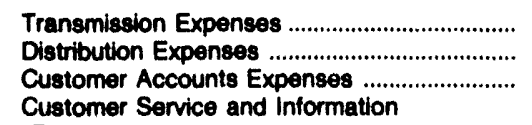 & $\begin{array}{r}19 \\
987 \\
226\end{array}$ & $\begin{array}{r}8 \\
882 \\
306\end{array}$ & $\begin{array}{r}0 \\
672 \\
202\end{array}$ & $\begin{array}{r}0 \\
563 \\
182\end{array}$ & $\begin{array}{r}0 \\
593 \\
151\end{array}$ & $\begin{array}{r}277 \\
2,031 \\
600\end{array}$ \\
\hline 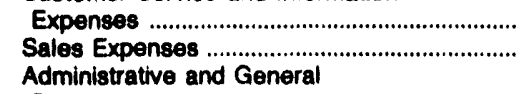 & $\begin{array}{l}0 \\
9\end{array}$ & $\begin{array}{l}39 \\
28\end{array}$ & $\begin{array}{l}0 \\
0\end{array}$ & $\begin{array}{r}43 \\
9\end{array}$ & $\begin{array}{l}16 \\
10\end{array}$ & $\begin{array}{l}0 \\
0\end{array}$ \\
\hline 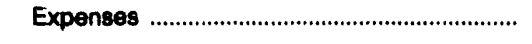 & 3,978 & 672 & 139 & 472 & 360 & 3,226 \\
\hline 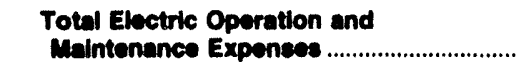 & 18,225 & 18,231 & 9,280 & 7,609 & 11,516 & 39,177 \\
\hline \multicolumn{7}{|l|}{ Fuel Exponses in Operation } \\
\hline 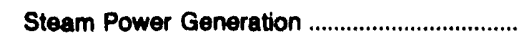 & 4,359 & 0 & 0 & 0 & 0 & 24,964 \\
\hline Nuclear Power Generation ................................ & 0 & 0 & 0 & 0 & 0 & 0 \\
\hline Other Power Generation ........................................ & 0 & 0 & 0 & 0 & 0 & 0 \\
\hline \multicolumn{7}{|l|}{ Number of Elec Dept Employees } \\
\hline 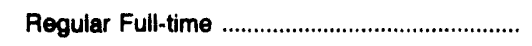 & 58 & 35 & 28 & 21 & 22 & 149 \\
\hline 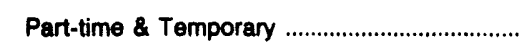 & 0 & 0 & 0 & 0 & 0 & 6 \\
\hline 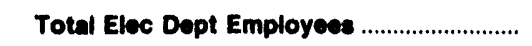 & 58 & 35 & 28 & 21 & 22 & 155 \\
\hline
\end{tabular}

Note: Totals may not equal sum of components because of independent rounding.

Source: Energy information Administration, Forn! EIA-412, "Annual Report of Public Electric Utilities." 
Table 23. Electric Operation and Maintenance Expenses by Major U.S. Publicly Owned Electric Utility Within State, 1992 (Continued) (Thousand Dollars)

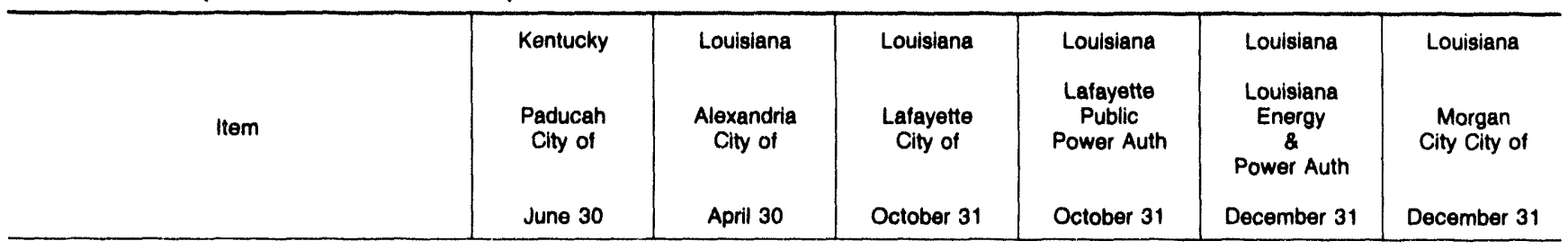

\section{Production Expenses}

Steam Power Generation

Nuclear Power Generation....

Hydraulic Power Generation

Other Power Generation

Purchased Power

Other Production Expenses

Total Production Expenses

Transmission Expenses

Distribution Expenses

Customer Accounts Expenses

Customer Service and Information

Expenses

Sales Expenses

Administrative and General

Expenses

Total Electric Operation and

Maintenance Expenses
1,959

0
0

0

19,357
0

23,242

34
1,575

723

82

230

1,212

27,098

21,315

0
2.870

0

0
0

1,315

25,501

0
0
0
0
23,242
0

1,010

Other Power Generation .

Number of Elec Dept Employees

Regular Full-time

Part-time \& Temporary

Total Elac Dept Employees
0

0

70

0

n

70
10,717

53,105

8,519

0

32,577

0
0

0
0
0

0
152

63,822

2,197

3,062

1,690

16
25

3,675

74,487

0

0

0

170

25

195

24

24

Note: Totals may not equal sum of components because of independent rounding.

Source: Energy Information Administration, Form ElA-412, "Annual Report of Public Electric Utilities." 
Table 23. Electric Operation and Maintenance Expenses by Major U.S. Publicly Owned Electric Utility Within State, 1992 (Continued) (Thousand Dollars)

\begin{tabular}{|c|c|c|c|c|c|c|}
\hline Item & $\begin{array}{l}\text { Louisiana } \\
\text { Natchitoches } \\
\text { City of }\end{array}$ & $\begin{array}{l}\text { Louisiana } \\
\text { Ruston } \\
\text { City of }\end{array}$ & $\begin{array}{c}\text { Louisiana } \\
\text { Terrebonne } \\
\text { Parish } \\
\text { Consol Govt }\end{array}$ & $\begin{array}{l}\text { Maryland } \\
\text { Easton } \\
\text { Utilities } \\
\text { Comm }\end{array}$ & $\begin{array}{l}\text { Maryland } \\
\text { Hagerstown } \\
\text { City of }\end{array}$ & $\begin{array}{c}\text { Massachusetts } \\
\text { Braintree } \\
\text { Town of }\end{array}$ \\
\hline & May 31 & September 30 & December 31 & June 30 & December 31 & December 31 \\
\hline
\end{tabular}

\section{Production Expenees}

Steam Power Generation

Nuclear Power Generation

Hydraulic Power Generation

Other Power Generation

Purchased Power

Other Production Expenses

Total Production Expenses

Transmission Expenses

Distribution Expenses

Customer Accounts Expenses

Customer Service and Information

Expenses

Administrative and General

Expenses

Total Electric Operation and

Maintenance Expenses

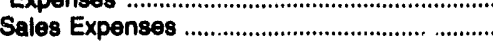

0
0
0
0
7.716
850

8,586

0
439

439
397

387

0
0

758

10,160
4,807
0
0
49
991
89

5,935

0

1,112

336

0
0

592

7,975

$7 \quad 1,621$

1,621
0

0
0
9,950

9,950
0

11,571

0

867
0

366

0

946

13,750

0
0
0
2,156
4,732
175

7,084

6

688

230

\section{0}

948

8,935

0

0

0
0
0
0
10,946

4,469

0

0
20

17,601

197

22,287

81

1,527

546

0

128

3,008

27,578

\section{Fuel Expenses in Operation}

Steam Power Generation

0

3,597

1,259

o

2,577

Nuclear Power Generation

0

0

0

0

Other Power Generation

0

0

0

1,195

36

0

36

54

62

36

78

38

1

0

63

37

78

Note: Totals may not equal sum of components because of independent rounding.

Source: Energy Information Administration, Form ElA-412, "Annual Report of Public Electric Utilities." 
Table 23. Electric Operation and Maintenance Expenses by Major U.S. Publicly Owned Electric Utillty Within State, 1992 (Continued) (Thousand Dollars)

\begin{tabular}{|c|c|c|c|c|c|c|}
\hline & Massachusetts & Massachusetts & Massachusetts & Massachusetts & Massachusetts & Massachusetts \\
\hline Item & $\begin{array}{c}\text { Chicopee } \\
\text { City of }\end{array}$ & $\begin{array}{l}\text { Concord } \\
\text { Town of }\end{array}$ & $\begin{array}{l}\text { Danvers } \\
\text { Town of }\end{array}$ & $\begin{array}{c}\text { Hingham } \\
\text { City of }\end{array}$ & $\begin{array}{c}\text { Holyoke } \\
\text { City of }\end{array}$ & $\begin{array}{l}\text { Hudson } \\
\text { Town of }\end{array}$ \\
\hline & December 31 & December 31 & December 31 & December 31 & December 31 & December 31 \\
\hline
\end{tabular}

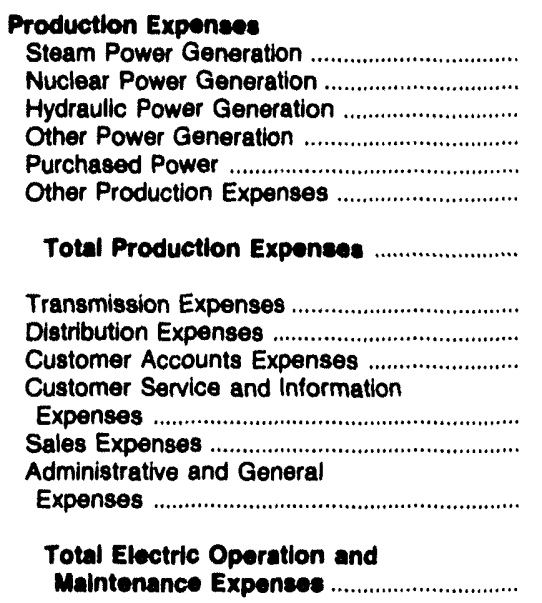

Steam Power Generation

Other Production Expenses

$$
\begin{array}{r}
0 \\
1,847 \\
0 \\
110 \\
15,964 \\
297
\end{array}
$$

0
1,847
0
110
5,964
297

0
0
0
0
8,882
707

18,219

$\mathbf{9 , 5 8 9}$

83

83
2,448

677

39

39
206

231

0

2,839

24,498

50

2

1,482

11,592

0
0
0
0
25,068
0

0

0
0
0
0
10,477

$\begin{array}{r}100 \\ \hline\end{array}$

25,008

10,578

1,519

1,243

1,006

610

722

337

30,474

12,991

$\begin{array}{rr}676 & 0 \\ 0 & 132 \\ 277 & 0 \\ 0 & 514 \\ 17,247 & 23,770 \\ 0 & 58\end{array}$

18,201

24,474

884

1,715

901

982

368

240

0

144

2,431

1,144

24,139

27,210

\section{Fuel Expenses in Operation}

Steam Power Generation

Nuclear Power Generation

$\begin{array}{rr}0 & 0 \\ 430 & 0\end{array}$

Other Power Generation

0

$\begin{array}{ll}75 & 22 \\ 2 & 3\end{array}$

Total Elec Dept Employees

77

25

40
2
42

26
28

77

77

34

Note: Totals may not equal sum of components because of independent rounding.

Source: Energy Information Administration, Form ElA-412, "Annual Report of Public Electric Utilities." 
Table 23. Electric Operation and Maintenance Expenses by Major U.S. Publicly Owned Electric Utility Within State, 1992 (Continued) (Thousand Dollars)

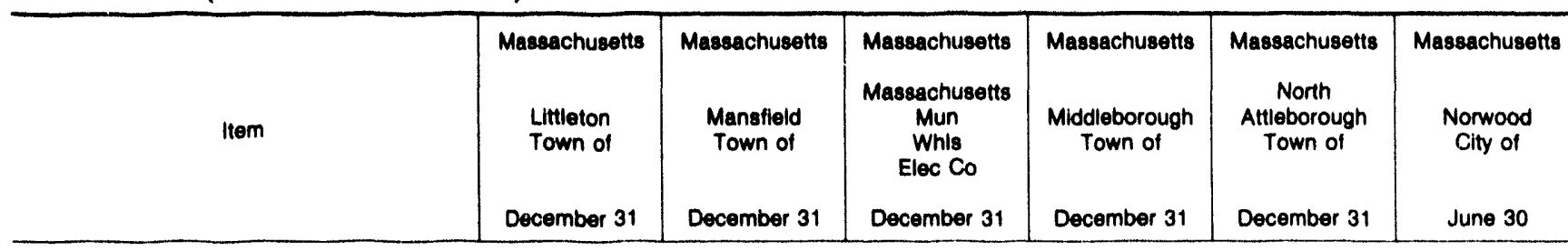

\section{Production Exponses}

Steam Power Generation

Nuclear Power Generation

Hydraulic Power Generation

Other Power Generation

Purchased Power

Other Production Expenses

Total Production Exponses

Transmission Expenses

Distribution Expenses

Customer Accounts Expenses ..........

Customer Service and Information

Expenses

Sales Expenses

Administrative and General

Expenses

Total Electric Oporation and

Maintenance Expenses.

Fual Expenses in Operation

Steam Power Generation

Nuclear Power Generation

Other Power Generation

Number of Elec Dept Employees

Regular Full-time

Part-time \& Temporany

Total Elec Dept Employees

130
0
0
0
10,813
156

0

0

14,438

11,100

14,438

666

766

329

0

1,294

14,164
1,103

30,895

17.436

74,738

65

124,036

4,812

0

0

0

16,902

145,850

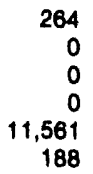

0
0
0
0
21,189
0

12,318

12,012

21,180

705

1.250

522

832

849

1.

1,207

0

162

0
27

1,105

1,475

1,005

15,059

24,568

787
13,404
8,640

9,640
0

0

21

0

21
128

3

131

37

16,927

Note: Totals may not equal sum of components because of independert rounding.

Source: Energy Information Administration, Form EIA-412, "Annual Report of Public Electric Utilities." 
Table 23. Electric Operation and Maintenance Expenses by Major U.S. Publicly Owned Electrlc Utility Within State, 1992 (Continued) (Thousand Dollars)

\begin{tabular}{|c|c|c|c|c|c|c|}
\hline & Massachusetts & Massachusetts & Massachusetts & Massachusetts & Massachusetts & Massachusetts \\
\hline Item & $\begin{array}{l}\text { Peabody } \\
\text { Clty of }\end{array}$ & $\begin{array}{l}\text { Reading } \\
\text { Town of }\end{array}$ & $\begin{array}{c}\text { Shrewsbury } \\
\text { Town of }\end{array}$ & $\begin{array}{l}\text { Taunton } \\
\text { City of }\end{array}$ & $\begin{array}{l}\text { Wakefield } \\
\text { Town of }\end{array}$ & $\begin{array}{l}\text { Wellesiey } \\
\text { Town of }\end{array}$ \\
\hline & December 31 & December 31 & December 31 & December 31 & December 31 & December 31 \\
\hline
\end{tabular}

Production Expenees

Steam Power Generation ...

Nuclear Power Generation

Hydraulic Power Generation

Other Power Generation

Purchased Power

Other Production Expenses

Total Production Expenese

Transmission Expenses

Distribution Expenses

Customer Accounts Expeneses...

Customer Service and Information

Expenses

Expes Expess

Administrative and Genera

Expenses

Total Electrlc Oporation and

Maintenance Exponses.

\section{Fuel Expenees In Operation}

Steam Power Generation

Nuclear Power Generation

Other Power Generation

Number of Elec Dept Employeses

Regular Full-time .

70

Part-time \& Temporary

8

78

Total Elec Dept Employees

$\begin{array}{rr}0 & 0 \\ 0 & 0 \\ 0 & 0 \\ 414 & 0 \\ 29,645 & 39,688 \\ 145 & 0\end{array}$

30,204

174

1,473
550

550

0
5

3,317

$\mathbf{3 5 , 7 2 2}$

39,699

1
2,257

2,257
1,567

1,587

0
227

1,524

45,244

0
0
0
132
15,898
261

7,967

7,967
0
0
240
12,073

16,291

20,330

248

2,426

1,589

308

0

42

977

19,028

30,246

0
0
0
0
11,489
0

11,490

0
1,045

1,045
375

0

13

640

0
3

914

13,827

16,449

$\begin{array}{rr}0 & 0 \\ 0 & 0 \\ 168 & 0\end{array}$

0
0
29

2,822

0

0

0

29

0

130

0

Note: Totals may not equal sum of components because of independent rounding.

Source: Energy Information Administration, Form EIA-412, "Annual Report of Public Electric Utilities." 
Table 23. Electric Operation and Maintenance Expenses by Major U.S. Publlcly Owned Electric Utillity Within State, 1992 (Continued) (Thousand Dollars)

\begin{tabular}{|c|c|c|c|c|c|c|}
\hline Item & $\begin{array}{c}\text { Massachusetts } \\
\text { Westfield } \\
\text { City of } \\
\text { December } 31\end{array}$ & $\begin{array}{l}\text { Michigan } \\
\text { Bay } \\
\text { City City of } \\
\text { June } 30\end{array}$ & $\begin{array}{l}\text { Michigan } \\
\text { Coldwater } \\
\text { Board } \\
\text { of } \\
\text { Public Util } \\
\text { June } 30\end{array}$ & $\begin{array}{l}\text { Michigan } \\
\text { Detroit } \\
\text { City of } \\
\text { June } 30\end{array}$ & $\begin{array}{c}\text { Michigan } \\
\text { Grand Haven } \\
\text { City of } \\
\text { June } 30\end{array}$ & $\begin{array}{l}\text { Michigan } \\
\text { Hillsdale } \\
\text { Board } \\
\text { of } \\
\text { Public Wks } \\
\text { June } 30\end{array}$ \\
\hline 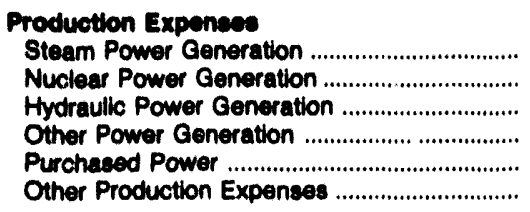 & $\begin{array}{r}0 \\
0 \\
0 \\
0 \\
23,405 \\
0\end{array}$ & $\begin{array}{r}0 \\
0 \\
0 \\
0 \\
8,686 \\
0\end{array}$ & $\begin{array}{r}100 \\
0 \\
0 \\
367 \\
7,643 \\
0\end{array}$ & $\begin{array}{r}19,097 \\
0 \\
0 \\
0 \\
11,122 \\
0\end{array}$ & $\begin{array}{r}9,658 \\
0 \\
0 \\
96 \\
879 \\
56\end{array}$ & $\begin{array}{r}0 \\
0 \\
0 \\
1,021 \\
6,068 \\
0\end{array}$ \\
\hline 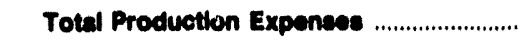 & 23,406 & 8,600 & 8,110 & 30,210 & 10,689 & 7,001 \\
\hline 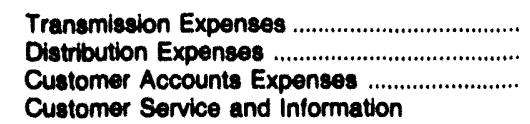 & $\begin{array}{r}0 \\
4,873 \\
0\end{array}$ & $\begin{array}{r}0 \\
993 \\
0\end{array}$ & $\begin{array}{r}0 \\
406 \\
142\end{array}$ & $\begin{array}{r}1,734 \\
10,978 \\
0\end{array}$ & $\begin{array}{r}0 \\
522 \\
228\end{array}$ & $\begin{array}{r}0 \\
551 \\
22\end{array}$ \\
\hline $\begin{array}{l}\text { Expenses } \\
\text { Sales Expenses } \\
\text { Administrattve and General }\end{array}$ & $\begin{array}{l}0 \\
0\end{array}$ & $\begin{array}{l}0 \\
0\end{array}$ & $\begin{array}{l}0 \\
0\end{array}$ & 0 & $\begin{array}{l}0 \\
8\end{array}$ & 0 \\
\hline Expenses & 2,483 & 1,301 & 818 & 1,533 & 1,289 & 621 \\
\hline 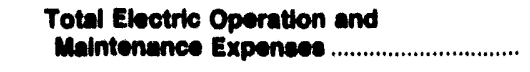 & 30,781 & 10,660 & 9,470 & 44,464 & 12,743 & 8,280 \\
\hline \multicolumn{7}{|l|}{ Fuel Exponsese in Operation } \\
\hline 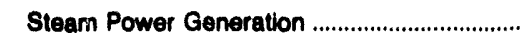 & 0 & 0 & 0 & 12,541 & 7,269 & 0 \\
\hline 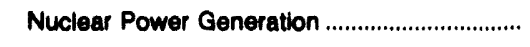 & 0 & 0 & 0 & 0 & 0 & 0 \\
\hline 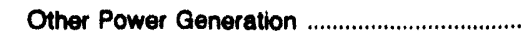 & 0 & 0 & 246 & 0 & 19 & 312 \\
\hline \multicolumn{7}{|l|}{ Number of Elec Dept Employees } \\
\hline 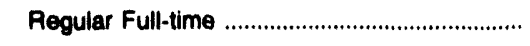 & 69 & 42 & 18 & 399 & 61 & 27 \\
\hline Part-time \& Temporary & 0 & 0 & 0 & 12 & 1 & 0 \\
\hline Total Elec Dept Employees & 69 & 42 & 18 & 411 & 62 & 27 \\
\hline
\end{tabular}

Note: Totals may not equal sum of components because of independent rounding.

Source: Energy Information Administration, Form EIA-412, "Annual Report of Public Electric Utilities." 
Table 23. Electrlc Operation and Maintenance Expenses by Major U.S. Publicly Owned Electric Utility Within State, 1992 (Continued) (Thousand Dollars)

\begin{tabular}{|c|c|c|c|c|c|c|}
\hline Item & $\begin{array}{l}\text { Michigan } \\
\text { Holland } \\
\text { City of } \\
\text { June } 30\end{array}$ & $\begin{array}{l}\text { Michigan } \\
\text { Lansing } \\
\text { City of } \\
\text { June } 30\end{array}$ & $\begin{array}{l}\text { Michigan } \\
\text { Marquette } \\
\text { City of } \\
\text { June } 30\end{array}$ & $\begin{array}{l}\text { Michigan } \\
\text { Michigari } \\
\text { Public } \\
\text { Power Agency } \\
\text { December } 31\end{array}$ & $\begin{array}{l}\text { Michigan } \\
\text { Michigan } \\
\text { South } \\
\text { Central } \\
\text { Pwr Agy } \\
\text { June } 30\end{array}$ & $\begin{array}{l}\text { Michigan } \\
\text { Sturgis } \\
\text { City of } \\
\text { September } 30\end{array}$ \\
\hline 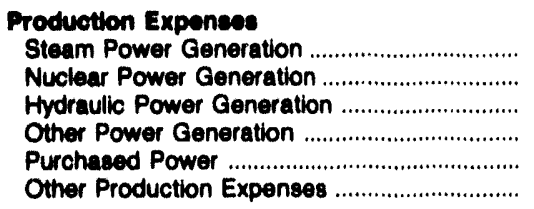 & $\begin{array}{r}10,439 \\
0 \\
0 \\
0 \\
12,131 \\
0\end{array}$ & $\begin{array}{r}57,533 \\
0 \\
25 \\
0 \\
9,412 \\
0\end{array}$ & $\begin{array}{r}7,734 \\
0 \\
111 \\
35 \\
455 \\
0\end{array}$ & $\begin{array}{r}18,417 \\
0 \\
0 \\
0 \\
8,202 \\
0\end{array}$ & $\begin{array}{r}7,196 \\
0 \\
0 \\
0 \\
6,874 \\
0\end{array}$ & $\begin{array}{r}0 \\
0 \\
65 \\
780 \\
6,743 \\
0\end{array}$ \\
\hline Total Production Expenses ......................... & 22,570 & 66,971 & 8,335 & 28,619 & 14,070 & 7,588 \\
\hline 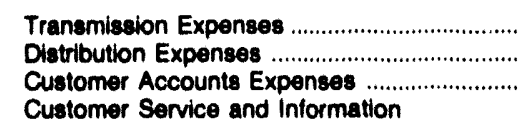 & $\begin{array}{r}0 \\
1,592 \\
550\end{array}$ & $\begin{array}{r}876 \\
5,061 \\
2,688\end{array}$ & $\begin{array}{r}0 \\
816 \\
343\end{array}$ & $\begin{array}{r}1,676 \\
0 \\
0\end{array}$ & $\begin{array}{r}132 \\
0 \\
0\end{array}$ & $\begin{array}{r}55 \\
602 \\
137\end{array}$ \\
\hline 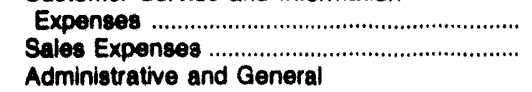 & $\begin{array}{r}0 \\
12\end{array}$ & $\begin{array}{r}0 \\
200\end{array}$ & $\begin{array}{l}21 \\
11\end{array}$ & $\begin{array}{l}0 \\
0\end{array}$ & $\begin{array}{l}0 \\
0\end{array}$ & $\begin{array}{l}0 \\
0\end{array}$ \\
\hline 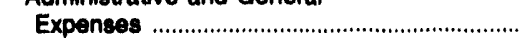 & 1,774 & 22,331 & 2.174 & 3,687 & 1,293 & 860 \\
\hline $\begin{array}{l}\text { Total Electric Operation and } \\
\text { Malntenance Expences }\end{array}$ & 26,490 & 98,126 & 11,700 & 31,982 & 15,495 & 0,243 \\
\hline \multicolumn{7}{|l|}{ Fuel Exponese in Operation } \\
\hline Steam Power Generation .................................... & 8,644 & 45,556 & 5,648 & 10,629 & 4,529 & 0 \\
\hline Nuclear Power Generation .............................. & 0 & 0 & 0 & 0 & 0 & 0 \\
\hline Other Power Generation .................................... & 0 & 0 & 11 & 0 & 0 & 276 \\
\hline \multicolumn{7}{|l|}{ Number of Elec Dept Employees } \\
\hline Regular Full-time & 100 & 742 & 90 & 7 & 54 & 27 \\
\hline 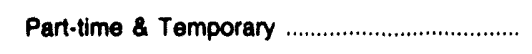 & 17 & 0 & 3 & 0 & 1 & 1 \\
\hline Total Elec Dept Employees ............................ & 117 & 742 & 93 & 7 & 55 & 28 \\
\hline
\end{tabular}

Note: Totals may not equal sum of components because of independent rounding.

Source: Energy information Administration, Form EIA-412, "Annual Report of Public Electric Utilities." 
Table 23. Electric Operation and Maintenance Expenses by Major U.S. Publicly Owned Electric UtIlity Within State, 1992 (Continued)

(Thousand Dollars)

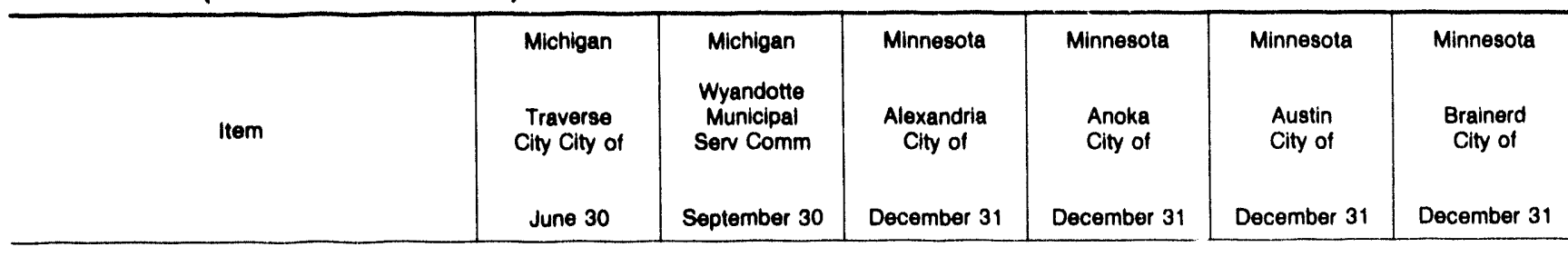

\section{Production Expenses}

Steam Power Generation

Nuclear Power Generation

Hydraulic Power Generation

Other Power Generation

Purchased Power

Other Production Expenses

Total Production Expenses

Transmission Expenses

Distribution Expenses ....

Customer Accounts Expenses

Customer Service and information

Expenses

Sales Expenses

Administrative and General

Expenses

Total Electric Operation and

Maintenance Expenees

Fuel Expenses in Operation

Steam Power Generation

1,958

6,608

0
0
0
48
4,890
22

8,147

0
1,611

13

259

38

1,125

11,193

14,345

$\mathbf{9 , 9 8 8}$

4,861

0

463

222

207
216

412

99

2
0

427

6,076

0
0
0
0
8,294
0

1,664

0

3
13,272

47

8,294

14,986

0
549

549
197

628
425

0

0

437

8,784

16,776

6,561
Nuclear Power Generation

Other Power Generation

0

0

60

5

65

$\begin{array}{lr}88 \\ 5 & 0\end{array}$

24

21

8

46

9

Part-time \& Temporary

88

24

29

8

4

54

13

Note: Totals may not equal sum of components because of independent rounding

Source: Energy Information Administration, Form EIA-412, "Annual Report of Public Electric Utilities." 
Table 23. Electric Operation and Maintenance Expenses by Major U.S. Publlcly Owned Electric Utility Within State, 1992 (Continued) (Thousand Dollars)

\begin{tabular}{|c|c|c|c|c|c|c|}
\hline Item & $\begin{array}{l}\text { Minnesota } \\
\text { Fairmont } \\
\text { Public } \\
\text { Utilities } \\
\text { Comm } \\
\text { December } 31\end{array}$ & $\begin{array}{l}\text { Minnesota } \\
\text { Hutchinson } \\
\text { Utilities } \\
\text { Comm } \\
\text { December } 31\end{array}$ & $\begin{array}{c}\text { Minnesota } \\
\text { Marshall } \\
\text { City of } \\
\text { December } 31\end{array}$ & $\begin{array}{c}\text { Minnesota } \\
\text { Moorhead } \\
\text { City of }\end{array}$ & $\begin{array}{l}\text { Minnesota } \\
\text { New Ulm } \\
\text { Public } \\
\text { Utilities } \\
\text { Comm } \\
\text { December } 31\end{array}$ & $\begin{array}{c}\text { Minnesota } \\
\text { Northern } \\
\text { Municipal } \\
\text { Power Agny } \\
\text { December } 31\end{array}$ \\
\hline
\end{tabular}

Production Expenses

Steam Power Generation

Nuclear Power Generation

Hydraulic Power Generation

Other Power Generation

Purchased Pow

Other Production Expenses

Total Production Exponses

Transmission Expenses

Oistribution Expenses

Customer Accounts Expenses

Customer Service and Information

Expenses .................

Sales Expenses

Administrative and General

Expenses

Total Electric Oporation and

Maintenance Expenses

\section{Fuel Expenses in Operation}

Steam Power Generation

Nuclear Power Generation

Other Power Generation

Number of Elec Dept Employees

Regular Full-time

Part-time \& Temporary

24

0

Total Elec Dept Employeet

9,845

6
498
0

0

0

71

10,419

928
0
0
0
8,917
0

$\begin{array}{cc}34 & 0 \\ 0 & 0 \\ 0 & 21\end{array}$

0
0
0
999
5,176
0

0
0
0
0
7,475

6,175

7,476

1,092

897

56
286
81

23
0

605

10,093

7,400

(1)

0
0
0
0
1

75
0
0
75
6,479
0

3,828

10,061

0
0
0

2,183

0

6,011

30
455

455
67

831

444

0

0

1,156

7,720

11,038

Note: Totals may not equal sum of components because of independent rounding.

Source: Energy Information Administration, Form ElA-412, "Annual Report of Public Electric Utilities." 
Table 23. Electric Operation and Maintenance Expenses by Major U.S. Publlcly Owned Electric Utility Within State, 1992 (Continued) (Thousand Dollars)

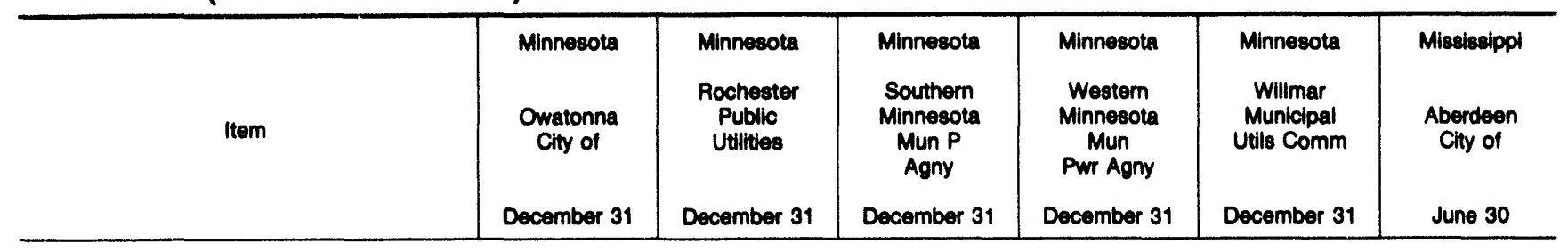

\section{Production Expones}

Steam Power Generation

Nuclear Power Generation

Hydraulic Power Generation

Other Power Generation

Purchaeed Power

Other Production Expenses

Total Production Expeneed

Transmiscion Expenses

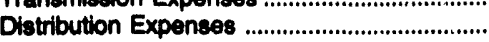

Customer Accounts Expenses

Customer Service and Information

Expenses

Administrative and General

Expenses

................

Total Electric Operation and

Malntenance Expences ....

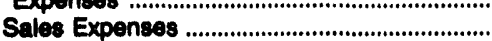

$\begin{array}{rr}0 & 2,584 \\ 0 & \\ 0 & 169 \\ 548 & 39 \\ 12,982 & 49,287 \\ 0 & 244\end{array}$

$13,530 \quad 52,322$

$0 \quad 175$

$952 \quad 2,243$

$295 \quad 886$

$0 \quad 150$

$38 \quad 21$

$292 \quad 3,087$

16,107

68,985

$584 \quad 36,643$

169
39

287

244

13,155

1,300

61,007

265

0
0

0
0

4,822

58,184

24,716

11,682

967

0

0

0

Number of Elec Dept Employees

Regular Full-time ...........................................

Part-time \& Temporary
35

0

35

$\begin{array}{ll}0 & 54 \\ 0 & 0 \\ 0 & 0\end{array}$

Total Elec Dept Employeer

162
3
192

182

36

0

38 $\begin{array}{rr}1,832 & 0 \\ 0 & 0 \\ 0 & 0 \\ 0 & 0 \\ 3,879 & 6,939 \\ 0 & 0\end{array}$

$6,711 \quad 6,980$

280

251

117

10
14

206

7,587

Note: Totals may not equal sum of components because of independent rounding

Source: Energy Information Administration, Form EIA-412, "Annual Report of Public Electric Utilities." 
Table 23. Electric Operation and Maintenance Expenses by Major U.S. Publicly Owned Electric Utility Within State, 1992 (Continued) (Thousand Dollars)

\begin{tabular}{|c|c|c|c|c|c|c|}
\hline Item & $\begin{array}{l}\text { Mississippi } \\
\text { Clarksdale } \\
\text { City of } \\
\text { September } 30\end{array}$ & $\begin{array}{l}\text { Mississippi } \\
\text { Columbus } \\
\text { Clty of } \\
\text { June } 30\end{array}$ & $\begin{array}{l}\text { Mississippi } \\
\text { Greenwood } \\
\text { Utilities } \\
\text { Comm } \\
\text { September } 30\end{array}$ & $\begin{array}{l}\text { Mississippi } \\
\text { Holly } \\
\text { Springs } \\
\text { City of } \\
\text { June } 30\end{array}$ & $\begin{array}{l}\text { Mississippi } \\
\text { Louisville } \\
\text { Electric } \\
\text { System } \\
\text { June } 30\end{array}$ & $\begin{array}{l}\text { Mississippi } \\
\text { Municipal } \\
\text { Energy } \\
\text { Agency } \\
\text { of MS } \\
\text { September } 30\end{array}$ \\
\hline 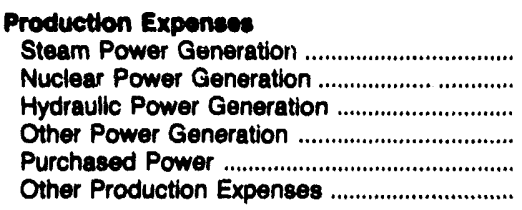 & $\begin{array}{r}2,536 \\
0 \\
0 \\
0 \\
5,753 \\
0\end{array}$ & $\begin{array}{r}0 \\
0 \\
0 \\
0 \\
21,021 \\
0\end{array}$ & $\begin{array}{r}1,732 \\
0 \\
0 \\
0 \\
9,012 \\
0\end{array}$ & $\begin{array}{r}0 \\
0 \\
0 \\
0 \\
8,777 \\
0\end{array}$ & $\begin{array}{r}0 \\
0 \\
0 \\
0 \\
7,027 \\
0\end{array}$ & $\begin{array}{r}0 \\
0 \\
0 \\
0 \\
24,515 \\
0\end{array}$ \\
\hline Total Production Expenses ............................ & 8,289 & 21,021 & 10,744 & 8,777 & 7,027 & 24,515 \\
\hline 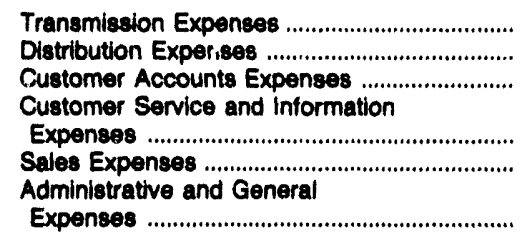 & $\begin{array}{r}0 \\
314 \\
180 \\
0 \\
0 \\
719\end{array}$ & $\begin{array}{r}0 \\
942 \\
215 \\
3 \\
75 \\
753\end{array}$ & $\begin{array}{r}0 \\
780 \\
188 \\
0 \\
1\end{array}$ & $\begin{array}{r}0 \\
700 \\
241 \\
9 \\
9 \\
904\end{array}$ & $\begin{array}{r}0 \\
260 \\
93 \\
7 \\
13\end{array}$ & $\begin{array}{r}2,841 \\
0 \\
0 \\
0 \\
0\end{array}$ \\
\hline $\begin{array}{l}\text { Total Electric Operation and } \\
\text { Malntenance Expenees }\end{array}$ & 9,502 & 22,600 & 12,674 & 10,040 & 7,628 & 27,873 \\
\hline \multicolumn{7}{|l|}{ Fuel Expenees in Operation } \\
\hline 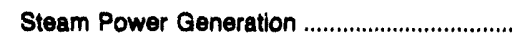 & 1,880 & 0 & 498 & 0 & 0 & 0 \\
\hline 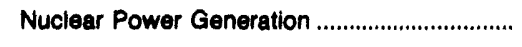 & 0 & 0 & 0 & 0 & 0 & 0 \\
\hline 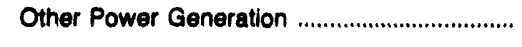 & 0 & 0 & 0 & 0 & 0 & 0 \\
\hline \multicolumn{7}{|l|}{ Number of Elec Dept Employees } \\
\hline Regular Full-time ............................................... & 37 & 31 & 79 & 42 & 16 & 4 \\
\hline 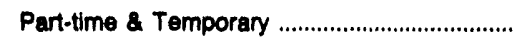 & 0 & 0 & 2 & 0 & 8 & 1 \\
\hline Total Elec Dept Employees & 37 & 31 & 81 & 42 & 24 & 5 \\
\hline
\end{tabular}

Note: Totals may not equal sum of components because of independent rounding.

Source: Energy Information Administration, Form EIA-412, "Annual Report of Public Electric Utilities." 
Table 23. Electric Operation and Maintenance Expenses by Major U.S. Publicly Owned Electric Utillty Within State, 1992 (Continued)

(Thousand Dollars)

\begin{tabular}{c|c|c|c|c|c|c}
\hline & Mississippl & Mississippl & Mississippi & Mississippi & Mississippi & Missouri \\
Item & $\begin{array}{c}\text { New Albany } \\
\text { City of }\end{array}$ & $\begin{array}{c}\text { Oxtord } \\
\text { City of }\end{array}$ & $\begin{array}{c}\text { Starkville } \\
\text { City of }\end{array}$ & $\begin{array}{c}\text { Tupelo } \\
\text { City of }\end{array}$ & $\begin{array}{c}\text { Point } \\
\text { City of }\end{array}$ & $\begin{array}{c}\text { Carthage } \\
\text { City of }\end{array}$ \\
& June 30 & June 30 & June 30 & June 30 & June 30 & June 30 \\
\hline
\end{tabular}

\section{Production Expenees}

Steam Power Generation

Nuclear Power Generation

Hydraulic Power Generation

Other Power Generation

Purcheged Power

Other Production Expenses.

Total Production Expenses

Transmission Expenses

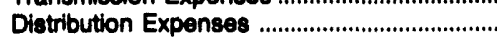

Customer Accounts Expenses.

Customer Service and Information

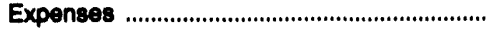

Sales Expenses ................................................

Administrative and General

Expenses

\section{Total Electrle Operation and}

Malntenance Expenses

0
0
0
0
10,097
0

0
0
0
0
6,502

0
0
0
0
13,633

6,502

10,007

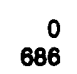

0
686
214

3
12

201

11,212

\section{0}

0
266

136

20

11

180

7,114
13,633

0
680

680
179

16

12

291

14,812

0
0
0
0
27,544
0

27,544

20,302

$\begin{array}{rr}0 & 0 \\ 0 & 0 \\ 0 & 0 \\ 0 & 356 \\ 8,396 & 6,513 \\ 0 & 65\end{array}$

8,396

6,034

0

405

130

4

887

168

487

8,965

7,960

\section{Fuel Expenese in Operation}

Steam Power Generation ...............................

Nuclear Power Generation

Other Power Generation

Number of Elec Dept Employees

Regular Full-time

Part-time \& Temporany

Total Elec Dept Employees
0

0

0

$\begin{array}{rr}29 & 20 \\ 0 & 0\end{array}$

$29 \quad 20$

0

0
20

Note: Totals may not equal sum of components because of independent rounding.

Source: Energy Information Administration, Form ElA-412, "Annual Report of Public Electric Utilities." 
Table 23. Electric Operation and Maintenance Expenses by Major U.S. Publicly Owned Electric Utillty Within State, 1992 (Continued) (Thousand Dollars)

\begin{tabular}{c|c|c|c|c|c|c}
\hline & Missouri & Missouri & Missouri & Missouri & Missouri & Missouri \\
& $\begin{array}{c}\text { Columbia } \\
\text { City of }\end{array}$ & $\begin{array}{c}\text { Hannibal } \\
\text { City of }\end{array}$ & $\begin{array}{c}\text { Independence } \\
\text { Clty of }\end{array}$ & $\begin{array}{c}\text { Kennett } \\
\text { City of }\end{array}$ & $\begin{array}{c}\text { Kirkwood } \\
\text { City of }\end{array}$ & $\begin{array}{c}\text { Lebanon } \\
\text { City of }\end{array}$ \\
September 30 & June 30 & June 30 & June 30 & March 31 & October 31 \\
\hline
\end{tabular}

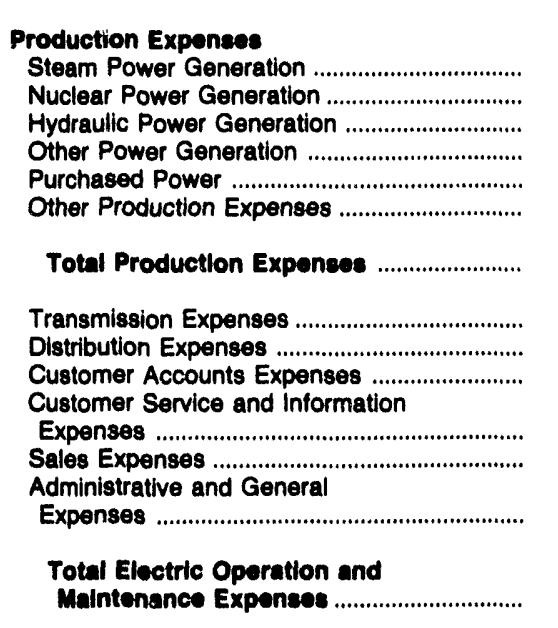

Production Expenses

Nuclear Power Generation.

ydraulic Power Generation

Other Production Expenses

\section{Fuel Exponses in Operation}

Steam Power Generation ................................

Nuclear Power Generation .

Other Power Generation

Number of Elec Dept Employees

Regular Full-time

Part-time \& Temporary

Total Elec Dept Employees

3,652
0
0
0
23,920
3

0
0
0
0
7,254
0

5,093
0
0
1,143
18,831
547

7,254

27,575

0
2,973

1,104

$$
\begin{aligned}
& 0 \\
& 0
\end{aligned}
$$

2,583

34,235

8,513

38,008

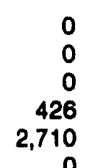

0
0
0
0
7,782
0

3,136

7,782

0
749
0

0

605

128

0

0
0

421

539

4,305

9,054

7,472

$\begin{array}{rrrrrr}2,117 & 0 & 1,591 & 0 & 0 & 0 \\ 0 & 0 & 0 & 0 & 0 & 0 \\ 0 & 0 & 504 & 28 & 0 & 0\end{array}$

Note: Totals may not equal sum of components because of independent rounding.

Source: Energy Information Administration, Form ElA-412, "Annual Report of Public Electric Utilities." 
Table 23. Electric Operation and Maintenance Expenses by Major U.S. Publicly Owned Electric Utility Within State, 1992 (Continued)

(Thousand Dollars)

\begin{tabular}{|c|c|c|c|c|c|c|}
\hline item & $\begin{array}{l}\text { Missouri } \\
\text { Marshall } \\
\text { City of } \\
\text { September } 30\end{array}$ & $\begin{array}{l}\text { Missouri } \\
\text { Monett } \\
\text { City of } \\
\text { March } 31\end{array}$ & $\begin{array}{l}\text { Missouri } \\
\text { Poplar } \\
\text { Bluff } \\
\text { City of } \\
\text { December } 31\end{array}$ & $\begin{array}{c}\text { Missouri } \\
\text { Rolla } \\
\text { City of } \\
\text { September } 30\end{array}$ & $\begin{array}{l}\text { Missouri } \\
\text { Sikeston } \\
\text { City of } \\
\text { May } 31\end{array}$ & $\begin{array}{c}\text { Missouri } \\
\text { Springtield } \\
\text { City of } \\
\text { September } 30\end{array}$ \\
\hline 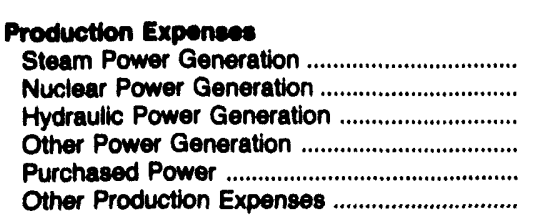 & $\begin{array}{r}2,650 \\
0 \\
0 \\
0 \\
1,420 \\
0\end{array}$ & $\begin{array}{r}0 \\
0 \\
0 \\
0 \\
4,396 \\
0\end{array}$ & $\begin{array}{r}0 \\
0 \\
0 \\
41 \\
4,680 \\
124\end{array}$ & $\begin{array}{r}0 \\
0 \\
0 \\
0 \\
7,696 \\
0\end{array}$ & $\begin{array}{r}27,982 \\
0 \\
0 \\
0 \\
2,207 \\
0\end{array}$ & $\begin{array}{r}40,581 \\
0 \\
0 \\
1,236 \\
4,663 \\
0\end{array}$ \\
\hline Total Production Expenses ........................... & 4,089 & 4,396 & 4,845 & 7,696 & 30,189 & 46,480 \\
\hline 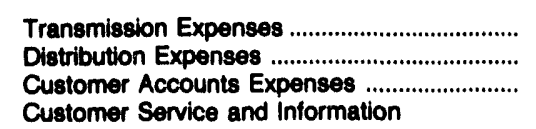 & $\begin{array}{r}6 \\
383 \\
327\end{array}$ & $\begin{array}{r}32 \\
0 \\
0\end{array}$ & $\begin{array}{r}0 \\
997 \\
0\end{array}$ & $\begin{array}{r}0 \\
295 \\
124\end{array}$ & $\begin{array}{r}0 \\
817 \\
274\end{array}$ & $\begin{array}{r}306 \\
6,830 \\
1,626\end{array}$ \\
\hline 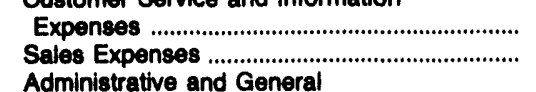 & $\begin{array}{l}0 \\
0\end{array}$ & $\begin{array}{l}0 \\
0\end{array}$ & $\begin{array}{l}0 \\
0\end{array}$ & $\begin{array}{l}0 \\
0\end{array}$ & $\begin{array}{l}0 \\
0\end{array}$ & $\begin{array}{r}26 \\
0\end{array}$ \\
\hline 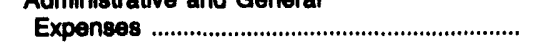 & 340 & 538 & 1,386 & 311 & 2,675 & 8,037 \\
\hline $\begin{array}{l}\text { Total Eloctric Oporation and } \\
\text { Maintenance Expenses }\end{array}$ & 6,127 & 4,966 & 7,228 & 8,427 & 33,956 & 63,306 \\
\hline \multicolumn{7}{|l|}{ Fuel Expenses in Operation } \\
\hline 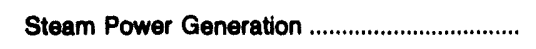 & 1,341 & 0 & 0 & 0 & 22,064 & 27,061 \\
\hline 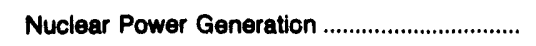 & 0 & 0 & 0 & 0 & 0 & 0 \\
\hline 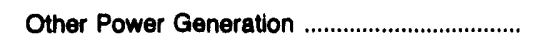 & 0 & 0 & 16 & 0 & 0 & 915 \\
\hline \multicolumn{7}{|l|}{ Number of Elac Dept Employees } \\
\hline Regular Full-time & 48 & 8 & 85 & 11 & 133 & 170 \\
\hline 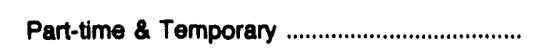 & 1 & 0 & 1 & 0 & 1 & 2 \\
\hline Total Elec Dopt Employees ................................. & 49 & 8 & 86 & 11 & 134 & 172 \\
\hline
\end{tabular}

Note: Totals may not equal sum of components because of independent rounding.

Source: Energy Information Administration, Form EIA-412, "Annual Report of Public Electric Utilities." 
Table 23. Electric Operation and Maintenance Expenses by Major U.S. Publicly Owned Electric Utility Within State, 1992 (Continued)

(Thousand Dollars)

\begin{tabular}{|c|c|c|c|c|c|c|}
\hline Item & $\begin{array}{c}\text { Nebraska } \\
\text { Central } \\
\text { Nebraska } \\
\text { Pub } \\
\text { P\&l Dist } \\
\text { December } 31\end{array}$ & $\begin{array}{l}\text { Nebraska } \\
\text { Cornhusker } \\
\text { Public } \\
\text { Power Dist } \\
\text { December } 31\end{array}$ & $\begin{array}{l}\text { Nebraska } \\
\text { Dawson } \\
\text { County } \\
\text { Public } \\
\text { Pwr Dist } \\
\text { December } 31\end{array}$ & $\begin{array}{l}\text { Nebraska } \\
\text { Fremont } \\
\text { City of } \\
\text { July } 31\end{array}$ & $\begin{array}{l}\text { Nebraska } \\
\text { Grand Island } \\
\text { City of } \\
\text { July } 31\end{array}$ & $\begin{array}{c}\text { Nebraska } \\
\text { Hastings } \\
\text { City of } \\
\text { December } 31\end{array}$ \\
\hline 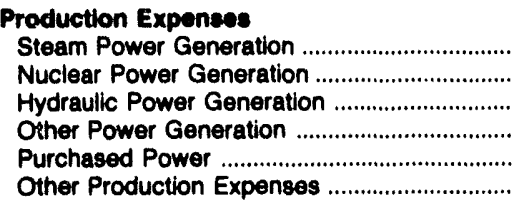 & $\begin{array}{r}688 \\
0 \\
3,056 \\
0 \\
0 \\
0\end{array}$ & $\begin{array}{r}0 \\
0 \\
0 \\
0 \\
6,071 \\
0\end{array}$ & $\begin{array}{r}0 \\
0 \\
0 \\
0 \\
8,702 \\
0\end{array}$ & $\begin{array}{r}5,234 \\
0 \\
0 \\
0 \\
784 \\
7\end{array}$ & $\begin{array}{r}6,513 \\
0 \\
0 \\
0 \\
977 \\
0\end{array}$ & $\begin{array}{r}5,656 \\
0 \\
0 \\
58 \\
1,534 \\
0\end{array}$ \\
\hline Total Production Exponses ............................. & 3,744 & 6,071 & 8,702 & 6,005 & 7,491 & 7,248 \\
\hline 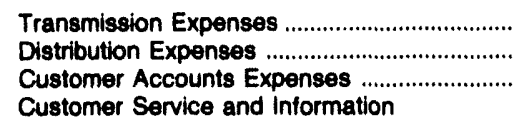 & $\begin{array}{r}38 \\
0 \\
0\end{array}$ & $\begin{array}{l}107 \\
868 \\
163\end{array}$ & $\begin{array}{r}44 \\
1,210 \\
377\end{array}$ & $\begin{array}{r}36 \\
1,138 \\
209\end{array}$ & $\begin{array}{l}116 \\
867 \\
542\end{array}$ & $\begin{array}{r}92 \\
415 \\
257\end{array}$ \\
\hline 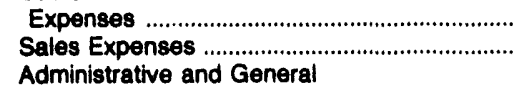 & $\begin{array}{l}0 \\
0\end{array}$ & $\begin{array}{r}130 \\
23\end{array}$ & $\begin{array}{l}58 \\
38\end{array}$ & $\begin{array}{l}0 \\
0\end{array}$ & $\begin{array}{l}0 \\
0\end{array}$ & $\begin{array}{r}36 \\
0\end{array}$ \\
\hline 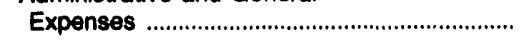 & 3,347 & 738 & 1,073 & 1,704 & 2,098 & 1,142 \\
\hline $\begin{array}{l}\text { Total Electric Operation and } \\
\text { Maintenance Expenses }\end{array}$ & 7,130 & 8,100 & 11,502 & 8,092 & 11,116 & 9,190 \\
\hline \multicolumn{7}{|l|}{ Fuel Exponses In Operation } \\
\hline 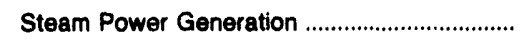 & 33 & 0 & 0 & 2,789 & 4,488 & 2,974 \\
\hline Nuclear Power Generation .................................. & 0 & 0 & 0 & 0 & 0 & 0 \\
\hline Other Power Generation ...................................... & 0 & 0 & 0 & 0 & 0 & 27 \\
\hline \multicolumn{7}{|l|}{ Number of Elec Dept Employees } \\
\hline Regular Full-time & 140 & 48 & 65 & 114 & 101 & 93 \\
\hline 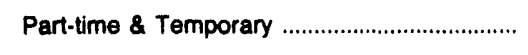 & 8 & 4 & 1 & 2 & 0 & 0 \\
\hline 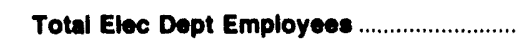 & 148 & 52 & 66 & 116 & 101 & 93 \\
\hline
\end{tabular}

Note: Totals may not equal sum of components because of independent rounding.

Source: Energy Information Administration, Form ElA-412, "Annual Report of Public Electric Utilities." 
Table 23. Electric Operation and Maintenance Expenses by Major U.S. Publicly Owned Electric Utillty Within State, 1992 (Continued) (Thousand Dollars)

\begin{tabular}{|c|c|c|c|c|c|c|}
\hline Item & $\begin{array}{l}\text { Nebraska } \\
\text { Lincoln } \\
\text { Electric } \\
\text { System } \\
\text { December } 31\end{array}$ & $\begin{array}{c}\text { Nebraska } \\
\text { Loup } \\
\text { River } \\
\text { Public } \\
\text { Power Dist } \\
\text { December } 31\end{array}$ & $\begin{array}{l}\text { Nebraska } \\
\text { Municipal } \\
\text { Energy } \\
\text { Agency } \\
\text { of NE } \\
\text { March } 31\end{array}$ & $\begin{array}{c}\text { Nebraska } \\
\text { Nebraska } \\
\text { Public } \\
\text { Power } \\
\text { District } \\
\text { December } 31\end{array}$ & $\begin{array}{c}\text { Nebraska } \\
\text { Norris } \\
\text { Public } \\
\text { Power } \\
\text { District } \\
\text { December } 31\end{array}$ & $\begin{array}{l}\text { Nebraska } \\
\text { North } \\
\text { Platte } \\
\text { City of } \\
\text { July } 31\end{array}$ \\
\hline 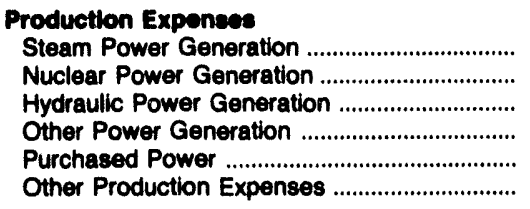 & $\begin{array}{r}13,116 \\
0 \\
0 \\
889 \\
48,501 \\
965\end{array}$ & $\begin{array}{r}0 \\
0 \\
1,185 \\
0 \\
22,851 \\
0\end{array}$ & $\begin{array}{r}2,014 \\
0 \\
0 \\
0 \\
15,355 \\
0\end{array}$ & $\begin{array}{r}100,684 \\
97,953 \\
2,345 \\
1,440 \\
36,269 \\
637\end{array}$ & $\begin{array}{r}0 \\
0 \\
0 \\
0 \\
12,428 \\
0\end{array}$ & $\begin{array}{r}0 \\
0 \\
0 \\
0 \\
7,365 \\
0\end{array}$ \\
\hline Total Production Expenses ............................ & 63,471 & 24,035 & 17,369 & 239,328 & 12,428 & 7,365 \\
\hline 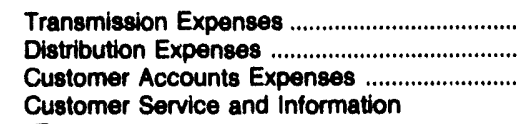 & $\begin{array}{l}1,717 \\
5,019 \\
2,056\end{array}$ & $\begin{array}{l}157 \\
857 \\
494\end{array}$ & $\begin{array}{r}2,970 \\
0 \\
0\end{array}$ & $\begin{array}{r}13,211 \\
10,029 \\
6,316\end{array}$ & $\begin{array}{r}33 \\
1,812 \\
405\end{array}$ & $\begin{array}{r}51 \\
541 \\
345\end{array}$ \\
\hline 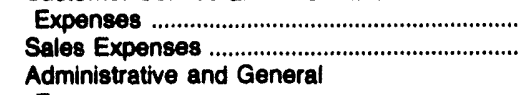 & $\begin{array}{r}1.474 \\
0\end{array}$ & $\begin{array}{r}111 \\
30\end{array}$ & $\begin{array}{l}0 \\
0\end{array}$ & $\begin{array}{l}2,124 \\
5,209\end{array}$ & $\begin{array}{r}177 \\
0\end{array}$ & $\begin{array}{r}66 \\
0\end{array}$ \\
\hline 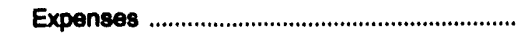 & 5,327 & 1,960 & 3,428 & 26,962 & 842 & 350 \\
\hline $\begin{array}{l}\text { Total Electric Operation and } \\
\text { Maintenance Expenses }\end{array}$ & 79,084 & 27,044 & 28,768 & 303,178 & 15,696 & 8,717 \\
\hline \multicolumn{7}{|l|}{ Fuel Expenses in Operation } \\
\hline Steam Power Generation ................................... & 8,621 & 0 & 1,289 & 66,165 & 0 & 0 \\
\hline Nuclear Power Generation ............................... & 0 & 0 & 0 & 32,161 & 0 & 0 \\
\hline Other Power Generation ................................... & 165 & 0 & 0 & 114 & 0 & 0 \\
\hline \multicolumn{7}{|l|}{ Number of Elec Dept Employees } \\
\hline 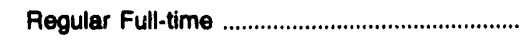 & 379 & 108 & 35 & 2,268 & 73 & 35 \\
\hline 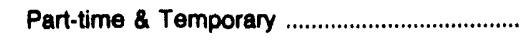 & 10 & 17 & 5 & 113 & 2 & 0 \\
\hline 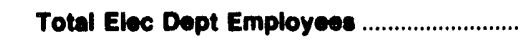 & 389 & 125 & 40 & 2,381 & 75 & 35 \\
\hline
\end{tabular}

Note: Totals may not equal sum of components because of independent rounding.

Source: Energy Information Administration, Form EIA-412, "Annual Report of Public Electric Utilities." 
Table 23. Electric Operation and Maintenance Expenses by Major U.S. Publicly Owned Electric Utility Within State, 1992 (Continued) (Thousand Dollars)

\begin{tabular}{|c|c|c|c|c|c|c|}
\hline Item & $\begin{array}{c}\text { Nebraska } \\
\text { Omaha Public } \\
\text { Power } \\
\text { District }\end{array}$ & $\begin{array}{c}\text { Nebraska } \\
\text { Southern } \\
\text { Nebraska Rural } \\
\text { P P D } \\
\text { December } 31\end{array}$ & $\begin{array}{l}\text { Nevada } \\
\text { Colorado } \\
\text { River } \\
\text { Comm } \\
\text { of Nevada } \\
\text { June } 30\end{array}$ & $\begin{array}{l}\text { New Jersey } \\
\text { Vineland } \\
\text { City of } \\
\text { June } 30\end{array}$ & $\begin{array}{l}\text { New Mexico } \\
\text { Farmington } \\
\text { City of } \\
\text { June } 30\end{array}$ & $\begin{array}{l}\text { New Mexico } \\
\text { Gallup } \\
\text { City of } \\
\text { June } 30\end{array}$ \\
\hline 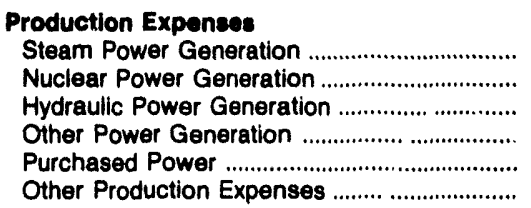 & $\begin{array}{r}69,376 \\
93,336 \\
0 \\
1,839 \\
-6,996 \\
-7,325\end{array}$ & $\begin{array}{r}0 \\
0 \\
0 \\
0 \\
14,425 \\
0\end{array}$ & $\begin{array}{r}0 \\
0 \\
0 \\
0 \\
23,777 \\
0\end{array}$ & $\begin{array}{r}6,747 \\
0 \\
0 \\
469 \\
16,341 \\
0\end{array}$ & $\begin{array}{r}8,624 \\
0 \\
548 \\
0 \\
1,955 \\
444\end{array}$ & $\begin{array}{r}0 \\
0 \\
0 \\
0 \\
10,076 \\
0\end{array}$ \\
\hline Total Production Expenses ......................... & 150,230 & 14,425 & 23,777 & 23,557 & 11,571 & 10,076 \\
\hline 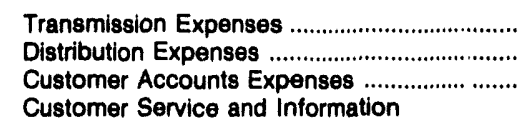 & $\begin{array}{r}3,556 \\
26,028 \\
10,647\end{array}$ & $\begin{array}{r}77 \\
1,093 \\
383\end{array}$ & $\begin{array}{l}0 \\
0 \\
0\end{array}$ & $\begin{array}{r}11 \\
2,162 \\
771\end{array}$ & $\begin{array}{r}262 \\
1,569 \\
793\end{array}$ & $\begin{array}{r}0 \\
113 \\
178\end{array}$ \\
\hline 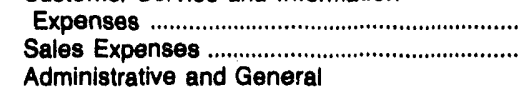 & $\begin{array}{r}4,412 \\
264\end{array}$ & $\begin{array}{r}117 \\
0\end{array}$ & $\begin{array}{l}0 \\
0\end{array}$ & $\begin{array}{l}0 \\
6\end{array}$ & $\begin{array}{r}34 \\
0\end{array}$ & $\begin{array}{r}101 \\
0\end{array}$ \\
\hline 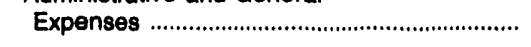 & 30,926 & 1,415 & 363 & 3,756 & 1,816 & 2,133 \\
\hline $\begin{array}{l}\text { Total Electric Operation and } \\
\text { Maintenance Expenses }\end{array}$ & 226,083 & 17,510 & 24,140 & 30,262 & 16,045 & 12,601 \\
\hline \multicolumn{7}{|l|}{ Fual Expenees in Operation } \\
\hline 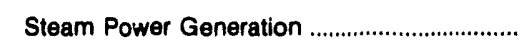 & 43,225 & 0 & 0 & 2,641 & 6,532 & 0 \\
\hline Nuclear Power Generation ................................ & 21,445 & 0 & 0 & 0 & 0 & 0 \\
\hline Other Power Generation .................................... & 335 & 0 & 0 & 367 & 0 & 0 \\
\hline \multicolumn{7}{|l|}{ Number of Elec Dept Employees } \\
\hline 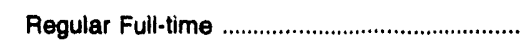 & 2,476 & 75 & 3 & 163 & 90 & 18 \\
\hline 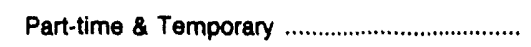 & 90 & 0 & 11 & 4 & 0 & 0 \\
\hline Total Elec Dept Employees & 2,568 & 75 & 14 & 167 & $\mathbf{9 0}$ & 18 \\
\hline
\end{tabular}

Note: Totals may not equal sum of components because of independent rounding.

Source: Energy Information Administration, Form ElA-412, "Annual Report of Public Electric Utilities." 
Table 23. Electrlc Operation and Malntenance Expenses by Major U.S. Publicly Owned Electric Utility Within State, 1992 (Continued) (Thousand Dollars)

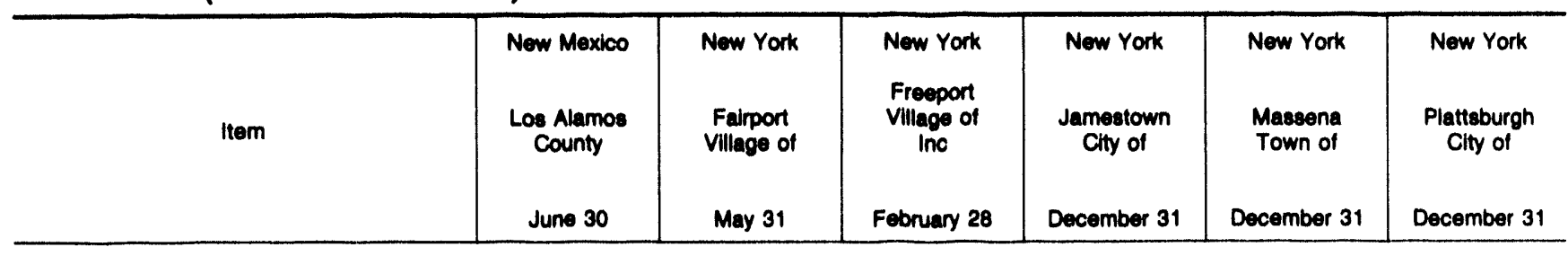

\section{Production Expenses}

Steam Power Generation

Nuclear Power Generation

Hydraulic Power Generation

Other Power Generation

Other Production Expenses

Total Production Expenese

Transmiselon Expenses

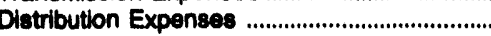

Customer Accounts Expenses ....

Customer Service and Information

Expenses

Sales Expenses

Adminiatrative and General

Expenses

\section{Total Eloctric Operation and}

Malntenance Expenses
4,332

321

0
4,288

594

9,685

1,639

471

103

1,875

19,729

3,296

Other Power Generation

Number of Elec Dept Employees

Regular Full-time

Part-time \& Temporary

Total Elec Dept Employese
0
0

0

0

0
0
0
0
6,052
0

0

3,080

4,792

0,052

7,092

93

812

244

0
1

724

7,020

58
687

523

\section{0}

1,268

10,303
6,691

8,581
0

0
5,022

5,022
0

11,614

141

837

349

0
-48

1,611

14,604

4,280

0

1,131

0

38

5

49

22
22
64

0

84

0

0
0
0
0
0
2,425
0

2,426

13

529

170

32

606

3,774

8,248

Note: Totals may not equal sum of components because of independent rounding

Source: Energy Information Administration, Form EIA-412, "Annual Report of Public Electric Utilities." 
Table 23. Electric Operation and Maintenance Expenses by Major U.S. Publicly Owned Electric Utillty Within State, 1992 (Continued) (Thousand Dollars)

\begin{tabular}{|c|c|c|c|c|c|c|}
\hline Item & $\begin{array}{c}\text { New York } \\
\text { Power } \\
\text { Authority } \\
\text { of State of NY } \\
\text { December } 31\end{array}$ & $\begin{array}{l}\text { New York } \\
\text { Rockville } \\
\text { Centre } \\
\text { Village of } \\
\text { May } 31\end{array}$ & $\begin{array}{l}\text { North Carollna } \\
\text { Albems.le } \\
\text { Clity of } \\
\text { June } 30\end{array}$ & $\begin{array}{l}\text { North Carolina } \\
\text { Concord } \\
\text { Clty of } \\
\text { June } 30\end{array}$ & $\begin{array}{l}\text { North Carolina } \\
\text { Elizabeth } \\
\text { City City of } \\
\text { June } 30\end{array}$ & $\begin{array}{l}\text { North Carolina } \\
\text { Fayetteville } \\
\text { Public } \\
\text { Works Comm } \\
\text { June } 30\end{array}$ \\
\hline 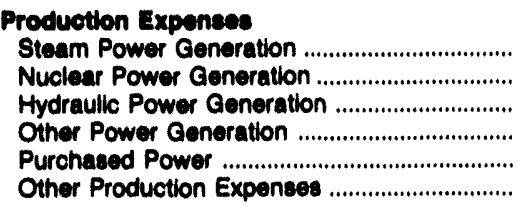 & $\begin{array}{r}110,935 \\
325,070 \\
52,457 \\
0 \\
173,052 \\
0\end{array}$ & $\begin{array}{r}0 \\
0 \\
0 \\
3,863 \\
2,744 \\
0\end{array}$ & $\begin{array}{r}0 \\
0 \\
0 \\
0 \\
12,856 \\
0\end{array}$ & $\begin{array}{r}0 \\
0 \\
0 \\
0 \\
18,939 \\
0\end{array}$ & $\begin{array}{r}0 \\
0 \\
0 \\
0 \\
14,499 \\
0\end{array}$ & $\begin{array}{r}0 \\
0 \\
0 \\
12,008 \\
63,078 \\
3\end{array}$ \\
\hline Total Produotion Expenese ......................... & 681,814 & 6,807 & 12,888 & 18,930 & 14,490 & 75,089 \\
\hline 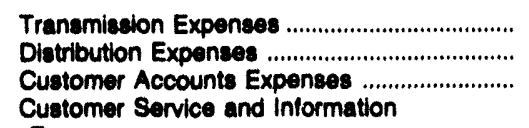 & $\begin{array}{r}279,303 \\
0 \\
0\end{array}$ & $\begin{array}{l}115 \\
498 \\
227\end{array}$ & $\begin{array}{r}0 \\
675 \\
0\end{array}$ & $\begin{array}{r}0 \\
3,256 \\
0\end{array}$ & $\begin{array}{r}0 \\
1,686 \\
0\end{array}$ & $\begin{array}{r}180 \\
4,360 \\
1,402\end{array}$ \\
\hline 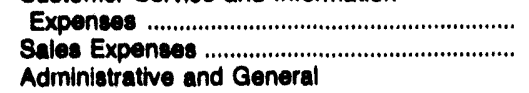 & $\begin{array}{l}0 \\
0\end{array}$ & $\begin{array}{l}0 \\
0\end{array}$ & $\begin{array}{l}0 \\
0\end{array}$ & $\begin{array}{l}0 \\
0\end{array}$ & $\begin{array}{r}182 \\
0\end{array}$ & $\begin{array}{r}131 \\
0\end{array}$ \\
\hline 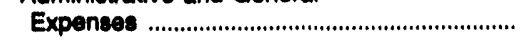 & 170,229 & 787 & 474 & 856 & 50 & 3,262 \\
\hline $\begin{array}{l}\text { Total Eketric Operation and } \\
\text { Malntenance Expenses }\end{array}$ & $1,111,046$ & 8,235 & 14,006 & 21,161 & 16,416 & 84,426 \\
\hline \multicolumn{7}{|l|}{ Fuel Expeneev in Operation } \\
\hline 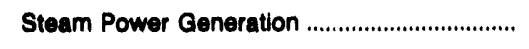 & 86,330 & 0 & 0 & 0 & 0 & 0 \\
\hline Nuclear Power Generation ................................ & 19,047 & 0 & 0 & 0 & 0 & 0 \\
\hline 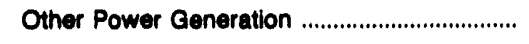 & 0 & 2,026 & 0 & 0 & 0 & 7,876 \\
\hline \multicolumn{7}{|l|}{ Number of Elec Dept Employeas } \\
\hline 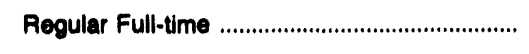 & 3,532 & 46 & 18 & 45 & 20 & 235 \\
\hline Part-time \& Temporary ........................................ & 320 & 0 & 1 & 0 & 0 & 1 \\
\hline Total Elec Dept Employees ........................... & 3,852 & 46 & 19 & 45 & 20 & 286 \\
\hline
\end{tabular}

Note: Totals may not equal sum of components because of independent rounding.

Source: Energy Information Adminiatration, Form ElA-412, "Annual Report of Public Electric Utilities." 
Table 23. Electric Operation and Maintenance Expenses by Major U.S. Publlcly Owned Electric Utillty Within State, 1992 (Continued) (Thousand Dollars)

\begin{tabular}{c|c|c|c|c|c|c|c}
\hline Item & North Carolina & $\begin{array}{c}\text { North Carolina } \\
\text { Greenville } \\
\text { Utilities } \\
\text { Comm }\end{array}$ & $\begin{array}{c}\text { North Carolina } \\
\text { High } \\
\text { Point } \\
\text { Town } \\
\text { of } \\
\text { Gastonia } \\
\text { Clty of }\end{array}$ & $\begin{array}{c}\text { Kinaton } \\
\text { City of }\end{array}$ & $\begin{array}{c}\text { Lexington } \\
\text { City of }\end{array}$ & $\begin{array}{c}\text { Lumberton } \\
\text { City of }\end{array}$ \\
June 30 & June 30 & June 30 & June 30 & June 30 \\
\hline
\end{tabular}

\section{Production Expences}

Steam Power Generation

Nuclear Power Generation

Hydraulic Power Generation

Other Power Generation

Purchased Power

Other Production Expenses

Total Production Expenses

Tranamiseion Expenses

Distribution Expenses

Customer Accounts Expenses

Customer Service and Information

Expenses

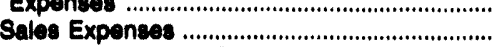

Administrative and General

Expenses

Total Electrle Operation and

Maintenance Expenses

0
0
0
0
28,139
0

0

0
0
0

0
0,808

28,139

0
1,181
0

es,en

89

89
2,278

622

400

113

3,678

1,133

20,462

70,140

0
0
0
0
26,862
0

0
0
0
0
22,483
0

0
0
0
0
17,524
0

40,097

20,062

22,493

17,624

3,291

806

0
2,559
0

108

537

687

158

515

0

535

46,072

10,893

\section{Full Exponese in Operation}

Steam Power Generation

Nuclear Power Generation

0

Other Power Generation

0
0

0

0

37

0

37

115
2

117

103
5

108

$\begin{array}{lll}0 & 0 & 0 \\ 0 & 0 & 0 \\ 0 & 0 & 0\end{array}$

Note: Totals may not equal sum of components because of independent rounding.

Source: Energy Information Administration, Form EIA-412, "Annual Report of Public Electric Utilities." 
Table 23. Electric Operation and Maintenance Expenses by Major U.S. Publicly Owned Electric UtIlity Within State, 1992 (Continued) (Thousand Dollars)

\begin{tabular}{|c|c|c|c|c|c|c|}
\hline Item & $\begin{array}{c}\text { North Carolina } \\
\text { Monroe } \\
\text { Clity of } \\
\text { June } 30\end{array}$ & $\begin{array}{l}\text { North Carolina } \\
\begin{array}{c}\text { Morganton } \\
\text { Clty of }\end{array} \\
\text { June } 30\end{array}$ & $\begin{array}{l}\text { North Carolina } \\
\text { Murphy } \\
\text { City of } \\
\text { June } 30\end{array}$ & $\begin{array}{l}\text { North Carolina } \\
\text { New Bern } \\
\text { Clty of } \\
\text { June } 30\end{array}$ & $\begin{array}{c}\text { North Carolina } \\
\text { New Aiver } \\
\text { Light } \\
\text { Power Co } \\
\text { December } 31\end{array}$ & $\begin{array}{c}\text { North Carolina } \\
\text { North } \\
\text { Carolina } \\
\text { Eastern M P A } \\
\text { December } 31\end{array}$ \\
\hline 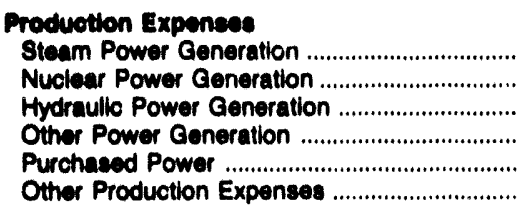 & $\begin{array}{r}0 \\
0 \\
0 \\
0 \\
19,301 \\
0\end{array}$ & $\begin{array}{r}0 \\
0 \\
0 \\
0 \\
12,136 \\
0\end{array}$ & $\begin{array}{r}0 \\
0 \\
0 \\
0 \\
6,770 \\
0\end{array}$ & $\begin{array}{r}0 \\
0 \\
0 \\
0 \\
23,786 \\
105\end{array}$ & $\begin{array}{r}0 \\
0 \\
0 \\
0 \\
8,378 \\
0\end{array}$ & $\begin{array}{r}25,791 \\
58,434 \\
0 \\
0 \\
144,465 \\
4,304\end{array}$ \\
\hline Total Production Expenses .......................... & 19,301 & 12,130 & 6,770 & 23,891 & 8,378 & 232,994 \\
\hline 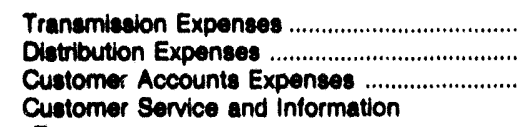 & $\begin{array}{r}0 \\
742 \\
137\end{array}$ & $\begin{array}{l}0 \\
0 \\
0\end{array}$ & $\begin{array}{r}0 \\
300 \\
64\end{array}$ & $\begin{array}{r}0 \\
746 \\
100\end{array}$ & $\begin{array}{r}0 \\
386 \\
297\end{array}$ & $\begin{array}{r}17,274 \\
2,260 \\
0\end{array}$ \\
\hline 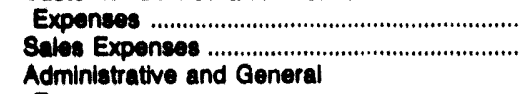 & 0 & $\begin{array}{l}0 \\
0\end{array}$ & $\begin{array}{l}7 \\
0\end{array}$ & $\begin{array}{l}0 \\
0\end{array}$ & $\begin{array}{r}21 \\
378\end{array}$ & $\begin{array}{l}0 \\
0\end{array}$ \\
\hline 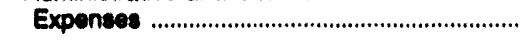 & 85 & 1,658 & 342 & 1,808 & 308 & 32,364 \\
\hline $\begin{array}{l}\text { Total Ebetrie Operation and } \\
\text { Maintenance Expenese }\end{array}$ & 20,284 & 13,795 & 7,403 & 20,843 & 9,768 & 284,912 \\
\hline \multicolumn{7}{|l|}{ Fuel Expenese in Operation } \\
\hline Steam Power Generation ................................... & 0 & 0 & 0 & 0 & 0 & 23,434 \\
\hline Nuclear Power Generation .................................. & 0 & 0 & 0 & 0 & 0 & 7,515 \\
\hline Other Power Generation ................................... & 0 & 0 & 0 & 0 & 0 & 0 \\
\hline \multicolumn{7}{|l|}{ Number of Eveo Dept Employees } \\
\hline Regular Full-time .............................................. & 9 & 21 & 12 & 60 & 28 & 0 \\
\hline 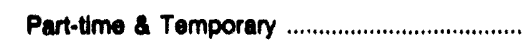 & 0 & 0 & 0 & 1 & 1 & 0 \\
\hline Total Elec Dopt Employees ........................... & 0 & 21 & 12 & 81 & 20 & 0 \\
\hline
\end{tabular}

Note: Totals may not equal sum of components because of independent rounding.

Source: Energy information Adminiatration, Form EIA-412, "Annual Report of Public Electric Utilties." 
Table 23. Electric Operation and Maintenance Expenses by Major U.S. Publicly Owned Electric Utillty Within State, 1992 (Continued) (Thousand Dollars)

\begin{tabular}{|c|c|c|c|c|c|c|}
\hline Item & $\begin{array}{c}\text { North Carolina } \\
\text { North } \\
\text { Carolina } \\
\text { Mun } \\
\text { Power Agny } \\
\text { December } 31\end{array}$ & $\begin{array}{l}\text { North Carolina } \\
\text { Rocky Mount } \\
\text { City of } \\
\text { June } 30\end{array}$ & $\begin{array}{l}\text { North Carolina } \\
\text { Shelby } \\
\text { Clty of } \\
\text { June } 30\end{array}$ & $\begin{array}{l}\text { North Carolina } \\
\text { Statesville } \\
\text { City of } \\
\text { June } 30\end{array}$ & $\begin{array}{c}\text { North Carolina } \\
\text { Tarboro } \\
\text { Town of } \\
\text { June } 30\end{array}$ & $\begin{array}{c}\text { North Carolina } \\
\text { Washington } \\
\text { City of } \\
\text { June } 30\end{array}$ \\
\hline 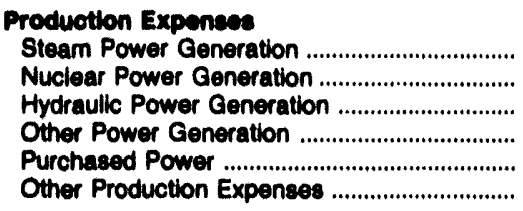 & $\begin{array}{r}0 \\
94,778 \\
0 \\
0 \\
125,058 \\
11,698\end{array}$ & $\begin{array}{r}0 \\
0 \\
0 \\
0 \\
48,568 \\
0\end{array}$ & $\begin{array}{r}0 \\
0 \\
0 \\
0 \\
7,779 \\
0\end{array}$ & $\begin{array}{r}0 \\
0 \\
0 \\
0 \\
17,171 \\
0\end{array}$ & $\begin{array}{r}0 \\
0 \\
0 \\
0 \\
15,748 \\
0\end{array}$ & $\begin{array}{r}0 \\
0 \\
0 \\
0 \\
15,378 \\
0\end{array}$ \\
\hline Total Production Expenses ......................... & 281,694 & 49,648 & 7,779 & 17,171 & 15,748 & 16,378 \\
\hline 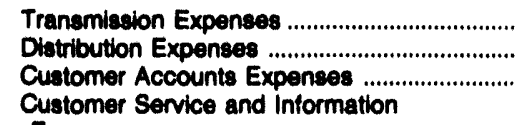 & $\begin{array}{r}9,469 \\
2,180 \\
0\end{array}$ & $\begin{array}{r}0 \\
3,391 \\
0\end{array}$ & $\begin{array}{r}0 \\
892 \\
0\end{array}$ & $\begin{array}{l}0 \\
0 \\
0\end{array}$ & $\begin{array}{l}0 \\
0 \\
0\end{array}$ & $\begin{array}{r}0 \\
1,379 \\
0\end{array}$ \\
\hline 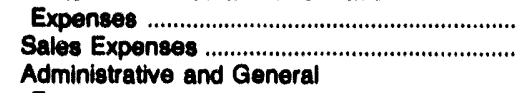 & $\begin{array}{l}0 \\
0\end{array}$ & $\begin{array}{l}0 \\
0\end{array}$ & $\begin{array}{l}0 \\
0\end{array}$ & $\begin{array}{l}0 \\
0\end{array}$ & $\begin{array}{l}0 \\
0\end{array}$ & $\begin{array}{l}0 \\
0\end{array}$ \\
\hline 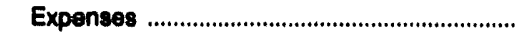 & 22,978 & 682 & 495 & 1,848 & 1,231 & 1,162 \\
\hline $\begin{array}{l}\text { Total Electric Operation and } \\
\text { Malntenance Exponese }\end{array}$ & 289,181 & 62,841 & 9,167 & 19,019 & 16,979 & 17,020 \\
\hline \multicolumn{7}{|l|}{ Fuel Expensese in Operation } \\
\hline Steam Power Generation .................................... & 0 & 0 & 0 & 0 & 0 & 0 \\
\hline Nuclear Power Generation ................................. & 32,972 & 0 & 0 & 0 & 0 & 0 \\
\hline Other Power Generation ................................. & 0 & 0 & 0 & 0 & 0 & 0 \\
\hline \multicolumn{7}{|l|}{ Number of Elec Dept Employees } \\
\hline 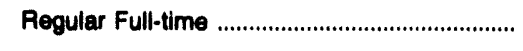 & 0 & 49 & 18 & 25 & 18 & 34 \\
\hline 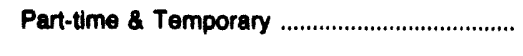 & 0 & 0 & 0 & 0 & 1 & 0 \\
\hline 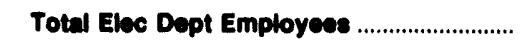 & 0 & 49 & 18 & 25 & 19 & 34 \\
\hline
\end{tabular}

Note: Totals may not equal sum of components because of independent rounding.

Source: Energy Information Administration, Form EIA-412, "Annual Report of Public Electric Utilities." 
Table 23. Electric Operation and Maintenance Expenses by Major U.S. Publicly Owned Electric Utility Within State, 1992 (Continued) (Thousand Dollars)

\begin{tabular}{|c|c|c|c|c|c|c|}
\hline Item & $\begin{array}{l}\text { North Carolina } \\
\text { Wilson } \\
\text { City of } \\
\text { June } 30\end{array}$ & $\begin{array}{c}\text { Ohio } \\
\text { American } \\
\text { Mun } \\
\text { Power } \\
\text { Ohio Inc } \\
\text { December } 31\end{array}$ & $\begin{array}{l}\text { Ohio } \\
\text { Bowling } \\
\text { Green } \\
\text { City of } \\
\text { December } 31\end{array}$ & $\begin{array}{c}\text { Onio } \\
\text { Bryan } \\
\text { City of } \\
\text { December } 31\end{array}$ & $\begin{array}{l}\text { Ohio } \\
\text { Celina } \\
\text { City of } \\
\text { December } 31\end{array}$ & $\begin{array}{c}\text { Onio } \\
\text { Cleveland } \\
\text { City of } \\
\text { December } 31\end{array}$ \\
\hline 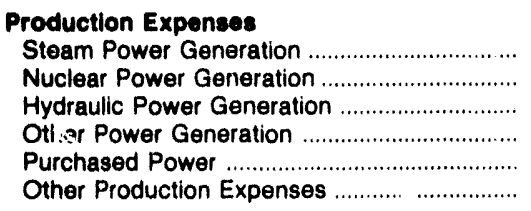 & $\begin{array}{r}0 \\
0 \\
0 \\
0 \\
60,522 \\
0\end{array}$ & $\begin{array}{r}20,514 \\
0 \\
0 \\
24 \\
96,777 \\
0\end{array}$ & $\begin{array}{r}0 \\
0 \\
0 \\
0 \\
10,831 \\
0\end{array}$ & $\begin{array}{r}0 \\
0 \\
0 \\
250 \\
6,112 \\
52\end{array}$ & $\begin{array}{r}0 \\
0 \\
0 \\
0 \\
5,749 \\
75\end{array}$ & $\begin{array}{r}291 \\
0 \\
0 \\
498 \\
28,449 \\
0\end{array}$ \\
\hline Total Production Expenses & 60,522 & 117,315 & 10,831 & 6,413 & 5,824 & 29,238 \\
\hline 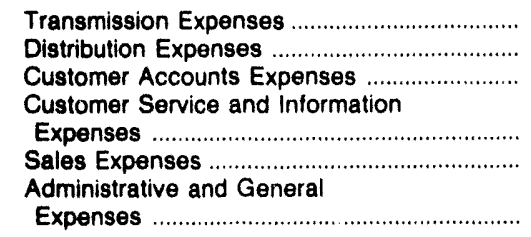 & $\begin{array}{r}0 \\
2,467 \\
1,785 \\
0 \\
74 \\
1,398\end{array}$ & $\begin{array}{r}0 \\
528 \\
0 \\
0 \\
0\end{array}$ & $\begin{array}{r}215 \\
1,079 \\
330 \\
0 \\
50\end{array}$ & $\begin{array}{r}0 \\
684 \\
0 \\
0 \\
0\end{array}$ & $\begin{array}{r}0 \\
647 \\
151 \\
0 \\
67 \\
157\end{array}$ & $\begin{array}{r}545 \\
13,418 \\
1,543 \\
269 \\
2\end{array}$ \\
\hline $\begin{array}{l}\text { Total Eiectric Operation and } \\
\text { Malntenance Expenses }\end{array}$ & 66,246 & 121,884 & 13,156 & 9,607 & 6,847 & 48,230 \\
\hline
\end{tabular}

\section{Fuel Expenses in Operation}

Steam Power Generation

0

11,190

0

0

0

Nuclear Power Generation

0

0

0

0

0

Other Power Generation

0

24

0

60

289

Number of Elec Dept Employees

Regular Full-time

83

116
0

31

31

286

Part-time \& Temporary .

0

116

3

1

2

Total Elec Dept Employees

83

34

32

288

Note: Totals may not equal sum of components because of independent rounding.

Source: Energy Information Administration, Form ElA-412, "Annual Peport of Public Electric Utilities." 
Table 23. Electric Operation and Maintenance Expenses by Major U.S. Publicly Owned Electric Utility Within State, 1992 (Continued) (Thousand Dollars)

\begin{tabular}{|c|c|c|c|c|c|c|}
\hline Item & $\begin{array}{c}\text { Ohio } \\
\text { Columbus } \\
\text { City of } \\
\text { December } 31\end{array}$ & $\begin{array}{c}\text { Ohio } \\
\text { Cuyahoga } \\
\text { Falls } \\
\text { City of } \\
\text { December } 31\end{array}$ & $\begin{array}{c}\text { Ohio } \\
\text { Dover } \\
\text { City of } \\
\text { December } 31\end{array}$ & $\begin{array}{c}\text { Ohio } \\
\begin{array}{c}\text { Hamilton } \\
\text { City of }\end{array} \\
\text { December } 31\end{array}$ & $\begin{array}{c}\text { Ohio } \\
\text { Niles } \\
\text { City of } \\
\text { December } 31\end{array}$ & $\begin{array}{c}\text { Ohio } \\
\text { Orrville } \\
\text { City of } \\
\text { December } 31\end{array}$ \\
\hline 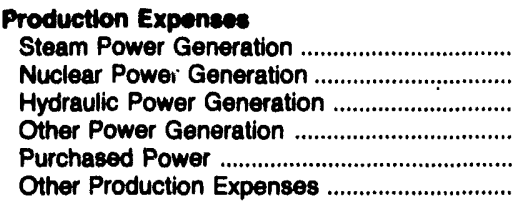 & $\begin{array}{r}2,475 \\
0 \\
161 \\
19,921 \\
9,374 \\
0\end{array}$ & $\begin{array}{r}0 \\
0 \\
0 \\
0 \\
11,818 \\
0\end{array}$ & $\begin{array}{r}0 \\
0 \\
0 \\
0 \\
3,535 \\
0\end{array}$ & $\begin{array}{r}8,550 \\
0 \\
762 \\
172 \\
5,252 \\
663\end{array}$ & $\begin{array}{r}0 \\
0 \\
0 \\
0 \\
9,778 \\
2,553\end{array}$ & $\begin{array}{r}7,783 \\
0 \\
0 \\
0 \\
2,113 \\
0\end{array}$ \\
\hline Total Production Expenses ........................... & 31,932 & 11,818 & 3,535 & 15,399 & 12,331 & 9,895 \\
\hline 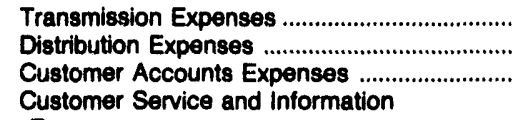 & $\begin{array}{r}4 \\
6,747 \\
347\end{array}$ & $\begin{array}{r}0 \\
1,966 \\
419\end{array}$ & $\begin{array}{r}0 \\
2,553 \\
0\end{array}$ & $\begin{array}{r}443 \\
1,291 \\
379\end{array}$ & $\begin{array}{r}0 \\
513 \\
0\end{array}$ & $\begin{array}{r}0 \\
772 \\
0\end{array}$ \\
\hline 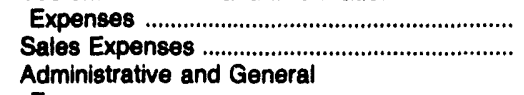 & $\begin{array}{r}439 \\
0\end{array}$ & $\begin{array}{l}0 \\
0\end{array}$ & $\begin{array}{l}0 \\
0\end{array}$ & $\begin{array}{l}0 \\
0\end{array}$ & $\begin{array}{l}0 \\
0\end{array}$ & $\begin{array}{l}0 \\
0\end{array}$ \\
\hline 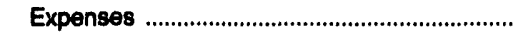 & 2,950 & 2,112 & 1,524 & 3,655 & 107 & 2,701 \\
\hline $\begin{array}{l}\text { Total Electric Operation and } \\
\text { Malntenance Expenses ............................... }\end{array}$ & 42,419 & 16,315 & 7,612 & 21,167 & 12,951 & 13,368 \\
\hline \multicolumn{7}{|l|}{ Fuel Expences in Operation } \\
\hline Steam Power Generation ..................................... & 78 & 0 & 0 & 5,104 & 0 & 4,575 \\
\hline Nuclear Power Generation ................................ & 0 & 0 & 0 & 0 & 0 & 0 \\
\hline Other Power Generation ...................................... & 985 & 0 & 0 & 20 & 0 & 0 \\
\hline \multicolumn{7}{|l|}{ Numbar of Elec Dept Employees } \\
\hline Regular Full-time & 415 & 43 & 39 & 103 & 41 & 60 \\
\hline Part-time \& Temporary ........................................... & 3 & 1 & 0 & 0 & 2 & 0 \\
\hline Total Elec Dept Employees ............................. & 418 & 44 & 39 & 103 & 43 & 60 \\
\hline
\end{tabular}

Note: Totals may not equal sum of components because of independent rounding.

Source: Energy Information Administration, Form ElA-412, "Annual Report of Public Electric Utilities." 
Table 23. Electric Operation and Maintenance Expenses by Major U.S. Publicly Owned Electric Utility Within State, 1992 (Continued) (Thousand Dollars)

\begin{tabular}{|c|c|c|c|c|c|c|}
\hline . & Ohio & Ohio & Ohio & Ohio & Ohio & Ohio \\
\hline \multirow[t]{2}{*}{ Item } & $\begin{array}{c}\text { Painesville } \\
\text { City of }\end{array}$ & $\begin{array}{l}\text { Piqua } \\
\text { City of }\end{array}$ & $\begin{array}{l}\text { St Marys } \\
\text { City of }\end{array}$ & $\begin{array}{l}\text { Wadsworth } \\
\text { City of }\end{array}$ & $\begin{array}{l}\text { Wapakoneta } \\
\text { City of }\end{array}$ & $\begin{array}{c}\text { Westerville } \\
\text { City of }\end{array}$ \\
\hline & December 31 & December 31 & December 31 & December 31 & December 31 & December 31 \\
\hline
\end{tabular}

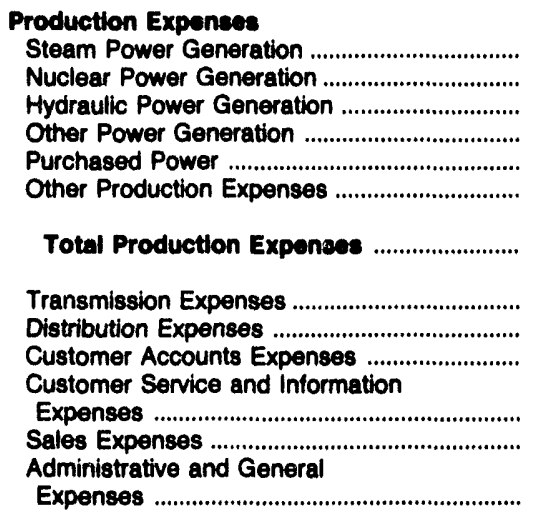

Total Electric Operation and Malntenance Expenses

\section{Fuel Expenses in Operation}

Steam Power Generation

Nuclear Power Generation

Other Power Generation

Number of Elec Dept Employees

Regular Full-time

Part-time \& Temporany

Total Elec Dept Employees

2,605
0
0
0
1,884
0

5,184

0
0
0
131

4,131
0

4,480

0
6,202
0

0,314

41

690

251

10

100

1,088

11,484

10,001
0
0
0
0
7,462
0

4,807

13

685

154$$
0
$$

30

9,929

T,462

3.

1,454
197

0

816

816

0

0
0
0
0
4,696
0

0
0
0
0
9,789
0

4,696

9,789

0
1.079

1,079
75

20

2,449
0

0

105

78

5,928

12,343

Note: Totals may not equal sum of components because of independent rounding

Source: Energy Information Administration, Form EIA-412, "Annual Report of Public Electric Utilities." 
Table 23. Electric Operation and Maintenance Expenses by Major U.S. Publicly Owned Electric Utility Within State, 1992 (Continued)

(Thousand Dollars)

\begin{tabular}{|c|c|c|c|c|c|c|}
\hline Item & $\begin{array}{l}\text { Oklahoma } \\
\text { Altus } \\
\text { City of } \\
\text { June } 30\end{array}$ & $\begin{array}{l}\text { Oklahoma } \\
\text { Claremore } \\
\text { City of } \\
\text { June } 30\end{array}$ & $\begin{array}{l}\text { Oklahoma } \\
\text { Duncan } \\
\text { City of } \\
\text { June } 30\end{array}$ & $\begin{array}{l}\text { Oklahoma } \\
\text { Edmond } \\
\text { City of } \\
\text { June } 30\end{array}$ & $\begin{array}{l}\text { Oklahoma } \\
\text { Grand River } \\
\text { Dam } \\
\text { Authority } \\
\text { December } 31\end{array}$ & $\begin{array}{l}\text { Oklahoma } \\
\text { Oklahoma } \\
\text { Municipal } \\
\text { Power Auth } \\
\text { December } 31\end{array}$ \\
\hline 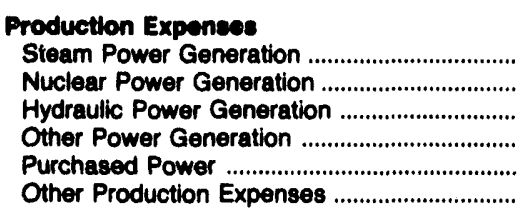 & $\begin{array}{r}0 \\
0 \\
0 \\
0 \\
5,941 \\
0\end{array}$ & $\begin{array}{r}0 \\
0 \\
0 \\
0 \\
7,884 \\
0\end{array}$ & $\begin{array}{r}0 \\
0 \\
0 \\
0 \\
4,508 \\
0\end{array}$ & $\begin{array}{r}0 \\
0 \\
0 \\
0 \\
18,731 \\
0\end{array}$ & $\begin{array}{r}52,276 \\
0 \\
4,136 \\
0 \\
2,326 \\
0\end{array}$ & $\begin{array}{r}12,952 \\
0 \\
273 \\
0 \\
23,766 \\
0\end{array}$ \\
\hline Total Production Expenees ........................... & 5,941 & 7,884 & 4,508 & 18,731 & 58,739 & 36,991 \\
\hline 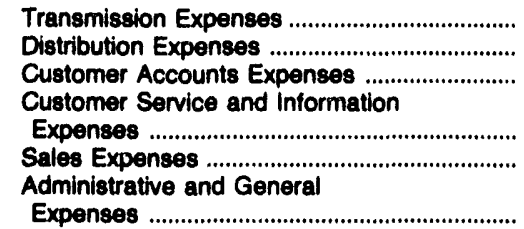 & $\begin{array}{r}0 \\
426 \\
0 \\
0 \\
0 \\
621\end{array}$ & $\begin{array}{r}0 \\
965 \\
235 \\
0 \\
0 \\
0\end{array}$ & $\begin{array}{r}1,122 \\
0 \\
0 \\
0 \\
0 \\
0\end{array}$ & $\begin{array}{r}0 \\
1,718 \\
147 \\
114 \\
0 \\
163\end{array}$ & $\begin{array}{r}5,157 \\
0 \\
133 \\
\\
101 \\
0 \\
\\
8,637\end{array}$ & $\begin{array}{r}9,089 \\
0 \\
0 \\
0 \\
0 \\
1,762\end{array}$ \\
\hline 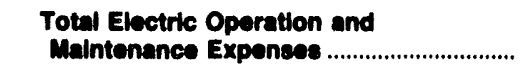 & 6,987 & 9,084 & 5,630 & 20,872 & 72,767 & 47,841 \\
\hline \multicolumn{7}{|l|}{ Fuel Expenses in Operation } \\
\hline 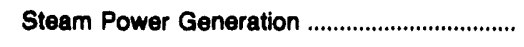 & 0 & 0 & 0 & 0 & 42,914 & 10,808 \\
\hline 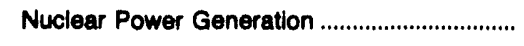 & 0 & 0 & 0 & 0 & 0 & 0 \\
\hline 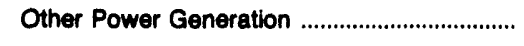 & 0 & 0 & 0 & 0 & 0 & 0 \\
\hline \multicolumn{7}{|l|}{ Number of Elec Dept Employees } \\
\hline Regular Full-time & 17 & 20 & 19 & 41 & 473 & 24 \\
\hline 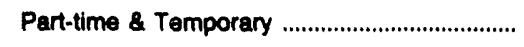 & 0 & 0 & 0 & 0 & 1 & 0 \\
\hline Total Elec Dept Employees & 17 & 20 & 19 & 41 & 474 & 24 \\
\hline
\end{tabular}

Note: Totals may not equal sum of components because of independent rounding.

Source: Energy Information Administration, Form ElA-412, "Annual Report of Public Electric Utilities." 
Table 23. Electric Operation and Maintenance Expenses by Major U.S. Publicly Owned Electric Utility Within State, 1992 (Continued) (Thousand Dollars)

\begin{tabular}{|c|c|c|c|c|c|c|}
\hline Item & $\begin{array}{c}\text { Oklahoma } \\
\text { Ponca } \\
\text { (ity City of } \\
\text { June } 30\end{array}$ & $\begin{array}{l}\text { Oklahoma } \\
\text { Stillwater } \\
\text { Utillties } \\
\text { Authority } \\
\text { June } 30\end{array}$ & $\begin{array}{l}\text { Oregon } \\
\text { Ashland } \\
\text { City of } \\
\text { June } 30\end{array}$ & $\begin{array}{c}\text { Oregon } \\
\text { Central } \\
\text { Lincoln } \\
\text { Peoples } \\
\text { Utt Dt } \\
\text { December } 31\end{array}$ & $\begin{array}{c}\text { Oregon } \\
\text { Clatskanie } \\
\text { Peoples } \\
\text { Util Dist } \\
\text { December } 31\end{array}$ & $\begin{array}{c}\text { Oregon } \\
\text { Columbla } \\
\text { River } \\
\text { Peoples } \\
\text { Ut Dist } \\
\text { December } 31\end{array}$ \\
\hline 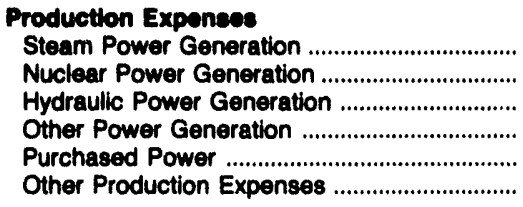 & $\begin{array}{r}1,071 \\
0 \\
0 \\
714 \\
11,280 \\
0\end{array}$ & $\begin{array}{r}177 \\
0 \\
0 \\
0 \\
11,016 \\
0\end{array}$ & $\begin{array}{r}0 \\
0 \\
0 \\
0 \\
3,926 \\
16\end{array}$ & $\begin{array}{r}0 \\
0 \\
0 \\
0 \\
31,853 \\
0\end{array}$ & $\begin{array}{r}0 \\
0 \\
0 \\
0 \\
20,165 \\
0\end{array}$ & $\begin{array}{r}0 \\
0 \\
0 \\
0 \\
6,321 \\
0\end{array}$ \\
\hline Total Production Expenses ............................ & 13,075 & 11,193 & 3,942 & 31,853 & 20,165 & 6,321 \\
\hline 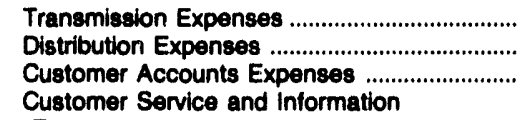 & $\begin{array}{r}0 \\
1,008 \\
0\end{array}$ & $\begin{array}{r}183 \\
1,466 \\
15\end{array}$ & $\begin{array}{r}0 \\
549 \\
0\end{array}$ & $\begin{array}{r}0 \\
2,813 \\
987\end{array}$ & $\begin{array}{r}0 \\
436 \\
177\end{array}$ & $\begin{array}{r}0 \\
905 \\
390\end{array}$ \\
\hline 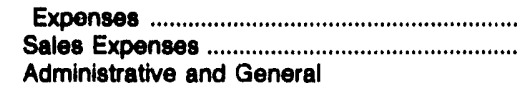 & $\begin{array}{r}118 \\
0\end{array}$ & $\begin{array}{r}245 \\
56\end{array}$ & $\begin{array}{r}470 \\
0\end{array}$ & $\begin{array}{r}308 \\
0\end{array}$ & $\begin{array}{r}30 \\
0\end{array}$ & $\begin{array}{l}359 \\
116\end{array}$ \\
\hline 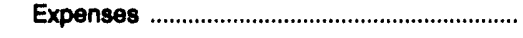 & 0 & 1,104 & 907 & 2,370 & 792 & 985 \\
\hline $\begin{array}{l}\text { Total Electric Operation and } \\
\text { Maintenance Expenses }\end{array}$ & 14,201 & 14,281 & 5,869 & 38,331 & 21,599 & 9,076 \\
\hline
\end{tabular}

\section{Fuel Expenees in Operation}

Steam Power Generation

Nuclear Power Generation

Other Power Generation

\section{Number of Elec Dept Employees}

\begin{tabular}{|c|c|c|c|c|c|c|}
\hline 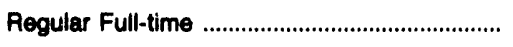 & 49 & 62 & 20 & 143 & 20 & 34 \\
\hline 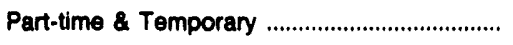 & 0 & 9 & 0 & 10 & 0 & 6 \\
\hline Total Elec Dept Employees & 40 & 71 & 20 & 153 & 20 & 40 \\
\hline
\end{tabular}

Note: Totals may not equal sum of components because of independent rounding.

Source: Energy Information Administration, Form EIA-412, "Annual Report of Public Electric Utilities." 
Table 23. Electric Operation and Maintenance Expenses by Major U.S. Publlcly Owned Electric Utillty Within State, 1992 (Continued) (Thousand Dollars)

\begin{tabular}{|c|c|c|c|c|c|c|}
\hline Item & $\begin{array}{l}\text { Oregon } \\
\text { Emerald } \\
\text { Peoples } \\
\text { Utility Dist } \\
\text { December } 31\end{array}$ & $\begin{array}{l}\text { Oregon } \\
\text { Eugene } \\
\text { City of } \\
\text { December } 31\end{array}$ & $\begin{array}{c}\text { Oregon } \\
\begin{array}{c}\text { Forest Grove } \\
\text { Clty of }\end{array} \\
\text { June } 30\end{array}$ & $\begin{array}{l}\text { Oregon } \\
\text { McMinnville } \\
\text { City of } \\
\text { June } 30\end{array}$ & $\begin{array}{c}\text { Oregon } \\
\text { Northern } \\
\text { Wasco County } \\
\text { P U D } \\
\text { December } 31\end{array}$ & $\begin{array}{l}\text { Oregon } \\
\begin{array}{c}\text { Springfleld } \\
\text { City of }\end{array} \\
\text { December } 31\end{array}$ \\
\hline 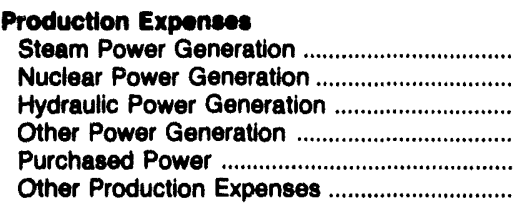 & $\begin{array}{r}0 \\
0 \\
0 \\
192 \\
8,708 \\
0\end{array}$ & $\begin{array}{r}5,596 \\
0 \\
1,863 \\
0 \\
0 \\
43,258 \\
1,385\end{array}$ & $\begin{array}{r}0 \\
0 \\
0 \\
0 \\
3,896 \\
0\end{array}$ & $\begin{array}{r}0 \\
0 \\
0 \\
0 \\
12,118 \\
0\end{array}$ & $\begin{array}{r}0 \\
0 \\
162 \\
0 \\
5,977 \\
0\end{array}$ & $\begin{array}{r}0 \\
0 \\
0 \\
0 \\
18,645 \\
0\end{array}$ \\
\hline Total Production Expenes & 8,900 & 52,102 & 3,896 & 12,118 & 6,139 & 18,646 \\
\hline 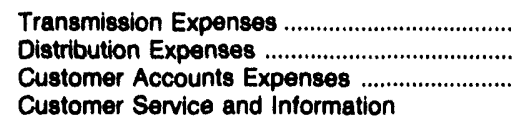 & $\begin{array}{r}0 \\
794 \\
554\end{array}$ & $\begin{array}{l}1,509 \\
6,431 \\
2,786\end{array}$ & $\begin{array}{r}0 \\
288 \\
67\end{array}$ & $\begin{array}{r}0 \\
780 \\
114\end{array}$ & $\begin{array}{r}88 \\
626 \\
192\end{array}$ & $\begin{array}{r}8 \\
1,289 \\
780\end{array}$ \\
\hline 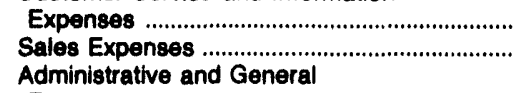 & $\begin{array}{r}223 \\
0\end{array}$ & $\begin{array}{r}2,444 \\
0\end{array}$ & $\begin{array}{l}0 \\
0\end{array}$ & $\begin{array}{l}0 \\
0\end{array}$ & $\begin{array}{r}109 \\
0\end{array}$ & $\begin{array}{r}987 \\
0\end{array}$ \\
\hline 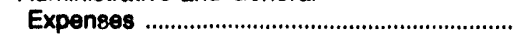 & 639 & 9,562 & 1,003 & 604 & 803 & 385 \\
\hline $\begin{array}{l}\text { Total Electric Operation and } \\
\text { Malntenance Expenses }\end{array}$ & 11,110 & $\mathbf{7 4 , 8 3 3}$ & 5,254 & 13,616 & 7,956 & 22,073 \\
\hline
\end{tabular}

Fuel Expenses in Operation

Steam Power Generation

Nuclear Power Generation

Other Power Generation

$\begin{array}{rr}0 & 2,671 \\ 0 & 0 \\ 155 & 0\end{array}$

409

11
$62 \quad 420$
23

0

23

0

0

0

Total Elec Dept Employees

ts because of independent rounding.

Note: Totals may not equal sum of components because of independent rounding.

Source: Energy Information Administration, Form ElA-412, "Annual Report of Public Electric Utilities." 
Table 23. Electric Operation and Maintenance Expenses by Major U.S. Publicly Owned Electric Utility Within State, 1992 (Continued) (Thousand Dollars)

\begin{tabular}{|c|c|c|c|c|c|c|}
\hline Item & $\begin{array}{l}\text { Oregon } \\
\text { Tillamook } \\
\text { Peoples } \\
\text { Utility Dist } \\
\text { December } 31\end{array}$ & $\begin{array}{l}\text { Pennsytvania } \\
\text { Chambersburg } \\
\text { Borough of } \\
\text { December } 31\end{array}$ & $\begin{array}{l}\text { South Carolina } \\
\text { Camden } \\
\text { City of } \\
\text { June } 30\end{array}$ & $\begin{array}{l}\text { South Carolina } \\
\text { Easley } \\
\text { Combined } \\
\text { Utility } \\
\text { System } \\
\text { March } 31\end{array}$ & $\begin{array}{l}\text { South Carolina } \\
\text { Gaffney } \\
\text { City of } \\
\text { March } 31\end{array}$ & $\begin{array}{l}\text { South Carolina } \\
\text { Greenwood } \\
\text { Commissioners } \\
\text { Pub Wk } \\
\text { December } 31\end{array}$ \\
\hline 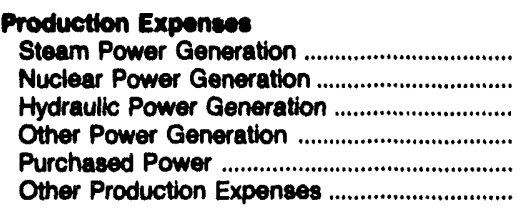 & $\begin{array}{r}0 \\
0 \\
0 \\
0 \\
8,115 \\
53\end{array}$ & $\begin{array}{r}0 \\
0 \\
0 \\
103 \\
8,063 \\
244\end{array}$ & $\begin{array}{r}0 \\
0 \\
0 \\
0 \\
8,822 \\
768\end{array}$ & $\begin{array}{r}0 \\
0 \\
0 \\
0 \\
9,880 \\
0\end{array}$ & $\begin{array}{r}0 \\
0 \\
0 \\
0 \\
8,683 \\
0\end{array}$ & $\begin{array}{r}0 \\
0 \\
0 \\
0 \\
9,755 \\
0\end{array}$ \\
\hline Total Production Expenses .......................... & 8,160 & 8,411 & 9,590 & 9,880 & 8,693 & 9,755 \\
\hline 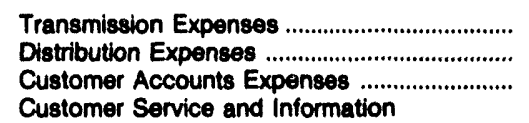 & $\begin{array}{r}0 \\
1,851 \\
380\end{array}$ & $\begin{array}{r}29 \\
375 \\
180\end{array}$ & $\begin{array}{l}0 \\
0 \\
0\end{array}$ & $\begin{array}{r}0 \\
663 \\
47\end{array}$ & $\begin{array}{r}0 \\
766 \\
0\end{array}$ & $\begin{array}{r}0 \\
1,142 \\
76\end{array}$ \\
\hline 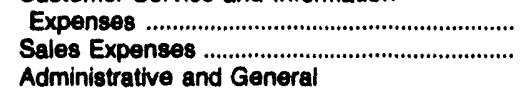 & $\begin{array}{r}133 \\
54\end{array}$ & $\begin{array}{l}0 \\
0\end{array}$ & $\begin{array}{l}0 \\
0\end{array}$ & $\begin{array}{l}0 \\
8\end{array}$ & $\begin{array}{l}0 \\
0\end{array}$ & $\begin{array}{l}0 \\
0\end{array}$ \\
\hline 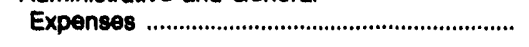 & 1,710 & 435 & 0 & 488 & 1,028 & 556 \\
\hline $\begin{array}{l}\text { Total Electric Operation and } \\
\text { Maintenance Expenses }\end{array}$ & 12,205 & 9,439 & $9,5 \bullet 0$ & 11,008 & 10,477 & 11,529 \\
\hline \multicolumn{7}{|l|}{ Fual Expenese in Operation } \\
\hline 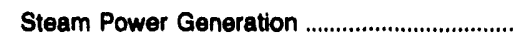 & 0 & 0 & 0 & 0 & 0 & 0 \\
\hline Nuclear Power Generation ............................... & 0 & 0 & 0 & 0 & 0 & 0 \\
\hline Other Power Generation ..................................... & 0 & 63 & 0 & 0 & 0 & 0 \\
\hline \multicolumn{7}{|l|}{ Number of Elec Dopt Employees } \\
\hline 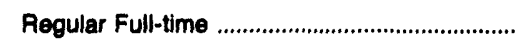 & 66 & 28 & 18 & 19 & 19 & 18 \\
\hline 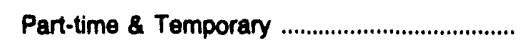 & 17 & 0 & 2 & 0 & 1 & 0 \\
\hline Total Elec Dept Employees ............................. & 83 & 28 & 20 & 19 & 20 & 10 \\
\hline
\end{tabular}

Note: Totals may not equal sum of components because of independent rounding.

Source: Energy Information Administration, Form EIA-412, "Annual Report of Public Electric Utilities." 


\section{Table 23. Electric Operation and Maintenance Expenses by Major U.S. Publicly Owned Electric Utility Within State, 1992 (Continued) (Thousand Dollars)}

\begin{tabular}{|c|c|c|c|c|c|c|}
\hline Item & $\begin{array}{c}\text { South Carolina } \\
\text { Greer } \\
\text { Comm } \\
\text { of } \\
\text { Public Works } \\
\text { December } 31\end{array}$ & $\begin{array}{l}\text { South Carolina } \\
\text { Newberry } \\
\text { City of } \\
\text { June } 30\end{array}$ & $\begin{array}{c}\text { South Carolina } \\
\text { Orangeburg } \\
\text { City of }\end{array}$ & $\begin{array}{l}\text { South Carolina } \\
\text { Piedmont } \\
\text { Municipal } \\
\text { Power Agny } \\
\text { December } 31\end{array}$ & $\begin{array}{l}\text { South Carolina } \\
\text { Rock Hill } \\
\text { City of } \\
\text { December } 31\end{array}$ & $\begin{array}{c}\text { South Carolina } \\
\text { South } \\
\text { Carolina } \\
\text { Pub } \\
\text { Serv Auth } \\
\text { December } 31\end{array}$ \\
\hline
\end{tabular}

Production Exponses

Steam Power Generation

Nuclear Power Generation

Hydraulic Power Generation

Other Power Generation

Purchased Power

Other Production Expenses

Totel Production Expenese

Transmission Expenses

Distribution Expenses

Customer Accounts E

Customer Service and Information

Expenses .......

Sales Expenses

Administrative and General

Expenses

Total Electric Operation and

Malntenance Expenses

0
0
0
0
7,134
0

0
0
0
0
6,971

7,134

663

220

0

0

121

8,137
0
0
0
474
24,813
0

25,286

0
373

373
62

0

171

163

7,740
0
44,969

$$
\begin{array}{r}
0 \\
49,777
\end{array}
$$

0

04,746

4,747

46
0

0

2,130

2,130

101,669

$\begin{array}{rr}0 & 210,562 \\ 0 & 41,431 \\ 0 & 4,843 \\ 0 & 843 \\ 23,467 & 10,425 \\ 0 & 507\end{array}$

23,467

268,611

$\begin{array}{rr}0 & 9,450 \\ 1,888 & 6,646 \\ 0 & 3,050 \\ & \\ 0 & 869 \\ 0 & 1,296 \\ 1,044 & 42,096\end{array}$

26,398

332,018

\section{Fuel Expenses in Operation}

Steam Power Generation

\section{0}

Nuclear Power Generation

Other Power Generation

Number of Elec Dept Employees

Regular Full-time

Part-time \& Temporary

Total Elec Dept Employees
0

0

92

2

84

0

$$
0
$$$$
0
$$

0

11

0

11

0
0

209

9,110

37

0

37

9

2

Note: Totals may not equal sum of components because of independent rounding.

Source: Energy Information Administration, Form EIA-412, "Annual Report of Public Electric Utilities." 
Table 23. Electric Operation and Maintenance Expenses by Major U.S. Publicly Owned Electric Utillty Within State, 1992 (Continued) (Thousand Dollars)

\begin{tabular}{|c|c|c|c|c|c|c|}
\hline Item & $\begin{array}{c}\text { South Dakota } \\
\text { Brookings } \\
\text { City of } \\
\text { December } 31\end{array}$ & $\begin{array}{l}\text { South Dakota } \\
\text { Heartland } \\
\text { Consumers } \\
\text { Power Dist } \\
\text { December } 31\end{array}$ & $\begin{array}{l}\text { South Dakota } \\
\text { Missouri } \\
\text { Basin } \\
\text { Mun } \\
\text { Power Agny } \\
\text { December } 31\end{array}$ & $\begin{array}{c}\text { South Dakota } \\
\text { Pierre } \\
\text { City of } \\
\text { December } 31\end{array}$ & $\begin{array}{l}\text { South Dakota } \\
\text { Watertown } \\
\text { Municipal } \\
\text { Utilities } \\
\text { December } 31\end{array}$ & $\begin{array}{c}\text { Tennessee } \\
\text { Alcoa } \\
\text { Utilities } \\
\text { June } 30\end{array}$ \\
\hline
\end{tabular}

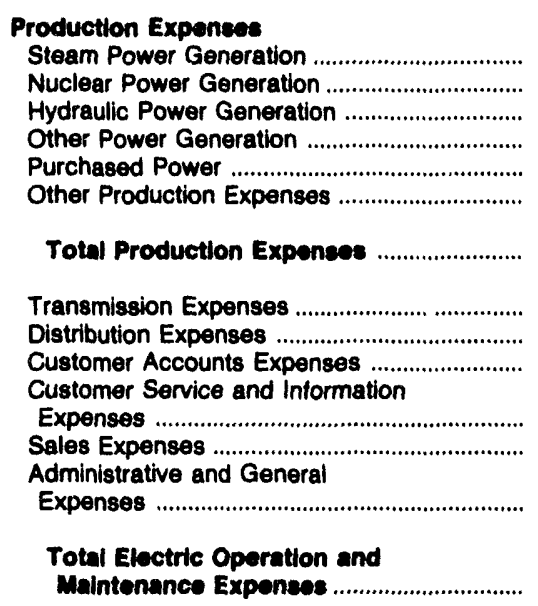

Steam Power Generation

Nuclear Power Generation

Hydraulic Power Generation

er Power Generation

Other Production Expenses...

Fuel Expenese in Operation

Steam Power Generation

Nuclear Power Generation

Other Power Generation

Number of Elec Dept Employees

Regular Full-time

Part-time \& Temporary

Total Elec Dept Employees

$\begin{array}{rr}0 & 3,682 \\ 0 & 0 \\ 0 & 0 \\ 0 & 0 \\ 3,848 & 1,067 \\ 11 & 80\end{array}$

3,059

4,820

1,426

77

712
139

0
0

423

5,210

0
0
0
0
41,231
72

41,303

10,480

0
4

0

.752

53,540

0
0
0
0
2,926
0

2,926

0
424

424
0

0
0

0

3,350

$\begin{array}{rr}0 & 0 \\ 0 & 0 \\ 0 & 0 \\ 0 & 0 \\ 4,454 & 18,519 \\ 17 & 0\end{array}$

4,471

18,519

$\begin{array}{rr}0 & 208 \\ 725 & 1,295 \\ 257 & 529\end{array}$

$\begin{array}{rr}0 & 208 \\ 725 & 1,295 \\ 257 & 529\end{array}$

$\begin{array}{rr}0 & 0 \\ 42 & \end{array}$

$243 \quad 860$

5,739

21,438

Note: Totals may not equal sum of components because of independent rounding.

Source: Energy Information Administration, Form ElA-412, "Annual Report of Public Electric Utilities." 
Table 23. Electric Operation and Maintenance Expenses by Major U.S. Publicly Owned Electric Utillty Within State, 1992 (Continued) (Thousand Dollars)

\begin{tabular}{|c|c|c|c|c|c|c|}
\hline \multirow{3}{*}{ Item } & Tennessee & Tennessee & Tennesser & Tennessee & Tennessee & Tennessee \\
\hline & $\begin{array}{l}\text { Athens } \\
\text { City of }\end{array}$ & $\begin{array}{l}\text { Benton } \\
\text { County }\end{array}$ & $\begin{array}{l}\text { Bolivar } \\
\text { City of }\end{array}$ & $\begin{array}{l}\text { Bristol } \\
\text { City of }\end{array}$ & $\begin{array}{c}\text { Brownsville } \\
\text { City of }\end{array}$ & $\begin{array}{l}\text { Carroll } \\
\text { County }\end{array}$ \\
\hline & June 30 & June 30 & June 30 & June 30 & June 30 & June 30 \\
\hline
\end{tabular}

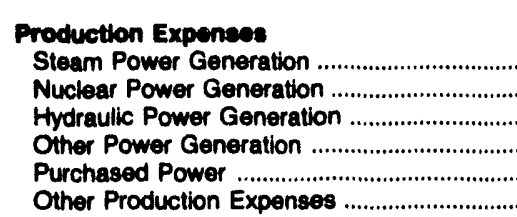

Totel Production Expenses

Transmission Expenses

Distribution Expenses

Customer Accounts Expenses .........................

Customer Senvice and Information

Expenses

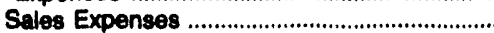

Administrative and General

Expenses

Total Electric Operation and

Malntenance Expenses.

0
0
0
0
22,104
0

22,104

52

1,120

335

9

22

555

24,107

0
0
0
0
2,595
0

0
0
0
0
10,627

10,627
0

2,505

0

83

5

0

151

3,033

10,627

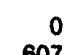

607

248

24

10

442

11,957

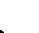

\section{(1)}

0

0
0
0
0
33,480
0

0
0
0
0
8,656
0

33,460

8,858

154
1,992

1,992
739

111

79

819

37,374

18,385

\section{Fual Expenses in Operation}

Steam Power Generation .

$\begin{array}{ll}0 & 0 \\ 0 & 0 \\ 0 & 0\end{array}$

0
0
0

0
0
0

Nuclear Power Generation .

Other Power Generation

Number of Elec Dept Employees

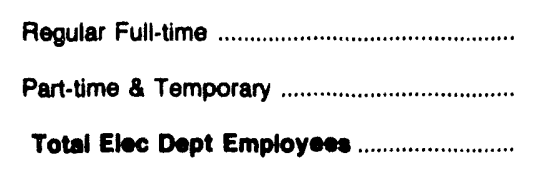

\begin{tabular}{rrrccc}
42 & 10 & 37 & 59 & 13 & 48 \\
0 & 0 & 4 & 0 & 0 & 0 \\
42 & 10 & 41 & 59 & 13 & 48 \\
\hline
\end{tabular}

Note: Totals may not equal sum of components because of independent rounding.

Source: Energy Information Administration, Form EIA-412, "Annual Report of Public Electric Utilities." 
Table 23. Electric Operation and Maintenance Expenses by Major U.S. Publlcly Owned Electric Utility Within State, 1992 (Continued) (Thousand Dollars)

\begin{tabular}{|c|c|c|c|c|c|c|}
\hline Item & $\begin{array}{c}\text { Tennessee } \\
\text { Chattanooga } \\
\text { City of } \\
\text { June } 30\end{array}$ & $\begin{array}{l}\text { Tennessee } \\
\text { Clarksville } \\
\text { City of } \\
\text { June } 30\end{array}$ & $\begin{array}{l}\text { Tennessee } \\
\text { Cleveland } \\
\text { City of } \\
\text { June } 30\end{array}$ & $\begin{array}{l}\text { Tennessee } \\
\text { Clinton } \\
\text { City of } \\
\text { June } 30\end{array}$ & $\begin{array}{c}\text { Tennessee } \\
\text { Columble } \\
\text { Clty of } \\
\text { June } 30\end{array}$ & $\begin{array}{l}\text { Tennessee } \\
\text { Cookeville } \\
\text { Clty of } \\
\text { June } 30\end{array}$ \\
\hline 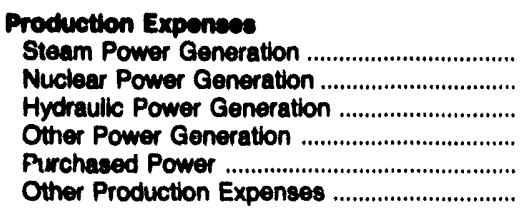 & $\begin{array}{r}0 \\
0 \\
0 \\
0 \\
230,178 \\
0\end{array}$ & $\begin{array}{r}0 \\
0 \\
0 \\
0 \\
35,454 \\
0\end{array}$ & $\begin{array}{r}0 \\
0 \\
0 \\
0 \\
37,524 \\
0\end{array}$ & $\begin{array}{r}0 \\
0 \\
0 \\
0 \\
26,494 \\
0\end{array}$ & $\begin{array}{r}0 \\
0 \\
0 \\
0 \\
22,384 \\
0\end{array}$ & $\begin{array}{r}0 \\
0 \\
0 \\
0 \\
20,595 \\
0\end{array}$ \\
\hline Totel Production Expenses ........................... & 230,178 & 36,454 & 37,524 & 26,494 & 22,384 & 20,598 \\
\hline 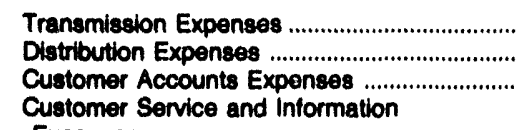 & $\begin{array}{r}1,211 \\
13,875 \\
5,156\end{array}$ & $\begin{array}{r}269 \\
1,837 \\
782\end{array}$ & $\begin{array}{r}247 \\
1,836 \\
606\end{array}$ & $\begin{array}{r}202 \\
1,604 \\
734\end{array}$ & $\begin{array}{r}0 \\
1,387 \\
347\end{array}$ & $\begin{array}{r}0 \\
1,437 \\
223\end{array}$ \\
\hline 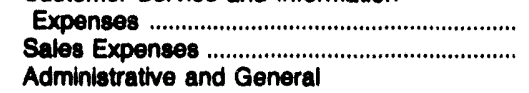 & $\begin{array}{r}0 \\
1,274\end{array}$ & $\begin{array}{r}143 \\
60\end{array}$ & $\begin{array}{l}57 \\
70\end{array}$ & $\begin{array}{l}14 \\
24\end{array}$ & $\begin{array}{l}21 \\
11\end{array}$ & $\begin{array}{l}0 \\
0\end{array}$ \\
\hline 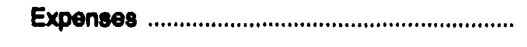 & 7,746 & 1,079 & 939 & 963 & 573 & 31 \\
\hline \multicolumn{7}{|l|}{ Total Eleotric Operation and } \\
\hline \multicolumn{7}{|l|}{ Fuel Expenses in Operation } \\
\hline 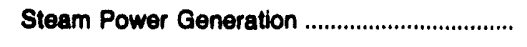 & 0 & 0 & 0 & 0 & 0 & 0 \\
\hline Nuclear Power Generation ................................. & 0 & 0 & 0 & 0 & 0 & 0 \\
\hline 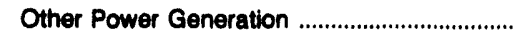 & 0 & 0 & 0 & 0 & 0 & 0 \\
\hline \multicolumn{7}{|l|}{ Number of Elec Dept Employees } \\
\hline Regular Full-time & 490 & 76 & 84 & 79 & 60 & 40 \\
\hline Part-time \& Temporary ........................................ & 0 & 2 & 0 & 0 & 0 & 2 \\
\hline Total Elec Dept Employees ........................... & 490 & 78 & 84 & 79 & 60 & 42 \\
\hline
\end{tabular}

Note: Totals may not equal sum of components because of independent rounding.

Source: Energy Information Administration, Form EIA-412, "Annual Report of Public Electric Utilities." 
Table 23. Electric Operation and Maintenance Expenses by Major U.S. Publicly Owned Electric Utillty Within State, 1992 (Continued) (Thousand Dollars)

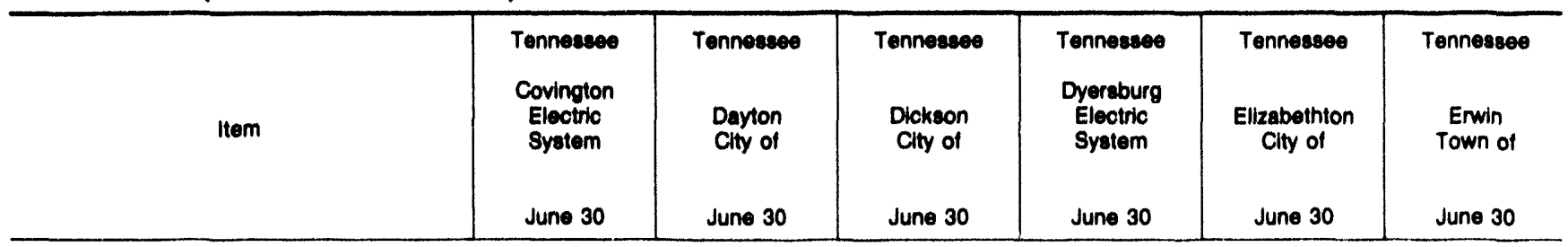

\section{Production Expences}

Steam Power Generation

Nuclear Power Generation

Hydraulio Power Generation

Other Power Generation

Purchased Power

Other Production Expenses

Total Production Exponses

Transmission Expenses

Distribution Expenses

Customer Accounts Expenses

Customer Service and Information

Expenses

Expenses ..........................................................

Administrative and General

Expenses

0
0
0
0
8,705
0

0
0
0
0
8,573
0

8,705

8,673

0
383

383

120

5
10

279

Total Electrle Operation and

Malntenance Exponses
279

0,602

0
374

171

5

20

187

9,330

0
0
0
0
24,340
0

24,340

0
1,366
672

672

1

14

518

26,912

0
0
0
0
22,870
0

22,878

12
1,184
361

361

36

90

853

25,422

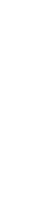

0
0
0
0
21,841
0

0
0
0
0
0,297
0

9,297

1,841

40
1,685

1,685

0
+35

2.15

50

108

772

Fuel Expenses in Operation

Steam Power Generation

Nuclear Power Generation .

Other Power Generation

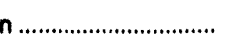

0

0

0

0

0

0

0

0

16

16
18

0

18
58

0

58
25,117

10,186

Total Elec Dept Employees

Note: Totals may not equal sum of components because of independent rounding.
Source: Energy Intormation Administration, Form EIA-412, "Annual Report of Public Electric Utilitius." 
Table 23. Electric Operation and Maintenance Expenses by Major U.S. Publicly Owned Electric Utillty Within State, 1992 (Continued)

(Thousand Dollars)

\begin{tabular}{|c|c|c|c|c|c|c|}
\hline \multirow{3}{*}{ Item } & Tennesser & Tennessee & Tennesser & Tennessee & Tennessee & Tennessee \\
\hline & $\begin{array}{l}\text { Etowah } \\
\text { Clty of }\end{array}$ & $\begin{array}{c}\text { Fayetteville } \\
\text { City of }\end{array}$ & $\begin{array}{l}\text { Gallatin } \\
\text { Clty of }\end{array}$ & $\begin{array}{c}\text { Greeneville } \\
\text { Clty of }\end{array}$ & $\begin{array}{c}\text { Harriman } \\
\text { City of }\end{array}$ & $\begin{array}{l}\text { Humboldt } \\
\text { City of }\end{array}$ \\
\hline & June 30 & June 30 & June 30 & June 30 & June 30 & June 30 \\
\hline
\end{tabular}

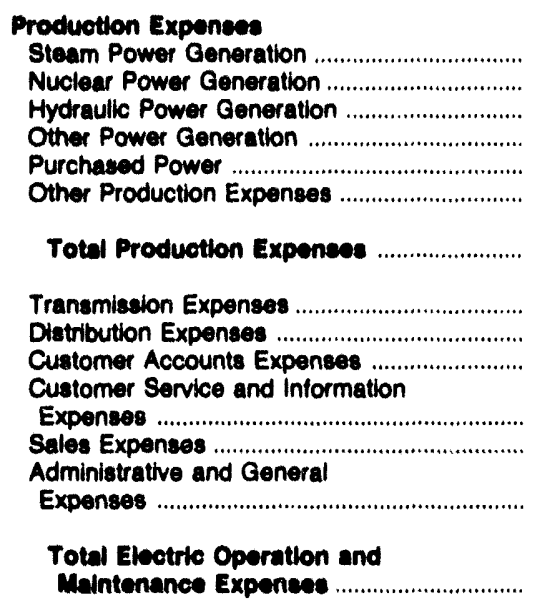

Nuclear Power Generation

Hydraulic Power Generation

Power Generation

Other Production Expenses

Malntenance Expences
Gtaem Power Generation .

$\begin{array}{rr}0 & 0 \\ 0 & 0 \\ 0 & 0 \\ 0 & 0 \\ 0,098 & 15,625 \\ 0 & 0\end{array}$

$6,008 \quad 15,025$

$\begin{array}{rr}3 & 0 \\ 395 & 1,051\end{array}$

132

5

10

181

6,834

17,840

0
0
0
0
18,489
0

18,489

0
731
269

6
14

365

19,078

0
0
0
0
37,492
0

37,492

226

2,136
586

580

61

122

1,298

41,920

11,983

$\begin{array}{rr}0 & 0 \\ 0 & 0 \\ 0 & 0 \\ 0 & 0 \\ 8,899 & 9,123 \\ 0 & 0 \\ 9,890 & 9,123 \\ 0 & 12 \\ 796 & 453 \\ 633 & 100 \\ 19 & 12 \\ 0 & 11 \\ 636 & 240 \\ 11,983 & \end{array}$

\section{Fuet Expenses in Operation}

Steam Power Generation

Nuclear Power Generation.

Other Power Generation

Number of Elec Dept Employees

Regular Full-time

15

61

28

61

38

17

Part-time \& Temporary

0

0

15

81

29

13

74

0

0

Note: Totals may not equal sum of components because of independent rounding.

Source: Energy Information Administration, Form EIA-412, "Annual Report of Public Electric Utilities." 
Table 23. Electric Operation and Malntenance Expenses by Major U.S. Publicly Owned Electric Utility Within State, 1992 (Continued) (Thousand Dollars)

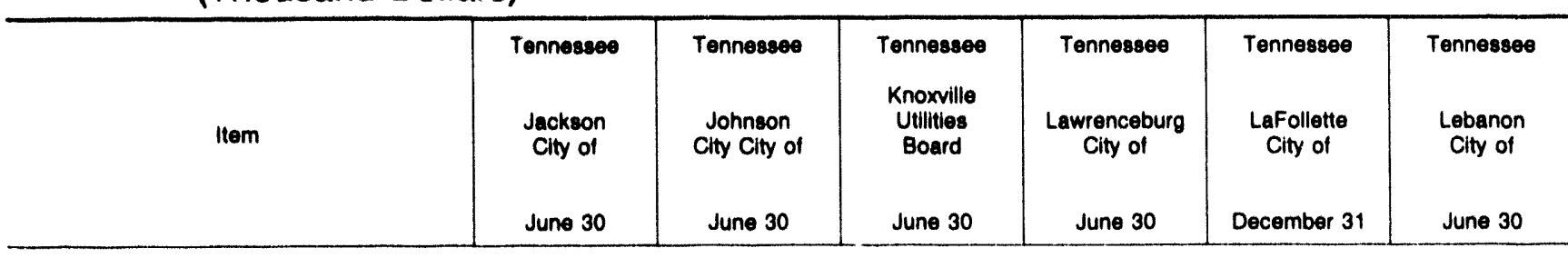

Production Expenses

Steam Power Generation

Nuclear Power Generation

Hydraulic Power Generation

Other Power Generation

Purchased Power

Other Production Expenses ..

Total Production Expense:

Tranemiasion Expenses

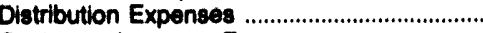

Customer Accounts Expenses

Customer Senvice and Information

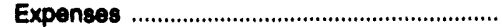

Sales Expenses ..................................................

Administrative and General

Expenses

Total Electric Operation and

Maintenance Expenses

\section{Fuel Expenees in Operation}

Steam Power Generation

Nuclear Power Generation

Other Power Generation

Number of Elec Dept Employese

Regular Full-time

Part-time \& Temporary

Total Elec Dept Employees

0
0
0
0
48,778
0

0
0
0
0
66,675
0

49,778

60,975

156

1,739

701

134

30

1,395

52,035

787

3,220

1,282

55

136

889

73,054

0
0
0
0
208,085
0

0
0
0
0
19,544

208,095

236,563

19,544

12,914

6,169

554

788

21,683

$\begin{array}{rr}0 & 0 \\ 0 & 0 \\ 0 & 0 \\ 0 & 0 \\ 14,541 & 14,529 \\ 0 & 0\end{array}$

14,541

14,620

136
1,236

0

885

511

196

33

10

576

489

17,040

16,108

Note: Totals may not equal sum of components because of independent rounding

Source: Energy Information Administration, Form EIA-412, "Annual Report of Public Electric Utilities." 
Table 23. Electric Operation and Maintenance Expenses by Major U.S. Publicly Owned Electrlc Utility Within State, 1992 (Continued) (Thousand Dollars)

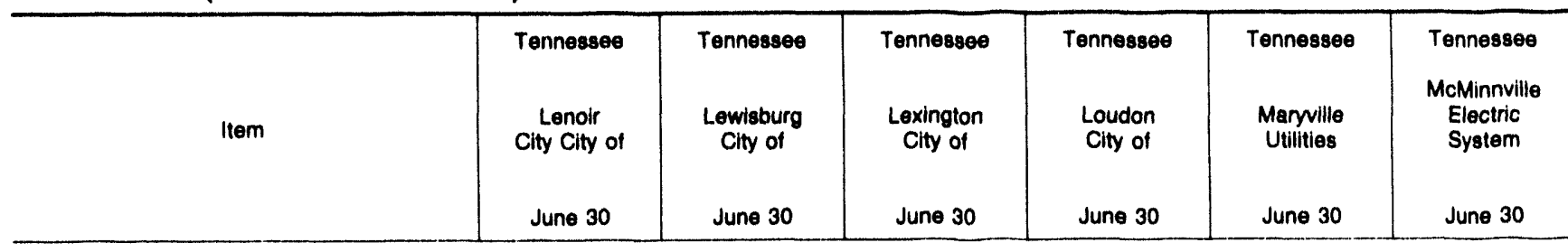

Production Expenees

Steam Power Generation

Nuclear Power Generation

Hydraulic Power Generation

Other Power Generation

Purchased Power

Other Production Expenses

Total Production Expenses

Transmission Expenses

Distribution Expenses

Customer Accounts Expenses

Expenses

Sales Expenses

Administrative and General

Expenses

$\begin{array}{rr}0 & \\ 0 & \\ 0 & \\ 0 & \\ 44,925 & \\ 0 & 12,501 \\ 44,025 & 12,501\end{array}$

0
0
0
0
15.712
0

15,712

0
2,542

1,222

0
15

1,387

Total Electric Operation and

Maintenance Expenses
Customer Service and Information
50,102

0
0
0
0
12,501
0
12,501

0
465

465

125

17

3

377

13,487
86
1,588
407

24

32

818

18,688

0
0
0
0
10,748
0

0

0
0

20,850

0,850
0

10,748

20,850

85

935

335

382
108

108

0
9

368

11,617

22,814

10,603

Fuel Expenses in Operation

Steam Power Generation

Nuclear Power Generation

Other Power Generation

n ...............................

0

0

0

0

0

91

25

0

91

$\begin{array}{ll}25 \\ 0 & 0\end{array}$

71
0

16

39

28

Part-time \& Temporary

25

71

0

Total Elec Dept Employees

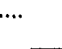

Note: Totals may not equal sum of components because of independent rounding

Source: Energy Information Administration, Form EIA-412, "Annual Report of Public Electric Utilities." 
Table 23. Electric Operation and Maintenance Expenses by Major U.S. Publlcly Owned Electric Utillty Within State, 1992 (Continued) (Thousand Dollars)

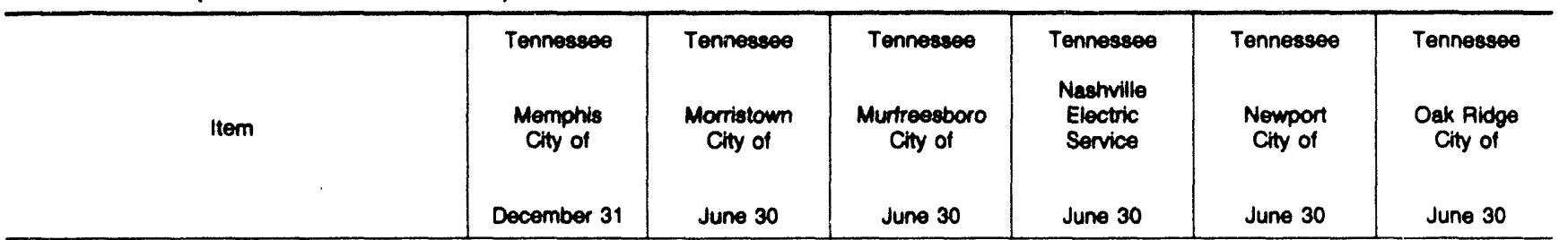

\section{Production Expenece}

Steam Power Generation

Nuclear Power Generation

Hydraulic Power Generation

Other Power Generation

Purchased Power

Other Production Expenses

Total Production Expenses

Transmission Expenses

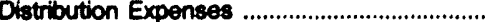

Customer Accounts Expenses

Customer Service and Information

Einirinses ...........

Administrative and Genere

Expenses

Total Electric Operation and

Meintemance Expenses

$\begin{array}{rr}0 & 0 \\ 0 & 0 \\ 0 & 0 \\ 0 & 0 \\ 498,794 & 27,009 \\ 0 & \end{array}$

$498,7 \times 4$

27,000

3,588

37,707

7,442

722
657

31,974

580,093

44
1,306

275

0

125

747

20,507

0
0
0
0
35,694
0

1,146

801

39,200

0
0
0
0
445,923
0

0
0
0
0
18,345

18,345
0

445,923

18,345

$\begin{array}{rr}0 & 0 \\ 1,146 & 24324\end{array}$

13,318

1,145

1,884

18,426

502,020

22,020

Fuel Expensese in Operation

Steam Power Generation

Nuclear Power Generation

Other Power Generation

$\begin{array}{ll}0 & 0 \\ 0 & 0 \\ 0 & 0\end{array}$

0
0
0

0
0
0

$\begin{array}{ll}0 & 0 \\ 0 & 0 \\ 0 & 0\end{array}$

Number of Elec Dept Employees

Regular Full-time

$\begin{array}{rr}1,745 & 67 \\ 0 & 0\end{array}$

67

67

940

51

68

Part-time \& Temporary

0

0

67

67

241

0

0

Total Elec Dept Employees

1,745

51

68

Source: Energy Information Administration, Form ElA-412, "Annual Report of Public Electric Utilities." 
Table 23. Electric Operation and Maintenance Expenses by Major U.S. Publicly Owned Electric Utility Within State, 1992 (Continued) (Thousand Dollars)

\begin{tabular}{|c|c|c|c|c|c|c|}
\hline Item & $\begin{array}{c}\text { Tennessee } \\
\text { Paris } \\
\text { Clty of } \\
\text { June } 30\end{array}$ & $\begin{array}{l}\text { Tennessee } \\
\text { Pulaski } \\
\text { City of } \\
\text { June } 30\end{array}$ & $\begin{array}{l}\text { Tennessee } \\
\text { Ripley } \\
\text { City of } \\
\text { June } 30\end{array}$ & $\begin{array}{c}\text { Tennessee } \\
\text { Rockwood } \\
\text { City of } \\
\text { June } 30\end{array}$ & $\begin{array}{l}\text { Tennessee } \\
\text { Sevier } \\
\text { County } \\
\text { Electric } \\
\text { System } \\
\text { June } 30\end{array}$ & $\begin{array}{c}\text { Tennessee } \\
\text { Shelbyville } \\
\text { City of } \\
\text { June } 30\end{array}$ \\
\hline 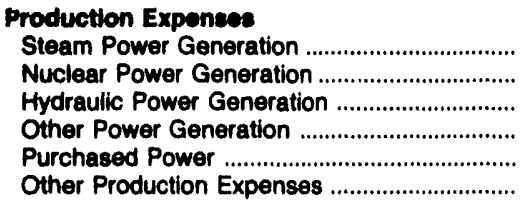 & $\begin{array}{r}0 \\
0 \\
0 \\
0 \\
18,591 \\
0\end{array}$ & $\begin{array}{r}0 \\
0 \\
0 \\
0 \\
15,575 \\
0\end{array}$ & $\begin{array}{r}0 \\
0 \\
0 \\
0 \\
11,139 \\
0\end{array}$ & $\begin{array}{r}0 \\
0 \\
0 \\
0 \\
12,520 \\
0\end{array}$ & $\begin{array}{r}0 \\
0 \\
0 \\
0 \\
37,592 \\
0\end{array}$ & $\begin{array}{r}0 \\
0 \\
0 \\
0 \\
14,091 \\
0\end{array}$ \\
\hline Total Production Exponses ............................ & 18,591 & 15,575 & 11,139 & 12,520 & 37,592 & 14,091 \\
\hline 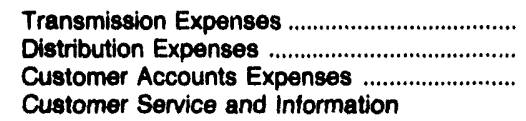 & $\begin{array}{r}0 \\
888 \\
394\end{array}$ & $\begin{array}{r}0 \\
1,030 \\
236\end{array}$ & $\begin{array}{r}38 \\
386 \\
150\end{array}$ & $\begin{array}{r}0 \\
557 \\
302\end{array}$ & $\begin{array}{r}144 \\
1,809 \\
896\end{array}$ & $\begin{array}{r}0 \\
676 \\
175\end{array}$ \\
\hline $\begin{array}{l}\text { Expenses } \\
\text { Sales Expenses } \\
\text { Administrative and General }\end{array}$ & $\begin{array}{l}41 \\
14\end{array}$ & $\begin{array}{l}84 \\
11\end{array}$ & $\begin{array}{r}4 \\
39\end{array}$ & $\begin{array}{l}4 \\
0\end{array}$ & $\begin{array}{l}37 \\
75\end{array}$ & $\begin{array}{r}16 \\
0\end{array}$ \\
\hline 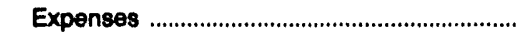 & 453 & 609 & 551 & 463 & 927 & 345 \\
\hline $\begin{array}{l}\text { Total Electric Operation and } \\
\text { Maintenance Expenese ................................ }\end{array}$ & 20,380 & 17,544 & 12,307 & 13,846 & 41,481 & 15,304 \\
\hline
\end{tabular}

Fual Expenses in Operation

Steam Power Generation

Nuclear Power Generation

0

0

0

0

0

Other Power Generation

0

0

0

0

0

Number of Elec Dept Employees

Regular Full-time

50

55

22

27

84

27

Part-time \& Temporary

0

0

0

50

55

22

0

0

0

Total Elec Dept Employees

Note: Totals may not equal sum of components because of independent rounding.

Source: Energy Information Administration, Form ElA-412, "Annual Report of Public Electric Utilities." 
Table 23. Electric Operation and Maintenance Expenses by Major U.S. Publicly Owned Electric Utillty Within State, 1992 (Continued) (Thousand Dollars)

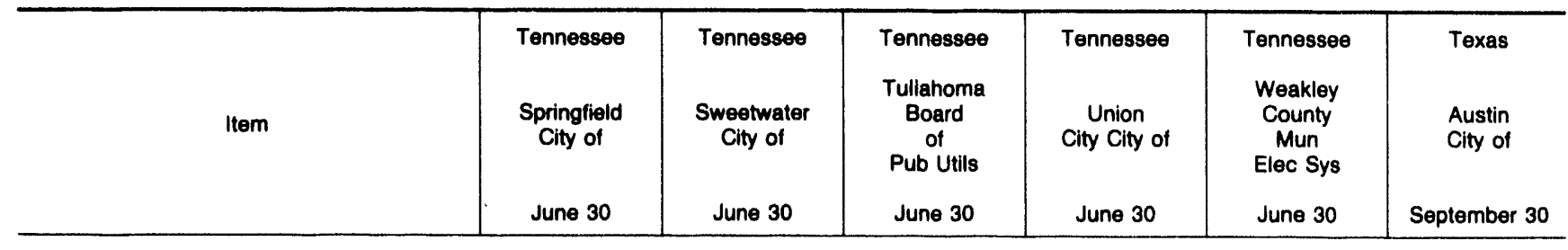

\section{Production Exponses}

Steam Power Generation

Nuclear Power Generation

Hydraulic Power Generation

Other Power Generation

Purchased Power

Other Production Expenses

Total Production Expenses

Transmission Expenses

Distribution Expenses

Customer Accounts Expenses ..........................

Customer Service and Information

Expenses

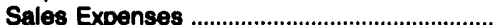

Administrative and General

Expenses

Total Electric Operation and

Maintenance Expences
0
0
0
0
8.492

8,492

8,492

0
347

147

12

354

9,359

0
0
0
0
7,925
0

0
0
0
0
12,025
0

7,925

12,025

0
742

220

12

20

342

13,361

8,895
108,336

42,869

3,971

1,955
0

157,131

1,533

19,183

11,358

3,428

19,147

597

22,657

211,780

Fuel Expenses in Operation

Steam Power Generation

Nuclear Power Generation

Other Power Generation

0

0

0

20

0

20
0

0

\section{0}

0

0

0

81,177

0

15,206

1,384

Number of Elec Dept Employees

Regular Full-time

Part-time \& Temporary

Total Elec Dept Employees

....

Note: Totals may not equal sum of components because of independent rounding.

Source: Energy Information Administration, Form ElA-412, "Annual Report of Public Electric Utilities." 
Table 23. Electrlc Operation and Maintenance Expenses by Major U.S. Publicly Owned Electric Utility Within State, 1992 (Continued) (Thousand Dollars)

\begin{tabular}{|c|c|c|c|c|c|c|}
\hline Item & $\begin{array}{c}\text { Texas } \\
\text { Brenham } \\
\text { Clty of } \\
\text { September } 30\end{array}$ & $\begin{array}{c}\text { Texas } \\
\text { Brownsville } \\
\text { Public } \\
\text { Utils Board } \\
\text { September } 30\end{array}$ & $\begin{array}{l}\text { Texas } \\
\text { Bryan } \\
\text { City of } \\
\text { September } 30\end{array}$ & $\begin{array}{l}\text { Texas } \\
\text { College } \\
\text { Station } \\
\text { City of } \\
\text { September } 30\end{array}$ & $\begin{array}{l}\text { Texas } \\
\text { Denton } \\
\text { City of } \\
\text { September } 30\end{array}$ & $\begin{array}{c}\text { Texas } \\
\text { Fioresville } \\
\text { City of } \\
\text { December } 31\end{array}$ \\
\hline 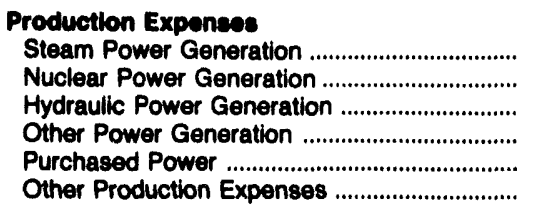 & $\begin{array}{r}0 \\
0 \\
0 \\
0 \\
8,615 \\
0\end{array}$ & $\begin{array}{r}15,084 \\
0 \\
0 \\
0 \\
5,771 \\
2,149\end{array}$ & $\begin{array}{r}9,888 \\
0 \\
0 \\
4,251 \\
37,841 \\
207\end{array}$ & $\begin{array}{r}0 \\
0 \\
0 \\
0 \\
18,638 \\
3\end{array}$ & $\begin{array}{r}4,950 \\
0 \\
12 \\
0 \\
40,520 \\
0\end{array}$ & $\begin{array}{r}0 \\
0 \\
0 \\
0 \\
5,699 \\
0\end{array}$ \\
\hline Total Production Expenses .......................... & 9,615 & 23,004 & 52,187 & 18,641 & 45,482 & 5,699 \\
\hline 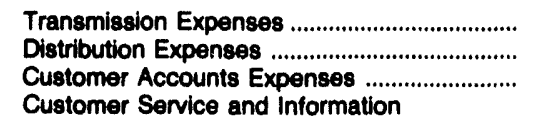 & $\begin{array}{r}0 \\
448 \\
0\end{array}$ & $\begin{array}{r}1,589 \\
781 \\
595\end{array}$ & $\begin{array}{r}0 \\
2,907 \\
1,255\end{array}$ & $\begin{array}{r}83 \\
817 \\
847\end{array}$ & $\begin{array}{r}0 \\
4.133 \\
0\end{array}$ & $\begin{array}{r}0 \\
237 \\
0\end{array}$ \\
\hline 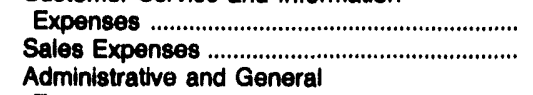 & $\begin{array}{l}0 \\
0\end{array}$ & $\begin{array}{l}0 \\
0\end{array}$ & $\begin{array}{r}49 \\
0\end{array}$ & $\begin{array}{l}0 \\
0\end{array}$ & $\begin{array}{l}0 \\
0\end{array}$ & $\begin{array}{l}0 \\
0\end{array}$ \\
\hline 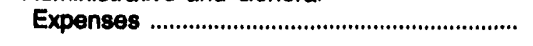 & 592 & 2,787 & 2,020 & 770 & 876 & 1,693 \\
\hline $\begin{array}{l}\text { Total Electric Operation and } \\
\text { Maintenance Expences }\end{array}$ & 10,655 & 28,757 & 58,419 & 21,159 & 50,491 & 7,629 \\
\hline \multicolumn{7}{|l|}{ Fuel Expenses in Operation } \\
\hline 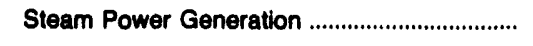 & 0 & 10,404 & 8,238 & 0 & 2,931 & 0 \\
\hline 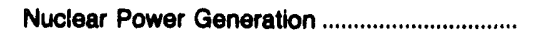 & 0 & 0 & 0 & 0 & 0 & 0 \\
\hline 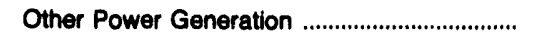 & 0 & 0 & 2,445 & 0 & 0 & 0 \\
\hline \multicolumn{7}{|l|}{ Number of Elec Dept Employees } \\
\hline 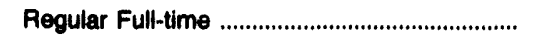 & 9 & 112 & 186 & 51 & 36 & 58 \\
\hline 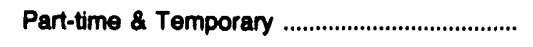 & , & 47 & 3 & 1 & 3 & 5 \\
\hline Total Elec Dept Employees ............................... & 9 & 169 & 189 & 52 & 39 & 63 \\
\hline
\end{tabular}

Note: Totals may not equal sum of components because of independent rounding.

Source: Energy Information Administration, Form EIA-412, "Annual Report of Public Electric Utilities." 
Table 23. Electrlc Operation and Maintenance Expenses by Major U.S. Publicly Owned Electric UtIlity Within State, 1992 (Continued) (Thousand Dollars)

\begin{tabular}{|c|c|c|c|c|c|c|}
\hline Item & $\begin{array}{l}\text { Texas } \\
\text { Garland } \\
\text { City of } \\
\text { September } 30\end{array}$ & $\begin{array}{c}\text { Texas } \\
\text { Georgetown } \\
\text { City of } \\
\text { September } 30\end{array}$ & $\begin{array}{c}\text { Texas } \\
\text { Greenville } \\
\text { City of } \\
\text { September } 30\end{array}$ & $\begin{array}{c}\text { Texas } \\
\text { Kerrville } \\
\text { Public } \\
\text { Utility } \\
\text { Board } \\
\text { September } 30\end{array}$ & $\begin{array}{l}\text { Texas } \\
\text { Lower } \\
\text { Colorado } \\
\text { River } \\
\text { Authority } \\
\text { June } 30\end{array}$ & $\begin{array}{l}\text { Texas } \\
\text { Lubbock } \\
\text { City of } \\
\text { September } 30\end{array}$ \\
\hline 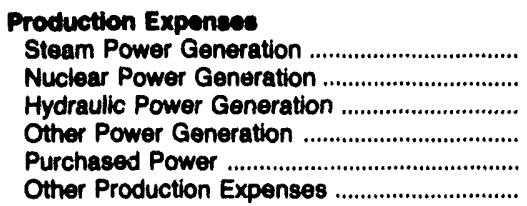 & $\begin{array}{r}23,975 \\
0 \\
0 \\
0 \\
65,881 \\
1,228\end{array}$ & $\begin{array}{r}0 \\
0 \\
0 \\
0 \\
7,032 \\
0\end{array}$ & $\begin{array}{r}2,624 \\
0 \\
0 \\
564 \\
17,113 \\
0\end{array}$ & $\begin{array}{r}0 \\
0 \\
0 \\
0 \\
14,263 \\
0\end{array}$ & $\begin{array}{r}152,449 \\
0 \\
4,483 \\
0 \\
40 \\
4,122\end{array}$ & $\begin{array}{r}14,154 \\
0 \\
0 \\
3,694 \\
8,407 \\
0\end{array}$ \\
\hline Total Production Expenes ............................ & 91,084 & 7,032 & 20,300 & 14,263 & 161,094 & 26,264 \\
\hline 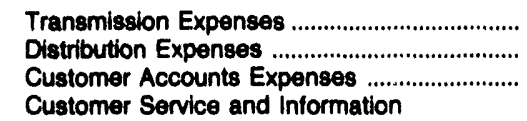 & $\begin{array}{r}885 \\
7,758 \\
3,156\end{array}$ & $\begin{array}{r}0 \\
33 \\
0\end{array}$ & $\begin{array}{r}0 \\
1,320 \\
0\end{array}$ & $\begin{array}{r}0 \\
1,284 \\
414\end{array}$ & $\begin{array}{r}21,896 \\
0 \\
683\end{array}$ & $\begin{array}{r}0 \\
2,765 \\
3,591\end{array}$ \\
\hline 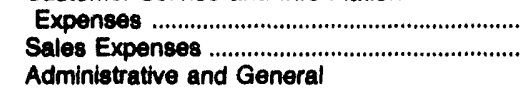 & $\begin{array}{l}1,047 \\
1,109\end{array}$ & $\begin{array}{l}0 \\
0\end{array}$ & $\begin{array}{l}0 \\
0\end{array}$ & $\begin{array}{r}50 \\
0\end{array}$ & $\begin{array}{r}1,066 \\
0\end{array}$ & $\begin{array}{r}0 \\
873\end{array}$ \\
\hline 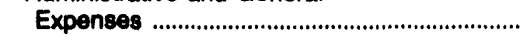 & 1,347 & 1,126 & 3,304 & 991 & 2,671 & 417 \\
\hline 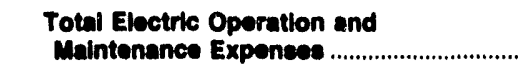 & 106,386 & 8,191 & 24,924 & 17,003 & 187,410 & 33,800 \\
\hline \multicolumn{7}{|l|}{ Fual Expenses in Operation } \\
\hline 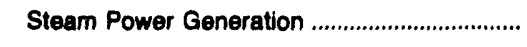 & 18,918 & 0 & 916 & 0 & 113,834 & 11,495 \\
\hline 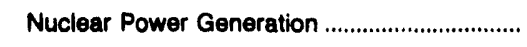 & 0 & 0 & 0 & 0 & 0 & 0 \\
\hline 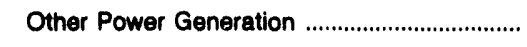 & 0 & 0 & 0 & 0 & 0 & 3,358 \\
\hline \multicolumn{7}{|l|}{ Number of Elec Dept Employees } \\
\hline Regular Full-time & 184 & 10 & 75 & 66 & 1,679 & 222 \\
\hline Part-time \& Temporary & 8 & 0 & 1 & 0 & 19 & 1 \\
\hline Total Elec Dept Employees .............................. & 192 & 10 & 76 & 66 & 1,698 & 223 \\
\hline
\end{tabular}

Note: Totals may not equal sum of components because of independent rounding.

Source: Energy information Administration, Form EIA-412, "Annual Report of Public Electric Utilities." 
Table 23. Electric Operation and Maintenance Expenses by Major U.S. Publicly Owned Electrlc Utility Within State, 1992 (Continued) (Thousand Dollars)

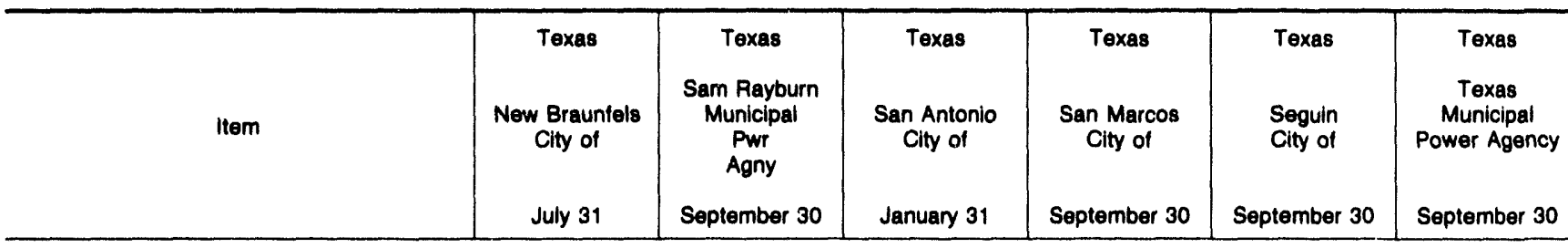

Production Expenses

Steam Power Generation.

Nuclear Power Generation

Hydraulic Power Generation

Other Power Generation

Purchased Power

Other Production Expenses

Total Production Exponese

Transmission Expenses

Distribution Expenses

Customer Accounts Expenses ............................

Customer Service and Information

Expenses ...........

Administrative and Genera

Expenses

Total Electric Oporation and

Malntenance Expeness

Fuel Exponses in Operation

Steam Power Generation

Nuclear Power Generation ................................

Other Power Generation

Number of Elec Dept Employees

Regular Full-time .

72

Part-time \& Temporary

Total Elec Dept Employese
0
0
14
0
28,390
0

28,404

98
1,055

1,055
264

0

1,457

31,278
13,182
0
0
0
2,515

145,889

70,530

0

1,040
3,944

3,944

16,697

221,403

2,705

28,232

6,796

1,904

60,382

585

16,282

321,433

0
0
0
0
12,280
0

0
0
0
0
7,607
0

67,700

0

45

12,280

7,607

67,746

3,902

0
604

961

744

57

745

14,787

Note: Totals may not equal sum of components beceuse of independent rounding

Source: Energy Information Administration, Form ElA-412, "Annual Report of Public Electric Utilities."
118,055

27,101

0

2,768

0

2,768

39
52,286

0

0

0

18

339

0

339 
Table 23. Electric Operation and Maintenance Expenses by Major U.S. Publicly Owned Electrlc Utility Within State, 1992 (Continued) (Thousand Dollars)

\begin{tabular}{|c|c|c|c|c|c|c|}
\hline Item & $\begin{array}{c}\text { Texas } \\
\text { Toledo Bend } \\
\text { Project } \\
\text { Joint } \\
\text { Oper } \\
\text { August } 30\end{array}$ & $\begin{array}{c}\text { Texas } \\
\text { Weatherford } \\
\text { Mun } \\
\text { Utility } \\
\text { System } \\
\text { September } 30\end{array}$ & $\begin{array}{c}\text { Utah } \\
\text { Bountiful } \\
\text { City Clty of } \\
\text { June } 30\end{array}$ & $\begin{array}{c}\text { Utah } \\
\text { Intermountain } \\
\text { Power Agency } \\
\text { June } 30\end{array}$ & $\begin{array}{l}\text { Utah } \\
\text { Logan } \\
\text { City of } \\
\text { June } 30\end{array}$ & $\begin{array}{l}\text { Utah } \\
\text { Murray } \\
\text { City of } \\
\text { June } 30\end{array}$ \\
\hline
\end{tabular}

Production Expenees

Steam Power Generation

Nuclear Power Generation......

Hydraulic Power Generation

Other Power Generation

..............................

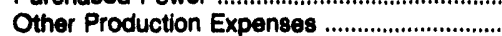

Total Production Expenees

Transmission Expenses ...................................

Distribution Expenses ........................................

Customer Accounts Expenses

Customer Service and Information

Expenses

Sales Expenses

Administrative and General

Expenses

0
0
100
0
0
0

0
0
0
142
5,767
0

0
0
199
279
4,359
0

221,458

0

0

0
0

$100 \quad 5,909$

4,838

0
674

24

0

0

0
0

161

6,257

0

6,357

2,919

9,882

$$
\begin{aligned}
& 678 \\
& 287
\end{aligned}
$$$$
\begin{aligned}
& 0 \\
& 0
\end{aligned}
$$

863

6,690

221,458

10,162

0
0

0

0

12,720

244,340

0
0
60
142
8,883
0

9,100

77

1,116

388

226
0

1,624

Malntenance Expenses

(2)

Fuel Expenses in Operation

Steam Power Generation

Nuclear Power Generation

Other Power Generation

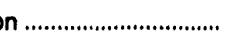

0

\section{0}

0

177,245

0

0

0

57

0

0

0

0

0

0

180

12

Number of Elec Dopt Employese

Regular Full-time .

$\begin{array}{ll}14 & 15 \\ 0 & 0\end{array}$

Total Elec Dept Employees

14

15

64

612

58

50

0

1

Note: Totals may not equal sum of components because of independent rounding.

Source: Energy Information Administration, Form ElA-412, "Annual Report of Public Electric Utilities." 
Table 23. Electric Operation and Maintenance Expenses by Major U.S. Publicly Owned Electric Utility Within State, 1992 (Continued) (Thousand Dollars)

\begin{tabular}{|c|c|c|c|c|c|c|}
\hline Item & $\begin{array}{l}\text { Utah } \\
\text { Provo } \\
\text { City Corp } \\
\text { June } 30\end{array}$ & $\begin{array}{c}\text { Utah } \\
\text { St George } \\
\text { City of } \\
\text { June } 30\end{array}$ & $\begin{array}{c}\text { Utah } \\
\text { Utah } \\
\text { Associated } \\
\text { Mun } \\
\text { Power Sys } \\
\text { March } 31\end{array}$ & $\begin{array}{c}\text { Uiah } \\
\text { Utah } \\
\text { Municipal } \\
\text { Power Agency } \\
\text { June } 30\end{array}$ & $\begin{array}{c}\text { Vermont } \\
\text { Burlington } \\
\text { City of } \\
\text { December } 31\end{array}$ & $\begin{array}{l}\text { Vermont } \\
\text { Vermont } \\
\text { Public } \\
\text { Pwr } \\
\text { Supply Auth } \\
\text { December } 31\end{array}$ \\
\hline 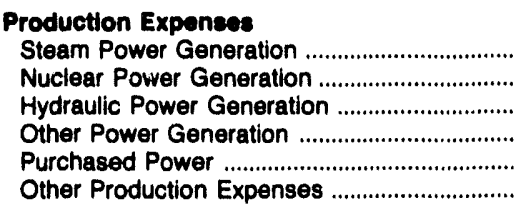 & $\begin{array}{r}0 \\
0 \\
0 \\
0 \\
17,499 \\
0\end{array}$ & $\begin{array}{r}0 \\
0 \\
0 \\
140 \\
9,077 \\
0\end{array}$ & $\begin{array}{r}5,864 \\
0 \\
0 \\
0 \\
14,279 \\
0\end{array}$ & $\begin{array}{r}6,512 \\
0 \\
0 \\
10,024 \\
6,533 \\
0\end{array}$ & $\begin{array}{r}4,502 \\
0 \\
0 \\
156 \\
12,750 \\
532\end{array}$ & $\begin{array}{r}1,628 \\
0 \\
0 \\
0 \\
2,705 \\
3\end{array}$ \\
\hline Total Production Expenses ............................. & 17,499 & 9,218 & 20,142 & 23,070 & 17,939 & 4,336 \\
\hline 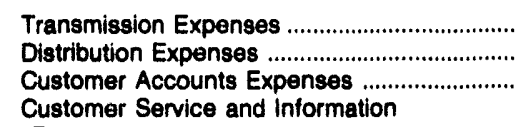 & $\begin{array}{r}627 \\
1,463 \\
631\end{array}$ & $\begin{array}{l}0 \\
0 \\
0\end{array}$ & $\begin{array}{r}3,916 \\
0 \\
0\end{array}$ & $\begin{array}{r}731 \\
0 \\
0\end{array}$ & $\begin{array}{r}327 \\
2,174 \\
1,257\end{array}$ & $\begin{array}{r}32 \\
0 \\
0\end{array}$ \\
\hline 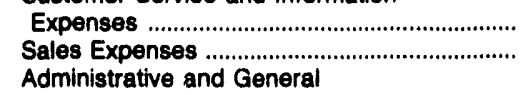 & $\begin{array}{r}912 \\
0\end{array}$ & $\begin{array}{l}0 \\
0\end{array}$ & $\begin{array}{l}0 \\
0\end{array}$ & $\begin{array}{l}0 \\
0\end{array}$ & $\begin{array}{r}294 \\
0\end{array}$ & $\begin{array}{l}0 \\
0\end{array}$ \\
\hline 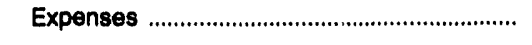 & 1,070 & 2,369 & 2,383 & 638 & 2,660 & 1,495 \\
\hline $\begin{array}{l}\text { Total Electric Operation and } \\
\text { Malntenance Expenses }\end{array}$ & 22,202 & 11,586 & 28,442 & 24,439 & 24,650 & 5,864 \\
\hline \multicolumn{7}{|l|}{ Fual Expenses in Operation } \\
\hline Steam Power Generation ...................................... & 0 & 0 & 4,268 & 4,254 & 2,964 & 1,105 \\
\hline Nuclear Power Generation .................................... & 0 & 0 & 0 & 0 & 0 & 0 \\
\hline Other Power Generation ..................................... & 0 & 100 & 0 & 4,254 & 32 & 0 \\
\hline \multicolumn{7}{|l|}{ Number of Elec Dept Employees } \\
\hline Regular Full-time & 104 & 42 & 22 & 4 & 169 & 11 \\
\hline Part-time \& Temporary ........................................ & 26 & 5 & 0 & 0 & 8 & 0 \\
\hline Total Elec Dept Employees & 130 & 47 & 22 & 4 & 177 & 11 \\
\hline
\end{tabular}

Note: Totals may not equal sum of components because of independent rounding.

Source: Energy Information Administration, Form EIA-412, "Annual Report of Public Electric Utillties." 
Table 23. Electric Operation and Maintenance Expenses by Major U.S. Publlcly Owned Electric Utillty Within State, 1992 (Continued) (Thousand Dollars)

\begin{tabular}{|c|c|c|c|c|c|c|}
\hline Item & $\begin{array}{l}\text { Virginia } \\
\text { Bedford } \\
\text { Clty of } \\
\text { June } 30\end{array}$ & $\begin{array}{c}\text { Virginia } \\
\text { Bristol } \\
\text { Virginia } \\
\text { Utillties Bd } \\
\text { June } 30\end{array}$ & $\begin{array}{l}\text { Virginia } \\
\text { Danville } \\
\text { City of } \\
\text { June } 30\end{array}$ & $\begin{array}{c}\text { Virginia } \\
\begin{array}{c}\text { Harrisonburg } \\
\text { City of }\end{array} \\
\text { Juns } 30\end{array}$ & $\begin{array}{l}\text { Virginia } \\
\text { Manassas } \\
\text { City of } \\
\text { June } 30\end{array}$ & $\begin{array}{l}\text { Virginia } \\
\text { Martinsville } \\
\text { City of } \\
\text { June } 30\end{array}$ \\
\hline 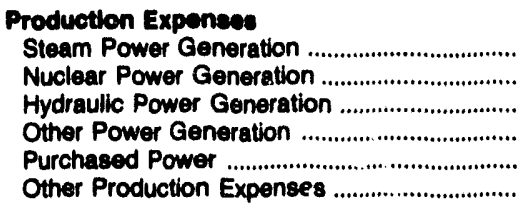 & $\begin{array}{r}0 \\
0 \\
99 \\
0 \\
6,826 \\
0\end{array}$ & $\begin{array}{r}0 \\
0 \\
0 \\
0 \\
24,039 \\
0\end{array}$ & $\begin{array}{r}0 \\
0 \\
385 \\
0 \\
26,531 \\
137\end{array}$ & $\begin{array}{r}0 \\
0 \\
0 \\
0 \\
21,456 \\
0\end{array}$ & $\begin{array}{r}0 \\
0 \\
0 \\
0 \\
11,133 \\
0\end{array}$ & $\begin{array}{r}0 \\
0 \\
143 \\
0 \\
6,798 \\
0\end{array}$ \\
\hline Total Production Expenees ............................. & 6,926 & 24,039 & 27,053 & 21,466 & 11,133 & 6,941 \\
\hline 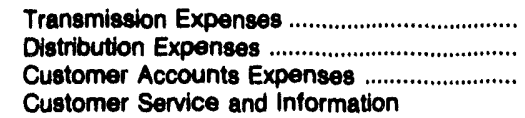 & $\begin{array}{l}185 \\
224 \\
102\end{array}$ & $\begin{array}{r}0 \\
1,023 \\
349\end{array}$ & $\begin{array}{r}216 \\
1,204 \\
866\end{array}$ & $\begin{array}{r}12 \\
886 \\
404\end{array}$ & $\begin{array}{r}0 \\
1,600 \\
0\end{array}$ & $\begin{array}{r}0 \\
658 \\
0\end{array}$ \\
\hline 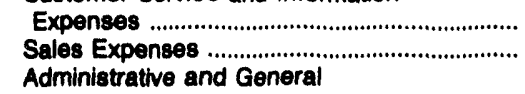 & $\begin{array}{l}0 \\
0\end{array}$ & $\begin{array}{l}28 \\
35\end{array}$ & $\begin{array}{l}0 \\
0\end{array}$ & $\begin{array}{l}0 \\
6\end{array}$ & $\begin{array}{r}489 \\
0\end{array}$ & $\begin{array}{l}0 \\
0\end{array}$ \\
\hline 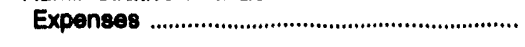 & 460 & 748 & 505 & 698 & 1,110 & 322 \\
\hline $\begin{array}{l}\text { Total Electric Operation and } \\
\text { Maintenance Expenses .............................. }\end{array}$ & 7,896 & 26,221 & 29,945 & 23,472 & 14,332 & 7,920 \\
\hline \multicolumn{7}{|l|}{ Fuvi Expenses in Operation } \\
\hline Steam Power Generation ................................... & 0 & 0 & 0 & 0 & 0 & 0 \\
\hline Nuclear Power Generation ................................ & 0 & 0 & 0 & 0 & 0 & 0 \\
\hline Other Power Generation ....................................... & 0 & 0 & 0 & 0 & 0 & 0 \\
\hline \multicolumn{7}{|l|}{ Number of Elec Dept Employees } \\
\hline 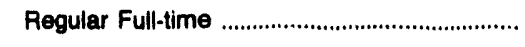 & 15 & 34 & 71 & 48 & 42 & 20 \\
\hline Part-time \& Temporary .......................................... & 0 & 0 & 0 & 4 & 0 & 1 \\
\hline Total Elec Dept Employees & 15 & 34 & 71 & 52 & 42 & 21 \\
\hline
\end{tabular}

Note: Totals may not equal sum of components because of independent rounding.

Source: Energy Information Administration, Form EIA-412, "Annual Feport of Public Electric Utilities." 
Table 23. Electric Operation and Maintenance Expenses by Major U.S. Publicly Owned Electric Utility Within State, 1992 (Continued) (Thousand Dollars)

\begin{tabular}{|c|c|c|c|c|c|c|}
\hline \multirow{3}{*}{ Item. } & Virginia & Virginia & Virginia & Washington & Washington & Washington \\
\hline & $\begin{array}{l}\text { Radford } \\
\text { Clty of }\end{array}$ & $\begin{array}{l}\text { Salem } \\
\text { City of }\end{array}$ & $\begin{array}{l}\text { Virginia } \\
\text { Tech } \\
\text { Electric }\end{array}$ & $\begin{array}{l}\text { Centralia } \\
\text { City of }\end{array}$ & $\begin{array}{l}\text { Ellensburg } \\
\text { City of }\end{array}$ & $\begin{array}{l}\text { Port Angeles } \\
\text { City of }\end{array}$ \\
\hline & June 30 & June 30 & June 30 & December 31 & December 31 & December 31 \\
\hline
\end{tabular}

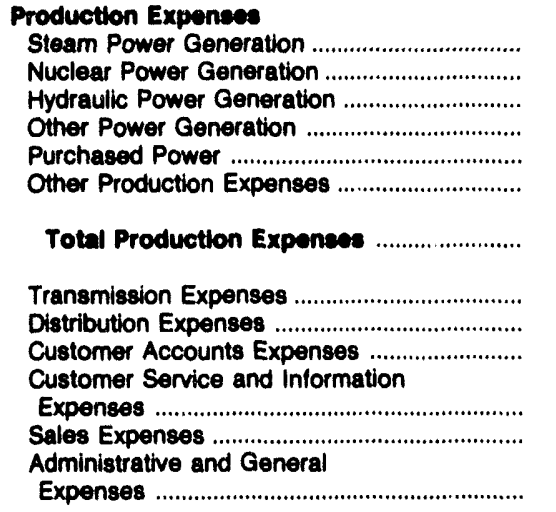

Expenses

Total Electric Operation and Malntenance Expenese

\section{Expensese in Operation}

Steam Power Generation

Nuclear Power Generation

Other Power Generation

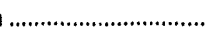

Number of Elec Dept Employees

Regular Full-time

Part-time \& Temporary

Total Elec Dept Employees

0
0
14
0
9,265

9,265
19

$\cos$

9,298

2
378

0

135

474

10,288

0
0
0
0
11,063
0

ร1,083

0
1,115
0

187

4

468

12,833
110
0
0
0
6,781
0

0
0
559
0
4,275
0

4,834

6,892

1.818

1,818
305

0
0

1,156

10,171

120

777
74

$\begin{array}{rr}0 & 0 \\ 0 & 0 \\ 0 & 51 \\ 0 & 0 \\ 3,884 & 15,580 \\ 0 & 0\end{array}$

3,884

15,631

0
337

191

2

940

184

444

395

4,811

17,004

Note: Totals may not equal sum of components because of independent rounding.

Source: Energy Information Administration, Form EIA-412, "Anirual Report of Public Electric Utilities." 
Table 23. Electric Operation and Maintenance Expenses by Major U.S. Publicly Owned Electric Utility Within State, 1992 (Continued) (Thousand Dollars)

\begin{tabular}{|c|c|c|c|c|c|c|}
\hline \multirow{3}{*}{ Item } & Washington & Wathington & Washington & Washington & Washington & Washington \\
\hline & $\begin{array}{c}\text { PUD No } 1 \\
\text { of } \\
\text { Benton } \\
\text { County }\end{array}$ & $\begin{array}{c}\text { PUD No } 1 \\
\text { of } \\
\text { Chelan } \\
\text { County }\end{array}$ & $\begin{array}{l}\text { PIJD No } 1 \text { of } \\
\text { Clallam } \\
\text { County }\end{array}$ & $\begin{array}{c}\text { PUD No } 1 \\
\text { of } \\
\text { Clark } \\
\text { County }\end{array}$ & $\begin{array}{l}\text { PUD No } 1 \text { of } \\
\text { Cowlitz } \\
\text { County }\end{array}$ & $\begin{array}{c}\text { PUD No } 1 \text { of } \\
\text { Douglas } \\
\text { County }\end{array}$ \\
\hline & December 31 & December 31 & December 31 & December 31 & December 31 & December 31 \\
\hline
\end{tabular}

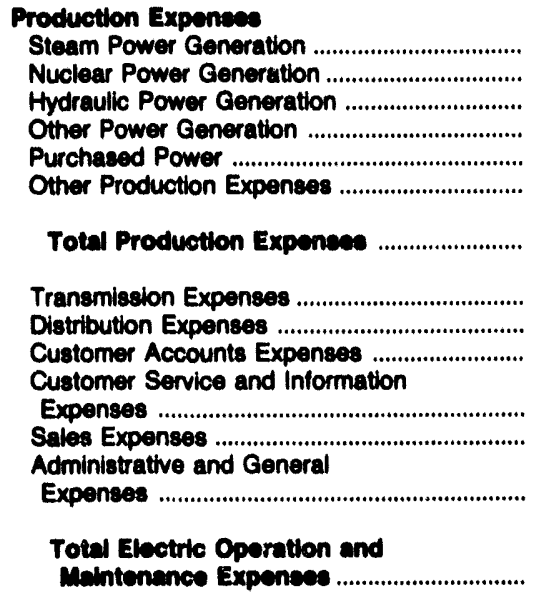

Production Expenses

Staam Power Generavion ...

Other Power Generation

Purchased Power ................

Total Production Expenees

Transmission Expenses

Distribution Expenses ........................................

Customer Accounts Expenses

Customer Service and Information

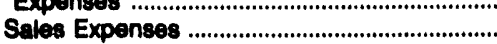

Administrative and Genera

Total Electric Operation and

Maintenance Expenees

\section{Fuel Exponses in Operation}

Steam Power Generation

Nuclear Power Generation

Other Power Generation

Number of Elec Dept Employees

Regular Full-time

124

Part-time \& Temporary

Total Elec Dept Employese

$\begin{array}{rr}0 & 0 \\ 0 & 0 \\ 0 & 18,880 \\ 0 & 0 \\ 31,311 & 9,748 \\ 0 & 183\end{array}$

31,311

20,911

$$
\begin{array}{r}
10 \\
3,444
\end{array}
$$

3,444
1,066

308

2,880

30,017

4,728

570

574

14,064

$\mathbf{0 0 , 9 1 3}$

0
0
0
0
11,518
0

0
0
0
0
77,436
367

11,518

155

1,716

16,690
0
0
226

0

95,512
57

95,795

404

2,377

1,181

294

3,369

103,421

0
0
5,175

0
1,276

231

6,682

804

2,062

295

46
0

3,755

13,643

Note: Totals may not equal sum of components because of independent rounding.

Source: Energy Information Administration, Form EIA-412, "Annual Report of Public Electric Utilities." 
Table 23. Electric Operation and Maintenance Expenses by Major U.S. Publicly Owned Electric Utility Within State, 1992 (Continued) (Thousand Dollars)

\begin{tabular}{|c|c|c|c|c|c|c|}
\hline Item & $\begin{array}{l}\text { Washington } \\
\text { PUD No } 1 \text { of } \\
\text { Franklin } \\
\text { County } \\
\text { December } 31\end{array}$ & $\begin{array}{c}\text { Washington } \\
\text { PUD No } 1 \\
\text { of } \\
\text { Grays } \\
\text { Harbor Cnty } \\
\text { December } 31\end{array}$ & $\begin{array}{l}\text { Washington } \\
\text { PUD No } 1 \text { of } \\
\text { Klickitat } \\
\text { County } \\
\text { December } 31\end{array}$ & $\begin{array}{c}\text { Washington } \\
\text { PUD No } 1 \\
\text { of } \\
\text { Lewis } \\
\text { County } \\
\text { December } 31\end{array}$ & $\begin{array}{l}\text { Washington } \\
\text { PUD No } 1 \text { of } \\
\text { Okanogan } \\
\text { County } \\
\text { December } 31\end{array}$ & $\begin{array}{l}\text { Washington } \\
\text { PUD No } 1 \text { of } \\
\text { Pend Oreille } \\
\text { Cnty } \\
\text { December } 31\end{array}$ \\
\hline 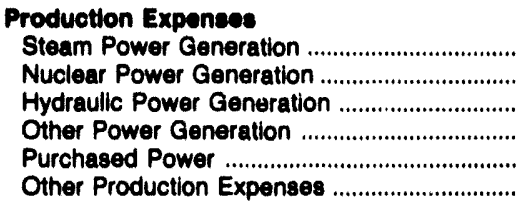 & $\begin{array}{r}0 \\
0 \\
0 \\
0 \\
14,447 \\
0\end{array}$ & $\begin{array}{r}7,271 \\
0 \\
0 \\
0 \\
25,311 \\
4\end{array}$ & $\begin{array}{r}0 \\
0 \\
0 \\
0 \\
6,112 \\
0\end{array}$ & $\begin{array}{r}0 \\
0 \\
19 \\
0 \\
14,924 \\
0\end{array}$ & $\begin{array}{r}0 \\
0 \\
1 \\
0 \\
6,514 \\
25\end{array}$ & $\begin{array}{r}0 \\
0 \\
1,637 \\
0 \\
9,106 \\
728\end{array}$ \\
\hline Total Production Expenese .......................... & 14,447 & 32,697 & 6,112 & 14,843 & 6,539 & 11,470 \\
\hline 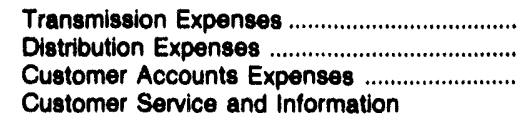 & $\begin{array}{r}0 \\
1,636 \\
488\end{array}$ & $\begin{array}{r}541 \\
5,655 \\
1,486\end{array}$ & $\begin{array}{r}12 \\
927 \\
353\end{array}$ & $\begin{array}{r}118 \\
2,031 \\
1,271\end{array}$ & $\begin{array}{r}25 \\
1,452 \\
449\end{array}$ & $\begin{array}{r}20 \\
904 \\
317\end{array}$ \\
\hline 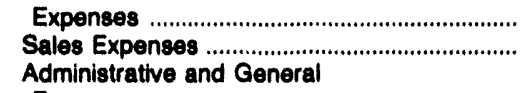 & $\begin{array}{r}-24 \\
0\end{array}$ & $\begin{array}{r}98 \\
0\end{array}$ & $\begin{array}{r}67 \\
0\end{array}$ & $\begin{array}{r}0 \\
10\end{array}$ & $\begin{array}{r}238 \\
0\end{array}$ & $\begin{array}{l}2 \\
0\end{array}$ \\
\hline 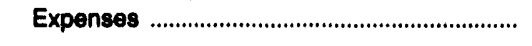 & 1,632 & 3,287 & 753 & 698 & 1,280 & 1,803 \\
\hline $\begin{array}{l}\text { Total Eketric Operation and } \\
\text { Maintenance Expensee }\end{array}$ & 18,170 & 43,663 & 8,225 & 19,070 & 9,984 & 14,516 \\
\hline \multicolumn{7}{|l|}{ Fual Expenses in Operation } \\
\hline Steam Power Generation ..................................... & 0 & 6,235 & 0 & 0 & 0 & 0 \\
\hline Nuclear Power Generation ................................... & 0 & 0 & 0 & 0 & 0 & 0 \\
\hline 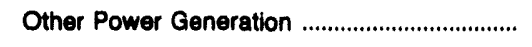 & 0 & 0 & 0 & 0 & 0 & 0 \\
\hline \multicolumn{7}{|l|}{ Number of Elec Dept Employees } \\
\hline 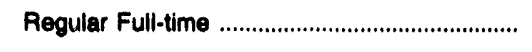 & 57 & 161 & 48 & 76 & 60 & 56 \\
\hline Part-time \& Temporary ......................................... & 6 & 8 & 8 & 7 & 6 & 4 \\
\hline Total Elec Dopt Employees ............................ & 63 & 170 & 58 & 83 & 68 & 60 \\
\hline
\end{tabular}

Note: Totals may not equal sum of components because of i: dependent rounding.

Source: Energy Information Administration, Form ElA-412, "Annual Report of Public Electric Utilities." 
Table 23. Electric Operation and Maintenance Expenses by Major U.S. Publicly Owned Electric UtIlity Within State, 1992 (Continued) (Thousand Dollars)

\begin{tabular}{|c|c|c|c|c|c|c|}
\hline Item & $\begin{array}{l}\text { Washington } \\
\text { PUD No } 1 \text { of } \\
\text { Snohomish } \\
\text { County } \\
\text { December } 31\end{array}$ & $\begin{array}{l}\text { Waahington } \\
\text { PUD No } 1 \text { of } \\
\text { Whatcom } \\
\text { County } \\
\text { December } 31\end{array}$ & $\begin{array}{c}\text { Washington } \\
\text { PUD No } 2 \\
\text { of } \\
\text { Grant } \\
\text { County } \\
\text { December } 31\end{array}$ & $\begin{array}{l}\text { Washington } \\
\text { PUD No } 2 \text { of } \\
\text { Pactic } \\
\text { County } \\
\text { December } 31\end{array}$ & $\begin{array}{c}\text { Washington } \\
\text { PUD No } 3 \\
\text { of } \\
\text { Mason } \\
\text { County } \\
\text { December } 31\end{array}$ & $\begin{array}{l}\text { Washington } \\
\text { Richland } \\
\text { City of } \\
\text { December } 31\end{array}$ \\
\hline
\end{tabular}

\section{Production Expenece}

Steam Power Generation

Nuclear Power Generation

Hydraulic Power Generation

Other Power Generation

Purchased Power

Other Production Expenses

Total Production Expenses

Transmission Expenses

Distribution Expenseg

Customer Accounts Expenses

Customer Service and Information

Expenses .

Sales Expenses

Administrative and General

Expenses

Total Electric Operation and

Malntenance Expenses.

Fud Expenses in Oporation

Steam Power Generation

Nuclear Power Generation

Other Power Generation

Number of Elec Dept Employees

Regular Full-time

Part-time \& Temporary

Total Elec Dopt Employees
887

14,208

1,291

130,971

0

149,497

2,081

18,844

7,675

4,446

14,602

194,215

11,960

0

0

88

$\mathbf{8 9 7}$

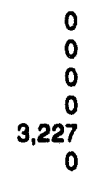

3,227

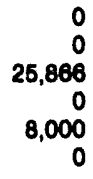

1,034

4,527

1,762

583

10,215

61

3,337

51,997

$\begin{array}{rr}0 & 0 \\ 0 & 0 \\ 0 & 0 \\ 0 & 0 \\ 11,126 & 14,555 \\ 0 & 0\end{array}$

11,126

14,555

0
2150

867

620

1,385

16,149

18,115

Note: Totals may not equal sum of components because of independent rounding.

Source: Energy Information Administration, Form EIA-412, "Annual Report of Public Electric Utilities." 
Table 23. Electric Operation and Maintenance Expenses by Major U.S. Publicly Owned Electric Utility Within State, 1992 (ContInued) (Thousand Dollars)

\begin{tabular}{|c|c|c|c|c|c|c|}
\hline Itemi & $\begin{array}{c}\text { Washington } \\
\text { Seattie } \\
\text { City of } \\
\text { December } 31\end{array}$ & $\begin{array}{c}\text { Washington } \\
\text { Tacoma } \\
\text { City of } \\
\text { Docember } 31\end{array}$ & $\begin{array}{c}\text { Washington } \\
\text { Vera } \\
\text { Imigation } \\
\text { District } 15 \\
\text { December } 31\end{array}$ & $\begin{array}{c}\text { Washington } \\
\text { Washington } \\
\text { Pub } \\
\text { Pwr } \\
\text { Supply Sys } \\
\text { June } 30\end{array}$ & $\begin{array}{l}\text { Wisconsin } \\
\text { Badger Power } \\
\text { Marketing } \\
\text { Auth }\end{array}$ & $\begin{array}{c}\text { Wisconsin } \\
\text { Jefferson } \\
\text { City of } \\
\text { December } 31\end{array}$ \\
\hline
\end{tabular}

\begin{tabular}{|c|c|c|c|c|c|c|}
\hline 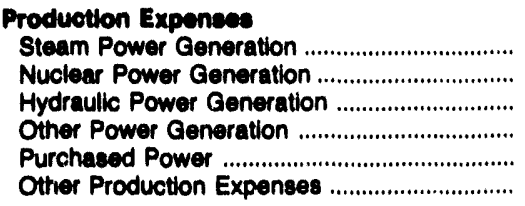 & $\begin{array}{r}14,098 \\
0 \\
14,599 \\
0 \\
83,366 \\
1,863\end{array}$ & $\begin{array}{r}21,703 \\
0 \\
11,035 \\
0 \\
68,859 \\
549\end{array}$ & $\begin{array}{r}0 \\
0 \\
0 \\
0 \\
4,005 \\
0\end{array}$ & $\begin{array}{r}0 \\
117,097 \\
311 \\
0 \\
0 \\
0\end{array}$ & $\begin{array}{r}0 \\
0 \\
0 \\
0 \\
8,006 \\
0\end{array}$ & $\begin{array}{r}0 \\
0 \\
0 \\
0 \\
5,085 \\
0\end{array}$ \\
\hline Total Production Expenees ............................ & 114,026 & 102,146 & 4,005 & 117,407 & 8,006 & 5,085 \\
\hline 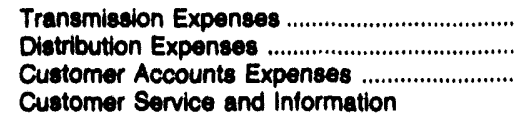 & $\begin{array}{l}12,687 \\
32,414 \\
15,154\end{array}$ & $\begin{array}{r}3,892 \\
13,656 \\
3,589\end{array}$ & $\begin{array}{r}0 \\
450 \\
338\end{array}$ & $\begin{array}{r}304 \\
0 \\
0\end{array}$ & $\begin{array}{r}24 \\
0 \\
0\end{array}$ & $\begin{array}{r}0 \\
144 \\
-59\end{array}$ \\
\hline $\begin{array}{l}\text { Expenses } \\
\text { Sales Expenses } \\
\text { Adminiatrative and General }\end{array}$ & $\begin{array}{r}8,313 \\
0\end{array}$ & $\begin{array}{r}3,713 \\
238\end{array}$ & $\begin{array}{r}35 \\
0\end{array}$ & $\begin{array}{l}0 \\
0\end{array}$ & $\begin{array}{l}0 \\
0\end{array}$ & $\begin{array}{r}0 \\
25\end{array}$ \\
\hline 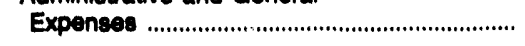 & 40,032 & 17,659 & 242 & 54,194 & 100 & 150 \\
\hline 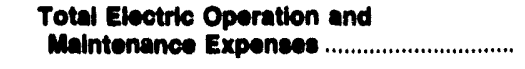 & 222,628 & 144,893 & 5,070 & 171,008 & 8,138 & 5,344 \\
\hline \multicolumn{7}{|l|}{ Fuel Exponeese in Oporation } \\
\hline 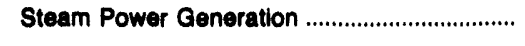 & 12,001 & 14,512 & 0 & 0 & 0 & 0 \\
\hline 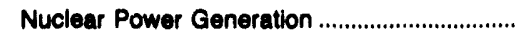 & 0 & 0 & 0 & 15,467 & 0 & 0 \\
\hline 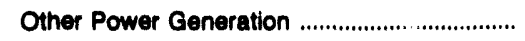 & 0 & 0 & 0 & 0 & 0 & 0 \\
\hline \multicolumn{7}{|l|}{ Number of Elec Dept Employese } \\
\hline Regular Full-time ................................................ & 1,840 & 786 & 23 & 1,243 & 0 & 7 \\
\hline 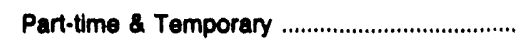 & 167 & 70 & 1 & 159 & 0 & 0 \\
\hline Total Elec Dept Employees & 2,007 & 836 & 24 & 1,402 & $\mathbf{0}$ & 7 \\
\hline
\end{tabular}

Note: Totals may not equal sum of components because of independent rounding.

Source: Energy Information Adminiatration, Form EIA-412, "Annual Report of Public Electric Utilities." 
Table 23. Electric Operation sid Maintenance Expenses by Major U.S. Publicly Owned Electric Utility Within State, 1992 (Coninued) (Thousand Dollars)

\begin{tabular}{|c|c|c|c|c|c|c|}
\hline Item & $\begin{array}{c}\text { Wisconsin } \\
\text { Kaukauna } \\
\text { City of } \\
\text { December } 31\end{array}$ & $\begin{array}{c}\text { Wisconsin } \\
\text { Manitowoc } \\
\text { Publlc } \\
\text { Utilities } \\
\text { December } 31\end{array}$ & $\begin{array}{c}\text { Wisconsin } \\
\text { Marshfield } \\
\text { City of } \\
\text { December } 31\end{array}$ & $\begin{array}{l}\text { Wisconsin } \\
\text { Menasha } \\
\text { City of } \\
\text { December } 31\end{array}$ & $\begin{array}{c}\text { Wisconsin } \\
\text { New London } \\
\text { City of } \\
\text { December } 31\end{array}$ & $\begin{array}{c}\text { Wisconsin } \\
\begin{array}{c}\text { Oconomowoc } \\
\text { City of }\end{array} \\
\text { December } 31\end{array}$ \\
\hline 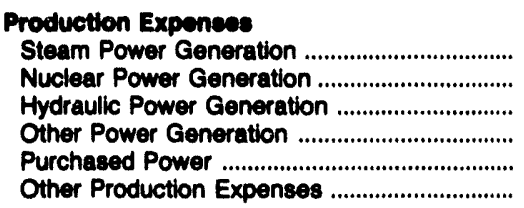 & $\begin{array}{r}0 \\
0 \\
966 \\
42 \\
13,280 \\
182\end{array}$ & $\begin{array}{r}9,826 \\
0 \\
0 \\
120 \\
5,059 \\
0\end{array}$ & $\begin{array}{r}342 \\
0 \\
0 \\
0 \\
10,226 \\
0\end{array}$ & $\begin{array}{r}995 \\
0 \\
0 \\
0 \\
17,548 \\
1\end{array}$ & $\begin{array}{r}0 \\
0 \\
0 \\
0 \\
6,055 \\
0\end{array}$ & $\begin{array}{r}0 \\
0 \\
0 \\
0 \\
5,560 \\
0\end{array}$ \\
\hline Total Production Expenese ........................... & 14,471 & 16,008 & 10,589 & 18,644 & 6,055 & 6,680 \\
\hline 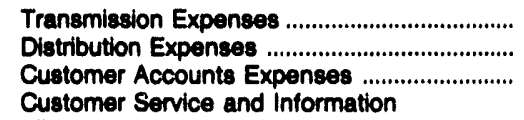 & $\begin{array}{r}14 \\
541 \\
179\end{array}$ & $\begin{array}{r}24 \\
551 \\
232\end{array}$ & $\begin{array}{r}22 \\
614 \\
178\end{array}$ & $\begin{array}{r}52 \\
384 \\
133\end{array}$ & $\begin{array}{r}0 \\
186 \\
90\end{array}$ & $\begin{array}{r}0 \\
248 \\
118\end{array}$ \\
\hline 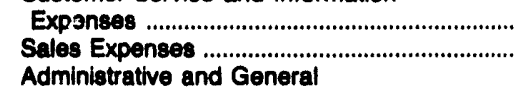 & $\begin{array}{r}0 \\
26\end{array}$ & $\begin{array}{r}0 \\
287\end{array}$ & $\begin{array}{r}0 \\
75\end{array}$ & $\begin{array}{r}0 \\
65\end{array}$ & $\begin{array}{r}0 \\
70\end{array}$ & $\begin{array}{r}0 \\
105\end{array}$ \\
\hline 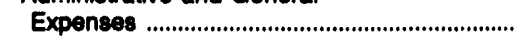 & 810 & 1,656 & 612 & 796 & 178 & 353 \\
\hline $\begin{array}{l}\text { Total Electric Operation and } \\
\text { Malntenance Expenses ................................. }\end{array}$ & 16,040 & 17,765 & 12,080 & 19,973 & 6,579 & 6,383 \\
\hline
\end{tabular}

\section{Fud Expenses in Operation}

Steam Power Generation

$\begin{array}{lr}0 & 7,189 \\ 0 & 0 \\ 0 & 59\end{array}$

Nuclear Power Generation ..............................

Other Power Generation

0

$\begin{array}{ll}45 & 3 \\ 2 & 98\end{array}$

14

36

16

18

Part-time \& Temporary

88 
Table 23. Electric Operation and Maintenance Expenses by Major U.S. Publicly Owned Electric UtIlity Within State, 1992 (Continued) (Thousand Dollars)

\begin{tabular}{|c|c|c|c|c|c|c|}
\hline Item & $\begin{array}{l}\text { Wisconsin } \\
\text { Plymouth } \\
\text { City of } \\
\text { December } 31\end{array}$ & $\begin{array}{l}\text { Wisconsin } \\
\text { Reedsburg } \\
\text { Utility Comm } \\
\text { December } 31\end{array}$ & $\begin{array}{l}\text { Wisconsin } \\
\text { Shawano } \\
\text { Municipal } \\
\text { Utilities } \\
\text { December } 31\end{array}$ & $\begin{array}{c}\text { Wiscons n } \\
\text { Sheboygan } \\
\text { Falls } \\
\text { City of } \\
\text { December } 31\end{array}$ & $\begin{array}{l}\text { Wisconsin } \\
\text { Sturgeon Bay } \\
\text { Combined } \\
\text { Utils }\end{array}$ & $\begin{array}{l}\text { Wisconsin } \\
\text { Wisconsin } \\
\text { Public } \\
\text { Power } \\
\text { Inc Sys } \\
\text { June } 30\end{array}$ \\
\hline 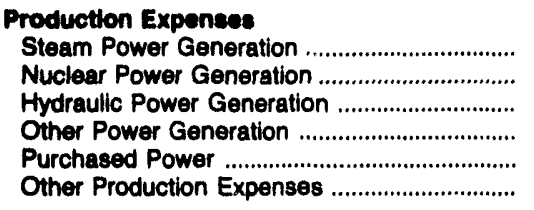 & $\begin{array}{r}0 \\
0 \\
0 \\
0 \\
5,018 \\
0\end{array}$ & $\begin{array}{r}0 \\
0 \\
0 \\
0 \\
5,189 \\
0\end{array}$ & $\begin{array}{r}0 \\
0 \\
0 \\
0 \\
6,195 \\
0\end{array}$ & $\begin{array}{r}0 \\
0 \\
0 \\
0 \\
5,578 \\
0\end{array}$ & $\begin{array}{r}0 \\
0 \\
0 \\
0 \\
5,197 \\
0\end{array}$ & $\begin{array}{r}9,966 \\
0 \\
0 \\
0 \\
80,141 \\
32\end{array}$ \\
\hline Total Production Expenese ......................... & 5,018 & 5,180 & 6,195 & 5,578 & 5,197 & $\bullet 0,140$ \\
\hline 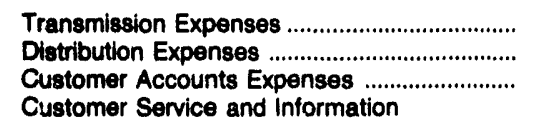 & $\begin{array}{r}0 \\
387 \\
104\end{array}$ & $\begin{array}{r}8 \\
125 \\
51\end{array}$ & $\begin{array}{r}4 \\
152 \\
65\end{array}$ & $\begin{array}{r}0 \\
240 \\
47\end{array}$ & $\begin{array}{r}6 \\
420 \\
129\end{array}$ & $\begin{array}{r}3,119 \\
0 \\
0\end{array}$ \\
\hline 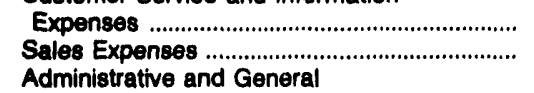 & $\begin{array}{r}0 \\
17\end{array}$ & $\begin{array}{l}0 \\
0\end{array}$ & $\begin{array}{l}0 \\
0\end{array}$ & $\begin{array}{l}0 \\
4\end{array}$ & $\begin{array}{r}0 \\
15\end{array}$ & $\begin{array}{l}0 \\
0\end{array}$ \\
\hline 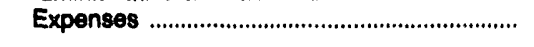 & 286 & 198 & 244 & 134 & 277 & 3,183 \\
\hline $\begin{array}{l}\text { Total Electric Operatton and } \\
\text { Maintenance Expenses }\end{array}$ & 5,812 & 5,572 & 6,680 & 6,003 & 6,043 & 86,442 \\
\hline \multicolumn{7}{|l|}{ Funf Expenses in Operation } \\
\hline Steam Power Generation ..................................... & 0 & 0 & 0 & 0 & 0 & 8,135 \\
\hline Nuclear Power Generation ................................ & 0 & 0 & 0 & 0 & 0 & 0 \\
\hline Other Power Generation ................................. & 0 & 0 & 0 & 0 & 0 & 0 \\
\hline \multicolumn{7}{|l|}{ Number of Elec Dept Employees } \\
\hline Regular Full-time & 17 & 9 & 11 & 8 & 15 & 34 \\
\hline Part-time \& Temporary ........................................ & 0 & 0 & 1 & 0 & 0 & 2 \\
\hline Total Elec Dept Employees ............................ & 17 & 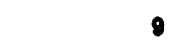 & 12 & $\bullet$ & 16 & 38 \\
\hline
\end{tabular}

Note: Totals may not equal sum of components because of independent rounding.

Source: Energy information Administration, Form ElA-412, "Annual Report of Public Electric Utilities." 
Table 23. Electric Operation and Maintenance Expenses by Major U.S. Publicly Owned Electric Utility Within State, 1992 (Continued) (Thousand Dollars)

\begin{tabular}{c|c|c|c|c}
\hline & $\begin{array}{c}\text { Wisconsin } \\
\text { Wlsconsin }\end{array}$ & Wyoming & Wyoming \\
Raplds W W & Gillette & Wyoming \\
Municipal \\
Comm & City of & Power Agency \\
& & & \\
& Decomber 31 & June 30 & December 31 & \\
\hline
\end{tabular}

\section{Production Expensee}

Steam Power Generation

Nuclear Power Generation....

Hydraulic Power Generation

Other Power Generation

Purchased Power

Other Production Expenses

Total Production Expences

Tranemiseion Expenses

Dratribution Expenees

Customer Accounts Expenses ...........................

Customer Service and Information

Expenses .

Sales Expenses .................................................

Administrative and General

Expenses

Total Electiv Operation and

Malntenance Expenses.

Fuel Expienses in Operation

Steam Power Generation .................................

Nuclear Power Generation ...

Other Power Generation

Number of Elec Dept Employees

Regular Full-time

Part-time \& Temporary

Total Elec Dept Employees
0
0
0
0
7,133
0

7,133

0

220

0

543

8,435

$\begin{array}{rr}0 & 1,552 \\ 0 & 0 \\ 0 & 0 \\ 0 & 0 \\ 7,942 & 1,169 \\ 0 & 0\end{array}$

7,042

2,722

223

0

16

402

504

3,303

9,084

52

0

69

0

31
367

55

165

04

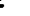


Table 24. Electric Utility Plant by Major U.S. Publicly Owned Electric Utility Within State at End of Period, 1992 (Thousand Dollars)

\begin{tabular}{|c|c|c|c|c|c|c|}
\hline Item & $\begin{array}{l}\text { Alabama } \\
\text { Alabama } \\
\text { Municipal } \\
\text { Elec Auth } \\
\text { September } 30\end{array}$ & $\begin{array}{l}\text { Alabama } \\
\text { Albertville } \\
\text { Municipal } \\
\text { Utils Bd } \\
\text { June } 30\end{array}$ & $\begin{array}{c}\text { Alabama } \\
\text { Andalusia } \\
\text { City of } \\
\text { September } 30\end{array}$ & $\begin{array}{l}\text { Alabama } \\
\text { Athens } \\
\text { City of } \\
\text { December } 31\end{array}$ & $\begin{array}{l}\text { Alabama } \\
\text { Bessemer } \\
\text { City of } \\
\text { June } 30\end{array}$ & $\begin{array}{l}\text { Alabama } \\
\text { Cullman } \\
\text { Power Buard } \\
\text { June } 30\end{array}$ \\
\hline 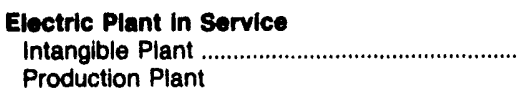 & 0 & 0 & 0 & 0 & 0 & 0 \\
\hline 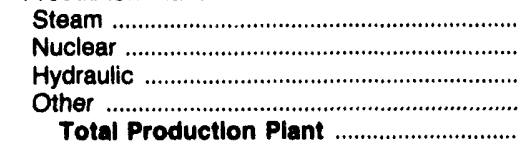 & $\begin{array}{l}0 \\
0 \\
0 \\
0 \\
0\end{array}$ & $\begin{array}{l}0 \\
0 \\
0 \\
0 \\
0\end{array}$ & $\begin{array}{l}0 \\
0 \\
0 \\
0 \\
0\end{array}$ & $\begin{array}{l}0 \\
0 \\
0 \\
0 \\
0\end{array}$ & $\begin{array}{l}0 \\
0 \\
0 \\
0 \\
0\end{array}$ & $\begin{array}{l}0 \\
0 \\
0 \\
0 \\
0\end{array}$ \\
\hline 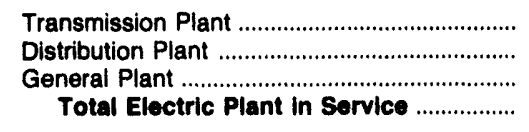 & $\begin{array}{l}0 \\
0 \\
0 \\
0\end{array}$ & $\begin{array}{r}0 \\
10,279 \\
1,484 \\
11,763\end{array}$ & $\begin{array}{r}0 \\
3,566 \\
0 \\
3,566\end{array}$ & $\begin{array}{r}0 \\
31,609 \\
2,058 \\
33,667\end{array}$ & $\begin{array}{r}0 \\
16,974 \\
2,118 \\
19,093\end{array}$ & $\begin{array}{r}0 \\
8,109 \\
2,262 \\
10,371\end{array}$ \\
\hline 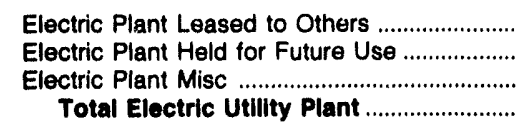 & $\begin{array}{l}0 \\
0 \\
0 \\
0\end{array}$ & $\begin{array}{r}0 \\
0 \\
0 \\
11,763\end{array}$ & $\begin{array}{r}0 \\
0 \\
0 \\
3,566\end{array}$ & $\begin{array}{r}0 \\
0 \\
48 \\
33,715\end{array}$ & $\begin{array}{r}0 \\
53 \\
0 \\
19,146\end{array}$ & $\begin{array}{r}0 \\
0 \\
0 \\
10,371\end{array}$ \\
\hline $\begin{array}{l}\text { Construction Work in Progress - Electric ....... } \\
\text { Accumulated Provision for }\end{array}$ & 0 & 210 & 0 & 4,736 & 995 & 29 \\
\hline 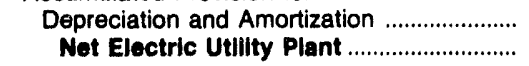 & $\begin{array}{l}0 \\
0\end{array}$ & $\begin{array}{l}4,233 \\
7,749\end{array}$ & $\begin{array}{l}1,101 \\
2,464\end{array}$ & $\begin{array}{l}12,639 \\
25,813\end{array}$ & $\begin{array}{r}8,252 \\
11,889\end{array}$ & $\begin{array}{l}5,024 \\
5,376\end{array}$ \\
\hline
\end{tabular}

\begin{tabular}{|c|c|c|c|c|c|c|}
\hline Item & $\begin{array}{l}\text { Alabama } \\
\text { Decatur } \\
\text { City of } \\
\text { June } 30\end{array}$ & $\begin{array}{l}\text { Alabama } \\
\text { Dothan } \\
\text { City of } \\
\text { September } 30\end{array}$ & $\begin{array}{l}\text { Alabama } \\
\text { Florence } \\
\text { City of } \\
\text { June } 30\end{array}$ & $\begin{array}{c}\text { Alabama } \\
\text { Foley } \\
\text { City of } \\
\text { (Riviera Utils) } \\
\text { December } 31\end{array}$ & $\begin{array}{c}\text { Alabama } \\
\text { Fort Payne } \\
\text { Improvement } \\
\text { Auth } \\
\text { June } 30\end{array}$ & $\begin{array}{l}\text { Alabama } \\
\text { Guntersville } \\
\text { Electric } \\
\text { Board } \\
\text { June } 30\end{array}$ \\
\hline 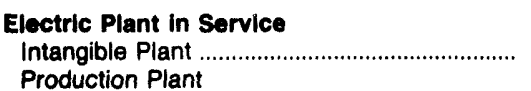 & 0 & 0 & 0 & 0 & 0 & 0 \\
\hline 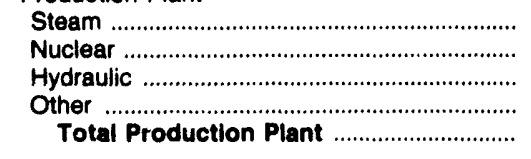 & $\begin{array}{l}0 \\
0 \\
0 \\
0 \\
0\end{array}$ & $\begin{array}{l}0 \\
0 \\
0 \\
0 \\
0\end{array}$ & $\begin{array}{l}0 \\
0 \\
0 \\
0 \\
0\end{array}$ & $\begin{array}{l}0 \\
0 \\
0 \\
4 \\
4\end{array}$ & $\begin{array}{l}0 \\
0 \\
0 \\
0 \\
0\end{array}$ & $\begin{array}{l}0 \\
0 \\
0 \\
0 \\
0\end{array}$ \\
\hline 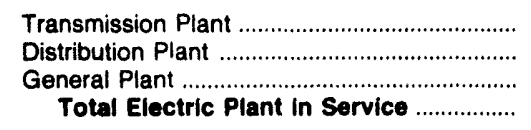 & $\begin{array}{r}0 \\
33,321 \\
2,854 \\
36,175\end{array}$ & $\begin{array}{r}0 \\
0 \\
50,147 \\
50,147\end{array}$ & $\begin{array}{r}12,668 \\
48,818 \\
6,017 \\
67,504\end{array}$ & $\begin{array}{r}12,293 \\
29,767 \\
7,723 \\
49,786\end{array}$ & $\begin{array}{r}0 \\
9,547 \\
1,363 \\
10,910\end{array}$ & $\begin{array}{r}0 \\
7,713 \\
707 \\
8,420\end{array}$ \\
\hline 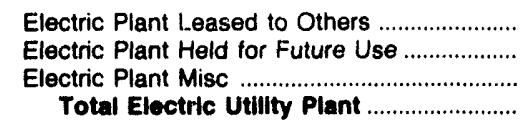 & $\begin{array}{r}0 \\
432 \\
0 \\
36,607\end{array}$ & $\begin{array}{r}0 \\
0 \\
0 \\
\mathbf{5 0}, 147\end{array}$ & $\begin{array}{r}0 \\
0 \\
0 \\
67,504\end{array}$ & $\begin{array}{r}0 \\
0 \\
0 \\
49,786\end{array}$ & $\begin{array}{r}0 \\
0 \\
0 \\
10,910\end{array}$ & $\begin{array}{r}0 \\
0 \\
0 \\
8,420\end{array}$ \\
\hline $\begin{array}{l}\text { Construction Work in Progress - Electric ........ } \\
\text { Accumulated Provision for }\end{array}$ & 3,090 & 0 & 955 & 0 & 508 & 176 \\
\hline $\begin{array}{l}\text { Depreciation and Amortization } \\
\text { Net Electric Utllity Plant }\end{array}$ & $\begin{array}{l}15,200 \\
24,496\end{array}$ & $\begin{array}{l}17,980 \\
32,167\end{array}$ & $\begin{array}{l}27,091 \\
41,368\end{array}$ & $\begin{array}{l}15,787 \\
33,998\end{array}$ & $\begin{array}{l}3,888 \\
7,530\end{array}$ & $\begin{array}{l}3,824 \\
4,772\end{array}$ \\
\hline
\end{tabular}

Note: Totals may not equal sum of components because of independent rounding.

Source: Energy Information Administration, Form EIA-412, "Annual Report of Public Electric Utilities." 
Table 24. Electric Utility Plant by Major U.S. Publicly Owned Electric Utility Within State at End of Period, 1992 (Continued)

(Thousand Dollars)

\begin{tabular}{|c|c|c|c|c|c|c|}
\hline Item & $\begin{array}{l}\text { Alabama } \\
\text { Huntsville } \\
\text { City of } \\
\text { September } 30\end{array}$ & $\begin{array}{l}\text { Alabama } \\
\text { Muscle } \\
\text { Shoals } \\
\text { City of } \\
\text { June } 30\end{array}$ & $\begin{array}{l}\text { Alabama } \\
\text { Opelika } \\
\text { City of } \\
\text { September } 30\end{array}$ & $\begin{array}{c}\text { Alabama } \\
\text { Scottsboro } \\
\text { City of } \\
\text { June } 30\end{array}$ & $\begin{array}{l}\text { Alabama } \\
\text { Sheffield } \\
\text { Utilities } \\
\text { June } 30\end{array}$ & $\begin{array}{l}\text { Alabama } \\
\text { Sylacauga } \\
\text { Utilities } \\
\text { Board } \\
\text { September } 30\end{array}$ \\
\hline 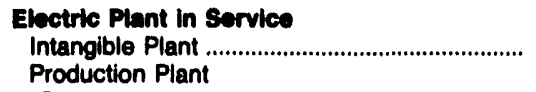 & 0 & 0 & 0 & 0 & 0 & 0 \\
\hline 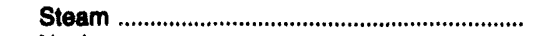 & 0 & 0 & 0 & 0 & 0 & 0 \\
\hline 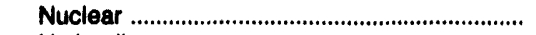 & 0 & 0 & 0 & 0 & 0 & 0 \\
\hline 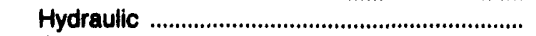 & 0 & 0 & 0 & 0 & 0 & 0 \\
\hline Other & 0 & 0 & 0 & 0 & 0 & 0 \\
\hline 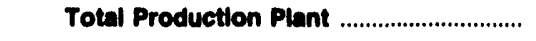 & 0 & 0 & 0 & 0 & 0 & 0 \\
\hline 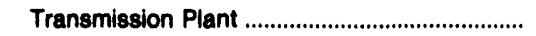 & 14,111 & 0 & 16,287 & 0 & 1,107 & 0 \\
\hline 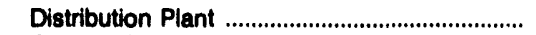 & 124,116 & 10,160 & 0 & 12,477 & 25,958 & 9,016 \\
\hline 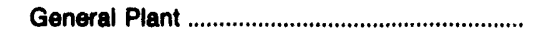 & 9,247 & 1,511 & 0 & 1,465 & 3,312 & 1,044 \\
\hline Total Eloctric Plant in Sorvice ....................... & 147,474 & 11,671 & 16,287 & 13,941 & 30,377 & 10,059 \\
\hline Electric Plant Leased to Others ........................... & 0 & 0 & 0 & 0 & 0 & 0 \\
\hline Electric Plant Held for Future Use .................... & 0 & 0 & 0 & 0 & 0 & 0 \\
\hline Electric Plant Misc & 0 & 0 & 0 & 0 & 182 & \\
\hline 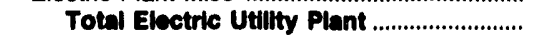 & 147,474 & 11,671 & 16,287 & 13,941 & 30,559 & 10,059 \\
\hline $\begin{array}{l}\text { Construction Work in Progress - Electric ....... } \\
\text { Accumulated Provision for }\end{array}$ & 1,312 & 980 & 159 & 110 & 1,410 & 0 \\
\hline 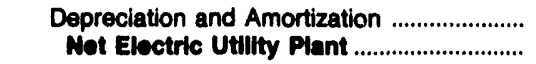 & $\begin{array}{l}54,514 \\
94,272\end{array}$ & $\begin{array}{l}3,702 \\
8,949\end{array}$ & $\begin{array}{l}9,248 \\
7,198\end{array}$ & $\begin{array}{l}4,762 \\
9,289\end{array}$ & $\begin{array}{l}13,343 \\
18,626\end{array}$ & $\begin{array}{l}6,054 \\
4,005\end{array}$ \\
\hline
\end{tabular}

\begin{tabular}{|c|c|c|c|c|c|c|}
\hline Item & $\begin{array}{c}\text { Alabama } \\
\text { Troy } \\
\text { City of } \\
\text { September } 30\end{array}$ & $\begin{array}{c}\text { Alabama } \\
\text { Tuskegee } \\
\text { City of } \\
\text { September } 30\end{array}$ & $\begin{array}{l}\text { Alaska } \\
\text { Alaska } \\
\text { Energy } \\
\text { Authority } \\
\text { June } 30\end{array}$ & $\begin{array}{c}\text { Alaska } \\
\text { Anchorage } \\
\text { City of } \\
\text { December } 31\end{array}$ & $\begin{array}{l}\text { Alaska } \\
\text { Fairbanks } \\
\text { City of } \\
\text { December } 31\end{array}$ & $\begin{array}{c}\text { Alaska } \\
\text { Ketchikan } \\
\text { City of } \\
\text { December } 31\end{array}$ \\
\hline $\begin{array}{l}\text { Eloctric Plant In Sorvice } \\
\text { Intangible Plant ................................................ } \\
\text { Production Plant }\end{array}$ & 0 & 0 & 2,947 & 13,049 & 120 & 0 \\
\hline Steam & 0 & 0 & 3,535 & 17,440 & 30,718 & 0 \\
\hline 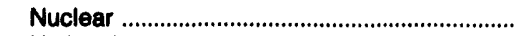 & 0 & 0 & & 0 & 0 & 0 \\
\hline Hydraulic ………………………………….... & 0 & 0 & 579,193 & 0 & 0 & 16,511 \\
\hline Other & 0 & 0 & & 84,495 & 4,311 & 4,867 \\
\hline Total Production Plant .................................... & 0 & 0 & 582,728 & 101,935 & 35,029 & 21,378 \\
\hline 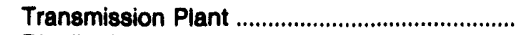 & 0 & 0 & 324,610 & 16,602 & 3,632 & 1,183 \\
\hline 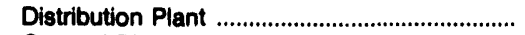 & 8,306 & 6,810 & & 83,121 & 7,428 & 16,838 \\
\hline $\begin{array}{l}\text { General Plant } \\
\text { Total Electric Piant in Service ....................... }\end{array}$ & $\begin{array}{l}1,145 \\
8,451\end{array}$ & $\begin{array}{r}0 \\
6,810\end{array}$ & $\begin{array}{r}7,135 \\
917,420\end{array}$ & $\begin{array}{r}26,233 \\
240,941\end{array}$ & $\begin{array}{r}1,127 \\
47,336\end{array}$ & $\begin{array}{r}2,686 \\
42,086\end{array}$ \\
\hline Electric Plant Leased to Others. & 0 & 0 & 0 & 0 & 0 & 0 \\
\hline Electric Plant Held for Future Use ..................... & 0 & 0 & 0 & 0 & 0 & 76 \\
\hline 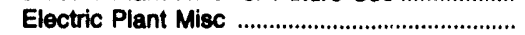 & & 0 & 0 & 5.669 & 0 & \\
\hline Total Electric Utility Plant ................................ & 9,451 & 6,810 & 917,420 & 246,610 & 47,336 & 42,162 \\
\hline $\begin{array}{l}\text { Construction Work in Progress - Electric ........ } \\
\text { Accumulated Provision for }\end{array}$ & 0 & 0 & 0 & 3,886 & 511 & 2,712 \\
\hline 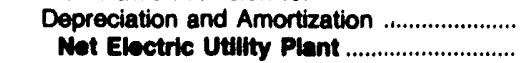 & $\begin{array}{l}5,049 \\
4,402\end{array}$ & $\begin{array}{l}2,883 \\
3,927\end{array}$ & $\begin{array}{l}127,723 \\
789,697\end{array}$ & $\begin{array}{l}105,807 \\
144,689\end{array}$ & $\begin{array}{l}25,746 \\
22,101\end{array}$ & $\begin{array}{l}18,504 \\
26,369\end{array}$ \\
\hline
\end{tabular}

Note: Totals may not equal sum of components because of independent rounding.

Source: Energy Information Administration, Form ElA-412, "Annual Report of Public Electric Utilities." 
Table 24. Electric Utility Plant by Major U.S. Publicly Owned Electric Utility Within State at End of Period, 1992 (Continued) (Thousand Dollars)

\begin{tabular}{|c|c|c|c|c|c|c|}
\hline Item & $\begin{array}{l}\text { Arizona } \\
\text { Arizona } \\
\text { Power } \\
\text { Authority } \\
\text { June } 30\end{array}$ & $\begin{array}{c}\text { Arizona } \\
\text { Electrical } \\
\text { Dist } \\
\text { No2 } \\
\text { Pinal Cnty } \\
\text { December } 31\end{array}$ & $\begin{array}{l}\text { Arizona } \\
\text { Mesa } \\
\text { City of } \\
\text { June } 30\end{array}$ & $\begin{array}{c}\text { Arizona } \\
\text { Navajo } \\
\text { Tribal } \\
\text { Utility } \\
\text { Auth } \\
\text { December } 31\end{array}$ & $\begin{array}{l}\text { Arizona } \\
\text { Salt River } \\
\text { Proj Ag } \\
\text { I \& P Dist } \\
\text { April } 30\end{array}$ & $\begin{array}{c}\text { Arizona } \\
\text { Tohono } \\
\text { OOdham } \\
\text { Utility Auth } \\
\text { December } 31\end{array}$ \\
\hline 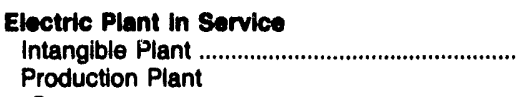 & 0 & 0 & 0 & 0 & 18,893 & 0 \\
\hline 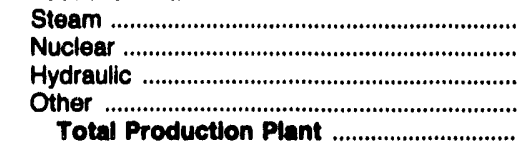 & $\begin{array}{l}0 \\
0 \\
0 \\
0 \\
0\end{array}$ & $\begin{array}{l}0 \\
0 \\
0 \\
0 \\
0\end{array}$ & $\begin{array}{l}0 \\
0 \\
0 \\
0 \\
0\end{array}$ & $\begin{array}{l}0 \\
0 \\
0 \\
0 \\
0\end{array}$ & $\begin{array}{r}1,513,542 \\
1,524,434 \\
69,993 \\
111,875 \\
3,219,843\end{array}$ & $\begin{array}{l}0 \\
0 \\
0 \\
0 \\
0\end{array}$ \\
\hline 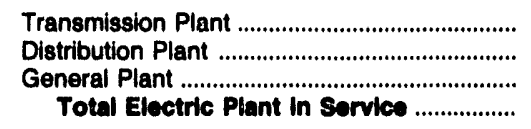 & $\begin{array}{r}289 \\
150 \\
687 \\
1,106\end{array}$ & $\begin{array}{r}0 \\
12,184 \\
1,045 \\
13,229\end{array}$ & $\begin{array}{r}0 \\
0 \\
47,151 \\
47,151\end{array}$ & $\begin{array}{r}7,313 \\
73,329 \\
9,470 \\
90,112\end{array}$ & $\begin{array}{r}462,370 \\
989,275 \\
480,206 \\
5,170,586\end{array}$ & $\begin{array}{r}938 \\
7,291 \\
822 \\
9,051\end{array}$ \\
\hline 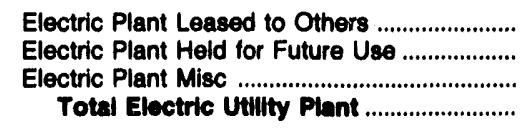 & $\begin{array}{r}0 \\
0 \\
0 \\
1,108\end{array}$ & $\begin{array}{r}0 \\
0 \\
1,090 \\
14,319\end{array}$ & $\begin{array}{r}0 \\
0 \\
0 \\
47,151\end{array}$ & $\begin{array}{r}0 \\
0 \\
5,237 \\
95,349\end{array}$ & $\begin{array}{r}49,801 \\
92,824 \\
41,847 \\
5,355,058\end{array}$ & $\begin{array}{r}0 \\
0 \\
0 \\
9,051\end{array}$ \\
\hline $\begin{array}{l}\text { Construction Work in Progress - Electric ........ } \\
\text { Accumulated Provision for }\end{array}$ & 0 & 0 & 3,204 & 6,854 & 210,090 & 51 \\
\hline 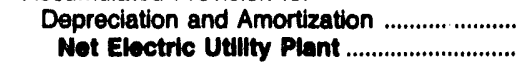 & $\begin{array}{l}571 \\
535\end{array}$ & $\begin{array}{l}6,449 \\
7,869\end{array}$ & $\begin{array}{l}11,002 \\
30,353\end{array}$ & $\begin{array}{l}32,774 \\
69,430\end{array}$ & $\begin{array}{l}1,454,475 \\
4,110,673\end{array}$ & $\begin{array}{l}2,384 \\
6,719\end{array}$ \\
\hline
\end{tabular}

\begin{tabular}{|c|c|c|c|c|c|c|}
\hline Item & $\begin{array}{l}\text { Arkansas } \\
\text { Benton } \\
\text { City of } \\
\text { December } 31\end{array}$ & $\begin{array}{c}\text { Arkaneas } \\
\text { Bentonville } \\
\text { City of } \\
\text { December } 31\end{array}$ & $\begin{array}{l}\text { Arkansas } \\
\text { Conway } \\
\text { Corp } \\
\text { December } 31\end{array}$ & $\begin{array}{c}\text { Arkansas } \\
\text { Hope } \\
\text { City of } \\
\text { December } 31\end{array}$ & $\begin{array}{c}\text { Arkansas } \\
\text { Jonesboro } \\
\text { City of } \\
\text { December } 31\end{array}$ & $\begin{array}{c}\text { Arkansas } \\
\text { North } \\
\text { Little } \\
\text { Rock } \\
\text { City of } \\
\text { December } 31\end{array}$ \\
\hline $\begin{array}{l}\text { Electuic Plant in service } \\
\text { Intangible Plant } \\
\text { Production Plant }\end{array}$ & 0 & 5,312 & 0 & 0 & 8,121 & 0 \\
\hline 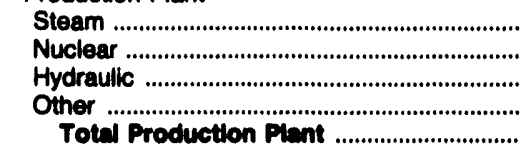 & $\begin{array}{r}0 \\
0 \\
0 \\
1,688 \\
1,896\end{array}$ & $\begin{array}{l}0 \\
0 \\
0 \\
0 \\
0\end{array}$ & $\begin{array}{r}38,147 \\
0 \\
0 \\
0 \\
38,147\end{array}$ & $\begin{array}{r}0 \\
0 \\
0 \\
4,395 \\
4,395\end{array}$ & $\begin{array}{r}75,596 \\
0 \\
0 \\
0 \\
75,596\end{array}$ & $\begin{array}{r}0 \\
0 \\
111,246 \\
0 \\
111,246\end{array}$ \\
\hline 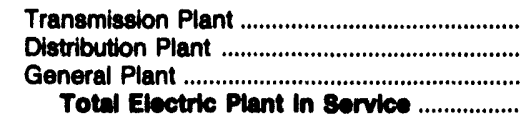 & $\begin{array}{r}0 \\
4,883 \\
0 \\
6,570\end{array}$ & $\begin{array}{r}0 \\
0 \\
20,697 \\
26,000\end{array}$ & $\begin{array}{r}0 \\
18,092 \\
4,587 \\
60,828\end{array}$ & $\begin{array}{r}0 \\
5,072 \\
623 \\
10,001\end{array}$ & $\begin{array}{r}511 \\
41,663 \\
6,895 \\
132,786\end{array}$ & $\begin{array}{r}0 \\
30,910 \\
4,452 \\
146,608\end{array}$ \\
\hline 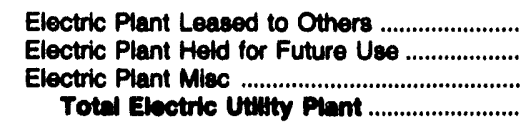 & $\begin{array}{r}0 \\
0 \\
0 \\
6,570\end{array}$ & $\begin{array}{r}0 \\
0 \\
0 \\
28,000\end{array}$ & $\begin{array}{r}0 \\
0 \\
0 \\
60,828\end{array}$ & $\begin{array}{r}0 \\
0 \\
0 \\
10,001\end{array}$ & $\begin{array}{r}0 \\
0 \\
0 \\
132,788\end{array}$ & $\begin{array}{r}0 \\
0 \\
0 \\
146,008\end{array}$ \\
\hline $\begin{array}{l}\text { Construction Work in Progress - Electric ....... } \\
\text { Accumulated Provision for }\end{array}$ & 0 & 1,841 & 69 & 386 & 2,622 & 812 \\
\hline 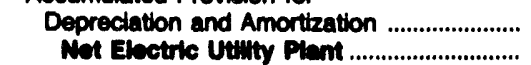 & $\begin{array}{l}4,867 \\
1,612\end{array}$ & $\begin{array}{r}7,713 \\
20,237\end{array}$ & $\begin{array}{l}20,645 \\
40,251\end{array}$ & $\begin{array}{l}4,223 \\
6,254\end{array}$ & $\begin{array}{l}53,073 \\
82,335\end{array}$ & $\begin{array}{r}26,840 \\
120,600\end{array}$ \\
\hline
\end{tabular}

Note: Totale may not equal sum of components because of independent rounding.

Source: Energy Information Adminietration, Form ElA-412, "Annual Report of Publlc Electric Utilities." 
Table 24. Electric Utility Plant by Major U.S. Publicly Owned Electric Utility Within State at End of Period, 1992 (Continued) (Thousand Dollars)

\begin{tabular}{|c|c|c|c|c|c|c|}
\hline Item & $\begin{array}{l}\text { Arkanses } \\
\text { Osceola } \\
\text { City of } \\
\text { December } 31\end{array}$ & $\begin{array}{c}\text { Arkansas } \\
\text { Paragould } \\
\text { Light } \\
\text { Water Comm } \\
\text { December } 31\end{array}$ & $\begin{array}{c}\text { Arkansas } \\
\text { Siloam } \\
\text { Springs } \\
\text { City of } \\
\text { December } 31\end{array}$ & $\begin{array}{c}\text { Arkansas } \\
\text { West } \\
\text { Memphis } \\
\text { City of } \\
\text { December } 31\end{array}$ & $\begin{array}{l}\text { Callfornia } \\
\text { Alameda } \\
\text { City of } \\
\text { June } 30\end{array}$ & $\begin{array}{l}\text { California } \\
\begin{array}{c}\text { Anaheim } \\
\text { City of }\end{array} \\
\text { June } 30\end{array}$ \\
\hline 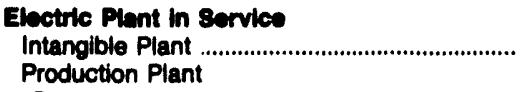 & 0 & 0 & 0 & 9,645 & 0 & 0 \\
\hline 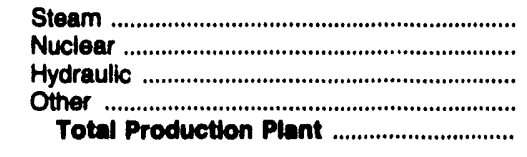 & $\begin{array}{l}0 \\
0 \\
0 \\
0 \\
0\end{array}$ & $\begin{array}{r}0 \\
0 \\
0 \\
8,863 \\
8,883\end{array}$ & $\begin{array}{l}0 \\
0 \\
0 \\
0 \\
0\end{array}$ & $\begin{array}{r}18,415 \\
0 \\
0 \\
0 \\
18,415\end{array}$ & $\begin{array}{l}0 \\
0 \\
0 \\
0 \\
0\end{array}$ & $\begin{array}{r}0 \\
184,869 \\
0 \\
32,798 \\
217,687\end{array}$ \\
\hline 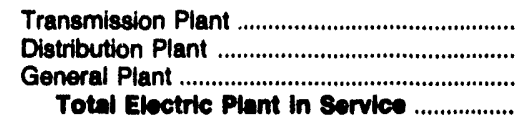 & $\begin{array}{r}0 \\
10,332 \\
7,900 \\
18,232\end{array}$ & $\begin{array}{r}0 \\
9,822 \\
5,586 \\
24,272\end{array}$ & $\begin{array}{r}550 \\
4,889 \\
50 \\
5,489\end{array}$ & $\begin{array}{r}0 \\
0 \\
0 \\
28,059\end{array}$ & $\begin{array}{r}3,488 \\
31,275 \\
4,694 \\
39,457\end{array}$ & $\begin{array}{r}13,052 \\
118,712 \\
11,740 \\
\mathbf{3 6 1 , 1 7 1}\end{array}$ \\
\hline 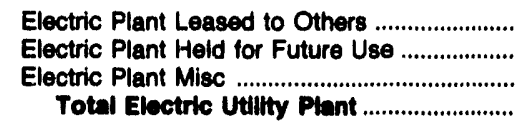 & $\begin{array}{r}0 \\
0 \\
0 \\
18,232\end{array}$ & $\begin{array}{r}0 \\
0 \\
0 \\
24,272\end{array}$ & $\begin{array}{r}0 \\
0 \\
0 \\
5,480\end{array}$ & $\begin{array}{r}0 \\
0 \\
0 \\
28,059\end{array}$ & $\begin{array}{r}0 \\
0 \\
0 \\
39,457\end{array}$ & $\begin{array}{r}0 \\
0 \\
0 \\
361,171\end{array}$ \\
\hline $\begin{array}{l}\text { Construction Work in Progress - Electric ........ } \\
\text { Accumulated Provision for }\end{array}$ & 0 & 151 & 397 & 0 & 0 & 40,568 \\
\hline 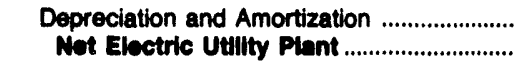 & $\begin{array}{r}7,569 \\
10,683\end{array}$ & $\begin{array}{r}8,697 \\
15,725\end{array}$ & $\begin{array}{l}3,010 \\
2,876\end{array}$ & $\begin{array}{l}11,449 \\
16,610\end{array}$ & $\begin{array}{l}10,945 \\
28,512\end{array}$ & $\begin{array}{r}95,052 \\
308,687\end{array}$ \\
\hline
\end{tabular}

\begin{tabular}{|c|c|c|c|c|c|c|}
\hline Item & $\begin{array}{l}\text { California } \\
\text { Azusa } \\
\text { City of } \\
\text { June } 30\end{array}$ & $\begin{array}{c}\text { California } \\
\text { Burbank } \\
\text { City of } \\
\text { June } 30\end{array}$ & $\begin{array}{l}\text { California } \\
\text { California } \\
\text { Dept } \\
\text { Wtr } \\
\text { Resources } \\
\text { June } 30\end{array}$ & $\begin{array}{l}\text { California } \\
\text { Colton } \\
\text { City of } \\
\text { June } 30\end{array}$ & $\begin{array}{c}\text { California } \\
\text { Glendale } \\
\text { City of } \\
\text { June } 30\end{array}$ & $\begin{array}{c}\text { California } \\
\text { Imperial } \\
\text { Imigation } \\
\text { District } \\
\text { December } 31\end{array}$ \\
\hline $\begin{array}{l}\text { Electric Piant in Service } \\
\text { Intangible Plant .................................................. } \\
\text { Production Plant }\end{array}$ & 0 & 15,973 & 0 & 0 & 0 & 769 \\
\hline 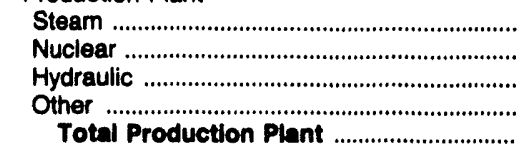 & $\begin{array}{l}0 \\
0 \\
0 \\
0 \\
0\end{array}$ & $\begin{array}{r}41,894 \\
0 \\
0 \\
0 \\
41,884\end{array}$ & $\begin{array}{r}0 \\
0 \\
546,977 \\
313,163 \\
860,140\end{array}$ & $\begin{array}{l}0 \\
0 \\
0 \\
0 \\
0\end{array}$ & $\begin{array}{r}59,318 \\
0 \\
0 \\
0 \\
59,318\end{array}$ & $\begin{array}{r}32,026 \\
0 \\
51,406 \\
21,284 \\
104,716\end{array}$ \\
\hline 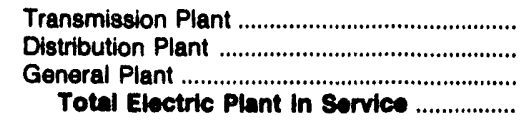 & $\begin{array}{r}0 \\
11,901 \\
0 \\
11,001\end{array}$ & $\begin{array}{r}16,504 \\
69,247 \\
9,551 \\
153,169\end{array}$ & $\begin{array}{r}0 \\
0 \\
0 \\
860,140\end{array}$ & $\begin{array}{r}0 \\
0 \\
13,270 \\
13,270\end{array}$ & $\begin{array}{r}47,020 \\
105,818 \\
12,535 \\
224,691\end{array}$ & $\begin{array}{r}187,975 \\
182,501 \\
49,304 \\
525,264\end{array}$ \\
\hline 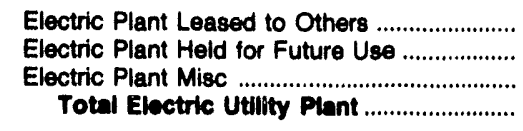 & $\begin{array}{r}0 \\
0 \\
0 \\
11,001\end{array}$ & $\begin{array}{r}0 \\
0 \\
0 \\
153,169\end{array}$ & $\begin{array}{r}0 \\
0 \\
0 \\
860,140\end{array}$ & $\begin{array}{r}0 \\
0 \\
0 \\
13,270\end{array}$ & $\begin{array}{r}0 \\
0 \\
0 \\
224,691\end{array}$ & $\begin{array}{r}0 \\
677 \\
0 \\
525,941\end{array}$ \\
\hline $\begin{array}{l}\text { Construction Work in Progress - Electric ........ } \\
\text { Accumulated Provision for }\end{array}$ & 0 & 12,038 & 0 & 0 & 27,183 & 49,547 \\
\hline 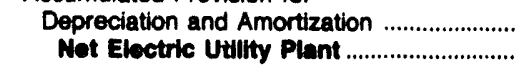 & $\begin{array}{l}4,023 \\
7,878\end{array}$ & $\begin{array}{l}87,386 \\
77,841\end{array}$ & $\begin{array}{l}244,388 \\
615,752\end{array}$ & $\begin{array}{l}4,664 \\
8,606\end{array}$ & $\begin{array}{l}116,910 \\
134,964\end{array}$ & $\begin{array}{l}162,822 \\
412,867\end{array}$ \\
\hline
\end{tabular}

Note: Totals may not equal sum of components because of independent rounding.

Source: Energy Information Administration, Form EIA-412, "Annual Report of Public Electric Utilities." 
Table 24. Electric Utility Plant by Major U.S. Publicly Owned Electric Utility Within State at End of Period, 1992 (Continued) (Thousand Dollars)

\begin{tabular}{|c|c|c|c|c|c|c|}
\hline Item & $\begin{array}{l}\text { Calfornia } \\
\text { Lodi } \\
\text { City of } \\
\text { June } 30\end{array}$ & $\begin{array}{l}\text { California } \\
\text { Los Angeles } \\
\text { City of } \\
\text { June } 30\end{array}$ & $\begin{array}{l}\text { California } \\
\text { Metropolitan } \\
\text { Water } \\
\text { District } \\
\text { June } 30\end{array}$ & $\begin{array}{l}\text { California } \\
\text { Modesto } \\
\text { Irrigation } \\
\text { District } \\
\text { December } 31\end{array}$ & $\begin{array}{c}\text { California } \\
\text { MSA } \\
\text { Public } \\
\text { Power } \\
\text { Agency } \\
\text { December } 31\end{array}$ & $\begin{array}{l}\text { California } \\
\text { Northern } \\
\text { California } \\
\text { Power Agny } \\
\text { June } 30\end{array}$ \\
\hline 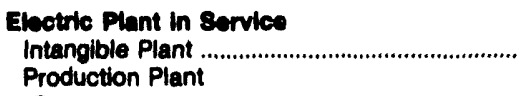 & 0 & 0 & 0 & 122 & 99 & 0 \\
\hline 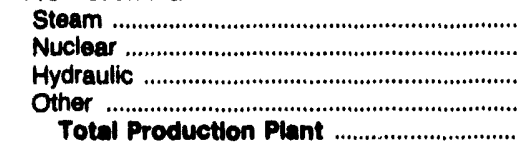 & $\begin{array}{l}0 \\
0 \\
0 \\
0 \\
0\end{array}$ & $\begin{array}{r}.924,632 \\
504,275 \\
474,612 \\
11,946 \\
1,915,464\end{array}$ & $\begin{array}{r}0 \\
0 \\
103,038 \\
0 \\
103,038\end{array}$ & $\begin{array}{r}0 \\
0 \\
26,424 \\
23,302 \\
49,727\end{array}$ & $\begin{array}{r}274,278 \\
0 \\
0 \\
0 \\
274,278\end{array}$ & $\begin{array}{r}490,888 \\
0 \\
361,979 \\
47,737 \\
900,804\end{array}$ \\
\hline 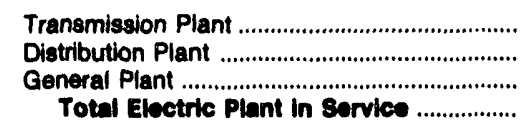 & $\begin{array}{r}0 \\
20,814 \\
0 \\
20,814\end{array}$ & $\begin{array}{r}712,470 \\
2,584,713 \\
546,154 \\
5,758,802\end{array}$ & $\begin{array}{r}0 \\
0 \\
0 \\
103,038\end{array}$ & $\begin{array}{r}9,234 \\
105,773 \\
37,514 \\
202,370\end{array}$ & $\begin{array}{r}0 \\
0 \\
954 \\
275,331\end{array}$ & $\begin{array}{r}3,831 \\
0 \\
4,937 \\
909,372\end{array}$ \\
\hline 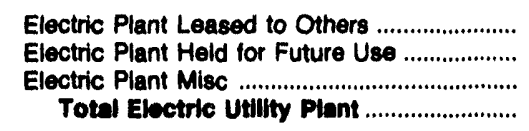 & $\begin{array}{r}0 \\
0 \\
0 \\
20,814\end{array}$ & $\begin{array}{r}0 \\
0 \\
-42,622 \\
5,716,181\end{array}$ & $\begin{array}{r}0 \\
0 \\
0 \\
103,038\end{array}$ & $\begin{array}{r}0 \\
0 \\
0 \\
202,370\end{array}$ & $\begin{array}{r}0 \\
0 \\
0 \\
275,331\end{array}$ & $\begin{array}{r}0 \\
0 \\
0 \\
909,372\end{array}$ \\
\hline $\begin{array}{l}\text { Construction Work in Progress - Electric ........ } \\
\text { Accumulated Provision for }\end{array}$ & 6,553 & 356,913 & 9,670 & 30,694 & 5,308 & 10,125 \\
\hline $\begin{array}{l}\text { Depreciation and Amortization } \\
\text { Not Eloctric Utillty Plant }\end{array}$ & $\begin{array}{r}9,567 \\
17,790\end{array}$ & $\begin{array}{l}1,790,020 \\
4,283,074\end{array}$ & $\begin{array}{l}17,989 \\
94,719\end{array}$ & $\begin{array}{r}76,812 \\
156,251\end{array}$ & $\begin{array}{r}76,505 \\
204,134\end{array}$ & $\begin{array}{l}170,973 \\
748,524\end{array}$ \\
\hline
\end{tabular}

\begin{tabular}{|c|c|c|c|c|c|c|}
\hline Item & $\begin{array}{l}\text { California } \\
\text { Oakdale \& } \\
\text { South } \\
\text { San Joaquin } \\
\text { December } 31\end{array}$ & $\begin{array}{c}\text { Callfornia } \\
\text { Oroville } \\
\text { Wyandotte } \\
\text { Irrig Dist } \\
\text { December } 31\end{array}$ & $\begin{array}{l}\text { California } \\
\text { Palo Alto } \\
\text { City of } \\
\text { June } 30\end{array}$ & $\begin{array}{l}\text { California } \\
\text { Pasadena } \\
\text { City of } \\
\text { June } 30\end{array}$ & $\begin{array}{c}\text { California } \\
\text { Placer } \\
\text { County } \\
\text { Water } \\
\text { Agency } \\
\text { December } 31\end{array}$ & $\begin{array}{l}\text { California } \\
\text { Redding } \\
\text { City of } \\
\text { June } 30\end{array}$ \\
\hline 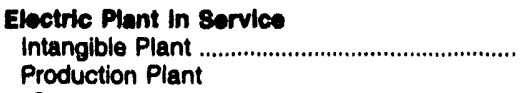 & 0 & 0 & 0 & 0 & 143 & 0 \\
\hline 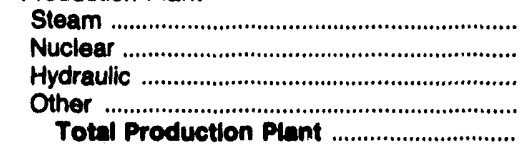 & $\begin{array}{r}0 \\
0 \\
58,353 \\
0 \\
68,353\end{array}$ & $\begin{array}{r}0 \\
0 \\
79,926 \\
0 \\
79,928\end{array}$ & $\begin{array}{l}0 \\
0 \\
0 \\
0 \\
0\end{array}$ & $\begin{array}{r}38,220 \\
0 \\
5,601 \\
6,388 \\
50,210\end{array}$ & $\begin{array}{r}0 \\
0 \\
110,924 \\
8 \\
110,932\end{array}$ & $\begin{array}{l}0 \\
0 \\
0 \\
0 \\
0\end{array}$ \\
\hline 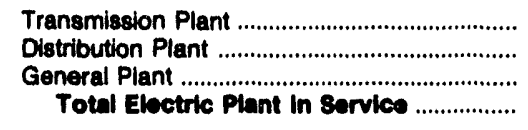 & $\begin{array}{r}0 \\
0 \\
1,862 \\
60,213\end{array}$ & $\begin{array}{r}1,136 \\
0 \\
4,010 \\
85,072\end{array}$ & $\begin{array}{r}0 \\
97,144 \\
0 \\
97,144\end{array}$ & $\begin{array}{r}38,535 \\
120,268 \\
4,106 \\
213,118\end{array}$ & $\begin{array}{r}437 \\
0 \\
5,707 \\
117,220\end{array}$ & $\begin{array}{r}0 \\
0 \\
101,222 \\
101,222\end{array}$ \\
\hline 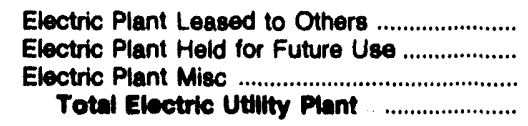 & $\begin{array}{r}0 \\
0 \\
0 \\
60,218\end{array}$ & $\begin{array}{r}0 \\
0 \\
0 \\
85,072\end{array}$ & $\begin{array}{r}0 \\
0 \\
0 \\
97,144\end{array}$ & $\begin{array}{r}0 \\
0 \\
0 \\
213,118\end{array}$ & $\begin{array}{r}0 \\
0 \\
0 \\
117,220\end{array}$ & $\begin{array}{r}0 \\
13,734 \\
0 \\
114,955\end{array}$ \\
\hline $\begin{array}{l}\text { Construction Work in Progress - Electric ........ } \\
\text { Accumulated Provision for }\end{array}$ & 339 & 783 & 13,064 & 10,005 & 0 & 10,370 \\
\hline 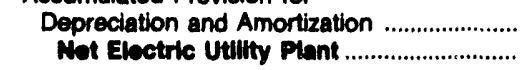 & $\begin{array}{l}21,834 \\
38,620\end{array}$ & $\begin{array}{l}35,511 \\
60,343\end{array}$ & $\begin{array}{l}38,401 \\
71,807\end{array}$ & $\begin{array}{r}99,851 \\
123,272\end{array}$ & $\begin{array}{l}39,743 \\
77,477\end{array}$ & $\begin{array}{l}34,534 \\
90,791\end{array}$ \\
\hline
\end{tabular}

Note: Totals may not equal sum of components because of independent rounding.

Source: Energy Information Administration, Form ElA-412, "Annual Report of Public Electric Utilities." 
Table 24. Electric Utillty Plant by Major U.S. Publicly Owned Electric Utillty Within State at End of Period, 1992 (Continued)

(Thousand Dollars)

\begin{tabular}{|c|c|c|c|c|c|c|}
\hline Item & $\begin{array}{l}\text { California } \\
\text { Riverside } \\
\text { City of } \\
\text { June } 30\end{array}$ & $\begin{array}{l}\text { Callfornia } \\
\text { Roseville } \\
\text { Clty of } \\
\text { June } 30\end{array}$ & $\begin{array}{l}\text { California } \\
\text { Sacramento } \\
\text { Municipal } \\
\text { Utii Dist } \\
\text { December } 31\end{array}$ & $\begin{array}{c}\text { Callfornia } \\
\text { San Francisco } \\
\text { City } \\
\& \\
\text { County of } \\
\text { June } 30\end{array}$ & $\begin{array}{c}\text { California } \\
\text { Santa } \\
\text { Clara } \\
\text { City of } \\
\text { June } 30\end{array}$ & $\begin{array}{l}\text { California } \\
\text { Southern } \\
\text { California } \\
\text { P P } \\
\text { A } \\
\text { June } 30\end{array}$ \\
\hline 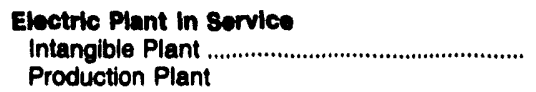 & 0 & 0 & 147 & 7,658 & 0 & 7,445 \\
\hline 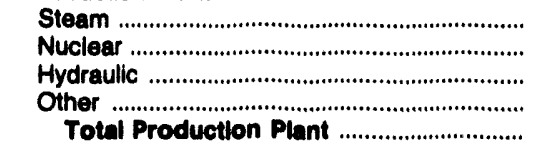 & $\begin{array}{r}0 \\
116,779 \\
0 \\
0 \\
116,770\end{array}$ & $\begin{array}{l}0 \\
0 \\
0 \\
0 \\
0\end{array}$ & $\begin{array}{r}93,187 \\
0 \\
230,320 \\
31,812 \\
355,419\end{array}$ & $\begin{array}{r}0 \\
0 \\
90,874 \\
0 \\
90,874\end{array}$ & $\begin{array}{r}0 \\
0 \\
58,019 \\
18,792 \\
76,812\end{array}$ & $\begin{array}{r}0 \\
592,034 \\
0 \\
0 \\
502,034\end{array}$ \\
\hline 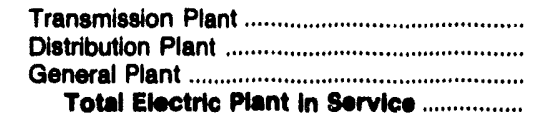 & $\begin{array}{r}11,408 \\
125,967 \\
7,655 \\
281,808\end{array}$ & $\begin{array}{r}0 \\
66,919 \\
777 \\
67,696\end{array}$ & $\begin{array}{r}142,249 \\
622,089 \\
191,233 \\
1,311,137\end{array}$ & $\begin{array}{r}14,052 \\
78,157 \\
3,128 \\
193,870\end{array}$ & $\begin{array}{r}0 \\
0 \\
89,532 \\
186,343\end{array}$ & $\begin{array}{r}684,715 \\
0 \\
21,161 \\
1,305,355\end{array}$ \\
\hline 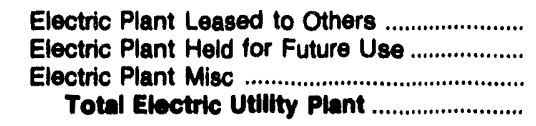 & $\begin{array}{r}0 \\
0 \\
0 \\
281,808\end{array}$ & $\begin{array}{r}0 \\
0 \\
0 \\
67,698\end{array}$ & $\begin{array}{r}15,128 \\
111 \\
13,241 \\
1,339,617\end{array}$ & $\begin{array}{r}0 \\
0 \\
242,147 \\
436,016\end{array}$ & $\begin{array}{r}0 \\
0 \\
0 \\
166,343\end{array}$ & $\begin{array}{r}0 \\
0 \\
0 \\
1,305,355\end{array}$ \\
\hline $\begin{array}{l}\text { Construction Work in Progress - Electric ........ } \\
\text { Accumulated Provision for }\end{array}$ & 20,543 & 228 & 122,893 & 7,254 & 43,155 & 30,786 \\
\hline 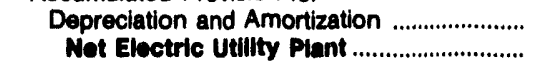 & $\begin{array}{r}85,481 \\
198,870\end{array}$ & $\begin{array}{l}11,074 \\
56,850\end{array}$ & $\begin{array}{r}368,795 \\
1,093,715\end{array}$ & $\begin{array}{l}178,337 \\
284,033\end{array}$ & $\begin{array}{r}47,738 \\
161,760\end{array}$ & $\begin{array}{r}244,218 \\
1,001,023\end{array}$ \\
\hline
\end{tabular}

\begin{tabular}{|c|c|c|c|c|c|c|}
\hline Item & $\begin{array}{c}\text { Calfornia } \\
\text { Turlock } \\
\text { Irrigation } \\
\text { District } \\
\text { December } 31\end{array}$ & $\begin{array}{l}\text { California } \\
\text { Vernon } \\
\text { City of } \\
\text { June } 30\end{array}$ & $\begin{array}{c}\text { California } \\
\text { Yuba } \\
\text { County } \\
\text { Water } \\
\text { Agency } \\
\text { June } 30\end{array}$ & $\begin{array}{c}\text { Colorado } \\
\text { Arkansas } \\
\text { Rlver } \\
\text { Power } \\
\text { Authority } \\
\text { December } 31\end{array}$ & $\begin{array}{l}\text { Colorado } \\
\text { Colorado } \\
\text { Springs } \\
\text { City of } \\
\text { December } 31\end{array}$ & $\begin{array}{l}\text { Colorado } \\
\begin{array}{c}\text { Fort Collins } \\
\text { City of }\end{array} \\
\text { December } 31\end{array}$ \\
\hline 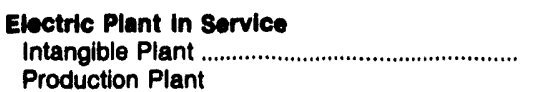 & 0 & 0 & 334 & 0 & 0 & 3 \\
\hline $\begin{array}{l}\text { Steam } \\
\text { Nuclear } \\
\text { Hydraulic } \\
\text { Other } \\
\text { Total Production Plant }\end{array}$ & $\begin{array}{r}0 \\
0 \\
80,482 \\
15,070 \\
95,552\end{array}$ & $\begin{array}{r}0 \\
0 \\
0 \\
4,358 \\
4,368\end{array}$ & $\begin{array}{r}0 \\
0 \\
187,803 \\
0 \\
187,803\end{array}$ & $\begin{array}{l}0 \\
0 \\
0 \\
0 \\
0\end{array}$ & $\begin{array}{r}233,775 \\
0 \\
2,384 \\
0 \\
236,150\end{array}$ & $\begin{array}{l}0 \\
0 \\
0 \\
0 \\
0\end{array}$ \\
\hline 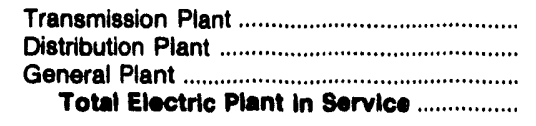 & $\begin{array}{r}18,672 \\
80,982 \\
18,685 \\
213,002\end{array}$ & $\begin{array}{r}12,492 \\
19,462 \\
1,430 \\
37,741\end{array}$ & $\begin{array}{r}1,153 \\
0 \\
2,465 \\
191,755\end{array}$ & $\begin{array}{r}2,710 \\
0 \\
0 \\
2,710\end{array}$ & $\begin{array}{r}47,352 \\
313,304 \\
23,948 \\
620,764\end{array}$ & $\begin{array}{r}1,782 \\
64,465 \\
13,138 \\
79,388\end{array}$ \\
\hline 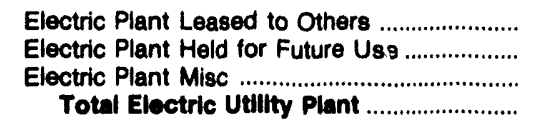 & $\begin{array}{r}0 \\
0 \\
0 \\
213,902\end{array}$ & $\begin{array}{r}0 \\
0 \\
0 \\
37,741\end{array}$ & $\begin{array}{r}0 \\
0 \\
4,485 \\
196,241\end{array}$ & $\begin{array}{r}0 \\
0 \\
0 \\
2,710\end{array}$ & $\begin{array}{r}377 \\
0 \\
0 \\
621,142\end{array}$ & $\begin{array}{r}0 \\
0 \\
0 \\
79,388\end{array}$ \\
\hline $\begin{array}{l}\text { Construction Work in Progress - Electric ........ } \\
\text { Accumulated Provision for }\end{array}$ & 5,412 & in, & 0 & 0 & 15,024 & 3,772 \\
\hline 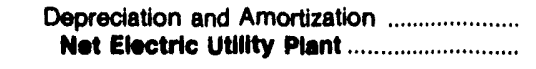 & $\begin{array}{r}66,739 \\
152,575\end{array}$ & $\begin{array}{l}19,729 \\
44,880\end{array}$ & $\begin{array}{r}49,878 \\
146,363\end{array}$ & $\begin{array}{r}215 \\
2,405\end{array}$ & $\begin{array}{r}154,561 \\
481,604\end{array}$ & $\begin{array}{l}31,711 \\
51,450\end{array}$ \\
\hline
\end{tabular}

Note: Totals may not equal sum of components because of independent rC unding.

Source: Energy Information Administration, Form EIA-412, "Annual Report of Public Electric Utilities." 
Table 24. Electric Utility Plant by Major U.S. Publlcly Owned Electric Utillty Within State at End of Period, 1992 (Continued) (Thousand Dollars)

\begin{tabular}{|c|c|c|c|c|c|c|}
\hline Item & $\begin{array}{l}\text { Colorado } \\
\text { Longmont } \\
\text { City of }\end{array}$ & $\begin{array}{l}\text { Colorado } \\
\text { Loveland } \\
\text { City of } \\
\text { December } 31\end{array}$ & $\begin{array}{l}\text { Colorado } \\
\text { Platte River } \\
\text { Power } \\
\text { Authority } \\
\text { December } 31\end{array}$ & $\begin{array}{l}\text { Connecticut } \\
\text { Connecticut } \\
\text { Mun } \\
\text { Elec } \\
\text { Engy Coop } \\
\text { December } 31\end{array}$ & $\begin{array}{l}\text { Connecticut } \\
\text { Groton } \\
\text { City of } \\
\text { June } 30\end{array}$ & $\begin{array}{l}\text { Connecticut } \\
\text { Nonwich } \\
\text { City of } \\
\text { June } 30\end{array}$ \\
\hline 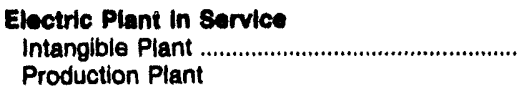 & 0 & 0 & 0 & 942 & 0 & 0 \\
\hline 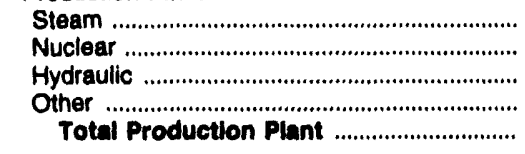 & $\begin{array}{r}0 \\
0 \\
3,738 \\
0 \\
3,738\end{array}$ & $\begin{array}{r}0 \\
0 \\
1,354 \\
0 \\
1,354\end{array}$ & $\begin{array}{r}628,298 \\
0 \\
0 \\
0 \\
628,290\end{array}$ & $\begin{array}{r}0 \\
50,238 \\
0 \\
0 \\
50,238\end{array}$ & $\begin{array}{l}0 \\
0 \\
0 \\
0 \\
0\end{array}$ & $\begin{array}{r}0 \\
0 \\
2,485 \\
2,377 \\
4,882\end{array}$ \\
\hline 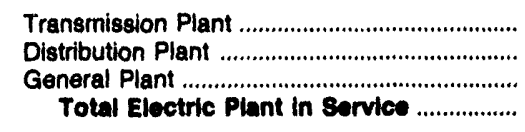 & $\begin{array}{r}0 \\
30,885 \\
306 \\
34,910\end{array}$ & $\begin{array}{r}3,833 \\
31,027 \\
3,566 \\
39,881\end{array}$ & $\begin{array}{r}94,517 \\
0 \\
10,111 \\
732,026\end{array}$ & $\begin{array}{r}272 \\
0 \\
1,844 \\
63,395\end{array}$ & $\begin{array}{r}5,149 \\
14,703 \\
2,768 \\
22,620\end{array}$ & $\begin{array}{r}2,523 \\
13,423 \\
2,900 \\
23,708\end{array}$ \\
\hline 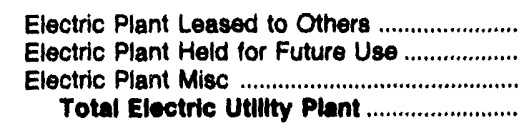 & $\begin{array}{r}0 \\
0 \\
0 \\
34,910\end{array}$ & $\begin{array}{r}0 \\
0 \\
0 \\
39,881\end{array}$ & $\begin{array}{r}0 \\
0 \\
24,387 \\
757,313\end{array}$ & $\begin{array}{r}0 \\
0 \\
0 \\
53,395\end{array}$ & $\begin{array}{r}0 \\
0 \\
827 \\
23,446\end{array}$ & $\begin{array}{r}0 \\
0 \\
0 \\
23,708\end{array}$ \\
\hline $\begin{array}{l}\text { Construction Work in Progress - Electric ....... } \\
\text { Accumulated Provision for }\end{array}$ & 0 & 623 & 4,830 & 863 & 0 & 3,907 \\
\hline 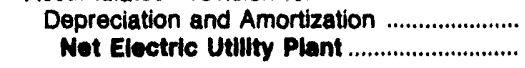 & $\begin{array}{l}13,586 \\
21,324\end{array}$ & $\begin{array}{r}8,613 \\
31,890\end{array}$ & $\begin{array}{l}206,349 \\
555,794\end{array}$ & $\begin{array}{l}10,717 \\
43,842\end{array}$ & $\begin{array}{l}13,228 \\
10,219\end{array}$ & $\begin{array}{l}15,617 \\
11,090\end{array}$ \\
\hline
\end{tabular}

\begin{tabular}{|c|c|c|c|c|c|c|}
\hline Item & $\begin{array}{l}\text { Connecticut } \\
\text { Wallingford } \\
\text { Town of } \\
\text { June } 30\end{array}$ & $\begin{array}{l}\text { Delaware } \\
\text { Dover } \\
\text { City of } \\
\text { June } 30\end{array}$ & $\begin{array}{l}\text { Delaware } \\
\text { Miliord } \\
\text { City of } \\
\text { September } 30\end{array}$ & $\begin{array}{l}\text { Delaware } \\
\text { Newark } \\
\text { City of } \\
\text { December } 31\end{array}$ & $\begin{array}{l}\text { Florida } \\
\text { Bartow } \\
\text { City of } \\
\text { September } 30\end{array}$ & $\begin{array}{c}\text { Florida } \\
\text { Florida } \\
\text { Municipal } \\
\text { Power Agency } \\
\text { September } 30\end{array}$ \\
\hline $\begin{array}{l}\text { Ebetric Plant In Sorvice } \\
\text { Intangible Plant ........................................................ } \\
\text { Production Plant }\end{array}$ & 0 & 0 & 0 & 0 & 0 & 42 \\
\hline 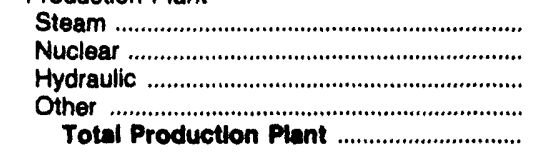 & $\begin{array}{r}6,301 \\
0 \\
0 \\
0 \\
6,301\end{array}$ & $\begin{array}{r}58,898 \\
0 \\
0 \\
0 \\
59,808\end{array}$ & $\begin{array}{l}0 \\
0 \\
0 \\
0 \\
0\end{array}$ & $\begin{array}{l}0 \\
0 \\
0 \\
0 \\
0\end{array}$ & $\begin{array}{l}0 \\
0 \\
0 \\
0 \\
0\end{array}$ & $\begin{array}{r}130,448 \\
169,589 \\
0 \\
18,021 \\
318,098\end{array}$ \\
\hline 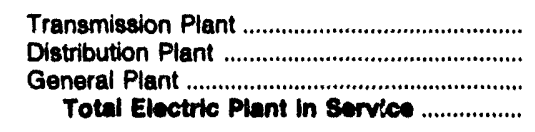 & $\begin{array}{r}1,269 \\
29,163 \\
3,730 \\
10,462\end{array}$ & $\begin{array}{r}14,572 \\
15,912 \\
1,506 \\
91,898\end{array}$ & $\begin{array}{r}0 \\
0 \\
6,795 \\
6,795\end{array}$ & $\begin{array}{l}0 \\
0 \\
0 \\
0\end{array}$ & $\begin{array}{r}0 \\
9,658 \\
0 \\
9,658\end{array}$ & $\begin{array}{r}0 \\
0 \\
55 \\
318,185\end{array}$ \\
\hline 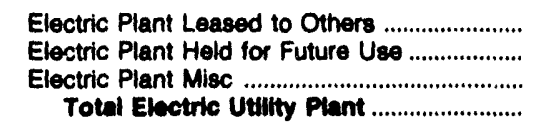 & $\begin{array}{r}0 \\
0 \\
0 \\
40,402\end{array}$ & $\begin{array}{r}0 \\
0 \\
0 \\
91,898\end{array}$ & $\begin{array}{r}0 \\
0 \\
0 \\
6,795\end{array}$ & $\begin{array}{l}0 \\
0 \\
0 \\
0\end{array}$ & $\begin{array}{r}0 \\
0 \\
0 \\
9,868\end{array}$ & $\begin{array}{r}0 \\
0 \\
0 \\
318,185\end{array}$ \\
\hline $\begin{array}{l}\text { Construction Work in Progress - Electric ........ } \\
\text { Accumulated Provision for }\end{array}$ & 803 & 0 & 0 & 0 & 0 & 8,976 \\
\hline 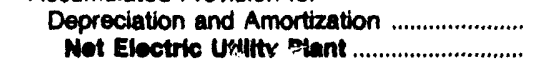 & $\begin{array}{l}23,377 \\
17,808\end{array}$ & $\begin{array}{l}27,649 \\
64,230\end{array}$ & $\begin{array}{l}3,283 \\
3,612\end{array}$ & $\begin{array}{l}0 \\
0\end{array}$ & $\begin{array}{l}4,555 \\
5,103\end{array}$ & $\begin{array}{r}56,286 \\
270,856\end{array}$ \\
\hline
\end{tabular}

Note: Totals may not equal sum of components because of independent rounding.

Source: Energy information Administration, Form ElA-412, "Annual Report of Public Electric Utilites." 
Table 24. Electric Utility Plant by Major U.S. Publlcly Owned Electric Utillty Within State at End of Perlod, 1992 (Continued)

(Thousand Dollars)

\begin{tabular}{|c|c|c|c|c|c|c|}
\hline Item & $\begin{array}{l}\text { Florida } \\
\text { Fort Plerce } \\
\text { Utilities } \\
\text { Auth } \\
\text { September } 30\end{array}$ & $\begin{array}{c}\text { Florida } \\
\text { Gainesville } \\
\text { Regional } \\
\text { Utilities } \\
\text { September } 30\end{array}$ & $\begin{array}{c}\text { Florida } \\
\begin{array}{c}\text { Homestead } \\
\text { Clty of }\end{array} \\
\text { September } 30\end{array}$ & $\begin{array}{c}\text { Florida } \\
\text { Jacksonville } \\
\text { Beach } \\
\text { City of } \\
\text { September } 30\end{array}$ & $\begin{array}{l}\text { Florida } \\
\text { Jacksonville } \\
\text { Electric } \\
\text { Auth } \\
\text { September } 30\end{array}$ & $\begin{array}{l}\text { Florida } \\
\text { Key West } \\
\text { City of } \\
\text { September } 30\end{array}$ \\
\hline $\begin{array}{l}\text { Electiric Pient in service } \\
\text { Intangible Plant ..................................................... } \\
\text { Production Plant }\end{array}$ & 0 & 0 & 0 & 0 & 0 & 220 \\
\hline 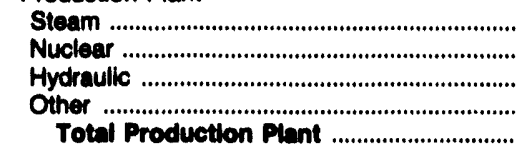 & $\begin{array}{r}38,695 \\
0 \\
0 \\
781 \\
39,476\end{array}$ & $\begin{array}{r}223,299 \\
10,015 \\
0 \\
11,571 \\
244,096\end{array}$ & $\begin{array}{r}0 \\
0 \\
0 \\
38,927 \\
38,927\end{array}$ & $\begin{array}{l}0 \\
0 \\
0 \\
0 \\
0\end{array}$ & $\begin{array}{r}1,811,847 \\
0 \\
0 \\
48,131 \\
1,858,977\end{array}$ & $\begin{array}{r}40,741 \\
0 \\
0 \\
35,582 \\
76,323\end{array}$ \\
\hline 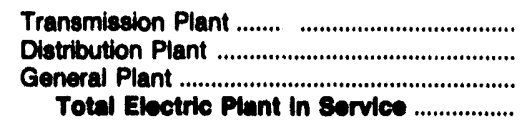 & $\begin{array}{r}15,864 \\
28,405 \\
6,654 \\
80,4 \oplus 0\end{array}$ & $\begin{array}{r}127,947 \\
0 \\
25,084 \\
397,016\end{array}$ & $\begin{array}{r}0 \\
0 \\
0 \\
\mathbf{3 8 , 9 2 7}\end{array}$ & $\begin{array}{r}0 \\
60,177 \\
0 \\
60,177\end{array}$ & $\begin{array}{r}249,096 \\
529,170 \\
96,353 \\
2,734,596\end{array}$ & $\begin{array}{r}31,211 \\
27,298 \\
7,882 \\
142,035\end{array}$ \\
\hline 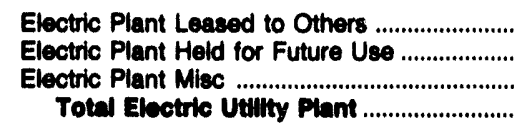 & $\begin{array}{r}0 \\
0 \\
0 \\
80,490\end{array}$ & $\begin{array}{r}0 \\
0 \\
0 \\
397,916\end{array}$ & $\begin{array}{r}0 \\
0 \\
0 \\
38,927\end{array}$ & $\begin{array}{r}0 \\
0 \\
0 \\
60,177\end{array}$ & $\begin{array}{r}0 \\
1,048 \\
0 \\
2,735,644\end{array}$ & $\begin{array}{r}0 \\
0 \\
0 \\
142,935\end{array}$ \\
\hline $\begin{array}{l}\text { Construction Work in Progress - Electric ........ } \\
\text { Accumulated Provision for }\end{array}$ & 6,753 & 8,308 & 2,388 & 6,141 & 30,977 & 3,297 \\
\hline 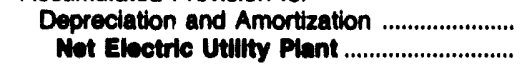 & $\begin{array}{l}38,902 \\
58,350\end{array}$ & $\begin{array}{l}125,011 \\
281,213\end{array}$ & $\begin{array}{l}18,865 \\
22,460\end{array}$ & $\begin{array}{l}17,416 \\
48,902\end{array}$ & $\begin{array}{r}492,838 \\
2,273,783\end{array}$ & $\begin{array}{l}54,325 \\
91,806\end{array}$ \\
\hline
\end{tabular}

\begin{tabular}{|c|c|c|c|c|c|c|}
\hline Item & $\begin{array}{c}\text { Florida } \\
\text { Kissimmee } \\
\text { Utility } \\
\text { Authority } \\
\text { September } 30\end{array}$ & $\begin{array}{l}\text { Florida } \\
\text { Lake Worth } \\
\text { City of } \\
\text { September } 30\end{array}$ & $\begin{array}{l}\text { Florida } \\
\text { Lakeland } \\
\text { City of } \\
\text { September } 30\end{array}$ & $\begin{array}{l}\text { Florida } \\
\text { Leesburg } \\
\text { City of } \\
\text { September } 30\end{array}$ & $\begin{array}{c}\text { Florida } \\
\text { New Smyrna } \\
\text { Beach } \\
\text { Utils Comm } \\
\text { September } 30\end{array}$ & $\begin{array}{c}\text { Florida } \\
\text { Ocala } \\
\text { City of } \\
\text { September } 30\end{array}$ \\
\hline $\begin{array}{l}\text { Electric Plant in Sorvice } \\
\text { Intangible Plant ................................................. } \\
\text { Production Plant }\end{array}$ & 387 & 59 & 0 & 97 & 408 & 0 \\
\hline 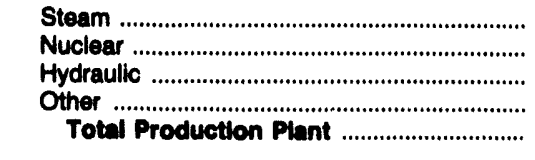 & $\begin{array}{r}20,912 \\
4,610 \\
0 \\
42,883 \\
68,416\end{array}$ & $\begin{array}{r}18,600 \\
0 \\
0 \\
17,964 \\
36,584\end{array}$ & $\begin{array}{r}250,920 \\
0 \\
0 \\
36,465 \\
287,385\end{array}$ & $\begin{array}{r}0 \\
7,310 \\
0 \\
0 \\
7,310\end{array}$ & $\begin{array}{r}0 \\
3,900 \\
0 \\
6,510 \\
10,410\end{array}$ & $\begin{array}{r}0 \\
10,103 \\
0 \\
0 \\
10,103\end{array}$ \\
\hline 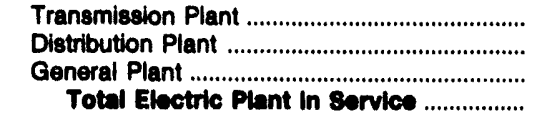 & $\begin{array}{r}22,347 \\
28,626 \\
15,223 \\
134,098\end{array}$ & $\begin{array}{r}25,856 \\
0 \\
0 \\
62,470\end{array}$ & $\begin{array}{r}47,366 \\
107,386 \\
42,186 \\
484,332\end{array}$ & $\begin{array}{r}0 \\
32,297 \\
5,403 \\
45,108\end{array}$ & $\begin{array}{r}6,537 \\
27,445 \\
3,110 \\
47,810\end{array}$ & $\begin{array}{r}6,787 \\
52,522 \\
835 \\
70,247\end{array}$ \\
\hline 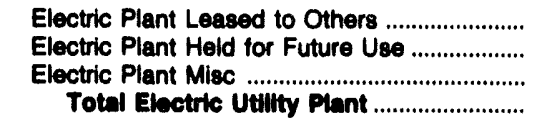 & $\begin{array}{r}0 \\
504 \\
0 \\
135,502\end{array}$ & $\begin{array}{r}0 \\
68 \\
0 \\
62,547\end{array}$ & $\begin{array}{r}0 \\
2,631 \\
0 \\
496,803\end{array}$ & $\begin{array}{r}0 \\
0 \\
0 \\
45,108\end{array}$ & $\begin{array}{r}0 \\
0 \\
0 \\
47,810\end{array}$ & $\begin{array}{r}0 \\
0 \\
0 \\
70,247\end{array}$ \\
\hline $\begin{array}{l}\text { Construction Work in Progress - Electric ........ } \\
\text { Accumulated Provision for }\end{array}$ & 8,788 & 8,267 & 39,835 & 1,717 & 3,314 & 12,931 \\
\hline 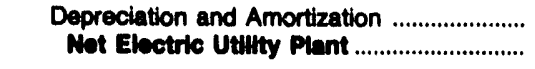 & $\begin{array}{r}43,643 \\
100,640\end{array}$ & $\begin{array}{l}33,957 \\
37,858\end{array}$ & $\begin{array}{l}145,884 \\
380,014\end{array}$ & $\begin{array}{l}14,957 \\
31,806\end{array}$ & $\begin{array}{l}17,933 \\
33,292\end{array}$ & $\begin{array}{l}25,784 \\
57,394\end{array}$ \\
\hline
\end{tabular}

Note: Totals may not equal sum of components because of independent rounding.

Source: Energy Information Administratic ?, Form EIA-412, "Annual Report of Public Electric Utilities." 
Table 24. Electric Utility Plant by Major U.S. Publicly Owned Electric Utility Within State at End of Period, 1992 (Continued) (Thousand Dollars)

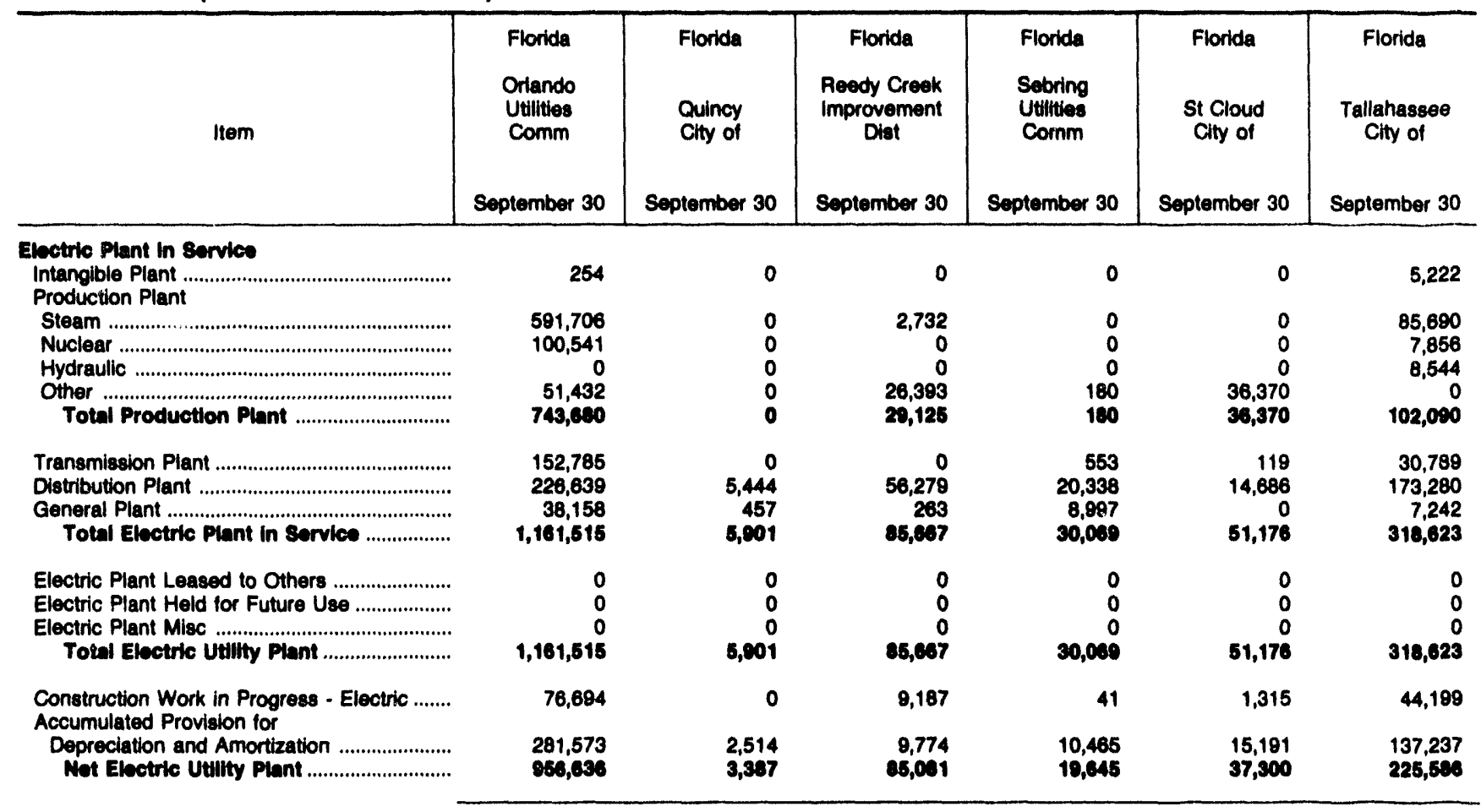

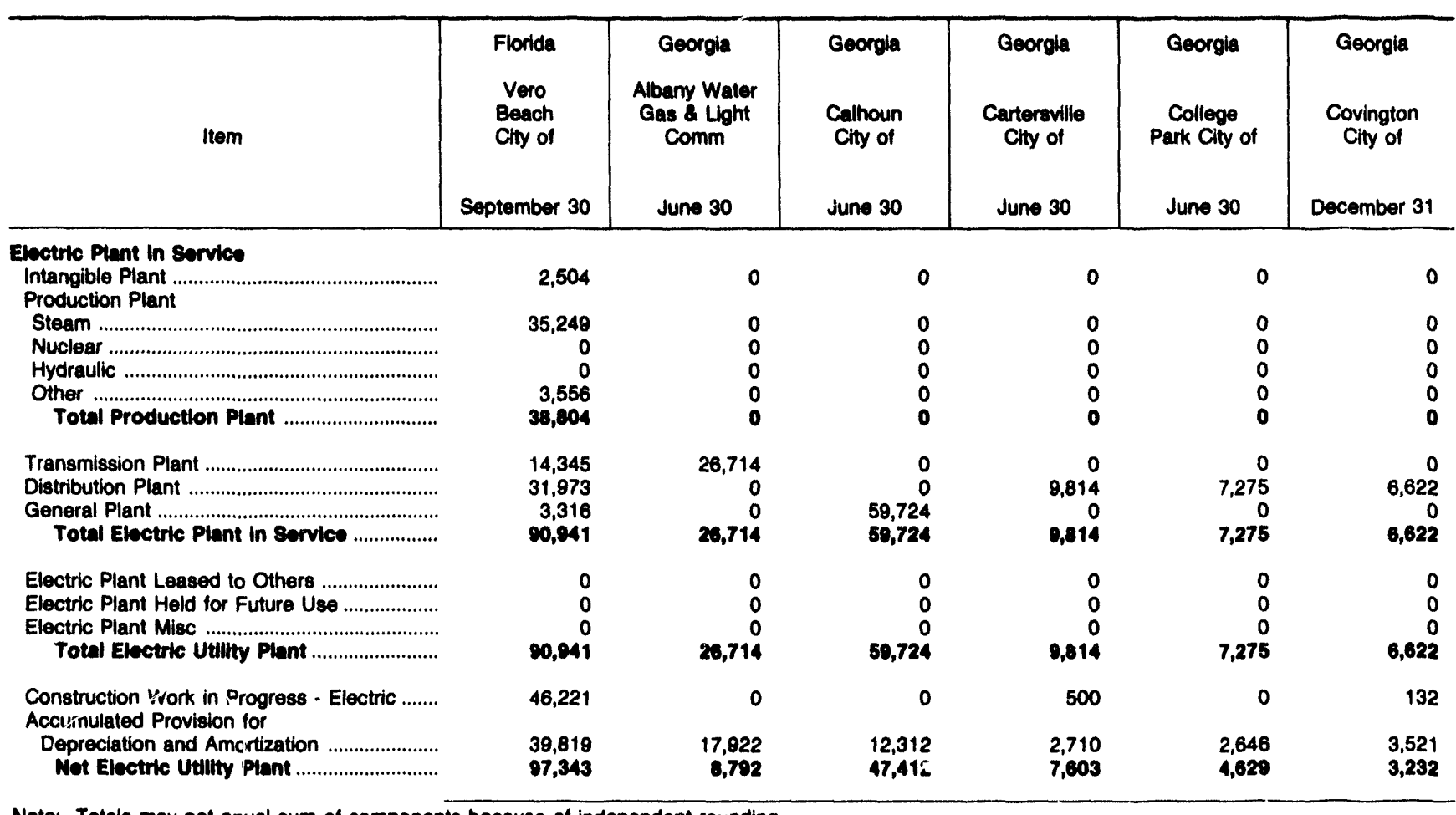

Note: Totals may not equal sum of components because of independent rounding.

Source: Energy Information Administration, Form ElA-412, "Annual Report of Public Electric Utilties." 
Table 24. Electric Utility Plant by Major U.S. Publlcly Owned Electric Utility
Within State at End of Period, 1992 (Continued) (Thousand Dollars)

\begin{tabular}{|c|c|c|c|c|c|c|}
\hline Hem & $\begin{array}{l}\text { Georgia } \\
\text { Crisp } \\
\text { County } \\
\text { Power } \\
\text { Comm } \\
\text { December } 31\end{array}$ & $\begin{array}{l}\text { Georgia } \\
\text { Dalton } \\
\text { City of } \\
\text { November } 30\end{array}$ & $\begin{array}{l}\text { Georgia } \\
\text { Douglas } \\
\text { City of } \\
\text { June } 30\end{array}$ & $\begin{array}{c}\text { Georgia } \\
\text { East } \\
\text { Point } \\
\text { City of } \\
\text { June } 30 \\
\end{array}$ & $\begin{array}{l}\text { Georgia } \\
\text { Fitzgerald } \\
\text { Wtr Lgt } \\
\text { \& Bond Comm } \\
\text { December } 31\end{array}$ & $\begin{array}{l}\text { Georgia } \\
\text { Grittin } \\
\text { City of } \\
\text { June } 30\end{array}$ \\
\hline 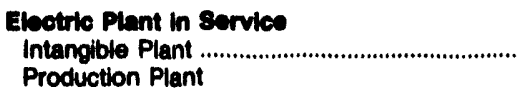 & 106 & 0 & 0 & 0 & 0 & 0 \\
\hline 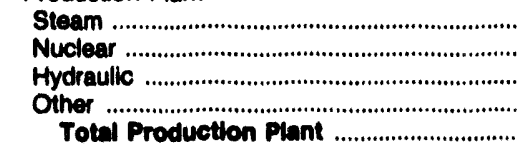 & $\begin{array}{r}4,945 \\
0 \\
4,536 \\
0 \\
9,481\end{array}$ & $\begin{array}{r}22,260 \\
130,781 \\
0 \\
0 \\
153,041\end{array}$ & $\begin{array}{l}0 \\
0 \\
0 \\
0 \\
0\end{array}$ & $\begin{array}{l}0 \\
0 \\
0 \\
0 \\
0\end{array}$ & $\begin{array}{l}0 \\
0 \\
0 \\
0 \\
0\end{array}$ & $\begin{array}{l}0 \\
0 \\
0 \\
0 \\
0\end{array}$ \\
\hline 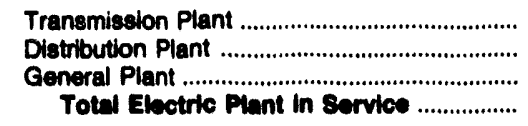 & $\begin{array}{r}1,865 \\
20,323 \\
3,483 \\
35,257\end{array}$ & $\begin{array}{r}25,932 \\
16,262 \\
1,256 \\
180,491\end{array}$ & $\begin{array}{r}0 \\
3,678 \\
0 \\
3,678\end{array}$ & $\begin{array}{r}0 \\
1,504 \\
7,293 \\
8,788\end{array}$ & $\begin{array}{l}1,796 \\
2,948 \\
1,263 \\
6,008\end{array}$ & $\begin{array}{r}0 \\
0 \\
10,110 \\
10,110\end{array}$ \\
\hline 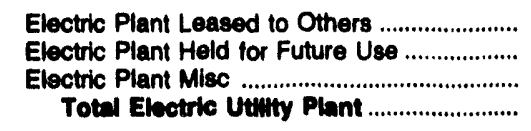 & $\begin{array}{r}0 \\
0 \\
0 \\
35,257\end{array}$ & $\begin{array}{r}0 \\
0 \\
0 \\
196,491\end{array}$ & $\begin{array}{r}0 \\
0 \\
0 \\
3,678\end{array}$ & $\begin{array}{r}0 \\
0 \\
0 \\
8,798\end{array}$ & $\begin{array}{r}0 \\
0 \\
0 \\
6,008\end{array}$ & $\begin{array}{r}0 \\
0 \\
0 \\
10,110\end{array}$ \\
\hline $\begin{array}{l}\text { Construction Work in Progress - Electric ........ } \\
\text { Accumulated Provision for }\end{array}$ & 252 & 44 & 0 & 0 & 0 & 0 \\
\hline 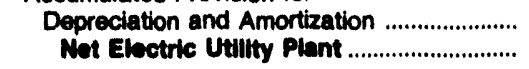 & $\begin{array}{l}19,956 \\
15,554\end{array}$ & $\begin{array}{r}52,906 \\
143,629\end{array}$ & $\begin{array}{l}2,014 \\
1,664\end{array}$ & $\begin{array}{l}4,262 \\
3,536\end{array}$ & $\begin{array}{l}2,635 \\
3,373\end{array}$ & $\begin{array}{r}381 \\
9,728\end{array}$ \\
\hline
\end{tabular}

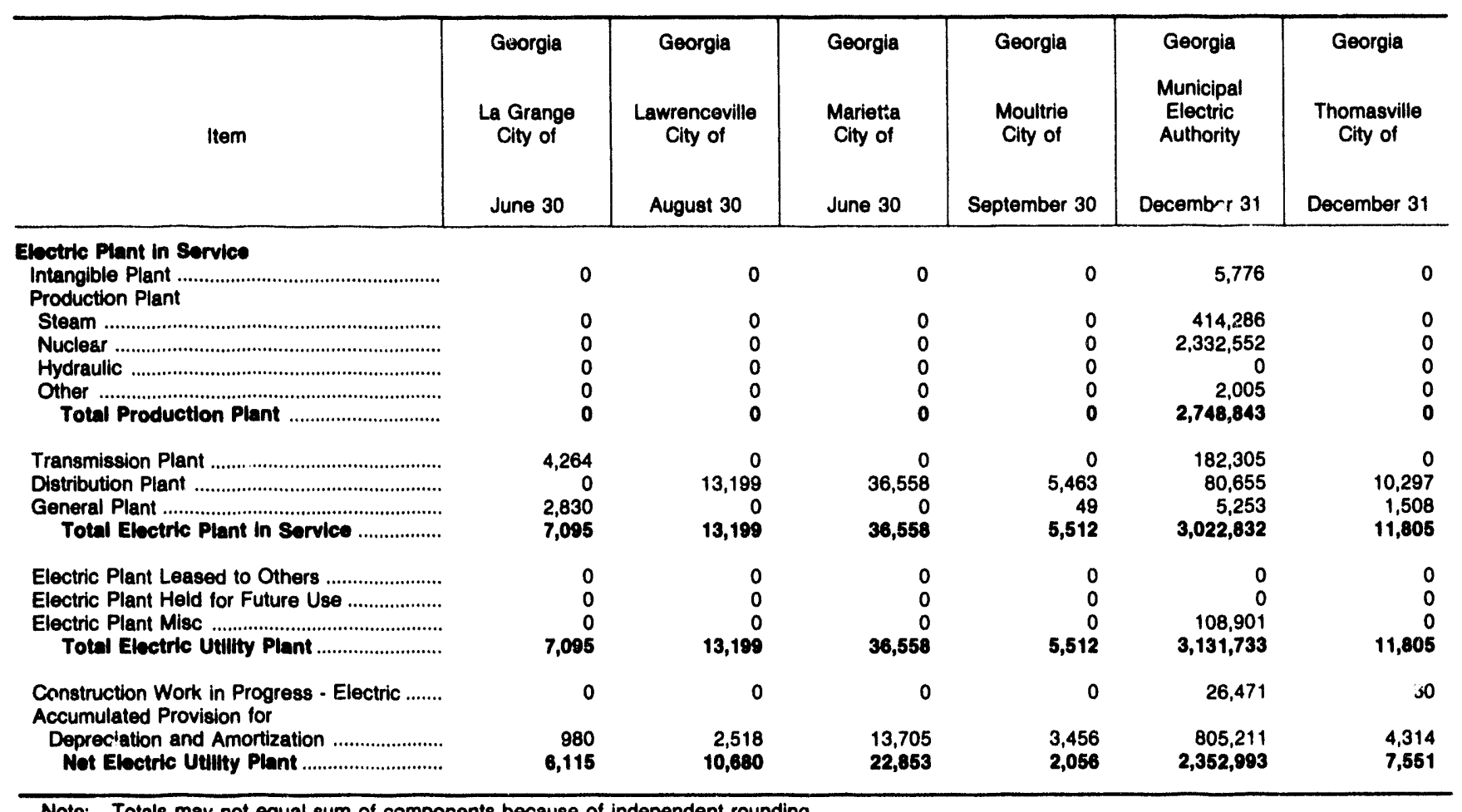

Note: Totals may not equal sum of components because of independent rounding.

Source: Energy Information Administration, Form EIA-412, "Annual Report of Public Electric Utilities." 
Table 24. Electric Utility Plant by Major U.S. Publicly Owned Electric Utility Within State at End of Period, 1992 (Continued) (Thousand Dollars)

\begin{tabular}{|c|c|c|c|c|c|c|}
\hline Item & $\begin{array}{c}\text { Idaho } \\
\text { Idaho } \\
\text { Fails } \\
\text { City of } \\
\text { September } 30\end{array}$ & $\begin{array}{c}\text { Illinois } \\
\text { Batavia } \\
\text { City of } \\
\text { December } 31\end{array}$ & $\begin{array}{l}\text { Illinois } \\
\text { Geneva } \\
\text { City of } \\
\text { April } 30\end{array}$ & $\begin{array}{c}\text { Illinois } \\
\text { Illinois } \\
\text { Municipal } \\
\text { Elec Agency } \\
\text { April } 30\end{array}$ & $\begin{array}{l}\text { Illinois } \\
\text { Naperville } \\
\text { City of } \\
\text { April } 30\end{array}$ & $\begin{array}{l}\text { Illinois } \\
\text { Rochelle } \\
\text { Municipal } \\
\text { Utilities } \\
\text { April } 30\end{array}$ \\
\hline 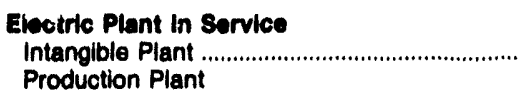 & 2,036 & 0 & 0 & 0 & 0 & 0 \\
\hline 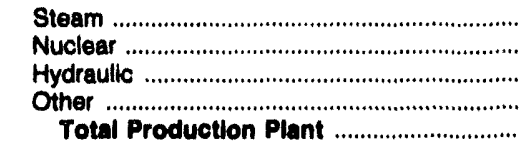 & $\begin{array}{r}0 \\
0 \\
92,744 \\
0 \\
92,744\end{array}$ & $\begin{array}{l}0 \\
0 \\
0 \\
0 \\
0\end{array}$ & $\begin{array}{l}0 \\
0 \\
0 \\
0 \\
0\end{array}$ & $\begin{array}{r}94,164 \\
0 \\
0 \\
0 \\
94,184\end{array}$ & $\begin{array}{l}0 \\
0 \\
0 \\
0 \\
0\end{array}$ & $\begin{array}{r}5,889 \\
0 \\
0 \\
5,681 \\
11,570\end{array}$ \\
\hline 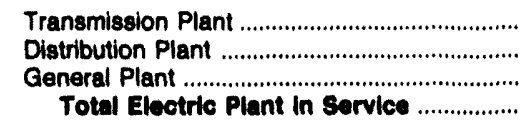 & $\begin{array}{r}6,163 \\
21,438 \\
3,759 \\
126,140\end{array}$ & $\begin{array}{r}0 \\
12,768 \\
1,846 \\
14,615\end{array}$ & $\begin{array}{r}0 \\
0 \\
18,622 \\
18,622\end{array}$ & $\begin{array}{r}0 \\
0 \\
1,122 \\
95,287\end{array}$ & $\begin{array}{r}0 \\
0 \\
101,066 \\
101,086\end{array}$ & $\begin{array}{r}3,302 \\
6,635 \\
1,688 \\
23,176\end{array}$ \\
\hline 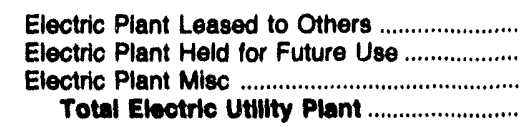 & $\begin{array}{r}0 \\
0 \\
0 \\
126,140\end{array}$ & $\begin{array}{r}0 \\
0 \\
0 \\
14,615\end{array}$ & $\begin{array}{r}0 \\
0 \\
0 \\
18,622\end{array}$ & $\begin{array}{r}0 \\
0 \\
0 \\
95,287\end{array}$ & $\begin{array}{r}0 \\
0 \\
0 \\
101,088\end{array}$ & $\begin{array}{r}0 \\
0 \\
0 \\
23,176\end{array}$ \\
\hline $\begin{array}{l}\text { Construction Work in Progress - Electric ....... } \\
\text { Accumulated Provision for }\end{array}$ & 53 & 0 & 50 & 0 & 0 & 3,815 \\
\hline 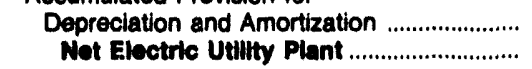 & $\begin{array}{l}27,506 \\
98,688\end{array}$ & $\begin{array}{l}5,798 \\
8,817\end{array}$ & $\begin{array}{r}7,503 \\
11,169\end{array}$ & $\begin{array}{r}3,407 \\
91,680\end{array}$ & $\begin{array}{l}67,035 \\
34,031\end{array}$ & $\begin{array}{l}13,634 \\
13,357\end{array}$ \\
\hline
\end{tabular}

\begin{tabular}{|c|c|c|c|c|c|c|}
\hline Item & $\begin{array}{c}\text { Illinois } \\
\text { Springfield } \\
\text { City of }\end{array}$ & $\begin{array}{l}\text { Illinols } \\
\text { St Charles } \\
\text { City of } \\
\text { April } 30\end{array}$ & $\begin{array}{l}\text { Indiana } \\
\text { Anderson } \\
\text { City of } \\
\text { December } 31\end{array}$ & $\begin{array}{l}\text { Indiana } \\
\text { Auburn } \\
\text { Clty of } \\
\text { December } 31\end{array}$ & $\begin{array}{l}\text { Indiana } \\
\text { Bluftion } \\
\text { City of } \\
\text { December } 31\end{array}$ & $\begin{array}{c}\text { Indiana } \\
\text { Crantordsulle } \\
\text { Elec } \\
\text { Lgt\&Pwr Co } \\
\text { December } 31\end{array}$ \\
\hline 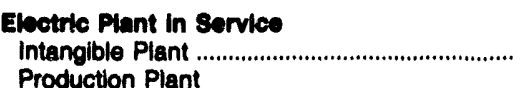 & 0 & 0 & 0 & 0 & 0 & 184 \\
\hline 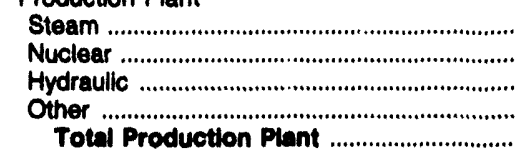 & $\begin{array}{r}171,765 \\
0 \\
0 \\
6,508 \\
178,274\end{array}$ & $\begin{array}{l}0 \\
0 \\
0 \\
0 \\
0\end{array}$ & $\begin{array}{l}0 \\
0 \\
0 \\
0 \\
0\end{array}$ & $\begin{array}{r}0 \\
0 \\
0 \\
26 \\
26\end{array}$ & $\begin{array}{r}0 \\
0 \\
0 \\
1,237 \\
1,237\end{array}$ & $\begin{array}{r}9,612 \\
0 \\
0 \\
0 \\
9,812\end{array}$ \\
\hline 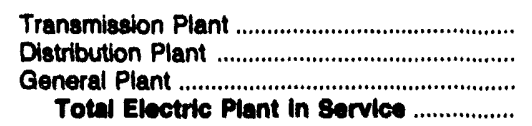 & $\begin{array}{r}33,389 \\
98,355 \\
18,553 \\
328,571\end{array}$ & $\begin{array}{r}0 \\
25,582 \\
67 \\
25,629\end{array}$ & $\begin{array}{r}1,172 \\
37,672 \\
6,698 \\
\mathbf{4 6 , 5 4 3}\end{array}$ & $\begin{array}{r}267 \\
10,711 \\
1,485 \\
12,480\end{array}$ & $\begin{array}{r}268 \\
5,682 \\
921 \\
8,107\end{array}$ & $\begin{array}{r}1,034 \\
13,253 \\
3,119 \\
27,201\end{array}$ \\
\hline 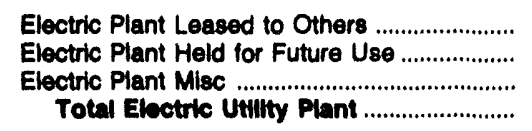 & $\begin{array}{r}0 \\
4,987 \\
2,179 \\
335,737\end{array}$ & $\begin{array}{r}0 \\
0 \\
0 \\
25,820\end{array}$ & $\begin{array}{r}0 \\
0 \\
0 \\
45,543\end{array}$ & $\begin{array}{r}0 \\
0 \\
0 \\
12,480\end{array}$ & $\begin{array}{r}0 \\
0 \\
0 \\
8,107\end{array}$ & $\begin{array}{r}0 \\
51 \\
24 \\
27,276\end{array}$ \\
\hline $\begin{array}{l}\text { Construction Work in Progress - Electric ........ } \\
\text { Accumulated Provision for }\end{array}$ & 7,973 & 0 & 1,552 & 111 & 0 & 313 \\
\hline 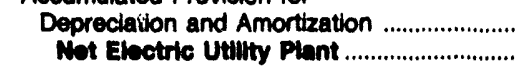 & $\begin{array}{l}155,843 \\
187,866\end{array}$ & $\begin{array}{r}7,195 \\
18,433\end{array}$ & $\begin{array}{l}19,095 \\
28,000\end{array}$ & $\begin{array}{l}4,444 \\
8,157\end{array}$ & $\begin{array}{l}3,880 \\
4,227\end{array}$ & $\begin{array}{l}14,677 \\
12,012\end{array}$ \\
\hline
\end{tabular}

Note: Totals may not equal sum of components because of independent rounding.

Source: Energy Information Administration, Form EIA-412, "Annual Report of Public Electric Utillies." 
Table 24. Electric Utility Plant by Major U.S. Publicly Owned Electric Utillity Within State at End of Period, 1992 (Continued) (Thousand Dollars)

\begin{tabular}{|c|c|c|c|c|c|c|}
\hline ltem & $\begin{array}{l}\text { Indiana } \\
\text { Frankfort } \\
\text { City of } \\
\text { December } 31\end{array}$ & $\begin{array}{l}\text { Indiana } \\
\text { Greentield } \\
\text { City of } \\
\text { December } 31\end{array}$ & $\begin{array}{c}\text { Indiana } \\
\text { Indiana } \\
\text { Municipal } \\
\text { Power Agency } \\
\text { December } 31\end{array}$ & $\begin{array}{l}\text { Indiana } \\
\text { Jasper } \\
\text { City of } \\
\text { December } 31\end{array}$ & $\begin{array}{l}\text { Indiana } \\
\text { Logansport } \\
\text { City of } \\
\text { December } 31\end{array}$ & $\begin{array}{c}\text { Indiana } \\
\text { Mishawaka } \\
\text { City of } \\
\text { December } 31\end{array}$ \\
\hline 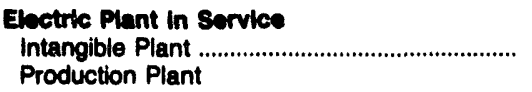 & 0 & 0 & 0 & 0 & 518 & 0 \\
\hline 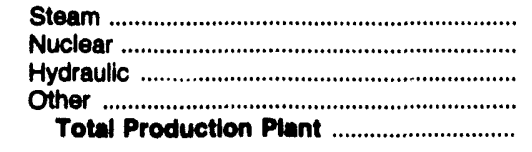 & $\begin{array}{l}0 \\
0 \\
0 \\
0 \\
0\end{array}$ & $\begin{array}{l}0 \\
0 \\
0 \\
0 \\
0\end{array}$ & $\begin{array}{r}102,310 \\
0 \\
0 \\
66,737 \\
189,047\end{array}$ & $\begin{array}{r}5,678 \\
0 \\
0 \\
0 \\
5,678\end{array}$ & $\begin{array}{r}11,917 \\
0 \\
0 \\
1,025 \\
12,942\end{array}$ & $\begin{array}{l}0 \\
0 \\
0 \\
0 \\
0\end{array}$ \\
\hline 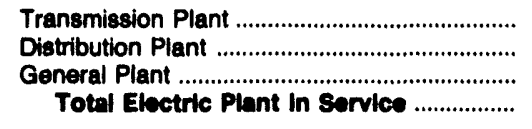 & $\begin{array}{r}0 \\
14,751 \\
2,254 \\
17,005\end{array}$ & $\begin{array}{r}0 \\
5,900 \\
1,037 \\
6,937\end{array}$ & $\begin{array}{r}35,468 \\
6,534 \\
1,985 \\
213,034\end{array}$ & $\begin{array}{r}8 \\
7,127 \\
781 \\
13,593\end{array}$ & $\begin{array}{r}4,753 \\
23,664 \\
5,641 \\
47,519\end{array}$ & $\begin{array}{r}0 \\
27,074 \\
2,692 \\
29,766\end{array}$ \\
\hline 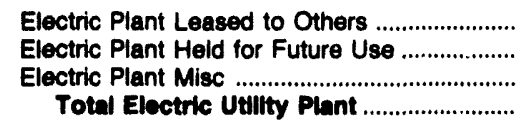 & $\begin{array}{r}0 \\
0 \\
0 \\
17,005\end{array}$ & $\begin{array}{r}0 \\
0 \\
0 \\
6,937\end{array}$ & $\begin{array}{r}0 \\
0 \\
0 \\
213,034\end{array}$ & $\begin{array}{r}0 \\
0 \\
7 \\
13,600\end{array}$ & $\begin{array}{r}0 \\
0 \\
0 \\
47,519\end{array}$ & $\begin{array}{r}0 \\
0 \\
0 \\
29,768\end{array}$ \\
\hline $\begin{array}{l}\text { Construction Work in Progress - Electric ....... } \\
\text { Accumulated Provision for }\end{array}$ & 0 & 0 & 4,842 & 1,750 & 5,088 & 0 \\
\hline $\begin{array}{l}\text { Depreciation and Amortization } \\
\text { Not Electric Utillty Plant }\end{array}$ & $\begin{array}{r}5,416 \\
11,688\end{array}$ & $\begin{array}{l}1,860 \\
5,077\end{array}$ & $\begin{array}{r}46,481 \\
171,394\end{array}$ & $\begin{array}{l}7,358 \\
7,992\end{array}$ & $\begin{array}{l}25,716 \\
26,891\end{array}$ & $\begin{array}{l}14,150 \\
15,616\end{array}$ \\
\hline
\end{tabular}

\begin{tabular}{|c|c|c|c|c|c|c|}
\hline Item & $\begin{array}{c}\text { Indiana } \\
\text { Peru } \\
\text { City of } \\
\text { December } 31\end{array}$ & $\begin{array}{l}\text { Indiana } \\
\text { Richmond } \\
\text { City of } \\
\text { December } 31\end{array}$ & $\begin{array}{c}\text { Indiana } \\
\text { Washington } \\
\text { City of } \\
\text { December } 31\end{array}$ & $\begin{array}{l}\text { lowa } \\
\text { Ames } \\
\text { City of } \\
\text { June } 30\end{array}$ & $\begin{array}{c}\text { lowa } \\
\text { Cedar } \\
\text { Falls } \\
\text { City of } \\
\text { December } 31\end{array}$ & $\begin{array}{c}\text { lowa } \\
\text { Muscatine } \\
\text { City of } \\
\text { December } 31\end{array}$ \\
\hline $\begin{array}{l}\text { Electric Plant In Sorvice } \\
\text { Intangible Plant ................................................. } \\
\text { Production Plant }\end{array}$ & 0 & 0 & 0 & 0 & 0 & 0 \\
\hline 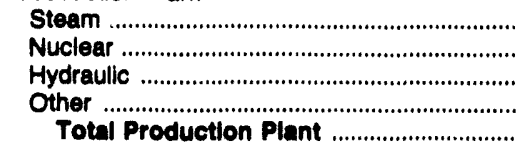 & $\begin{array}{r}8,386 \\
0 \\
0 \\
0 \\
8,386\end{array}$ & $\begin{array}{r}28,145 \\
0 \\
0 \\
0 \\
28,145\end{array}$ & $\begin{array}{l}0 \\
0 \\
0 \\
0 \\
0\end{array}$ & $\begin{array}{r}95,519 \\
0 \\
0 \\
0 \\
95,510\end{array}$ & $\begin{array}{r}37,611 \\
0 \\
0 \\
2,509 \\
40,120\end{array}$ & $\begin{array}{r}234,158 \\
0 \\
0 \\
0 \\
234,169\end{array}$ \\
\hline 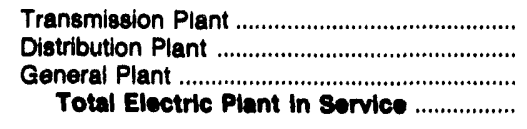 & $\begin{array}{r}2,891 \\
14,014 \\
1,832 \\
27,123\end{array}$ & $\begin{array}{r}7,333 \\
37,257 \\
10,353 \\
83,080\end{array}$ & $\begin{array}{r}500 \\
9,393 \\
1,091 \\
10,985\end{array}$ & $\begin{array}{r}0 \\
0 \\
0 \\
95,619\end{array}$ & $\begin{array}{r}6,224 \\
15,519 \\
3,685 \\
65,547\end{array}$ & $\begin{array}{r}29,657 \\
0 \\
7,869 \\
271,685\end{array}$ \\
\hline 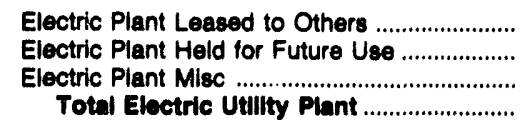 & $\begin{array}{r}0 \\
0 \\
0 \\
27,123\end{array}$ & $\begin{array}{r}0 \\
476 \\
0 \\
83,586\end{array}$ & $\begin{array}{r}0 \\
0 \\
0 \\
10,985\end{array}$ & $\begin{array}{r}0 \\
0 \\
0 \\
\mathbf{9 6 , 5 1 0}\end{array}$ & $\begin{array}{r}0 \\
0 \\
1,236 \\
\mathbf{8 6 , 7 8 3}\end{array}$ & $\begin{array}{r}0 \\
0 \\
0 \\
271,685\end{array}$ \\
\hline $\begin{array}{l}\text { Construction Work in Progress - Electric ....... } \\
\text { Accumulated Provision for }\end{array}$ & 3 & 628 & 25 & 0 & 385 & 5,091 \\
\hline 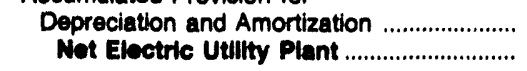 & $\begin{array}{l}14,566 \\
12,650\end{array}$ & $\begin{array}{l}35,471 \\
49,721\end{array}$ & $\begin{array}{l}4,387 \\
6,623\end{array}$ & $\begin{array}{l}47,968 \\
47,551\end{array}$ & $\begin{array}{l}31,505 \\
35,664\end{array}$ & $\begin{array}{l}106,373 \\
170,404\end{array}$ \\
\hline
\end{tabular}

Note: Totals may not equal sum of components because of independent rounding.

Source: Energy Information Administration, Form ElA.412, "Annual Peport of Public Electric Utilities." 
Table 24. Electric Utility Plant by Major U.S. Publicly Owned Electric Utility Within State at End of Period, 1992 (Continued)

(Thousand Dollars)

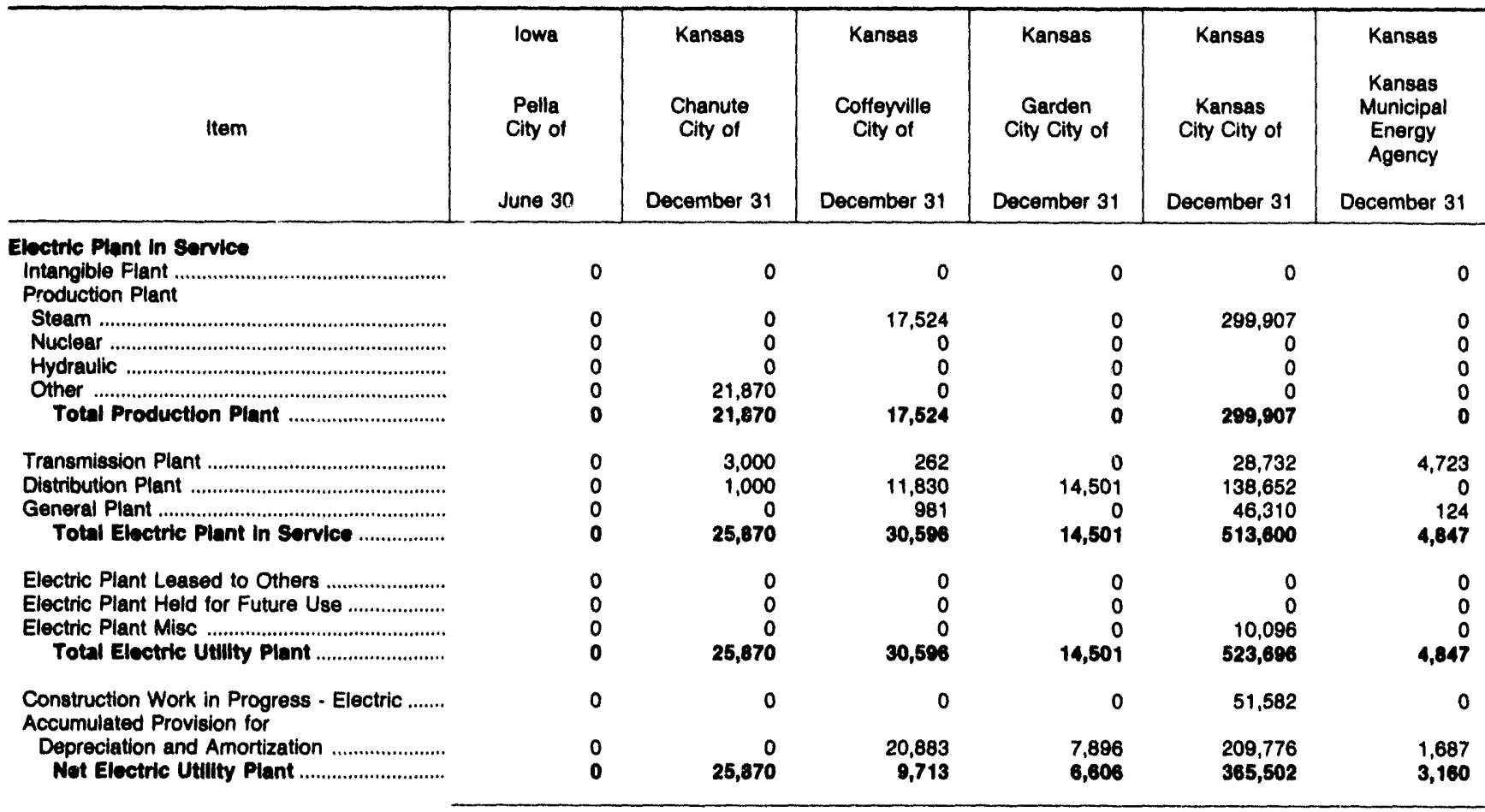

\begin{tabular}{|c|c|c|c|c|c|c|}
\hline Item & $\begin{array}{c}\text { Kansas } \\
\text { McPherson } \\
\text { City of } \\
\text { December } 31\end{array}$ & $\begin{array}{l}\text { Kansas } \\
\text { Winfield } \\
\text { City of } \\
\text { December } 31\end{array}$ & $\begin{array}{l}\text { Kentucky } \\
\text { Bowling } \\
\text { Green } \\
\text { City of } \\
\text { June } 30\end{array}$ & $\begin{array}{l}\text { Kentucky } \\
\text { Frankfort } \\
\text { City of } \\
\text { June } 30\end{array}$ & $\begin{array}{l}\text { Kentucky } \\
\text { Franklin } \\
\text { City of } \\
\text { June } 30\end{array}$ & $\begin{array}{l}\text { Kentucky } \\
\text { Glasgow } \\
\text { City of } \\
\text { June } 30\end{array}$ \\
\hline 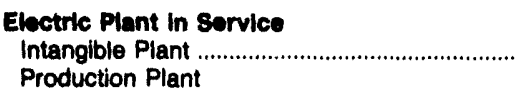 & 169 & 0 & 0 & 0 & 0 & 0 \\
\hline 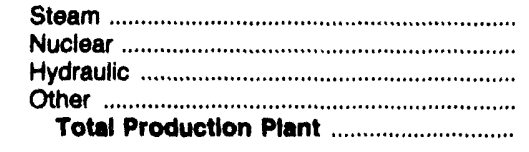 & $\begin{array}{r}5,415 \\
0 \\
0 \\
18,261 \\
23,675\end{array}$ & $\begin{array}{r}11,932 \\
0 \\
0 \\
0 \\
11,932\end{array}$ & $\begin{array}{l}0 \\
0 \\
0 \\
0 \\
0\end{array}$ & $\begin{array}{l}0 \\
0 \\
0 \\
0 \\
0\end{array}$ & $\begin{array}{l}0 \\
0 \\
0 \\
0 \\
0\end{array}$ & $\begin{array}{l}0 \\
0 \\
0 \\
0 \\
0\end{array}$ \\
\hline 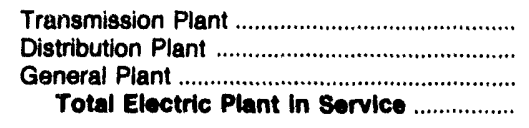 & $\begin{array}{r}11,448 \\
10,276 \\
889 \\
46,457\end{array}$ & $\begin{array}{r}0 \\
9,047 \\
1,232 \\
22,211\end{array}$ & $\begin{array}{r}738 \\
29,015 \\
3,797 \\
33,561\end{array}$ & $\begin{array}{r}7,825 \\
13,401 \\
0 \\
21,226\end{array}$ & $\begin{array}{r}0 \\
3,829 \\
974 \\
4,803\end{array}$ & $\begin{array}{r}954 \\
8,625 \\
3,727 \\
13,306\end{array}$ \\
\hline 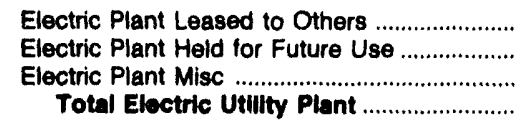 & $\begin{array}{r}0 \\
0 \\
0 \\
46,457\end{array}$ & $\begin{array}{r}0 \\
0 \\
0 \\
22,211\end{array}$ & $\begin{array}{r}0 \\
0 \\
334 \\
33,885\end{array}$ & $\begin{array}{r}0 \\
0 \\
0 \\
21,226\end{array}$ & $\begin{array}{r}0 \\
0 \\
0 \\
4,803\end{array}$ & $\begin{array}{r}0 \\
0 \\
82 \\
13,388\end{array}$ \\
\hline $\begin{array}{l}\text { Construction Work in Progress - Electric ....... } \\
\text { Accumulated Provision for }\end{array}$ & 66 & 7,684 & 1,254 & 0 & 179 & 165 \\
\hline 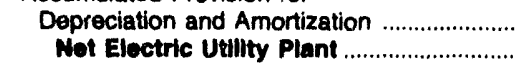 & $\begin{array}{l}23,777 \\
22,747\end{array}$ & $\begin{array}{l}13,445 \\
16,450\end{array}$ & $\begin{array}{l}10,870 \\
24,268\end{array}$ & $\begin{array}{l}11,013 \\
10,213\end{array}$ & $\begin{array}{l}1,682 \\
3,301\end{array}$ & $\begin{array}{l}4,579 \\
8,975\end{array}$ \\
\hline
\end{tabular}

Note: Totals may not equal sum of components because of independent rounding.

Source: Energy Information Administration, Form ElA-412, "Annual Report of Public Electric Utilities." 
Table 24. Electric Utillity Plant by Major U.S. Publicly Owned Electric Utility Within State at End of Period, 1992 (Continued) (Thousand Dollars)

\begin{tabular}{|c|c|c|c|c|c|c|}
\hline Item & $\begin{array}{l}\text { Kentucky } \\
\text { Henderson } \\
\text { City } \\
\text { Utility Comm } \\
\text { May } 31\end{array}$ & $\begin{array}{l}\text { Kentucky } \\
\begin{array}{c}\text { Hopkinsville } \\
\text { City of }\end{array} \\
\text { June } 30\end{array}$ & $\begin{array}{l}\text { Kentucky } \\
\text { Madisonville } \\
\text { Municipal } \\
\text { Utils } \\
\text { June } 30\end{array}$ & $\begin{array}{l}\text { Kentucky } \\
\text { Maytield } \\
\text { City of } \\
\text { June } 30\end{array}$ & $\begin{array}{l}\text { Kentucky } \\
\text { Murray } \\
\text { City of } \\
\text { June } 30\end{array}$ & $\begin{array}{l}\text { Kentucky } \\
\text { Owensboro } \\
\text { City of } \\
\text { May } 31\end{array}$ \\
\hline 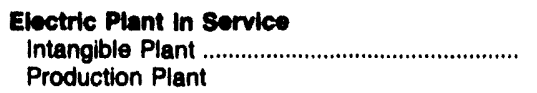 & 0 & 0 & 0 & 0 & 0 & 0 \\
\hline $\begin{array}{c}\text { Steam } \\
\text { Nuclear } \\
\text { Othaulic } \\
\text { Other } \\
\text { Total Production Piant }\end{array}$ & $\begin{array}{r}82,233 \\
0 \\
0 \\
413 \\
82,646\end{array}$ & $\begin{array}{l}0 \\
0 \\
0 \\
0 \\
0\end{array}$ & $\begin{array}{l}0 \\
0 \\
0 \\
0 \\
0\end{array}$ & $\begin{array}{l}0 \\
0 \\
0 \\
0 \\
0\end{array}$ & $\begin{array}{l}0 \\
0 \\
0 \\
0 \\
0\end{array}$ & $\begin{array}{r}73,859 \\
0 \\
0 \\
0 \\
73,859\end{array}$ \\
\hline 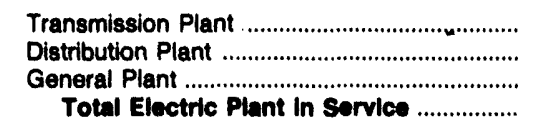 & $\begin{array}{r}5,699 \\
10,691 \\
2,251 \\
101,286\end{array}$ & $\begin{array}{r}445 \\
10,528 \\
3,808 \\
14,781\end{array}$ & $\begin{array}{r}0 \\
6,497 \\
0 \\
6,497\end{array}$ & $\begin{array}{r}45 \\
4,669 \\
795 \\
5,509\end{array}$ & $\begin{array}{r}434 \\
6,673 \\
943 \\
8,050\end{array}$ & $\begin{array}{r}15,320 \\
29,845 \\
4,290 \\
123,314\end{array}$ \\
\hline 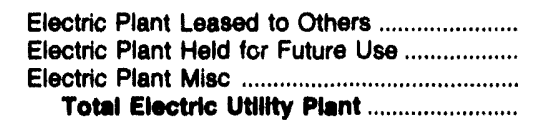 & $\begin{array}{r}0 \\
0 \\
0 \\
101,286\end{array}$ & $\begin{array}{r}0 \\
0 \\
0 \\
14,781\end{array}$ & $\begin{array}{r}0 \\
0 \\
0 \\
6,497\end{array}$ & $\begin{array}{r}0 \\
0 \\
0 \\
5,509\end{array}$ & $\begin{array}{r}0 \\
0 \\
0 \\
8,050\end{array}$ & $\begin{array}{r}0 \\
0 \\
0 \\
123,314\end{array}$ \\
\hline $\begin{array}{l}\text { Construction Work in Progress - Electric ....... } \\
\text { Accumulated Provision for }\end{array}$ & 0 & 106 & 0 & 86 & 31 & 20,458 \\
\hline 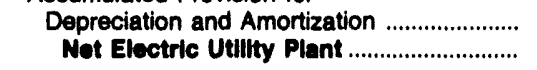 & $\begin{array}{l}53,740 \\
47,546\end{array}$ & $\begin{array}{l}6,001 \\
8,886\end{array}$ & $\begin{array}{l}2,863 \\
3,634\end{array}$ & $\begin{array}{l}2,333 \\
3,262\end{array}$ & $\begin{array}{l}3,548 \\
4,534\end{array}$ & $\begin{array}{l}68,235 \\
75,537\end{array}$ \\
\hline
\end{tabular}

\begin{tabular}{|c|c|c|c|c|c|c|}
\hline Item & $\begin{array}{l}\text { Kentucky } \\
\text { Paducah } \\
\text { City of } \\
\text { June } 30\end{array}$ & $\begin{array}{l}\text { Louisiana } \\
\text { Alexandria } \\
\text { City of } \\
\text { April } 30\end{array}$ & $\begin{array}{l}\text { Louisiana } \\
\text { Lafayette } \\
\text { City of } \\
\text { October } 31\end{array}$ & $\begin{array}{l}\text { Louisiana } \\
\text { Lafayette } \\
\text { Public } \\
\text { Power Auth } \\
\text { October } 31\end{array}$ & $\begin{array}{c}\text { Louisiana } \\
\text { Louisiana } \\
\text { Energy } \\
\& \\
\text { Power Auth } \\
\text { December } 31\end{array}$ & $\begin{array}{l}\text { Louisiana } \\
\text { Morgan } \\
\text { City City of } \\
\text { December } 31\end{array}$ \\
\hline 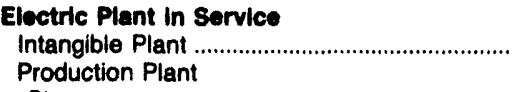 & 0 & 0 & 31 & 0 & 8,575 & 0 \\
\hline 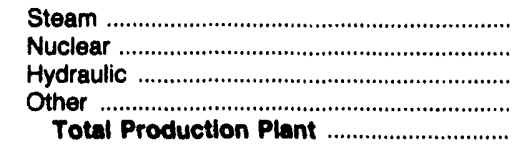 & $\begin{array}{l}0 \\
0 \\
0 \\
0 \\
0\end{array}$ & $\begin{array}{r}15,325 \\
0 \\
0 \\
0 \\
15,325\end{array}$ & $\begin{array}{r}50,658 \\
0 \\
0 \\
172 \\
50,830\end{array}$ & $\begin{array}{r}149,647 \\
0 \\
0 \\
0 \\
149,647\end{array}$ & $\begin{array}{r}57,761 \\
0 \\
0 \\
0 \\
57,761\end{array}$ & $\begin{array}{l}0 \\
0 \\
0 \\
0 \\
0\end{array}$ \\
\hline 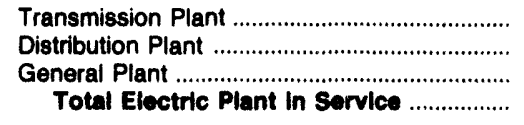 & $\begin{array}{r}2,220 \\
31,457 \\
3,483 \\
37,160\end{array}$ & $\begin{array}{r}0 \\
33,379 \\
0 \\
48,704\end{array}$ & $\begin{array}{r}5,082 \\
71,364 \\
20,548 \\
147,855\end{array}$ & $\begin{array}{r}0 \\
0 \\
617 \\
150,264\end{array}$ & $\begin{array}{r}410 \\
16 \\
4,641 \\
71,402\end{array}$ & $\begin{array}{r}0 \\
0 \\
23,246 \\
23,246\end{array}$ \\
\hline 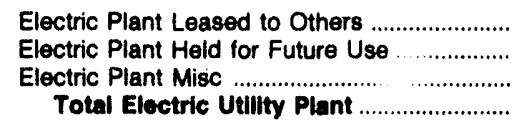 & $\begin{array}{r}0 \\
0 \\
2,682 \\
39,842\end{array}$ & $\begin{array}{r}0 \\
88,430 \\
0 \\
137,134\end{array}$ & $\begin{array}{r}0 \\
0 \\
57,861 \\
205,716\end{array}$ & $\begin{array}{r}0 \\
0 \\
0 \\
150,264\end{array}$ & $\begin{array}{r}0 \\
0 \\
15,722 \\
87,124\end{array}$ & $\begin{array}{r}0 \\
0 \\
0 \\
23,248\end{array}$ \\
\hline $\begin{array}{l}\text { Construction Work in Progress - Electric ........ } \\
\text { Accumulated Provision for }\end{array}$ & 926 & 3 & 528 & 1,168 & 0 & 0 \\
\hline $\begin{array}{l}\text { Depreciation and Amortization } \\
\text { Net Electric Utillty Plant }\end{array}$ & $\begin{array}{l}11,621 \\
29,146\end{array}$ & $\begin{array}{l}55,358 \\
81,779\end{array}$ & $\begin{array}{r}78,979 \\
127,265\end{array}$ & $\begin{array}{r}48,605 \\
102,827\end{array}$ & $\begin{array}{l}14,181 \\
72,943\end{array}$ & $\begin{array}{r}3,757 \\
19,490\end{array}$ \\
\hline
\end{tabular}

Note: Totals may not equal sum of components because of independent rounding.

Source: Energy Information Administration, Form EIA-412, "Annual Report of Public Electric Utilities." 
Table 24. Electric Utility Piant by Major U.S. Publicly Owned Electric Utility Within State at End of Period, 1992 (Continued)

(Thousand Dollars)

\begin{tabular}{|c|c|c|c|c|c|c|}
\hline Item & $\begin{array}{l}\text { Louisiana } \\
\begin{array}{c}\text { Natchitoches } \\
\text { City of }\end{array} \\
\text { May } 31\end{array}$ & $\begin{array}{l}\text { Louisiana } \\
\text { Ruston } \\
\text { City of } \\
\text { September } 30\end{array}$ & $\begin{array}{c}\text { Louisiana } \\
\text { Terrebonne } \\
\text { Parish } \\
\text { Consol Govt } \\
\text { December } 31\end{array}$ & $\begin{array}{l}\text { Maryland } \\
\text { Easton } \\
\text { Utilities } \\
\text { Comm } \\
\text { June } 30\end{array}$ & $\begin{array}{l}\text { Maryland } \\
\text { Hagerstown } \\
\text { City of } \\
\text { December } 31\end{array}$ & $\begin{array}{c}\text { Massachusetts } \\
\text { Braintree } \\
\text { Town of } \\
\text { December } 31\end{array}$ \\
\hline 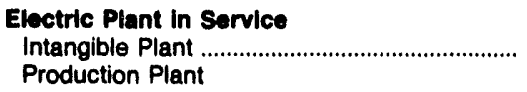 & 0 & 0 & 0 & 0 & 0 & 0 \\
\hline 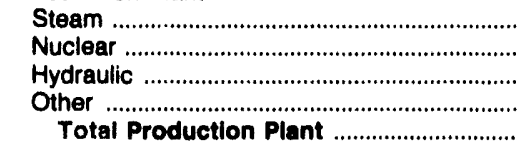 & $\begin{array}{l}0 \\
0 \\
0 \\
0 \\
0\end{array}$ & $\begin{array}{r}13,037 \\
0 \\
0 \\
3,190 \\
16,227\end{array}$ & $\begin{array}{r}25,420 \\
0 \\
0 \\
0 \\
25,420\end{array}$ & $\begin{array}{r}0 \\
0 \\
0 \\
20,422 \\
20,422\end{array}$ & $\begin{array}{r}11,710 \\
0 \\
0 \\
8 \\
11,718\end{array}$ & $\begin{array}{r}26,933 \\
0 \\
0 \\
755 \\
27,688\end{array}$ \\
\hline 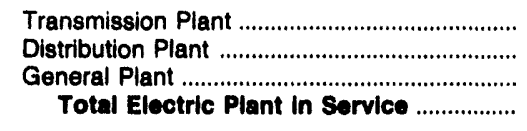 & $\begin{array}{r}0 \\
43,985 \\
0 \\
43,985\end{array}$ & $\begin{array}{r}0 \\
11,745 \\
549 \\
28,521\end{array}$ & $\begin{array}{r}0 \\
21,845 \\
0 \\
47,265\end{array}$ & $\begin{array}{r}0 \\
13,693 \\
2,013 \\
36,128\end{array}$ & $\begin{array}{r}1,839 \\
18,868 \\
1,426 \\
33,852\end{array}$ & $\begin{array}{r}13,071 \\
19,423 \\
2,726 \\
62,808\end{array}$ \\
\hline 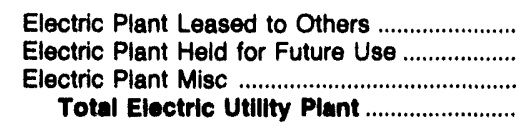 & $\begin{array}{r}0 \\
0 \\
0 \\
43,985\end{array}$ & $\begin{array}{r}0 \\
0 \\
0 \\
28,521\end{array}$ & $\begin{array}{r}0 \\
0 \\
0 \\
47,265\end{array}$ & $\begin{array}{r}0 \\
0 \\
0 \\
36,128\end{array}$ & $\begin{array}{r}0 \\
0 \\
0 \\
33,852\end{array}$ & $\begin{array}{r}0 \\
0 \\
0 \\
62,908\end{array}$ \\
\hline $\begin{array}{l}\text { Construction Work in Progress - Electric ........ } \\
\text { Accumulated Provision for }\end{array}$ & 0 & 0 & 911 & 2,662 & 0 & 0 \\
\hline 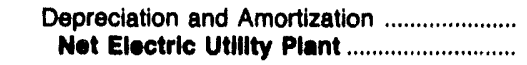 & $\begin{array}{l}13,565 \\
30,420\end{array}$ & $\begin{array}{l}17,084 \\
11,437\end{array}$ & $\begin{array}{l}32,211 \\
15,965\end{array}$ & $\begin{array}{l}14,694 \\
24,096\end{array}$ & $\begin{array}{l}20,204 \\
13,648\end{array}$ & $\begin{array}{l}29,499 \\
33,409\end{array}$ \\
\hline
\end{tabular}

\begin{tabular}{|c|c|c|c|c|c|c|}
\hline Item & $\begin{array}{c}\text { Massachusetts } \\
\text { Chicopee } \\
\text { City of } \\
\text { December } 31\end{array}$ & $\begin{array}{l}\text { Massachusetts } \\
\text { Concord } \\
\text { Town of } \\
\text { December } 31\end{array}$ & $\begin{array}{c}\text { Massachusetts } \\
\text { Danvers } \\
\text { Town of } \\
\text { December } 31\end{array}$ & $\begin{array}{l}\text { Massachusetts } \\
\text { Hingham } \\
\text { City of } \\
\text { December } 31\end{array}$ & $\begin{array}{l}\text { Massachusetts } \\
\text { Holyoke } \\
\text { Clty of }\end{array}$ & $\begin{array}{c}\text { Massachusetts } \\
\text { Hudson } \\
\text { Town of } \\
\text { December } 31\end{array}$ \\
\hline $\begin{array}{l}\text { Electric Plant in Service } \\
\text { Intangible Plant ................................................. } \\
\text { Production Plant }\end{array}$ & 0 & 1,056 & 0 & 0 & 0 & 4 \\
\hline 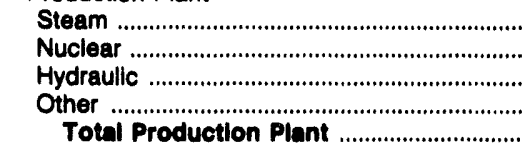 & $\begin{array}{r}0 \\
38,474 \\
0 \\
1,720 \\
40,194\end{array}$ & $\begin{array}{l}0 \\
0 \\
0 \\
0 \\
0\end{array}$ & $\begin{array}{l}0 \\
0 \\
0 \\
0 \\
0\end{array}$ & $\begin{array}{l}0 \\
0 \\
0 \\
0 \\
0\end{array}$ & $\begin{array}{r}17,044 \\
0 \\
1,836 \\
1,930 \\
20,811\end{array}$ & $\begin{array}{r}0 \\
2,706 \\
0 \\
4,090 \\
6,796\end{array}$ \\
\hline 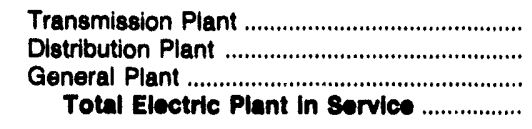 & $\begin{array}{r}204 \\
18,774 \\
4,772 \\
63,944\end{array}$ & $\begin{array}{r}2,925 \\
10,227 \\
1,727 \\
15,936\end{array}$ & $\begin{array}{r}0 \\
16,063 \\
2,673 \\
18,736\end{array}$ & $\begin{array}{r}1,438 \\
17,558 \\
1,189 \\
20,185\end{array}$ & $\begin{array}{r}6,183 \\
22,294 \\
1,835 \\
51,123\end{array}$ & $\begin{array}{r}1,632 \\
7,288 \\
1,564 \\
17,283\end{array}$ \\
\hline 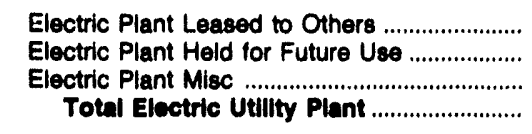 & $\begin{array}{r}0 \\
0 \\
265 \\
64,210\end{array}$ & $\begin{array}{r}0 \\
0 \\
0 \\
16,935\end{array}$ & $\begin{array}{r}0 \\
0 \\
0 \\
18,736\end{array}$ & $\begin{array}{r}0 \\
0 \\
0 \\
20,185\end{array}$ & $\begin{array}{r}0 \\
0 \\
0 \\
\mathbf{5 1 , 1 2 3}\end{array}$ & $\begin{array}{r}0 \\
0 \\
0 \\
17,283\end{array}$ \\
\hline $\begin{array}{l}\text { Construction Work in Progress - Electric ....... } \\
\text { Accumulated Provision for }\end{array}$ & 672 & 2,020 & 2,173 & 0 & 674 & 0 \\
\hline 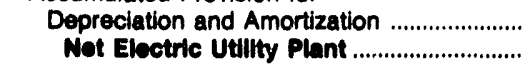 & $\begin{array}{l}21,597 \\
43,284\end{array}$ & $\begin{array}{l}8,021 \\
9,033\end{array}$ & $\begin{array}{r}9,286 \\
11,623\end{array}$ & $\begin{array}{r}4,970 \\
16,216\end{array}$ & $\begin{array}{l}28,392 \\
23,405\end{array}$ & $\begin{array}{r}11,522 \\
6,761\end{array}$ \\
\hline
\end{tabular}


Table 24. Electric Utility Plant by Major U.S. Publicly Owned Electric Utility Within State at End of Period, 1992 (Continued) (Thousand Dollars)

\begin{tabular}{|c|c|c|c|c|c|c|}
\hline Item & $\begin{array}{l}\text { Massachusetts } \\
\text { Littleton } \\
\text { Town of } \\
\text { December } 31\end{array}$ & $\begin{array}{l}\text { Massachusetts } \\
\text { Mansfield } \\
\text { Town of } \\
\text { December } 31\end{array}$ & $\begin{array}{l}\text { Massachusetts } \\
\text { Massachusetts } \\
\text { Mun } \\
\text { Whis } \\
\text { Elec Co } \\
\text { December } 31\end{array}$ & $\begin{array}{l}\text { Massachusetts } \\
\text { Middleborough } \\
\text { Town of } \\
\text { December } 31\end{array}$ & $\begin{array}{l}\text { Massachusetts } \\
\text { North } \\
\text { Attleborough } \\
\text { Town of } \\
\text { December } 31\end{array}$ & $\begin{array}{l}\text { Massachusetts } \\
\text { Norwood } \\
\text { City of } \\
\text { June } 30\end{array}$ \\
\hline 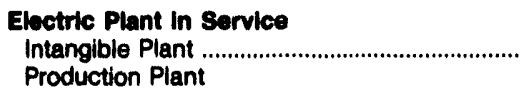 & 0 & 0 & 1,169 & 0 & 0 & 0 \\
\hline 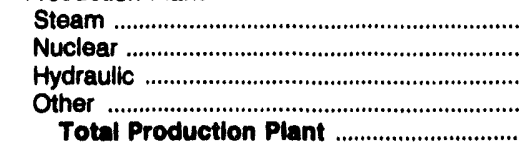 & $\begin{array}{r}337 \\
0 \\
0 \\
0 \\
337\end{array}$ & $\begin{array}{l}0 \\
0 \\
0 \\
0 \\
0\end{array}$ & $\begin{array}{r}7,311 \\
991,730 \\
0 \\
182,105 \\
1,181,145\end{array}$ & $\begin{array}{l}0 \\
0 \\
0 \\
0 \\
0\end{array}$ & $\begin{array}{r}666 \\
0 \\
0 \\
0 \\
666\end{array}$ & $\begin{array}{l}0 \\
6 \\
0 \\
0 \\
0\end{array}$ \\
\hline 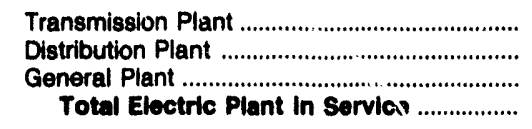 & $\begin{array}{r}15 \\
9,990 \\
3,603 \\
13,945\end{array}$ & $\begin{array}{r}0 \\
8,091 \\
925 \\
9,016\end{array}$ & $\begin{array}{r}30,656 \\
0 \\
16,975 \\
1,229,945\end{array}$ & $\begin{array}{r}2,762 \\
9,762 \\
2,278 \\
14,801\end{array}$ & $\begin{array}{r}1,774 \\
11,485 \\
960 \\
14,885\end{array}$ & $\begin{array}{r}509 \\
18,276 \\
1,654 \\
20,439\end{array}$ \\
\hline 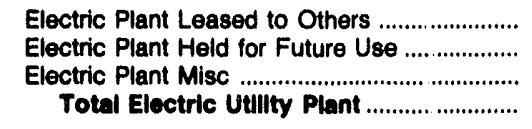 & $\begin{array}{r}0 \\
0 \\
0 \\
13,945\end{array}$ & $\begin{array}{r}0 \\
0 \\
0 \\
9,016\end{array}$ & $\begin{array}{r}0 \\
0 \\
0 \\
1,229,945\end{array}$ & $\begin{array}{r}0 \\
0 \\
0 \\
14,801\end{array}$ & $\begin{array}{r}0 \\
0 \\
0 \\
14,885\end{array}$ & $\begin{array}{r}0 \\
0 \\
0 \\
20,439\end{array}$ \\
\hline 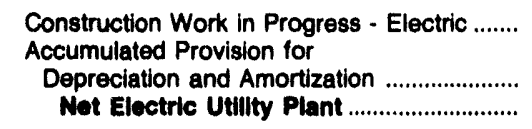 & $\begin{array}{r}155 \\
5,388 \\
8,7111\end{array}$ & $\begin{array}{l}5,276 \\
3,739\end{array}$ & $\begin{array}{r}1,414 \\
201,172 \\
1,030,187\end{array}$ & $\begin{array}{l}6,017 \\
8,793\end{array}$ & $\begin{array}{r}2,538 \\
5,166 \\
12,257\end{array}$ & $\begin{array}{r}13,131 \\
7,308\end{array}$ \\
\hline
\end{tabular}

\begin{tabular}{|c|c|c|c|c|c|c|}
\hline Item & $\begin{array}{l}\text { Massachusetts } \\
\text { Peabody } \\
\text { Clty of } \\
\text { December } 31\end{array}$ & $\begin{array}{l}\text { Massachusetts } \\
\text { Reading } \\
\text { Town of } \\
\text { December } 31\end{array}$ & $\begin{array}{l}\text { Massachusetts } \\
\text { Shrewsbury } \\
\text { Town of } \\
\text { December } 31\end{array}$ & $\begin{array}{l}\text { Massachusetts } \\
\text { Taunton } \\
\text { City of } \\
\text { December } 31\end{array}$ & $\begin{array}{c}\text { Massachusetts } \\
\text { Wakefield } \\
\text { Town of } \\
\text { December } 31\end{array}$ & $\begin{array}{c}\text { Massachusetts } \\
\text { Wellesley } \\
\text { Town of } \\
\text { December } 31\end{array}$ \\
\hline 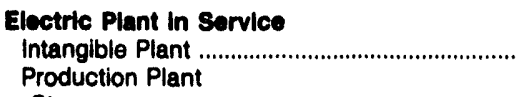 & 0 & 0 & 0 & 0 & 0 & 0 \\
\hline 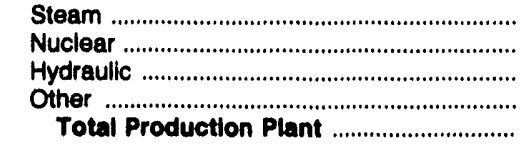 & $\begin{array}{r}0 \\
0 \\
0 \\
22,874 \\
22,874\end{array}$ & $\begin{array}{l}0 \\
0 \\
0 \\
0 \\
0\end{array}$ & $\begin{array}{r}0 \\
0 \\
0 \\
2,984 \\
2,884\end{array}$ & $\begin{array}{r}47,169 \\
0 \\
0 \\
4,951 \\
52,120\end{array}$ & $\begin{array}{l}0 \\
0 \\
0 \\
0 \\
0\end{array}$ & $\begin{array}{l}0 \\
0 \\
0 \\
0 \\
0\end{array}$ \\
\hline 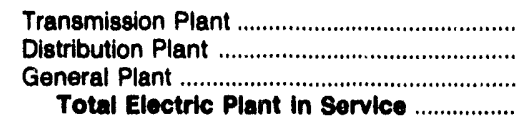 & $\begin{array}{r}7,365 \\
21,043 \\
7,823 \\
59,105\end{array}$ & $\begin{array}{r}2,220 \\
31,898 \\
6,003 \\
40,121\end{array}$ & $\begin{array}{r}2,247 \\
13,804 \\
2,918 \\
21,954\end{array}$ & $\begin{array}{r}7,026 \\
25,264 \\
3,510 \\
87,821\end{array}$ & $\begin{array}{r}0 \\
12,149 \\
557 \\
12,707\end{array}$ & $\begin{array}{r}3,710 \\
17,972 \\
1,509 \\
23,180\end{array}$ \\
\hline 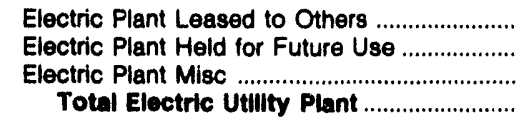 & $\begin{array}{r}0 \\
0 \\
0 \\
59,105\end{array}$ & $\begin{array}{r}0 \\
0 \\
0 \\
40,121\end{array}$ & $\begin{array}{r}0 \\
0 \\
0 \\
\mathbf{2 1 , 9 5 4}\end{array}$ & $\begin{array}{r}0 \\
0 \\
0 \\
87,921\end{array}$ & $\begin{array}{r}0 \\
0 \\
0 \\
12,707\end{array}$ & $\begin{array}{r}0 \\
0 \\
0 \\
23,190\end{array}$ \\
\hline $\begin{array}{l}\text { Construction Work in Progress - Electric ....... } \\
\text { Accumulated Provision for }\end{array}$ & 0 & 0 & 0 & 3,754 & 0 & 1,086 \\
\hline 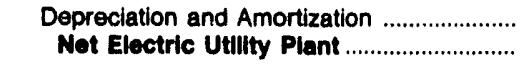 & $\begin{array}{l}20,229 \\
38,876\end{array}$ & $\begin{array}{l}18,204 \\
21,917\end{array}$ & $\begin{array}{l}10,335 \\
11,619\end{array}$ & $\begin{array}{l}49,081 \\
42,594\end{array}$ & $\begin{array}{r}10,331 \\
2,375\end{array}$ & $\begin{array}{l}11,160 \\
13,117\end{array}$ \\
\hline
\end{tabular}

Note: Totals may not equal sum of components because of independent rounding.

Source: Energy Information Administration, Form EIA-412, "Annual Report of Public Electric Utilities." 
Table 24. Electric Utility Plant by Major U.S. Publicly Owned Electric Utility Within State at End of Period, 1992 (Continued) (Thousand Dollars)

\begin{tabular}{|c|c|c|c|c|c|c|}
\hline Item & $\begin{array}{l}\text { Massachusetts } \\
\text { Westfield } \\
\text { City of } \\
\text { December } 31\end{array}$ & $\begin{array}{l}\text { Michigan } \\
\text { Bay } \\
\text { City City of } \\
\text { June } 30\end{array}$ & $\begin{array}{l}\text { Michigan } \\
\text { Coldwater } \\
\text { Board } \\
\text { of } \\
\text { Public Util } \\
\text { June } 30\end{array}$ & $\begin{array}{l}\text { Michigan } \\
\text { Detroit } \\
\text { City of } \\
\text { June } 30\end{array}$ & $\begin{array}{l}\text { Michigan } \\
\text { Grand Haven } \\
\text { City of } \\
\text { June } 30\end{array}$ & $\begin{array}{l}\text { Michigan } \\
\text { Hillsdale } \\
\text { Board } \\
\text { of } \\
\text { Public Wks } \\
\text { June } 30\end{array}$ \\
\hline 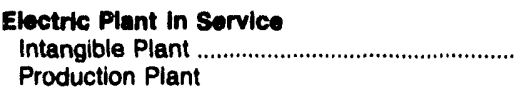 & 0 & 0 & 0 & 0 & 0 & 0 \\
\hline 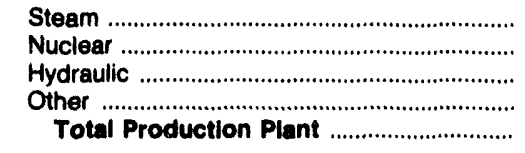 & $\begin{array}{l}0 \\
0 \\
0 \\
0 \\
0\end{array}$ & $\begin{array}{r}0 \\
0 \\
0 \\
7,815 \\
7,815\end{array}$ & $\begin{array}{r}0 \\
0 \\
0 \\
7,006 \\
7,006\end{array}$ & $\begin{array}{r}91,921 \\
0 \\
0 \\
2,458 \\
94,379\end{array}$ & $\begin{array}{r}80,617 \\
0 \\
0 \\
4,431 \\
85,048\end{array}$ & $\begin{array}{r}0 \\
0 \\
0 \\
5,255 \\
5,255\end{array}$ \\
\hline 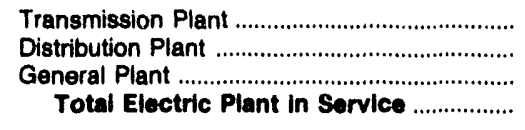 & $\begin{array}{r}17,853 \\
3,153 \\
0 \\
21,006\end{array}$ & $\begin{array}{r}0 \\
28,726 \\
826 \\
37,368\end{array}$ & $\begin{array}{r}0 \\
4,619 \\
2,196 \\
13,821\end{array}$ & $\begin{array}{r}22,169 \\
138,675 \\
11,621 \\
266,843\end{array}$ & $\begin{array}{r}0 \\
14,384 \\
1,239 \\
100,670\end{array}$ & $\begin{array}{r}25 \\
4,132 \\
853 \\
10,265\end{array}$ \\
\hline 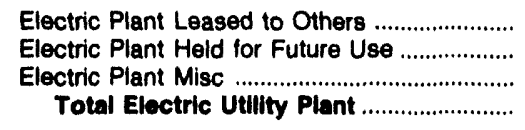 & $\begin{array}{r}0 \\
0 \\
0 \\
21,006\end{array}$ & $\begin{array}{r}0 \\
0 \\
0 \\
37,368\end{array}$ & $\begin{array}{r}0 \\
0 \\
0 \\
13,821\end{array}$ & $\begin{array}{r}0 \\
0 \\
0 \\
266,843\end{array}$ & $\begin{array}{r}0 \\
0 \\
0 \\
100,670\end{array}$ & $\begin{array}{r}0 \\
17 \\
0 \\
10,282\end{array}$ \\
\hline $\begin{array}{l}\text { Construction Work in Progress - Electric ........ } \\
\text { Accumulated Provision for }\end{array}$ & 25 & 0 & 0 & 15,502 & 304 & 547 \\
\hline 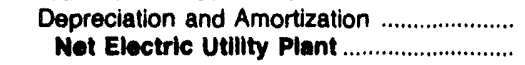 & $\begin{array}{r}1,832 \\
19,200\end{array}$ & $\begin{array}{l}11,120 \\
26,248\end{array}$ & $\begin{array}{l}7,989 \\
\mathbf{5 , 8 3 2}\end{array}$ & $\begin{array}{l}111,299 \\
171,046\end{array}$ & $\begin{array}{l}37,176 \\
63,797\end{array}$ & $\begin{array}{l}6,416 \\
4,414\end{array}$ \\
\hline
\end{tabular}

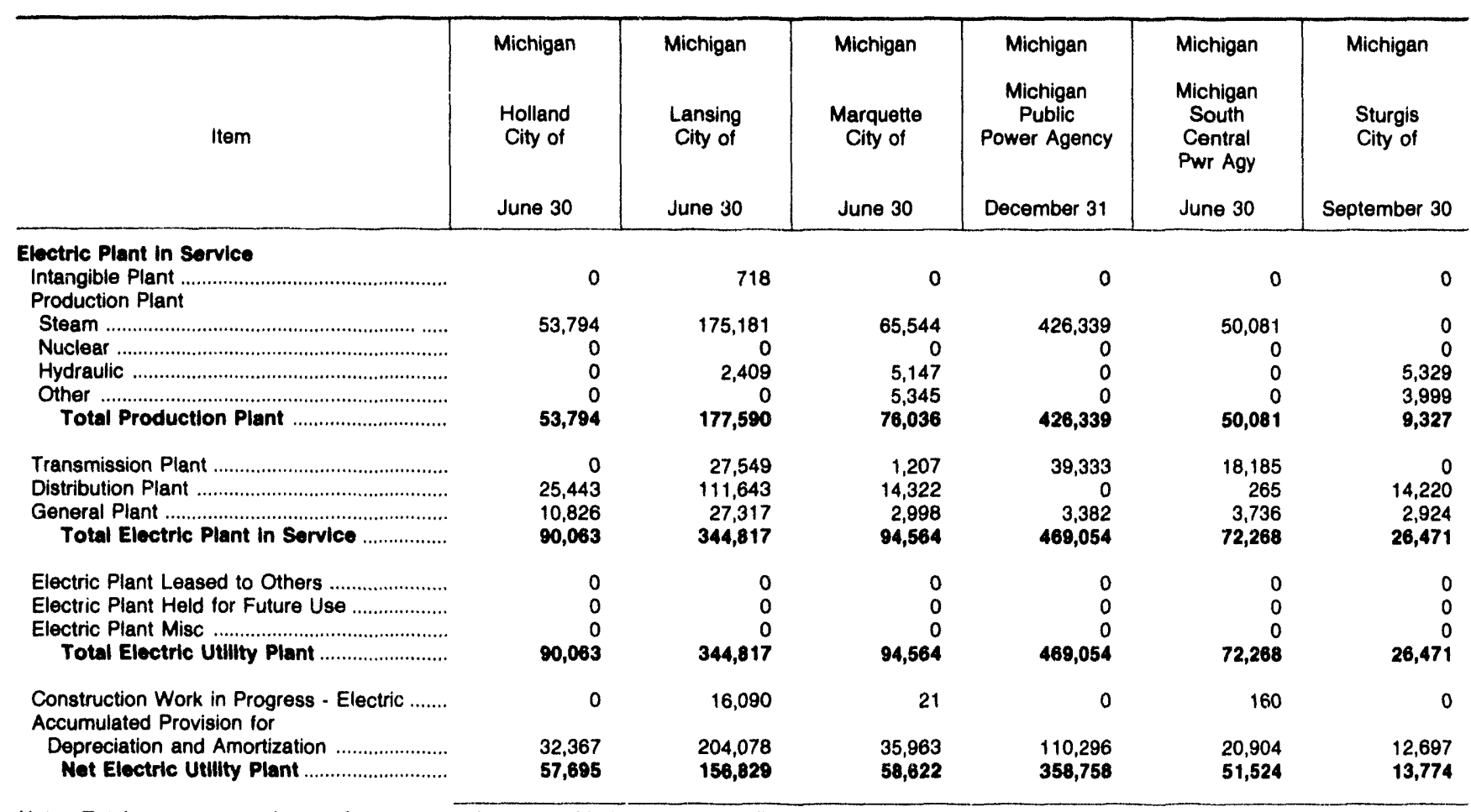

Note: Totals may not equal sum of components because of independent rounding.

Source: Energy Information Administration, Form ElA-412, "Annual Report of Public Electric Utilities." 
Table 24. Electric Utility Plant by Major U.S. Publicly Owned Electric Utility Within State at End of Period, 1992 (Continued) (Thousand Dollars)

\begin{tabular}{|c|c|c|c|c|c|c|}
\hline Item & $\begin{array}{l}\text { Michigan } \\
\text { Traverse } \\
\text { City City of } \\
\text { June } 30\end{array}$ & $\begin{array}{l}\text { Michigan } \\
\text { Wyandotte } \\
\text { Municipal } \\
\text { Serv Comm } \\
\text { September } 30\end{array}$ & $\begin{array}{c}\text { Minnesota } \\
\begin{array}{c}\text { Alexandria } \\
\text { City of }\end{array} \\
\text { December } 31\end{array}$ & $\begin{array}{c}\text { Minnesota } \\
\text { Anoka } \\
\text { City of } \\
\text { December } 31\end{array}$ & $\begin{array}{c}\text { Minnesota } \\
\text { Austin } \\
\text { City of } \\
\text { December } 31\end{array}$ & $\begin{array}{c}\text { Minnesota } \\
\text { Brainerd } \\
\text { City of } \\
\text { December } 31\end{array}$ \\
\hline 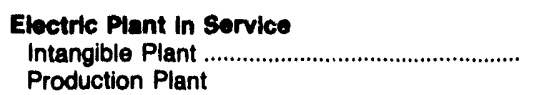 & 0 & 0 & 0 & 0 & 0 & 0 \\
\hline 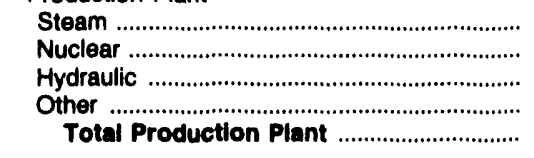 & $\begin{array}{r}10,251 \\
0 \\
4,590 \\
0 \\
14,841\end{array}$ & $\begin{array}{r}40,266 \\
0 \\
0 \\
0 \\
40,286\end{array}$ & $\begin{array}{r}1,842 \\
0 \\
0 \\
1,951 \\
\mathbf{3 , 7 9 4}\end{array}$ & $\begin{array}{l}0 \\
0 \\
0 \\
0 \\
0\end{array}$ & $\begin{array}{r}15,255 \\
0 \\
0 \\
0 \\
15,255\end{array}$ & $\begin{array}{l}0 \\
0 \\
0 \\
0 \\
0\end{array}$ \\
\hline 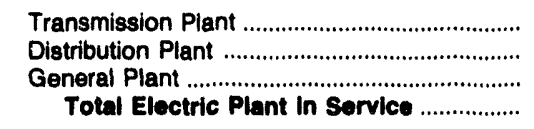 & $\begin{array}{r}4,589 \\
9,479 \\
426 \\
29,336\end{array}$ & $\begin{array}{r}5,447 \\
16,068 \\
2,468 \\
64,249\end{array}$ & $\begin{array}{r}837 \\
9,206 \\
1,450 \\
15,287\end{array}$ & $\begin{array}{r}0 \\
0 \\
12,252 \\
12,252\end{array}$ & $\begin{array}{r}1,175 \\
13,793 \\
1,675 \\
31,898\end{array}$ & $\begin{array}{r}0 \\
5,672 \\
0 \\
5,672\end{array}$ \\
\hline 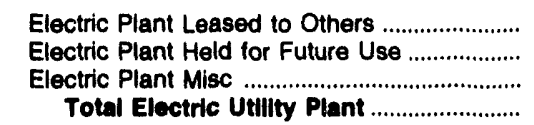 & $\begin{array}{r}0 \\
0 \\
0 \\
29,336\end{array}$ & $\begin{array}{r}0 \\
0 \\
0 \\
64,249\end{array}$ & $\begin{array}{r}0 \\
0 \\
0 \\
15,287\end{array}$ & $\begin{array}{r}0 \\
0 \\
0 \\
12,252\end{array}$ & $\begin{array}{r}1,065 \\
0 \\
0 \\
32,963\end{array}$ & $\begin{array}{r}0 \\
0 \\
0 \\
5,672\end{array}$ \\
\hline $\begin{array}{l}\text { Construction Work in Progress - Electric ....... } \\
\text { Accumulated Provision for }\end{array}$ & 150 & 38,331 & 146 & 0 & 71 & 1 \\
\hline 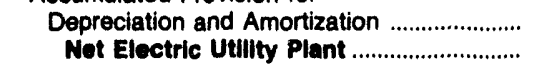 & $\begin{array}{l}10,810 \\
18,877\end{array}$ & $\begin{array}{l}30,230 \\
72,350\end{array}$ & $\begin{array}{l}9,039 \\
6,394\end{array}$ & $\begin{array}{l}5,872 \\
6,380\end{array}$ & $\begin{array}{l}20,904 \\
12,130\end{array}$ & $\begin{array}{l}2,540 \\
3,133\end{array}$ \\
\hline
\end{tabular}

\begin{tabular}{|c|c|c|c|c|c|c|}
\hline Item & $\begin{array}{l}\text { Minnesota } \\
\text { Fairmont } \\
\text { Public } \\
\text { Utilities } \\
\text { Comm } \\
\text { December } 31\end{array}$ & $\begin{array}{l}\text { Minnesota } \\
\text { Hutchiiıson } \\
\text { Utilities } \\
\text { Comm } \\
\text { December } 31\end{array}$ & $\begin{array}{l}\text { Minnesota } \\
\text { Marshall } \\
\text { City of } \\
\text { December } 31\end{array}$ & $\begin{array}{c}\text { Minnesota } \\
\text { Moorhead } \\
\text { City of }\end{array}$ & $\begin{array}{l}\text { Minnesota } \\
\text { New Ulm } \\
\text { Public } \\
\text { Utilities } \\
\text { Comm } \\
\text { December } 31\end{array}$ & $\begin{array}{c}\text { Minnesota } \\
\text { Northern } \\
\text { Municipal } \\
\text { Power Agny } \\
\text { December } 31\end{array}$ \\
\hline 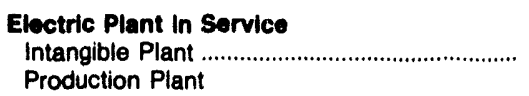 & 390 & 0 & 0 & 255 & 0 & 0 \\
\hline 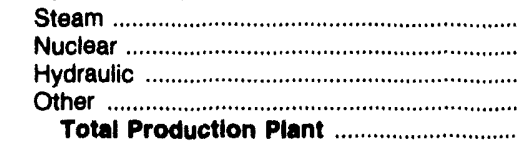 & $\begin{array}{r}5,086 \\
0 \\
0 \\
2,349 \\
7,435\end{array}$ & $\begin{array}{r}0 \\
0 \\
0 \\
10,263 \\
10,263\end{array}$ & $\begin{array}{r}0 \\
0 \\
0 \\
1,770 \\
1,770\end{array}$ & $\begin{array}{r}3,048 \\
0 \\
0 \\
0 \\
3,048\end{array}$ & $\begin{array}{r}12,064 \\
0 \\
0 \\
0 \\
12,064\end{array}$ & $\begin{array}{r}289,261 \\
0 \\
0 \\
0 \\
289,261\end{array}$ \\
\hline 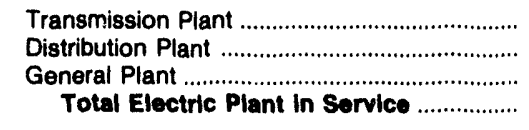 & $\begin{array}{r}2,756 \\
4,909 \\
2,095 \\
17,586\end{array}$ & $\begin{array}{r}5,925 \\
7,479 \\
1,390 \\
25,057\end{array}$ & $\begin{array}{r}3,167 \\
9,750 \\
1,111 \\
15,798\end{array}$ & $\begin{array}{r}2,586 \\
12,352 \\
1,283 \\
19,524\end{array}$ & $\begin{array}{r}4,341 \\
7,444 \\
0 \\
23,849\end{array}$ & $\begin{array}{r}24,600 \\
0 \\
0 \\
313,861\end{array}$ \\
\hline 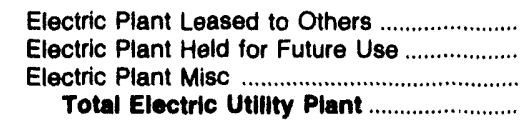 & $\begin{array}{r}0 \\
0 \\
0 \\
17,586\end{array}$ & $\begin{array}{r}0 \\
0 \\
0 \\
25,057\end{array}$ & $\begin{array}{r}0 \\
0 \\
0 \\
15,798\end{array}$ & $\begin{array}{r}0 \\
0 \\
9,194 \\
28,718\end{array}$ & $\begin{array}{r}0 \\
0 \\
0 \\
23,849\end{array}$ & $\begin{array}{r}0 \\
0 \\
0 \\
313,861\end{array}$ \\
\hline $\begin{array}{l}\text { Construction Work in Progress - Electric ....... } \\
\text { Accumulated Provision for }\end{array}$ & 77 & 3,633 & 394 & 651 & 0 & 0 \\
\hline $\begin{array}{l}\text { Depreciation and Amortization } \\
\text { Net Electric Utility Plant }\end{array}$ & $\begin{array}{r}10,680 \\
6,982\end{array}$ & $\begin{array}{l}13,275 \\
15,415\end{array}$ & $\begin{array}{r}5,523 \\
10,670\end{array}$ & $\begin{array}{l}14,340 \\
15,029\end{array}$ & $\begin{array}{l}12,381 \\
11,467\end{array}$ & $\begin{array}{r}9,195 \\
\mathbf{3 0 4 , 6 6 6}\end{array}$ \\
\hline
\end{tabular}

Note: Totals may not equal sum of components because of independent rounding.

Source: Energy Information Administration, Form EIA-412, "Annual Report of Public Electric Utilities." 
Table 24. Electric Utillty Plant by Major U.S. Publicly Owned Electric Utility Within State at End of Period, 1992 (Continued)

(Thousarıd Dollars)

\begin{tabular}{|c|c|c|c|c|c|c|}
\hline Item & $\begin{array}{c}\text { Minnesota } \\
\text { Owatonna } \\
\text { City of }\end{array}$ & $\begin{array}{l}\text { Minnesota } \\
\text { Rochester } \\
\text { Public } \\
\text { Utillties } \\
\text { December } 31\end{array}$ & $\begin{array}{c}\text { Minnesota } \\
\text { Southern } \\
\text { Minnesota } \\
\text { Mun P } \\
\text { Agny } \\
\text { December } 31\end{array}$ & $\begin{array}{c}\text { Minnesota } \\
\text { Western } \\
\text { Minnesota } \\
\text { Mun } \\
\text { Pwr Agny } \\
\text { December } 31\end{array}$ & $\begin{array}{c}\text { Minnesota } \\
\text { Wilimar } \\
\text { Municipal } \\
\text { Utils Comm } \\
\text { December } 31\end{array}$ & $\begin{array}{l}\text { Mississippi } \\
\text { Aberdeen } \\
\text { City of } \\
\text { June } 30\end{array}$ \\
\hline 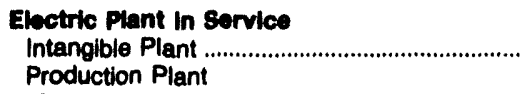 & 0 & 148 & 15,999 & 0 & 0 & 0 \\
\hline 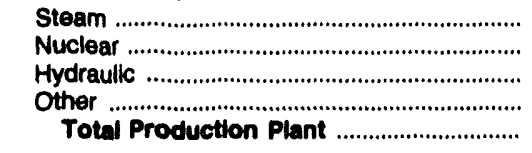 & $\begin{array}{r}6,796 \\
0 \\
0 \\
1,936 \\
8,731\end{array}$ & $\begin{array}{r}25,360 \\
0 \\
2,467 \\
2,554 \\
30,381\end{array}$ & $\begin{array}{r}434,069 \\
0 \\
0 \\
0 \\
434,089\end{array}$ & $\begin{array}{r}167,261 \\
0 \\
0 \\
0 \\
167,261\end{array}$ & $\begin{array}{r}7,700 \\
0 \\
0 \\
0 \\
7,700\end{array}$ & $\begin{array}{l}0 \\
0 \\
0 \\
0 \\
0\end{array}$ \\
\hline 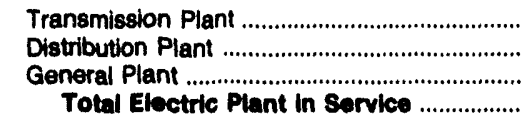 & $\begin{array}{r}2,525 \\
11,639 \\
3,241 \\
26,136\end{array}$ & $\begin{array}{r}5,707 \\
38,310 \\
17,498 \\
92,044\end{array}$ & $\begin{array}{r}57,146 \\
0 \\
4,520 \\
511,734\end{array}$ & $\begin{array}{r}55,886 \\
0 \\
0 \\
223,147\end{array}$ & $\begin{array}{r}6,167 \\
11,197 \\
2,574 \\
27,638\end{array}$ & $\begin{array}{r}0 \\
3,282 \\
871 \\
4,153\end{array}$ \\
\hline 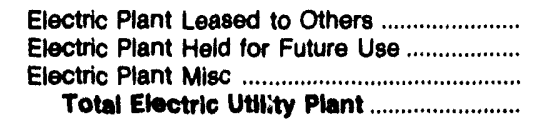 & $\begin{array}{r}0 \\
0 \\
0 \\
26,136\end{array}$ & $\begin{array}{r}0 \\
0 \\
0 \\
92,044\end{array}$ & $\begin{array}{r}0 \\
0 \\
407 \\
512,141\end{array}$ & $\begin{array}{r}0 \\
14,094 \\
0 \\
237,241\end{array}$ & $\begin{array}{r}806 \\
0 \\
0 \\
28,444\end{array}$ & $\begin{array}{r}0 \\
0 \\
0 \\
4,153\end{array}$ \\
\hline $\begin{array}{l}\text { Construction Work in Progress - Electric ........ } \\
\text { Accumulated Provision for }\end{array}$ & 414 & 6,469 & 4,261 & 608 & 1,286 & 35 \\
\hline 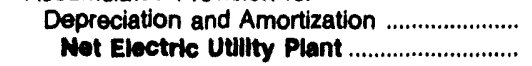 & $\begin{array}{l}11,709 \\
14,841\end{array}$ & $\begin{array}{l}49,639 \\
48,874\end{array}$ & $\begin{array}{r}85,068 \\
431,334\end{array}$ & $\begin{array}{r}41,795 \\
196,054\end{array}$ & $\begin{array}{l}14,333 \\
15,397\end{array}$ & $\begin{array}{l}1,807 \\
2,381\end{array}$ \\
\hline
\end{tabular}

\begin{tabular}{|c|c|c|c|c|c|c|}
\hline Item & $\begin{array}{l}\text { Mississippi } \\
\text { Clarksdale } \\
\text { Clty of } \\
\text { September } 30\end{array}$ & $\begin{array}{l}\text { Mississippi } \\
\text { Columbus } \\
\text { City of } \\
\text { June } 30\end{array}$ & $\begin{array}{l}\text { Mississippi } \\
\text { Greenwood } \\
\text { Utilities } \\
\text { Comm } \\
\text { September } 30\end{array}$ & $\begin{array}{l}\text { Mississippi } \\
\text { Holly } \\
\text { Springs } \\
\text { City of } \\
\text { June } 30\end{array}$ & $\begin{array}{l}\text { Mississippi } \\
\text { Louisville } \\
\text { Electric } \\
\text { System } \\
\text { June } 30\end{array}$ & $\begin{array}{c}\text { Mississippi } \\
\text { Municipal } \\
\text { Energy } \\
\text { Agency } \\
\text { of MS } \\
\text { September } 30\end{array}$ \\
\hline 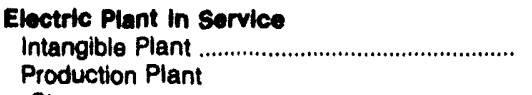 & 0 & 0 & 0 & 0 & 0 & 131 \\
\hline 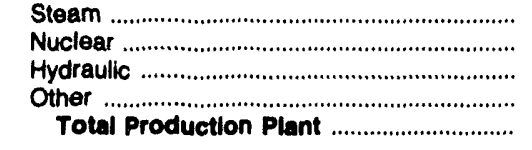 & $\begin{array}{r}14,443 \\
0 \\
0 \\
0 \\
14,443\end{array}$ & $\begin{array}{l}0 \\
0 \\
0 \\
0 \\
0\end{array}$ & $\begin{array}{r}13,829 \\
0 \\
0 \\
1,163 \\
14,991\end{array}$ & $\begin{array}{l}0 \\
0 \\
0 \\
0 \\
0\end{array}$ & $\begin{array}{l}0 \\
0 \\
0 \\
0 \\
0\end{array}$ & $\begin{array}{l}0 \\
0 \\
0 \\
0 \\
0\end{array}$ \\
\hline 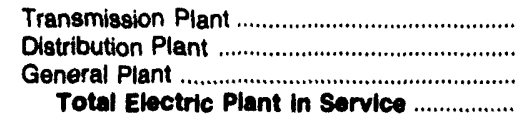 & $\begin{array}{r}1,774 \\
8,364 \\
897 \\
25,478\end{array}$ & $\begin{array}{r}10 \\
11,958 \\
1,137 \\
13,105\end{array}$ & $\begin{array}{r}731 \\
7,876 \\
1,894 \\
25,592\end{array}$ & $\begin{array}{r}0 \\
8,881 \\
1,901 \\
10,783\end{array}$ & $\begin{array}{r}202 \\
5,350 \\
984 \\
6,536\end{array}$ & $\begin{array}{r}0 \\
0 \\
261 \\
391\end{array}$ \\
\hline 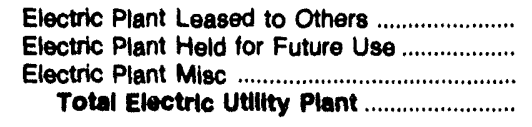 & $\begin{array}{r}0 \\
0 \\
0 \\
25,478\end{array}$ & $\begin{array}{r}0 \\
0 \\
0 \\
13,105\end{array}$ & $\begin{array}{r}0 \\
0 \\
0 \\
25,592\end{array}$ & $\begin{array}{r}0 \\
0 \\
77 \\
10,859\end{array}$ & $\begin{array}{r}0 \\
0 \\
0 \\
6,536\end{array}$ & $\begin{array}{r}0 \\
0 \\
0 \\
391\end{array}$ \\
\hline $\begin{array}{l}\text { Construction Work in Progress - Electric ....... } \\
\text { Accumulated Provision for }\end{array}$ & 49 & 608 & 55 & 399 & 313 & 275 \\
\hline 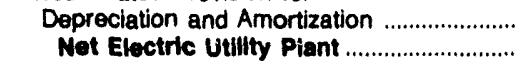 & $\begin{array}{r}16,906 \\
8,821\end{array}$ & $\begin{array}{l}6,941 \\
6,772\end{array}$ & $\begin{array}{l}14,737 \\
10,911\end{array}$ & $\begin{array}{l}3,530 \\
7,728\end{array}$ & $\begin{array}{l}2,113 \\
4,736\end{array}$ & $\begin{array}{l}133 \\
533\end{array}$ \\
\hline
\end{tabular}

Note: Totals may not equal sum of components because of independent rounding.

Source: Energy Information Administration, Form ElA-412, "Annual Report of Public Electric Utilities." 
Table 24. Electric Utility Plant by Major U.S. Publicly Owned Electric Utillty Within State at End of Perlod, 1992 (Continued) (Thousana Dollars)

\begin{tabular}{|c|c|c|c|c|c|c|}
\hline Item & $\begin{array}{l}\text { Mississippi } \\
\text { New Albany } \\
\text { City of } \\
\text { June } 30\end{array}$ & $\begin{array}{l}\text { Mississippi } \\
\text { Oxford } \\
\text { City of } \\
\text { June } 30\end{array}$ & $\begin{array}{l}\text { Mississippi } \\
\text { Starkville } \\
\text { City of } \\
\text { June } 30\end{array}$ & $\begin{array}{l}\text { Mississippi } \\
\text { Tupelo } \\
\text { City of } \\
\text { June } 30\end{array}$ & $\begin{array}{c}\text { Mississippi } \\
\text { West } \\
\text { Point } \\
\text { City of } \\
\\
\text { June } 30\end{array}$ & $\begin{array}{l}\text { Missouri } \\
\text { Carthage } \\
\text { City of } \\
\text { June } 30\end{array}$ \\
\hline 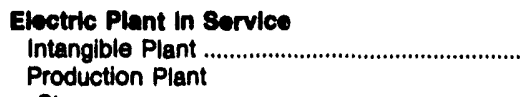 & 0 & 0 & 0 & 0 & 0 & 0 \\
\hline 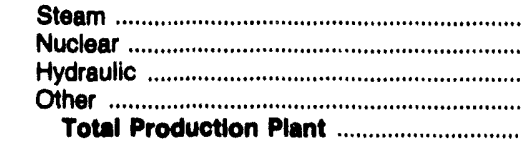 & $\begin{array}{l}0 \\
0 \\
0 \\
0 \\
0\end{array}$ & $\begin{array}{l}0 \\
0 \\
0 \\
0 \\
0\end{array}$ & $\begin{array}{l}0 \\
0 \\
0 \\
0 \\
0\end{array}$ & $\begin{array}{l}0 \\
0 \\
0 \\
0 \\
0\end{array}$ & $\begin{array}{l}0 \\
0 \\
0 \\
0 \\
0\end{array}$ & $\begin{array}{r}0 \\
0 \\
0 \\
8,169 \\
8,169\end{array}$ \\
\hline 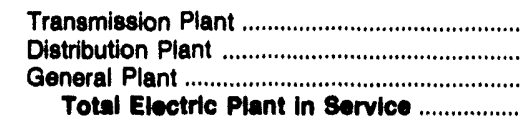 & $\begin{array}{r}0 \\
9,083 \\
909 \\
9,903\end{array}$ & $\begin{array}{r}0 \\
4,232 \\
919 \\
5,152\end{array}$ & $\begin{array}{r}303 \\
8,266 \\
1,487 \\
10,056\end{array}$ & $\begin{array}{r}875 \\
17,435 \\
2,012 \\
20,322\end{array}$ & $\begin{array}{r}76 \\
5,507 \\
782 \\
6,365\end{array}$ & $\begin{array}{r}1,140 \\
7,638 \\
1,411 \\
18,358\end{array}$ \\
\hline 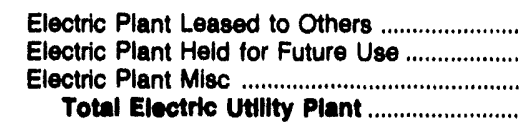 & $\begin{array}{r}0 \\
0 \\
46 \\
10,030\end{array}$ & $\begin{array}{r}0 \\
0 \\
0 \\
\mathbf{5 , 1 5 2}\end{array}$ & $\begin{array}{r}0 \\
0 \\
52 \\
10,108\end{array}$ & $\begin{array}{r}0 \\
0 \\
0 \\
20,322\end{array}$ & $\begin{array}{r}0 \\
0 \\
1 \\
6,366\end{array}$ & $\begin{array}{r}0 \\
0 \\
0 \\
18,368\end{array}$ \\
\hline $\begin{array}{l}\text { Construction Work in Progress - Electric ....... } \\
\text { Accumulated Provision for }\end{array}$ & 946 & 265 & 148 & 252 & 178 & 11 \\
\hline 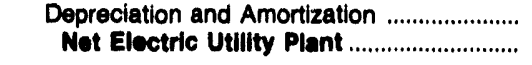 & $\begin{array}{l}3,517 \\
7,460\end{array}$ & $\begin{array}{l}2,038 \\
3,377\end{array}$ & $\begin{array}{l}3,510 \\
6,746\end{array}$ & $\begin{array}{r}6,579 \\
13,995\end{array}$ & $\begin{array}{l}2,181 \\
4,363\end{array}$ & $\begin{array}{r}12,119 \\
6,260\end{array}$ \\
\hline
\end{tabular}

\begin{tabular}{|c|c|c|c|c|c|c|}
\hline Item & $\begin{array}{l}\text { Missouri } \\
\text { Columbia } \\
\text { Clty of } \\
\text { September } 30\end{array}$ & $\begin{array}{l}\text { Missouri } \\
\text { Hannibal } \\
\text { City of } \\
\text { June } 30\end{array}$ & $\begin{array}{c}\text { Missouri } \\
\text { Independence } \\
\text { Clty of } \\
\text { June } 30\end{array}$ & $\begin{array}{l}\text { Missouri } \\
\text { Kennett } \\
\text { City of } \\
\text { June } 30\end{array}$ & $\begin{array}{l}\text { Missouri } \\
\text { Kirkwood } \\
\text { City of } \\
\text { March } 31\end{array}$ & $\begin{array}{l}\text { Missouri } \\
\text { Lebanon } \\
\text { City of } \\
\text { October } 31\end{array}$ \\
\hline 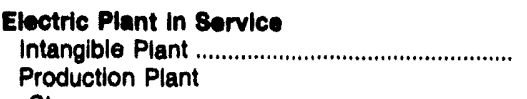 & 0 & 0 & 0 & 0 & 0 & 0 \\
\hline $\begin{array}{l}\text { Steam } \\
\text { Nuclear } \\
\text { Other } \\
\text { Total }\end{array}$ & $\begin{array}{r}21,178 \\
0 \\
0 \\
2,029 \\
23,207\end{array}$ & $\begin{array}{l}0 \\
0 \\
0 \\
0 \\
0\end{array}$ & $\begin{array}{r}49,541 \\
0 \\
0 \\
20,888 \\
70,429\end{array}$ & $\begin{array}{r}0 \\
0 \\
0 \\
8,017 \\
8,017\end{array}$ & $\begin{array}{l}0 \\
0 \\
0 \\
0 \\
0\end{array}$ & $\begin{array}{l}0 \\
0 \\
0 \\
0 \\
0\end{array}$ \\
\hline 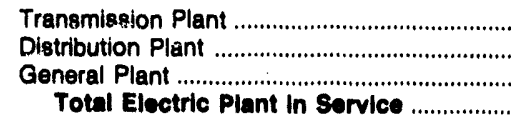 & $\begin{array}{r}14,172 \\
30,868 \\
4,011 \\
72,258\end{array}$ & $\begin{array}{l}1,989 \\
5,624 \\
1,611 \\
9,224\end{array}$ & $\begin{array}{r}17,047 \\
46,709 \\
10,153 \\
144,337\end{array}$ & $\begin{array}{r}401 \\
4,885 \\
0 \\
13,302\end{array}$ & $\begin{array}{r}0 \\
4,139 \\
0 \\
4,139\end{array}$ & $\begin{array}{l}0 \\
0 \\
0 \\
0\end{array}$ \\
\hline 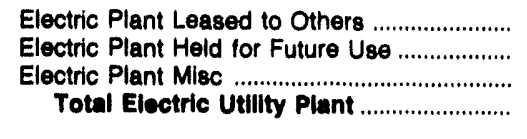 & $\begin{array}{r}0 \\
0 \\
0 \\
72,258\end{array}$ & $\begin{array}{r}0 \\
0 \\
0 \\
9,224\end{array}$ & $\begin{array}{r}0 \\
0 \\
2,756 \\
147,092\end{array}$ & $\begin{array}{r}0 \\
0 \\
0 \\
13,302\end{array}$ & $\begin{array}{r}0 \\
0 \\
1,050 \\
5,189\end{array}$ & $\begin{array}{l}0 \\
0 \\
0 \\
0\end{array}$ \\
\hline $\begin{array}{l}\text { Construction Work in Progress - Electric ....... } \\
\text { Accumulated Provision for }\end{array}$ & 1,578 & 560 & 8,048 & 0 & 0 & 0 \\
\hline 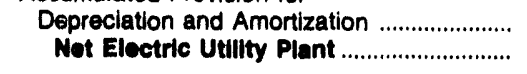 & $\begin{array}{l}30,496 \\
43,340\end{array}$ & $\begin{array}{l}6,395 \\
3,389\end{array}$ & $\begin{array}{l}79,042 \\
76,099\end{array}$ & $\begin{array}{l}9,220 \\
4,083\end{array}$ & $\begin{array}{l}3,084 \\
2,104\end{array}$ & $\begin{array}{l}0 \\
\mathbf{0}\end{array}$ \\
\hline
\end{tabular}

Note: Totals may not equal sum of components because of independent rounding

Source: Energy Information Administration, Form ElA-412, "Annual Report of Public Electric Utilities." 
Table 24. Electric Utility Plant by Major U.S. Publicly Owned Electric Utility Within State at End of Period, 1992 (Continued) (Thousand Dollars)

\begin{tabular}{|c|c|c|c|c|c|c|}
\hline Item & $\begin{array}{c}\text { Missouri } \\
\text { Marshail } \\
\text { City of } \\
\text { September } 30\end{array}$ & $\begin{array}{l}\text { Missouri } \\
\text { Monett } \\
\text { City of } \\
\text { March } 31\end{array}$ & $\begin{array}{l}\text { Missouri } \\
\text { Popiar } \\
\text { Bluff } \\
\text { Clty of } \\
\text { December } 31\end{array}$ & $\begin{array}{c}\text { Missouri } \\
\text { Rolla } \\
\text { City of } \\
\text { September } 30\end{array}$ & $\begin{array}{l}\text { Missouri } \\
\text { Sikeston } \\
\text { City of } \\
\text { May } 31\end{array}$ & $\begin{array}{l}\text { Missouri } \\
\text { Springfield } \\
\text { Clty of }\end{array}$ \\
\hline 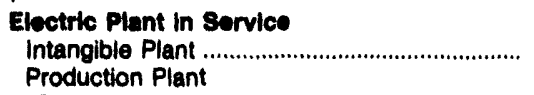 & 0 & 0 & 0 & 0 & 0 & 0 \\
\hline 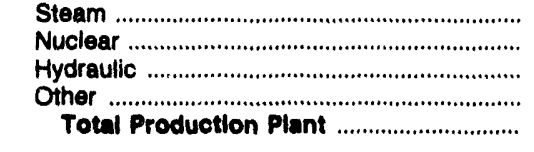 & $\begin{array}{r}12,756 \\
0 \\
0 \\
7,062 \\
18,818\end{array}$ & $\begin{array}{l}0 \\
0 \\
0 \\
0 \\
0\end{array}$ & $\begin{array}{r}0 \\
0 \\
0 \\
3,120 \\
\mathbf{3 , 1 2 0}\end{array}$ & $\begin{array}{l}0 \\
0 \\
0 \\
0 \\
0\end{array}$ & $\begin{array}{r}198,710 \\
0 \\
0 \\
0 \\
198,710\end{array}$ & $\begin{array}{r}148,677 \\
0 \\
0 \\
51,842 \\
200,519\end{array}$ \\
\hline 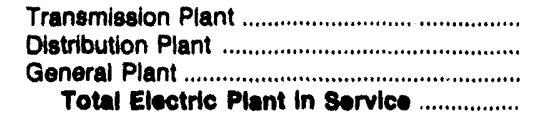 & $\begin{array}{r}4,862 \\
3,793 \\
1,709 \\
30,182\end{array}$ & $\begin{array}{r}0 \\
0 \\
1,164 \\
1,164\end{array}$ & $\begin{array}{r}0 \\
12,669 \\
2,063 \\
17,851\end{array}$ & $\begin{array}{r}108 \\
6,025 \\
2,151 \\
8,285\end{array}$ & $\begin{array}{r}4,594 \\
13,099 \\
2,509 \\
218,913\end{array}$ & $\begin{array}{r}46,525 \\
105,366 \\
7,874 \\
380,284\end{array}$ \\
\hline 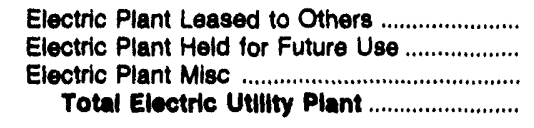 & $\begin{array}{r}0 \\
0 \\
0 \\
30,182\end{array}$ & $\begin{array}{r}0 \\
0 \\
0 \\
1,164\end{array}$ & $\begin{array}{r}0 \\
0 \\
0 \\
17,851\end{array}$ & $\begin{array}{r}0 \\
0 \\
0 \\
8,285\end{array}$ & $\begin{array}{r}0 \\
0 \\
0 \\
218,913\end{array}$ & $\begin{array}{r}0 \\
0 \\
0 \\
360,284\end{array}$ \\
\hline $\begin{array}{l}\text { Construction Work in Progress - Electric ........ } \\
\text { Accumulated Provision for }\end{array}$ & 1,714 & 0 & 0 & 0 & 712 & 3,901 \\
\hline 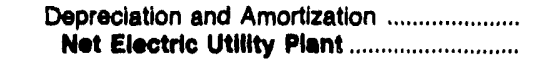 & $\begin{array}{l}15,450 \\
18,446\end{array}$ & 1,184 & $\begin{array}{r}7,447 \\
10,404\end{array}$ & $\begin{array}{l}5,469 \\
2,816\end{array}$ & $\begin{array}{r}61,228 \\
168,396\end{array}$ & $\begin{array}{l}116,089 \\
248,008\end{array}$ \\
\hline
\end{tabular}

\begin{tabular}{|c|c|c|c|c|c|c|}
\hline Item & $\begin{array}{c}\text { Nebraska } \\
\text { Central } \\
\text { Nebraska } \\
\text { Pub } \\
\text { P\&I Dist } \\
\text { December } 31\end{array}$ & $\begin{array}{c}\text { Nebraska } \\
\text { Cornhusker } \\
\text { Public } \\
\text { Power Dist } \\
\text { December } 31\end{array}$ & $\begin{array}{c}\text { Nebraska } \\
\text { Dawson } \\
\text { County } \\
\text { Public } \\
\text { Pwr Dist } \\
\text { December } 31\end{array}$ & $\begin{array}{l}\text { Nebraska } \\
\text { Fremont } \\
\text { City of } \\
\text { July } 31\end{array}$ & $\begin{array}{l}\text { Nebraska } \\
\text { Grand Island } \\
\text { City of } \\
\text { July } 31\end{array}$ & $\begin{array}{c}\text { Nebraska } \\
\text { Hastings } \\
\text { City of } \\
\text { December } 31\end{array}$ \\
\hline 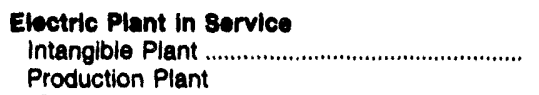 & 13,596 & 1 & 3 & 0 & 3,118 & 0 \\
\hline 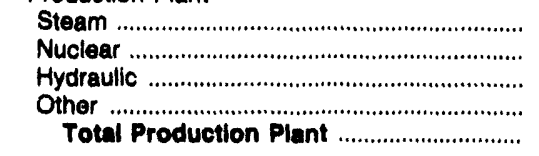 & $\begin{array}{r}16,320 \\
0 \\
96,093 \\
0 \\
112,412\end{array}$ & $\begin{array}{l}0 \\
0 \\
0 \\
0 \\
0\end{array}$ & $\begin{array}{l}0 \\
0 \\
0 \\
0 \\
0\end{array}$ & $\begin{array}{r}47,423 \\
0 \\
0 \\
0 \\
47,423\end{array}$ & $\begin{array}{r}117,001 \\
0 \\
0 \\
0 \\
117,001\end{array}$ & $\begin{array}{r}74,625 \\
0 \\
0 \\
2,454 \\
77,079\end{array}$ \\
\hline 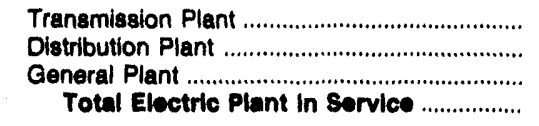 & $\begin{array}{r}5,717 \\
0 \\
4,360 \\
138,086\end{array}$ & $\begin{array}{r}2,476 \\
23,560 \\
3,018 \\
29,056\end{array}$ & $\begin{array}{r}4,025 \\
33,963 \\
4,683 \\
42,674\end{array}$ & $\begin{array}{r}289 \\
11,945 \\
2,277 \\
61,033\end{array}$ & $\begin{array}{r}9,475 \\
24,344 \\
2,157 \\
166,095\end{array}$ & $\begin{array}{r}6,332 \\
14,801 \\
1,809 \\
100,021\end{array}$ \\
\hline 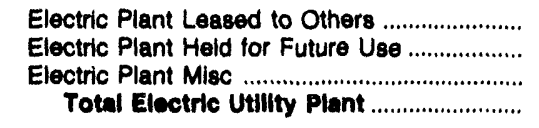 & $\begin{array}{r}0 \\
0 \\
0 \\
136,086\end{array}$ & $\begin{array}{r}0 \\
0 \\
0 \\
28,056\end{array}$ & $\begin{array}{r}4 \\
1 \\
0 \\
42,679\end{array}$ & $\begin{array}{r}0 \\
0 \\
0 \\
61,933\end{array}$ & $\begin{array}{r}0 \\
0 \\
2,167 \\
158,262\end{array}$ & $\begin{array}{r}0 \\
0 \\
0 \\
100,021\end{array}$ \\
\hline $\begin{array}{l}\text { Construction Work in Progress . Electric ....... } \\
\text { Accumulated Provision for }\end{array}$ & 198 & 317 & 246 & 1,302 & 99 & 488 \\
\hline 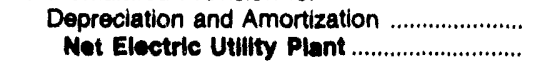 & $\begin{array}{l}51,476 \\
84,808\end{array}$ & $\begin{array}{r}9,431 \\
18,941\end{array}$ & $\begin{array}{l}19,217 \\
23,708\end{array}$ & $\begin{array}{l}43,082 \\
20,164\end{array}$ & $\begin{array}{r}57,845 \\
100,617\end{array}$ & $\begin{array}{l}32,657 \\
67,853\end{array}$ \\
\hline
\end{tabular}

Note: Totals may not equal sum of components because of independent rounding.

Source: Energy Information Administration, Form ElA-412, "Annual Report of Public Electric Utilities." 
Table 24. Electric Utility Plant by Major U.S. Publicly Owned Electric Utility Within State at End of Period, 1992 (Continued) (Thousand Dollars)

\begin{tabular}{|c|c|c|c|c|c|c|}
\hline Item & $\begin{array}{c}\text { Nebraska } \\
\text { Lincoin } \\
\text { Electric } \\
\text { System } \\
\text { December } 31\end{array}$ & $\begin{array}{c}\text { Nebraska } \\
\text { Loup } \\
\text { Rlver } \\
\text { Public } \\
\text { Power Dist } \\
\text { December } 31\end{array}$ & $\begin{array}{c}\text { Nebraska } \\
\text { Municipal } \\
\text { Energy } \\
\text { Agency } \\
\text { of NE } \\
\text { March } 31\end{array}$ & $\begin{array}{c}\text { Nebraska } \\
\text { Nebraska } \\
\text { Public } \\
\text { Power } \\
\text { District } \\
\text { December } 31\end{array}$ & $\begin{array}{c}\text { Nebraska } \\
\text { Norris } \\
\text { Public } \\
\text { Power } \\
\text { District } \\
\text { December } 31\end{array}$ & $\begin{array}{c}\text { Nebraska } \\
\text { North } \\
\text { Platte } \\
\text { City of } \\
\text { July } 31\end{array}$ \\
\hline 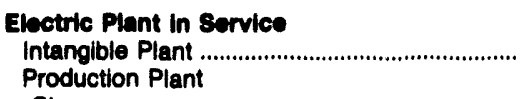 & 10,188 & 2,873 & 0 & 1,452 & 2 & 0 \\
\hline 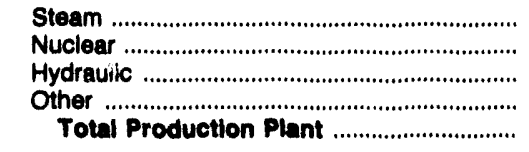 & $\begin{array}{r}138,607 \\
0 \\
0 \\
9,885 \\
149,493\end{array}$ & $\begin{array}{r}0 \\
0 \\
8,612 \\
0 \\
8,612\end{array}$ & $\begin{array}{r}28,653 \\
0 \\
0 \\
0 \\
28,653\end{array}$ & $\begin{array}{r}754,249 \\
355,037 \\
15,846 \\
15,113 \\
1,140,244\end{array}$ & $\begin{array}{l}0 \\
0 \\
0 \\
0 \\
0\end{array}$ & $\begin{array}{l}0 \\
0 \\
0 \\
0 \\
0\end{array}$ \\
\hline 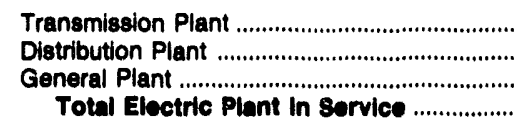 & $\begin{array}{r}83,348 \\
140,710 \\
23,304 \\
408,043\end{array}$ & $\begin{array}{r}9,713 \\
18,774 \\
5,933 \\
45,904\end{array}$ & $\begin{array}{r}0 \\
0 \\
0 \\
28,653\end{array}$ & $\begin{array}{r}455,180 \\
93,236 \\
100,434 \\
1,790,646\end{array}$ & $\begin{array}{r}7,460 \\
42,594 \\
6,396 \\
\mathbf{5 6 , 4 5 3}\end{array}$ & $\begin{array}{r}557 \\
8,925 \\
2,687 \\
12,170\end{array}$ \\
\hline 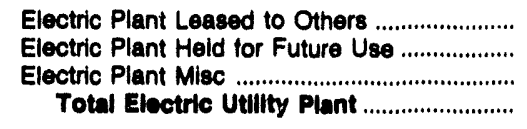 & $\begin{array}{r}0 \\
0 \\
4,829 \\
410,872\end{array}$ & $\begin{array}{r}0 \\
0 \\
457 \\
46,382\end{array}$ & $\begin{array}{r}0 \\
0 \\
0 \\
28,653\end{array}$ & $\begin{array}{r}0 \\
0 \\
0 \\
1,790,546\end{array}$ & $\begin{array}{r}0 \\
0 \\
459 \\
56,911\end{array}$ & $\begin{array}{r}0 \\
0 \\
0 \\
12,170\end{array}$ \\
\hline $\begin{array}{l}\text { Construction Work in Progress - Electric ....... } \\
\text { Accumulated Provision for }\end{array}$ & 20,234 & 3,978 & 8,775 & 150,896 & 214 & 164 \\
\hline 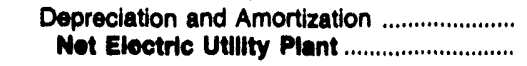 & $\begin{array}{l}118,125 \\
312,981\end{array}$ & $\begin{array}{l}23,425 \\
26,916\end{array}$ & $\begin{array}{r}2,261 \\
35,187\end{array}$ & $\begin{array}{r}687,976 \\
1,253,666\end{array}$ & $\begin{array}{l}17,086 \\
40,039\end{array}$ & $\begin{array}{l}7,575 \\
4,769\end{array}$ \\
\hline
\end{tabular}

\begin{tabular}{|c|c|c|c|c|c|c|}
\hline Item & $\begin{array}{c}\text { Nebraska } \\
\text { Omaha Public } \\
\text { Power } \\
\text { District } \\
\text { December } 31\end{array}$ & $\begin{array}{c}\text { Nebraska } \\
\text { Southern } \\
\text { Nebraska Rural } \\
\text { P P D } \\
\text { December } 31\end{array}$ & $\begin{array}{l}\text { Nevada } \\
\text { Colorado } \\
\text { River } \\
\text { Comm } \\
\text { of Nevada } \\
\text { June } 30\end{array}$ & $\begin{array}{l}\text { New Jersey } \\
\text { Vineland } \\
\text { City of } \\
\text { June } 30\end{array}$ & $\begin{array}{c}\text { New Mexico } \\
\text { Farmington } \\
\text { City of } \\
\text { June } 30\end{array}$ & $\begin{array}{l}\text { New Mexico } \\
\text { Gallup } \\
\text { City of } \\
\text { June } 30\end{array}$ \\
\hline 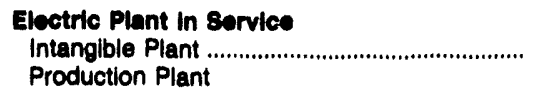 & 0 & 0 & 0 & 0 & 5,784 & 0 \\
\hline 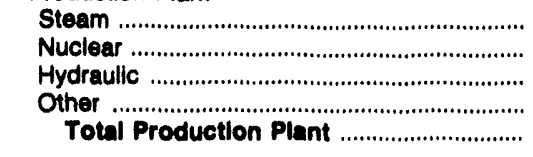 & $\begin{array}{r}603,895 \\
383,642 \\
0 \\
21,256 \\
1,008,792\end{array}$ & $\begin{array}{l}0 \\
0 \\
0 \\
0 \\
0\end{array}$ & $\begin{array}{l}0 \\
0 \\
0 \\
0 \\
0\end{array}$ & $\begin{array}{r}34,399 \\
0 \\
0 \\
4,044 \\
38,443\end{array}$ & $\begin{array}{r}72,935 \\
0 \\
16,367 \\
0 \\
89,302\end{array}$ & $\begin{array}{l}0 \\
0 \\
0 \\
0 \\
0\end{array}$ \\
\hline 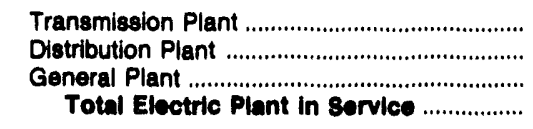 & $\begin{array}{r}147,690 \\
510,083 \\
162,563 \\
1,829,128\end{array}$ & $\begin{array}{r}3,100 \\
60,088 \\
5,336 \\
68,524\end{array}$ & $\begin{array}{l}0 \\
0 \\
0 \\
0\end{array}$ & $\begin{array}{r}1,484 \\
22,616 \\
2,497 \\
65,041\end{array}$ & $\begin{array}{r}15,114 \\
49,583 \\
6,353 \\
168,136\end{array}$ & $\begin{array}{r}0 \\
9,483 \\
1,125 \\
10,609\end{array}$ \\
\hline 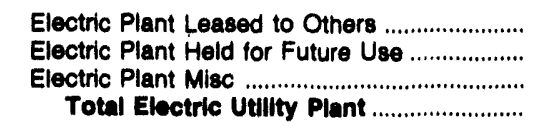 & $\begin{array}{r}0 \\
0 \\
7,998 \\
1,837,128\end{array}$ & $\begin{array}{r}0 \\
0 \\
0 \\
68,624\end{array}$ & $\begin{array}{l}0 \\
0 \\
0 \\
0\end{array}$ & $\begin{array}{r}0 \\
0 \\
0 \\
65,041\end{array}$ & $\begin{array}{r}0 \\
0 \\
0 \\
166,136\end{array}$ & $\begin{array}{r}0 \\
0 \\
0 \\
10,609\end{array}$ \\
\hline $\begin{array}{l}\text { Construction Work in Progress - Electric ....... } \\
\text { Accumulated Provision for }\end{array}$ & 92,376 & 137 & 0 & 2,928 & 3,831 & 0 \\
\hline 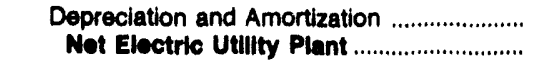 & $\begin{array}{r}656,420 \\
1,273,082\end{array}$ & $\begin{array}{l}29,545 \\
39,116\end{array}$ & $\begin{array}{l}0 \\
\mathbf{0}\end{array}$ & $\begin{array}{l}31,767 \\
36,201\end{array}$ & $\begin{array}{r}49,618 \\
120,349\end{array}$ & $\begin{array}{l}5,411 \\
5,108\end{array}$ \\
\hline
\end{tabular}

Note: Totals may not equal sum of components because of independent rounding.

Source: Energy Information Administration, Form ElA-412, "Annual Report of Public Electric Utilitie:s." 
Table 24. Electric Utility Plant by Major U.S. Publicly Owned Electric Utility Within State at End of Period, 1992 (Continued) (Thousand Dollars)

\begin{tabular}{|c|c|c|c|c|c|c|}
\hline Item & $\begin{array}{l}\text { New Mexico } \\
\text { Los Alamos } \\
\text { County } \\
\text { June } 30\end{array}$ & $\begin{array}{l}\text { New York } \\
\text { Fairport } \\
\text { Village of } \\
\text { May } 31\end{array}$ & $\begin{array}{c}\text { New York } \\
\text { Freeport } \\
\begin{array}{c}\text { Village of } \\
\text { Inc }\end{array} \\
\text { February } 28\end{array}$ & $\begin{array}{c}\text { New York } \\
\text { Jamestown } \\
\text { City of } \\
\text { December } 31\end{array}$ & $\begin{array}{c}\text { New York } \\
\text { Massena } \\
\text { Town of } \\
\text { December } 31\end{array}$ & $\begin{array}{l}\text { New York } \\
\text { Plattsburgh } \\
\text { City of } \\
\text { December } 31\end{array}$ \\
\hline 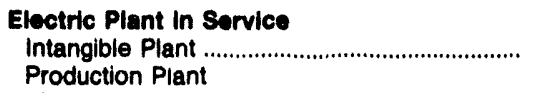 & 22 & 0 & 0 & 0 & 2,163 & 4 \\
\hline 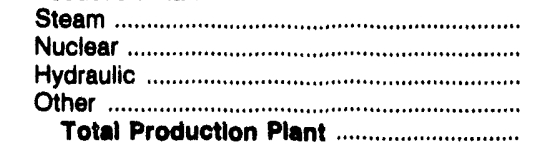 & $\begin{array}{r}41,874 \\
0 \\
51,171 \\
0 \\
93,045\end{array}$ & $\begin{array}{l}0 \\
0 \\
0 \\
0 \\
0\end{array}$ & $\begin{array}{r}0 \\
0 \\
0 \\
14,206 \\
14,206\end{array}$ & $\begin{array}{r}41,087 \\
0 \\
0 \\
0 \\
41,087\end{array}$ & $\begin{array}{l}0 \\
0 \\
0 \\
0 \\
0\end{array}$ & $\begin{array}{l}0 \\
0 \\
0 \\
0 \\
0\end{array}$ \\
\hline 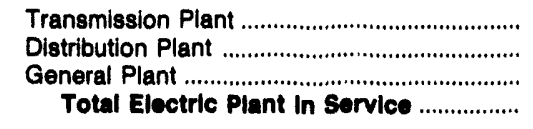 & $\begin{array}{r}334 \\
7,529 \\
2,036 \\
102,967\end{array}$ & $\begin{array}{r}3,795 \\
10,667 \\
1,534 \\
15,905\end{array}$ & $\begin{array}{r}1,683 \\
11,966 \\
1,428 \\
29,283\end{array}$ & $\begin{array}{r}7,800 \\
20,007 \\
3,669 \\
\mathbf{7 2 , 5 6 3}\end{array}$ & $\begin{array}{r}5,366 \\
8,388 \\
1,266 \\
17,184\end{array}$ & $\begin{array}{r}7,940 \\
14,794 \\
3,285 \\
26,023\end{array}$ \\
\hline 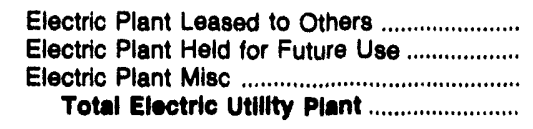 & $\begin{array}{r}0 \\
0 \\
7,454 \\
110,421\end{array}$ & $\begin{array}{r}0 \\
0 \\
0 \\
15,985\end{array}$ & $\begin{array}{r}0 \\
13 \\
0 \\
29,298\end{array}$ & $\begin{array}{r}0 \\
0 \\
0 \\
\mathbf{7 2 , 5 6 3}\end{array}$ & $\begin{array}{r}0 \\
0 \\
4,448 \\
21,632\end{array}$ & $\begin{array}{r}0 \\
0 \\
0 \\
26,023\end{array}$ \\
\hline $\begin{array}{l}\text { Construction Work in Progress - Electric ....... } \\
\text { Accumulated Provision for }\end{array}$ & 439 & 25 & 1,743 & 5,410 & 70 & 2,423 \\
\hline 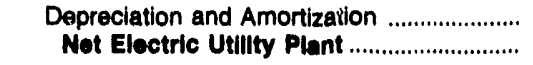 & $\begin{array}{l}17,699 \\
93,162\end{array}$ & $\begin{array}{l}7,083 \\
8,937\end{array}$ & $\begin{array}{l}17,727 \\
13,312\end{array}$ & $\begin{array}{l}24,456 \\
53,517\end{array}$ & $\begin{array}{r}6,948 \\
14,755\end{array}$ & $\begin{array}{r}9,741 \\
18,705\end{array}$ \\
\hline
\end{tabular}

\begin{tabular}{|c|c|c|c|c|c|c|}
\hline Item & $\begin{array}{c}\text { New York } \\
\text { Power } \\
\text { Authority } \\
\text { of State of NY } \\
\text { December } 31\end{array}$ & $\begin{array}{l}\text { New York } \\
\text { Rockville } \\
\text { Centre } \\
\text { Village of } \\
\text { May } 31\end{array}$ & $\begin{array}{l}\text { North Carolina } \\
\text { Albemarle } \\
\text { City of } \\
\text { June } 30\end{array}$ & $\begin{array}{l}\text { North Carolina } \\
\text { Concord } \\
\text { City of } \\
\text { June } 30\end{array}$ & $\begin{array}{l}\text { North Carolina } \\
\text { Elizabeth } \\
\text { City City of } \\
\text { June } 30\end{array}$ & $\begin{array}{l}\text { North Carolina } \\
\text { Fayetteville } \\
\text { Public } \\
\text { Works Comm } \\
\text { June } 30\end{array}$ \\
\hline $\begin{array}{l}\text { Electric Plant in Service } \\
\text { Intangible Plant ................................................ } \\
\text { Production Plant }\end{array}$ & 0 & 0 & 0 & 0 & 0 & 847 \\
\hline 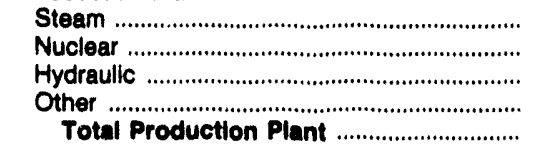 & $\begin{array}{r}426,755 \\
1,492,866 \\
1,243,055 \\
0 \\
3,162,676\end{array}$ & $\begin{array}{r}0 \\
0 \\
0 \\
7,-59 \\
7,559\end{array}$ & $\begin{array}{l}0 \\
0 \\
0 \\
0 \\
0\end{array}$ & $\begin{array}{l}0 \\
0 \\
0 \\
0 \\
0\end{array}$ & $\begin{array}{l}0 \\
0 \\
0 \\
0 \\
0\end{array}$ & $\begin{array}{r}38,262 \\
0 \\
0 \\
38,636 \\
78,808\end{array}$ \\
\hline 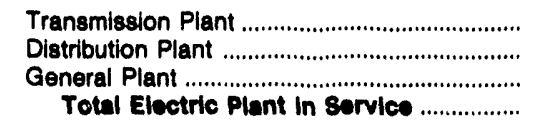 & $\begin{array}{r}1,464,632 \\
0 \\
217,827 \\
4,845,235\end{array}$ & $\begin{array}{r}1,265 \\
11,412 \\
1,090 \\
21,320\end{array}$ & $\begin{array}{r}0 \\
0 \\
17,529 \\
17,529\end{array}$ & $\begin{array}{r}0 \\
0 \\
25,634 \\
25,834\end{array}$ & $\begin{array}{r}0 \\
17,482 \\
4,854 \\
22,336\end{array}$ & $\begin{array}{r}10,375 \\
68,107 \\
8,347 \\
165,675\end{array}$ \\
\hline 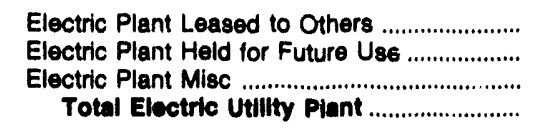 & $\begin{array}{r}0 \\
0 \\
0 \\
4,845,236\end{array}$ & $\begin{array}{r}0 \\
0 \\
0 \\
21,326\end{array}$ & $\begin{array}{r}0 \\
0 \\
0 \\
17,529\end{array}$ & $\begin{array}{r}0 \\
0 \\
0 \\
25,634\end{array}$ & $\begin{array}{r}0 \\
0 \\
0 \\
22,336\end{array}$ & $\begin{array}{r}0 \\
0 \\
0 \\
165,575\end{array}$ \\
\hline $\begin{array}{l}\text { Construction Work in Progress - Electric ....... } \\
\text { Accumulated Provision for }\end{array}$ & 215,776 & 2,758 & 0 & 0 & 14 & 15,074 \\
\hline $\begin{array}{l}\text { Depreciation and Amortization } \\
\text { Not Electrlc Utllity Plant }\end{array}$ & $\begin{array}{l}1,485,305 \\
3,675,708\end{array}$ & $\begin{array}{l}13,009 \\
11,075\end{array}$ & $\begin{array}{l}9,081 \\
8,446\end{array}$ & $\begin{array}{r}17,054 \\
8,580\end{array}$ & $\begin{array}{r}6,325 \\
16,025\end{array}$ & $\begin{array}{r}53,155 \\
127,494\end{array}$ \\
\hline
\end{tabular}

Note: Totals may not equal sum of components because of independent rounding

Source: Energy Information Administration, Form ElA-412, "Annual Report of Public Electric Utilities." 
Table 24. Electric Utility Plant by Major U.S. Publicly Owned Electric Utility Within State at End of Period, 1992 (Continued) (Thousand Dollars)

\begin{tabular}{|c|c|c|c|c|c|c|}
\hline Item & $\begin{array}{c}\text { North Carolina } \\
\text { Gastonia } \\
\text { City of } \\
\text { June } 30\end{array}$ & $\begin{array}{c}\text { North Carolina } \\
\text { Greenville } \\
\text { Utilities } \\
\text { Comm } \\
\text { June } 30\end{array}$ & $\begin{array}{c}\text { North Carolina } \\
\text { High } \\
\text { Point } \\
\text { Town } \\
\text { of } \\
\text { June } 30\end{array}$ & $\begin{array}{l}\text { North Carolina } \\
\text { Kinston } \\
\text { City of } \\
\text { June } 30\end{array}$ & $\begin{array}{l}\text { North Carolina } \\
\text { Lexington } \\
\text { City of } \\
\text { June } 30\end{array}$ & $\begin{array}{l}\text { North Carolina } \\
\text { Lumberton } \\
\text { City of } \\
\text { June } 30\end{array}$ \\
\hline 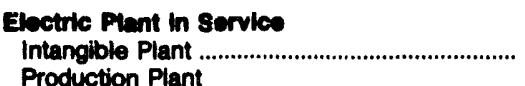 & 0 & 0 & 0 & 0 & 0 & 0 \\
\hline 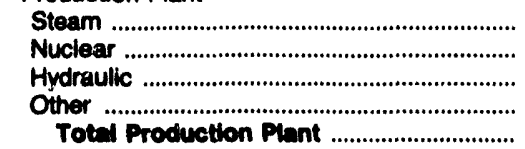 & $\begin{array}{l}0 \\
0 \\
0 \\
0 \\
0\end{array}$ & $\begin{array}{l}0 \\
0 \\
0 \\
0 \\
0\end{array}$ & $\begin{array}{l}0 \\
0 \\
0 \\
0 \\
0\end{array}$ & $\begin{array}{l}0 \\
0 \\
0 \\
0 \\
0\end{array}$ & $\begin{array}{l}0 \\
0 \\
0 \\
0 \\
0\end{array}$ & $\begin{array}{l}0 \\
0 \\
0 \\
0 \\
0\end{array}$ \\
\hline 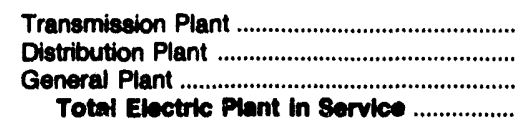 & $\begin{array}{r}33,979 \\
0 \\
0 \\
32,979\end{array}$ & $\begin{array}{r}0 \\
68,700 \\
9,133 \\
77,834\end{array}$ & $\begin{array}{r}0 \\
0 \\
52,573 \\
52,573\end{array}$ & $\begin{array}{r}10,787 \\
5,182 \\
0 \\
15,969\end{array}$ & $\begin{array}{r}3,486 \\
18,734 \\
2,884 \\
25,104\end{array}$ & $\begin{array}{r}0 \\
8,549 \\
1,911 \\
10,460\end{array}$ \\
\hline 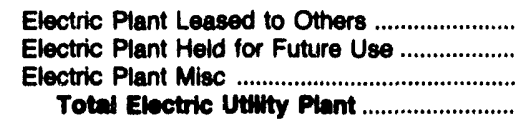 & $\begin{array}{r}0 \\
0 \\
0 \\
33,979\end{array}$ & $\begin{array}{r}0 \\
0 \\
0 \\
77,834\end{array}$ & $\begin{array}{r}0 \\
0 \\
0 \\
52,573\end{array}$ & $\begin{array}{r}0 \\
0 \\
0 \\
15,969\end{array}$ & $\begin{array}{r}0 \\
0 \\
0 \\
25,104\end{array}$ & $\begin{array}{r}0 \\
0 \\
0 \\
10,460\end{array}$ \\
\hline $\begin{array}{l}\text { Construction Work in Progress - Electric ....... } \\
\text { Accumulated Provision for }\end{array}$ & 0 & 0 & 124 & 927 & 661 & 24 \\
\hline 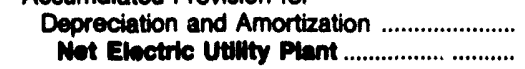 & $\begin{array}{l}17,433 \\
16,547\end{array}$ & $\begin{array}{l}36,244 \\
11,590\end{array}$ & $\begin{array}{l}21,062 \\
31,636\end{array}$ & $\begin{array}{l}7,039 \\
9,858\end{array}$ & $\begin{array}{r}8,310 \\
17,455\end{array}$ & $\begin{array}{l}5,266 \\
5,218\end{array}$ \\
\hline
\end{tabular}

\begin{tabular}{|c|c|c|c|c|c|c|}
\hline Item & $\begin{array}{l}\text { North Carolina } \\
\text { Monroe } \\
\text { City of } \\
\text { June } 30\end{array}$ & $\begin{array}{c}\text { North Carolina } \\
\text { Morganton } \\
\text { City of } \\
\text { June } 30\end{array}$ & $\begin{array}{l}\text { North Caroline } \\
\text { Murphy } \\
\text { City of } \\
\text { June } 30\end{array}$ & $\begin{array}{l}\text { North Carolina } \\
\text { New Bern } \\
\text { City of } \\
\text { June } 30\end{array}$ & $\begin{array}{l}\text { North Carolina } \\
\text { New River } \\
\text { Light } \\
\& \\
\text { Power Co } \\
\text { December } 31\end{array}$ & $\begin{array}{c}\text { North Carolina } \\
\text { North } \\
\text { Carolina } \\
\text { Eastern M P A } \\
\text { December } 31\end{array}$ \\
\hline $\begin{array}{l}\text { Electric Plant in Service } \\
\text { Intangible Plant ................................................. } \\
\text { Production Plant }\end{array}$ & 0 & 0 & 0 & 0 & 0 & 0 \\
\hline 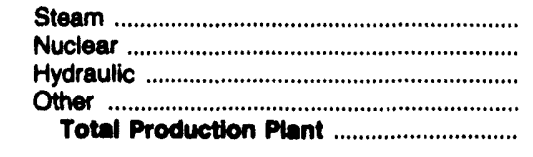 & $\begin{array}{l}0 \\
0 \\
0 \\
0 \\
0\end{array}$ & $\begin{array}{l}0 \\
0 \\
0 \\
0 \\
0\end{array}$ & $\begin{array}{l}0 \\
0 \\
0 \\
0 \\
0\end{array}$ & $\begin{array}{l}0 \\
0 \\
0 \\
0 \\
0\end{array}$ & $\begin{array}{l}0 \\
0 \\
0 \\
0 \\
0\end{array}$ & $\begin{array}{r}129,138 \\
1,108,929 \\
0 \\
0 \\
1,238,067\end{array}$ \\
\hline 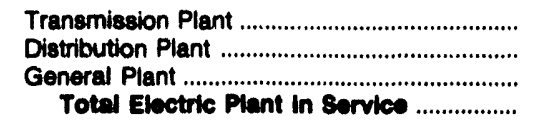 & $\begin{array}{r}0 \\
18,157 \\
0 \\
18,157\end{array}$ & $\begin{array}{r}0 \\
9,666 \\
0 \\
9,686\end{array}$ & $\begin{array}{r}0 \\
5,104 \\
1,493 \\
6,507\end{array}$ & $\begin{array}{r}0 \\
0 \\
17,880 \\
17,880\end{array}$ & $\begin{array}{r}0 \\
7,827 \\
1,636 \\
9,464\end{array}$ & $\begin{array}{r}0 \\
0 \\
0 \\
1,238,087\end{array}$ \\
\hline 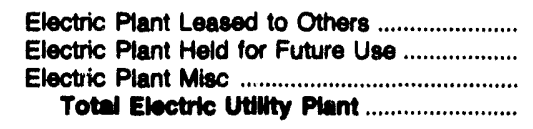 & $\begin{array}{r}0 \\
0 \\
0 \\
18,157\end{array}$ & $\begin{array}{r}0 \\
0 \\
0 \\
9,686\end{array}$ & $\begin{array}{r}0 \\
0 \\
0 \\
6,597\end{array}$ & $\begin{array}{r}0 \\
0 \\
0 \\
17,880\end{array}$ & $\begin{array}{r}0 \\
0 \\
0 \\
9,464\end{array}$ & $\begin{array}{r}0 \\
0 \\
134,086 \\
1,372,153\end{array}$ \\
\hline $\begin{array}{l}\text { Construction Work in Progress - Electric ....... } \\
\text { Accumulated Provision for }\end{array}$ & 1,480 & $\theta$ & 145 & 0 & 35 & 16,730 \\
\hline 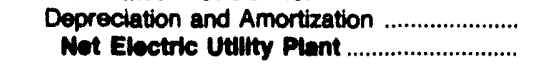 & $\begin{array}{r}5,965 \\
13,682\end{array}$ & $\begin{array}{l}4,227 \\
5,448\end{array}$ & $\begin{array}{l}1,814 \\
4,928\end{array}$ & $\begin{array}{r}7,486 \\
10,394\end{array}$ & $\begin{array}{l}2,487 \\
7,012\end{array}$ & $\begin{array}{r}320,940 \\
1,067,943\end{array}$ \\
\hline
\end{tabular}

Note: Totals may not equal sum of components because of independent rounding.

Source: Energy Information Administration, Form EIA-412, "Annual Report of Public Electric Utilities." 
Table 24. Electric Utility Plant by Major U.S. Publicly Owned Electric Utility Within State at End of Period, 1992 (Continued) (Thousand Dollars)

\begin{tabular}{|c|c|c|c|c|c|c|}
\hline Item & $\begin{array}{c}\text { North Carolina } \\
\text { North } \\
\text { Carolina } \\
\text { Mun } \\
\text { Power Agny } \\
\text { December } 31\end{array}$ & $\begin{array}{l}\text { North Carolina } \\
\text { Rocky Mount } \\
\text { City of } \\
\text { June } 30\end{array}$ & $\begin{array}{l}\text { North Carolina } \\
\text { Shelby } \\
\text { City of } \\
\text { June } 30\end{array}$ & $\begin{array}{l}\text { North Carolina } \\
\text { Statesville } \\
\text { City of } \\
\text { June } 30\end{array}$ & $\begin{array}{l}\text { North Carolina } \\
\text { Tarboro } \\
\text { Town of } \\
\text { June } 30\end{array}$ & $\begin{array}{c}\text { North Carolina } \\
\text { Washington } \\
\text { City of } \\
\text { June } 30\end{array}$ \\
\hline $\begin{array}{l}\text { Electric Plant In Service } \\
\text { Intangible Plant ............................................... } \\
\text { Production Plant }\end{array}$ & 0 & 0 & 0 & 0 & 102 & 0 \\
\hline 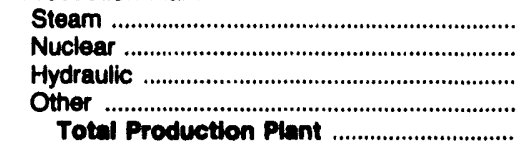 & $\begin{array}{r}0 \\
1,402,570 \\
0 \\
0 \\
1,402,570\end{array}$ & $\begin{array}{l}0 \\
0 \\
0 \\
0 \\
0\end{array}$ & $\begin{array}{l}0 \\
0 \\
0 \\
0 \\
0\end{array}$ & $\begin{array}{l}0 \\
0 \\
0 \\
0 \\
0\end{array}$ & $\begin{array}{l}0 \\
0 \\
0 \\
0 \\
0\end{array}$ & $\begin{array}{l}0 \\
0 \\
0 \\
0 \\
0\end{array}$ \\
\hline 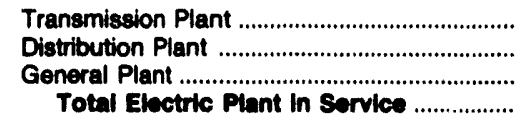 & $\begin{array}{r}10,946 \\
0 \\
0 \\
1,413,516\end{array}$ & $\begin{array}{r}0 \\
29,682 \\
0 \\
29,682\end{array}$ & $\begin{array}{r}0 \\
6,111 \\
0 \\
6,111\end{array}$ & $\begin{array}{r}0 \\
14,679 \\
0 \\
14,679\end{array}$ & $\begin{array}{r}0 \\
14,614 \\
0 \\
14,716\end{array}$ & $\begin{array}{r}21,433 \\
0 \\
2,553 \\
23,986\end{array}$ \\
\hline 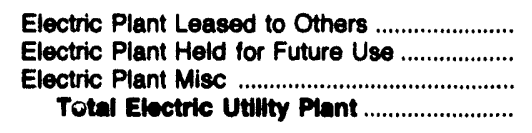 & $\begin{array}{r}0 \\
0 \\
0 \\
1,413,516\end{array}$ & $\begin{array}{r}0 \\
0 \\
0 \\
29,682\end{array}$ & $\begin{array}{r}0 \\
0 \\
0 \\
6,111\end{array}$ & $\begin{array}{r}0 \\
0 \\
0 \\
14,679\end{array}$ & $\begin{array}{r}0 \\
0 \\
0 \\
14,716\end{array}$ & $\begin{array}{r}0 \\
0 \\
0 \\
23,888\end{array}$ \\
\hline $\begin{array}{l}\text { Construction Work in Progress - Electric ........ } \\
\text { Accumulated Provision for }\end{array}$ & 7,049 & 3,825 & 33 & 0 & 0 & 102 \\
\hline 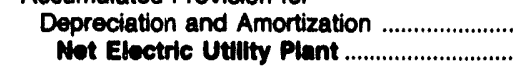 & $\begin{array}{r}275,239 \\
1,145,326\end{array}$ & $\begin{array}{l}12,135 \\
21,373\end{array}$ & $\begin{array}{l}4,112 \\
2,031\end{array}$ & $\begin{array}{l}5,760 \\
8,918\end{array}$ & $\begin{array}{l}5,072 \\
9,644\end{array}$ & $\begin{array}{r}9,916 \\
14,172\end{array}$ \\
\hline
\end{tabular}

\begin{tabular}{|c|c|c|c|c|c|c|}
\hline Item & $\begin{array}{l}\text { North Carolina } \\
\text { wisson } \\
\text { City of } \\
\text { June } 30\end{array}$ & $\begin{array}{c}\text { Ohio } \\
\text { American } \\
\text { Mun } \\
\text { Power } \\
\text { Ohio Inc } \\
\text { December } 31\end{array}$ & $\begin{array}{l}\text { Ohio } \\
\text { Bowling } \\
\text { Green } \\
\text { City of } \\
\text { December } 31\end{array}$ & $\begin{array}{l}\text { Ohio } \\
\text { Bryan } \\
\text { City of } \\
\text { December } 31\end{array}$ & $\begin{array}{l}\text { Ohio } \\
\text { Celina } \\
\text { City of } \\
\text { December } 31\end{array}$ & $\begin{array}{c}\text { Ohio } \\
\text { Cleveland } \\
\text { City of } \\
\text { December } 31\end{array}$ \\
\hline 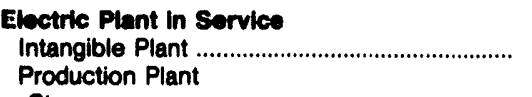 & 0 & 7,718 & 0 & 0 & 0 & 0 \\
\hline 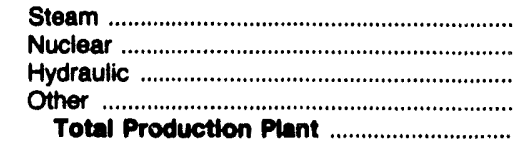 & $\begin{array}{l}0 \\
0 \\
0 \\
0 \\
0\end{array}$ & $\begin{array}{r}52,908 \\
0 \\
0 \\
145 \\
53,053\end{array}$ & $\begin{array}{l}0 \\
0 \\
0 \\
0 \\
0\end{array}$ & $\begin{array}{l}0 \\
0 \\
0 \\
0 \\
0\end{array}$ & $\begin{array}{r}5,888 \\
0 \\
0 \\
0 \\
5,888\end{array}$ & $\begin{array}{r}37,037 \\
0 \\
0 \\
6,528 \\
43,565\end{array}$ \\
\hline 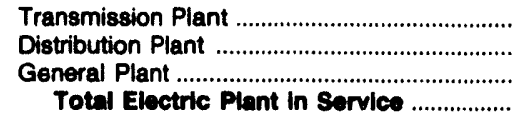 & $\begin{array}{r}0 \\
41,541 \\
5,026 \\
46,567\end{array}$ & $\begin{array}{r}616 \\
687 \\
777 \\
62,851\end{array}$ & $\begin{array}{r}588 \\
8,397 \\
3,128 \\
12,113\end{array}$ & $\begin{array}{l}0 \\
0 \\
0 \\
0\end{array}$ & $\begin{array}{r}0 \\
11,007 \\
520 \\
17,415\end{array}$ & $\begin{array}{r}62,976 \\
55,182 \\
12,696 \\
174,420\end{array}$ \\
\hline 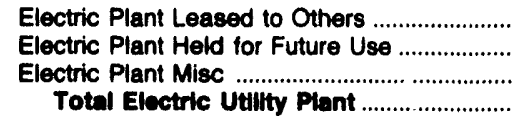 & $\begin{array}{r}0 \\
0 \\
0 \\
\mathbf{4 6 , 5 6 7}\end{array}$ & $\begin{array}{r}0 \\
0 \\
0 \\
62,851\end{array}$ & $\begin{array}{r}0 \\
0 \\
0 \\
12,113\end{array}$ & $\begin{array}{l}0 \\
0 \\
0 \\
0\end{array}$ & $\begin{array}{r}0 \\
0 \\
0 \\
17,415\end{array}$ & $\begin{array}{r}0 \\
0 \\
0 \\
174,420\end{array}$ \\
\hline $\begin{array}{l}\text { Construction Work in Progress - Electric ....... } \\
\text { Accumulated Provision for }\end{array}$ & 742 & 1,346 & 3,064 & 0 & 0 & 37,870 \\
\hline 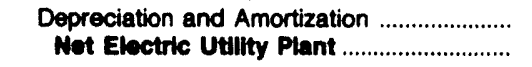 & $\begin{array}{l}23,378 \\
23,931\end{array}$ & $\begin{array}{l}12,643 \\
51,554\end{array}$ & $\begin{array}{l}8,031 \\
7,145\end{array}$ & $\begin{array}{l}0 \\
0\end{array}$ & $\begin{array}{r}0 \\
17,415\end{array}$ & $\begin{array}{r}86,413 \\
125,877\end{array}$ \\
\hline
\end{tabular}

Source: Energy Information Administration, Form EIA-412, "Annual Report of Public Electric Utilities." 
Table 24. Electric Utility Plant by Major U.S. Publicly Owned Electric Utility Within State at End of Period, 1992 (Continued) (Thousand Dollars)

\begin{tabular}{|c|c|c|c|c|c|c|}
\hline Item & $\begin{array}{c}\text { Ohio } \\
\text { Columbus } \\
\text { City of } \\
\text { December } 31\end{array}$ & $\begin{array}{c}\text { Ohio } \\
\text { Cuyahoga } \\
\text { Falls } \\
\text { Clty of } \\
\text { December } 31\end{array}$ & $\begin{array}{c}\text { Ohio } \\
\text { Dover } \\
\text { City of } \\
\text { December } 31\end{array}$ & $\begin{array}{c}\text { Ohio } \\
\text { Hamilton } \\
\text { City of } \\
\text { December } 31\end{array}$ & $\begin{array}{c}\text { Ohio } \\
\text { Niles } \\
\text { City of } \\
\text { December } 31\end{array}$ & $\begin{array}{c}\text { Ohio } \\
\text { Orrville } \\
\text { City of } \\
\text { December } 31\end{array}$ \\
\hline $\begin{array}{l}\text { Eloctirc Plent in Service } \\
\text { Intangible Plant ................................................ } \\
\text { Production Plant }\end{array}$ & 0 & 0 & 0 & 0 & 0 & 0 \\
\hline 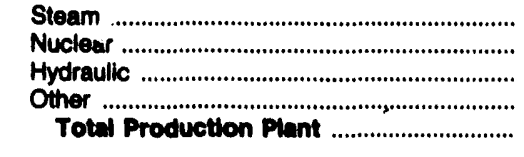 & $\begin{array}{r}11,472 \\
0 \\
0 \\
0 \\
11,472\end{array}$ & $\begin{array}{l}0 \\
0 \\
0 \\
0 \\
\mathbf{0}\end{array}$ & $\begin{array}{l}0 \\
0 \\
0 \\
0 \\
0\end{array}$ & $\begin{array}{r}25,083 \\
0 \\
140,737 \\
5,973 \\
171,793\end{array}$ & $\begin{array}{l}0 \\
0 \\
0 \\
0 \\
0\end{array}$ & $\begin{array}{r}39,314 \\
0 \\
0 \\
0 \\
39,314\end{array}$ \\
\hline 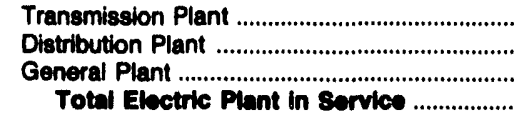 & $\begin{array}{r}145,916 \\
30,859 \\
88,130 \\
276,378\end{array}$ & $\begin{array}{r}711 \\
16,320 \\
1,302 \\
18,333\end{array}$ & $\begin{array}{r}0 \\
0 \\
10,094 \\
10,094\end{array}$ & $\begin{array}{r}24,583 \\
19,740 \\
5,769 \\
221,885\end{array}$ & $\begin{array}{r}0 \\
0 \\
11,993 \\
11,993\end{array}$ & $\begin{array}{r}0 \\
8,565 \\
2,258 \\
50,137\end{array}$ \\
\hline 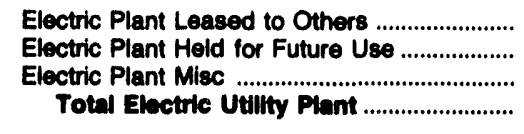 & $\begin{array}{r}0 \\
0 \\
0 \\
276,378\end{array}$ & $\begin{array}{r}0 \\
0 \\
0 \\
18,333\end{array}$ & $\begin{array}{r}0 \\
0 \\
0 \\
10,004\end{array}$ & $\begin{array}{r}0 \\
0 \\
0 \\
221,885\end{array}$ & $\begin{array}{r}0 \\
0 \\
0 \\
11,993\end{array}$ & $\begin{array}{r}0 \\
0 \\
0 \\
50,137\end{array}$ \\
\hline $\begin{array}{l}\text { Construction Work in Progress - Electric ....... } \\
\text { Accumulated Provision for }\end{array}$ & 0 & 419 & 0 & 0 & 0 & 120 \\
\hline 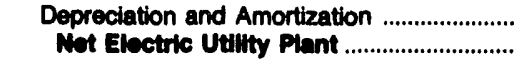 & $\begin{array}{l}100,788 \\
175,579\end{array}$ & $\begin{array}{l}9,876 \\
\mathbf{8 , 8 7 7}\end{array}$ & $\begin{array}{r}0 \\
10,094\end{array}$ & $\begin{array}{r}66,954 \\
164,931\end{array}$ & $\begin{array}{l}6,586 \\
5,407\end{array}$ & $\begin{array}{l}24,054 \\
26,202\end{array}$ \\
\hline
\end{tabular}

\begin{tabular}{|c|c|c|c|c|c|c|}
\hline Item & $\begin{array}{c}\text { Onio } \\
\text { Painesville } \\
\text { City of } \\
\text { December } 31\end{array}$ & $\begin{array}{c}\text { Ohio } \\
\text { Piqua } \\
\text { City of } \\
\text { December } 31\end{array}$ & $\begin{array}{c}\text { Ohio } \\
\text { St Marys } \\
\text { City of } \\
\text { December } 31\end{array}$ & $\begin{array}{c}\text { Ohio } \\
\text { Wadsworth } \\
\text { City of } \\
\text { December } 31\end{array}$ & $\begin{array}{c}\text { Ohio } \\
\text { Wapakoneta } \\
\text { City of } \\
\text { December } 31\end{array}$ & $\begin{array}{c}\text { Ohio } \\
\text { Westerville } \\
\text { City of }\end{array}$ \\
\hline 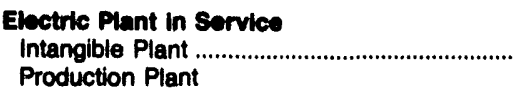 & 0 & 822 & 0 & 0 & 0 & 0 \\
\hline 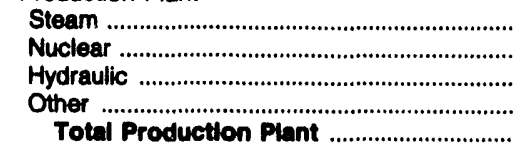 & $\begin{array}{r}35,777 \\
0 \\
0 \\
0 \\
35,777\end{array}$ & $\begin{array}{r}19,998 \\
0 \\
0 \\
99 \\
20,097\end{array}$ & $\begin{array}{r}13,789 \\
0 \\
0 \\
0 \\
13,789\end{array}$ & $\begin{array}{l}0 \\
0 \\
0 \\
0 \\
0\end{array}$ & $\begin{array}{l}0 \\
0 \\
0 \\
0 \\
0\end{array}$ & $\begin{array}{l}0 \\
0 \\
0 \\
0 \\
0\end{array}$ \\
\hline 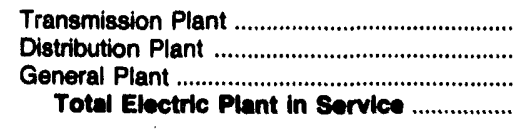 & $\begin{array}{r}0 \\
0 \\
0 \\
35,777\end{array}$ & $\begin{array}{r}2,557 \\
15,992 \\
2,138 \\
41,608\end{array}$ & $\begin{array}{r}0 \\
0 \\
0 \\
13,789\end{array}$ & $\begin{array}{r}0 \\
9,405 \\
224 \\
9,630\end{array}$ & $\begin{array}{l}0 \\
0 \\
0 \\
0\end{array}$ & $\begin{array}{r}0 \\
9,786 \\
0 \\
9,786\end{array}$ \\
\hline 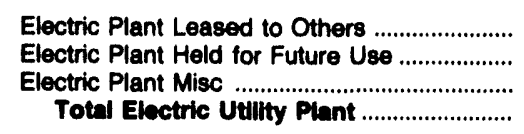 & $\begin{array}{r}0 \\
0 \\
0 \\
35,777\end{array}$ & $\begin{array}{r}0 \\
0 \\
0 \\
41,606\end{array}$ & $\begin{array}{r}0 \\
0 \\
0 \\
13,789\end{array}$ & $\begin{array}{r}0 \\
0 \\
0 \\
9,630\end{array}$ & $\begin{array}{l}0 \\
0 \\
0 \\
0\end{array}$ & $\begin{array}{r}0 \\
0 \\
0 \\
9,786\end{array}$ \\
\hline $\begin{array}{l}\text { Construction Work in Progress - Electric ....... } \\
\text { Accumulated Provision for }\end{array}$ & 2,159 & 692 & 1,314 & 0 & 0 & 0 \\
\hline 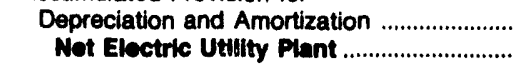 & $\begin{array}{l}20,542 \\
17,395\end{array}$ & $\begin{array}{l}18,523 \\
23,775\end{array}$ & $\begin{array}{l}9,941 \\
5,161\end{array}$ & $\begin{array}{l}5,909 \\
3,720\end{array}$ & $\begin{array}{l}0 \\
\mathbf{0}\end{array}$ & $\begin{array}{l}4,907 \\
4,879\end{array}$ \\
\hline
\end{tabular}

Note: Totals may not equal sum of components because of independent rounding.

Source: Energy Information Administration, Form EIA-412, "Annual Report of Public Electric Utilities." 
Table 24. Electric Utility Plant by Major U.S. Publicly Owned Electric Utility Within State at End of Period, 1992 (Continued)

(Thousand Dollars)

\begin{tabular}{|c|c|c|c|c|c|c|}
\hline Item & $\begin{array}{l}\text { Oklahoma } \\
\text { Altus } \\
\text { City of } \\
\text { June } 30\end{array}$ & $\begin{array}{l}\text { Oklahoma } \\
\text { Claremore } \\
\text { City of } \\
\text { June } 30\end{array}$ & $\begin{array}{l}\text { Oklahoma } \\
\text { Duncan } \\
\text { City of } \\
\text { June } 30\end{array}$ & $\begin{array}{l}\text { Oklahoma } \\
\text { Edmond } \\
\text { City of } \\
\text { June } 30\end{array}$ & $\begin{array}{c}\text { Oklahoma } \\
\text { Grand River } \\
\text { Dam } \\
\text { Authority } \\
\text { December } 31\end{array}$ & $\begin{array}{c}\text { Oklahoma } \\
\text { Oklahoma } \\
\text { Municipal } \\
\text { Power Auth } \\
\text { December } 31\end{array}$ \\
\hline 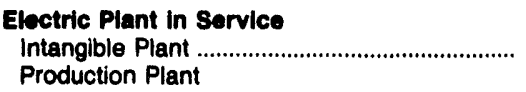 & 0 & 0 & 0 & 0 & 0 & 0 \\
\hline 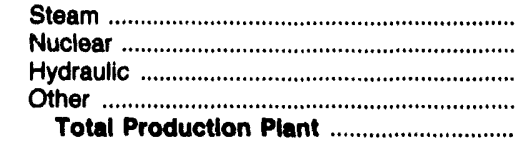 & $\begin{array}{l}0 \\
0 \\
0 \\
0 \\
0\end{array}$ & $\begin{array}{l}0 \\
0 \\
0 \\
0 \\
0\end{array}$ & $\begin{array}{l}0 \\
0 \\
0 \\
0 \\
0\end{array}$ & $\begin{array}{l}0 \\
0 \\
0 \\
0 \\
0\end{array}$ & $\begin{array}{r}610,988 \\
0 \\
70,308 \\
0 \\
681,296\end{array}$ & $\begin{array}{r}111,667 \\
0 \\
35,297 \\
0 \\
146,864\end{array}$ \\
\hline 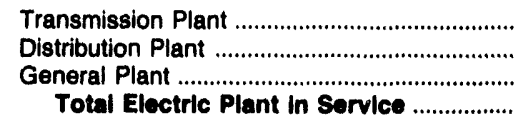 & $\begin{array}{r}7,650 \\
0 \\
0 \\
7,650\end{array}$ & $\begin{array}{l}0 \\
0 \\
0 \\
0\end{array}$ & $\begin{array}{r}700 \\
12,274 \\
350 \\
13,324\end{array}$ & $\begin{array}{r}0 \\
32,668 \\
0 \\
32,688\end{array}$ & $\begin{array}{r}72,500 \\
0 \\
15,853 \\
769,650\end{array}$ & $\begin{array}{r}4,193 \\
2,415 \\
0 \\
153,571\end{array}$ \\
\hline 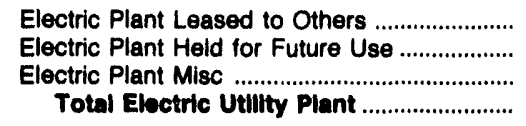 & $\begin{array}{r}0 \\
0 \\
0 \\
7,650\end{array}$ & $\begin{array}{l}0 \\
0 \\
0 \\
0\end{array}$ & $\begin{array}{r}0 \\
0 \\
0 \\
13,324\end{array}$ & $\begin{array}{r}0 \\
0 \\
0 \\
32,688\end{array}$ & $\begin{array}{r}0 \\
14 \\
109,750 \\
879,415\end{array}$ & $\begin{array}{r}0 \\
3,555 \\
0 \\
157,127\end{array}$ \\
\hline $\begin{array}{l}\text { Construction Work in Progress - Electric ........ } \\
\text { Accumulated Provision for }\end{array}$ & 0 & 0 & 5,933 & 0 & 12,558 & 1,101 \\
\hline 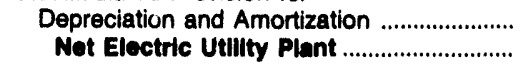 & $\begin{array}{l}4,486 \\
3,163\end{array}$ & $\begin{array}{l}0 \\
0\end{array}$ & $\begin{array}{r}8,312 \\
10,945\end{array}$ & $\begin{array}{l}14,487 \\
18,182\end{array}$ & $\begin{array}{l}254,509 \\
637,464\end{array}$ & $\begin{array}{r}25,365 \\
132,862\end{array}$ \\
\hline
\end{tabular}

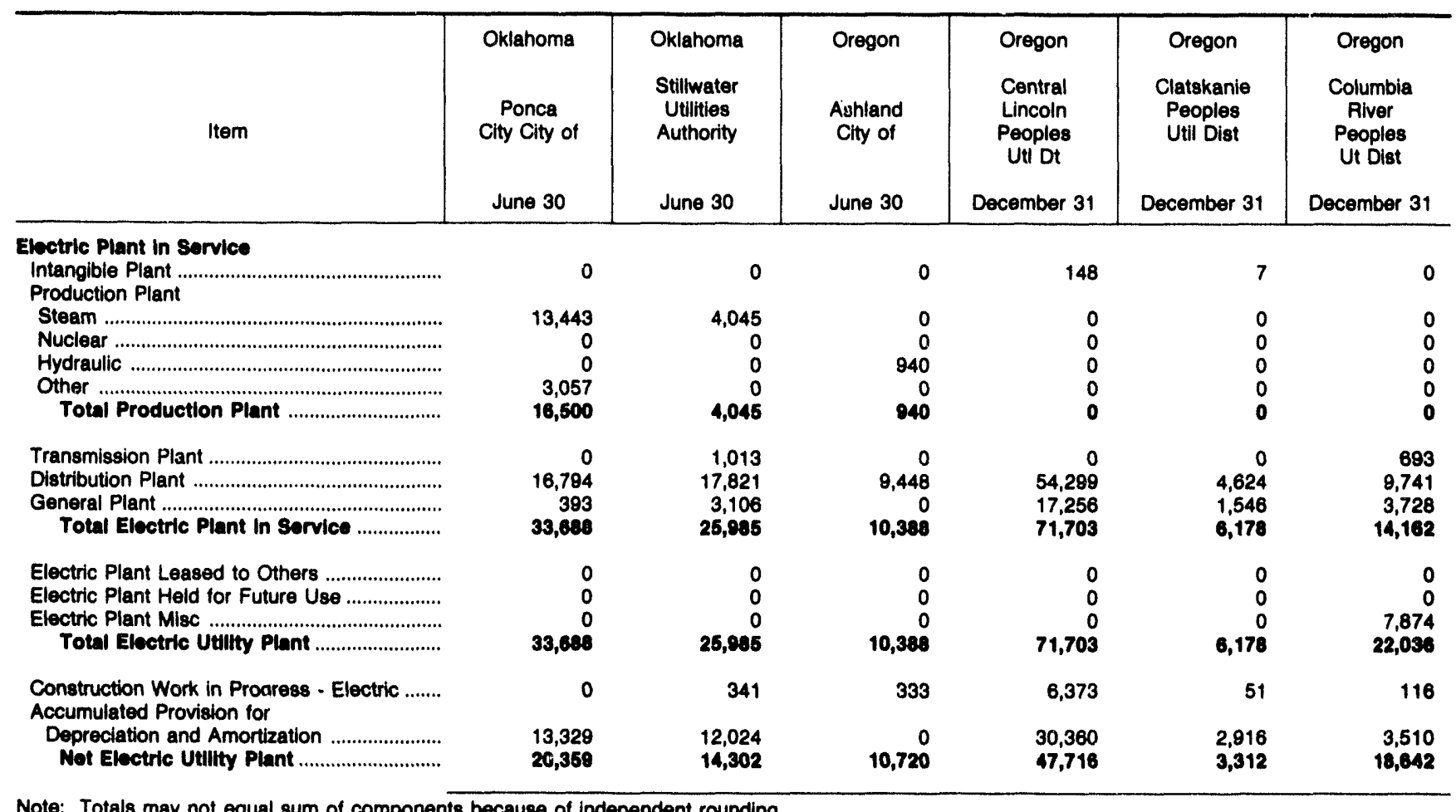

Note: Totals may not equal sum of components because of independent rounding.

Source: Energy Information Administration, Form ElA-412, "Annual Report of Public Electric Utilities." 
Table 24. Electric Utility Plant by Major U.S. Publicly Owned Electrlc Utillty Within State at End of Period, 1992 (Continued) (Thousand Dollars)

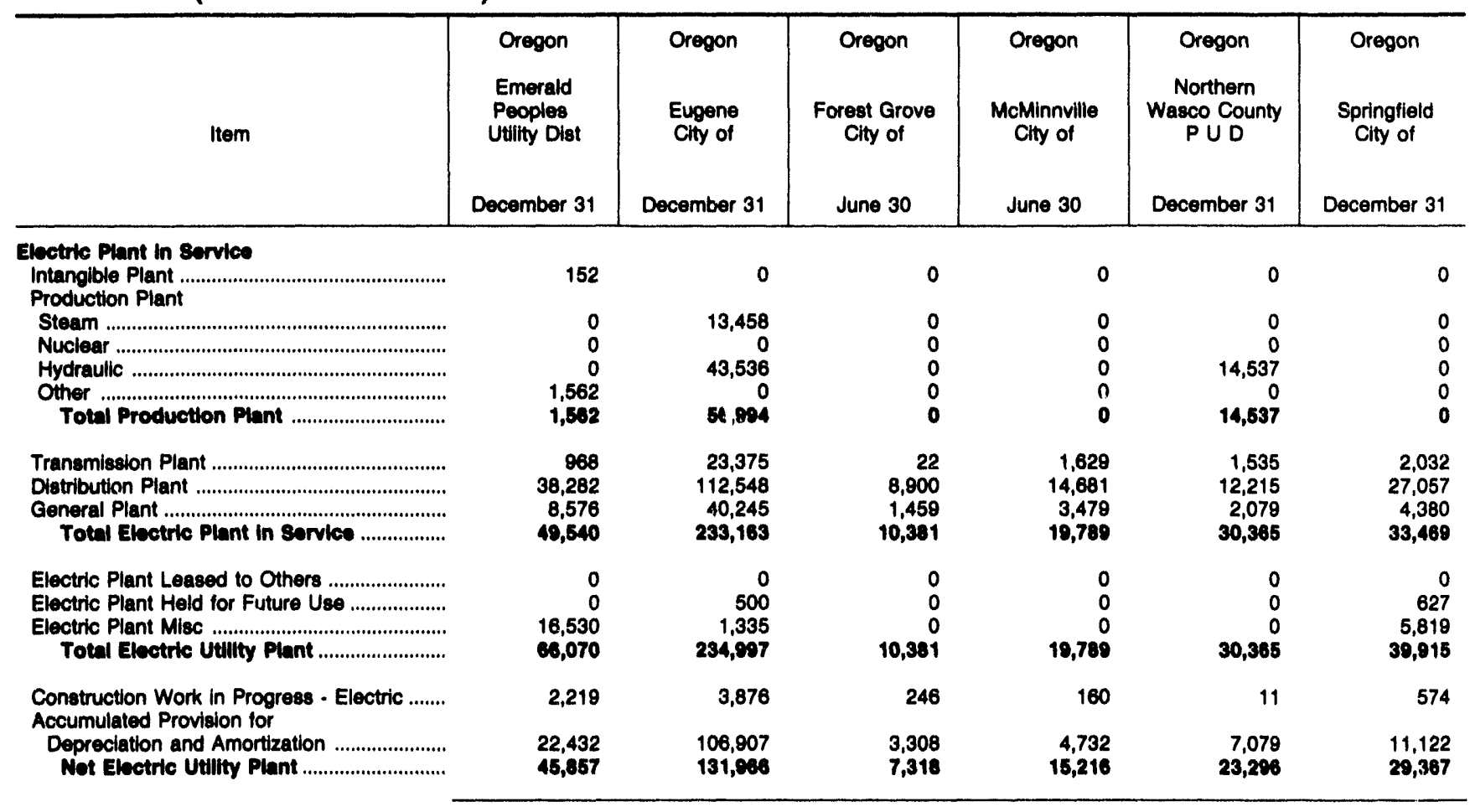

\begin{tabular}{|c|c|c|c|c|c|c|}
\hline Item & $\begin{array}{l}\text { Oregon } \\
\text { Tillamook } \\
\text { Peoples } \\
\text { Utility Dist } \\
\text { December } 31\end{array}$ & $\begin{array}{c}\text { Pennsylvania } \\
\text { Chambersburg } \\
\text { Borough of } \\
\text { December } 31\end{array}$ & $\begin{array}{l}\text { South Carolina } \\
\text { Camden } \\
\text { City of } \\
\text { June } 30\end{array}$ & $\begin{array}{l}\text { South Carolina } \\
\text { Easley } \\
\text { Combined } \\
\text { Utility } \\
\text { System } \\
\text { March } 31\end{array}$ & $\begin{array}{l}\text { South Carolina } \\
\text { Gaffney } \\
\text { City of } \\
\text { March } 31\end{array}$ & $\begin{array}{c}\text { South Carolina } \\
\text { Greenwood } \\
\text { Commissioners } \\
\text { Pub Wk } \\
\text { December } 31\end{array}$ \\
\hline 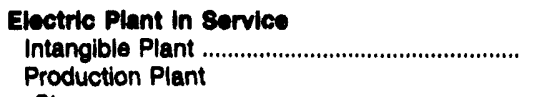 & 1 & 5 & 0 & 0 & 0 & 0 \\
\hline 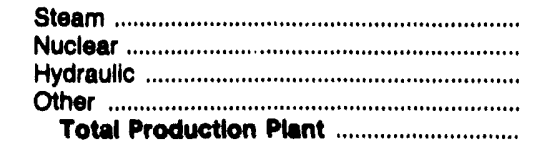 & $\begin{array}{l}0 \\
0 \\
0 \\
0 \\
0\end{array}$ & $\begin{array}{r}4,186 \\
0 \\
0 \\
1,381 \\
5,687\end{array}$ & $\begin{array}{l}0 \\
0 \\
0 \\
0 \\
0\end{array}$ & $\begin{array}{l}0 \\
0 \\
0 \\
0 \\
0\end{array}$ & $\begin{array}{l}0 \\
0 \\
0 \\
0 \\
0\end{array}$ & $\begin{array}{l}0 \\
0 \\
0 \\
0 \\
0\end{array}$ \\
\hline 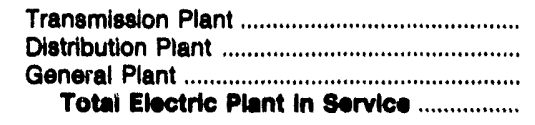 & $\begin{array}{r}1,032 \\
22,558 \\
5,502 \\
29,003\end{array}$ & $\begin{array}{r}3,963 \\
14,436 \\
876 \\
24,847\end{array}$ & $\begin{array}{r}0 \\
0 \\
21,016 \\
21,016\end{array}$ & $\begin{array}{r}0 \\
13,211 \\
0 \\
13,211\end{array}$ & $\begin{array}{r}0 \\
1,565 \\
0 \\
1,585\end{array}$ & $\begin{array}{r}0 \\
13,833 \\
0 \\
13,833\end{array}$ \\
\hline 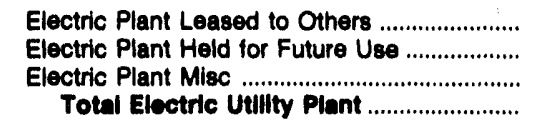 & $\begin{array}{r}0 \\
0 \\
1,603 \\
30,687\end{array}$ & $\begin{array}{r}0 \\
0 \\
0 \\
\mathbf{2 4 , 8 4 7}\end{array}$ & $\begin{array}{r}0 \\
0 \\
0 \\
21,016\end{array}$ & $\begin{array}{r}0 \\
0 \\
0 \\
13,211\end{array}$ & $\begin{array}{r}0 \\
0 \\
0 \\
1,585\end{array}$ & $\begin{array}{r}0 \\
0 \\
0 \\
13,833\end{array}$ \\
\hline $\begin{array}{l}\text { Construction Work in Progress - Electric ....... } \\
\text { Accumulated Provision for }\end{array}$ & 1,471 & 338 & $1,62 \theta$ & 0 & 0 & 0 \\
\hline 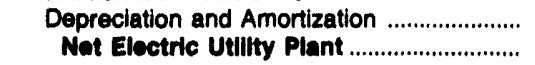 & $\begin{array}{r}8,073 \\
24,004\end{array}$ & $\begin{array}{l}12,505 \\
12,680\end{array}$ & $\begin{array}{r}8,847 \\
12,798\end{array}$ & $\begin{array}{l}4,882 \\
8,329\end{array}$ & $\begin{array}{l}685 \\
879\end{array}$ & $\begin{array}{l}8,733 \\
5,101\end{array}$ \\
\hline
\end{tabular}

Note: Totals may not equal sum of components because of independent rounding.

Source: Energy Information Administration, Form EIA-412, "Annual Feport of Public Electric Utilities." 
Table 24. Electric Utility Plant by Major U.S. Publicly Owned Electric Utility Within State at End of Period, 1992 (Continued) (Thousand Dollars)

\begin{tabular}{|c|c|c|c|c|c|c|}
\hline Item & $\begin{array}{c}\text { South Carolina } \\
\text { Greer } \\
\text { Comm } \\
\text { of } \\
\text { Public Works } \\
\text { December } 31\end{array}$ & $\begin{array}{l}\text { South Carolina } \\
\text { Newberry } \\
\text { City of } \\
\text { June } 30\end{array}$ & $\begin{array}{l}\text { South Carolina } \\
\text { Orangeburg } \\
\text { Clty of }\end{array}$ & $\begin{array}{l}\text { South Carolina } \\
\text { Piedmont } \\
\text { Municipal } \\
\text { Power Agny } \\
\text { December } 31\end{array}$ & $\begin{array}{l}\text { South Carolina } \\
\text { Pock Hill } \\
\text { City of } \\
\text { December } 31\end{array}$ & $\begin{array}{c}\text { South Carolina } \\
\text { South } \\
\text { Carolina } \\
\text { Pub } \\
\text { Serv Auth } \\
\text { December } 31\end{array}$ \\
\hline 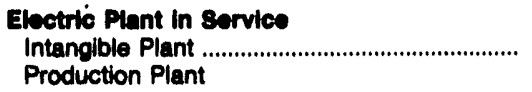 & 0 & 0 & 0 & 0 & 0 & 5,274 \\
\hline 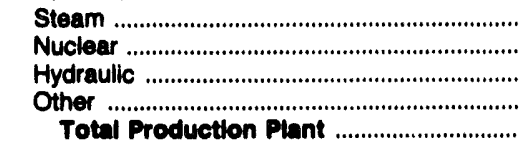 & $\begin{array}{l}0 \\
0 \\
0 \\
0 \\
0\end{array}$ & $\begin{array}{l}0 \\
0 \\
0 \\
0 \\
0\end{array}$ & $\begin{array}{r}0 \\
0 \\
0 \\
6,536 \\
6,636\end{array}$ & $\begin{array}{r}0 \\
545,302 \\
0 \\
0 \\
545,302\end{array}$ & $\begin{array}{l}0 \\
0 \\
0 \\
0 \\
0\end{array}$ & $\begin{array}{r}952,380 \\
430,312 \\
66,233 \\
24,489 \\
1,473,414\end{array}$ \\
\hline 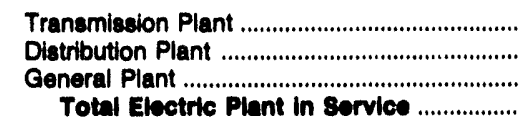 & $\begin{array}{r}9,624 \\
0 \\
59,097 \\
68,721\end{array}$ & $\begin{array}{r}0 \\
0 \\
7,425 \\
7,425\end{array}$ & $\begin{array}{r}37,711 \\
0 \\
0 \\
44,246\end{array}$ & $\begin{array}{r}0 \\
0 \\
1,191 \\
546,493\end{array}$ & $\begin{array}{r}0 \\
28,138 \\
0 \\
28,138\end{array}$ & $\begin{array}{r}392,164 \\
191,780 \\
123,239 \\
2,185,871\end{array}$ \\
\hline 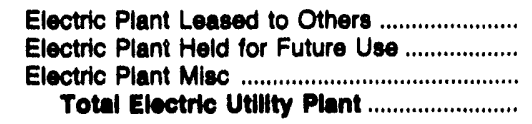 & $\begin{array}{r}0 \\
0 \\
0 \\
68,721\end{array}$ & $\begin{array}{r}0 \\
0 \\
0 \\
7,425\end{array}$ & $\begin{array}{r}0 \\
0 \\
0 \\
44,246\end{array}$ & $\begin{array}{r}0 \\
0 \\
0 \\
546,493\end{array}$ & $\begin{array}{r}0 \\
0 \\
0 \\
28,138\end{array}$ & $\begin{array}{r}0 \\
12,347 \\
277,546 \\
2,475,764\end{array}$ \\
\hline $\begin{array}{l}\text { Construction Work in Progress - Electric ....... } \\
\text { Accumulated Provision for }\end{array}$ & 205 & 0 & 1,159 & 3,952 & 1,065 & 267,411 \\
\hline 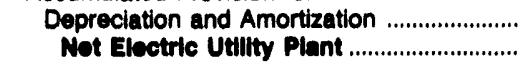 & $\begin{array}{l}18,764 \\
50,162\end{array}$ & $\begin{array}{l}3,801 \\
3,624\end{array}$ & $\begin{array}{l}10,479 \\
\mathbf{3 4 , 0 2 7}\end{array}$ & $\begin{array}{l}123,540 \\
428,805\end{array}$ & $\begin{array}{l}10,326 \\
18,876\end{array}$ & $\begin{array}{r}746,749 \\
1,908,426\end{array}$ \\
\hline
\end{tabular}

\begin{tabular}{|c|c|c|c|c|c|c|}
\hline Item & $\begin{array}{l}\text { South Dakota } \\
\text { Brookings } \\
\text { City of } \\
\text { December } 31\end{array}$ & $\begin{array}{l}\text { South Dakota } \\
\text { Heartland } \\
\text { Consumers } \\
\text { Power Dist } \\
\text { December } 31\end{array}$ & $\begin{array}{l}\text { South Dakota } \\
\text { Missouri } \\
\text { Basin } \\
\text { Mun } \\
\text { Power Agny } \\
\text { December } 31\end{array}$ & $\begin{array}{c}\text { South Dakota } \\
\text { Plerre } \\
\text { City of } \\
\text { December } 31\end{array}$ & $\begin{array}{l}\text { South Dakota } \\
\text { Watertown } \\
\text { Municipal } \\
\text { Utilities } \\
\text { December } 31\end{array}$ & $\begin{array}{c}\text { Tennessee } \\
\text { Alcoa } \\
\text { Utilities } \\
\text { June } 30\end{array}$ \\
\hline $\begin{array}{l}\text { Electric Plant in Eervice } \\
\text { Intangible Plant ................................................ } \\
\text { Production Plant }\end{array}$ & 0 & 0 & 0 & 0 & 12 & 0 \\
\hline 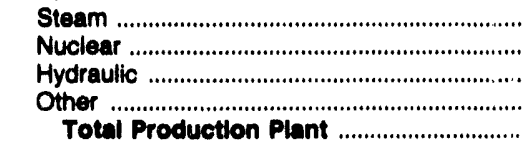 & $\begin{array}{l}0 \\
0 \\
0 \\
0 \\
0\end{array}$ & $\begin{array}{r}48,111 \\
0 \\
0 \\
0 \\
48,111\end{array}$ & $\begin{array}{l}0 \\
0 \\
0 \\
0 \\
0\end{array}$ & $\begin{array}{l}0 \\
0 \\
0 \\
0 \\
0\end{array}$ & $\begin{array}{l}0 \\
0 \\
0 \\
0 \\
0\end{array}$ & $\begin{array}{l}0 \\
0 \\
0 \\
0 \\
0\end{array}$ \\
\hline 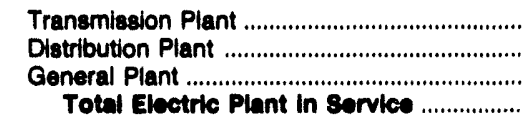 & $\begin{array}{r}3,699 \\
9,335 \\
2,810 \\
15,844\end{array}$ & $\begin{array}{r}8,380 \\
0 \\
776 \\
57,267\end{array}$ & $\begin{array}{r}0 \\
0 \\
2,582 \\
2,582\end{array}$ & $\begin{array}{r}0 \\
6,145 \\
951 \\
7,098\end{array}$ & $\begin{array}{r}364 \\
13,421 \\
1,115 \\
14,912\end{array}$ & $\begin{array}{r}1,126 \\
15,163 \\
1,586 \\
17,875\end{array}$ \\
\hline 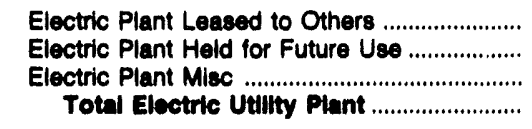 & $\begin{array}{r}0 \\
0 \\
0 \\
15,844\end{array}$ & $\begin{array}{r}0 \\
0 \\
0 \\
\mathbf{5 7 , 2 6 7}\end{array}$ & $\begin{array}{r}0 \\
0 \\
0 \\
2,682\end{array}$ & $\begin{array}{r}0 \\
0 \\
0 \\
7,088\end{array}$ & $\begin{array}{r}0 \\
0 \\
0 \\
14,912\end{array}$ & $\begin{array}{r}0 \\
0 \\
0 \\
17,875\end{array}$ \\
\hline $\begin{array}{l}\text { Construction Work in Progress - Electric ....... } \\
\text { Accumulated Provision for }\end{array}$ & 638 & 111 & 0 & 584 & 20 & 354 \\
\hline $\begin{array}{l}\text { Depreciation and Amortization } \\
\text { Not Electric Utility Plant }\end{array}$ & $\begin{array}{r}4,572 \\
11,010\end{array}$ & $\begin{array}{r}6,183 \\
51,105\end{array}$ & $\begin{array}{r}618 \\
1,964\end{array}$ & $\begin{array}{l}2,065 \\
5,616\end{array}$ & $\begin{array}{l}8,658 \\
6,273\end{array}$ & $\begin{array}{r}5,658 \\
12,571\end{array}$ \\
\hline
\end{tabular}

Note: Totals may not equal sum of components because of independent rounding.

Source: Energy information Administration, Form EIA-412, "Annual Report of Public Electric Utilities." 
Table 24. Electric Utility Plant by Major U.S. Publlcly Owned Electric UtIlity Within State at End of Perlod, 1992 (Continued) (Thousand Dollars)

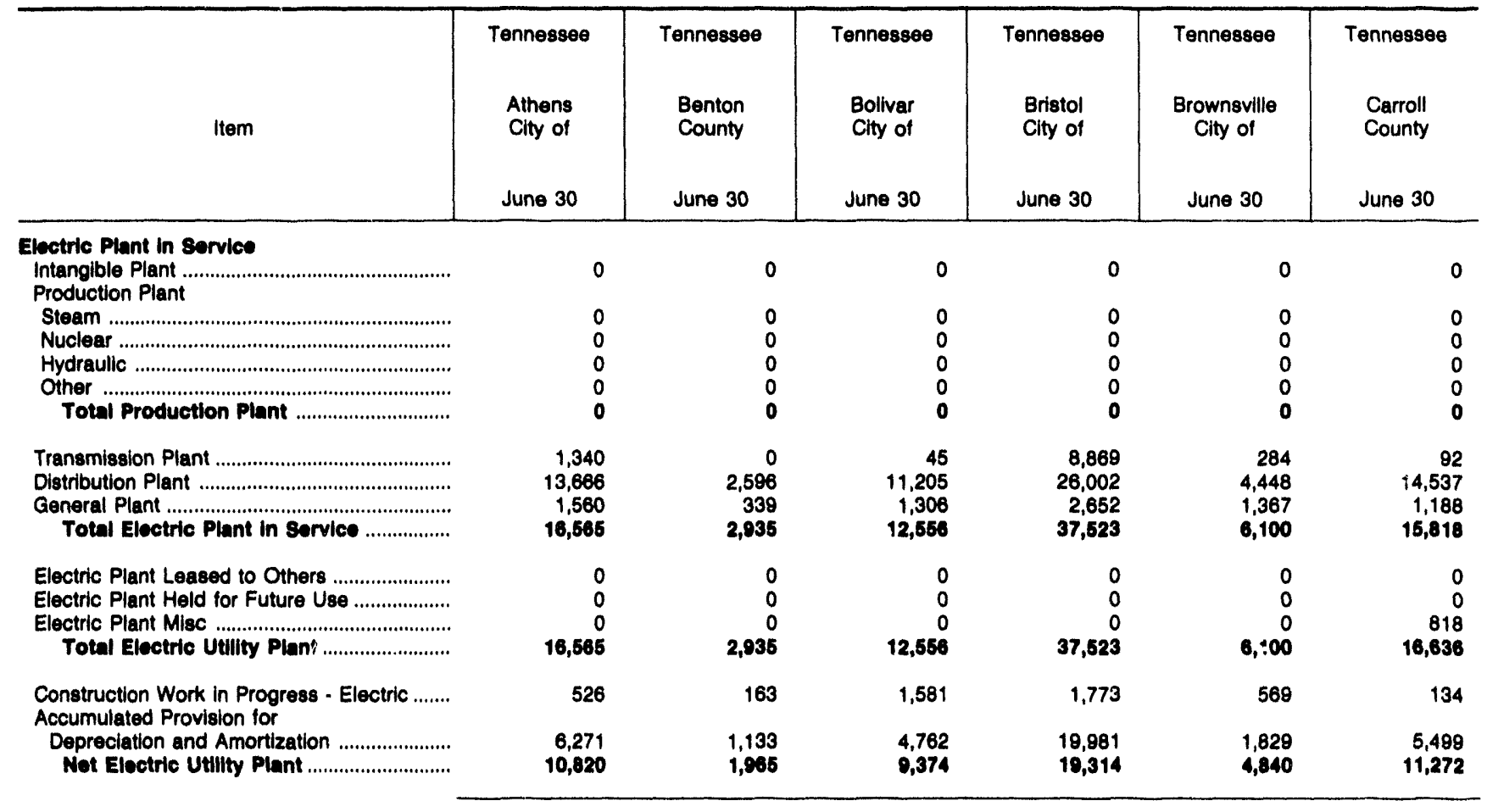

\begin{tabular}{|c|c|c|c|c|c|c|}
\hline Item & $\begin{array}{c}\text { Tennessee } \\
\begin{array}{c}\text { Chattanooga } \\
\text { City of }\end{array} \\
\text { June } 30\end{array}$ & $\begin{array}{l}\text { Tennessee } \\
\text { Clarksville } \\
\text { City of } \\
\text { June } 30\end{array}$ & $\begin{array}{l}\text { Tennessee } \\
\text { Cleveland } \\
\text { City of } \\
\text { June } 30\end{array}$ & $\begin{array}{l}\text { Tennessee } \\
\text { Clinton } \\
\text { City of } \\
\text { June } 30\end{array}$ & $\begin{array}{l}\text { Tennessee } \\
\text { Columbia } \\
\text { Clty of } \\
\text { June } 30\end{array}$ & $\begin{array}{c}\text { Tennessee } \\
\text { Cookeville } \\
\text { City of } \\
\text { June } 30\end{array}$ \\
\hline 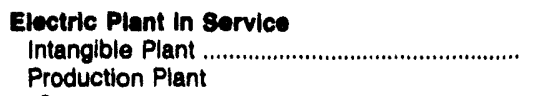 & 0 & 0 & 0 & 0 & 0 & 0 \\
\hline 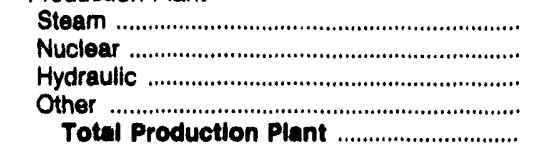 & $\begin{array}{l}0 \\
0 \\
0 \\
0 \\
0\end{array}$ & $\begin{array}{l}0 \\
0 \\
0 \\
0 \\
0\end{array}$ & $\begin{array}{l}0 \\
0 \\
0 \\
0 \\
0\end{array}$ & $\begin{array}{l}0 \\
0 \\
0 \\
0 \\
0\end{array}$ & $\begin{array}{l}0 \\
0 \\
0 \\
0 \\
0\end{array}$ & $\begin{array}{l}0 \\
0 \\
0 \\
0 \\
0\end{array}$ \\
\hline 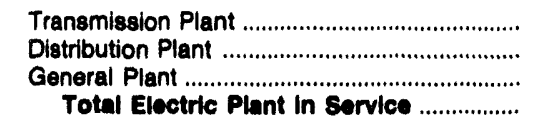 & $\begin{array}{r}24,339 \\
176,953 \\
25,468 \\
226,761\end{array}$ & $\begin{array}{r}543 \\
22,883 \\
4,635 \\
28,071\end{array}$ & $\begin{array}{r}3,178 \\
35,836 \\
3,592 \\
42,606\end{array}$ & $\begin{array}{r}5,422 \\
23,970 \\
3,167 \\
32,680\end{array}$ & $\begin{array}{r}1,726 \\
18,763 \\
2,854 \\
23,343\end{array}$ & $\begin{array}{r}265 \\
11,617 \\
2,696 \\
14,678\end{array}$ \\
\hline 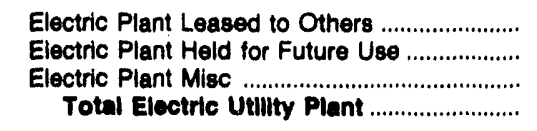 & $\begin{array}{r}0 \\
0 \\
0 \\
228,781\end{array}$ & $\begin{array}{r}0 \\
69 \\
10,878 \\
38,818\end{array}$ & $\begin{array}{r}0 \\
0 \\
0 \\
\mathbf{4 2 , 6 0 6}\end{array}$ & $\begin{array}{r}0 \\
0 \\
0 \\
32,580\end{array}$ & $\begin{array}{r}0 \\
0 \\
4 \\
23,347\end{array}$ & $\begin{array}{r}0 \\
0 \\
837 \\
15,415\end{array}$ \\
\hline $\begin{array}{l}\text { Construction Work in Progress - Electric ....... } \\
\text { Accumulated Provision for }\end{array}$ & 4,958 & 841 & 607 & 391 & 276 & 1,853 \\
\hline $\begin{array}{l}\text { Depreciation and Amortization ...................... } \\
\text { Not Electric Utility Plant ............................ }\end{array}$ & $\begin{array}{r}88,950 \\
142,789\end{array}$ & $\begin{array}{r}8,437 \\
31,221\end{array}$ & $\begin{array}{l}12,246 \\
30,988\end{array}$ & $\begin{array}{l}11,213 \\
21,738\end{array}$ & $\begin{array}{r}9,119 \\
14,604\end{array}$ & $\begin{array}{r}4,473 \\
12,895\end{array}$ \\
\hline
\end{tabular}

Note: Totals may not equal sum of components because of independent rounding.

Source: Energy Information Administration, Form ElA-412, "Annual Report of Public Electric Utillties." 
Table 24. Electric Utility Plant by Major U.S. Publicly Owned Electrlc Utillty Within State at End of Period, 1992 (Continued) (Thousand Dollars)

\begin{tabular}{|c|c|c|c|c|c|c|}
\hline Item & $\begin{array}{l}\text { Tennessee } \\
\text { Covington } \\
\text { Eiectric } \\
\text { System } \\
\text { June } 30\end{array}$ & $\begin{array}{l}\text { Tennessee } \\
\begin{array}{l}\text { Dayton } \\
\text { Clty of }\end{array} \\
\text { June } 30\end{array}$ & $\begin{array}{l}\text { Tennessee } \\
\text { Dickson } \\
\text { City of } \\
\text { June } 30\end{array}$ & $\begin{array}{c}\text { Tennessee } \\
\text { Dyersburg } \\
\text { Electric } \\
\text { System } \\
\text { June } 30 \\
\end{array}$ & $\begin{array}{c}\text { Tennessee } \\
\text { Ellzabethton } \\
\text { City of } \\
\text { June } 30 \\
\end{array}$ & $\begin{array}{l}\text { Tennessee } \\
\text { Enwin } \\
\text { Town of } \\
\text { June } 30\end{array}$ \\
\hline $\begin{array}{l}\text { Ebctric Plant In Sorvice } \\
\text { Intangible Plant } \\
\text { Production Plant }\end{array}$ & 0 & 0 & 0 & 0 & 0 & 0 \\
\hline 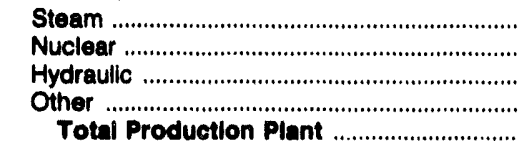 & $\begin{array}{l}0 \\
0 \\
0 \\
0 \\
0\end{array}$ & $\begin{array}{l}0 \\
0 \\
0 \\
0 \\
0\end{array}$ & $\begin{array}{l}0 \\
0 \\
0 \\
0 \\
0\end{array}$ & $\begin{array}{l}0 \\
0 \\
0 \\
0 \\
0\end{array}$ & $\begin{array}{l}0 \\
0 \\
0 \\
0 \\
0\end{array}$ & $\begin{array}{l}0 \\
0 \\
0 \\
0 \\
0\end{array}$ \\
\hline 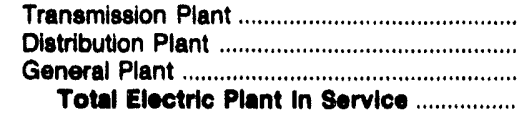 & $\begin{array}{r}1,307 \\
4,210 \\
811 \\
6,328\end{array}$ & $\begin{array}{r}0 \\
7,975 \\
1,153 \\
9,127\end{array}$ & $\begin{array}{r}0 \\
28,872 \\
1,811 \\
30,683\end{array}$ & $\begin{array}{r}1,925 \\
16,310 \\
4,354 \\
22,589\end{array}$ & $\begin{array}{r}597 \\
19,100 \\
3,287 \\
22,984\end{array}$ & $\begin{array}{r}0 \\
6,213 \\
1,123 \\
7,335\end{array}$ \\
\hline 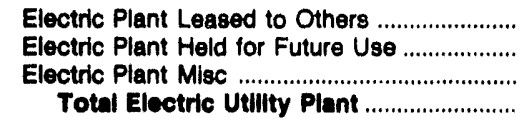 & $\begin{array}{r}0 \\
0 \\
1,600 \\
7,828\end{array}$ & $\begin{array}{r}0 \\
0 \\
0 \\
9,127\end{array}$ & $\begin{array}{r}0 \\
135 \\
47 \\
30,866\end{array}$ & $\begin{array}{r}0 \\
0 \\
0 \\
22,589\end{array}$ & $\begin{array}{r}0 \\
0 \\
0 \\
22,984\end{array}$ & $\begin{array}{r}0 \\
0 \\
0 \\
7,335\end{array}$ \\
\hline $\begin{array}{l}\text { Construction Work in Progress - Flectric ....... } \\
\text { Accumulated Provision for }\end{array}$ & 55 & 59 & 1,944 & 2,175 & 237 & 238 \\
\hline 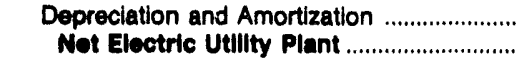 & $\begin{array}{l}1,894 \\
6,089\end{array}$ & $\begin{array}{l}2,884 \\
6,302\end{array}$ & $\begin{array}{r}\theta, 915 \\
22,894\end{array}$ & $\begin{array}{r}6,727 \\
18,037\end{array}$ & $\begin{array}{r}7,994 \\
15,227\end{array}$ & $\begin{array}{l}3,034 \\
4,539\end{array}$ \\
\hline
\end{tabular}

\begin{tabular}{|c|c|c|c|c|c|c|}
\hline Item & $\begin{array}{l}\text { Tennessee } \\
\text { Etowah } \\
\text { City of } \\
\text { June } 30\end{array}$ & $\begin{array}{c}\text { Tennessee } \\
\text { Fayetteville } \\
\text { City of } \\
\text { June } 30\end{array}$ & $\begin{array}{l}\text { Tennessee } \\
\text { Gallatin } \\
\text { City of } \\
\text { June } 30\end{array}$ & $\begin{array}{l}\text { Tennessee } \\
\text { Greeneville } \\
\text { City of } \\
\text { June } 30\end{array}$ & $\begin{array}{c}\text { Tennessee } \\
\text { Harriman } \\
\text { City of } \\
\text { June } 30\end{array}$ & $\begin{array}{l}\text { Tennessee } \\
\text { Humboldt } \\
\text { Clty of } \\
\text { June } 30\end{array}$ \\
\hline 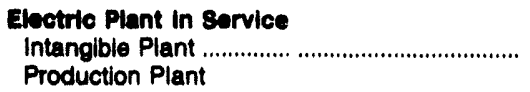 & 0 & 0 & 0 & 0 & 0 & 0 \\
\hline 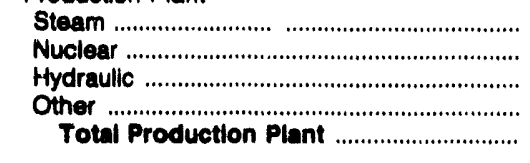 & $\begin{array}{l}0 \\
0 \\
0 \\
0 \\
0\end{array}$ & $\begin{array}{l}0 \\
0 \\
0 \\
0 \\
0\end{array}$ & $\begin{array}{l}0 \\
0 \\
0 \\
0 \\
0\end{array}$ & $\begin{array}{l}0 \\
0 \\
0 \\
0 \\
0\end{array}$ & $\begin{array}{l}0 \\
0 \\
0 \\
0 \\
0\end{array}$ & $\begin{array}{l}0 \\
0 \\
0 \\
0 \\
0\end{array}$ \\
\hline 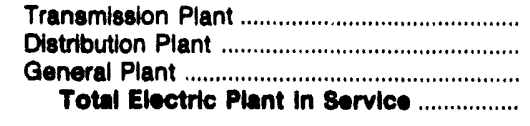 & $\begin{array}{r}0 \\
4,507 \\
315 \\
4,822\end{array}$ & $\begin{array}{r}619 \\
16,704 \\
4,393 \\
21,716\end{array}$ & $\begin{array}{r}501 \\
8,181 \\
1,288 \\
9,970\end{array}$ & $\begin{array}{r}6,100 \\
27,333 \\
3,943 \\
37,376\end{array}$ & $\begin{array}{r}0 \\
13,546 \\
2,022 \\
15,689\end{array}$ & $\begin{array}{r}603 \\
3,943 \\
1,611 \\
6,168\end{array}$ \\
\hline 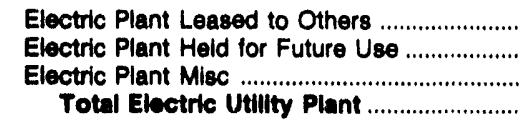 & $\begin{array}{r}0 \\
0 \\
0 \\
4,822\end{array}$ & $\begin{array}{r}0 \\
1 \\
0 \\
21,717\end{array}$ & $\begin{array}{r}0 \\
0 \\
171 \\
10,141\end{array}$ & $\begin{array}{r}0 \\
0 \\
0 \\
37,378\end{array}$ & $\begin{array}{r}0 \\
0 \\
0 \\
15,589\end{array}$ & $\begin{array}{r}0 \\
0 \\
645 \\
6,802\end{array}$ \\
\hline $\begin{array}{l}\text { Construction Work in Progress - Electric ....... } \\
\text { Acoumulated Provision for }\end{array}$ & 6 & 1,281 & 103 & 674 & 209 & 222 \\
\hline 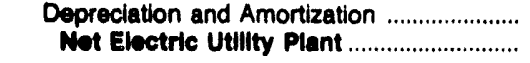 & $\begin{array}{l}2,006 \\
2,623\end{array}$ & $\begin{array}{r}7,031 \\
15,067\end{array}$ & $\begin{array}{l}4,655 \\
6,580\end{array}$ & $\begin{array}{l}14,152 \\
23,898\end{array}$ & $\begin{array}{l}6,546 \\
9,231\end{array}$ & $\begin{array}{l}2,114 \\
4,011\end{array}$ \\
\hline
\end{tabular}

Note: Totals may not equal sum of components because of independent rounding.

Source: Energy information Administration, Form ElA-412, "Annual Report of Public Eloctric Utilities." 
Table 24. Electric UtIlity Plant by Major U.S. Publlcly Owned Electrlc Utility Within State at End of Period, 1992 (Continued) (Thousand Dollars)

\begin{tabular}{|c|c|c|c|c|c|c|}
\hline Item & $\begin{array}{l}\text { Tennessee } \\
\text { Jackson } \\
\text { City of } \\
\text { June } 30\end{array}$ & $\begin{array}{l}\text { Tennessee } \\
\text { Johnson } \\
\text { City Clty of } \\
\text { June } 30\end{array}$ & $\begin{array}{l}\text { Tennessee } \\
\text { Knoxville } \\
\text { Utillities } \\
\text { Board } \\
\text { June } 30\end{array}$ & $\begin{array}{l}\text { Tennessea } \\
\text { Lawrenceburg } \\
\text { City of } \\
\text { June } 30\end{array}$ & $\begin{array}{l}\text { Tennessee } \\
\text { LaFollette } \\
\text { City of } \\
\text { June } 30\end{array}$ & $\begin{array}{l}\text { Tennessee } \\
\text { Lebanon } \\
\text { City of } \\
\text { June } 30\end{array}$ \\
\hline 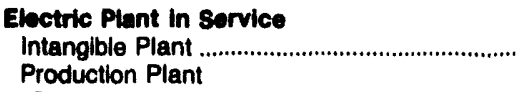 & 0 & 0 & 0 & 0 & 0 & 0 \\
\hline 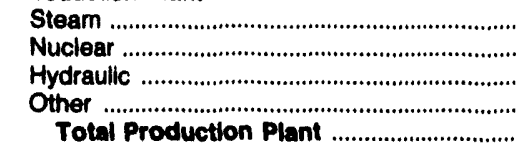 & $\begin{array}{l}0 \\
0 \\
0 \\
0 \\
0\end{array}$ & $\begin{array}{l}0 \\
0 \\
0 \\
0 \\
0\end{array}$ & $\begin{array}{l}0 \\
0 \\
0 \\
0 \\
0\end{array}$ & $\begin{array}{l}0 \\
0 \\
0 \\
0 \\
0\end{array}$ & $\begin{array}{l}0 \\
0 \\
0 \\
0 \\
0\end{array}$ & $\begin{array}{l}0 \\
0 \\
0 \\
0 \\
0\end{array}$ \\
\hline 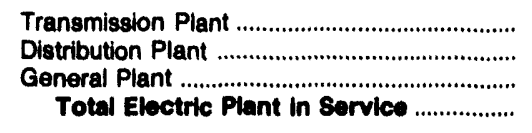 & $\begin{array}{r}9,120 \\
35,444 \\
8,191 \\
52,756\end{array}$ & $\begin{array}{r}3,205 \\
39,688 \\
2,229 \\
45,123\end{array}$ & $\begin{array}{r}0 \\
243,555 \\
20,670 \\
264,225\end{array}$ & $\begin{array}{r}3,924 \\
16,087 \\
2,194 \\
22,205\end{array}$ & $\begin{array}{r}0 \\
21,084 \\
2,125 \\
23,209\end{array}$ & $\begin{array}{r}0 \\
9,953 \\
789 \\
10,741\end{array}$ \\
\hline 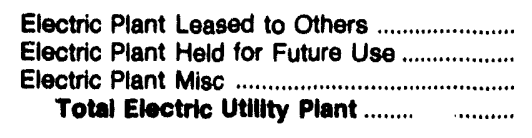 & $\begin{array}{r}0 \\
0 \\
312 \\
53,068\end{array}$ & $\begin{array}{r}0 \\
0 \\
0 \\
45,123\end{array}$ & $\begin{array}{r}0 \\
0 \\
0 \\
264,225\end{array}$ & $\begin{array}{r}0 \\
0 \\
0 \\
22,205\end{array}$ & $\begin{array}{r}0 \\
0 \\
0 \\
23,209\end{array}$ & $\begin{array}{r}0 \\
0 \\
5 \\
10,747\end{array}$ \\
\hline $\begin{array}{l}\text { Construction Work in Progress - Electric ........ } \\
\text { Accumulated Provision for }\end{array}$ & 1,040 & 1,761 & $7,30^{-}$ & 146 & 165 & 1,264 \\
\hline 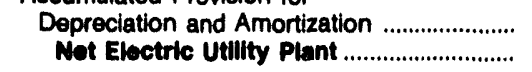 & $\begin{array}{l}20,179 \\
33,929\end{array}$ & $\begin{array}{l}17,959 \\
28,925\end{array}$ & $\begin{array}{l}124,299 \\
147,233\end{array}$ & $\begin{array}{r}8,7,6 \\
13,5,6\end{array}$ & $\begin{array}{r}8,205 \\
15,169\end{array}$ & $\begin{array}{l}4,241 \\
7,771\end{array}$ \\
\hline
\end{tabular}

\begin{tabular}{|c|c|c|c|c|c|c|}
\hline Item & $\begin{array}{l}\text { Tennessee } \\
\text { Lenoir } \\
\text { City City of } \\
\text { June } 30\end{array}$ & $\begin{array}{c}\text { Tennessee } \\
\begin{array}{c}\text { Lewisburg } \\
\text { City of }\end{array} \\
\text { June } 30\end{array}$ & $\begin{array}{c}\text { Tennessee } \\
\text { Lexington } \\
\text { City of } \\
\text { June } 30\end{array}$ & $\begin{array}{l}\text { Tennessee } \\
\text { Loudon } \\
\text { City of } \\
\text { June } 30\end{array}$ & $\begin{array}{c}\text { Tennessee } \\
\text { Maryille } \\
\text { Utillites } \\
\text { June } 30\end{array}$ & $\begin{array}{l}\text { Tennessee } \\
\text { McMinnville } \\
\text { Electric } \\
\text { System } \\
\text { June } 30\end{array}$ \\
\hline 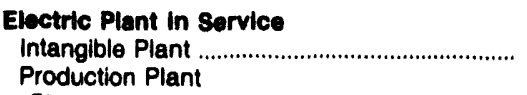 & 0 & 0 & 0 & 0 & 0 & 0 \\
\hline 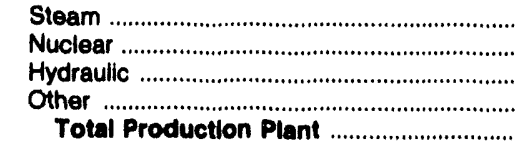 & $\begin{array}{l}0 \\
0 \\
0 \\
0 \\
0\end{array}$ & $\begin{array}{l}0 \\
0 \\
0 \\
0 \\
0\end{array}$ & $\begin{array}{l}0 \\
0 \\
0 \\
0 \\
0\end{array}$ & $\begin{array}{l}0 \\
0 \\
0 \\
0 \\
0\end{array}$ & $\begin{array}{l}0 \\
0 \\
0 \\
0 \\
0\end{array}$ & $\begin{array}{l}0 \\
0 \\
0 \\
0 \\
0\end{array}$ \\
\hline 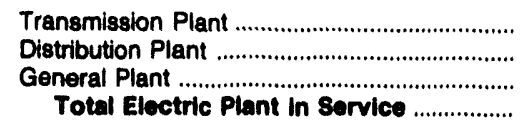 & $\begin{array}{r}0 \\
50,602 \\
3,039 \\
53,641\end{array}$ & $\begin{array}{r}0 \\
6,849 \\
1,780 \\
8,628\end{array}$ & $\begin{array}{r}22 \\
15,543 \\
2,694 \\
18,260\end{array}$ & $\begin{array}{r}3,396 \\
9,590 \\
468 \\
13,454\end{array}$ & $\begin{array}{r}820 \\
17,045 \\
4,294 \\
22,159\end{array}$ & $\begin{array}{r}0 \\
8,649 \\
1,344 \\
9,993\end{array}$ \\
\hline 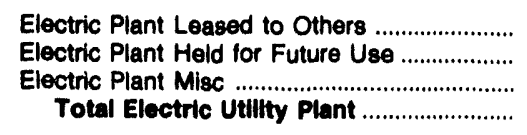 & $\begin{array}{r}0 \\
237 \\
0 \\
53,877\end{array}$ & $\begin{array}{r}0 \\
0 \\
310 \\
8,938\end{array}$ & $\begin{array}{r}0 \\
0 \\
625 \\
18,885\end{array}$ & $\begin{array}{r}0 \\
0 \\
0 \\
13,454\end{array}$ & $\begin{array}{r}0 \\
0 \\
29 \\
22,188\end{array}$ & $\begin{array}{r}0 \\
0 \\
228 \\
10,221\end{array}$ \\
\hline $\begin{array}{l}\text { Construction Work in Progress - Electric ....... } \\
\text { Accumulated Provision for }\end{array}$ & 687 & 315 & 164 & 2,466 & 160 & 30 \\
\hline 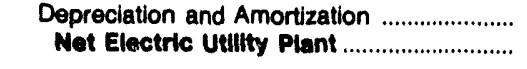 & $\begin{array}{l}13,395 \\
41,169\end{array}$ & $\begin{array}{l}3,283 \\
5,971\end{array}$ & $\begin{array}{r}5,715 \\
13,334\end{array}$ & $\begin{array}{r}3,206 \\
12,714\end{array}$ & $\begin{array}{r}6,639 \\
15,709\end{array}$ & $\begin{array}{l}3,913 \\
6,338\end{array}$ \\
\hline
\end{tabular}

Note: Totals may not equal sum of components because of independent rounding.

Source: Energy Information Administration, Form EIA-412, "Annual Report of Public Electric Utilities." 
Table 24. Electric Utility Plant by Major U.S. Publicly Owned Electric Utility Within State at End of Period, 1992 (Continued) (Thousand Dollars)

\begin{tabular}{|c|c|c|c|c|c|c|}
\hline Item & $\begin{array}{l}\text { Tennessee } \\
\text { Memphis } \\
\text { City of } \\
\text { June } 30\end{array}$ & $\begin{array}{l}\text { Tennessee } \\
\text { Morristown } \\
\text { City of } \\
\text { June } 30\end{array}$ & $\begin{array}{c}\text { Tennessee } \\
\begin{array}{c}\text { Murfreesboro } \\
\text { City of }\end{array} \\
\text { June } 30\end{array}$ & $\begin{array}{c}\text { Tennessee } \\
\text { Nashville } \\
\text { Electric } \\
\text { Service } \\
\text { June } 30\end{array}$ & $\begin{array}{l}\text { Tennessee } \\
\text { Newport } \\
\text { City of } \\
\text { June } 30\end{array}$ & $\begin{array}{l}\text { Tennessee } \\
\text { Oak Ridge } \\
\text { City of } \\
\text { June } 30\end{array}$ \\
\hline \multicolumn{7}{|l|}{ Electric Plant In Service } \\
\hline $\begin{array}{l}\text { Intangible Plant } \\
\text { Production Plant }\end{array}$ & 0 & 0 & 0 & 0 & 0 & 0 \\
\hline Steam & 0 & 0 & 0 & 0 & 0 & 0 \\
\hline 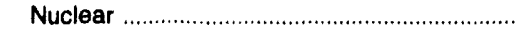 & 0 & 0 & 0 & 0 & 0 & 0 \\
\hline 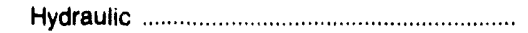 & 0 & 0 & 0 & 0 & 0 & 0 \\
\hline Other & 0 & 0 & 0 & 0 & 0 & 0 \\
\hline Total Production Plant .............................. & 0 & 0 & 0 & $\mathbf{0}$ & $\mathbf{0}$ & $\mathbf{0}$ \\
\hline 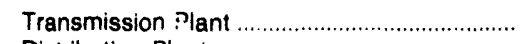 & 124,503 & 3,595 & 0 & 0 & 0 & 0 \\
\hline 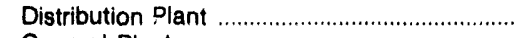 & 510,595 & 16,317 & 26,153 & 458,897 & 18,829 & 20,162 \\
\hline 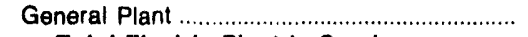 & 39,650 & 3,549 & 3,956 & 49,195 & 3,859 & 1,089 \\
\hline Total Electric Plant in Service .................. & 674,748 & 23,461 & 30,110 & 508,092 & 22,689 & 21,251 \\
\hline Electric Plant Leased to Others ......................... & 0 & 0 & 0 & 0 & 0 & 0 \\
\hline Electric Plant Held for Future Use .................. & 0 & 0 & 0 & 0 & 0 & 0 \\
\hline 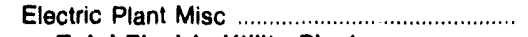 & 0 & 1,620 & 607 & -54 & 0 & 133 \\
\hline Total Electric Utillty Plant ........................... & 674,748 & 25,082 & 30,717 & 508,037 & 22,689 & 21,384 \\
\hline $\begin{array}{l}\text { Construction Work in Progress - Electric ....... } \\
\text { Accumulated Provision for }\end{array}$ & 33,784 & 116 & 1.742 & 15,254 & 2,142 & 1,119 \\
\hline 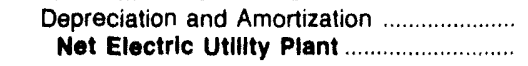 & $\begin{array}{l}233,774 \\
474,758\end{array}$ & $\begin{array}{r}7,902 \\
17,296\end{array}$ & $\begin{array}{r}9,438 \\
23,021\end{array}$ & $\begin{array}{l}175,242 \\
348,049\end{array}$ & $\begin{array}{r}7,344 \\
17,486\end{array}$ & $\begin{array}{r}8,379 \\
14,124\end{array}$ \\
\hline
\end{tabular}

\begin{tabular}{|c|c|c|c|c|c|c|}
\hline Item & $\begin{array}{c}\text { Tennessee } \\
\text { Paris } \\
\text { City of } \\
\text { June } 30\end{array}$ & $\begin{array}{l}\text { Tennessee } \\
\text { Pulaski } \\
\text { City of } \\
\text { June } 30\end{array}$ & $\begin{array}{l}\text { Tennessee } \\
\text { Ripley } \\
\text { City of } \\
\text { June } 30\end{array}$ & $\begin{array}{c}\text { Tennessee } \\
\text { Rockwood } \\
\text { City of } \\
\text { June } 30\end{array}$ & $\begin{array}{c}\text { Tennessee } \\
\text { Sevier } \\
\text { County } \\
\text { Electric } \\
\text { System } \\
\text { June } 30\end{array}$ & $\begin{array}{c}\text { Tennessee } \\
\text { Shelbyvilie } \\
\text { City of } \\
\text { June } 30\end{array}$ \\
\hline 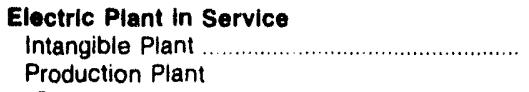 & 0 & 0 & 0 & 0 & 0 & 0 \\
\hline $\begin{array}{l}\text { Steam } \\
\text { Nuclear } \\
\text { Hydraulic } \\
\text { Other } \\
\text { Total Production Plant }\end{array}$ & $\begin{array}{l}0 \\
0 \\
0 \\
0 \\
0\end{array}$ & $\begin{array}{l}0 \\
0 \\
0 \\
0 \\
0\end{array}$ & $\begin{array}{l}0 \\
0 \\
0 \\
0 \\
0\end{array}$ & $\begin{array}{l}0 \\
0 \\
0 \\
0 \\
0\end{array}$ & $\begin{array}{l}0 \\
0 \\
0 \\
0 \\
0\end{array}$ & $\begin{array}{l}0 \\
0 \\
0 \\
0 \\
\mathbf{0}\end{array}$ \\
\hline 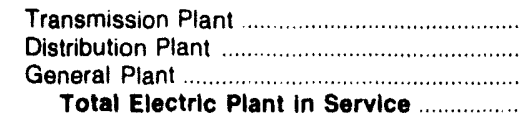 & $\begin{array}{r}1,929 \\
19,851 \\
1,511 \\
23,291\end{array}$ & $\begin{array}{r}0 \\
15,906 \\
2,809 \\
\mathbf{1 8 , 7 1 5}\end{array}$ & $\begin{array}{r}583 \\
4,814 \\
1,345 \\
6,742\end{array}$ & $\begin{array}{r}0 \\
13,965 \\
1,068 \\
15,032\end{array}$ & $\begin{array}{r}10,160 \\
40,226 \\
4,741 \\
55,126\end{array}$ & $\begin{array}{r}0 \\
9,510 \\
1,300 \\
10,810\end{array}$ \\
\hline 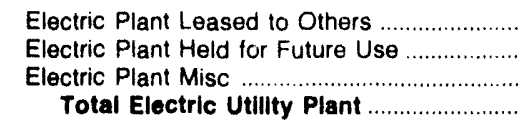 & $\begin{array}{r}0 \\
0 \\
281 \\
23,572\end{array}$ & $\begin{array}{r}0 \\
0 \\
0 \\
18,715\end{array}$ & $\begin{array}{r}0 \\
0 \\
394 \\
7,137\end{array}$ & $\begin{array}{r}0 \\
0 \\
271 \\
15,304\end{array}$ & $\begin{array}{r}0 \\
0 \\
517 \\
\mathbf{5 5 , 6 4 3}\end{array}$ & $\begin{array}{r}0 \\
0 \\
120 \\
10,930\end{array}$ \\
\hline $\begin{array}{l}\text { Construction Work in Progress - Electric ....... } \\
\text { Accumulated Provision for }\end{array}$ & 724 & 2,898 & 27 & 141 & 404 & 85 \\
\hline $\begin{array}{l}\text { Depreciation and Amortization } \\
\text { Not Electric Utillty Plant }\end{array}$ & $\begin{array}{r}9,776 \\
14,520\end{array}$ & $\begin{array}{r}7,860 \\
13,753\end{array}$ & $\begin{array}{l}2,234 \\
4,930\end{array}$ & $\begin{array}{r}4,984 \\
10,461\end{array}$ & $\begin{array}{l}13,790 \\
42,258\end{array}$ & $\begin{array}{l}4,174 \\
6,841\end{array}$ \\
\hline
\end{tabular}

Note: Totals may not equal sum of components because of independent rounding

Source: Energy Information Administration. Form EIA.412. "Annual Report of Public Electric Utilities." 
Table 24. Electric Utllity Plant by Major U.S. Publicly Owned Electric Utility Within State at End of Perlod, 1992 (Continued) (Thousand Dollars)

\begin{tabular}{|c|c|c|c|c|c|c|}
\hline Item & $\begin{array}{c}\text { Tennessee } \\
\text { Springfield } \\
\text { City of } \\
\text { June } 30\end{array}$ & $\begin{array}{c}\text { Tennessee } \\
\text { Sweetwater } \\
\text { City of } \\
\text { June } 30\end{array}$ & $\begin{array}{c}\text { Tennessee } \\
\text { Tullahoma } \\
\text { Board } \\
\text { of } \\
\text { Pub Utils } \\
\text { June } 30\end{array}$ & $\begin{array}{c}\text { Tennessee } \\
\text { Union } \\
\text { City City of } \\
\text { June } 30\end{array}$ & $\begin{array}{l}\text { Tennessee } \\
\text { Weakley } \\
\text { County } \\
\text { Mun } \\
\text { Elec Sys } \\
\text { June } 30\end{array}$ & $\begin{array}{l}\text { Texas } \\
\text { Austin } \\
\text { City of } \\
\text { September } 30\end{array}$ \\
\hline 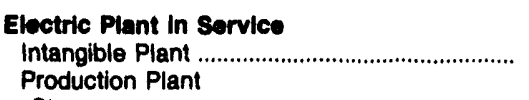 & 0 & 0 & 0 & 0 & 0 & 0 \\
\hline 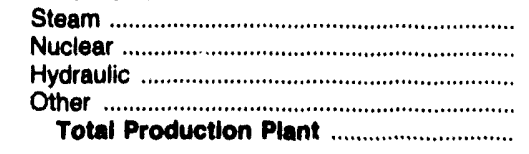 & $\begin{array}{l}0 \\
0 \\
0 \\
0 \\
0\end{array}$ & $\begin{array}{l}0 \\
0 \\
0 \\
0 \\
0\end{array}$ & $\begin{array}{l}0 \\
0 \\
0 \\
0 \\
0\end{array}$ & $\begin{array}{l}0 \\
0 \\
0 \\
0 \\
0\end{array}$ & $\begin{array}{l}0 \\
0 \\
0 \\
0 \\
0\end{array}$ & $\begin{array}{r}431,359 \\
911,014 \\
0 \\
3,296 \\
1,345,669\end{array}$ \\
\hline 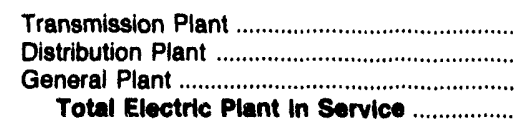 & $\begin{array}{r}0 \\
7,615 \\
1,243 \\
8,858\end{array}$ & $\begin{array}{r}0 \\
8,636 \\
927 \\
9,563\end{array}$ & $\begin{array}{r}0 \\
7,437 \\
1,837 \\
\mathbf{9 , 2 7 5}\end{array}$ & $\begin{array}{l}1,108 \\
6,425 \\
1,484 \\
9,017\end{array}$ & $\begin{array}{r}2,761 \\
20,324 \\
2,467 \\
25,552\end{array}$ & $\begin{array}{r}103,369 \\
462,768 \\
67,227 \\
1,979,034\end{array}$ \\
\hline 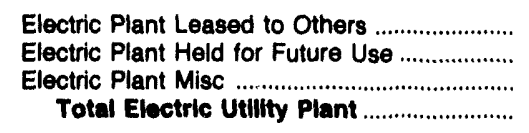 & $\begin{array}{r}0 \\
0 \\
118 \\
8,877\end{array}$ & $\begin{array}{r}0 \\
0 \\
0 \\
9,563\end{array}$ & $\begin{array}{r}0 \\
0 \\
801 \\
10,076\end{array}$ & $\begin{array}{r}0 \\
104 \\
34 \\
9,155\end{array}$ & $\begin{array}{r}0 \\
0 \\
0 \\
25,552\end{array}$ & $\begin{array}{r}0 \\
38,450 \\
0 \\
0,017,484\end{array}$ \\
\hline $\begin{array}{l}\text { Construction Work in Progress - Electric ....... } \\
\text { Accumulated Provision for }\end{array}$ & 627 & 1,247 & 178 & 182 & 971 & 106,502 \\
\hline 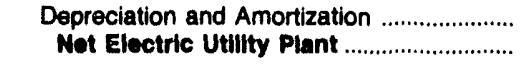 & $\begin{array}{l}3,603 \\
6,001\end{array}$ & $\begin{array}{l}3,180 \\
7,630\end{array}$ & $\begin{array}{l}3,636 \\
6,619\end{array}$ & $\begin{array}{l}3,188 \\
6,150\end{array}$ & $\begin{array}{l}11,965 \\
14,558\end{array}$ & $\begin{array}{r}498,858 \\
1,625,128\end{array}$ \\
\hline
\end{tabular}

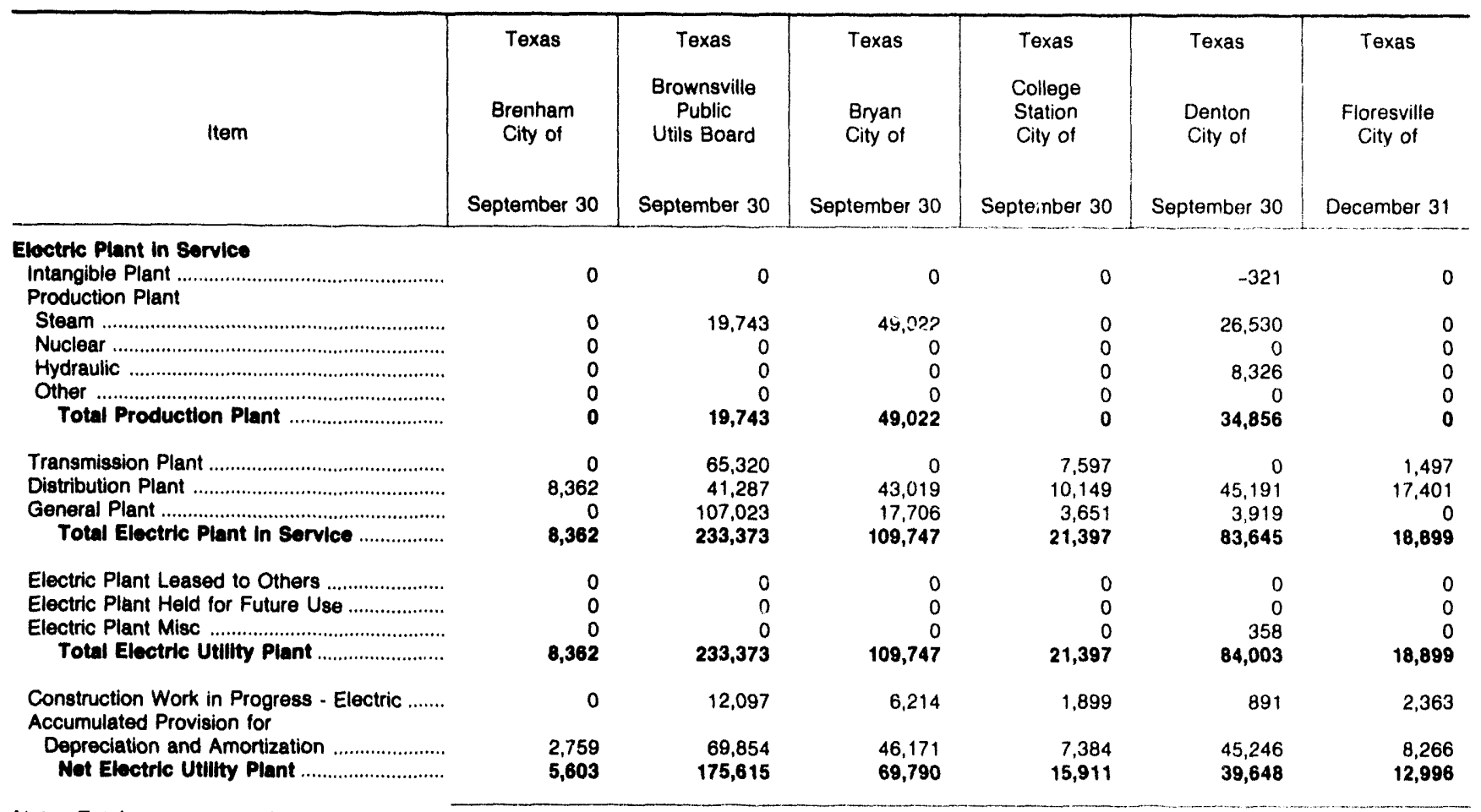

Note: Totals may not equal sum of components because of independent rounding.

Source: Energy Information Administration, Form ElA-412, "Annual Report of Public Electric Utilities." 
Table 24. Electric Utility Plant by Major U.S. Publlcly Owned Electric Utility Within State at End of Period, 1992 (Continued) (Thousand Dollars)

\begin{tabular}{|c|c|c|c|c|c|c|}
\hline Item & $\begin{array}{l}\text { Texas } \\
\text { Garland } \\
\text { City of } \\
\text { September } 30\end{array}$ & $\begin{array}{l}\text { Texas } \\
\text { Georgetown } \\
\text { City of } \\
\text { September } 30\end{array}$ & $\begin{array}{l}\text { Texas } \\
\text { Greenville } \\
\text { City of } \\
\text { September } 30\end{array}$ & $\begin{array}{c}\text { Texas } \\
\text { Kerrville } \\
\text { Public } \\
\text { Utility } \\
\text { Board } \\
\text { September } 30\end{array}$ & $\begin{array}{l}\text { Texas } \\
\text { Lower } \\
\text { Colorado } \\
\text { River } \\
\text { Authority } \\
\text { June } 30\end{array}$ & $\begin{array}{l}\text { Texas } \\
\text { Lubbock } \\
\text { City of } \\
\text { September } 30\end{array}$ \\
\hline 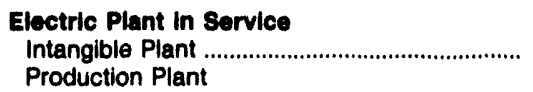 & 390 & 0 & 0 & 226 & 366 & 0 \\
\hline 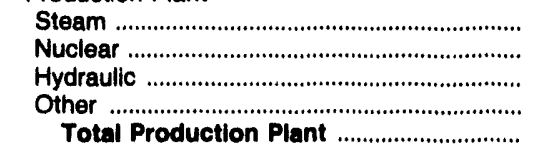 & $\begin{array}{r}75,757 \\
0 \\
0 \\
0 \\
75,757\end{array}$ & $\begin{array}{l}0 \\
0 \\
0 \\
0 \\
0\end{array}$ & $\begin{array}{r}19,809 \\
0 \\
0 \\
3,315 \\
23,124\end{array}$ & $\begin{array}{l}0 \\
0 \\
0 \\
0 \\
0\end{array}$ & $\begin{array}{r}877,984 \\
0 \\
70,623 \\
0 \\
948,607\end{array}$ & $\begin{array}{r}35,533 \\
0 \\
0 \\
18,916 \\
54,449\end{array}$ \\
\hline 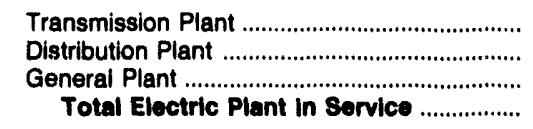 & $\begin{array}{r}20,041 \\
82,904 \\
13,749 \\
192,841\end{array}$ & $\begin{array}{r}0 \\
0 \\
4,536 \\
4,536\end{array}$ & $\begin{array}{r}0 \\
21,222 \\
2,047 \\
46,393\end{array}$ & $\begin{array}{r}0 \\
21,852 \\
4,477 \\
26,555\end{array}$ & $\begin{array}{r}264,130 \\
3,674 \\
118,040 \\
1,334,817\end{array}$ & $\begin{array}{r}0 \\
42,657 \\
0 \\
97,105\end{array}$ \\
\hline 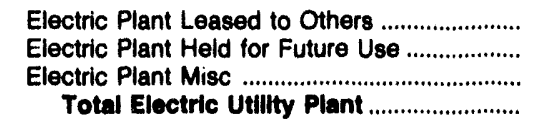 & $\begin{array}{r}0 \\
0 \\
0 \\
192,841\end{array}$ & $\begin{array}{r}0 \\
0 \\
0 \\
4,536\end{array}$ & $\begin{array}{r}0 \\
0 \\
0 \\
46,393\end{array}$ & $\begin{array}{r}0 \\
0 \\
-693 \\
25,863\end{array}$ & $\begin{array}{r}1 \\
0 \\
1,697 \\
1,336,514\end{array}$ & $\begin{array}{r}0 \\
0 \\
0 \\
97,105\end{array}$ \\
\hline $\begin{array}{l}\text { Construction Work in Progress - Electric ....... } \\
\text { Accumulated Provision for }\end{array}$ & 0 & 0 & 0 & 408 & 153,398 & 35,254 \\
\hline 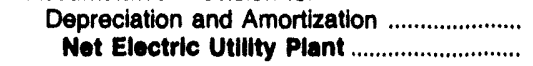 & $\begin{array}{r}78,799 \\
114,042\end{array}$ & $\begin{array}{l}1,779 \\
2,757\end{array}$ & $\begin{array}{l}26,134 \\
20,280\end{array}$ & $\begin{array}{r}7,727 \\
18,544\end{array}$ & $\begin{array}{r}354,737 \\
1,135,175\end{array}$ & $\begin{array}{l}47,978 \\
84,381\end{array}$ \\
\hline
\end{tabular}

\begin{tabular}{|c|c|c|c|c|c|c|}
\hline Item & $\begin{array}{c}\text { Texas } \\
\text { New Braunfels } \\
\text { City of } \\
\text { July } 31\end{array}$ & $\begin{array}{c}\text { Texas } \\
\text { Sam Rayburn } \\
\text { Municipal } \\
\text { Pwr } \\
\text { Agny } \\
\text { September } 30\end{array}$ & $\begin{array}{c}\text { Texas } \\
\text { San Antonio } \\
\text { City of } \\
\text { January } 31\end{array}$ & $\begin{array}{c}\text { Texas } \\
\text { San Marcos } \\
\text { Clty of } \\
\text { September } 30\end{array}$ & $\begin{array}{l}\text { Texas } \\
\text { Seguin } \\
\text { Clty of } \\
\text { September } 30\end{array}$ & $\begin{array}{c}\text { Texas } \\
\text { Texas } \\
\text { Municipal } \\
\text { Power Agency } \\
\text { September } 30\end{array}$ \\
\hline 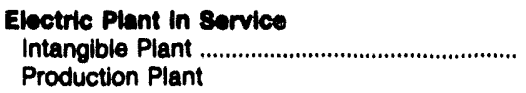 & 0 & 337 & 0 & 0 & 0 & 0 \\
\hline 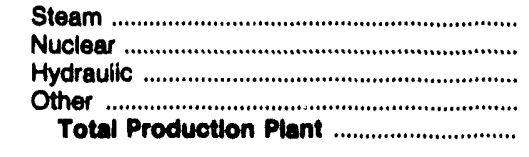 & $\begin{array}{r}0 \\
0 \\
14,752 \\
0 \\
14,752\end{array}$ & $\begin{array}{r}133,084 \\
0 \\
0 \\
0 \\
133,084\end{array}$ & $\begin{array}{r}1,117,463 \\
2,144,631 \\
0 \\
0 \\
3,262,004\end{array}$ & $\begin{array}{l}0 \\
0 \\
0 \\
0 \\
0\end{array}$ & $\begin{array}{r}0 \\
0 \\
522 \\
0 \\
522\end{array}$ & $\begin{array}{r}601,288 \\
0 \\
0 \\
0 \\
601,288\end{array}$ \\
\hline 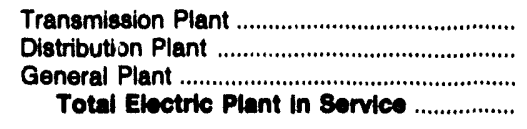 & $\begin{array}{r}8,543 \\
20,785 \\
5,068 \\
40,147\end{array}$ & $\begin{array}{r}0 \\
4,748 \\
0 \\
138,189\end{array}$ & $\begin{array}{r}210,817 \\
673,817 \\
142,425 \\
4,289,153\end{array}$ & $\begin{array}{r}0 \\
9,974 \\
1,837 \\
11,811\end{array}$ & $\begin{array}{r}883 \\
3,837 \\
952 \\
6,194\end{array}$ & $\begin{array}{r}139,211 \\
0 \\
8,412 \\
748,911\end{array}$ \\
\hline 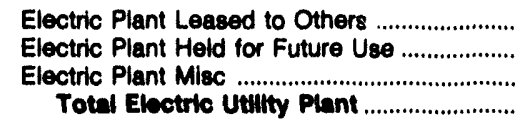 & $\begin{array}{r}0 \\
0 \\
0 \\
49,147\end{array}$ & $\begin{array}{r}0 \\
0 \\
0 \\
138,169\end{array}$ & $\begin{array}{r}0 \\
34,129 \\
0 \\
4,323,282\end{array}$ & $\begin{array}{r}0 \\
0 \\
3,266 \\
15,076\end{array}$ & $\begin{array}{r}0 \\
0 \\
0 \\
6,194\end{array}$ & $\begin{array}{r}403 \\
7,415 \\
415 \\
757,144\end{array}$ \\
\hline $\begin{array}{l}\text { Construction Work in Progress - Electric ....... } \\
\text { Accumulated Provision for }\end{array}$ & 437 & 1,184 & 98,333 & 597 & 0 & 113,192 \\
\hline 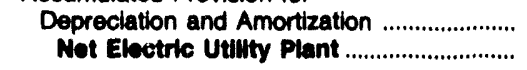 & $\begin{array}{l}17,808 \\
31,778\end{array}$ & $\begin{array}{r}35,291 \\
104,092\end{array}$ & $\begin{array}{r}633,919 \\
3,787,696\end{array}$ & $\begin{array}{r}4,884 \\
10,789\end{array}$ & $\begin{array}{l}3,442 \\
2,752\end{array}$ & $\begin{array}{l}219,846 \\
660,390\end{array}$ \\
\hline
\end{tabular}


Table 24. Electric Utillty Plant by Major U.S. Publlcly Owned Electric Utility Within State at End of Period, 1992 (Continued) (Thousand Dollars)

\begin{tabular}{|c|c|c|c|c|c|c|}
\hline Item & $\begin{array}{l}\text { Texas } \\
\text { Toledo Bend } \\
\text { Project } \\
\text { Joint } \\
\text { Oper } \\
\text { August } 30\end{array}$ & $\begin{array}{c}\text { Texas } \\
\text { Weatherlord } \\
\text { Mun } \\
\text { Utility } \\
\text { System } \\
\text { September } 30\end{array}$ & $\begin{array}{c}\text { Utah } \\
\text { Bountiful } \\
\text { City City of } \\
\text { June } 30\end{array}$ & $\begin{array}{c}\text { Utah } \\
\text { Intermountain } \\
\text { Power Agency } \\
\text { June } 30\end{array}$ & $\begin{array}{l}\text { Utah } \\
\text { Logan } \\
\text { City of } \\
\text { June } 30\end{array}$ & $\begin{array}{l}\text { Utah } \\
\text { Murray } \\
\text { City of } \\
\text { June } 30\end{array}$ \\
\hline 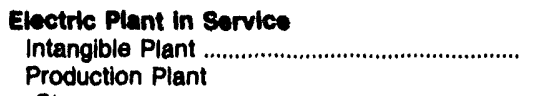 & 0 & 0 & 0 & 43,938 & 334 & 0 \\
\hline 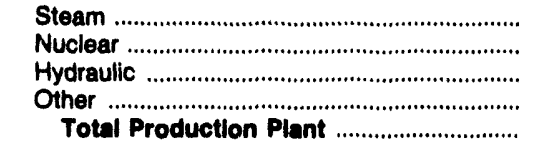 & $\begin{array}{r}0 \\
0 \\
71,179 \\
0 \\
71,179\end{array}$ & $\begin{array}{r}0 \\
0 \\
0 \\
971 \\
971\end{array}$ & $\begin{array}{r}0 \\
0 \\
8,499 \\
9,544 \\
18,043\end{array}$ & $\begin{array}{r}2,592,759 \\
0 \\
0 \\
0 \\
2,592,759\end{array}$ & $\begin{array}{r}0 \\
0 \\
12,981 \\
0 \\
12,981\end{array}$ & $\begin{array}{r}0 \\
0 \\
8,178 \\
1,838 \\
10,016\end{array}$ \\
\hline 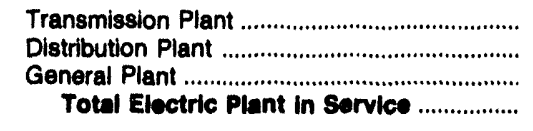 & $\begin{array}{r}0 \\
0 \\
1,067 \\
72,245\end{array}$ & $\begin{array}{r}0 \\
9,032 \\
1,214 \\
11,217\end{array}$ & $\begin{array}{r}4,340 \\
13,129 \\
3,523 \\
39,036\end{array}$ & $\begin{array}{r}43,666 \\
0 \\
112,100 \\
2,792,463\end{array}$ & $\begin{array}{r}1,021 \\
11,204 \\
2,238 \\
27,778\end{array}$ & $\begin{array}{r}4,313 \\
19,107 \\
6,097 \\
39,532\end{array}$ \\
\hline 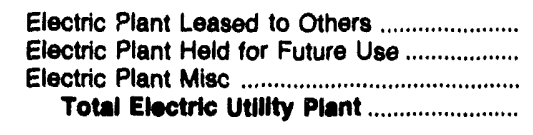 & $\begin{array}{r}0 \\
0 \\
0 \\
72,245\end{array}$ & $\begin{array}{r}0 \\
0 \\
0 \\
11,217\end{array}$ & $\begin{array}{r}0 \\
0 \\
0 \\
39,036\end{array}$ & $\begin{array}{r}0 \\
0 \\
0 \\
2,792,463\end{array}$ & $\begin{array}{r}0 \\
0 \\
0 \\
27,778\end{array}$ & $\begin{array}{r}0 \\
0 \\
0 \\
39,532\end{array}$ \\
\hline $\begin{array}{l}\text { Construction Work in Progress - Electric ....... } \\
\text { Accumulated Provision for }\end{array}$ & 0 & 0 & 656 & 39,166 & 192 & 58 \\
\hline 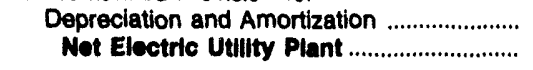 & $\begin{array}{r}0 \\
72,245\end{array}$ & $\begin{array}{l}6,100 \\
5,118\end{array}$ & $\begin{array}{l}15,214 \\
24,478\end{array}$ & $\begin{array}{r}433,032 \\
2,398,597\end{array}$ & $\begin{array}{r}8,189 \\
19,781\end{array}$ & $\begin{array}{l}17,742 \\
21,848\end{array}$ \\
\hline
\end{tabular}

\begin{tabular}{|c|c|c|c|c|c|c|}
\hline Item & $\begin{array}{l}\text { Utah } \\
\text { Provo } \\
\text { City Corp } \\
\text { June } 30\end{array}$ & $\begin{array}{l}\text { Utah } \\
\text { St George } \\
\text { City of } \\
\text { June } 30\end{array}$ & $\begin{array}{c}\text { Utah } \\
\text { Utah } \\
\text { Associated } \\
\text { Mun } \\
\text { Power Sys } \\
\text { March } 31\end{array}$ & $\begin{array}{c}\text { Utah } \\
\text { Utah } \\
\text { Municipal } \\
\text { Power Agency } \\
\text { June } 30\end{array}$ & $\begin{array}{c}\text { Vermont } \\
\text { Burlington } \\
\text { City of } \\
\text { December } 31\end{array}$ & $\begin{array}{l}\text { Vermont } \\
\text { Vermont } \\
\text { Public } \\
\text { Pwr } \\
\text { Supply Auth } \\
\text { December } 31\end{array}$ \\
\hline $\begin{array}{l}\text { Electrke Plant in Service } \\
\text { Intangible Plant ................................................ } \\
\text { Production Plant }\end{array}$ & 0 & 0 & 0 & 0 & 477 & 0 \\
\hline 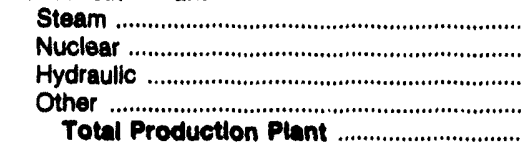 & $\begin{array}{r}41,363 \\
0 \\
0 \\
10,230 \\
\mathbf{5 1 , 5 9 3}\end{array}$ & $\begin{array}{r}0 \\
0 \\
554 \\
6,198 \\
6,752\end{array}$ & $\begin{array}{r}44,045 \\
0 \\
0 \\
0 \\
44,045\end{array}$ & $\begin{array}{r}25,705 \\
0 \\
0 \\
9 \\
26,714\end{array}$ & $\begin{array}{r}39,444 \\
0 \\
0 \\
3,474 \\
42,918\end{array}$ & $\begin{array}{r}16,805 \\
0 \\
0 \\
0 \\
16,805\end{array}$ \\
\hline 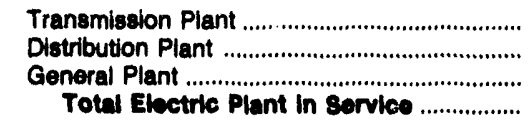 & $\begin{array}{r}8,900 \\
17,761 \\
3,791 \\
82,044\end{array}$ & $\begin{array}{r}7,841 \\
7,800 \\
1,981 \\
24,474\end{array}$ & $\begin{array}{r}22,303 \\
0 \\
0 \\
66,340\end{array}$ & $\begin{array}{r}8,020 \\
0 \\
0 \\
33,734\end{array}$ & $\begin{array}{r}3,674 \\
19,526 \\
5,158 \\
71,752\end{array}$ & $\begin{array}{r}2,955 \\
0 \\
747 \\
20,807\end{array}$ \\
\hline 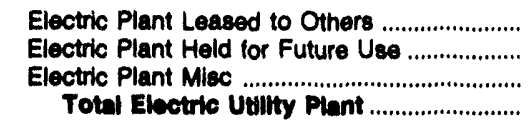 & $\begin{array}{r}0 \\
0 \\
0 \\
82,044\end{array}$ & $\begin{array}{r}0 \\
0 \\
0 \\
24,474\end{array}$ & $\begin{array}{r}0 \\
0 \\
0 \\
66,340\end{array}$ & $\begin{array}{r}0 \\
0 \\
0 \\
33,734\end{array}$ & $\begin{array}{r}0 \\
89 \\
0 \\
71,841\end{array}$ & $\begin{array}{r}0 \\
0 \\
0 \\
20,507\end{array}$ \\
\hline $\begin{array}{l}\text { Construction Work in Progress - Electric ........ } \\
\text { Accumulated Provision for }\end{array}$ & 0 & 0 & 8,148 & 0 & 51 & 0 \\
\hline $\begin{array}{l}\text { Depreclation and Amortization } \\
\text { Net Electile Utility Plant }\end{array}$ & $\begin{array}{l}29,238 \\
52,006\end{array}$ & $\begin{array}{r}7,236 \\
17,230\end{array}$ & $\begin{array}{l}14,540 \\
50,057\end{array}$ & $\begin{array}{r}5,515 \\
28,218\end{array}$ & $\begin{array}{l}16,499 \\
55,393\end{array}$ & $\begin{array}{r}7,160 \\
13,347\end{array}$ \\
\hline
\end{tabular}

Note: Totals may not equal sum of components because of independent rounding.

Source: Energy Information Administration, Form ElA-412, "Annual Report of Public Electric Utilities." 
Table 24. Electric Utility Plant by Major U.S. Publicly Owned Electric Utility Within State at End of Perlod, 1992 (Continued) (Thousand Dollars)

\begin{tabular}{|c|c|c|c|c|c|c|}
\hline Item & $\begin{array}{l}\text { Virginia } \\
\text { Bedford } \\
\text { City of } \\
\text { June } 30\end{array}$ & $\begin{array}{l}\text { Virginia } \\
\text { Bristol } \\
\text { Utilities } \\
\text { Board } \\
\text { June } 30\end{array}$ & $\begin{array}{l}\text { Virginia } \\
\text { Danville } \\
\text { Clty of } \\
\text { June } 30\end{array}$ & $\begin{array}{c}\text { Virginia } \\
\begin{array}{c}\text { Harrisonburg } \\
\text { City of }\end{array} \\
\text { June } 30\end{array}$ & $\begin{array}{c}\text { Virginia } \\
\begin{array}{c}\text { Manassas } \\
\text { City of }\end{array} \\
\text { June } 30\end{array}$ & $\begin{array}{l}\text { Virginia } \\
\begin{array}{c}\text { Martinsville } \\
\text { City of }\end{array} \\
\text { June } 30\end{array}$ \\
\hline 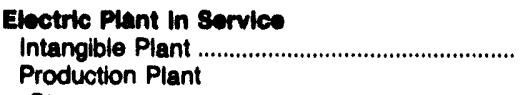 & 164 & 0 & 908 & 0 & 0 & 0 \\
\hline 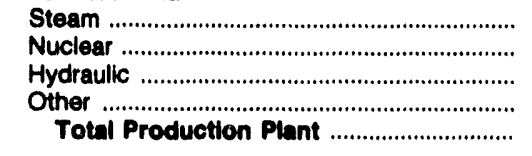 & $\begin{array}{r}0 \\
0 \\
11,084 \\
0 \\
11,084\end{array}$ & $\begin{array}{l}0 \\
0 \\
0 \\
0 \\
0\end{array}$ & $\begin{array}{r}0 \\
0 \\
2,983 \\
0 \\
2,983\end{array}$ & $\begin{array}{r}286 \\
0 \\
0 \\
2,385 \\
2,672\end{array}$ & $\begin{array}{l}0 \\
0 \\
0 \\
0 \\
0\end{array}$ & $\begin{array}{r}0 \\
0 \\
255 \\
0 \\
255\end{array}$ \\
\hline 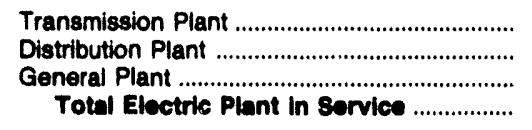 & $\begin{array}{r}2,196 \\
3,293 \\
527 \\
17,264\end{array}$ & $\begin{array}{r}0 \\
18,212 \\
2,755 \\
20,987\end{array}$ & $\begin{array}{r}1,847 \\
42,060 \\
2,212 \\
50,010\end{array}$ & $\begin{array}{r}4,572 \\
25,355 \\
3,017 \\
35,616\end{array}$ & $\begin{array}{r}15 \\
35,042 \\
0 \\
35,057\end{array}$ & $\begin{array}{r}0 \\
15,076 \\
711 \\
16,042\end{array}$ \\
\hline 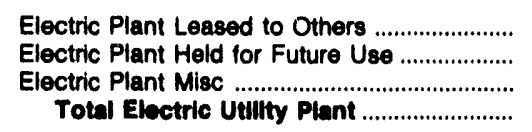 & $\begin{array}{r}0 \\
0 \\
0 \\
17,284\end{array}$ & $\begin{array}{r}0 \\
0 \\
0 \\
\mathbf{2 0 , 9 8 7}\end{array}$ & $\begin{array}{r}0 \\
0 \\
0 \\
\mathbf{5 0 , 0 1 0}\end{array}$ & $\begin{array}{r}0 \\
0 \\
3,753 \\
39,369\end{array}$ & $\begin{array}{r}0 \\
0 \\
0 \\
35,057\end{array}$ & $\begin{array}{r}0 \\
0 \\
0 \\
16,042\end{array}$ \\
\hline $\begin{array}{l}\text { Construction Work in Progress - Electric ........ } \\
\text { Accumulated Provision for }\end{array}$ & 0 & 1,042 & 1,392 & 1,287 & 72 & 0 \\
\hline 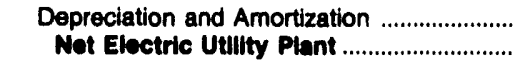 & $\begin{array}{r}4,457 \\
12,807\end{array}$ & $\begin{array}{l}10,047 \\
11,962\end{array}$ & $\begin{array}{l}21,336 \\
30,065\end{array}$ & $\begin{array}{l}12,299 \\
28,357\end{array}$ & $\begin{array}{r}9,896 \\
25,233\end{array}$ & $\begin{array}{r}5,408 \\
10,634\end{array}$ \\
\hline
\end{tabular}

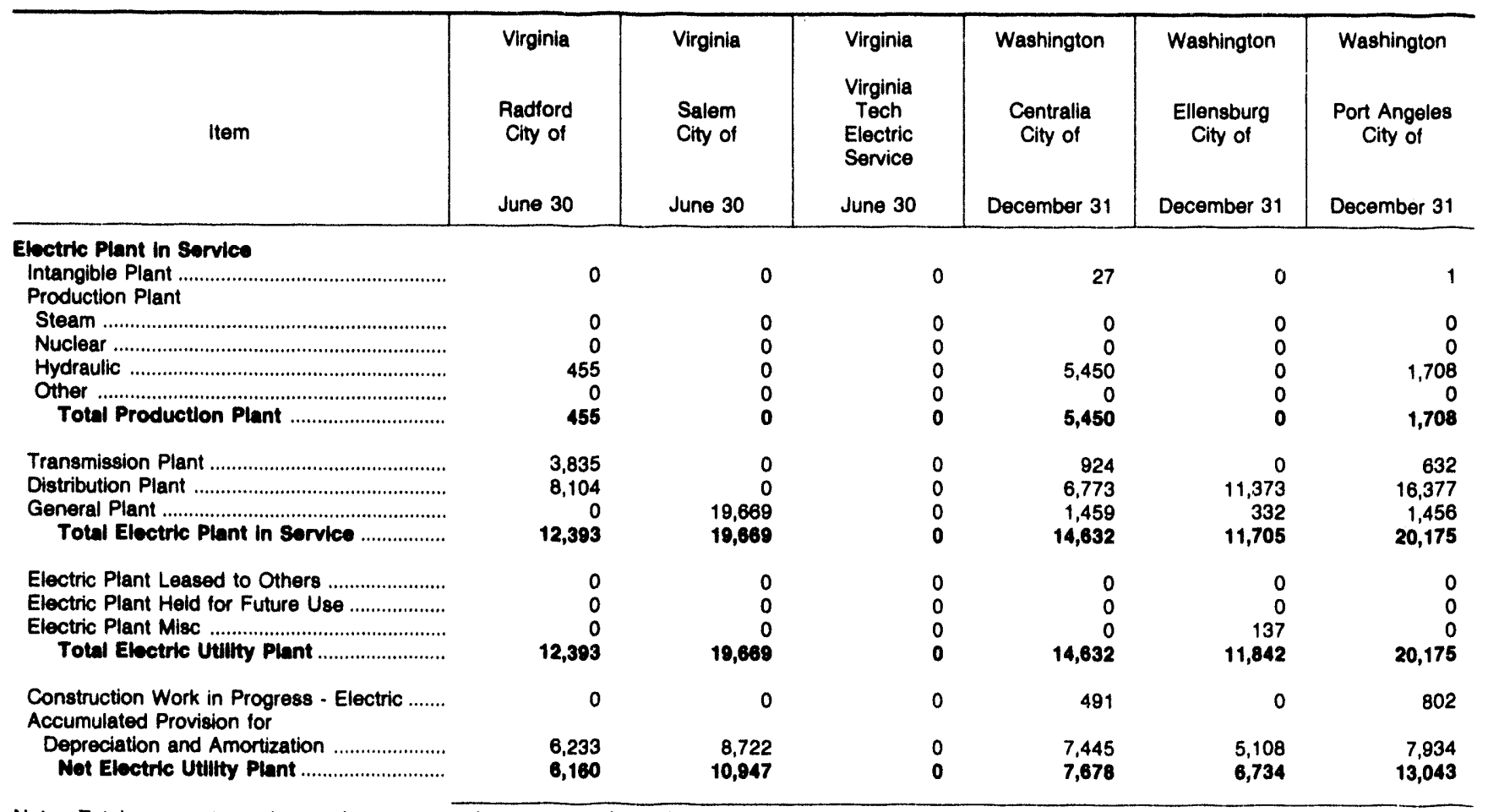

Note: Totals may not equal sum of components because of independent rounding.

Source: Energy Information Administration, Form EIA-412, "Annual Report of Public Electric Utilities." 
Table 24. Electric Utillty Plant by Major U.S. Publlcly Owned Electric Utility Within State at End of Period, 1992 (Continued) (Thousand Dollars)

\begin{tabular}{|c|c|c|c|c|c|c|}
\hline item & $\begin{array}{c}\text { Washington } \\
\text { PUD No } 1 \\
\text { of } \\
\text { Benton } \\
\text { County } \\
\text { December } 31\end{array}$ & $\begin{array}{c}\text { Washington } \\
\text { PUD No } 1 \\
\text { of } \\
\text { Chelan } \\
\text { County } \\
\text { December } 31\end{array}$ & $\begin{array}{l}\text { Washingtor. } \\
\text { PUD No } 1 \text { of } \\
\text { Clallam } \\
\text { County } \\
\text { December } 31\end{array}$ & $\begin{array}{c}\text { Washington } \\
\text { PUD No } 1 \\
\text { of } \\
\text { Clark } \\
\text { County } \\
\text { December } 31\end{array}$ & $\begin{array}{l}\text { Washington } \\
\text { PUD No } 1 \text { of } \\
\text { Cowlitz } \\
\text { County } \\
\text { December } 31\end{array}$ & $\begin{array}{l}\text { Washington } \\
\text { PUD No } 1 \text { of } \\
\text { Douglas } \\
\text { County } \\
\text { December } 31\end{array}$ \\
\hline $\begin{array}{l}\text { Electric Pient In Service } \\
\text { Intangible Plant .................................................. } \\
\text { Production Plant }\end{array}$ & 58 & 1,641 & 17 & 387 & 146 & 160 \\
\hline 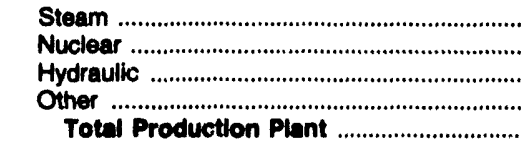 & $\begin{array}{l}0 \\
0 \\
0 \\
0 \\
0\end{array}$ & $\begin{array}{r}0 \\
0 \\
687,071 \\
0 \\
687,071\end{array}$ & $\begin{array}{l}0 \\
0 \\
0 \\
0 \\
0\end{array}$ & $\begin{array}{l}0 \\
0 \\
0 \\
0 \\
0\end{array}$ & $\begin{array}{r}0 \\
0 \\
19,513 \\
0 \\
19,513\end{array}$ & $\begin{array}{r}0 \\
0 \\
187,258 \\
0 \\
187,258\end{array}$ \\
\hline 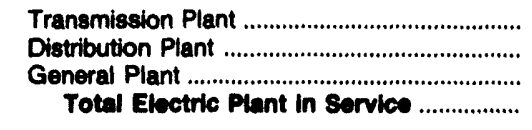 & $\begin{array}{r}2,394 \\
65,716 \\
7,829 \\
75,997\end{array}$ & $\begin{array}{r}44,574 \\
88,275 \\
19,589 \\
841,150\end{array}$ & $\begin{array}{r}4,871 \\
41,558 \\
7,432 \\
53,878\end{array}$ & $\begin{array}{r}7,388 \\
165,407 \\
23,334 \\
196,526\end{array}$ & $\begin{array}{r}7,700 \\
68,936 \\
10,993 \\
107,288\end{array}$ & $\begin{array}{r}19,382 \\
50,129 \\
8,257 \\
285,186\end{array}$ \\
\hline $\begin{array}{l}\text { Electric Plant Leased to Others ...................... } \\
\text { Electric Plant Held for Future Use } \\
\text { Electric Plant Misc ........................................................ } \\
\text { Total Electric Utilty Piant ........................ }\end{array}$ & $\begin{array}{r}0 \\
472 \\
0 \\
76,469\end{array}$ & $\begin{array}{r}0 \\
0 \\
0 \\
841,150\end{array}$ & $\begin{array}{r}0 \\
85 \\
0 \\
53,883\end{array}$ & $\begin{array}{r}611 \\
90 \\
2,593 \\
190,820\end{array}$ & $\begin{array}{r}0 \\
0 \\
0 \\
107,288\end{array}$ & $\begin{array}{r}0 \\
0 \\
862 \\
286,049\end{array}$ \\
\hline $\begin{array}{l}\text { Construction Work in Progress - Electric ....... } \\
\text { Accumulated Provision for }\end{array}$ & 1,788 & 18,885 & 2,025 & 4,988 & 352 & 5,019 \\
\hline 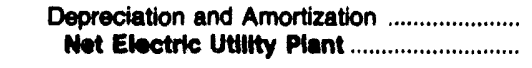 & $\begin{array}{l}31,012 \\
47,245\end{array}$ & $\begin{array}{l}143,508 \\
716,827\end{array}$ & $\begin{array}{l}26,723 \\
29,298\end{array}$ & $\begin{array}{r}77,503 \\
127,305\end{array}$ & $\begin{array}{l}45,933 \\
61,707\end{array}$ & $\begin{array}{r}41,914 \\
220,154\end{array}$ \\
\hline
\end{tabular}

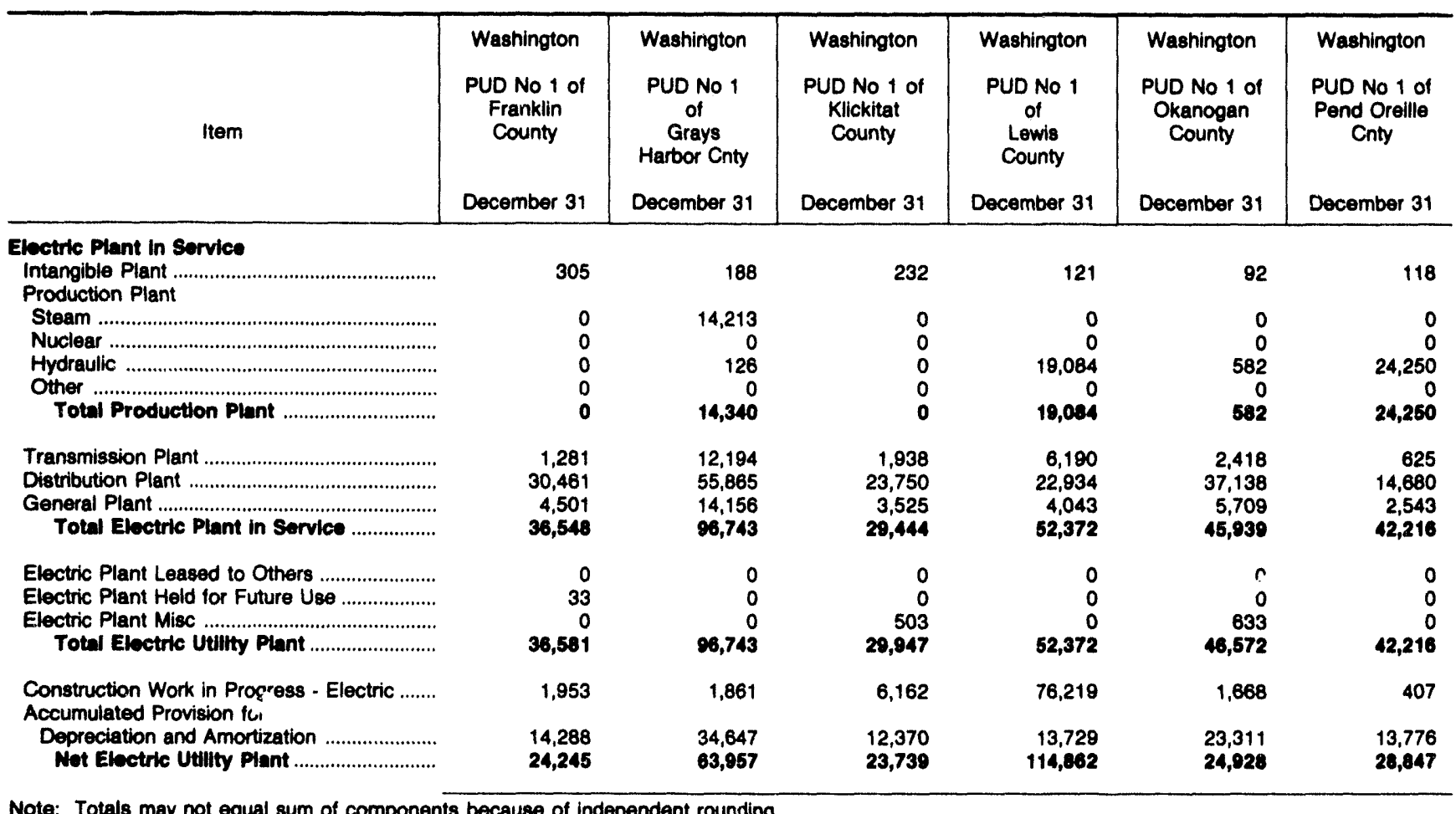

Note: Totals may not equal sum of components because of independent rounding.

Source: Energy Information Administration, Form EIA-412, "Annual Report of Public Electric Utilities." 
Table 24. Electric Utlilty Plant by Major U.S. Publicly Owned Electric Utility Within State at End of Period, 1992 (Continued) (Thousand Dollars)

\begin{tabular}{|c|c|c|c|c|c|c|}
\hline Item & $\begin{array}{l}\text { Washington } \\
\text { PUD No } 1 \text { of } \\
\text { Snohomish } \\
\text { County } \\
\text { December } 31\end{array}$ & $\begin{array}{l}\text { Washington } \\
\text { PUD No } 1 \text { of } \\
\text { Whatcom } \\
\text { County } \\
\text { December } 31\end{array}$ & $\begin{array}{c}\text { Washington } \\
\text { PUD No } 2 \\
\text { of } \\
\text { Grant } \\
\text { County } \\
\text { December } 31\end{array}$ & $\begin{array}{l}\text { Washington } \\
\text { PUD No } 2 \text { of } \\
\text { Pacific } \\
\text { County } \\
\text { December } 31\end{array}$ & $\begin{array}{c}\text { Washington } \\
\text { PUD No } 3 \\
\text { of } \\
\text { Mason } \\
\text { County } \\
\text { December } 31\end{array}$ & $\begin{array}{l}\text { Washington } \\
\text { Richland } \\
\text { City of } \\
\text { December } 31\end{array}$ \\
\hline 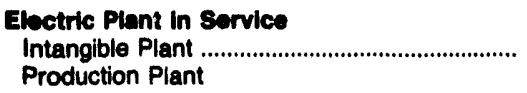 & 14 & 0 & 33,048 & 0 & 12 & 0 \\
\hline 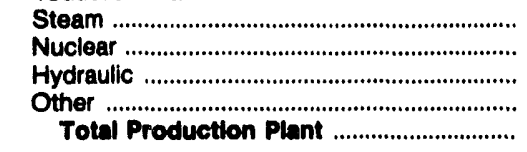 & $\begin{array}{r}28,664 \\
0 \\
208,396 \\
0 \\
237,090\end{array}$ & $\begin{array}{l}0 \\
0 \\
0 \\
0 \\
0\end{array}$ & $\begin{array}{r}0 \\
0 \\
316,536 \\
0 \\
318,536\end{array}$ & $\begin{array}{l}0 \\
0 \\
0 \\
0 \\
0\end{array}$ & $\begin{array}{l}0 \\
0 \\
0 \\
0 \\
0\end{array}$ & $\begin{array}{l}0 \\
0 \\
0 \\
0 \\
0\end{array}$ \\
\hline 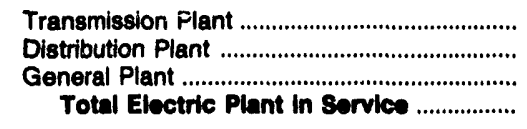 & $\begin{array}{r}34,284 \\
352,952 \\
72,033 \\
698,344\end{array}$ & $\begin{array}{r}926 \\
0 \\
69 \\
998\end{array}$ & $\begin{array}{r}50,478 \\
131,849 \\
44,281 \\
576,192\end{array}$ & $\begin{array}{r}1,191 \\
20,432 \\
2,449 \\
24,072\end{array}$ & $\begin{array}{r}945 \\
48,207 \\
4,206 \\
53,369\end{array}$ & $\begin{array}{r}659 \\
38,142 \\
1,376 \\
40,178\end{array}$ \\
\hline 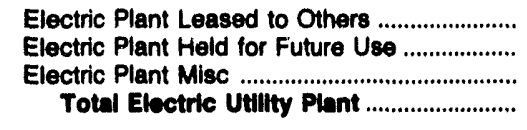 & $\begin{array}{r}0 \\
211 \\
0 \\
698,555\end{array}$ & $\begin{array}{r}0 \\
0 \\
0 \\
9\end{array}$ & $\begin{array}{r}0 \\
0 \\
584 \\
576,776\end{array}$ & $\begin{array}{r}0 \\
0 \\
0 \\
24,072\end{array}$ & $\begin{array}{r}0 \\
0 \\
0 \\
53,369\end{array}$ & $\begin{array}{r}0 \\
0 \\
0 \\
40,178\end{array}$ \\
\hline $\begin{array}{l}\text { Construction Work in Progress - Electric ....... } \\
\text { Accumulated Provision for }\end{array}$ & 28,498 & 148 & 43,661 & 5,184 & 5,766 & 1,125 \\
\hline $\begin{array}{l}\text { Depreciation and Amortization } \\
\text { Not Electric Utilty Plant }\end{array}$ & $\begin{array}{l}173,146 \\
551,007\end{array}$ & $\begin{array}{l}611 \\
533\end{array}$ & $\begin{array}{l}197,524 \\
422,013\end{array}$ & $\begin{array}{l}13,425 \\
16,832\end{array}$ & $\begin{array}{l}14,953 \\
44,182\end{array}$ & $\begin{array}{l}14,653 \\
26,650\end{array}$ \\
\hline
\end{tabular}

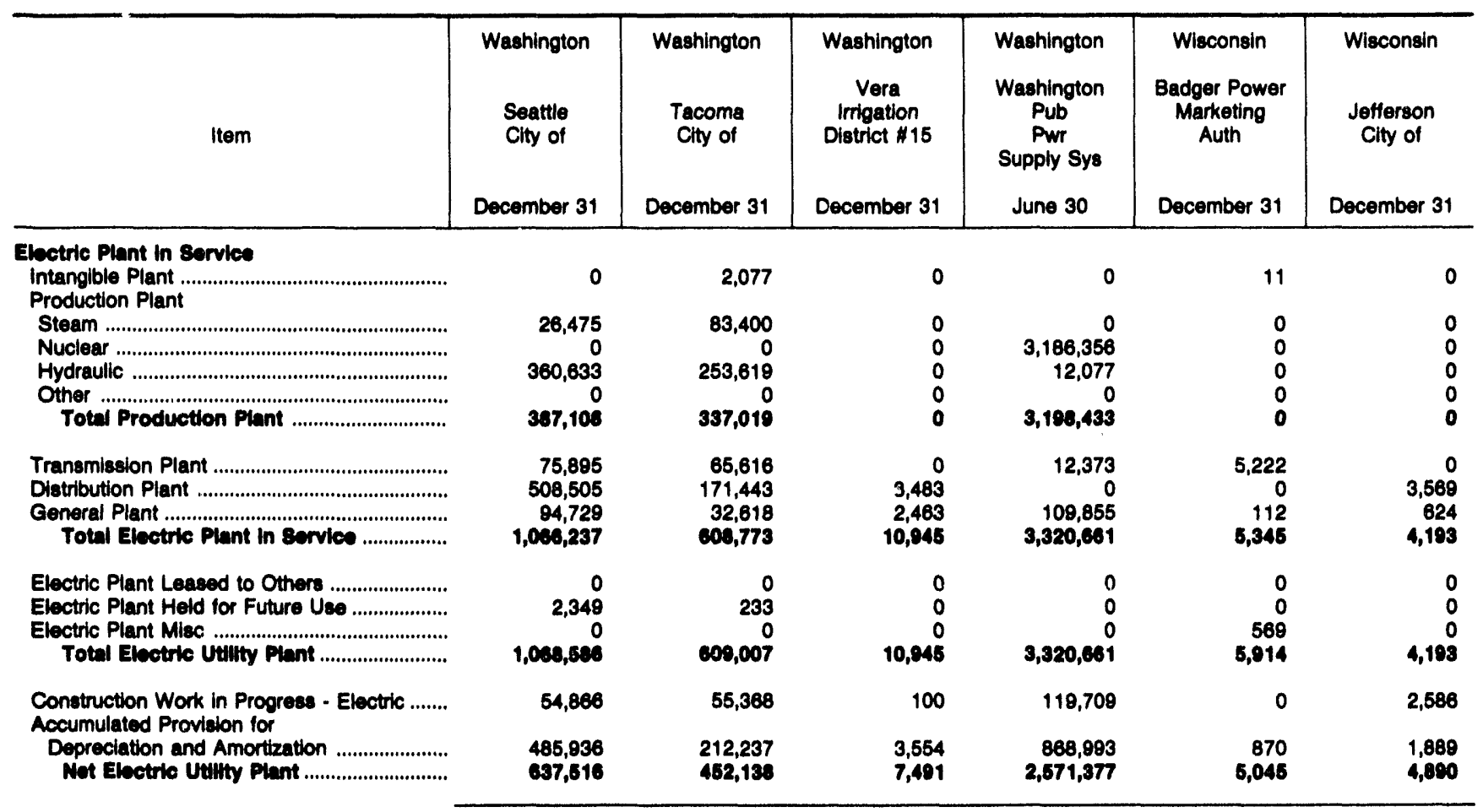

Note: Totais may not equal sum of component's because of independent rounding.

Source: Energy Information Adminiatration, Form EIA-412, "Annual Report of Public Electric Uttities." 
Table 24. Electric Utillty Plant by Major U.S. Publlcly Owned Electric Utility Within State at End of Period, 1992 (Continued) (Thousand Dollars)

\begin{tabular}{|c|c|c|c|c|c|c|}
\hline Item & $\begin{array}{c}\text { Wisconsin } \\
\text { Kaukauna } \\
\text { City of } \\
\text { December } 31\end{array}$ & $\begin{array}{l}\text { Wisconsin } \\
\text { Manitowoc } \\
\text { Public } \\
\text { Utilities } \\
\text { December } 31\end{array}$ & $\begin{array}{c}\text { Wisconsin } \\
\text { Marshitield } \\
\text { City of } \\
\text { December } 31\end{array}$ & $\begin{array}{c}\text { Wisconsin } \\
\text { Menasha } \\
\text { City of } \\
\text { December } 31\end{array}$ & $\begin{array}{l}\text { Wisconsin } \\
\text { New London } \\
\text { City of } \\
\text { December } 31\end{array}$ & $\begin{array}{c}\text { Wisconsin } \\
\text { Oconomowoc } \\
\text { City of } \\
\text { December } 31\end{array}$ \\
\hline 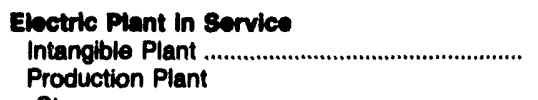 & 0 & 0 & 0 & 0 & 0 & 0 \\
\hline 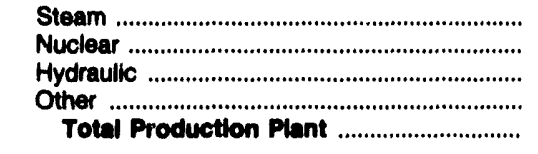 & $\begin{array}{r}0 \\
0 \\
16,113 \\
2,423 \\
18,635\end{array}$ & $\begin{array}{r}38,299 \\
0 \\
0 \\
6,110 \\
44,409\end{array}$ & $\begin{array}{r}636 \\
0 \\
0 \\
0 \\
638\end{array}$ & $\begin{array}{r}7,745 \\
0 \\
0 \\
122 \\
7,806\end{array}$ & $\begin{array}{l}0 \\
0 \\
0 \\
0 \\
0\end{array}$ & $\begin{array}{l}0 \\
0 \\
0 \\
0 \\
0\end{array}$ \\
\hline 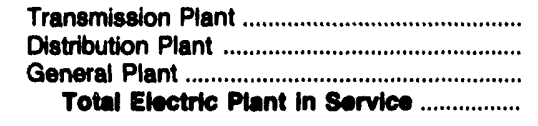 & $\begin{array}{r}1,029 \\
11,839 \\
2,775 \\
34,178\end{array}$ & $\begin{array}{r}2,979 \\
11,582 \\
3,000 \\
61,970\end{array}$ & $\begin{array}{r}7,212 \\
9,317 \\
1,688 \\
18,854\end{array}$ & $\begin{array}{r}1,568 \\
7,900 \\
857 \\
18,192\end{array}$ & $\begin{array}{r}372 \\
6,010 \\
1,179 \\
7,561\end{array}$ & $\begin{array}{r}0 \\
13,172 \\
756 \\
13,929\end{array}$ \\
\hline 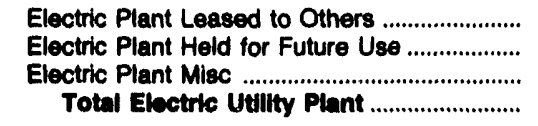 & $\begin{array}{r}0 \\
0 \\
0 \\
\mathbf{3 4 , 1 7 8}\end{array}$ & $\begin{array}{r}0 \\
203 \\
21 \\
62,195\end{array}$ & $\begin{array}{r}0 \\
0 \\
0 \\
18,854\end{array}$ & $\begin{array}{r}0 \\
61 \\
55 \\
18,307\end{array}$ & $\begin{array}{r}0 \\
0 \\
0 \\
7,561\end{array}$ & $\begin{array}{r}0 \\
0 \\
663 \\
14,591\end{array}$ \\
\hline $\begin{array}{l}\text { Construction Work in Progress - Electric ....... } \\
\text { Accumulated Provision for }\end{array}$ & 3,490 & 686 & 175 & 5,317 & 121 & 6 \\
\hline 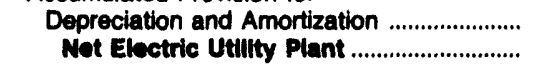 & $\begin{array}{l}14,844 \\
22,824\end{array}$ & $\begin{array}{l}19,636 \\
43,244\end{array}$ & $\begin{array}{r}5,909 \\
13,120\end{array}$ & $\begin{array}{l}10,467 \\
13,168\end{array}$ & $\begin{array}{l}1,839 \\
5,844\end{array}$ & $\begin{array}{l}4,755 \\
9,842\end{array}$ \\
\hline
\end{tabular}

\begin{tabular}{|c|c|c|c|c|c|c|}
\hline Item & $\begin{array}{l}\text { Wisconsin } \\
\text { Plymouth } \\
\text { Clty of } \\
\text { Decernber } 31\end{array}$ & $\begin{array}{l}\text { Wisconsin } \\
\text { Reedsburg } \\
\text { Utilty Comm } \\
\text { December } 31\end{array}$ & $\begin{array}{c}\text { Wisconsin } \\
\text { Shawano } \\
\text { Municipal } \\
\text { Utilities } \\
\text { December } 31\end{array}$ & $\begin{array}{c}\text { Wisconsin } \\
\text { Sheboygan } \\
\text { Falls } \\
\text { City of } \\
\text { December } 31\end{array}$ & $\begin{array}{l}\text { Wisconsin } \\
\text { Sturgeon Bay } \\
\text { Combined } \\
\text { Utils }\end{array}$ & $\begin{array}{l}\text { Wisconsin } \\
\text { Wisconsin } \\
\text { Public } \\
\text { Power } \\
\text { Inc Sys } \\
\text { June } 30\end{array}$ \\
\hline $\begin{array}{l}\text { Eloctric Plant in Service } \\
\text { Intangible Plant .................................................. } \\
\text { Production Plant }\end{array}$ & 0 & 0 & 0 & 0 & 0 & 15,931 \\
\hline 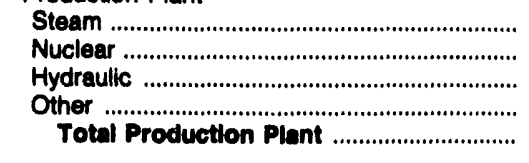 & $\begin{array}{l}0 \\
0 \\
0 \\
0 \\
0\end{array}$ & $\begin{array}{l}0 \\
0 \\
0 \\
0 \\
0\end{array}$ & $\begin{array}{l}0 \\
0 \\
0 \\
0 \\
0\end{array}$ & $\begin{array}{l}0 \\
0 \\
0 \\
0 \\
0\end{array}$ & $\begin{array}{l}0 \\
0 \\
0 \\
0 \\
0\end{array}$ & $\begin{array}{r}75,846 \\
0 \\
0 \\
0 \\
75,846\end{array}$ \\
\hline 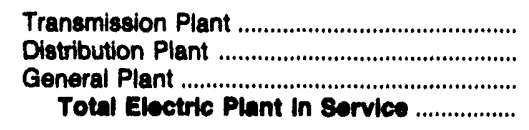 & $\begin{array}{r}218 \\
11,499 \\
942 \\
12,659\end{array}$ & $\begin{array}{r}641 \\
6,199 \\
571 \\
7,411\end{array}$ & $\begin{array}{r}353 \\
6,483 \\
1,076 \\
7,911\end{array}$ & $\begin{array}{r}512 \\
6,130 \\
880 \\
7,322\end{array}$ & $\begin{array}{r}2,153 \\
11,055 \\
2,215 \\
15,423\end{array}$ & $\begin{array}{r}0 \\
0 \\
4,374 \\
96,151\end{array}$ \\
\hline 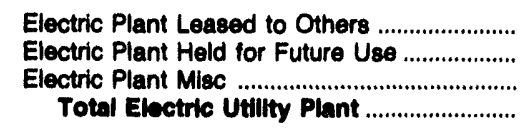 & $\begin{array}{r}0 \\
0 \\
0 \\
12,650\end{array}$ & $\begin{array}{r}0 \\
0 \\
38 \\
7,440\end{array}$ & $\begin{array}{r}0 \\
0 \\
0 \\
7,011\end{array}$ & $\begin{array}{r}0 \\
0 \\
0 \\
7,322\end{array}$ & $\begin{array}{r}0 \\
0 \\
0 \\
15,423\end{array}$ & $\begin{array}{r}0 \\
0 \\
15,117 \\
111,268\end{array}$ \\
\hline $\begin{array}{l}\text { Construction Work in Progress - Electric ........ } \\
\text { Accumulated Provision for }\end{array}$ & 11 & 5 & 77 & 16 & 126 & 26,330 \\
\hline 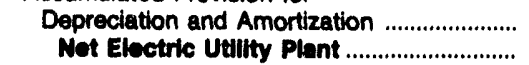 & $\begin{array}{l}5,217 \\
7,454\end{array}$ & $\begin{array}{l}1,970 \\
5,484\end{array}$ & $\begin{array}{l}2,487 \\
5,601\end{array}$ & $\begin{array}{l}2,775 \\
4,663\end{array}$ & $\begin{array}{r}4,273 \\
11,276\end{array}$ & $\begin{array}{r}28,184 \\
109,413\end{array}$ \\
\hline
\end{tabular}

Note: Totals may not equal sum of components because of independent rounding.

Source: Energy Information Administration, Form ElA-412, "Annual Report of Public Electric Utilities." 
Table 24. Electric Utility Plant by Major U.S. Publicly Owned Electric Utility Within State at End of Perlod, 1992 (Continued)

(Thousand Dollars)

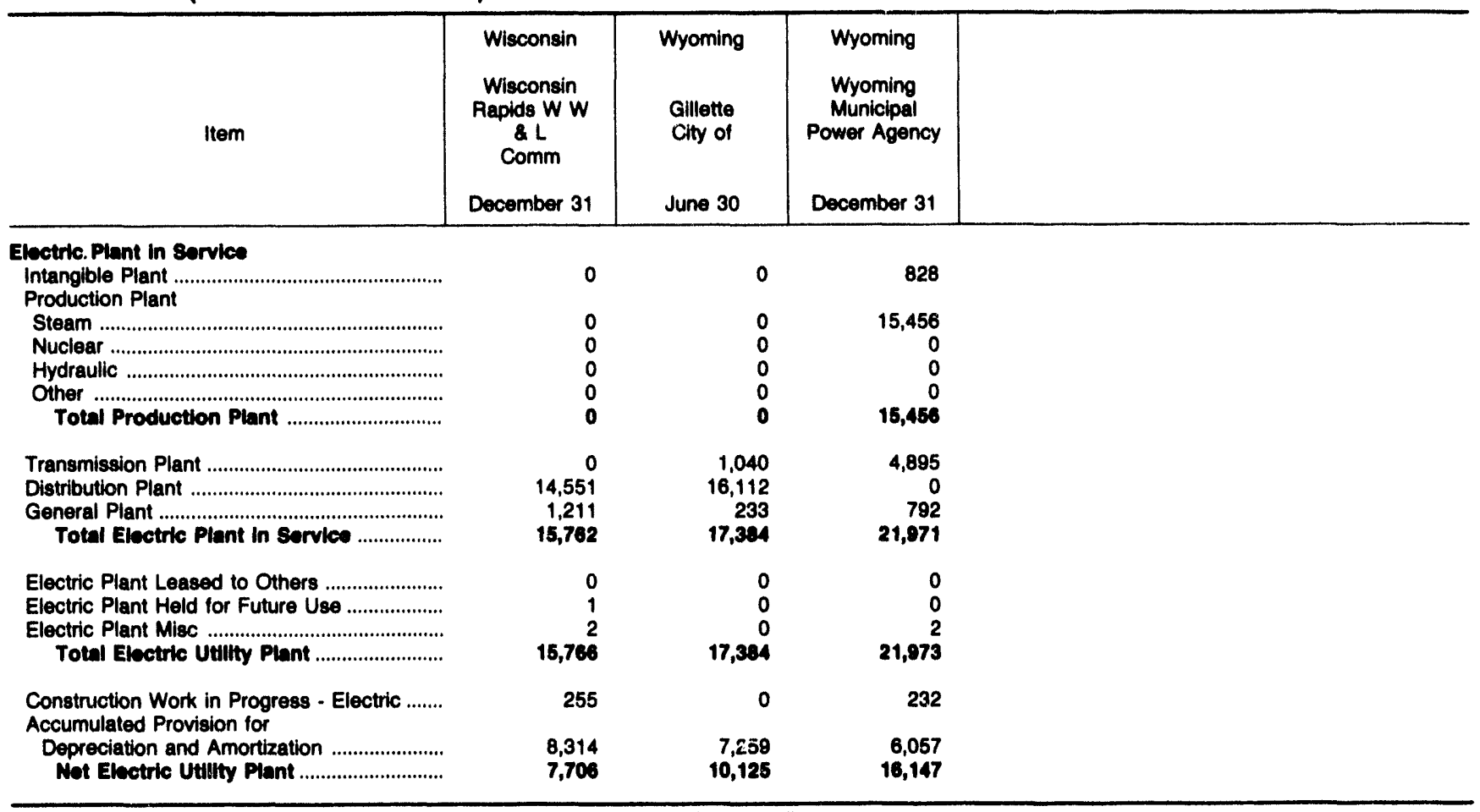

Note: Totals may not equal sum of components because of independent rounding.

Source: Energy Information Administration, Form ElA-412, "Annual Report of Public Electric Utilities." 
Table 25. Number of Consumers, Sales, and Operating Revenue by Major U.S. Publicly Owned Electric Utility Within State, 1992

\begin{tabular}{|c|c|c|c|c|c|c|}
\hline Item & $\begin{array}{l}\text { Alabama } \\
\text { Alabama } \\
\text { Municipal } \\
\text { Elec Auth } \\
\text { December } 31\end{array}$ & $\begin{array}{c}\text { Alabama } \\
\text { Albertville } \\
\text { Municipal } \\
\text { Utils Bd } \\
\text { December } 31\end{array}$ & $\begin{array}{c}\text { Alabama } \\
\text { Andalusia } \\
\text { City of } \\
\text { December } 31\end{array}$ & $\begin{array}{c}\text { Alabama } \\
\text { Athens } \\
\text { City of } \\
\text { December } 31\end{array}$ & $\begin{array}{c}\text { Alabama } \\
\text { Bessemer } \\
\text { City of } \\
\text { December } 31\end{array}$ & $\begin{array}{c}\text { Alabama } \\
\text { Cullman } \\
\text { Power Board } \\
\text { December } 31\end{array}$ \\
\hline \multicolumn{7}{|l|}{ Number of Consumers } \\
\hline 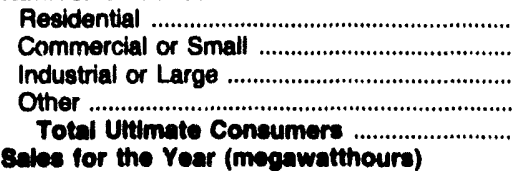 & $\begin{array}{l}0 \\
0 \\
0 \\
0 \\
0\end{array}$ & $\begin{array}{r}6,606 \\
1,329 \\
144 \\
8 \\
8,087\end{array}$ & $\begin{array}{r}3,707 \\
686 \\
46 \\
6 \\
4,445\end{array}$ & $\begin{array}{r}23,107 \\
3,534 \\
277 \\
71 \\
26,989\end{array}$ & $\begin{array}{r}11,149 \\
1,268 \\
165 \\
22 \\
12,604\end{array}$ & $\begin{array}{r}5,887 \\
1,362 \\
189 \\
36 \\
7,474\end{array}$ \\
\hline 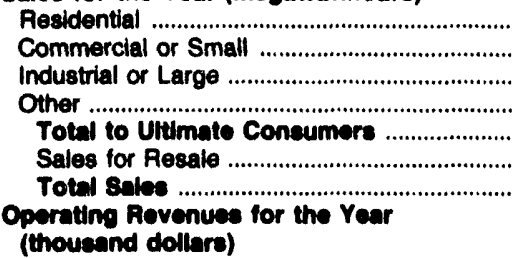 & $\begin{array}{r}0 \\
0 \\
0 \\
0 \\
0 \\
2,252,354 \\
2,252,354\end{array}$ & $\begin{array}{r}96,410 \\
26,805 \\
282,734 \\
3,619 \\
409,668 \\
0 \\
409,668\end{array}$ & $\begin{array}{r}40,154 \\
20,338 \\
235,261 \\
1,060 \\
298,813 \\
0 \\
296,813\end{array}$ & $\begin{array}{r}367,599 \\
59,404 \\
157,315 \\
7,555 \\
591,873 \\
0 \\
591,873\end{array}$ & $\begin{array}{r}118,602 \\
43,305 \\
134,087 \\
5,470 \\
301,464 \\
0 \\
301,464\end{array}$ & $\begin{array}{r}86,813 \\
34,334 \\
160,127 \\
6,134 \\
287,408 \\
0 \\
287,408\end{array}$ \\
\hline 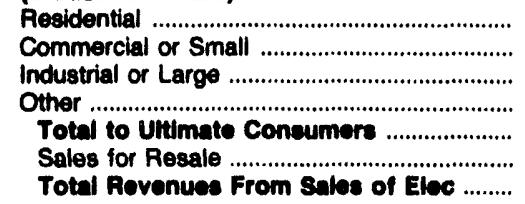 & $\begin{array}{r}0 \\
0 \\
0 \\
0 \\
0 \\
88,400 \\
88,400\end{array}$ & $\begin{array}{r}5,328 \\
1,731 \\
11,738 \\
274 \\
19,071 \\
0 \\
18,071\end{array}$ & $\begin{array}{r}2,756 \\
1,568 \\
9,120 \\
101 \\
13,545 \\
0 \\
13,545\end{array}$ & $\begin{array}{r}20,814 \\
3,989 \\
8,855 \\
701 \\
34,359 \\
0 \\
34,359\end{array}$ & $\begin{array}{r}7,136 \\
2,799 \\
6,361 \\
406 \\
16,702 \\
0 \\
18,702\end{array}$ & $\begin{array}{r}4,794 \\
2,192 \\
8,675 \\
360 \\
16,021 \\
0 \\
16,021\end{array}$ \\
\hline
\end{tabular}

\begin{tabular}{|c|c|c|c|c|c|c|}
\hline Item & $\begin{array}{l}\text { Alabama } \\
\text { Decatur } \\
\text { City of } \\
\text { December } 31\end{array}$ & $\begin{array}{l}\text { Alabama } \\
\text { Dothan } \\
\text { City of } \\
\text { December } 31\end{array}$ & $\begin{array}{c}\text { Alabama } \\
\text { Florence } \\
\text { City of } \\
\text { December } 31\end{array}$ & $\begin{array}{c}\text { Alabama } \\
\text { Foley } \\
\text { City of } \\
\text { (Riviera Utils) } \\
\text { December } 31\end{array}$ & $\begin{array}{c}\text { Alabama } \\
\text { Fort Payne } \\
\text { Improvement } \\
\text { Auth }\end{array}$ & $\begin{array}{c}\text { Alabama } \\
\text { Guntersville } \\
\text { Electric } \\
\text { Board } \\
\text { December } 31\end{array}$ \\
\hline \multicolumn{7}{|l|}{ Number of Consumers } \\
\hline 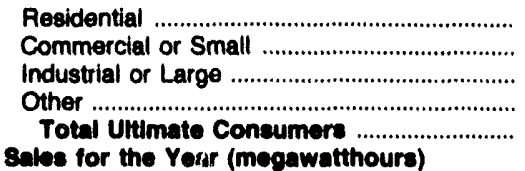 & $\begin{array}{r}20,704 \\
2,598 \\
366 \\
60 \\
23,728\end{array}$ & $\begin{array}{r}21,973 \\
3,408 \\
242 \\
249 \\
25,872\end{array}$ & $\begin{array}{r}33,610 \\
5,013 \\
523 \\
247 \\
39,393\end{array}$ & $\begin{array}{r}18,118 \\
3,504 \\
4 \\
84 \\
21,710\end{array}$ & $\begin{array}{r}5,686 \\
1,278 \\
199 \\
6 \\
7,169\end{array}$ & $\begin{array}{r}4,325 \\
999 \\
109 \\
30 \\
5,463\end{array}$ \\
\hline 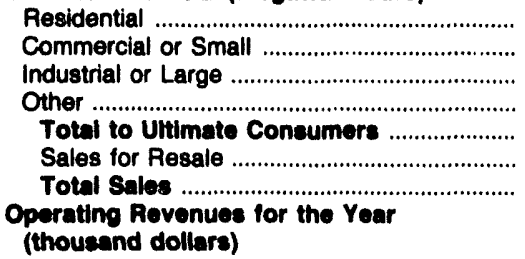 & $\begin{array}{r}342,113 \\
78,324 \\
921,008 \\
7,184 \\
1,348,629 \\
0 \\
1,348,629\end{array}$ & $\begin{array}{r}330,969 \\
107,038 \\
282,136 \\
180,144 \\
900,287 \\
0 \\
900,287\end{array}$ & $\begin{array}{r}529,495 \\
95,001 \\
298,766 \\
8,889 \\
932,151 \\
0 \\
932,151\end{array}$ & $\begin{array}{r}254,153 \\
134,742 \\
39,545 \\
8,614 \\
437,054 \\
0 \\
437,054\end{array}$ & $\begin{array}{r}81,343 \\
28,426 \\
150,789 \\
4,963 \\
265,521 \\
0 \\
265,521\end{array}$ & $\begin{array}{r}58,317 \\
20,802 \\
124,521 \\
4,014 \\
207,654 \\
0 \\
207,654\end{array}$ \\
\hline 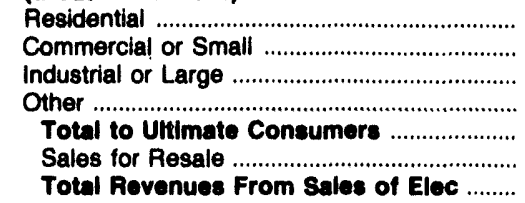 & $\begin{array}{r}17,514 \\
4,557 \\
36,482 \\
666 \\
59,219 \\
0 \\
59,219\end{array}$ & $\begin{array}{r}20,487 \\
8,087 \\
15,968 \\
5,523 \\
50,065 \\
0 \\
50,065\end{array}$ & $\begin{array}{r}30,610 \\
6,451 \\
17,514 \\
934 \\
55,509 \\
0 \\
55,509\end{array}$ & $\begin{array}{r}17,482 \\
9,953 \\
2,329 \\
709 \\
30,473 \\
0 \\
30,473\end{array}$ & $\begin{array}{r}4,714 \\
1,923 \\
8,276 \\
330 \\
15,243 \\
0 \\
15,243\end{array}$ & $\begin{array}{r}3,338 \\
1,375 \\
6,343 \\
251 \\
11,307 \\
0 \\
11,307\end{array}$ \\
\hline
\end{tabular}

Note: Totals may not equal sum of components because of independent rounding.

Source: Energy Information Administration, Form ElA-861, "Annual Electric Utility Report." Data are submitted on a calendar year. 
Table 25. Number of Consumers, Sales, and Operating Revenue by Major U.S. Publicly Owned Electric Utility Within State, 1992 (Continued)

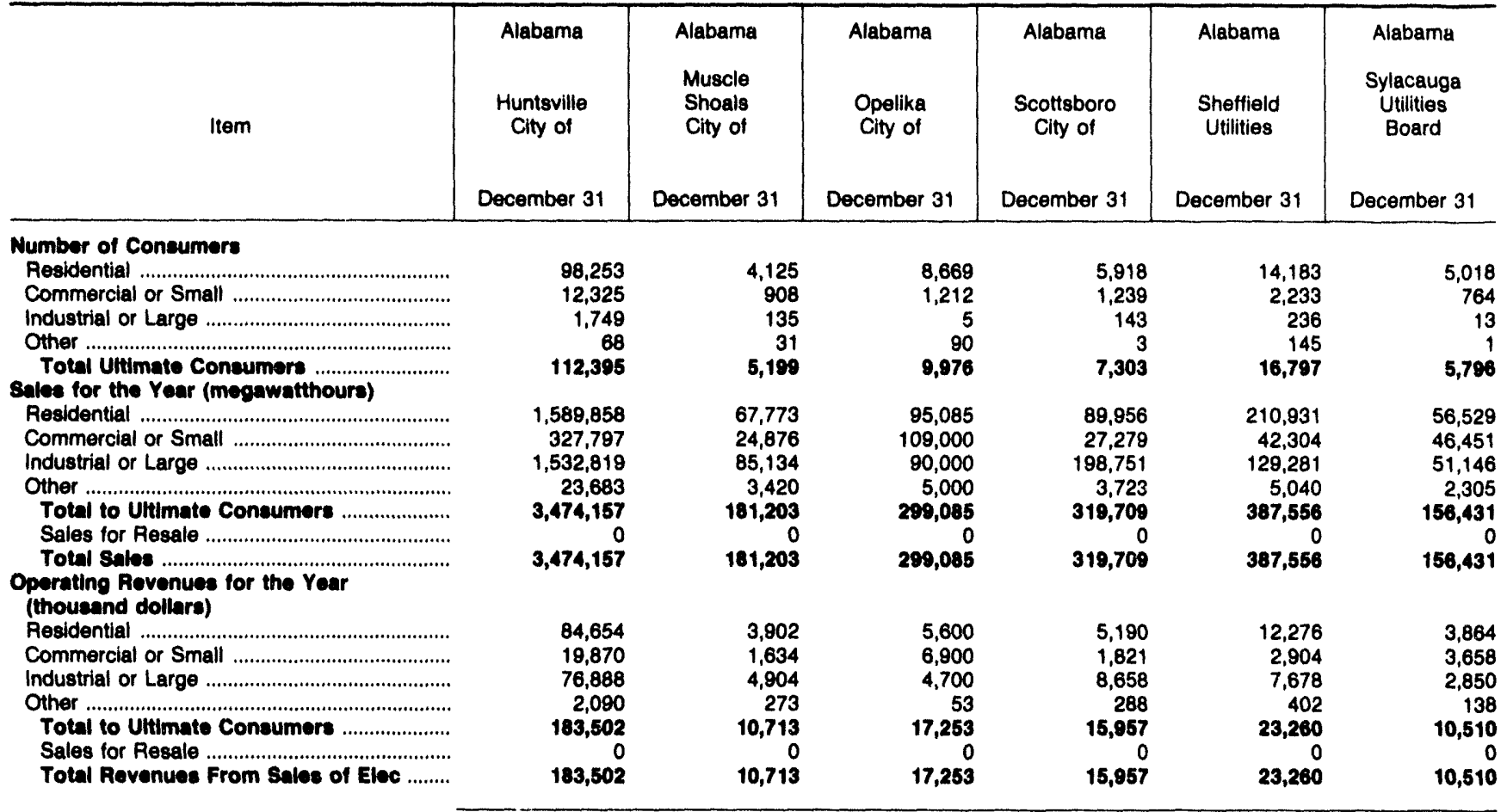

\begin{tabular}{|c|c|c|c|c|c|c|}
\hline ltem & $\begin{array}{c}\text { Alabama } \\
\text { Troy } \\
\text { City of } \\
\text { December } 31\end{array}$ & $\begin{array}{l}\text { Alabama } \\
\text { Tuskegee } \\
\text { City of } \\
\text { December } 31\end{array}$ & $\begin{array}{c}\text { Alaska } \\
\text { Alaska } \\
\text { Energy } \\
\text { Authority } \\
\text { December } 31\end{array}$ & $\begin{array}{c}\text { Alaska } \\
\text { Anchorage } \\
\text { City of } \\
\text { December } 31\end{array}$ & $\begin{array}{l}\text { Alaska } \\
\text { Fairbanks } \\
\text { City of } \\
\text { December } 31\end{array}$ & $\begin{array}{c}\text { Alaska } \\
\text { Ketchikan } \\
\text { City of } \\
\text { December } 31\end{array}$ \\
\hline \multicolumn{7}{|l|}{ Number of Consumere } \\
\hline 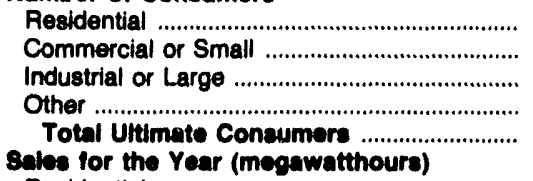 & $\begin{array}{r}4,947 \\
919 \\
106 \\
62 \\
6,034\end{array}$ & $\begin{array}{r}6,431 \\
622 \\
75 \\
0 \\
7,128\end{array}$ & $\begin{array}{l}0 \\
0 \\
0 \\
0 \\
0\end{array}$ & $\begin{array}{r}23,504 \\
5,500 \\
0 \\
3 \\
29,007\end{array}$ & $\begin{array}{r}4,435 \\
1,502 \\
1 \\
52 \\
5,990\end{array}$ & $\begin{array}{r}5,739 \\
951 \\
11 \\
1 \\
6,702\end{array}$ \\
\hline 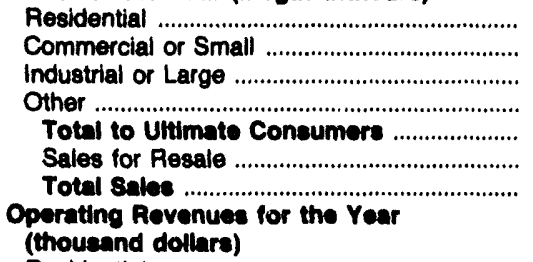 & $\begin{array}{r}70,001 \\
19,644 \\
110,553 \\
1,400 \\
201,598 \\
0 \\
201,598\end{array}$ & $\begin{array}{r}48,546 \\
12,572 \\
63,359 \\
0 \\
124,477 \\
0 \\
124,477\end{array}$ & $\begin{array}{r}0 \\
0 \\
0 \\
0 \\
0 \\
620,768 \\
620,766\end{array}$ & $\begin{array}{r}143,451 \\
636,184 \\
0 \\
9,075 \\
788,710 \\
17,125 \\
805,835\end{array}$ & $\begin{array}{r}26,392 \\
108,619 \\
162 \\
12,057 \\
147,230 \\
0 \\
147,230\end{array}$ & $\begin{array}{r}55,849 \\
54,822 \\
28,896 \\
712 \\
140,370 \\
0 \\
140,370\end{array}$ \\
\hline 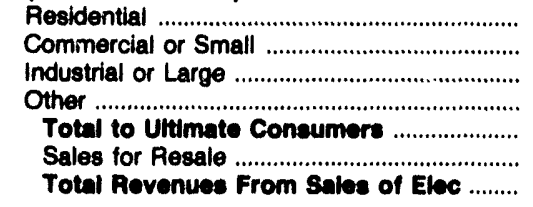 & $\begin{array}{r}3,770 \\
1,223 \\
6,178 \\
88 \\
11,250 \\
0 \\
11,259\end{array}$ & $\begin{array}{r}4,095 \\
1,028 \\
3,234 \\
0 \\
8,357 \\
0 \\
8,357\end{array}$ & $\begin{array}{r}0 \\
0 \\
0 \\
0 \\
0 \\
28,141 \\
28,141\end{array}$ & $\begin{array}{r}13,820 \\
50,122 \\
0 \\
1,267 \\
65,209 \\
610 \\
65,819\end{array}$ & $\begin{array}{r}2,527 \\
11,109 \\
6 \\
1,475 \\
15,117 \\
0 \\
15,117\end{array}$ & $\begin{array}{r}4,832 \\
4,321 \\
1,146 \\
144 \\
10,443 \\
0 \\
10,443\end{array}$ \\
\hline
\end{tabular}

Note: Totals may not equal sum of components because of independent rounding.

Source: Energy Information Administration, Form ElA-861, "Annual Electric Utility Report." Data are submitted on a calendar year. 
Table 25. Number of Consumers, Sales, and Operating Revenue by Major U.S. Publicly Owned Electrlc Utility Within State, 1992 (Continued)

\begin{tabular}{|c|c|c|c|c|c|c|}
\hline Item & $\begin{array}{c}\text { Arizona } \\
\text { Arizona } \\
\text { Power } \\
\text { Authority } \\
\text { December } 31\end{array}$ & $\begin{array}{c}\text { Arizona } \\
\text { Electrical } \\
\text { Dist } \\
\text { No2 } \\
\text { Pinal Cnty } \\
\text { December } 31\end{array}$ & $\begin{array}{c}\text { Arizona } \\
\text { Mesa } \\
\text { City of } \\
\text { December } 31\end{array}$ & $\begin{array}{c}\text { Arizona } \\
\text { Navajo } \\
\text { Tribal } \\
\text { Utility } \\
\text { Auth } \\
\text { December } 31\end{array}$ & $\begin{array}{l}\text { Arizona } \\
\text { Sait River } \\
\text { Proj Ag } \\
\text { I \& P Dist } \\
\text { Decamber } 31\end{array}$ & $\begin{array}{l}\text { Arizona } \\
\text { Tohono } \\
\text { OOdham } \\
\text { Utility Auth } \\
\text { December } 31\end{array}$ \\
\hline 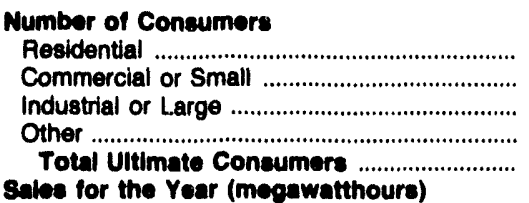 & $\begin{array}{l}0 \\
0 \\
0 \\
0 \\
0\end{array}$ & $\begin{array}{r}1,919 \\
277 \\
22 \\
452 \\
2,670\end{array}$ & $\begin{array}{r}12,376 \\
2,073 \\
0 \\
131 \\
14,580\end{array}$ & $\begin{array}{r}22,340 \\
2,561 \\
4 \\
8,200 \\
33,105\end{array}$ & $\begin{array}{r}500,545 \\
42,310 \\
38 \\
8,855 \\
551,757\end{array}$ & $\begin{array}{r}2,424 \\
366 \\
1 \\
20 \\
2,811\end{array}$ \\
\hline 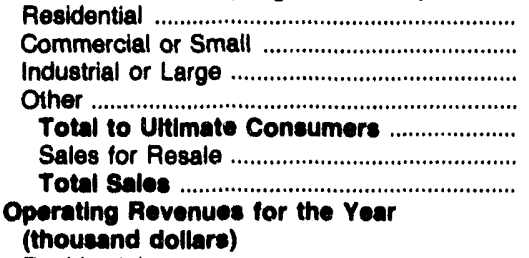 & $\begin{array}{r}0 \\
0 \\
0 \\
0 \\
0 \\
692,340 \\
692,340\end{array}$ & $\begin{array}{r}25,042 \\
9,512 \\
34,002 \\
60,955 \\
129,511 \\
6,425 \\
135,936\end{array}$ & $\begin{array}{r}118,972 \\
147,253 \\
0 \\
36,900 \\
303,125 \\
6,542 \\
309,687\end{array}$ & $\begin{array}{r}100,377 \\
140,051 \\
258,077 \\
17,708 \\
516,213 \\
0 \\
516,213\end{array}$ & $\begin{array}{r}6,536,797 \\
5,148,912 \\
3,059,210 \\
608,382 \\
15,353,301 \\
4,018,753 \\
19,372,054\end{array}$ & $\begin{array}{r}16,653 \\
17,875 \\
145,197 \\
3,010 \\
182,735 \\
0 \\
182,735\end{array}$ \\
\hline 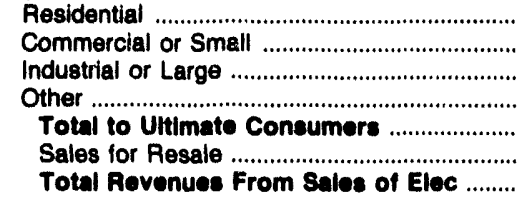 & $\begin{array}{r}0 \\
0 \\
0 \\
0 \\
0 \\
17,381 \\
17,381\end{array}$ & $\begin{array}{r}2,055 \\
931 \\
2,264 \\
1,805 \\
7,055 \\
92 \\
7,147\end{array}$ & $\begin{array}{r}9,835 \\
10,991 \\
0 \\
2,005 \\
22,831 \\
144 \\
22,975\end{array}$ & $\begin{array}{r}6,494 \\
9,987 \\
13,283 \\
1,564 \\
31,328 \\
0 \\
31,328\end{array}$ & $\begin{array}{r}571,058 \\
381,868 \\
152,134 \\
45,992 \\
1,161,052 \\
100,842 \\
1,251,894\end{array}$ & $\begin{array}{r}1,010 \\
1,028 \\
6,368 \\
267 \\
8,673 \\
0 \\
0 \\
8,673\end{array}$ \\
\hline
\end{tabular}

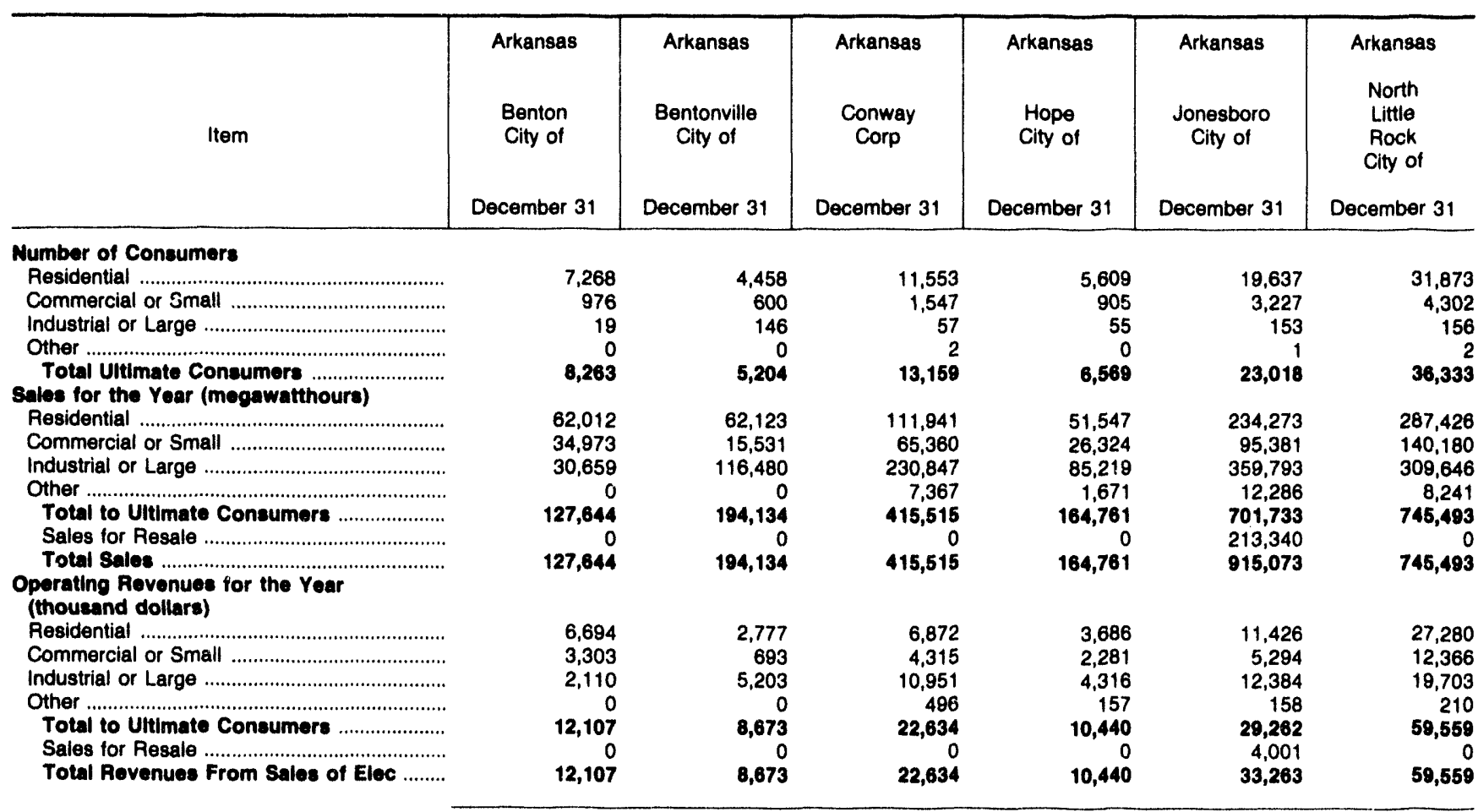

Note: Totals may not equal sum of components because of independent rounding

Source: Energy information Administration, Form EIA-861, "Annual Electric Utility Report." Data are submitted on a calendar year. 
Table 25. Number of Consumers, Sales, and Operating Revenue by Major U.S. Publicly Owned Electric Utillty Within State, 1992 (Continued)

\begin{tabular}{|c|c|c|c|c|c|c|}
\hline Item & $\begin{array}{c}\text { Arkansas } \\
\text { Osceola } \\
\text { City of } \\
\text { December } 31\end{array}$ & $\begin{array}{c}\text { Arkansas } \\
\text { Paragould } \\
\text { Light } \\
\& \\
\text { Water Comm } \\
\text { December } 31\end{array}$ & $\begin{array}{l}\text { Arkansas } \\
\text { Siloam } \\
\text { Springs } \\
\text { City of } \\
\text { December } 31\end{array}$ & $\begin{array}{l}\text { Arkansas } \\
\text { West } \\
\text { Memphis } \\
\text { City of } \\
\text { December } 31\end{array}$ & $\begin{array}{l}\text { Calliornia } \\
\text { Alameda } \\
\text { City of } \\
\text { December } 31\end{array}$ & $\begin{array}{l}\text { California } \\
\text { Anaheim } \\
\text { City of } \\
\text { December } 31\end{array}$ \\
\hline \multicolumn{7}{|l|}{ Number of Concumere } \\
\hline 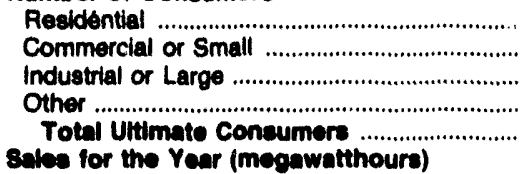 & $\begin{array}{r}3,121 \\
510 \\
20 \\
0 \\
3,651\end{array}$ & $\begin{array}{r}7,919 \\
1,252 \\
48 \\
2,160 \\
11,379\end{array}$ & $\begin{array}{r}3,719 \\
523 \\
78 \\
0 \\
4,320\end{array}$ & $\begin{array}{r}9,900 \\
1,258 \\
0 \\
42 \\
11,200\end{array}$ & $\begin{array}{r}27,784 \\
3,132 \\
3 \\
214 \\
31,133\end{array}$ & $\begin{array}{r}87,110 \\
14,671 \\
580 \\
674 \\
103,035\end{array}$ \\
\hline 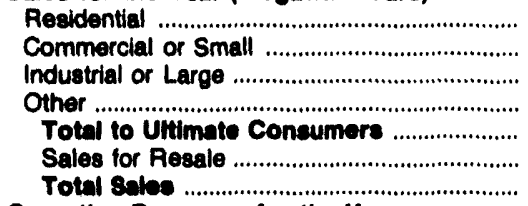 & $\begin{array}{r}38,131 \\
18,567 \\
121,736 \\
0 \\
178,434 \\
0 \\
178,434\end{array}$ & $\begin{array}{r}112,595 \\
45,080 \\
146,690 \\
4,329 \\
308,694 \\
4,872 \\
313,568\end{array}$ & $\begin{array}{r}35,180 \\
9,367 \\
118,308 \\
0 \\
162,855 \\
0 \\
162,856\end{array}$ & $\begin{array}{r}118,581 \\
148,734 \\
0 \\
3,443 \\
270,758 \\
0 \\
270,758\end{array}$ & $\begin{array}{r}125,349 \\
177,361 \\
179,806 \\
8,996 \\
491,512 \\
0 \\
491,612\end{array}$ & $\begin{array}{r}533,448 \\
509,104 \\
1,151,918 \\
84,867 \\
2,280,337 \\
414,245 \\
2,703,592\end{array}$ \\
\hline $\begin{array}{l}\text { Operating Revenues for the Year } \\
\text { (thousand dollara) }\end{array}$ & & & & & & \\
\hline 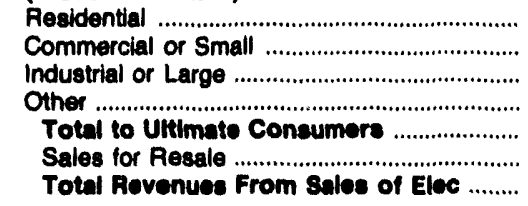 & $\begin{array}{r}2,473 \\
1,259 \\
5,197 \\
0 \\
8,829 \\
0 \\
8,929\end{array}$ & $\begin{array}{r}4,493 \\
1,883 \\
4,535 \\
207 \\
11,118 \\
83 \\
11,201\end{array}$ & $\begin{array}{r}2,248 \\
751 \\
5,850 \\
0 \\
8,840 \\
0 \\
8,840\end{array}$ & $\begin{array}{r}7,671 \\
9,517 \\
0 \\
189 \\
17,377 \\
0 \\
17,377\end{array}$ & $\begin{array}{r}13,013 \\
16,960 \\
12,578 \\
943 \\
43,494 \\
0 \\
43,494\end{array}$ & $\begin{array}{r}50,328 \\
52,281 \\
98,470 \\
8,165 \\
209,244 \\
7,832 \\
217,070\end{array}$ \\
\hline
\end{tabular}

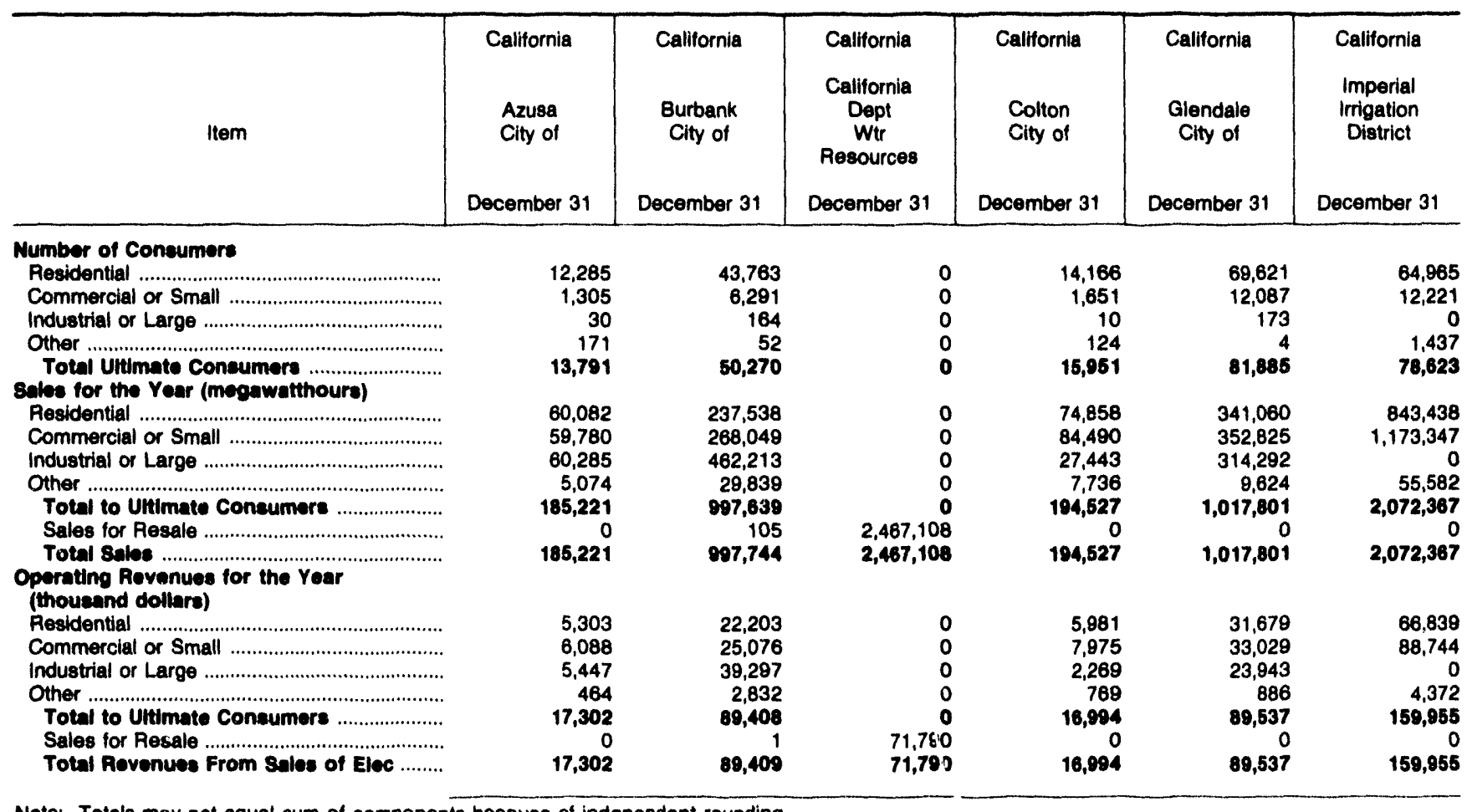

Note: Totals may not equal sum of components because of independent rounding.

Source: Energy Information Administration, Form ElA-861, "Annual Electric Utility Report." Data are submitted on a calendar year. 
Table 25. Number of Consumers, Sales, and Operating Revenue by Major U.S. Publicly Owned Electric Utility Withln State, 1992 (Continued)

\begin{tabular}{|c|c|c|c|c|c|c|}
\hline ltem & $\begin{array}{l}\text { California } \\
\text { Lodi } \\
\text { City of } \\
\text { December } 31\end{array}$ & $\begin{array}{c}\text { Calliornia } \\
\text { Los Angeles } \\
\text { City of } \\
\text { December } 31\end{array}$ & $\begin{array}{c}\text { Callfornia } \\
\text { Metropolitan } \\
\text { Water } \\
\text { District } \\
\text { December } 31\end{array}$ & $\begin{array}{c}\text { Callfornia } \\
\text { Modesto } \\
\text { Irrigation } \\
\text { District } \\
\text { December } 31\end{array}$ & $\begin{array}{c}\text { California } \\
\text { MSR } \\
\text { Public } \\
\text { Power } \\
\text { Agency } \\
\text { December } 31\end{array}$ & $\begin{array}{c}\text { California } \\
\text { Northern } \\
\text { California } \\
\text { Power Agny } \\
\text { December } 31\end{array}$ \\
\hline 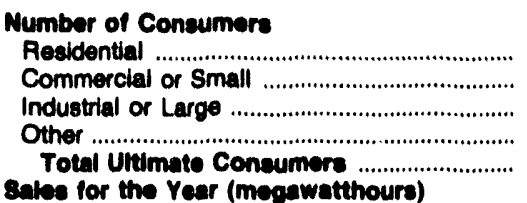 & $\begin{array}{r}18,817 \\
2,915 \\
23 \\
250 \\
22,005\end{array}$ & $\begin{array}{r}1,168,524 \\
170,191 \\
17,873 \\
4,345 \\
1,380,933\end{array}$ & $\begin{array}{l}0 \\
0 \\
0 \\
0 \\
0\end{array}$ & $\begin{array}{r}75,597 \\
9,961 \\
43 \\
1,614 \\
87,215\end{array}$ & $\begin{array}{l}0 \\
0 \\
0 \\
0 \\
0\end{array}$ & $\begin{array}{l}0 \\
0 \\
0 \\
0 \\
0\end{array}$ \\
\hline 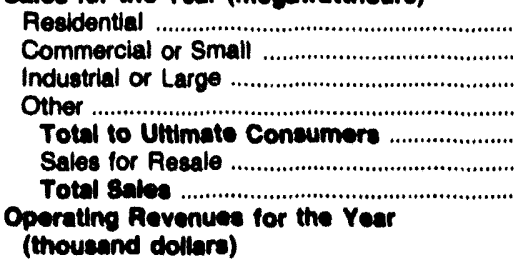 & $\begin{array}{r}127,430 \\
122,454 \\
103,424 \\
8,090 \\
381,398 \\
0 \\
361,388\end{array}$ & $\begin{array}{r}6,202,474 \\
11,915,166 \\
2,862,859 \\
839,285 \\
21,819,784 \\
411,239 \\
22,231,023\end{array}$ & $\begin{array}{r}0 \\
0 \\
0 \\
0 \\
0 \\
305,344 \\
305,344\end{array}$ & $\begin{array}{r}676,061 \\
627,836 \\
431,808 \\
70,137 \\
1,805,842 \\
43,733 \\
1,849,575\end{array}$ & $\begin{array}{r}0 \\
0 \\
0 \\
0 \\
0 \\
796,866 \\
788,886\end{array}$ & $\begin{array}{r}0 \\
0 \\
0 \\
0 \\
0 \\
1,789,180 \\
1,789,180\end{array}$ \\
\hline 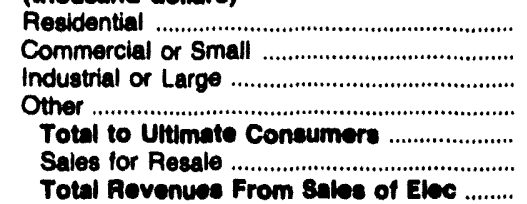 & $\begin{array}{r}13,318 \\
12,566 \\
7,943 \\
771 \\
34,598 \\
0 \\
34,598\end{array}$ & $\begin{array}{r}569,689 \\
1,024,076 \\
222,649 \\
68,083 \\
1,884,497 \\
10,069 \\
1,895,168\end{array}$ & $\begin{array}{r}0 \\
0 \\
0 \\
0 \\
0 \\
13,902 \\
13,902\end{array}$ & $\begin{array}{r}46,733 \\
50,305 \\
24,901 \\
4,620 \\
128,559 \\
1,126 \\
127,685\end{array}$ & $\begin{array}{r}0 \\
0 \\
0 \\
0 \\
0 \\
44,100 \\
44,100\end{array}$ & $\begin{array}{r}0 \\
0 \\
0 \\
0 \\
0 \\
156,937 \\
156,937\end{array}$ \\
\hline
\end{tabular}

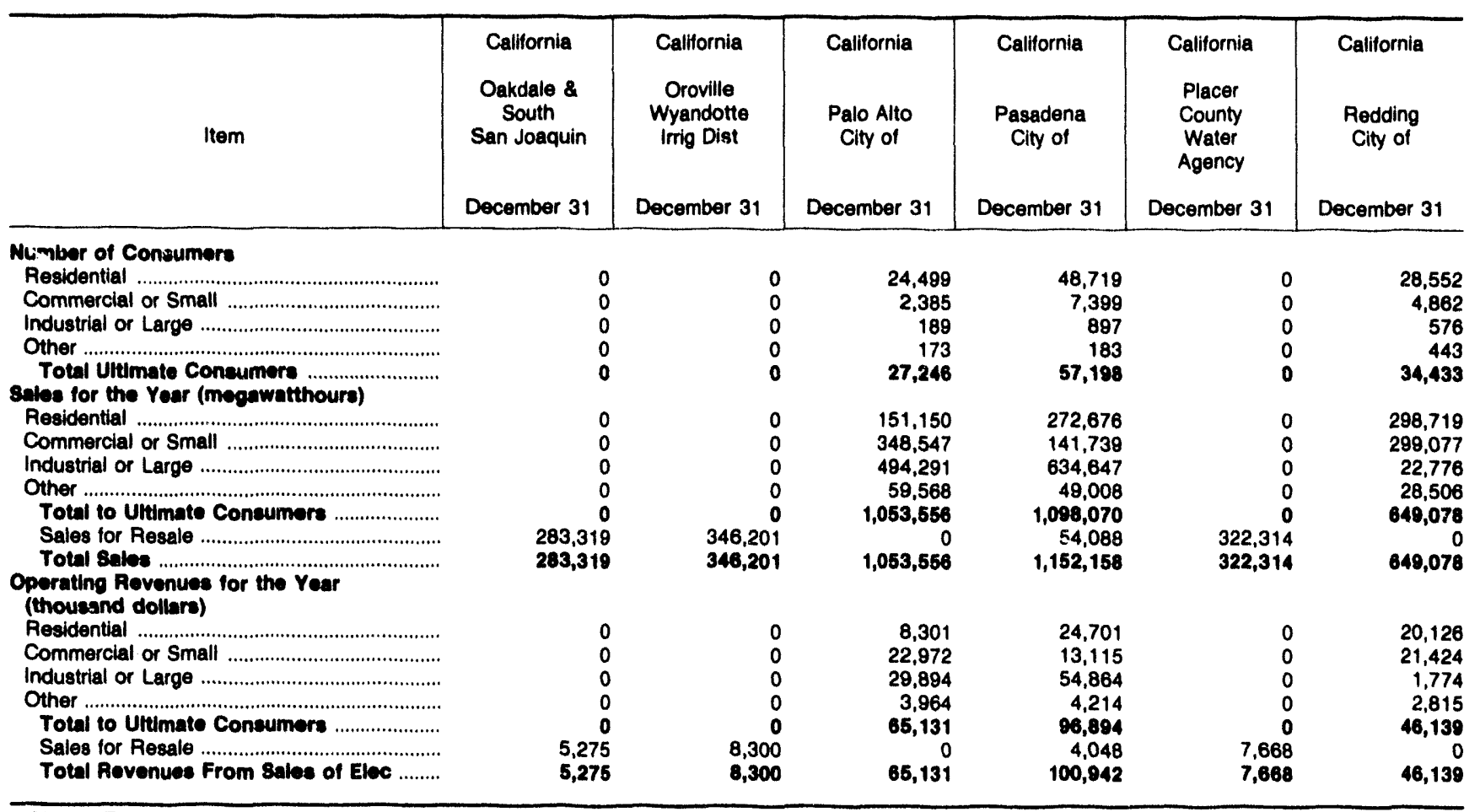

Note: Totals may not equal sum of components because of independentrounding.

Source: Energy Information Administration, Form ElA-861, "Annual Electric Utility Report." Data are submitted on a calendar year. 
Table 25. Number of Consumers, Sales, and Operating Revenue by Major U.S. Publicly Owned Electric Utllity Within State, 1992 (Continued)

\begin{tabular}{|c|c|c|c|c|c|c|}
\hline Item & $\begin{array}{l}\text { California } \\
\text { Piverside } \\
\text { City of } \\
\text { December } 31\end{array}$ & $\begin{array}{c}\text { California } \\
\text { Roseville } \\
\text { City of } \\
\text { December } 31\end{array}$ & $\begin{array}{l}\text { California } \\
\text { Sacramento } \\
\text { Municipal } \\
\text { Util Dist } \\
\text { December } 31\end{array}$ & $\begin{array}{c}\text { California } \\
\text { San Francisco } \\
\text { City } \\
\& \\
\text { County of } \\
\text { December } 31\end{array}$ & $\begin{array}{l}\text { California } \\
\text { Santa } \\
\text { Clara } \\
\text { City of } \\
\text { December } 31\end{array}$ & $\begin{array}{l}\text { California } \\
\text { Southern } \\
\text { California } \\
\text { P P } \\
\text { A } \\
\text { December } 31\end{array}$ \\
\hline \multicolumn{7}{|l|}{ Number of Consumers } \\
\hline 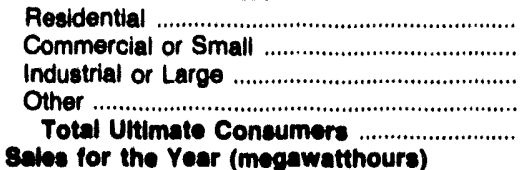 & $\begin{array}{r}79,877 \\
8,481 \\
181 \\
147 \\
89,686\end{array}$ & $\begin{array}{r}21,165 \\
2,756 \\
27 \\
256 \\
24,204\end{array}$ & $\begin{array}{r}414,149 \\
43,599 \\
7,175 \\
1,577 \\
486,500\end{array}$ & $\begin{array}{r}0 \\
6 \\
7 \\
2 \\
15\end{array}$ & $\begin{array}{r}38,013 \\
5,300 \\
1,461 \\
634 \\
\mathbf{4 5 , 4 0 8}\end{array}$ & $\begin{array}{l}0 \\
0 \\
0 \\
0 \\
0\end{array}$ \\
\hline 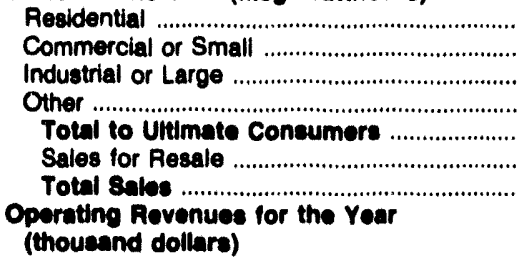 & $\begin{array}{r}551,899 \\
397,562 \\
555,437 \\
41,858 \\
1,546,756 \\
109,903 \\
1,656,658\end{array}$ & $\begin{array}{r}177,198 \\
149,160 \\
186,170 \\
25,045 \\
537,573 \\
0 \\
537,573\end{array}$ & $\begin{array}{r}3,620,303 \\
743,647 \\
4,037,452 \\
69,800 \\
8,471,202 \\
0 \\
8,471,202\end{array}$ & $\begin{array}{r}0 \\
455 \\
71,648 \\
543,216 \\
615,319 \\
999,552 \\
1,614,87\end{array}$ & $\begin{array}{r}196,690 \\
90,951 \\
1,935,261 \\
17,548 \\
2,240,450 \\
108,617 \\
2,349,067\end{array}$ & $\begin{array}{r}0 \\
0 \\
0 \\
0 \\
0 \\
1,434,034 \\
1,434,034\end{array}$ \\
\hline 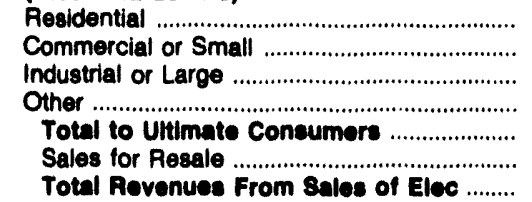 & $\begin{array}{r}54,686 \\
39,431 \\
45,970 \\
4,501 \\
144,588 \\
2,197 \\
149,705\end{array}$ & $\begin{array}{r}14,214 \\
12,415 \\
13,219 \\
2,138 \\
41,986 \\
0 \\
41,986\end{array}$ & $\begin{array}{r}296,640 \\
63,138 \\
296,458 \\
4,704 \\
660,940 \\
0 \\
660,940\end{array}$ & $\begin{array}{r}0 \\
20 \\
1,683 \\
29,604 \\
31,307 \\
34,552 \\
65,859\end{array}$ & $\begin{array}{r}13,916 \\
9,337 \\
143,076 \\
1,398 \\
167,727 \\
4,021 \\
171,748\end{array}$ & $\begin{array}{r}0 \\
0 \\
0 \\
0 \\
0 \\
123,031 \\
123,031\end{array}$ \\
\hline
\end{tabular}

\begin{tabular}{|c|c|c|c|c|c|c|}
\hline Item & $\begin{array}{l}\text { California } \\
\text { Turlock } \\
\text { Irrigation } \\
\text { District } \\
\text { December } 31\end{array}$ & $\begin{array}{l}\text { California } \\
\text { Vernon } \\
\text { City of } \\
\text { December } 31\end{array}$ & $\begin{array}{l}\text { California } \\
\text { Yuba } \\
\text { County } \\
\text { Water } \\
\text { Agency } \\
\text { December } 31\end{array}$ & $\begin{array}{l}\text { Colorado } \\
\text { Arkansas } \\
\text { River } \\
\text { Power } \\
\text { Authority } \\
\text { December } 31\end{array}$ & $\begin{array}{l}\text { Colorado } \\
\text { Colorado } \\
\text { Springs } \\
\text { City of } \\
\text { December } 31\end{array}$ & $\begin{array}{l}\text { Colorado } \\
\text { Fort Collins } \\
\text { City of } \\
\text { December } 31\end{array}$ \\
\hline 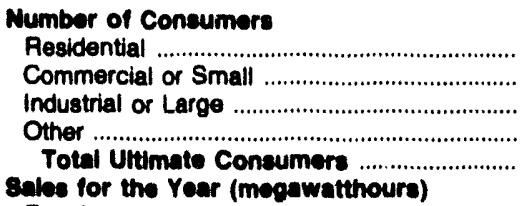 & $\begin{array}{r}48,114 \\
5,748 \\
793 \\
4,692 \\
60,347\end{array}$ & $\begin{array}{r}28 \\
997 \\
856 \\
96 \\
1,977\end{array}$ & $\begin{array}{l}0 \\
0 \\
0 \\
0 \\
0\end{array}$ & $\begin{array}{l}0 \\
0 \\
0 \\
0\end{array}$ & $\begin{array}{r}130,076 \\
17,639 \\
311 \\
836 \\
148,862\end{array}$ & $\begin{array}{r}33,831 \\
4,716 \\
11 \\
1 \\
38,569\end{array}$ \\
\hline 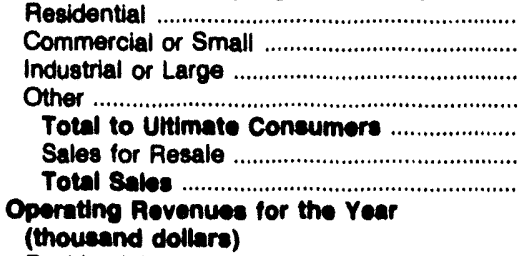 & $\begin{array}{r}461,734 \\
113,219 \\
457,319 \\
157,350 \\
1,180,622 \\
21,507 \\
1,211,129\end{array}$ & $\begin{array}{r}124 \\
234,864 \\
787,610 \\
4,881 \\
1,027,479 \\
0 \\
1,027,479\end{array}$ & $\begin{array}{r}0 \\
0 \\
0 \\
0 \\
0 \\
621,064 \\
621,084\end{array}$ & $\begin{array}{r}0 \\
0 \\
0 \\
0 \\
0 \\
265,274 \\
265,274\end{array}$ & $\begin{array}{r}921,691 \\
741,762 \\
1,137,070 \\
72,761 \\
2,873,284 \\
126,313 \\
2,999,697\end{array}$ & $\begin{array}{r}258,285 \\
280,909 \\
279,019 \\
1,795 \\
821,008 \\
0 \\
821,008\end{array}$ \\
\hline 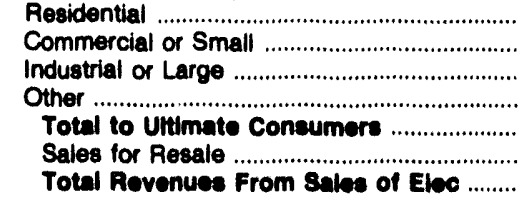 & $\begin{array}{r}36,483 \\
11,016 \\
33,340 \\
8,980 \\
89,029 \\
1,044 \\
\mathbf{8 0 , 8 7 3}\end{array}$ & $\begin{array}{r}4 \\
14,822 \\
41,057 \\
434 \\
56,317 \\
0 \\
56,317\end{array}$ & $\begin{array}{r}0 \\
0 \\
0 \\
0 \\
0 \\
7,700 \\
7,700\end{array}$ & $\begin{array}{r}0 \\
0 \\
0 \\
0 \\
0 \\
9,308 \\
9,308\end{array}$ & $\begin{array}{r}52,581 \\
38,734 \\
45,983 \\
5,241 \\
142,539 \\
4,391 \\
146,930\end{array}$ & $\begin{array}{r}14,035 \\
14,863 \\
10,464 \\
72 \\
39,434 \\
0 \\
39,434\end{array}$ \\
\hline
\end{tabular}

Note: Totals may not equal sum of components because of independent rounding.

Source: Energy Information Administration. Form ElA-861. "Annual Electric Utility Report." Data are submitted on a calendar year. 
Table 25. Number of Consumers, Sales, and Operating Revenue by Major U.S. Publicly Owned Electric Utility Within State, 1992 (Continued)

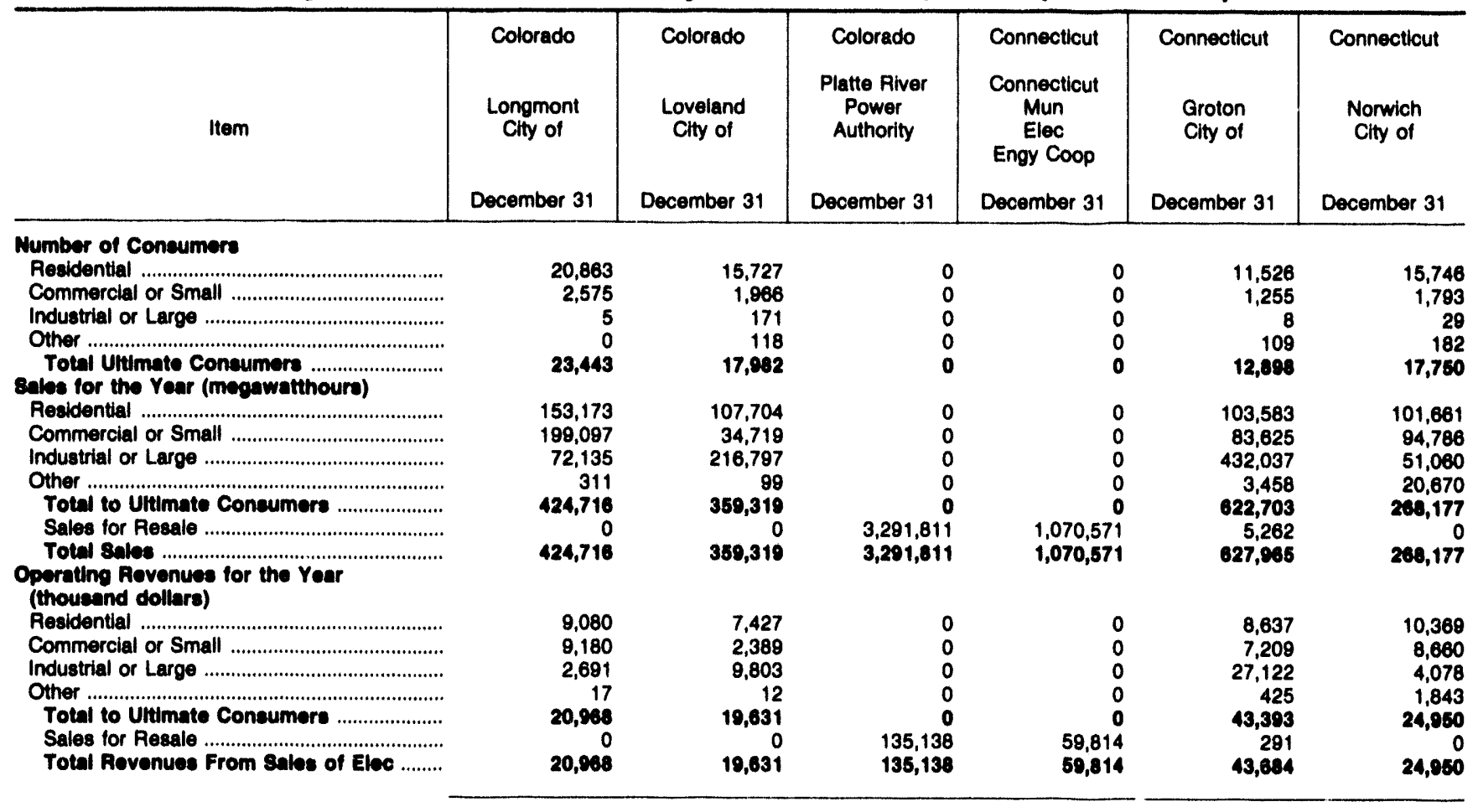

\begin{tabular}{|c|c|c|c|c|c|c|}
\hline Item & $\begin{array}{l}\text { Connecticut } \\
\text { Wallingford } \\
\text { Town of } \\
\text { December } 31\end{array}$ & $\begin{array}{c}\text { Delaware } \\
\text { Dover } \\
\text { City of } \\
\text { December } 31\end{array}$ & $\begin{array}{l}\text { Delaware } \\
\text { Milford } \\
\text { City of } \\
\text { December } 31\end{array}$ & $\begin{array}{l}\text { Delaware } \\
\text { Newark } \\
\text { Clty of } \\
\text { December } 31\end{array}$ & $\begin{array}{l}\text { Florida } \\
\text { Bartow } \\
\text { City of } \\
\text { December } 31\end{array}$ & $\begin{array}{c}\text { Florida } \\
\text { Florida } \\
\text { Municipal } \\
\text { Power Agency } \\
\text { December } 31\end{array}$ \\
\hline \multicolumn{7}{|l|}{ Number of Consumers } \\
\hline 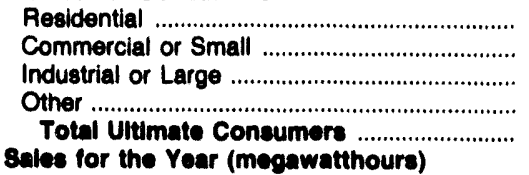 & $\begin{array}{r}18,721 \\
2,755 \\
30 \\
149 \\
21,655\end{array}$ & $\begin{array}{r}15,408 \\
3,143 \\
47 \\
1 \\
18,599\end{array}$ & $\begin{array}{r}3,648 \\
623 \\
23 \\
248 \\
4,542\end{array}$ & $\begin{array}{r}8,205 \\
1,014 \\
29 \\
0 \\
9,248\end{array}$ & $\begin{array}{r}8,289 \\
1,164 \\
264 \\
0 \\
9,717\end{array}$ & $\begin{array}{l}0 \\
0 \\
0 \\
0 \\
0\end{array}$ \\
\hline 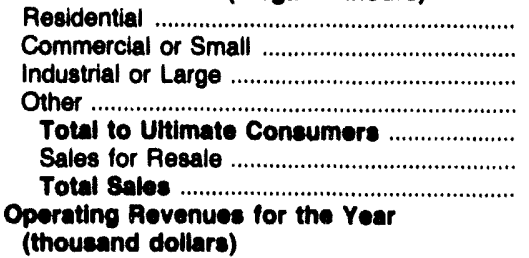 & $\begin{array}{r}153,530 \\
133,323 \\
212,562 \\
17,011 \\
516,426 \\
0 \\
516,426\end{array}$ & $\begin{array}{r}138,348 \\
165,300 \\
185,207 \\
9,017 \\
497,872 \\
24,237 \\
522,109\end{array}$ & $\begin{array}{r}34,786 \\
25,317 \\
64,901 \\
2,539 \\
127,543 \\
0 \\
127,543\end{array}$ & $\begin{array}{r}64,978 \\
48,390 \\
146,131 \\
0 \\
259,490 \\
0 \\
259,490\end{array}$ & $\begin{array}{r}110,685 \\
19,368 \\
104,068 \\
0 \\
234,121 \\
0 \\
234,121\end{array}$ & $\begin{array}{r}0 \\
0 \\
0 \\
0 \\
0 \\
3,140,965 \\
3,140,985\end{array}$ \\
\hline 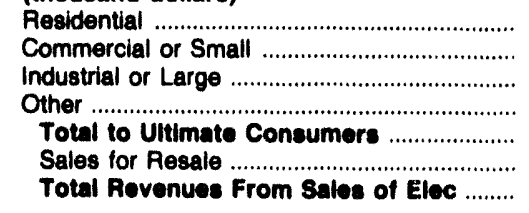 & $\begin{array}{r}13,356 \\
12,076 \\
15,009 \\
1,582 \\
42,023 \\
0 \\
42,023\end{array}$ & $\begin{array}{r}10,188 \\
11,653 \\
8,648 \\
748 \\
31,238 \\
1,088 \\
32,328\end{array}$ & $\begin{array}{r}3,320 \\
2,484 \\
4,036 \\
192 \\
10,032 \\
0 \\
10,032\end{array}$ & $\begin{array}{r}5,254 \\
4,363 \\
9,233 \\
0 \\
18,850 \\
0 \\
18,850\end{array}$ & $\begin{array}{r}7,888 \\
1,753 \\
7,669 \\
0 \\
17,310 \\
0 \\
17,310\end{array}$ & $\begin{array}{r}0 \\
0 \\
0 \\
0 \\
0 \\
158,582 \\
159,582\end{array}$ \\
\hline
\end{tabular}

Note: Totals may not equal sum of components because of independent rounding.

Source: Energy Information Administration, Form EIA-861, "Annual Electric Utility Report." Data are submitted on a calendar year. 
Table 25. Number of Consumers, Sales, and Operating Revenue by Major U.S. Publicly Owned Electric Utility Within State, 1992 (Continued)

\begin{tabular}{|c|c|c|c|c|c|c|}
\hline Item. & $\begin{array}{c}\text { Florida } \\
\text { Fort Pierce } \\
\text { Utilities } \\
\text { Auth } \\
\text { December } 31\end{array}$ & $\begin{array}{c}\text { Florida } \\
\text { Gainesville } \\
\text { Regional } \\
\text { Utilities }\end{array}$ & $\begin{array}{c}\text { Florida } \\
\text { Homestead } \\
\text { City of }\end{array}$ & $\begin{array}{c}\text { Florida } \\
\text { Jacksonville } \\
\text { Beach } \\
\text { City of } \\
\text { December } 31\end{array}$ & $\begin{array}{c}\text { Florida } \\
\text { Jacksonville } \\
\text { Electric } \\
\text { Auth } \\
\text { December } 31\end{array}$ & $\begin{array}{l}\text { Florida } \\
\text { Key West } \\
\text { City of } \\
\text { December } 31\end{array}$ \\
\hline \multicolumn{7}{|l|}{ Number of Consumers } \\
\hline 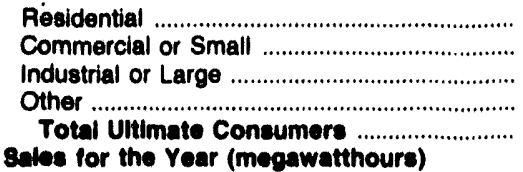 & $\begin{array}{r}19,575 \\
3,896 \\
0 \\
3 \\
23,474\end{array}$ & $\begin{array}{r}56,730 \\
6,708 \\
13 \\
1,950 \\
65,401\end{array}$ & $\begin{array}{r}11,997 \\
1,527 \\
270 \\
74 \\
13,868\end{array}$ & $\begin{array}{r}20,442 \\
3,527 \\
0 \\
3 \\
23,972\end{array}$ & $\begin{array}{r}266,219 \\
31,626 \\
122 \\
1,768 \\
299,735\end{array}$ & $\begin{array}{r}19,999 \\
2,224 \\
0 \\
16 \\
22,239\end{array}$ \\
\hline 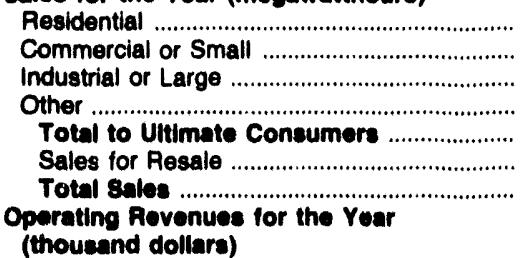 & $\begin{array}{r}205,084 \\
271,191 \\
0 \\
8,504 \\
484,779 \\
66,928 \\
551,707\end{array}$ & $\begin{array}{r}609,647 \\
506,661 \\
128,089 \\
16,378 \\
1,260,775 \\
558,813 \\
1,819,588\end{array}$ & $\begin{array}{r}129,801 \\
28,907 \\
68,674 \\
12,332 \\
239,714 \\
33,869 \\
273,583\end{array}$ & $\begin{array}{r}258,951 \\
198,582 \\
0 \\
4,038 \\
461,571 \\
0 \\
481,571\end{array}$ & $\begin{array}{r}3,695,942 \\
2,689,395 \\
1,843,485 \\
59,278 \\
8,288,100 \\
506,685 \\
8,794,765\end{array}$ & $\begin{array}{r}197,416 \\
283,907 \\
0 \\
7,336 \\
488,659 \\
4,333 \\
492,992\end{array}$ \\
\hline 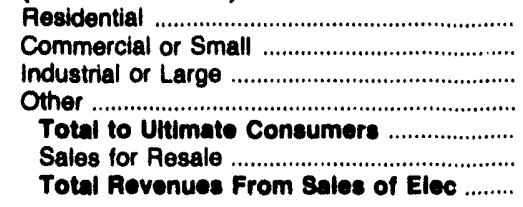 & $\begin{array}{r}16,356 \\
20,670 \\
0 \\
867 \\
37,893 \\
2,011 \\
39,904\end{array}$ & $\begin{array}{r}45,346 \\
36,715 \\
6,654 \\
2,195 \\
90,910 \\
18,639 \\
109,549\end{array}$ & $\begin{array}{r}10,014 \\
2,398 \\
5,893 \\
799 \\
19,104 \\
1,590 \\
20,694\end{array}$ & $\begin{array}{r}19,028 \\
16,384 \\
0 \\
493 \\
35,908 \\
0 \\
35,908\end{array}$ & $\begin{array}{r}260,005 \\
179,923 \\
106,844 \\
6,421 \\
553,193 \\
32,137 \\
585,330\end{array}$ & $\begin{array}{r}17,313 \\
26,616 \\
0 \\
735 \\
44,684 \\
137 \\
44,801\end{array}$ \\
\hline
\end{tabular}

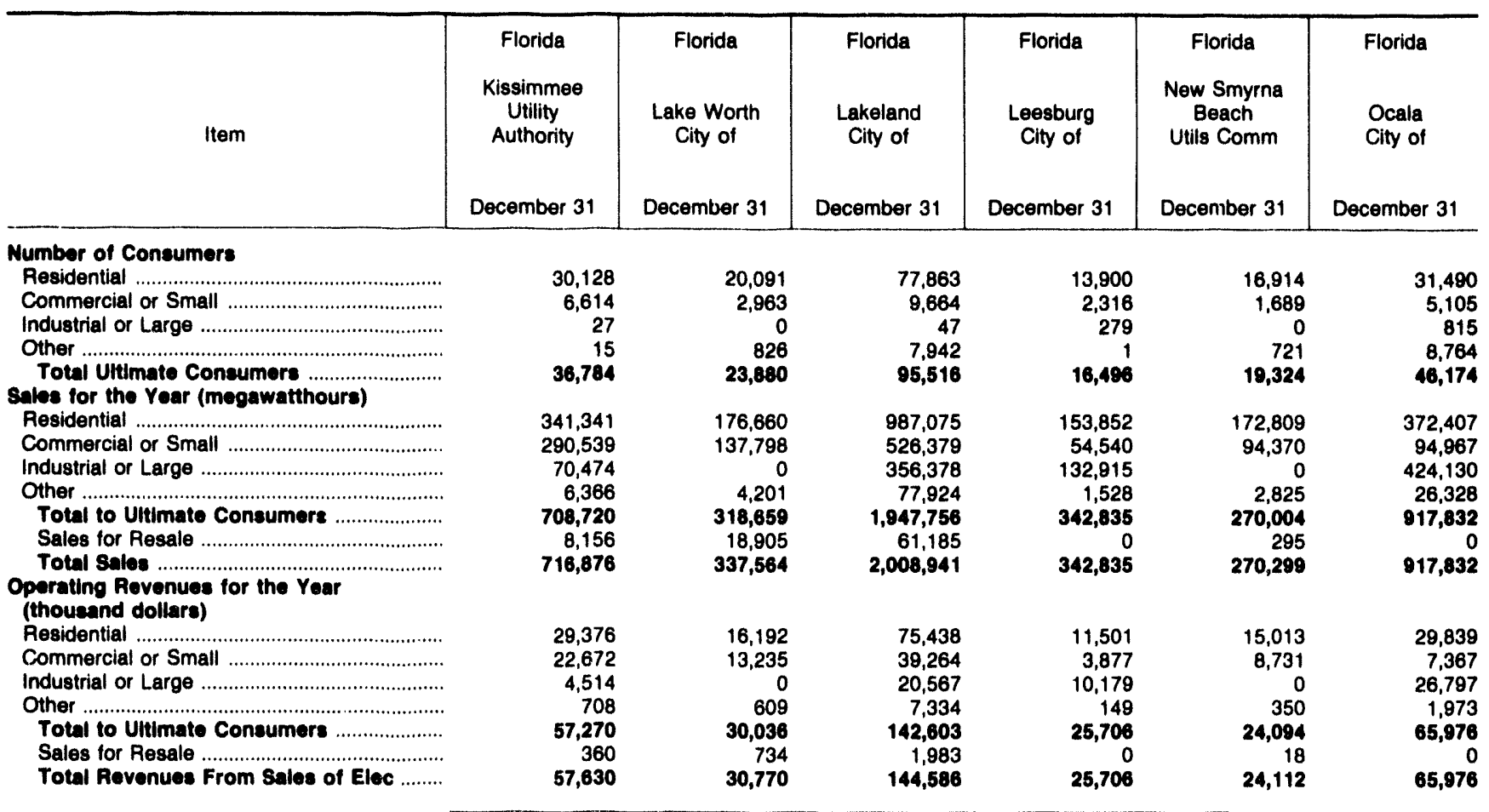

Note: Totals may not equal sum of components because of independent rounding.

Source: Energy Information Administration, Form EIA-861, "Annual Electric Utility Report." Data are submitted on a calendar year. 
Table 25. Number of Consumers, Sales, and Operating Revenue by Major U.S. Publicly Owned Electric Utllity Within State, 1992 (Continued)

\begin{tabular}{|c|c|c|c|c|c|c|}
\hline Item & $\begin{array}{l}\text { Florida } \\
\text { Orlando } \\
\text { Utilities } \\
\text { Comm } \\
\text { December } 31\end{array}$ & $\begin{array}{l}\text { Florida } \\
\text { Quincy } \\
\text { City of } \\
\text { December } 31\end{array}$ & $\begin{array}{c}\text { Florida } \\
\text { Reedy Creek } \\
\text { Improvement } \\
\text { Dist }\end{array}$ & $\begin{array}{l}\text { Florida } \\
\text { Sebring } \\
\text { Utilities } \\
\text { Comm } \\
\text { December } 31\end{array}$ & $\begin{array}{l}\text { Florida } \\
\text { St Cloud } \\
\text { City of } \\
\text { December } 31\end{array}$ & $\begin{array}{c}\text { Florida } \\
\text { Tallahassee } \\
\text { City of } \\
\text { December } 31\end{array}$ \\
\hline \multicolumn{7}{|l|}{ Number of Consumers } \\
\hline 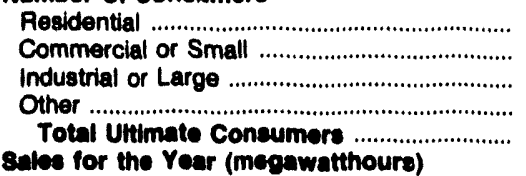 & $\begin{array}{r}103,495 \\
16,403 \\
30 \\
40,081 \\
160,009\end{array}$ & $\begin{array}{r}3,682 \\
674 \\
25 \\
1,910 \\
6,291\end{array}$ & $\begin{array}{r}0 \\
854 \\
0 \\
99 \\
953\end{array}$ & $\begin{array}{r}10,929 \\
1,886 \\
0 \\
150 \\
12,985\end{array}$ & $\begin{array}{r}13,065 \\
1,290 \\
106 \\
0 \\
14,461\end{array}$ & $\begin{array}{r}66,616 \\
9,395 \\
0 \\
4,221 \\
80,232\end{array}$ \\
\hline 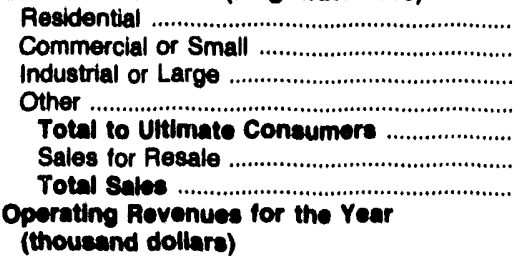 & $\begin{array}{r}1,215,763 \\
1,884,396 \\
390,940 \\
69,533 \\
3,580,632 \\
1,371,645 \\
4,932,277\end{array}$ & $\begin{array}{r}42,800 \\
30,700 \\
59,900 \\
6,600 \\
140,000 \\
0 \\
140,000\end{array}$ & $\begin{array}{r}0 \\
641,523 \\
0 \\
150,678 \\
792,201 \\
0 \\
792,201\end{array}$ & $\begin{array}{r}87,216 \\
66,449 \\
0 \\
16,090 \\
169,755 \\
0 \\
169,755\end{array}$ & $\begin{array}{r}142,742 \\
16,492 \\
47,256 \\
0 \\
206,490 \\
0 \\
206,490\end{array}$ & $\begin{array}{r}765,867 \\
1,006,140 \\
0 \\
84,637 \\
1,856,644 \\
122,928 \\
1,979,572\end{array}$ \\
\hline 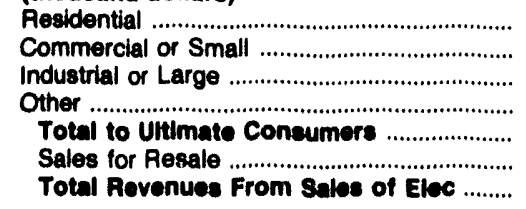 & $\begin{array}{r}90,782 \\
118,380 \\
20,713 \\
6,020 \\
235,895 \\
47,595 \\
283,480\end{array}$ & $\begin{array}{r}2,674 \\
2,133 \\
3,342 \\
361 \\
8,510 \\
0 \\
8,510\end{array}$ & $\begin{array}{r}0 \\
41,982 \\
0 \\
10,448 \\
52,430 \\
0 \\
52,430\end{array}$ & $\begin{array}{r}9,700 \\
6,902 \\
0 \\
1,574 \\
18,176 \\
0 \\
18,176\end{array}$ & $\begin{array}{r}13,535 \\
1,740 \\
4,358 \\
0 \\
19,633 \\
0 \\
19,633\end{array}$ & $\begin{array}{r}65,351 \\
80,279 \\
0 \\
6,759 \\
152,389 \\
5,098 \\
157,487\end{array}$ \\
\hline
\end{tabular}

\begin{tabular}{|c|c|c|c|c|c|c|}
\hline Item & $\begin{array}{l}\text { Florida } \\
\text { Vero } \\
\text { Beach } \\
\text { City of } \\
\text { December } 31\end{array}$ & $\begin{array}{l}\text { Georgia } \\
\text { Albany Water } \\
\text { Gas \& Light } \\
\text { Comm } \\
\text { December } 31\end{array}$ & $\begin{array}{l}\text { Georgia } \\
\text { Calhoun } \\
\text { City of } \\
\text { December } 31\end{array}$ & $\begin{array}{c}\text { Georgia } \\
\text { Cartersville } \\
\text { City of }\end{array}$ & $\begin{array}{c}\text { Georgia } \\
\text { College } \\
\text { Park City of } \\
\text { December } 31\end{array}$ & $\begin{array}{l}\text { Georgia } \\
\text { Covington } \\
\text { City of } \\
\text { December } 31\end{array}$ \\
\hline \multicolumn{7}{|l|}{ Number of Coneumers } \\
\hline Residential & 21,607 & 31,523 & 2,810 & 4,090 & 9,589 & 6,439 \\
\hline 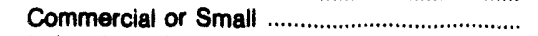 & 3,941 & 4,838 & 671 & 990 & 866 & 1,501 \\
\hline Industrial or Large & 1 & 34 & 53 & 31 & 0 & 7 \\
\hline Other & 330 & 3,455 & 95 & 52 & 0 & 0 \\
\hline Total Uitimate Consumere ............................. & 25,879 & 39,850 & 3,629 & 5,163 & 10,455 & 7,947 \\
\hline \multicolumn{7}{|l|}{ Sales for the Year (megawatthoura) } \\
\hline 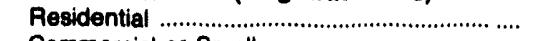 & 262,530 & 364,759 & 24,355 & 43,309 & 83,227 & 71,787 \\
\hline Commercial or Small & 210,596 & 444,272 & 43,444 & 66,855 & 137,829 & 78,539 \\
\hline Industrial or Large & 8,679 & 10,711 & 207,037 & 236,871 & 0 & 45,788 \\
\hline 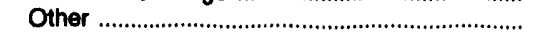 & 3,098 & 17,972 & 19,685 & 14,677 & 0 & \\
\hline Total to Uitimate Consumers ........................ & 484,903 & 837,714 & 294,521 & 361,712 & 221,056 & 196,114 \\
\hline 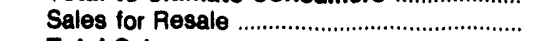 & 6.480 & & & & & \\
\hline \multirow{2}{*}{\multicolumn{7}{|c|}{$\begin{array}{l}\text { Operating Rovenues for the Yoar } \\
\text { (thousand dollare) }\end{array}$}} \\
\hline & & & & & & \\
\hline 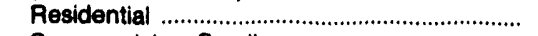 & 22,495 & 25,675 & 1,452 & 3,185 & 5,560 & 5,760 \\
\hline 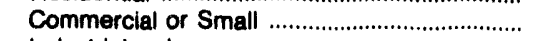 & 16,239 & 25,532 & 3,106 & 5,804 & 9,857 & 6,976 \\
\hline Industrial or Large & 633 & 626 & 11,788 & 12,027 & 0 & 1,841 \\
\hline Other & 358 & 1,411 & 1,716 & 1,147 & 0 & \\
\hline Total to Uitimate Coneumere ...................... & 39,725 & 54,244 & 18,062 & 22,163 & 15,417 & 14,577 \\
\hline Sales for Resale & 200 & & & & & \\
\hline & 39,925 & 54,244 & 18,062 & 22,163 & 15,417 & 14,577 \\
\hline
\end{tabular}

Note: Totals may not equal sum of components because of independent rounding.

Source: Energy Information Administration. Form ElA-861, "Annual Electric Utility Report." Data are submitted on a calendar year. 
Table 25. Number of Consumers, Sales, and Operating Revenue by Major U.S. Publicly Owned Electric Utility Within State, 1992 (Continued)

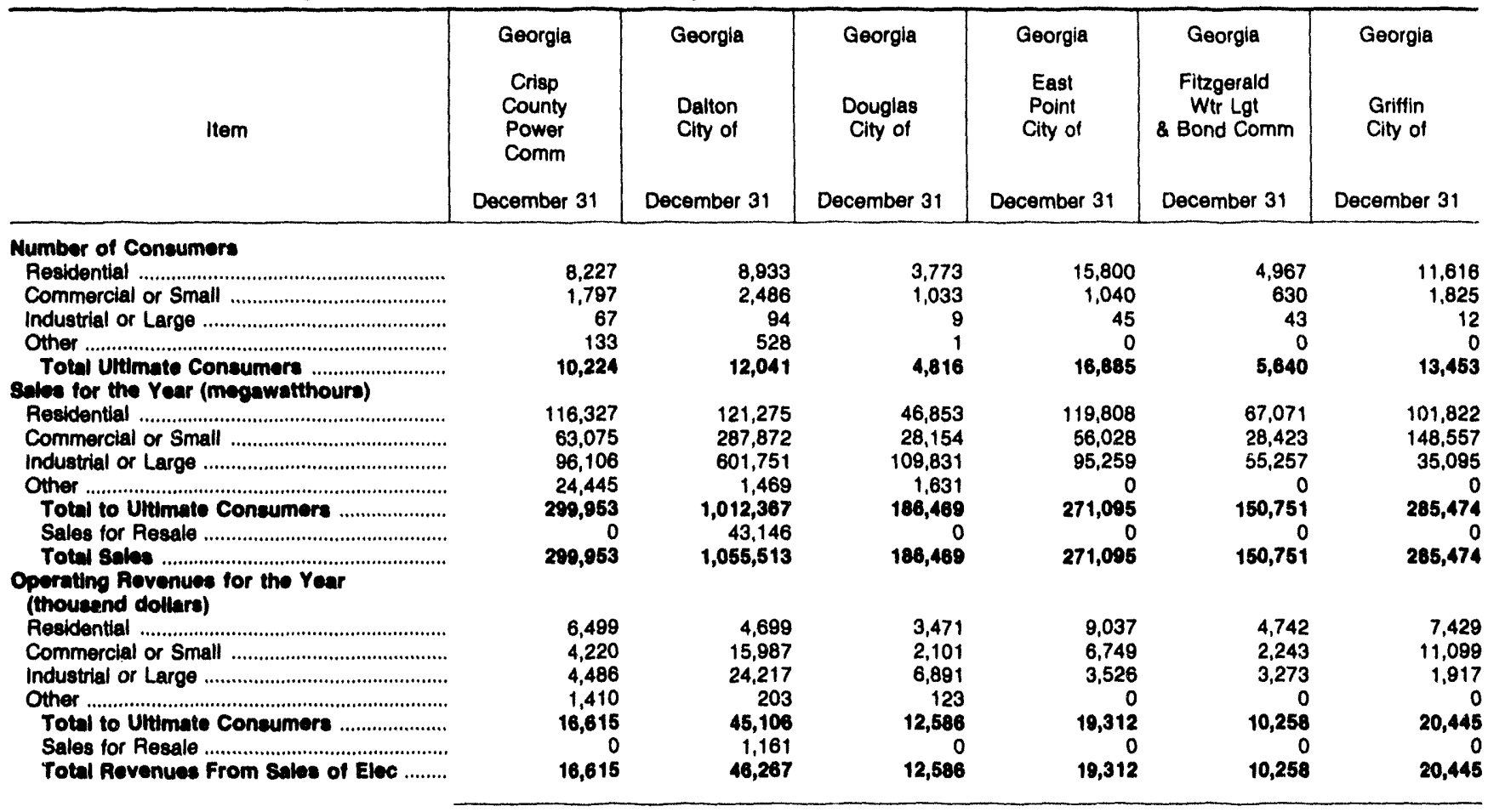

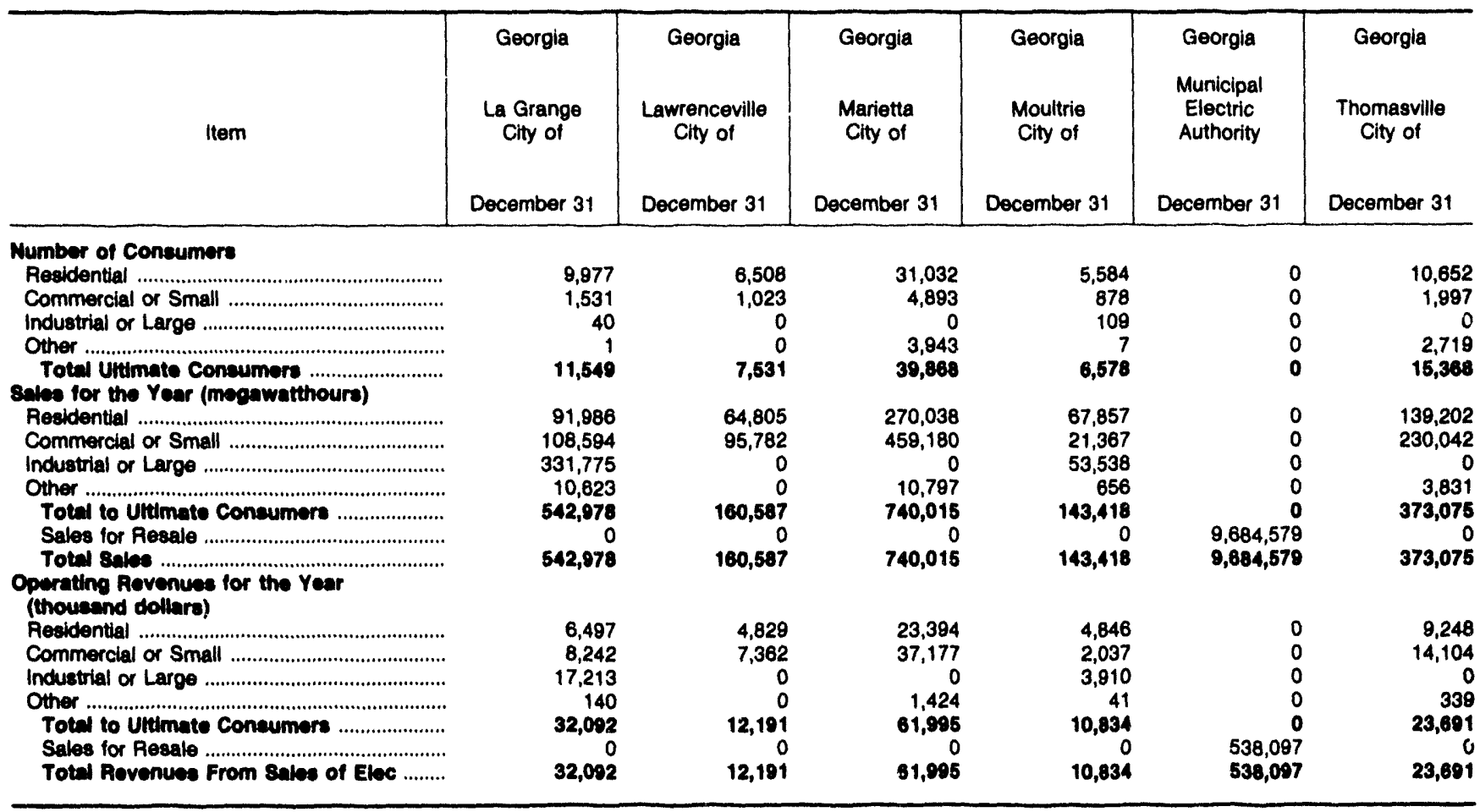

Note: Totals may not equal sum of components because of independentrounding.

Source: Energy Information Administration, Form EIA-861, "Annual Electric Utility Report." Data are submitted on a calendar year. 
Table 25. Number of Consumers, Sales, and Operating Revenue by Major U.S. Publicly Owned Electric Utility Within State, 1992 (Continued)

\begin{tabular}{|c|c|c|c|c|c|c|}
\hline Item & $\begin{array}{l}\text { Idaho } \\
\text { Idaho } \\
\text { Falls } \\
\text { City of } \\
\text { December } 31\end{array}$ & $\begin{array}{l}\text { Illinols } \\
\text { Batavia } \\
\text { City of } \\
\text { December } 31\end{array}$ & $\begin{array}{c}\text { Illinois } \\
\text { Geneva } \\
\text { Clity of } \\
\text { December } 31\end{array}$ & $\begin{array}{c}\text { Illinois } \\
\text { Illinois } \\
\text { Municipal } \\
\text { Elec Agency } \\
\text { December } 31\end{array}$ & $\begin{array}{c}\text { Illinois } \\
\text { Naperville } \\
\text { City of } \\
\text { December } 31\end{array}$ & $\begin{array}{c}\text { Illinois } \\
\text { Rochelle } \\
\text { Municipal } \\
\text { Utilities } \\
\text { December } 31\end{array}$ \\
\hline \multicolumn{7}{|l|}{ Number of Concumers } \\
\hline 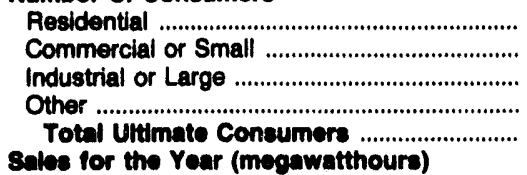 & $\begin{array}{r}17,917 \\
2,541 \\
7 \\
191 \\
20,658\end{array}$ & $\begin{array}{r}6,770 \\
784 \\
8 \\
0 \\
7,562\end{array}$ & $\begin{array}{r}4,728 \\
961 \\
39 \\
2 \\
5,730\end{array}$ & $\begin{array}{l}0 \\
0 \\
0 \\
0 \\
0\end{array}$ & $\begin{array}{r}32,118 \\
2,542 \\
26 \\
179 \\
34,865\end{array}$ & $\begin{array}{r}5,221 \\
734 \\
2 \\
8 \\
5,985\end{array}$ \\
\hline 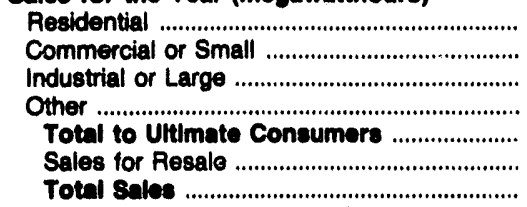 & $\begin{array}{r}265,163 \\
219,831 \\
49,675 \\
41,167 \\
575,836 \\
0 \\
575,836\end{array}$ & $\begin{array}{r}47,511 \\
72,287 \\
60,140 \\
0 \\
179,088 \\
0 \\
179,038\end{array}$ & $\begin{array}{r}\mathbf{3}, 002 \\
33,953 \\
56,987 \\
5,657 \\
132,590 \\
0 \\
132,500\end{array}$ & $\begin{array}{r}0 \\
0 \\
0 \\
0 \\
0 \\
1,271,443 \\
1,271,443\end{array}$ & $\begin{array}{r}287,642 \\
265,160 \\
55,456 \\
65,727 \\
873,985 \\
0 \\
673,986\end{array}$ & $\begin{array}{r}36,853 \\
46,712 \\
60,437 \\
6,631 \\
160,633 \\
0 \\
150,833\end{array}$ \\
\hline \multicolumn{7}{|l|}{$\begin{array}{l}\text { Operating Rovenues for the Year } \\
\text { (thouseand dollare) }\end{array}$} \\
\hline 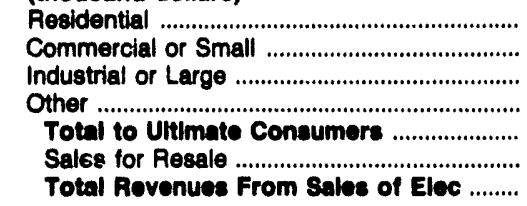 & $\begin{array}{r}10,781 \\
10,218 \\
1,708 \\
1,467 \\
24,174 \\
6,654 \\
30,828\end{array}$ & $\begin{array}{r}3,545 \\
4,998 \\
3,388 \\
0 \\
11,931 \\
0 \\
11,981\end{array}$ & $\begin{array}{r}2,487 \\
2,314 \\
2,834 \\
322 \\
7,957 \\
0 \\
7,957\end{array}$ & $\begin{array}{r}0 \\
0 \\
0 \\
0 \\
0 \\
57,015 \\
57,015\end{array}$ & $\begin{array}{r}25,323 \\
18,966 \\
3,644 \\
5,704 \\
53,637 \\
0 \\
53,637\end{array}$ & $\begin{array}{r}2,954 \\
3,546 \\
3,328 \\
330 \\
10,158 \\
0 \\
10,150\end{array}$ \\
\hline
\end{tabular}

\begin{tabular}{|c|c|c|c|c|c|c|}
\hline Item & $\begin{array}{c}\text { Illinois } \\
\begin{array}{c}\text { Springfield } \\
\text { City of }\end{array} \\
\text { December } 34\end{array}$ & $\begin{array}{c}\text { Ilinois } \\
\text { St Charles } \\
\text { Clty of } \\
\text { December } 31\end{array}$ & $\begin{array}{l}\text { Indlana } \\
\text { Anderson } \\
\text { City of } \\
\text { December } 31\end{array}$ & $\begin{array}{l}\text { Indiana } \\
\text { Auburn } \\
\text { City of } \\
\text { December } 31\end{array}$ & $\begin{array}{l}\text { Indiana } \\
\text { Blutfton } \\
\text { City of } \\
\text { December } 31\end{array}$ & $\begin{array}{c}\text { Indiana } \\
\text { Crawtordsville } \\
\text { Elec } \\
\text { Lgt\&Pwr Co } \\
\text { December } 31\end{array}$ \\
\hline \multicolumn{7}{|l|}{ Number of Consumers } \\
\hline 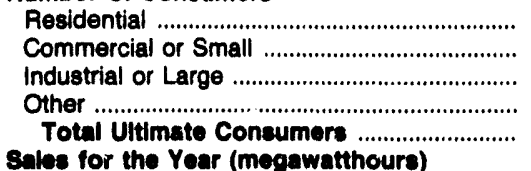 & $\begin{array}{r}52,343 \\
6,142 \\
1 \\
2,599 \\
62,085\end{array}$ & $\begin{array}{r}9,113 \\
1,396 \\
0 \\
60 \\
10,569\end{array}$ & $\begin{array}{r}30,686 \\
3,242 \\
35 \\
2,678 \\
36,641\end{array}$ & $\begin{array}{r}4,350 \\
648 \\
73 \\
3 \\
5,074\end{array}$ & $\begin{array}{r}4,143 \\
544 \\
30 \\
64 \\
4,781\end{array}$ & $\begin{array}{r}7,165 \\
1,150 \\
113 \\
37 \\
\mathbf{8 , 4 6 5}\end{array}$ \\
\hline 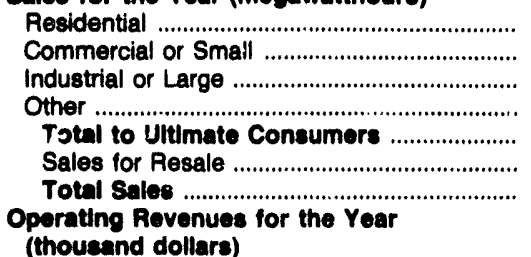 & $\begin{array}{r}516,869 \\
804,782 \\
17,232 \\
95,137 \\
1,434,020 \\
128,757 \\
1,562,777\end{array}$ & $\begin{array}{r}73,525 \\
250,249 \\
0 \\
8,012 \\
331,786 \\
0 \\
331,786\end{array}$ & $\begin{array}{r}263,498 \\
247,795 \\
68,866 \\
10,990 \\
501,149 \\
0 \\
591,149\end{array}$ & $\begin{array}{r}37,920 \\
15,704 \\
244,166 \\
1,180 \\
298,970 \\
0 \\
298,970\end{array}$ & $\begin{array}{r}34,814 \\
22,062 \\
83,800 \\
4,138 \\
144,814 \\
0 \\
144,814\end{array}$ & $\begin{array}{r}60,840 \\
23,832 \\
236,084 \\
3,245 \\
324,001 \\
27,195 \\
351,196\end{array}$ \\
\hline 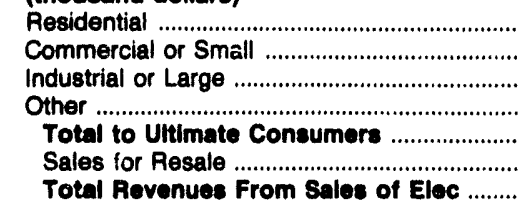 & $\begin{array}{r}27,300 \\
50,032 \\
919 \\
5,371 \\
83,622 \\
3,765 \\
87,387\end{array}$ & $\begin{array}{r}6,290 \\
16,984 \\
0 \\
629 \\
23,903 \\
0 \\
23,903\end{array}$ & $\begin{array}{r}17,339 \\
14,675 \\
3,201 \\
618 \\
35,833 \\
0 \\
35,833\end{array}$ & $\begin{array}{r}1,823 \\
1,011 \\
11,616 \\
154 \\
14,604 \\
0 \\
14,604\end{array}$ & $\begin{array}{r}1,991 \\
1,349 \\
3,863 \\
230 \\
7,433 \\
0 \\
7,433\end{array}$ & $\begin{array}{r}3,804 \\
1,516 \\
10,485 \\
243 \\
16,048 \\
2,228 \\
18,276\end{array}$ \\
\hline
\end{tabular}

Note: Totals may not equal sum of components because of independent rounding.

Source: Energy Information Administration, Form EIA-861, "Annual Electric Utility Report." Data are submitted on a calendar year. 
Table 25. Number of Consumers, Sales, and Operating Revenue by Major U.S. Publicly Owned Electric Utillty Within State, 1992 (Continued)

\begin{tabular}{|c|c|c|c|c|c|c|}
\hline Item & $\begin{array}{l}\text { Indiana } \\
\text { Frankfort } \\
\text { City of } \\
\text { December } 31\end{array}$ & $\begin{array}{l}\text { Indiana } \\
\text { Greenfield } \\
\text { City of } \\
\text { December } 31\end{array}$ & $\begin{array}{c}\text { Indiana } \\
\text { Indiana } \\
\text { Municipal } \\
\text { Power Agency } \\
\text { December } 31\end{array}$ & $\begin{array}{l}\text { Indiana } \\
\text { Jasper } \\
\text { City of } \\
\text { December } 31\end{array}$ & $\begin{array}{l}\text { Indiana } \\
\text { Logansport } \\
\text { City of } \\
\text { December } 31\end{array}$ & $\begin{array}{c}\text { Indiana } \\
\text { Mishawaka } \\
\text { City of } \\
\text { December } 31\end{array}$ \\
\hline 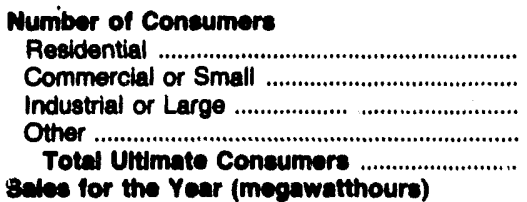 & $\begin{array}{r}7,494 \\
1,073 \\
87 \\
0 \\
8,654\end{array}$ & $\begin{array}{r}4,851 \\
600 \\
22 \\
49 \\
5,522\end{array}$ & $\begin{array}{l}0 \\
0 \\
0 \\
0 \\
0\end{array}$ & $\begin{array}{r}4,664 \\
745 \\
83 \\
2 \\
5,494\end{array}$ & $\begin{array}{r}10,083 \\
2,188 \\
55 \\
65 \\
12,391\end{array}$ & $\begin{array}{r}19,490 \\
2,675 \\
0 \\
141 \\
22,306\end{array}$ \\
\hline 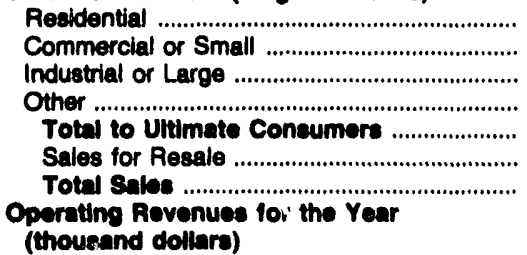 & $\begin{array}{r}58,344 \\
22,013 \\
186,422 \\
2,580 \\
280,358 \\
0 \\
269,350\end{array}$ & $\begin{array}{r}38,886 \\
27,633 \\
71,321 \\
4,885 \\
142,826 \\
0 \\
142,825\end{array}$ & $\begin{array}{r}0 \\
0 \\
0 \\
0 \\
0 \\
3,393,949 \\
3,393,949\end{array}$ & $\begin{array}{r}53,291 \\
16,474 \\
155,864 \\
6,140 \\
231,769 \\
0 \\
231,780\end{array}$ & $\begin{array}{r}79,118 \\
66,984 \\
134,590 \\
11,609 \\
292,301 \\
0 \\
292,301\end{array}$ & $\begin{array}{r}132,281 \\
243,303 \\
0 \\
19,487 \\
395,071 \\
0 \\
395,071\end{array}$ \\
\hline 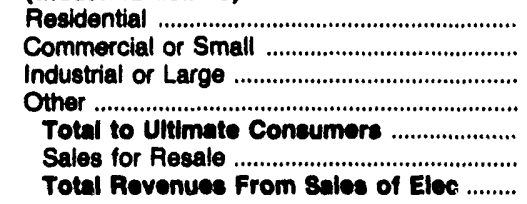 & $\begin{array}{r}3,621 \\
1,399 \\
7,999 \\
212 \\
13,231 \\
0 \\
13,231\end{array}$ & $\begin{array}{r}2,426 \\
1,554 \\
3,531 \\
256 \\
7,767 \\
0 \\
7,767\end{array}$ & $\begin{array}{r}0 \\
0 \\
0 \\
0 \\
0 \\
141,753 \\
141,763\end{array}$ & $\begin{array}{r}3,333 \\
2,094 \\
7,467 \\
378 \\
13,272 \\
0 \\
13,272\end{array}$ & $\begin{array}{r}5,045 \\
4,286 \\
6,585 \\
574 \\
16,480 \\
0 \\
16,480\end{array}$ & $\begin{array}{r}10,162 \\
11,836 \\
0 \\
1,310 \\
23,308 \\
0 \\
23,308\end{array}$ \\
\hline
\end{tabular}

\begin{tabular}{|c|c|c|c|c|c|c|}
\hline Item & $\begin{array}{c}\text { Indiana } \\
\text { Peru } \\
\text { City of } \\
\text { December } 31\end{array}$ & $\begin{array}{l}\text { Indiana } \\
\text { Richmond } \\
\text { City of } \\
\text { December } 31\end{array}$ & $\begin{array}{c}\text { Indiana } \\
\text { Washington } \\
\text { City of } \\
\text { December } 31\end{array}$ & $\begin{array}{c}\text { lowa } \\
\text { Ames } \\
\text { City of } \\
\text { December } 31\end{array}$ & $\begin{array}{l}\text { lowa } \\
\text { Cedar } \\
\text { Falls } \\
\text { City of } \\
\text { December } 31\end{array}$ & $\begin{array}{c}\text { lowa } \\
\text { Muscatine } \\
\text { City of } \\
\text { December } 31\end{array}$ \\
\hline 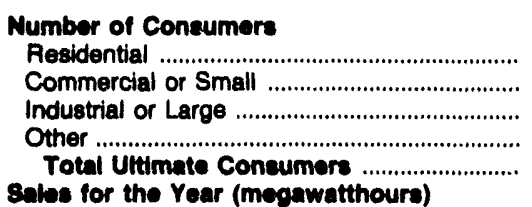 & $\begin{array}{r}9,146 \\
376 \\
725 \\
55 \\
10,302\end{array}$ & $\begin{array}{r}18,226 \\
2,618 \\
156 \\
73 \\
21,073\end{array}$ & $\begin{array}{r}6,033 \\
846 \\
2 \\
38 \\
6,019\end{array}$ & $\begin{array}{r}14,697 \\
1,796 \\
243 \\
\$, 53 \\
16,880\end{array}$ & $\begin{array}{r}12,681 \\
1,620 \\
44 \\
217 \\
14,562\end{array}$ & $\begin{array}{r}9,157 \\
1,415 \\
112 \\
33 \\
10,717\end{array}$ \\
\hline 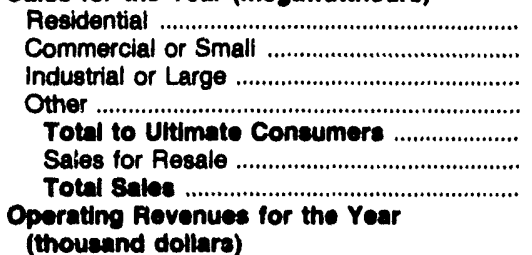 & $\begin{array}{r}73,204 \\
8,518 \\
83,458 \\
8,740 \\
173,921 \\
0 \\
173,921\end{array}$ & $\begin{array}{r}169,278 \\
103,245 \\
412,470 \\
15,118 \\
700,111 \\
0 \\
700,111\end{array}$ & $\begin{array}{r}56,004 \\
52,878 \\
25,833 \\
8,011 \\
142,728 \\
0 \\
142,728\end{array}$ & $\begin{array}{r}92,289 \\
37,780 \\
138,584 \\
54,093 \\
322,746 \\
7,300 \\
330,046\end{array}$ & $\begin{array}{r}111,014 \\
84,184 \\
45,248 \\
45,284 \\
285,730 \\
17,197 \\
302,927\end{array}$ & $\begin{array}{r}81,714 \\
39,868 \\
623,228 \\
16,150 \\
781,060 \\
532,972 \\
1,294,032\end{array}$ \\
\hline 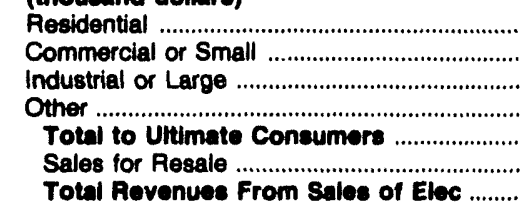 & $\begin{array}{r}4,118 \\
440 \\
3,924 \\
406 \\
8,888 \\
0 \\
8,888\end{array}$ & $\begin{array}{r}9,852 \\
6,835 \\
20,229 \\
1,007 \\
37,923 \\
0 \\
37,923\end{array}$ & $\begin{array}{r}3,320 \\
2,772 \\
1,013 \\
362 \\
7,467 \\
0 \\
7,467\end{array}$ & $\begin{array}{r}6,705 \\
2,502 \\
7,029 \\
2,443 \\
18,679 \\
124 \\
18,803\end{array}$ & $\begin{array}{r}5,492 \\
3,719 \\
1,790 \\
1,779 \\
12,780 \\
255 \\
13,035\end{array}$ & $\begin{array}{r}5,230 \\
2,608 \\
28,196 \\
687 \\
36,721 \\
36,091 \\
72,812\end{array}$ \\
\hline
\end{tabular}

Note: Totals may not equal sum of components because of independent rounding.

Source: Energy Information Administration, Form ElA-861, "Annual Electric Utility Report." Data are submitted on a calendar year. 
Table 25. Number of Consumers, Sales, and Operating Revenue by Major U.S. Publicly Owned Electric UtIllty Within State, 1992 (Continued)

\begin{tabular}{|c|c|c|c|c|c|c|}
\hline Item & $\begin{array}{c}\text { lowa } \\
\text { Pella } \\
\text { City of } \\
\text { December } 31\end{array}$ & $\begin{array}{l}\text { Kanses } \\
\text { Chanute } \\
\text { City of } \\
\text { December } 31\end{array}$ & $\begin{array}{c}\text { Kansas } \\
\text { Coffeyville } \\
\text { City of }\end{array}$ & $\begin{array}{c}\text { Kansas } \\
\text { Garden } \\
\text { City City of } \\
\text { December } 31\end{array}$ & $\begin{array}{c}\text { Kansas } \\
\text { Kansas } \\
\text { City Clty of } \\
\text { December } 31\end{array}$ & $\begin{array}{c}\text { Kansas } \\
\text { Kansas } \\
\text { Municipal } \\
\text { Energy } \\
\text { Agency } \\
\text { December } 31\end{array}$ \\
\hline \multicolumn{7}{|l|}{ Number of Consumers } \\
\hline 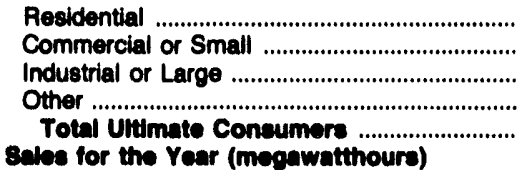 & $\begin{array}{r}3,278 \\
474 \\
34 \\
91 \\
3,877\end{array}$ & $\begin{array}{r}4,598 \\
833 \\
75 \\
0 \\
5,508\end{array}$ & $\begin{array}{r}6,244 \\
1,778 \\
0 \\
0 \\
8,022\end{array}$ & $\begin{array}{r}8,359 \\
846 \\
374 \\
0 \\
9,579\end{array}$ & $\begin{array}{r}58,927 \\
6,557 \\
140 \\
228 \\
65,852\end{array}$ & $\begin{array}{l}0 \\
0 \\
0 \\
0 \\
0\end{array}$ \\
\hline 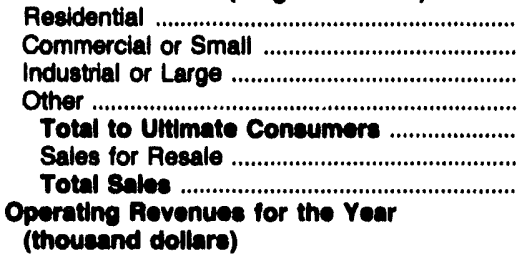 & $\begin{array}{r}26,900 \\
17,200 \\
82,800 \\
3,700 \\
130,600 \\
0 \\
130,600\end{array}$ & $\begin{array}{r}35,032 \\
35,224 \\
60,769 \\
0 \\
131,026 \\
0 \\
131,026\end{array}$ & $\begin{array}{r}45,834 \\
110,039 \\
0 \\
0 \\
155,873 \\
0 \\
155,073\end{array}$ & $\begin{array}{r}57,675 \\
15,741 \\
67,104 \\
0 \\
140,620 \\
0 \\
140,520\end{array}$ & $\begin{array}{r}442,970 \\
768,304 \\
705,182 \\
56,653 \\
1,073,109 \\
414,020 \\
2,387,120\end{array}$ & $\begin{array}{r}0 \\
0 \\
0 \\
0 \\
0 \\
311,554 \\
311,654\end{array}$ \\
\hline 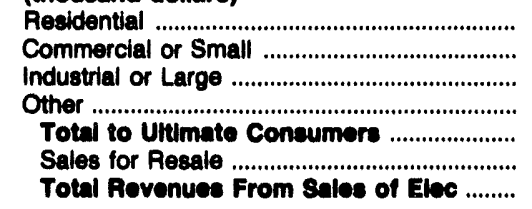 & $\begin{array}{r}1,807 \\
1,267 \\
4,244 \\
241 \\
7,550 \\
0 \\
7,550\end{array}$ & $\begin{array}{r}2,549 \\
2,291 \\
3,090 \\
0 \\
7,030 \\
0 \\
7,930\end{array}$ & $\begin{array}{r}3,312 \\
6,943 \\
0 \\
0 \\
10,255 \\
0 \\
10,255\end{array}$ & $\begin{array}{r}4,929 \\
787 \\
4,640 \\
0 \\
10,356 \\
0 \\
10,356\end{array}$ & $\begin{array}{r}27,303 \\
41,559 \\
28,568 \\
2,850 \\
100,278 \\
13,658 \\
113,986\end{array}$ & $\begin{array}{r}0 \\
0 \\
0 \\
0 \\
0 \\
9,881 \\
9,881\end{array}$ \\
\hline
\end{tabular}

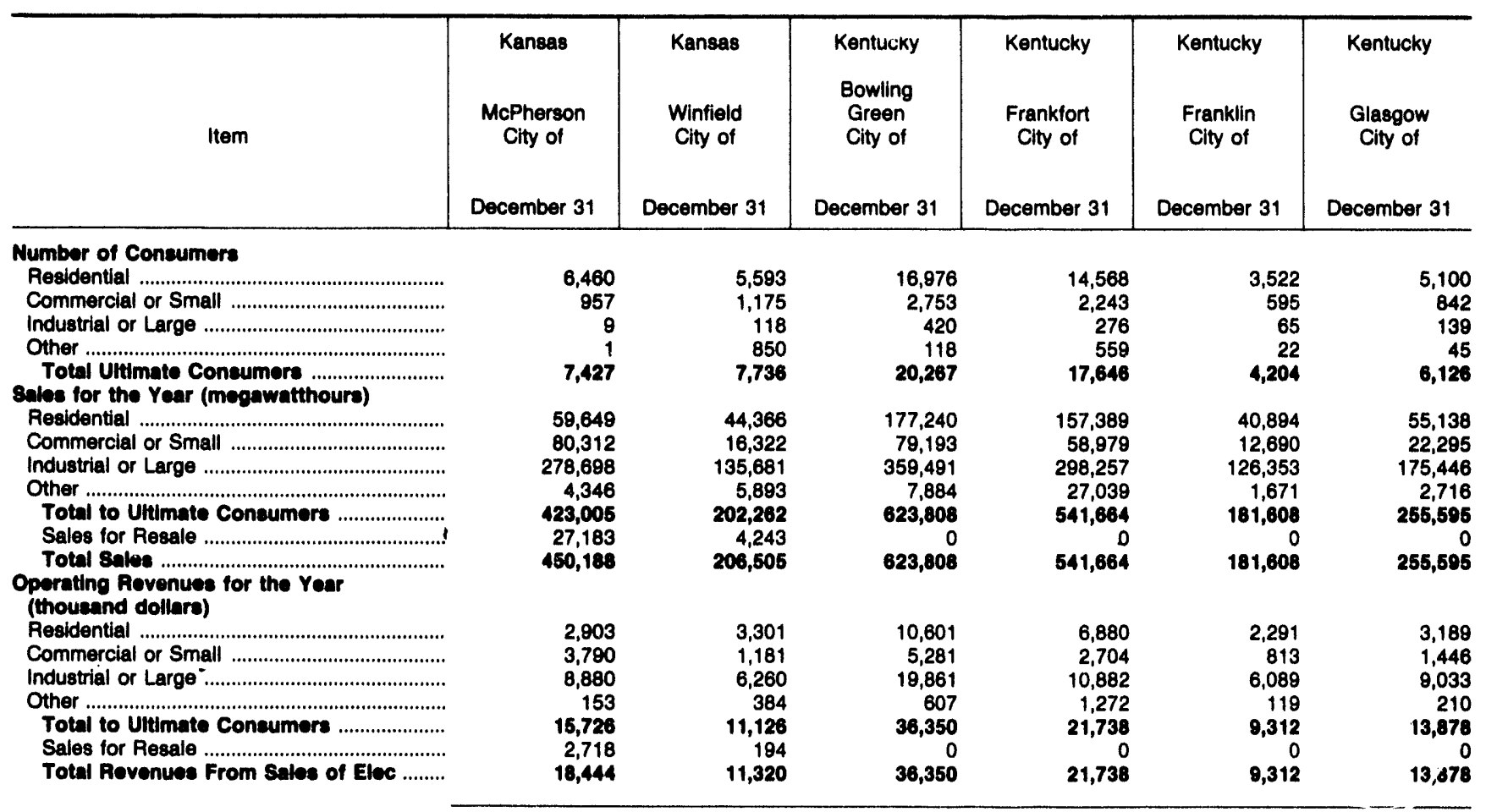

Note: Totals may not equal sum of components because of independent rounding.

Source: Energy Information Administration, Form ElA-861, "Annual Electric Utility Report." Data are submitted on a calendar year. 
Table 25. Number of Consumers, Sales, and Operating Revenue by Major U.S. Publicly Owned Electric Utility Within State, 1992 (Continued)

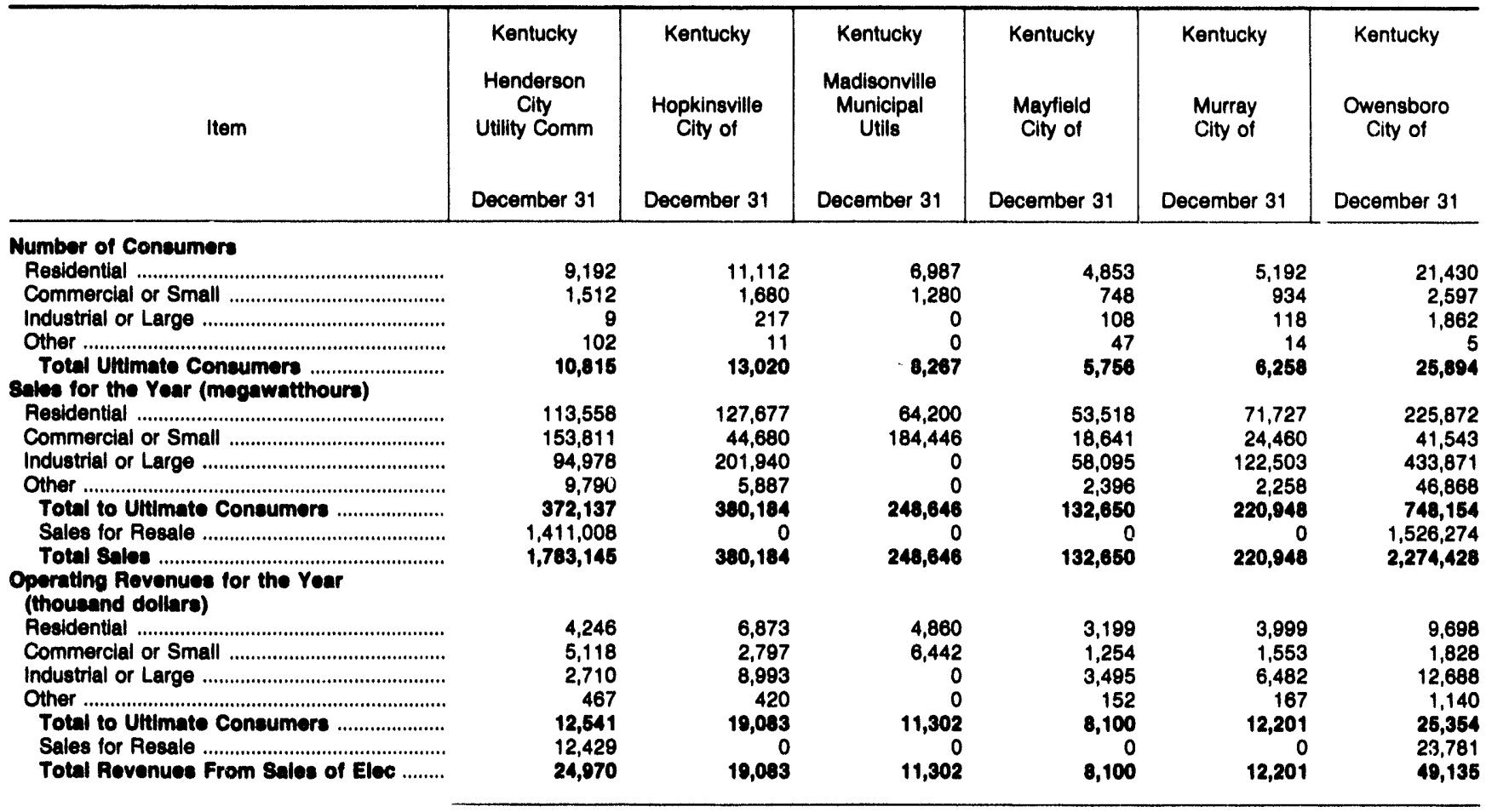

\begin{tabular}{|c|c|c|c|c|c|c|}
\hline Item & $\begin{array}{l}\text { Kentucky } \\
\text { Paducah } \\
\text { City of } \\
\text { December } 31\end{array}$ & $\begin{array}{c}\text { Louisiana } \\
\text { Alexandria } \\
\text { City of } \\
\text { December } 31\end{array}$ & $\begin{array}{l}\text { Louisiana } \\
\text { Lafayette } \\
\text { City of } \\
\text { December } 31\end{array}$ & $\begin{array}{l}\text { Louisiana } \\
\text { Lafayette } \\
\text { Public } \\
\text { Power Auth } \\
\text { December } 31\end{array}$ & $\begin{array}{c}\text { Louisiana } \\
\text { Louisiana } \\
\text { Energy } \\
\& \\
\text { Power Auth } \\
\text { December } 31\end{array}$ & $\begin{array}{l}\text { Louisiana } \\
\text { Morgan } \\
\text { City City of } \\
\text { December } 31\end{array}$ \\
\hline \multicolumn{7}{|l|}{ Number of Consumers } \\
\hline 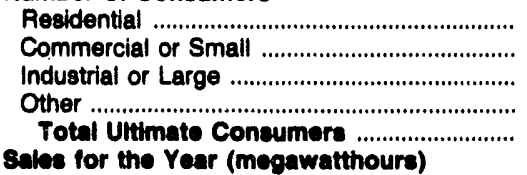 & $\begin{array}{r}18,056 \\
2,742 \\
444 \\
316 \\
21,558\end{array}$ & $\begin{array}{r}18,585 \\
1,687 \\
0 \\
161 \\
20,443\end{array}$ & $\begin{array}{r}40,209 \\
5,918 \\
0 \\
2,052 \\
48,170\end{array}$ & $\begin{array}{l}0 \\
0 \\
0 \\
0 \\
0\end{array}$ & $\begin{array}{l}0 \\
0 \\
0 \\
0 \\
0\end{array}$ & $\begin{array}{r}5,056 \\
1,175 \\
0 \\
0 \\
6,231\end{array}$ \\
\hline 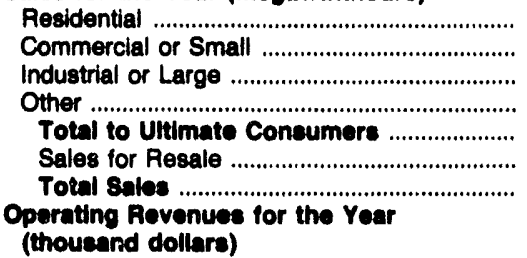 & $\begin{array}{r}208,720 \\
62,757 \\
224,082 \\
8,413 \\
503,972 \\
0 \\
503,972\end{array}$ & $\begin{array}{r}236,898 \\
300,004 \\
0 \\
8,269 \\
545,171 \\
0 \\
545,171\end{array}$ & $\begin{array}{r}545,142 \\
678,753 \\
0 \\
71,199 \\
1,295,094 \\
554,250 \\
1,849,344\end{array}$ & $\begin{array}{r}0 \\
0 \\
0 \\
0 \\
0 \\
1,394,430 \\
1,394,430\end{array}$ & $\begin{array}{r}0 \\
0 \\
0 \\
0 \\
0 \\
1,485,052 \\
1,485,052\end{array}$ & $\begin{array}{r}82,071 \\
60,278 \\
0 \\
0 \\
142,340 \\
0 \\
142,340\end{array}$ \\
\hline 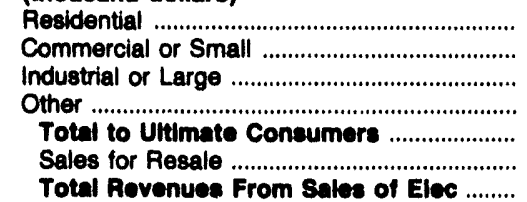 & $\begin{array}{r}12,358 \\
4,317 \\
12,930 \\
724 \\
30,329 \\
0 \\
30,329\end{array}$ & $\begin{array}{r}17,182 \\
21,133 \\
0 \\
136 \\
38,451 \\
0 \\
38,451\end{array}$ & $\begin{array}{r}35,223 \\
41,522 \\
0 \\
3,987 \\
80,732 \\
20,314 \\
101,046\end{array}$ & $\begin{array}{r}0 \\
0 \\
0 \\
0 \\
0 \\
48,744 \\
48,744\end{array}$ & $\begin{array}{r}0 \\
0 \\
0 \\
0 \\
0 \\
62,572 \\
62,572\end{array}$ & $\begin{array}{r}7,176 \\
2,234 \\
0 \\
0 \\
9,410 \\
0 \\
9,410\end{array}$ \\
\hline
\end{tabular}

Note: Totals may not equal sum of components because of independent rounding.

Source: Energy Information Administration, Form ElA-861, "Annual Electric Utility Report." Data are submitted on a calendar year. 
Table 25. Number of Consumers, Sales, and Operating Revenue by Major U.S. Publicly Owned Electric Utillty Within State, 1992 (Continued)

\begin{tabular}{|c|c|c|c|c|c|c|}
\hline Item & $\begin{array}{l}\text { Loulsiana } \\
\text { Natchitoches } \\
\text { City of } \\
\text { December } 31\end{array}$ & $\begin{array}{l}\text { Louisiana } \\
\text { Ruston } \\
\text { City of } \\
\text { December } 31\end{array}$ & $\begin{array}{c}\text { Louisiana } \\
\text { Terrebonne } \\
\text { Parish } \\
\text { Consol Govt } \\
\text { December } 31\end{array}$ & $\begin{array}{l}\text { Maryland } \\
\text { Easton } \\
\text { Utilities } \\
\text { Comm } \\
\text { December } 31\end{array}$ & $\begin{array}{l}\text { Maryland } \\
\text { Hagerstown } \\
\text { City of } \\
\text { December } 31\end{array}$ & $\begin{array}{c}\text { Massachusetts } \\
\text { Braintree } \\
\text { Town of } \\
\text { December } 31\end{array}$ \\
\hline \multicolumn{7}{|l|}{ Number of Conoumere } \\
\hline 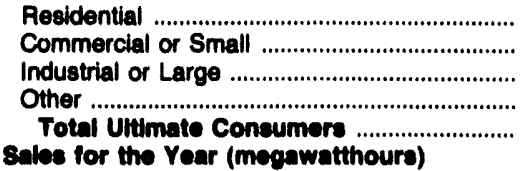 & $\begin{array}{r}5,565 \\
762 \\
9 \\
1 \\
6,337\end{array}$ & $\begin{array}{r}7,241 \\
1,010 \\
85 \\
0 \\
8,336\end{array}$ & $\begin{array}{r}7,444 \\
1,296 \\
0 \\
0 \\
8,740\end{array}$ & $\begin{array}{r}5,815 \\
1,486 \\
0 \\
106 \\
7,407\end{array}$ & $\begin{array}{r}15,309 \\
1,966 \\
130 \\
67 \\
17,472\end{array}$ & $\begin{array}{r}11,450 \\
1,788 \\
10 \\
279 \\
13,527\end{array}$ \\
\hline 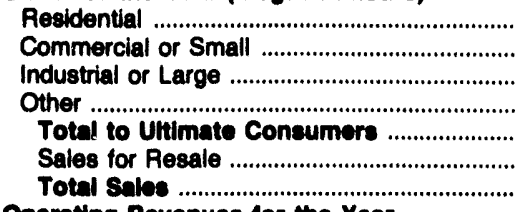 & $\begin{array}{r}56,247 \\
43,351 \\
65,334 \\
4,855 \\
169,787 \\
0 \\
169,787\end{array}$ & $\begin{array}{r}71,225 \\
42,747 \\
54,801 \\
0 \\
168,873 \\
0 \\
168,873\end{array}$ & $\begin{array}{r}104,213 \\
104,730 \\
0 \\
0 \\
208,943 \\
102,412 \\
311,355\end{array}$ & $\begin{array}{r}65,276 \\
115,034 \\
0 \\
9,813 \\
190,123 \\
2,275 \\
192,388\end{array}$ & $\begin{array}{r}110,778 \\
56,352 \\
113,000 \\
8,379 \\
288,509 \\
0 \\
288,509\end{array}$ & $\begin{array}{r}88,306 \\
195,848 \\
52,119 \\
12,042 \\
348,315 \\
29,780 \\
378,095\end{array}$ \\
\hline $\begin{array}{l}\text { Operating Rovenues for the Year } \\
\text { (thousand dollare) }\end{array}$ & & & & & & \\
\hline 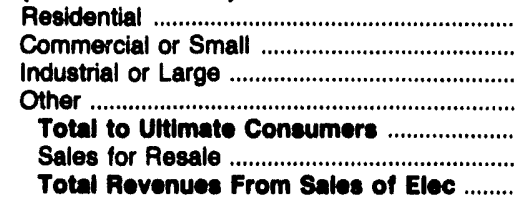 & $\begin{array}{r}3,507 \\
3,170 \\
3,462 \\
322 \\
10,481 \\
0 \\
10,461\end{array}$ & $\begin{array}{r}4,222 \\
3,233 \\
2,296 \\
0 \\
9,751 \\
0 \\
9,751\end{array}$ & $\begin{array}{r}7,875 \\
7,737 \\
0 \\
0 \\
15,612 \\
2,024 \\
17,636\end{array}$ & $\begin{array}{r}4,289 \\
7,216 \\
0 \\
679 \\
12,184 \\
215 \\
12,390\end{array}$ & $\begin{array}{r}6,672 \\
3,248 \\
4,985 \\
537 \\
15,442 \\
0 \\
15,442\end{array}$ & $\begin{array}{r}7,330 \\
16,747 \\
4,144 \\
1,034 \\
29,255 \\
2,189 \\
31,444\end{array}$ \\
\hline
\end{tabular}

\begin{tabular}{|c|c|c|c|c|c|c|}
\hline Item & $\begin{array}{l}\text { Massachusetts } \\
\text { Chicopee } \\
\text { City of } \\
\text { December } 31\end{array}$ & $\begin{array}{l}\text { Massachusetts } \\
\text { Concord } \\
\text { Town of } \\
\text { December } 31\end{array}$ & $\begin{array}{c}\text { Massachusetts } \\
\text { Danvers } \\
\text { Town of } \\
\text { December } 31\end{array}$ & $\begin{array}{l}\text { Massachusetts } \\
\text { Hingham } \\
\text { City of } \\
\text { December } 31\end{array}$ & $\begin{array}{l}\text { Massachusetts } \\
\text { Holyoke } \\
\text { City of } \\
\text { December } 31\end{array}$ & $\begin{array}{l}\text { Massachusetts } \\
\text { Hudson } \\
\text { Town of } \\
\text { December } 31\end{array}$ \\
\hline \multicolumn{7}{|l|}{ Number of Consumers } \\
\hline Residential .............................. & 22,061 & 5,899 & 9,190 & 7,636 & 15,399 & 8,487 \\
\hline Commercial or Small ............................................... & 1,871 & 1,058 & 1,338 & 886 & 2,209 & 1,105 \\
\hline Industrial or Large & 0 & 14 & 217 & 38 & 10 & 189 \\
\hline $\begin{array}{l}\text { Other } \\
\text { Total Uitimate Consumere } \\
\text { 8ales for the Year (megawathours) }\end{array}$ & $\begin{array}{r}475 \\
24,407\end{array}$ & $\begin{array}{r}53 \\
7,124\end{array}$ & $\begin{array}{r}319 \\
11,085\end{array}$ & $\begin{array}{r}53 \\
8,613\end{array}$ & $\begin{array}{r}529 \\
18,147\end{array}$ & $\begin{array}{r}246 \\
10,027\end{array}$ \\
\hline 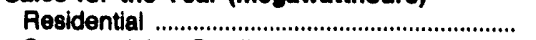 & 152,526 & 51,274 & 69,138 & 62,059 & 89,868 & 65,189 \\
\hline Commercial or Small & 169,018 & 35,530 & 35,751 & 21,584 & 137,460 & 11,048 \\
\hline Industrial or Large & & 45,034 & 161,882 & 41,074 & 9,940 & 157,610 \\
\hline $\begin{array}{l}\text { Other } \\
\text { Total to Uitimate Consumers }\end{array}$ & $\begin{array}{r}49,254 \\
370,798\end{array}$ & $\begin{array}{r}7,718 \\
139,558\end{array}$ & $\begin{array}{r}13,569 \\
280,341\end{array}$ & $\begin{array}{r}5,401 \\
130,118\end{array}$ & $\begin{array}{r}22,660 \\
260,028\end{array}$ & $\begin{array}{r}13,933 \\
247,780\end{array}$ \\
\hline & $\begin{array}{r}0 \\
247,780\end{array}$ \\
\hline Residential ........................................................ & 11,947 & 4,586 & 7,128 & 6,101 & 9,135 & 7,823 \\
\hline 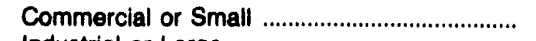 & 13,347 & 4,319 & 4,661 & 2,815 & 14,523 & 1,797 \\
\hline Industrial or Large & 0 & 3,062 & 18,876 & 4,085 & 894 & 17,826 \\
\hline $\begin{array}{l}\text { Other } \\
\text { Total to Uitimate Consumers }\end{array}$ & $\begin{array}{r}3,673 \\
28,967\end{array}$ & $\begin{array}{r}776 \\
12,743\end{array}$ & $\begin{array}{r}1,505 \\
32,170\end{array}$ & $\begin{array}{r}655 \\
13.856\end{array}$ & $\begin{array}{r}2,246 \\
26,798\end{array}$ & $\begin{array}{r}965 \\
28.411\end{array}$ \\
\hline 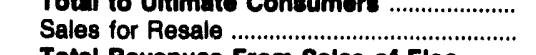 & $\begin{aligned} 20,00 \% \\
1,805\end{aligned}$ & $\begin{array}{r}12,143 \\
0\end{array}$ & 174 & 55 & 144 & 0 \\
\hline Total Revenues From sales of Elec ......... & 30,772 & 12,743 & 32,344 & 13,711 & 26,942 & 28,411 \\
\hline
\end{tabular}

Note: Totals may not equal sum of components because of independentrounding.

Source: Energy Information Administration, Form EIA-861, "Annual Electric Utility Report." Data are submitted on a calendar year. 
Table 25. Number of Consumers, Sales, and Operating Revenue by Major U.S. Publicly Owned Electric Utility Within State, 1992 (Continued)

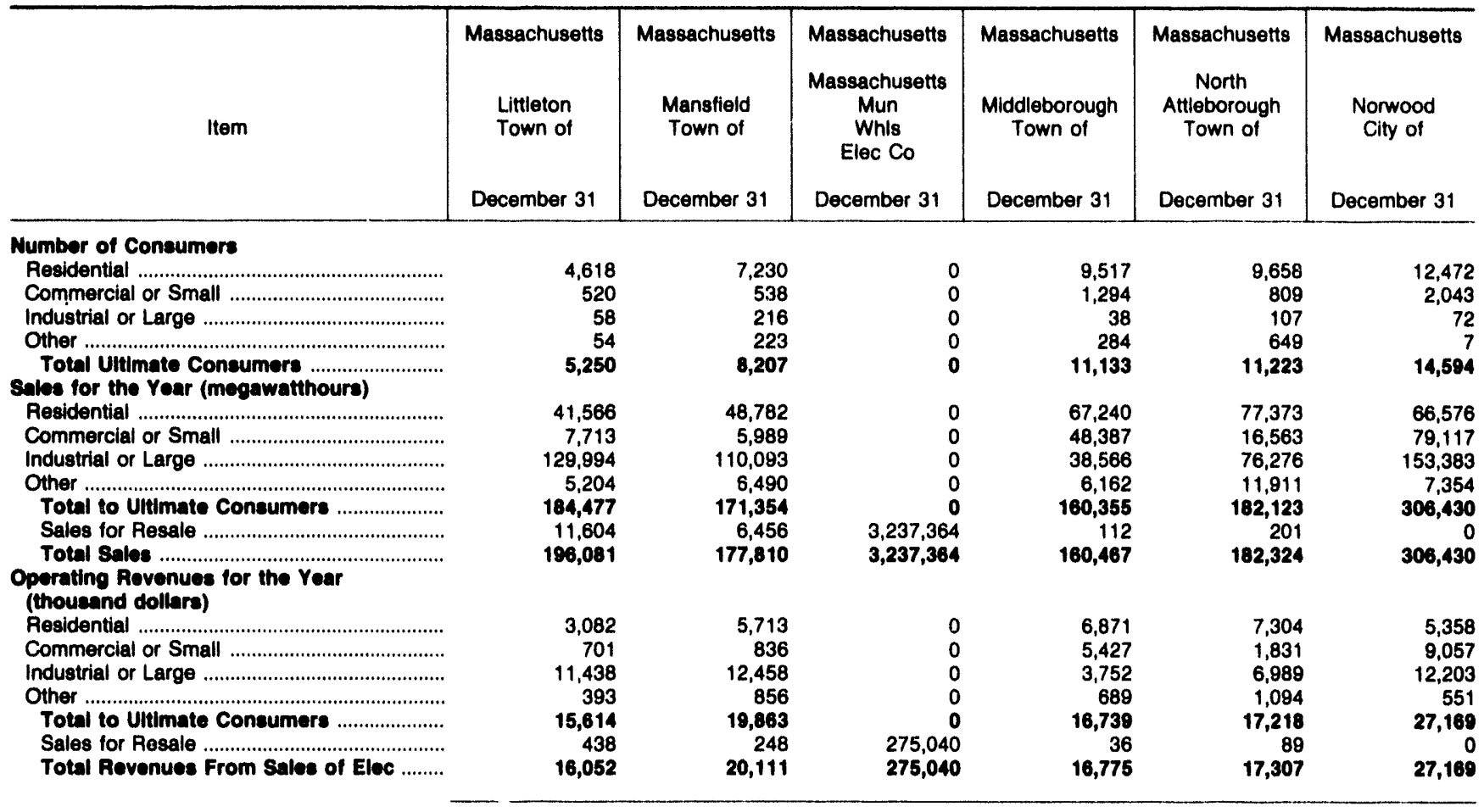

\begin{tabular}{|c|c|c|c|c|c|c|}
\hline Item & $\begin{array}{l}\text { Massachusetts } \\
\text { Peabody } \\
\text { City of } \\
\text { December } 31\end{array}$ & $\begin{array}{l}\text { Massachusetts } \\
\text { Reading } \\
\text { Town of } \\
\text { December } 31\end{array}$ & $\begin{array}{l}\text { Massachusetts } \\
\text { Shrewsbury } \\
\text { Town of } \\
\text { December } 31\end{array}$ & $\begin{array}{c}\text { Massachusetts } \\
\text { Taunton } \\
\text { City of } \\
\text { December } 31\end{array}$ & $\begin{array}{c}\text { Massachusetts } \\
\text { Wakefield } \\
\text { Town of } \\
\text { December } 31\end{array}$ & $\begin{array}{c}\text { Massachusetts } \\
\text { Wellesley } \\
\text { Town of } \\
\text { December } 31\end{array}$ \\
\hline \multicolumn{7}{|l|}{ Number of Coneumers } \\
\hline Residential ................... & 18,737 & 21,546 & 10,841 & 25,667 & 9,316 & 8,451 \\
\hline 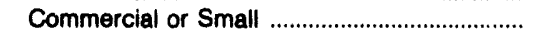 & 1,721 & 0 & 745 & 4,008 & 1,211 & 972 \\
\hline Industrial or Large & 1,145 & 2,192 & 45 & 80 & 285 & 0 \\
\hline Other ....... & 114 & 422 & 369 & 123 & 1 & 70 \\
\hline \multicolumn{7}{|l|}{ Sales for the Year (megawatthoure) } \\
\hline 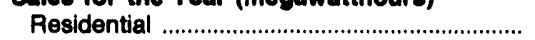 & 133,696 & 171,335 & 85,167 & 176,313 & 58,585 & 69,475 \\
\hline Commercial or Small ……………………........... & 17,363 & & 27,276 & 131,023 & 16,974 & 114,806 \\
\hline 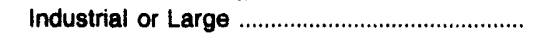 & 182,954 & 349,190 & 113,716 & 123,849 & 59,099 & 0 \\
\hline Other & 35,692 & 20,694 & 15,980 & 18,556 & 4,758 & 8,324 \\
\hline Total to Ulitimate Consumers ....................... & 369,705 & 541,219 & 242,139 & 449,741 & 139,416 & 192,605 \\
\hline Sales for Resale ................................................. & & 632 & 1,328 & 36,434 & & \\
\hline Total Salos & 369,705 & 541,851 & 243,467 & 486,175 & 139,416 & 192,605 \\
\hline \multicolumn{7}{|l|}{$\begin{array}{l}\text { Operating Revenues for the Year } \\
\text { (thousand dollars) }\end{array}$} \\
\hline 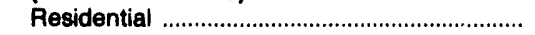 & 14,182 & 15,478 & 6,947 & 13,138 & 5,790 & 6,538 \\
\hline Commercial or Small & 2,152 & & 2,893 & 11,033 & 1,919 & 10,245 \\
\hline Industrial or Large & 21,523 & 26,322 & 9,700 & 8,101 & 6,430 & 0 \\
\hline Other & 4,141 & 1,913 & 1,486 & 1,556 & 534 & 830 \\
\hline Total to Uitimate Consumers ......................... & 41,998 & 43,713 & 21,026 & 33,828 & 14,673 & 17,613 \\
\hline Sales for Resale .. & & 64 & 108 & 3,946 & & \\
\hline Total Revenues From Sales of Elec ......... & 41,998 & 43,777 & 21,134 & 37,774 & 14,673 & 17,613 \\
\hline
\end{tabular}

Note: Totals may not equal sum of components because of independent rounding.

Source: Energy Information Administration, Form ElA-861, "Annual Electric Utility Report." Data are submitted on a calendar year. 
Table 25. Number of Consumers, Sales, and Operating Revenue by Major U.S. Publicly Owned Electric Utility Within State, 1992 (Continued)

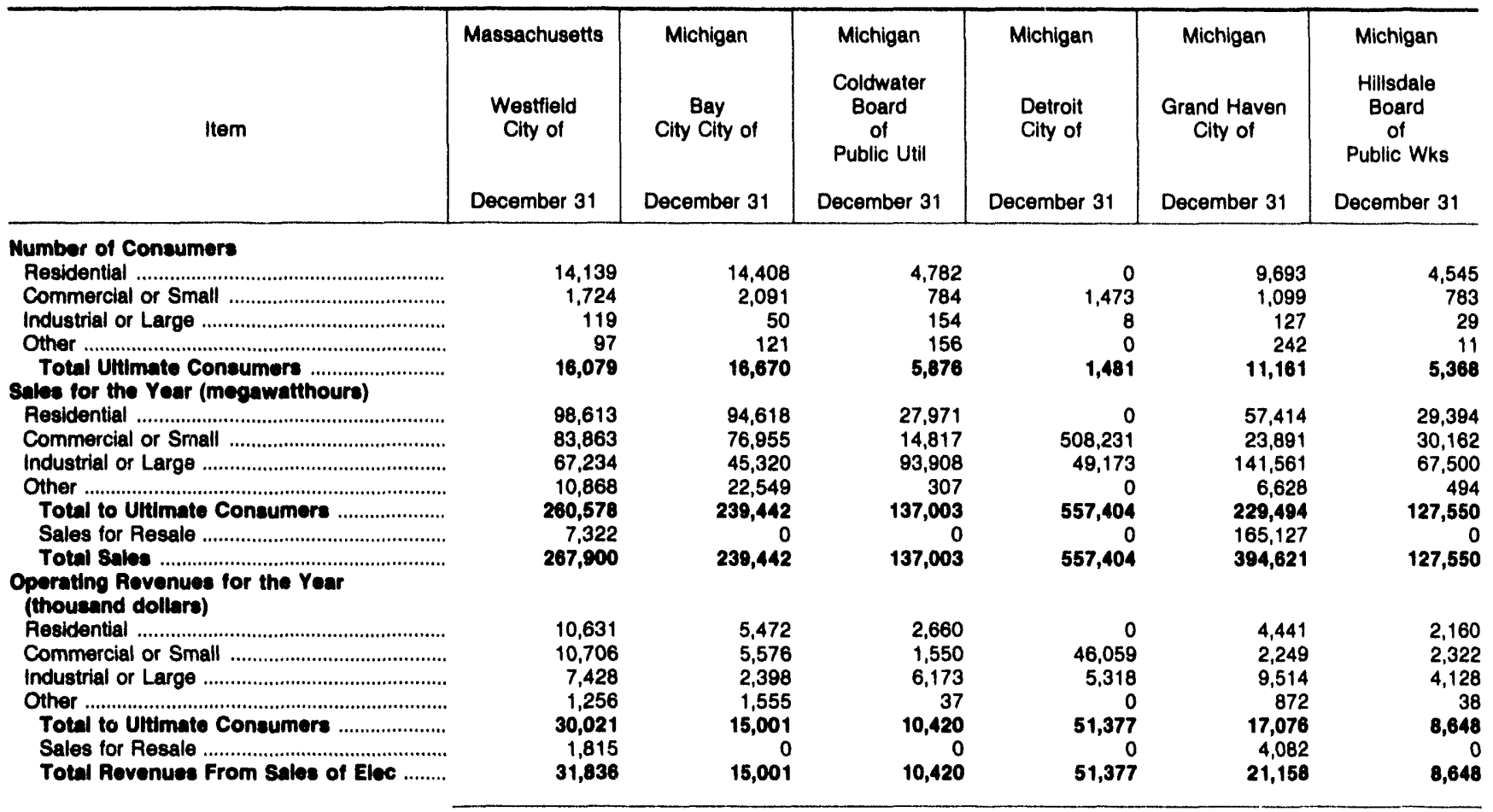

\begin{tabular}{|c|c|c|c|c|c|c|}
\hline Item & $\begin{array}{l}\text { Michigan } \\
\text { Holland } \\
\text { City of } \\
\text { December } 31\end{array}$ & $\begin{array}{l}\text { Michigan } \\
\text { Lansing } \\
\text { City of } \\
\text { December } 31\end{array}$ & $\begin{array}{l}\text { Michigan } \\
\text { Marquette } \\
\text { City of } \\
\text { December } 31\end{array}$ & $\begin{array}{c}\text { Michigan } \\
\text { Michigan } \\
\text { Public } \\
\text { Power Agency } \\
\text { December } 31\end{array}$ & $\begin{array}{l}\text { Michigan } \\
\text { Michigan } \\
\text { South } \\
\text { Central } \\
\text { Pwr Agy } \\
\text { December } 31\end{array}$ & $\begin{array}{c}\text { Michigan } \\
\text { Sturgis } \\
\text { City of } \\
\text { December } 31\end{array}$ \\
\hline \multicolumn{7}{|l|}{ Number of Consumers } \\
\hline Resident & 17,011 & 77,646 & 12,656 & 0 & 0 & 5,526 \\
\hline Commercial or Small . & 2,957 & 11,652 & 1,408 & 0 & 0 & 798 \\
\hline 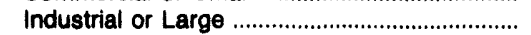 & 107 & 151 & 0 & 0 & 0 & 73 \\
\hline 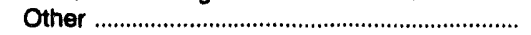 & 26 & 0 & 717 & 0 & 0 & 231 \\
\hline \multicolumn{3}{|l|}{ Sales for the Year (megawatthoure) } & 14,781 & 0 & 0 & 6,628 \\
\hline Residential. & 108,640 & 523,290 & 81,115 & 0 & 0 & 40,702 \\
\hline 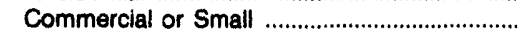 & 73,820 & 940,834 & 103,838 & 0 & 0 & 46,697 \\
\hline Industrial or Large & 439,267 & 671,975 & 0 & 0 & 0 & 95,713 \\
\hline 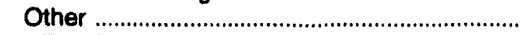 & 2,781 & 36,597 & 41,219 & 0 & 0 & 1,780 \\
\hline Total to Ultimate Consumers & 624,508 & $2,172,696$ & 226,172 & 0 & 0 & 184,892 \\
\hline 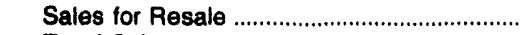 & & 187,643 & 13,374 & $2,212,905$ & 423,114 & \\
\hline 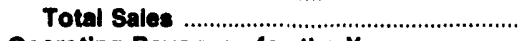 & 624,508 & $2,360,339$ & 239,546 & $2,212,905$ & 423,114 & 184,892 \\
\hline \multicolumn{7}{|l|}{$\begin{array}{l}\text { Operating Revenues for the Year } \\
\text { (thousand dollars) }\end{array}$} \\
\hline$x_{1}$ & 6,796 & 28,320 & 6,193 & 0 & 0 & 2,712 \\
\hline 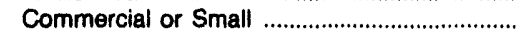 & 5.429 & 46,631 & 6,709 & 0 & 0 & 3,710 \\
\hline 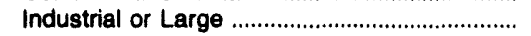 & 22,910 & 29,177 & 0 & 0 & 0 & 5,581 \\
\hline 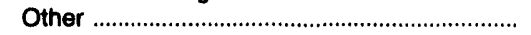 & 330 & 4,423 & 2,759 & 0 & 0 & 123 \\
\hline Total to Uitimate Consumers ........................ & 35,465 & 108,551 & 15,661 & $\mathbf{0}$ & 0 & 12,126 \\
\hline 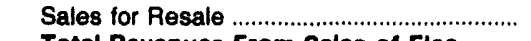 & 0 & 5,903 & 2,905 & 91,992 & 20,668 & \\
\hline Total Revenues From Sales of Elec & 35,465 & 114,454 & 18,566 & 91,992 & 20,668 & 12,126 \\
\hline
\end{tabular}

Note: Totals may not equal sum of ccmponents because of independent rounding.

Source: Energy Information Administration, Form EIA-861, "Annual Electric Utility Report." Data are submitted on a calendar year. 
Table 25. Number of Consumers, Sales, and Operating Revenue by Major U.S. Publicly Owned Electric Utility Within State, 1992 (Continued)

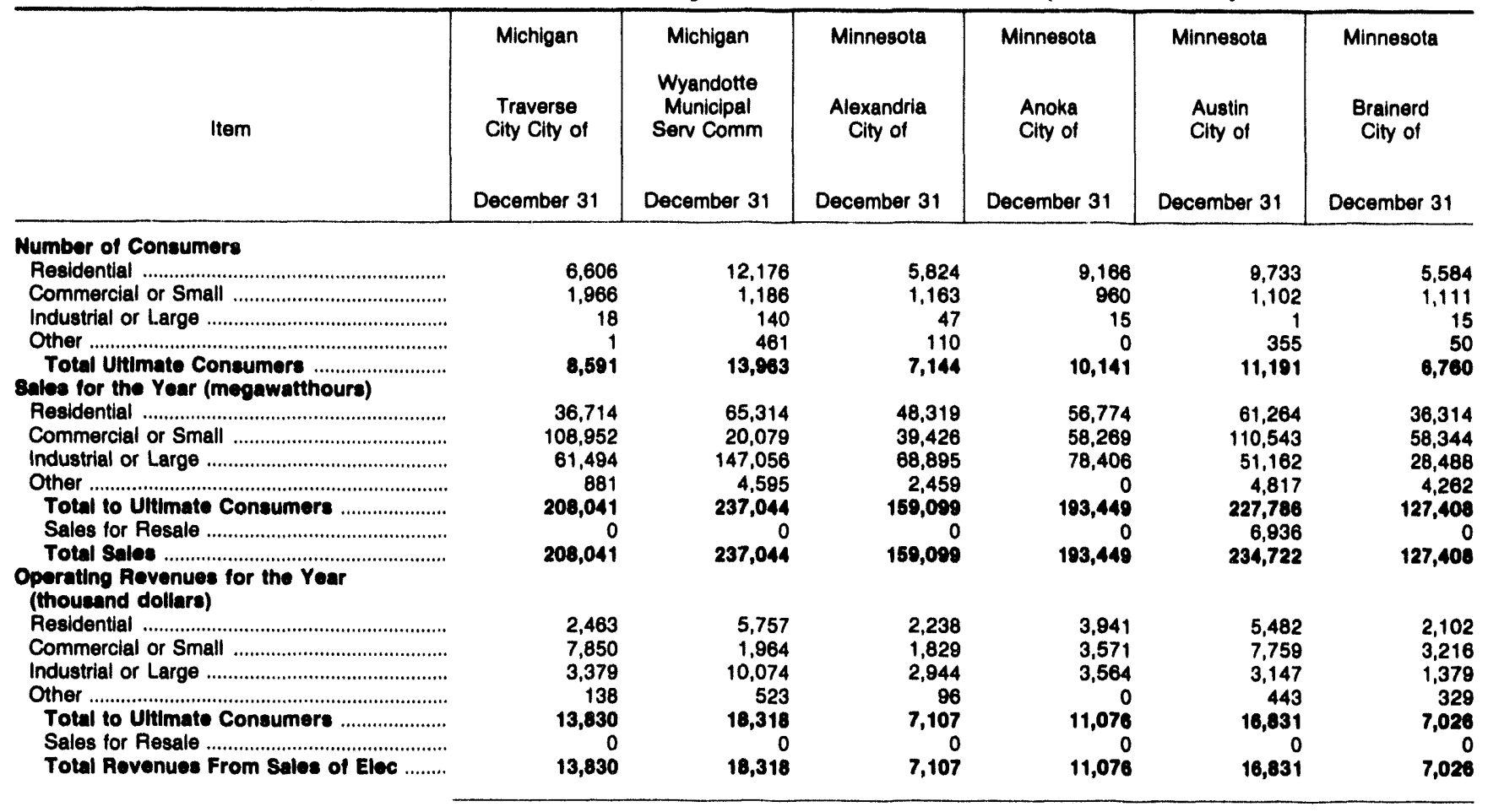

\begin{tabular}{|c|c|c|c|c|c|c|}
\hline Item & $\begin{array}{l}\text { Minnesota } \\
\text { Fairmont } \\
\text { Public } \\
\text { Utilities } \\
\text { Comm } \\
\text { December } 31\end{array}$ & $\begin{array}{l}\text { Minnesota } \\
\text { Hutchinson } \\
\text { Utilities } \\
\text { Comm } \\
\text { December } 31\end{array}$ & $\begin{array}{l}\text { Minnesota } \\
\text { Marshall } \\
\text { City of } \\
\text { December } 31\end{array}$ & $\begin{array}{l}\text { Minnesota } \\
\text { Moorhead } \\
\text { City of } \\
\text { December } 31\end{array}$ & $\begin{array}{l}\text { Minnesota } \\
\text { New Ulm } \\
\text { Public } \\
\text { Utilities } \\
\text { Comm } \\
\text { December } 31\end{array}$ & $\begin{array}{l}\text { Minnesota } \\
\text { Northern } \\
\text { Municipal } \\
\text { Power Agny } \\
\text { December } 31\end{array}$ \\
\hline 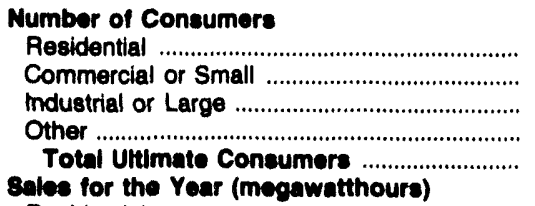 & $\begin{array}{r}5,012 \\
765 \\
18 \\
8 \\
8,803\end{array}$ & $\begin{array}{r}4,732 \\
640 \\
1 \\
1 \\
5,374\end{array}$ & $\begin{array}{r}5,024 \\
654 \\
178 \\
0 \\
5,856\end{array}$ & $\begin{array}{r}11,150 \\
1,080 \\
553 \\
3 \\
3 \\
12,786\end{array}$ & $\begin{array}{r}5,516 \\
828 \\
5 \\
75 \\
6,424\end{array}$ & $\begin{array}{l}0 \\
0 \\
0 \\
0 \\
0\end{array}$ \\
\hline 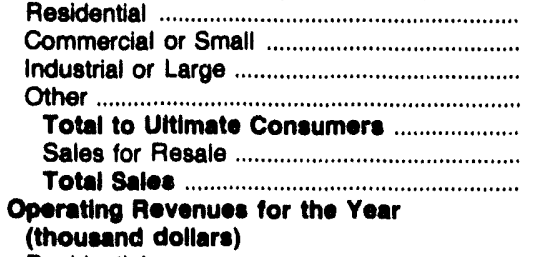 & $\begin{array}{r}33,514 \\
34,907 \\
72,112 \\
5,564 \\
146,097 \\
0 \\
146,097\end{array}$ & $\begin{array}{r}36,127 \\
85,911 \\
123,323 \\
1,063 \\
246,424 \\
18 \\
246,442\end{array}$ & $\begin{array}{r}43,694 \\
12,781 \\
247,469 \\
1,174 \\
305,118 \\
0 \\
305,118\end{array}$ & $\begin{array}{r}118,382 \\
17,750 \\
172,440 \\
6,645 \\
315,217 \\
0 \\
315,217\end{array}$ & $\begin{array}{r}35,150 \\
48,300 \\
62,541 \\
10,324 \\
156,315 \\
0 \\
166,316\end{array}$ & $\begin{array}{r}0 \\
0 \\
0 \\
0 \\
0 \\
716,084 \\
716,004\end{array}$ \\
\hline 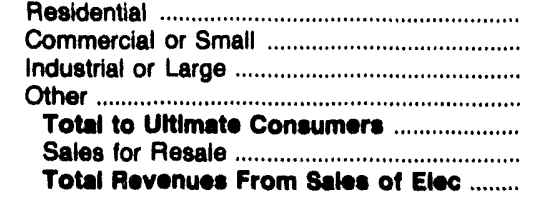 & $\begin{array}{r}2,824 \\
2,730 \\
4,758 \\
291 \\
10,603 \\
0 \\
10,603\end{array}$ & $\begin{array}{r}1,719 \\
3,705 \\
4,082 \\
39 \\
9,545 \\
1 \\
9,546\end{array}$ & $\begin{array}{r}1,786 \\
520 \\
7,428 \\
99 \\
9,833 \\
0 \\
9,833\end{array}$ & $\begin{array}{r}4,522 \\
739 \\
6,300 \\
290 \\
11,851 \\
0 \\
11,851\end{array}$ & $\begin{array}{r}2,326 \\
2,925 \\
3,126 \\
567 \\
8,944 \\
0 \\
8,944\end{array}$ & $\begin{array}{r}0 \\
0 \\
0 \\
0 \\
0 \\
34,518 \\
34,518\end{array}$ \\
\hline
\end{tabular}

Note: Totais may not equal sum of components because of independent rounding.

Source: Energy Information Administration, Form EIA-861, "Annual Electric Utility Report." Data are submitted on a calendar year. 
Table 25. Number of Consumers, Sales, and Operating Revenue by Major U.S. Publlcly Owned Electric Utillty Within State, 1992 (Continued)

\begin{tabular}{|c|c|c|c|c|c|c|}
\hline Item & $\begin{array}{l}\text { Minnesota } \\
\text { Owatonna } \\
\text { City of }\end{array}$ & $\begin{array}{c}\text { Minnesota } \\
\text { Rochester } \\
\text { Public } \\
\text { Utilities } \\
\text { Docember } 31\end{array}$ & $\begin{array}{l}\text { Minnesota } \\
\text { Southern } \\
\text { Minnesota } \\
\text { Mun P } \\
\text { Agny } \\
\text { December } 31\end{array}$ & $\begin{array}{l}\text { Minnesota } \\
\text { Western } \\
\text { Minnesota } \\
\text { Mun } \\
\text { Pwr Agny } \\
\text { December } 31\end{array}$ & $\begin{array}{l}\text { Minnesota } \\
\text { Willmar } \\
\text { Municipal } \\
\text { Utils Comm } \\
\text { December } 31\end{array}$ & $\begin{array}{l}\text { Mississippi } \\
\text { Aberdeen } \\
\text { Clty of } \\
\text { December } 31\end{array}$ \\
\hline 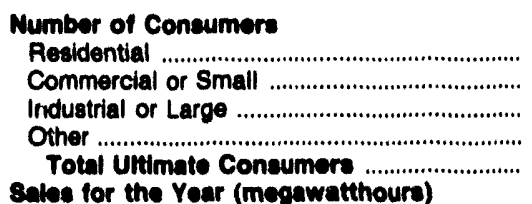 & $\begin{array}{r}7,858 \\
798 \\
103 \\
25 \\
8,785\end{array}$ & $\begin{array}{r}29,989 \\
3,153 \\
18 \\
4 \\
39,164\end{array}$ & $\begin{array}{l}0 \\
0 \\
0 \\
0 \\
0\end{array}$ & $\begin{array}{l}0 \\
0 \\
0 \\
0 \\
0\end{array}$ & $\begin{array}{r}7,053 \\
1,219 \\
0 \\
105 \\
8,377\end{array}$ & $\begin{array}{r}2,882 \\
546 \\
62 \\
16 \\
3,608\end{array}$ \\
\hline 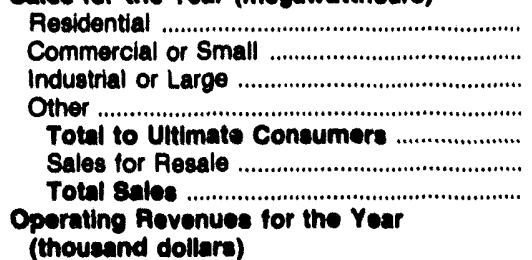 & $\begin{array}{r}49,372 \\
17,628 \\
140,785 \\
3,408 \\
211,373 \\
0 \\
211,373\end{array}$ & $\begin{array}{r}180,593 \\
274,277 \\
376,086 \\
12,580 \\
863,636 \\
199,620 \\
1,083,156\end{array}$ & $\begin{array}{r}0 \\
0 \\
0 \\
0 \\
0 \\
2,394,509 \\
2,394,600\end{array}$ & $\begin{array}{r}0 \\
0 \\
0 \\
0 \\
0 \\
1,948,458 \\
1,948,468\end{array}$ & $\begin{array}{r}49,024 \\
133,258 \\
0 \\
249 \\
182,631 \\
0 \\
182,631\end{array}$ & $\begin{array}{r}36,614 \\
12,605 \\
99,509 \\
2,728 \\
151,488 \\
0 \\
161,488\end{array}$ \\
\hline 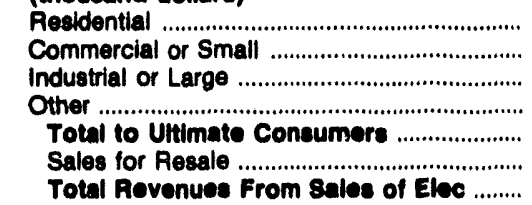 & $\begin{array}{r}4,977 \\
1,512 \\
8,100 \\
184 \\
14,773 \\
0 \\
14,773\end{array}$ & $\begin{array}{r}15,600 \\
20,073 \\
22,410 \\
1,276 \\
60,350 \\
8,627 \\
67,986\end{array}$ & $\begin{array}{r}0 \\
0 \\
0 \\
0 \\
0 \\
120,562 \\
120,582\end{array}$ & $\begin{array}{r}0 \\
0 \\
0 \\
0 \\
0 \\
40,094 \\
40,094\end{array}$ & $\begin{array}{r}2,956 \\
7,033 \\
0 \\
21 \\
10,010 \\
0 \\
10,010\end{array}$ & $\begin{array}{r}2,058 \\
807 \\
4,828 \\
197 \\
7,090 \\
0 \\
7,800\end{array}$ \\
\hline
\end{tabular}

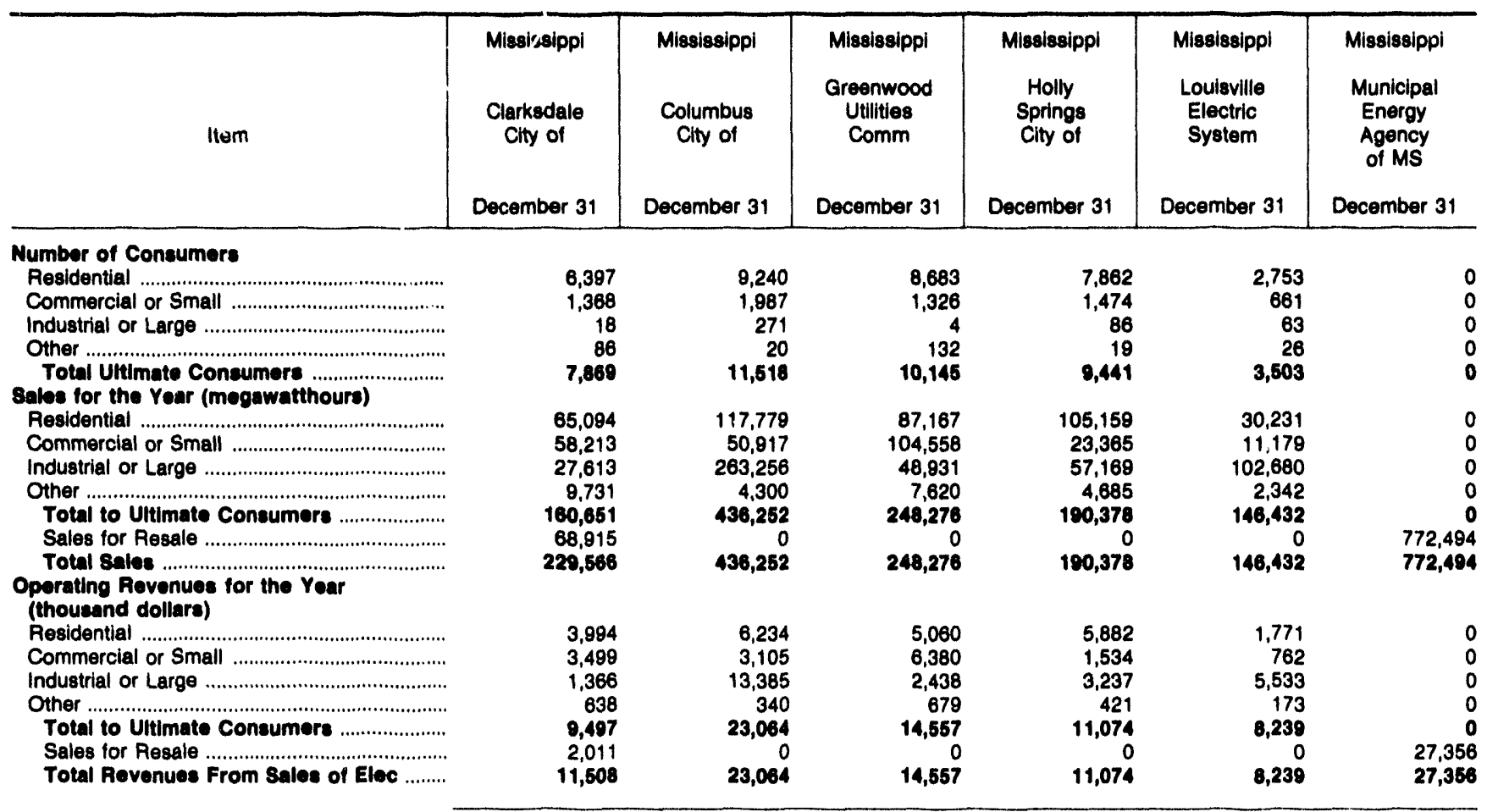

Note: Totals may not equal sum of components because of independent rounding

Source: Energy Information Admiristration, Form ElA-861, "Annual Electric Utility Report." Data are submitted on a calendar year. 
Table 25. Number of Consumers, Sales, and Operating Revenue by Major U.S. Publicly Owned Electric Utillty Within State, i.992 (Continued)

\begin{tabular}{|c|c|c|c|c|c|c|}
\hline Item & $\begin{array}{l}\text { Misaisaippi } \\
\text { New Albany } \\
\text { City of } \\
\text { December } 31\end{array}$ & $\begin{array}{l}\text { Misaissippi } \\
\text { Oxford } \\
\text { City of } \\
\text { December } 31\end{array}$ & $\begin{array}{c}\text { Misaiasippi } \\
\text { Starkville } \\
\text { Clty of } \\
\text { December } 31\end{array}$ & $\begin{array}{l}\text { Mlssissippi } \\
\text { Tupelo } \\
\text { City of } \\
\text { December } 31\end{array}$ & $\begin{array}{c}\text { Misgisaippl } \\
\text { West } \\
\text { Point } \\
\text { City of } \\
\text { December } 31\end{array}$ & $\begin{array}{l}\text { Miseouri } \\
\text { Carthage } \\
\text { City of }\end{array}$ \\
\hline \multicolumn{7}{|l|}{ Number of conaumere } \\
\hline 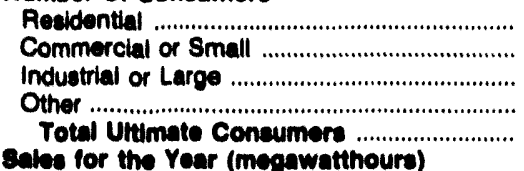 & $\begin{array}{r}7,313 \\
1,380 \\
118 \\
21 \\
8,842\end{array}$ & $\begin{array}{r}4,533 \\
727 \\
105 \\
24 \\
5,399\end{array}$ & $\begin{array}{r}7,400 \\
900 \\
150 \\
50 \\
\mathbf{8 , 6 0 0}\end{array}$ & $\begin{array}{r}10,680 \\
2,895 \\
416 \\
17 \\
14,008\end{array}$ & $\begin{array}{r}3,379 \\
533 \\
77 \\
9 \\
3,908\end{array}$ & $\begin{array}{r}5,585 \\
831 \\
19 \\
0 \\
0,835\end{array}$ \\
\hline 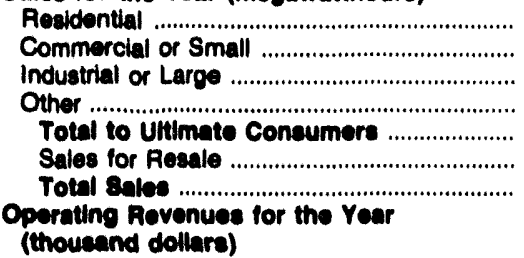 & $\begin{array}{r}96,916 \\
25,682 \\
77,115 \\
3,777 \\
203,490 \\
0 \\
203,490\end{array}$ & $\begin{array}{r}56,184 \\
24,034 \\
50,763 \\
2,486 \\
133,467 \\
0 \\
133,467\end{array}$ & $\begin{array}{r}81,214 \\
22,353 \\
191,447 \\
2,952 \\
297,986 \\
0 \\
297,096\end{array}$ & $\begin{array}{r}146,269 \\
78,743 \\
348,543 \\
9,017 \\
\mathbf{5 8 3 , 5 7 2} \\
0 \\
683,572\end{array}$ & $\begin{array}{r}34,664 \\
14,583 \\
126,953 \\
2,994 \\
179,104 \\
0 \\
179,194\end{array}$ & $\begin{array}{r}44,814 \\
35,651 \\
82,741 \\
8,043 \\
171,349 \\
0 \\
171,349\end{array}$ \\
\hline 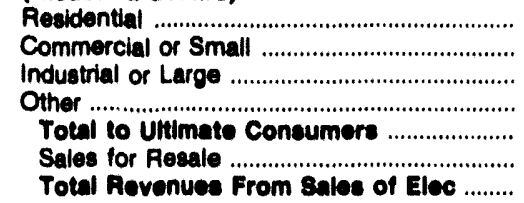 & $\begin{array}{r}5,551 \\
1,692 \\
4,556 \\
265 \\
12,084 \\
0 \\
12,084\end{array}$ & $\begin{array}{r}2,907 \\
1,420 \\
2,630 \\
204 \\
7,181 \\
0 \\
7,161\end{array}$ & $\begin{array}{r}4,734 \\
1,468 \\
9,176 \\
215 \\
16,603 \\
0 \\
16,603\end{array}$ & $\begin{array}{r}7,841 \\
4,834 \\
17,818 \\
722 \\
31,215 \\
0 \\
31,215\end{array}$ & $\begin{array}{r}2,084 \\
970 \\
6,723 \\
219 \\
9,900 \\
0 \\
9,988\end{array}$ & $\begin{array}{r}2,762 \\
2,020 \\
3,466 \\
442 \\
8,890 \\
0 \\
8,690\end{array}$ \\
\hline
\end{tabular}

\begin{tabular}{|c|c|c|c|c|c|c|}
\hline Item & $\begin{array}{c}\text { Missouri } \\
\text { Columbia } \\
\text { City of }\end{array}$ & $\begin{array}{l}\text { Missouri } \\
\text { Hannibal } \\
\text { City of } \\
\text { December } 31\end{array}$ & $\begin{array}{c}\text { Missouri } \\
\text { Independence } \\
\text { City of }\end{array}$ & $\begin{array}{l}\text { Missouri } \\
\text { Kennett } \\
\text { City of } \\
\text { December } 31\end{array}$ & $\begin{array}{l}\text { Missouri } \\
\text { Kirkwood } \\
\text { City of } \\
\text { December } 31\end{array}$ & $\begin{array}{l}\text { Missouri } \\
\text { Lebanon } \\
\text { City of } \\
\text { December } 31\end{array}$ \\
\hline \multicolumn{7}{|l|}{ Number of Consumers } \\
\hline 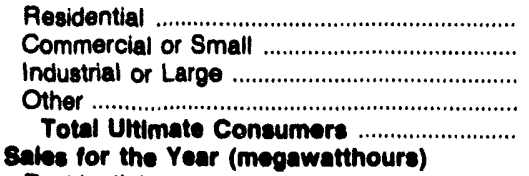 & $\begin{array}{r}24,844 \\
3,629 \\
387 \\
1 \\
28,861\end{array}$ & $\begin{array}{r}7,391 \\
1,082 \\
125 \\
22 \\
8,620\end{array}$ & $\begin{array}{r}44,736 \\
4,332 \\
15 \\
58 \\
49,141\end{array}$ & $\begin{array}{r}4,673 \\
823 \\
122 \\
0 \\
5,618\end{array}$ & $\begin{array}{r}8,306 \\
961 \\
51 \\
0 \\
9,318\end{array}$ & $\begin{array}{r}3,640 \\
947 \\
43 \\
0 \\
4,630\end{array}$ \\
\hline 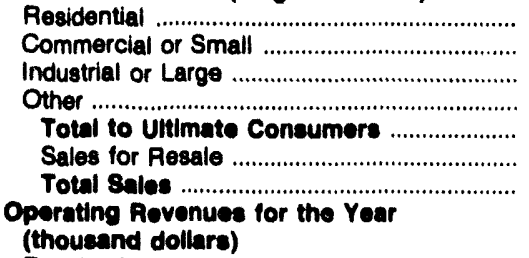 & $\begin{array}{r}221,512 \\
134,720 \\
337,830 \\
6,673 \\
700,735 \\
0 \\
700,735\end{array}$ & $\begin{array}{r}61,124 \\
19,428 \\
75,649 \\
6,535 \\
162,734 \\
0 \\
162,734\end{array}$ & $\begin{array}{r}345,043 \\
356,487 \\
38,457 \\
9,062 \\
749,049 \\
12,050 \\
761,099\end{array}$ & $\begin{array}{r}58,062 \\
13,800 \\
63,085 \\
0 \\
134,747 \\
0 \\
134,747\end{array}$ & $\begin{array}{r}71,959 \\
27,663 \\
65,309 \\
408 \\
165,339 \\
0 \\
165,339\end{array}$ & $\begin{array}{r}32,241 \\
31,586 \\
60,887 \\
0 \\
124,714 \\
0 \\
124,71 d\end{array}$ \\
\hline 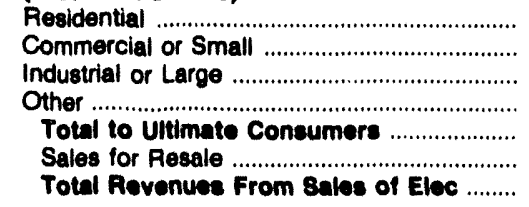 & $\begin{array}{r}15,498 \\
7,844 \\
19,934 \\
511 \\
43,788 \\
0 \\
43,788\end{array}$ & $\begin{array}{r}3,865 \\
1,369 \\
3,987 \\
269 \\
9,490 \\
0 \\
9,480\end{array}$ & $\begin{array}{r}25,853 \\
22,239 \\
1,695 \\
653 \\
50,440 \\
1,052 \\
51,482\end{array}$ & $\begin{array}{r}2,199 \\
673 \\
1,950 \\
0 \\
4,822 \\
0 \\
4,822\end{array}$ & $\begin{array}{r}5,360 \\
2,015 \\
3,464 \\
66 \\
10,805 \\
0 \\
10,905\end{array}$ & $\begin{array}{r}2,312 \\
2,157 \\
3,280 \\
0 \\
7,740 \\
0 \\
7,740\end{array}$ \\
\hline
\end{tabular}

Note: Totals may not equal sum of components because of independentrounding

Source: Energy Information Administration, Form ElA-861, "Annual Electric Utility Report." Data are submitted on a calendar year. 
Table 25. Number of Consumers, Sales, and Operating Revenue by Major U.S. Publicly Owned Electric Utillty Within State, 1992 (Continued)

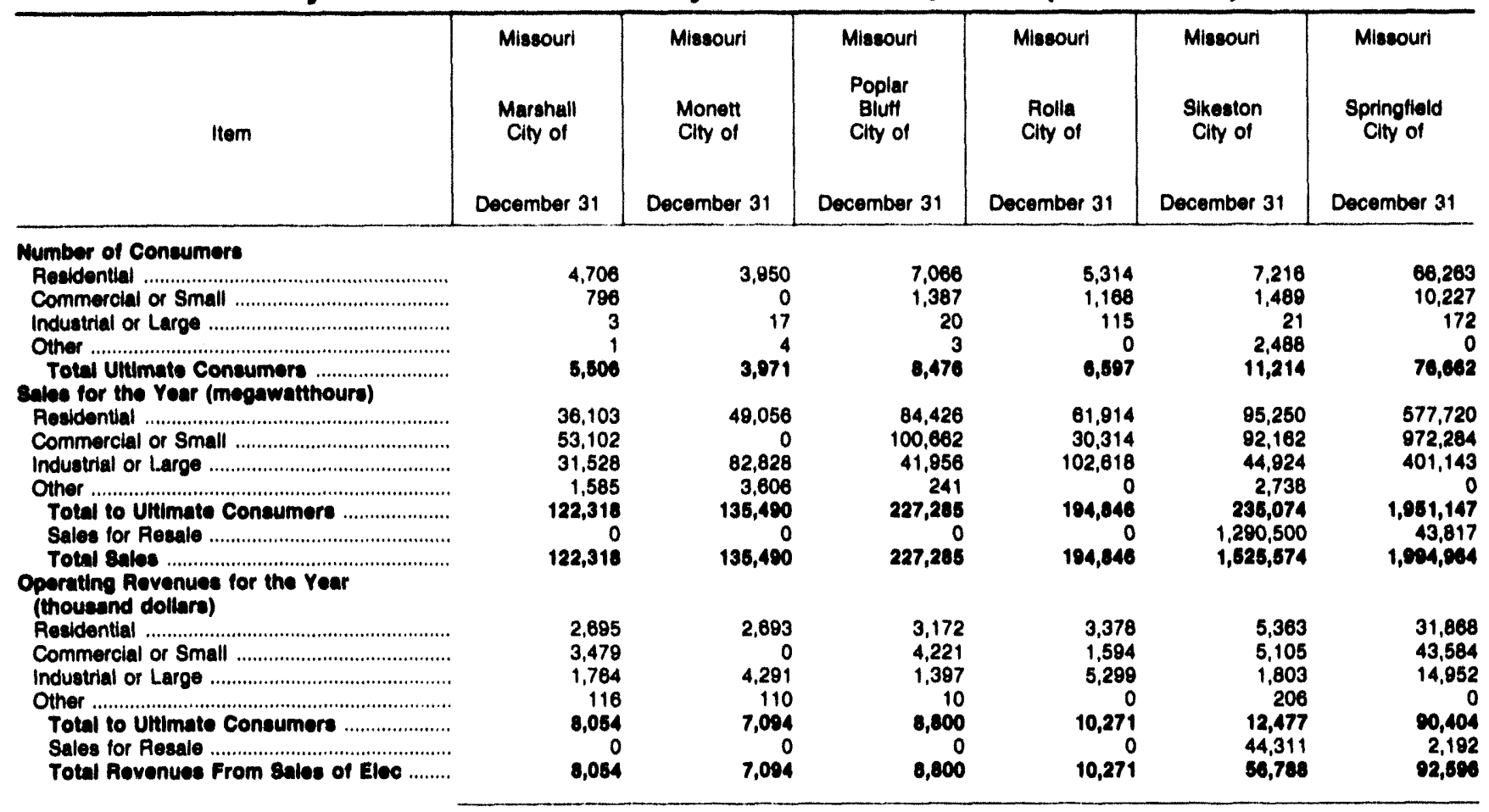

\begin{tabular}{|c|c|c|c|c|c|c|}
\hline Item & $\begin{array}{c}\text { Nebraska } \\
\text { Central } \\
\text { Nebraska } \\
\text { Pub } \\
\text { P\&I Dist } \\
\text { December } 31\end{array}$ & $\begin{array}{l}\text { Nebraska } \\
\text { Cornhusker } \\
\text { Public } \\
\text { Power Dist } \\
\text { December } 31\end{array}$ & $\begin{array}{c}\text { Nebraska } \\
\text { Dawson } \\
\text { County } \\
\text { Public } \\
\text { Pwr Dist } \\
\text { December } 31\end{array}$ & $\begin{array}{c}\text { Nebraska } \\
\text { Fremont } \\
\text { City of } \\
\text { December } 31\end{array}$ & $\begin{array}{c}\text { Nebraska } \\
\text { Grand Island } \\
\text { City of } \\
\text { December } 31\end{array}$ & $\begin{array}{c}\text { Nebraska } \\
\text { Hastings } \\
\text { City of } \\
\text { December } 31\end{array}$ \\
\hline \multicolumn{7}{|l|}{ Number of Coneumera } \\
\hline 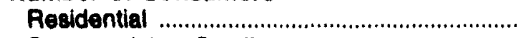 & 0 & 6,118 & 11,077 & 10,605 & 16,884 & 9,560 \\
\hline 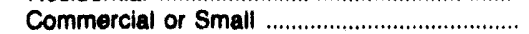 & 0 & 192 & 698 & 1,787 & 3,036 & 1,825 \\
\hline Industrial or Large & 0 & 4 & 2 & 470 & 53 & 34 \\
\hline Other & 0 & 1.276 & 4,088 & 2 & 500 & \\
\hline $\begin{array}{l}\text { Total Ultimate Consumers ......................... } \\
\text { salee for the Year (megawatthours) }\end{array}$ & 0 & 7,591 & 15,846 & 12,864 & 20,473 & 11,498 \\
\hline 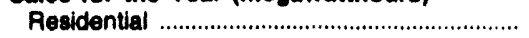 & 0 & 111,845 & 138,652 & 101,406 & 130,431 & 70,503 \\
\hline 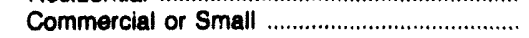 & 0 & 18,684 & 31,049 & 35,133 & $116,-222$ & 61,902 \\
\hline Industrial or Large & 0 & 29,760 & 6,464 & 136,576 & 198,416 & 96,757 \\
\hline Other & 0 & 3,562 & 46,914 & $7,22 \theta$ & 6,491 & 11,879 \\
\hline Total to Uitimate Consumers ........................ & 0 & 163,851 & 223,079 & 280,344 & 451,660 & 241,041 \\
\hline 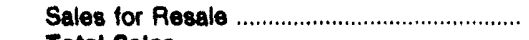 & 253,110 & 1,986 & 4,800 & 4,885 & 55,344 & 99,685 \\
\hline \multicolumn{7}{|l|}{$\begin{array}{l}\text { Operating Rovenues for the Year } \\
\text { (thoueand dollare) }\end{array}$} \\
\hline 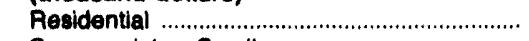 & 0 & 6,438 & 7,610 & 4,803 & 7,644 & 4,204 \\
\hline Commercial or Small & 0 & 978 & 1,753 & 1,880 & 0,432 & 3,283 \\
\hline Industrial or Large & 0 & 1,137 & 265 & 5,724 & 7,458 & 3,545 \\
\hline Other & 0 & 918 & 4,331 & 268 & 333 & 444 \\
\hline Total to Uitimate Consumers ......................... & 0 & 8,471 & 13,950 & 12,673 & 21,867 & 11,470 \\
\hline Sales for Resale & 8,039 & 27 & 214 & 89 & $\begin{array}{r}730 \\
507\end{array}$ & 1,128 \\
\hline Total Revenues From Sales of Elec ......... & 8,039 & 9,498 & 14,173 & 12,762 & 22,597 & 12,604 \\
\hline
\end{tabular}

Note: Totals may not equal surn of components because of independent rounding.

Source: Energy information Administration, Form ElA-861, "Annual Electric Utility Report." Data are submitted on a calendar year. 
Table 25. Number of Consumers, Sales, and Operating Revenue by Major U.S. Publicly Owned Electric UtIllty Within State, 1992 (Continued)

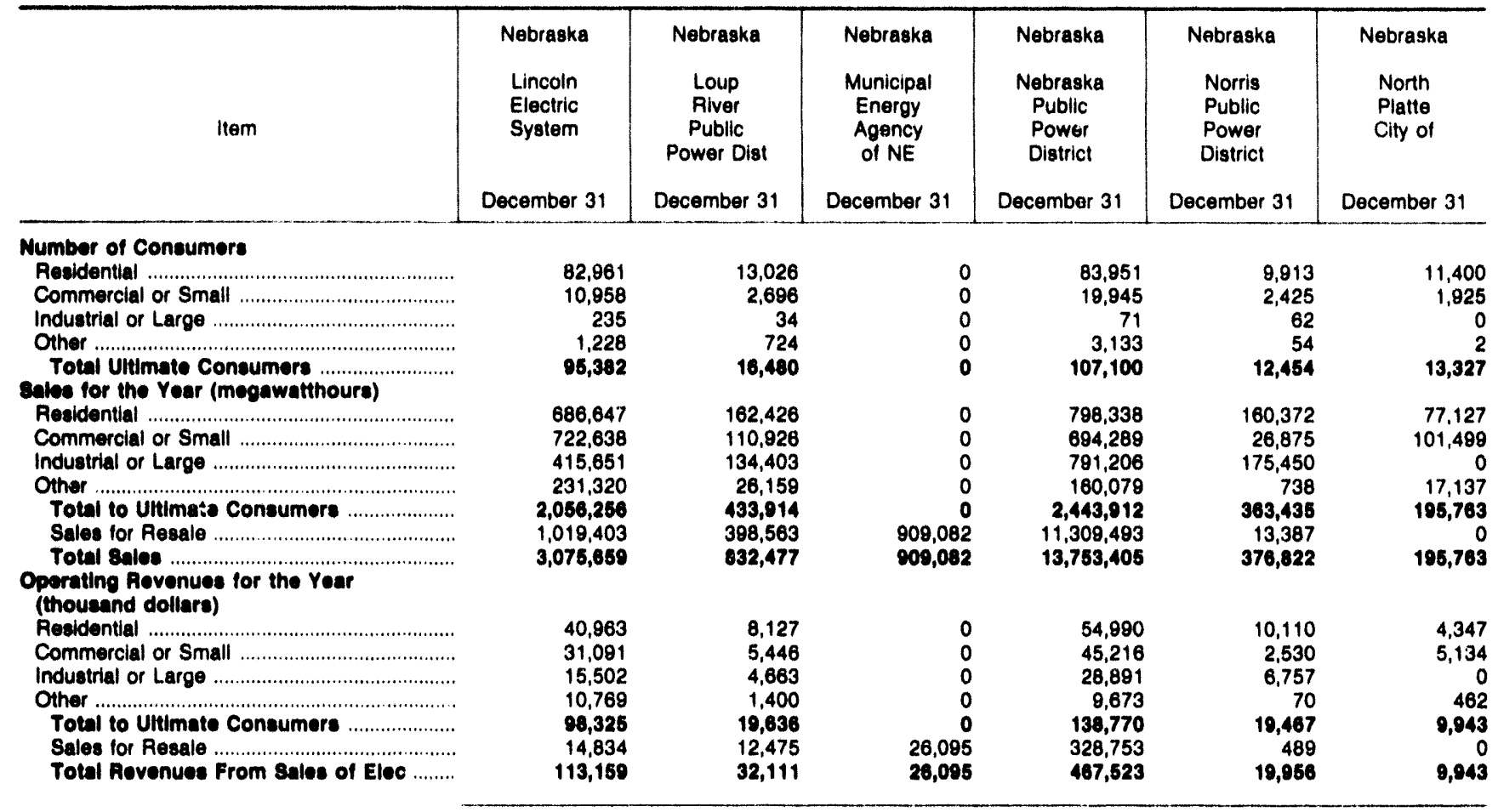

\begin{tabular}{|c|c|c|c|c|c|c|}
\hline Item & $\begin{array}{c}\text { Nebraska } \\
\text { Omaha Public } \\
\text { Power } \\
\text { District } \\
\text { December } 31\end{array}$ & $\begin{array}{c}\text { Nebraska } \\
\text { Southern } \\
\text { Nobraska Rural } \\
\text { P P D } \\
\text { Docember } 31\end{array}$ & $\begin{array}{c}\text { Nevada } \\
\text { Colorado } \\
\text { Alver } \\
\text { Comm } \\
\text { of Nevada } \\
\text { December } 31\end{array}$ & $\begin{array}{c}\text { New Jersey } \\
\text { Vineland } \\
\text { City of } \\
\text { December } 31\end{array}$ & $\begin{array}{l}\text { New Mexico } \\
\text { Farmington } \\
\text { City of } \\
\text { Decemiber } 31\end{array}$ & $\begin{array}{l}\text { New Mexico } \\
\text { Gallup } \\
\text { City of } \\
\text { December } 31\end{array}$ \\
\hline \multicolumn{7}{|l|}{ Number of Consumers } \\
\hline 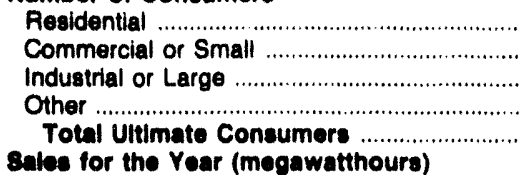 & $\begin{array}{r}224,107 \\
31,259 \\
92 \\
497 \\
255,955\end{array}$ & $\begin{array}{r}10,602 \\
873 \\
137 \\
6,880 \\
18,492\end{array}$ & $\begin{array}{l}0 \\
2 \\
5 \\
0 \\
7\end{array}$ & $\begin{array}{r}14,865 \\
2,298 \\
90 \\
3 \\
17,256\end{array}$ & $\begin{array}{r}23,167 \\
4,085 \\
3 \\
2,723 \\
29,978\end{array}$ & $\begin{array}{r}7,166 \\
1,556 \\
0 \\
432 \\
9,164\end{array}$ \\
\hline 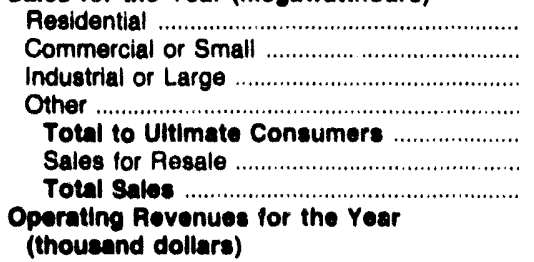 & $\begin{array}{r}2,142,857 \\
2,366,332 \\
1,862,495 \\
80,731 \\
6,452,515 \\
138,862 \\
6,591,377\end{array}$ & $\begin{array}{r}144,876 \\
13,006 \\
103,400 \\
72,342 \\
333,624 \\
0 \\
333,624\end{array}$ & $\begin{array}{r}0 \\
32,662 \\
681,503 \\
0 \\
714,165 \\
799,335 \\
1,613,500\end{array}$ & $\begin{array}{r}115,626 \\
80,471 \\
197,698 \\
2,403 \\
398,199 \\
0 \\
398,199\end{array}$ & $\begin{array}{r}146,294 \\
242,339 \\
116,013 \\
9,617 \\
514,263 \\
19,044 \\
533,307\end{array}$ & $\begin{array}{r}38,294 \\
105,820 \\
0 \\
20,396 \\
184,510 \\
0 \\
164,510\end{array}$ \\
\hline 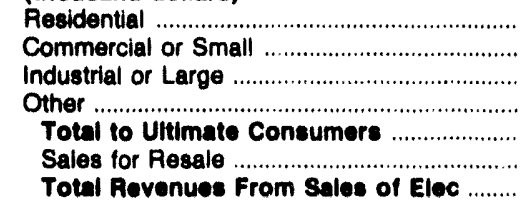 & $\begin{array}{r}142,212 \\
135,926 \\
76,265 \\
10,187 \\
364,690 \\
3,046 \\
367,636\end{array}$ & $\begin{array}{r}7,733 \\
900 \\
4,702 \\
7,709 \\
21,044 \\
0 \\
21,044\end{array}$ & $\begin{array}{r}0 \\
664 \\
12,423 \\
0 \\
13,087 \\
12,820 \\
25,907\end{array}$ & $\begin{array}{r}11,921 \\
8,977 \\
16,811 \\
330 \\
38,039 \\
0 \\
38,039\end{array}$ & $\begin{array}{r}12,188 \\
19,097 \\
5,734 \\
1,582 \\
38,611 \\
859 \\
39,470\end{array}$ & $\begin{array}{r}3,241 \\
8,871 \\
0 \\
1,633 \\
13,746 \\
0 \\
13,745\end{array}$ \\
\hline
\end{tabular}

Note: Totals may not equal sum of components because of independent rounding.

Source: Energy Information Administration, Form ElA-861, "Annual Electric Utility Report." Data are submitted on a calendar year. 
Table 25. Number of Consumers, Sales, and Operating Revenue by Major U.S. Publicly Owned Electric Utility Within State, 1992 (Continued)

\begin{tabular}{|c|c|c|c|c|c|c|}
\hline Item & $\begin{array}{l}\text { New Mexico } \\
\text { Los Alamos } \\
\text { County }\end{array}$ & $\begin{array}{c}\text { New York } \\
\text { Fairport } \\
\text { Village of } \\
\text { December } 31\end{array}$ & $\begin{array}{c}\text { New York } \\
\text { Freeport } \\
\text { Village of } \\
\text { Inc }\end{array}$ & $\begin{array}{c}\text { New York } \\
\text { Jamestown } \\
\text { City of } \\
\text { December } 31\end{array}$ & $\begin{array}{c}\text { New York } \\
\text { Massena } \\
\text { Town of } \\
\text { December } 31\end{array}$ & $\begin{array}{c}\text { Now York } \\
\text { Piattsburgh } \\
\text { City of } \\
\text { December } 31\end{array}$ \\
\hline \multicolumn{7}{|l|}{ Number of Consumere } \\
\hline 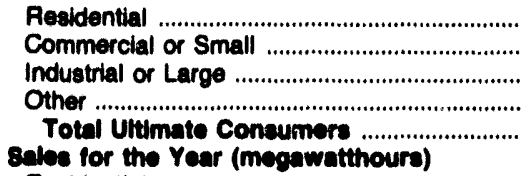 & $\begin{array}{r}7,256 \\
607 \\
0 \\
5 \\
7,868\end{array}$ & $\begin{array}{r}12,802 \\
1,069 \\
37 \\
182 \\
14,000\end{array}$ & $\begin{array}{r}12,860 \\
1,772 \\
0 \\
126 \\
14,858\end{array}$ & $\begin{array}{r}17,169 \\
2,646 \\
128 \\
194 \\
20,197\end{array}$ & $\begin{array}{r}7,677 \\
772 \\
156 \\
213 \\
8,818\end{array}$ & $\begin{array}{r}7,431 \\
1,295 \\
3 \\
196 \\
8,925\end{array}$ \\
\hline 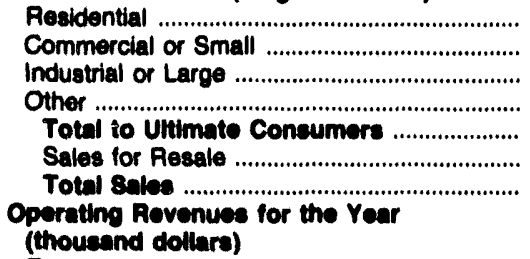 & $\begin{array}{r}43,413 \\
27,812 \\
0 \\
399,520 \\
470,746 \\
25,367 \\
484,112\end{array}$ & $\begin{array}{r}201,392 \\
54,162 \\
72,933 \\
2,711 \\
331,198 \\
0 \\
331,190\end{array}$ & $\begin{array}{r}95,027 \\
114,997 \\
0 \\
15,010 \\
225,034 \\
0 \\
225,034\end{array}$ & $\begin{array}{r}132,790 \\
123,125 \\
138,078 \\
33,359 \\
427,352 \\
165,565 \\
692,017\end{array}$ & $\begin{array}{r}72,249 \\
12,126 \\
53,596 \\
4,175 \\
142,146 \\
0 \\
142,146\end{array}$ & $\begin{array}{r}164,170 \\
165,516 \\
187,831 \\
4,988 \\
522,605 \\
0 \\
522,505\end{array}$ \\
\hline 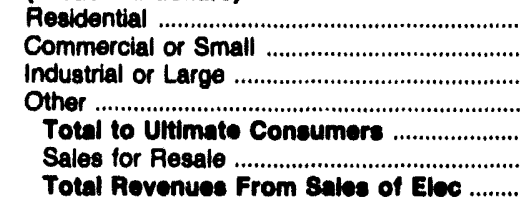 & $\begin{array}{r}4,584 \\
2,779 \\
0 \\
17,619 \\
24,982 \\
471 \\
25,453\end{array}$ & $\begin{array}{r}6,209 \\
1,785 \\
2,102 \\
155 \\
10,251 \\
0 \\
10,251\end{array}$ & $\begin{array}{r}6,123 \\
6,775 \\
0 \\
1,104 \\
14,002 \\
0 \\
14,002\end{array}$ & $\begin{array}{r}5,008 \\
5,331 \\
5,265 \\
1,349 \\
16,953 \\
4,277 \\
21,230\end{array}$ & $\begin{array}{r}3,368 \\
628 \\
1,965 \\
280 \\
6,241 \\
0 \\
6,241\end{array}$ & $\begin{array}{r}4,145 \\
3,682 \\
2,764 \\
302 \\
10,893 \\
0 \\
10,893\end{array}$ \\
\hline
\end{tabular}

\begin{tabular}{|c|c|c|c|c|c|c|}
\hline Item & $\begin{array}{c}\text { New York } \\
\text { Power } \\
\text { Authority } \\
\text { of State of NY } \\
\text { December } 31\end{array}$ & $\begin{array}{c}\text { New York } \\
\text { Rockville } \\
\text { Centre } \\
\text { Village of } \\
\text { December } 31\end{array}$ & $\begin{array}{c}\text { North Carolina } \\
\text { Albemarle } \\
\text { City of } \\
\text { December } 31\end{array}$ & $\begin{array}{l}\text { North Carolina } \\
\text { Concord } \\
\text { City of } \\
\text { December } 31\end{array}$ & $\begin{array}{l}\text { North Carolina } \\
\text { Elizabeth } \\
\text { City Clty of } \\
\text { December } 31\end{array}$ & $\begin{array}{l}\text { North Carolina } \\
\text { Fayetteville } \\
\text { Public } \\
\text { Works Comm } \\
\text { December } 31\end{array}$ \\
\hline \multicolumn{7}{|l|}{ Number of Consumers } \\
\hline 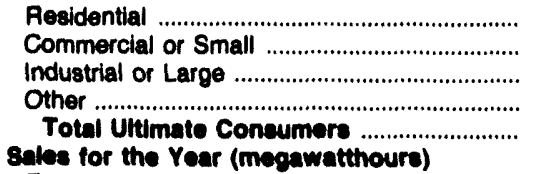 & $\begin{array}{r}0 \\
2 \\
16 \\
82 \\
100\end{array}$ & $\begin{array}{r}8,728 \\
1,209 \\
0 \\
67 \\
10,004\end{array}$ & $\begin{array}{r}8,866 \\
1,663 \\
25 \\
2,653 \\
13,207\end{array}$ & $\begin{array}{r}14,014 \\
1,894 \\
65 \\
66 \\
18,039\end{array}$ & $\begin{array}{r}8,360 \\
1,262 \\
0 \\
91 \\
9,713\end{array}$ & $\begin{array}{r}53,050 \\
5,983 \\
12 \\
3,577 \\
62,622\end{array}$ \\
\hline 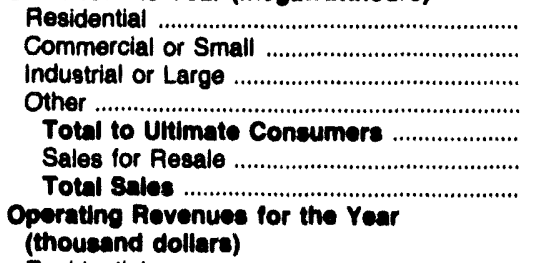 & $\begin{array}{r}0 \\
56,677 \\
4,898,131 \\
8,287,308 \\
13,242,116 \\
20,862,342 \\
34,204,468\end{array}$ & $\begin{array}{r}75,309 \\
88,218 \\
0 \\
7,694 \\
171,221 \\
0 \\
171,221\end{array}$ & $\begin{array}{r}97,221 \\
77,461 \\
56,198 \\
12,059 \\
242,040 \\
0 \\
242,240\end{array}$ & $\begin{array}{r}164,552 \\
118,250 \\
58,815 \\
5,525 \\
347,142 \\
0 \\
347,142\end{array}$ & $\begin{array}{r}99,536 \\
103,011 \\
0 \\
14,485 \\
217,032 \\
0 \\
217,032\end{array}$ & $\begin{array}{r}698,608 \\
476,568 \\
388,825 \\
24,693 \\
1,689,604 \\
423 \\
1,600,117\end{array}$ \\
\hline 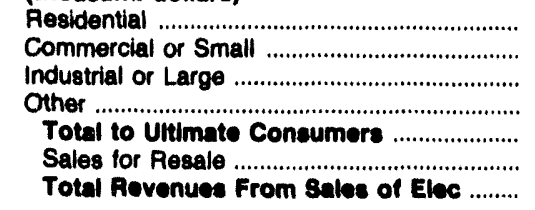 & $\begin{array}{r}0 \\
2,884 \\
100,909 \\
685,610 \\
769,403 \\
473,972 \\
1,243,375\end{array}$ & $\begin{array}{r}4,223 \\
4,789 \\
0 \\
388 \\
9,380 \\
0 \\
0 \\
9,380\end{array}$ & $\begin{array}{r}7,571 \\
5,457 \\
2,933 \\
700 \\
16,681 \\
0 \\
18,681\end{array}$ & $\begin{array}{r}12,550 \\
7,935 \\
2,824 \\
264 \\
23,573 \\
0 \\
23,573\end{array}$ & $\begin{array}{r}9,408 \\
8,247 \\
0 \\
1,121 \\
18,776 \\
0 \\
18,776\end{array}$ & $\begin{array}{r}51,595 \\
31,434 \\
21,513 \\
2,486 \\
107,038 \\
7 \\
107,046\end{array}$ \\
\hline
\end{tabular}

Note: Totals may not equal sum of components because of independent rounding.

Source: Energy Information Administration, Form EIA-861, "Annual Electric Utility Report." Data are submitted on a calendar year. 
Table 25. Number of Consumers, Sales, and Operating Revenue by Major U.S. Publicly Owned Electric Utility Within State, 1992 (Continued)

\begin{tabular}{|c|c|c|c|c|c|c|}
\hline Item & $\begin{array}{c}\text { North Carolina } \\
\text { Gastonia } \\
\text { City of } \\
\text { December } 31\end{array}$ & $\begin{array}{l}\text { North Carolina } \\
\text { Greenvilie } \\
\text { Utilities } \\
\text { Comm } \\
\text { Cecember } 31\end{array}$ & $\begin{array}{c}\text { North Carolina } \\
\text { High } \\
\text { Point } \\
\text { Town } \\
\text { of } \\
\text { December } 31\end{array}$ & $\begin{array}{l}\text { North Carolina } \\
\text { Kinston } \\
\text { City of } \\
\text { December } 31\end{array}$ & $\begin{array}{l}\text { North Carolina } \\
\text { Lexington } \\
\text { City of }\end{array}$ & $\begin{array}{c}\text { North Carolina } \\
\text { Lumberton } \\
\text { City of }\end{array}$ \\
\hline \multicolumn{7}{|l|}{ Number of Consumers } \\
\hline Residential .................... & 20,546 & 33,614 & 26,420 & 10,772 & 14,186 & 7,342 \\
\hline Commercial or Smail .......................................... & 2,679 & 4,448 & 4,228 & 1,842 & 2,034 & 1,842 \\
\hline 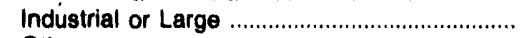 & 70 & 12 & 316 & 8 & 60 & 0 \\
\hline 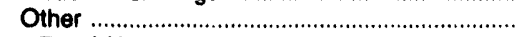 & 2 & 2 & 2 & 1,989 & 385 & \\
\hline $\begin{array}{l}\text { Total Uitimate Consumers ............................ } \\
\text { Sales for the Year (megawatthours) }\end{array}$ & 23,297 & 38,076 & 30,866 & 14,611 & 16,665 & 9,185 \\
\hline 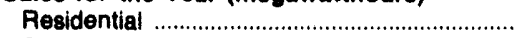 & 200,391 & 399,664 & 270,775 & 126,240 & 169,610 & 84,399 \\
\hline 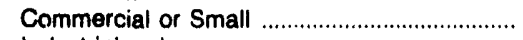 & 237,936 & 277,412 & 348,697 & 144,053 & 119,948 & 165,823 \\
\hline Industrial or Large & 106,277 & 319,784 & 126,010 & 113,017 & 111,877 & 0 \\
\hline 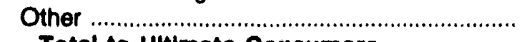 & 35,084 & 7,916 & 13,883 & 17,367 & 7,077 & 1,452 \\
\hline Total to Uitimate Consumers ..................... & 579,688 & $1,004,776$ & 759,365 & 400,677 & 408,412 & 251,674 \\
\hline 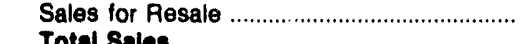 & & 23,491 & & & & \\
\hline \multicolumn{7}{|l|}{$\begin{array}{l}\text { Operating Revenues for the Year } \\
\text { (thousand dollars) }\end{array}$} \\
\hline 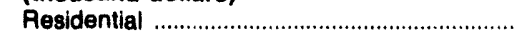 & 17,071 & 38,449 & 22,211 & 12,304 & 13,476 & 7,789 \\
\hline 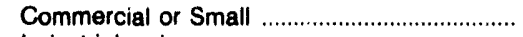 & 17,726 & 24,841 & 24,174 & 12,073 & 8,764 & 14,225 \\
\hline Industrial or Large & 6,339 & 20,454 & 7,792 & 7,369 & 6,692 & \\
\hline Other & 1,756 & 1,117 & 2,302 & 1,673 & 555 & 269 \\
\hline Total to Ultimate Consumers ...................... & 42,892 & 84,861 & 56,479 & 33,419 & 29,487 & 22,283 \\
\hline 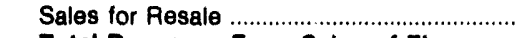 & & 1,800 & & & 0 & \\
\hline Total Revenues From Sales of Elec ......... & 42,892 & 86,661 & 56,479 & 33,419 & 29,487 & 22,283 \\
\hline
\end{tabular}

\begin{tabular}{|c|c|c|c|c|c|c|}
\hline Item & $\begin{array}{c}\text { North Carolina } \\
\text { Monroe } \\
\text { City of } \\
\text { December } 31\end{array}$ & $\begin{array}{c}\text { North Carolina } \\
\text { Morganton } \\
\text { City of } \\
\text { December } 31\end{array}$ & $\begin{array}{l}\text { North Carolina } \\
\text { Murphy } \\
\text { City of } \\
\text { December } 31\end{array}$ & $\begin{array}{l}\text { North Carolina } \\
\text { New Bern } \\
\text { City of } \\
\text { December } 31\end{array}$ & $\begin{array}{c}\text { North Carolina } \\
\text { New River } \\
\text { Light } \\
\& \\
\text { Power Co } \\
\text { December } 31\end{array}$ & $\begin{array}{c}\text { North Carolina } \\
\text { North } \\
\text { Carolina } \\
\text { Eastern M P A } \\
\text { December } 31\end{array}$ \\
\hline \multicolumn{7}{|l|}{ Number of Consumers } \\
\hline 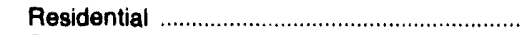 & 6,024 & 6,276 & 2,275 & 12,408 & 4,913 & 0 \\
\hline 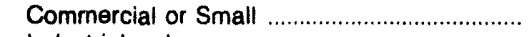 & 1,366 & 1,130 & 981 & 1,876 & 1,265 & 0 \\
\hline Industrial or Large & 961 & 51 & 78 & 7 & 5 & 0 \\
\hline 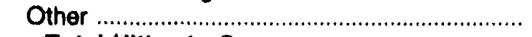 & 1,049 & 58 & 5 & 1 & 224 & 0 \\
\hline $\begin{array}{l}\text { Total Ultimate Consumers } \\
\text { Sales for the Yea....................... (megawatthours) }\end{array}$ & 9,400 & 7,515 & 3,339 & 14,292 & 6,407 & $\mathbf{0}$ \\
\hline 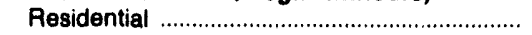 & 69,247 & 60,858 & 28,203 & 155,230 & 40,724 & 0 \\
\hline 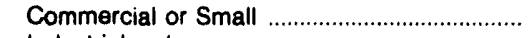 & 18,966 & 49,124 & 15,761 & 116,216 & 75,221 & 0 \\
\hline 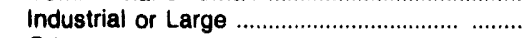 & 290,722 & 129,965 & 95,825 & 56,767 & 7,709 & 0 \\
\hline 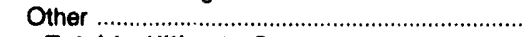 & 1,764 & 18,219 & 1,157 & 419 & 38,820 & 0 \\
\hline 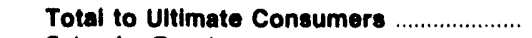 & 380,699 & 258,166 & 140,946 & 328,632 & 162,474 & \\
\hline $\begin{array}{l}\text { Sales for Resale } \\
\text { Total Sales }\end{array}$ & $\begin{array}{r}0 \\
380,699\end{array}$ & $\begin{array}{r}0 \\
258,166\end{array}$ & $\begin{array}{r}0 \\
140,946\end{array}$ & $\begin{array}{r}0 \\
328,632\end{array}$ & $\begin{array}{r}0 \\
162,474\end{array}$ & $\begin{array}{l}5,899,408 \\
5,899,408\end{array}$ \\
\hline \multicolumn{7}{|l|}{$\begin{array}{l}\text { Operating Revenues for the Year } \\
\text { (thousand dollars) }\end{array}$} \\
\hline 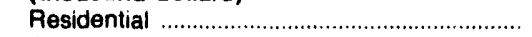 & 5,273 & 4,720 & 1,717 & 15,879 & 3,313 & 0 \\
\hline Commercial or Small & 1,624 & 3,738 & 1,154 & 10,559 & 5,132 & 0 \\
\hline Industrial or Large & 17,090 & 7,073 & 5,091 & 4,442 & 499 & 0 \\
\hline Other & 198 & 898 & 97 & 34 & 2,803 & 0 \\
\hline 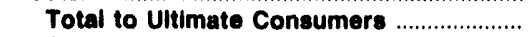 & 24,185 & 16,429 & 8,059 & 30,914 & 11,747 & \\
\hline Sales for Resale . & & 0 & & & & 398,585 \\
\hline Total Rovenues From Sales of Elec ........ & 24,185 & 16,429 & 8,059 & 30,914 & 11,747 & $398,58 \mathrm{~K}$ \\
\hline
\end{tabular}

Note: Totals may not equal sum of components because of independent rounding.

Source: Energy Information Administration, Form ElA-861, "Annual Electric Utility Report." Data are submitted on a calendar year. 
Table 25. Number of Consumers, Sales, and Operating Revenue by Major U.S. Publicly Owned Electric Utility Within State, 1992 (Continued)

\begin{tabular}{|c|c|c|c|c|c|c|}
\hline Item & $\begin{array}{c}\text { North Carolina } \\
\text { North } \\
\text { Carolina } \\
\text { Mun } \\
\text { Power Agny } \\
\text { December } 31\end{array}$ & $\begin{array}{l}\text { North Carolina } \\
\text { Rocky Mount } \\
\text { City of } \\
\text { December } 31\end{array}$ & $\begin{array}{c}\text { North Carolina } \\
\text { Shelby } \\
\text { City of } \\
\text { December } 31\end{array}$ & $\begin{array}{l}\text { North Carolina } \\
\text { Statesville } \\
\text { City of } \\
\text { December } 31\end{array}$ & $\begin{array}{c}\text { North Carolina } \\
\text { Tarboro } \\
\text { Town of } \\
\text { December } 31\end{array}$ & $\begin{array}{l}\text { North Carolina } \\
\text { Washington } \\
\text { City of } \\
\text { December } 31\end{array}$ \\
\hline \multicolumn{7}{|l|}{ Number of Consumers } \\
\hline 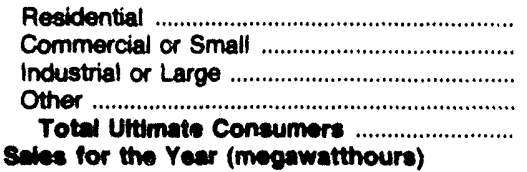 & $\begin{array}{l}0 \\
0 \\
0 \\
0 \\
0\end{array}$ & $\begin{array}{r}22,425 \\
3,192 \\
10 \\
117 \\
25,744\end{array}$ & $\begin{array}{r}6,371 \\
1,266 \\
13 \\
121 \\
7,771\end{array}$ & $\begin{array}{r}9,116 \\
1,824 \\
51 \\
2 \\
10,993\end{array}$ & $\begin{array}{r}4,927 \\
673 \\
34 \\
1,316 \\
6,950\end{array}$ & $\begin{array}{r}8,910 \\
1,744 \\
3 \\
103 \\
10,760\end{array}$ \\
\hline 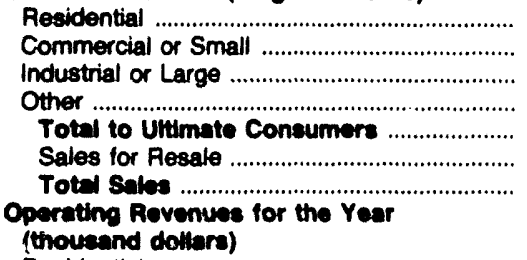 & $\begin{array}{r}0 \\
0 \\
0 \\
0 \\
0 \\
7,962,505 \\
7,962,505\end{array}$ & $\begin{array}{r}263,372 \\
294,241 \\
151,590 \\
9,633 \\
718,836 \\
15,873 \\
734,709\end{array}$ & $\begin{array}{r}69,361 \\
82,185 \\
5,743 \\
50 \\
157,339 \\
0 \\
157,339\end{array}$ & $\begin{array}{r}82,247 \\
140,437 \\
101,362 \\
17,428 \\
341,474 \\
0 \\
341,474\end{array}$ & $\begin{array}{r}52,001 \\
35,068 \\
139,391 \\
6,536 \\
232,996 \\
0 \\
232,998\end{array}$ & $\begin{array}{r}94,302 \\
107,521 \\
7,847 \\
6,153 \\
215,823 \\
0 \\
215,823\end{array}$ \\
\hline 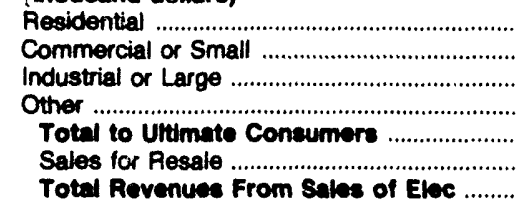 & $\begin{array}{r}0 \\
0 \\
0 \\
0 \\
0 \\
418,234 \\
418,234\end{array}$ & $\begin{array}{r}22,897 \\
22,829 \\
9,591 \\
980 \\
56,297 \\
989 \\
57,286\end{array}$ & $\begin{array}{r}5,398 \\
5,636 \\
371 \\
4 \\
11,409 \\
0 \\
11,409\end{array}$ & $\begin{array}{r}6,469 \\
9,757 \\
5,950 \\
1,054 \\
23,230 \\
0 \\
23,230\end{array}$ & $\begin{array}{r}5,462 \\
3,180 \\
10,096 \\
611 \\
19,349 \\
0 \\
19,349\end{array}$ & $\begin{array}{r}10,087 \\
9,445 \\
560 \\
412 \\
20,504 \\
0 \\
20,504\end{array}$ \\
\hline
\end{tabular}

\begin{tabular}{|c|c|c|c|c|c|c|}
\hline Item & $\begin{array}{c}\text { North Carolina } \\
\text { Wilson } \\
\text { City of } \\
\text { December } 31\end{array}$ & $\begin{array}{c}\text { Ohio } \\
\text { American } \\
\text { Mun } \\
\text { Power } \\
\text { Ohio Inc } \\
\text { December } 31\end{array}$ & $\begin{array}{c}\text { Onio } \\
\text { Bowling } \\
\text { Green } \\
\text { City of } \\
\text { December } 31\end{array}$ & $\begin{array}{c}\text { Ohio } \\
\text { Bryan } \\
\text { City of } \\
\text { December } 31\end{array}$ & $\begin{array}{l}\text { Onio } \\
\text { Celina } \\
\text { City of } \\
\text { December } 31\end{array}$ & $\begin{array}{c}\text { Onio } \\
\text { Cleveland } \\
\text { City of } \\
\text { December } 31\end{array}$ \\
\hline \multicolumn{7}{|l|}{ Number of Consumers } \\
\hline 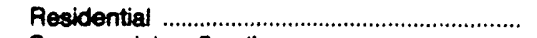 & 23,117 & 0 & 9,158 & 4,328 & 6,048 & 48,484 \\
\hline 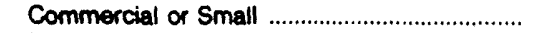 & 3,464 & 0 & 1,327 & 511 & 1,010 & 6,109 \\
\hline Industrial or Large & 13 & 1 & 63 & 121 & 52 & 17 \\
\hline Other & 3,566 & 0 & 82 & 0 & 0 & 3 \\
\hline $\begin{array}{l}\text { Toted Uitimate Consumere } \\
\text { sel........................ }\end{array}$ & 30,160 & 1 & 10,630 & 4,980 & 7,110 & 54,613 \\
\hline 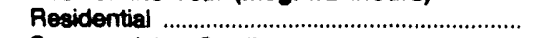 & 276,585 & 0 & 63,388 & 37,659 & 55,784 & 229,800 \\
\hline 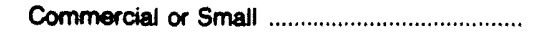 & 228,537 & 0 & 45,618 & 13,153 & 18,938 & 258,903 \\
\hline 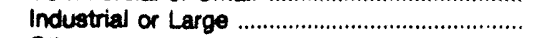 & 348,975 & 584,907 & 152,657 & 138.884 & 67,546 & 264,271 \\
\hline Other & 13,036 & 0 & 701 & 0 & 0 & 48,012 \\
\hline Totet to Ultmate Consumers .......................... & 867,133 & 584,907 & 262,364 & 189,696 & 142,268 & 800,986 \\
\hline 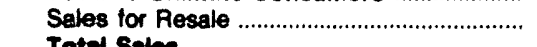 & 58,174 & $3,730,661$ & 3,454 & 0 & 0 & \\
\hline \multicolumn{7}{|l|}{$\begin{array}{l}\text { Operating Rovenues for the Year } \\
\text { (thousend dolters) }\end{array}$} \\
\hline 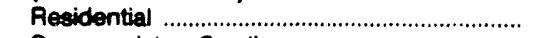 & 24,918 & 0 & 3,979 & 2,037 & 2,987 & 18,856 \\
\hline Commercial or Small ....................................... & 19,451 & 0 & 2,472 & 864 & 1,097 & 20.784 \\
\hline 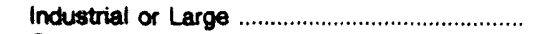 & 22,706 & 8,777 & 7,741 & 6,713 & 3,176 & 14,537 \\
\hline 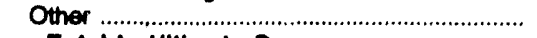 & 1,886 & 0 & 69 & 0 & 0 & 4,607 \\
\hline Total to Uitimate Consumere ........................ & 68,861 & 8,777 & 14,261 & 9,614 & 7,260 & 58,784 \\
\hline 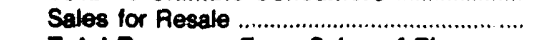 & 4,407 & 126,893 & 152 & & 0 & \\
\hline Totel Revenues From Sales of Elec ......... & 73,368 & 135,670 & 14,413 & 9,614 & 7,260 & 58,784 \\
\hline
\end{tabular}

Note: Totals may not equal sum of components because of independentrounding.

Source: Energy Information Administration, Form ElA-861, "Annual Electric Utility Report." Data are submitted on a calendar year. 
Table 25. Number of Consumers, Sales, and Operating Revenue by Major U.S. Publicly Owned Electric Utility Within State, 1992 (Continued)

\begin{tabular}{|c|c|c|c|c|c|c|}
\hline Item & $\begin{array}{c}\text { Ohio } \\
\text { Columbus } \\
\text { Clty of } \\
\text { December } 31\end{array}$ & $\begin{array}{l}\text { Ohio } \\
\text { Cuyahoga } \\
\text { Falls } \\
\text { City of } \\
\text { December } 31\end{array}$ & $\begin{array}{l}\text { Ohio } \\
\text { Dover } \\
\text { City of } \\
\text { December } 31\end{array}$ & $\begin{array}{c}\text { Ohio } \\
\text { Hamilton } \\
\text { City of } \\
\text { December } 31\end{array}$ & $\begin{array}{c}\text { Ohio } \\
\text { Niles } \\
\text { City of } \\
\text { December } 31\end{array}$ & $\begin{array}{l}\text { Ohio } \\
\text { Orrville } \\
\text { City of } \\
\text { December } 31\end{array}$ \\
\hline \multicolumn{7}{|l|}{ Number of Consumere } \\
\hline 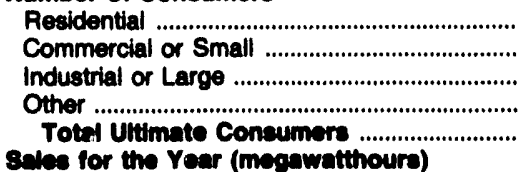 & $\begin{array}{r}7,195 \\
2,292 \\
325 \\
801 \\
10,613\end{array}$ & $\begin{array}{r}18,729 \\
1,311 \\
124 \\
144 \\
20,309\end{array}$ & $\begin{array}{r}5,155 \\
742 \\
67 \\
0 \\
5,964\end{array}$ & $\begin{array}{r}23,722 \\
2,769 \\
92 \\
0 \\
28,683\end{array}$ & $\begin{array}{r}10,175 \\
1,012 \\
89 \\
490 \\
11,768\end{array}$ & $\begin{array}{r}5,118 \\
572 \\
15 \\
22 \\
5,727\end{array}$ \\
\hline 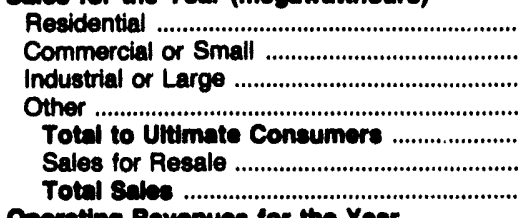 & $\begin{array}{r}38,682 \\
58,188 \\
404,241 \\
75,600 \\
576,711 \\
988 \\
577,690\end{array}$ & $\begin{array}{r}116,596 \\
37,280 \\
99,274 \\
8,641 \\
281,791 \\
0 \\
281,791\end{array}$ & $\begin{array}{r}56,905 \\
37,937 \\
77,598 \\
0 \\
172,440 \\
0 \\
172,440\end{array}$ & $\begin{array}{r}183,795 \\
173,280 \\
106,758 \\
0 \\
463,833 \\
82,858 \\
546,691\end{array}$ & $\begin{array}{r}72,126 \\
75,747 \\
71,440 \\
1,169 \\
220,482 \\
0 \\
220,482\end{array}$ & $\begin{array}{r}56,768 \\
46,288 \\
121,941 \\
4,511 \\
229,508 \\
109,450 \\
338,958\end{array}$ \\
\hline 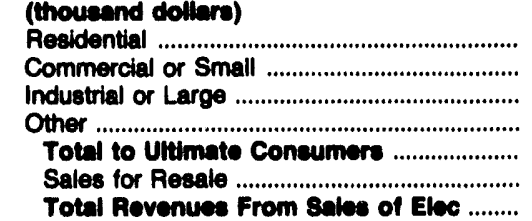 & $\begin{array}{r}2,616 \\
4,155 \\
19,077 \\
4,717 \\
30,585 \\
4,718 \\
35,283\end{array}$ & $\begin{array}{r}8,253 \\
2,805 \\
5,608 \\
548 \\
17,214 \\
0 \\
17,214\end{array}$ & $\begin{array}{r}2,895 \\
1,930 \\
3,947 \\
0 \\
8,772 \\
0 \\
8,772\end{array}$ & $\begin{array}{r}14,098 \\
14,377 \\
6,379 \\
0 \\
34,854 \\
1,879 \\
36,733\end{array}$ & $\begin{array}{r}5,603 \\
4,928 \\
3,721 \\
136 \\
14,388 \\
0 \\
14,388\end{array}$ & $\begin{array}{r}3,440 \\
3,070 \\
6,210 \\
261 \\
12,981 \\
2,557 \\
15,538\end{array}$ \\
\hline
\end{tabular}

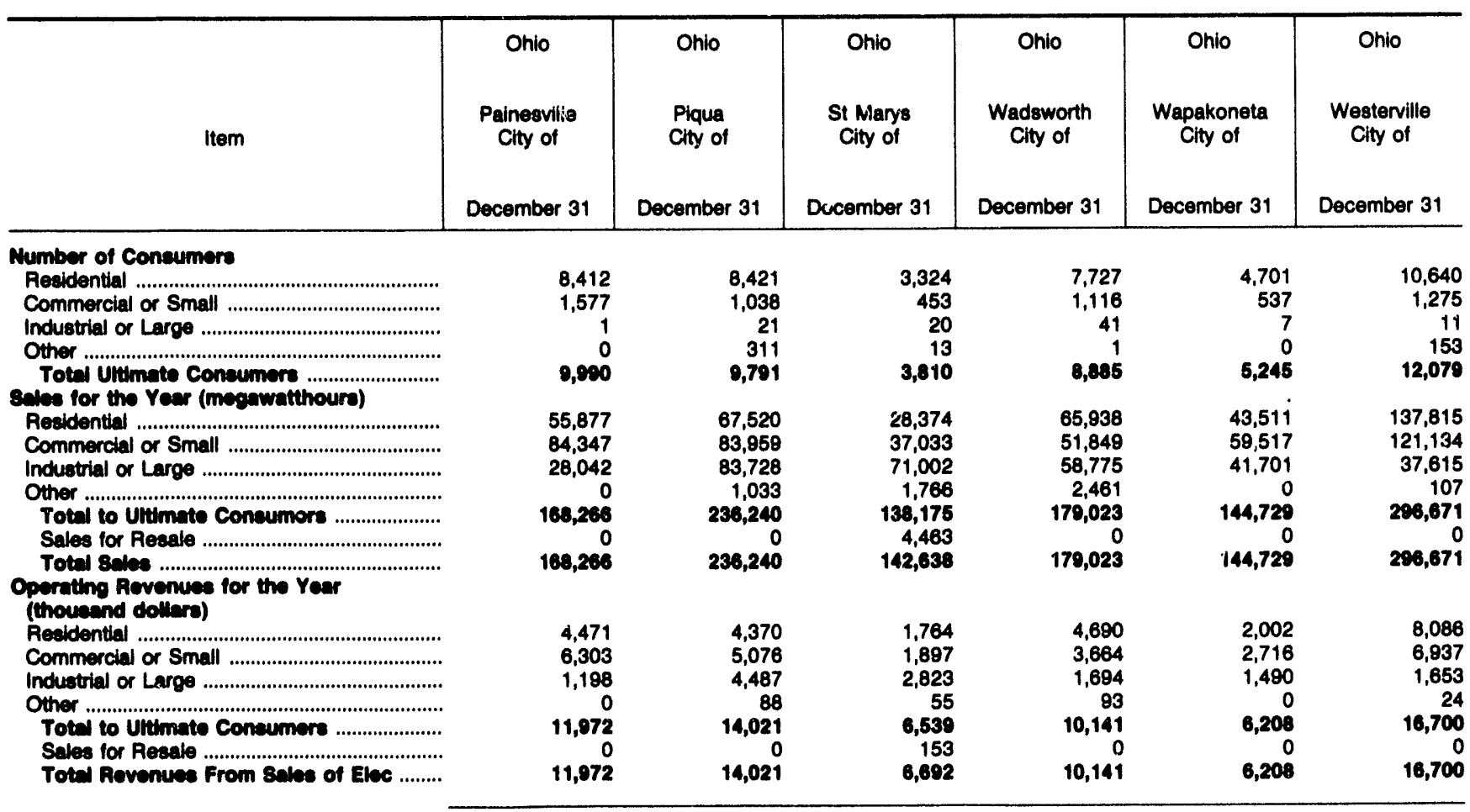

Note: Totals may not equal sum of components because of independent rounding.

Source: Energy Information Administration, Form ElA-861, "Annual Electric Utility Report." Data are submitted on a calendar year. 
Table 25. Number of Consumers, Sales, and Operating Revenue by Major U.S. Publicly Owned Electric Utility Within State, 1992 (Continued)

\begin{tabular}{|c|c|c|c|c|c|c|}
\hline Item & $\begin{array}{c}\text { Oklahoma } \\
\text { Altus } \\
\text { City of } \\
\text { December } 31\end{array}$ & $\begin{array}{c}\text { Oklahoma } \\
\text { Claremore } \\
\text { City of }\end{array}$ & $\begin{array}{l}\text { Oklahoma } \\
\text { Duncan } \\
\text { City of } \\
\text { December } 31\end{array}$ & $\begin{array}{l}\text { Oklahoma } \\
\text { Edmond } \\
\text { Clty of } \\
\text { December } 31\end{array}$ & $\begin{array}{l}\text { Oklahoma } \\
\text { Grand River } \\
\text { Dam } \\
\text { Authority } \\
\text { December } 31\end{array}$ & $\begin{array}{c}\text { Oklahoma } \\
\text { Oklahoma } \\
\text { Municipal } \\
\text { Power Auth } \\
\text { December } 31\end{array}$ \\
\hline \multicolumn{7}{|l|}{ Number of Consumers } \\
\hline$\ldots$ & 7,776 & 7,180 & 6,660 & 20,280 & 0 & 0 \\
\hline 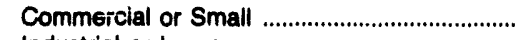 & 1,034 & 898 & 1,033 & 2,227 & 59 & 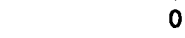 \\
\hline 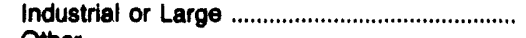 & 86 & 89 & 79 & 0 & 18 & 0 \\
\hline 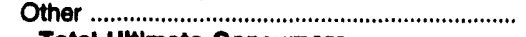 & 0 & 0 & 1 & 0 & 0 & 0 \\
\hline $\begin{array}{l}\text { Total Ultimate Consumers .......................... } \\
\text { Sales for the Year (megawatthours) }\end{array}$ & 8,898 & 8,167 & $\mathbf{7 , 7 7 3}$ & 22,507 & 77 & 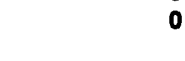 \\
\hline 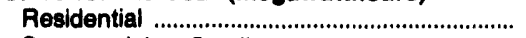 & 61,508 & 74,873 & 66,276 & 219,184 & 0 & 0 \\
\hline $\begin{array}{l}\text { Commercial or Small } \\
\text { industrial or Large }\end{array}$ & $\begin{array}{l}20,706 \\
38,828\end{array}$ & $\begin{array}{l}20,908 \\
97,248\end{array}$ & 46,799 & 169,872 & $\begin{array}{r}30,924 \\
627750\end{array}$ & 0 \\
\hline Other & $\begin{array}{r}30,0<0 \\
0\end{array}$ & $\begin{array}{r}97,248 \\
0\end{array}$ & $\begin{array}{r}18,313 \\
1,059\end{array}$ & $\begin{array}{l}0 \\
0\end{array}$ & $\begin{array}{r}627,750 \\
0\end{array}$ & 0 \\
\hline Total to Uitimate Consumers ....................... & 121,042 & 183,029 & 132,447 & 389,056 & 658,674 & \\
\hline $\begin{array}{l}\text { Sales for Resale } \\
\text { Total Sales }\end{array}$ & $\begin{array}{r}0 \\
121.042\end{array}$ & $\begin{array}{r}0 \\
193.029\end{array}$ & $\begin{array}{r}0 \\
132.447\end{array}$ & $\begin{array}{r}0 \\
389.056\end{array}$ & $4,160,380$ & $1,344,275$ \\
\hline \multicolumn{7}{|l|}{$\begin{array}{l}\text { Operating Rovenues for the Year } \\
\text { (thousand dollars) }\end{array}$} \\
\hline 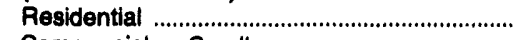 & 4,665 & 5,120 & 4,299 & 15,066 & 0 & \\
\hline Commercial or Small ............................................. & 1,585 & 1,579 & 2,466 & 8,888 & 1,205 & \\
\hline Industrial or Large & 1,599 & 4,655 & 965 & 0 & 19,435 & \\
\hline Other & 0 & 0 & 105 & 0 & 0 & 0 \\
\hline Total to Ultimate Consumers .......................... & 7,849 & 11,354 & 7,835 & 23,954 & 20,640 & \\
\hline 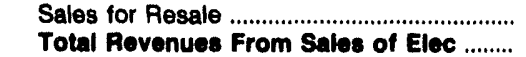 & $\begin{array}{r}0 \\
7,849\end{array}$ & $\begin{array}{r}0 \\
11,354\end{array}$ & $\begin{array}{r}0 \\
7,835\end{array}$ & $\begin{array}{r}0 \\
23,954\end{array}$ & $\begin{array}{l}125,223 \\
145,863\end{array}$ & $\begin{array}{l}60,040 \\
60,040\end{array}$ \\
\hline
\end{tabular}

\begin{tabular}{|c|c|c|c|c|c|c|}
\hline Item & $\begin{array}{c}\text { Okiahoma } \\
\text { Ponca } \\
\text { City City of } \\
\text { December } 31\end{array}$ & $\begin{array}{c}\text { Oklahoma } \\
\text { Stillwater } \\
\text { Utilities } \\
\text { Authority } \\
\text { December } 31\end{array}$ & $\begin{array}{l}\text { Oregon } \\
\text { Ashland } \\
\text { City of } \\
\text { December } 31\end{array}$ & $\begin{array}{c}\text { Oregon } \\
\text { Central } \\
\text { Lincoln } \\
\text { Peoples } \\
\text { Uti Dt } \\
\text { December } 31\end{array}$ & $\begin{array}{c}\text { Oregon } \\
\text { Clatskanie } \\
\text { Peoples } \\
\text { Util Dist } \\
\text { December } 31\end{array}$ & $\begin{array}{c}\text { Oregon } \\
\text { Columbia } \\
\text { River } \\
\text { Peoples } \\
\text { Ut Dist } \\
\text { December } 31\end{array}$ \\
\hline \multicolumn{7}{|l|}{ Number of Consumers } \\
\hline 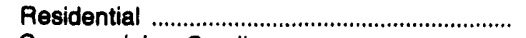 & 13,817 & 13,341 & 7,132 & 25,037 & 2,806 & 6,508 \\
\hline 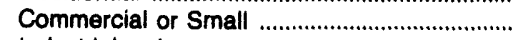 & 1,629 & 1,338 & 1,058 & 4,027 & 385 & 603 \\
\hline 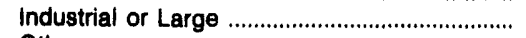 & 40 & 5 & 0 & 97 & 2 & \\
\hline Other & 93 & 0 & 105 & 2,020 & 1 & 515 \\
\hline $\begin{array}{l}\text { Total Uitimate Consumers ............................. } \\
\text { Sales for the Year (megawatthours) }\end{array}$ & 15,579 & 14,684 & 8,285 & 31,181 & 3,194 & 7,634 \\
\hline 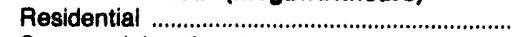 & 127,397 & 113,030 & 74,964 & 329,297 & 48,955 & 92,474 \\
\hline Commercial or Small & 93,735 & 101,231 & 55,047 & 183,660 & 23,429 & 21,051 \\
\hline Industrial or Large & 36,209 & 118,745 & 0 & 813,385 & 806,445 & 151,149 \\
\hline 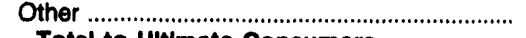 & 16,884 & 0 & 21,175 & 2,960 & 621 & 1,269 \\
\hline Total to Uitimate Consumers ........................ & 274,225 & 333,006 & 151,186 & $1,329,302$ & 879,450 & 265,943 \\
\hline 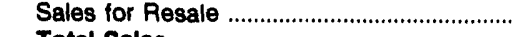 & & & 0 & & & \\
\hline Total Sales & 274,225 & 333,006 & 151,186 & $1,329,302$ & 879,450 & 265,843 \\
\hline \multicolumn{7}{|l|}{$\begin{array}{l}\text { Operating Revenues for the Year } \\
\text { (thousand dollars) }\end{array}$} \\
\hline 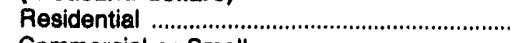 & 9,564 & 8,534 & 3,087 & 15,895 & 1,611 & 4,126 \\
\hline 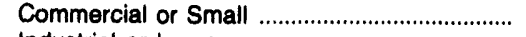 & 6,785 & 6,721 & 2,448 & 7,866 & 1,009 & 1,155 \\
\hline Industrial or Large & 2,169 & 5,488 & 0 & 22,080 & 20,116 & 5,700 \\
\hline Other & 954 & 0 & 972 & 542 & 48 & 102 \\
\hline Total to Ultimate Consumers ........................ & 19,472 & 20,743 & 6,507 & 46,383 & 22,784 & 11,083 \\
\hline 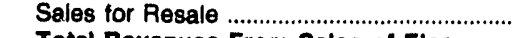 & & & & & 0 & \\
\hline Total Revenues From Sales of Elec ......... & 18,472 & 20,743 & 6,507 & 46,383 & 22,784 & 11,083 \\
\hline
\end{tabular}

Note: Totals may not equal sum of components because of independent rounding.

Source: Energy Information Administration, Form ElA-861, "Annual Electric Utility Report." Data are submitted on a calendar year. 
Table 25. Number of Consumers, Sales, and Operating Revenue by Major U.S. Publlcly Owned Electric Utllity Within State, 1992 (Continued)

\begin{tabular}{|c|c|c|c|c|c|c|}
\hline Item & $\begin{array}{l}\text { Oregon } \\
\text { Emerald } \\
\text { Peoples } \\
\text { Utility Jist } \\
\text { Decembc: } 31\end{array}$ & $\begin{array}{l}\text { Oregon } \\
\text { Eugene } \\
\text { City of } \\
\text { December } 31\end{array}$ & $\begin{array}{c}\text { Oregon } \\
\text { Forest Grove } \\
\text { City of } \\
\text { December } 31\end{array}$ & $\begin{array}{c}\text { Oregon } \\
\text { McMinnville } \\
\text { City of } \\
\text { December } 31\end{array}$ & $\begin{array}{l}\text { Oregon } \\
\text { Northern } \\
\text { Wasco County } \\
\text { P U D } \\
\text { December } 31\end{array}$ & $\begin{array}{l}\text { Oregon } \\
\text { Springfield } \\
\text { City of } \\
\text { December } 31\end{array}$ \\
\hline \multicolumn{7}{|l|}{ Number of Consumers } \\
\hline 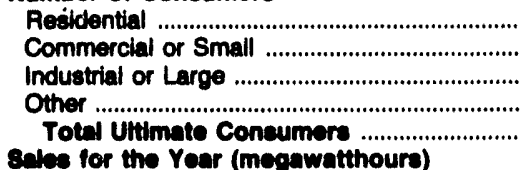 & $\begin{array}{r}12,755 \\
1,350 \\
9 \\
660 \\
14,774\end{array}$ & $\begin{array}{r}61,428 \\
7,465 \\
1 \\
11 \\
68,905\end{array}$ & $\begin{array}{r}5,762 \\
728 \\
81 \\
363 \\
6,934\end{array}$ & $\begin{array}{r}8,275 \\
2,597 \\
2 \\
1 \\
10,875\end{array}$ & $\begin{array}{r}7,208 \\
1,153 \\
134 \\
38 \\
8,533\end{array}$ & $\begin{array}{r}20,286 \\
1,761 \\
134 \\
220 \\
22,401\end{array}$ \\
\hline 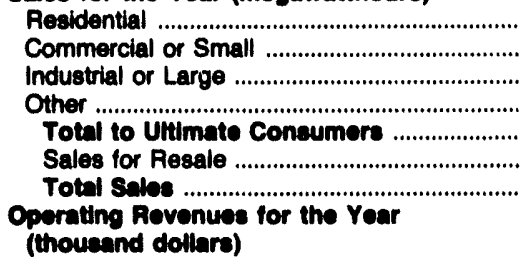 & $\begin{array}{r}196,503 \\
67,244 \\
96,628 \\
10,522 \\
370,897 \\
116 \\
371,013\end{array}$ & $\begin{array}{r}899,540 \\
934,760 \\
433,703 \\
22,692 \\
2,280,695 \\
245,786 \\
2,538,481\end{array}$ & $\begin{array}{r}88,556 \\
45,822 \\
59,729 \\
1,699 \\
195,806 \\
0 \\
195,806\end{array}$ & $\begin{array}{r}141,592 \\
125,597 \\
233,926 \\
1,271 \\
502,386 \\
0 \\
502,386\end{array}$ & $\begin{array}{r}110,136 \\
25,994 \\
93,575 \\
2,369 \\
232,074 \\
37,910 \\
269,984\end{array}$ & $\begin{array}{r}287,922 \\
136,714 \\
301,338 \\
24,596 \\
750,570 \\
0 \\
750,570\end{array}$ \\
\hline 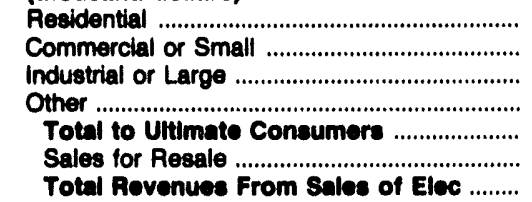 & $\begin{array}{r}10,105 \\
3,840 \\
4,324 \\
423 \\
18,692 \\
3 \\
18,695\end{array}$ & $\begin{array}{r}37,123 \\
33,278 \\
12,096 \\
765 \\
83,262 \\
6,445 \\
89,707\end{array}$ & $\begin{array}{r}3,174 \\
1,426 \\
1,655 \\
81 \\
6,336 \\
0 \\
6,336\end{array}$ & $\begin{array}{r}4,025 \\
4,407 \\
6,890 \\
37 \\
15,359 \\
0 \\
15,359\end{array}$ & $\begin{array}{r}4,502 \\
1,185 \\
3,421 \\
205 \\
9,313 \\
1,756 \\
11,069\end{array}$ & $\begin{array}{r}11,358 \\
4,576 \\
8,012 \\
885 \\
24,831 \\
0 \\
24,831\end{array}$ \\
\hline
\end{tabular}

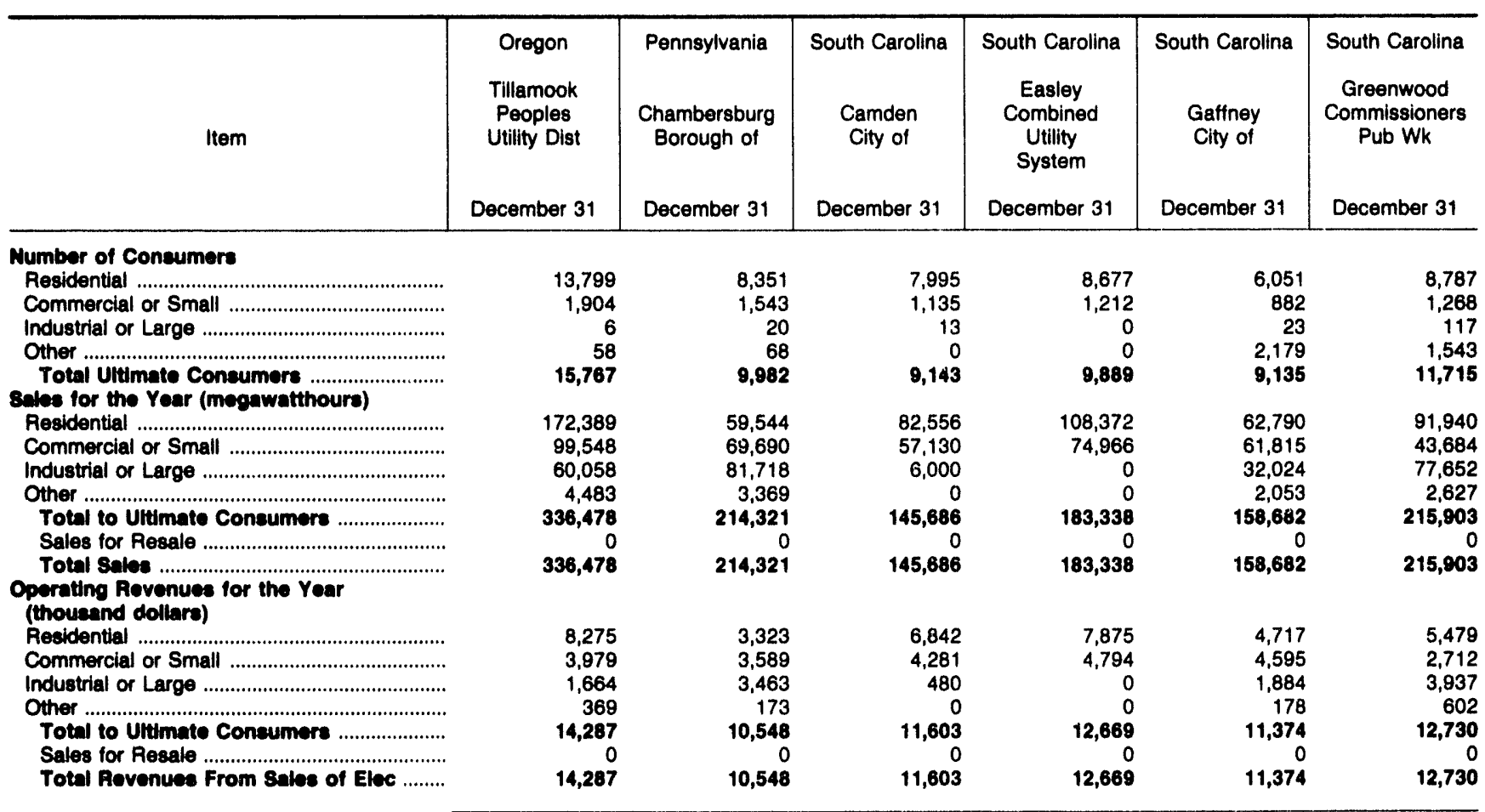

Note: Totals may not equal sum of components because of independent rounding.

Source: Energy Information Administration, Form ElA-861, "Annual Electric Utility Report." Data are submitted on a calendar year. 
Table 25. Number of Consumers, Sales, and Operating Revenue by Major U.S. Publicly Owned Electric Utillty Within State, 1992 (Continued)

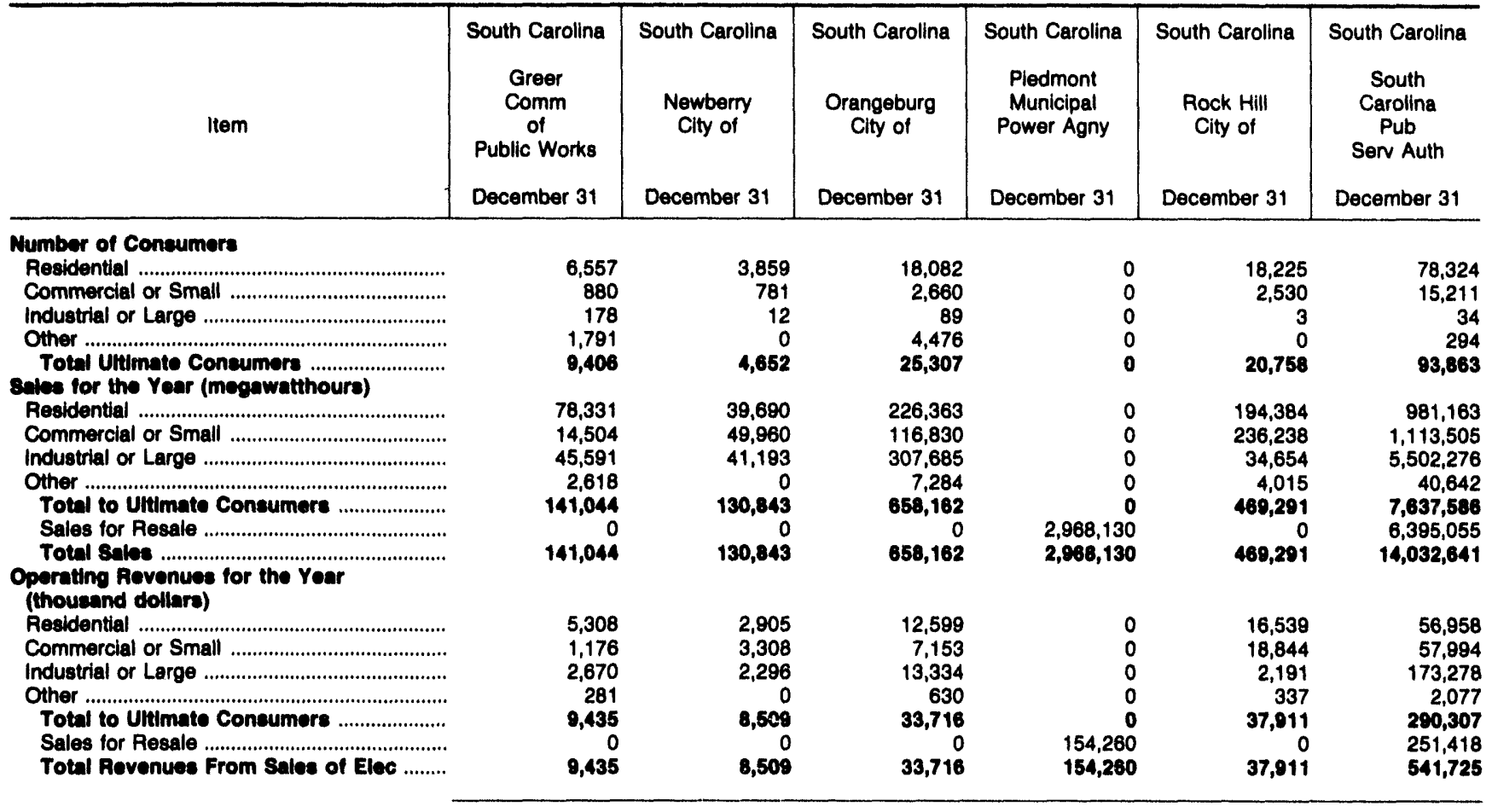

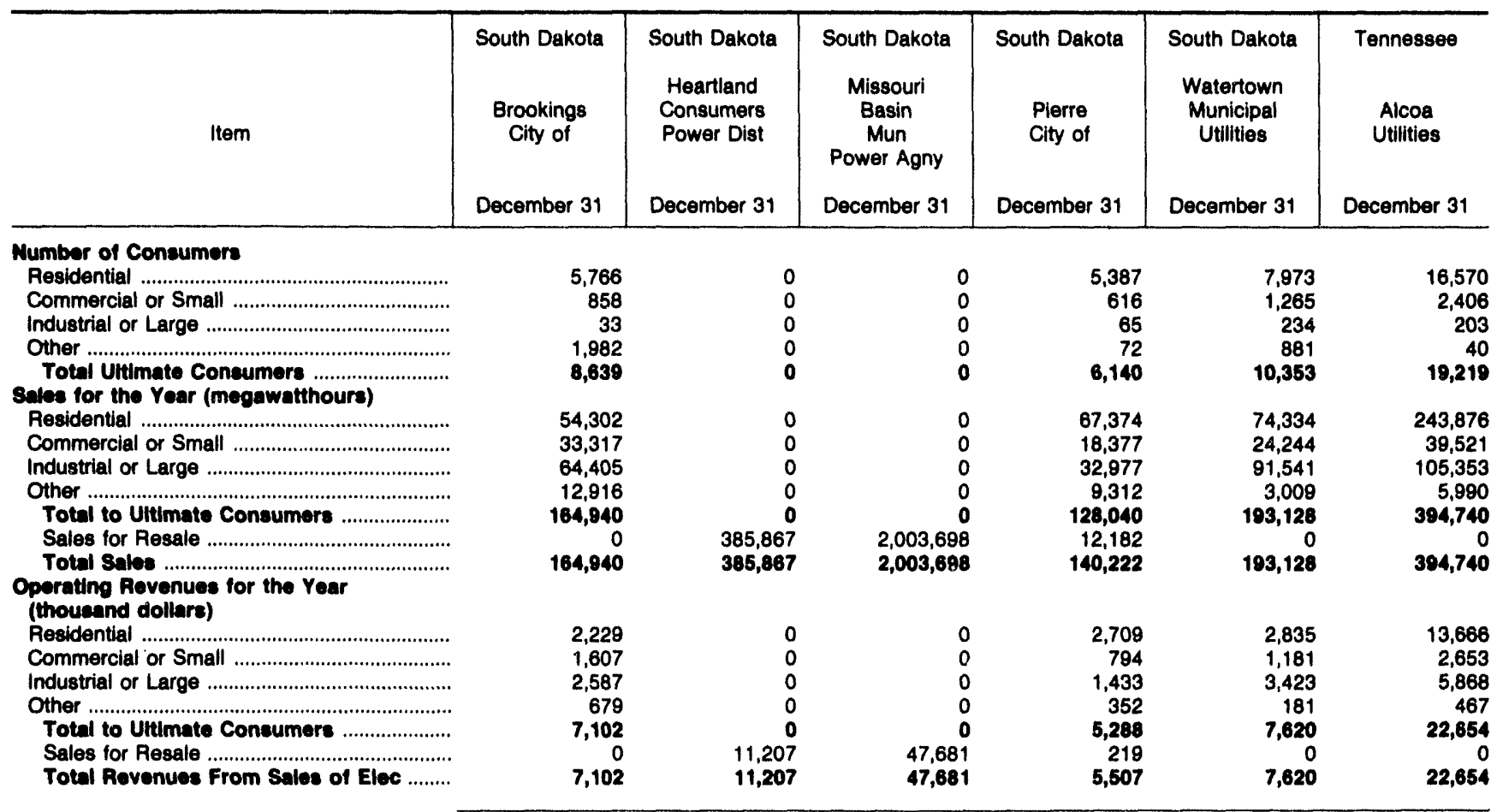

Note: Totals may not equal sum of components because of independent rounding.

Source: Energy Information Administration, Form ElA-861, "Annual Electric Utility Report." Data are submitted on a calendar year. 
Table 25. Number of Consumers, Sales, and Operating Revenue by Major U.S. Publicly Owned Electric Utllity Within State, 1992 (Continued)

\begin{tabular}{|c|c|c|c|c|c|c|}
\hline Item & $\begin{array}{c}\text { Tennessee } \\
\text { Athens } \\
\text { City of } \\
\text { December } 31\end{array}$ & $\begin{array}{l}\text { Tennessee } \\
\text { Benton } \\
\text { County } \\
\text { December } 31\end{array}$ & $\begin{array}{c}\text { Tennessee } \\
\text { Bolivar } \\
\text { City of } \\
\text { December } 31\end{array}$ & $\begin{array}{c}\text { Tennessee } \\
\text { Bristol } \\
\text { City of } \\
\text { December } 31\end{array}$ & $\begin{array}{c}\text { Tennessee } \\
\text { Brownsville } \\
\text { City of }\end{array}$ & $\begin{array}{c}\text { Tennessee } \\
\text { Carroll } \\
\text { County } \\
\text { December } 31\end{array}$ \\
\hline \multicolumn{7}{|l|}{ Number of Coneumars } \\
\hline 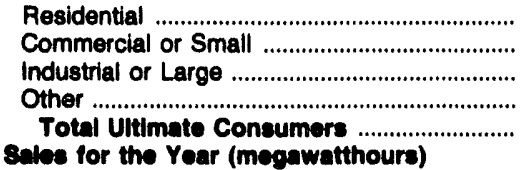 & $\begin{array}{r}9,527 \\
1,854 \\
218 \\
112 \\
11,711\end{array}$ & $\begin{array}{r}7,326 \\
1,353 \\
74 \\
142 \\
8,895\end{array}$ & $\begin{array}{r}8,580 \\
1,594 \\
75 \\
25 \\
10,274\end{array}$ & $\begin{array}{r}24,349 \\
2,892 \\
469 \\
168 \\
27,878\end{array}$ & $\begin{array}{r}3,963 \\
661 \\
77 \\
22 \\
4,723\end{array}$ & $\begin{array}{r}11,573 \\
2,405 \\
165 \\
92 \\
14,236\end{array}$ \\
\hline 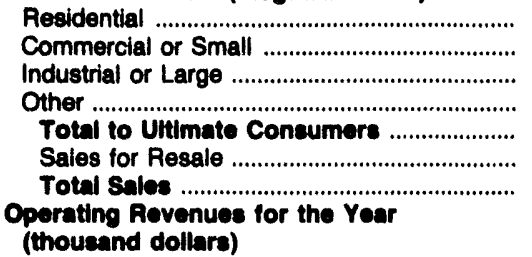 & $\begin{array}{r}133,738 \\
38,898 \\
302,421 \\
6,066 \\
481,123 \\
0 \\
481,123\end{array}$ & $\begin{array}{r}92,629 \\
17,830 \\
76,605 \\
3,981 \\
191,045 \\
0 \\
191,045\end{array}$ & $\begin{array}{r}112,160 \\
20,974 \\
75,599 \\
3,732 \\
212,465 \\
0 \\
212,465\end{array}$ & $\begin{array}{r}384,685 \\
54,122 \\
293,995 \\
8,431 \\
741,233 \\
0 \\
741,233\end{array}$ & $\begin{array}{r}52,319 \\
14,535 \\
111,455 \\
1,886 \\
180,195 \\
0 \\
180,195\end{array}$ & $\begin{array}{r}164,650 \\
33,793 \\
136,495 \\
6,984 \\
341,922 \\
0 \\
341,922\end{array}$ \\
\hline 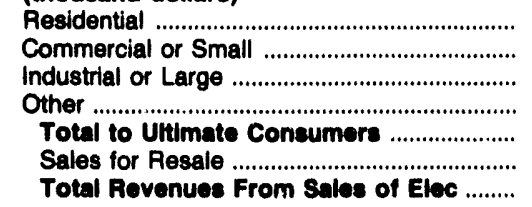 & $\begin{array}{r}7,406 \\
2,504 \\
15,191 \\
486 \\
25,587 \\
0 \\
25,587\end{array}$ & $\begin{array}{r}5,315 \\
1,299 \\
4,109 \\
353 \\
11,076 \\
0 \\
11,076\end{array}$ & $\begin{array}{r}6,460 \\
1,458 \\
4,056 \\
374 \\
12,348 \\
0 \\
12,348\end{array}$ & $\begin{array}{r}20,386 \\
3,366 \\
15,745 \\
747 \\
40,244 \\
0 \\
40,244\end{array}$ & $\begin{array}{r}2,802 \\
888 \\
5,654 \\
142 \\
9,486 \\
0 \\
9,486\end{array}$ & $\begin{array}{r}9,396 \\
2,318 \\
7,129 \\
519 \\
19,362 \\
0 \\
19,362\end{array}$ \\
\hline
\end{tabular}

\begin{tabular}{|c|c|c|c|c|c|c|}
\hline Item & $\begin{array}{c}\text { Tennessee } \\
\text { Chattanooga } \\
\text { City of }\end{array}$ & $\begin{array}{l}\text { Tennessee } \\
\text { Clarksville } \\
\text { City of }\end{array}$ & $\begin{array}{c}\text { Tennessee } \\
\text { Cleveland } \\
\text { City of } \\
\text { December } 31\end{array}$ & $\begin{array}{l}\text { Tennessee } \\
\text { Clinton } \\
\text { City of } \\
\text { December } 31\end{array}$ & $\begin{array}{c}\text { Tennessee } \\
\text { Columbia } \\
\text { City of } \\
\text { December } 31\end{array}$ & $\begin{array}{c}\text { Tennessee } \\
\text { Cookeville } \\
\text { City of }\end{array}$ \\
\hline \multicolumn{7}{|l|}{ Number of Consumers } \\
\hline 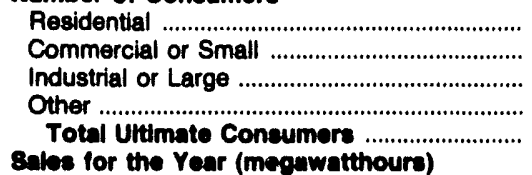 & $\begin{array}{r}126,103 \\
14,616 \\
1,794 \\
149 \\
142,662\end{array}$ & $\begin{array}{r}27,960 \\
3,321 \\
364 \\
251 \\
31,898\end{array}$ & $\begin{array}{r}19,820 \\
2,687 \\
405 \\
61 \\
22,973\end{array}$ & $\begin{array}{r}21,657 \\
2,072 \\
225 \\
38 \\
23,002\end{array}$ & $\begin{array}{r}16,070 \\
2,504 \\
232 \\
26 \\
18,832\end{array}$ & $\begin{array}{r}9,076 \\
2,174 \\
317 \\
62 \\
11,620\end{array}$ \\
\hline 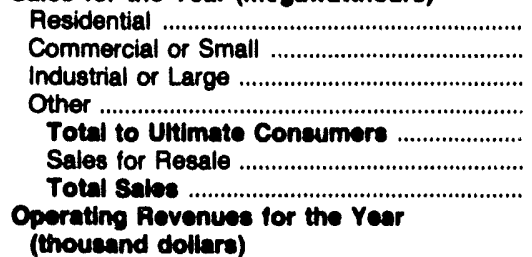 & $\begin{array}{r}1,937,504 \\
398,193 \\
2,699,741 \\
54,896 \\
5,000,334 \\
0 \\
5,000,334\end{array}$ & $\begin{array}{r}400,296 \\
80,029 \\
257,880 \\
10,589 \\
748,804 \\
0 \\
748,804\end{array}$ & $\begin{array}{r}307,449 \\
73,263 \\
435,702 \\
7,743 \\
824,157 \\
0 \\
824,157\end{array}$ & $\begin{array}{r}320,393 \\
40,050 \\
190,311 \\
7,670 \\
558,424 \\
0 \\
558,424\end{array}$ & $\begin{array}{r}227,399 \\
60,162 \\
179,146 \\
7,148 \\
473,855 \\
0 \\
473,855\end{array}$ & $\begin{array}{r}118,997 \\
45,595 \\
246,913 \\
7,257 \\
418,762 \\
0 \\
418,762\end{array}$ \\
\hline 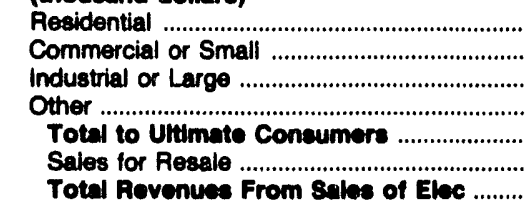 & $\begin{array}{r}110,449 \\
25,878 \\
133,898 \\
3,864 \\
274,089 \\
0 \\
274,089\end{array}$ & $\begin{array}{r}22,496 \\
5,148 \\
13,981 \\
725 \\
42,350 \\
0 \\
42,350\end{array}$ & $\begin{array}{r}17,160 \\
4,669 \\
21,467 \\
551 \\
43,847 \\
0 \\
43,847\end{array}$ & $\begin{array}{r}18,220 \\
2,660 \\
10,440 \\
676 \\
31,996 \\
0 \\
31,996\end{array}$ & $\begin{array}{r}12,424 \\
3,770 \\
9,046 \\
456 \\
25,696 \\
0 \\
25,696\end{array}$ & $\begin{array}{r}6,679 \\
2,954 \\
13,044 \\
431 \\
23,108 \\
0 \\
0 \\
23,108\end{array}$ \\
\hline
\end{tabular}

Note: Totals may not equal sum of components because of independentrounding.

Source: Energy Information Administration, Form ElA-861, "Annual Electric Utility Report." Data are submitted on a calendar year. 
Table 25. Number of Consumers, Sales, and Operating Revenue by Major U.S. Publicly Owned Electric Utility Within State, 1992 (Continued)

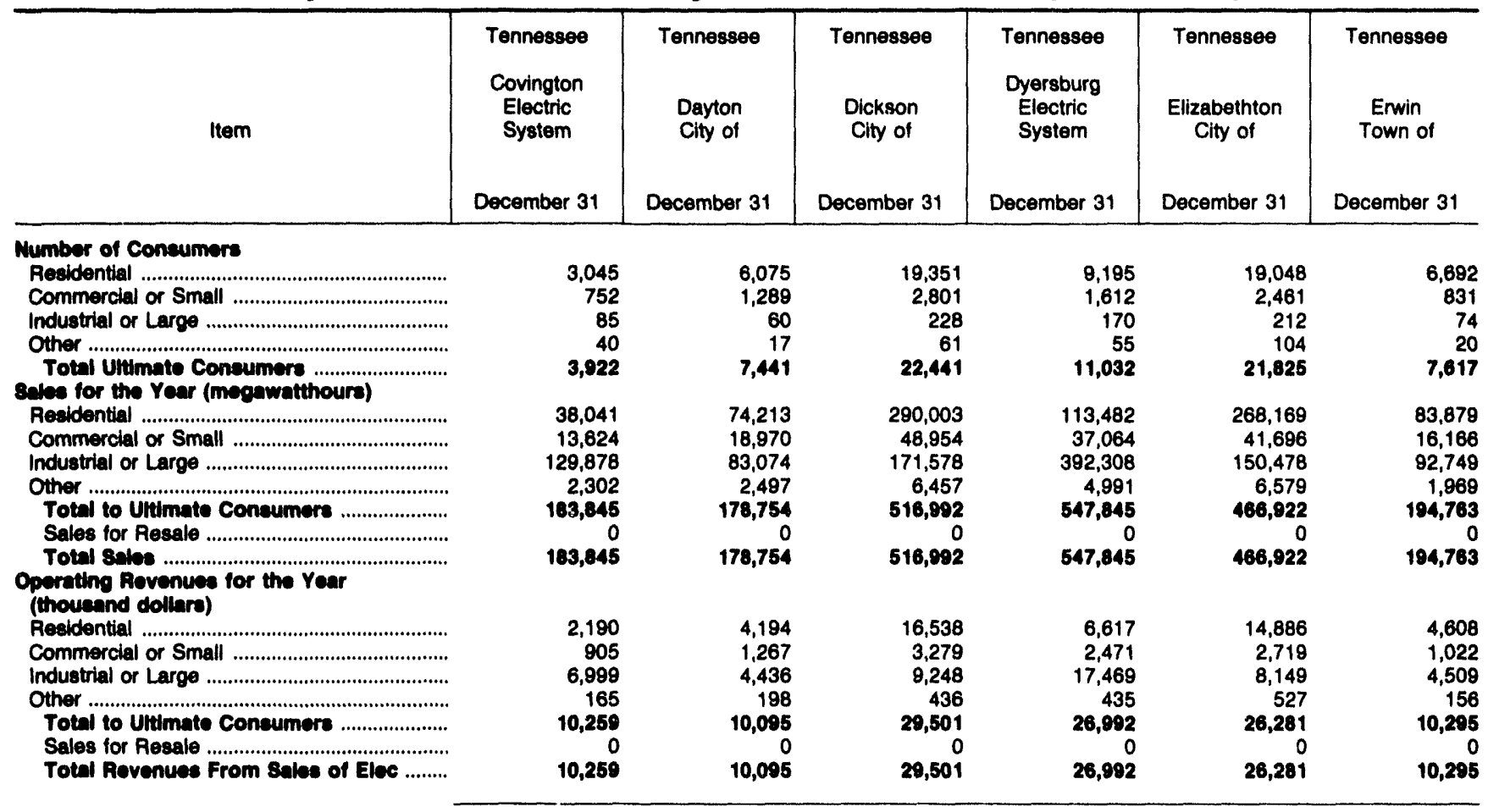

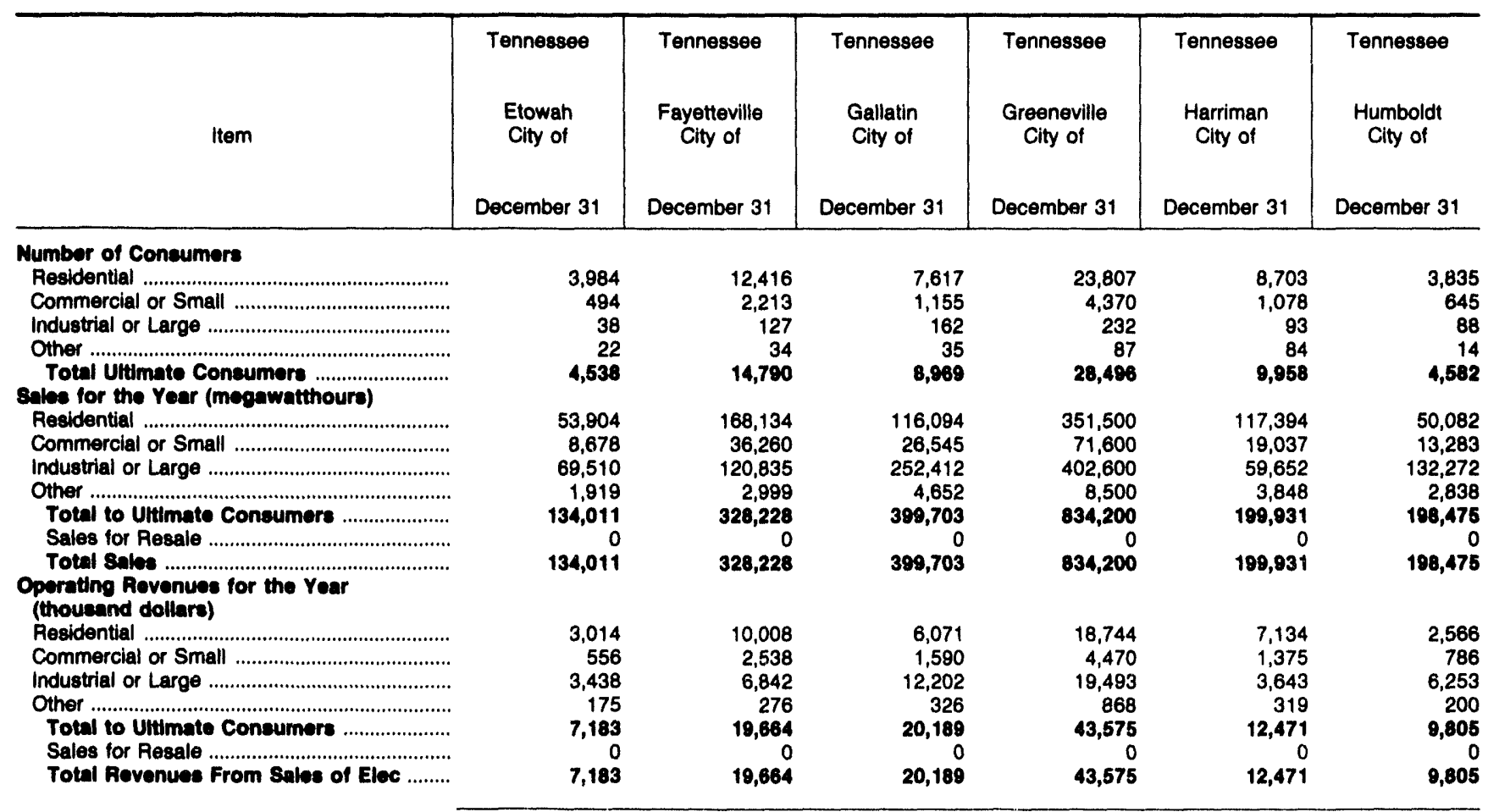

Note: Totals may not equal sum of components because of independent rounding.

Source: Energy Information Administration, Form ElA-861, "Annual Electric Utility Report." Data are submitted on a calendar year. 
Table 25. Number of Consumers, Sales, and Operating Revenue by Major U.S. Publicly Owned Electric Utility Within State, 1992 (Continued)

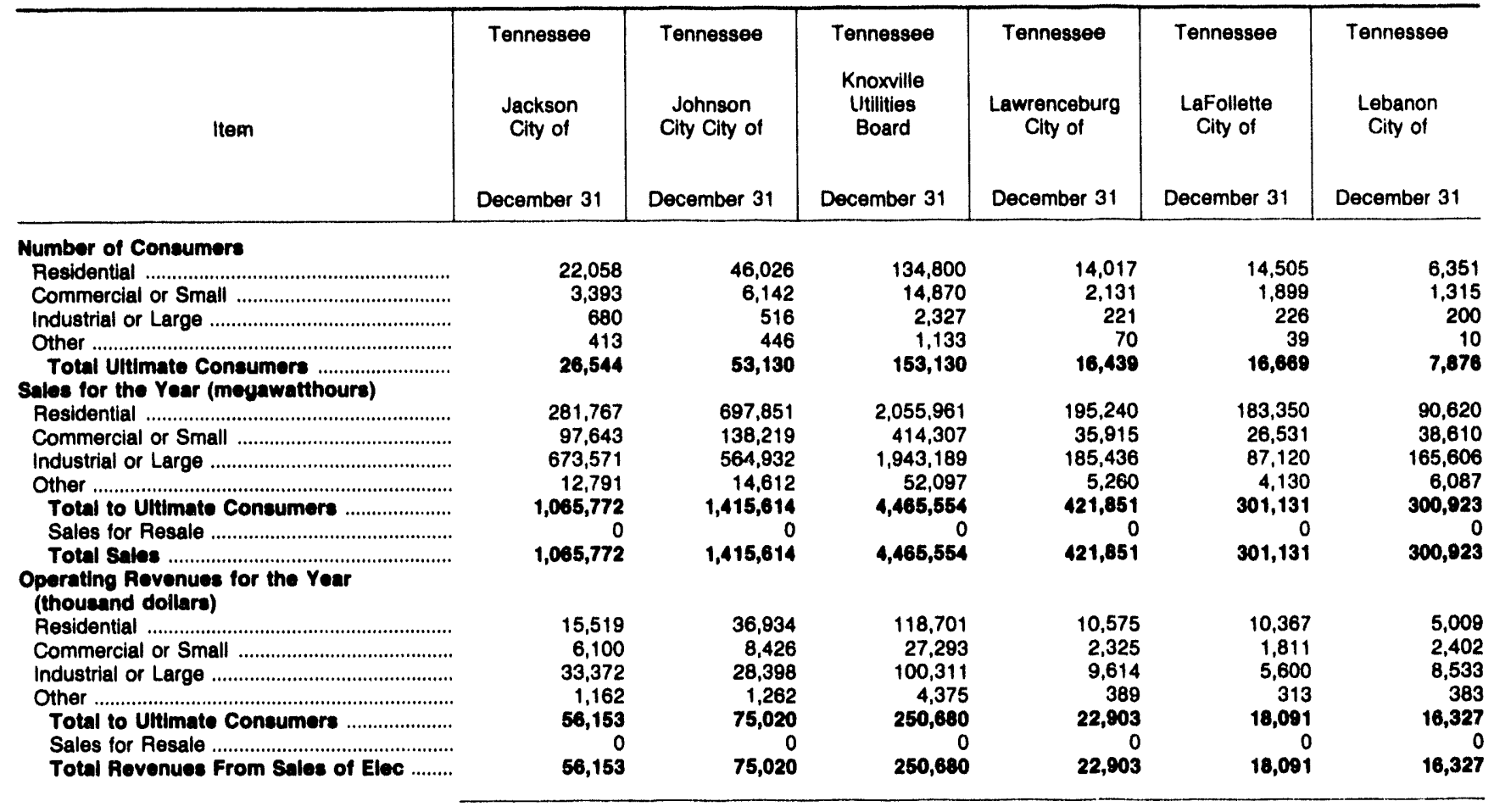

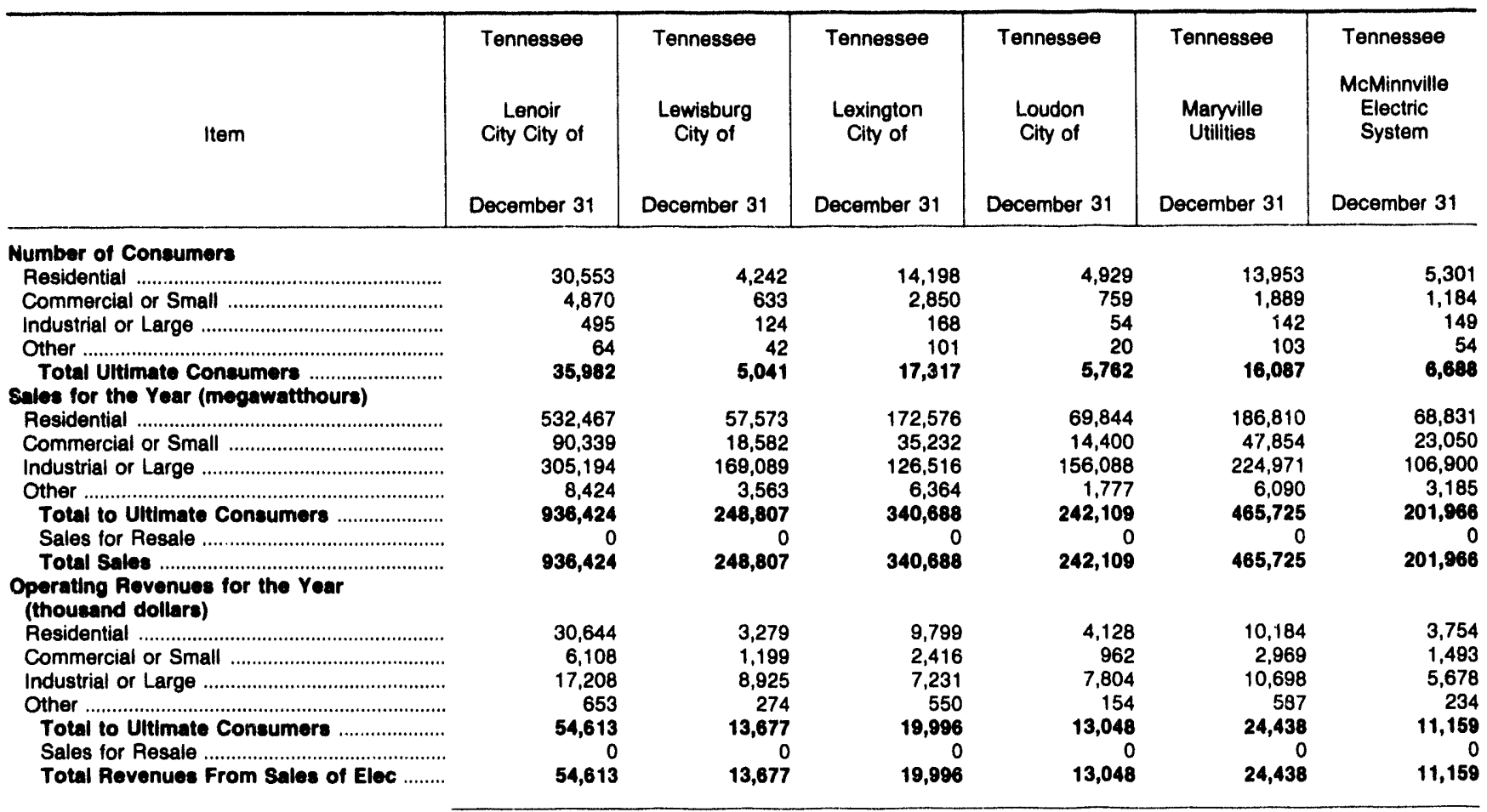

Note: Totals may not equal sum of components because of independent rounding.

Source: Energy Information Administration, Form ElA-861. "Annual Electric Utility Report." Data are submitted on a calendar year. 
Table 25. Number of Consumers, Sales, and Operating Revenue by Major U.S. Publicly Owned Electric Utility Within State, 1992 (Continued)

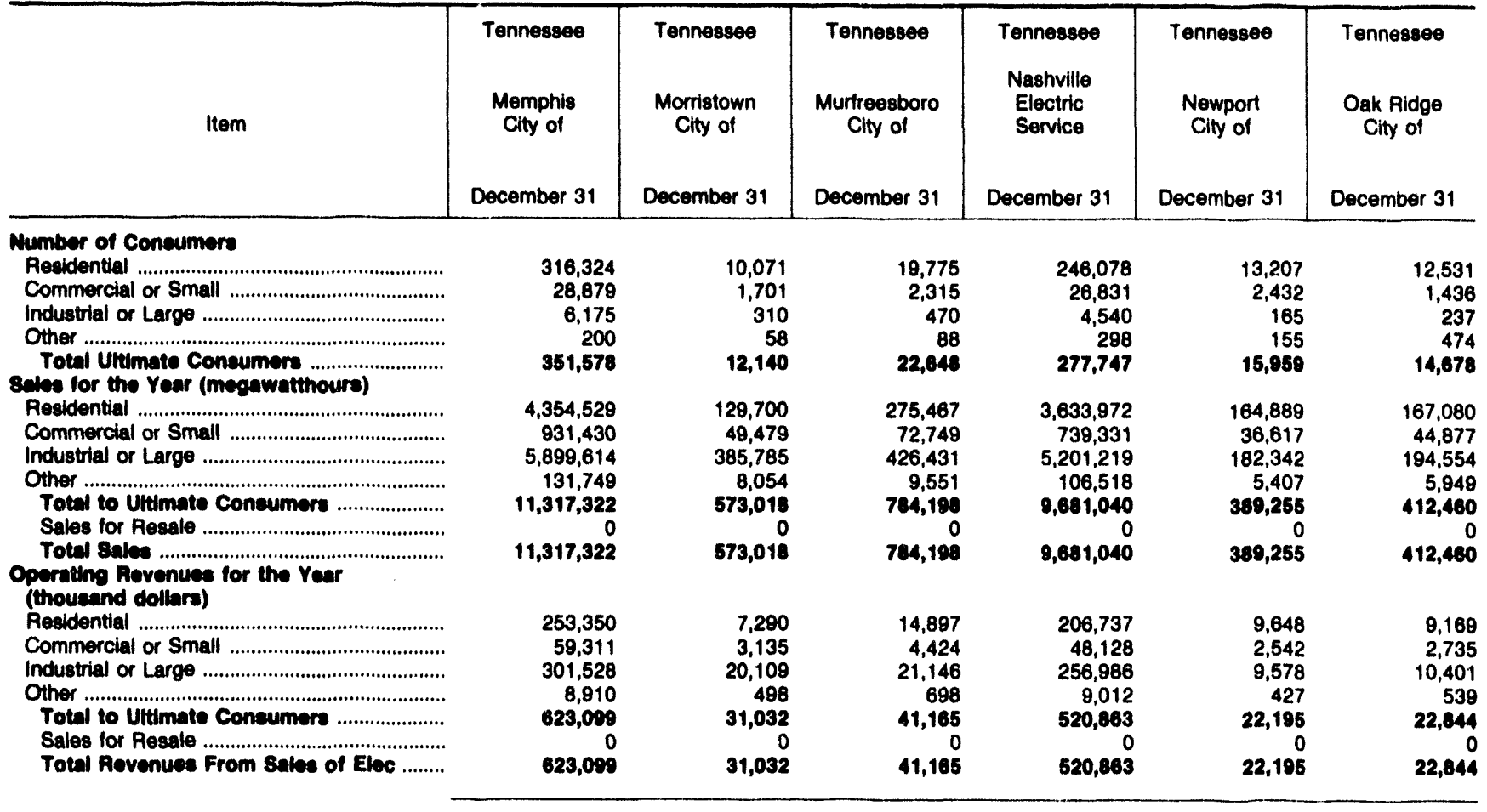

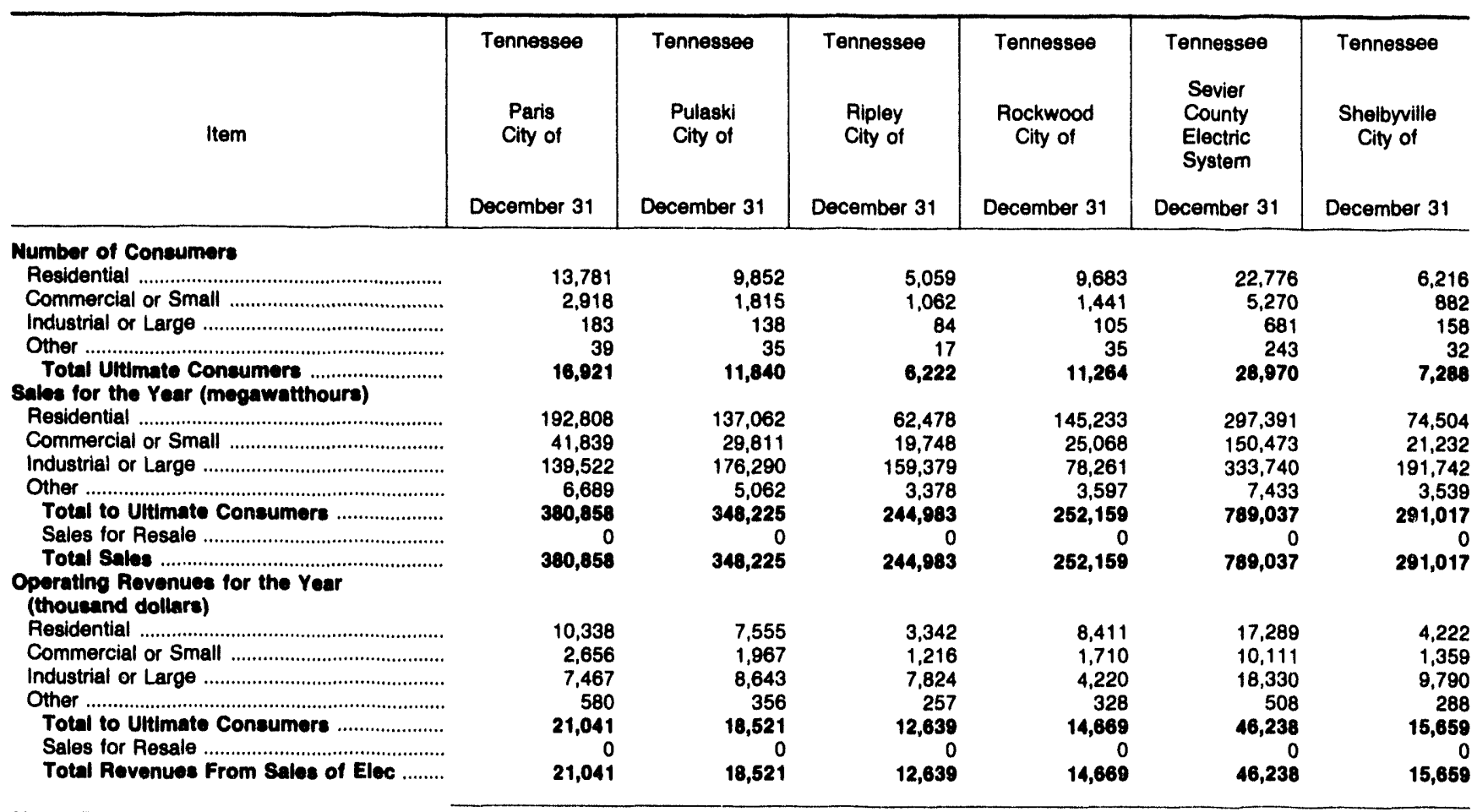

Note: Totals may not equal sum of components because of independent rounding.

Source: Energy Information Administration, Form EIA-861, "Annual Electric Utility Report." Data are submitted on a calendar year. 
Table 25. Number of Consumers, Sales, and Operating Revenue by Major U.S. Publicly Owned Electric Utility Within State, 1992 (Continued)

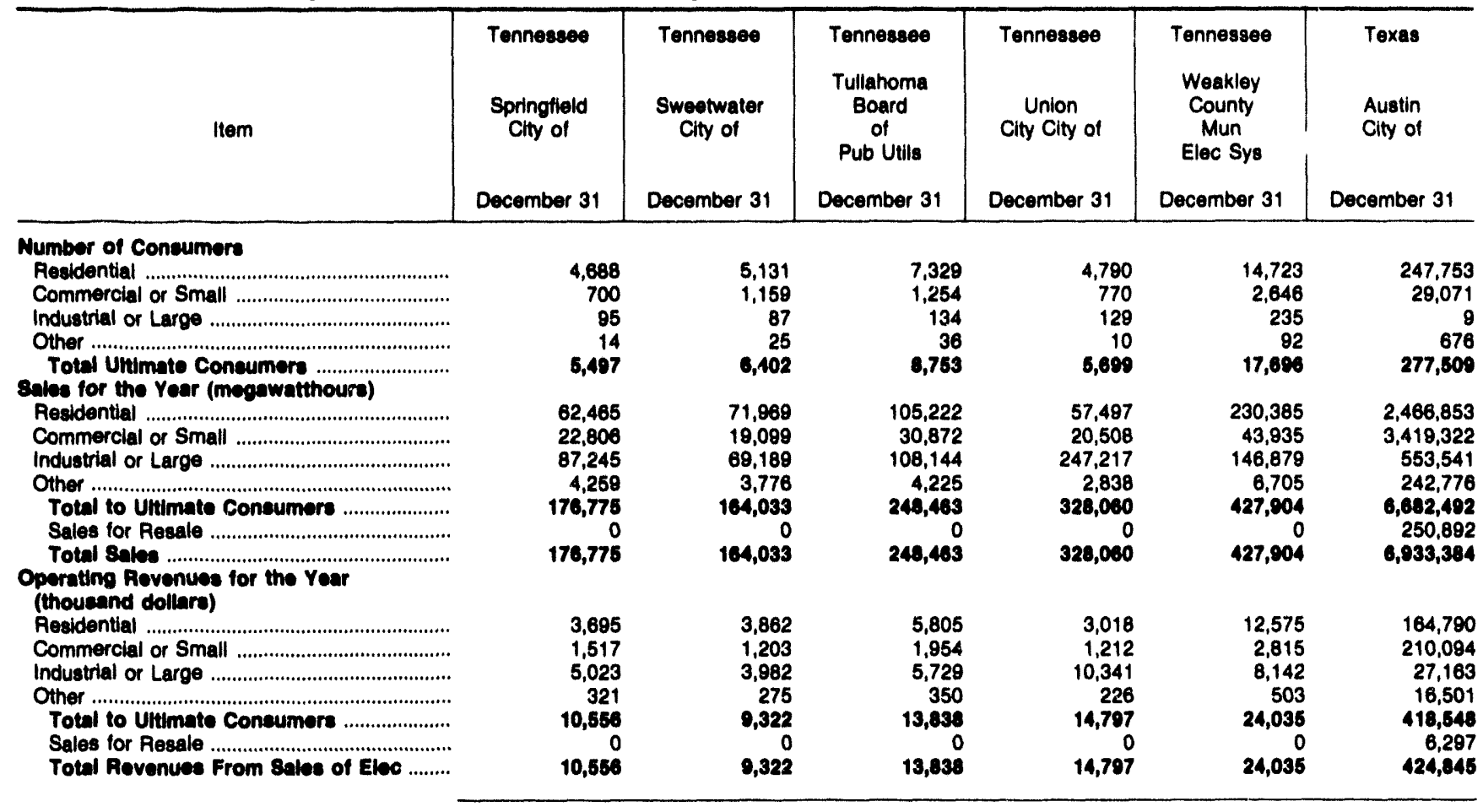

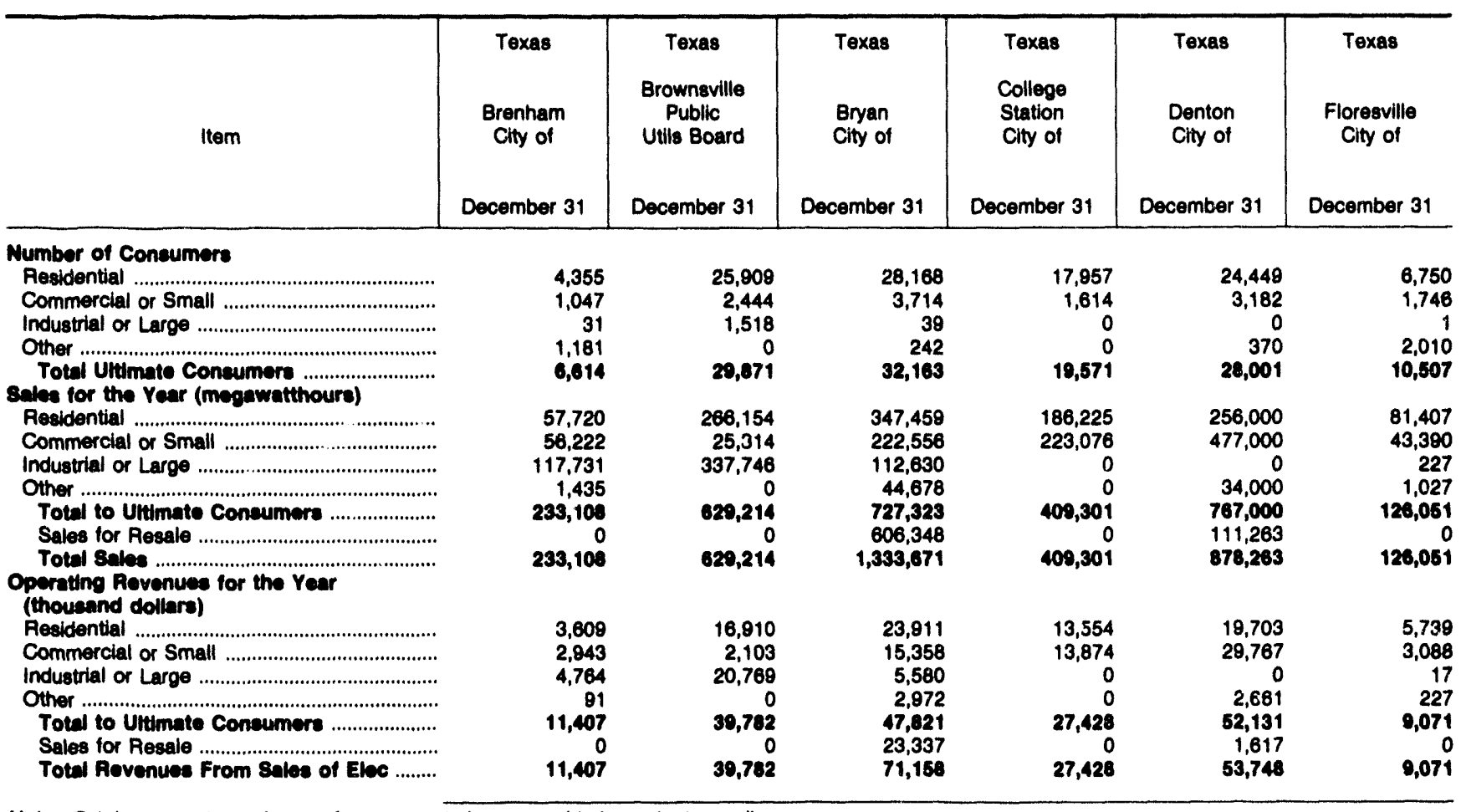

Note: Totals may not equal sum of components because of independent rounding.

Source: Energy Information Administration, Form ElA-861, "Annual Electric Utility Report." Data are submitted on a calendar year. 
Table 25. Number of Consumers, Sales, and Operating Revenue by Major U.S. Publlcly Owned Electrlc Utillty Within State, 1992 (Continued)

\begin{tabular}{|c|c|c|c|c|c|c|}
\hline Item & $\begin{array}{l}\text { Texas } \\
\text { Garland } \\
\text { Clty of } \\
\text { December } 31\end{array}$ & $\begin{array}{l}\text { Texas } \\
\text { Georgetown } \\
\text { Clty of }\end{array}$ & $\begin{array}{c}\text { Texas } \\
\text { Greenville } \\
\text { Clty of } \\
\text { December } 31\end{array}$ & $\begin{array}{l}\text { Texas } \\
\text { Kerville } \\
\text { Public } \\
\text { Utllty } \\
\text { Board } \\
\text { December } 31\end{array}$ & $\begin{array}{l}\text { Texas } \\
\text { Lower } \\
\text { Colorado } \\
\text { River } \\
\text { Authority } \\
\text { December } 31\end{array}$ & $\begin{array}{c}\text { Texas } \\
\text { Lubbock } \\
\text { Clty of }\end{array}$ \\
\hline \multicolumn{7}{|l|}{ Number of Concumore } \\
\hline 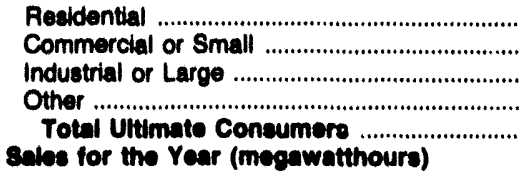 & $\begin{array}{r}55,291 \\
3,709 \\
1,019 \\
215 \\
00,234\end{array}$ & $\begin{array}{r}6,810 \\
937 \\
39 \\
29 \\
7,815\end{array}$ & $\begin{array}{r}9,889 \\
1,740 \\
3 \\
7 \\
11,639\end{array}$ & $\begin{array}{r}13,370 \\
2,747 \\
0 \\
151 \\
16,298\end{array}$ & $\begin{array}{r}10 \\
32 \\
15 \\
0 \\
57\end{array}$ & $\begin{array}{r}40,287 \\
5,049 \\
74 \\
842 \\
46,252\end{array}$ \\
\hline 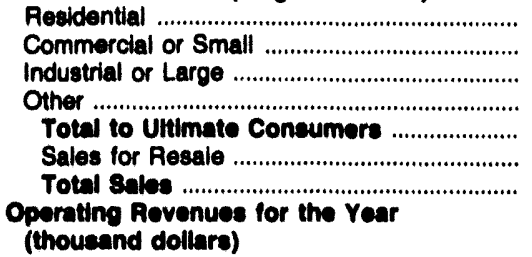 & $\begin{array}{r}793,720 \\
66,131 \\
716,854 \\
89,887 \\
1,868,592 \\
583,575 \\
2,260,167\end{array}$ & $\begin{array}{r}88,294 \\
39,755 \\
27,572 \\
4,952 \\
160,573 \\
0 \\
160,573\end{array}$ & $\begin{array}{r}96,127 \\
252,302 \\
44,216 \\
2,607 \\
395,252 \\
49,219 \\
444,471\end{array}$ & $\begin{array}{r}171,962 \\
150,370 \\
0 \\
5,768 \\
328,100 \\
0 \\
328,100\end{array}$ & $\begin{array}{r}135 \\
848 \\
147,437 \\
0 \\
148,420 \\
8,226,028 \\
8,374,448\end{array}$ & $\begin{array}{r}338,881 \\
202,010 \\
246,801 \\
112,602 \\
\boldsymbol{9 0 2 , 2 0 4} \\
0 \\
902,204\end{array}$ \\
\hline 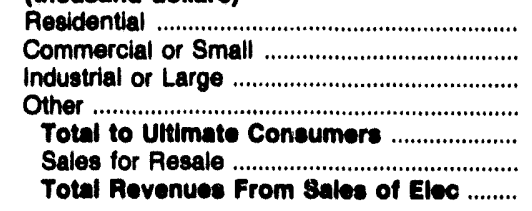 & $\begin{array}{r}62,042 \\
5,489 \\
39,241 \\
5,722 \\
112,494 \\
15,276 \\
127,770\end{array}$ & $\begin{array}{r}6,226 \\
2,821 \\
1,443 \\
301 \\
10,791 \\
0 \\
10,791\end{array}$ & $\begin{array}{r}7,375 \\
16,242 \\
2,299 \\
324 \\
26,240 \\
2,396 \\
28,686\end{array}$ & $\begin{array}{r}11,352 \\
9,250 \\
0 \\
298 \\
20,900 \\
0 \\
20,900\end{array}$ & $\begin{array}{r}9 \\
54 \\
6,208 \\
0 \\
6,271 \\
322,052 \\
328,323\end{array}$ & $\begin{array}{r}21,702 \\
11,642 \\
11,003 \\
5,849 \\
50,190 \\
0 \\
50,190\end{array}$ \\
\hline
\end{tabular}

\begin{tabular}{|c|c|c|c|c|c|c|}
\hline Item & $\begin{array}{c}\text { Texas } \\
\text { New Braunfels } \\
\text { City of } \\
\text { December } 31\end{array}$ & $\begin{array}{c}\text { Texas } \\
\text { Sam Rayburn } \\
\text { Municipal } \\
\text { Pwr } \\
\text { Agny } \\
\text { December } 31\end{array}$ & $\begin{array}{c}\text { Texas } \\
\text { San Antonio } \\
\text { City of } \\
\text { December } 31\end{array}$ & $\begin{array}{c}\text { Texas } \\
\text { San Marcos } \\
\text { City of } \\
\text { December } 31\end{array}$ & $\begin{array}{l}\text { Texas } \\
\text { Seguin } \\
\text { City of } \\
\text { December } 31\end{array}$ & $\begin{array}{c}\text { Texas } \\
\text { Texes } \\
\text { Municipal } \\
\text { Power Agency } \\
\text { December } 31\end{array}$ \\
\hline \multicolumn{7}{|l|}{ Number of Consumors } \\
\hline 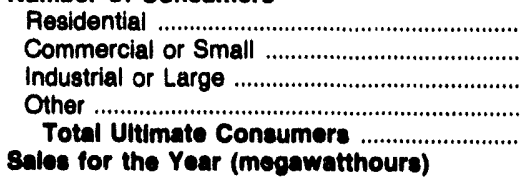 & $\begin{array}{r}13,749 \\
2,030 \\
10 \\
880 \\
16,679\end{array}$ & $\begin{array}{l}0 \\
0 \\
0 \\
0 \\
0\end{array}$ & $\begin{array}{r}422,460 \\
48,281 \\
1,452 \\
12,321 \\
484,514\end{array}$ & $\begin{array}{r}11,129 \\
2,587 \\
9 \\
109 \\
13,834\end{array}$ & $\begin{array}{r}6,395 \\
1,016 \\
7 \\
938 \\
8,356\end{array}$ & \\
\hline 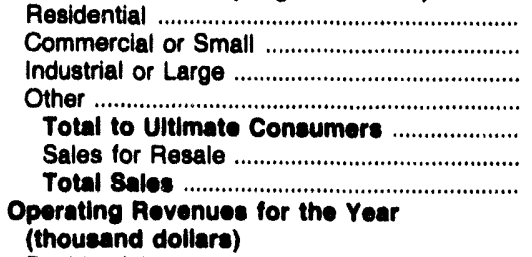 & $\begin{array}{r}191,298 \\
135,531 \\
354,464 \\
24,593 \\
705,886 \\
0 \\
705,886\end{array}$ & $\begin{array}{r}0 \\
0 \\
0 \\
0 \\
0 \\
578,182 \\
578,182\end{array}$ & $\begin{array}{r}4,823,873 \\
2,185,820 \\
3,233,063 \\
1,709,229 \\
11,951,985 \\
280,346 \\
12,242,331\end{array}$ & $\begin{array}{r}113,807 \\
111,520 \\
46,744 \\
7,157 \\
279,228 \\
0 \\
279,228\end{array}$ & $\begin{array}{r}65,467 \\
61,989 \\
46,954 \\
6,472 \\
180,882 \\
0 \\
180,882\end{array}$ & $\begin{array}{r}0 \\
0 \\
0 \\
2,805,067 \\
2,805,067\end{array}$ \\
\hline 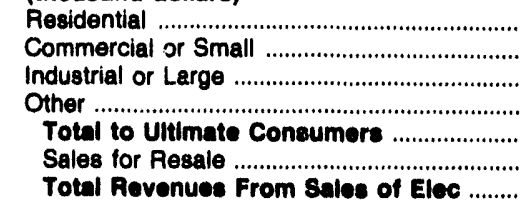 & $\begin{array}{r}11,523 \\
8,431 \\
15,365 \\
1,605 \\
36,024 \\
0 \\
36,924\end{array}$ & $\begin{array}{r}0 \\
0 \\
0 \\
0 \\
0 \\
25,399 \\
25,399\end{array}$ & $\begin{array}{r}318,371 \\
129,724 \\
153,112 \\
87,468 \\
688,673 \\
10,128 \\
608,801\end{array}$ & $\begin{array}{r}7,336 \\
6,723 \\
2,825 \\
437 \\
17,321 \\
0 \\
17,321\end{array}$ & $\begin{array}{r}4,634 \\
4,047 \\
2,517 \\
400 \\
11,598 \\
0 \\
11,598\end{array}$ & $\begin{array}{r}0 \\
0 \\
0 \\
168,381 \\
168,381\end{array}$ \\
\hline
\end{tabular}

Note: Totcls may not equal sum of components bocause of independentrounding

Source: Energy Information Administration, Form ElA-861, "Annual Electric Utility Report." Data are submitted on a calendar year. 
Table 25. Number of Consumers, Sales, and Operating Revenue by Major U.S. Publicly Owned Electric Utillty Within State, 1992 (Continued)

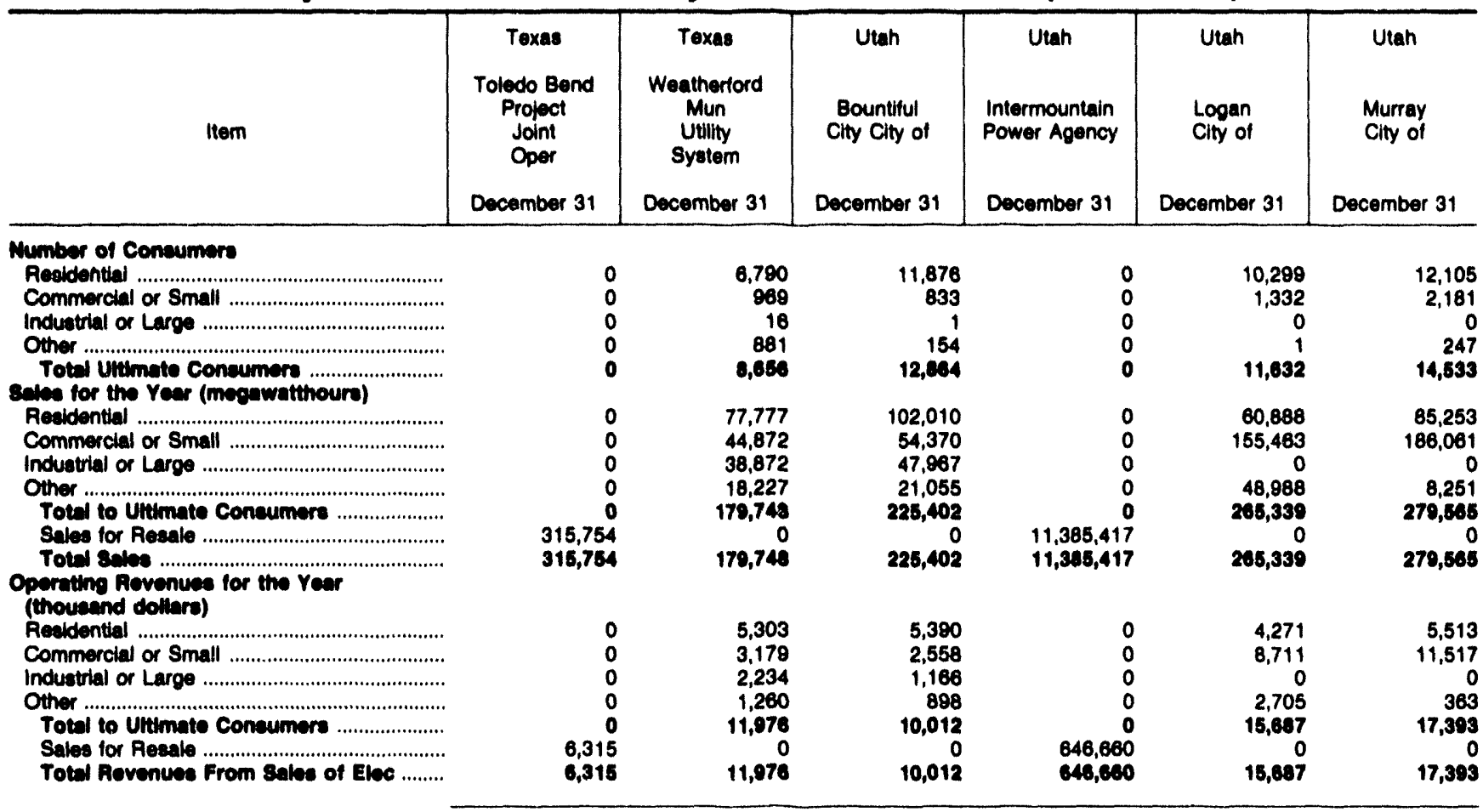

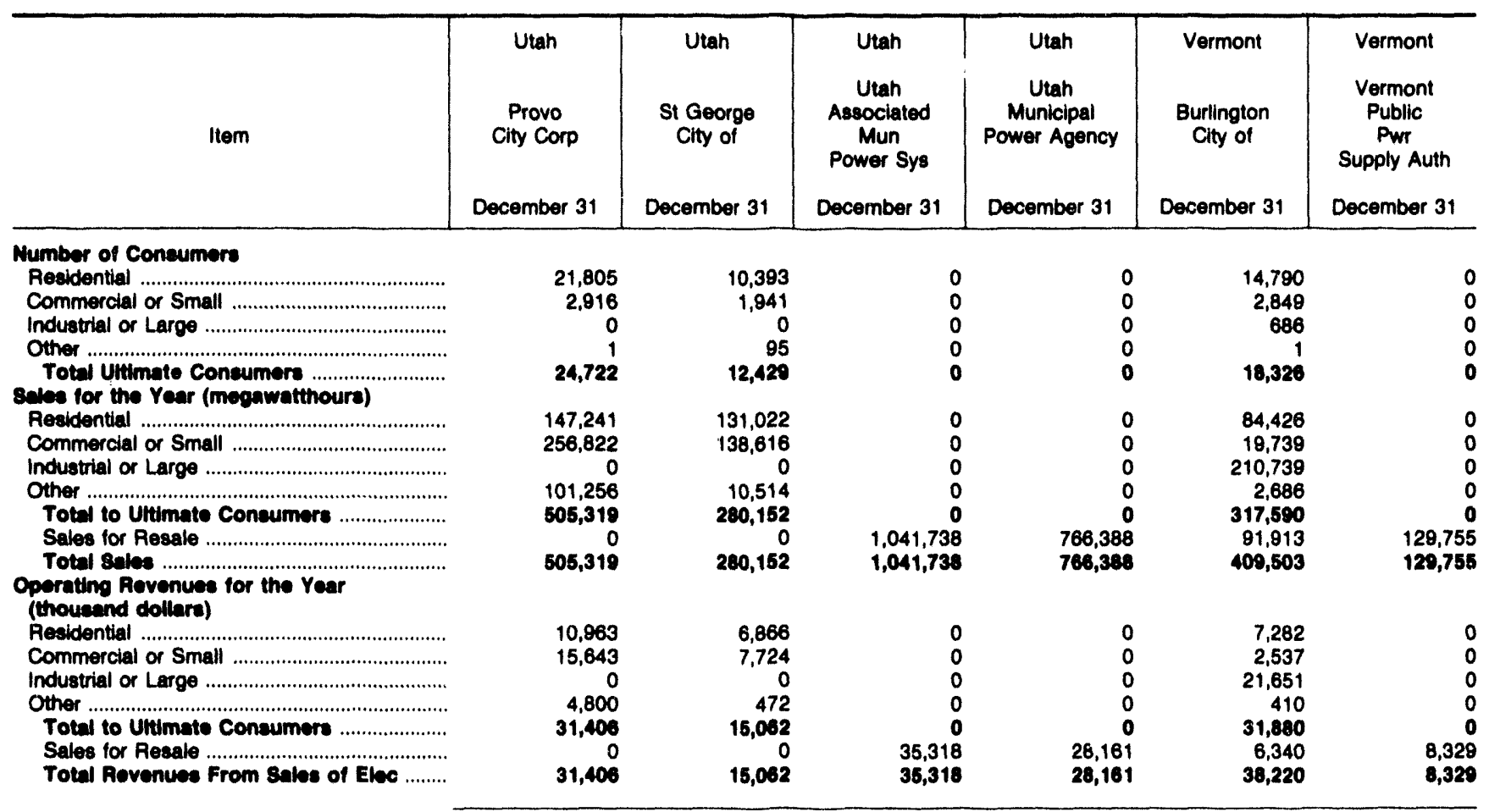

Note: Totals may not equal sum of components because of independent rounding.

Source: Energy information Administration, Form EIA-861, "Annual Electric Utility Report." Data are submitted on a calendar year. 
Table 25. Number of Consumers, Sales, and Operating Revenue by Major U.S. Publloly Owned Electric Utility Within State, 1992 (Continued)

\begin{tabular}{|c|c|c|c|c|c|c|}
\hline Item & $\begin{array}{l}\text { Virginia } \\
\text { Bediord } \\
\text { City of } \\
\text { December } 31\end{array}$ & $\begin{array}{c}\text { Virginia } \\
\text { Bristol } \\
\text { Virginia } \\
\text { Utilities Bd } \\
\text { December } 31\end{array}$ & $\begin{array}{l}\text { Virginia } \\
\text { Danvilie } \\
\text { City of } \\
\text { December } 31\end{array}$ & $\begin{array}{c}\text { Virginia } \\
\text { Harrisonburg } \\
\text { City of }\end{array}$ & $\begin{array}{c}\text { Virginia } \\
\text { Manassas } \\
\text { Clty of } \\
\text { December } 31\end{array}$ & $\begin{array}{c}\text { Virginia } \\
\text { Martinsville } \\
\text { City of } \\
\text { December } 31\end{array}$ \\
\hline \multicolumn{7}{|l|}{ Number of concumer } \\
\hline 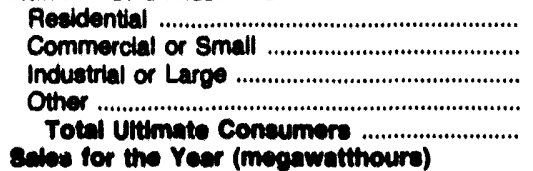 & $\begin{array}{r}5,039 \\
1,085 \\
30 \\
0 \\
6,154\end{array}$ & $\begin{array}{r}12,432 \\
1,747 \\
234 \\
26 \\
14,439\end{array}$ & $\begin{array}{r}29,306 \\
3,515 \\
76 \\
4,202 \\
37,000\end{array}$ & $\begin{array}{r}10,873 \\
2,591 \\
12 \\
151 \\
13,627\end{array}$ & $\begin{array}{r}10,291 \\
1,655 \\
107 \\
1 \\
12,054\end{array}$ & $\begin{array}{r}7,745 \\
202 \\
6 \\
142 \\
8,005\end{array}$ \\
\hline 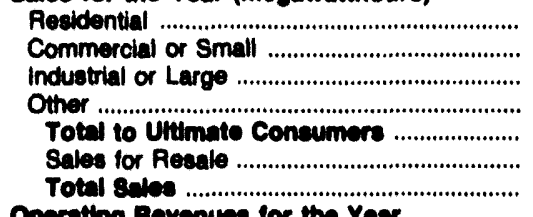 & $\begin{array}{r}62,427 \\
30,270 \\
95,709 \\
0 \\
184,400 \\
0 \\
189,406\end{array}$ & $\begin{array}{r}176,929 \\
36,139 \\
278,218 \\
6,787 \\
498,073 \\
0 \\
498,073\end{array}$ & $\begin{array}{r}388,434 \\
209,829 \\
87,821 \\
47,618 \\
733,802 \\
0 \\
733,802\end{array}$ & $\begin{array}{r}110,255 \\
178,183 \\
130,071 \\
55,343 \\
473,852 \\
0 \\
473,852\end{array}$ & $\begin{array}{r}139,980 \\
38,499 \\
76,331 \\
1,434 \\
256,244 \\
0 \\
256,244\end{array}$ & $\begin{array}{r}84,794 \\
68,152 \\
29,135 \\
11,005 \\
193,008 \\
0 \\
193,088\end{array}$ \\
\hline 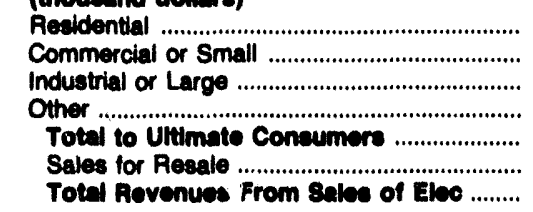 & $\begin{array}{r}3,928 \\
1,950 \\
4,624 \\
0 \\
10,502 \\
0 \\
10,502\end{array}$ & $\begin{array}{r}9,696 \\
2,257 \\
13,951 \\
553 \\
28,467 \\
0 \\
26,457\end{array}$ & $\begin{array}{r}21,880 \\
11,348 \\
3,958 \\
2,448 \\
39,634 \\
0 \\
39,634\end{array}$ & $\begin{array}{r}7,070 \\
11,857 \\
6,857 \\
3,679 \\
29,463 \\
0 \\
29,483\end{array}$ & $\begin{array}{r}9,737 \\
2,849 \\
4,775 \\
86 \\
17,447 \\
0 \\
17,447\end{array}$ & $\begin{array}{r}4,900 \\
3,202 \\
1,162 \\
559 \\
9,823 \\
0 \\
9,823\end{array}$ \\
\hline
\end{tabular}

\begin{tabular}{|c|c|c|c|c|c|c|}
\hline Item & $\begin{array}{l}\text { Virginia } \\
\text { Radiord } \\
\text { City of } \\
\text { December } 31\end{array}$ & $\begin{array}{l}\text { Virginia } \\
\text { Salem } \\
\text { City of } \\
\text { December } 31\end{array}$ & $\begin{array}{l}\text { Virginia } \\
\text { Virginia } \\
\text { Tech } \\
\text { Electric } \\
\text { Service } \\
\text { December } 31\end{array}$ & $\begin{array}{l}\text { Washington } \\
\text { Centralia } \\
\text { City of } \\
\text { December } 31\end{array}$ & $\begin{array}{l}\text { Washington } \\
\text { Ellensburg } \\
\text { City of } \\
\text { December } 31\end{array}$ & $\begin{array}{l}\text { Washington } \\
\text { Port Angeles } \\
\text { City of } \\
\text { December } 31\end{array}$ \\
\hline 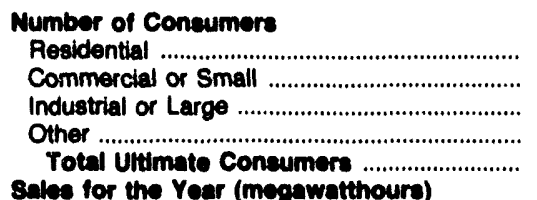 & $\begin{array}{r}5,890 \\
658 \\
20 \\
51 \\
6,619\end{array}$ & $\begin{array}{r}9,503 \\
1,797 \\
90 \\
2 \\
11,392\end{array}$ & $\begin{array}{r}4,466 \\
529 \\
2 \\
308 \\
5,305\end{array}$ & $\begin{array}{r}6,835 \\
1,090 \\
47 \\
1 \\
7,973\end{array}$ & $\begin{array}{r}4,575 \\
892 \\
1 \\
57 \\
5,525\end{array}$ & $\begin{array}{r}7,786 \\
1,291 \\
8 \\
164 \\
0,240\end{array}$ \\
\hline $\begin{array}{l}\text { Residential } \\
\text { Commercial or Small } \\
\text { Industrial or Large } \\
\text { Other } \\
\text { Total to Uitimate Coneumere } \\
\text { Sales for Resale } \\
\text { Total Sabes }\end{array}$ & $\begin{array}{r}61,033 \\
22,429 \\
190,206 \\
4,475 \\
278,143 \\
0 \\
278,143\end{array}$ & $\begin{array}{r}107,665 \\
59,043 \\
124,480 \\
16,975 \\
308,163 \\
0 \\
308,163\end{array}$ & $\begin{array}{r}45,568 \\
29,074 \\
9,079 \\
127,971 \\
211,692 \\
0 \\
211,692\end{array}$ & $\begin{array}{r}102,484 \\
73,847 \\
22,178 \\
1,060 \\
199,569 \\
0 \\
199,569\end{array}$ & $\begin{array}{r}48,894 \\
51,054 \\
11,220 \\
41,813 \\
152,981 \\
0 \\
152,981\end{array}$ & $\begin{array}{r}124,788 \\
78,631 \\
468,176 \\
3,868 \\
675,463 \\
0 \\
675,463\end{array}$ \\
\hline 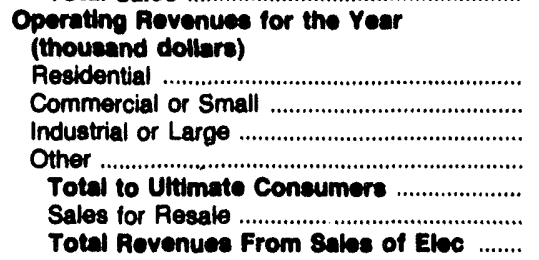 & $\begin{array}{r}3,477 \\
1,316 \\
7,435 \\
365 \\
12,593 \\
0 \\
12,593\end{array}$ & $\begin{array}{r}6,237 \\
3,312 \\
5,318 \\
918 \\
15,785 \\
0 \\
15,785\end{array}$ & $\begin{array}{r}2,641 \\
1,700 \\
373 \\
6,246 \\
10,960 \\
0 \\
10,960\end{array}$ & $\begin{array}{r}3,434 \\
2,419 \\
746 \\
23 \\
6,622 \\
0 \\
6,622\end{array}$ & $\begin{array}{r}2,223 \\
2,125 \\
492 \\
1,459 \\
6,299 \\
0 \\
6,299\end{array}$ & $\begin{array}{r}5,148 \\
2,923 \\
11,428 \\
114 \\
19,613 \\
0 \\
19,613\end{array}$ \\
\hline
\end{tabular}

Note: Totals may not equal sum of components bectuse of independent rounding.

Source: Energy Information Administration, Form ElA-861, "Annual Electric Utility Report." Data are submitted on a calendar year. 
Table 25. Number of Consumers, Sales, and Operating Revenue by Major U.S. Publicly Owned Electric UtIllty Within State, 1992 (Continued)

\begin{tabular}{|c|c|c|c|c|c|c|}
\hline Item & $\begin{array}{c}\text { Washington } \\
\text { PUD No } 1 \\
\text { of } \\
\text { Benton } \\
\text { County } \\
\text { December } 31\end{array}$ & $\begin{array}{c}\text { Washington } \\
\text { PUD No } 1 \\
\text { of } \\
\text { Chelan } \\
\text { County } \\
\text { December } 31\end{array}$ & $\begin{array}{l}\text { Washington } \\
\text { PUD No } 1 \text { of } \\
\text { Clallam } \\
\text { County } \\
\text { December } 31\end{array}$ & $\begin{array}{c}\text { Washington } \\
\text { PUD No } 1 \\
\text { of } \\
\text { Clark } \\
\text { County } \\
\text { December } 31\end{array}$ & $\begin{array}{l}\text { Washington } \\
\text { PUD No } 1 \text { of } \\
\text { Cowlitz } \\
\text { County } \\
\text { December } 31\end{array}$ & $\begin{array}{l}\text { Washington } \\
\text { PUD No } 1 \text { of } \\
\text { Douglas } \\
\text { County } \\
\text { December } 31\end{array}$ \\
\hline \multicolumn{7}{|l|}{ Number of Concumere } \\
\hline 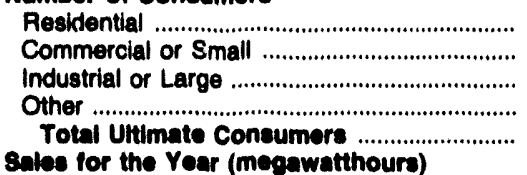 & $\begin{array}{r}28,324 \\
3,287 \\
21 \\
2,112 \\
33,744\end{array}$ & $\begin{array}{r}26,326 \\
4,066 \\
27 \\
400 \\
30,819\end{array}$ & $\begin{array}{r}19,275 \\
2,111 \\
191 \\
197 \\
21,774\end{array}$ & $\begin{array}{r}101,325 \\
8,059 \\
15 \\
989 \\
110,388\end{array}$ & $\begin{array}{r}34,520 \\
4,453 \\
67 \\
44 \\
39,084\end{array}$ & $\begin{array}{r}10,972 \\
901 \\
1 \\
791 \\
12,685\end{array}$ \\
\hline 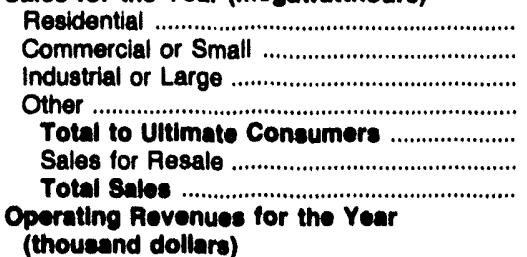 & $\begin{array}{r}545,387 \\
304,826 \\
191,184 \\
254,288 \\
1,295,685 \\
0 \\
1,295,685\end{array}$ & $\begin{array}{r}531,677 \\
337,210 \\
268,163 \\
20,820 \\
1,157,870 \\
7,898,961 \\
9,058,831\end{array}$ & $\begin{array}{r}297,298 \\
55,327 \\
74,578 \\
10,740 \\
437,943 \\
0 \\
437,943\end{array}$ & $\begin{array}{r}1,661,506 \\
935,810 \\
467,955 \\
32,427 \\
3,097,698 \\
0 \\
3,097,698\end{array}$ & $\begin{array}{r}620,644 \\
307,945 \\
3,466,499 \\
9,116 \\
4,404,204 \\
17,970 \\
4,422,174\end{array}$ & $\begin{array}{r}243,622 \\
83,420 \\
171,117 \\
55,285 \\
553,444 \\
3,067,097 \\
3,620,541\end{array}$ \\
\hline 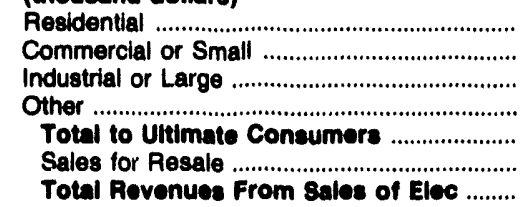 & $\begin{array}{r}23,634 \\
10,895 \\
5,862 \\
7,121 \\
47,512 \\
0 \\
47,512\end{array}$ & $\begin{array}{r}10,427 \\
7,594 \\
3,866 \\
314 \\
22,201 \\
80,832 \\
103,033\end{array}$ & $\begin{array}{r}15,129 \\
2,732 \\
2,897 \\
472 \\
21,230 \\
0 \\
21,230\end{array}$ & $\begin{array}{r}71,041 \\
29,800 \\
11,880 \\
1,913 \\
114,634 \\
0 \\
114,634\end{array}$ & $\begin{array}{r}16,122 \\
10,673 \\
85,015 \\
309 \\
112,119 \\
324 \\
112,443\end{array}$ & $\begin{array}{r}3,759 \\
1,180 \\
2,470 \\
808 \\
8,217 \\
23,512 \\
31,729\end{array}$ \\
\hline
\end{tabular}

\begin{tabular}{|c|c|c|c|c|c|c|}
\hline Item & $\begin{array}{l}\text { Washington } \\
\text { PUD No } 1 \text { of } \\
\text { Franklin } \\
\text { County } \\
\text { December } 31\end{array}$ & $\begin{array}{c}\text { Washington } \\
\text { PUD No } 1 \\
\text { of } \\
\text { Grays } \\
\text { Harbor Cnty } \\
\text { December } 31\end{array}$ & $\begin{array}{l}\text { Washington } \\
\text { PUD No } 1 \text { of } \\
\text { Klickitat } \\
\text { County }\end{array}$ & $\begin{array}{c}\text { Washington } \\
\text { PUD No } 1 \\
\text { of } \\
\text { Lowis } \\
\text { County } \\
\text { December } 31\end{array}$ & $\begin{array}{l}\text { Washington } \\
\text { PUD No } 1 \text { of } \\
\text { Okanogan } \\
\text { County }\end{array}$ & $\begin{array}{l}\text { Washington } \\
\text { PUD No } 1 \text { of } \\
\text { Pend Orelle } \\
\text { Cnty } \\
\text { December } 31\end{array}$ \\
\hline 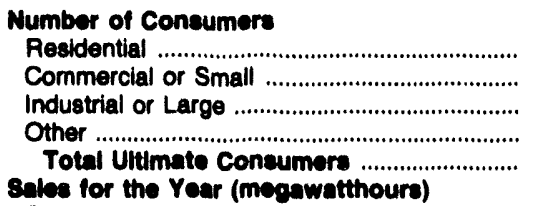 & $\begin{array}{r}11,910 \\
2,357 \\
0 \\
0 \\
1,266 \\
15,533\end{array}$ & $\begin{array}{r}30,863 \\
4,272 \\
41 \\
27 \\
35,203\end{array}$ & $\begin{array}{r}7,109 \\
1,186 \\
127 \\
223 \\
8,645\end{array}$ & $\begin{array}{r}19,429 \\
2,742 \\
78 \\
728 \\
22,977\end{array}$ & $\begin{array}{r}13,907 \\
2,069 \\
5 \\
1,895 \\
17,876\end{array}$ & $\begin{array}{r}5,658 \\
586 \\
9 \\
8 \\
8,282\end{array}$ \\
\hline $\begin{array}{l}\text { Residential } \\
\text { Commercial or Small } \\
\text { Industrial or Large } \\
\text { Other } \\
\text { Total to Uitimate Coneumere } \\
\text { Sales for Resale } \\
\text { Total sales }\end{array}$ & $\begin{array}{r}208,188 \\
272,273 \\
0 \\
115,031 \\
595,492 \\
0 \\
595,492\end{array}$ & $\begin{array}{r}493,287 \\
222,257 \\
364,842 \\
3,760 \\
1,084,146 \\
410,097 \\
1,494,243\end{array}$ & $\begin{array}{r}96,356 \\
23,413 \\
117,768 \\
20,428 \\
257,965 \\
0 \\
257,965\end{array}$ & $\begin{array}{r}300,298 \\
106,655 \\
137,163 \\
58,784 \\
602,900 \\
0 \\
602,900\end{array}$ & $\begin{array}{r}236,707 \\
170,837 \\
59,156 \\
64,336 \\
531,036 \\
0 \\
531,036\end{array}$ & $\begin{array}{r}85,682 \\
31,877 \\
721,164 \\
342 \\
839,005 \\
137,819 \\
976,884\end{array}$ \\
\hline 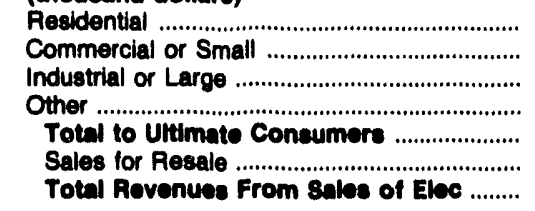 & $\begin{array}{r}9,452 \\
8,605 \\
0 \\
3,359 \\
22,416 \\
0 \\
22,416\end{array}$ & $\begin{array}{r}20,916 \\
10,061 \\
11,055 \\
428 \\
12,400 \\
9,337 \\
51,797\end{array}$ & $\begin{array}{r}4,988 \\
1,197 \\
3,806 \\
762 \\
10,753 \\
0 \\
10,763\end{array}$ & $\begin{array}{r}12,202 \\
4,419 \\
5,103 \\
2,323 \\
24,047 \\
0 \\
24,047\end{array}$ & $\begin{array}{r}6,362 \\
5,106 \\
1,214 \\
1,316 \\
13,908 \\
0 \\
13,908\end{array}$ & $\begin{array}{r}2,762 \\
785 \\
14,326 \\
26 \\
17,090 \\
1,050 \\
18,940\end{array}$ \\
\hline
\end{tabular}

Note: Totals may not equal sum of components because of independent rounding.

Source: Energy Information Administration, Form EIA-861, "Annual Electric Utility Report." Data are submitted on a calendar year. 
Table 25. Number of Consumers, Sales, and Operating Revenue by Major U.S. Publicly Owned Electric Utility Within State, 1992 (Continued)

\begin{tabular}{|c|c|c|c|c|c|c|}
\hline Item & $\begin{array}{l}\text { Washington } \\
\text { PUD No } 1 \text { of } \\
\text { Snohomish } \\
\text { County } \\
\text { December } 31\end{array}$ & $\begin{array}{l}\text { Washington } \\
\text { PUD No } 1 \text { of } \\
\text { Whatcom } \\
\text { County } \\
\text { December } 31\end{array}$ & $\begin{array}{c}\text { Washington } \\
\text { PUD No } 2 \\
\text { of } \\
\text { Grant } \\
\text { County } \\
\text { December } 31\end{array}$ & $\begin{array}{l}\text { Washington } \\
\text { PUD No } 2 \text { of } \\
\text { Pacific } \\
\text { County } \\
\text { December } 31\end{array}$ & $\begin{array}{c}\text { Washington } \\
\text { PUD No } 3 \\
\text { of } \\
\text { Mason } \\
\text { County } \\
\text { December } 31\end{array}$ & $\begin{array}{l}\text { Washington } \\
\text { Richland } \\
\text { City of } \\
\text { December } 31\end{array}$ \\
\hline \multicolumn{7}{|l|}{ Number of Coneumors } \\
\hline 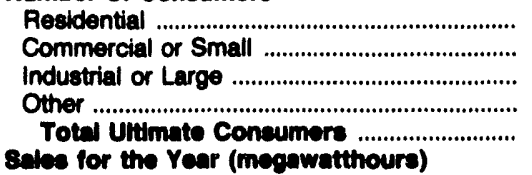 & $\begin{array}{r}186,115 \\
18,863 \\
86 \\
948 \\
216,122\end{array}$ & $\begin{array}{l}0 \\
0 \\
1 \\
0 \\
1\end{array}$ & $\begin{array}{r}24,306 \\
8,305 \\
73 \\
106 \\
32,700\end{array}$ & $\begin{array}{r}12,096 \\
1,349 \\
4 \\
489 \\
13,038\end{array}$ & $\begin{array}{r}20,910 \\
1,703 \\
1 \\
65 \\
22,670\end{array}$ & $\begin{array}{r}13,857 \\
975 \\
205 \\
454 \\
15,491\end{array}$ \\
\hline 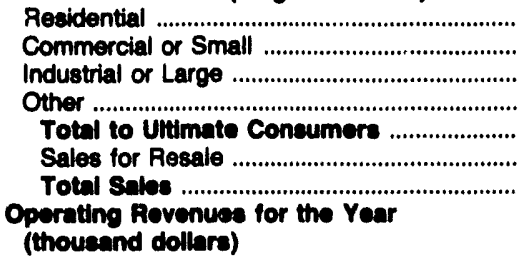 & $\begin{array}{r}2,859,045 \\
1,584,617 \\
860,642 \\
17,165 \\
5,421,469 \\
86,833 \\
5,508,302\end{array}$ & $\begin{array}{r}0 \\
0 \\
141,788 \\
0 \\
141,788 \\
0 \\
141,788\end{array}$ & $\begin{array}{r}529,289 \\
728,054 \\
1,303,414 \\
4,083 \\
2,564,840 \\
6,367,661 \\
8,932,501\end{array}$ & $\begin{array}{r}135,866 \\
51,140 \\
25,707 \\
17,869 \\
230,682 \\
0 \\
230,682\end{array}$ & $\begin{array}{r}265,775 \\
120,537 \\
59,284 \\
1,666 \\
447,262 \\
1,269 \\
448,531\end{array}$ & $\begin{array}{r}250,342 \\
48,684 \\
278,052 \\
3,502 \\
580,580 \\
0 \\
580,580\end{array}$ \\
\hline 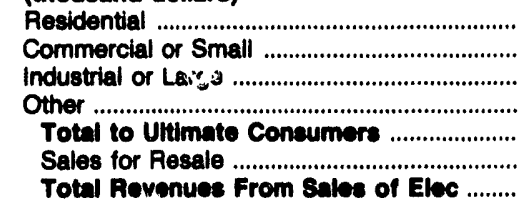 & $\begin{array}{r}124,446 \\
60,592 \\
28,661 \\
1,238 \\
214,037 \\
1,951 \\
216,888\end{array}$ & $\begin{array}{r}0 \\
0 \\
3,346 \\
0 \\
3,346 \\
0 \\
3,346\end{array}$ & $\begin{array}{r}11,321 \\
13,436 \\
14,051 \\
340 \\
39,148 \\
45,759 \\
84,907\end{array}$ & $\begin{array}{r}6,229 \\
2,547 \\
884 \\
990 \\
10,650 \\
0 \\
10,650\end{array}$ & $\begin{array}{r}12,851 \\
5,512 \\
1,793 \\
102 \\
20,258 \\
38 \\
20,296\end{array}$ & $\begin{array}{r}11,738 \\
1,857 \\
8,571 \\
224 \\
22,390 \\
0 \\
22,390\end{array}$ \\
\hline
\end{tabular}

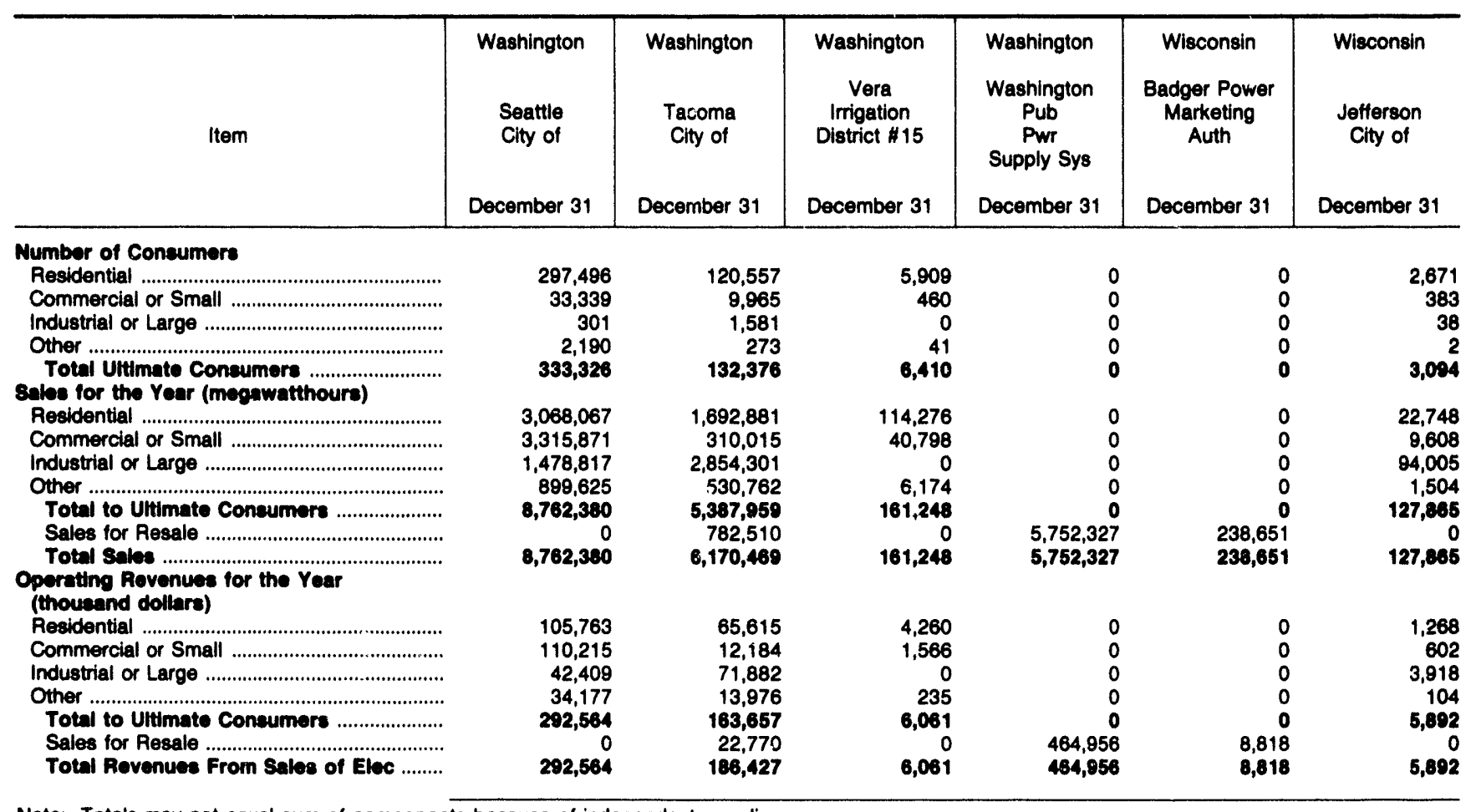

Note: Totais may not equal sum of components because of independent rounding.

Source: Energy Information Administration, Form ElA-861, "Annual Electric Utility Report." Data are submitted on a calendar year. 
Table 25. Number of Consumers, Sales, and Operating Revenue by Major U.S. Publicly Owned Electric Utility Within State, 1992 (Continued)

\begin{tabular}{|c|c|c|c|c|c|c|}
\hline Item & $\begin{array}{l}\text { Wisconsin } \\
\text { Kaukauna } \\
\text { City of } \\
\text { December } 31\end{array}$ & $\begin{array}{l}\text { Wisconsin } \\
\text { Manitowoc } \\
\text { Public } \\
\text { Utilities } \\
\text { December } 31\end{array}$ & $\begin{array}{c}\text { Wisconsin } \\
\text { Marshfield } \\
\text { City of } \\
\text { December } 31\end{array}$ & $\begin{array}{c}\text { Wisconsin } \\
\text { Menasha } \\
\text { City of } \\
\text { December } 31\end{array}$ & $\begin{array}{l}\text { Wisconsin } \\
\begin{array}{c}\text { New London } \\
\text { City of }\end{array} \\
\text { December } 31\end{array}$ & $\begin{array}{c}\text { Wisconsin } \\
\begin{array}{c}\text { Oconomowoc } \\
\text { City of }\end{array} \\
\text { December } 31\end{array}$ \\
\hline 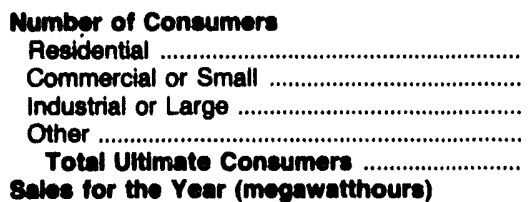 & $\begin{array}{r}8,630 \\
782 \\
22 \\
76 \\
9,510\end{array}$ & $\begin{array}{r}14,002 \\
1,658 \\
104 \\
2 \\
15,786\end{array}$ & $\begin{array}{r}9,691 \\
1,673 \\
29 \\
128 \\
11,521\end{array}$ & $\begin{array}{r}5,964 \\
566 \\
59 \\
4 \\
4,593\end{array}$ & $\begin{array}{r}2,847 \\
277 \\
20 \\
46 \\
3,190\end{array}$ & $\begin{array}{r}5,337 \\
765 \\
86 \\
77 \\
6,285\end{array}$ \\
\hline 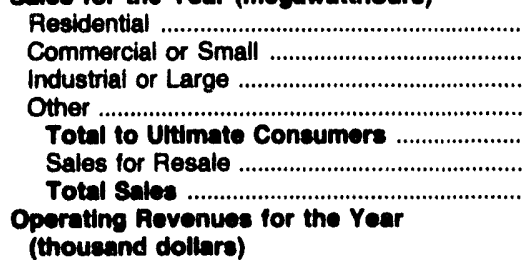 & $\begin{array}{r}91,512 \\
38,020 \\
388,698 \\
3,155 \\
521,385 \\
0 \\
521,385\end{array}$ & $\begin{array}{r}84,183 \\
50,266 \\
284,384 \\
9,869 \\
428,702 \\
0 \\
428,702\end{array}$ & $\begin{array}{r}80,478 \\
60,319 \\
135,993 \\
8,092 \\
284,882 \\
0 \\
284,882\end{array}$ & $\begin{array}{r}43,200 \\
8,600 \\
450,800 \\
3,100 \\
505,700 \\
14,300 \\
520,000\end{array}$ & $\begin{array}{r}25,084 \\
12,840 \\
114,839 \\
2,823 \\
155,586 \\
0 \\
155,586\end{array}$ & $\begin{array}{r}43,916 \\
18,236 \\
77,439 \\
2,497 \\
142,088 \\
0 \\
142,088\end{array}$ \\
\hline 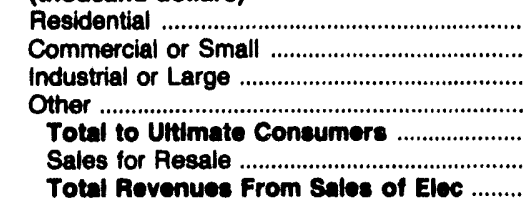 & $\begin{array}{r}3,760 \\
1,742 \\
13,036 \\
222 \\
18,760 \\
0 \\
18,760\end{array}$ & $\begin{array}{r}5,248 \\
2,962 \\
12,287 \\
619 \\
21,116 \\
0 \\
21,116\end{array}$ & $\begin{array}{r}4,085 \\
1,971 \\
5,567 \\
1,646 \\
13,269 \\
0 \\
13,269\end{array}$ & $\begin{array}{r}2,623 \\
553 \\
15,968 \\
214 \\
19,358 \\
80 \\
19,438\end{array}$ & $\begin{array}{r}1,520 \\
815 \\
4,954 \\
212 \\
7,501 \\
0 \\
7,501\end{array}$ & $\begin{array}{r}2,645 \\
1,058 \\
3,826 \\
217 \\
7,746 \\
0 \\
0 \\
7,746\end{array}$ \\
\hline
\end{tabular}

\begin{tabular}{|c|c|c|c|c|c|c|}
\hline Item & $\begin{array}{l}\text { Wisconsin } \\
\text { Plymouth } \\
\text { City of } \\
\text { December } 31\end{array}$ & $\begin{array}{l}\text { Wisconsin } \\
\text { Reedsburg } \\
\text { Utility Comm } \\
\text { December } 31\end{array}$ & $\begin{array}{c}\text { Wisconsin } \\
\text { Shawano } \\
\text { Municipal } \\
\text { Utilities } \\
\text { December } 31\end{array}$ & $\begin{array}{c}\text { Wisconsin } \\
\text { Sheboygan } \\
\text { Falls } \\
\text { City of } \\
\text { December } 31\end{array}$ & $\begin{array}{c}\text { Wisconsin } \\
\text { Sturgeon Bay } \\
\text { Combined } \\
\text { Utils }\end{array}$ & $\begin{array}{l}\text { Wisconsin } \\
\text { Wisconsin } \\
\text { Public } \\
\text { Power } \\
\text { Inc Sys } \\
\text { December } 31\end{array}$ \\
\hline \multicolumn{7}{|l|}{ Number of Consumers } \\
\hline 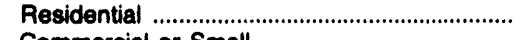 & 5,098 & 2,656 & 3,740 & 2,570 & 6,418 & 0 \\
\hline 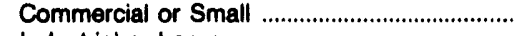 & 592 & 473 & 720 & 321 & 712 & 0 \\
\hline Industrial or Large & 66 & 34 & 89 & 34 & 45 & 0 \\
\hline 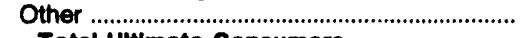 & 10 & 44 & 100 & 189 & 48 & 0 \\
\hline $\begin{array}{l}\text { Total Ultimate Consumers } \\
\text { sales for the Year (megawatthours) }\end{array}$ & 5,766 & 3,207 & 4,649 & 3,114 & 7,223 & $\mathbf{0}$ \\
\hline 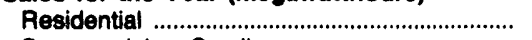 & 50,791 & 22,592 & 28,360 & 18,211 & 47,624 & 0 \\
\hline 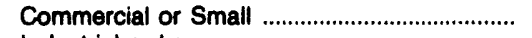 & 14,100 & 15,976 & 13,662 & 8,253 & 25,445 & 0 \\
\hline Industrial or Large & 78,280 & 102,730 & 125,886 & 138,127 & 51,447 & 0 \\
\hline Other & 4,042 & 1,342 & 1,846 & 3,398 & 3,128 & 0 \\
\hline Total to Uitimate Consumers .......................... & 147,213 & $i 42,640$ & 169,754 & 167,989 & 127,644 & 0 \\
\hline $\begin{array}{l}\text { Sales for Resale } \\
\text { Total Sales }\end{array}$ & $\begin{array}{r}0 \\
147,213\end{array}$ & $\begin{array}{r}0 \\
142,640\end{array}$ & $\begin{array}{r}0 \\
169,754\end{array}$ & $\begin{array}{r}0 \\
167,989\end{array}$ & $\begin{array}{r}0 \\
127,644\end{array}$ & $\begin{array}{l}2,723,600 \\
2,723,600\end{array}$ \\
\hline \multicolumn{7}{|l|}{$\begin{array}{l}\text { Operating Revenues for the Year } \\
\text { (thousand dollare) }\end{array}$} \\
\hline 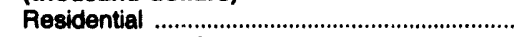 & 2,733 & 1,037 & 1,670 & 826 & 2,890 & 0 \\
\hline Commercial or Small & 830 & 842 & 887 & 387 & 1,508 & 0 \\
\hline Industrial or Large & 3,227 & 4,137 & 4,981 & 5,310 & 2,719 & 0 \\
\hline Other & 271 & 77 & 149 & 188 & 243 & 0 \\
\hline Total to Uitimate Consumers ......................... & 7,061 & 6,093 & 7,687 & 6,711 & 7,360 & 0 \\
\hline Sales for Resale & & & & & 0 & 101,327 \\
\hline Total Revenues From Sales of Elec ........ & 7,061 & 6,083 & 7,687 & 6,711 & 7,360 & 101,327 \\
\hline
\end{tabular}

Note: Totals may not equal sum of components because of independentrounding.

Source: Energy Information Administration, Form EIA-861, "Annual Electric Utility Report." Data are submitted on a calendar year. 
Table 25. Number of Consumers, Sales, and Operating Revenue by Major U.S. Publicly Owned Electric Utility Within State, 1992 (Continued)

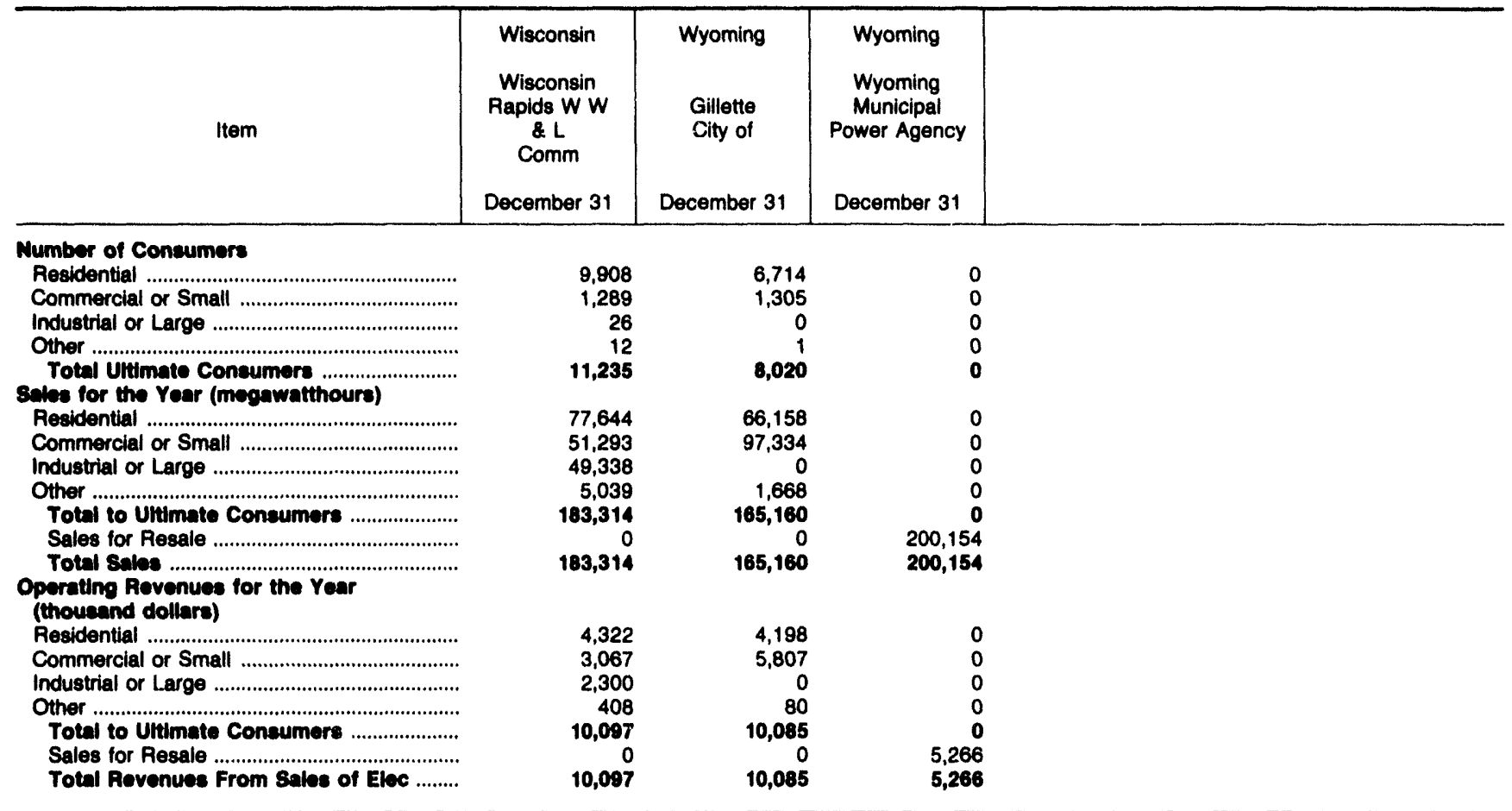

Note: Totals may not equal sum of components because of independentrounding.

Source: Energy Information Administration, Form ElA-861, "Annual Electric Utility Report." Data are submitted on a calendar year. 
Table 26. Electric Energy Account by Major U.S. Publicly Owned Electric Utility Within State, 1992

(Megawatthours)

\begin{tabular}{|c|c|c|c|c|c|c|}
\hline Item & $\begin{array}{l}\text { Alabama } \\
\text { Alabama } \\
\text { Municipal } \\
\text { Elec Auth } \\
\text { September } 30\end{array}$ & $\begin{array}{l}\text { Alabama } \\
\text { Albertville } \\
\text { Municipal } \\
\text { Utils Bd } \\
\text { June } 30\end{array}$ & $\begin{array}{c}\text { Alabama } \\
\text { Andalusia } \\
\text { City of } \\
\text { September } 30\end{array}$ & $\begin{array}{c}\text { Alabama } \\
\text { Athens } \\
\text { City of } \\
\text { December } 31\end{array}$ & $\begin{array}{c}\text { Alabama } \\
\text { Bessemer } \\
\text { City of } \\
\text { June } 30\end{array}$ & $\begin{array}{l}\text { Alabama } \\
\text { Cullman } \\
\text { Power Board } \\
\text { June } 30\end{array}$ \\
\hline 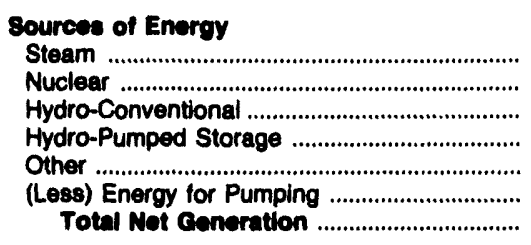 & $\begin{array}{l}0 \\
0 \\
0 \\
0 \\
0 \\
0 \\
0\end{array}$ & $\begin{array}{l}0 \\
0 \\
0 \\
0 \\
0 \\
0 \\
0\end{array}$ & $\begin{array}{l}0 \\
0 \\
0 \\
0 \\
0 \\
0 \\
0\end{array}$ & $\begin{array}{l}0 \\
0 \\
0 \\
0 \\
0 \\
0 \\
0\end{array}$ & $\begin{array}{l}0 \\
0 \\
0 \\
0 \\
0 \\
0 \\
0\end{array}$ & $\begin{array}{l}0 \\
0 \\
0 \\
0 \\
0 \\
0 \\
0\end{array}$ \\
\hline 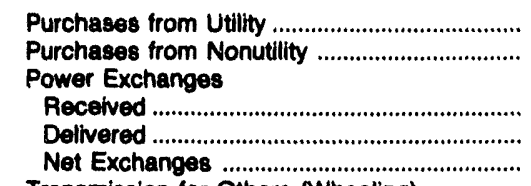 & $\begin{array}{r}2,252,355 \\
0\end{array}$ & $\begin{array}{r}426,744 \\
0\end{array}$ & $\begin{array}{r}305,070 \\
0\end{array}$ & $\begin{array}{r}648,620 \\
0\end{array}$ & $\begin{array}{r}316,785 \\
0\end{array}$ & 299,934 \\
\hline 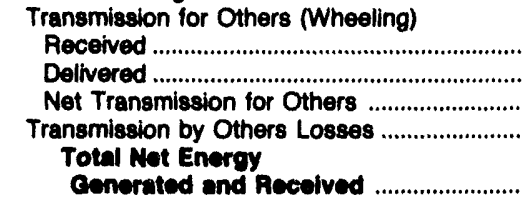 & $\begin{array}{l}0 \\
0 \\
0 \\
0\end{array}$ & $\begin{array}{l}0 \\
0 \\
0 \\
0\end{array}$ & 305,070 & 648,620 & 316,785 & 299,934 \\
\hline 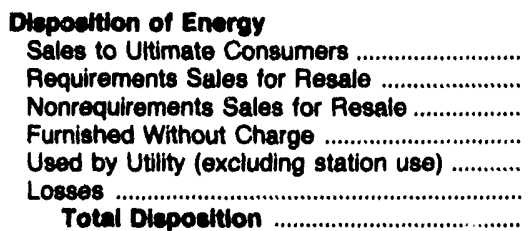 & $\begin{array}{r}0 \\
2,252,355 \\
0 \\
0 \\
0 \\
0 \\
2,252,355\end{array}$ & $\begin{array}{r}409,667 \\
0 \\
0 \\
0 \\
0 \\
17,076 \\
426,744\end{array}$ & $\begin{array}{r}296,813 \\
0 \\
0 \\
0 \\
57 \\
8,200 \\
305,070\end{array}$ & $\begin{array}{r}591,873 \\
0 \\
0 \\
0 \\
0 \\
56,746 \\
648,620\end{array}$ & $\begin{array}{r}299,014 \\
0 \\
0 \\
0 \\
480 \\
17,291 \\
316,785\end{array}$ & $\begin{array}{r}287,408 \\
0 \\
0 \\
0 \\
60 \\
12,465 \\
299,934\end{array}$ \\
\hline
\end{tabular}

Note: Totals may not equal sum of components because of independent rounding. Double counting occurs in components of both sources and disposition of energy and thus neither provides a true total. Purchases from utilities, net interchanges, and net wheeling (except for imports) are included in net generation. Sales for resale is included in sales to ultimate consumers.

Source: Energy Information Administration, Form EIA-412, "Annual Report of Public Electric Utilities." 
Table 26. Electric Energy Account by Major U.S. Publicly Owned Electric Utility Within State, 1992 (Continued) (Megawatthours)

\begin{tabular}{|c|c|c|c|c|c|c|}
\hline Item & $\begin{array}{l}\text { Alabama } \\
\text { Decatur } \\
\text { Clty of } \\
\text { June } 30\end{array}$ & $\begin{array}{l}\text { Alabama } \\
\text { Dothan } \\
\text { Clty of } \\
\text { September } 30\end{array}$ & $\begin{array}{l}\text { Alabama } \\
\text { Florence } \\
\text { City of } \\
\text { June } 30\end{array}$ & $\begin{array}{c}\text { Alabama } \\
\text { Foley } \\
\text { City of } \\
\text { (Riviera Utils) } \\
\text { December } 31\end{array}$ & $\begin{array}{c}\text { Alabama } \\
\text { Fort Payne } \\
\text { Improvement } \\
\text { Auth } \\
\text { June } 30\end{array}$ & $\begin{array}{c}\text { Alabama } \\
\text { Guntersville } \\
\text { Electric } \\
\text { Board } \\
\text { June } 30\end{array}$ \\
\hline Sources of Enorgy & & & & & & \\
\hline 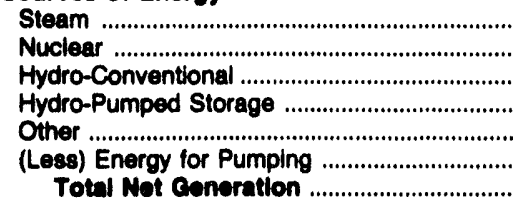 & $\begin{array}{l}0 \\
0 \\
0 \\
0 \\
0 \\
0 \\
0\end{array}$ & $\begin{array}{l}0 \\
0 \\
0 \\
0 \\
0 \\
0 \\
0\end{array}$ & $\begin{array}{l}0 \\
0 \\
0 \\
0 \\
0 \\
0 \\
0\end{array}$ & $\begin{array}{l}0 \\
0 \\
0 \\
0 \\
0 \\
0 \\
0\end{array}$ & $\begin{array}{l}0 \\
0 \\
0 \\
0 \\
0 \\
0 \\
0\end{array}$ & $\begin{array}{l}0 \\
0 \\
0 \\
0 \\
0 \\
0 \\
0\end{array}$ \\
\hline 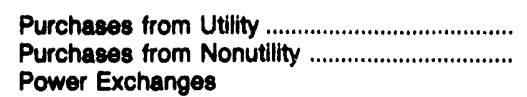 & $\begin{array}{r}1,386,397 \\
0\end{array}$ & $\begin{array}{r}973,656 \\
15,196\end{array}$ & $\begin{array}{r}1,004,216 \\
0\end{array}$ & $\begin{array}{r}464,045 \\
0\end{array}$ & $\begin{array}{r}280,484 \\
0\end{array}$ & $\begin{array}{r}218,360 \\
0\end{array}$ \\
\hline 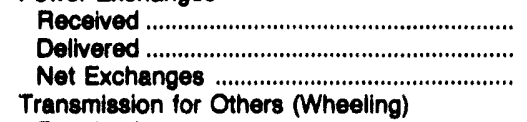 & $\begin{array}{l}0 \\
0 \\
0\end{array}$ & $\begin{array}{l}0 \\
0 \\
0\end{array}$ & $\begin{array}{l}0 \\
0 \\
0\end{array}$ & $\begin{array}{l}0 \\
0 \\
0\end{array}$ & $\begin{array}{l}0 \\
0 \\
0\end{array}$ & $\begin{array}{l}0 \\
0 \\
0\end{array}$ \\
\hline 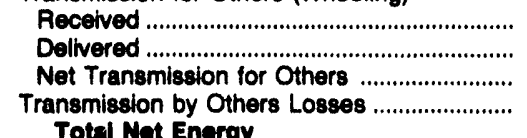 & $\begin{array}{l}0 \\
0 \\
0 \\
0\end{array}$ & $\begin{array}{l}0 \\
0 \\
0 \\
0\end{array}$ & $\begin{array}{l}0 \\
0 \\
0 \\
0\end{array}$ & $\begin{array}{l}0 \\
0 \\
0 \\
0\end{array}$ & $\begin{array}{l}0 \\
0 \\
0 \\
0\end{array}$ & $\begin{array}{l}0 \\
0 \\
0 \\
0\end{array}$ \\
\hline 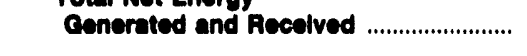 & $1,386,397$ & 984,052 & $1,004,216$ & 484,046 & $2 \bullet 0,494$ & 218,360 \\
\hline Dieposttion of Energy & & & & & & \\
\hline 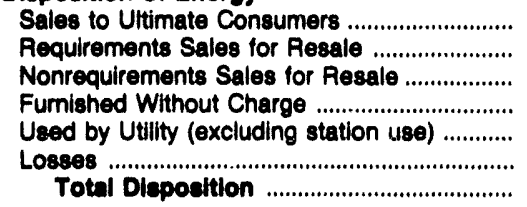 & $\begin{array}{r}1,348,629 \\
0 \\
0 \\
0 \\
0 \\
37,768 \\
1,388,397\end{array}$ & $\begin{array}{r}900,327 \\
0 \\
0 \\
39,750 \\
0 \\
48,775 \\
988,852\end{array}$ & $\begin{array}{r}932,150 \\
0 \\
0 \\
0 \\
441 \\
71,624 \\
1,004,216\end{array}$ & $\begin{array}{r}437,054 \\
0 \\
0 \\
0 \\
0 \\
26,891 \\
484,045\end{array}$ & $\begin{array}{r}265,521 \\
0 \\
0 \\
0 \\
212 \\
24,750 \\
200,494\end{array}$ & $\begin{array}{r}207,654 \\
0 \\
0 \\
0 \\
155 \\
10,551 \\
218,380\end{array}$ \\
\hline
\end{tabular}


Table 26. Electric Energy Account by Major U.S. Publicly Owned Electric Utility Within State, 1992 (Continued)

(Megawatthours)

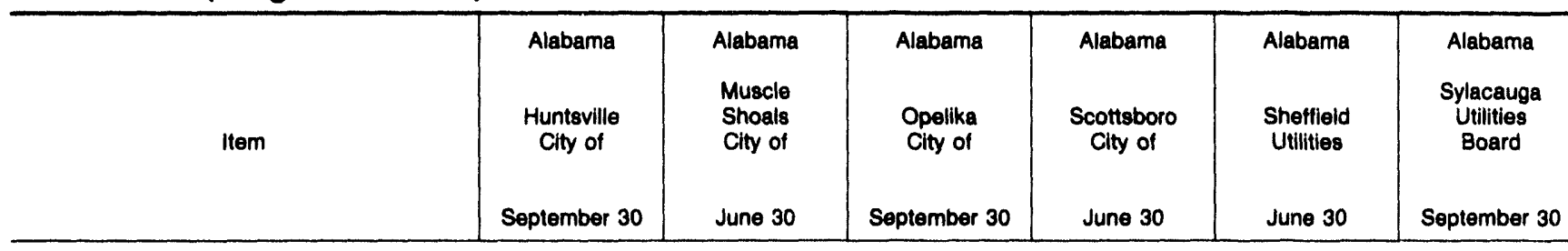

\footnotetext{
Sources of Energy

Steam

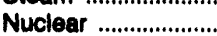

Hydro-Pumped Storage

Other

(Less) Energy for Pumping

Total Not Coneration

Purchases from Utility

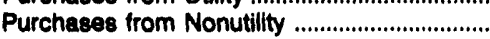

Power Exeinangse

Received.

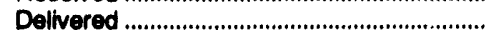

Net Exchanges

Tranamission for Others (Wheeling)

Recelved.

Dellvered

Net Transmission for Others

Transmission by Others Losses .........

Total Nat Energy

Conerated at

Dieposition of Eneroy

Sales to Uitimate Consumers

Requirements Sale

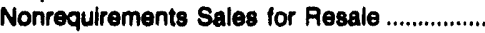

Furnished Without Charge

Used by Utility (excluding station use) ............

Losses

Total Diepostion

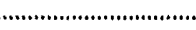

0
0
0
0
0
0
0
$3,644,300$
0
0
0
0
0
0
0
0
$3,644,300$
$3,474,156$
0
0
0
2,433
$3,644,300$

$\begin{array}{ll}0 & 0 \\ 0 & 0 \\ 0 & 0 \\ 0 & 0 \\ 0 & 0 \\ 0 & 0 \\ 0 & 0\end{array}$

0
0
0
0
0
0
0

0
0
0
0
0
0
0

190,351

321,845

0

0

0
0
0
0
0
0
0

0
0
0
0
0
0
0

0
0
0
0
0
0
0

$3,644,300$

$\begin{array}{ll}0 & 0 \\ 0 & 0 \\ 0 & 0\end{array}$

0
0
0
0

180,351

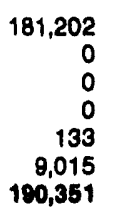
298,105

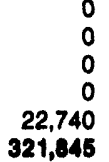

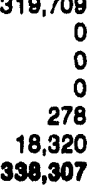

387,556
0
0
0
0
28,771
416,327

157,671

398,307

166,336

0

0

0
0

Note: Totals may not equal sum of components because of independent rounding. Double counting cccurs in components of both sources and disposition of energy and thus neither provides a true total. Purchases from utilities, net interchanges, and net wheeling (except for imports) are included in net generation. Sales for resale is included in sales to ultimate consumers.

Source: Energy Information Administration, Form ElA-412, "Annual Report of Public Electric Utilities." 
Table 26. Electric Energy Account by Major U.S. Publicly Owned Electric Utillty Within State, 1992 (Continued) (Megawatthours)

\begin{tabular}{|c|c|c|c|c|c|c|}
\hline Item & $\begin{array}{c}\text { Alabama } \\
\text { Troy } \\
\text { City of } \\
\text { September } 30\end{array}$ & $\begin{array}{l}\text { Alabama } \\
\text { Tuskegee } \\
\text { Clity of } \\
\text { September } 30\end{array}$ & $\begin{array}{l}\text { Alaska } \\
\text { Alaska } \\
\text { Energy } \\
\text { Authority } \\
\text { June } 30\end{array}$ & $\begin{array}{c}\text { Alaska } \\
\text { Anchorage } \\
\text { City of } \\
\text { December } 31\end{array}$ & $\begin{array}{l}\text { Alaska } \\
\text { Fairbanks } \\
\text { City of } \\
\text { December } 31\end{array}$ & $\begin{array}{c}\text { Alaska } \\
\begin{array}{c}\text { Ketchikan } \\
\text { City of }\end{array} \\
\text { December } 31\end{array}$ \\
\hline 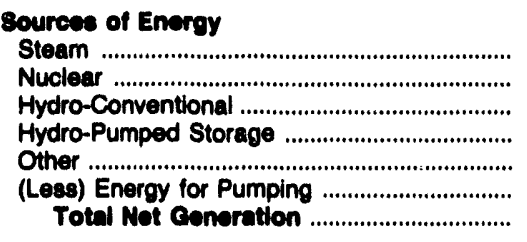 & $\begin{array}{l}0 \\
0 \\
0 \\
0 \\
0 \\
0 \\
0\end{array}$ & $\begin{array}{l}0 \\
0 \\
0 \\
0 \\
0 \\
0 \\
0\end{array}$ & $\begin{array}{r}0 \\
0 \\
620,766 \\
0 \\
0 \\
0 \\
620,766\end{array}$ & $\begin{array}{r}35,430 \\
0 \\
0 \\
0 \\
666,428 \\
0 \\
701,858\end{array}$ & $\begin{array}{r}143,857 \\
0 \\
0 \\
0 \\
0 \\
0 \\
143,857\end{array}$ & $\begin{array}{r}0 \\
0 \\
68,964 \\
0 \\
-1,139 \\
0 \\
67,825\end{array}$ \\
\hline 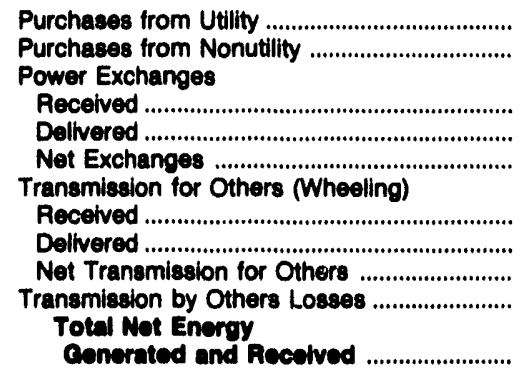 & $\begin{array}{r}220,068 \\
0\end{array}$ & $\begin{array}{r}0 \\
0 \\
0 \\
0\end{array}$ & $\begin{array}{r}0 \\
0 \\
0 \\
0 \\
620,768\end{array}$ & $\begin{array}{r}143,834 \\
0 \\
0\end{array}$ & $\begin{array}{r}0 \\
0 \\
0 \\
0 \\
168,639\end{array}$ & $\begin{array}{r}81,833 \\
0 \\
81 \\
0 \\
81\end{array}$ \\
\hline 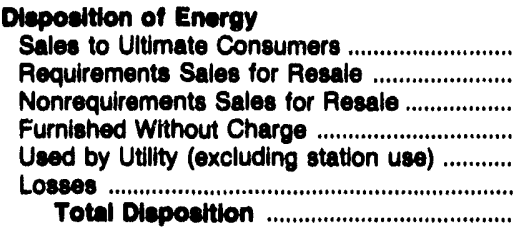 & $\begin{array}{r}201,602 \\
0 \\
0 \\
0 \\
14,255 \\
4,211 \\
220,008\end{array}$ & $\begin{array}{r}127,447 \\
0 \\
0 \\
4,583 \\
417 \\
11,516 \\
143,993\end{array}$ & $\begin{array}{r}0 \\
610,896 \\
0 \\
0 \\
0 \\
9,870 \\
620,786\end{array}$ & $\begin{array}{r}788,710 \\
17,125 \\
0 \\
0 \\
0 \\
39,857 \\
845,892\end{array}$ & $\begin{array}{r}147,230 \\
0 \\
0 \\
0 \\
11,539 \\
9,870 \\
188,630\end{array}$ & $\begin{array}{r}140,379 \\
0 \\
0 \\
0 \\
3,223 \\
6,237 \\
149,839\end{array}$ \\
\hline
\end{tabular}

Note: Totals may not equal sum of components because of independent rounding. Double counting occurs in components of both sources and disposition of energy and thus neither provides a true total. Purchases from utilities, net interchanges, and net wheeling (except for imports) are included in net generation. Sales for resale is included in sales to ultimate consumers.

Source: Energy Information Administration, Form EIA-412, "Annual Report of Public Electric Utilities." 
Table 26. Electric Energy Account by Major U.S. Publicly Owned Electric Utility Within State, 1992 (Continued) (Megawatthours)

\begin{tabular}{|c|c|c|c|c|c|c|}
\hline Item & $\begin{array}{l}\text { Arizona } \\
\text { Arizona } \\
\text { Power } \\
\text { Authority } \\
\text { June } 30\end{array}$ & $\begin{array}{c}\text { Arizona } \\
\text { Electrical } \\
\text { Dist } \\
\text { No2 } \\
\text { Pinal Cnty } \\
\text { December } 31\end{array}$ & $\begin{array}{l}\text { Arizona } \\
\text { Mesa } \\
\text { City of } \\
\text { June } 30\end{array}$ & $\begin{array}{c}\text { Arizona } \\
\text { Navajo } \\
\text { Tribal } \\
\text { Utility } \\
\text { Auth } \\
\text { December } 31\end{array}$ & $\begin{array}{l}\text { Arizona } \\
\text { Salt River } \\
\text { Prol Ag } \\
\text { I \& Dist } \\
\text { April } 30\end{array}$ & $\begin{array}{c}\text { Arizona } \\
\text { Tohono } \\
\text { OOdham } \\
\text { Utility Auth } \\
\text { December } 31\end{array}$ \\
\hline 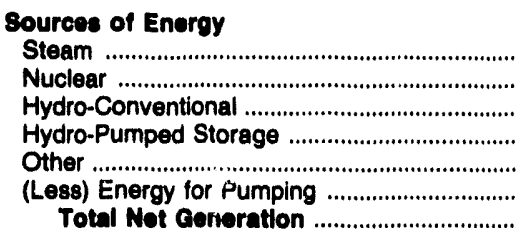 & $\begin{array}{l}0 \\
0 \\
0 \\
0 \\
0 \\
0 \\
0\end{array}$ & $\begin{array}{l}0 \\
0 \\
0 \\
0 \\
0 \\
0 \\
0\end{array}$ & $\begin{array}{l}0 \\
0 \\
0 \\
0 \\
0 \\
0 \\
0\end{array}$ & $\begin{array}{l}0 \\
0 \\
0 \\
0 \\
0 \\
0 \\
0\end{array}$ & $\begin{array}{r}13,160,138 \\
4,231,935 \\
643,390 \\
137,635 \\
90,622 \\
196,619 \\
18,067,101\end{array}$ & $\begin{array}{l}0 \\
0 \\
0 \\
0 \\
0 \\
0 \\
0\end{array}$ \\
\hline 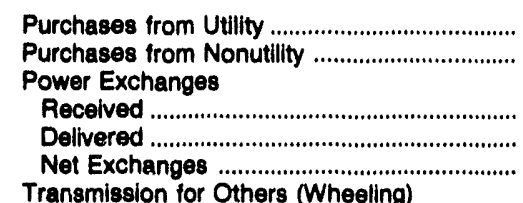 & $\begin{array}{r}767,068 \\
0 \\
0 \\
0 \\
0\end{array}$ & $\begin{array}{r}145,396 \\
0 \\
0 \\
0 \\
0\end{array}$ & $\begin{array}{r}322,026 \\
0 \\
0 \\
0 \\
0\end{array}$ & $\begin{array}{r}562,485 \\
0 \\
0\end{array}$ & $\begin{array}{r}1,417,309 \\
610 \\
\\
150,594 \\
130,634 \\
19,960\end{array}$ & $\begin{array}{r}189,161 \\
0 \\
0\end{array}$ \\
\hline 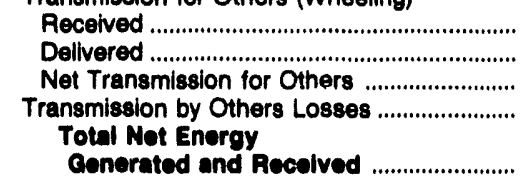 & $\begin{array}{l}0 \\
0 \\
0 \\
0\end{array}$ & $\begin{array}{r}0 \\
0 \\
0 \\
0\end{array}$ & $\begin{array}{r}0 \\
0 \\
0 \\
0\end{array}$ & $\begin{array}{r}0 \\
0 \\
0 \\
0\end{array}$ & $\begin{array}{r}229,197 \\
221,971 \\
7,226 \\
0 \\
19,612,206\end{array}$ & $\begin{array}{r}0 \\
0 \\
0 \\
0\end{array}$ \\
\hline 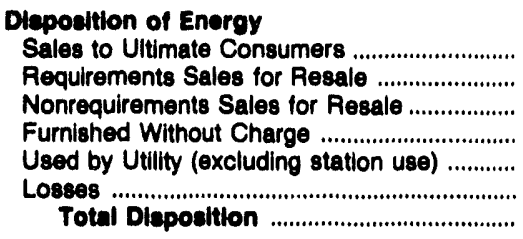 & $\begin{array}{r}0 \\
740,505 \\
0 \\
0 \\
0 \\
26,563 \\
767,088\end{array}$ & $\begin{array}{r}129,511 \\
0 \\
6,425 \\
0 \\
222 \\
9,238 \\
145,340\end{array}$ & $\begin{array}{r}293,193 \\
0 \\
6,542 \\
0 \\
0 \\
22,291 \\
322,026\end{array}$ & $\begin{array}{r}516,214 \\
0 \\
0 \\
0 \\
0 \\
46,271 \\
582,486\end{array}$ & $\begin{array}{r}14,678,648 \\
887,731 \\
2,705,611 \\
0 \\
0 \\
1,240,216 \\
19,512,208\end{array}$ & $\begin{array}{r}182,735 \\
0 \\
0 \\
0 \\
168 \\
6,258 \\
180,161\end{array}$ \\
\hline
\end{tabular}


Table 26. Electric Energy Account by Major U.S. Publlcly Owned Electric Utility Within State, 1992 (Continued)

(Megawatthours)

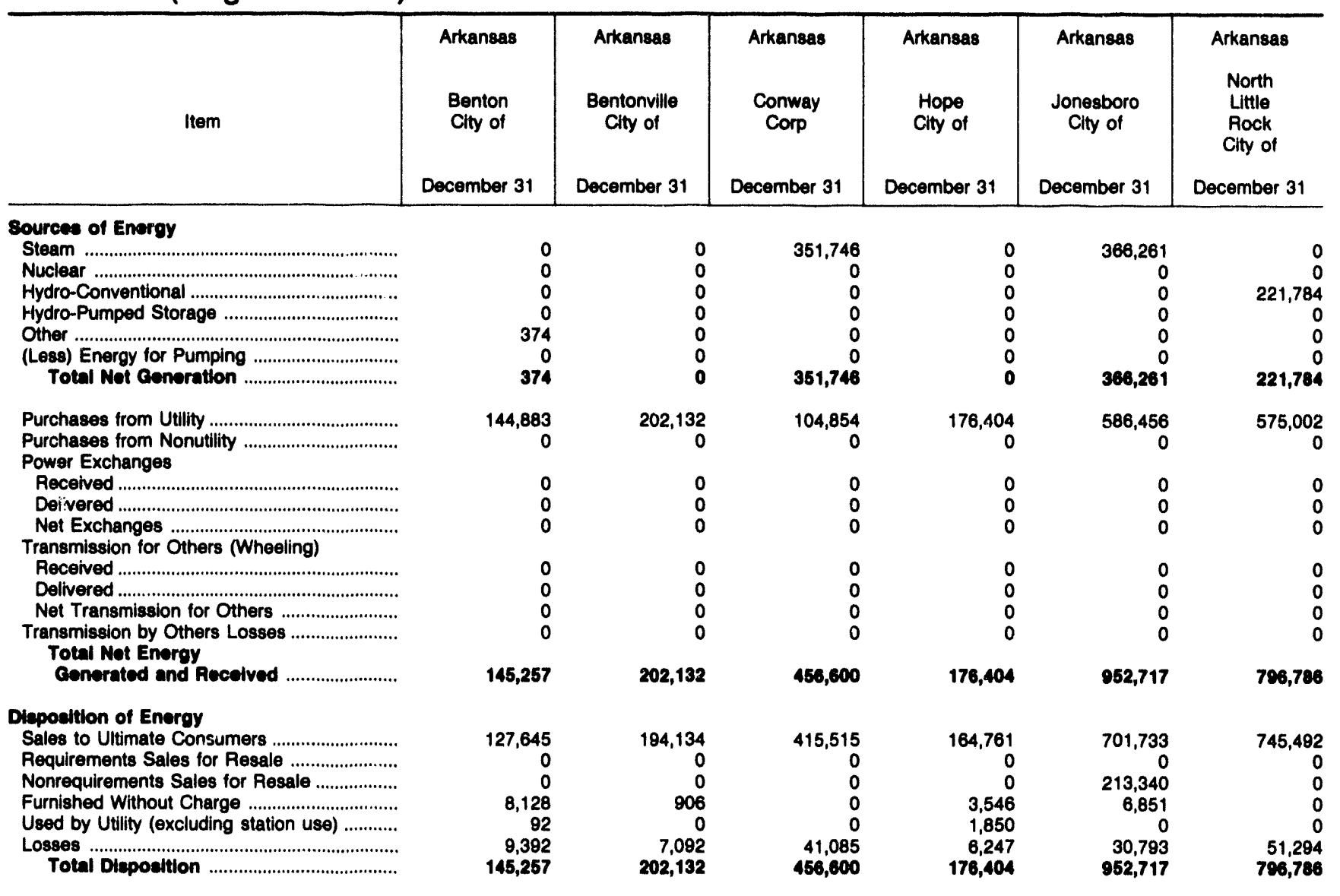

Note: Totals may not equal sum of components because of independent rounding. Double counting occurs in components of both sources and disposition of energy and thus neither provides a true total. Purchases from utilities, net interchanges, and net wheeling (except for imports) are included in net generation. Sales for resale is included in sales to ultimate consumers.

Source: Energy Information Administration, Form EIA-412, "Annual Report of Public Electric Utilities." 
Table 26. Electric Energy Account by Major U.S. Publicly Owned Electric Utility Within State, 1992 (Continued)

(Megawatthours)

\begin{tabular}{|c|c|c|c|c|c|c|}
\hline Item & $\begin{array}{c}\text { Arkansas } \\
\text { Osceola } \\
\text { City of } \\
\text { December } 31\end{array}$ & $\begin{array}{l}\text { Arkansas } \\
\text { Paragould } \\
\text { Light } \\
\& \\
\text { Water Comm } \\
\text { December } 31\end{array}$ & $\begin{array}{l}\text { Arkansas } \\
\text { Siloam } \\
\text { Springs } \\
\text { City of } \\
\text { December } 31\end{array}$ & $\begin{array}{c}\text { Arkansas } \\
\text { West } \\
\text { Memphis } \\
\text { Clty of } \\
\text { December } 31\end{array}$ & $\begin{array}{l}\text { Callfornia } \\
\text { Alameda } \\
\text { City of } \\
\text { June } 30\end{array}$ & $\begin{array}{l}\text { California } \\
\text { Anaheim } \\
\text { City of } \\
\text { June } 30\end{array}$ \\
\hline 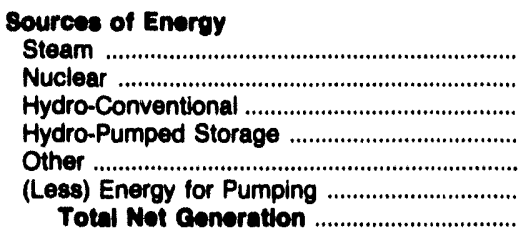 & $\begin{array}{l}0 \\
0 \\
0 \\
0 \\
0 \\
0 \\
0\end{array}$ & $\begin{array}{r}0 \\
0 \\
0 \\
0 \\
141 \\
0 \\
141\end{array}$ & $\begin{array}{l}0 \\
0 \\
0 \\
0 \\
0 \\
0 \\
0\end{array}$ & $\begin{array}{r}175,873 \\
0 \\
0 \\
0 \\
0 \\
0 \\
175,873\end{array}$ & $\begin{array}{l}0 \\
0 \\
0 \\
0 \\
0 \\
0 \\
0\end{array}$ & $\begin{array}{r}0 \\
419,121 \\
0 \\
0 \\
10,557 \\
0 \\
429,678\end{array}$ \\
\hline 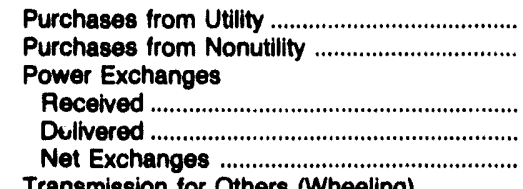 & $\begin{array}{r}180,644 \\
0\end{array}$ & $\begin{array}{r}329,005 \\
0 \\
0 \\
0 \\
0\end{array}$ & $\begin{array}{r}173,435 \\
0 \\
0 \\
0 \\
0\end{array}$ & $\begin{array}{r}130,050 \\
0 \\
0 \\
0 \\
0\end{array}$ & $\begin{array}{r}500,600 \\
0 \\
0 \\
0 \\
0\end{array}$ & $\begin{array}{r}2,389,270 \\
0 \\
21,245 \\
54,397 \\
-33,152\end{array}$ \\
\hline 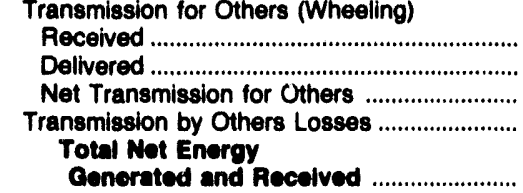 & $\begin{array}{r}0 \\
0 \\
0 \\
0\end{array}$ & $\begin{array}{r}0 \\
0 \\
0 \\
0 \\
329,146\end{array}$ & $\begin{array}{r}0 \\
0 \\
0 \\
0\end{array}$ & $\begin{array}{r}0 \\
0 \\
0 \\
0\end{array}$ & $\begin{array}{r}0 \\
0 \\
0 \\
0 \\
500,600\end{array}$ & $\begin{array}{r}0 \\
0 \\
0 \\
-88,478 \\
2,697,318\end{array}$ \\
\hline 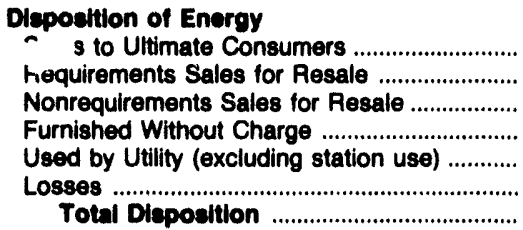 & $\begin{array}{r}178,181 \\
0 \\
0 \\
2,027 \\
436 \\
0 \\
180,644\end{array}$ & $\begin{array}{r}308,694 \\
4,872 \\
0 \\
0 \\
0 \\
15,580 \\
329,146\end{array}$ & $\begin{array}{r}162,855 \\
0 \\
0 \\
2,876 \\
0 \\
7,704 \\
173,435\end{array}$ & $\begin{array}{r}270,758 \\
0 \\
0 \\
1,535 \\
4,625 \\
29,005 \\
305,023\end{array}$ & $\begin{array}{r}481,773 \\
0 \\
0 \\
0 \\
0 \\
18,827 \\
600,600\end{array}$ & $\begin{array}{r}2,095,993 \\
0 \\
369,399 \\
0 \\
0 \\
231,926 \\
2,697,318\end{array}$ \\
\hline
\end{tabular}



Table 26. Electric Energy Account by Major U.S. Publicly Owned Electric
Utillity Within State, 1992 (Continued)

(Megawatthours)

\begin{tabular}{|c|c|c|c|c|c|c|}
\hline Hem & $\begin{array}{l}\text { California } \\
\text { Azusa } \\
\text { City of } \\
\text { June } 30\end{array}$ & $\begin{array}{l}\text { California } \\
\text { Burbank } \\
\text { City of } \\
\text { June } 30\end{array}$ & $\begin{array}{l}\text { Callfornia } \\
\text { California } \\
\text { Dept } \\
\text { Wtr } \\
\text { Resources } \\
\text { June } 30\end{array}$ & $\begin{array}{l}\text { California } \\
\text { Colton } \\
\text { City of } \\
\text { June } 30\end{array}$ & $\begin{array}{l}\text { Callfornia } \\
\text { Glendale } \\
\text { City of } \\
\text { June } 30\end{array}$ & $\begin{array}{l}\text { California } \\
\text { Imperial } \\
\text { Irrigatlon } \\
\text { District } \\
\text { December } 31\end{array}$ \\
\hline 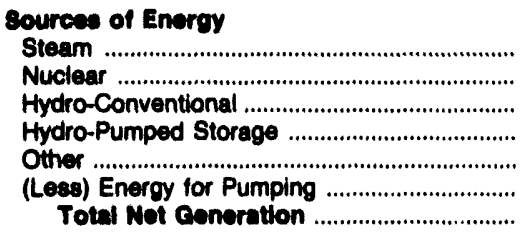 & $\begin{array}{l}0 \\
0 \\
0 \\
0 \\
0 \\
0 \\
0\end{array}$ & $\begin{array}{r}179,442 \\
0 \\
0 \\
0 \\
941 \\
0 \\
180,303\end{array}$ & $\begin{array}{r}1,073,622 \\
0 \\
1,439,404 \\
601,393 \\
0 \\
350,000 \\
2,764,419\end{array}$ & $\begin{array}{l}0 \\
0 \\
0 \\
0 \\
0 \\
0 \\
0\end{array}$ & $\begin{array}{r}108,463 \\
0 \\
0 \\
0 \\
53,312 \\
0 \\
161,775\end{array}$ & $\begin{array}{r}371,147 \\
0 \\
235,083 \\
0 \\
8,434 \\
0 \\
614,664\end{array}$ \\
\hline 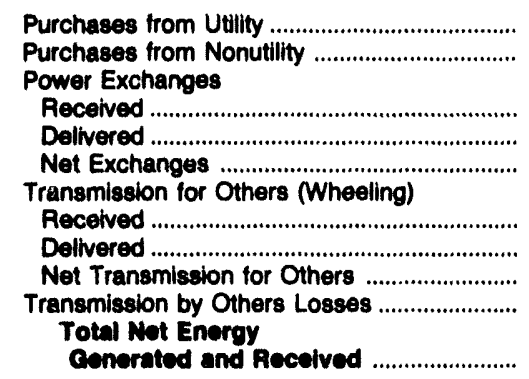 & $\begin{array}{r}206,328 \\
0 \\
0 \\
0 \\
0 \\
0 \\
0 \\
0 \\
0 \\
206,328\end{array}$ & $\begin{array}{r}930,266 \\
4,751 \\
34,415 \\
73,194 \\
-38,779 \\
0 \\
0 \\
0 \\
-43,399 \\
1,033,222\end{array}$ & $\begin{array}{r}1,023,281 \\
3,491 \\
4,038,007 \\
1,470,477 \\
2,567,530 \\
0 \\
0 \\
0 \\
0 \\
6,358,721\end{array}$ & $\begin{array}{r}215,429 \\
0 \\
0 \\
0 \\
0\end{array}$ & $\begin{array}{r}939,766 \\
0 \\
0 \\
0 \\
0 \\
0 \\
0 \\
0 \\
0 \\
1,101,541\end{array}$ & $\begin{array}{r}1,569,185 \\
0 \\
118,763 \\
30,964 \\
87,799 \\
3,546,408 \\
3,466,710 \\
79,698 \\
0 \\
2,351,346\end{array}$ \\
\hline 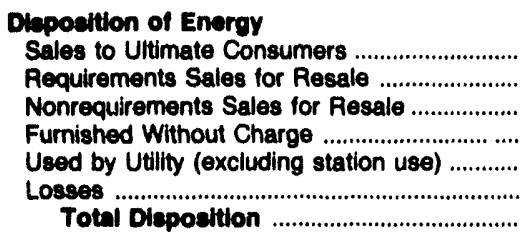 & $\begin{array}{r}185,221 \\
0 \\
0 \\
0 \\
2,184 \\
0 \\
18,923 \\
206,328\end{array}$ & $\begin{array}{r}972,739 \\
0 \\
105 \\
0 \\
0 \\
0 \\
60,378 \\
1,033,222\end{array}$ & $\begin{array}{r}0 \\
2,467,108 \\
0 \\
0 \\
3,680,054 \\
211,559 \\
6,358,721\end{array}$ & $\begin{array}{r}194,527 \\
0 \\
0 \\
0 \\
0 \\
20,902 \\
215,429\end{array}$ & $\begin{array}{r}957,898 \\
0 \\
0 \\
52,943 \\
0 \\
90,700 \\
1,101,541\end{array}$ & $\begin{array}{r}2,072,367 \\
0 \\
0 \\
0 \\
0 \\
278,979 \\
2,351,346\end{array}$ \\
\hline
\end{tabular}

Note: Totals may not equal sum of components because of independent rounding. Double counting occurs in components of both sources and disposition of energy and thus neither provides a true total. Purchases from utilities, net interchanges, and net wheeling (except for imports) are included in net generation. Sales for resale is included in sales to ultimate consumers.

Source: Energy Information Administration, Form EIA-412, "Annual Report of Public Electric Utilities." 
Table 26. Electric Energy Account by Major U.S. Publicly Owned Electric Utility Within State, 1992 (Continued) (Megawatthours)

\begin{tabular}{|c|c|c|c|c|c|c|}
\hline Item & $\begin{array}{l}\text { California } \\
\text { Lodi } \\
\text { City of } \\
\text { June } 30\end{array}$ & $\begin{array}{l}\text { California } \\
\text { Los Angeles } \\
\text { City of } \\
\text { June } 30\end{array}$ & $\begin{array}{l}\text { California } \\
\text { Metropolitan } \\
\text { Water } \\
\text { District } \\
\text { June } 30\end{array}$ & $\begin{array}{c}\text { California } \\
\text { Modesto } \\
\text { Irrigation } \\
\text { District } \\
\text { December } 31\end{array}$ & $\begin{array}{c}\text { California } \\
\text { MSR } \\
\text { Public } \\
\text { Power } \\
\text { Agency } \\
\text { December } 31\end{array}$ & $\begin{array}{l}\text { Callfornia } \\
\text { Northern } \\
\text { California } \\
\text { Power Agny } \\
\text { June } 30\end{array}$ \\
\hline 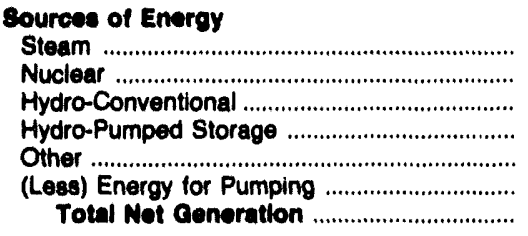 & $\begin{array}{l}0 \\
0 \\
0 \\
0 \\
0 \\
0 \\
0\end{array}$ & $\begin{array}{r}10,605,948 \\
1,363,996 \\
398,622 \\
888,727 \\
-199 \\
811,213 \\
12,445,881\end{array}$ & $\begin{array}{r}0 \\
0 \\
1,800,449 \\
0 \\
0 \\
0 \\
1,800,449\end{array}$ & $\begin{array}{r}0 \\
0 \\
77,268 \\
0 \\
387 \\
0 \\
77,685\end{array}$ & $\begin{array}{r}782,017 \\
0 \\
0 \\
0 \\
0 \\
0 \\
782,017\end{array}$ & $\begin{array}{r}1,237,473 \\
0 \\
203,148 \\
0 \\
5,604 \\
0 \\
0 \\
1,446,226\end{array}$ \\
\hline 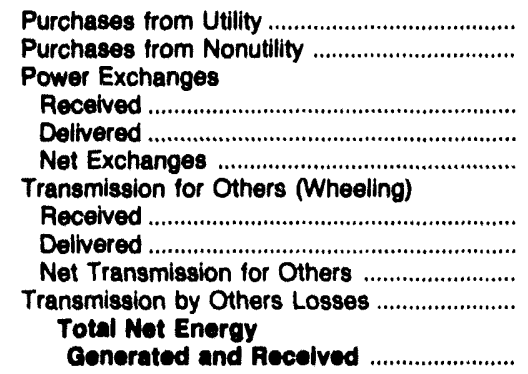 & $\begin{array}{r}372,796 \\
0 \\
0 \\
0 \\
0\end{array}$ & $\begin{array}{r}12,209,513 \\
1,070 \\
438,555 \\
1,074,855 \\
-636,300 \\
13,817,218 \\
13,768,595 \\
48,623 \\
0 \\
24,068,787\end{array}$ & $\begin{array}{r}893,279 \\
0 \\
0 \\
0 \\
28,220 \\
-28,220 \\
0 \\
0 \\
0 \\
-1,983 \\
2,683,525\end{array}$ & $\begin{array}{r}1,859,641 \\
0 \\
1,467 \\
0 \\
1,467 \\
0\end{array}$ & $\begin{array}{r}1,887 \\
0\end{array}$ & $\begin{array}{r}319,063 \\
0 \\
0\end{array}$ \\
\hline 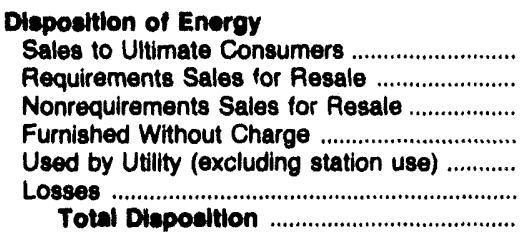 & $\begin{array}{r}361,240 \\
0 \\
0 \\
0 \\
0 \\
11,556 \\
372,798\end{array}$ & $\begin{array}{r}21,515,437 \\
411,239 \\
0 \\
0 \\
90,000 \\
2,052,111 \\
24,068,787\end{array}$ & $\begin{array}{r}0 \\
296,558 \\
0 \\
0 \\
0 \\
2,330,579 \\
36,388 \\
2,663,525\end{array}$ & $\begin{array}{r}1,805,802 \\
0 \\
43,773 \\
0 \\
0 \\
80,188 \\
1,938,763\end{array}$ & $\begin{array}{r}0 \\
783,904 \\
0 \\
0 \\
0 \\
0 \\
783,904\end{array}$ & $\begin{array}{r}0 \\
1,734,112 \\
2,041 \\
0 \\
0 \\
29,135 \\
1,785,298\end{array}$ \\
\hline
\end{tabular}

Note: Totals may not equal sum of components because of independent rounding. Double counting occurs in components of both sources and disposition of energy and thus neither provides a true total. Purchases from utilities, net interchanges, and net wheeling (except for imports) are included in net generation. Sales for resale is included in sales to ultimate consumers.

Source: Energy Information Administration, Form ElA-412, "Annual Report of Public Electric Utilities." 
Table 26. Electric Energy Account by Major U.S. Publicly Owned Electric Utillty Within State, 1992 (Continued)

(Megawatthours)

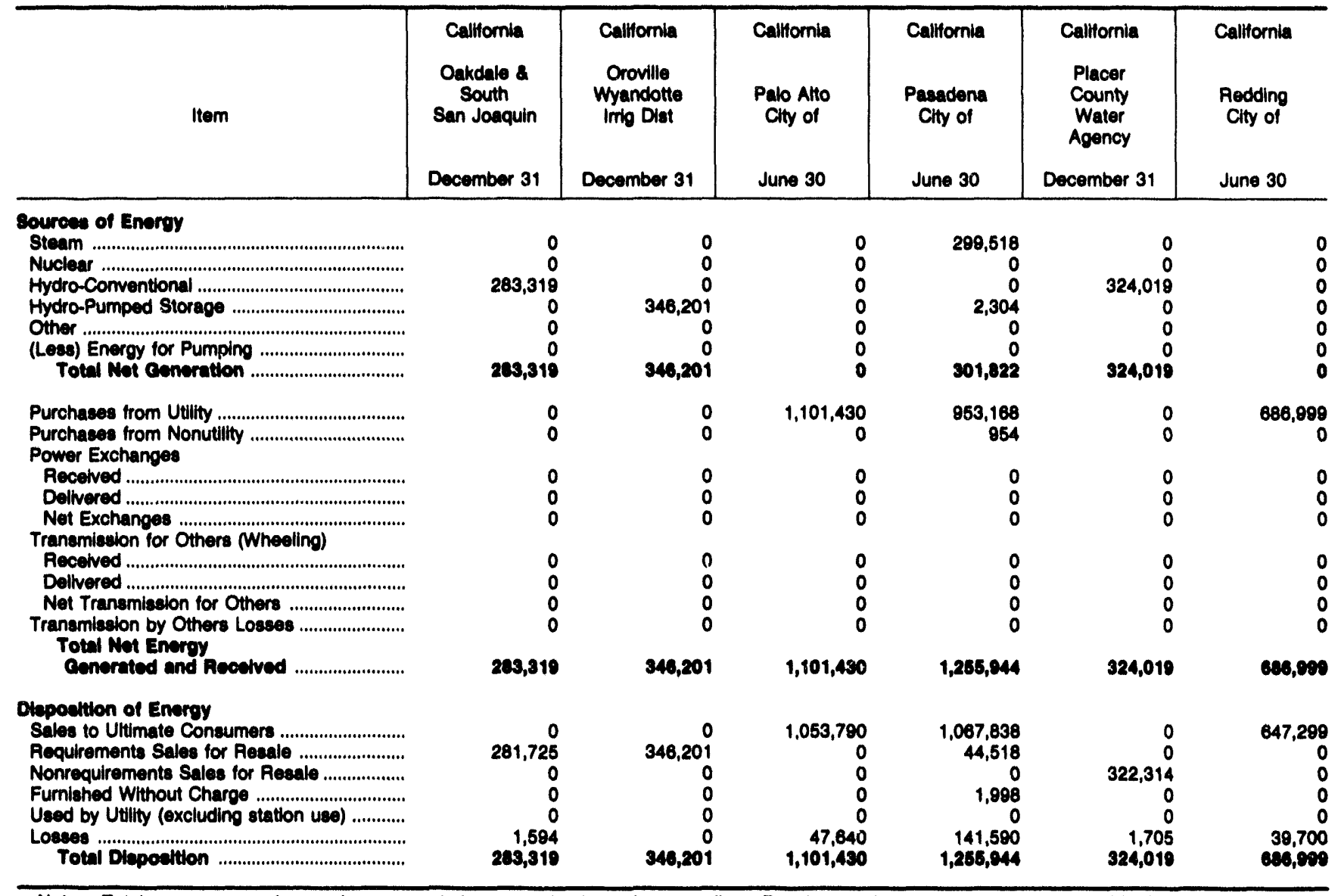

Note: Totals may not equal sum of components because of independent rounding. Double counting occurs in components of both sources and dispoation of energy and thus netther provides a true total. Purchaees from utilities, net interchanges, and net wheoling (except for imports) are included in net generation. Sales for resale is included in sales to ultimate consumers.

Source: Energy Information Adminiatration, Form EIA-412, "Annual Report of Public Electric Utillties." 
Table 26. Electrlc Energy Account by Major U.S. Publicly Owned Electric Utillty Within State, 1992 (Continued)

(Megawatthours)

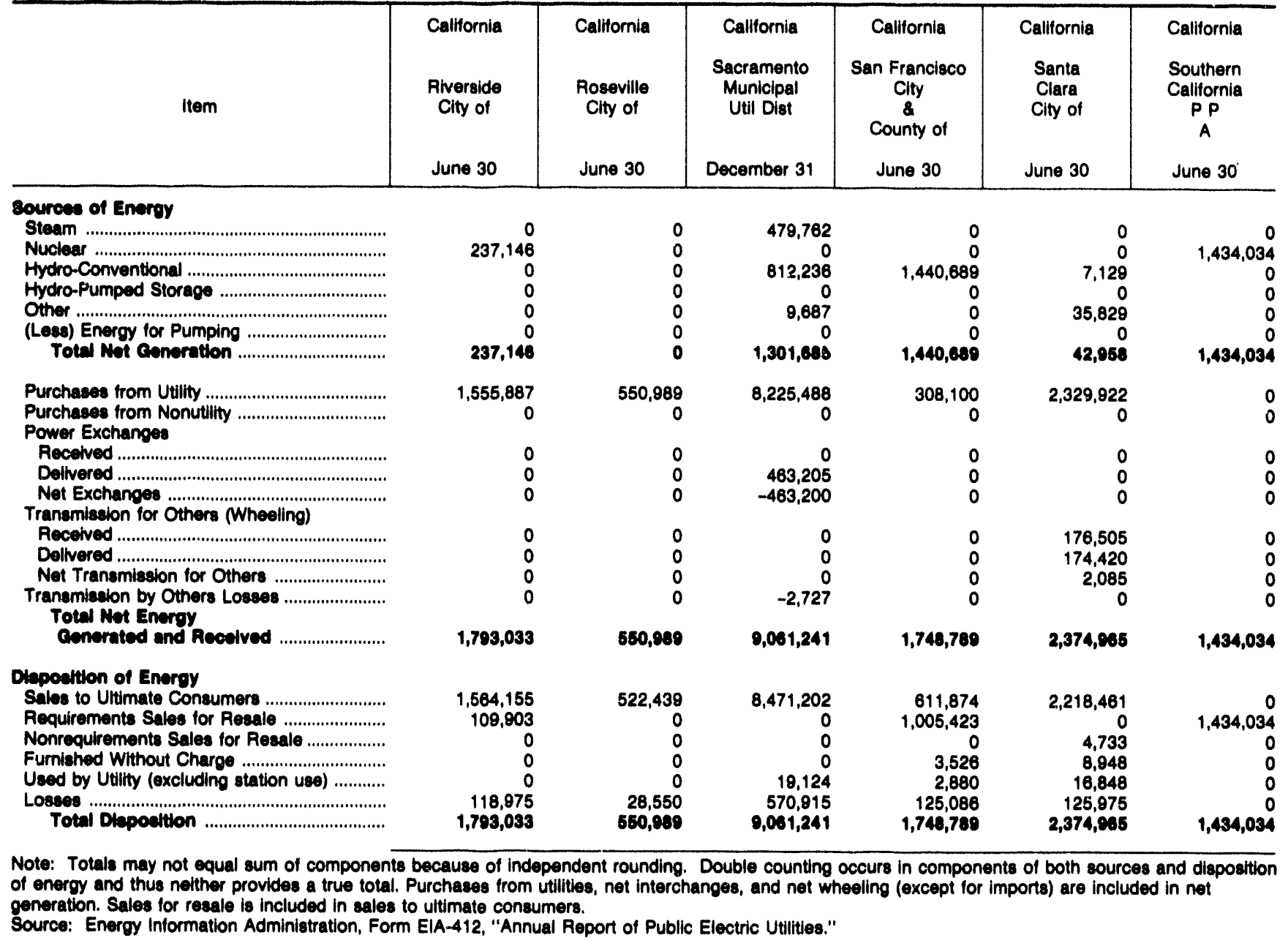


Table 26. Electrlc Energy Accoun: $2 y:$ Major U.S. Publicly Owned Electric Utllity Within State, 1992 (Continued) (Megawatthours)

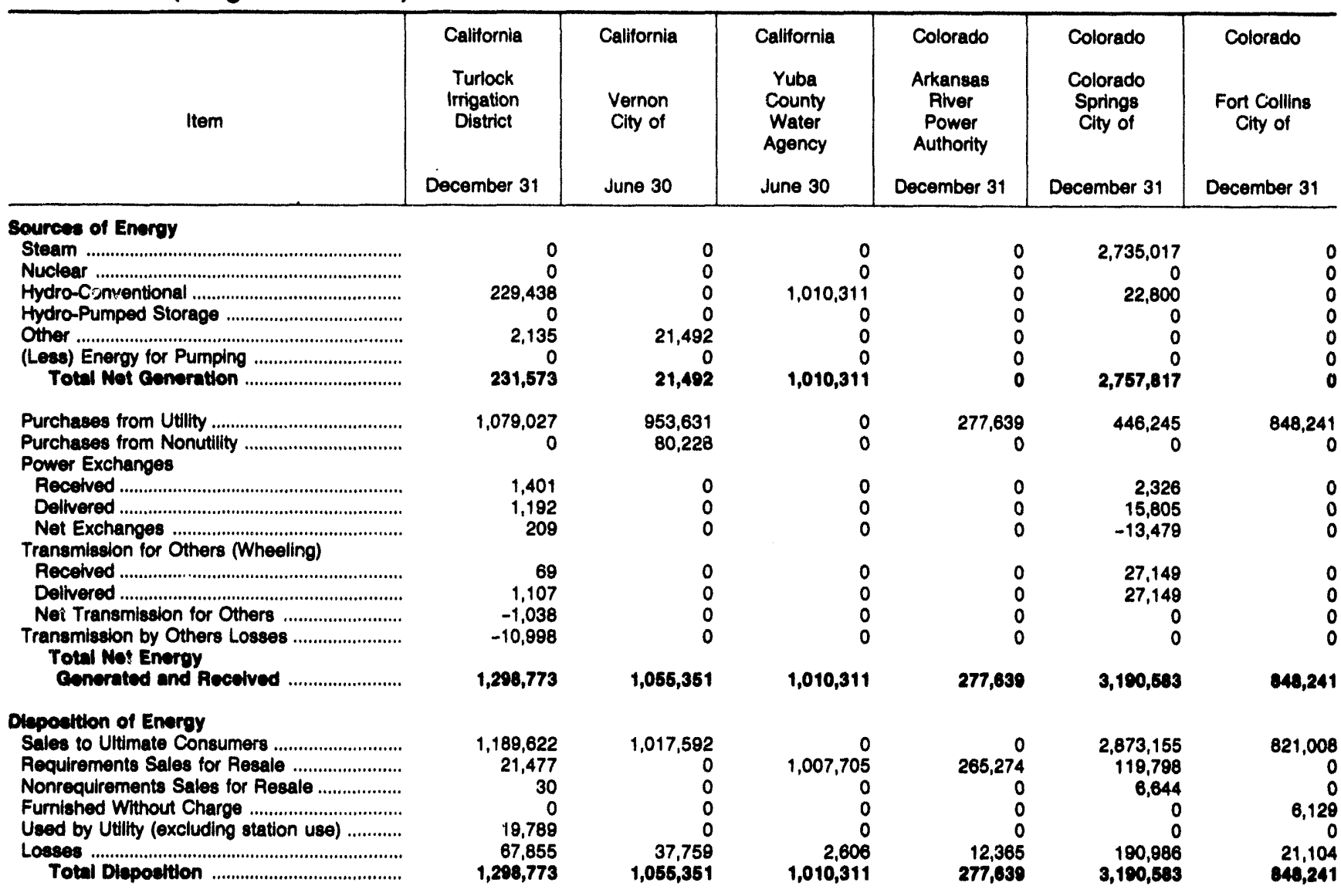

Note: Totals may not equal sum of components because of independent rounding. Double counting occurs in components of both sources and disposition of energy and thus neither provides a true total. Purchases from utlities, net interchanges, an " helling (except for imports) are included in net generation. Sales for resale is included in sales to ultimate consumers.

Source: Energy Information Administration, Form ElA-412, "Annual Report of Public Electr: 
Table 26. Electrlc Energy Account by Major U.S. Publicly Owned Electric Utillty Within State, 1992 (Continued) (Megawatthours)

\begin{tabular}{|c|c|c|c|c|c|c|}
\hline Item & $\begin{array}{c}\text { Colorado } \\
\text { Longmont } \\
\text { City of }\end{array}$ & $\begin{array}{l}\text { Colorado } \\
\text { Loveland } \\
\text { Cit; of } \\
\text { December } 31\end{array}$ & $\begin{array}{c}\text { Colorado } \\
\text { Platte River } \\
\text { Power } \\
\text { Authority } \\
\text { December } 31\end{array}$ & $\begin{array}{c}\text { Connecticut } \\
\text { Connecticut } \\
\text { Mun } \\
\text { Elec } \\
\text { Engy Coop } \\
\text { December } 31\end{array}$ & $\begin{array}{l}\text { Connecticut } \\
\text { Groton } \\
\text { City of } \\
\text { June } 30\end{array}$ & $\begin{array}{l}\text { Connecticut } \\
\text { Norwich } \\
\text { City of } \\
\text { June } 30\end{array}$ \\
\hline 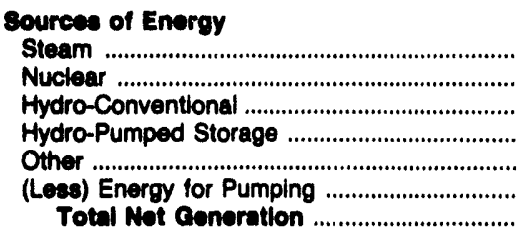 & $\begin{array}{r}0 \\
0 \\
3,244 \\
0 \\
0 \\
0 \\
3,244\end{array}$ & $\begin{array}{r}0 \\
0 \\
3,521 \\
0 \\
0 \\
0 \\
3,521\end{array}$ & $\begin{array}{r}2,623,156 \\
0 \\
0 \\
0 \\
0 \\
0 \\
2,623,156\end{array}$ & $\begin{array}{r}0 \\
72,036 \\
0 \\
0 \\
0 \\
0 \\
72,036\end{array}$ & $\begin{array}{l}0 \\
0 \\
0 \\
0 \\
0 \\
0 \\
0\end{array}$ & $\begin{array}{r}0 \\
0 \\
12,087 \\
0 \\
0 \\
0 \\
12,087\end{array}$ \\
\hline 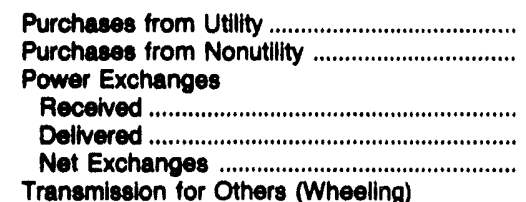 & $\begin{array}{r}440,084 \\
0\end{array}$ & $\begin{array}{r}369,505 \\
0\end{array}$ & $\begin{array}{r}732,901 \\
0 \\
23,075 \\
87,321 \\
-64,246\end{array}$ & $\begin{array}{r}702,020 \\
0 \\
318,764 \\
21,781 \\
296,983\end{array}$ & $\begin{array}{r}644,861 \\
0\end{array}$ & $\begin{array}{r}272,060 \\
0\end{array}$ \\
\hline 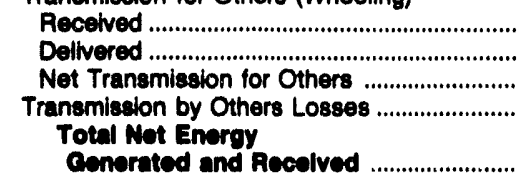 & $\begin{array}{r}6,648 \\
6,644 \\
4 \\
0\end{array}$ & $\begin{array}{l}0 \\
0 \\
0 \\
0\end{array}$ & $\begin{array}{r}0 \\
0 \\
0 \\
0 \\
3,291,811\end{array}$ & $\begin{array}{r}0 \\
1,071,038\end{array}$ & $\begin{array}{l}0 \\
0 \\
0 \\
0\end{array}$ & 284,147 \\
\hline 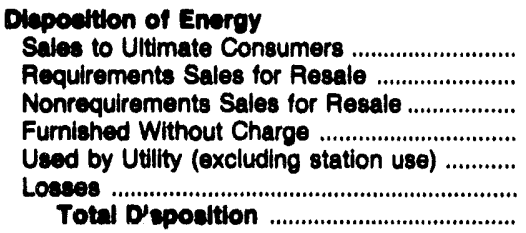 & $\begin{array}{r}424,716 \\
0 \\
0 \\
5,513 \\
0 \\
13,103 \\
443,332\end{array}$ & $\begin{array}{r}359,319 \\
0 \\
0 \\
5,000 \\
0 \\
8,707 \\
373,028\end{array}$ & $\begin{array}{r}0 \\
2,905,056 \\
366,535 \\
0 \\
1,149 \\
19,071 \\
3,291,811\end{array}$ & $\begin{array}{r}0 \\
1,070,571 \\
0 \\
0 \\
0 \\
468 \\
1,071,030\end{array}$ & $\begin{array}{r}624,024 \\
5,908 \\
0 \\
1,413 \\
773 \\
12,743 \\
644,861\end{array}$ & $\begin{array}{r}268,447 \\
0 \\
0 \\
0 \\
0 \\
15,700 \\
284,147\end{array}$ \\
\hline
\end{tabular}

Note: Totals may not equal sum of components because of independent rounding. Double counting occurs in components of both sources and disposition of energy and thus neither provides a true total. Purchases from utllites, net interchanges, and net wheeling (except for imports) are included in net generation. Sales for resale is included in sales to ultimate consumers.

Source: Energy information Administration, Form EIA-412, "Annual Report of Public Electric Utilities." 
Table 26. Electric Energy Account by Major U.S. Publicly Owned Electric Utility Within State, 1992 (Continued)

(Megawatthours)

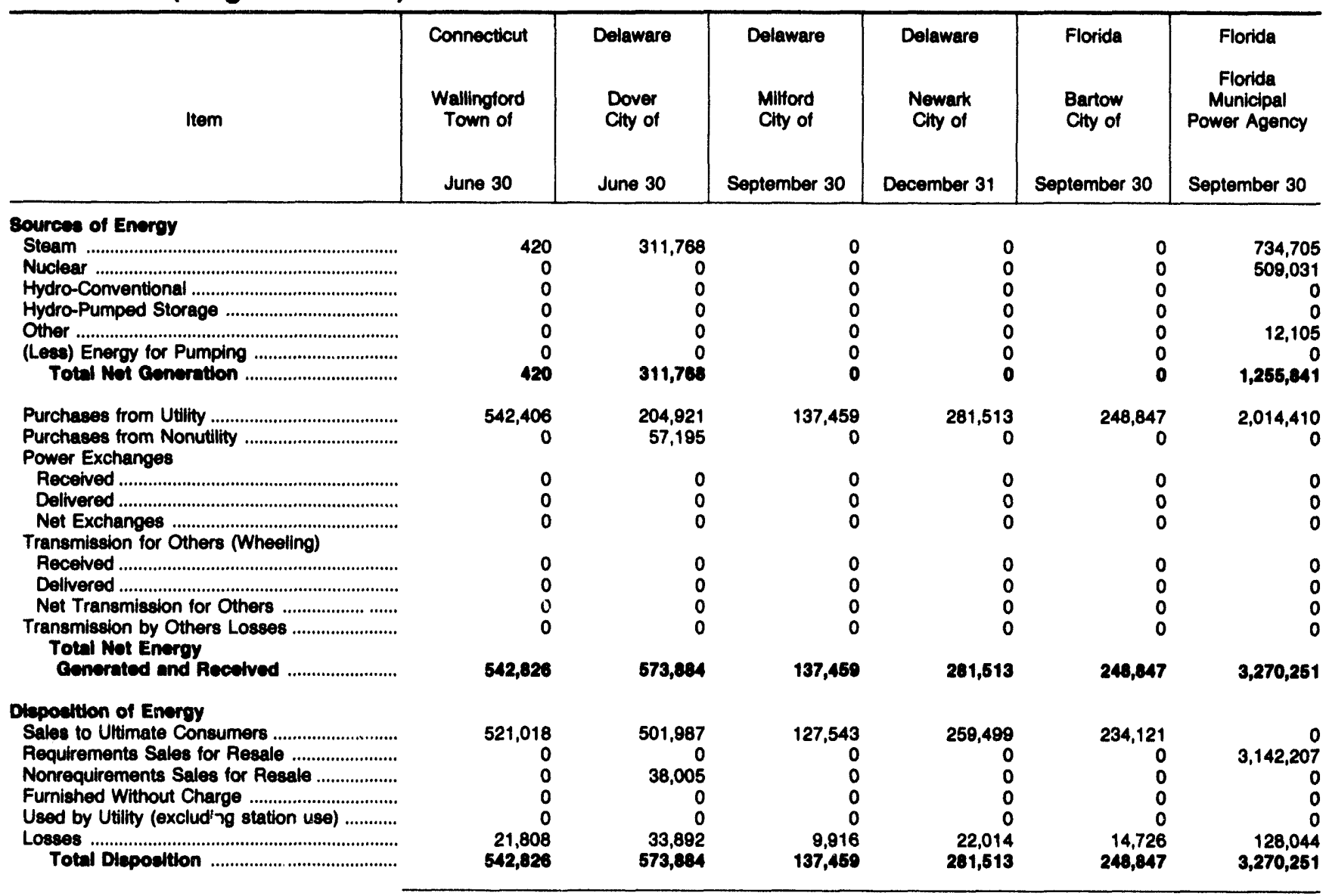

Note: Totals may not equal sum of components because of independent rounding. Double counting occurs in components of both sources and disposition of energy and thus neither provides a true total. Purchases from utilities, net interchanges, and net wheeling (except for imports) are included in net generation. Sales for resale is included in sales to ultimate consumers.

Source: Energy Information Administration, Form EIA-412, "Annual Report of Public Electric Utilities." 
Table 26. Electric Energy Account by Major U.S. Publicly Owned Electric Utility Within State, 1992 (Continued)

(Megawatthours)

\begin{tabular}{|c|c|c|c|c|c|c|}
\hline Item & $\begin{array}{c}\text { Florida } \\
\text { Fort Pierce } \\
\text { Utilities } \\
\text { A } 1 \text { ith } \\
\text { September } 30\end{array}$ & $\begin{array}{c}\text { Florida } \\
\text { Gainesville } \\
\text { Regional } \\
\text { Utilities } \\
\text { September } 30\end{array}$ & $\begin{array}{l}\text { Florida } \\
\begin{array}{c}\text { Homestead } \\
\text { City of }\end{array} \\
\text { September } 30\end{array}$ & $\begin{array}{c}\text { Florida } \\
\text { Jacksonville } \\
\text { Beach } \\
\text { City of } \\
\text { September } 30\end{array}$ & $\begin{array}{l}\text { Fiorida } \\
\text { Jacksonville } \\
\text { Electric } \\
\text { Auth } \\
\text { September } 30\end{array}$ & $\begin{array}{l}\text { Florida } \\
\text { Key West } \\
\text { City of } \\
\text { September } 30\end{array}$ \\
\hline \multicolumn{7}{|l|}{ Sources of Energy } \\
\hline Steam & 328,143 & $1,795,906$ & 0 & 0 & $7,953,929$ & 74,905 \\
\hline Nuclear & 0 & 57,033 & 0 & 0 & 0 & 0 \\
\hline Hydro-Conventional & 0 & 0 & 0 & 0 & 0 & 0 \\
\hline Hydro-Pumped Storgge & 0 & 0 & 0 & 0 & 0 & 0 \\
\hline Other & 165 & 10,660 & 72,278 & 0 & 6,452 & 41,627 \\
\hline (Less) Energy for Pumping ................................. & 0 & 0 & 0 & 0 & 0 & 0 \\
\hline 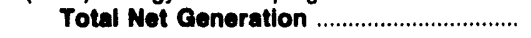 & 328,308 & $1,863,599$ & 72,278 & $\mathbf{0}$ & $7,980,381$ & 116,532 \\
\hline 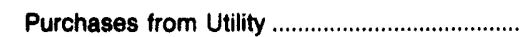 & 255,263 & 0 & 185,709 & 495,944 & $1,237,784$ & 398,768 \\
\hline $\begin{array}{l}\text { Purchases from Nonutility } \\
\text { Power Exchanges }\end{array}$ & 0 & 0 & 0 & 0 & 9,156 & 6,691 \\
\hline 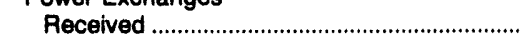 & 0 & 0 & 0 & 0 & 0 & 0 \\
\hline 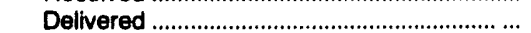 & 0 & 0 & 0 & 0 & 0 & 0 \\
\hline Net Exchanges & 0 & 0 & 0 & 0 & 0 & 0 \\
\hline \multicolumn{7}{|l|}{ Transmission for Others (Wheeling) } \\
\hline 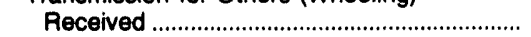 & 0 & 0 & 0 & 0 & 0 & 0 \\
\hline 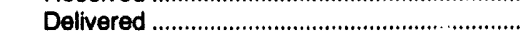 & 0 & 0 & 0 & 0 & 0 & 0 \\
\hline Net Transmission for Others ......................... & 0 & 0 & 0 & 0 & 0 & 0 \\
\hline 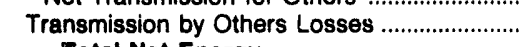 & $-1,183$ & 0 & 0 & 0 & 0 & $\mathbf{0}$ \\
\hline $\begin{array}{l}\text { Total Net Energy } \\
\text { Generated and Recelved .......................... }\end{array}$ & 582,388 & $1,863,599$ & 257,987 & 495,944 & $9,207,321$ & 521,991 \\
\hline \multicolumn{7}{|l|}{ Dieposition of Energy } \\
\hline 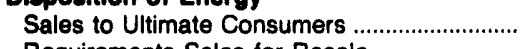 & 480,504 & $1,295,915$ & 191,345 & 462,362 & $8,199,190$ & 478,894 \\
\hline $\begin{array}{l}\text { Requirements Sales for Resale .......................... } \\
\text { Nonrequirements Sales for Resale }\end{array}$ & $\begin{array}{r}0 \\
78,438\end{array}$ & $\begin{array}{r}0 \\
508,500\end{array}$ & $\begin{array}{r}33,869 \\
0\end{array}$ & $\begin{array}{l}0 \\
0\end{array}$ & $\begin{array}{l}326,532 \\
204,189\end{array}$ & $\begin{array}{r}0 \\
4,333\end{array}$ \\
\hline Furnished Without Charge & & 0 & 6,204 & 0 & 0 & 950 \\
\hline Used by Utility (excluding station use) ............ & 866 & 0 & 0 & 0 & 15,750 & 9,426 \\
\hline 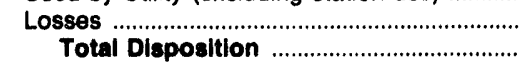 & $\begin{array}{r}22,580 \\
582,388\end{array}$ & $\begin{array}{r}59,184 \\
1,863,599\end{array}$ & $\begin{array}{r}26,569 \\
257,987\end{array}$ & $\begin{array}{r}33,582 \\
495,944\end{array}$ & $\begin{array}{r}461,660 \\
9,207,321\end{array}$ & $\begin{array}{r}28,388 \\
521,891\end{array}$ \\
\hline
\end{tabular}

Note: Tolals may not equal sum of components because of independent rounding. Double counting occurs in components of both sources and disposition of energy and thus neither provides a true total. Purchases from utilities, net interchanges, and net wheeling (except for imports) are included in net generation. Sales for resale is included in sales to ultimate consumers.

Source: Energy Information Administration, Form EIA-412, "Annual Report of Public Electric Utilities." 
Table 26. Electric Energy Account by Major U.S. Publicly Owned Electric Utility Within State, 1992 (Continued)

(Megawatthours)

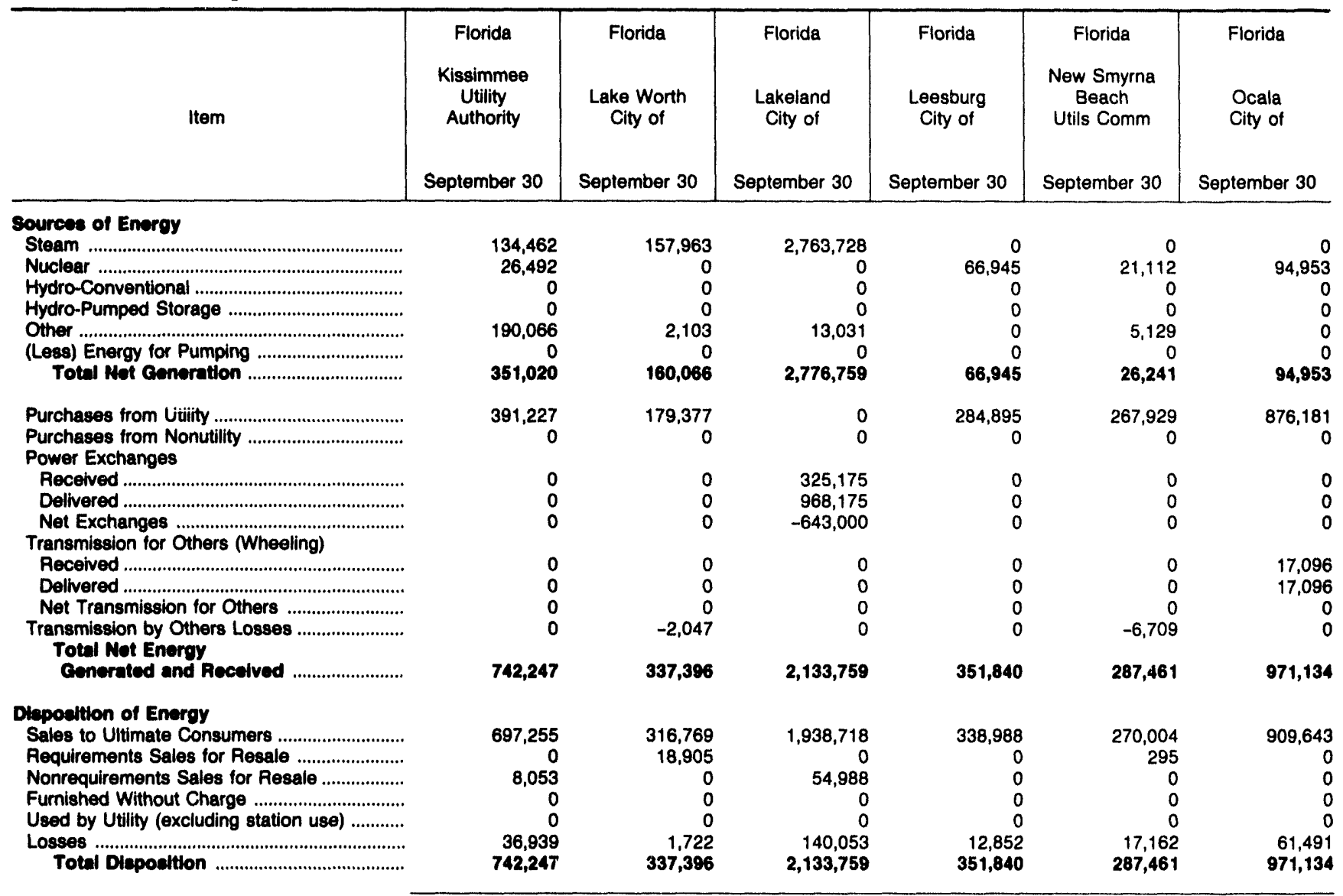

Note: Totals may not equal sum of components because of independent rounding. Double counting occurs in components of both sources and disposition of energy and thus neither provides a true total. Purchases from utilities, net interchanges, and net wheeling (except for imports) are included in net generation. Sales for resale is included in sales to ultimate consumers.

Source: Energy Information Administration, Form EIA-412, "Annual Report of Public Electric Utilities." 
Table 26. Electric Energy Account by Major U.S. Publicly Owned Electric Utility Within State, 1992 (Continued)

(Megawatthours)

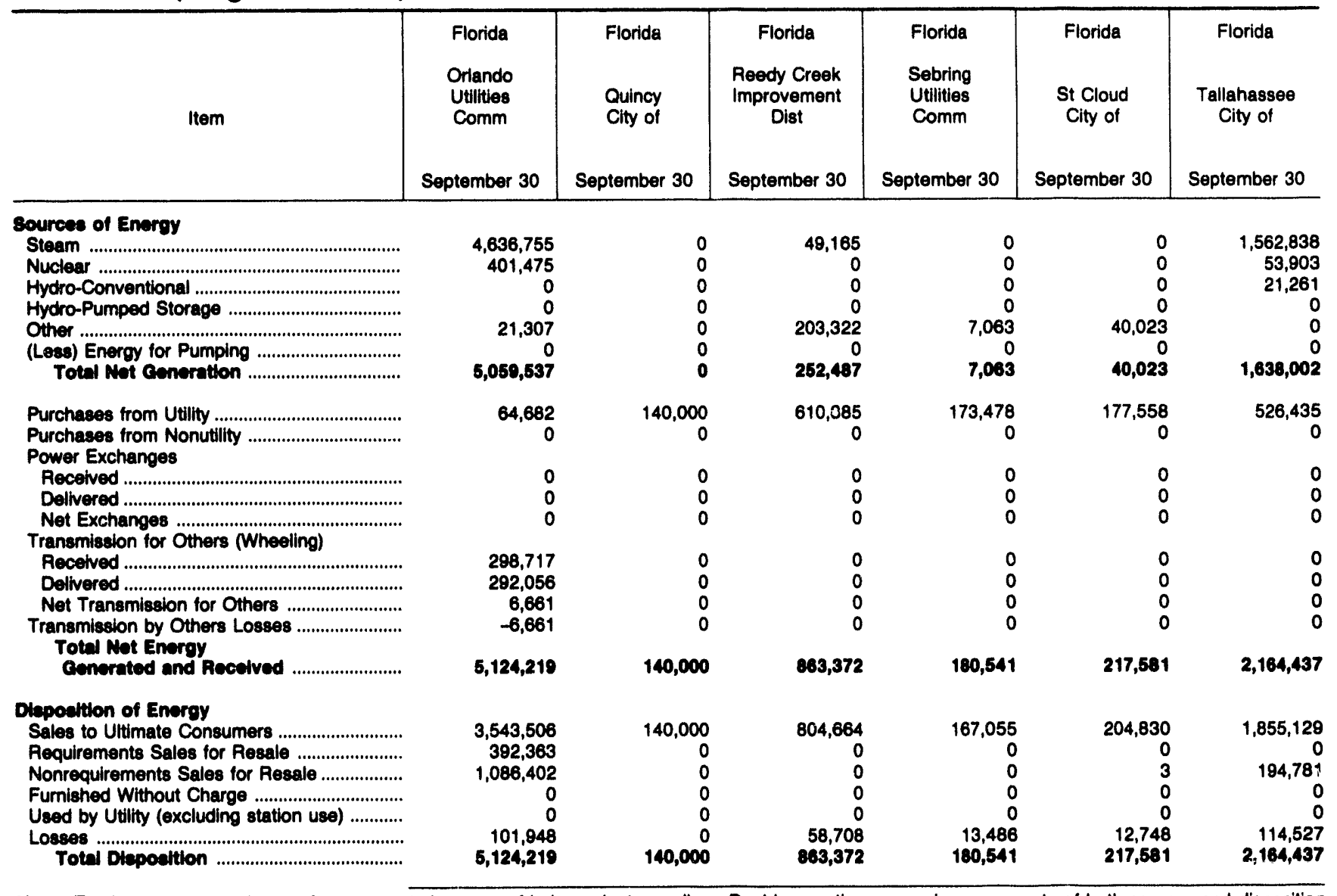

Note: Totals may not equal sum of components because of independent rounding. Double counting occurs in components of both sources and disposition of energy and thus neither provides a true total. Purchases from utilities, net interchanges, and net wheeling (except for imports) are included in net generation. Sales for resale is included in sales to ultimate consumers.

Source: Energy Information Administration, Form EIA-412, "Annual Report of Public Electric Utilities." 
Table 26. Electric Energy Account by Major U.S. Publicly Owned Electric Utility Within State, 1992 (Continued) (Megawatthours)

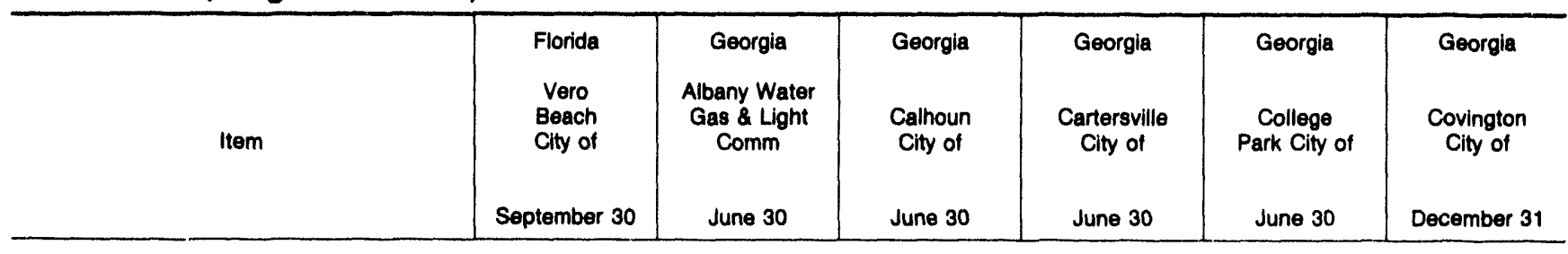

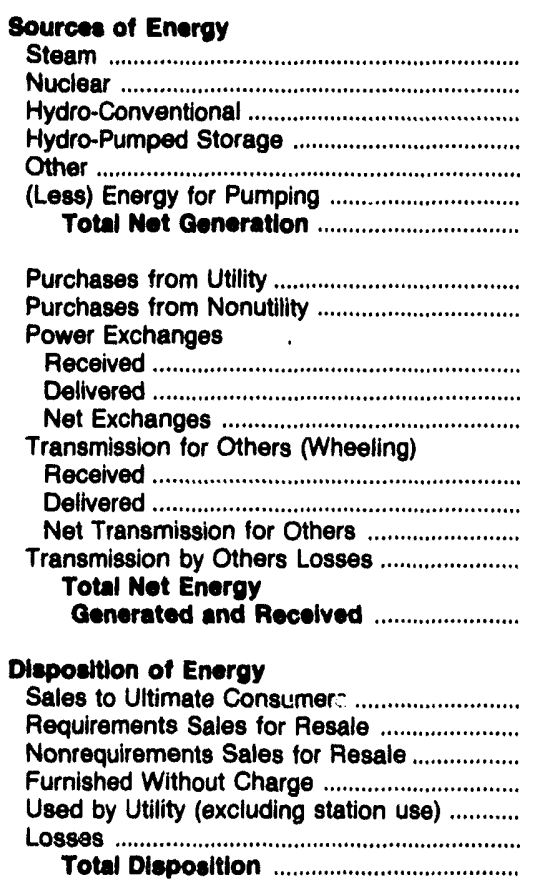

$\begin{array}{rr}224,346 & 0 \\ 0 & 0 \\ 0 & 0 \\ 0 & 0 \\ 0 & 0 \\ 0 & 0 \\ 224,346 & 0\end{array}$

$\begin{array}{ll}0 & 0 \\ 0 & 0 \\ 0 & 0 \\ 0 & 0 \\ 0 & 0 \\ 0 & 0 \\ 0 & 0\end{array}$

291,405

874,117

0

0
0
0

0
0
0
$-1,239$

514,512

874,117
0

302,674

674
0
0

0 0
0
0

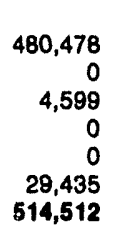

837,714
0
0
0
0
36,403
874,117
294,161

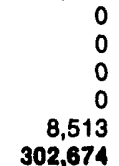

0
0
0
0
0
0
0

Sales to Ultimate Consumer-

Requirements Sales for Resale

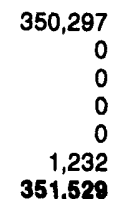

222,075

196,114

351,529

Note: Totals may not equal sum of components because of independent rounding. Double counting occurs in components of both sources and disposition of energy and thus neither provides a true total. Purchases from utilities, net interchanges, and net wheeling (except for imports) are included in net generation. Sales for resale is included in sales to ultimate consumers.

Source: Energy Information Administration, Form EIA-412, "Annual Report of Public Electric Utilities." 

Table 26. Electric Energy Account by Major U.S. Publicly Owned Electric
Utillty Within State, 1992 (Continued)

(Megawatthours)

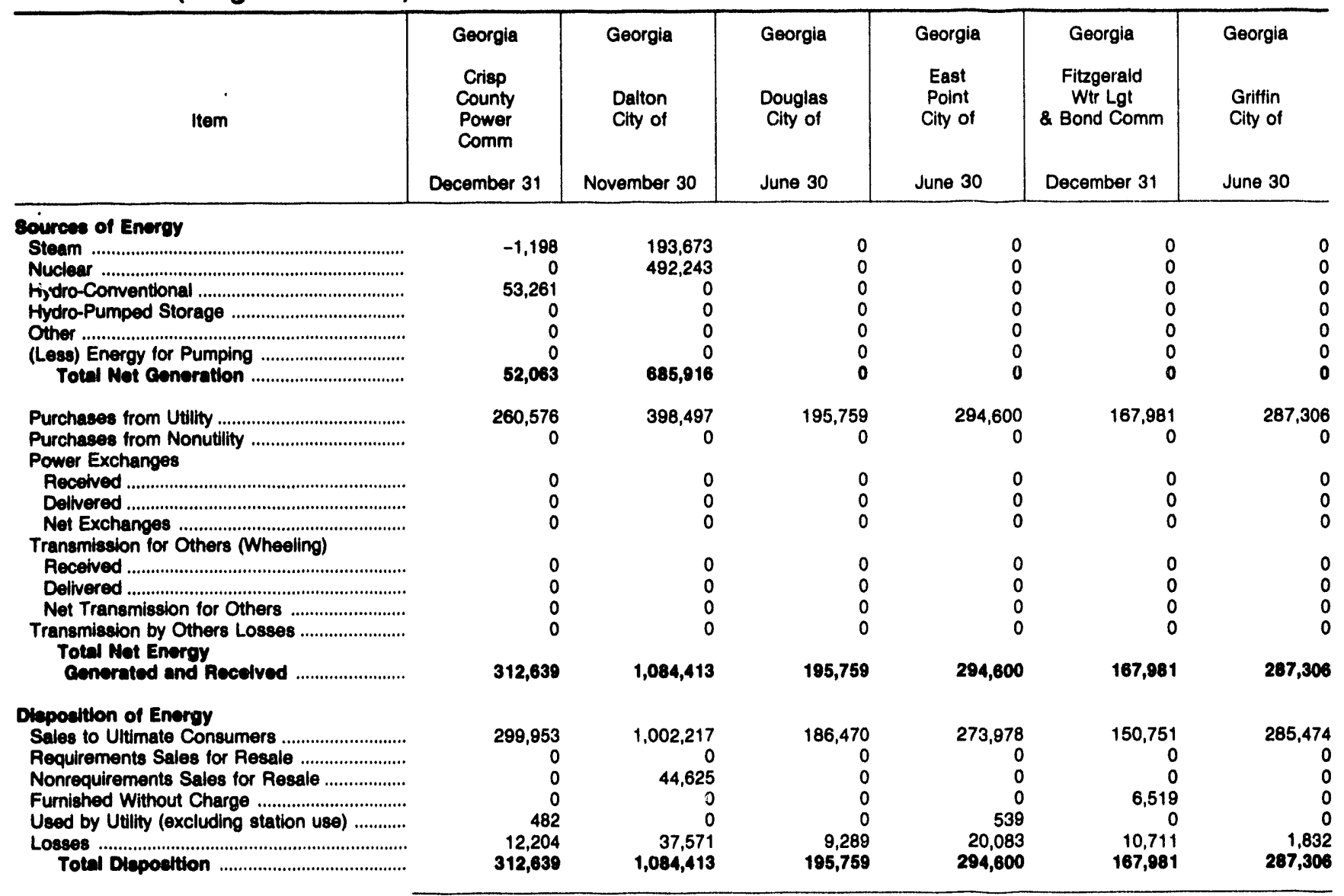

Note: Totals may not equal sum of components because of independent rounding. Double counting occurs in components of both sources and disposition of energy and thus neither provides a true total. Purchases from utilities, net interchanges, and net wheeling (except for imports) are included in net generation. Sales for resale is included in sales to ultimate consumers.

Source: Energy Information Administration, Form EIA-412, "Annual Report of Public Electric Utilities." 
Table 26. Electric Energy Account by Major U.S. Publicly Owned Electric Utility Within State, 1992 (Continued)

(Megawatthours)

\begin{tabular}{|c|c|c|c|c|c|c|}
\hline Item & $\begin{array}{l}\text { Georgia } \\
\text { La Grange } \\
\text { City of } \\
\text { June } 30\end{array}$ & $\begin{array}{c}\text { Georgia } \\
\text { Lawrenceville } \\
\text { City of } \\
\text { August } 30\end{array}$ & $\begin{array}{c}\text { Georgia } \\
\text { Marietta } \\
\text { City of } \\
\text { June } 30\end{array}$ & $\begin{array}{l}\text { Georgia } \\
\text { Moultrie } \\
\text { City of } \\
\text { September } 30\end{array}$ & $\begin{array}{l}\text { Georgia } \\
\text { Municipal } \\
\text { Electric } \\
\text { Authority } \\
\text { December } 31\end{array}$ & $\begin{array}{c}\text { Georgia } \\
\text { Thomasville } \\
\text { City of } \\
\text { December } 31\end{array}$ \\
\hline 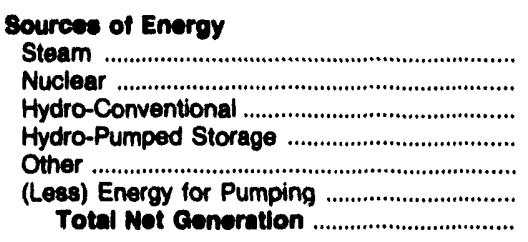 & $\begin{array}{l}0 \\
0 \\
0 \\
0 \\
0 \\
0 \\
0\end{array}$ & $\begin{array}{l}0 \\
0 \\
0 \\
0 \\
0 \\
0 \\
0\end{array}$ & $\begin{array}{l}0 \\
0 \\
0 \\
0 \\
0 \\
0 \\
0\end{array}$ & $\begin{array}{l}0 \\
0 \\
0 \\
0 \\
0 \\
0 \\
0\end{array}$ & $\begin{array}{r}2,717,774 \\
5,812,874 \\
0 \\
0 \\
0 \\
0 \\
8,530,648\end{array}$ & $\begin{array}{l}0 \\
0 \\
0 \\
0 \\
0 \\
0 \\
0\end{array}$ \\
\hline 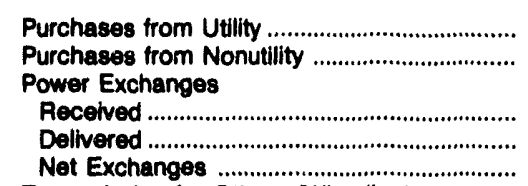 & $\begin{array}{r}553,601 \\
0 \\
0 \\
0 \\
0\end{array}$ & $\begin{array}{r}173,676 \\
0\end{array}$ & $\begin{array}{r}806,283 \\
0\end{array}$ & $\begin{array}{r}185,986 \\
0\end{array}$ & $\begin{array}{r}1,491,775 \\
7,923\end{array}$ & $\begin{array}{r}396,772 \\
0\end{array}$ \\
\hline 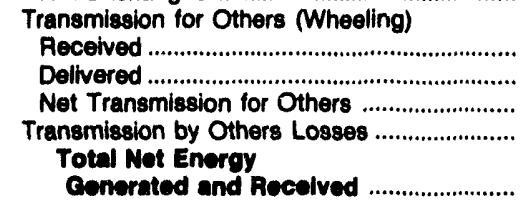 & $\begin{array}{l}0 \\
0 \\
0 \\
0\end{array}$ & 173,676 & $\begin{array}{r}0 \\
0 \\
0 \\
0 \\
806,283\end{array}$ & $\begin{array}{r}0 \\
0 \\
0 \\
0 \\
165,986\end{array}$ & $\begin{array}{r}822,455 \\
777,220 \\
45,235 \\
0 \\
10,075,581\end{array}$ & $\begin{array}{r}0 \\
0 \\
0 \\
0 \\
3 \leftrightarrow 6,772\end{array}$ \\
\hline 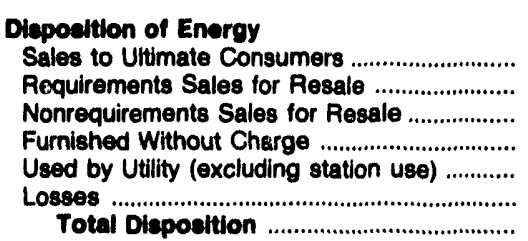 & $\begin{array}{r}542,978 \\
0 \\
0 \\
0 \\
0 \\
10,623 \\
553,601\end{array}$ & $\begin{array}{r}160,496 \\
0 \\
0 \\
1,182 \\
11,998 \\
0 \\
173,878\end{array}$ & $\begin{array}{r}745,682 \\
0 \\
0 \\
4,489 \\
8,113 \\
47,989 \\
806,283\end{array}$ & $\begin{array}{r}143,418 \\
0 \\
0 \\
22,568 \\
0 \\
0 \\
165,088\end{array}$ & $\begin{array}{r}0 \\
9,684,579 \\
0 \\
0 \\
0 \\
391,002 \\
10,675,581\end{array}$ & $\begin{array}{r}373,075 \\
0 \\
0 \\
2,472 \\
0 \\
21,225 \\
398,772\end{array}$ \\
\hline
\end{tabular}

Note: Totals may not equal sum of components because of independent rounding. Double counting occurs in components of both sources and disposition of energy and thus neither provides a true total. Purchases from utilities, net interchanges, and net wheeling (except for imports) are included in net generation. Sales for resale is included in sales to ultimate consumers.

Source: Energy Information Administ"ation, Form EIA-412, "Annual Report of Public Electric Utilities." 
Table 26. Electric Energy Account by Major U.S. Publicly Owned Electric Utility Within State, 1992 (Continued) (Megawatthours)

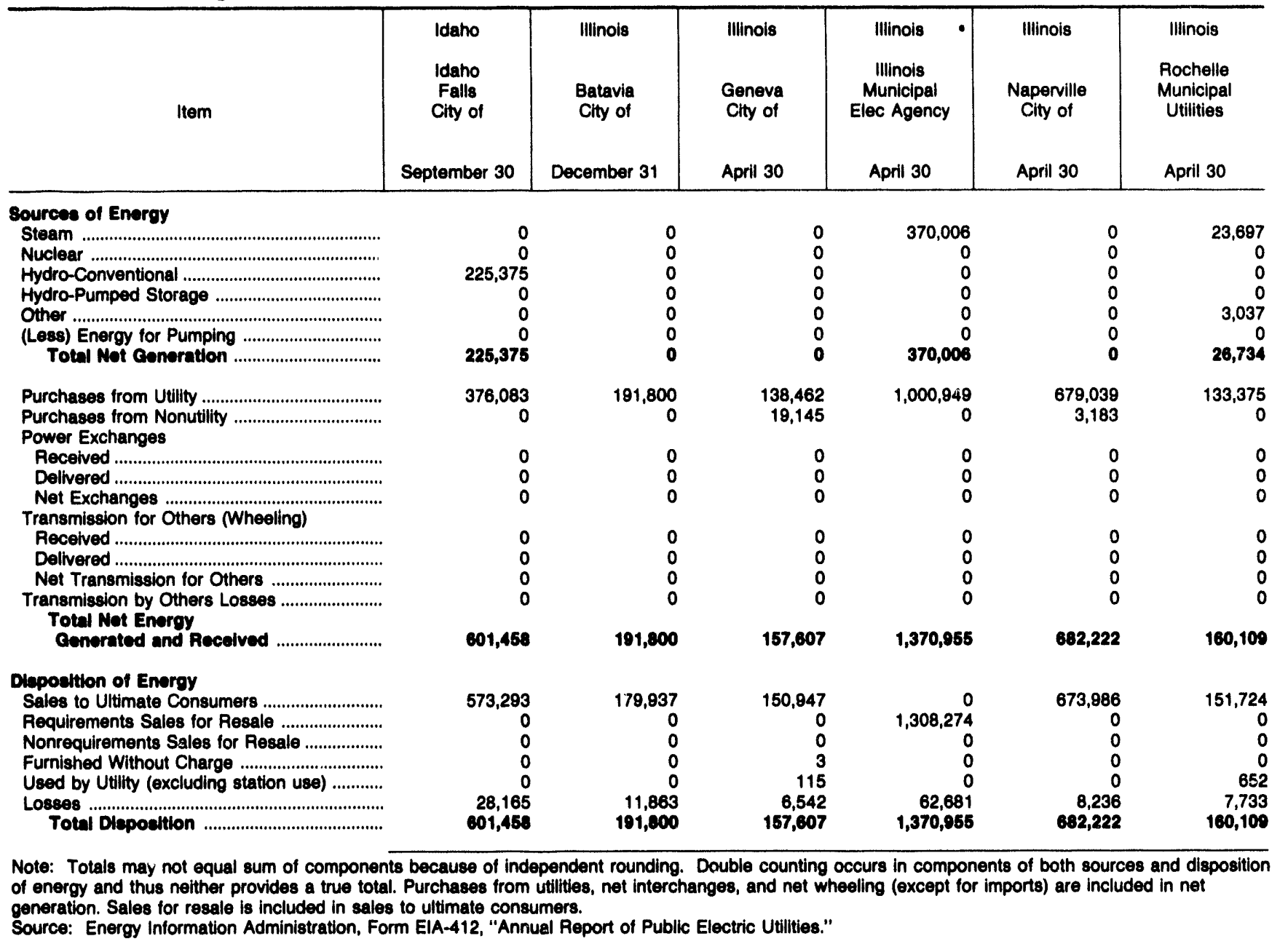


Table 26. Electric Energy Account by Major U.S. Publicly Owned Electric UtIlity Within State, 1992 (Continued) (Megawatthours)

\begin{tabular}{|c|c|c|c|c|c|c|}
\hline Item & $\begin{array}{c}\text { Illinois } \\
\text { Springfield } \\
\text { City of } \\
\text { February } 28\end{array}$ & $\begin{array}{l}\text { Illinois } \\
\text { St Charles } \\
\text { City of } \\
\text { April } 30\end{array}$ & $\begin{array}{c}\text { Indiana } \\
\text { Anderson } \\
\text { Clty of } \\
\text { December } 31\end{array}$ & $\begin{array}{l}\text { Indiana } \\
\text { Auburn } \\
\text { City of } \\
\text { December } 31\end{array}$ & $\begin{array}{c}\text { Indiana } \\
\text { Bluftion } \\
\text { City of } \\
\text { December } 31\end{array}$ & $\begin{array}{c}\text { Indiana } \\
\text { Crawfordsville } \\
\text { Elec } \\
\text { Lgt\&Pwr Co } \\
\text { December } 31\end{array}$ \\
\hline 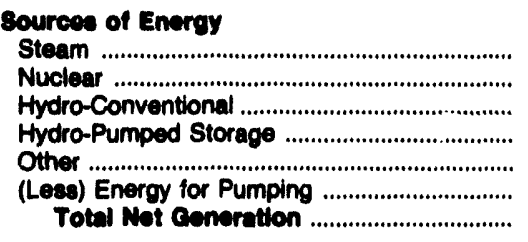 & $\begin{array}{r}1,736,744 \\
0 \\
0 \\
0 \\
712 \\
0 \\
1,737,456\end{array}$ & $\begin{array}{l}0 \\
0 \\
0 \\
0 \\
0 \\
0 \\
0\end{array}$ & $\begin{array}{l}0 \\
0 \\
0 \\
0 \\
0 \\
0 \\
0\end{array}$ & $\begin{array}{l}0 \\
0 \\
0 \\
0 \\
0 \\
0 \\
0\end{array}$ & $\begin{array}{r}0 \\
0 \\
0 \\
0 \\
3,291 \\
0 \\
3,291\end{array}$ & $\begin{array}{r}27,195 \\
0 \\
0 \\
0 \\
0 \\
0 \\
27,105\end{array}$ \\
\hline 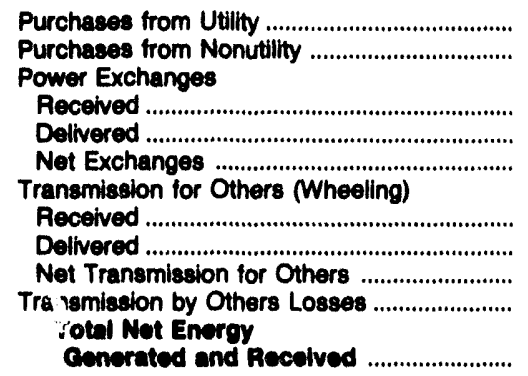 & $\begin{array}{r}7,510 \\
0\end{array}$ & $\begin{array}{r}352,224 \\
0\end{array}$ & $\begin{array}{r}619,455 \\
0\end{array}$ & $\begin{array}{r}310,566 \\
0\end{array}$ & $\begin{array}{r}148,142 \\
0\end{array}$ & $\begin{array}{r}330,063 \\
0\end{array}$ \\
\hline 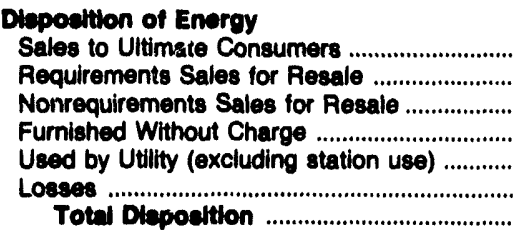 & $\begin{array}{r}1,518,773 \\
94,433 \\
26,041 \\
16,783 \\
3,376 \\
85,560 \\
1,744,966\end{array}$ & $\begin{array}{r}332,787 \\
0 \\
0 \\
0 \\
0 \\
19,437 \\
352,224\end{array}$ & $\begin{array}{r}585,374 \\
0 \\
0 \\
0 \\
0 \\
34,081 \\
619,455\end{array}$ & $\begin{array}{r}298,969 \\
0 \\
0 \\
674 \\
0 \\
10,921 \\
310,566\end{array}$ & $\begin{array}{r}144,814 \\
0 \\
0 \\
0 \\
0 \\
6,619 \\
151,433\end{array}$ & $\begin{array}{r}324,001 \\
27,195 \\
0 \\
0 \\
1,465 \\
4,597 \\
357,268\end{array}$ \\
\hline
\end{tabular}

Note: Totals may not equal sum of components because of independent rounding. Double counting occurs in components of both sources and disposition of energy and thus neither provides a true total. Purchases from utilities, net interchanges, and net wheeling (except for imports) are included in net generation. Sales for resale is included in sales to ultimate consumers.

Source: Energy Information Administration, Form ElA-412, "Annual Report of Public Electric Utilities." 
Table 26. Electric Energy Account by Major U.S. Publicly Owned Electric Utility Within State, 1992 (Continued) (Megawatthours)

\begin{tabular}{|c|c|c|c|c|c|c|}
\hline Item & $\begin{array}{l}\text { Indiana } \\
\text { Frankfort } \\
\text { City of }\end{array}$ & $\begin{array}{l}\text { Indiana } \\
\text { Greenfield } \\
\text { City of }\end{array}$ & $\begin{array}{c}\text { Indiana } \\
\text { Indiana } \\
\text { Municipal } \\
\text { Power Agency }\end{array}$ & $\begin{array}{l}\text { Indiana } \\
\text { Jasper } \\
\text { City of }\end{array}$ & $\begin{array}{l}\text { Indiana } \\
\text { Loganspon } \\
\text { City of }\end{array}$ & $\begin{array}{c}\text { Mishawaka } \\
\text { City of }\end{array}$ \\
\hline & December 31 & December 31 & December 31 & December 31 & December 31 & December 31 \\
\hline
\end{tabular}

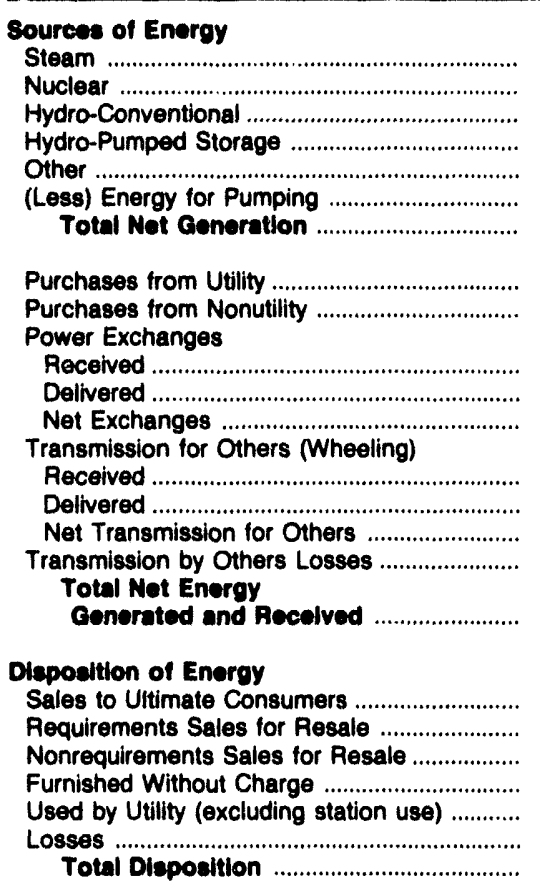

(a)

0
0
0
0
0
0
0

$\begin{array}{ll}0 & 0 \\ 0 & 0 \\ 0 & 0 \\ 0 & 0 \\ 0 & 0 \\ 0 & 0 \\ 0 & 0\end{array}$

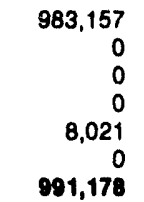

279,064
0

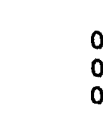

0
0
0
0

279,084

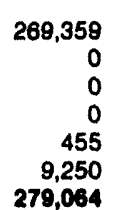

150,635

150,635
0

$2,516,968$

$$
0
$$$$
\begin{aligned}
& 0 \\
& 0 \\
& 0
\end{aligned}
$$$$
0
$$$$
\begin{aligned}
& 0 \\
& 0 \\
& 0
\end{aligned}
$$

449,365

$$
\begin{array}{lr}
0 & 449,365 \\
0 & 449,365 \\
0 & 0 \\
0 & 0
\end{array}
$$

150,635

$3,508,146$

$\begin{array}{rr}142,825 & 0 \\ 0 & 3,393,949 \\ 0 & 0 \\ 0 & 0 \\ 0 & 0 \\ 7,810 & 114.407 \\ 150,635 & 3,508,146\end{array}$

52,978
0
0
0
0
0
52,978

187,314

0

$$
0
$$$$
0
$$

0

0
0
0
0

240,292

$$
\begin{array}{r}
231,769 \\
0 \\
0 \\
75 \\
684 \\
7,764 \\
240,292
\end{array}
$$

$\begin{array}{rr}87,810 & 0 \\ 0 & 0 \\ 0 & 0 \\ 0 & 0 \\ 3,582 & 0 \\ 0 & 0 \\ 91,392 & 0\end{array}$

$226,255 \quad 419,850$

Note: Totals may not equal sum of components because of independent rounding. Double counting occurs in components of both sources and disposition of energy and thus neither provides a true total. Purchases from utilities, net interchanges, and net wheeling (except for imports) are included in net generation. Sales for resale is included in sales to ultimate consumers.

Source: Energy Information Administration, Form EIA-412, "Annual Report of Public Electric Utilities." 
Table 26. Electric Energy Account by Major U.S. Publicly Owned Electric Utility Within State, 1992 (Continued) (Megawatthours)

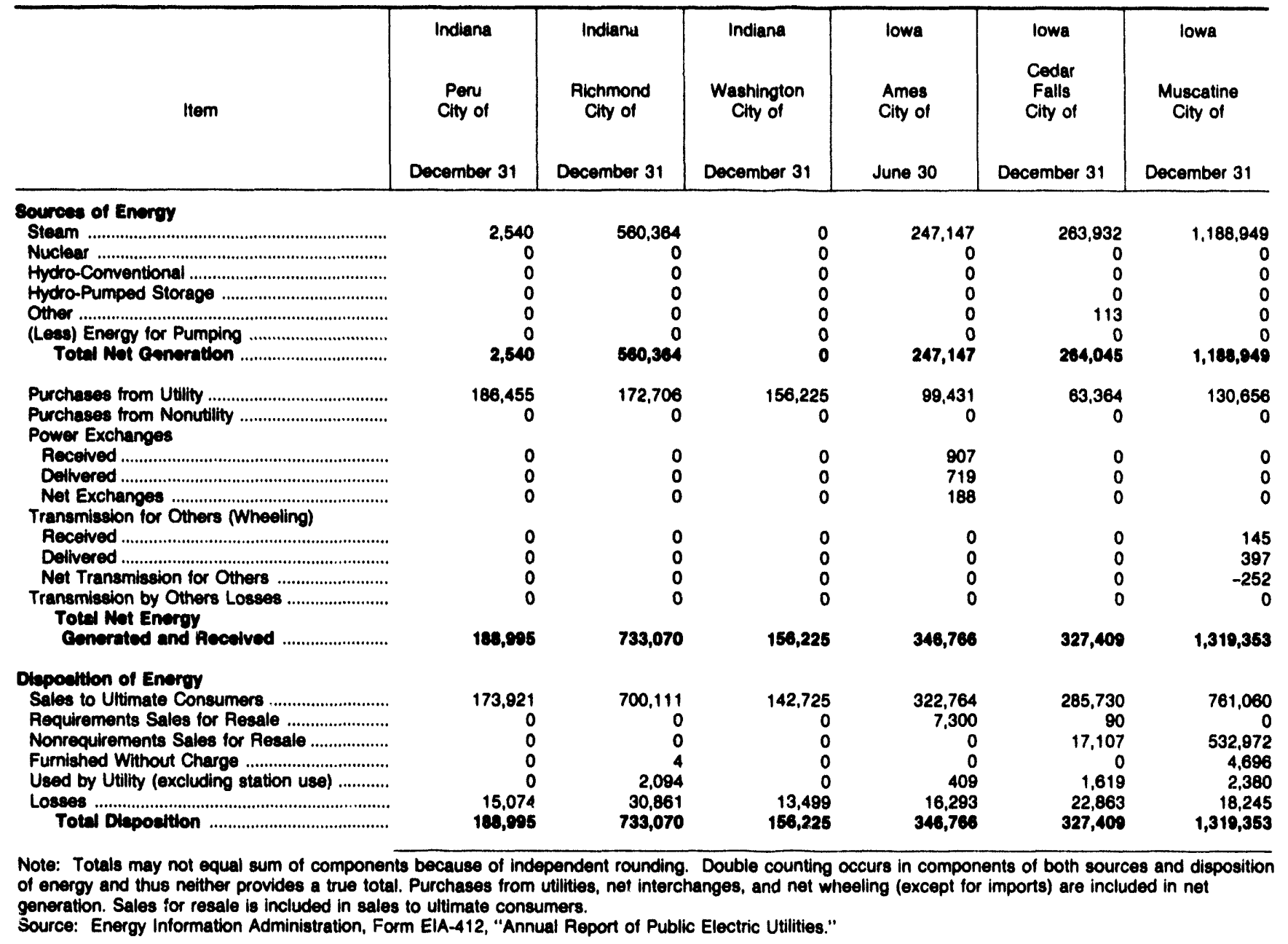


Table 26. Electric Energy Account by Major U.S. Publicly Owned Electric Utillty Within State, 1992 (Continued) (Megawatthours)

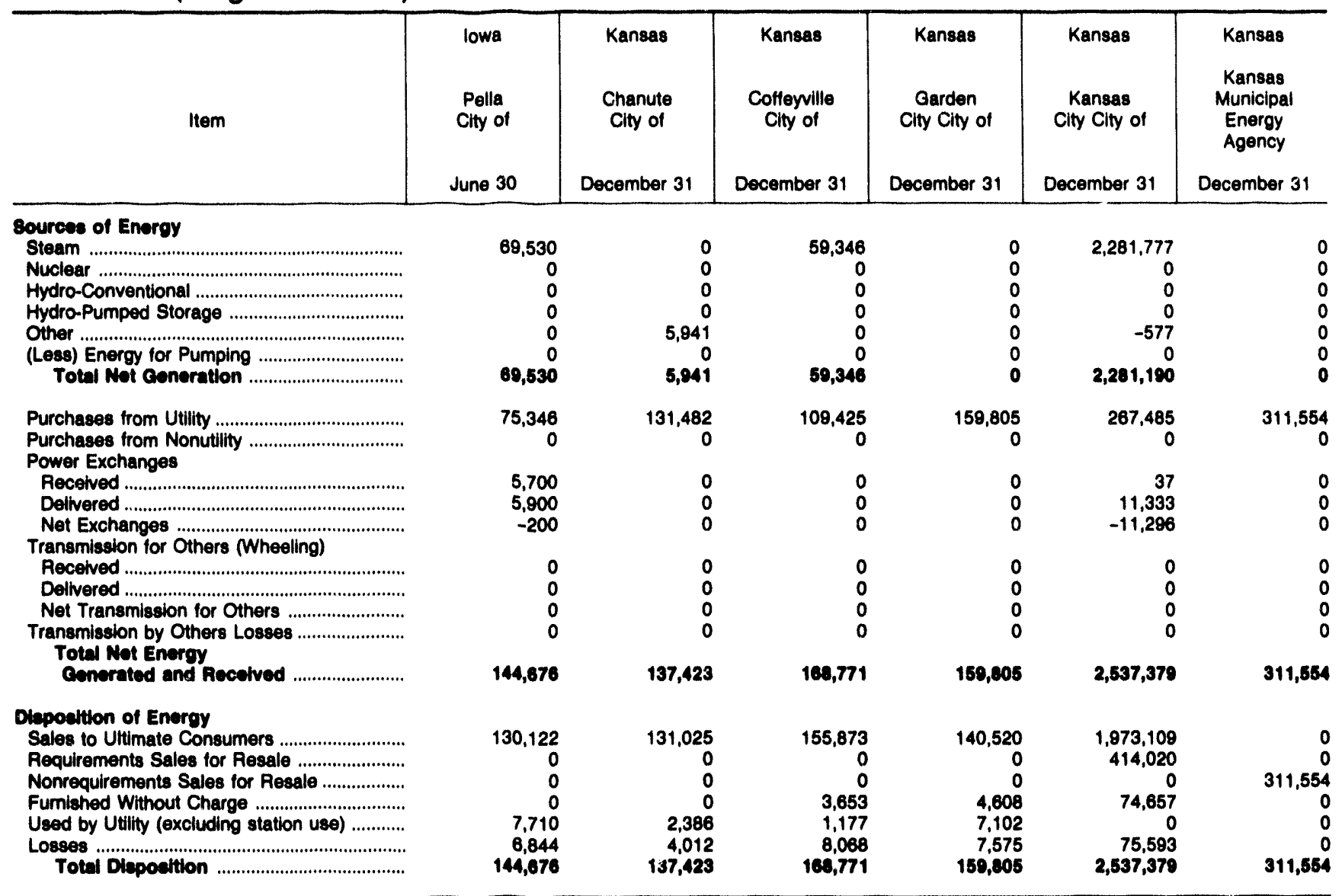

Note: Totals may not equal sum of components because of independent rounding. Double counting occurs in components of both sources and disposition of energy and thus neither provides a true total. Purchases from utilities, net interchanges, and net wheeling (except for imports) are included in net generation. Sales for resale is included in sales to ultimate consumers.

Source: Energy infermation Administration, Form EIA-412, "Annual Report of Public Elactric Utilities." 
Table 26. Electric Energy Account by Major U.S. Publicly Owned Electric Utility Within State, 1992 (Continued) (Megawatthours)

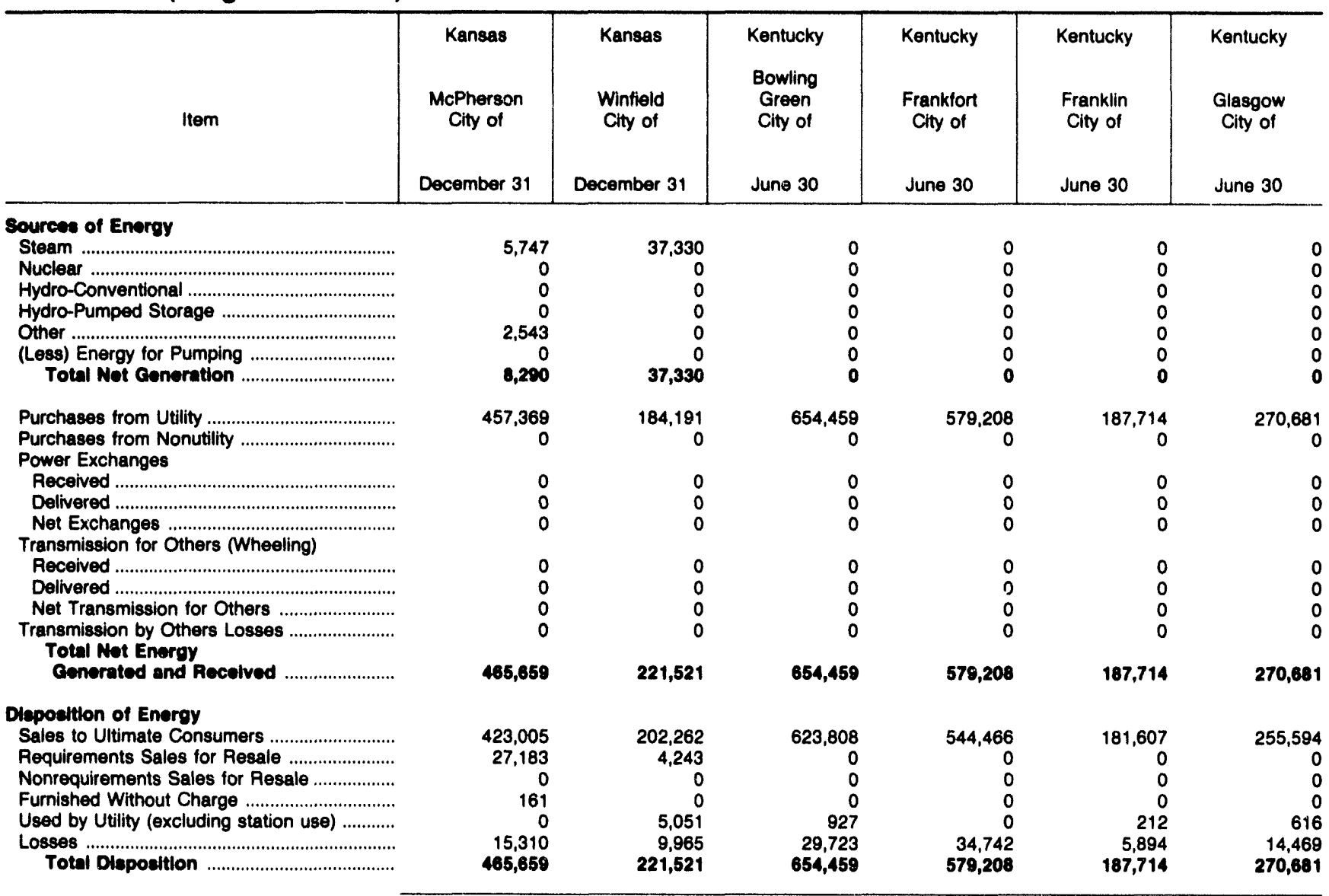

Note: Totals may not equal sum of components because of independent rounding. Double counting occurs in components of both sources and disposition of energy and thus neither provides a true total. Purchases from utilities, net interchanges, and net wheeling (except for imports) are included in net generation. Sales for resale is included in sales to ultimate consumers.

Source: Energy Information Administration, Form EIA-412, "Annual Report of Public Electric Utilities." 
Table 26. Electric Energy Account by Major U.S. Publicly Owned Electric Utillty Within State, 1992 (Continued) (Megawatthours)

\begin{tabular}{|c|c|c|c|c|c|c|}
\hline Item & $\begin{array}{c}\text { Kentucky } \\
\text { Henderson } \\
\text { City } \\
\text { Utility Comm } \\
\text { May } 31\end{array}$ & $\begin{array}{c}\text { Kentucky } \\
\text { Hopkinsville } \\
\text { City of } \\
\text { June } 30\end{array}$ & $\begin{array}{l}\text { Kentucky } \\
\text { Madisonville } \\
\text { Municipal } \\
\text { Utils }\end{array}$ & $\begin{array}{c}\text { Kentucky } \\
\text { Maytield } \\
\text { City of } \\
\text { June } 30\end{array}$ & $\begin{array}{l}\text { Kentucky } \\
\text { Murray } \\
\text { City of } \\
\text { June } 30\end{array}$ & $\begin{array}{l}\text { Kentucky } \\
\text { Owensboro } \\
\text { City of } \\
\text { May } 31\end{array}$ \\
\hline 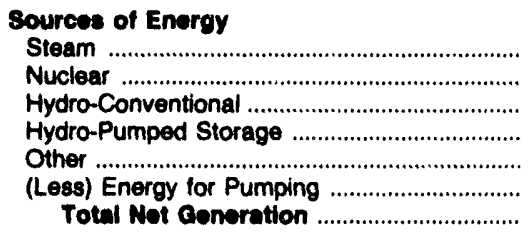 & $\begin{array}{r}1,776,962 \\
0 \\
0 \\
0 \\
0 \\
0 \\
1,776,962\end{array}$ & $\begin{array}{l}0 \\
0 \\
0 \\
0 \\
0 \\
0 \\
0\end{array}$ & $\begin{array}{l}0 \\
0 \\
0 \\
0 \\
0 \\
0 \\
0\end{array}$ & $\begin{array}{l}0 \\
0 \\
0 \\
0 \\
0 \\
0 \\
0\end{array}$ & $\begin{array}{l}0 \\
0 \\
0 \\
0 \\
0 \\
0 \\
0\end{array}$ & $\begin{array}{r}2,271,085 \\
0 \\
0 \\
0 \\
0 \\
0 \\
2,271,085\end{array}$ \\
\hline $\begin{array}{l}\text { Purchases from Utility } \\
\text { Purchases from Nonutility } \\
\text { Power Exchanges } \\
\text { Received } \\
\text { Delivered } \\
\text { Net Exchanges }\end{array}$ & $\begin{array}{r}23,549 \\
0\end{array}$ & $\begin{array}{r}394,779 \\
0\end{array}$ & $\begin{array}{r}258,954 \\
0\end{array}$ & $\begin{array}{r}137,719 \\
0\end{array}$ & $\begin{array}{r}228,933 \\
0\end{array}$ & $\begin{array}{r}28,631 \\
0 \\
0 \\
0 \\
0\end{array}$ \\
\hline 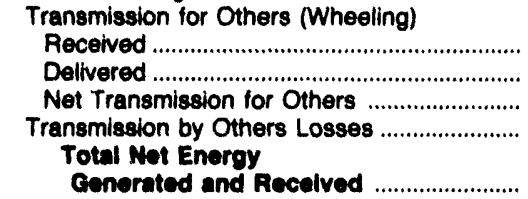 & $\begin{array}{l}0 \\
0 \\
0 \\
0\end{array}$ & $\begin{array}{l}0 \\
0 \\
0 \\
0\end{array}$ & $\begin{array}{l}0 \\
0 \\
0 \\
0\end{array}$ & $\begin{array}{l}0 \\
0 \\
0 \\
0\end{array}$ & $\begin{array}{r}0 \\
0 \\
0 \\
0 \\
228,933\end{array}$ & $\begin{array}{r}0 \\
2,299,716\end{array}$ \\
\hline 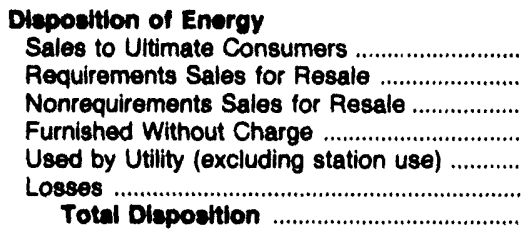 & $\begin{array}{r}372,137 \\
1,411,008 \\
0 \\
6,038 \\
301 \\
11,027 \\
1,800,511\end{array}$ & $\begin{array}{r}380,183 \\
0 \\
0 \\
0 \\
423 \\
14,171 \\
384,779\end{array}$ & $\begin{array}{r}251,151 \\
0 \\
0 \\
0 \\
0 \\
7,803 \\
258,954\end{array}$ & $\begin{array}{r}132,649 \\
0 \\
0 \\
0 \\
167 \\
4,902 \\
137,719\end{array}$ & $\begin{array}{r}220,947 \\
0 \\
0 \\
0 \\
209 \\
7,776 \\
228,933\end{array}$ & $\begin{array}{r}748,154 \\
0 \\
1,526,274 \\
0 \\
2,080 \\
23,208 \\
2,299,716\end{array}$ \\
\hline
\end{tabular}

Note: Totals may not equal sum of components because of independent rounding. Double counting occurs in components of both sources and disposition of energy and thus neither provides a true total. Purchases from utilities, net interchanges, and net wheeling (except for imports) are included in net generation. Sales for resale is included in sales to ultimate consumers.

Source: Energy information Administration, Form EIA-412, "Annual Report of Public Electric Utilities." 
Table 26. Electric Energy Account by Major U.S. Publicly Owned Electric Utility Within State, 1992 (Continued)

(Megawatthours)

\begin{tabular}{|c|c|c|c|c|c|c|}
\hline Item & $\begin{array}{l}\text { Kentucky } \\
\text { Paducah } \\
\text { City of } \\
\text { June } 30\end{array}$ & $\begin{array}{l}\text { Louisiana } \\
\text { Alexandria } \\
\text { City of } \\
\text { April } 30\end{array}$ & $\begin{array}{l}\text { Louisiana } \\
\text { Lafayette } \\
\text { City of } \\
\text { October } 31\end{array}$ & $\begin{array}{l}\text { Louisiana } \\
\text { Lafayette } \\
\text { Public } \\
\text { Power Auth } \\
\text { October } 31\end{array}$ & 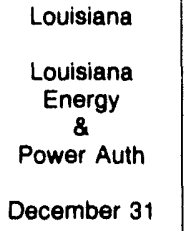 & $\begin{array}{l}\text { Louisiana } \\
\text { Morgan } \\
\text { City City of } \\
\text { December } 31\end{array}$ \\
\hline Sources of Energy & & & & & & \\
\hline 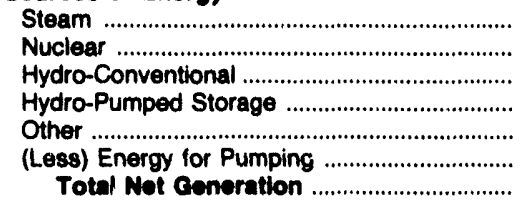 & $\begin{array}{l}0 \\
0 \\
0 \\
0 \\
0 \\
0 \\
0\end{array}$ & $\begin{array}{r}47,120 \\
0 \\
0 \\
0 \\
0 \\
0 \\
47,120\end{array}$ & $\begin{array}{r}342,981 \\
0 \\
0 \\
0 \\
0 \\
0 \\
342,981\end{array}$ & $\begin{array}{r}1,418,646 \\
0 \\
0 \\
0 \\
0 \\
0 \\
1,418,646\end{array}$ & $\begin{array}{r}737,480 \\
0 \\
0 \\
0 \\
0 \\
0 \\
737,480\end{array}$ & $\begin{array}{r}58,453 \\
0 \\
0 \\
0 \\
0 \\
0 \\
58,453\end{array}$ \\
\hline 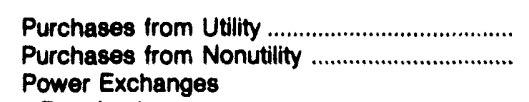 & $\begin{array}{r}525,689 \\
0\end{array}$ & $\begin{array}{r}563,928 \\
0\end{array}$ & $\begin{array}{r}1,603,926 \\
0\end{array}$ & $\begin{array}{l}0 \\
0\end{array}$ & $\begin{array}{r}793,704 \\
0\end{array}$ & $\begin{array}{r}96,747 \\
0\end{array}$ \\
\hline 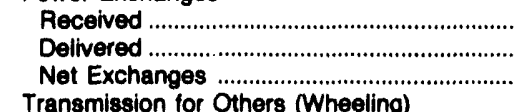 & $\begin{array}{l}0 \\
0 \\
0\end{array}$ & $\begin{array}{l}0 \\
0 \\
0\end{array}$ & $\begin{array}{r}26,238 \\
26,226 \\
12\end{array}$ & $\begin{array}{l}0 \\
0 \\
0\end{array}$ & $\begin{array}{l}0 \\
0 \\
0\end{array}$ & $\begin{array}{l}0 \\
0 \\
0\end{array}$ \\
\hline 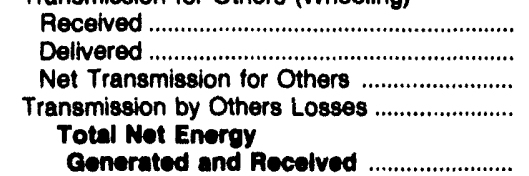 & $\begin{array}{r}0 \\
0 \\
0 \\
0\end{array}$ & $\begin{array}{r}0 \\
0 \\
0 \\
0\end{array}$ & $\begin{array}{r}0 \\
0 \\
0 \\
0\end{array}$ & $\begin{array}{r}0 \\
0 \\
0 \\
0\end{array}$ & $\begin{array}{r}0 \\
0 \\
0 \\
0\end{array}$ & $\begin{array}{r}0 \\
0 \\
0 \\
0 \\
155,200\end{array}$ \\
\hline 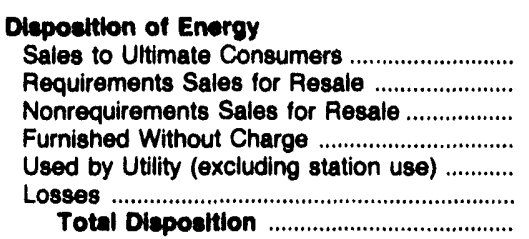 & $\begin{array}{r}503,971 \\
0 \\
0 \\
0 \\
904 \\
20,813 \\
525,689\end{array}$ & $\begin{array}{r}553,972 \\
0 \\
0 \\
16,000 \\
6,000 \\
35,076 \\
611,048\end{array}$ & $\begin{array}{r}1,304,541 \\
560,650 \\
0 \\
0 \\
0 \\
81,728 \\
1,948,919\end{array}$ & $\begin{array}{r}0 \\
1,402,971 \\
0 \\
0 \\
0 \\
15,675 \\
1,418,646\end{array}$ & $\begin{array}{r}0 \\
1,485,052 \\
0 \\
0 \\
0 \\
46,132 \\
1,531,184\end{array}$ & $\begin{array}{r}142,626 \\
0 \\
0 \\
0 \\
0 \\
12,574 \\
155,200\end{array}$ \\
\hline
\end{tabular}


Table 26. Electric Energy Account by Major U.S. Publicly Owned Electric Utility Within State, 1992 (Continued) (Megawatthours)

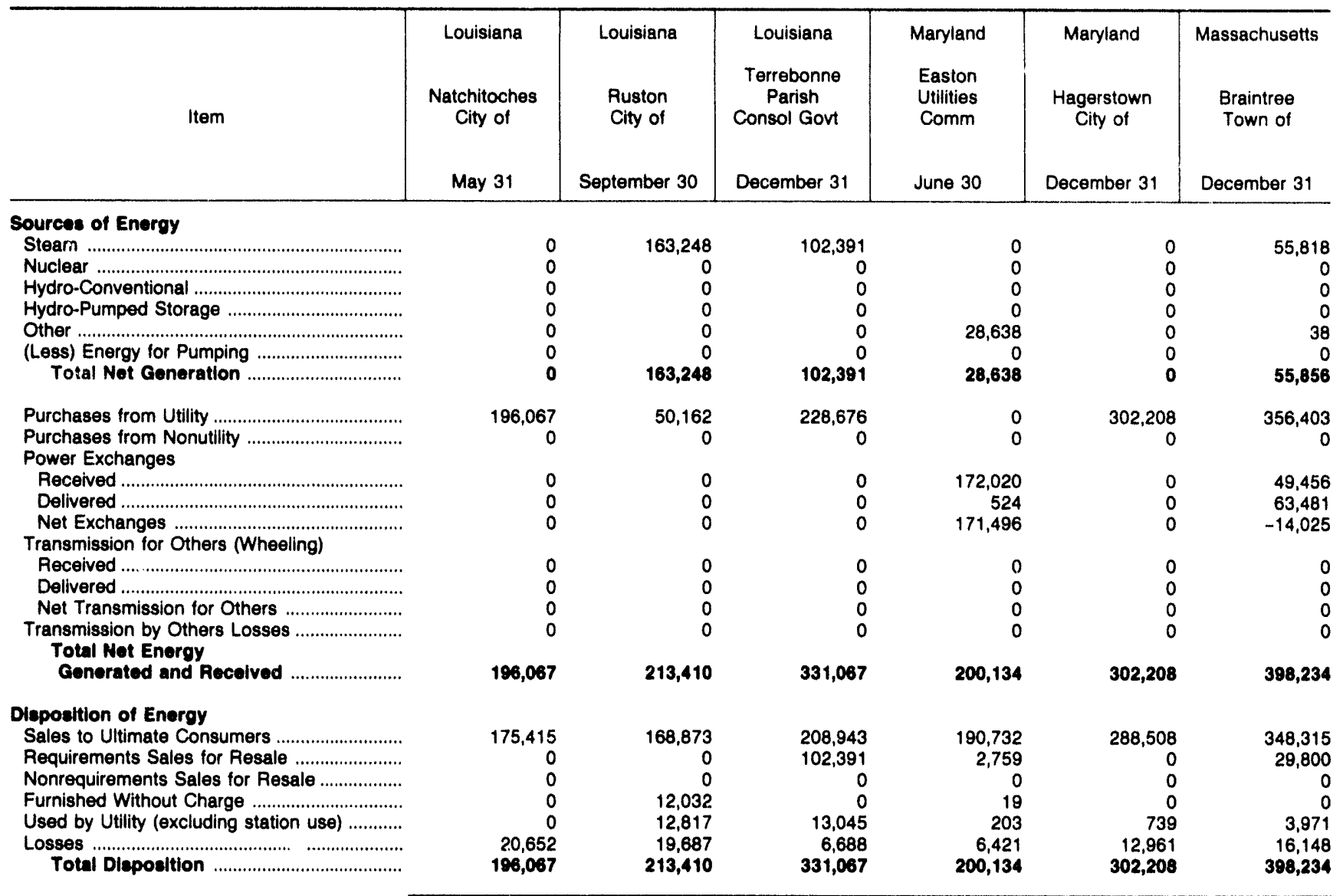

Note: Totals may not equal sum of components because of independent rounding. Double counting occurs in components of both sources and disposition of energy and thus neither provides a true total. Purchases from utilities, net interchanges, and net wheeling (except for imports) are included in net generation. Sales for resale is included in sales to ultimate consumers.

Source: Energy Information Administration, Form ElA-412, "Annual Report of Public Electric Utilities." 
Table 26. Electric Energy Account by Major U.S. Publicly Owned Electric Utility Within State, 1992 (Continued) (Megawatthours)

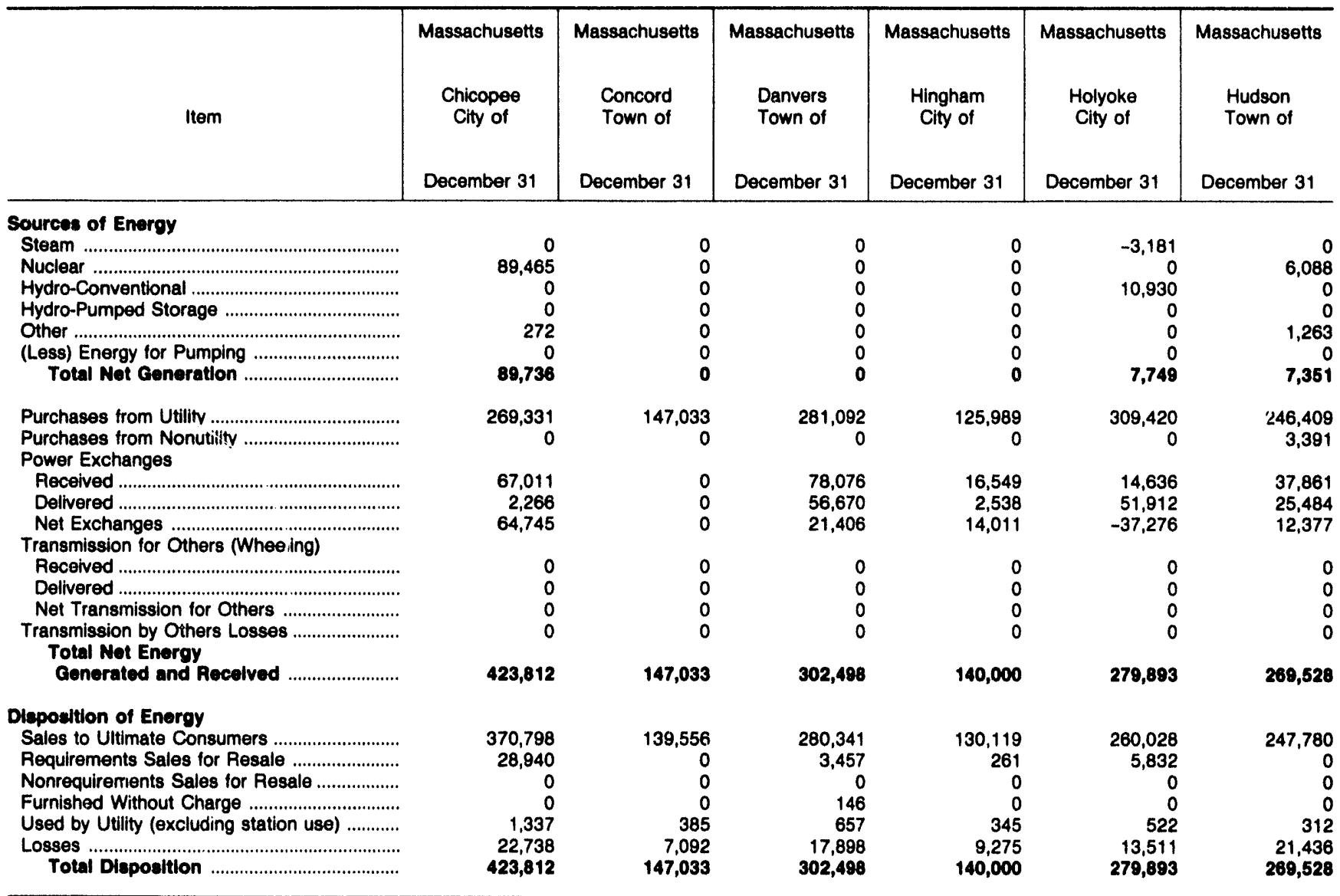

Note: Totals may not equal sum of components because of independent rounding. Double counting occurs in components of both sources and disposition of energy and thus neither provides a true total. Purchases from utilities, net interchanges, and net wheeling (except for imports) are included in net generation. Sales for resale is included in sales to uitimate consumers.

Source: Energy Information Administration, Form EIA-412, "Annual Report of Public Electric Utilities." 
Table 26. Electric Energy Account by Major U.S. Publicly Owned Electric Utility Within State, 1992 (Continued)

(Megawatthours)

\begin{tabular}{|c|c|c|c|c|c|c|}
\hline Item & $\begin{array}{l}\text { Massachusetts } \\
\text { Littleton } \\
\text { Town of } \\
\text { December } 31\end{array}$ & $\begin{array}{l}\text { Massachusetts } \\
\text { Mansfield } \\
\text { Town of } \\
\text { December } 31\end{array}$ & $\begin{array}{c}\text { Massachusetts } \\
\text { Massachusetts } \\
\text { Mun } \\
\text { Whls } \\
\text { Elec Co } \\
\text { December } 31\end{array}$ & $\begin{array}{l}\text { Massachusetts } \\
\text { Middleborough } \\
\text { Town of } \\
\text { December } 31\end{array}$ & $\begin{array}{c}\text { Massachusetts } \\
\text { North } \\
\text { Attleborough } \\
\text { Town of } \\
\text { December } 31\end{array}$ & $\begin{array}{l}\text { Massachusetts } \\
\text { Norwood } \\
\text { City of } \\
\text { June } 30\end{array}$ \\
\hline \multicolumn{7}{|l|}{ Sources of Energy } \\
\hline 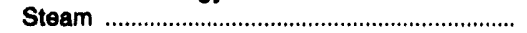 & 4,479 & 0 & 612,651 & 0 & 9,001 & 0 \\
\hline 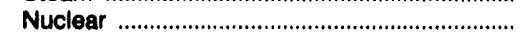 & 0 & 0 & 944,759 & 0 & 0 & 0 \\
\hline 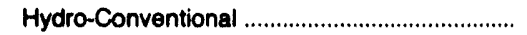 & 0 & 0 & 0 & 0 & 0 & 0 \\
\hline 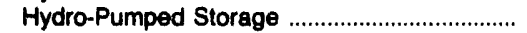 & 0 & 0 & 0 & 0 & 0 & 0 \\
\hline Other & 0 & 0 & 118,000 & 0 & 0 & 0 \\
\hline 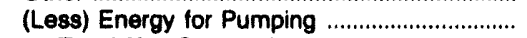 & 0 & 0 & 0 & 0 & 0 & 0 \\
\hline Total Net Generation ................................. & 4,479 & $\mathbf{0}$ & $1,675,410$ & $\mathbf{0}$ & 9,001 & 0 \\
\hline 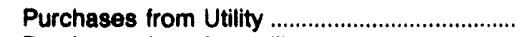 & 130,260 & 158,294 & $1,147,516$ & 171,581 & 120,072 & 327,305 \\
\hline $\begin{array}{l}\text { Purchases from Nonutility .................................. } \\
\text { Power Exchanges }\end{array}$ & 0 & 0 & 42,002 & 0 & 0 & 0 \\
\hline 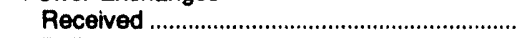 & 83,549 & 70,387 & 774,820 & 0 & 80,748 & 0 \\
\hline 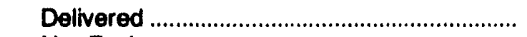 & 11,776 & 28,110 & 402,384 & 2,278 & 21,721 & 0 \\
\hline 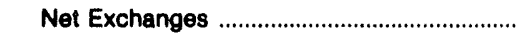 & 71.773 & 42,277 & 372,436 & $-2,278$ & 59,027 & 0 \\
\hline \multicolumn{7}{|l|}{ Transmission for Others (Wheeling) } \\
\hline 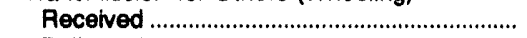 & 0 & 0 & 0 & 0 & 0 & 0 \\
\hline 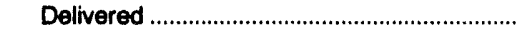 & 0 & 0 & 0 & 0 & 0 & 0 \\
\hline 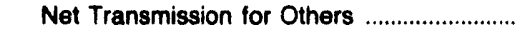 & 0 & 0 & 0 & 0 & 0 & 0 \\
\hline $\begin{array}{l}\text { Transmission by Others Losses ........................ } \\
\text { Total Net Energy }\end{array}$ & 0 & 0 & 0 & 0 & 0 & 0 \\
\hline Generated and Received .......................... & 208,512 & 200,570 & $3,237,364$ & 169,303 & 188,100 & 327,305 \\
\hline \multicolumn{7}{|l|}{ Disposition of Energy } \\
\hline 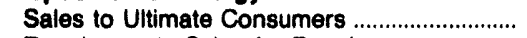 & 184,478 & 171,355 & 0 & 160,356 & 182,123 & 314,580 \\
\hline Requirements Sales for Resale ....................... & 11,604 & 6,455 & $3,237,364$ & 111 & 0 & \\
\hline Nonrequirements Sales for Resale ................. & 0 & 0 & 0 & 0 & 201 & 0 \\
\hline 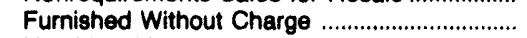 & 0 & 0 & 0 & 0 & 0 & 0 \\
\hline Used by Utility (excluding station use) ............ & 171 & 30 & 0 & 0 & 30 & 0 \\
\hline $\begin{array}{l}\text { Losses } \\
\text { Total Dieposition }\end{array}$ & $\begin{array}{r}10,259 \\
206,512\end{array}$ & $\begin{array}{r}22,730 \\
200,570\end{array}$ & $\begin{array}{r}0 \\
3,237,364\end{array}$ & $\begin{array}{r}8,836 \\
169,303\end{array}$ & $\begin{array}{r}5,746 \\
188,100\end{array}$ & $\begin{array}{r}12,725 \\
327,305\end{array}$ \\
\hline
\end{tabular}


Table 26. Electric Energy Account by Major U.S. Publicly Owned Electric Utility Within State, 1992 (Continued)

(Megawatthours)

\begin{tabular}{|c|c|c|c|c|c|c|}
\hline Item & $\begin{array}{l}\text { Massachusetts } \\
\text { Peabody } \\
\text { City of } \\
\text { December } 31\end{array}$ & $\begin{array}{c}\text { Massachusetts } \\
\text { Reading } \\
\text { Town of } \\
\text { December } 31\end{array}$ & $\begin{array}{l}\text { Massachusetts } \\
\begin{array}{c}\text { Shrewsbury } \\
\text { Town of }\end{array} \\
\text { December } 31\end{array}$ & $\begin{array}{c}\text { Massachusetts } \\
\begin{array}{c}\text { Taunton } \\
\text { City of }\end{array} \\
\text { December } 31\end{array}$ & $\begin{array}{c}\text { Massachusetts } \\
\text { Wakefield } \\
\text { Town of } \\
\text { December } 31\end{array}$ & $\begin{array}{c}\text { Massachusetts } \\
\text { Wellesley } \\
\text { Town of } \\
\text { December } 31\end{array}$ \\
\hline \multicolumn{7}{|l|}{ Sources of Energy } \\
\hline Steam . & 0 & 0 & 0 & 75,561 & 0 & 0 \\
\hline 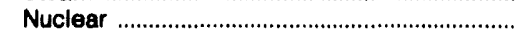 & 0 & 0 & 0 & 0 & 0 & 0 \\
\hline 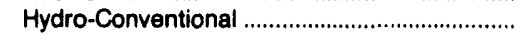 & 0 & 0 & 0 & 0 & 0 & 0 \\
\hline Hydro-Pumped Storage ……………………….......... & 0 & 0 & 0 & 0 & 0 & 0 \\
\hline Other & 4,144 & 0 & 558 & 21,652 & 0 & 0 \\
\hline $\begin{array}{l}\text { (Less) Energy for Pumping .................................... } \\
\text { Total Not Generation }\end{array}$ & 0 & 0 & 0 & 0 & 0 & 0 \\
\hline 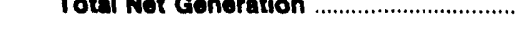 & 4,144 & 0 & 558 & 97,213 & 0 & 0 \\
\hline 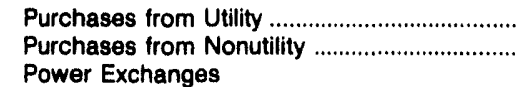 & $\begin{array}{r}335,182 \\
0\end{array}$ & $\begin{array}{r}529,262 \\
0\end{array}$ & $\begin{array}{r}266,546 \\
0\end{array}$ & $\begin{array}{r}141,852 \\
0\end{array}$ & $\begin{array}{r}157,285 \\
0\end{array}$ & $\begin{array}{r}207,900 \\
0\end{array}$ \\
\hline 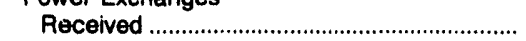 & 133,804 & 128,583 & 0 & 297,002 & 0 & 0 \\
\hline 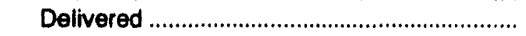 & 81,699 & 69,203 & 0 & 13,987 & 0 & 0 \\
\hline Net Exchanges .................................................... & 52,106 & 59,380 & 0 & 283,015 & 0 & 0 \\
\hline \multicolumn{7}{|l|}{ Transmission for Others (Wheeling) } \\
\hline 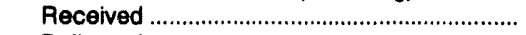 & 0 & 0 & 0 & 0 & 0 & 0 \\
\hline Delivered .......... & 0 & 0 & 0 & 0 & 0 & 0 \\
\hline Net Transmission for Others & 0 & 0 & 0 & 0 & 0 & 0 \\
\hline $\begin{array}{l}\text { Transmission by Others Losses ...................................... } \\
\text { Total Not Energy }\end{array}$ & 0 & 0 & 0 & 0 & 0 & 0 \\
\hline Generated and Received ........................... & 391,432 & 588,642 & 267,104 & 522,080 & 157,285 & 207,900 \\
\hline \multicolumn{7}{|l|}{ Dleposition of Energy } \\
\hline 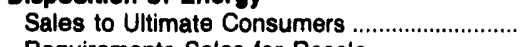 & 369,705 & 541,219 & 242,139 & 449,741 & 141,768 & 192,600 \\
\hline Requirements Sales for Resale ...................... & & 632 & 1,329 & 36,434 & 0 & \\
\hline Nonrequirements Sales for Resale ................. & 0 & 0 & 0 & 0 & 0 & 0 \\
\hline Furnished Without Charge ......................................... & 11 & 0 & 0 & 0 & 0 & 200 \\
\hline Used by Utility (excluding station use) ............. & 1,869 & 803 & 1,420 & 5,815 & 273 & 400 \\
\hline Losses & $\begin{array}{r}19,847 \\
391,432\end{array}$ & $\begin{array}{r}45,988 \\
588,642\end{array}$ & $\begin{array}{r}22,216 \\
267,104\end{array}$ & $\begin{array}{r}30,090 \\
522,080\end{array}$ & $\begin{array}{r}15,244 \\
157,285\end{array}$ & $\begin{array}{r}14,700 \\
207,900\end{array}$ \\
\hline
\end{tabular}

Note: Totals may not equal sum of components because of independent rounding. Double counting occurs in components of both sources and disposition of energy and thus neither provides a true total. Purchases from utilities, net interchanges, and net wheeling (except for imports) are included in net generation. Sales for resale is included in sales to ultimate consumers.

Source: Energy Information Administration, Form EIA-412, "Annual Report of Public Electric Utilities." 
Table 26. Electric Energy Account by Major U.S. Publicly Owned Electric Utility Within State, 1992 (Continued)

(Megawatthours)

\begin{tabular}{|c|c|c|c|c|c|c|}
\hline Item & $\begin{array}{l}\text { Massachusetts } \\
\text { Westfield } \\
\text { City of } \\
\text { December } 31\end{array}$ & $\begin{array}{c}\text { Michigan } \\
\text { Bay } \\
\text { City City of } \\
\text { June } 30\end{array}$ & $\begin{array}{l}\text { Michigan } \\
\text { Coldwater } \\
\text { Board } \\
\text { of } \\
\text { Public Util } \\
\text { June } 30\end{array}$ & $\begin{array}{l}\text { Michigan } \\
\text { Detroit } \\
\text { City of } \\
\text { June } 30\end{array}$ & $\begin{array}{c}\text { Michigan } \\
\begin{array}{c}\text { Grand Haven } \\
\text { City of }\end{array} \\
\text { June } 30\end{array}$ & $\begin{array}{l}\text { Michigan } \\
\text { Hillsdale } \\
\text { Board } \\
\text { of } \\
\text { Public Wks } \\
\text { June } 30\end{array}$ \\
\hline \multicolumn{7}{|l|}{ Sources of Energy } \\
\hline Nuclear & 0 & 0 & 0 & 0 & 0 & 0 \\
\hline 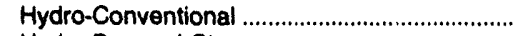 & 0 & 0 & 0 & 0 & 0 & 0 \\
\hline Hydro-Pumped Storage ........................................ & 0 & 0 & 0 & 0 & 0 & 0 \\
\hline Other & 0 & 863 & 11,599 & 0 & 66,460 & 4,057 \\
\hline 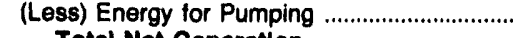 & 0 & 0 & 0 & 0 & 0 & 0 \\
\hline 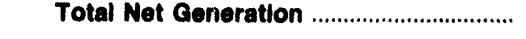 & $\mathbf{0}$ & 883 & 11,599 & 298,172 & 403,627 & 4,057 \\
\hline 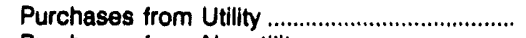 & 285,895 & 253,159 & 135,407 & 419,470 & 12,055 & 130,425 \\
\hline $\begin{array}{l}\text { Purchases from Nonutility ...................................... } \\
\text { Power Exchanges }\end{array}$ & 0 & 0 & 0 & 0 & 0 & 0 \\
\hline Received & 0 & 0 & 0 & 0 & 0 & 0 \\
\hline 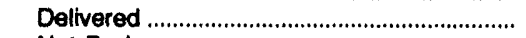 & 0 & 0 & 0 & 0 & 0 & 0 \\
\hline Net Exchanges & 0 & 0 & 0 & 0 & 0 & 0 \\
\hline \multicolumn{7}{|l|}{ Transmission for Others (Wheeling) } \\
\hline 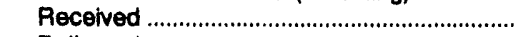 & 0 & 0 & 0 & 0 & 0 & 0 \\
\hline Delivered & 0 & 0 & 0 & 0 & 0 & 0 \\
\hline 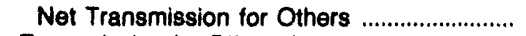 & 0 & 0 & 0 & 0 & 0 & 0 \\
\hline $\begin{array}{l}\text { Transmission by Others Losses ......................... } \\
\text { Total Not Energy }\end{array}$ & 0 & 0 & 0 & 0 & 0 & 0 \\
\hline Generated and Recelved .......................... & 285,895 & 254,022 & 147,006 & 717,642 & 415,682 & 134,482 \\
\hline \multicolumn{7}{|l|}{ Dieposition of Energy } \\
\hline 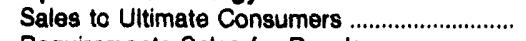 & 263,023 & 239,442 & 135,956 & 557,404 & 275,853 & 125,634 \\
\hline 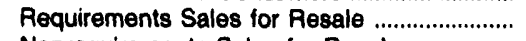 & 7,202 & 0 & 0 & 0 & 131,828 & \\
\hline Nonrequirements Sales for Resale ................... & 0 & 0 & 0 & 0 & 0 & 0 \\
\hline 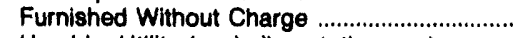 & 0 & 0 & 0 & 118,550 & 0 & 0 \\
\hline Usod by Utility (excluding station use) ............ & 650 & 0 & 1,617 & 4,630 & 361 & 0 \\
\hline 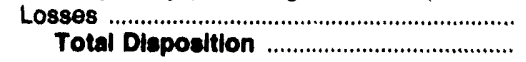 & $\begin{array}{r}15,020 \\
285,895\end{array}$ & $\begin{array}{r}14,580 \\
254,022\end{array}$ & $\begin{array}{r}9,433 \\
147,006\end{array}$ & $\begin{array}{r}37,057 \\
717,642\end{array}$ & $\begin{array}{r}7,640 \\
415,682\end{array}$ & $\begin{array}{r}8,848 \\
134,482\end{array}$ \\
\hline
\end{tabular}

Note: Totals may not equal surn of components because of independent rounding. Double counting occurs in components of both sources and disposition of energy and thus neither provides a true total. Purchases from utilities, net interchanges, and net wheeling (except for imports) are included in net generation. Sales for resale is included in sales to ultimate consumers.

Source: Energy Information Administration. Form EIA-412, "Annual Report of Public Electric Utilities." 
Table 26. Electric Energy Account by Major U.S. Publicly Owned Electric Utility Within State, 1992 (Continued) (Megawatthours)

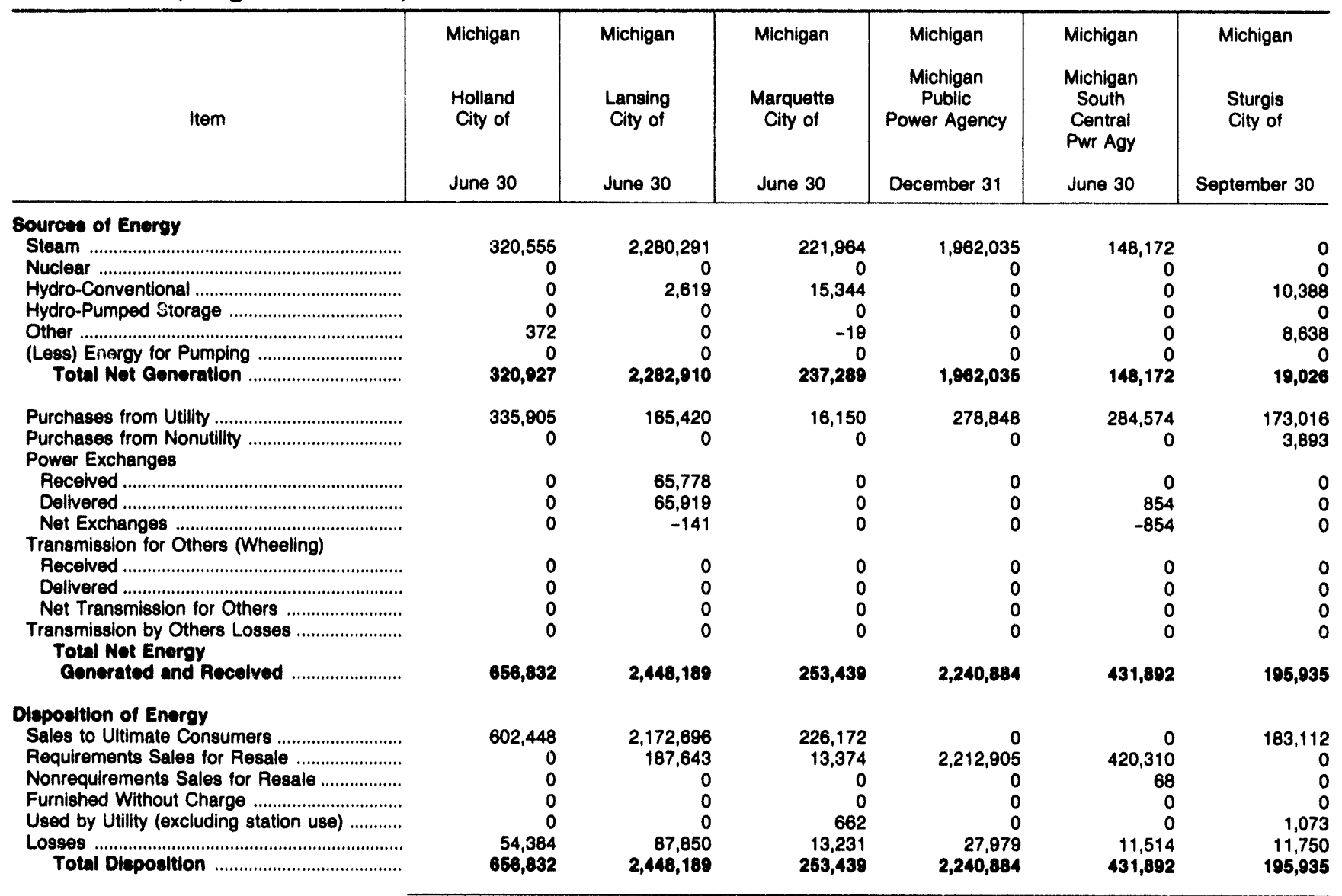

Note: Totals may not equal sum of components because of independent rounding. Double counting occurs in components of both sources and disposition of energy and thus neither provides a true total. Purchases from utilities, net interchanges, and net wheeling (except for imports) are included in net generation. Sales for resale is included in sales to ultimate consumers.

Source: Energy Information Administration. Form EIA-412, "Annual Report of Public Electric Utilities." 
Table 26. Electric Energy Account by Major U.S. Publicly Owned Electric Utility Within State, 1992 (Continued) (Megawatthours)

\begin{tabular}{|c|c|c|c|c|c|c|}
\hline Item & $\begin{array}{c}\text { Michigan } \\
\text { Traverse } \\
\text { City City of } \\
\text { June } 30\end{array}$ & $\begin{array}{l}\text { Michigan } \\
\text { Wyandotte } \\
\text { Municipal } \\
\text { Serv Comm } \\
\text { September } 30\end{array}$ & $\begin{array}{l}\text { Minnesota } \\
\text { Alexandria } \\
\text { City of }\end{array}$ & $\begin{array}{l}\text { Minnesota } \\
\text { Anoka } \\
\text { City of } \\
\text { December } 31\end{array}$ & $\begin{array}{c}\text { Minnesota } \\
\text { Austin } \\
\text { City of } \\
\text { December } 31\end{array}$ & $\begin{array}{l}\text { Minnesota } \\
\text { Brainerd } \\
\text { City of } \\
\text { December } 31\end{array}$ \\
\hline 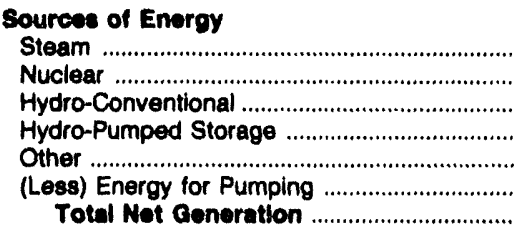 & $\begin{array}{r}75,569 \\
0 \\
0 \\
14,592 \\
0 \\
0 \\
90,161\end{array}$ & $\begin{array}{r}237,540 \\
0 \\
0 \\
0 \\
0 \\
0 \\
237,540\end{array}$ & $\begin{array}{r}0 \\
0 \\
0 \\
0 \\
-388 \\
0 \\
-388\end{array}$ & $\begin{array}{l}0 \\
0 \\
0 \\
0 \\
0 \\
0 \\
0\end{array}$ & $\begin{array}{r}6.936 \\
0 \\
0 \\
0 \\
0 \\
0 \\
6,936\end{array}$ & $\begin{array}{l}0 \\
0 \\
0 \\
0 \\
0 \\
0 \\
0\end{array}$ \\
\hline $\begin{array}{l}\text { Purchases from Utility } \\
\text { Purchases from Nonutility } \\
\text { Power Exchanges } \\
\text { Recelved } \\
\text { Dellvered } \\
\text { Net Exchanges }\end{array}$ & $\begin{array}{r}126,172 \\
0\end{array}$ & $\begin{array}{r}12,903 \\
0\end{array}$ & $\begin{array}{r}172,855 \\
0\end{array}$ & $\begin{array}{r}185,064 \\
0\end{array}$ & $\begin{array}{r}241,559 \\
0\end{array}$ & $\begin{array}{r}140,657 \\
0\end{array}$ \\
\hline 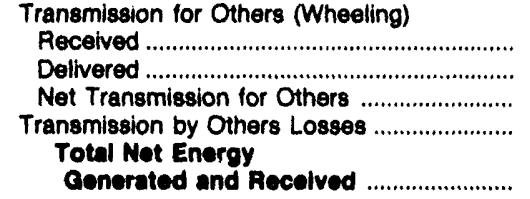 & $\begin{array}{r}0 \\
0 \\
0 \\
0 \\
216,333\end{array}$ & $\begin{array}{r}0 \\
0 \\
0 \\
0\end{array}$ & $\begin{array}{r}0 \\
0 \\
0 \\
0 \\
172,467\end{array}$ & $\begin{array}{r}0 \\
0 \\
0 \\
0 \\
185,064\end{array}$ & $\begin{array}{l}0 \\
0 \\
0 \\
0\end{array}$ & 140,657 \\
\hline 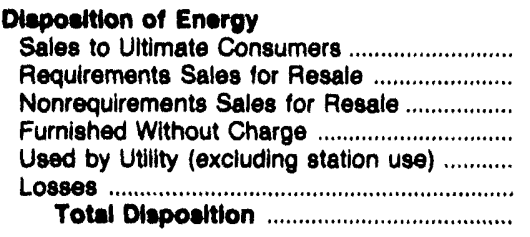 & $\begin{array}{r}208,041 \\
0 \\
0 \\
0 \\
0 \\
8,292 \\
216,333\end{array}$ & $\begin{array}{r}211,647 \\
0 \\
0 \\
0 \\
25,397 \\
13,399 \\
250,443\end{array}$ & $\begin{array}{r}159,099 \\
0 \\
0 \\
0 \\
0 \\
13,368 \\
172,467\end{array}$ & $\begin{array}{r}193,449 \\
0 \\
0 \\
0 \\
0 \\
-8,385 \\
185,064\end{array}$ & $\begin{array}{r}227,786 \\
6,836 \\
0 \\
0 \\
374 \\
13,399 \\
248,496\end{array}$ & $\begin{array}{r}127,408 \\
0 \\
0 \\
0 \\
1,619 \\
11,630 \\
140,667\end{array}$ \\
\hline
\end{tabular}

Note: Totals may not equal sum of components because of independent rounding. Double counting occurs in components of both sources and disposition of energy and thus neither provides a true total. Purchases from utilities, net interchanges, and net wheeling (except for imports) are included in net generation. Sales for resale is included in sales to ultimate consumers.

Source: Energy Information Administration, Form ElA-412, "Annual Report of Public Electric Utilities." 
Table 26. Electric Energy Account by Major U.S. Publicly Owned Electric Utillty Within State, 1992 (Continued) (Megawatthours)

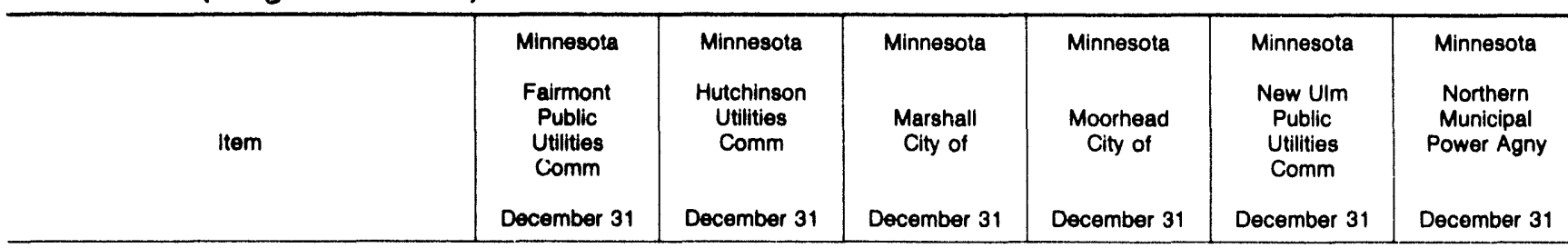

\section{Sourcee of Energy}

\section{Steam}

Nuclear

Hydro-Conventional

Hydro-Pumped Storage

Other

(Less) Energy for Pumping Total Not Ceneration

Purchases from Utility

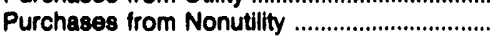

Power Exchanges

Recelved.

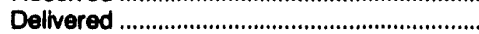

Net Exchanges

Transmission for Others (Wheeling)

Recelved.

Delivered ...............

Net Transmission for Others

Transmiseion by Others Loseos

Total Not Eneroy

Cenerated and Recolved

Diepocition of Enorgy

Sales to Uitimate Consumers

Requirements Sales for Resale

Nonrequirements Sales for Resale

Furnished Without Charge

Used by Utllity (excluding station use) ............

Losses

Total Diepostion

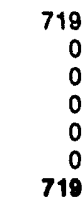

152,055

055
0

0

0

0

0

0

0

162,774

146,097

718
0
0
0
5,958
152,774

0
0
0
0
29,959
0
29,950

224,955

0

0

0
0

0

0
0
0

0

254,014

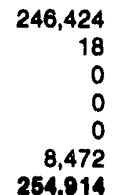

0
0
0
0
82
0
82

310,133

302$$
\begin{aligned}
& 0 \\
& 0 \\
& 0
\end{aligned}
$$$$
\begin{aligned}
& 0 \\
& 0 \\
& 0 \\
& 0
\end{aligned}
$$

10,517

305,337

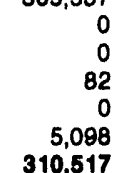

58,231

231
0

0

0

58,238

103,546

330,406

0

0
0

0

0

0
0

0

0
0

0
0

161,774

718,084

330,406

313,530

313,530
0
0
0
0
16,876
330,406

716,084

0

0

Note: Totals may not equal sum of components because of independent rounding. Double counting occurs in components of both sources and disposition of energy and thus neither provides a true total. Purchases from utilities, net interchanges, and net wheeling (except for imports) are included in net generation. Sales for resale is included in sales to ultimate consumers.

Source: Energy Information Administration, Form EIA-412, "Annual Report of Public Electric Utilities." 
Table 26. Electric Energy Account by Major U.S. Publicly Owned Electric Utility Within State, 1992 (Continued)

(Megawatthours)

\begin{tabular}{|c|c|c|c|c|c|c|}
\hline Item & $\begin{array}{c}\text { Minnesota } \\
\text { Owatonna } \\
\text { City of } \\
\text { Jecember } 31\end{array}$ & $\begin{array}{c}\text { Minnesota } \\
\text { Rochester } \\
\text { Public } \\
\text { Utilities } \\
\text { December } 31\end{array}$ & $\begin{array}{c}\text { Minnesota } \\
\text { Southern } \\
\text { Minnesota } \\
\text { Mun P } \\
\text { Agny } \\
\text { December } 31\end{array}$ & $\begin{array}{c}\text { Minnesota } \\
\text { Western } \\
\text { Minnesota } \\
\text { Mun } \\
\text { Pwr Agny } \\
\text { December } 31\end{array}$ & $\begin{array}{c}\text { Minnesota } \\
\text { Willmar } \\
\text { Municipal } \\
\text { Utils Comm } \\
\text { December } 31\end{array}$ & $\begin{array}{l}\text { Mississippi } \\
\text { Aberdeen } \\
\text { City of } \\
\text { June } 30\end{array}$ \\
\hline \multicolumn{7}{|l|}{ Sources of Enorgy } \\
\hline Steam & 0 & 199,079 & $2,161,584$ & $1,948,290$ & 25,220 & 0 \\
\hline Nuclear & 0 & 0 & $\begin{array}{r}0.1,004 \\
0\end{array}$ & $\begin{array}{r}1,040,200 \\
0\end{array}$ & $\begin{array}{r}20,2<0 \\
0\end{array}$ & 0 \\
\hline 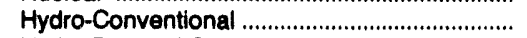 & 0 & 15,253 & 0 & 0 & 0 & 0 \\
\hline 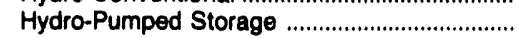 & 0 & 0 & 0 & 0 & 0 & 0 \\
\hline Other & 0 & 541 & 0 & 0 & 0 & 0 \\
\hline 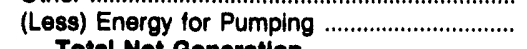 & 0 & 0 & 0 & 0 & 0 & 0 \\
\hline 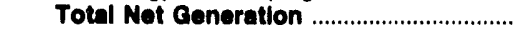 & 0 & 214,873 & $2,161,584$ & $1,948,290$ & 25,220 & $\mathbf{0}$ \\
\hline 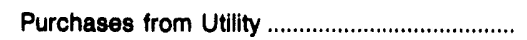 & 225,828 & 873,060 & 290,292 & 168 & 171,355 & 157,479 \\
\hline $\begin{array}{l}\text { Purchases from Nonutility ....................................... } \\
\text { Power Exchanges }\end{array}$ & 0 & 0 & 8,017 & 0 & 0 & $\begin{array}{r}101,470 \\
0\end{array}$ \\
\hline 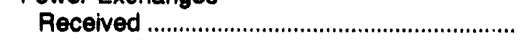 & 0 & 0 & 0 & 0 & 0 & 0 \\
\hline Delivered & 0 & 0 & 0 & 0 & 0 & 0 \\
\hline 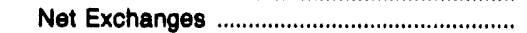 & 0 & 0 & 0 & 0 & 0 & 0 \\
\hline \multicolumn{7}{|l|}{ Transmission for Others (Wheeling) } \\
\hline 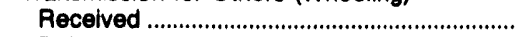 & 0 & 0 & 0 & 0 & 0 & 0 \\
\hline 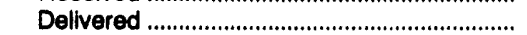 & 0 & 0 & 0 & 0 & 0 & 0 \\
\hline 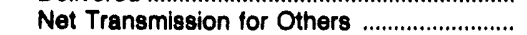 & 0 & 0 & 0 & 0 & 0 & 0 \\
\hline 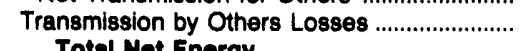 & 0 & 0 & 0 & 0 & 0 & 0 \\
\hline $\begin{array}{l}\text { Total Net Energy } \\
\text { Generated and Recelved } \ldots . . . . . . . . . . . . . . . . .\end{array}$ & 225,828 & $1,087,933$ & $2,459,893$ & $1,948,468$ & 196,575 & 157,479 \\
\hline \multicolumn{7}{|l|}{ Dieposttion of Energy } \\
\hline Sales to Ultimate Consumers .......................... & 211,373 & 853,536 & 0 & 0 & 182,531 & 151,456 \\
\hline Requirements Sales for Resale ......................... & 0 & 199,620 & $2,394,509$ & $1,948,458$ & 0 & \\
\hline Nonrequirements Sales for Resale .................... & 0 & 0 & 0 & 0 & 0 & 0 \\
\hline 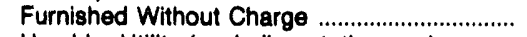 & 6,848 & 0 & 0 & 0 & 2,409 & 0 \\
\hline Used by Utility (excluding station use) ............ & 0 & 2,401 & 0 & 0 & 2,062 & 80 \\
\hline $\begin{array}{l}\text { Losses } \\
\text { Total Diepoaltion }\end{array}$ & $\begin{array}{r}7,607 \\
225,828\end{array}$ & $\begin{array}{r}32,376 \\
1,087,933\end{array}$ & $\begin{array}{r}65,384 \\
2,459,893\end{array}$ & $\begin{array}{r}0 \\
1,948,458\end{array}$ & $\begin{array}{r}9,573 \\
196,575\end{array}$ & $\begin{array}{r}5,943 \\
157,470\end{array}$ \\
\hline
\end{tabular}

Note: Totals may not equal sum of components because of independent rounding. Double counting occurs in components of both sources and disposition of energy and thus neither provides a true total. Purchases from utilities, net interchanges, and net wheeling (except for imports) are included in net generation. Sales for resale is included in sales to ultimate consumers.

Source: Energy Information Administration, Form EIA-412, "Annual Report of Public Electric Utilities." 
Table 26. Electric Energy Account by Major U.S. Publicly Owned Electric Utility Within State, 1992 (Continued)

(Megawatthours)

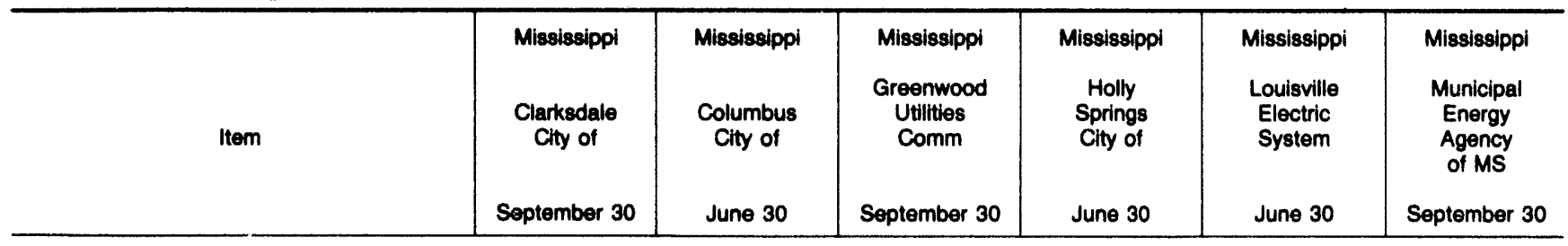

\section{Sourees of Energy}

Steam

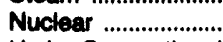

Hydro-Conventional

Hydro-Pumped Storage

Other

(Less) Energy for Pumping

Totel Mol Ceneration

78,311

Purchases from Utility

Purchases from Nonutility

Power Exchanges

Recelved

Delivered ..................................................

Net Exchanges

Transmission for Others (Wheeling)

Received

Delivered

Net Transmission for Others

Tranamission by Others Losses

Total Net Energy

Cenerated and Recelved

Diepoettion of Energy

Sales to Ultimate Consumers

Requirements Sales for Resale

Nonrequirements Sales for Resale

Furnished Without Charge

Used by Utility (excluding station use)

Losses

Total Diepoaltion
0
0

0

78,311

178,476

0

444,087

0

0
0

0
0
0
0

266,787

$444,08 ?$

161,011

78,311

0

0
17,465

256,787

436,252

436,252
0
0

88
7,747

444,087

$\begin{array}{rr}11,508 & 0 \\ 0 & 0 \\ 0 & 0 \\ 0 & 0 \\ 0 & 0 \\ 0 & 0 \\ 11,508 & 0\end{array}$

260,726

204,445
0

0

0
0
0

0

0
0
0

0

272,234

\section{6,938}

0
0

1,709

23,587

272,234
204,445

190,378

13,758

204,445
155,117

0

772,493

0
0
0

(

0

0
0
0

155,117

772,493

148,287

0
0

772,498

115

6,715

155,117

$\begin{array}{ll}0 & 0 \\ 0 & 0 \\ 0 & 0 \\ 0 & 0 \\ 0 & 0 \\ 0 & 0 \\ 0 & 0\end{array}$

Note: Totals may not equal sum of components because of independent rounding. Double counting occurs in components of both sources and disposition of energy and thus neither provides a true total. Purchases from utilities, net interchanges, and net wheeling (except for imports) are included in net generation. Sales for resale is included in sales to ultimate consumers.

Source: Energy Information Administration, Form ElA-412, "Annual Report of Public Electric Utilities." 
Table 26. Electric Energy Account by Major U.S. Publicly Owned Electric Utility Within State, 1992 (Continued) (Megawatthours)

\begin{tabular}{|c|c|c|c|c|c|c|}
\hline Item & $\begin{array}{l}\text { Mississippi } \\
\text { New Albany } \\
\text { City of } \\
\text { June } 30\end{array}$ & $\begin{array}{l}\text { Mississippi } \\
\text { Oxford } \\
\text { City of } \\
\text { June } 30\end{array}$ & $\begin{array}{l}\text { Mississippi } \\
\text { Starkville } \\
\text { City of } \\
\text { June } 30\end{array}$ & $\begin{array}{l}\text { Mississippi } \\
\text { Tupelo } \\
\text { City of } \\
\text { June } 30\end{array}$ & $\begin{array}{l}\text { Mississippi } \\
\text { West } \\
\text { Point } \\
\text { City of } \\
\\
\text { June } 30\end{array}$ & $\begin{array}{l}\text { Missouri } \\
\text { Carthage } \\
\text { City of } \\
\text { June } 30\end{array}$ \\
\hline 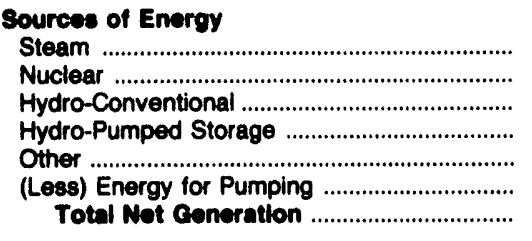 & $\begin{array}{l}0 \\
0 \\
0 \\
0 \\
0 \\
0 \\
0\end{array}$ & $\begin{array}{l}0 \\
0 \\
0 \\
0 \\
0 \\
0 \\
0\end{array}$ & $\begin{array}{l}0 \\
0 \\
0 \\
0 \\
0 \\
0 \\
0\end{array}$ & $\begin{array}{l}0 \\
0 \\
0 \\
0 \\
0 \\
0 \\
0\end{array}$ & $\begin{array}{l}0 \\
0 \\
0 \\
0 \\
0 \\
0 \\
0\end{array}$ & $\begin{array}{r}0 \\
0 \\
0 \\
0 \\
-193 \\
0 \\
-193\end{array}$ \\
\hline 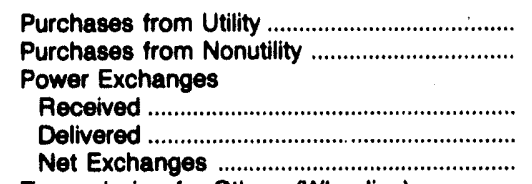 & $\begin{array}{r}221,626 \\
0\end{array}$ & $\begin{array}{r}142,141 \\
0 \\
0 \\
0 \\
0\end{array}$ & $\begin{array}{r}312,833 \\
0\end{array}$ & $\begin{array}{r}601,344 \\
0 \\
0\end{array}$ & $\begin{array}{r}180,529 \\
0 \\
0\end{array}$ & $\begin{array}{r}184,905 \\
0\end{array}$ \\
\hline 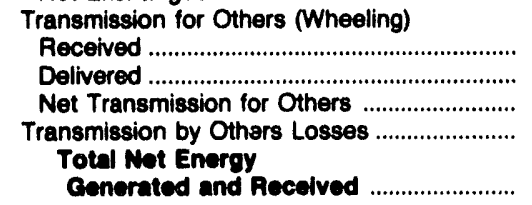 & $\begin{array}{l}0 \\
0 \\
0 \\
0\end{array}$ & $\begin{array}{l}0 \\
0 \\
0 \\
0\end{array}$ & 312,833 & $\begin{array}{l}0 \\
0 \\
0 \\
0\end{array}$ & $\begin{array}{r}0 \\
0 \\
0 \\
0 \\
180,529\end{array}$ & $\begin{array}{r}0 \\
0 \\
0 \\
-7,910 \\
176,802\end{array}$ \\
\hline 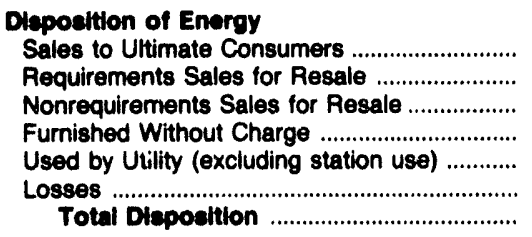 & $\begin{array}{r}203,490 \\
0 \\
0 \\
0 \\
183 \\
17,952 \\
221,626\end{array}$ & $\begin{array}{r}133,467 \\
0 \\
0 \\
0 \\
92 \\
8,582 \\
142,141\end{array}$ & $\begin{array}{r}297,976 \\
0 \\
0 \\
199 \\
0 \\
14,657 \\
312,833\end{array}$ & $\begin{array}{r}583,572 \\
0 \\
0 \\
0 \\
346 \\
17,425 \\
601,344\end{array}$ & $\begin{array}{r}179,193 \\
0 \\
0 \\
0 \\
0 \\
1,335 \\
180,520\end{array}$ & $\begin{array}{r}171,348 \\
0 \\
0 \\
0 \\
0 \\
5,454 \\
176,802\end{array}$ \\
\hline
\end{tabular}

Note: Totals may not equal sum of components because of independent rounding. Double counting occurs in components of both sources and disposition of energy and thus neither provides a true total. Purchases from utilities, net interchanges, and net wheeling (except for imports) are included in net generation. Sales for resale is included in sales to ultimate consumers.

Source: Energy Information Administration, Form EIA-412, "Annual Report of Public Electric Utilities." 


\section{Table 26. Electric Energy Account by Major U.S. Publicly Owned Electric Utillty Within State, 1992 (Continued) (Megawatthours)}

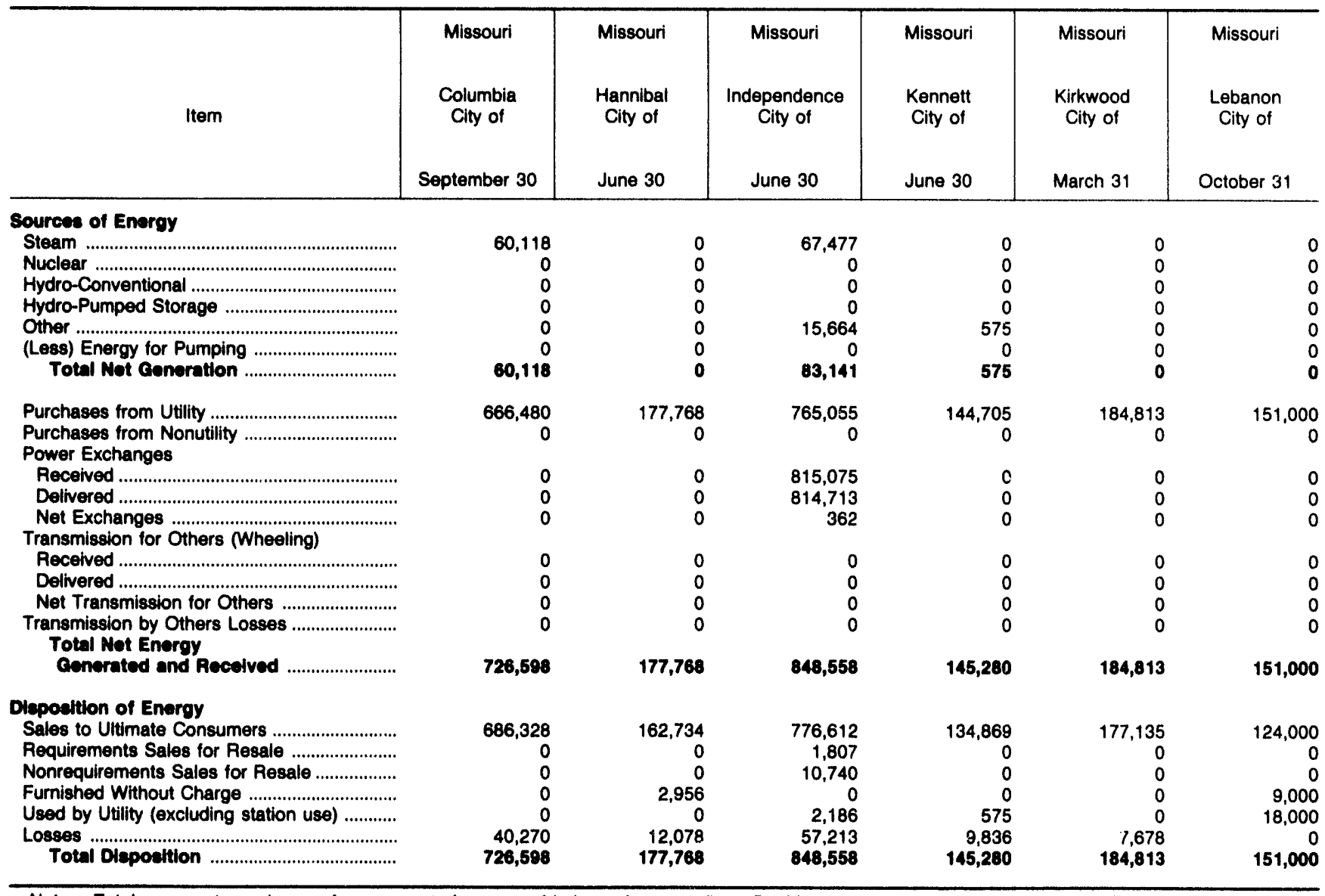

Note: Totals may not equal sum of components because of independent rounding. Double counting occurs in components of both sources and disposition of energy and thus neither provides a true total. Purchases from utilities, net interchanges, and net wheeling (except for imports) are included in net generation. Sales for resale is included in sales to ultimate consumers.

Source: Energy Information Administration, Form ElA-412, "Annual Report of Public Electric Utilities." 
Table 26. Electric Energy Account by Major U.S. Publicly Owned Electric Utility Within State, 1992 (Continued)

(Megawatthours)

\begin{tabular}{|c|c|c|c|c|c|c|}
\hline Item & $\begin{array}{l}\text { Missouri } \\
\text { Marshall } \\
\text { City of } \\
\text { September } 30\end{array}$ & $\begin{array}{l}\text { Missouri } \\
\text { Monett } \\
\text { City of } \\
\text { March } 31\end{array}$ & $\begin{array}{l}\text { Missouri } \\
\text { Poplar } \\
\text { Bluff } \\
\text { City of } \\
\text { December } 31\end{array}$ & $\begin{array}{l}\text { Missouri } \\
\text { Rolla } \\
\text { City of } \\
\text { September } 30\end{array}$ & $\begin{array}{l}\text { Missouri } \\
\text { Sikeston } \\
\text { City of } \\
\text { May } 31\end{array}$ & $\begin{array}{l}\text { Missouri } \\
\text { Springfield } \\
\text { City of } \\
\text { September } 30\end{array}$ \\
\hline 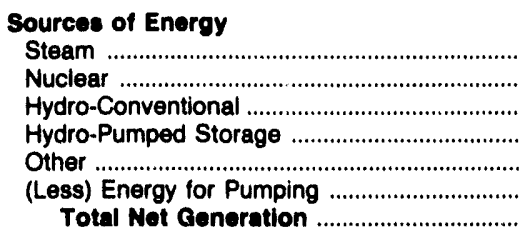 & $\begin{array}{r}59,508 \\
0 \\
0 \\
0 \\
0 \\
0 \\
59,508\end{array}$ & $\begin{array}{l}0 \\
0 \\
0 \\
0 \\
0 \\
0 \\
0\end{array}$ & $\begin{array}{r}0 \\
0 \\
0 \\
0 \\
555 \\
0 \\
555\end{array}$ & $\begin{array}{l}0 \\
0 \\
0 \\
0 \\
0 \\
0 \\
0\end{array}$ & $\begin{array}{r}1,372,997 \\
0 \\
0 \\
0 \\
0 \\
0 \\
1,372,997\end{array}$ & $\begin{array}{r}1,793,876 \\
0 \\
0 \\
0 \\
35,788 \\
0 \\
1,829,664\end{array}$ \\
\hline 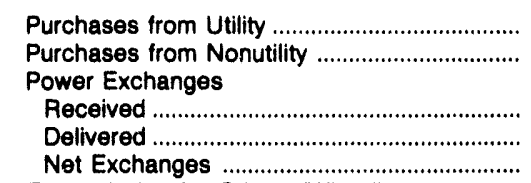 & $\begin{array}{r}71,302 \\
0\end{array}$ & $\begin{array}{r}149,947 \\
0\end{array}$ & $\begin{array}{r}250,811 \\
0\end{array}$ & $\begin{array}{r}194,076 \\
0\end{array}$ & $\begin{array}{r}84,069 \\
0 \\
141,855 \\
64,077 \\
77,778\end{array}$ & $\begin{array}{r}363,031 \\
0 \\
39,997 \\
88,829 \\
-48,832\end{array}$ \\
\hline 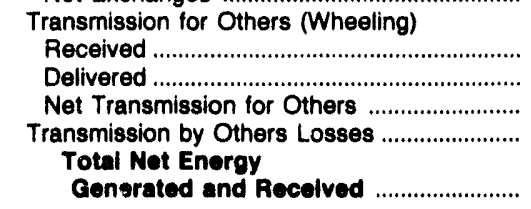 & $\begin{array}{l}0 \\
0 \\
0 \\
0\end{array}$ & $\begin{array}{r}0 \\
0 \\
0 \\
0 \\
149,947\end{array}$ & 251,366 & 194,076 & $\begin{array}{r}0 \\
0 \\
0 \\
0 \\
1,534,844\end{array}$ & $\begin{array}{r}0 \\
0 \\
0 \\
-1,597 \\
2,142,266\end{array}$ \\
\hline 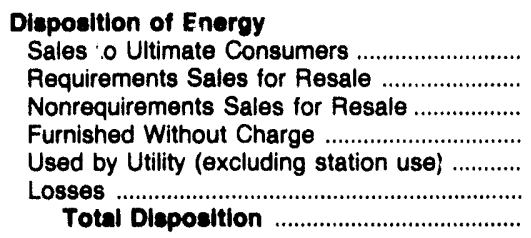 & $\begin{array}{r}123,697 \\
0 \\
0 \\
0 \\
0 \\
7,113 \\
130,810\end{array}$ & $\begin{array}{r}140,692 \\
0 \\
0 \\
0 \\
3,453 \\
5,802 \\
149,947\end{array}$ & $\begin{array}{r}227,285 \\
0 \\
0 \\
5,122 \\
10 \\
18,949 \\
251,366\end{array}$ & $\begin{array}{r}181,203 \\
0 \\
0 \\
1,523 \\
2,263 \\
9,087 \\
194,076\end{array}$ & $\begin{array}{r}235,074 \\
1,290,500 \\
0 \\
0 \\
0 \\
9,270 \\
1,534,844\end{array}$ & $\begin{array}{r}1,951,378 \\
49,766 \\
1,519 \\
28,630 \\
30,288 \\
80,685 \\
2,142,266\end{array}$ \\
\hline
\end{tabular}

Note: Totals may not equal sum of components because of independent rounding. Double counting occurs in components of both sources and disposition of energy and thus neither provides a true total. Purchases from utilities, net interchanges, and net wheeling (except for imports) are included in net generation. Sales for resale is included in sales to ultimate consumers.

Source: Energy Information Administration, Form EIA-412, "Annual Report of Public Electric Utilities." 
Table 26. Electric Energy Account by Major U.S. Publicly Owned Electric Utility Within State, 1992 (Continued)

(Megawatthours)

\begin{tabular}{|c|c|c|c|c|c|c|}
\hline Item & $\begin{array}{l}\text { Nebraska } \\
\text { Central } \\
\text { Nebraska } \\
\text { Pub } \\
\text { P\&I Dist } \\
\text { December } 31\end{array}$ & $\begin{array}{l}\text { Nebraska } \\
\text { Cornhusker } \\
\text { Public } \\
\text { Power Dist } \\
\text { December } 31\end{array}$ & $\begin{array}{l}\text { Nebraska } \\
\text { Dawson } \\
\text { County } \\
\text { Public } \\
\text { Pwr Dist } \\
\text { December } 31\end{array}$ & $\begin{array}{l}\text { Nebraska } \\
\text { Fremont } \\
\text { City of } \\
\text { July } 31\end{array}$ & $\begin{array}{l}\text { Nebraska } \\
\text { Grand Island } \\
\text { City of } \\
\text { July } 31\end{array}$ & $\begin{array}{l}\text { Nebraska } \\
\text { Hastings } \\
\text { City of } \\
\text { December } 31\end{array}$ \\
\hline 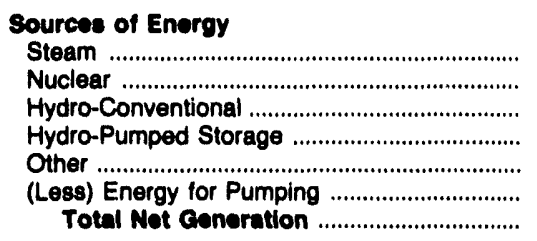 & $\begin{array}{r}0 \\
0 \\
253,110 \\
0 \\
0 \\
0 \\
253,110\end{array}$ & $\begin{array}{l}0 \\
0 \\
0 \\
0 \\
0 \\
0 \\
0\end{array}$ & $\begin{array}{l}0 \\
0 \\
0 \\
0 \\
0 \\
0 \\
0\end{array}$ & $\begin{array}{r}241,938 \\
0 \\
0 \\
0 \\
0 \\
0 \\
241,938\end{array}$ & $\begin{array}{r}496,813 \\
0 \\
0 \\
0 \\
0 \\
0 \\
496,813\end{array}$ & $\begin{array}{r}255,402 \\
0 \\
0 \\
0 \\
521 \\
0 \\
255,923\end{array}$ \\
\hline 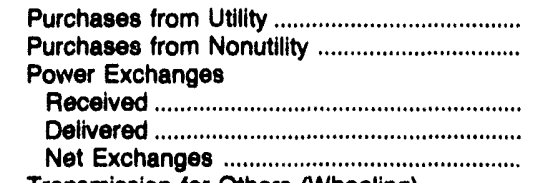 & $\begin{array}{l}0 \\
0 \\
0\end{array}$ & $\begin{array}{r}181,396 \\
0 \\
0 \\
0 \\
0\end{array}$ & $\begin{array}{r}250,884 \\
0\end{array}$ & $\begin{array}{r}59,292 \\
0\end{array}$ & $\begin{array}{r}56,427 \\
0 \\
1,099 \\
1,032 \\
67\end{array}$ & $\begin{array}{r}98,863 \\
0\end{array}$ \\
\hline 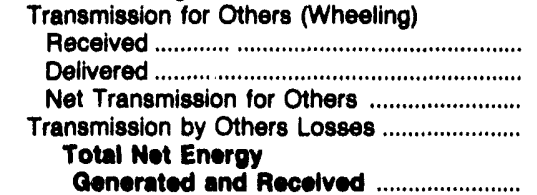 & $\begin{array}{l}0 \\
0 \\
0 \\
0\end{array}$ & $\begin{array}{r}1,986 \\
1,986 \\
0 \\
0\end{array}$ & $\begin{array}{l}0 \\
0 \\
0 \\
0\end{array}$ & $\begin{array}{l}0 \\
0 \\
0 \\
0\end{array}$ & $\begin{array}{r}0 \\
0 \\
0 \\
0 \\
553,307\end{array}$ & $\begin{array}{r}5,228 \\
5,228 \\
0 \\
0 \\
354,786\end{array}$ \\
\hline 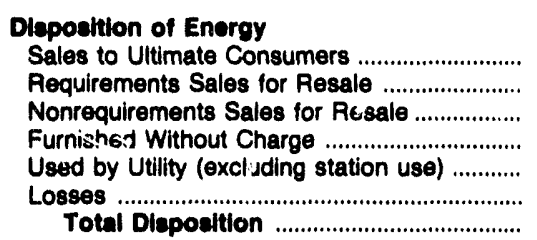 & $\begin{array}{r}0 \\
253,110 \\
0 \\
0 \\
0 \\
0 \\
253,110\end{array}$ & $\begin{array}{r}163,851 \\
1,986 \\
0 \\
0 \\
547 \\
15,012 \\
181,396\end{array}$ & $\begin{array}{r}223,079 \\
4,800 \\
0 \\
0 \\
112 \\
22,793 \\
250,884\end{array}$ & $\begin{array}{r}280,344 \\
0 \\
4,885 \\
4,944 \\
1,636 \\
9,421 \\
301,230\end{array}$ & $\begin{array}{r}459,519 \\
0 \\
78,460 \\
0 \\
0 \\
15,328 \\
553,307\end{array}$ & $\begin{array}{r}241,041 \\
99,685 \\
0 \\
0 \\
0 \\
14,060 \\
354,786\end{array}$ \\
\hline
\end{tabular}

Note: Totals may not equal sum of components because of independent rounding. Double counting occurs in components of both sources and disposition of energy and thus neither provides a true total. Purchases from utilities, net interchang9s, and net wheeling (except for imports) are included in net generation. Sales for resale is included in sales to ultimate consumers.

Source: Energy Information Administration, Form EIA-412, "Annual Report of Public Electric Utilities." 
Table 26. Electric Energy Account by Major U.S. Publicly Owned Electric Utillty Within State, 1992 (Continued) (Megawatthours)

\begin{tabular}{|c|c|c|c|c|c|c|}
\hline Item & $\begin{array}{c}\text { Nebraska } \\
\text { Lincoln } \\
\text { Electric } \\
\text { System } \\
\text { December } 31\end{array}$ & $\begin{array}{c}\text { Nebraska } \\
\text { Loup } \\
\text { River } \\
\text { Public } \\
\text { Power Dist } \\
\text { December } 31\end{array}$ & $\begin{array}{l}\text { Nebraska } \\
\text { Municipal } \\
\text { Energy } \\
\text { Agency } \\
\text { of NE } \\
\text { March } 31\end{array}$ & $\begin{array}{c}\text { Nebraska } \\
\text { Nebraska } \\
\text { Public } \\
\text { Power } \\
\text { District } \\
\text { December } 31\end{array}$ & $\begin{array}{c}\text { Nebraska } \\
\text { Norris } \\
\text { Public } \\
\text { Power } \\
\text { District } \\
\text { December } 31\end{array}$ & $\begin{array}{c}\text { Nebraska } \\
\text { North } \\
\text { Platte } \\
\text { City of } \\
\\
\text { July } 31\end{array}$ \\
\hline \multicolumn{7}{|l|}{ Sources of Energy } \\
\hline Steam & $1,345,658$ & 0 & 183,278 & $6,463,332$ & 0 & 0 \\
\hline 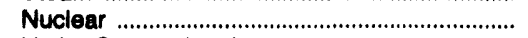 & 0 & 0 & 0 & $6,227,929$ & 0 & 0 \\
\hline 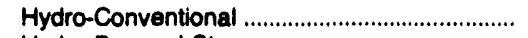 & 0 & 144,070 & 0 & 93,746 & 0 & 0 \\
\hline 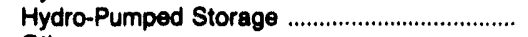 & 0 & 0 & 0 & 0 & 0 & 0 \\
\hline 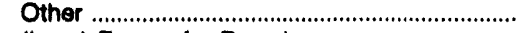 & 3,672 & 0 & 0 & 1,833 & 0 & 0 \\
\hline 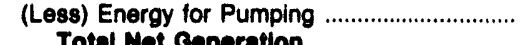 & & $\begin{array}{r}0 \\
14070\end{array}$ & 0 & 0 & 0 & 0 \\
\hline Total Not Generation ................................. & $1,349,330$ & 144,070 & 183,278 & $12,786,840$ & 0 & 0 \\
\hline 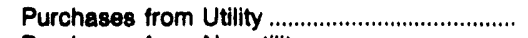 & $1,829,026$ & 712,277 & 733,123 & $1,646,794$ & 400,140 & 211,581 \\
\hline $\begin{array}{l}\text { Purchases from Nonutility ................................... } \\
\text { Power Exchanges }\end{array}$ & 5 & 0 & 0 & 0 & 0 & 0 \\
\hline 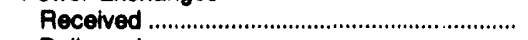 & 0 & 0 & 0 & 63,517 & 0 & 0 \\
\hline 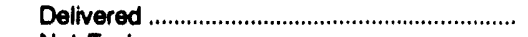 & 129 & 0 & 0 & 72,713 & 0 & 0 \\
\hline Net Exchanges ................................................. & -129 & 0 & 0 & $-9,196$ & 0 & 0 \\
\hline \multicolumn{7}{|l|}{ Transmission for Others (Wheeling) } \\
\hline 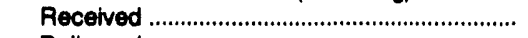 & 105,494 & 0 & 0 & 0 & 0 & 0 \\
\hline 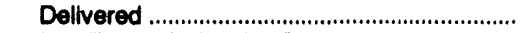 & 105,484 & 0 & 0 & 0 & 0 & 0 \\
\hline 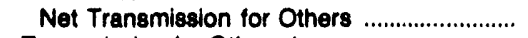 & 0 & 0 & 0 & 0 & 0 & 0 \\
\hline $\begin{array}{l}\text { Transmission by Others Losses ............................ } \\
\text { Total Net Eneroy }\end{array}$ & 0 & 0 & 0 & 0 & 0 & 0 \\
\hline Cenerated and Recelved ........................... & $3,178,232$ & 856,347 & 916,401 & $14,424,438$ & 400,140 & 211,581 \\
\hline \multicolumn{7}{|l|}{ Dlepodition of Enorgy } \\
\hline 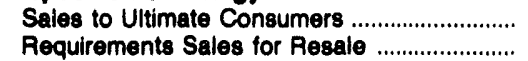 & $\begin{array}{r}2,056,256 \\
80,261\end{array}$ & $\begin{array}{l}433,914 \\
254,493\end{array}$ & $\begin{array}{r}0 \\
873,231\end{array}$ & $\begin{array}{l}2,443,913 \\
5,555,924\end{array}$ & $\begin{array}{r}363,435 \\
13,387\end{array}$ & $\begin{array}{r}198,867 \\
0\end{array}$ \\
\hline Nonrequirements Sales for Resale .................. & 939,142 & 144,070 & 0 & $5,753,568$ & 0 & 0 \\
\hline Furnished Without Charge ............................ & & & 0 & $\begin{array}{r}0 \\
15801\end{array}$ & 0 & 3,020 \\
\hline Used by Utlity (excluding station use) ............ & 4,344 & $\begin{array}{r}1,506 \\
\end{array}$ & $\begin{array}{r}0 \\
0\end{array}$ & $\begin{array}{r}15,691 \\
\end{array}$ & $\begin{array}{r}0 \\
02010\end{array}$ & 532 \\
\hline Los8es & $\begin{array}{r}98,229 \\
3,178,232\end{array}$ & $\begin{array}{r}22,364 \\
856,347\end{array}$ & $\begin{array}{r}43,170 \\
916,401\end{array}$ & $\begin{array}{r}655,342 \\
14,424,438\end{array}$ & $\begin{array}{r}23,318 \\
400,140\end{array}$ & $\begin{array}{r}9,162 \\
211,581\end{array}$ \\
\hline
\end{tabular}

Note: Totals may not equal sum of components because of independent rounding. Double counting occurs in components of both sources and disposition of energy and thus nelther provides a true total. Purchases from utilities, net interchanges, and net wheeling (except for imports) are included in net generation. Sales for resale is included in sales to ultimate consumers.

Source: Energy Information Administration, Form EIA-412, "Annual Report of Public Electric Utilities." 
Table 26. Electric Energy Account by Major U.S. Publicly Owned Electric Utility Within State, 1992 (Continued)

(Megawatthours)

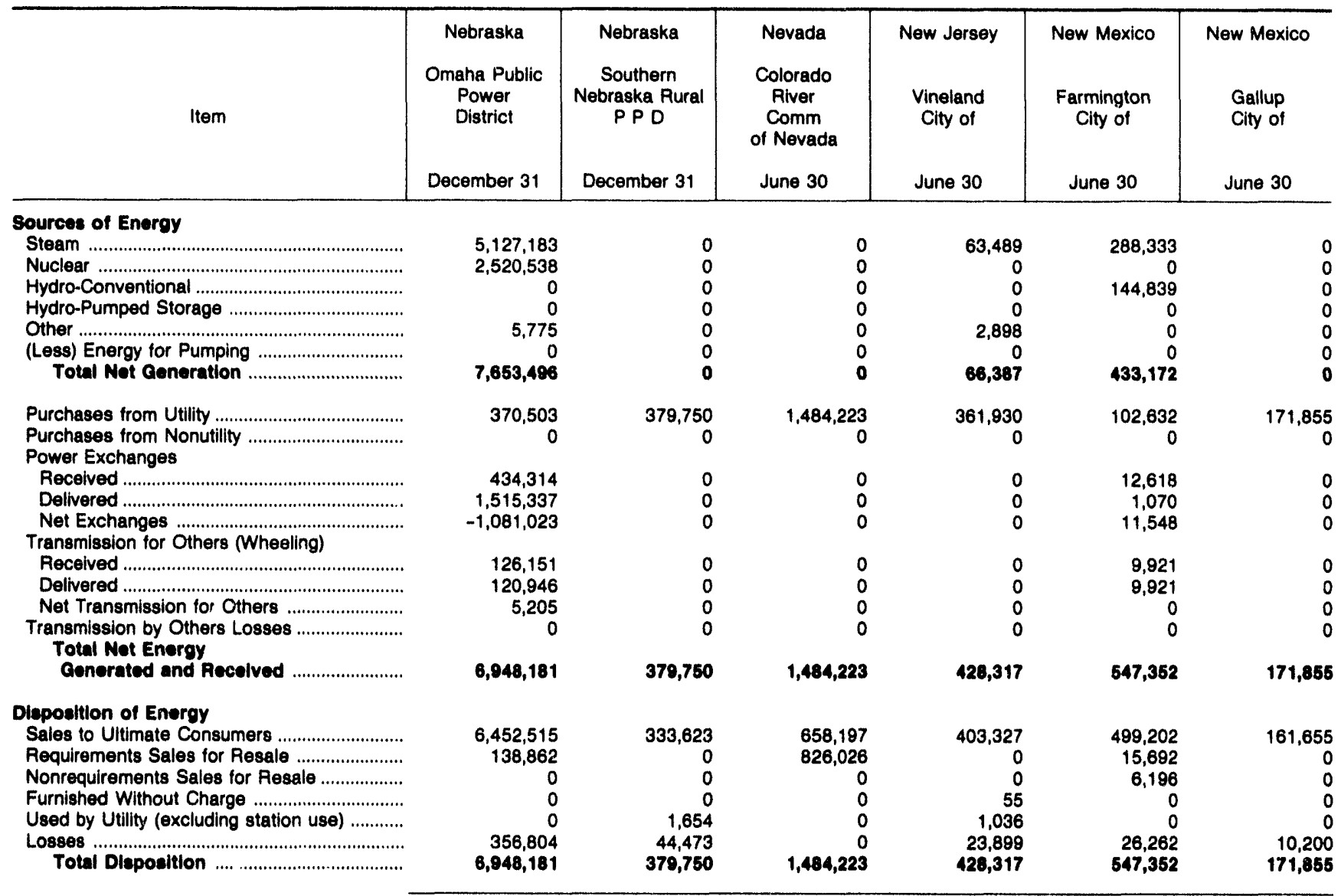

Note: Totals may not equal sum of components because of independent rounding. Double counting occurs in components of both sources and disposition of energy and thus neither provides a true total. Purchases from utilities, net interchanges, and net wheeling (except for imports) are included in net generation. Sales for resale is included in sales to ultimate consumers.

Source: Energy Information Administration, Form ElA-412, "Annual Report of Public Electric Utilities." 
Table 26. Electric Energy Account by Major U.S. Publicly Owned Electric Utility Within State, 1992 (Continued)

(Megawatthours)

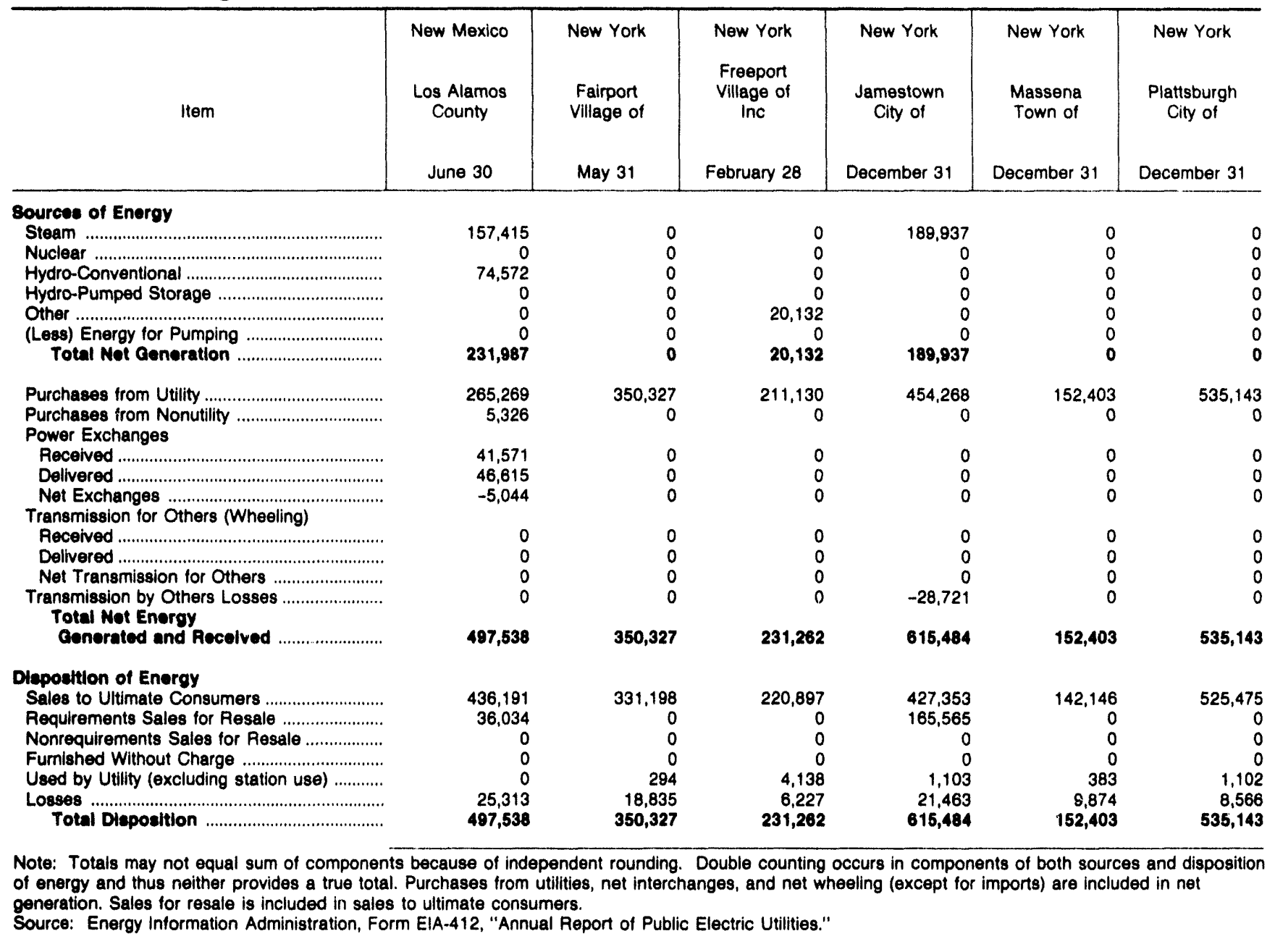


Table 26. Electric Energy Account by Major U.S. Publicly Owned Electric Utillty Within State, 1992 (Continued)

(Megawatthours)

\begin{tabular}{|c|c|c|c|c|c|c|}
\hline Item & $\begin{array}{c}\text { New York } \\
\text { Power } \\
\text { Authority } \\
\text { of State of NY } \\
\text { December } 31\end{array}$ & $\begin{array}{l}\text { New York } \\
\text { Rockville } \\
\text { Centre } \\
\text { Village of } \\
\text { May } 31\end{array}$ & $\begin{array}{l}\text { North Carolina } \\
\text { Albemarle } \\
\text { City of } \\
\text { June } 30\end{array}$ & $\begin{array}{l}\text { North Carolina } \\
\text { Concord } \\
\text { City of } \\
\text { June } 30\end{array}$ & $\begin{array}{l}\text { North Carolina } \\
\text { Elizabeth } \\
\text { City City of } \\
\text { June } 30\end{array}$ & $\begin{array}{c}\text { North Carolina } \\
\text { Fayetteville } \\
\text { Public } \\
\text { Works Comm } \\
\text { June } 30\end{array}$ \\
\hline \multicolumn{7}{|l|}{ Sources of Energy } \\
\hline Steam & $2,445,011$ & 0 & 0 & 0 & 0 & 0 \\
\hline 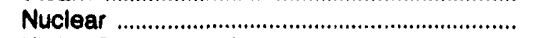 & $4,760,596$ & 0 & 0 & 0 & 0 & 0 \\
\hline 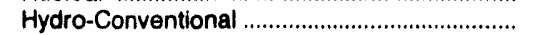 & $22,422,097$ & 0 & 0 & 0 & 0 & 0 \\
\hline 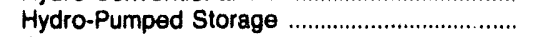 & $1,793,104$ & 0 & 0 & 0 & 0 & 0 \\
\hline Other & 0 & 46,060 & 0 & 0 & 0 & 251,277 \\
\hline 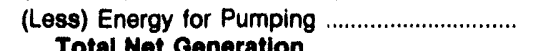 & $2,824,749$ & & 0 & 0 & 0 & $\begin{array}{r}0 \\
05197\end{array}$ \\
\hline & & & & & & \\
\hline 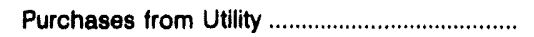 & $5,988,441$ & 134,749 & 258,061 & 374,867 & 231,930 & $1,374,532$ \\
\hline $\begin{array}{l}\text { Purchases from Nonutility .................................... } \\
\text { Power Exchanges }\end{array}$ & 0 & 0 & 0 & 0 & 0 & 0 \\
\hline 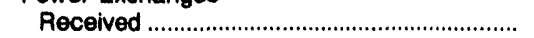 & 366,987 & 0 & 0 & 0 & 0 & 53,577 \\
\hline 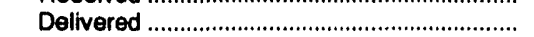 & 294,029 & 0 & 0 & 0 & 0 & 135 \\
\hline 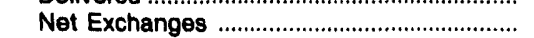 & 72,958 & 0 & 0 & 0 & 0 & 53,442 \\
\hline \multicolumn{7}{|l|}{ Transmission for Others (Wheeling) } \\
\hline 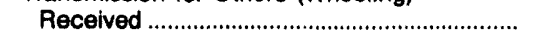 & 212,944 & 0 & 0 & 0 & 0 & 0 \\
\hline 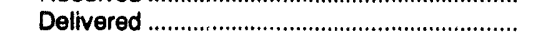 & 208,342 & 0 & 0 & 0 & 0 & 0 \\
\hline 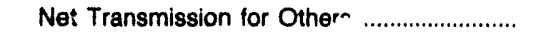 & 4,602 & 0 & 0 & 0 & 0 & 0 \\
\hline Transmission by Others Losses ........................ & 0 & 0 & 0 & 0 & 0 & 0 \\
\hline 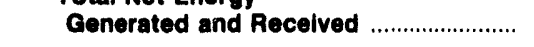 & $34,662,060$ & 180,809 & 258,061 & 374,867 & 231,930 & $1,679,251$ \\
\hline \multicolumn{7}{|l|}{ Disposltion of Energy } \\
\hline 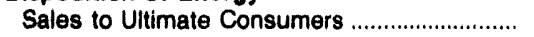 & $13,242,116$ & 171,221 & 240,185 & 347,142 & 214,810 & $1,565,103$ \\
\hline 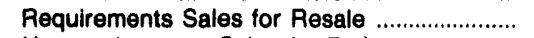 & $3,803,029$ & 0 & 0 & 0 & 0 & \\
\hline Nonrequirements Sales for Resiale .................. & $17,159,313$ & 0 & 0 & 0 & 0 & 843 \\
\hline 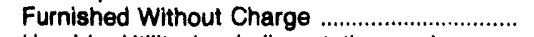 & 6,167 & 0 & 4,005 & 0 & 0 & \\
\hline Used by Utility (excluding station use) ............ & 12,146 & 3,268 & 0 & 3,536 & 0 & 23,500 \\
\hline $\begin{array}{l}\text { Losses } \\
\text { Total Disposition }\end{array}$ & $\begin{array}{r}439,289 \\
34,662,060\end{array}$ & $\begin{array}{r}6,320 \\
180,809\end{array}$ & $\begin{array}{r}13,871 \\
268,061\end{array}$ & $\begin{array}{r}24,189 \\
374,867\end{array}$ & $\begin{array}{r}17,120 \\
231,930\end{array}$ & $\begin{array}{r}89,805 \\
1,679,251\end{array}$ \\
\hline
\end{tabular}

Note: Totals may not equal sum of components because of independent rounding. Double counting occurs in components of both sources and disposition of energy and thus neither provides a true total. Purchases from utilities, net interchanges, and net wheeling (except for imports) are included in net generation. Sales for resale is included in sales to ultimate consumers.

Source: Energy Information Administration, Form ElA-412, "Annual Report of Public Electric Utilities." 
Table 26. Electric Energy Account by Major U.S. Publicly Owned Electric Utility Within State, 1992 (Continued)

(Megawatthours)

\begin{tabular}{|c|c|c|c|c|c|c|}
\hline Item & $\begin{array}{l}\text { North Carolina } \\
\text { Gastonia } \\
\text { City of } \\
\text { June } 30\end{array}$ & $\begin{array}{l}\text { North Carolina } \\
\text { Greenville } \\
\text { Utilities } \\
\text { Comm } \\
\text { June } 30\end{array}$ & $\begin{array}{l}\text { North Carolina } \\
\text { High } \\
\text { Point } \\
\text { Town } \\
\text { of } \\
\text { June } 30\end{array}$ & $\begin{array}{l}\text { North Carolina } \\
\text { Kinston } \\
\text { City of } \\
\text { June } 30\end{array}$ & $\begin{array}{l}\text { North Carolina } \\
\text { Lexington } \\
\text { City of } \\
\text { June } 30\end{array}$ & $\begin{array}{l}\text { North Carolina } \\
\text { Lumberton } \\
\text { City of } \\
\text { June } 30\end{array}$ \\
\hline \multicolumn{7}{|l|}{ Sources of Energy } \\
\hline 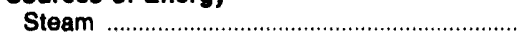 & 0 & 0 & 0 & 0 & 0 & 0 \\
\hline 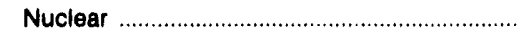 & 0 & 0 & 0 & 0 & 0 & 0 \\
\hline 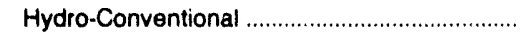 & 0 & 0 & 0 & 0 & 0 & 0 \\
\hline Hydro-Pumped Storage & 0 & 0 & 0 & 0 & 0 & 0 \\
\hline Other & 0 & 0 & 0 & 0 & 0 & 0 \\
\hline (Less) Energy for Pumping .................................. & 0 & 0 & 0 & 0 & 0 & 0 \\
\hline 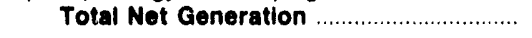 & 0 & 0 & $\mathbf{0}$ & 0 & $\mathbf{0}$ & $\mathbf{0}$ \\
\hline 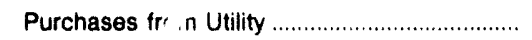 & 597,479 & $1,047,000$ & 805,481 & 416,870 & 424,061 & 266,620 \\
\hline $\begin{array}{l}\text { Purchases from Nonutility .................................. } \\
\text { Power Exchanges }\end{array}$ & 0 & 0 & 0 & 0 & 0 & 0 \\
\hline 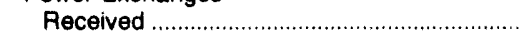 & 0 & 0 & 0 & 0 & 0 & 0 \\
\hline 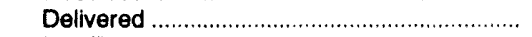 & 0 & 0 & 0 & 0 & 0 & 0 \\
\hline 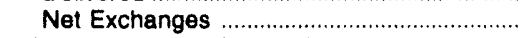 & 0 & 0 & 0 & 0 & 0 & 0 \\
\hline \multicolumn{7}{|l|}{ Transmission for Others (Wheeling) } \\
\hline 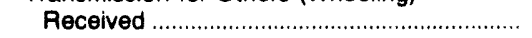 & 0 & 0 & 0 & 0 & 0 & 0 \\
\hline 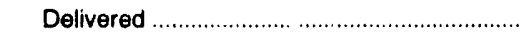 & 0 & 0 & 0 & 0 & 0 & 0 \\
\hline 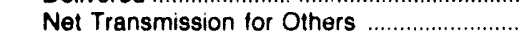 & 0 & 0 & 0 & 0 & 0 & 0 \\
\hline 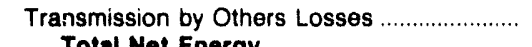 & 0 & 0 & 0 & 0 & 0 & 0 \\
\hline $\begin{array}{l}\text { Total Net Energy } \\
\text { Generated and Received } \ldots \ldots \ldots \ldots \ldots \ldots \ldots \ldots \ldots\end{array}$ & 597,479 & $1,047,000$ & 805,481 & 416,870 & 424,061 & 266,620 \\
\hline \multicolumn{7}{|l|}{ Disposition of Energy } \\
\hline Sales to Uitimate Consumers ............................. & 581,347 & 988,749 & 759,365 & 390,190 & 409,412 & 252,446 \\
\hline 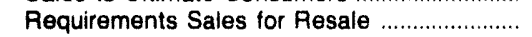 & 0 & 23,700 & 0 & 0 & 0 & 0 \\
\hline 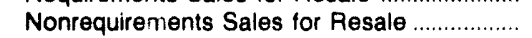 & 0 & 0 & 0 & 0 & 0 & 0 \\
\hline Furnished Without Charge & 0 & 0 & 0 & 0 & 0 & 3,088 \\
\hline Used by Utility (excluding station use) ............ & 0 & 0 & 0 & 0 & 0 & 0 \\
\hline $\begin{array}{l}\text { Losses . } \\
\text { Total Disposition }\end{array}$ & $\begin{array}{r}16,132 \\
597,479\end{array}$ & $\begin{array}{r}34,551 \\
1,047,000\end{array}$ & $\begin{array}{r}46,116 \\
805,481\end{array}$ & $\begin{array}{r}26,680 \\
416,870\end{array}$ & $\begin{array}{r}14,649 \\
424,081\end{array}$ & $\begin{array}{r}11,086 \\
286,620\end{array}$ \\
\hline
\end{tabular}


Table 26. Electric Energy Account by Major U.S. Publicly Owned Electric Utillty Within State, 1992 (Continued)

(Megawatthours)

\begin{tabular}{|c|c|c|c|c|c|c|}
\hline Item & $\begin{array}{l}\text { North Carolina } \\
\text { Monroe } \\
\text { City of } \\
\text { June } 30\end{array}$ & $\begin{array}{l}\text { North Carolina } \\
\text { Morganton } \\
\text { City of } \\
\text { June } 30\end{array}$ & $\begin{array}{l}\text { North Carolina } \\
\text { Murphy } \\
\text { City of } \\
\text { June } 30\end{array}$ & $\begin{array}{l}\text { North Carolina } \\
\text { New Bern } \\
\text { City of } \\
\text { June } 30\end{array}$ & $\begin{array}{c}\text { North Carolina } \\
\text { New River } \\
\text { Light } \\
\& \\
\text { Power Co } \\
\text { December } 31\end{array}$ & $\begin{array}{l}\text { North Carolina } \\
\text { North } \\
\text { Carolina } \\
\text { Eastern M P A } \\
\text { December } 31\end{array}$ \\
\hline \multicolumn{7}{|l|}{ Sources of Energy } \\
\hline Steam ……….............. & 0 & 0 & 0 & 0 & 0 & $1,535,168$ \\
\hline 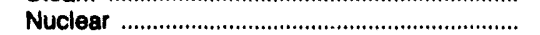 & 0 & 0 & 0 & 0 & 0 & $1,447,611$ \\
\hline 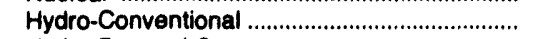 & 0 & 0 & 0 & 0 & 0 & 0 \\
\hline 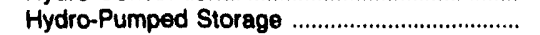 & 0 & 0 & 0 & 0 & 0 & 0 \\
\hline Other & 0 & 0 & 0 & 0 & 0 & 0 \\
\hline (Less) Energy for Pumping ..................................... & 0 & 0 & 0 & 0 & 0 & 0 \\
\hline 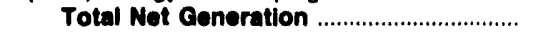 & 0 & 0 & 0 & 0 & 0 & $2,982,779$ \\
\hline Purchases from Utility. & 401,180 & 272,269 & 146,259 & 360,214 & 165,753 & $3,020,814$ \\
\hline $\begin{array}{l}\text { Purchases from Nonutility ..................................... } \\
\text { Power Exchanges }\end{array}$ & 0 & 0 & 0 & 0 & 0 & 0 \\
\hline 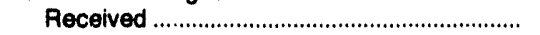 & 0 & 0 & 0 & 0 & 0 & 0 \\
\hline 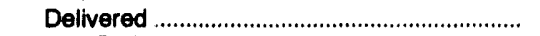 & 0 & 0 & 0 & 0 & 0 & 0 \\
\hline 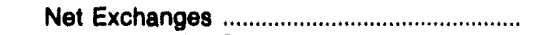 & 0 & 0 & 0 & 0 & 0 & 0 \\
\hline \multicolumn{7}{|l|}{ Transmission for Others (Wheeling) } \\
\hline 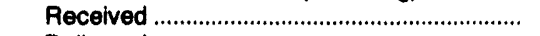 & 0 & 0 & 0 & 0 & 0 & 0 \\
\hline Delivered ......... & 0 & 0 & 0 & 0 & 0 & 0 \\
\hline Net Transmission for Others ....... & 0 & 0 & 0 & 0 & 0 & 0 \\
\hline 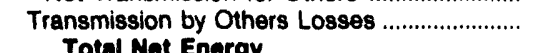 & 0 & 0 & 0 & 0 & 0 & 0 \\
\hline Gonerated and Recelved ........................ & 401,180 & 272,269 & 146,259 & 360,214 & 165,753 & $6,003,593$ \\
\hline \multicolumn{7}{|l|}{ Diaposition of Energy } \\
\hline Sales to Ultimate Consumers ................................ & 376,709 & 255,636 & 140,946 & 334,999 & 160,204 & 0 \\
\hline Requirements Sales for Resale ........................ & & 0 & 0 & 0 & 0 & $5,899,408$ \\
\hline Nonrequirements Sales for Resale ...................... & 0 & 0 & 0 & 0 & 0 & 0 \\
\hline Furnished Without Charge ……............................... & 0 & 1.115 & 0 & 0 & 0 & 0 \\
\hline Used by Utility (excluding station use) ............. & 0 & 0 & 207 & 3,602 & 0 & 0 \\
\hline Losses & 24,471 & 15,518 & 5,105 & 21,613 & 5,549 & 104,185 \\
\hline Total Disposition ............................................... & 401,180 & 272,269 & 146,259 & 360,214 & 165,753 & $6,003,593$ \\
\hline
\end{tabular}

Note: Totals may not equal sum of components because of independent rounding. Double counting occurs in components of both sources and disposition of energy and thus neither provides a true total. Purchases from utilities, net interchanges, and net wheeling (except for imports) are included in net generation. Sales for resale is included in sales to ultimate consumers.

Source: Energy Information Administration, Form EIA-412, "Annual Report of Public Electric Utilities." 
Table 26. Electric Energy Account by Major U.S. Publicly Owned Electric Utility Within State, 1992 (Continued)

(Megawatthours)

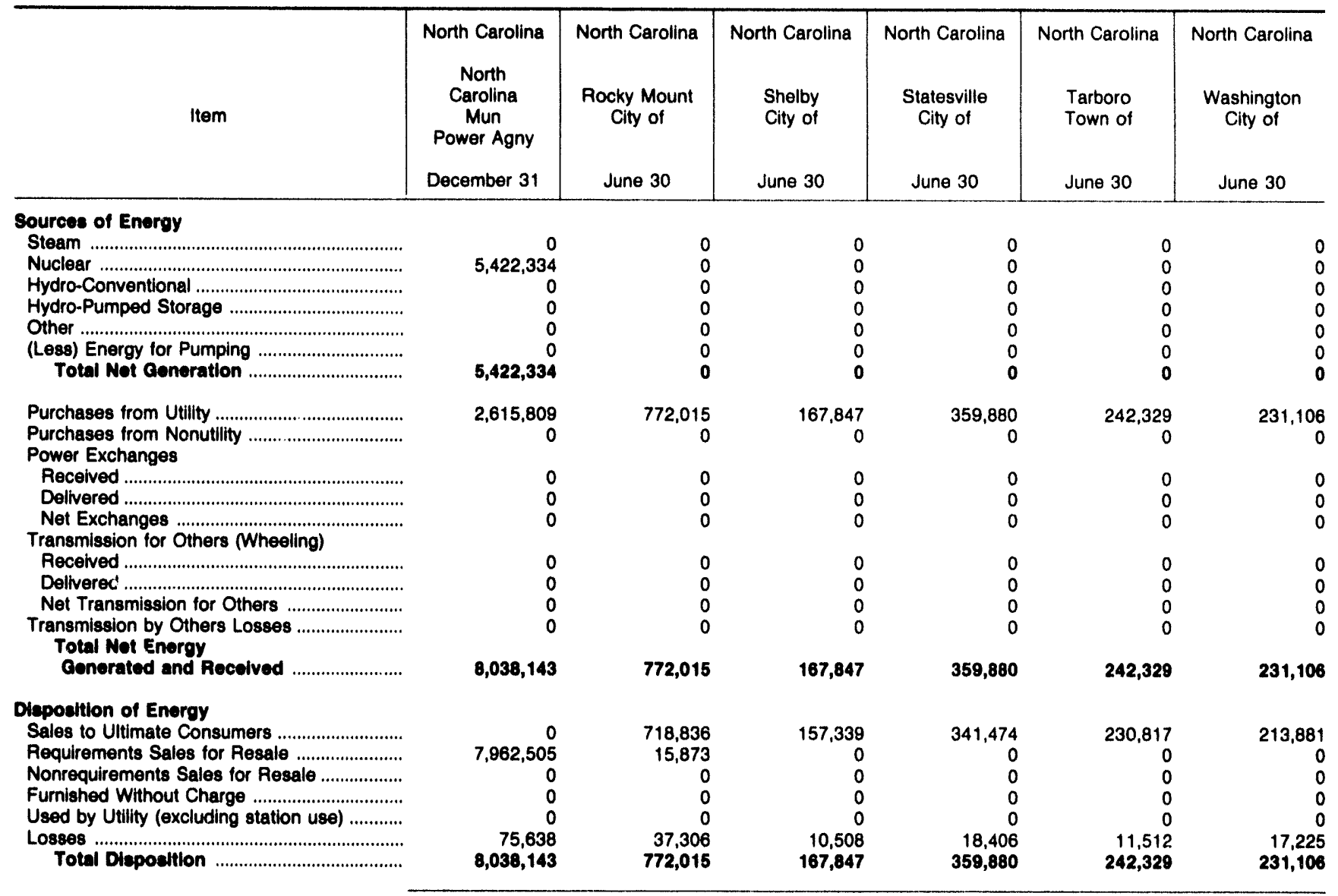

Note: Totals may not equal sum of components because of independent rounding. Double counting occurs in components of both sources and disposition of energy and thus neither provides a true total. Purchases from utilities, net interchanges, and net wheeling (except for imports) are included in net generation. Sales for resale is included in sales to ultimate consumers.

Source: Energy Information Administration, Form EIA-412, "Annual Report of Public Electric Utilities." 
Table 26. Electric Energy Account by Major U.S. Publicly Owned Electric Utility Within State, 1992 (Continued)

(Megawatthours)

\begin{tabular}{|c|c|c|c|c|c|c|}
\hline Item & $\begin{array}{l}\text { North Carolina } \\
\text { Wilson } \\
\text { City of } \\
\text { June } 30\end{array}$ & $\begin{array}{l}\text { Ohio } \\
\text { American } \\
\text { Mun } \\
\text { Power } \\
\text { Ohio Inc } \\
\text { December } 31\end{array}$ & $\begin{array}{l}\text { Ohio } \\
\text { Bowling } \\
\text { Green } \\
\text { City of } \\
\text { December } 31\end{array}$ & $\begin{array}{l}\text { Onio } \\
\text { Bryan } \\
\text { City of } \\
\text { Dovember } 31\end{array}$ & $\begin{array}{l}\text { Ohio } \\
\text { Celina } \\
\text { City of } \\
\text { December } 31\end{array}$ & $\begin{array}{l}\text { Ohlo } \\
\text { Cleveland } \\
\text { City of } \\
\text { December } 31\end{array}$ \\
\hline 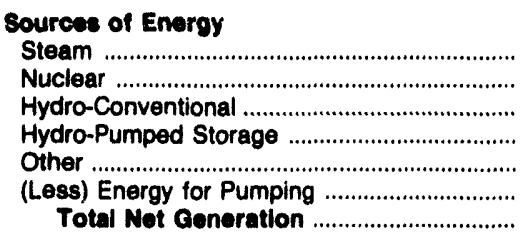 & $\begin{array}{l}0 \\
0 \\
0 \\
0 \\
0 \\
0 \\
0\end{array}$ & $\begin{array}{r}1,429,634 \\
0 \\
0 \\
0 \\
47 \\
0 \\
1,428,681\end{array}$ & $\begin{array}{l}0 \\
0 \\
0 \\
0 \\
0 \\
0 \\
0\end{array}$ & $\begin{array}{r}0 \\
0 \\
0 \\
0 \\
-545 \\
0 \\
-545\end{array}$ & $\begin{array}{l}0 \\
0 \\
0 \\
0 \\
0 \\
0 \\
0\end{array}$ & $\begin{array}{r}0 \\
0 \\
0 \\
0 \\
2,924 \\
0 \\
2,024\end{array}$ \\
\hline 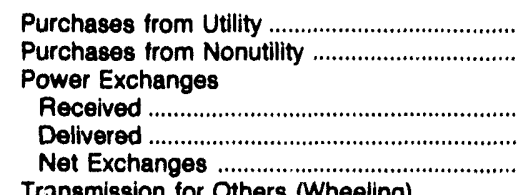 & $\begin{array}{r}964,449 \\
0\end{array}$ & $\begin{array}{r}3,014,188 \\
0\end{array}$ & $\begin{array}{r}280,308 \\
0\end{array}$ & $\begin{array}{r}193,545 \\
0\end{array}$ & $\begin{array}{r}154,454 \\
0\end{array}$ & $\begin{array}{r}883,313 \\
0\end{array}$ \\
\hline 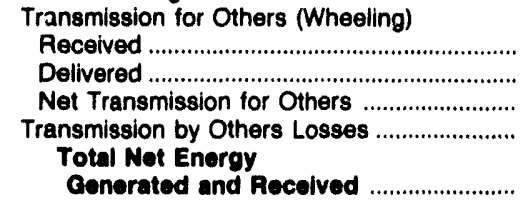 & $\begin{array}{l}0 \\
0 \\
0 \\
0\end{array}$ & $\begin{array}{r}149,389 \\
149,389 \\
0 \\
0\end{array}$ & $\begin{array}{l}0 \\
0 \\
0 \\
0\end{array}$ & $\begin{array}{l}0 \\
0 \\
0 \\
0\end{array}$ & $\begin{array}{l}0 \\
0 \\
0 \\
0\end{array}$ & $\begin{array}{l}0 \\
0 \\
0 \\
0\end{array}$ \\
\hline 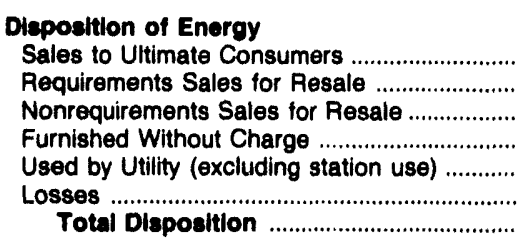 & $\begin{array}{r}850,715 \\
56,166 \\
0 \\
0 \\
0 \\
57,568 \\
964,449\end{array}$ & $\begin{array}{r}584,907 \\
3,730,661 \\
0 \\
0 \\
0 \\
128,301 \\
4,443,869\end{array}$ & $\begin{array}{r}262,364 \\
0 \\
3,454 \\
3,541 \\
158 \\
10,791 \\
280,308\end{array}$ & $\begin{array}{r}189,696 \\
0 \\
0 \\
2,306 \\
29 \\
969 \\
193,000\end{array}$ & $\begin{array}{r}142,268 \\
0 \\
0 \\
2,222 \\
368 \\
9,596 \\
154,454\end{array}$ & $\begin{array}{r}800,986 \\
0 \\
0 \\
1,944 \\
0 \\
83,307 \\
886,237\end{array}$ \\
\hline
\end{tabular}

Note: Totals may not equal sum of components because of independent rounding. Double counting occurs in components of both sources and disposition of energy and thus neither provides a true total. Purchases from utilities, net interchanges, and net wheeling (except for imports) are included in net generation. Sales for resale is included in sales to ultimate consumers.

Source: Energy Information Administration, Form ElA-412, "Annual Report of Public Electric Utilities." 
Table 26. Electric Energy Account by Major U.S. Publicly Owned Electric Utility Within State, 1992 (Continued)

(Megawatthours)

\begin{tabular}{|c|c|c|c|c|c|c|}
\hline Item & $\begin{array}{l}\text { Ohio } \\
\text { Columbus } \\
\text { City of } \\
\text { December } 31\end{array}$ & $\begin{array}{c}\text { Ohio } \\
\text { Cuyahoga } \\
\text { Falls } \\
\text { City of } \\
\text { December } 31\end{array}$ & $\begin{array}{c}\text { Ohio } \\
\text { Dover } \\
\text { City of } \\
\text { December } 3\end{array}$ & $\begin{array}{l}\text { Ohio } \\
\text { Hamilton } \\
\text { City of } \\
\text { Docember } 31\end{array}$ & $\begin{array}{c}\text { Ohio } \\
\text { Nites } \\
\text { City of } \\
\text { December } 31\end{array}$ & $\begin{array}{l}\text { Onio } \\
\text { Orrville } \\
\text { City of } \\
\text { December } 31\end{array}$ \\
\hline \multicolumn{7}{|l|}{ Sources of Energy } \\
\hline (n) & 31,783 & 0 & 66,423 & 201,680 & 0 & 324,234 \\
\hline Nuclear ... & & 0 & 0 & & 0 & \\
\hline Hydro-Conventional .............................................. & 9,379 & 0 & 0 & 360,735 & 0 & \\
\hline 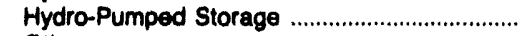 & 0 & 0 & 0 & 0 & 0 & \\
\hline Other & 288,064 & 0 & 0 & -74 & 0 & 0 \\
\hline (Less) Energy for Pumping .................................. & 0 & 0 & 0 & 0 & 0 & \\
\hline 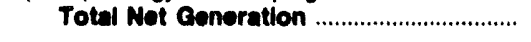 & 329,226 & 0 & 66,423 & 562,341 & 0 & 324,234 \\
\hline 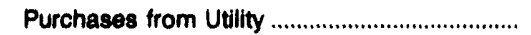 & 288,997 & 289,208 & 106,173 & 67,701 & 248,976 & 59,433 \\
\hline 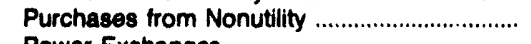 & 0 & 0 & 0 & 0 & 0 & \\
\hline $\begin{array}{l}\text { Power Exchanges } \\
\text { Recelved }\end{array}$ & & & & & & \\
\hline 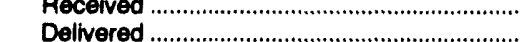 & 0 & 0 & 0 & 10,712 & 0 & \\
\hline Delivered & 0 & 0 & 0 & 18,695 & 0 & \\
\hline \multirow{2}{*}{\multicolumn{7}{|c|}{ Transmission for Others (Wheeling) }} \\
\hline Recelved .......................................... & & & & & & \\
\hline 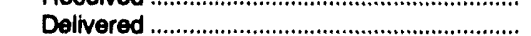 & $\begin{array}{l}298,376 \\
298,376\end{array}$ & $\begin{array}{l}0 \\
0\end{array}$ & 0 & 0 & 0 & $\begin{array}{l}0 \\
0\end{array}$ \\
\hline Net Transmission for Others .... & $\begin{array}{rl}298,36 & 0 \\
0\end{array}$ & $\begin{array}{l}0 \\
0\end{array}$ & $\begin{array}{l}0 \\
0\end{array}$ & 要 & o & $\begin{array}{l}0 \\
0\end{array}$ \\
\hline Transmission by Others Losses ........................... & 0 & 0 & 0 & 0 & 0 & \\
\hline $\begin{array}{l}\text { Total Not Enorgy } \\
\text { Gonerated and Rocelved .......................... }\end{array}$ & & & & & & \\
\hline Conerated and Received ......................... & 618,223 & 289,208 & 172,596 & 622,059 & 248,976 & 383,687 \\
\hline \multicolumn{7}{|l|}{ Diepoeltion of Energy } \\
\hline Sales to Uitimate Consumers .................................. & 576,711 & 261,791 & 172,440 & 463,833 & 220,500 & 229,508 \\
\hline Requirements Sales for Resale ...................... & 988 & 0 & 0 & 44,812 & 0 & 109,450 \\
\hline Nonrequirements Sales for Resale .................. & & & 0 & 38,046 & 0 & \\
\hline Furnished Without Charge ............................... & 0 & 8,662 & 0 & 11,487 & 9,533 & 1,868 \\
\hline Used by Utility (excluding station use) ............ & 1,221 & & 156 & 0 & 43 & 28,614 \\
\hline Losses & 39,303 & 18,755 & 0 & 63,881 & 18,900 & 14,227 \\
\hline Total Dieposition . & 618,223 & 289,208 & 172,596 & 622,059 & 248,976 & 383,667 \\
\hline
\end{tabular}

Note: Totals may not equal sum of components because of independent rounding. Double counting occurs in components of both sources and disposition of energy and thus neither provides a true total. Purchases from utilities, net interchanges, and net wheeling (except for imports) are included in net generation. Sales for resale is included in sales to ultimate consumers.

Source: Energy Information Administration, Form EIA-412, "Annual Report of Public Electric Utilities." 
Table 26. Electric Energy Account by Major U.S. Publicly Owned Electric Utility Within State, 1992 (Continued)

(Megawatthours)

\begin{tabular}{|c|c|c|c|c|c|c|}
\hline Item & $\begin{array}{l}\text { Ohio } \\
\text { Painesville } \\
\text { City of } \\
\text { December } 31\end{array}$ & $\begin{array}{l}\text { Onio } \\
\text { Piqua } \\
\text { City of } \\
\text { December } 31\end{array}$ & $\begin{array}{l}\text { Ohio } \\
\text { St Marys } \\
\text { City of } \\
\text { December } 31\end{array}$ & $\begin{array}{l}\text { Onio } \\
\text { Wadsworth } \\
\text { City of } \\
\text { December } 31\end{array}$ & $\begin{array}{l}\text { Onio } \\
\text { Wapakoneta } \\
\text { City of } \\
\text { December } 31\end{array}$ & $\begin{array}{l}\text { Ohio } \\
\text { Westerville } \\
\text { City of } \\
\text { December } 31\end{array}$ \\
\hline 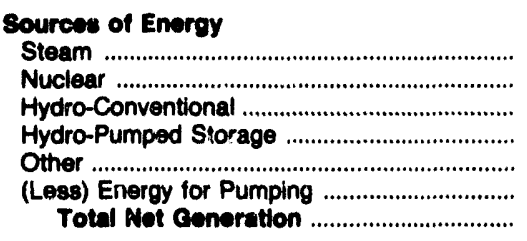 & $\begin{array}{r}111,753 \\
0 \\
0 \\
0 \\
0 \\
0 \\
111,753\end{array}$ & $\begin{array}{r}99,478 \\
0 \\
0 \\
0 \\
0 \\
0 \\
90,478\end{array}$ & $\begin{array}{r}43,652 \\
0 \\
0 \\
0 \\
0 \\
0 \\
0 \\
43,652\end{array}$ & $\begin{array}{l}0 \\
0 \\
0 \\
0 \\
0 \\
0 \\
0\end{array}$ & $\begin{array}{l}0 \\
0 \\
0 \\
0 \\
0 \\
0 \\
0\end{array}$ & $\begin{array}{l}0 \\
0 \\
0 \\
0 \\
0 \\
0 \\
0\end{array}$ \\
\hline 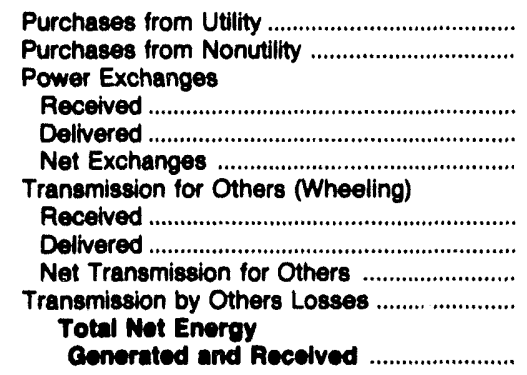 & $\begin{array}{r}77,658 \\
0 \\
\\
1,705 \\
7,465 \\
-5,759\end{array}$ & $\begin{array}{r}151,060 \\
0 \\
0 \\
0 \\
0\end{array}$ & $\begin{array}{r}107,597 \\
954 \\
\\
1.169 \\
1,448 \\
-278\end{array}$ & $\begin{array}{r}195,494 \\
0 \\
0 \\
0 \\
0\end{array}$ & $\begin{array}{r}151,739 \\
0 \\
0 \\
0 \\
0\end{array}$ & $\begin{array}{r}312,649 \\
0 \\
0 \\
0 \\
0 \\
0 \\
0 \\
0 \\
-220 \\
312,420\end{array}$ \\
\hline 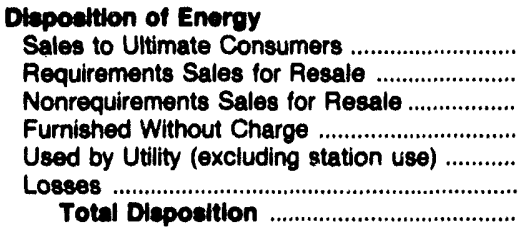 & $\begin{array}{r}168,266 \\
0 \\
0 \\
4,367 \\
0 \\
11,019 \\
183,652\end{array}$ & $\begin{array}{r}235,207 \\
0 \\
0 \\
3,052 \\
0 \\
12,279 \\
250,538\end{array}$ & $\begin{array}{r}138,175 \\
0 \\
4,463 \\
2,402 \\
0 \\
6,884 \\
151,924\end{array}$ & $\begin{array}{r}179,023 \\
0 \\
0 \\
5,791 \\
174 \\
10,506 \\
195,494\end{array}$ & $\begin{array}{r}144,729 \\
0 \\
0 \\
7,010 \\
0 \\
0 \\
151,739\end{array}$ & $\begin{array}{r}296,671 \\
0 \\
0 \\
0 \\
0 \\
15,758 \\
312,429\end{array}$ \\
\hline
\end{tabular}

Note: Totals may not equal sum of components because of independent rounding. Double counting occurs in components of both sources and disposition $\therefore$ ingrgy and thus neither provides a true total. Purchases from utilities, net interchanges, and net wheeling (except for imports) are included in net generation. Sales for resale is included in sales to ultimate consumers.

Source: Energy Information Administration, Form EIA-412, "Annual Report of Public Electric Utilities." 


\section{Table 26. Electric Energy Account by Major U.S. Publicly Owned Electric Utility Within State, 1992 (Continued)}

(Megawatthours)

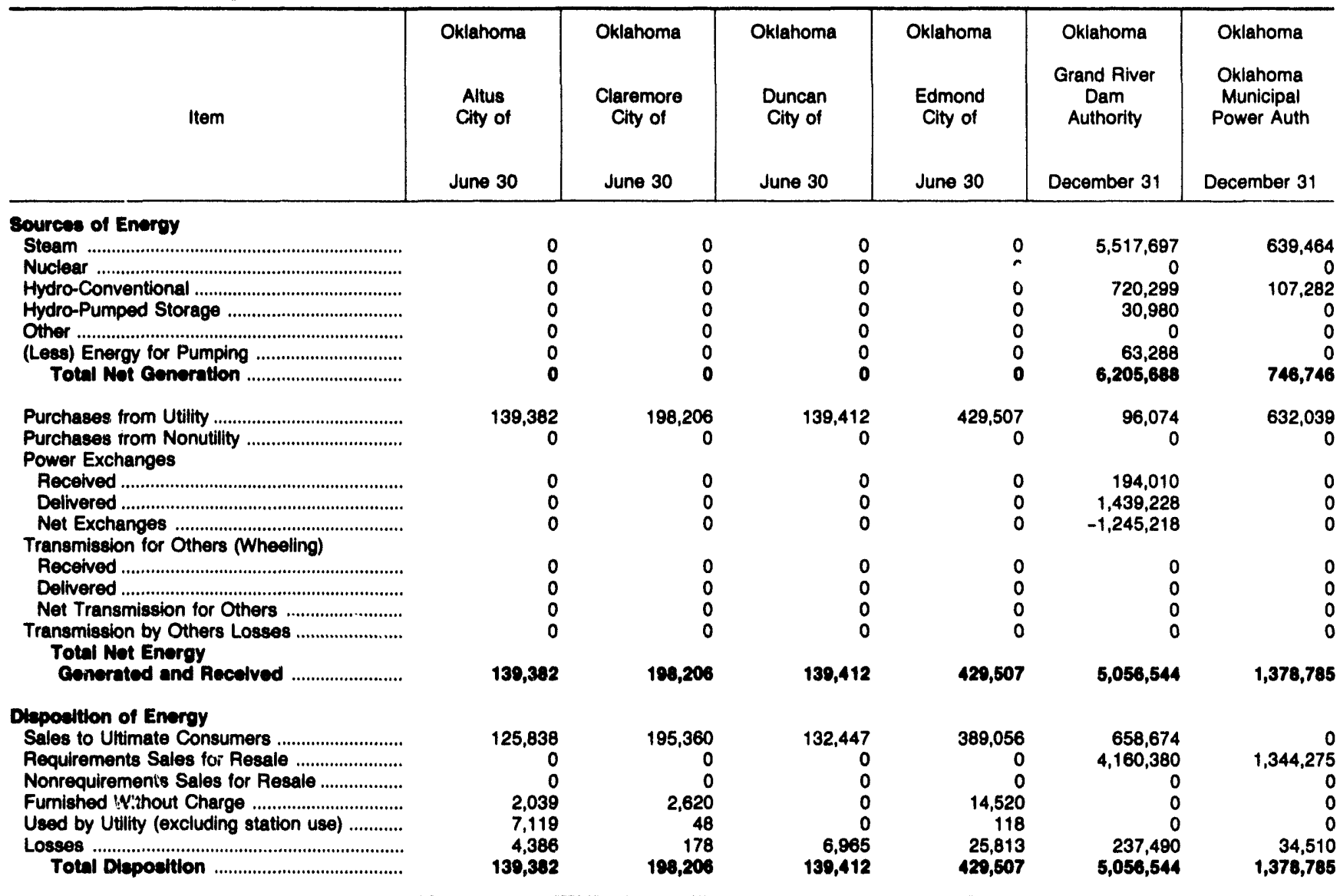

Note: Totals may not equal sum of components because of independent rounding. Double counting occurs in components of both sources and disposition of energy and thus reither provides a true total. Purchases from utilities, net interchanges, and net wheeling (except for imports) are included in net generation. Sales for resaie is included in sales to ultimate consumers.

Source: Energy Information Administration, Form EIA-412, "Annual Report of Public Electric Utilities." 
Table 26. Electric Energy Account by Major U.S. Publicly Owned Electric Utility Within State, 1992 (Continued)

(Megawatthours)

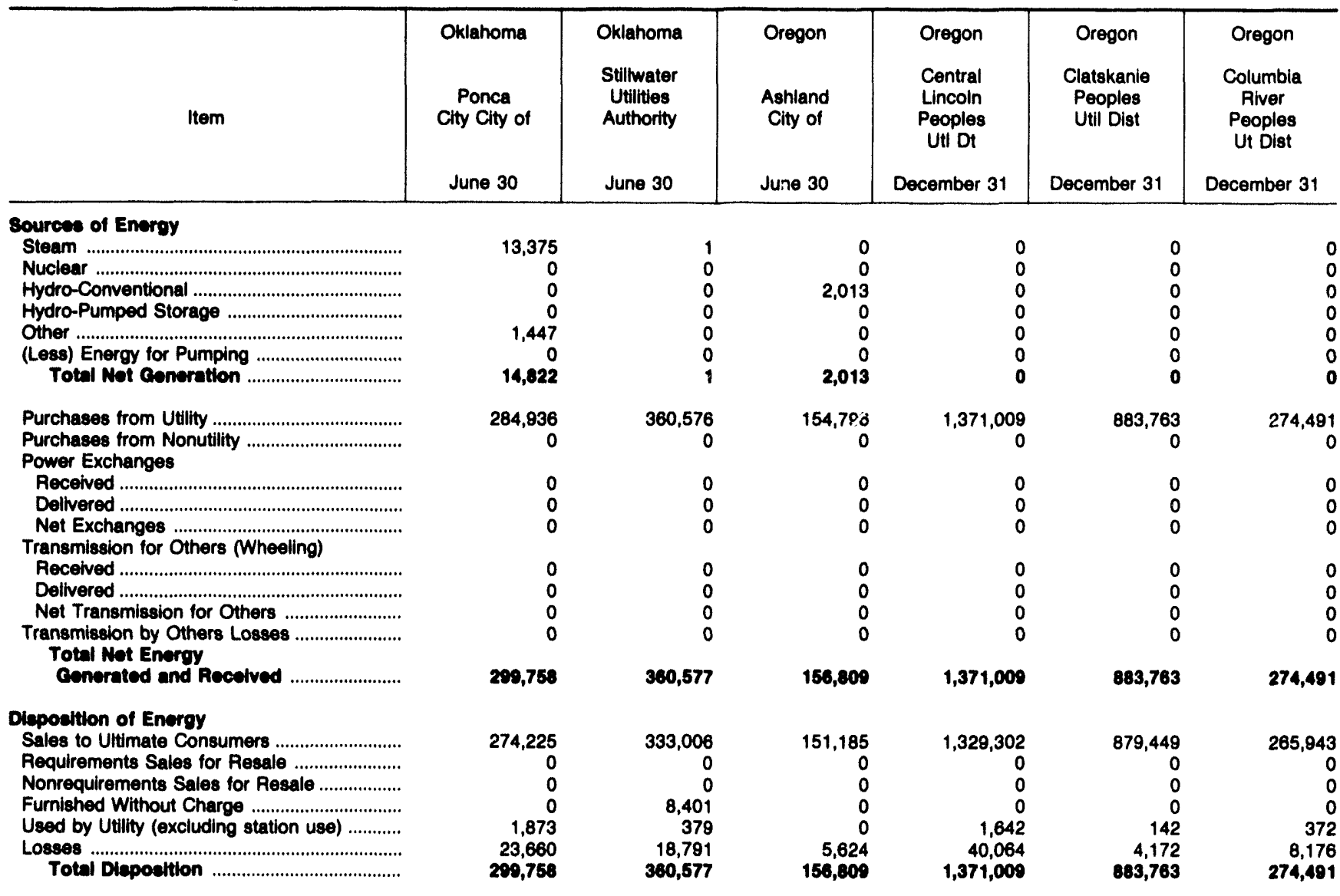

Note: Totals may not equal sum of components because of independent rounding. Double counting occurs in components of both sources and disposition of energy and thus neither provides a true total. Purchases from utilities, net interchanges, and net wheeling (except for imports) are included in net generation. Sales for resale is included in sales to ultimate consumers.

Source: Energy Information Administration, Form EIA-412, "Annual Report of Public Electric Utilities." 
Table 26. Electric Energy Account by Major U.S. Publicly Owned Electric Utillty Within State, 1992 (Continued)

(Megawatthours)

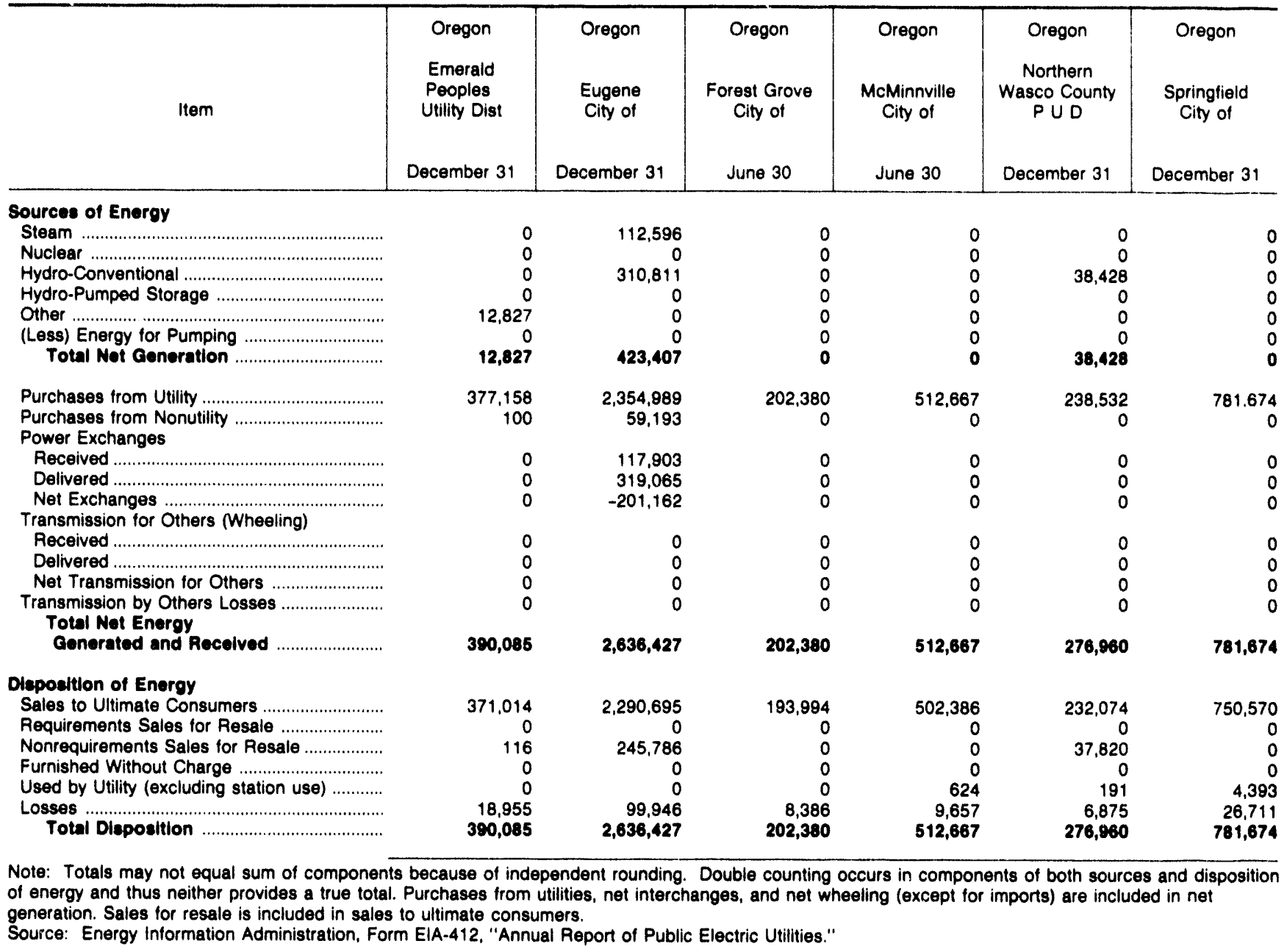


Table 26. Electric Energy Account by Major U.S. Publicly Owned Electric Utility Within State, 1992 (Continued)

(Megawatthours)

\begin{tabular}{|c|c|c|c|c|c|c|}
\hline Item & $\begin{array}{l}\text { Oregon } \\
\text { Tillamook } \\
\text { Peoples } \\
\text { Utility Dist } \\
\text { December } 31\end{array}$ & $\begin{array}{c}\text { Pennsylvania } \\
\text { Chambersburg } \\
\text { Borough of } \\
\text { December } 31\end{array}$ & $\begin{array}{l}\text { South Carolina } \\
\text { Camden } \\
\text { City of } \\
\text { June } 30\end{array}$ & $\begin{array}{l}\text { South Carolina } \\
\text { Easley } \\
\text { Combined } \\
\text { Utility } \\
\text { System } \\
\text { March } 31\end{array}$ & $\begin{array}{l}\text { South Carolina } \\
\text { Gattney } \\
\text { City of } \\
\text { March } 31\end{array}$ & $\begin{array}{l}\text { South Carolina } \\
\text { Greenwood } \\
\text { Commissioners } \\
\text { Pub Wk } \\
\text { December } 31\end{array}$ \\
\hline \multicolumn{7}{|l|}{ Sourcee of Energy } \\
\hline Steam .. & 0 & 0 & 0 & 0 & 0 & 0 \\
\hline 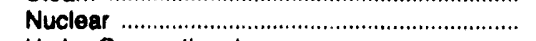 & 0 & 0 & 0 & 0 & 0 & 0 \\
\hline 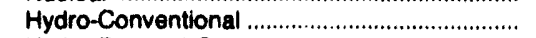 & 0 & 0 & 0 & 0 & 0 & 0 \\
\hline 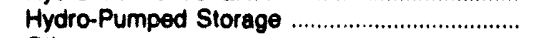 & 0 & 0 & 0 & 0 & 0 & 0 \\
\hline Other ..................................................... & 0 & 802 & 0 & 0 & 0 & 0 \\
\hline $\begin{array}{l}\text { (Less) Energy for Pumping } \\
\text { Total Net Generation }\end{array}$ & $\begin{array}{l}0 \\
0\end{array}$ & $\begin{array}{r}0 \\
802\end{array}$ & $\begin{array}{l}0 \\
0\end{array}$ & $\stackrel{0}{0}$ & $\begin{array}{l}0 \\
0\end{array}$ & $\begin{array}{l}0 \\
0\end{array}$ \\
\hline Purchases from Utility & 355,234 & 227,539 & 151,412 & 208,543 & 189,215 & 236,690 \\
\hline $\begin{array}{l}\text { Purchases from Nonutility ..................................... } \\
\text { Power Exchanges }\end{array}$ & 0 & 0 & 2 & 0 & 0 & \\
\hline Recelved ................................................... & 0 & 0 & 0 & 0 & 0 & 0 \\
\hline Delivered .................................................... & 0 & 0 & 0 & 0 & 0 & 0 \\
\hline Net Exchanges & 0 & 0 & 0 & 0 & 0 & 0 \\
\hline \multicolumn{7}{|l|}{ Transmission for Others (Wheeling) } \\
\hline 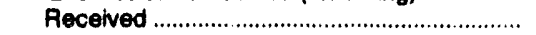 & 0 & 0 & 0 & 0 & 0 & 0 \\
\hline 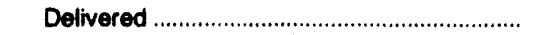 & 0 & 0 & 0 & 0 & 0 & 0 \\
\hline Net Transmiss & 0 & 0 & 0 & 0 & 0 & 0 \\
\hline $\begin{array}{l}\text { Transmission by Others Losses ........................... } \\
\text { Total Not Energy }\end{array}$ & 0 & 0 & 0 & 0 & 0 & 0 \\
\hline 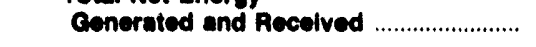 & 355,234 & 228,341 & 151,414 & 208,543 & 189,215 & 236,680 \\
\hline \multicolumn{7}{|l|}{ Diepoattion of Energy } \\
\hline Sales to Ultimate Consumers ..... & 336,478 & 214,321 & 145,686 & 183,000 & 160,056 & 215,903 \\
\hline Requirements Sales for Resale ..... & 0 & 0 & 0 & 0 & 0 & \\
\hline Nonrequirements Sales for Resale. & 0 & 0 & 0 & 0 & 0 & \\
\hline 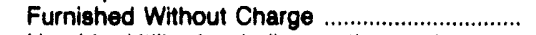 & 0 & 0 & 0 & 2,198 & 2,082 & \\
\hline Used by Utility (exciuding station use) ............. & 0 & 0 & 0 & 10,092 & 9,650 & 0 \\
\hline Losses & 18,756 & 14,020 & 5,728 & 13,253 & 17,427 & 20,787 \\
\hline Total Diaposition & 355,234 & 228,341 & 151,414 & 200,543 & 189,215 & 236,690 \\
\hline
\end{tabular}

Note: Totals may not equal sum of cornponents because of independent rounding. Double counting occurs in components of both sources and disposition of energy and thus neither provides a true total. Purchases from utilities, net interchanges, and net wheeling (except :or imports) are included in net generation. Sales for resale is included in sales to ultimate consumers.

Source: Energy Information Administration, Form EIA-412, "Annual Report of Public Electric Utilities." 
Table 26. Electric Energy Account by Major U.S. Publicly Owned Electric Utility Within State, 1992 (Continued)

(Megawatthours)

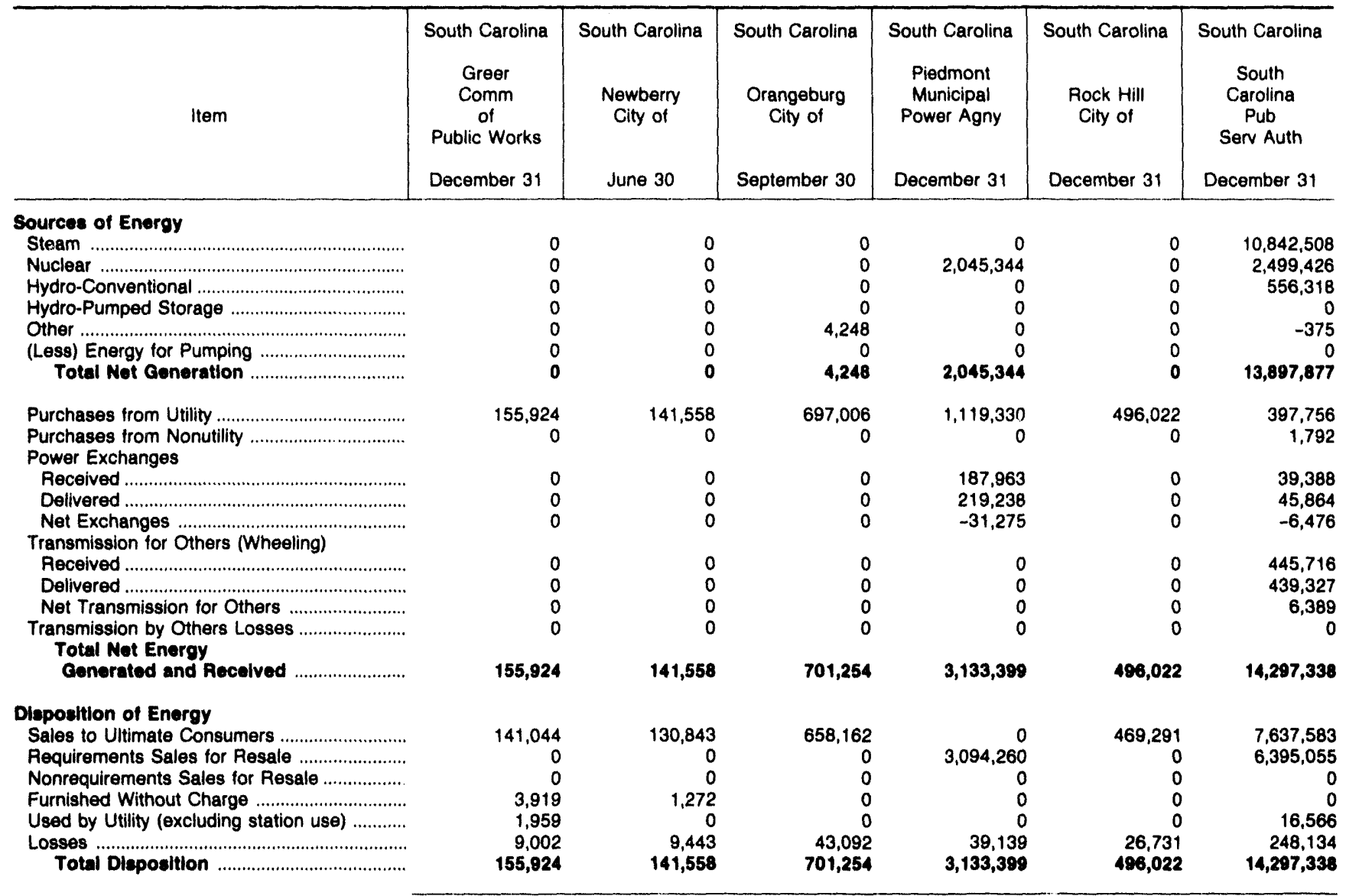

Note: Totals may not equal sum of components because of independent rounding. Double counting occurs in components of both sources and disposition of energy and thus neither provides a true total. Purchases from utilities, net interchanges, and net wheeling (except for imports) are included in net generation. Sales for resale is included in sales to ultimate consumers.

Source: Energy Information Administration, Form ElA-412, "Annual Report of Public Electric Utilities." 
Table 26. Electric Energy Account by Major U.S. Publicly Owned Electric Utility Within State, 1992 (Continued)

(Megawatthours)

\begin{tabular}{|c|c|c|c|c|c|c|}
\hline Item & $\begin{array}{l}\text { South Dakota } \\
\text { Brookings } \\
\text { City of } \\
\text { December } 31\end{array}$ & $\begin{array}{l}\text { South Dakota } \\
\text { Heartland } \\
\text { Consumers } \\
\text { Power Dist } \\
\text { December } 31\end{array}$ & $\begin{array}{l}\text { South Dakota } \\
\text { Missouri } \\
\text { Basin } \\
\text { Mun } \\
\text { Power Agny } \\
\text { December } 31\end{array}$ & $\begin{array}{c}\text { South Dakota } \\
\text { Pierre } \\
\text { City of } \\
\text { December } 31\end{array}$ & $\begin{array}{l}\text { South Dakota } \\
\text { Watertown } \\
\text { Municipal } \\
\text { Utilities } \\
\text { December } 31\end{array}$ & $\begin{array}{l}\text { Tennessee } \\
\text { Alcoa } \\
\text { Utilities } \\
\text { June } 30\end{array}$ \\
\hline \multicolumn{7}{|l|}{ Sources of Energy } \\
\hline Steam & 0 & 383,676 & 0 & 0 & 0 & 0 \\
\hline 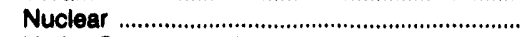 & 0 & 0 & 0 & 0 & 0 & 0 \\
\hline 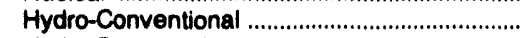 & 0 & 0 & 0 & 0 & 0 & 0 \\
\hline 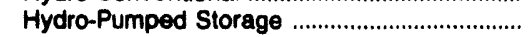 & 0 & 0 & 0 & 0 & 0 & 0 \\
\hline Other & 0 & 0 & 0 & 0 & 0 & 0 \\
\hline (Less) Energy for Pumping ................................. & 0 & 0 & 0 & 0 & 0 & 0 \\
\hline 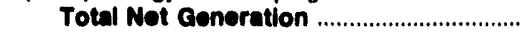 & $\mathbf{0}$ & 383,676 & $\mathbf{0}$ & 0 & 0 & $\mathbf{0}$ \\
\hline 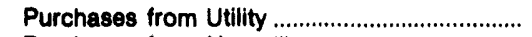 & 173,514 & 32,187 & $1,983,287$ & 148,759 & 201,019 & 418,443 \\
\hline $\begin{array}{l}\text { Purchases from Nonutility ........................................... } \\
\text { Power Exchanges }\end{array}$ & 0 & 0 & 0 & 0 & 0 & 0 \\
\hline 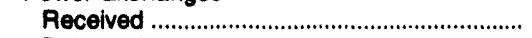 & 0 & 24,880 & 69,497 & 0 & 0 & 0 \\
\hline 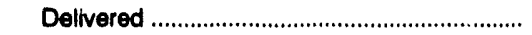 & 0 & 5,088 & 198 & 0 & 0 & 0 \\
\hline Net Exchanges & 0 & 19,792 & 69,299 & 0 & 0 & 0 \\
\hline \multicolumn{7}{|l|}{ Transmission for Others (Wheeling) } \\
\hline 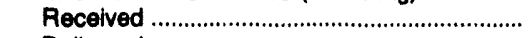 & 0 & 0 & 0 & 0 & 0 & 0 \\
\hline 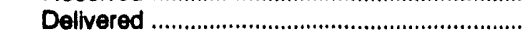 & 0 & 0 & 0 & 0 & 0 & 0 \\
\hline Net Transmission for Others .......................... & 0 & 0 & 0 & 0 & 0 & 0 \\
\hline 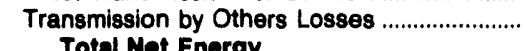 & 0 & 0 & 0 & 0 & 0 & 0 \\
\hline Generated and Recelved ......................... & 173,514 & 435,655 & $2,052,586$ & 148,759 & 201,019 & 418,443 \\
\hline \multicolumn{7}{|l|}{ Dispostion of Energy } \\
\hline 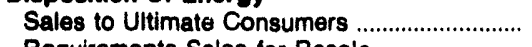 & 164,940 & 0 & 0 & 128,040 & 193,128 & 394,739 \\
\hline Requirements Sales for Resale ......................... & 0 & 385,867 & 904,164 & 12,182 & 0 & 0 \\
\hline Nonrequirements Sales for Resale .................. & 0 & 0 & $1,099,534$ & 0 & 0 & 0 \\
\hline Furnished Without Charge ................................ & 0 & 0 & 0 & 0 & 0 & 0 \\
\hline Used by Utility (excluding station use) ............ & 0 & 0 & 0 & 2,000 & 0 & 239 \\
\hline $\begin{array}{l}\text { Losses ... Dieposition } \\
\text { Total }\end{array}$ & $\begin{array}{r}8,574 \\
173,514\end{array}$ & $\begin{array}{r}49,788 \\
435,655\end{array}$ & $\begin{array}{r}48,888 \\
2,052,586\end{array}$ & $\begin{array}{r}6,537 \\
148,759\end{array}$ & $\begin{array}{r}7,891 \\
201,019\end{array}$ & $\begin{array}{r}23,463 \\
418,443\end{array}$ \\
\hline
\end{tabular}

Note: Totals may not equal sum of components because of independent rounding. Double counting occurs in components of both sources and disposition of energy and thus neither provides a true total. Purchases from utilities, net interchanges, and net wheeling (except for imports) are included in net generation. Sales for resale is included in sales to ultimate consumers.

Source: Energy Information Administration, Form E1A-412, "Annual Report of Public Electric Utilities." 
Table 26. Electric Energy Account by Major U.S. Publicly Owned Electric UtIlity Within State, 1992 (Continued) (Megawatthours)

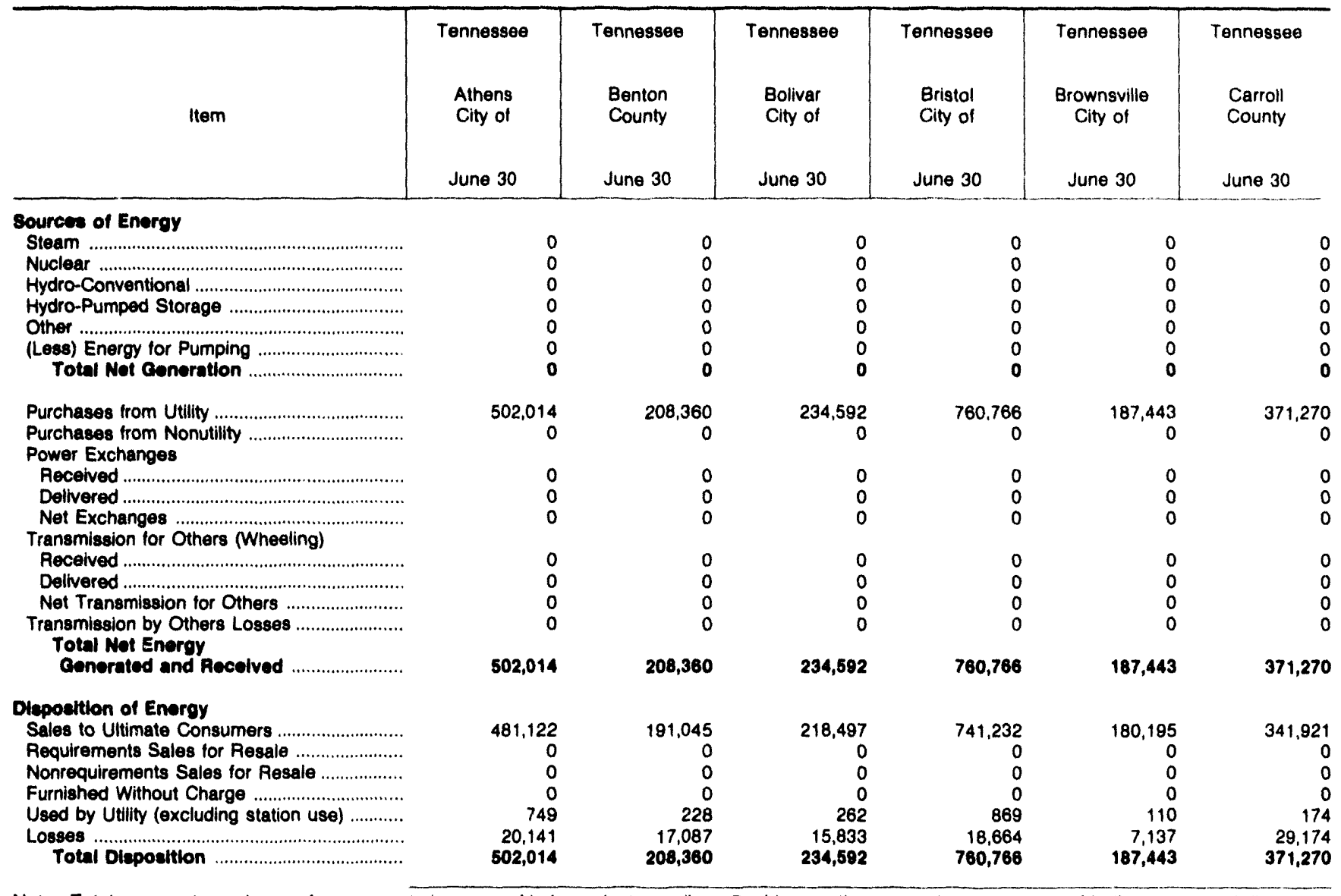

Note: Totals may not equal sum of components because of independent rounding. Double counting occurs in components of both sources and disposition of energy and thus neither provides a true total. Purchases from utilities, net interchanges, and net wheeling (except for imports) are included in net generation. Sales for resale is included in sales to ultimate consumers.

Source: Energy Information Adminigtration, Form EIA.412, "Annual Peport of Public Electric Utilities." 
Table 26. Electric Energy Account by Major U.S. Publicly Owned Electrlc Utillty Within State, 1992 (Continued) (Megawatthours)

\begin{tabular}{|c|c|c|c|c|c|c|}
\hline & Tennessee & Tennessee & Tennessee & Tennessee & Tennessee & Tennessee \\
\hline Item & $\begin{array}{c}\text { Chattanooga } \\
\text { City of }\end{array}$ & $\begin{array}{c}\text { Clarksville } \\
\text { Clty of }\end{array}$ & $\begin{array}{l}\text { Cleveland } \\
\text { City of }\end{array}$ & $\begin{array}{l}\text { Clinton } \\
\text { City of }\end{array}$ & $\begin{array}{l}\text { Columbia } \\
\text { City of }\end{array}$ & $\begin{array}{l}\text { Cookeville } \\
\text { City of }\end{array}$ \\
\hline & June 30 & June 30 & June 30 & June 30 & June 30 & June 30 \\
\hline
\end{tabular}

\section{Sources of Energy}

Steam

Nuclear

Hydro-Conventional

Hydro-Pumped Storage

Other

(Less) Energy for Pumping

Total Not Conoration

Purchases from Utility

Purchases from Nonutility

Power Exchanges

Pecelved

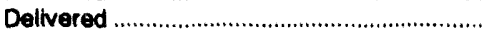

Net Exchanges

Transmission for Others (Wheeling)

Received

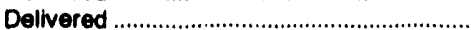

Net Transmission for Others

Transmission by Others Losses

Total Not Enorgy

Cenerated and Recelved

........................

.

Olepostion of Enorgy

Sales to Uitimate Consumers

Requirements Sales for Resale

Nonrequirements Sales for Resale

Furnished Without Charge

Used by Utilty (excluding atation uso)

Losses

Total Diepooltion

0
0
0
0
0
0
0

$5,318,656$

$$
\begin{array}{r}
656 \\
0
\end{array}
$$

0

0
0
0

0

0
0
0

0

$5,318,656$

$5,090,333$

5
0
0

8,711

219,611

$5,318,656$

0

0

0

0
0

Note: Totals may not equal sum of components because of independent rounding. Double counting occurs in components of both sources and disposition of energy and thus neither provides a true total. Purchases from utilities, net interchanges, and net wheeling (except for imports) are included in net generation. Sales for resale is included in sales to ultimate consumers.

Source: Energy Information Administration, Form ElA-412, "Annual Report of Public Electric Utilities." 
Table 26. Electric Energy Account by Major U.S. Publicly Owned Electric Utillty Within State, 1992 (Continued)

(Megawatthours)

\begin{tabular}{|c|c|c|c|c|c|c|}
\hline Item & $\begin{array}{l}\text { Tennessee } \\
\text { Covington } \\
\text { Electric } \\
\text { System }\end{array}$ & $\begin{array}{l}\text { Tennessee } \\
\text { Dayton } \\
\text { City of }\end{array}$ & $\begin{array}{l}\text { Tennessee } \\
\text { Dickson } \\
\text { City of }\end{array}$ & $\begin{array}{c}\text { Tennessee } \\
\text { Dyersburg } \\
\text { Electric } \\
\text { System }\end{array}$ & $\begin{array}{c}\text { Tennessee } \\
\text { Elizabethton } \\
\text { City of }\end{array}$ & $\begin{array}{c}\text { Tennessee } \\
\text { Enwin } \\
\text { Town of }\end{array}$ \\
\hline & June 30 & June 30 & June 30 & June 30 & June 30 & June 30 \\
\hline
\end{tabular}

\section{Sources of Energy}

Steam

Nuclear

Hydro-Conventional

Hydro-Pumped Storage

Other

(Less) Energy for Pumping

Total Net Gonoration

Purchases from Utility

Purchases from Nonutility

Power Exchanges

Recelved

Delivered

Net Exchanges

Transmission for Others (Wheeling)

Received

Delivered.....

Net Transmission for Others

Transmission by Others Losses Total Not Enorgy

Generated and Recelved

Diepostion of Energy

Sales to Uitimate Consumers

Requirements Sales for Resale

Nonrequirements Sales for Resale..

Furnished Without Charge

Used by Utility (excluding station use)

Losses

Total Disposition

$\begin{array}{ll}0 & 0 \\ 0 & 0 \\ 0 & 0 \\ 0 & 0 \\ 0 & 0 \\ 0 & 0 \\ 0 & 0\end{array}$

189,241

191,009

0

0

0
0
0

0

0
0
0

189,241

191,000

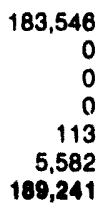

0
0
0
0
0
0
0

546,251

0

0
0
0

0

0
0
0
0

546,251

516,991
0
0
0
258
29,000
546,251

204,000

Note: Totals may not equal sum of components because of independent rounding. Double counting occurs in components of both sources and disposition of energy and thus neither provides a true total. Purchases from utilities, net interchanges, and net wheeling (except for imports) are included in net generation. Sales for resale is included in sales to ultimate consumers.

Source: Energy Information Administration, Form EIA-412, "Annual Report of Public Electric Utilities." 
Table 26. Electric Energy Account by Major U.S. Publlcly Owned Electrlc Utility Within State, 1992 (Continued)

(Megawatthours)

\begin{tabular}{|c|c|c|c|c|c|c|}
\hline Item & $\begin{array}{l}\text { Tennessee } \\
\text { Etowah } \\
\text { Clty of } \\
\text { June } 30\end{array}$ & $\begin{array}{l}\text { Tennessee } \\
\text { Fayetteville } \\
\text { City of } \\
\text { June } 30\end{array}$ & $\begin{array}{l}\text { Tennessee } \\
\text { Gallatin } \\
\text { City of } \\
\text { June } 30\end{array}$ & $\begin{array}{l}\text { Tennessee } \\
\text { Greeneville } \\
\text { City of } \\
\text { June } 30\end{array}$ & $\begin{array}{l}\text { Tennessee } \\
\text { Harriman } \\
\text { City of } \\
\text { June } 30\end{array}$ & $\begin{array}{l}\text { Tennessee } \\
\text { Humboldt } \\
\text { City of } \\
\text { June } 30\end{array}$ \\
\hline 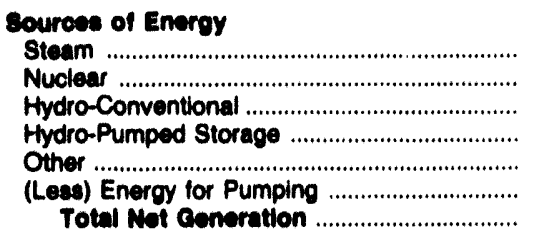 & $\begin{array}{l}0 \\
0 \\
0 \\
0 \\
0 \\
0 \\
0\end{array}$ & $\begin{array}{l}0 \\
0 \\
0 \\
0 \\
0 \\
0 \\
0\end{array}$ & $\begin{array}{l}0 \\
0 \\
0 \\
0 \\
0 \\
0 \\
0\end{array}$ & $\begin{array}{l}0 \\
0 \\
0 \\
0 \\
0 \\
0 \\
0\end{array}$ & $\begin{array}{l}0 \\
0 \\
0 \\
0 \\
0 \\
0 \\
0\end{array}$ & $\begin{array}{l}0 \\
0 \\
0 \\
0 \\
0 \\
0 \\
0\end{array}$ \\
\hline 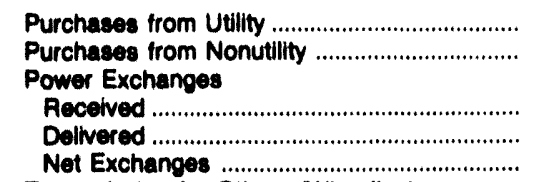 & $\begin{array}{r}139,024 \\
0 \\
0 \\
0 \\
0\end{array}$ & $\begin{array}{r}352,020 \\
0 \\
0 \\
0 \\
0\end{array}$ & $\begin{array}{r}412,411 \\
0 \\
0 \\
0 \\
0\end{array}$ & $\begin{array}{r}856,100 \\
0 \\
0 \\
0 \\
0\end{array}$ & $\begin{array}{r}214,947 \\
0 \\
0 \\
0 \\
0\end{array}$ & $\begin{array}{r}204,945 \\
0 \\
0 \\
0 \\
0\end{array}$ \\
\hline 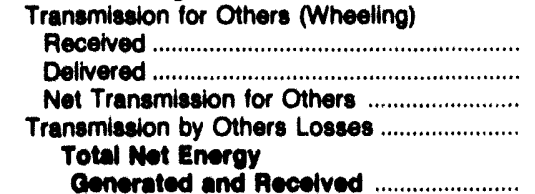 & $\begin{array}{r}0 \\
0 \\
0 \\
0 \\
139,024\end{array}$ & $\begin{array}{r}0 \\
0 \\
0 \\
0 \\
\mathbf{3 5 2 , 0 2 0}\end{array}$ & $\begin{array}{r}0 \\
0 \\
0 \\
0 \\
\$ 12,411\end{array}$ & $\begin{array}{r}0 \\
0 \\
0 \\
0\end{array}$ & $\begin{array}{r}0 \\
0 \\
0 \\
0\end{array}$ & 204,945 \\
\hline 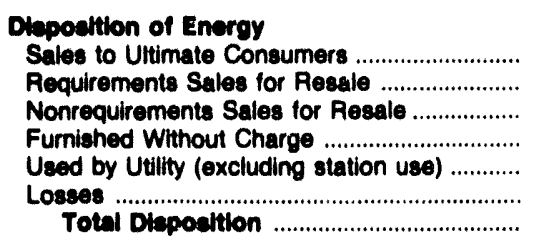 & $\begin{array}{r}134,011 \\
0 \\
0 \\
0 \\
0 \\
5,013 \\
139,024\end{array}$ & $\begin{array}{r}328,227 \\
0 \\
0 \\
0 \\
556 \\
23,236 \\
352,020\end{array}$ & $\begin{array}{r}389,468 \\
0 \\
0 \\
0 \\
281 \\
12,682 \\
412,411\end{array}$ & $\begin{array}{r}834,200 \\
0 \\
0 \\
0 \\
800 \\
21,100 \\
856,100\end{array}$ & $\begin{array}{r}199,831 \\
0 \\
0 \\
0 \\
418 \\
14,598 \\
214,947\end{array}$ & $\begin{array}{r}198,475 \\
0 \\
0 \\
0 \\
233 \\
6,237 \\
204,945\end{array}$ \\
\hline
\end{tabular}

Note: Totals may not equal sum of components because of independent rounding. Double counting occurs in components of both sources and disposition of energy and thus neither provides a true total. Purchases from utilities, net interchanges, and net wheeling (except for imports) are included in net generation. Sales for resale is included in sales to ultimate consumers.

Source: Energy Information Administration, Form ElA-412, "Annual Report of Public Electric Utilities." 
Table 26. Electric Energy Account by Major U.S. Publicly Owned Electric Utillty Within State, 1992 (Continued)

(Megawatthours)

\begin{tabular}{|c|c|c|c|c|c|c|}
\hline Item & $\begin{array}{l}\text { Tennessee } \\
\text { Jackson } \\
\text { City of } \\
\text { June } 30\end{array}$ & $\begin{array}{l}\text { Tennessee } \\
\text { Johnson } \\
\text { City City of } \\
\text { June } 30\end{array}$ & $\begin{array}{l}\text { Tennessee } \\
\text { Knoxville } \\
\text { Utilities } \\
\text { Board } \\
\text { June } 30\end{array}$ & $\begin{array}{l}\text { Tennessee } \\
\text { Lawrenceburg } \\
\text { City of } \\
\text { June } 30\end{array}$ & $\begin{array}{l}\text { Tennessee } \\
\text { LaFollette } \\
\text { City of } \\
\text { December } 31\end{array}$ & $\begin{array}{l}\text { Tennessee } \\
\text { Lebanon } \\
\text { City of } \\
\text { June } 30\end{array}$ \\
\hline 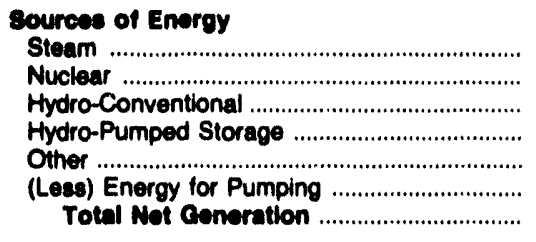 & $\begin{array}{l}0 \\
0 \\
0 \\
0 \\
0 \\
0 \\
0\end{array}$ & $\begin{array}{l}0 \\
0 \\
0 \\
0 \\
0 \\
0 \\
0\end{array}$ & $\begin{array}{l}0 \\
0 \\
0 \\
0 \\
0 \\
0 \\
0\end{array}$ & $\begin{array}{l}0 \\
0 \\
0 \\
0 \\
0 \\
0 \\
0\end{array}$ & $\begin{array}{l}0 \\
0 \\
0 \\
0 \\
0 \\
0 \\
0\end{array}$ & $\begin{array}{l}0 \\
0 \\
0 \\
0 \\
0 \\
0 \\
0\end{array}$ \\
\hline 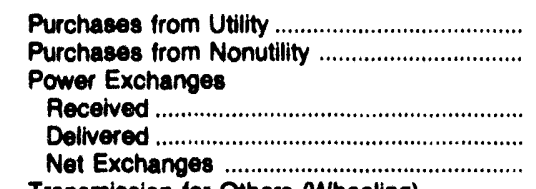 & $\begin{array}{r}1,115,881 \\
0 \\
0 \\
0 \\
0\end{array}$ & $\begin{array}{r}1,488,631 \\
0 \\
0 \\
0 \\
0\end{array}$ & $\begin{array}{r}4,685,726 \\
0 \\
0 \\
0 \\
0\end{array}$ & $\begin{array}{r}470,419 \\
0 \\
0 \\
0 \\
0\end{array}$ & $\begin{array}{r}327,446 \\
0 \\
0 \\
0 \\
0\end{array}$ & $\begin{array}{r}318,631 \\
0 \\
0 \\
0 \\
0\end{array}$ \\
\hline 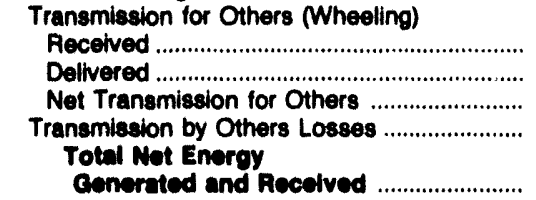 & $\begin{array}{r}0 \\
0 \\
0 \\
0\end{array}$ & $\begin{array}{r}0 \\
0 \\
0 \\
0 \\
1,498,631\end{array}$ & $\begin{array}{r}0 \\
0 \\
0 \\
0\end{array}$ & $\begin{array}{r}0 \\
0 \\
0 \\
0 \\
470,419\end{array}$ & $\begin{array}{r}0 \\
0 \\
0 \\
0 \\
327,446\end{array}$ & $\begin{array}{r}0 \\
0 \\
0 \\
0 \\
318,631\end{array}$ \\
\hline 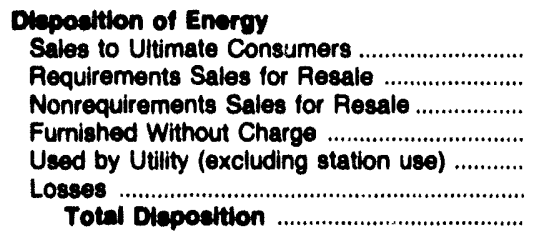 & $\begin{array}{r}1,065,771 \\
0 \\
0 \\
0 \\
1,005 \\
48,104 \\
1,115,881\end{array}$ & $\begin{array}{r}1,415,614 \\
0 \\
0 \\
0 \\
767 \\
72,249 \\
1,488,631\end{array}$ & $\begin{array}{r}4,465,554 \\
0 \\
0 \\
0 \\
14,202 \\
205,969 \\
4,885,726\end{array}$ & $\begin{array}{r}421,221 \\
0 \\
0 \\
0 \\
631 \\
48,568 \\
470,419\end{array}$ & $\begin{array}{r}301,130 \\
0 \\
0 \\
0 \\
673 \\
25,641 \\
327,446\end{array}$ & $\begin{array}{r}300,923 \\
0 \\
0 \\
0 \\
3 \\
17,704 \\
318,631\end{array}$ \\
\hline
\end{tabular}


Table 26. Electric Energy Account by Major U.S. Publicly Owned Electric Utility Within State, 1992 (Continued) (Megawatthours)

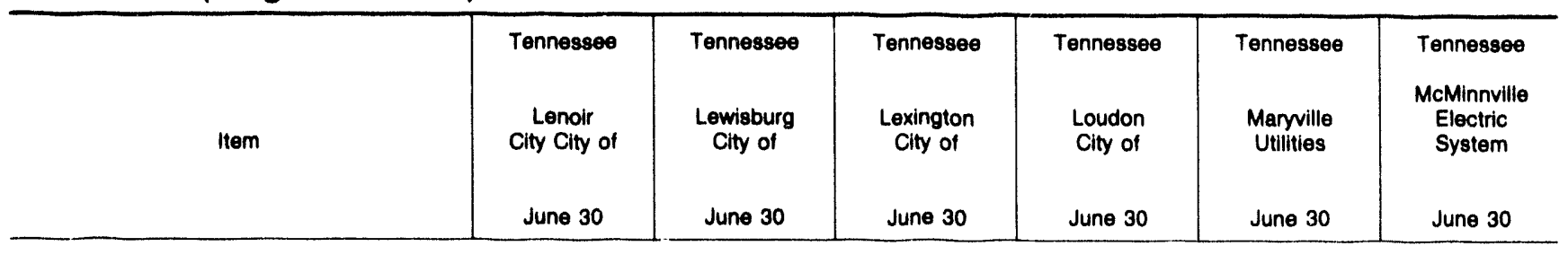

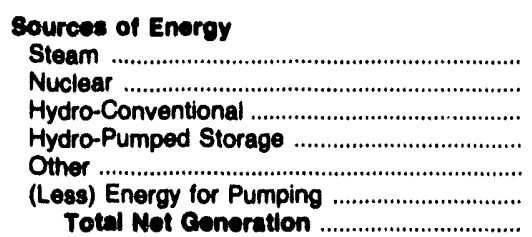

Toth Net Ceneration

Purchases from Utility

Purchases from Nonutility

Power Exchanges

Received

Net Exchanges

Transmission for Others (Wheeling)

Received.....

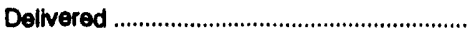

Net Transmission for Others

Transmission by Others Losses

Total Not Enorgy

cenerated and Recelved

......................

Dlepostion of Eneroy

Sales to Utimate Consumers

Requirements Sales for Resale

Nonrequirements Sales for Resale

Furnished Without Charge

Used by Utility (excluding station use)

Losses

Total Dieposition

$\begin{array}{ll}0 & 0 \\ 0 & 0 \\ 0 & 0 \\ 0 & 0 \\ 0 & 0 \\ 0 & 0 \\ 0 & 0\end{array}$

984,481

$481 \quad 274,731$

0

0
0
0

0
0
0

0

984,481

936,423
0
0

547

47.510

984,481
274,731

0

364,336

0
0
0

Note: Totals may not equal sum of components because of independent rounding. Double counting occurs in components of both sources and disposition of energy and thus neither provides a true total. Purchases from utilities, net interchanges, and net wheeling (except for imports) are included in net generation. Sales for resale is included in sales to ultimate consumers.

Source: Energy Information Administration, Form EIA-412, "Annual Report of Public Electric Utilities." 
Table 26. Electric Energy Account by Major U.S. Publicly Owned Electric Utility Within State, 1992 (Continued)

(Megawatthours)

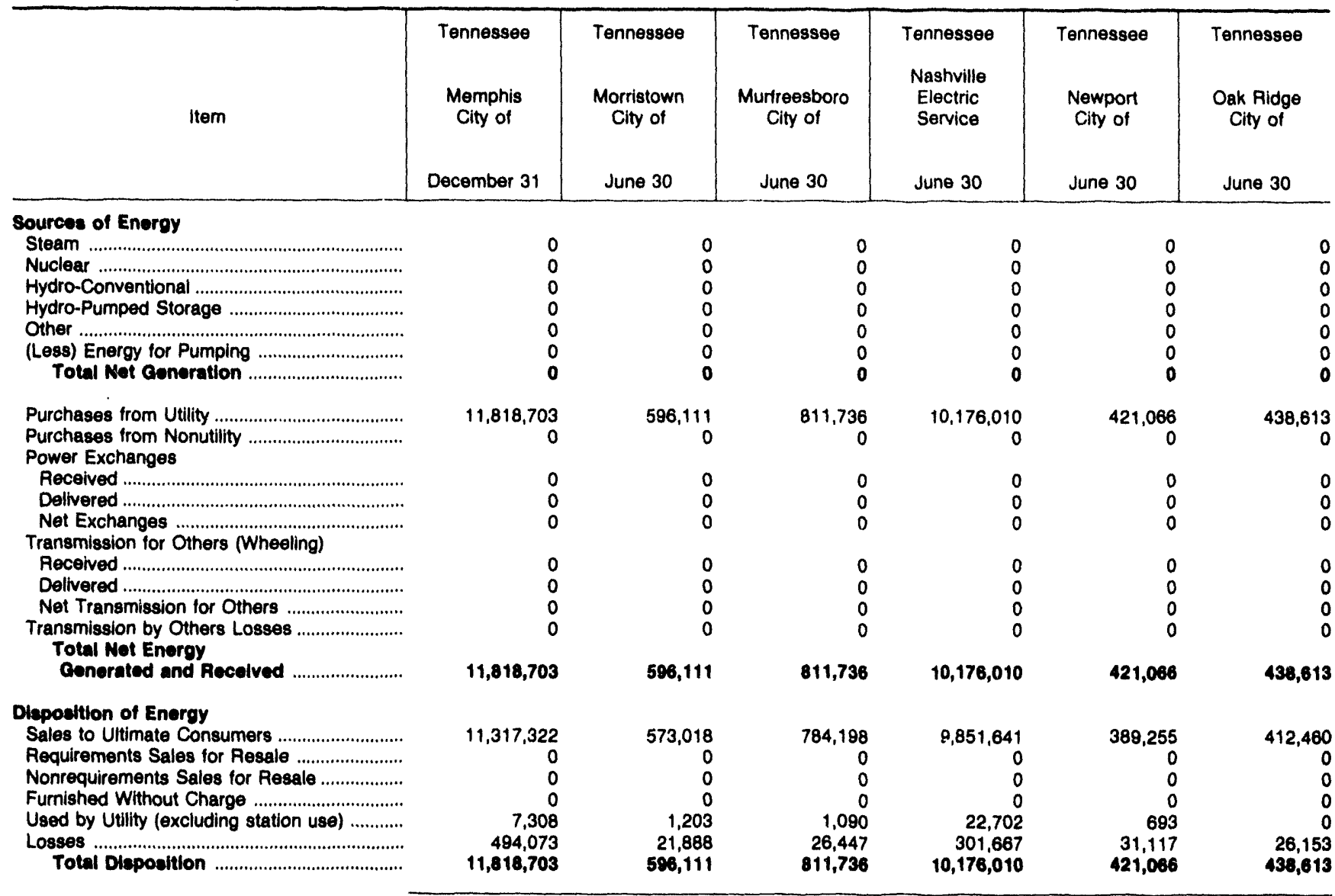

Note: Totals may not equal sum of components bocause of independent rounding. Double counting occurs in components of both sources and disposition of energy and thus neither provides a true total. Purchases from utilities, net interchanges, and net wheeling (except for imports) are included in net generation. Sales for resale is included in sales to ultimate consumers.

Source: Energy information Administration, Form EIA-412, "Annual Report of Public Electric Utilities." 
Table 26. Electric Energy Account by Major U.S. Publicly Owned Electric
Utility Within State, 1992 (Continued) (Megawatthours)

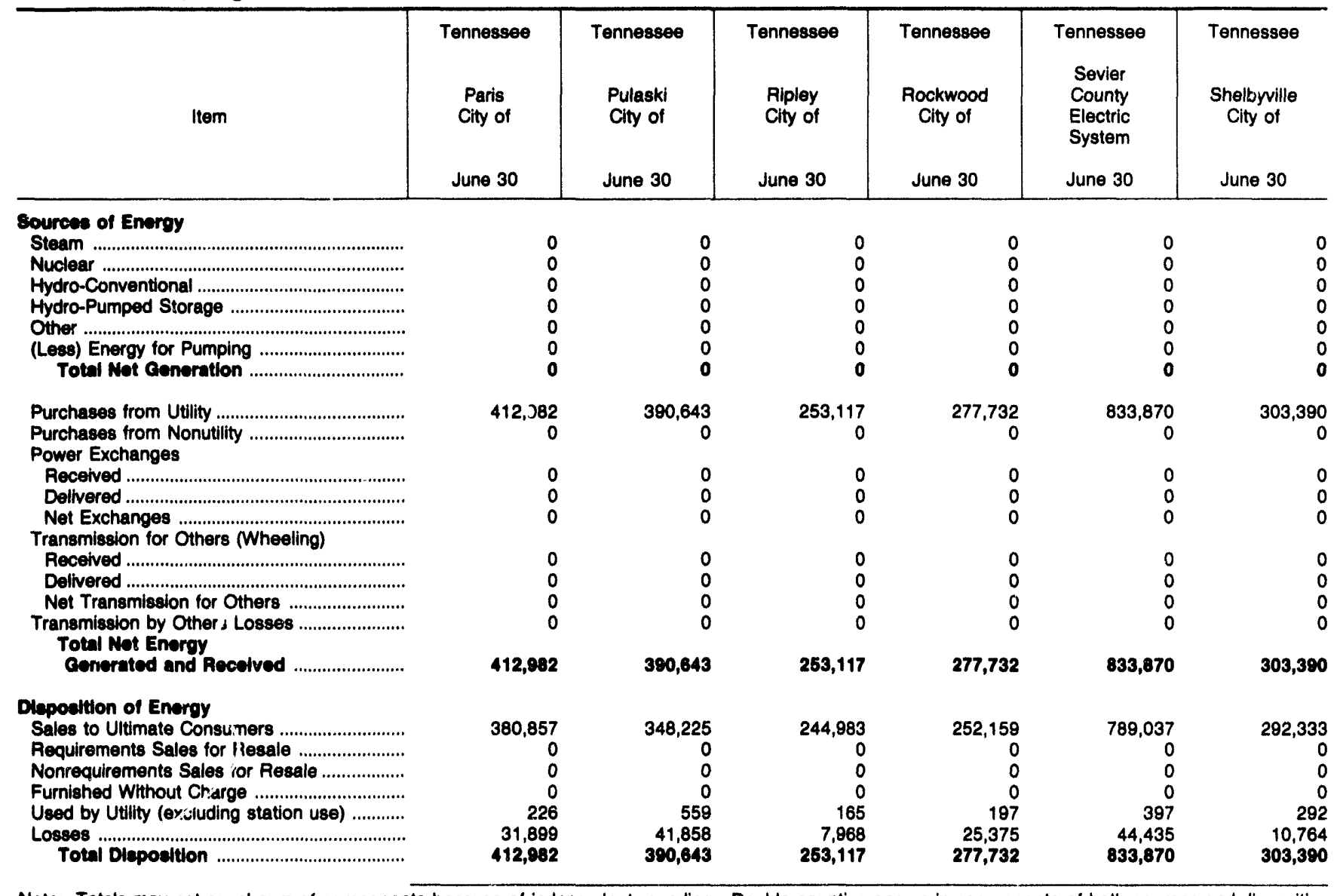

Note: Totals may not equal sum of components because of independent rounding. Double counting occurs in components of both sources and disposition of energy and thus neither provides a true total. Purchases from utilities, net interchanges, and net wheeling (except for imports) are included in net generation. Sales for resale is included in sales to ultimate coilsumers.

Source: Energy Information Administration, Form EIA-412, "Annual Report of Public Electric Utilities." 
Table 26. Electric Energy Account by Major U.S. Publicly Owned Electric Utility Within State, 1992 (Continued) (Megawatthours)

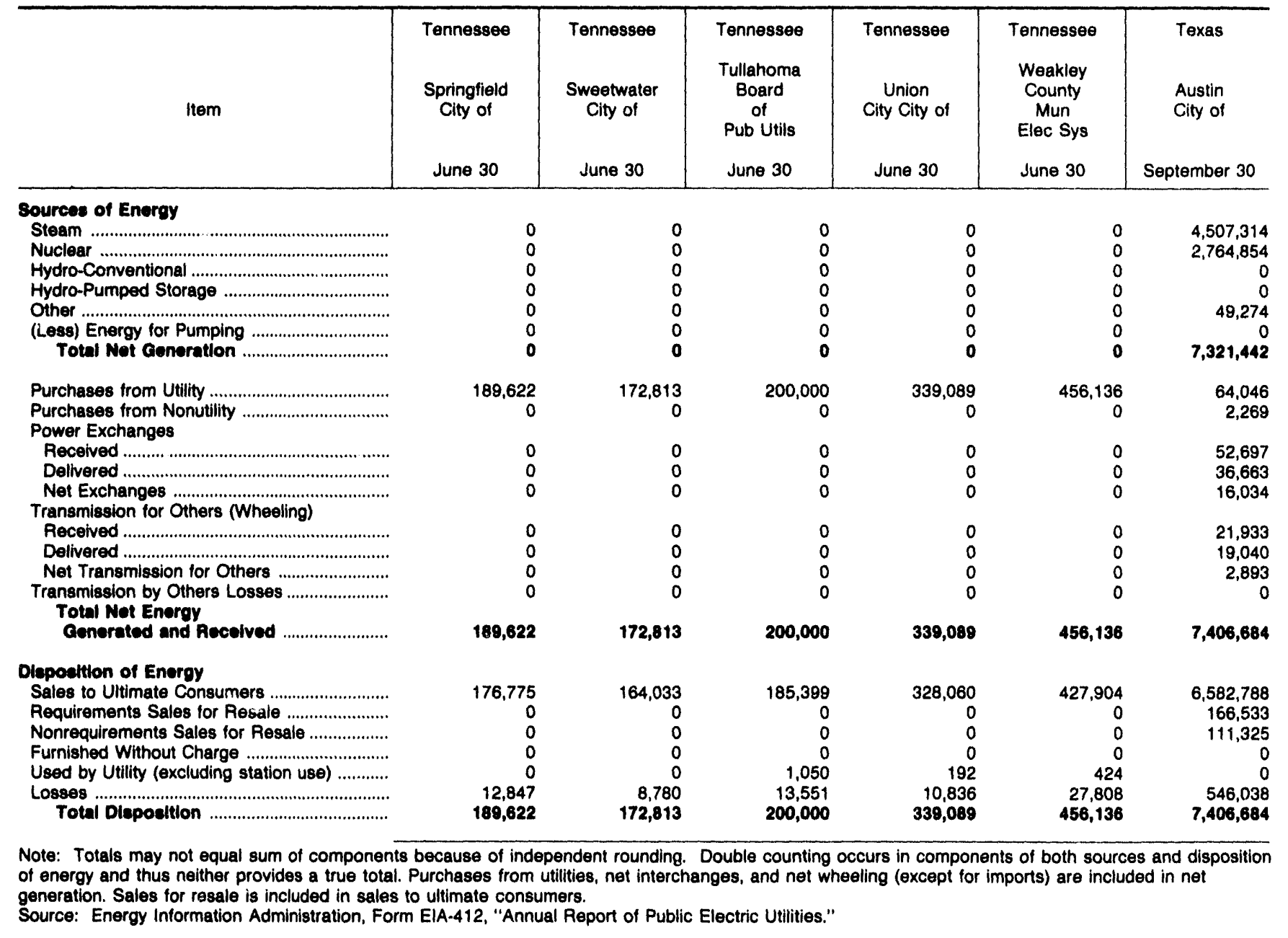


Table 26. Electric Energy Account by Major U.S. Publicly Owned Electric Utillty Within State, 1992 (Continued)

(Megawatthours)

\begin{tabular}{|c|c|c|c|c|c|c|}
\hline Item & $\begin{array}{c}\text { Texas } \\
\begin{array}{c}\text { Brenham } \\
\text { City of }\end{array} \\
\text { September } 30\end{array}$ & $\begin{array}{c}\text { Texas } \\
\text { Brownsville } \\
\text { Public } \\
\text { Utils Board } \\
\text { September } 30 \\
\end{array}$ & $\begin{array}{c}\text { Texas } \\
\text { Bryan } \\
\text { City of } \\
\text { September } 30\end{array}$ & $\begin{array}{c}\text { Texas } \\
\text { College } \\
\text { Station } \\
\text { City of } \\
\text { September } 30\end{array}$ & $\begin{array}{c}\text { Texas } \\
\text { Denton } \\
\text { City of } \\
\text { September } 30 \\
\end{array}$ & $\begin{array}{c}\text { Texas } \\
\begin{array}{c}\text { Floresville } \\
\text { City of }\end{array} \\
\text { December } 31\end{array}$ \\
\hline \multicolumn{7}{|l|}{ Sourcee of Energy } \\
\hline Steam & 0 & 558,512 & 454,611 & 0 & 106,666 & \\
\hline 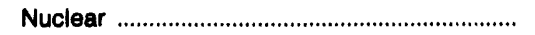 & 0 & & & 0 & & 0 \\
\hline 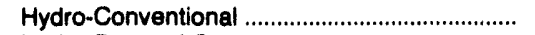 & 0 & 0 & 0 & 0 & 4,383 & 0 \\
\hline Hydro-Pumped Storage ............................................ & 0 & 0 & 0 & 0 & 0 & 0 \\
\hline Other & 0 & 0 & 108,368 & 0 & 0 & 0 \\
\hline $\begin{array}{l}\text { (Less) Energy for Pumping } \\
\text { Total Net Generation }\end{array}$ & $\begin{array}{l}0 \\
0\end{array}$ & $\begin{array}{r}0 \\
558,512\end{array}$ & $\begin{array}{r}0 \\
562,979\end{array}$ & $\begin{array}{l}0 \\
0\end{array}$ & $\begin{array}{r}0 \\
111,049\end{array}$ & $\begin{array}{l}0 \\
0\end{array}$ \\
\hline Purchases from Utility ............ & 241,947 & 193,524 & 770,986 & 424,685 & 789,578 & 138,763 \\
\hline $\begin{array}{l}\text { Purchases from Nonutility .................................. } \\
\text { Power Exchanges }\end{array}$ & 0 & 0 & & & 0 & \\
\hline 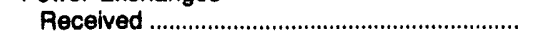 & 0 & 0 & 152,644 & 0 & 0 & 0 \\
\hline 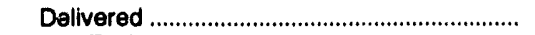 & 0 & 0 & 153,649 & 0 & 0 & 0 \\
\hline 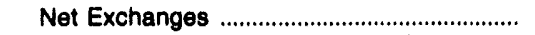 & 0 & 0 & $-1,005$ & 0 & 0 & 0 \\
\hline \multicolumn{7}{|l|}{ Transmission for Others (Wheeling) } \\
\hline 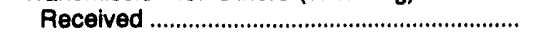 & 0 & 0 & 0 & 0 & 0 & \\
\hline 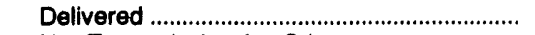 & 0 & 0 & 0 & 0 & 0 & 0 \\
\hline Net Transmission for Others .... & 0 & 0 & 0 & 0 & 0 & \\
\hline $\begin{array}{l}\text { Transmission by Others Losses ............................ } \\
\text { Total Net Eneroy }\end{array}$ & 0 & $-39,330$ & 0 & 0 & 0 & \\
\hline Generated and Recelved ........................ & 241,947 & 712,706 & $1,332,960$ & 424,685 & 900,627 & 136,763 \\
\hline \multicolumn{7}{|l|}{ Disposition of Energy } \\
\hline 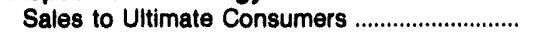 & 233,108 & 628,122 & 720,358 & 409,301 & 771,383 & 126,051 \\
\hline Requirements Sales for Resale .......................... & 0 & 0 & 549,289 & 0 & 104,358 & \\
\hline Nonrequirements Sales for Resale ..................... & 0 & & 0 & 0 & 0 & \\
\hline 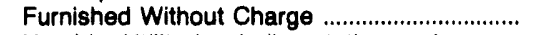 & 0 & 22,413 & 0 & 1,232 & 0 & 69 \\
\hline Used by Utility (excluding station use) ............ & 0 & 23,040 & 0 & 0 & 0 & 250 \\
\hline Losses & $\begin{array}{r}8,839 \\
\end{array}$ & 39,131 & 63,313 & 14,152 & 24,886 & $\begin{array}{r}12,393 \\
1383763\end{array}$ \\
\hline 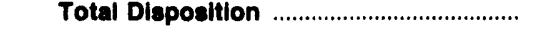 & 241,947 & 712,706 & $1,332,960$ & 424,685 & 900,627 & 138,763 \\
\hline
\end{tabular}


Table 26. Electric Energy Account by Major U.S. Publicly Owned Electric UtIllty Within State, 1992 (Continued) (Megawatthours)

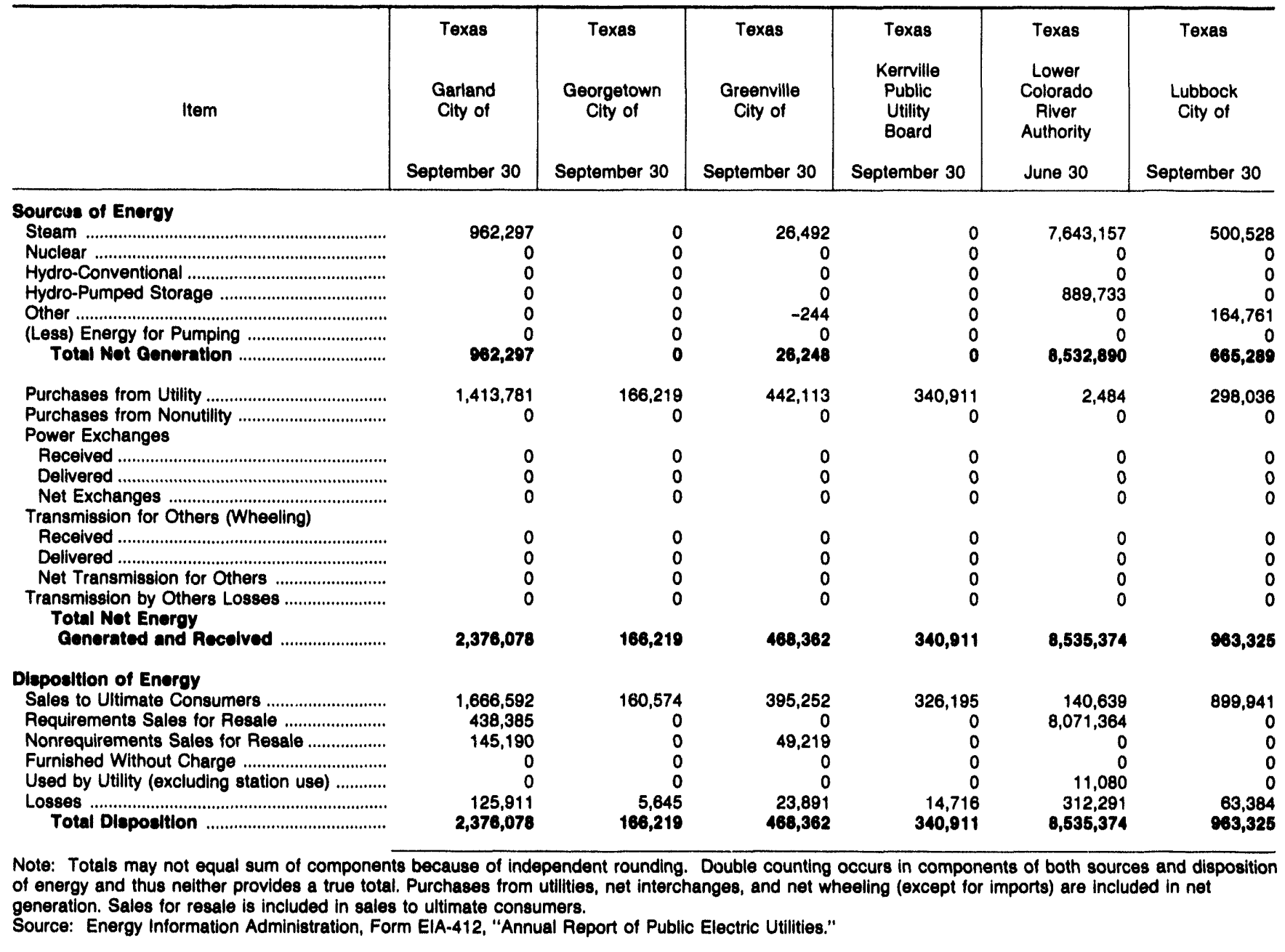


Table 26. Electric Energy Account by Major U.S. Publicly Owned Electric Utility Within State, 1992 (Continued) (Megawatthours)

\begin{tabular}{|c|c|c|c|c|c|c|}
\hline Item & $\begin{array}{c}\text { Texas } \\
\text { New Braunfels } \\
\text { City of } \\
\text { July } 31\end{array}$ & $\begin{array}{c}\text { Texas } \\
\text { Sam Rayburn } \\
\text { Municipal } \\
\text { Pwr } \\
\text { Agny } \\
\text { September } 30\end{array}$ & $\begin{array}{l}\text { Texas } \\
\text { San Antonio } \\
\text { City of } \\
\text { January } 31\end{array}$ & $\begin{array}{c}\text { Texas } \\
\text { San Marcos } \\
\text { City of } \\
\text { September } 30\end{array}$ & $\begin{array}{c}\text { Texas } \\
\text { Seguin } \\
\text { City of } \\
\text { September } 30\end{array}$ & $\begin{array}{c}\text { Texas } \\
\text { Texas } \\
\text { Municipal } \\
\text { Power Agency } \\
\text { September } 30\end{array}$ \\
\hline \multicolumn{7}{|l|}{ Sources of Eneroy } \\
\hline 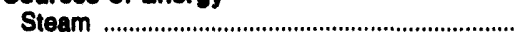 & 0 & 496,689 & $7,987,512$ & 0 & 0 & $2,917,053$ \\
\hline 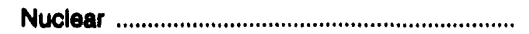 & 0 & 0 & $4,742,766$ & 0 & 0 & 0 \\
\hline 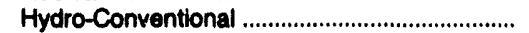 & 0 & 0 & 0 & 0 & 928 & 0 \\
\hline 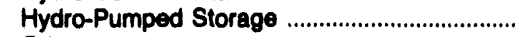 & 0 & 0 & 0 & 0 & 0 & 0 \\
\hline Other & 0 & 0 & 0 & 0 & 0 & 0 \\
\hline 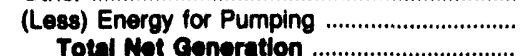 & $\begin{array}{l}0 \\
0\end{array}$ & & & $\begin{array}{l}0 \\
0\end{array}$ & & \\
\hline 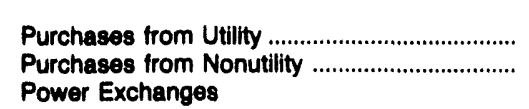 & $\begin{array}{r}732,745 \\
0\end{array}$ & $\begin{array}{r}87,716 \\
0\end{array}$ & $\begin{array}{r}292,686 \\
0\end{array}$ & $\begin{array}{r}303,205 \\
0\end{array}$ & $\begin{array}{r}189,467 \\
0\end{array}$ & $\begin{array}{l}0 \\
0\end{array}$ \\
\hline 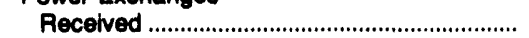 & 0 & 0 & 955,265 & 0 & 0 & 0 \\
\hline 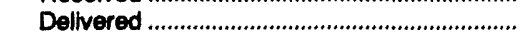 & 0 & 0 & 937,971 & 0 & 0 & 0 \\
\hline Net Exchanges & 0 & 0 & 17,294 & 0 & 0 & 0 \\
\hline \multicolumn{7}{|l|}{ Transmission for Others (Wheeling) } \\
\hline 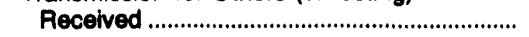 & 0 & 0 & 0 & 0 & 0 & 0 \\
\hline 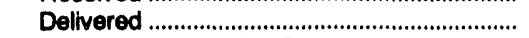 & 0 & 0 & 0 & 0 & 0 & 0 \\
\hline 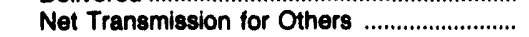 & 0 & 0 & 0 & 0 & 0 & 0 \\
\hline $\begin{array}{c}\text { Transmission by Others Losses ......................... } \\
\text { Tothl Fet Eneroy }\end{array}$ & 0 & 0 & 0 & 0 & 0 & 0 \\
\hline Cenorated and Accelved ........................ & 732,745 & 584,405 & $13,020,258$ & 303,205 & 190,395 & $2,917,053$ \\
\hline \multicolumn{7}{|l|}{ Diepostion of Enorgy } \\
\hline Sales to Ultimate Consumers ............................. & 708,436 & $\begin{array}{r}0 \\
317688\end{array}$ & $11,958,749$ & 279,926 & 179,114 & $\begin{array}{r}0 \\
2818708\end{array}$ \\
\hline Nonrequirements Sales for Resale ..................... & 0 & 260,494 & $\begin{array}{r}0<0,041 \\
0\end{array}$ & 0 & 0 & $\begin{array}{r}2,818,128 \\
0\end{array}$ \\
\hline 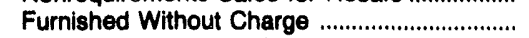 & 1,948 & 0 & 0 & 0 & 11,281 & 56,794 \\
\hline Used by Utility (excluding station use) ............. & 0 & 0 & 53,100 & 0 & 0 & 0 \\
\hline 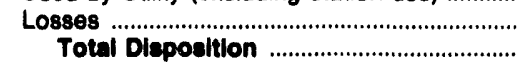 & $\begin{array}{r}22,361 \\
732,745\end{array}$ & $\begin{array}{r}6,223 \\
584,405\end{array}$ & $\begin{array}{r}679,862 \\
13,020,258\end{array}$ & $\begin{array}{r}23,279 \\
303,205\end{array}$ & $\begin{array}{r}0 \\
190,395\end{array}$ & $\begin{array}{r}41,531 \\
2,817,053\end{array}$ \\
\hline
\end{tabular}

Note: Totals may not equal sum of components because of independent rounding. Double counting occurs in components of both sources and disposition of energy and thus neither provides a true total. Purchases from utilities, net interchanges, and net wheeling (except for imports) are included in net generation. Sales for resale is included in sales to ultimate consumers.

Source: Energy Information Administration, Form EIA-412, "Annual Report of Public Electric Utilities." 
Table 26. Electric Energy Account by Major U.S. Publicly Owned Electric Utility Within State, 1992 (Continued)

(Megawatthours)

\begin{tabular}{|c|c|c|c|c|c|c|}
\hline Item & $\begin{array}{l}\text { Texas } \\
\text { Toledo Bend } \\
\text { Project } \\
\text { Joint } \\
\text { Oper } \\
\text { August } 30\end{array}$ & $\begin{array}{c}\text { Texas } \\
\text { Weatherford } \\
\text { Mun } \\
\text { Utility } \\
\text { System } \\
\text { September } 30\end{array}$ & $\begin{array}{l}\text { Utah } \\
\text { Bountiful } \\
\text { City City of } \\
\text { June } 30\end{array}$ & $\begin{array}{c}\text { Utah } \\
\text { Intermountain } \\
\text { Power Agency } \\
\text { June } 30\end{array}$ & $\begin{array}{l}\text { Utah } \\
\text { Logan } \\
\text { City of } \\
\text { June } 30\end{array}$ & $\begin{array}{l}\text { Utah } \\
\text { Murray } \\
\text { City of } \\
\text { June } 30\end{array}$ \\
\hline \multicolumn{7}{|l|}{ Sources of Energy } \\
\hline 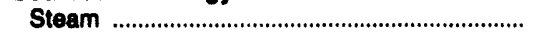 & 0 & 0 & 0 & $11,385,259$ & 0 & 0 \\
\hline 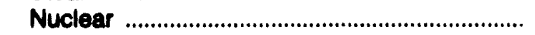 & 0 & 0 & 0 & 0 & 0 & 0 \\
\hline 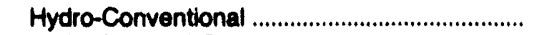 & 375,744 & 0 & 14,588 & 0 & 18,016 & 12,313 \\
\hline 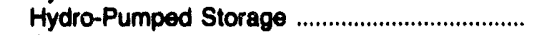 & 0 & 0 & 0 & 0 & 0 & 0 \\
\hline Other & 0 & 459 & 2,152 & 0 & -316 & 361 \\
\hline 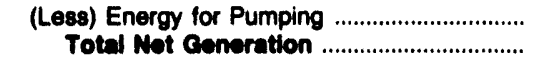 & $\begin{array}{r}0 \\
375,744\end{array}$ & $\begin{array}{r}0 \\
459\end{array}$ & $\begin{array}{r}0 \\
16,740\end{array}$ & $\begin{array}{r}0 \\
11,385,259\end{array}$ & $\begin{array}{r}0 \\
17,700\end{array}$ & $\begin{array}{r}0 \\
12,674\end{array}$ \\
\hline 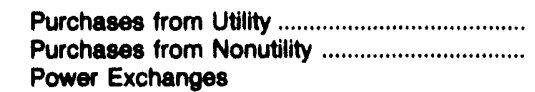 & $\begin{array}{l}0 \\
0\end{array}$ & $\begin{array}{r}195,922 \\
0\end{array}$ & $\begin{array}{r}213,995 \\
0\end{array}$ & $\begin{array}{r}158 \\
0\end{array}$ & $\begin{array}{r}265,775 \\
0\end{array}$ & $\begin{array}{r}295,256 \\
0\end{array}$ \\
\hline Recelved & 808 & 0 & 0 & 0 & 0 & 0 \\
\hline 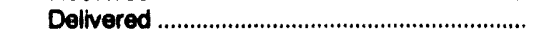 & 908 & 0 & 0 & 0 & 0 & 0 \\
\hline 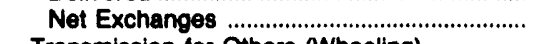 & 0 & 0 & 0 & 0 & 0 & 0 \\
\hline \multicolumn{7}{|l|}{ Transmission for Others (Wheeling) } \\
\hline 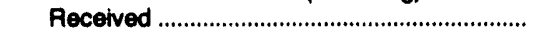 & 0 & 0 & 0 & 0 & 6,265 & 0 \\
\hline Delivered ...... & 0 & 0 & 0 & 0 & 6,265 & 0 \\
\hline Net Transmission for Others ............................ & 0 & 0 & 0 & 0 & 0 & 0 \\
\hline 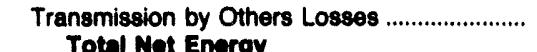 & 0 & 0 & 0 & 0 & 0 & 0 \\
\hline Generated and Recelved ............................ & 375,744 & 106,381 & 230,735 & $11,385,417$ & 283,475 & 307,930 \\
\hline \multicolumn{7}{|l|}{ Dispoaltion of Energy } \\
\hline 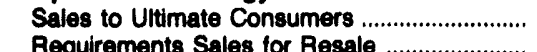 & $\begin{array}{l}0 \\
0\end{array}$ & 179,752 & $\begin{array}{r}220,118 \\
0\end{array}$ & $\begin{array}{r}0 \\
11.385417\end{array}$ & 266,151 & $\begin{array}{r}279,565 \\
0\end{array}$ \\
\hline $\begin{array}{l}\text { Requirements Sales for Resale .......................... } \\
\text { Nonrequirements Sales for Resale ................... }\end{array}$ & $\begin{array}{r}0 \\
374,836\end{array}$ & $\begin{array}{l}0 \\
0\end{array}$ & $\begin{array}{l}0 \\
0\end{array}$ & $\begin{array}{r}11,385,417 \\
0\end{array}$ & $\begin{array}{l}0 \\
0\end{array}$ & $\begin{array}{l}0 \\
0\end{array}$ \\
\hline Furnished Without Charge ............................. & & 0 & 0 & 0 & 2,342 & 1,911 \\
\hline Used by Utility (excluding station use) ............ & 514 & 0 & 1,732 & 0 & 1,389 & \\
\hline Losses & $\begin{array}{r}394 \\
375,744\end{array}$ & $\begin{array}{r}16,629 \\
196,381\end{array}$ & $\begin{array}{r}8,885 \\
230,735\end{array}$ & $\begin{array}{r}0 \\
11,385,417\end{array}$ & $\begin{array}{r}13,593 \\
283,475\end{array}$ & $\begin{array}{r}26,454 \\
307,930\end{array}$ \\
\hline
\end{tabular}


Table 26. Electric Energy Account by Major U.S. Publicly Owned Electric Utility Withln State, 1992 (Continued)

(Megawatthours)

\begin{tabular}{|c|c|c|c|c|c|c|}
\hline Item & $\begin{array}{l}\text { Utah } \\
\text { Provo } \\
\text { City Corp } \\
\text { June } 30\end{array}$ & $\begin{array}{l}\text { Utah } \\
\text { St George } \\
\text { City of } \\
\text { June } 30\end{array}$ & $\begin{array}{l}\text { Utah } \\
\text { Utah } \\
\text { Associated } \\
\text { Mun } \\
\text { Power Sys } \\
\text { March } 31\end{array}$ & $\begin{array}{l}\text { Utah } \\
\text { Utah } \\
\text { Municipal } \\
\text { Power Agency } \\
\text { June } 30\end{array}$ & $\begin{array}{l}\text { Vermont } \\
\text { Burlington } \\
\text { City of } \\
\text { December } 31\end{array}$ & $\begin{array}{l}\text { Vermont } \\
\text { Vermont } \\
\text { Public } \\
\text { Pwr } \\
\text { Supply Auth } \\
\text { December } 31\end{array}$ \\
\hline 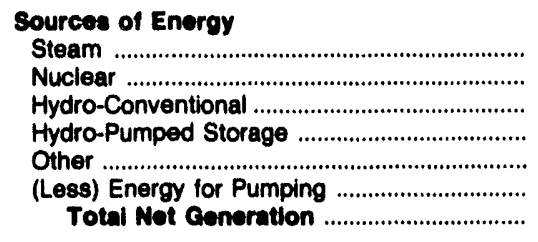 & $\begin{array}{l}0 \\
0 \\
0 \\
0 \\
0 \\
0 \\
0\end{array}$ & $\begin{array}{r}0 \\
0 \\
0 \\
0 \\
1,409 \\
0 \\
1,400\end{array}$ & $\begin{array}{r}389,541 \\
0 \\
0 \\
0 \\
0 \\
0 \\
389,541\end{array}$ & $\begin{array}{r}338,788 \\
0 \\
0 \\
0 \\
64,047 \\
0 \\
0 \\
402,833\end{array}$ & $\begin{array}{r}78,176 \\
0 \\
0 \\
0 \\
180 \\
0 \\
0 \\
78,356\end{array}$ & $\begin{array}{r}29,706 \\
0 \\
0 \\
0 \\
0 \\
0 \\
29,708\end{array}$ \\
\hline 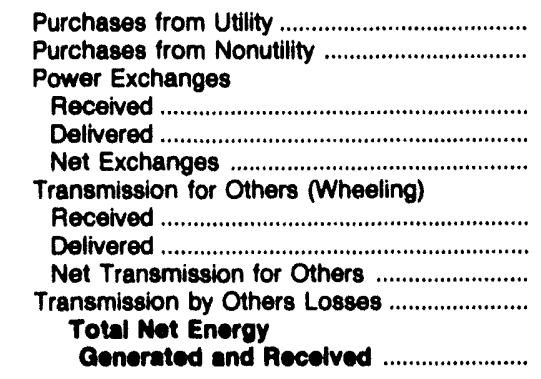 & $\begin{array}{r}539,737 \\
0 \\
0 \\
0 \\
0\end{array}$ & $\begin{array}{r}305,407 \\
0 \\
0 \\
0 \\
0\end{array}$ & $\begin{array}{r}652,197 \\
0 \\
23,649 \\
16,419 \\
7,230 \\
0 \\
0 \\
0 \\
0 \\
1,048,968\end{array}$ & $\begin{array}{r}0 \\
0 \\
0 \\
0 \\
783,839\end{array}$ & $\begin{array}{r}360,767 \\
0\end{array}$ & $\begin{array}{r}100,048 \\
0\end{array}$ \\
\hline 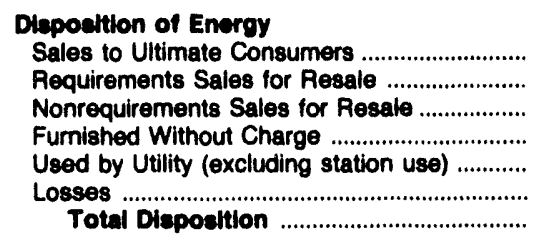 & $\begin{array}{r}505,314 \\
0 \\
0 \\
11,591 \\
0 \\
22,827 \\
539,737\end{array}$ & $\begin{array}{r}278,440 \\
0 \\
0 \\
0 \\
85 \\
28,291 \\
308,816\end{array}$ & $\begin{array}{r}0 \\
0 \\
1,041,738 \\
0 \\
0 \\
7,230 \\
1,048,968\end{array}$ & $\begin{array}{r}0 \\
766,388 \\
0 \\
0 \\
0 \\
17,451 \\
783,839\end{array}$ & $\begin{array}{r}324,196 \\
0 \\
91,913 \\
0 \\
0 \\
1,398 \\
21,616 \\
439,123\end{array}$ & $\begin{array}{r}0 \\
129,754 \\
0 \\
0 \\
0 \\
0 \\
129,754\end{array}$ \\
\hline
\end{tabular}

Note: Totals may not equal sum of components because of independent rounding. Double counting occurs in components of both sources and disposition of energy and thus neither provides a true total. Purchases from utilities, net interchanges, and net wheeling (except for imports) are included in net generation. Sales for resale is included in sales to ultimate consumers.

Source: Energy Information Administration, Form EIA-412, "Annual Report of Public Electric Utilities." 
Table 26. Electric Energy Account by Major U.S. Publicly Owned Electric Utility Within State, 1992 (Continued)

(Megawatthours)

\begin{tabular}{|c|c|c|c|c|c|c|}
\hline Item & $\begin{array}{l}\text { Virginia } \\
\text { Bedford } \\
\text { City of } \\
\text { June } 30\end{array}$ & $\begin{array}{l}\text { Virginia } \\
\text { Bristol } \\
\text { Virginia } \\
\text { Utilities Bd } \\
\text { June } 30\end{array}$ & $\begin{array}{l}\text { Virginia } \\
\text { Danville } \\
\text { City of } \\
\text { June } 30\end{array}$ & $\begin{array}{l}\text { Virginia } \\
\begin{array}{l}\text { Harrisonburg } \\
\text { City of }\end{array} \\
\text { June } 30\end{array}$ & $\begin{array}{l}\text { Virginia } \\
\text { Manassas } \\
\text { City of } \\
\text { June } 30\end{array}$ & $\begin{array}{l}\text { Virginia } \\
\begin{array}{c}\text { Martinsville } \\
\text { City of }\end{array} \\
\text { June } 30\end{array}$ \\
\hline \multicolumn{7}{|l|}{ Sources of Energy } \\
\hline Steam ....................... & 0 & 0 & 0 & 0 & 0 & 0 \\
\hline Nuclear & 0 & 0 & 0 & 0 & 0 & 0 \\
\hline Hydro-Conventional ................................................ & 0 & 0 & 28,041 & 0 & 0 & 4,600 \\
\hline Hydro-Pumped Storage & 18,102 & 0 & 0 & 0 & 0 & 0 \\
\hline 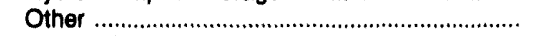 & 0 & 0 & 0 & 0 & 1,369 & 0 \\
\hline (Less) Energy for Pumping ..................................... & 0 & 0 & 0 & 0 & 0 & 0 \\
\hline 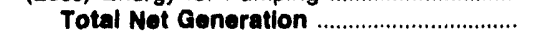 & 18,102 & 0 & 28,041 & 0 & 1,369 & 4,600 \\
\hline Purchases from Utility ................................ & 184,299 & 528,809 & 773,124 & 490,949 & 264,602 & 203,570 \\
\hline 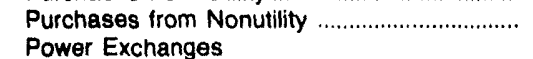 & & 0 \\
\hline 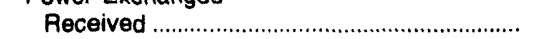 & 0 & 0 & 0 & 0 & 0 & 0 \\
\hline 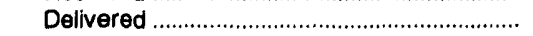 & 0 & 0 & 0 & 0 & 0 & 0 \\
\hline Net Exchanges ........................................ & 0 & 0 & 0 & 0 & 0 & 0 \\
\hline \multicolumn{7}{|l|}{ Transmission for Others (Wheeling) } \\
\hline 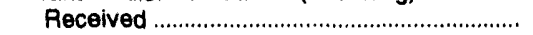 & 0 & 0 & 0 & 0 & 0 & 0 \\
\hline 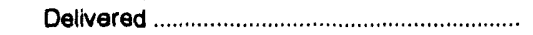 & 0 & 0 & 0 & 0 & 0 & 0 \\
\hline Net Transmission for Others .......................... & 0 & 0 & 0 & 0 & 0 & 0 \\
\hline 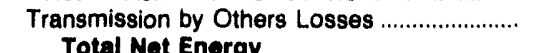 & 0 & 0 & 0 & 0 & 0 & 0 \\
\hline Generated and Recolved ......................... & 202,401 & 528,809 & 801,185 & 490,840 & 265,971 & 208,170 \\
\hline \multicolumn{7}{|l|}{ Dleposition of Energy } \\
\hline Sales to Ultimate Consumers & 188,406 & 498,073 & 753,433 & 472,082 & 256,244 & 195,768 \\
\hline Requirements Sales for Resale ....................... & 0 & 0 & 0 & 0 & 0 & 0 \\
\hline Nonrequirements Sales for Resale .................... & 0 & 0 & 0 & 0 & 0 & 0 \\
\hline Furnished Without Charge ................................ & 0 & 0 & 0 & 0 & 0 & 1,721 \\
\hline Used by Utility (excluding station use) ............ & 0 & 0 & 0 & 0 & 0 & 180 \\
\hline Losses & 13,994 & 30,736 & 47,732 & 18,867 & 9,727 & 10,501 \\
\hline Total Dleposition & 202,401 & 528,809 & 801,165 & 480,949 & 285,971 & 208,170 \\
\hline
\end{tabular}


Table 26. Electric Energy Account by Major U.S. Publicly Owned Electric Utility Within State, 1992 (Continued)

(Megawatthours)

\begin{tabular}{|c|c|c|c|c|c|c|}
\hline Item & $\begin{array}{l}\text { Virginia } \\
\text { Radford } \\
\text { City of } \\
\text { June } 30\end{array}$ & $\begin{array}{l}\text { Virginia } \\
\text { Salem } \\
\text { Clty of } \\
\text { June } 30\end{array}$ & $\begin{array}{l}\text { Virginia } \\
\text { Virginia } \\
\text { Tech } \\
\text { Electric } \\
\text { Service } \\
\text { June } 30\end{array}$ & $\begin{array}{l}\text { Washington } \\
\text { Centralia } \\
\text { City of } \\
\text { December } 31\end{array}$ & $\begin{array}{l}\text { Washington } \\
\text { Ellensburg } \\
\text { City of } \\
\text { December } 31\end{array}$ & $\begin{array}{l}\text { Washington } \\
\text { Port Angeles } \\
\text { City of } \\
\text { December } 31\end{array}$ \\
\hline 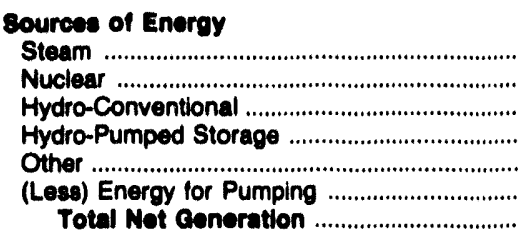 & $\begin{array}{r}0 \\
0 \\
5,441 \\
0 \\
0 \\
0 \\
5,441\end{array}$ & $\begin{array}{l}0 \\
0 \\
0 \\
0 \\
0 \\
0 \\
0\end{array}$ & $\begin{array}{r}14,860 \\
0 \\
0 \\
0 \\
0 \\
0 \\
14,860\end{array}$ & $\begin{array}{r}0 \\
0 \\
51,167 \\
0 \\
0 \\
0 \\
51,167\end{array}$ & $\begin{array}{l}0 \\
0 \\
0 \\
0 \\
0 \\
0 \\
0\end{array}$ & $\begin{array}{r}0 \\
0 \\
1,644 \\
0 \\
0 \\
0 \\
1,644\end{array}$ \\
\hline 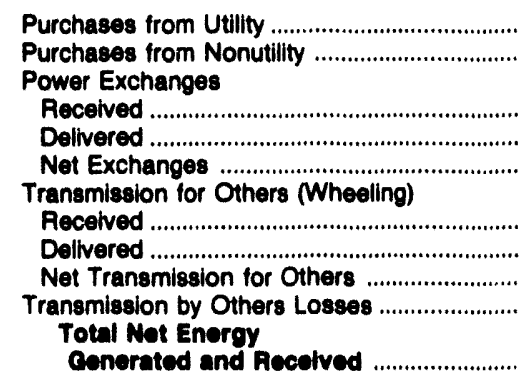 & $\begin{array}{r}283,464 \\
0 \\
\\
0 \\
0 \\
0\end{array}$ & $\begin{array}{r}324,954 \\
0 \\
0 \\
0 \\
0\end{array}$ & $\begin{array}{r}200,804 \\
0 \\
0 \\
0 \\
0\end{array}$ & $\begin{array}{r}162,458 \\
0 \\
0 \\
0 \\
0\end{array}$ & $\begin{array}{r}158,071 \\
0 \\
0 \\
0 \\
0\end{array}$ & $\begin{array}{r}678,841 \\
0 \\
0 \\
0 \\
0 \\
0 \\
0 \\
0 \\
0 \\
680,485\end{array}$ \\
\hline 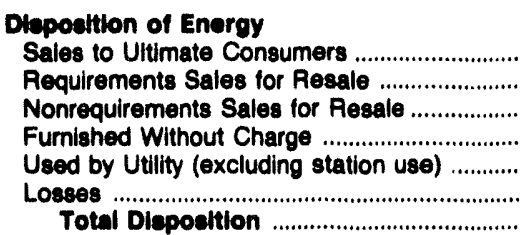 & $\begin{array}{r}280,018 \\
0 \\
0 \\
10 \\
12 \\
8,865 \\
288,905\end{array}$ & $\begin{array}{r}302,252 \\
0 \\
0 \\
0 \\
0 \\
22,702 \\
324,054\end{array}$ & $\begin{array}{r}207,679 \\
0 \\
0 \\
0 \\
0 \\
7,885 \\
215,864\end{array}$ & $\begin{array}{r}199,569 \\
0 \\
0 \\
0 \\
304 \\
304 \\
13,752 \\
213,625\end{array}$ & $\begin{array}{r}152,981 \\
0 \\
0 \\
0 \\
0 \\
6,090 \\
159,071\end{array}$ & $\begin{array}{r}875,463 \\
0 \\
0 \\
851 \\
510 \\
3,661 \\
680,485\end{array}$ \\
\hline
\end{tabular}

Note: Totals may not equal sum of components because of independent rounding. Double counting occurs in components of both sources and disposition of energy and thus neither provides a true total. Purchases from utilities, net interchanges, and net wheeling (except for imports) are included in net generation. Sales for resale is included in sales to ultimate consumers.

Source: Energy Information Administration, Form ElA-412, "Annual Report of Public Electric Utilities." 
Table 26. Electric Energy Account by Major U.S. Publicly Owned Electric Utillty Within State, 1992 (Continued)

(Megawatthours)

\begin{tabular}{|c|c|c|c|c|c|c|}
\hline Item & $\begin{array}{l}\text { Washington } \\
\text { PUD No } 1 \\
\text { of } \\
\text { Benton } \\
\text { County } \\
\text { December } 31\end{array}$ & $\begin{array}{c}\text { Washington } \\
\text { PUD No } 1 \\
\text { of } \\
\text { Chelan } \\
\text { County } \\
\text { December } 31\end{array}$ & $\begin{array}{l}\text { Washington } \\
\text { PUD No } 1 \text { of } \\
\text { Clallam } \\
\text { County } \\
\text { December } 31\end{array}$ & $\begin{array}{c}\text { Washington } \\
\text { PUD No } 1 \\
\text { of } \\
\text { Clark } \\
\text { County } \\
\text { December } 31\end{array}$ & $\begin{array}{l}\text { Washington } \\
\text { PUD No } 1 \text { of } \\
\text { Cowlitz } \\
\text { Count, } \\
\text { December } 31\end{array}$ & $\begin{array}{l}\text { Washington } \\
\text { PUD No } 1 \text { of } \\
\text { Douglas } \\
\text { County } \\
\text { December } 31\end{array}$ \\
\hline \multicolumn{7}{|l|}{ Sources of Energy } \\
\hline Steam & 0 & 0 & 0 & 0 & 0 & 0 \\
\hline Nuclear & 0 & 0 & 0 & 0 & 0 & 0 \\
\hline 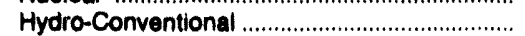 & 0 & $8,323,926$ & 0 & 0 & 162,475 & $4,035,812$ \\
\hline Hydro-Pumped Storage & 0 & 0 & 0 & 0 & 0 & 0 \\
\hline Other & 0 & 0 & 0 & 0 & 0 & 0 \\
\hline 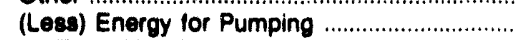 & 0 & 0 & 0 & 0 & 0 & 0 \\
\hline 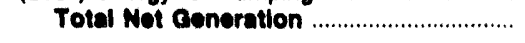 & 0 & $8,323,928$ & 0 & 0 & 162,475 & $4,035,812$ \\
\hline 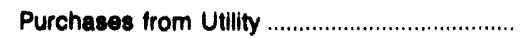 & $1,353,604$ & 229,962 & 473,811 & $3,085,950$ & $4,323,044$ & 162,510 \\
\hline $\begin{array}{l}\text { Purchases from Nonutllity ................................... } \\
\text { Power Exchanges }\end{array}$ & 0 & 0 & 248 & 157,712 & 0 & \\
\hline 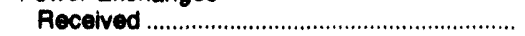 & 0 & 644,471 & 0 & 0 & 0 & 365,914 \\
\hline 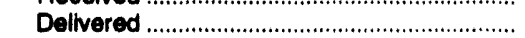 & 0 & 100,278 & 0 & 0 & 0 & 465,898 \\
\hline 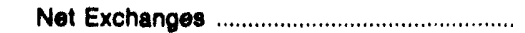 & 0 & 544,193 & 0 & 0 & 0 & $-99,984$ \\
\hline \multicolumn{7}{|l|}{ Transmission for Others (Wheeling) } \\
\hline 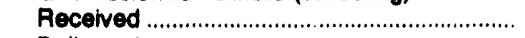 & 0 & 84,770 & 0 & 0 & 0 & 0 \\
\hline 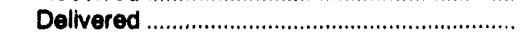 & 0 & 87,840 & 0 & 0 & 0 & 0 \\
\hline 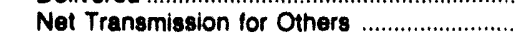 & 0 & $-3,070$ & 0 & 0 & 0 & 0 \\
\hline 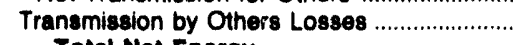 & 0 & 0 & 0 & 0 & 0 & 0 \\
\hline 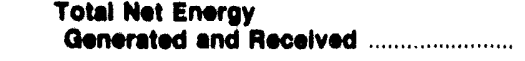 & $1,353,604$ & $9,095,011$ & 474,059 & $3,243,682$ & $4,485,519$ & $4,098,338$ \\
\hline \multicolumn{7}{|l|}{ Dlepositton of Energy } \\
\hline 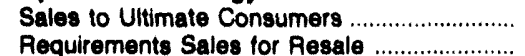 & $\begin{array}{r}1,295,684 \\
0\end{array}$ & $\begin{array}{l}1,157,860 \\
7,602,847\end{array}$ & $\begin{array}{r}437,843 \\
0\end{array}$ & $\begin{array}{r}3,097,698 \\
0\end{array}$ & $\begin{array}{r}4,404,205 \\
17,970\end{array}$ & $\begin{array}{r}553,444 \\
2,788,998\end{array}$ \\
\hline Nonrequirements Sales for Resale ................. & 0 & 296,114 & 0 & 0 & 0 & 278,099 \\
\hline Furnished Without Charge & 0 & 20 & 0 & 0 & 0 & 384,325 \\
\hline Used by Utility (excluding station use) ............ & 1,041 & 295 & 1,213 & 8,762 & 3,034 & 2,145 \\
\hline 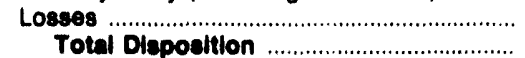 & $\begin{array}{r}56,879 \\
1,363,604\end{array}$ & $\begin{array}{r}37,875 \\
9,095,011\end{array}$ & $\begin{array}{r}34,903 \\
474,059\end{array}$ & $\begin{array}{r}137,202 \\
3,243,662\end{array}$ & $\begin{array}{r}60,310 \\
4,485,519\end{array}$ & $\begin{array}{r}91,327 \\
4,098,338\end{array}$ \\
\hline
\end{tabular}


Table 26. Electric Energy Account by Major U.S. Publicly Owned Electric Utility Within State, 1992 (Continued)

(Megawatthours)

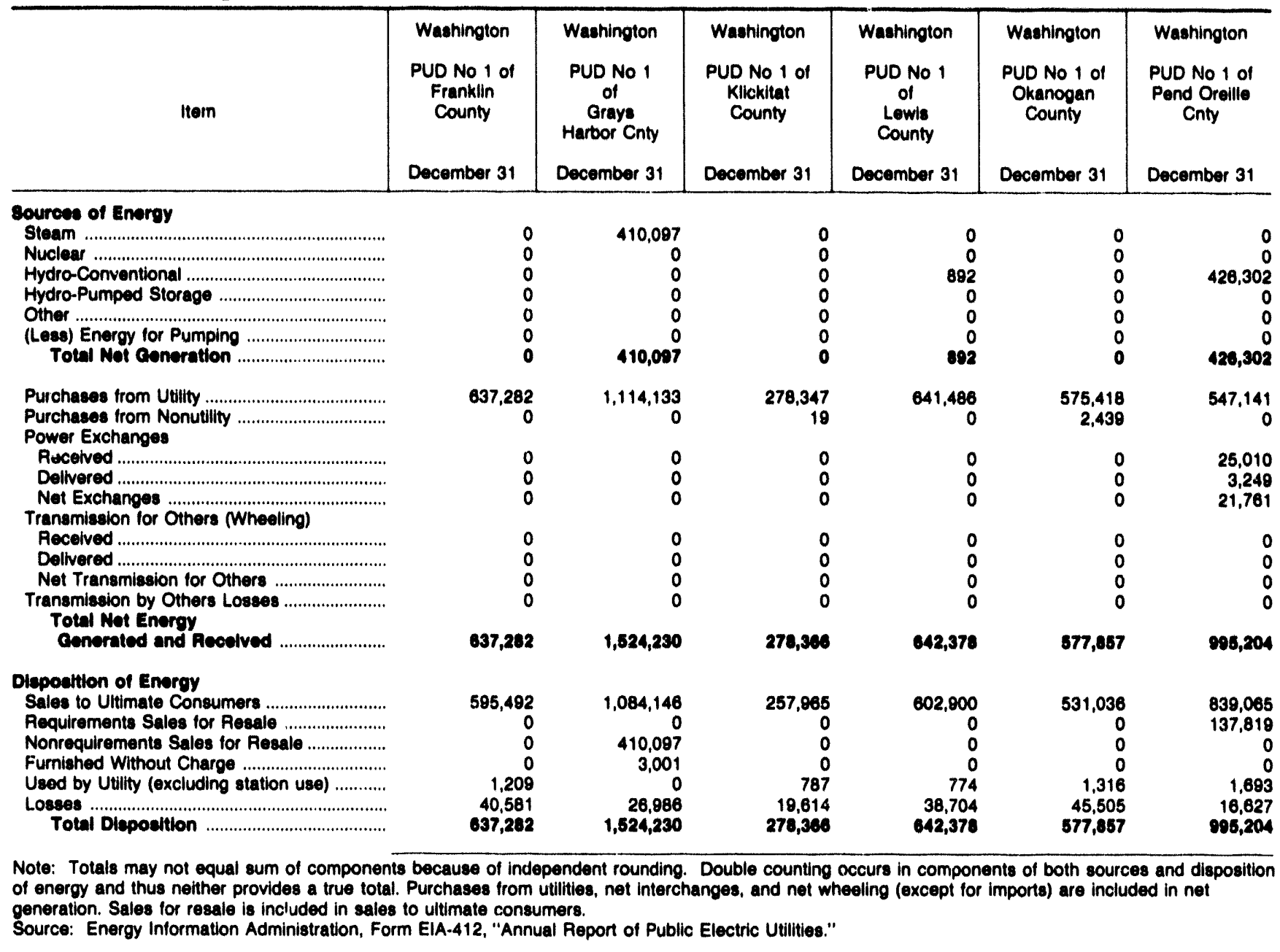


Table 26. Electric Energy Account by Major U.S. Publicly Owned Electric Utillty Within State, 1992 (Continued)

(Megawatthours)

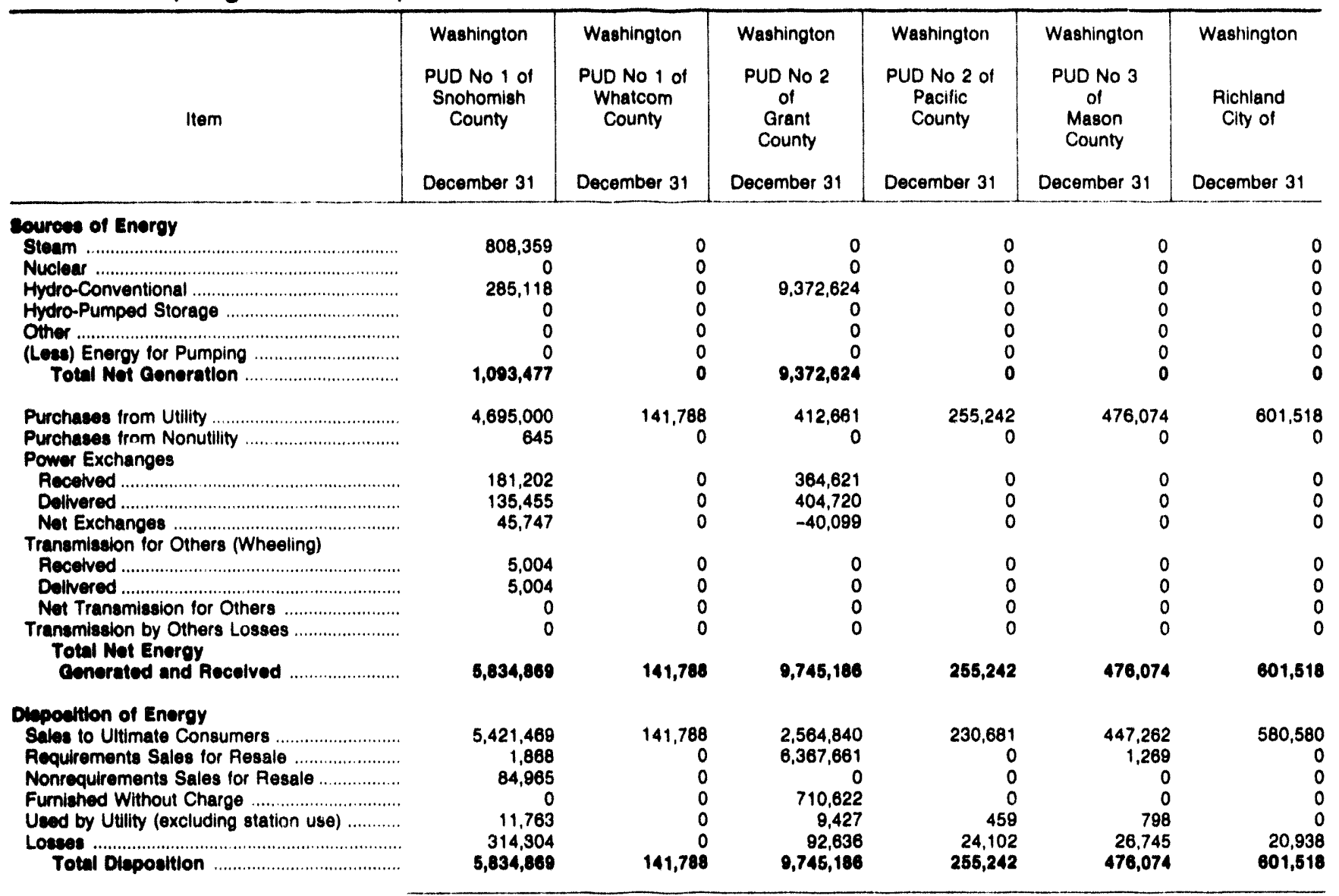

Note: Totals may not equal sum of components because of independent rounding. Double counting occurs in components of both sources and disposition of energy and thus neither provides a true total. Purchases from utilities, net interchanges, and net wheeling (except for imports) are included in net generation. Sales for resale is included in sales to ultimate consumers.

Source: Energy Information Administration, Form EIA-412, "Annual Report of Public Electric Utilities." 
Table 26. Electric Energy Account by Major U.S. Publicly Owned Electric UtIlity Within State, 1992 (Continued) (Megawatthours)

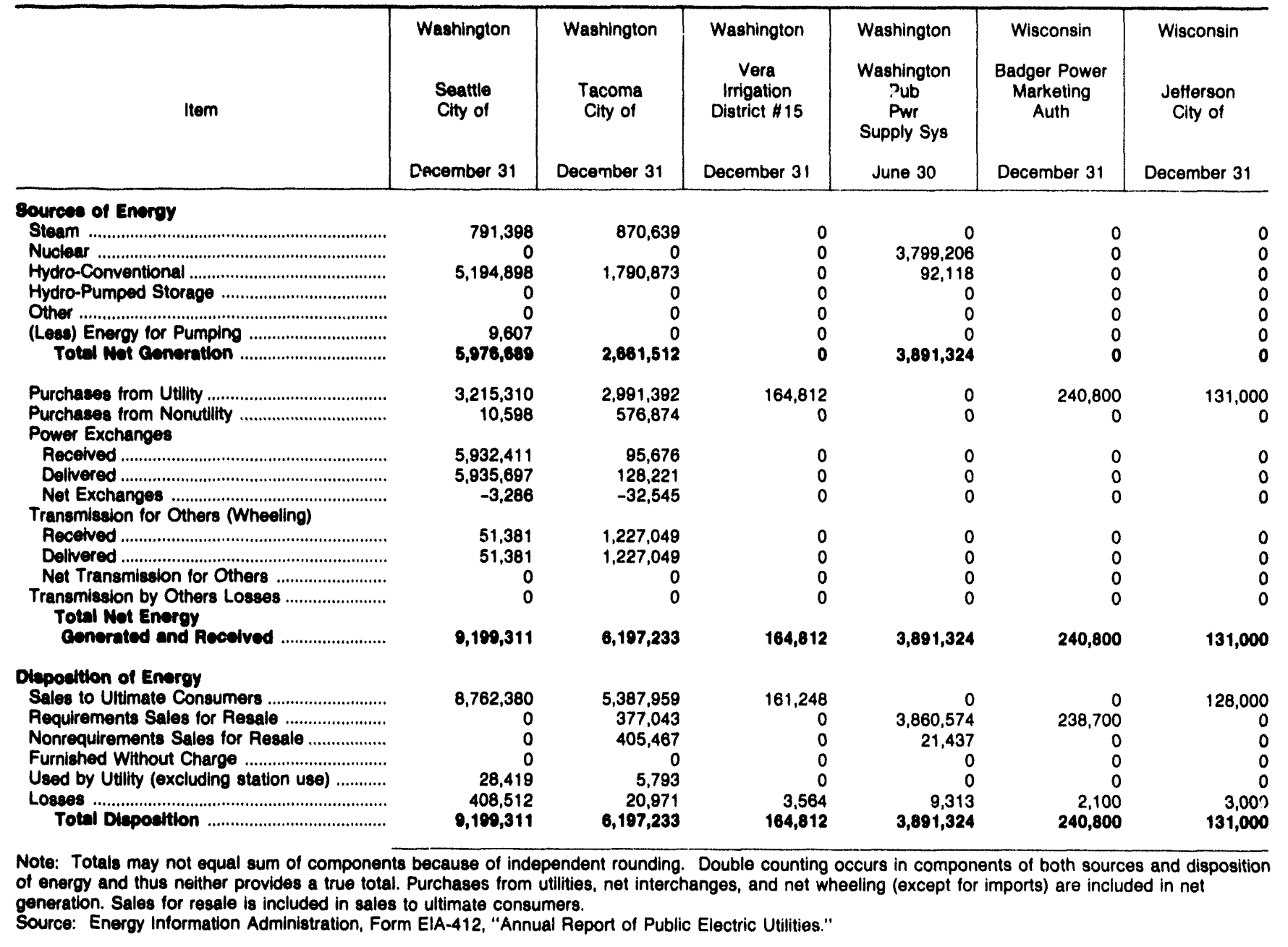


Table 26. Electric Energy Account by Major U.S. Publicly Owned Electric Utility Within State, 1992 (Continued)

(Megawatthours)

\begin{tabular}{|c|c|c|c|c|c|c|}
\hline Item. & $\begin{array}{c}\text { Wisconsin } \\
\begin{array}{c}\text { Kaukauna } \\
\text { City of }\end{array} \\
\text { December } 31\end{array}$ & $\begin{array}{c}\text { Wisconsin } \\
\text { Manitowoc } \\
\text { Public } \\
\text { Utilities } \\
\text { December } 31\end{array}$ & $\begin{array}{l}\text { Wisconsin } \\
\text { Marshfield } \\
\text { City of }\end{array}$ & $\begin{array}{c}\text { Wisconsin } \\
\text { Menasha } \\
\text { City of } \\
\text { December } 31\end{array}$ & $\begin{array}{l}\text { Wisconsin } \\
\text { New London } \\
\text { City of } \\
\text { December } 31\end{array}$ & $\begin{array}{c}\text { Wisconsin } \\
\text { Oconomowoc } \\
\text { Clty of }\end{array}$ \\
\hline \multicolumn{7}{|l|}{ Sources of Enorgy } \\
\hline 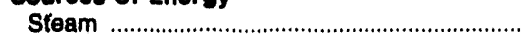 & 0 & 222,326 & 0 & 14,300 & 0 & \\
\hline Nuclear fon & 0 & $\begin{array}{r}02, w 2 \\
0\end{array}$ & 0 & 0 & 0 & 0 \\
\hline 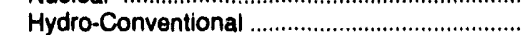 & 155,692 & 0 & 0 & 0 & 0 & 0 \\
\hline Hydro-Pumped Storage & 0 & 0 & 0 & 0 & 0 & 0 \\
\hline Other & 0 & 1,579 & 0 & 0 & 0 & 0 \\
\hline $\begin{array}{l}\text { (Less) Energy for Pumping } \\
\text { Total Not Generation }\end{array}$ & $\begin{array}{r}0 \\
155,692\end{array}$ & $\begin{array}{r}0 \\
223,905\end{array}$ & $\begin{array}{l}0 \\
0\end{array}$ & $\begin{array}{r}0 \\
14,300\end{array}$ & $\begin{array}{l}0 \\
0\end{array}$ & $\begin{array}{l}0 \\
0\end{array}$ \\
\hline 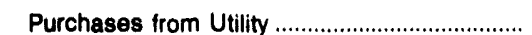 & 385,187 & 223,439 & 299,175 & 513,600 & 157,907 & 147,817 \\
\hline $\begin{array}{l}\text { Purchases from Nonutility } \\
\text { Power Exchanges }\end{array}$ & 0 & 0 & 0 & 0 & 0 & 0 \\
\hline 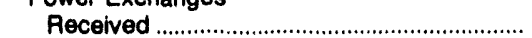 & 0 & 0 & 0 & 0 & 0 & 0 \\
\hline 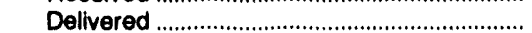 & 0 & 0 & 0 & 0 & 0 & 0 \\
\hline Net Exchanges & 0 & 0 & 0 & 0 & 0 & 0 \\
\hline \multicolumn{7}{|l|}{ Transmission for Others (Wheeling) } \\
\hline 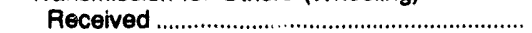 & 0 & 0 & 0 & 0 & 0 & 0 \\
\hline Delivered & 0 & 0 & 0 & 0 & 0 & 0 \\
\hline Net Transmission for Others ...................... & 0 & 0 & 0 & 0 & 0 & 0 \\
\hline 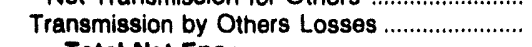 & 0 & 0 & 0 & 0 & 0 & 0 \\
\hline 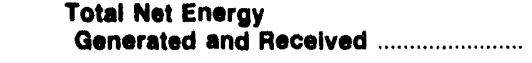 & 540,879 & 447,344 & 299,175 & 527,900 & 157,907 & 147,817 \\
\hline \multicolumn{7}{|l|}{ Disposition of Energy } \\
\hline 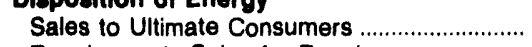 & 521,385 & 428,702 & 284,882 & 505,700 & 155,789 & 142,088 \\
\hline Requirements Sales for Resale ......................... & 0 & 0 & 0 & 14,300 & 0 & \\
\hline Nonrequirements Sales for Resale ................. & 0 & 0 & 0 & 0 & 0 & 0 \\
\hline Furnished Without Charge ................................... & 0 & 0 & 0 & 0 & 0 & \\
\hline Used by Utility (excluding station use) ............ & 597 & 438 & 1,750 & 0 & 203 & 0 \\
\hline $\begin{array}{l}\text { Losses } \\
\text { Total Disposition }\end{array}$ & $\begin{array}{r}18,897 \\
540,879\end{array}$ & $\begin{array}{r}18,204 \\
447,344\end{array}$ & $\begin{array}{r}12,543 \\
299,175\end{array}$ & $\begin{array}{r}7,900 \\
527,900\end{array}$ & $\begin{array}{r}1,915 \\
157,907\end{array}$ & $\begin{array}{r}5,729 \\
147,817\end{array}$ \\
\hline
\end{tabular}

Note: Totals may not equal sum of components because of independent rounding. Double counting occurs in components of both sources and disposition of energy and thus neither provides a true total. Purchases from utilities, net interchanges, and net wheeling (except for imports) are included in net generation. Sales for resale is included in sales to ultimate consumers.

Source: Energy Information Administration, Form ElA-412, "Annual Report of Public Electric Utilities." 
Table 26. Electric Energy Account by Major U.S. Publicly Owned Electric Utility Within State, 1992 (Continued) (Megawatthours)

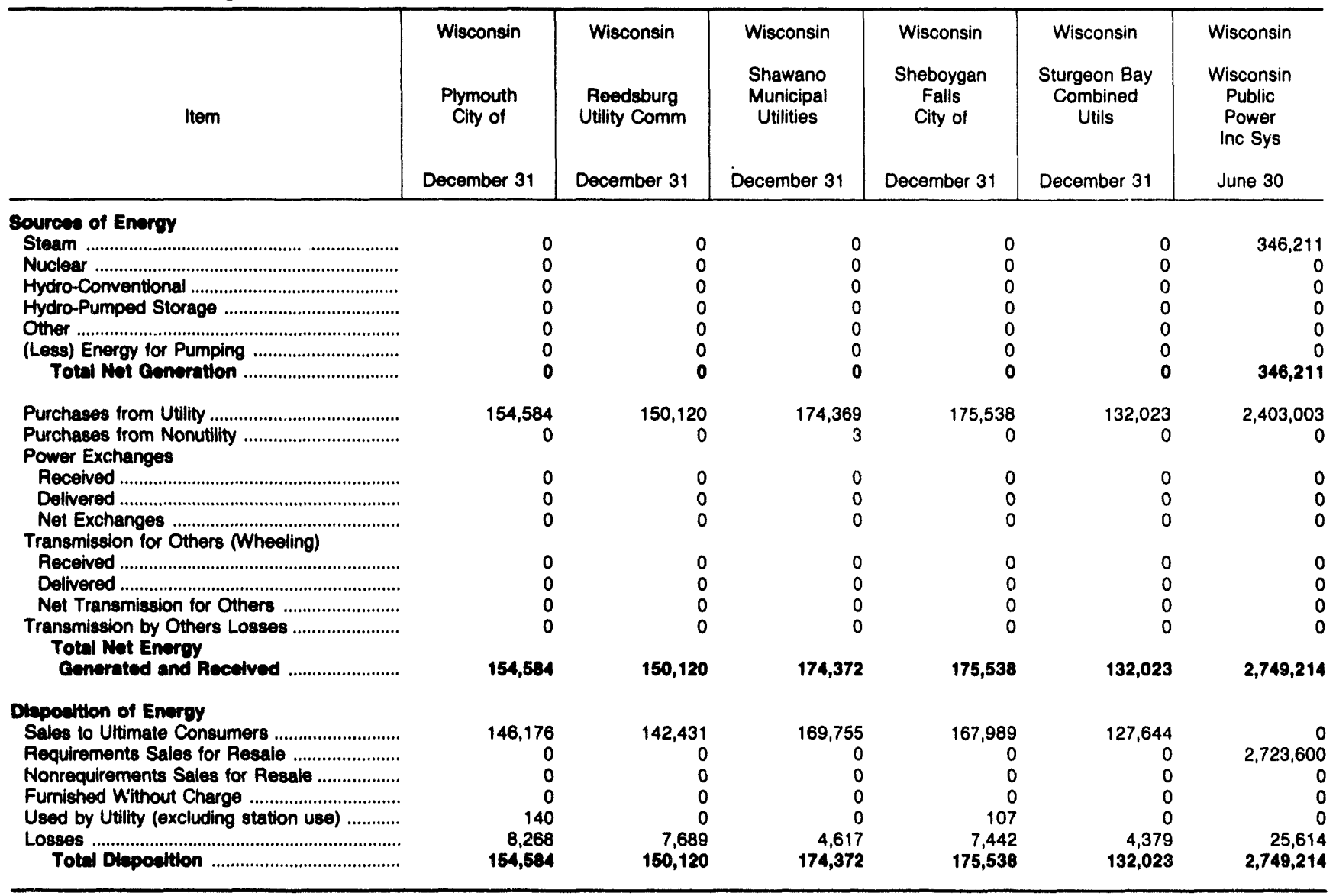

Note: Totals may not equal sum of components because of independent rounding. Double counting occurs in components of both sources and disposition of energy and thus neither provides a true total. Purchases from utilities, net interchanges, and net wheeling (except for imports) are included in net generation. Sales for resale is included in sales to ultimate consumers.

Source: Energy Information Administration, Form EIA-412, "Annual Report of Public Electric Utilities." 
Table 26. Electric Energy Account by Major U.S. Publicly Owned Electric Utility Within State, 1992 (Continued)

(Megawatthours)

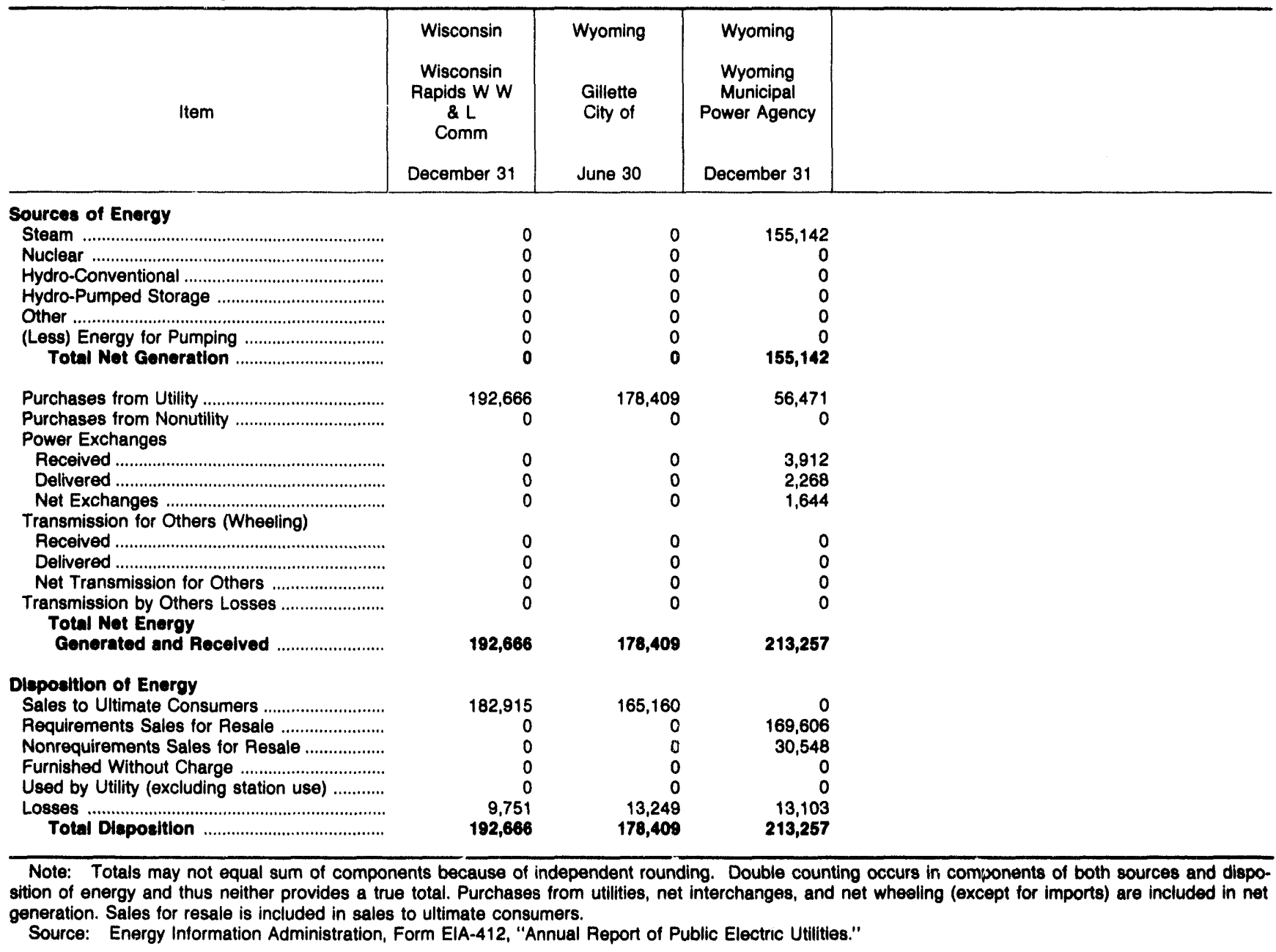




\section{Summary Statistics of U.S. Federal Electric Utilities}

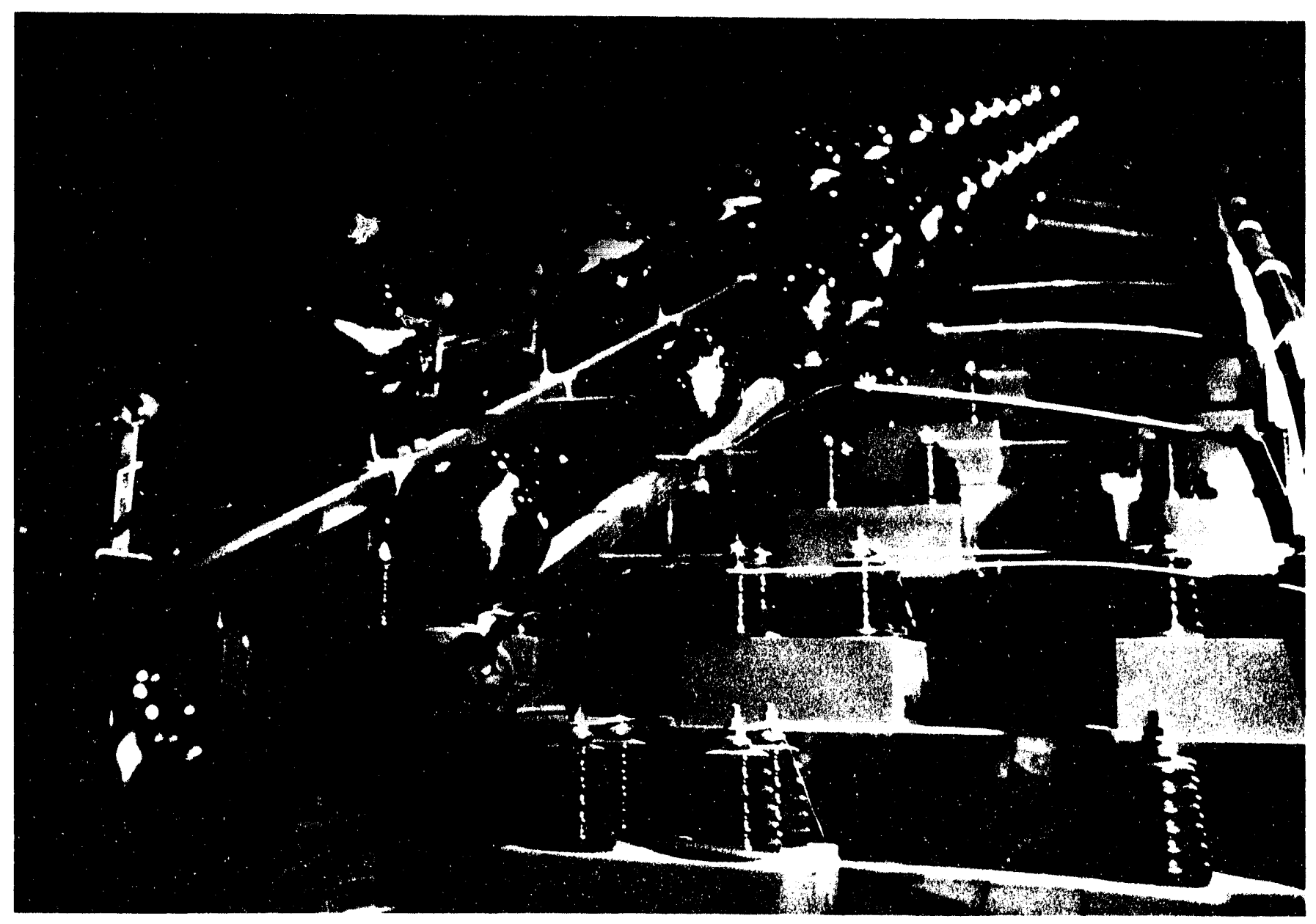

Ultra high voltage transmission lines near Vancouver, Washington, owned by Bonneville Power Administration. 


\section{Financial Performance}

\section{Background}

There are 10 Federal electric utilities in the United States. They are the Department of Defence-U.S. Army Corps of Engineers; the Department of Energy-the Alaska, Bonneville, Southeastern, Southivestern, and Western Area Power Administrations; the Department of Interior-U.S. Bureau of Indian Affairs and the U.S. Bureau of Reclamation; the Department of StateInternational Water and Boundary Commission; and, the Tennessee Valley Authority. The Federal electric utilities are primarily generators and wholesalers of electricity rather than distributors to ultimate consumers. Federal electric utilities operate over 150 power plants and produce approximately 8 percent of the electricity generated in the United States. Most of the power plants are Federal hydroelectric projects initially designed for flood control and irrigation purposes. Federal power is not sold for profit, but to recover the cost of operations. Most Federal generation is sold for resale to municipals, cooperative electric utilities, and other nonprofit preference customers, as required by law. There are three major producers of electricity: the Tennessee Valley Authority (TVA), the largest Federal producer, the U.S. Army Corps of Engineers (USCE), and the U.S. Bureau of Reclamation (USBR). The TVA markets its own power while the generation by the USCE, except for the North Central Division (Saint Mary's Falls at Sault St. Marie, Michigan), and the USBR is marketed by four of the Federal power marketing administrations - Bonneville, Suitheastern, Southwestern, and Western Area. These four power marketing administrations also purchase energy for resale from other electric utilities in the United States and Canada. Alaska, the fifth power marketing administration, operates its own power plants and distributes power to ultimate consumers.

The Tennessee Valley Authority (TVA) was the first of the wholesale marketing organizations to be formed. It was authorized under the Tennessee Valley Authority Act in 1933 "for the purposes of maintaining and operating the properties now owned by the United States in the vicinity of Muscle Shoals, Alabama, in the interest of national defense and for agricultural and industrial development, and to improve navigation in the Tennessee River and to control the destructive flood waters in the Tennessee River and Mississippi River Basins." It was given the authority to both own and operate dams, transmission lines, and power plants along the Tennessee River and its tributaries. By the beginning of World War II, the TVA had developed most of its water resources, but growing war demands and domestic needs required new capacity. In 1949,
Congress approved construction of a steam plant, opening the way for construction of other nonhydroelectric facilities. The TVA's fossil-fueled capacity and nuclear capacity now each exceed its hydroelectric capacity (run of river and pumped storage). In 1992, the TVA sold 93.6 million megawatthours to its wholesale customers.

During the depression in the early 1930 's, New Deal legislation was passed that authorized construction of a number of Federal dams, including Grand Coulee and Bonneville dams in the Pacific Northwest. In 1937, the Government decided that the U.S. Bureau of Reclamation would be responsible for building and operating the dams in the Northwest, and a new marketing administration, the Bonneville Power Administration (BPA), was created by the Bonneville Project Act of 1937 to build and operate transmission facilities and to market the power. The BPA grew, but in the late 1960 's, like the TVA, the BPA faced a potential shortage of hydroelectric capacity to meet their load. In 1980, the Pacific Northwest Electric Power Planning and Conservation Act gave the BPA the authority to plan for and acquire additional power to meet its growing load requirements. The BPA's responsibilities were also extended from only marketing Federal power to supplying the power. Its authority to supply power, however, was restricted to obtaining it from plants built by others. The BPA cannot build its own power plants. Only the BPA and the TVA are responsible for meeting their customers loads. Under the 1980 Act, the BPA also must protect and enhance the fish and wildlife of the Columbia River and its tributaries. In 1992, the BPA sold 48.9 million megawatthours of energy to its wholesale customers from over 30 Federally owned dams operated by either the U.S. Bureau of Reclamation or the U.S. Army Corps of Engineers and from non-Federal system generators.

In 1943, the Southwestern Power Administration (SWPA) was created using the Executive Branch's emergency war powers authority to meet the growing power demands from weapons development and domestic needs. Later, the SWPA's authority to continue to operate after World War II came from the Flood Control Act of 1944. Initially, the SWPA was assigned to market power from dams in Arkansas, Oklahoma, and Texas that were operated by the U.S. Department of Army to serve munitions plants. In 1945, the SWPA was designated as the agent for marketing power generated by the U.S. Army Corps of Engineers in the States of Arkansas, Kansas, Louisiana, Missouri, Oklahoma, and Texas. Today, the SWPA sells power from 24 hydroelectric facilities in these states that total 2,158 megawatts of installed capacity. In 1992, the SWPA sold 6.6 million megawatthours to its wholesale customers. 
The third power marketing administration, Southeastern Power Administration (SEPA), was established in 1950 under the authority of the Flood Control Act of 1944 to sell power produced by the U.S. Army Corps of Engineers in the Southeast. The SEPA currently markets power in West Virginia, Virginia, North Carolina, South Carolina, Georgia, Florida, Alabama, Mississippi, Tennessee, and Kentucky. The SEPA is unique from the other marketing authorities in that it owns no transmission lines. It must rely on private firms to transmit the power it sells. In its role to market the energy generated by the Southeastern Federal reservoir projects, it participated in the establishment of the Southeastern Federal Power Alliance last July, which consists of SEPA, the South Atlantic Division of the U.S. Army Corps of Engineers, and SEPA's preference customers. The purpose of this organization is to improve communication and establish a strategy by which the three groups can better implement the Federal Power Program in the southeast. In 1992, the SEPA sold over 7.0 million megawathours to its wholesale customers.

The Alaska Power Marketing Administration (APA) was formed in 1967 under the Flood Control Act of 1944 to both operate and market the power from two hydroelectric plants in Alaska: the Eklutna Project (30 megawatts) and the Snettisham Project (78 megawatts). The TVA and the APA are the only two Federal marketing organizations to operate their own plants. Cur- rently, the Federal Government is investigating the potential sale of this marketing administration.

The last Federal marketing administration to be created was the Western Area Power Administration (WAPA), which was formed in 1977 when the Congress created the U.S. Department of Energy and assigned the other Federal marketing administrations to be a part of the new energy department. The territory that the WAPA serves covers the 15 Central and Western States of Arizona, California, Colorado, Iowa, Kansas, Minnesota, Montana, Nebraska, Nevada, New Mex ico, North Dakota, South Dakota, Texas, Utah, and Wyoming. Its mission is to market Federally-owned hydroelectric resources "... in such a manner as to encourage the most widespread use thereof at the lowest possible rates to consumers consistent with sound business principles ..." The WAPA's authority was extended through the Hoover Power Plant Act of 1984 to require customer utilities to undertake certain conservation activities and to withhold a part of customer's power allocation if they did not comply. In 1992, the WAPA marketed hydroelectric power from 51 plants operated by the U.S. Bureau of Reclamation, the U.S. Army Corps of Engineers, and the International Boundary and Water Commission. In addition, the WAPA markets the Federal Government's 547 megawatt entitlement from the coal-fired Navajo Generating Station in Arizona. The WAPA was responsible for selling 29.7 million megawatthours to its wholesale customers in 1992. 


\section{The Largest Federal Producer}

The Tennessee Valley Authority provides power to approximately 110 municipal and 50 cooperative electric systems for distribution to over 3.3 million customers. The four largest municipalities are the Tennessee cities of Memphis, Nashville, Chattanooga, and Knoxville. Of the $124,080.5$ million megawatthours of electricity generated in 1992 by TVA, the four largest municipals distributed 30.8 million megawatthours or 24.9 percent of TVA's total generation to their customers. The 160 locally owned distributors serve an 80,000 -square-mile area in parts of seven States. In 1992, the TVA accounted for approximately half of the total net generation by the Federal electric utilities.

\section{Composite Income Statement}

As of the end of the fiscal year (September 31, 1992), operating revenues for the Federal electric utilities totaled $\$ 7,871.8$ million. Total electric utility operating expenses were $\$ 5,883.0$ million in 1992. A major portion of these total electric utility operating expenses include production expenses that totaled $\$ 4,143.8$ million. Production expenses for the Federal electric utilities were 70.4 percent of total electric utility operating expenses. Total electric operation and maintenance expenses were $\$ 4,989.3$ million, 84.8 percent of total electric utility operating expenses for the Federal electric utilities.

Total electric utility income for the Federal electric utilities was $\$ 2,043.1$ million. Income deductions totaled $\$ 1,987.8$ million. Of the income deductions,
$\$ 1,764.7$ million came from interest on long-term debt, which represented 88.8 percent of total income deductions. Net income for the Federal electric utilities as of the end of September 1992 was $-\$ 54.9$ million due to the fact that electric utility operating revenues decreased to $\$ 7,871.8$ million, compared with $\$ 8,193.9$ million in 1991.

\section{Balance Sheet}

As of September 30, 1992, net investment in electric utility plant for the Federal electric utilities was $\$ 32,463.9$ million, including construction work in progress which increased approximately 50 percent to $\$ 14,200.5$ million, compared with $\$ 7,097.2$ million in 1991.

Total proprietary capital was $\$ 10,925.3$ million in 1992 , a slight decrease from $\$ 11,251.7$ million in $1991,23.7$ percent of total liabilities and other credits. The amount of long-term debt and current and accrued liabilities was $\$ 35,179.4$ million, 76.2 percent of total liabilities and other credits of the Federal electric utilities.

\section{Sales of Electric Power}

In 1992, the Federal electric utilities had sales of electric energy to ultimate consumers of 49.9 million megawatthours and electricity sold for resale of 186.3 million megawatthours. Total disposition of energy was 251.8 million megawatthours of which the Federal electric utilities had a net generation of 240.1 million megawatthours (Table 32). 
Table 27. Statement of Income by U.S. Federal Electric Utility, 1992 (Thousand Dollars)

\begin{tabular}{|c|c|c|c|c|c|}
\hline Item & $\begin{array}{l}\text { Alaska } \\
\text { Power } \\
\text { Admin } \\
\text { September } 30\end{array}$ & $\begin{array}{l}\text { Bonnevilie } \\
\text { Power } \\
\text { Admin } \\
\text { September } 30\end{array}$ & $\begin{array}{l}\text { Southeastern } \\
\text { Power } \\
\text { Admin } \\
\text { September } 30\end{array}$ & $\begin{array}{l}\text { Southwestern } \\
\text { Power } \\
\text { Admin } \\
\text { September } 30\end{array}$ & $\begin{array}{l}\text { Western Area } \\
\text { Power } \\
\text { Admin } \\
\text { September } 30\end{array}$ \\
\hline 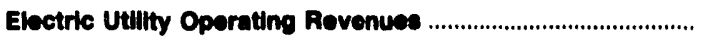 & 9,437 & $1,021,042$ & 148,212 & 102,789 & 598,178 \\
\hline 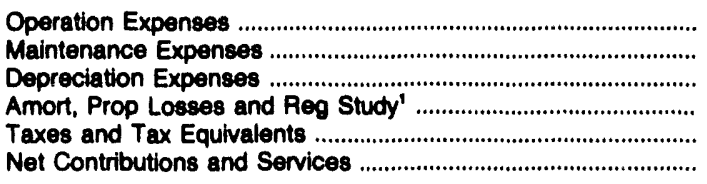 & $\begin{array}{r}3,177 \\
489 \\
2,869 \\
0 \\
0 \\
0\end{array}$ & $\begin{array}{r}1,740,702 \\
93,898 \\
101,381 \\
44,181 \\
0 \\
0\end{array}$ & $\begin{array}{r}30,854 \\
0 \\
97 \\
0 \\
0 \\
0\end{array}$ & $\begin{array}{r}75,718 \\
10,274 \\
2,547 \\
0 \\
0 \\
0\end{array}$ & $\begin{array}{r}555,686 \\
0 \\
0 \\
0 \\
0 \\
0\end{array}$ \\
\hline $\begin{array}{l}\text { Total Electric Utilty Operating } \\
\text { Expenses }\end{array}$ & 6,536 & $1,990,162$ & 30,950 & 88,539 & 555,686 \\
\hline 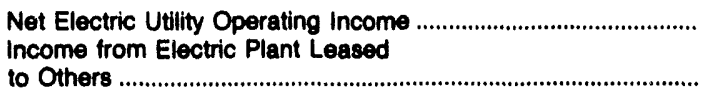 & $\begin{array}{r}2,902 \\
0\end{array}$ & $\begin{array}{r}-59,120 \\
325\end{array}$ & 115,262 & 14,250 & $\begin{array}{r}40,482 \\
0\end{array}$ \\
\hline 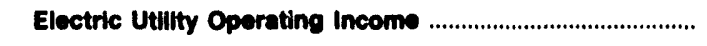 & 2,902 & $-68,796$ & 115,282 & 14,250 & 40,492 \\
\hline Other Electric Income & 0 & 4,897 & 15 & 0 & 161,510 \\
\hline $\begin{array}{l}\text { Other Electric Deductions } \\
\text { Allowance for Other Funds Used }\end{array}$ & 0 & 0 & 0 & 0 & 131,544 \\
\hline $\begin{array}{l}\text { During Construction } \\
\text { Taxes on Other Income and Deduct' }\end{array}$ & $\begin{array}{l}0 \\
0\end{array}$ & $\begin{array}{l}0 \\
0\end{array}$ & $\begin{array}{r}0 \\
63\end{array}$ & $\begin{array}{l}0 \\
0\end{array}$ & $\begin{array}{l}0 \\
0\end{array}$ \\
\hline 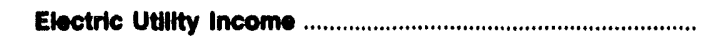 & 2,002 & $-53,898$ & 115,214 & 14,250 & 70,458 \\
\hline $\begin{array}{l}\text { Income Deductions from Interest } \\
\text { on Long-term Debt } \\
\text { Other Income Deductions } \\
\text { Allowance for Borrowed Funds Used }\end{array}$ & $\begin{array}{r}4,826 \\
0\end{array}$ & $\begin{array}{r}170,341 \\
2,214\end{array}$ & $\begin{array}{r}54 \\
115,159\end{array}$ & $\begin{array}{r}728 \\
0\end{array}$ & 50,504 \\
\hline 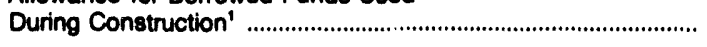 & 0 & $-15,407$ & 0 & 0 & 0 \\
\hline 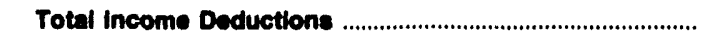 & 4,828 & 167,148 & 115,214 & 728 & 50,504 \\
\hline 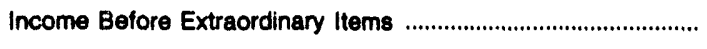 & $-1,924$ & $-211,046$ & 0 & 13,522 & 19,954 \\
\hline 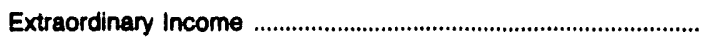 & 0 & 0 & 0 & 0 & 0 \\
\hline 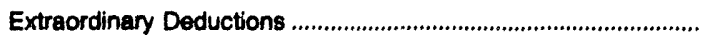 & 0 & 0 & 0 & 0 & 0 \\
\hline Net Income & $-1,924$ & $-211,046$ & $\mathbf{0}$ & 13,522 & 18,954 \\
\hline
\end{tabular}

Data reporting initiated in 1992.

See endnotes at end of this table. 
Table 28. Balance Sheet by U.S. Federal Electric Utility on September 30, 1992 (Continued)

(Thousand Dollars)

\begin{tabular}{|c|c|c|c|c|c|}
\hline \multirow[b]{2}{*}{ Item } & \multirow[b]{2}{*}{$\begin{array}{c}\text { Tennessee } \\
\text { Valley } \\
\text { Authority } \\
\text { September } 30\end{array}$} & \multicolumn{2}{|c|}{ U.S. Bureau of Indian Affairs } & \multirow[b]{2}{*}{$\begin{array}{l}\text { USCE- } \\
\text { North Central } \\
\text { Division }\end{array}$} & \multirow[b]{2}{*}{$\begin{array}{c}\text { Total } \\
\text { September } 30\end{array}$} \\
\hline & & $\begin{array}{c}\text { Mission } \\
\text { Valley Power }\end{array}$ & September 30 & & \\
\hline \multicolumn{6}{|l|}{ Electric Utility Plant } \\
\hline 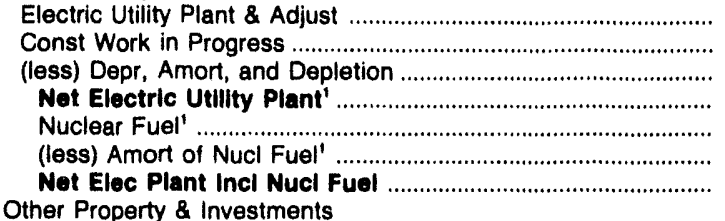 & $\begin{array}{r}16,558,879 \\
13,264,737 \\
4,931,940 \\
24,891,677 \\
1,220,621 \\
1,217,165 \\
24,895,133\end{array}$ & $\begin{array}{r}21,316 \\
992 \\
8,712 \\
13,596 \\
0 \\
0 \\
13,596\end{array}$ & $\begin{array}{r}24,064 \\
0 \\
9,539 \\
14,525 \\
0 \\
0 \\
14,525\end{array}$ & $\begin{array}{r}12,343 \\
0 \\
3,292 \\
9,052 \\
0 \\
0 \\
9,052\end{array}$ & $\begin{array}{r}24,863,032 \\
14,200,464 \\
6,599,583 \\
32,463,913 \\
1,220,621 \\
1,217,165 \\
32,467,369\end{array}$ \\
\hline Nonutility Property ................... & 4,105 & 0 & 0 & 0 & 4.144 \\
\hline 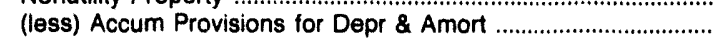 & 2,998 & 0 & 0 & 0 & $\begin{array}{l}4,144 \\
2,998\end{array}$ \\
\hline Invest in Assoc Enterprises & & 0 & 0 & 0 & 0 \\
\hline $\begin{array}{l}\text { Invest \& Special Funds } \\
\text { Total Other Property \& Investments }\end{array}$ & $\begin{array}{l}188,249 \\
189,357\end{array}$ & $\begin{array}{l}0 \\
0\end{array}$ & $\begin{array}{l}0 \\
0\end{array}$ & $\begin{array}{l}0 \\
\mathbf{0}\end{array}$ & $\begin{array}{l}188,249 \\
189,396\end{array}$ \\
\hline \multicolumn{6}{|l|}{ Current and Accrued Assets } \\
\hline 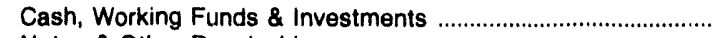 & 609,245 & 4,290 & 18,670 & 63 & $1,715,400$ \\
\hline 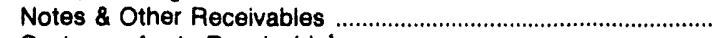 & 40,984 & 0 & 1,495 & 0 & 75,773 \\
\hline 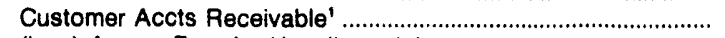 & 216,340 & 679 & 1,959 & 0 & 319,893 \\
\hline (less) Accum Prov for Uncollected Accts ..................................... & 0 & 36 & 223 & 0 & 329 \\
\hline Fuel Stock \& Exp Undistr' ${ }^{1} \ldots \ldots \ldots \ldots \ldots \ldots$ & 147,042 & 0 & 0 & 0 & 147,042 \\
\hline 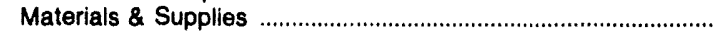 & 271,078 & 117 & 1,936 & 0 & 346,631 \\
\hline 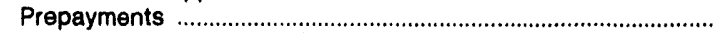 & 0 & 0 & 0 & 0 & 139,100 \\
\hline 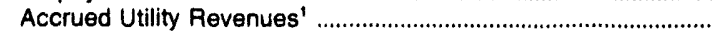 & 435,965 & 0 & 433 & 0 & 526,968 \\
\hline Miscellaneous Current \& Accrued Assets ....................................... & & 0 & 2,085 & 0 & 131,284 \\
\hline $\begin{array}{l}\text { Total Current a Accrued Assets } \\
\text { Deferred Debits }\end{array}$ & $1,720,654$ & 5,050 & 26,355 & 63 & $3,401,762$ \\
\hline Unamortized Debt Expenses & $1,061,606$ & 0 & 0 & 0 & $1,080,023$ \\
\hline Extraordinary Losses, Study Cost & 0 & 0 & 0 & 0 & $\begin{array}{r}1,000,0<0 \\
0\end{array}$ \\
\hline Misc Debt, R \& D Exp, Unamrt Losses .......................................... & $1,452,816$ & 0 & 0 & 0 & $9,010,000$ \\
\hline $\begin{array}{l}\text { Total Deferred Debits } \\
\text { Total Assets Q Other Debits }\end{array}$ & $\begin{array}{r}2,514,422 \\
29,319,566\end{array}$ & $\begin{array}{r}0 \\
18,647\end{array}$ & $\begin{array}{r}0 \\
40,880\end{array}$ & $\begin{array}{r}0 \\
9,115\end{array}$ & $\begin{array}{l}10,080,023 \\
46,148,550\end{array}$ \\
\hline \multicolumn{6}{|l|}{ Proprietary Capital } \\
\hline 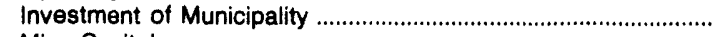 & 688,315 & 0 & 0 & 0 & $12,425,424$ \\
\hline 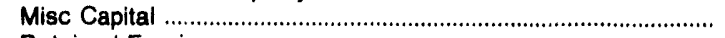 & 0 & 0 & 0 & 0 & $-6,721,010$ \\
\hline Retained Earnings & $3,062,003$ & 11,907 & 28,461 & 9,115 & $5,220,896$ \\
\hline \multirow{2}{*}{\multicolumn{6}{|c|}{ Long-term Debt }} \\
\hline Bonds ................. & & & & & \\
\hline Advances from Municipality \& Other & $\begin{array}{r}10,0<0,000 \\
0\end{array}$ & 6,140 & 8,083 & 0 & $\begin{array}{r}21,430,5 / 3 \\
6,826,193\end{array}$ \\
\hline 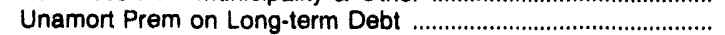 & 0 & 0 & 0 & 0 & $\begin{array}{r}0,820,183 \\
0\end{array}$ \\
\hline 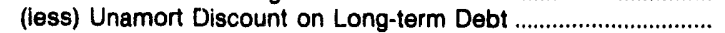 & 320,581 & 0 & 0 & 0 & 320,581 \\
\hline 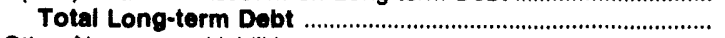 & $19,204,419$ & 6,140 & 8,083 & $\mathbf{0}$ & $27,936,186$ \\
\hline \multicolumn{6}{|l|}{ Other Noncurrent Liabilities } \\
\hline Accum Operating Provisions & 0 & 0 & 246 & 0 & 246 \\
\hline Accum Prov for Rate Refunds' & 0 & 0 & 0 & 0 & 0 \\
\hline 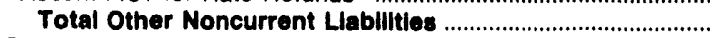 & 0 & $\mathbf{0}$ & 246 & $\mathbf{0}$ & 246 \\
\hline \multicolumn{6}{|l|}{ Current and Accrued Liabilities } \\
\hline 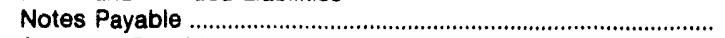 & $1.707,283$ & 0 & 479 & 0 & $1,707,762$ \\
\hline Accounts Payable & 883,849 & -96 & 1,879 & 0 & $1,298,858$ \\
\hline 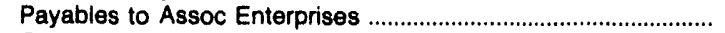 & 0 & 0 & 0 & 0 & 164 \\
\hline Customer Deposits . & 0 & 278 & 1,207 & 0 & 1,485 \\
\hline Taxes Accrued & 0 & 5 & 0 & 0 & 5 \\
\hline Interest Accrued & 478,573 & 0 & 0 & 0 & 508,868 \\
\hline 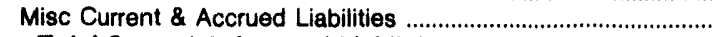 & $3,295,124$ & 134 & 505 & 0 & $3,726,031$ \\
\hline \multirow{2}{*}{\multicolumn{6}{|c|}{ Deferred Credits }} \\
\hline 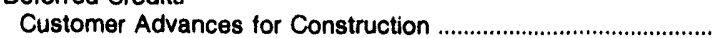 & 0 & 279 & & & \\
\hline Other Deferred Credits & 0 & 0 & 0 & 0 & 37,460 \\
\hline 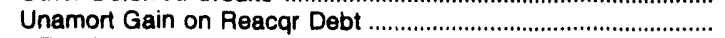 & 0 & 0 & 0 & 0 & 0 \\
\hline Total Deferred Credits & & 279 & 21 & & 43,636 \\
\hline 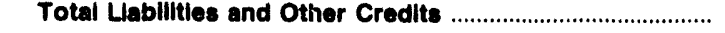 & $29,319,586$ & 18,647 & 40,880 & 9,115 & $46,148,560$ \\
\hline
\end{tabular}

1 Data reporting initiated in 1992.

2 Includes data only for Saint Mary's Falls at Sault St. Marie, Michigan. The rest of the generation produced by the U.S. Army Corps of Engineers (USCE) is sold by the Department of Energy-Bonneville, Southeastern, Southwestern, and Western Area Power Administrations.

Note: Totals may not equal sum of components because of independent rounding.

Source: Energy Information Administration, Form EIA-412, "Annual Report of Public Electric Utilities." 
Table 29. Electrlc Operation and Maintenance Expenses by

U.S. Federal Electric Utility, 1992

(Thousand Dollars)

\begin{tabular}{|c|c|c|c|c|c|}
\hline Item & $\begin{array}{l}\text { Alaska } \\
\text { Power } \\
\text { Admin } \\
\text { September } 30\end{array}$ & $\begin{array}{l}\text { Bonneville } \\
\text { Power } \\
\text { Admin } \\
\text { September } 30\end{array}$ & $\begin{array}{l}\text { Southeastern } \\
\text { Power } \\
\text { Admin } \\
\text { September } 30\end{array}$ & $\begin{array}{l}\text { Southwestern } \\
\text { Power } \\
\text { Admin } \\
\text { September } 30\end{array}$ & $\begin{array}{l}\text { Western Area } \\
\text { Power } \\
\text { Admin } \\
\text { September } 30\end{array}$ \\
\hline $\begin{array}{l}\text { Production Expenese } \\
\text { Steam Power Generation } \\
\text { Nuclear Power Generation } \\
\text { Hydraulic Power Generation } \\
\text { Other Power Generation } \\
\text { Purchased Power } \\
\text { Other Production Expenses }\end{array}$ & $\begin{array}{r}0 \\
0 \\
705 \\
0 \\
0 \\
0\end{array}$ & $\begin{array}{r}0 \\
0 \\
1,282 \\
0 \\
146,310 \\
1,440,486\end{array}$ & $\begin{array}{r}0 \\
0 \\
2,336 \\
0 \\
2,786 \\
0\end{array}$ & $\begin{array}{r}0 \\
0 \\
62,895 \\
0 \\
5,032 \\
2,582\end{array}$ & $\begin{array}{r}0 \\
0 \\
179,038 \\
0 \\
302,632 \\
25,248\end{array}$ \\
\hline 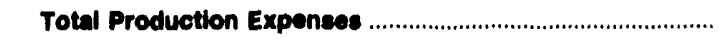 & 705 & $1,588,078$ & 5,122 & 70,509 & 506,918 \\
\hline 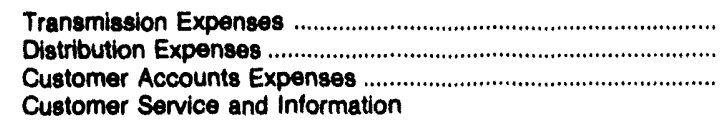 & $\begin{array}{r}912 \\
0 \\
0\end{array}$ & $\begin{array}{r}166,039 \\
0 \\
1,194\end{array}$ & $\begin{array}{r}23,102 \\
0 \\
40\end{array}$ & $\begin{array}{r}10,818 \\
0 \\
0\end{array}$ & $\begin{array}{r}3,570 \\
0 \\
0\end{array}$ \\
\hline $\begin{array}{l}\text { Expenses } \\
\text { Sales Expenses . } \\
\text { Administrattve and General }\end{array}$ & $\begin{array}{l}0 \\
0\end{array}$ & $\begin{array}{l}0 \\
0\end{array}$ & $\begin{array}{l}0 \\
2\end{array}$ & $\begin{array}{r}0 \\
4,864\end{array}$ & $\begin{array}{l}0 \\
0\end{array}$ \\
\hline 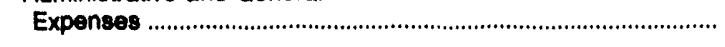 & 2,049 & 79,289 & 2,588 & 0 & 45,198 \\
\hline $\begin{array}{l}\text { Total Ebetrlc Operation and } \\
\text { Maintenance Expenses }\end{array}$ & 3,666 & $1,834,600$ & 30,854 & 85,992 & 555,686 \\
\hline \multicolumn{6}{|l|}{ Number of Eloc Dept Employees } \\
\hline Regular Full-time' & 30 & 3,542 & 40 & 192 & 1,502 \\
\hline Part-time \& Temporary' & 6 & 165 & 2 & 0 & 26 \\
\hline Total Elec Dept Employees' & 36 & 3,707 & 42 & 192 & 1,528 \\
\hline
\end{tabular}

1 Data reporting initiated in 1982.

See endnotes at end of this table. 
Table 29. Electric Operation and Maintenance Expenses by U.S. Federal Electric Utility, 1992 (Continued) (Thousand Dollars)

\begin{tabular}{|c|c|c|c|c|c|}
\hline \multirow{3}{*}{ Item } & \multirow{3}{*}{$\begin{array}{c}\text { Tennessee } \\
\text { Valley } \\
\text { Authority } \\
\text { September } 30\end{array}$} & \multicolumn{2}{|c|}{ U.S. Bureau of Indian Affairs } & \multirow{3}{*}{$\begin{array}{c}\text { USCE- } \\
\begin{array}{c}\text { North Central } \\
\text { Division }\end{array} \\
\text { September } 30\end{array}$} & \multirow{3}{*}{$\begin{array}{c}\text { Total } \\
\text { September } 30\end{array}$} \\
\hline & & $\begin{array}{c}\text { Mission } \\
\text { Valley Power }\end{array}$ & San Carlos & & \\
\hline & & September 30 & September 30 & & \\
\hline
\end{tabular}

Production Exponces

Steam Power Generation

Nuclear Power Generation

$1,384,805$

478,726

Hydraulic Power Generation

56,717

8,053

Other Power Generation

$-28,780$

Other Production Expenses

57,777

Total Production Expensea

$1,957,299$

66,878

Transmission Expenses

Distribution Expenses

Customer Accounts Expenses

Customer Service and Information

Expenses.

Sales Expenses

Administrative and General

Expenses

0
1,437

1,437

25,909

0

401,887

Total Electric Operation and

Maintenance Expenses

0
0
2
0
5,355
0

5,357

0

849

394

250

15

1,319

8,186

0

0
0

0
0
0

0
852

852
0

8,852

907

1,318

111

76

0

4,706

15,971

$\begin{array}{rr}0 & 1,384,805 \\ 0 & 478,726 \\ 973 & 303,948 \\ 0 & 8,053 \\ 0 & 442,188 \\ 0 & 1,526,093\end{array}$

$973 \quad 4,143,814$

$0 \quad 272,227$

$\begin{array}{ll}0 & 2,167 \\ 0 & 3,176\end{array}$

26,236

4,681

537,035

$, 989,336$

Number of Elec Dept Employees

Regular Full-time'

19,493

77

60

8

24,944

Part-time \& Temporary'

0

0

0

199

19,493

77

60

8

25,143

1 Data reporting initiated in 1992.

2 Includes data only for Saint Mary's Falls at Sault St. Marie, Michigan. The rest of the generation produced by the U.S. Army Corps of Engineers (USCE) is sold by the Department of Energy-Bonneville, Southeastern, Southwestern, and Western Area Power Administrations.

Note: Totals may not equal sum of components because of independent rounding.

Source: Energy Information Administration, Form EIA-412, "Annual Report of Public Electric Utilities." 


\begin{tabular}{|c|c|c|c|c|c|}
\hline Item & $\begin{array}{l}\text { Alaska } \\
\text { Power } \\
\text { Admin } \\
\text { September } 30\end{array}$ & $\begin{array}{l}\text { Bonneville } \\
\text { Power } \\
\text { Admin } \\
\text { September } 30\end{array}$ & $\begin{array}{l}\text { Southeastern } \\
\text { Power } \\
\text { Admin } \\
\text { September } 30\end{array}$ & $\begin{array}{l}\text { Southwestern } \\
\text { Power } \\
\text { Admin } \\
\text { September } 30\end{array}$ & $\begin{array}{l}\text { Western Area } \\
\text { Power } \\
\text { Admin } \\
\text { September } 30\end{array}$ \\
\hline 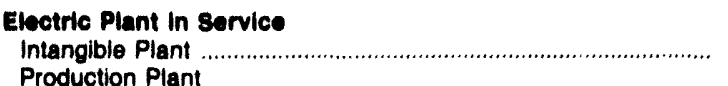 & 331 & 0 & 0 & 0 & 0 \\
\hline $\begin{array}{l}\text { Steam } \\
\text { Nuclear . Hydraulic } \\
\text { Other } \\
\text { Total Production Plant }\end{array}$ & $\begin{array}{r}0 \\
0 \\
143,136 \\
0 \\
143,136\end{array}$ & $\begin{array}{l}0 \\
0 \\
0 \\
0 \\
0\end{array}$ & $\begin{array}{r}0 \\
0 \\
744 \\
0 \\
744\end{array}$ & $\begin{array}{l}0 \\
0 \\
0 \\
0 \\
0\end{array}$ & $\begin{array}{r}0 \\
0 \\
2,435,719 \\
0 \\
2,435,719\end{array}$ \\
\hline 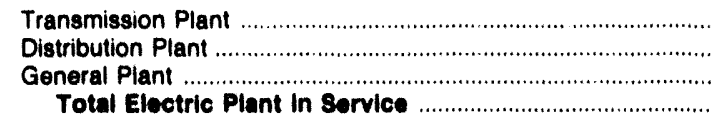 & $\begin{array}{r}32,518 \\
0 \\
5,012 \\
180,997\end{array}$ & $\begin{array}{r}3,336,097 \\
0 \\
430,350 \\
3,768,447\end{array}$ & $\begin{array}{r}0 \\
0 \\
0 \\
744\end{array}$ & $\begin{array}{r}88,818 \\
0 \\
21,421 \\
110,239\end{array}$ & $\begin{array}{r}1,150,522 \\
0 \\
0 \\
4,186,241\end{array}$ \\
\hline $\begin{array}{l}\text { Electric Plant Leased to Others } \\
\text { Construction Work in Progress - Electric } \\
\text { Electric Plant Heid for Future Use } \\
\text { Electric Plant Misc } \\
\text { Total Electric Utility Piant }\end{array}$ & $\begin{array}{r}0 \\
0 \\
0 \\
0 \\
180,997\end{array}$ & $\begin{array}{r}188 \\
297,517 \\
1,573 \\
0 \\
4,065,725\end{array}$ & $\begin{array}{r}0 \\
0 \\
0 \\
0 \\
744\end{array}$ & $\begin{array}{r}0 \\
6,124 \\
0 \\
0 \\
116,363\end{array}$ & $\begin{array}{r}0 \\
631,093 \\
0 \\
0 \\
4,817,334\end{array}$ \\
\hline Accumulated Provision for Depreciation and Amortization ........ & 31,453 & $1,251,875$ & 131 & 24,137 & 338,506 \\
\hline 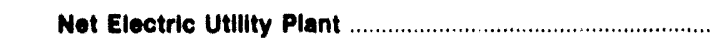 & 149,544 & $2,813,850$ & 614 & 92,226 & $4,478,828$ \\
\hline
\end{tabular}

\begin{tabular}{|c|c|c|c|c|c|}
\hline \multirow[b]{2}{*}{ ltem } & \multirow[b]{2}{*}{$\begin{array}{c}\text { Tennessee } \\
\text { Valley } \\
\text { Authority } \\
\text { September } 30\end{array}$} & \multicolumn{2}{|c|}{ U.S. Bureau of Indian Affairs } & \multirow[b]{2}{*}{$\begin{array}{l}\text { USCE:- } \\
\text { North Central } \\
\text { Division' } \\
\text { September } 30\end{array}$} & \multirow[b]{2}{*}{ September 30} \\
\hline & & $\begin{array}{c}\text { Mission } \\
\text { Valley PC'Ner } \\
\text { September } 30\end{array}$ & $\begin{array}{l}\text { San Carlos } \\
\text { September } 30\end{array}$ & & \\
\hline \multirow{2}{*}{$\begin{array}{l}\text { Electric Plant In Service } \\
\text { Intangible Plant . } \\
\text { Production Plant } \\
\text { Steam } \\
\text { Nuclear } \\
\text { Hydraulic } \\
\text { Other } \\
\text { Total Production Plant }\end{array}$} & 0 & 0 & 0 & 0 & 331 \\
\hline & $\begin{array}{r}4,821,637 \\
6,646,573 \\
1,093,512 \\
257,407 \\
12,819,129\end{array}$ & $\begin{array}{r}0 \\
0 \\
67 \\
0 \\
67\end{array}$ & $\begin{array}{l}0 \\
0 \\
0 \\
0 \\
0\end{array}$ & $\begin{array}{r}0 \\
0 \\
12,343 \\
0 \\
12,343\end{array}$ & $\begin{array}{r}4,821,637 \\
6,646,573 \\
3,685,521 \\
257,407 \\
15,411,137\end{array}$ \\
\hline 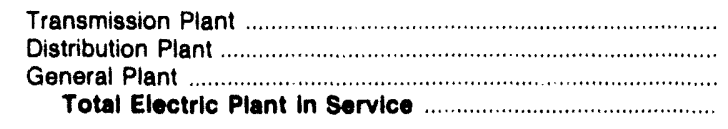 & $\begin{array}{r}2,119,196 \\
0 \\
1,050,535 \\
15,988,860\end{array}$ & $\begin{array}{r}3,216 \\
14,889 \\
3,145 \\
21,316\end{array}$ & $\begin{array}{r}0 \\
0 \\
24,064 \\
24,064\end{array}$ & $\begin{array}{r}0 \\
0 \\
0 \\
12,343\end{array}$ & $\begin{array}{r}7,330,367 \\
14,889 \\
1,534,528 \\
24,291,252\end{array}$ \\
\hline $\begin{array}{l}\text { Electric Plant Leased to Others } \\
\text { Construction Work in Progress - Electric } \\
\text { Electric Plant Held for Future Use } \\
\text { Electric Plant Misc } \\
\text { Total Electric Utility Plant }\end{array}$ & $\begin{array}{r}137,110 \\
13,264,737 \\
432,910 \\
0 \\
29,823,617\end{array}$ & $\begin{array}{r}0 \\
992 \\
0 \\
0 \\
22,308\end{array}$ & $\begin{array}{r}0 \\
0 \\
0 \\
0 \\
24,064\end{array}$ & $\begin{array}{r}0 \\
0 \\
0 \\
0 \\
12,343\end{array}$ & $\begin{array}{r}137,298 \\
14,200,464 \\
434,483 \\
0 \\
39,063,496\end{array}$ \\
\hline Accumulated Provision for Depreciation and Amortization ........ & $4,931,940$ & 8,712 & 9.539 & 3,292 & $6,599,583$ \\
\hline 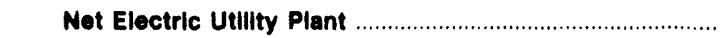 & $24,891,677$ & 13,596 & 14,525 & 9,052 & $32,463,913$ \\
\hline
\end{tabular}

1 Includes data only for Saint Mary's Falls at Sault St. Marie, Michigan. The rest of the generation produced by the U.S. Army Corps of Engineers (USCE) is sold by the Department of Energy-Bonneville, Southeastern, Southwestern, and Western Area Power Administrations.

Note: Totals may not equal sum of components because of independent rounding.

Source: Energy Information Administration, Form EIA.412, "Annual Report of Public Electric Utilities." 
Table 31. Number of Consumers, Sales, and Operating Revenue by U.S. Federal Electric Utility, 1992

\begin{tabular}{|c|c|c|c|c|c|}
\hline Item & $\begin{array}{l}\text { Alaska } \\
\text { Power } \\
\text { Admin } \\
\text { December } 31\end{array}$ & $\begin{array}{l}\text { Bonneville } \\
\text { Power } \\
\text { Admin } \\
\text { December } 31\end{array}$ & $\begin{array}{l}\text { Southeastern } \\
\text { Power } \\
\text { Admin } \\
\text { December } 31\end{array}$ & $\begin{array}{l}\text { Southwestern } \\
\text { Power } \\
\text { Admin } \\
\text { December } 31\end{array}$ & $\begin{array}{l}\text { Western Area } \\
\text { Power } \\
\text { Admin } \\
\text { December } 31\end{array}$ \\
\hline 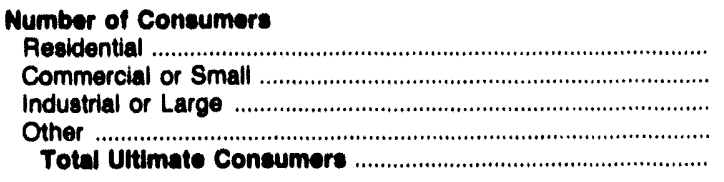 & $\begin{array}{l}0 \\
0 \\
0 \\
2 \\
2\end{array}$ & $\begin{array}{r}0 \\
0 \\
17 \\
11 \\
28\end{array}$ & $\begin{array}{l}0 \\
0 \\
0 \\
0 \\
0\end{array}$ & $\begin{array}{l}0 \\
0 \\
0 \\
0 \\
0\end{array}$ & $\begin{array}{r}0 \\
1 \\
0 \\
233 \\
234\end{array}$ \\
\hline 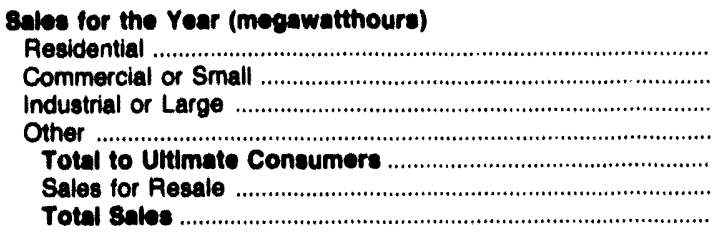 & $\begin{array}{r}0 \\
0 \\
0 \\
3,376 \\
3,376 \\
363,681 \\
367,057\end{array}$ & $\begin{array}{r}0 \\
0 \\
0 \\
23,547,414 \\
1,137,338 \\
24,684,752 \\
47,762,876 \\
72,447,628\end{array}$ & $\begin{array}{r}0 \\
0 \\
0 \\
0 \\
0 \\
7,029,787 \\
7,029,787\end{array}$ & $\begin{array}{r}0 \\
0 \\
0 \\
0 \\
0 \\
0 \\
6,563,871 \\
6,683,871\end{array}$ & $\begin{array}{r}0 \\
38 \\
0 \\
4,823,071 \\
4,823,109 \\
29,661,000 \\
34,484,109\end{array}$ \\
\hline 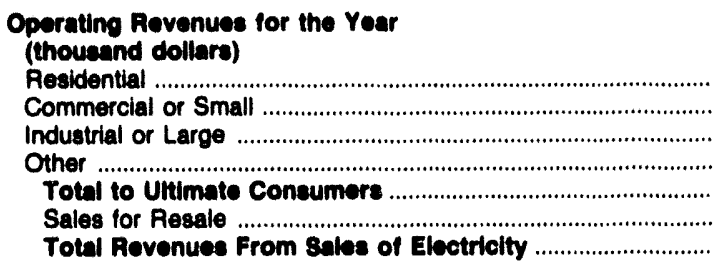 & $\begin{array}{r}0 \\
0 \\
0 \\
57 \\
57 \\
57 \\
9,324 \\
9,381\end{array}$ & $\begin{array}{r}0 \\
0 \\
422,181 \\
28,432 \\
448,613 \\
1,168,078 \\
1,616,691\end{array}$ & $\begin{array}{r}0 \\
0 \\
0 \\
0 \\
0 \\
146,212 \\
146,212\end{array}$ & $\begin{array}{r}0 \\
0 \\
0 \\
0 \\
0 \\
91,746 \\
91,740\end{array}$ & $\begin{array}{r}0 \\
1 \\
0 \\
85,242 \\
85,243 \\
510,933 \\
598,176\end{array}$ \\
\hline
\end{tabular}

\begin{tabular}{|c|c|c|c|c|c|}
\hline \multirow[b]{2}{*}{ Item } & \multirow[b]{2}{*}{$\begin{array}{c}\text { Tennessee } \\
\text { Valley } \\
\text { Authority } \\
\text { December } 31\end{array}$} & \multicolumn{2}{|c|}{ (1.S. Bureau of Indian Affairs } & \multirow[b]{2}{*}{$\begin{array}{l}\text { USCE. } \\
\text { North Central } \\
\text { Division' } \\
\text { December } 31\end{array}$} & \multirow[b]{2}{*}{$\begin{array}{c}\text { Total } \\
\text { December } 31\end{array}$} \\
\hline & & $\begin{array}{l}\text { Mission } \\
\text { Valley Po' is } \\
\text { December } 31\end{array}$ & $\begin{array}{l}\text { San Carlos } \\
\text { December } 31\end{array}$ & & \\
\hline \multicolumn{6}{|l|}{ Number of Consumere } \\
\hline 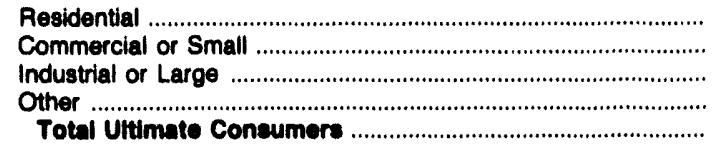 & $\begin{array}{r}0 \\
0 \\
65 \\
39 \\
104\end{array}$ & $\begin{array}{r}10,461 \\
2,101 \\
2 \\
1,071 \\
13,635\end{array}$ & $\begin{array}{r}12,390 \\
1,512 \\
86 \\
380 \\
14,388\end{array}$ & $\begin{array}{l}0 \\
0 \\
0 \\
0 \\
0\end{array}$ & $\begin{array}{r}22,851 \\
3,614 \\
170 \\
1,736 \\
28,371\end{array}$ \\
\hline \multicolumn{6}{|l|}{ Eales for the Year (megawatthours) } \\
\hline 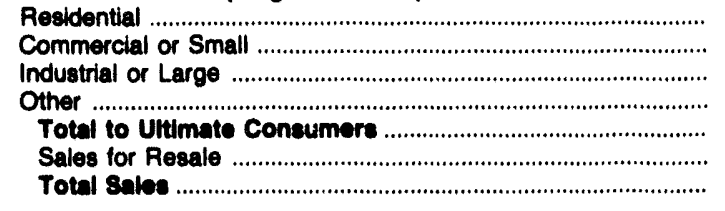 & $\begin{array}{r}0 \\
0 \\
18,535,956 \\
185,824 \\
18,721,780 \\
94,593,141 \\
113,314,921\end{array}$ & $\begin{array}{r}136,896 \\
65,682 \\
15,594 \\
20,436 \\
238,608 \\
0 \\
238,600\end{array}$ & $\begin{array}{r}82,000 \\
98,399 \\
49,198 \\
43,732 \\
273,330 \\
0 \\
273,330\end{array}$ & $\begin{array}{r}0 \\
0 \\
0 \\
0 \\
0 \\
155,362 \\
155,362\end{array}$ & $\begin{array}{r}218,886 \\
164,119 \\
42,148,163 \\
6,213,777 \\
49,744,065 \\
186,129,718 \\
234,874,673\end{array}$ \\
\hline \multicolumn{6}{|l|}{$\begin{array}{l}\text { Operating Revenues for the Year } \\
\text { (thoueand dollars) }\end{array}$} \\
\hline 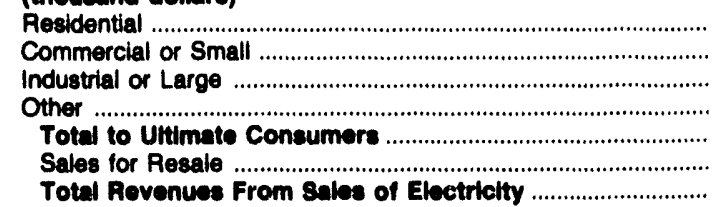 & $\begin{array}{r}0 \\
0 \\
703,275 \\
8,337 \\
711,612 \\
4,291,352 \\
5,002,984\end{array}$ & $\begin{array}{r}6,526 \\
3,573 \\
618 \\
786 \\
11,603 \\
0 \\
11,603\end{array}$ & $\begin{array}{r}6,076 \\
6,434 \\
2,377 \\
2,984 \\
17,871 \\
0 \\
17,871\end{array}$ & $\begin{array}{r}0 \\
0 \\
0 \\
0 \\
0 \\
1,838 \\
1,838\end{array}$ & $\begin{array}{r}12,602 \\
10,008 \\
1,128,451 \\
123,838 \\
1,274,890 \\
6,219,483 \\
7,404,392\end{array}$ \\
\hline
\end{tabular}

'Includes data only for Saint Mary's Falls at Sault St. Marie, Michigan. The rest of the generation produced by the U.S. Army Corps of Engineers (USCE) is sold by the Department of Energy-Bonneville, Southeastern, Southwestern, and Western Area Power Administrations.

Note: Totals may not equal sum of components because of independent rounding. Data are submitted on a calendar year.

Source: Energy Information Administration, Form ElA-861, "Annual Electric Utility Report." Data are submitted on a calendar year. 


\begin{tabular}{|c|c|c|c|c|c|}
\hline Item & $\begin{array}{c}\text { Alaska } \\
\text { Power } \\
\text { Admin } \\
\text { September } 30\end{array}$ & $\begin{array}{c}\text { Bonneville } \\
\text { Power } \\
\text { Admin }\end{array}$ & $\begin{array}{l}\text { Southeastern } \\
\text { Power } \\
\text { Admin } \\
\text { September } 30\end{array}$ & $\begin{array}{l}\text { Southwestern } \\
\text { Power } \\
\text { Admin } \\
\text { September } 30\end{array}$ & $\begin{array}{c}\text { Western Area } \\
\text { Power } \\
\text { Admin } \\
\text { September } 30\end{array}$ \\
\hline 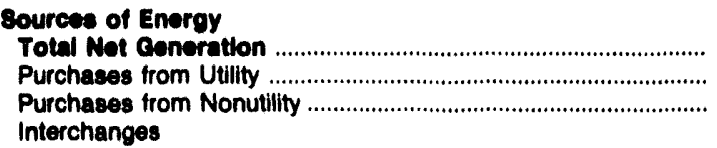 & $\begin{array}{r}370,338 \\
0 \\
0\end{array}$ & $\begin{array}{r}78,789,462 \\
7,678,177 \\
0\end{array}$ & $\begin{array}{r}7,283,162 \\
156,845 \\
0\end{array}$ & $\begin{array}{r}7,131,000 \\
36,000 \\
0\end{array}$ & $\begin{array}{r}26,368,412 \\
11,825,000 \\
0\end{array}$ \\
\hline 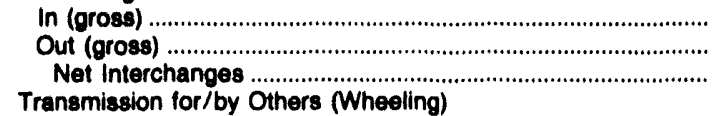 & $\begin{array}{l}0 \\
0 \\
0\end{array}$ & $\begin{array}{l}13,926,757 \\
21,503,191 \\
-7,576,434\end{array}$ & $\begin{array}{r}185 \\
0 \\
185\end{array}$ & $\begin{array}{r}390,000 \\
695,000 \\
-305,000\end{array}$ & $\begin{array}{r}1,841,000 \\
1,269,000 \\
572,000\end{array}$ \\
\hline 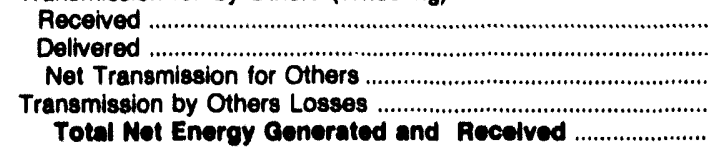 & $\begin{array}{r}319,543 \\
319,543 \\
0 \\
0 \\
370,336\end{array}$ & $\begin{array}{r}43,578,122 \\
40,961,262 \\
2,616,860 \\
0 \\
78,487,065\end{array}$ & $\begin{array}{r}4,154,527 \\
4,154,527 \\
0 \\
0 \\
7,420,192\end{array}$ & $\begin{array}{r}0 \\
0 \\
0 \\
0 \\
6,862,000\end{array}$ & $\begin{array}{r}6,144,038 \\
6,144,038 \\
0 \\
0 \\
37,763,412\end{array}$ \\
\hline 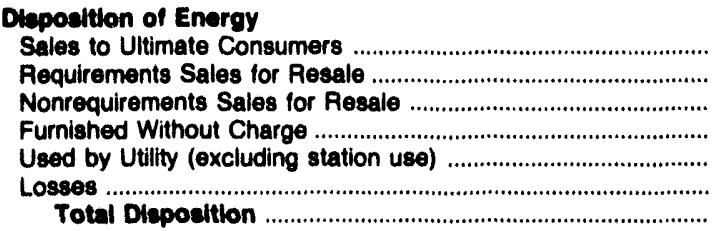 & $\begin{array}{r}3,338 \\
349,388 \\
8,805 \\
926 \\
0 \\
7,879 \\
370,386\end{array}$ & $\begin{array}{r}25,756,789 \\
48,875,042 \\
0 \\
0 \\
0 \\
3,855,234 \\
78,487,065\end{array}$ & $\begin{array}{r}0 \\
7,029,787 \\
0 \\
180,000 \\
6,660 \\
203,745 \\
7,420,192\end{array}$ & $\begin{array}{r}0 \\
6,606,000 \\
0 \\
0 \\
184,000 \\
0 \\
72,000 \\
6,862,000\end{array}$ & $\begin{array}{r}4,823,109 \\
29,200,000 \\
461,564 \\
0 \\
1,273,000 \\
2,005,739 \\
37,768,412\end{array}$ \\
\hline
\end{tabular}

\begin{tabular}{|c|c|c|c|c|c|}
\hline \multirow[b]{2}{*}{ Item } & \multirow[b]{2}{*}{$\begin{array}{l}\text { Tennessee } \\
\text { Valley } \\
\text { Authority } \\
\text { September } 30\end{array}$} & \multicolumn{2}{|c|}{ U.S. Bureau of Indian Affairs } & \multirow[b]{2}{*}{$\begin{array}{l}\text { USCE. } \\
\text { North Central } \\
\text { Division' } \\
\text { September } 30\end{array}$} & \multirow[b]{2}{*}{ September 30} \\
\hline & & $\begin{array}{l}\text { Mission } \\
\text { Valley Power } \\
\text { September } 30\end{array}$ & $\begin{array}{l}\text { San Carlos } \\
\text { September } 30\end{array}$ & & \\
\hline 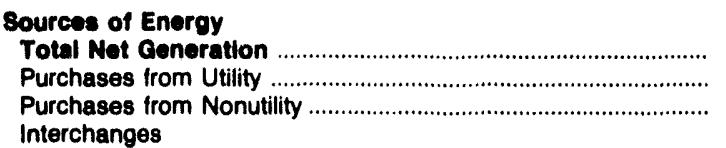 & $\begin{array}{r}124,080,503 \\
0 \\
305,509\end{array}$ & $\begin{array}{r}1,584 \\
286,294 \\
901\end{array}$ & $\begin{array}{r}0 \\
273,330 \\
0\end{array}$ & $\begin{array}{r}157,758 \\
0 \\
0\end{array}$ & $\begin{array}{r}240,139,216 \\
20,255,646 \\
306,410\end{array}$ \\
\hline 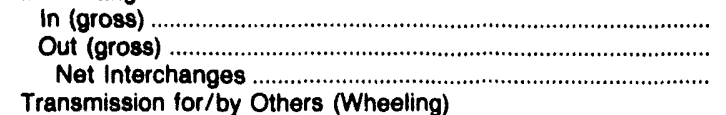 & $\begin{array}{l}22,759,681 \\
27,046,421 \\
-4,286,740\end{array}$ & $\begin{array}{l}0 \\
0 \\
0\end{array}$ & $\begin{array}{l}0 \\
0 \\
0\end{array}$ & $\begin{array}{l}0 \\
0 \\
0\end{array}$ & $\begin{array}{r}38,917,623 \\
50,513,612 \\
-11,595,989\end{array}$ \\
\hline 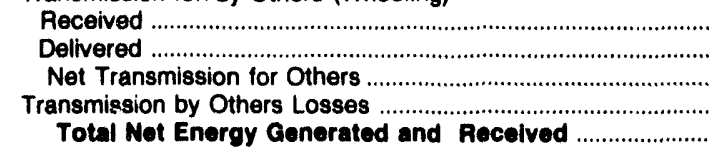 & $\begin{array}{r}1,791,524 \\
1,741,605 \\
49,919 \\
0 \\
120,149,191\end{array}$ & $\begin{array}{r}0 \\
0 \\
0 \\
0 \\
288,779\end{array}$ & $\begin{array}{r}0 \\
0 \\
0 \\
0 \\
273,330\end{array}$ & $\begin{array}{r}0 \\
0 \\
0 \\
0 \\
157,756\end{array}$ & $\begin{array}{r}55,987,754 \\
53,320,975 \\
2,666,779 \\
0 \\
251,772,061\end{array}$ \\
\hline 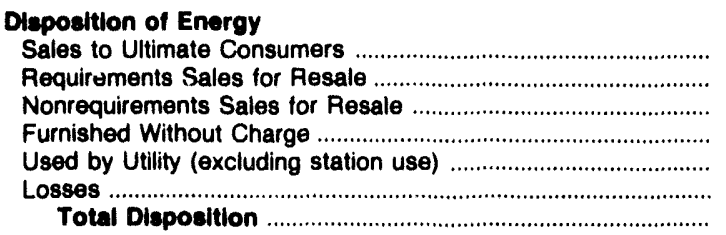 & $\begin{array}{r}18,780,324 \\
93,621,976 \\
0 \\
0 \\
8,056 \\
7,738,835 \\
120,149,191\end{array}$ & $\begin{array}{r}238,608 \\
0 \\
0 \\
0 \\
757 \\
49,414 \\
288,779\end{array}$ & $\begin{array}{r}263,763 \\
0 \\
0 \\
0 \\
0 \\
9,567 \\
273,330\end{array}$ & $\begin{array}{r}0 \\
151,141 \\
0 \\
4,439 \\
666 \\
1,510 \\
157,756\end{array}$ & $\begin{array}{r}49,865,931 \\
185,833,334 \\
470,369 \\
369,365 \\
1,289,139 \\
13,943,923 \\
251,772,081\end{array}$ \\
\hline
\end{tabular}

- Includes data only for Saint Mary's Falls at Sault St. Marie, Michigan. The rest of the generation produced by the U.S. Army Corps of Engineers (USCE) is sold by the Department of Energy-Bonneville, Southeastern, Southwestern, and Western Area Power Administrations

Note: Totals may not equal sum of components because of independent rounding.

Source: Energy Information Administration, Form ElA-412, "Annual Report of Public Electric Utilities." 
Appendix A

Summary

Statistics of U.S.

Rural Electric

Cooperative

Borrowers 


\section{Summary Statistics of U.S. Rural Electric Cooperative Borrowers}

\section{Background}

The Rural Electrification Administration (REA), U.S. Department of Agriculture, was established under the Rural Electrification Act of 1936. The purpose was to extend electric service to small rural communities (usually under 1,500 customers) and farms where it was more expensive to provide service. Through the REA, electric cooperatives (customer-owned, nonprofit entities) were formed and provided with low interest rate government-guaranteed loans to allow them to build po wrr lines to transmit and distribute wholesale electricity purchased from other electric utilities. By the early 1960 's, the REA began to make large loans to cooperatives for the construction of generating plants and transmission facilities to "protect the security and effectiveness of REA-financed systems."

The latest statistics taken from the 1992 Statistical Report, Rural Electric Borrowers ${ }^{3}$ publication show that 862 of the 916 cooperative borrowers were distribution borrowers. The remaining 54 were power supply borrowers. By the end of 1992, the REA-financed electric utilities were serving more than 11 million consumers in 46 States. When the REA was formed, less than 10 percent of the rural areas in the United States had electric service. Today, about 99 percent of U.S. farmers have electric power.

\section{Composite Income Account}

Operating revenues for the cooperative borrowers were $\$ 23.3$ billion in 1992 , compared with $\$ 22.8$ billion in 1991, and \$22.2 billion in 1990.

Total electric utility operating expenses for the cooperative borrowers were $\$ 20.4$ billion in 1992 . Operation and maintenance expenses represented $\$ 18.0$ billion or
88.7 percent of the total operating expenses. Purchased power, a major portion of operation and maintenance expenses, was $\$ 12.1$ billion. Taxes were $\$ 0.6$ billion or 3.0 percent of total electric operating expenses.

Utility operating income for the cooperative borrowers was $\$ 3.0$ billion in 1992 . Utility operating income, as a proportion of net utility plant, was 6.7 percent. Net income was $\$ 0.7$ billion.

Interest expense on long-term debt was $\$ 2.8$ billion in 1992 , a slight decrease from $\$ 2.9$ million in 1991 . Interest expenses as a percentage of long-term debt was 6.6 percent in 1992, compared with 6.8 percent in 1991.

\section{Balance Sheet}

The net investment in electric utility plant for the cooperative borrowers was $\$ 44.1$ billion at the end of 1992 , which includes $\$ 1.6$ billion for construction work in progress (CWIP). The CWIP was $\$ 2.1$ billion in 1988. As a percentage of net investment in electric utility plant, CWIP was about 34.4 percent lower in 1992, compared with 1988. The investment and funds accounts were $\$ 5.4$ billion and the long-term debt was $\$ 42.7$ billion at the end of 1992 .

\section{Electric Utility Operating Revenues}

The number of residential consumers served by the cooperative borrowers was 10.3 million in 1992, up slightly from 9.9 million in 1991. Revenues from residential consumers were $\$ 9.2$ billion or 66.1 percent of the total revenues from all ultimate consumers. In 1992, consumption of electricity by each residential customer averaged 11.5 megawatthours at an average annual cost of $\$ 888.76$, a slight decrease from 1991 .

${ }^{3}$ U.S. Department of Agriculture, Rural Electrification Administration, Bulletin No. 1-1. 
Table A1. Composite Statement of Income for the U.S. Cooperative Borrowers, 1988-1992

(Thousand Dollars)

\begin{tabular}{|c|c|c|c|c|c|}
\hline Item & 1992 & 1991 & 1990 & 1989 & $i 988$ \\
\hline $\begin{array}{l}\text { Electrlc Utility Operating Revenues .................. } \\
\text { Utility Operating Expenses }\end{array}$ & $23,325,191$ & $22,784,208$ & $22,226,008$ & $21,986,690$ & $20,886,316$ \\
\hline Operation and Maintenance Expenses ............... & $18,038,115$ & $17,654,756$ & $17,036,873$ & $16,800,017$ & $15,863,365$ \\
\hline Depreciation and Amortization .................................... & $1,709,293$ & $1,639,148$ & $1,616,945$ & $1,549,685$ & $1,435,593$ \\
\hline $\begin{array}{l}\text { Taxes } \\
\text { Total Electric Utility Opersting }\end{array}$ & 605,275 & 592,850 & 515,486 & 555,146 & 518,931 \\
\hline 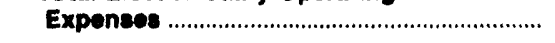 & $20,352,683$ & $19,886,754$ & $19,169,304$ & $18,904,848$ & $17,817,889$ \\
\hline 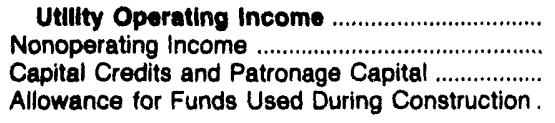 & $\begin{array}{r}2,972,507 \\
433,518 \\
248,996 \\
55,440\end{array}$ & $\begin{array}{r}2,897,454 \\
506,859 \\
234,137 \\
52,481\end{array}$ & $\begin{array}{r}3,056,704 \\
539,204 \\
178,520 \\
69,056\end{array}$ & $\begin{array}{r}3,081,842 \\
526,654 \\
157,501 \\
103,476\end{array}$ & $\begin{array}{r}3,068,427 \\
334,824 \\
185,057 \\
156,607\end{array}$ \\
\hline Grose Income & $3,710,461$ & $3,690,931$ & $3,843,484$ & $3,869,473$ & $3,744,815$ \\
\hline \multicolumn{6}{|l|}{ Income Deductions from } \\
\hline 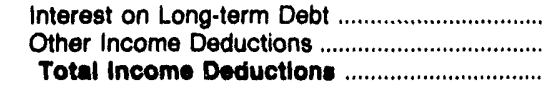 & $\begin{array}{r}2,833,653 \\
165,921 \\
2,998,574\end{array}$ & $\begin{array}{r}2,883,852 \\
67,847 \\
2,951,699\end{array}$ & $\begin{array}{r}2,875,063 \\
264,197 \\
3,139,260\end{array}$ & $\begin{array}{r}2,771,605 \\
358,795 \\
3,130,400\end{array}$ & $\begin{array}{r}2,891,079 \\
115,606 \\
3,006,685\end{array}$ \\
\hline Not Income and Patronage Capltal ............ & 710,887 & 739,232 & 704,224 & 739,073 & 738,230 \\
\hline
\end{tabular}

Notes: Totals may not equal sum of components because of independent rounding. Data for 1992 represent 862 Distribution Borrowers and 54 Power Supply Borrowers; data for 1991 represent 832 Distribution Borrowers and 55 Power Supply Borrowers; data for 1990 represent 838 Distribution Borrowers and 56 Power Supply Borrowers; data for 1989 represent 839 Distribution Borrowers and 58 Power Supply Borrowers; and data for 1988 represent 839 Distribution Borrowers and 55 Power Supply Borrowers.

Source: U.S. Department of Agriculture, Rural Electrification Administration, Statistical Report, Rural Electric Borrowers publications for the years 1988, 1989, 1980, 1991 and 1992.

\section{Table A2. Composite Balance Sheet for the U.S. Cooperative Borrowers on December 31, 1988-1992 (Thousand Dollars)}

\begin{tabular}{|c|c|c|c|c|c|}
\hline Item & 1992 & 1991 & 1990 & 1989 & 1988 \\
\hline \multicolumn{6}{|l|}{ Assots and Other Debits } \\
\hline 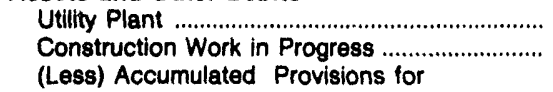 & $\begin{array}{r}59,043,411 \\
1,626,552\end{array}$ & $\begin{array}{r}56,752,533 \\
1,511,459\end{array}$ & $\begin{array}{r}56,211,882 \\
1,326,488\end{array}$ & $\begin{array}{r}55,102,550 \\
1,534,253\end{array}$ & $\begin{array}{r}51,326,306 \\
2,093,100\end{array}$ \\
\hline $\begin{array}{l}\text { Depreciation and Amortization } \\
\text { Net Utilfty Plant }\end{array}$ & $\begin{array}{l}16,594,358 \\
44,075,606\end{array}$ & $\begin{array}{l}15,093,304 \\
\mathbf{4 3 , 1 7 0 , 6 8 8}\end{array}$ & $\begin{array}{l}14,108,095 \\
\mathbf{4 3 , 4 3 0 , 2 7 5}\end{array}$ & $\begin{array}{l}12,867,844 \\
43,768,959\end{array}$ & $\begin{array}{l}11,275,176 \\
42,144,260\end{array}$ \\
\hline 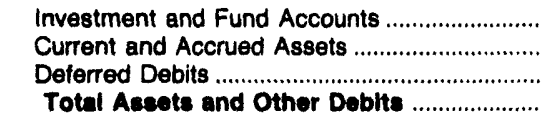 & $\begin{array}{r}\mathbf{5 , 3 7 9 , 4 0 0} \\
7,810,050 \\
2,287,018 \\
\mathbf{5 9 , 5 5 2 , 0 7 3}\end{array}$ & $\begin{array}{r}5,017,772 \\
8,002,973 \\
1,811,064 \\
\mathbf{5 8 , 0 0 2 , 4 9 7}\end{array}$ & $\begin{array}{r}4,675,202 \\
7,966,885 \\
2,028,760 \\
58,101,121\end{array}$ & $\begin{array}{r}4,204,565 \\
8,132,679 \\
2,604,551 \\
\mathbf{5 8 , 7 1 0 , 7 5 4}\end{array}$ & $\begin{array}{r}3,839,048 \\
7,154,734 \\
1,937,742 \\
55,075,782\end{array}$ \\
\hline \multicolumn{6}{|l|}{ Liablilties and Other Credits } \\
\hline 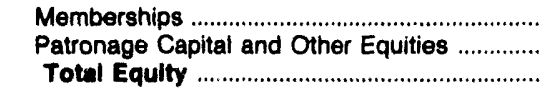 & $\begin{array}{r}96,146 \\
11,372,465 \\
11,468,611\end{array}$ & $\begin{array}{r}91,664 \\
10,470,168 \\
10,561,832\end{array}$ & $\begin{array}{r}91,122 \\
9,944,290 \\
10,035,412\end{array}$ & $\begin{array}{r}88,373 \\
9,391,401 \\
9,479,774\end{array}$ & $\begin{array}{r}85,355 \\
9,381,942 \\
9,467,297\end{array}$ \\
\hline 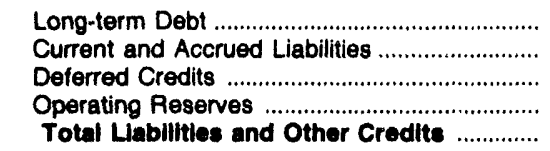 & $\begin{array}{r}42,691,944 \\
3,381,957 \\
1,469,722 \\
539,839 \\
59,552,073\end{array}$ & $\begin{array}{r}42,273,766 \\
3,194,377 \\
1,442,849 \\
529,673 \\
58,002,497\end{array}$ & $\begin{array}{r}42,887,350 \\
3,221,216 \\
1,546,174 \\
410,971 \\
58,101,121\end{array}$ & $\begin{array}{r}40,220,703 \\
6,955,326 \\
1,662,396 \\
392,555 \\
58,710,754\end{array}$ & $\begin{array}{r}40,228,411 \\
3,548,637 \\
1,512,523 \\
320,818 \\
55,075,782\end{array}$ \\
\hline
\end{tabular}

Notes: Totals may not equal sum of components because of independent rounding. Data for 1992 represent 862 Distribution Borrowers and 54 Power Supply Borrowers; data for 1991 represent 832 Distribution Borrowers and 55 Power Supply Borrowers; data for 1990 represent 838 Distribution Borrowers and 56 Power Supply Borrowers; data for 1989 represent 839 Distribution Borrowers and 58 Power Supply Borrowers; and data for 1988 represent 839 Distribution Borrowers and 55 Power Supply Borrowers.

Source: U.S. Department of Agriculture, Rural Electrification Administration, Statistical Report, Rural Electric Borrowers publications for the years $1988,1989,1990,1991$ and 1992. 


\begin{tabular}{|c|c|c|c|c|c|}
\hline Item & 1992 & 1991 & 1990 & 1989 & 1988 \\
\hline 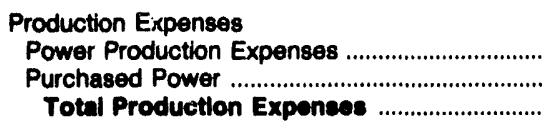 & $\begin{array}{r}2,998,260 \\
12,061,066 \\
15,059,328\end{array}$ & $\begin{array}{r}2,978,362 \\
11,857,765 \\
14,836,127\end{array}$ & $\begin{array}{r}3,100,268 \\
11,246,600 \\
14,346,868\end{array}$ & $\begin{array}{r}3,020,715 \\
11,250,727 \\
14,271,442\end{array}$ & $\begin{array}{r}2,832,442 \\
10,661,938 \\
13,494,380\end{array}$ \\
\hline 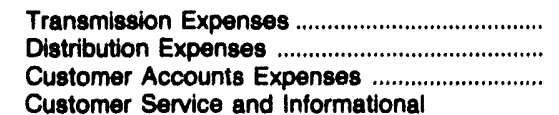 & $\begin{array}{l}323,527 \\
980,017 \\
368,563\end{array}$ & $\begin{array}{l}312,982 \\
916,569 \\
348,605\end{array}$ & $\begin{array}{l}318,117 \\
873,947 \\
334,288\end{array}$ & $\begin{array}{l}294,591 \\
821,151 \\
321,013\end{array}$ & $\begin{array}{l}280,777 \\
764,536 \\
314,429\end{array}$ \\
\hline 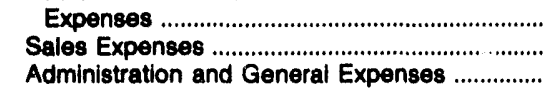 & $\begin{array}{r}94,907 \\
52,235 \\
1,159,540\end{array}$ & $\begin{array}{r}89,029 \\
47,153 \\
1,104,291\end{array}$ & $\begin{array}{r}82,714 \\
41,619 \\
1,039,319\end{array}$ & $\begin{array}{r}75,569 \\
35,144 \\
981,109\end{array}$ & $\begin{array}{r}62,740 \\
27,006 \\
919,499\end{array}$ \\
\hline $\begin{array}{l}\text { Total Electric Operation and } \\
\text { Malntenance Expenees }\end{array}$ & $18,038,115$ & $17,654,756$ & $17,036,872$ & $16,800,017$ & $15,663,367$ \\
\hline
\end{tabular}

Notes: Totals may not equal sum of components because of independent rounding. Data for 1892 represent 862 Distribution Borrowers and 54 Power Supply Borrowers; data for 1991 represent 832 Distribution Borrowers and 55 Power Supply Borrowers; data for 1990 represent 838 Distribution Borrowers and 56 Power Supply Borrowers; data for 1989 represent 839 Distribution Borrowers and 58 Power Supply Borrowers; and data for 1988 represent 839 Distribution Borrowers and 55 Power Supply Borrowers.

Source: U.S. Department of Agriculture, Rural Electrification Administration, Statiatical Report, Rural Electric Borrowere publications for the years 1988, 1989, 1990, 1991 and 1992.

Table A4. Number of Consumers, Sales, and Operating Revenue for the U.S. Cooperative Distributor Borrowers, 1988-1992

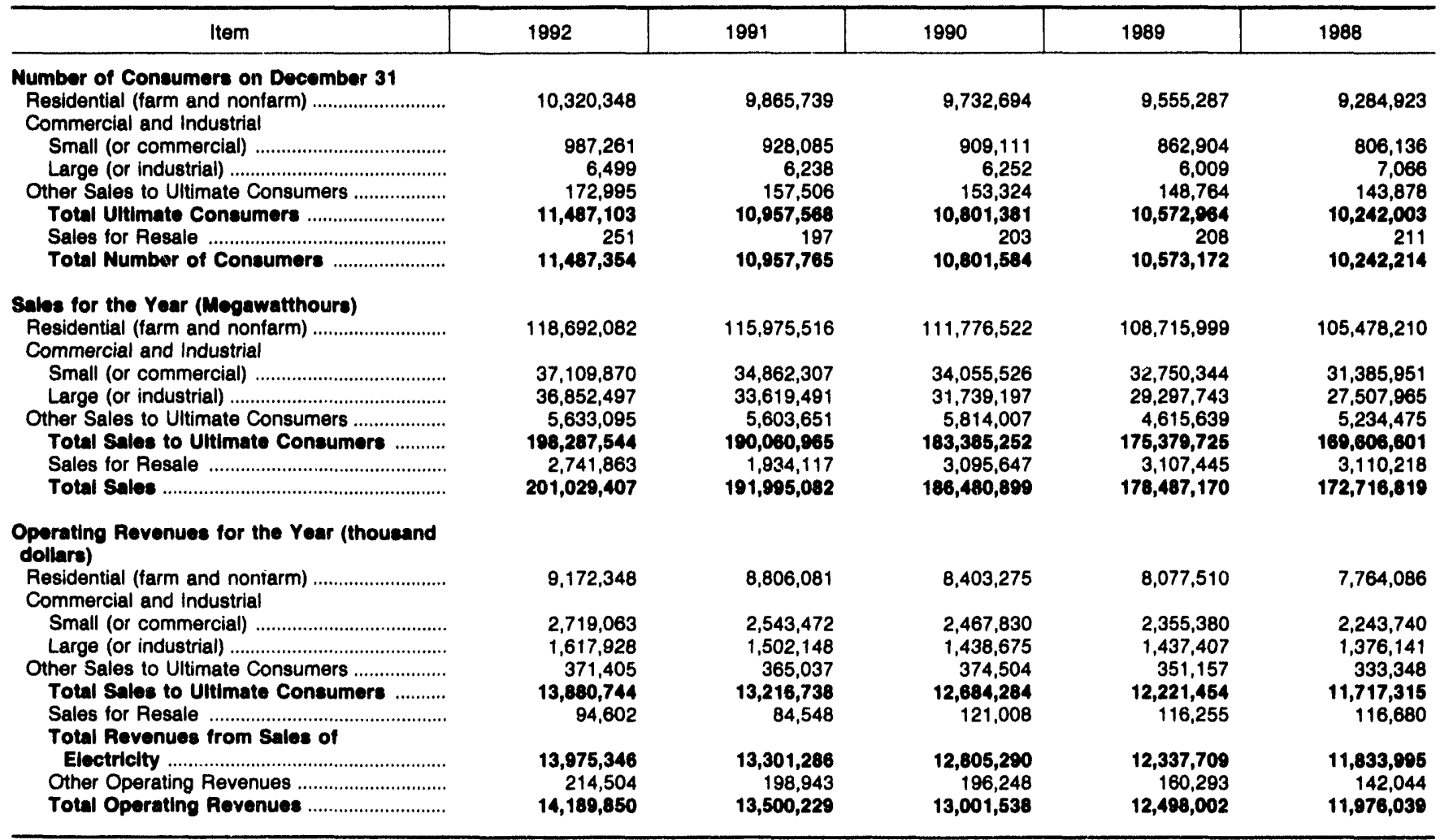

Notes: Totals may not equal sum of components because of independent rounding. This table does not include in 1992 the 54 Power Supply Borrowers, in 1981 the 55 Power Supply Borrowers, in 1990 the 56 Power Supply Borrowers, in 1989 the 58 Power Supply Borrowers, and in 1988 the 55 Power Supply Borrowers included in Tables A1, A2, and A3. Data for 1992 represent 862 Distribution Borrowers; 1991 represent 832 Distribution Borrowers; 1990 represent 838 Distribution Borrowers; 1989 represent 839 Distribution Borrowers; and data for 1988 represent 839 Distribution Borrowers.

Source: U.S. Department of Agriculture, Rural Electrification Administration, Statistical Report, Rural Electric Borrowers publications for the years 1988, 1989, 1990, 1991 and 1992. 
Appendix B

Major U.S. Publicly Owned Electric Utility

Respondents 


\section{Major U.S. Publicly Owned Electric Utility Respondents}

Table B1. Major U.S. Publicly Owned Electric Utilities Added to and Deleted from the Form EIA-412, 1989-1992

\begin{tabular}{|c|c|c|c|c|c|}
\hline \multirow{2}{*}{ Year } & \multicolumn{2}{|r|}{ Added } & \multicolumn{2}{|r|}{ Deleted } & \multirow{2}{*}{$\begin{array}{l}\text { Total Number } \\
\text { Available' }\end{array}$} \\
\hline & No. & Name & No. & Name & \\
\hline $1989^{\circ} \ldots . .$. & 4 & $\begin{array}{l}\text { Illinois Muni Elec Agency (Illinois) } \\
\text { Kerville Public Utility Board (Texas) } \\
\text { Southern Calif Pub Serv Auth (Calin) } \\
\text { Terrebone Paris Consol Govt (Louisiana) }\end{array}$ & 40 & 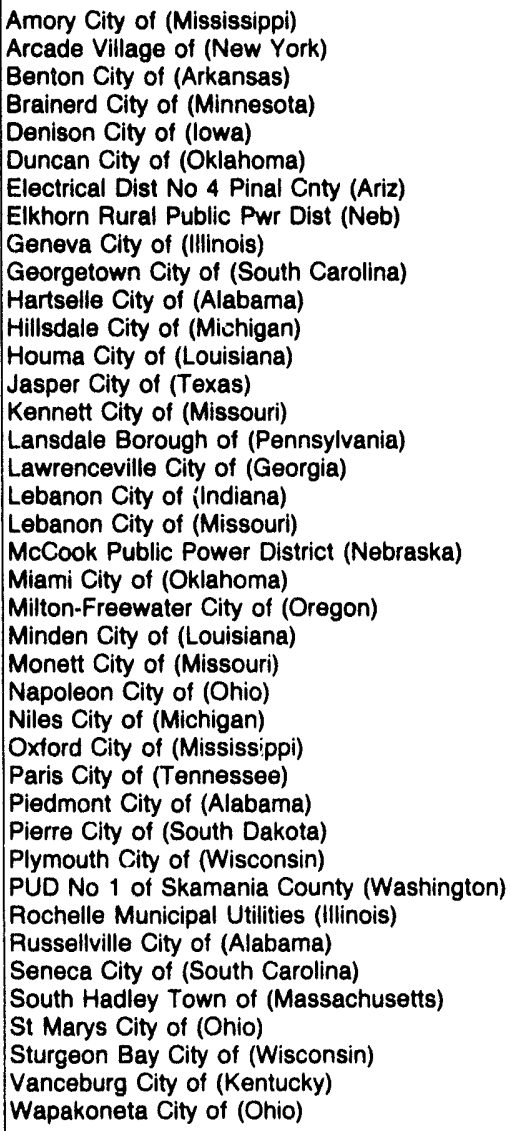 & 454 \\
\hline
\end{tabular}

1 Excluded are the Federal electric utilities.

2 The threshold for reporting requirements changed from 100,000 megawatthours to 120,000 megawatthours.

- Nongenerator.

Source: Energy Information Administration, Form EIA-412, "Annual Report of Public Electric Utilities." 
Table B1. Major U.S. Publicly Owned Electric Utilities Added to and Deleted from the Form ElA-412, 1989-1992 (Continued)

\begin{tabular}{|c|c|c|c|c|c|}
\hline \multirow{2}{*}{ Year } & \multicolumn{2}{|r|}{ Added } & \multicolumn{2}{|r|}{ Deleted } & \multirow{2}{*}{$\begin{array}{l}\text { Total Number } \\
\text { Available }^{\prime}\end{array}$} \\
\hline & No. & Name & No. & Name & \\
\hline $1990 \ldots \ldots$ & 13 & $\begin{array}{l}\text { Alabama Municipal Elec Auth (Alabama) } \\
\text { Geneva City of (Illinois) } \\
\text { Jefferson City of (Wisconsin) } \\
\text { Ketchikan City of (Alaska) } \\
\text { Lawrenceville City of (Georgia) } \\
\text { McCook Public Power Dist (Nebraska) } \\
\text { Oxford City of (Mississippi) } \\
\text { Paris City of (Tennessee) } \\
\text { Plerre City of (South Dakota) } \\
\text { Plymouth City of (Wisconsin) } \\
\text { Rochelle Municipal Utilities (lllinois) } \\
\text { San Marcos City of (Texas) } \\
\text { Wapakoneta City of (Ohio) }\end{array}$ & . & & 467 \\
\hline $1991 \ldots . . . .$. & 08 & $\begin{array}{l}\text { Benton City of (Arkansas) } \\
\text { Hillsdale Board of Pub Works (Michigan) } \\
\text { Kennett City of (Missouri) } \\
\text { Lebanon City of (Missouri) } \\
\text { Monett City of (Missouri) } \\
\text { Reedsburg Util Commission (Wisconsin) } \\
\text { St Marys City of (Ohio) } \\
\text { Sturgeon Bay Combined Utils(Wisconsin) }\end{array}$ & 05 & $\begin{array}{l}\text { Kings Piver Conserv Dist (California) } \\
\text { McCook Public Power Dist (Nebraska)" } \\
\text { Merced Irrigation District (California) } \\
\text { Sebring Utilities Commission (Florida) } \\
\text { Solvay Village of (New York) }\end{array}$ & 470 \\
\hline $1992 \ldots . . .$. & 14 & $\begin{array}{l}\text { Badger Power Marketing Auth (Wisconsin) } \\
\text { Brainerd City of (Minnesota) } \\
\text { Chanute City of (Kansas) } \\
\text { Duncan City of (Oklahoma) } \\
\text { Electrical District No2 Pinal Cnty (Arizona) } \\
\text { Floresville City of (Texas) } \\
\text { Greenfield City of (Indiana) } \\
\text { Lafayette Public Power Auth (Louisiana) } \\
\text { Massena Town of (New York) } \\
\text { Milford City of (Delaware) } \\
\text { Pella City of (lowa) } \\
\text { Reedy Creek Improvement Dist (Florida) } \\
\text { Sebring Utilities Commission (Florida) } \\
\text { Tohono O"dham Utility Auth (Arizona) }\end{array}$ & 01 & Milan City of (Tennessee)" & 483 \\
\hline
\end{tabular}

Excluded are the Federal electric utilities.

2 The threshold for reporting requirements changed from 100,000 megawatthours to 120,000 megawatthours.

- Nongenerator.

Source: Energy Information Administration, Form ElA-412, "Annual Report of Public Electric Utilities." 
Table B2. Publicly Owned Electric Utilities That Submitted the Form ElA-412, 1992

\begin{tabular}{|c|c|c|c|}
\hline Publlely Owned Electrle Utilitiee & State & Reporting Date & Generating Status \\
\hline 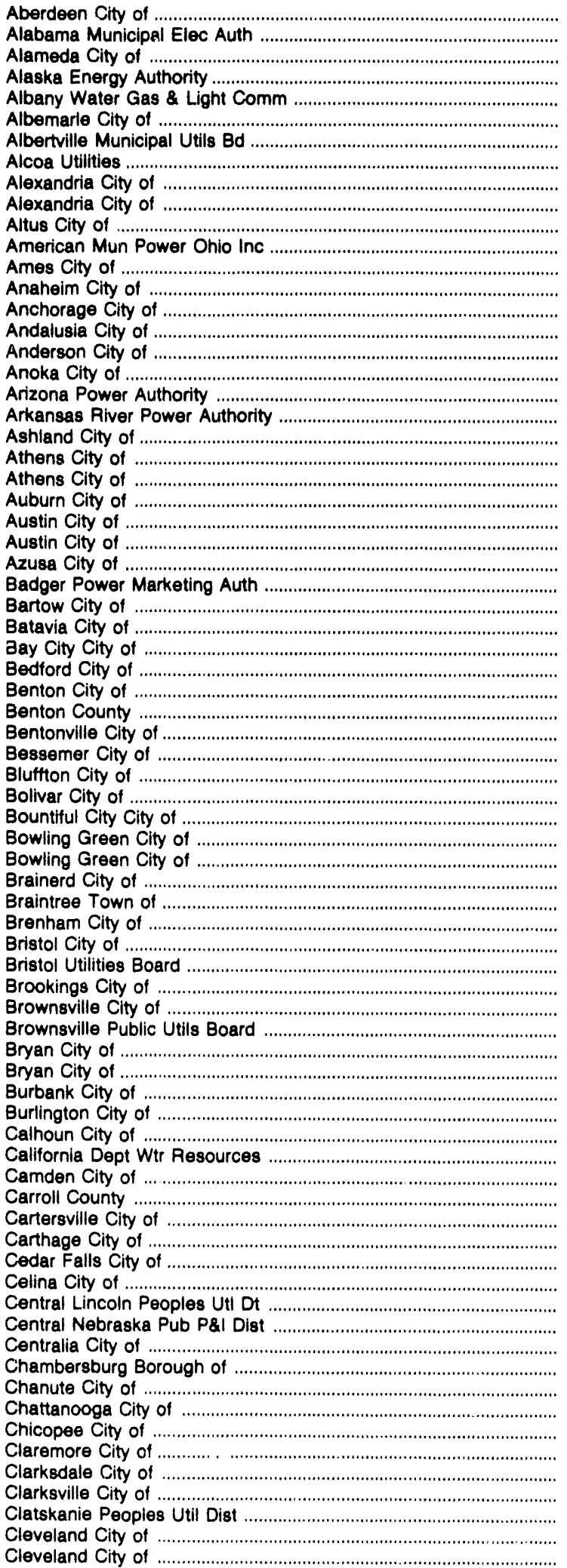 & 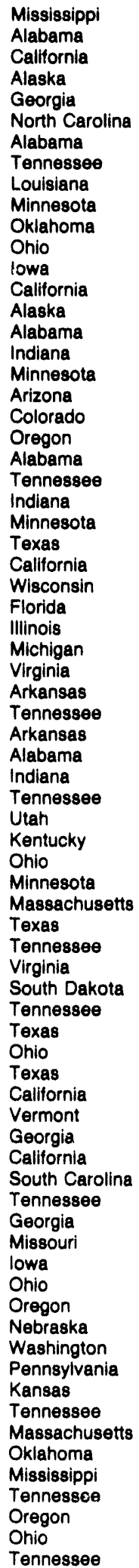 & 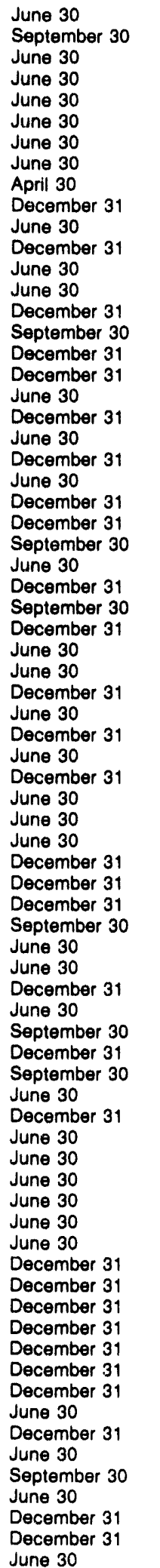 & 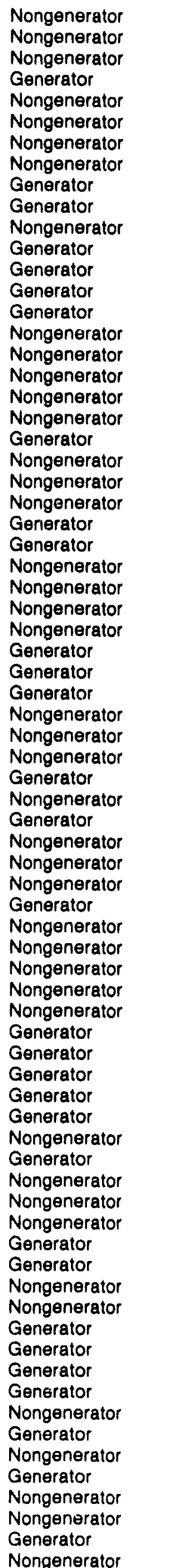 \\
\hline
\end{tabular}

See endnotes at end of this table. 
Table B2. Publicly Owned Electric Utilities That Submitted the Form EIA-412, 1992 (Continued)

\begin{tabular}{|c|c|c|c|}
\hline Publicly Owned Electric Utilities & State & Reporting Date & Generating Status \\
\hline 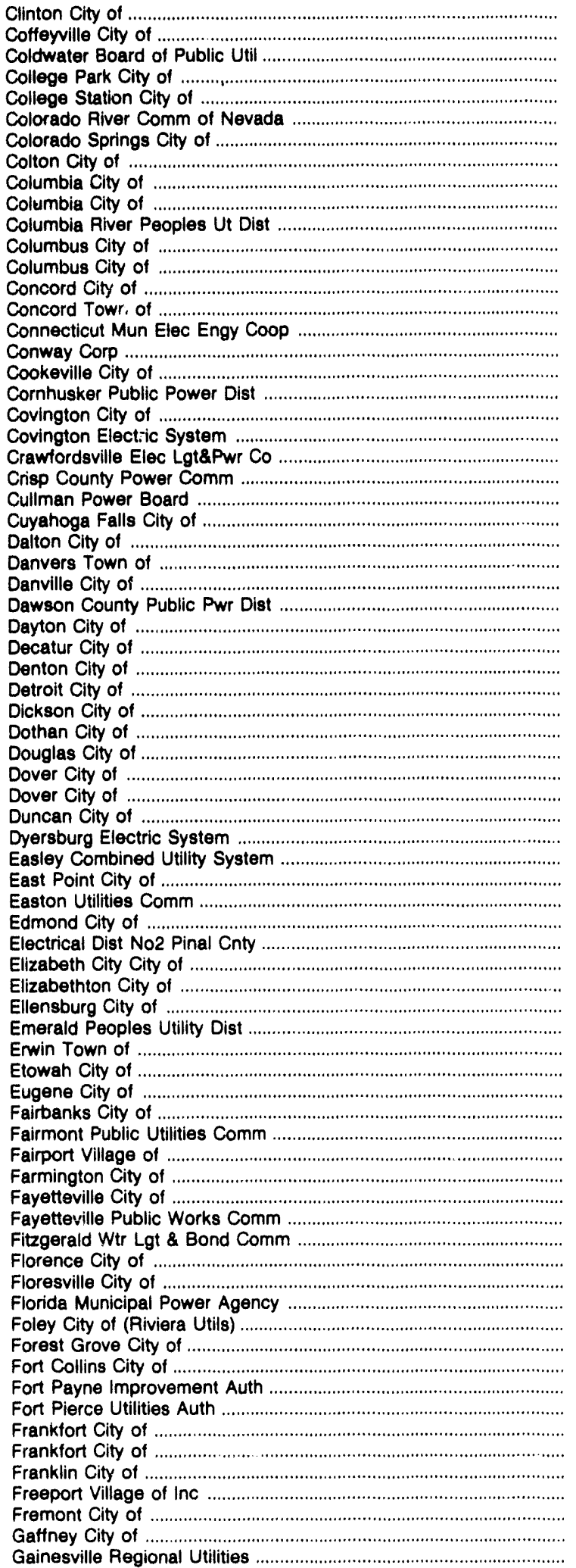 & 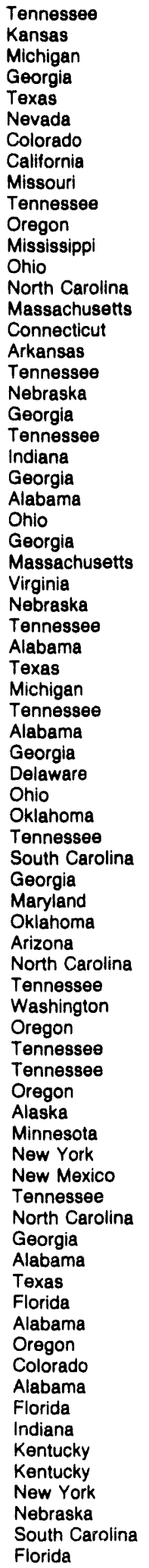 & 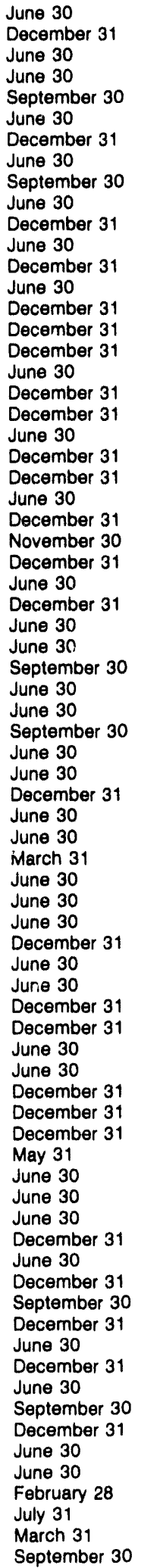 & 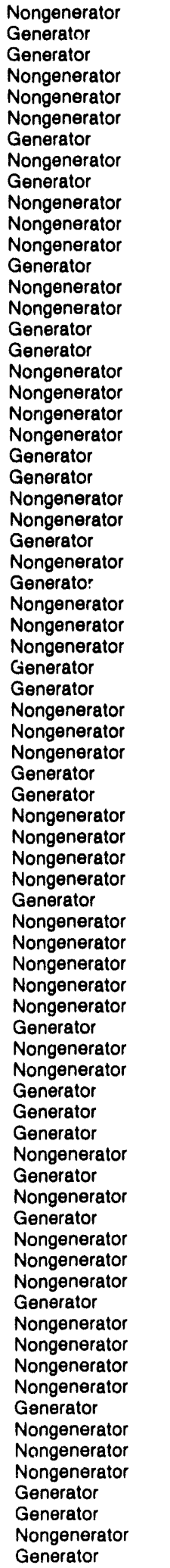 \\
\hline
\end{tabular}

See endnotes at end of this table. 
Table B2. Publicly Owned Electric Utilities That Submitted the Form ElA-412, 1992 (Continued)

\begin{tabular}{|c|c|c|c|}
\hline Publicly Owned Electric Utilities & State & Reporting Date & Generating Status \\
\hline 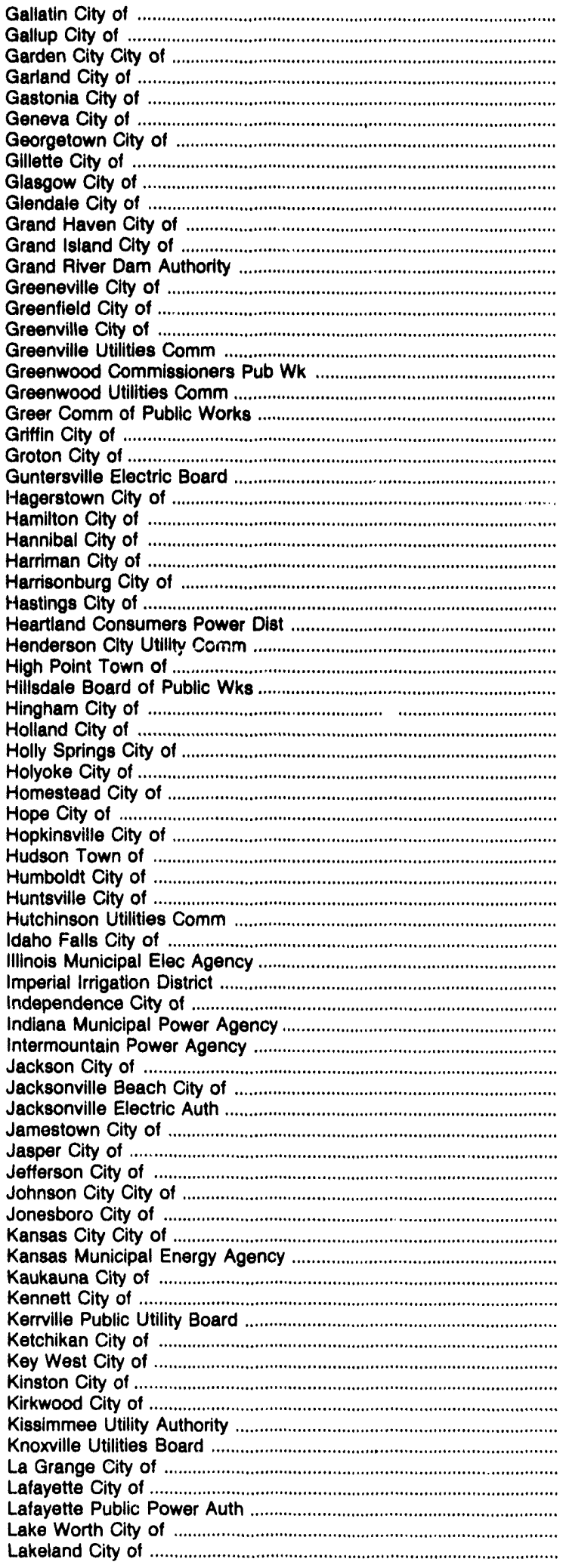 & 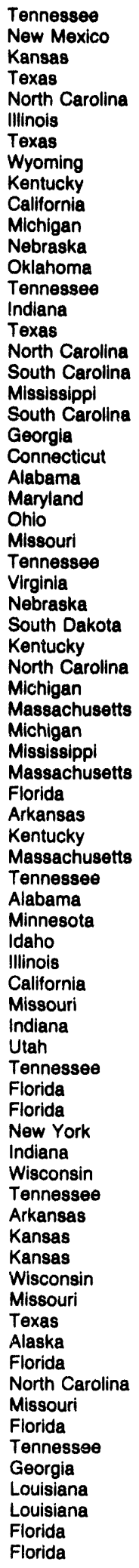 & 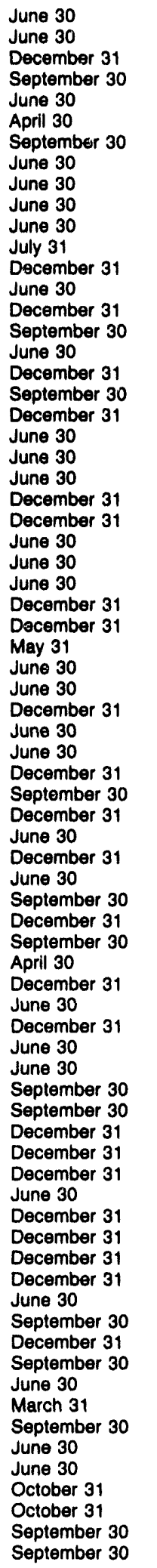 & 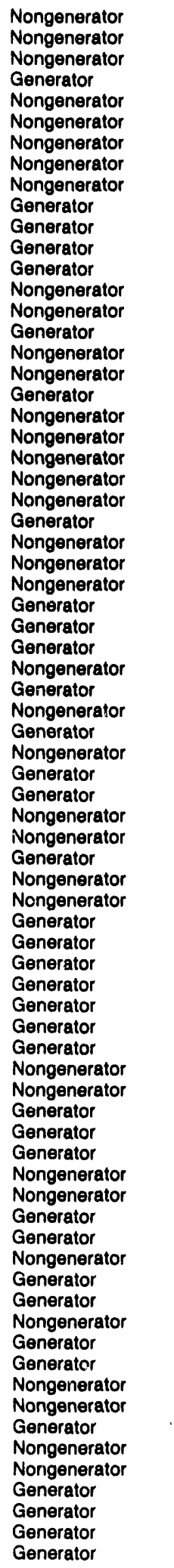 \\
\hline
\end{tabular}

See endnotes at end of this table. 
Table B2. Publicly Owned Electric Utilities That Submitted the Form ElA-412, 1992 (Continued)

\begin{tabular}{|c|c|c|c|}
\hline Publicly Owned Electric UtIIItles & State & Reporting Date & Generating Status \\
\hline 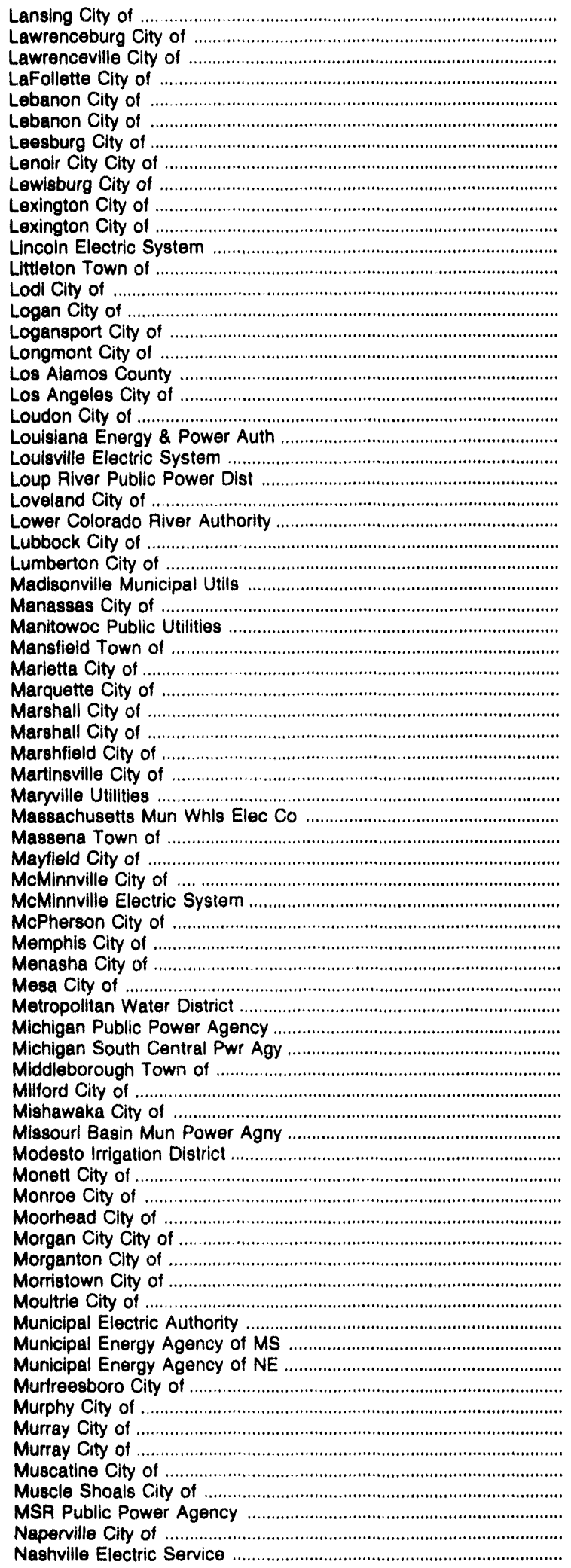 & 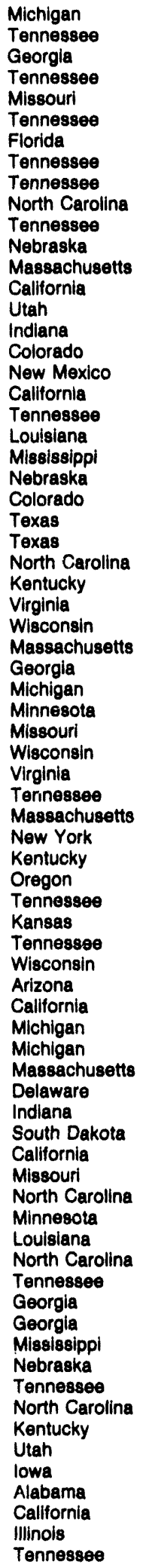 & 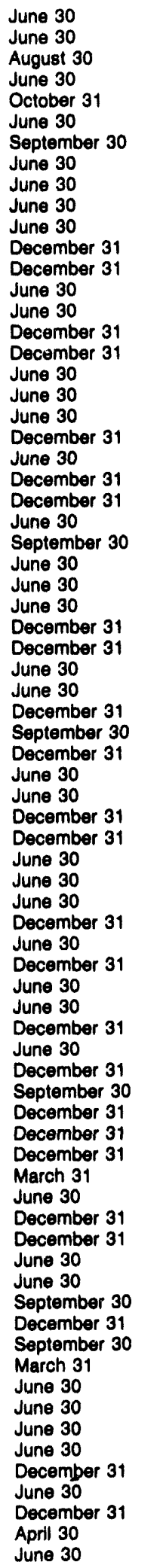 & 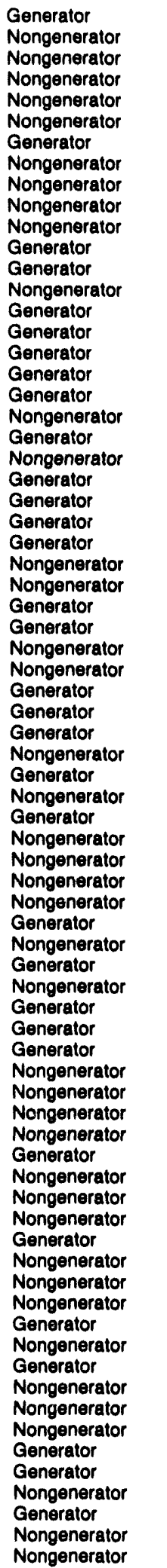 \\
\hline
\end{tabular}

See endnotes at end of this table. 
Table B2. Publicly Owned Electric Utillties That Submitted the Form EIA-412, 1992 (Continued)

\begin{tabular}{|c|c|c|c|}
\hline Publlely Owned Electric Utilltios & State & Reporting Date & Generating Status \\
\hline 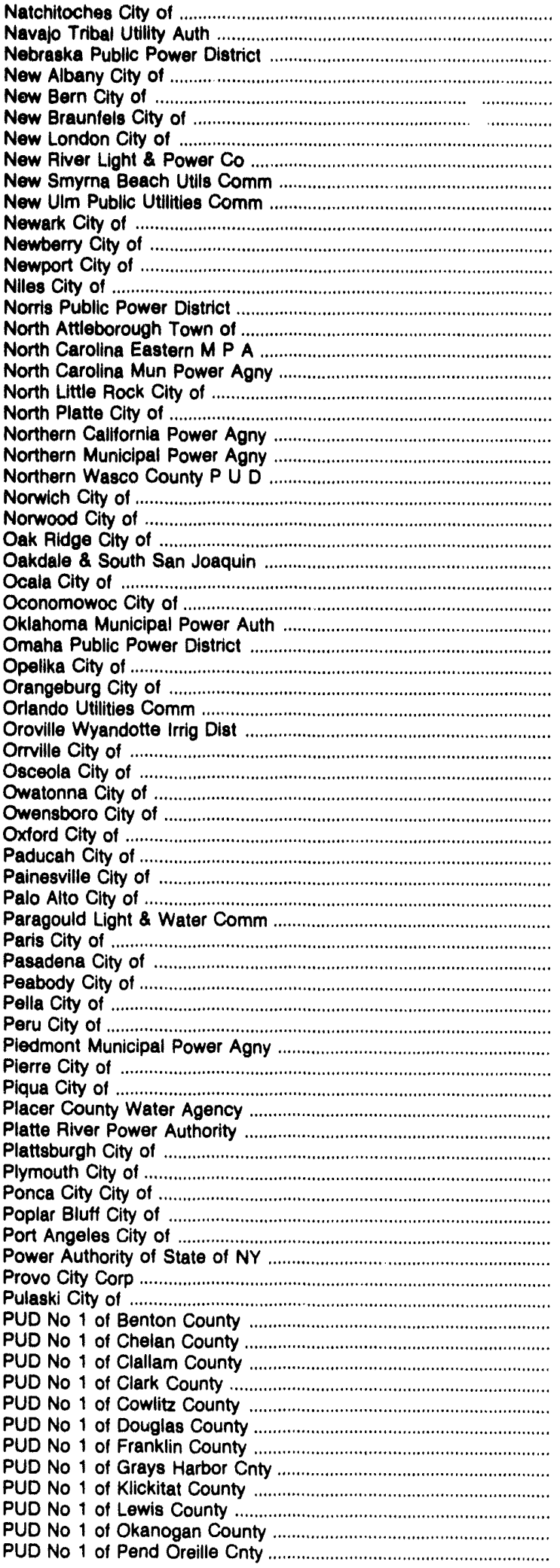 & 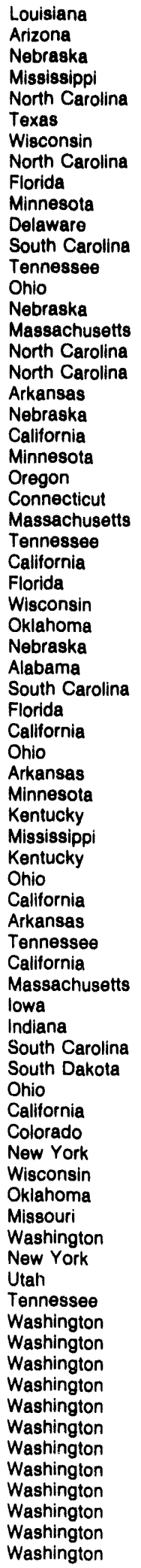 & 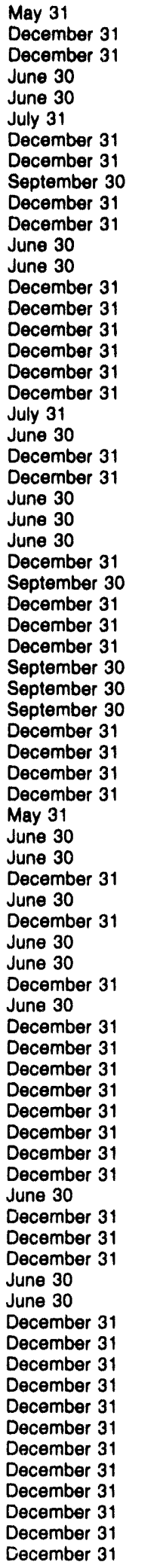 & 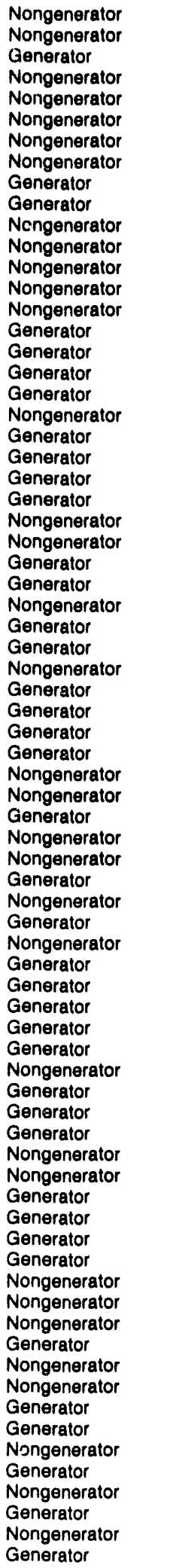 \\
\hline
\end{tabular}

See endnotes at end of this table. 
Table B2. Publicly Owned Electric Utllities That Submitted the Form ElA-412, 1992 (Continued)

\begin{tabular}{|c|c|c|c|}
\hline Publiciy Owned Electric Utilities & State & Reporting Date & Generating Status \\
\hline 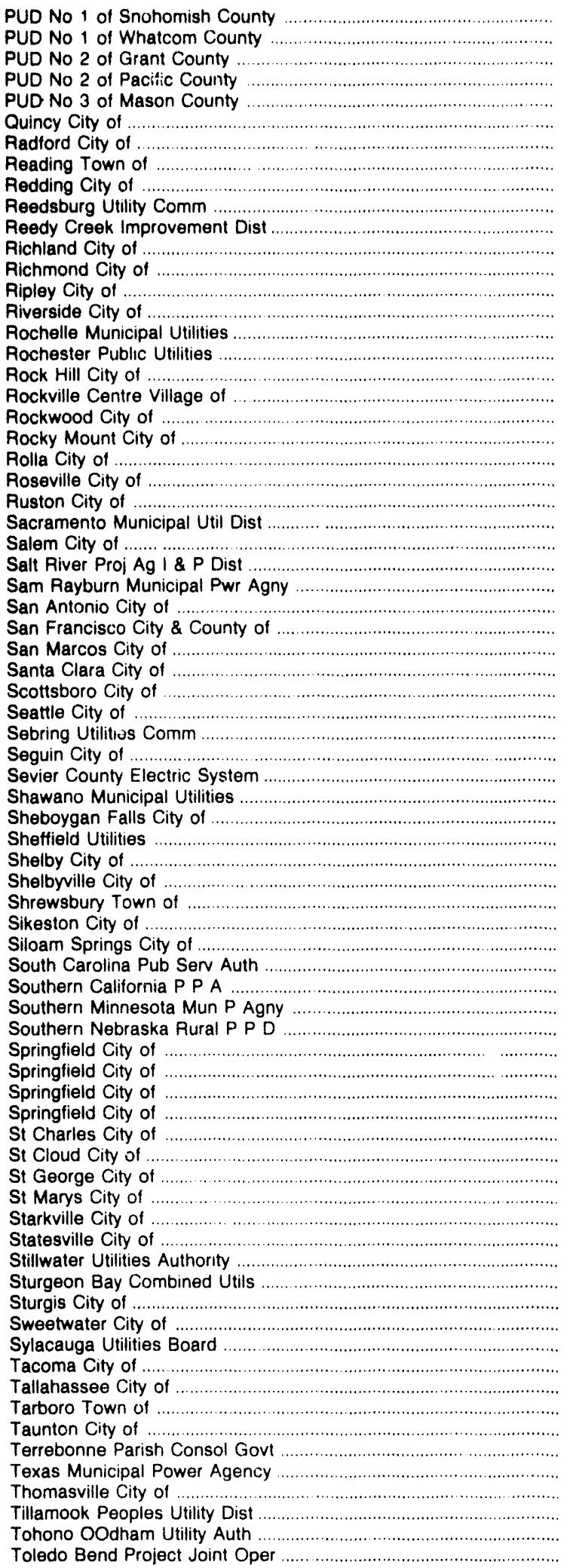 & 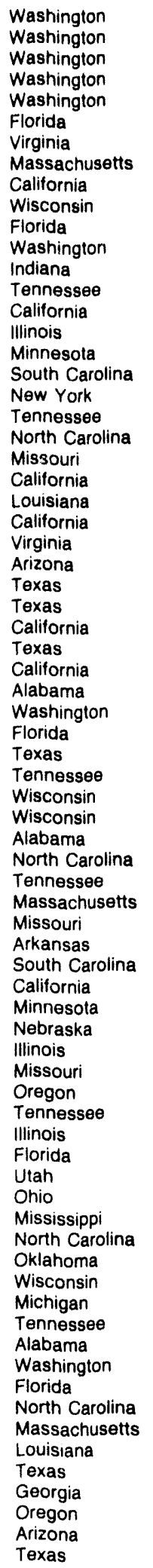 & 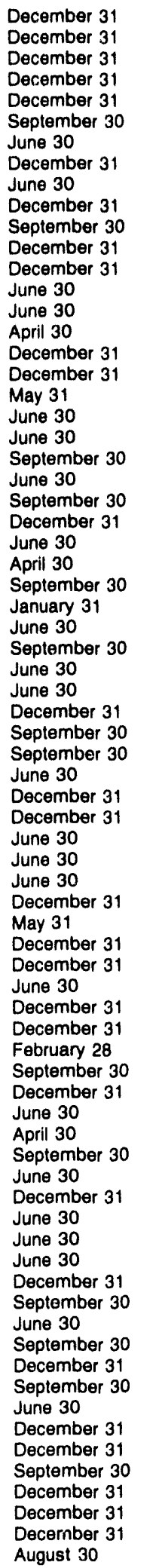 & 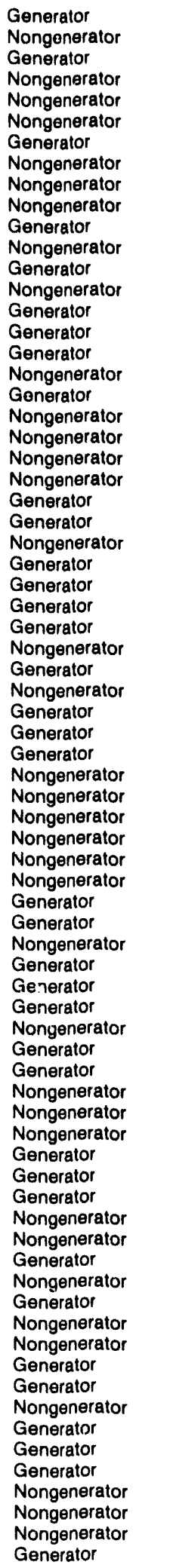 \\
\hline
\end{tabular}

See endnotes at end of this table. 
Table B2. Publicly Owned Electric Utilitles That Submitted the Form EIA-412, 1992 (Continued)

\begin{tabular}{|c|c|c|c|}
\hline Publlely Owned Electric Utilities & State & Reporting Date & Generating Status \\
\hline 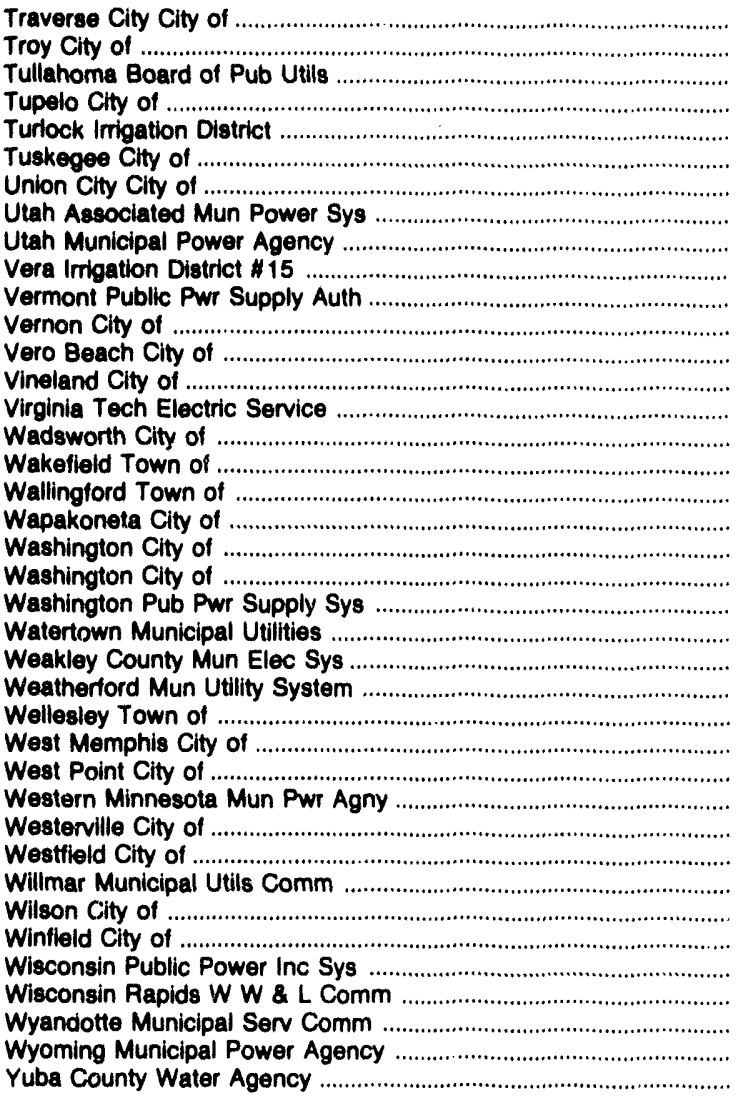 & $\begin{array}{l}\text { Michigan } \\
\text { Alabama } \\
\text { Tennessee } \\
\text { Mississippi } \\
\text { California } \\
\text { Alabama } \\
\text { Tennessee } \\
\text { Utah } \\
\text { Utah } \\
\text { Washington } \\
\text { Vermont } \\
\text { California } \\
\text { Florida } \\
\text { New Jersey } \\
\text { Virginia } \\
\text { Ohio } \\
\text { Massachusetts } \\
\text { Connecticut } \\
\text { Ohio } \\
\text { Indiana } \\
\text { North Carolina } \\
\text { Washington } \\
\text { South Dakota } \\
\text { Tennessee } \\
\text { Texas } \\
\text { Massachusetts } \\
\text { Arkansas } \\
\text { Mississippi } \\
\text { Minnesota } \\
\text { Ohio } \\
\text { Massachusetts } \\
\text { Minnesota } \\
\text { North Carolina } \\
\text { Kansas } \\
\text { Wisconsin } \\
\text { Wisconsin } \\
\text { Michigan } \\
\text { Wyoming } \\
\text { California } \\
\text { Masal }\end{array}$ & $\begin{array}{l}\text { June } 30 \\
\text { September } 30 \\
\text { June } 30 \\
\text { June } 30 \\
\text { December } 31 \\
\text { Seplember } 30 \\
\text { June } 30 \\
\text { March } 31 \\
\text { June } 30 \\
\text { December } 31 \\
\text { December } 31 \\
\text { June } 30 \\
\text { September } 30 \\
\text { June } 30 \\
\text { June } 30 \\
\text { December } 31 \\
\text { December } 31 \\
\text { June } 30 \\
\text { December } 31 \\
\text { December } 31 \\
\text { June } 30 \\
\text { June } 30 \\
\text { December } 31 \\
\text { June } 30 \\
\text { September } 30 \\
\text { December } 31 \\
\text { December } 31 \\
\text { June } 30 \\
\text { December } 31 \\
\text { December } 31 \\
\text { December } 31 \\
\text { December } 31 \\
\text { June } 30 \\
\text { December } 31 \\
\text { June } 30 \\
\text { December } 31 \\
\text { September } 30 \\
\text { December } 31 \\
\text { June } 30 \\
\text { Du }\end{array}$ & $\begin{array}{l}\text { Generator } \\
\text { Nongenerator } \\
\text { Nongenerator } \\
\text { Nongenerator } \\
\text { Generator } \\
\text { Nongenerator } \\
\text { Nongenerator } \\
\text { Generator } \\
\text { Generator } \\
\text { Nongenerator } \\
\text { Generator } \\
\text { Generator } \\
\text { Generator } \\
\text { Generator } \\
\text { Generator } \\
\text { Nongenerator } \\
\text { Nongenerator } \\
\text { Generator } \\
\text { Nongenerator } \\
\text { Nongenerator } \\
\text { Nongenerator } \\
\text { Generator } \\
\text { Nongenerator } \\
\text { Nongenerator } \\
\text { Generator } \\
\text { Nongenerator } \\
\text { Generator } \\
\text { Nongenerator } \\
\text { Generator } \\
\text { Nongenerator } \\
\text { Nongenerator } \\
\text { Generator } \\
\text { Nongenerator } \\
\text { Generator } \\
\text { Generator } \\
\text { Nongenerator } \\
\text { Generator } \\
\text { Generator } \\
\text { Generator }\end{array}$ \\
\hline
\end{tabular}

Source: Energy Information Administration, Form EIA-412, "Annual Report of Public Electric Utilities." 
Flgure B1. Principal Business Office of the Major U.S. Publicly Owned Electric Utilities, 1992

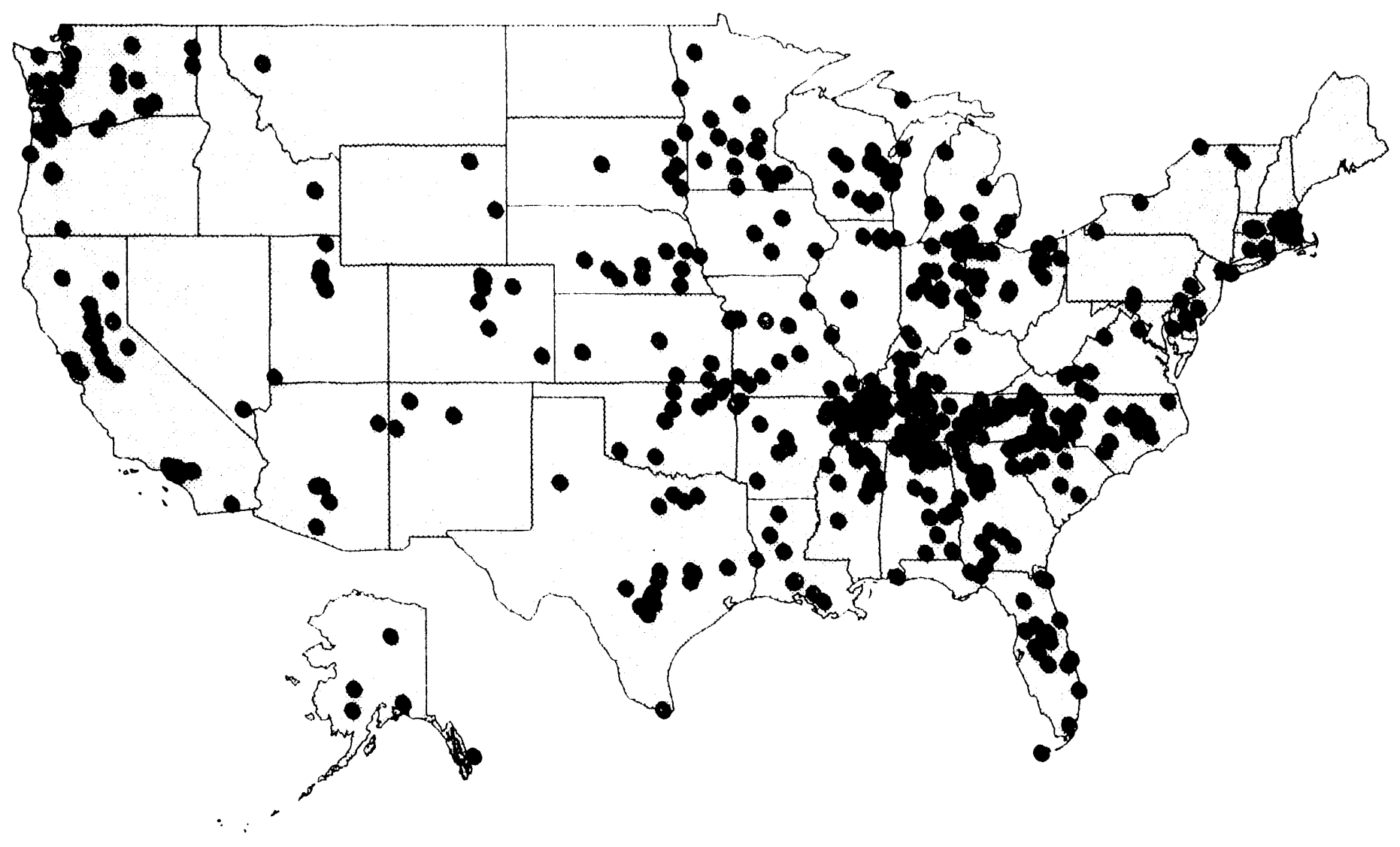

Source: Energy Information Administration, Form ElA-412, "Annual Report of Public Electric Utilities." 


\title{
Appendix C
}

\author{
Major U.S. \\ Generator/ \\ Nongenerator \\ Respondents by \\ June 30 and \\ December 31 \\ Fiscal Years and \\ by All \\ Respondents, \\ 1989-19??
}




\section{Appendix C}

\section{Major U.S. Generator/Nongenerator Respondents by June 30 and December 31 Fiscal Years and by All Respondents, 1989-1992}


Table C1. Ten Largest U.S. Publicly Owned Generator Electric Utilities Ranked by Megawatthour Sales to Ultimate Consumers with Financial Year Ending on June 30, 1992

\begin{tabular}{|c|c|c|c|}
\hline Publlcly Owned Electric Utllities & State & Amount & Percent \\
\hline 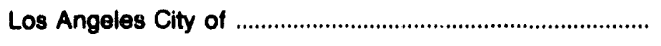 & CA & $21,515,437$ & 46.46 \\
\hline Santa Clara City of & CA & $2,218,461$ & 4.79 \\
\hline 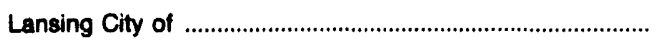 & MI & $2,172,696$ & 4.69 \\
\hline 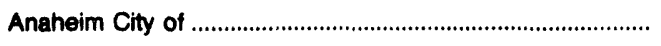 & CA & $2,095,993$ & 4.53 \\
\hline 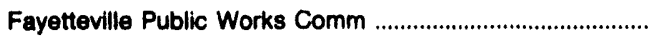 & NC & $1,565,103$ & 3.38 \\
\hline 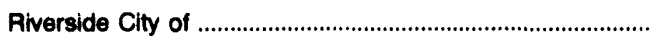 & CA & $1,564,155$ & 3.38 \\
\hline 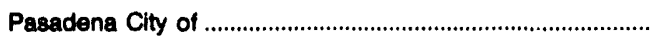 & CA & $1,067,838$ & 2.31 \\
\hline 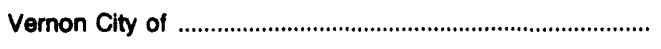 & CA & $1,017,592$ & 2.20 \\
\hline Burbank City of & CA & 972,739 & 2.10 \\
\hline Glendale City of & CA & 957,898 & 2.07 \\
\hline Subtotal & & $35,147,912$ & 75.89 \\
\hline
\end{tabular}

Source: Energy Information Administration, Form EIA-412, "Annual Report of Public Electric Utilities."

Table C2. Ten Largest U.S. Publicly Owned Generator Electric Utilities Ranked by Megawatthour Sales for Resale with Financial Year Ending on June 30, 1992

\begin{tabular}{|c|c|c|c|}
\hline Publlely Owned Electric Utilities & State & Amount & Percent \\
\hline 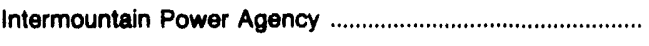 & UT & $11,385,417$ & 30.61 \\
\hline 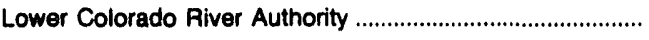 & TX & $8,071,364$ & 21.70 \\
\hline 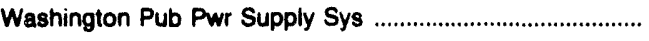 & WA & $3,882,011$ & 10.44 \\
\hline 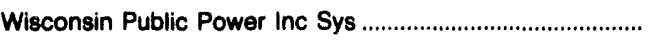 & $W I$ & $2,723,600$ & 7.32 \\
\hline California Dept-Wtr Resources & CA & $2,467,108$ & 6.63 \\
\hline 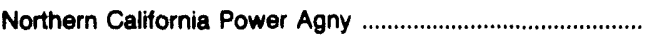 & CA & $1,736,153$ & 4.67 \\
\hline Southern California P P A & CA & $1,434,034$ & 3.86 \\
\hline 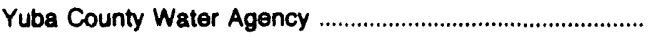 & CA & $1,007,705$ & 2.71 \\
\hline 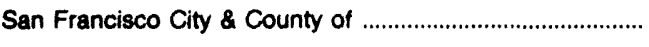 & CA & $1,005,423$ & 2.70 \\
\hline Utah Municipal Power Agency & UT & 766,388 & 2.06 \\
\hline Subtotal & & $34,479,203$ & 92.69 \\
\hline
\end{tabular}

Source: Energy Information Administration, Form ElA-412, "Annual Report of Public Electric Utilities." 


\section{Table C3. Composite Statement of Income for Major U.S. Publicly Owned Generator Electric Utilities with Financial Year Ending on June 30, 1989-1992}

(Thousand Dollars)

\begin{tabular}{|c|c|c|c|c|}
\hline Item & 1992 & 1991 & 1990 & 1989 \\
\hline Electr:- Utility Operating Rovenues ...................... & $5,873,621$ & $5,583,883$ & $5,522,510$ & $5,580,095$ \\
\hline 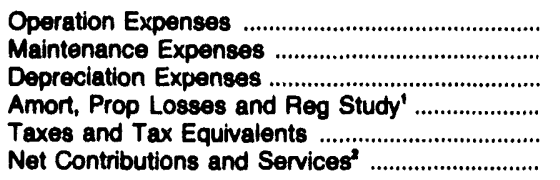 & $\begin{array}{r}3,525,928 \\
368,959 \\
627,770 \\
36,028 \\
109,783 \\
-\end{array}$ & $\begin{array}{r}3,389,558 \\
350,956 \\
623,168 \\
- \\
107,916 \\
66,809\end{array}$ & $\begin{array}{r}3,243,473 \\
404,302 \\
562,284 \\
- \\
101,236 \\
72,042\end{array}$ & $\begin{array}{r}3,167,210 \\
519,534 \\
641,313 \\
- \\
91,19 \overline{3} \\
91,112\end{array}$ \\
\hline $\begin{array}{l}\text { Total Electric Utllity Operating } \\
\text { Expenese }\end{array}$ & $4,668,460$ & $4,538,407$ & $4,383,337$ & $4,510,362$ \\
\hline 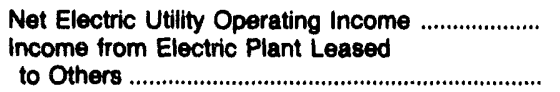 & $\begin{array}{r}1,205,152 \\
2,474\end{array}$ & $\begin{array}{r}1,045,576 \\
719\end{array}$ & $\begin{array}{r}1,139,173 \\
448\end{array}$ & $\begin{array}{r}1,069,733 \\
252\end{array}$ \\
\hline Electric Utility Operating Incoms ..................... & $1,207,627$ & $1,046,295$ & $1,139,621$ & $1,069,985$ \\
\hline Other Electric Income & 391,113 & 355,740 & 348,547 & 386,804 \\
\hline 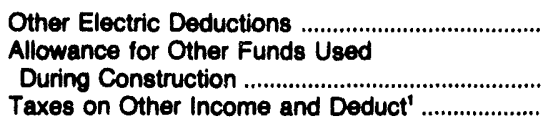 & 122,334 & $\begin{array}{r}1,824 \\
6,143 \\
-\end{array}$ & $\begin{array}{r}- \\
3,188 \\
-\end{array}$ & $\begin{array}{r}- \\
9,454 \\
-\end{array}$ \\
\hline Eloctric Utility income & $1,475,521$ & $1,406,354$ & $1,491,356$ & $1,466,243$ \\
\hline 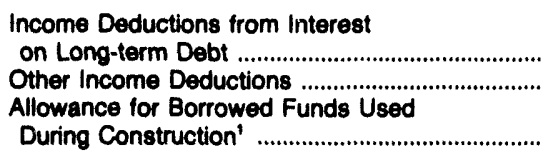 & $\begin{array}{r}1,298,247 \\
-12,878 \\
-10,592\end{array}$ & $\begin{array}{r}1,182,775 \\
-87,632 \\
-\end{array}$ & $\begin{array}{r}1,172,787 \\
57,623\end{array}$ & $\begin{array}{r}1,131,305 \\
-2,108 \\
-\end{array}$ \\
\hline 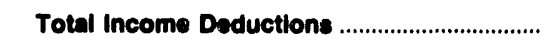 & $1,274,778$ & $1,095,143$ & $1,230,409$ & $1,129,196$ \\
\hline 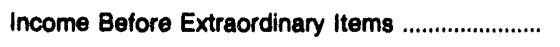 & 200,744 & 311,212 & 260,947 & 337,046 \\
\hline Extraordinary Income & 6,593 & 5,763 & 82,133 & 3,388 \\
\hline 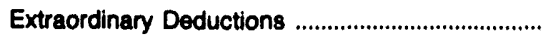 & 73,027 & 132,571 & 126,517 & 30,368 \\
\hline Not Income & 134,310 & 184,403 & 216,563 & 310,066 \\
\hline
\end{tabular}

Date reporting initiated in 1992.

- Data reporting discontinued in 1992.

- Data not available.

Note: Totals may not equal sum of components because of independent rounding. The number of generating publicly owned electric utilities for end of period is 56 for June 30, 1992; 53 for June 30, 1981; 52 for June 30, 1990; and 50 for June 30 , 1989 . The City of Vineland (NJ) changed fiscal year from June 30 to December 31 in 1981 and California Department of Water Resources (CA) changed fiscal year from December 31 to June 30 in 1992. Emerald Peoples Utility District (OR), City of Bryan (OH), and Northern Wasco County PUD (OR) were nongenerators for 1989 through 1891, but became generators in 1992. The South Carolina Public Service Authority (SC) changed fiscal year from June 30 to December 31 in 1990. The Utah Associated Municipal Power System (UT) changed fiscal year from June 30 to March 31 in 1991. The City of Marshfield (WI) was a generator in 1989 and 1990, but became a nongenerator in 1991 . The Wisconsin Public Power Incorporated System (WI) was a nongenerator in 1989 and 1990, but became a generator in 1991.

Source: Energy Information Administration, Form ElA-412, "Annual Report of Public Electric Utilities." 
Table C4. Composite Balance Sheet for Major U.S. Publicly Owned Generator Electric Utilities with Financial Year Ending on June 30 at End of Period, 1989-1992 (Thousand Dollars)

\begin{tabular}{|c|c|c|c|c|}
\hline Item & 1992 & 1991 & 1990 & 1989 \\
\hline \multicolumn{5}{|l|}{ Electric Utility Plant } \\
\hline 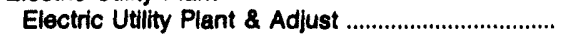 & $21,821,753$ & $21,287,167$ & $20,522,021$ & $22,055,492$ \\
\hline 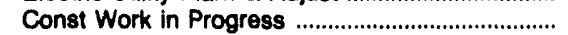 & $1,007,230$ & - & - & - \\
\hline (less) Depr, Amort, and Depletion ......................... & $6,047,224$ & $5,313,940$ & $4,722,915$ & $4,694,601$ \\
\hline Not Electric Utility Plant' ................................... & $16,781,759$ & - & - & - \\
\hline 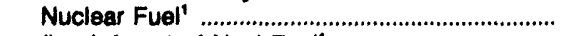 & 307,982 & - & - & - \\
\hline 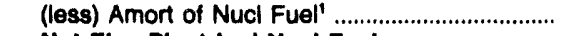 & 138,151 & - & - & - \\
\hline 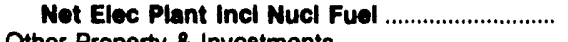 & $16,951,590$ & $15,973,226$ & $15,799,106$ & $17,360,891$ \\
\hline \multicolumn{5}{|l|}{ Other Property \& Investments } \\
\hline Nonutility Property & $4,390,194$ & $4,083,541$ & $3,669,756$ & $3,436,470$ \\
\hline (less) Accum Provisions for Depr \& Amort ........... & $1,426,040$ & $1,323,745$ & $1,212,730$ & $1,136,176$ \\
\hline 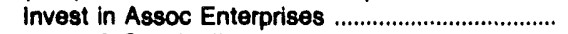 & 38,999 & 2,351 & 4,218 & 1,304 \\
\hline 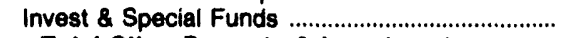 & $3,958,741$ & $4,048,793$ & $4,151,242$ & $4,370,717$ \\
\hline Total Other Property Investment ................. & $6,961,895$ & $6,810,940$ & $6,612,486$ & $6,672,314$ \\
\hline \multicolumn{5}{|l|}{ Current and Accrued Assets } \\
\hline 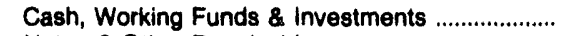 & $3,167,797$ & $2,879,170$ & $3,019,275$ & $2,309,479$ \\
\hline 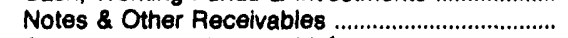 & 274,818 & 666,963 & 783,445 & 801,941 \\
\hline Customer Accts Receivable ${ }^{1}$...................................... & 521,135 & - & - & - \\
\hline (less) Accum Prov for Uncollected Accts ............ & 14,961 & 11,322 & 9,364 & 17,906 \\
\hline Fuel Stock \& Exp Undistr' & 230,592 & - & - & - \\
\hline 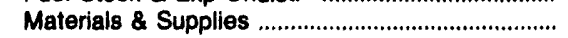 & 306,329 & 425,083 & 364,691 & 390,488 \\
\hline 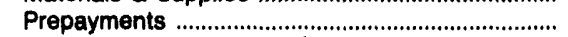 & 74,489 & 79,627 & 78,179 & 76,338 \\
\hline 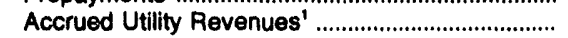 & 118,743 & - & - & - \\
\hline Miscellaneous Current \& Accrued Assets ............ & 267,360 & 269,715 & 132.754 & 119,826 \\
\hline $\begin{array}{l}\text { Total Current \& Accrued Aceats ............................... } \\
\text { Deferred Debits }\end{array}$ & $4,946,301$ & $4,309,236$ & $4,368,981$ & $3,680,165$ \\
\hline 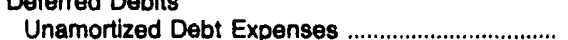 & \multicolumn{4}{|c|}{ Deferred Debits } \\
\hline 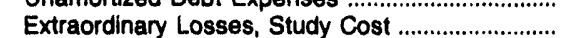 & 12,920 & $\begin{array}{r}901,022 \\
-\end{array}$ & $\begin{array}{r}986,193 \\
-\end{array}$ & $\begin{array}{r}1,011,199 \\
6,974\end{array}$ \\
\hline Misc Debt, A \& D Exp, Unamrt Losses ................. & $2,598,210$ & $2,399,812$ & $2,135,192$ & $2,382,447$ \\
\hline 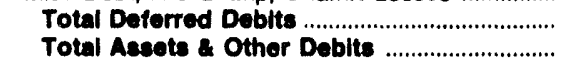 & $\begin{array}{r}3,531,511 \\
32,391,297\end{array}$ & $\begin{array}{r}3,351,435 \\
30,444,837\end{array}$ & $\begin{array}{r}3,121,386 \\
29,901,959\end{array}$ & $\begin{array}{r}3,401,220 \\
31,114,590\end{array}$ \\
\hline \multicolumn{5}{|l|}{ Proprietary Capital } \\
\hline 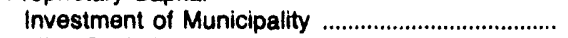 & $1,020,857$ & $1,171,715$ & $1,033,629$ & $1,025,960$ \\
\hline 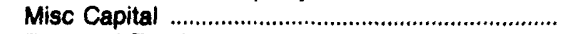 & $-14,376$ & $-251,794$ & $-82,290$ & 9,032 \\
\hline Retained Earnings & $6,911,454$ & $6,796,166$ & $6,482,752$ & $6,468,155$ \\
\hline Total Proprlotary Capltal .................................... & $7,917,934$ & $7,716,086$ & $7,434,090$ & $7,503,147$ \\
\hline \multicolumn{5}{|l|}{ Long-term Debt } \\
\hline 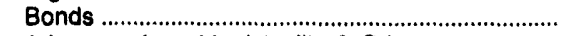 & $20,377,974$ & $18,835,964$ & $18,600,918$ & $19,241,142$ \\
\hline Advances from Municipality \& Other ........................ & 553,413 & 594,617 & 521,912 & 552,264 \\
\hline Unamort Prem on Long-term Debt .......................... & 3,743 & 688 & 743 & 798 \\
\hline (less) Unamort Discount on Long-term Debt ...... & $1,072,415$ & 986,782 & 944,583 & 912,420 \\
\hline 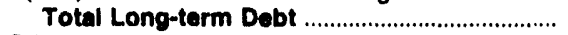 & $19,862,716$ & $18,444,488$ & $18,178,989$ & $18,881,783$ \\
\hline \multicolumn{5}{|l|}{ Other Noncurrent Liabilities } \\
\hline 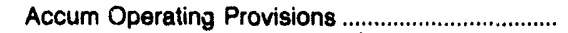 & 69,277 & 32,515 & 33,362 & 37,400 \\
\hline Accum Prov for Rate Refunds' ${ }^{\prime}$............................... & - & - & - & - \\
\hline Total Other Noncurrent Liabilities ................... & 69,277 & 32,515 & 33,362 & 37,400 \\
\hline \multicolumn{5}{|l|}{ Current and Accrued Liabilities } \\
\hline 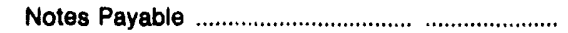 & 124,960 & 100,631 & 117,925 & 183,392 \\
\hline 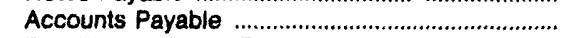 & 036,494 & 746,541 & 664,029 & 680,466 \\
\hline Payables to Assoc Enterprises .............................. & 145,023 & 149,637 & 139,883 & 124,922 \\
\hline 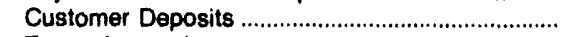 & 93,187 & 75,121 & 41,682 & 81,254 \\
\hline 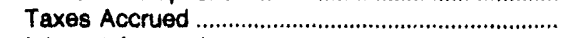 & 21,663 & 21,522 & 14,220 & 17,277 \\
\hline Interest Accrued & 382,500 & 410,709 & 342,985 & 397,198 \\
\hline Misc Current \& Accrued Liabilities ............................ & $1,940,659$ & $1,827,133$ & $1,824,711$ & $1,914,085$ \\
\hline Total Current \& Accrued Liabillties .................. & $3,544,487$ & $3,331,293$ & $3,145,434$ & $3,398,593$ \\
\hline \multicolumn{5}{|l|}{ Deferred Credits } \\
\hline Customer Advances for Construction ...................... & 42,340 & 51,082 & 34,180 & 30,886 \\
\hline Other Deferred Credits ............................................ & 811,973 & 695,188 & 928,499 & $1,125,854$ \\
\hline Unamort Gain on Reacqr Debt ............................... & 142,572 & 174,185 & 147,404 & 136,926 \\
\hline Total Deferred Credits ........................................... & 996,885 & 920,455 & $1,110,083$ & $1,293,667$ \\
\hline Total Llabilities and Other Credits ................... & $32,391,297$ & $30,444,837$ & $29,901,959$ & $31,114,580$ \\
\hline
\end{tabular}

Data reporting initiated in 1992.

Note: Totals may not equal sum of components because of independent rounding. The number of generating publicly owned electric utilities for end of period is 56 for June 30, 1992; 53 for June 30, 1991; 52 for June 30, 1990; and 50 for June 30 , 1989 . The City of Vineland (NJ) changed fiscal year from June 30 to December 31 in 1991 and California Department of Water Resources (CA) changed fiscal year from December 31 to June 30 in 1992. Emerald Peoples Utility District (OR), City of Bryan (OH), and Northern Wasco County PUD (OR) were nongenerators for 1989 through 1991, but became generators in 1992. The South Carolina Public Service Authority (SC) changed fiscal year from June 30 to December 31 in 1990. The Utah Associated Municipal Power System (UT) changed fiscal year from June 30 to March 31 in 1991. The City of Marshfield (WI) was a generator in 1989 and 1990, but became a nongenerator in 1991 . The Wisconsin Public Power incorporated System (WI) was a nongenerator in 1989 and 1990, but became a generator in 1991.

Source: Energy Information Administration, Form EIA-412, "Annual Report of Public Electric Utilities." 
Table C5. Composite Financial Indicators for Major U.S. Publicly Owned Generator Electric Utilities with Financial Year Ending on June 30, 1989-1992

\begin{tabular}{|c|c|c|c|c|}
\hline Item & 1992 & 1991 & 1990 & 1989 \\
\hline Total Electric Utility Plant per Dollar of Revenue & 3.9 & 3.8 & 3.7 & 4.0 \\
\hline Current Assets to Current Liabilities .......................... & 1.4 & 1.3 & 1.4 & 1.1 \\
\hline $\begin{array}{l}\text { Total Electric Utility Plant as a Percent of Total } \\
\text { Assets }\end{array}$ & 71.4 & 69.9 & 68.6 & 70.9 \\
\hline $\begin{array}{l}\text { Net Electric Utility Plant as a Percent of Total } \\
\text { Aseots }\end{array}$ & 52.3 & 52.5 & 52.8 & 55.8 \\
\hline Debt as a Percent of Totai Liabilities ..................... & 72.3 & 71.5 & 71.3 & 71.6 \\
\hline $\begin{array}{l}\text { Depreciation, Amortization and Depletion } \\
\text { as a Percent of Total Electric Utility Plant .......... }\end{array}$ & 26.7 & 25.0 & 23.0 & 21.3 \\
\hline $\begin{array}{l}\text { Electric Operation and Maintenance Expenses } \\
\text { as a Percent of } \\
\text { Electric Utility Operating Revenues ........................ }\end{array}$ & 66.3 & 67.0 & 66.1 & 66.1 \\
\hline $\begin{array}{l}\text { Electric Depreciation and Amortization } \\
\text { as a Percent of } \\
\text { Electric Utility Operating Revenues ........................... }\end{array}$ & 10.7 & 11.2 & 10.2 & 11.5 \\
\hline $\begin{array}{l}\text { Taxes and Tax Equivalents } \\
\text { as a Percent of } \\
\text { Electric Utility Operating Revenues ...................... }\end{array}$ & 1.9 & 1.9 & 1.8 & 1.6 \\
\hline $\begin{array}{l}\text { Interest on Long-term Debt } \\
\text { as a Percent of } \\
\text { Electric Utility Operating Revenues ......................... }\end{array}$ & 22.1 & 21.2 & 21.2 & 20.3 \\
\hline 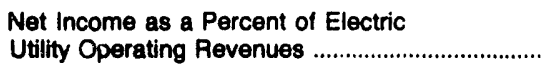 & 2.3 & 3.3 & 3.9 & 5.6 \\
\hline
\end{tabular}

Note: Totals may not equal sum of components because of independent rounding. The number of generating publicly owned electric utilities for end of period is 56 for June 30,$1992 ; 53$ for June 30,$1991 ; 52$ for June 30, 1990; and 50 for June 30 , 1989 . The City of Vineland (NJ) changed fiscal year from June 30 to Deceniber 31 in 1991 and California Department of Water Resources (CA) changed fiscal year from December 31 to June 30 in 1992. Emerald Peoples Utility District (OR), City of Bryan (OH), and Northern Wasco County PUD (OR) were nongenerators for 1989 through 1991, but became generators in 1992. The South Carolina Public Service Authority (SC) changed fiscal year from June 30 to December 31 in 1990. The Utah Associated Municipal Power System (UT) changed fiscal year from June 30 to March 31 in 1991. The City of Marshfield (WI) was a generator in 1989 and 1990, but became a nongenerator in 1991. The Wisconsin Public Power Incorporated System (WI) was a nongenerator in 1989 and 1990, but became a generator in 1991.

Source: Energy Information Administration, Form EIA-412, "Annual Report of Public Electric Utilities." 
Table C6. Electric Operation and Maintenance Expenses for Major U.S.

Publicly Owned Generator Electric Utilities with Financial

Year Ending on June 30, 1989-1992

(Thousand Dollars)

\begin{tabular}{l|l|l|l|l|l}
\hline Item & 1992 & 1991 & 1790 & 1989 & \\
\hline
\end{tabular}

\section{Production Exponses}

Steam Power Generation

952,188

Nuclear Power Generation

Hydraulic Power Generation

Other Power Generation

Purchased Power

Other Production Expenses

Total Production Expenses

Transmission Expenses .

Distribution Expenses

Customer Accounts Expenses

Customer Service and Information Expenses ....

Sales Expenses

Administrative and General Expenses

Total Electric Operation

and Malntenance Expenses

\section{5,820}

51,216

38,213

$1,696,102$

25,393

$2,958,932$

122,955

249,276

85,956

23,888

1,507

452,373

$3,894,887$

\section{0,777}

208,094

49,211

24,478

$1,634,208$

26,376

$2,863,145$

114,691

232,287

77,482

19,756

3,126

430,027

$3,740,513$

$3,647,775$

991,183

197,714

45,352

34,899

$1,542,275$

12,417

$2,823,839$

113,483

212,305

75,973

14,472

4,155

403,548

\section{Fual Expenses in Operation}

Steam Power Generation

702,909

651,050

729,064

918,618

Nuclear Power Generation

38,524

56,309

42,634

59,049

Other Pcwer Generation

17,832

16.092

11,879

14,297

Number of Elec Dept Employees

Regular Full-time'

16,894

Part-time \& Temporary'

1,217

Total Elec Dept Employees'

18,111

1 Data reporting initiated in 1992.

Note: Totals may not equal sum of components because of independent rounding. The number of generating publicly owned electric utilities for end of period is 56 for June 30, 1992; 53 for June 30, 1991; 52 for June 30, 1990; and 50 for June 30 , 1989. The City of Vineland (NJ) changed fiscal year from June 30 to December 31 in 1991 and California Department of Water Resources (CA) changed fiscal year from December 31 to June 30 in 1992. Emerald Peoples Utility District (OR), City of Bryan (OH), and Northern Wasco County PUD (OR) were nongenerators for 1989 through 1991, but became generators in 1992. The Soutt, Carolina Public Service Authority (SC) changed fiscal year from June 30 to December 31 in 1990 . The Utah Associated Municipal Power System (UT) changed fiscal year from June 30 to March 31 in 1991. The City of Marshfield (WI) was a generator in 1989 and 1990, but became a nongenerator in 1991 . The Wisconsin Public Power incorporated System (WI) was a nongenerator in 1989 and 1990, but became a generator in 1991.

Source: Energy Information Administration, Form EIA-412, "Annual Report of Public Electric Utilities." 
Table C7. Electric Utillty Plant for Major U.S. Publicly Owned

Generator Electric Utilities with Financial Year Ending

on June 30 at End of Period, 1989-1992

(Thousand Dollars)

\begin{tabular}{|c|c|c|c|c|}
\hline Item & 1992 & 1991 & 1990 & 1989 \\
\hline \multicolumn{5}{|l|}{ Electric Plant In Service } \\
\hline 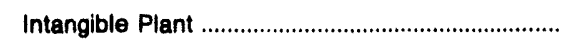 & 103,370 & 141,436 & 83,134 & 172,036 \\
\hline \multicolumn{5}{|l|}{ Production Plant } \\
\hline 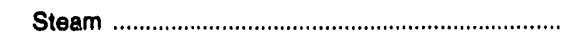 & $6,074,387$ & $5,849,534$ & $5,789,039$ & $6,485,865$ \\
\hline Nuclear & $4,584,312$ & $4,859,875$ & $4,857,227$ & $5,274,101$ \\
\hline 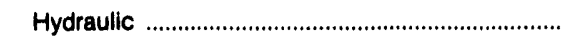 & $2,618,895$ & $1,794,146$ & $1,793,520$ & $1,457,555$ \\
\hline Other & 590,691 & 248,642 & 217,512 & 236,807 \\
\hline 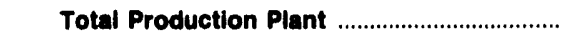 & $13,868,285$ & $12,752,197$ & $12,657,299$ & $13,454,328$ \\
\hline 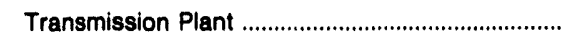 & $2,372,536$ & $2,257,636$ & $2,211,441$ & $2,450,653$ \\
\hline 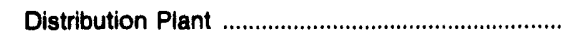 & $4,056,844$ & $3,757,918$ & $3,443,680$ & $3,486,859$ \\
\hline 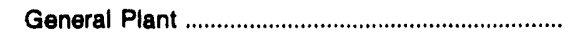 & $1,189,667$ & $1,123,472$ & $1,037,843$ & $1,099,187$ \\
\hline Total Electric Plant in Sorvice ................................... & $21,590,702$ & $20,032,658$ & $18,433,397$ & $20,663,064$ \\
\hline 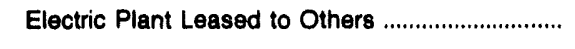 & 1 & 655 & 1,920 & 1 \\
\hline Construction Work in Progress - Electric ............... & $1,007,230$ & $1,002,642$ & 840,947 & $1,366,413$ \\
\hline 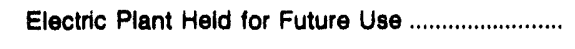 & 17 & 264,295 & 268,278 & 52,523 \\
\hline Electric Plant Misc & 231,033 & $-13,083$ & $-22,522$ & $-26,509$ \\
\hline Total Electric Utllity Plant ..................................... & $22,828,983$ & $21,287,167$ & $20,522,021$ & $22,055,492$ \\
\hline 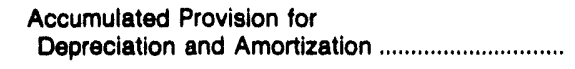 & $6,047,224$ & $5,313,940$ & $4,722,915$ & $4,694,601$ \\
\hline Not Electric Utility Plant ........................................ & $16,781,759$ & $15,973,226$ & $15,799,106$ & $17,360,891$ \\
\hline
\end{tabular}

Note: Totals may not equal sum of components because of independent rounding. The number of generating publicly owned electric utilities for end of period is 56 for June 30, 1992; 53 for June 30, 1991; 52 for June 30, 1990; and 50 for June 30, 1989. The City of Vineland (NJ) changed fiscal year from June 30 to December 31 in 1991 and California Department of Water Resources (CA) changed fiscal year from December 31 to June 30 in 1992. Emerald Peoples Utility District (OR), City of Bryan (OH), and Northern Wasco County PUD (OR) were nongenerators for 1989 through 1991, but became generators in.1992. The South Carolina Public Service Authority (SC) changed fiscal year from June 30 to December 31 in 1990. The Utah Associated Municipal Power System (UT) changed fiscal year from June 30 to March 31 in 1991. The City of Marshfleld (WI) was a generator in 1989 and 1990, but became a nongenerator in 1991 . The Wisconsin Public Power incorporated System (WI) was a nongenerator in 1989 and 1990, but became a generator in 1991.

Source: Energy Information Administration, Form ElA-412, "Annual Report of Public Electric Utilities." 
Table C8. Number of Consumers, Sales, and Operating Revenue for Major U.S. Publicly Owned Generator Electric Utilities with Financial Year Ending on June 30, 1989-1992

\begin{tabular}{|c|c|c|c|c|}
\hline Item & 1992 & 1991 & 1990 & 1989 \\
\hline \multicolumn{5}{|l|}{ Number of Consumere } \\
\hline 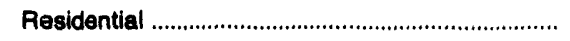 & $2,051,709$ & $2,099,789$ & $2,004,831$ & $2,045,125$ \\
\hline Commercial or Small & 298,130 & 234,033 & 237,665 & 303,841 \\
\hline Industrial or Large & 23,782 & 20,265 & 23,732 & 24,026 \\
\hline Other & 19,858 & 20,055 & 24,462 & 19,326 \\
\hline Total Uitimate Consumers ................................... & $2,393,479$ & $2,374,142$ & $2,290,680$ & $2,392,318$ \\
\hline \multicolumn{5}{|l|}{ Sales for the Year (megawatthours) } \\
\hline 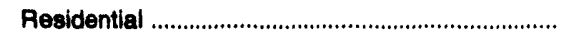 & $12,802,964$ & $12,232,289$ & $12,283,575$ & $12,797,465$ \\
\hline Commercial or Small & $18,772,290$ & $18,643,257$ & $19,535,853$ & $19,477,643$ \\
\hline Industrial or Large & $12,741,755$ & $12,451,053$ & $11,657,126$ & $17,450,359$ \\
\hline Other & $2,628,594$ & $2,299,173$ & $2,234,449$ & $2,220,118$ \\
\hline Total Sales to Uitimate Consumers ................. & $46,945,603$ & $45,625,772$ & $45,711,003$ & $51,945,585$ \\
\hline Sales for Resale & $39,068,959$ & $33,831,354$ & $35,636,950$ & $40,700,200$ \\
\hline 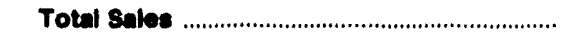 & $86,014,562$ & $79,457,126$ & $81,347,953$ & $92,645,785$ \\
\hline \multicolumn{5}{|l|}{$\begin{array}{l}\text { Operating Revenues for the Year } \\
\text { (thousand dollars) }\end{array}$} \\
\hline 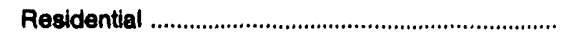 & $1,073,325$ & $1,002,074$ & 998,394 & 993,414 \\
\hline Commercial of Small & $1,535,038$ & $1,469,595$ & $1,576,384$ & $1,478,254$ \\
\hline Industrial or Large & 881,541 & 838,360 & 775,832 & 994,231 \\
\hline Other & 177,005 & 145,979 & 162,520 & 149,472 \\
\hline $\begin{array}{l}\text { Total Rovenues from Sales to } \\
\text { Uitimate Coneumers }\end{array}$ & $3,666,809$ & $3,456,008$ & $3,513,130$ & $3,615,371$ \\
\hline 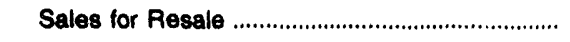 & $2,065,351$ & $1,858,972$ & $1,945,902$ & $1,982,161$ \\
\hline $\begin{array}{l}\text { Total Rovenues From Sales of } \\
\text { Ebetrictty }\end{array}$ & $5,732,260$ & $5,314,980$ & $5,459,032$ & $5,597,532$ \\
\hline
\end{tabular}

Note: Totals may not equal sum of components because of independent rounding. The number of generating publicly owned electric utilties for end of period is 56 for June 30,1992; 53 for June 30,1991; 52 for June 30, 1990; and 50 for June 30, 1989. The City of Vineland (NJ) changed fiscal year from June 30 to December 31 in 1991 and California Department of Water Resources (CA) changed fiscal year from December 31 to June 20 in 1992. Emerald Peoples Utility District (OR), City of Bryan (OH), and Northern Wasco County PUD (OA) were nongenerators for 1989 through 1991, but became generators in 1992. The City of Foley (AL) and the South Carolina Public Service Authority (SC) changed fiscal year from June 30 to December 31 in 1990. The Utah Associated Municipal Power System (UT) changed fiscal year from June 30 to March 31 in 1991. The City of Marshfield (WI) was a generator in 1989 and 1990, but became a nongenerator in 1991. The Wisconsin Public Power Incorporated System (WI) was a nongenerator in 1989 and 1990, but became a generator in 1991. sions.

Source: Energy Information Administration, Form EIA-861, "Annual Electric Utility Report." Data are based on calendar year submis- 
Table C9. Electric Energy Account for Major U.S. Publicly Owned Generator Electric Utillties with Financial Year Ending on June 30, 1989-1992

(Megawatthours)

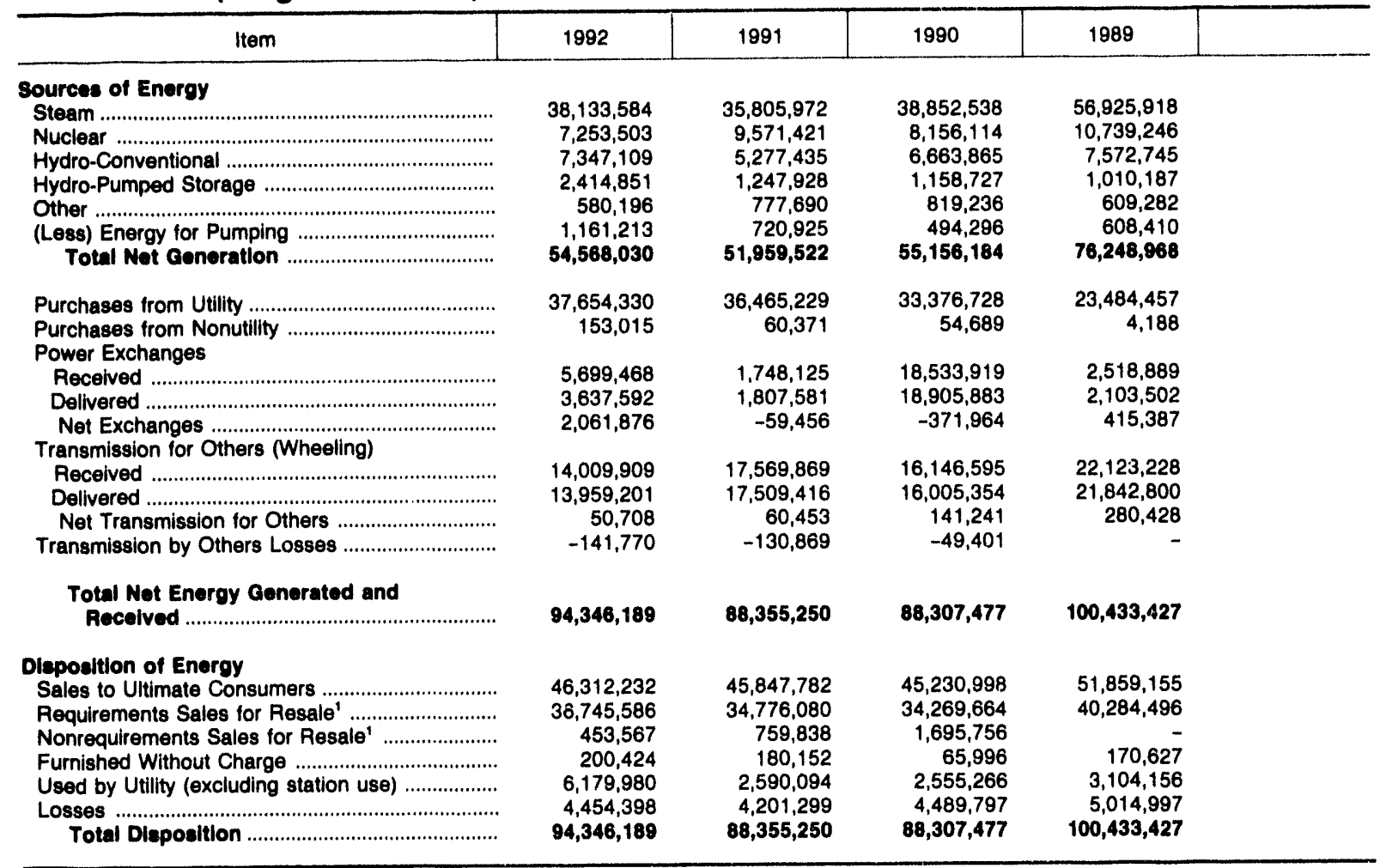

1 The 1989 data were reported as Sales for Resale (one entry) which is shown as Requirements Sales for Resale.

Note: Totals may not equal sum of components because of independent rounding. The number of generating publicly owned electric utilities for end of period is 56 for June 30, 1992; 53 for June 30, 1991; 52 for June 30, 1990; and 50 for June 30 , 1989 . The City of Vineland (NJ) changed fiscal year from June 30 to December 31 in 1991 and California Department of Water Resources (CA) changed fiscal year from December 31 to June 30 in 1992. Emerald Peoples Utility District (OR), City of Bryan (OH), and Northern Wasco County PUD (OR) were nonjenerators for 1989 through 1991, but became generators in 1992 . The South Carolina Public Service Authority (SC) changed fiscal year from June 30 to December 31 in 1990. The Utah Associated Municipal Power System (UT) changed fiscal year from June 30 to March 31 in 1991 . The City of Marshfield (WI) was a generator in 1989 and 1990 , but became a nongenerator in 1991 . The Wisconsin Public Power Incorporated System (WI) was a nongenerator in 1989 and 1990, but became a generator in 1991.

Source: Energy Information Administration, Form ElA-412, "Annual Peport of Public Electric Utilities." 
Table C10. Ten Largest U.S. Publicly Owned Generator Electric Utillties Ranked by Megawatthour Sales to Uitimate Consumers with Financial Year Ending on December 31, 1992

\begin{tabular}{|c|c|c|c|}
\hline Publicly Owned Electric Utilities & State & Amount & Percent \\
\hline Power Authority of State of NY & NY & $13,242,116$ & 12.48 \\
\hline Seattle City of & WA & $8,762,380$ & 8.25 \\
\hline 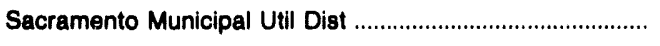 & CA & $8,471,202$ & 7.98 \\
\hline 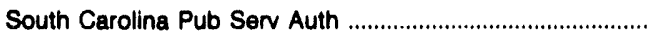 & SC & $7,637,583$ & 7.20 \\
\hline 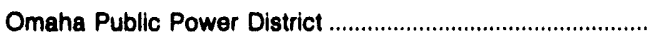 & NE & $6,452,515$ & 6.08 \\
\hline 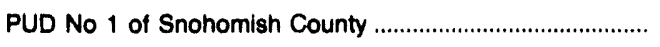 & WA & $5,421,469$ & 5.11 \\
\hline 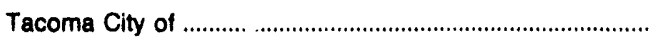 & WA & $5,387,959$ & 5.08 \\
\hline 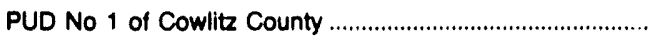 & WA & $4,404,205$ & 4.15 \\
\hline 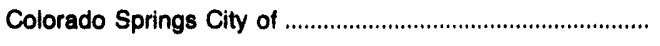 & $\mathrm{CO}$ & $2,873,155$ & 2.71 \\
\hline 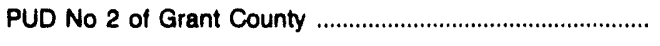 & WA & $2,564,840$ & 2.42 \\
\hline Subtotal & & $65,217,424$ & 61.44 \\
\hline
\end{tabular}

Source: Energy Information Administration, Form ElA-412, "Annual Report of Public Electric Utilities."

\section{Table C11. Ten Largest U.S. Publicly Owned Generator Electric Utilities Ranked by Megawatthour Sales for Resale with Financial Year Ending on December 31, 1992}

\begin{tabular}{|c|c|c|c|}
\hline Publicly Owned Electric Utllities & State & Amount & Percent \\
\hline Power Authority of State of NY & NY & $20,962,342$ & 17.40 \\
\hline 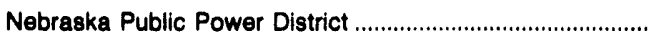 & NE & $\$ 1,309,492$ & 9.42 \\
\hline 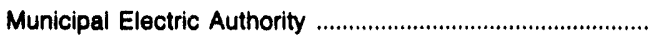 & GA & $9,684,579$ & 8.07 \\
\hline 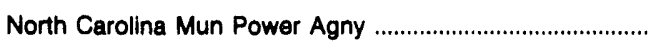 & NC & $7,962,505$ & 6.63 \\
\hline 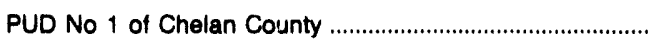 & WA & $7,898,961$ & 6.58 \\
\hline South Carolina Pub Serv Auth & SC & $6,395,055$ & 5.33 \\
\hline PUD No 2 of Grant County & WA & $6,367,661$ & 5.31 \\
\hline North Carolina Eastern M P A & NC & $5,899,408$ & 4.91 \\
\hline Grand River Dam Authority & OK & $4,160,380$ & 3.47 \\
\hline 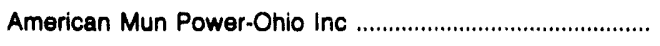 & $\mathrm{OH}$ & $3,730,661$ & 3.11 \\
\hline Subtotal & & $84,371,044$ & 70.29 \\
\hline
\end{tabular}

Source: Energy Information Administration, Form ElA-412, "Annual Report of Public Electric Utilities." 


\section{Table C12. Composite Statement of Income for Major U.S. Publicly Owned Generator Electric Utilities with Financial Year Ending on December 31, 1989-1992}

(Thousand Dollars)

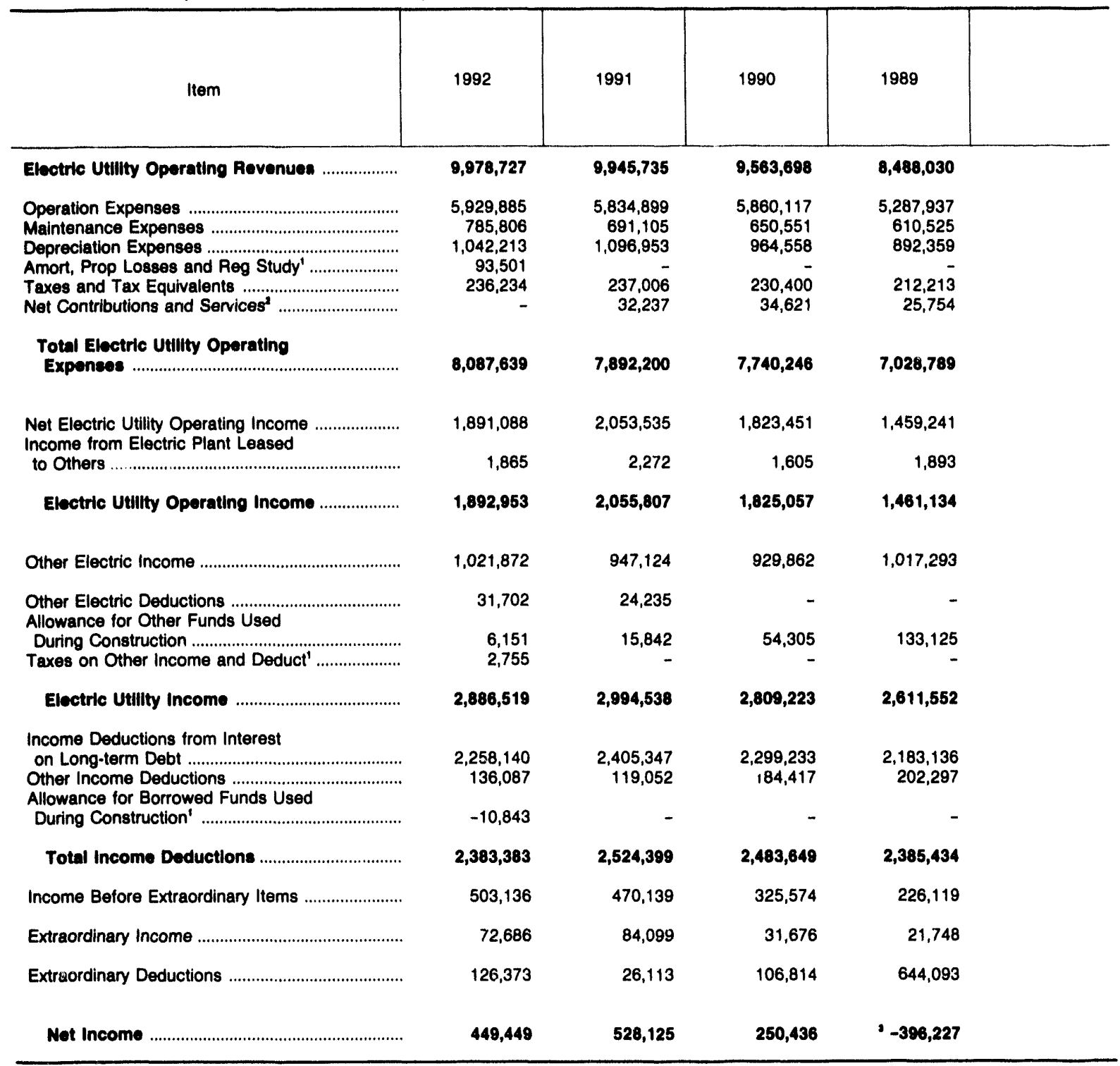

Data reporting initiated in 1992.

2 Data reporting discontinued in 1992.

- Net income reflects $\$ 584$ million of extraordinary deduction associated with the abandonment of the Rancho Seco Nuclear Plant reported by the Sacramento Municipal Utility District.

- Data not available.

Note: Totals may not equal sum of components because of independent rounding. The number of generating publicly owned electric utilities for end of period is 111 for December 31, 1992; 110 for December 31, 1991; 110 for December 31, 1990; and 108 for December 31, 1989. The City of Vineland (NJ) changed fiscal year from June 30 to December 31 in 1991 and California Department of Water Resources (CA) changed fiscal year from December 31 to June 30 in 1992. Emerald Peoples Utility District (OR), City of Bryan (OH), and Northern Wasco County PUD (OA) were nongenerators for 1989 through 1991, but became generators in 1992 . The South Carolina Public Service Authority (SC) changed fiscal year from June 30 to December 31 in 1990. The Utah Associated Municipal Power System (UT) changed fiscal year from June 30 to March 31 in 1991. The City of Marshfield (WI) was a generator in 1989 and 1990 , but became a nongenerator in 1991. The Wisconsin Public Power Incorporated System (WI) was a nongenerator in 1989 and 1990, but became a generator ir. 1991. Source: Energy Information Administration, Form EIA-412, "Annual Report of Public Electric Utilities." 
Table C13. Composite Balance Sheet for Major U.S. Publicly Owned

Generator Electric Utillties with Financial Year Ending on

December 31 at End of Period, 1989-1992

(Thousand Dollars)

\begin{tabular}{|c|c|c|c|c|}
\hline Item & 1992 & 1991 & 1990 & 1989 \\
\hline \multicolumn{5}{|l|}{ Electric Utility Plant } \\
\hline 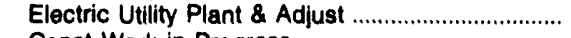 & $35,222,457$ & $37,479,683$ & $35,754,753$ & $32,508,145$ \\
\hline 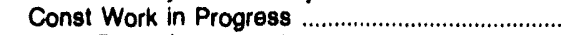 & $1,523,008$ & & & \\
\hline (less) Depr, Amort, and Depletion ............................. & $10,493,142$ & $10,075,535$ & $9,044,556$ & $7,623,800$ \\
\hline Not Electric Utility Plant' .................................. & $26,252,323$ & - & - & - \\
\hline Nuclear Fuel' & $1,653,317$ & - & - & - \\
\hline (less) Amort of Nucl Fuel ........................................ & $1,042,691$ & - & - & - \\
\hline $\begin{array}{l}\text { Not Eloc Plant Incl Nucl Fuel' ............................. } \\
\text { Other Property \& Investments }\end{array}$ & $26,862,950$ & $27,404,148$ & $26,710,198$ & $24,884,345$ \\
\hline \multicolumn{5}{|l|}{ Other Property \& Investments } \\
\hline $\begin{array}{l}\text { Nonutility Property } \\
\text { (less) Accum Provisions for Depr \& Amort }\end{array}$ & 370,608 & 403,811 & 371,810 & 431,129 \\
\hline (less) Accum Provisions for Depr \& Amort ........... & 172,216 & 163,570 & 160,561 & 179,516 \\
\hline 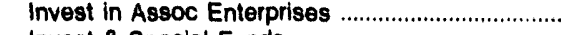 & 205,979 & 60,343 & 58,539 & 58,537 \\
\hline 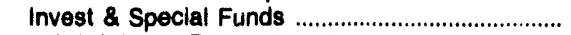 & $6,994,760$ & $6,462,983$ & $5,413,412$ & $5,158,118$ \\
\hline Total Other Property a Investments ............. & $7,399,131$ & $6,763,567$ & $5,683,199$ & $5,468,268$ \\
\hline \multicolumn{5}{|l|}{ Current and Accrued Assets } \\
\hline Cash, Working Funds \& Investments ........................ & $4,546,678$ & $5,266,571$ & $5,294,535$ & $5,264,132$ \\
\hline 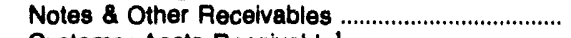 & 281,987 & 963,205 & 966,485 & 949,036 \\
\hline 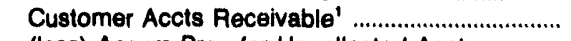 & 770,319 & & & \\
\hline (less) Accum Prov for Uncollected Accts ............. & 20,575 & 19,880 & 19,066 & 16,539 \\
\hline Fuel Stock \& Exp Undistr' & 183,952 & & & \\
\hline Materials \& Supplies & 436,404 & 700,104 & 623,849 & 534,578 \\
\hline & $\begin{array}{r}148,608 \\
88,636\end{array}$ & 148,138 & 74.488 & 77,638 \\
\hline & $\begin{array}{r}640,721 \\
7,076,731\end{array}$ & $\begin{array}{r}250,407 \\
7,308,543\end{array}$ & $\begin{array}{r}240,850 \\
7,181,141\end{array}$ & $\begin{array}{r}254,643 \\
7,063,488\end{array}$ \\
\hline \multicolumn{5}{|l|}{ Deferred Debits } \\
\hline Unamortized Debt Expenses ................................... & 942,727 & 736,895 & 643,102 & 650,285 \\
\hline Extraordinary Losses, Study Cost .............................. & 384,193 & 34,360 & 29,846 & 26,172 \\
\hline Misc Debt, R \& D Exp, Unamrt Losses ................. & $5,228,559$ & $5,075,383$ & $4,542,172$ & $3,415,442$ \\
\hline Total Deferred Debits ................................... & $6,555,478$ & $5,846,637$ & $5,215,120$ & $4,091,899$ \\
\hline 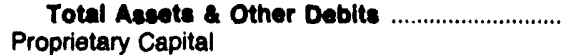 & $47,894,280$ & $47,322,895$ & $44,789,657$ & $41,508,000$ \\
\hline \multicolumn{5}{|l|}{ 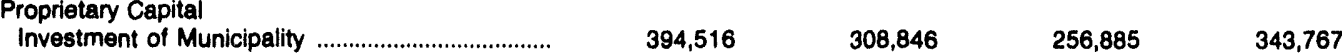 } \\
\hline 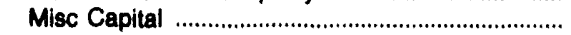 & 50,262 & 86,098 & 68,290 & 62,308 \\
\hline 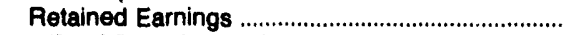 & $7,443,810$ & $7,426,859$ & $7,288,802$ & $6,390,869$ \\
\hline Total Proprietary Capltal ........................................ & 7,888,588 & $7,801,802$ & $7,613,988$ & $6,796,944$ \\
\hline \multirow{2}{*}{\multicolumn{5}{|c|}{$\begin{array}{l}\text { Long-term Debt } \\
\text { Bonds }\end{array}$}} \\
\hline & $34,287,344$ & $33,165,999$ & $30,950,035$ & $29,105,207$ \\
\hline 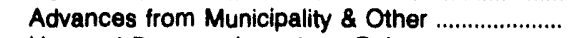 & $1,223,179$ & $1,883,188$ & $2,316,299$ & $2,202,953$ \\
\hline Unamort Prem on Long-term Debt ....................... & 35,176 & 8,141 & 855 & 487 \\
\hline (less) Unamon Discount on Long-term Debt ...... & $1,012,260$ & 984,342 & 917,760 & 879,102 \\
\hline Total Long-torm Debt & $34,533,438$ & $34,072,986$ & $32,349,429$ & $30,429,545$ \\
\hline \multicolumn{5}{|l|}{ Other Noncurrent Liabilities } \\
\hline 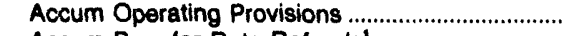 & 409,800 & 414,731 & 254,309 & 298,729 \\
\hline Accum Prov for Rate Refunds' & 4,277 & & & \\
\hline Total Other Noncurrent Llabilitios ..................... & 414,077 & 414,731 & 254,309 & 296,729 \\
\hline \multicolumn{5}{|l|}{ Current and Accrued Liabilities } \\
\hline 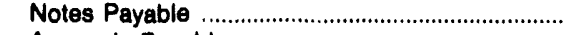 & 861,989 & 761,201 & 709,310 & 452,701 \\
\hline Accounts Payable & 690,877 & 646,324 & 778,237 & 726,594 \\
\hline 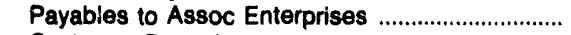 & 38,023 & 46,715 & 35,375 & 37,210 \\
\hline 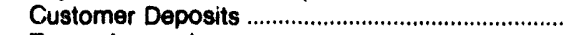 & 44,205 & 46,508 & 45,534 & 38,290 \\
\hline 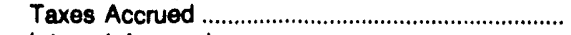 & 89,751 & 90,009 & 88,738 & 75,552 \\
\hline 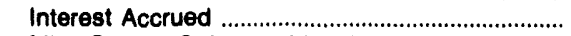 & 716,138 & 755,391 & 740,148 & 675,577 \\
\hline Misc Current \& Accrued Liabilities ............................ & 550,077 & 506,597 & 357,230 & 321,843 \\
\hline Total Current \& Accrued Llabilitios ................. & $2,991,060$ & $2,852,744$ & $2,754,571$ & $2,327,767$ \\
\hline \multicolumn{5}{|l|}{ Deferred Credits } \\
\hline Customer Advances for Construction ......................... & 37,120 & 27,116 & 30,138 & 28,297 \\
\hline 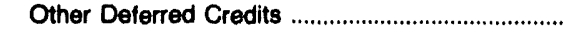 & $1,813,190$ & $1,914,443$ & $1,680,486$ & $1,513,951$ \\
\hline Unamort Gain on Reacqr Debt ................................. & 216,817 & 239,073 & 106,738 & 112,767 \\
\hline Total Doferrod Credits & $2,067,127$ & $2,180,632$ & $1,817,362$ & $1,655,015$ \\
\hline Total Labilitios and Other Credits ...................... & $47,894,290$ & $47,322,895$ & $44,789,857$ & $41,508,000$ \\
\hline
\end{tabular}

Data reporting initiated in 1992.

Note: Totals may not equal sum of components because of independent rounding. The number of generating publicly owned electric utilities for end of period is 111 for December 31, 1992; 110 for December 31, 1991; 110 for December 31, 1990; and 108 for December 31. 1989. The City of Vineland (NJ) changed fiscal year trom June 30 to December 31 in 1991 and California Department of Water Resources (CA) chariged fiscal year from December 31 to June 30 in 1992 . Emerald Peoples Utility District (OR), City of Bryan (OH), and Northern Wasco County PUD (OR) were nongenerators for 1989 through 1991, but became generators in 1992. The South Carolina Public Service Authority (SC) changed fiscal year from June 30 to December 31 in 1990 . The Utah Associated Municipal Power System (UT) changed fiscal year from June 30 to March 31 in 1991. The City of Marshfield (WI) was a generator in 1989 and 1990, but became a nongenerator in 1991. The Wisconsin Public Power Incorporated System (WI) was a nongenerator in 1989 and 1990 , but became a generator in 1991.

Source: Energy Information Administration, Form ElA-412, "Annual Report of Public Electric Utilities." 


\section{Table C14. Composite Financlal Indicators for Major U.S. Publicly Owned Generator Electric Utilities with FInanclal Year Ending on December 31, 1989-1992}

\begin{tabular}{|c|c|c|c|c|}
\hline Item & 1992 & 1991 & 1990 & 1989 \\
\hline Total Electric Utility Plant per Dollar of Revenue & 3.8 & 3.8 & 3.7 & 3.8 \\
\hline Current Assots to Current Liabilities ......................... & 2.4 & 2.6 & 2.6 & 3.0 \\
\hline $\begin{array}{l}\text { Total Electric Utllity Plant as a Percent of Total } \\
\text { Assets }\end{array}$ & 80.2 & 79.2 & 79.8 & 78.3 \\
\hline $\begin{array}{l}\text { Net Electric Utlity Plant as a Percent of Total } \\
\text { Assets }\end{array}$ & 56.1 & 57.9 & 59.6 & 60.0 \\
\hline Debt as a Percent of Total Liablities ........................ & 78.3 & 78.0 & 78.4 & 78.9 \\
\hline $\begin{array}{l}\text { Depreciation, Amortization and Depletion } \\
\text { as a Percent of Total Electric Utility Plant .......... }\end{array}$ & 30.0 & 26.9 & 25.3 & 23.5 \\
\hline $\begin{array}{l}\text { Electric Operation and Maintenance Expenses } \\
\text { as a Percent of } \\
\text { Electric Utility Operating Revenues ................................. }\end{array}$ & 67.3 & 65.6 & 68.1 & 69.5 \\
\hline $\begin{array}{l}\text { Electric Depreciation and Amortization } \\
\text { as a Percent of } \\
\text { Electric Utility Operating Revenues ....................... }\end{array}$ & 10.4 & 11.0 & 10.1 & 10.5 \\
\hline $\begin{array}{l}\text { Taxes and Tax Equivalents } \\
\text { as a Percent of } \\
\text { Electric Utility Operating Revenues ....................... }\end{array}$ & 2.4 & 2.4 & 2.4 & 2.5 \\
\hline $\begin{array}{l}\text { Interest on Long-term Debt } \\
\text { as a Percent of } \\
\text { Electric Utility Operating Revenues ....................... }\end{array}$ & 22.6 & 24.2 & 24.0 & 25.7 \\
\hline $\begin{array}{l}\text { Net Income as a Percent of Electric } \\
\text { Electric Operating Revenues ............... }\end{array}$ & 4.5 & 5.3 & 2.6 & -4.7 \\
\hline
\end{tabular}

Note: Totals may not equal sum of components because of independent rounding. The number of generating publicly owned electric utilities for end of period is 111 for December 31, 1992; 110 for December 31, 1991; 110 for December 31, 1990; and 108 for December 31 , 1989. The City of Vineland (NJ) changed fiscal year from June 30 to December 31 in 1991 and California Department of Water Resources (CA) changed fiscal year from December 31 to June 30 in 1992. Emerald Peoples Utility District (OR), City of Bryan (OH), and Northern Wasco County PUD (OR) were nongenerators for 1989 through 1991, but became generators in 1992 . The South Carolina Public Service Authority (SC) changed fiscal year from June 30 to December 31 in 1990. The Utah Associated Municipal Power System (UT) cha?: d fiscal year from June 30 to March 31 in 1991. The City of Marshfield (WI) was a generator in 1989 and 1990, but became a nongenerator in 1991. The Wisconsin Public Power Incorporated System (WI) was a nongenerator in 1989 and 1990, but became a generator in 1991.

Source: Energy Information Administration, Form EIA-412, "Annual Report of Public Electric Utilities." 
Table C14. Composite Financial Indicators for Major U.S. Publicly Owned Generator Electric Utilities with Financial Year Ending on December 31, 1989-1992

\begin{tabular}{|c|c|c|c|c|}
\hline Item & 1992 & 1991 & 1990 & 1989 \\
\hline Total Electric Utility Plant per Dollar of Revenue & 3.8 & 3.8 & 3.7 & 3.8 \\
\hline Current Assets to Current Liabilities ........................... & 2.4 & 2.6 & 2.6 & 3.0 \\
\hline $\begin{array}{l}\text { Tolal Electric Utility Plant as a Percent of Total } \\
\text { Assets }\end{array}$ & 80.2 & 79.2 & 79.8 & 78.3 \\
\hline $\begin{array}{l}\text { Net Electric Utility Plant as a Percent of Total } \\
\text { Assets }\end{array}$ & 56.1 & 57.9 & 59.6 & 60.0 \\
\hline Debt as a Percent of Total Liabilities ....................... & 78.3 & 78.0 & 78.4 & 78.9 \\
\hline $\begin{array}{l}\text { Depreciation, Amortization and Depletion } \\
\text { as a Percent of Total Electric Utility Plant .......... }\end{array}$ & 30.0 & 26.9 & 25.3 & 23.5 \\
\hline $\begin{array}{l}\text { Electric Operation and Maintenance Expenses } \\
\text { as a Percent of } \\
\text { Electric Utility Operating Revenues .......................... }\end{array}$ & 67.3 & 65.6 & 68.1 & 69.5 \\
\hline $\begin{array}{l}\text { Electric Depreciation and Amortization } \\
\text { as a Percent of } \\
\text { Electric Utility Operating Revenues .......................... }\end{array}$ & 10.4 & 11.0 & 10.1 & 10.5 \\
\hline $\begin{array}{l}\text { Taxes and Tax Equivalents } \\
\text { as a Percent of } \\
\text { Electric Utility Operating Revenues ......................... }\end{array}$ & 2.4 & 2.4 & 2.4 & 2.5 \\
\hline $\begin{array}{l}\text { Interest on Long-term Debt } \\
\text { as a Percent of } \\
\text { Electric Utility Operating Revenues ....................... }\end{array}$ & 22.6 & 24.2 & 24.0 & 25.7 \\
\hline 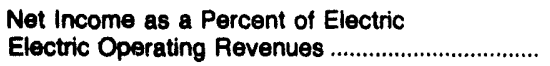 & 4.5 & 5.3 & 2.6 & -4.7 \\
\hline
\end{tabular}

Note: Totals may not equal sum of components because of independent rounding. The number of generating publicly owned electric utilities for end of period is 111 for December 31,$1992 ; 110$ for December 31,$1991 ; 110$ for December 31, 1990 ; and 108 for December 31, 1989. The City of Vineland (NJ) changed fiscal year from June 30 to December 31 in 1991 and California Department of Water Resources (CA) changed fiscal year from December 31 to June 30 in 1992. Emerald Peoples Utility District (OR), City of Bryan (OH), and Northern Wasco County PUD (OR) were nongenerators for 1989 through 1991, but became generators in 1992. The South Carolina Public Service Authority (SC) changed fiscal year from June 30 to December 31 in 1990. The Utah Associated Municipal Power System (UT) changed fiscal year from June 30 to March 31 in 1991. The City of Marshfield (WI) was a generator in 1989 and 1990, but became a nongenerator in 1991. The Wisconsin Public Power Incorporated System (WI) was a nongenerator in 1989 and 1990, but became a generator in 1991.

Source: Energy Information Administration, Form EIA-412, "Annual Report of Public Electric Utilities." 
Table C16. Electric Utility Plant for Major U.S. Publicly Owned Generator Electric Utilities with Financlal Year Ending on December 31 at End of Period, 1989-1992 (Thousand Dollars)

\begin{tabular}{|c|c|c|c|c|}
\hline liem & 1992 & 1991 & 1990 & 1989 \\
\hline \multicolumn{5}{|l|}{ Electric Plant in Sorvice } \\
\hline 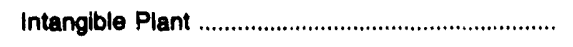 & 147,119 & 166,530 & 193,723 & 157,599 \\
\hline \multicolumn{5}{|l|}{ Production Plant } \\
\hline Steam & $8,631,927$ & $8,826,802$ & $7,965,718$ & $6,622,860$ \\
\hline Nuclear & $9,134,357$ & $9,494,275$ & $8,966,077$ & $8,028,487$ \\
\hline 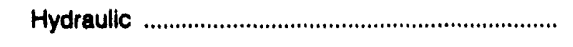 & $4,615,920$ & $4,940,668$ & $4,799,518$ & $4,6.43,098$ \\
\hline Other & 653,883 & 896,234 & 921,650 & 804,293 \\
\hline 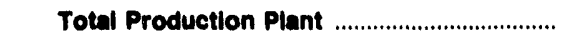 & $23,036,088$ & $24,157,980$ & $22,652,963$ & $20,098,738$ \\
\hline 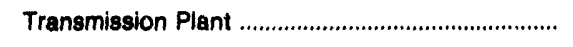 & $4,391,256$ & $4,332,303$ & $3,860,130$ & $3,314,733$ \\
\hline 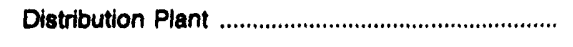 & $5,099,992$ & $4,908,645$ & $4,567,340$ & $4,153,899$ \\
\hline 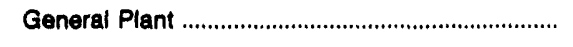 & $1,761,568$ & $1,928,771$ & $1,801,420$ & $1,491,094$ \\
\hline 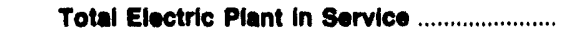 & $34,436,024$ & $35,494,228$ & $33,075,576$ & $29,216,062$ \\
\hline 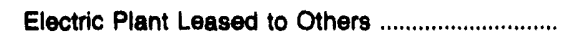 & 17,376 & 18,558 & 19,533 & 16,549 \\
\hline Construction Work in Progress - Electric ................ & $1,523,008$ & $1,524,793$ & $1,984,117$ & $2,609,383$ \\
\hline 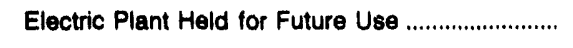 & 35,048 & 96,163 & 85,069 & 235,480 \\
\hline Electric Plant Misc & 734,009 & 345,941 & 590,458 & 430,670 \\
\hline 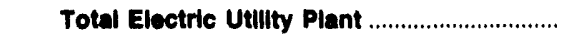 & $36,745,465$ & $37,479,683$ & $35,754,753$ & $32,508,145$ \\
\hline 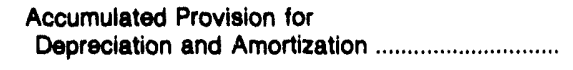 & $10,493,142$ & $10,075,535$ & $9,044,556$ & $7,623,800$ \\
\hline Not Electrle Utility Plant ......................................... & $26,252,323$ & $27,404,148$ & $26,710,198$ & $24,684,345$ \\
\hline
\end{tabular}

Note: Totals may not equal sum of components because of independent rounding. The number of generating publicly owned electric utilities for end of period is 111 for December 31, 1992; 110 for December 31, 1991; 110 for December 31, 1990; and 108 for December 31, 1989. The Clty of Vineland (NJ) changed fiscal year from June 30 to December 31 in 1991 and Callfornia Department of Water Resources (CA) changed fiscal year from December 31 to June 30 in 1992 . Emerald Peoples Utility District (OR), City of Bryan (OH), and Northern Wasco County PUD (OR) were nongenerators for 1989 through 1991, but became generators in 1992. The South Carolina Public Service Authority (SC) changed fiscal year from June 30 to December 31 in 1990 . The Utah Associated Municipal Power System (UT) changed fis. cal year from June 30 to March 31 in 1991. The City of Marshfield (WI) was a generator in 1989 and 1990, but became a nongenerator in 1991. The Wisconsin Public Power Incorporated System (WI) was a nongenerator in 1989 and 1990, but became a generator in 1991. Source: Energy Information Administration, Form ElA-412, "Annual Report of Public Electric Utilities." 
Table C17. Number of Consumers, Sales, and Operating Revenue for Major U.S. Publicly Owned Generator Electric Utilities with Financial Year Ending on December 31, 1989-1992

\begin{tabular}{|c|c|c|c|c|}
\hline Item & 1992 & 1991 & 1990 & 1989 \\
\hline \multicolumn{5}{|l|}{ Number of Consumers } \\
\hline 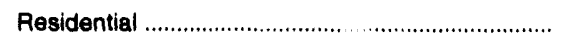 & $2,814,249$ & $2,764,821$ & $2,715,134$ & $2,582,601$ \\
\hline Commercial or Small & 374,138 & 364,247 & 359,959 & 336,873 \\
\hline Industrial or Large & 17,308 & 17,030 & 18,626 & 16,447 \\
\hline Other & 31,715 & 38,909 & 35,493 & 30,932 \\
\hline 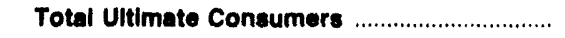 & $3,237,410$ & $3,185,007$ & $3,129,212$ & $2,966,853$ \\
\hline \multicolumn{5}{|l|}{ Sales for the Year (megawatthours) } \\
\hline 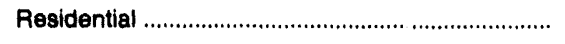 & $28,973,686$ & $30,255,280$ & $29,060,284$ & $27,672,270$ \\
\hline 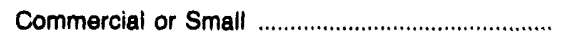 & $22,588,007$ & $22,393,283$ & $21,894,020$ & $20,215,328$ \\
\hline Industrial or Large & $43,005,294$ & $41,800,834$ & $41,714,889$ & $32,954,353$ \\
\hline Other & $11,573,845$ & $11,674,348$ & $11,358,773$ & $11,080,275$ \\
\hline Total Sales to Uitimate Consumers ............... & $106,140,832$ & $106,123,745$ & $104,027,966$ & $91,922,226$ \\
\hline Sales for Resale & $119,936,732$ & $127,090,088$ & $128,453,278$ & $118,654,857$ \\
\hline Total Sales & $226,077,564$ & $233,213,833$ & $232,481,244$ & $210,577,083$ \\
\hline \multicolumn{5}{|l|}{$\begin{array}{l}\text { Operating Revenues for the Yoar } \\
\text { (thousand dollars) }\end{array}$} \\
\hline 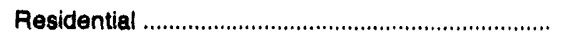 & $1,643,062$ & $1,662,361$ & $1,595,478$ & $1,476,648$ \\
\hline 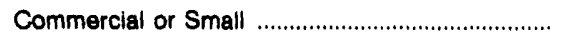 & $1,207,356$ & $1,182,160$ & $1,136,745$ & $1,044,373$ \\
\hline Industrial or Large & $1,606,898$ & $1,571,144$ & $1,550,851$ & $1,227,393$ \\
\hline Other & 829,977 & 739,838 & 745,745 & 711,863 \\
\hline $\begin{array}{l}\text { Total Revenues from Sales to } \\
\text { Ultimate Coneumere }\end{array}$ & $5,287,293$ & $5,155,503$ & $5,028,819$ & $4,460,277$ \\
\hline Sales for Resale & $4,266,138$ & $4,317,957$ & $4,373,787$ & $4,008,169$ \\
\hline 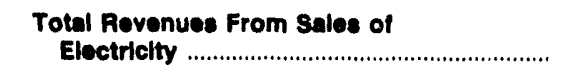 & $9,553,431$ & $9,473,460$ & $9,402,606$ & $8,468,446$ \\
\hline
\end{tabular}

Note: Totals may not equal sum of components because of independent rounding. The number of generating publicly owned electric utilities for end of period is 111 for December 31, 1992; 110 for December 31, 1991; 110 for December 31, 1990; and 108 for December 31, 1889. The City of Vineland (NJ) changed fiscal year from June 30 to December 31 in 1991 and California Department of Water Resources (CA) changed fiscal year from December 31 to June 30 in 1992. Emerald Peoples Utility District (OR), City of Bryan (OH), and Northern Wasco County PUD (OR) were nongenerators for 1989 through 1991, but became generators in 1992. The City of Foley (AL) and the South Carolina Public Service Authority (SC) changed fiscal year from June 30 to December 31 in 1990 . The Utah Associated Municipal Power System (UT) changed fiscal year from June 30 to March 31 in 1991. The City of Marshfield (WI) was a generator in 1989 and 1990, but became a nongenerator in 1991. The Wisconsin Public Power Incorporated System (WI) was a nongenerator in 1989 and 1990 , but became a generator in 1991. sions.

Source: Energy Information Administration, Form ElA-861, "Annual Electric Utility Report." Data are based on calendar year submis- 


\section{Table C18. Electric Energy Account for Major U.S. Publicly Owned Generator Electric Utilities with Financial Year Ending on December 31, 1989-1992 (Megawatthours)}

\begin{tabular}{|c|c|c|c|c|}
\hline Item & 1992 & 1991 & 1990 & 1989 \\
\hline \multicolumn{5}{|l|}{ Sources of Energy } \\
\hline 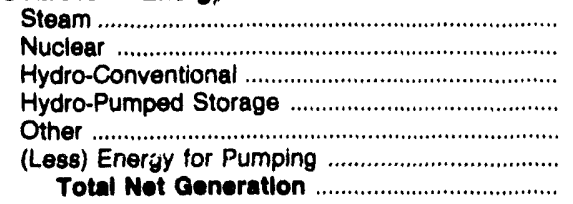 & $\begin{array}{r}65,609,210 \\
31,849,000 \\
57,178,818 \\
2,170,285 \\
1,203,274 \\
2,897,644 \\
155,112,932\end{array}$ & $\begin{array}{r}66,891,679 \\
36,462,063 \\
67,268,340 \\
2,364,088 \\
1,302,950 \\
2,942,457 \\
171,346,662\end{array}$ & $\begin{array}{r}68,121,001 \\
34,561,351 \\
67,433,345 \\
3,537,783 \\
1,316,570 \\
2,983,818 \\
171,986,234\end{array}$ & $\begin{array}{r}53,992,903 \\
36,125,796 \\
60,581,382 \\
3,048,854 \\
1,374,343 \\
2,995,236 \\
152,127,942\end{array}$ \\
\hline 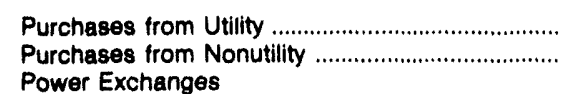 & $\begin{array}{r}79,898,277 \\
711,796\end{array}$ & $\begin{array}{r}76,660,807 \\
925,307\end{array}$ & $\begin{array}{r}78,428,609 \\
864,340\end{array}$ & $\begin{array}{r}73,986,902 \\
779,593\end{array}$ \\
\hline 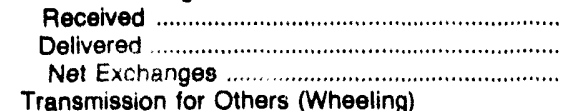 & $\begin{array}{l}11,060,566 \\
12,420,396 \\
-1,359,823\end{array}$ & $\begin{array}{l}15,364,045 \\
18,418,514 \\
-3,054,468\end{array}$ & $\begin{array}{l}14,622,676 \\
16,409,072 \\
-1,786,397\end{array}$ & $\begin{array}{r}16,049,716 \\
16,700,782 \\
-651,067\end{array}$ \\
\hline 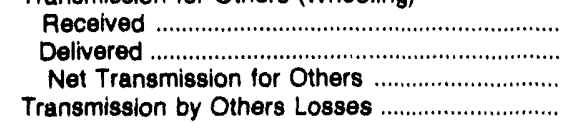 & $\begin{array}{r}7,563,741 \\
7,426,968 \\
136,773 \\
-42,446\end{array}$ & $\begin{array}{r}6,457,352 \\
6,321,064 \\
136,287 \\
-12,108\end{array}$ & $\begin{array}{r}12,322,641 \\
12,203,547 \\
119,093 \\
-16,107\end{array}$ & $\begin{array}{r}5,160,664 \\
5,074,696 \\
85,968 \\
-\end{array}$ \\
\hline $\begin{array}{l}\text { Total Net Energy Generated and } \\
\text { Recelved } \ldots \ldots \ldots \ldots \ldots \ldots \ldots \ldots \ldots \ldots \ldots \ldots \ldots \ldots \ldots \ldots \ldots\end{array}$ & $234,457,495$ & $246,002,489$ & $249,595,771$ & $226,329,339$ \\
\hline 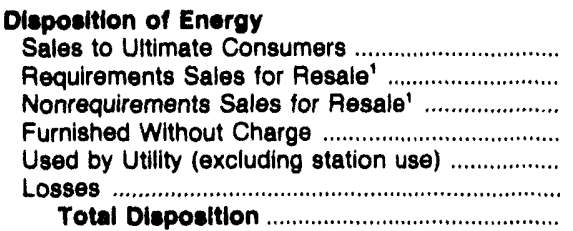 & $\begin{array}{r}106,146,840 \\
92,606,439 \\
27,422,443 \\
1,250,309 \\
258,375 \\
6,773,090 \\
234,457,495\end{array}$ & $\begin{array}{r}106,253,382 \\
102,726,112 \\
24,241,019 \\
1,279,635 \\
4,793,554 \\
6,688,779 \\
246,002,489\end{array}$ & $\begin{array}{r}104,050,549 \\
101,969,005 \\
26,484,486 \\
1,474,860 \\
8,867,221 \\
6,749,649 \\
249,595,771\end{array}$ & $\begin{array}{r}91,842,235 \\
118,681,859 \\
- \\
1,395,340 \\
7,954,930 \\
6,454,962 \\
226,329,339\end{array}$ \\
\hline
\end{tabular}

1 The 1889 deta were reported as Sales for Resale (one entry) which is shown as Requirements Sales for Resale.

Note: Totals may not equal sum of components because of independent rounding. The number of generating publicly owned electric utilities for end of period is 111 for December 31, 1992; 110 for December 31, 1991; 110 for December 31, 1990; and 108 for December 31, 1989. The City of Vineland (NJ) changed fiscal year from June 30 to December 31 in 1991 and California Department of Water Resources (CA) changed fiscal year from December 31 to June 30 in 1992. Emerald Peoples Utility District (OR), City of Bryan (OH), and Northern Wasco County PUD (OR) were nongenerators for 1989 through 1991, but became generators in 1992. The South Carolina Public Service Authority (SC) changed fiscal year from June 30 to December 31 in 1990. The Utah Associated Municipal Power System (UT) changed fis. cal year from June 30 to March 31 in 1991. The City of Marshfield (WI) was a generator in 1989 and 1990, but became a nongenerator in 1891. The Wisconsin Public Pcwer Incorporated System (WI) was a nongenerator in 1989 and 1990, but became a generator in 1991.

Source: Energy Information Administration, Form ElA-412, "Annual Report of Public Electric Utilities." 
Table C19. Ten Largest U.S. Publicly Owned Nongenerator Electric Utilities Ranked by Megawatthour Sales to Ultimate Consumers with Financial Year Ending on June 30, 1992

\begin{tabular}{|c|c|c|c|}
\hline Publlcly Owned Electric Utllities & State & Amount & Percent \\
\hline Memphis City of & TN & $11,317,322$ & 13.60 \\
\hline 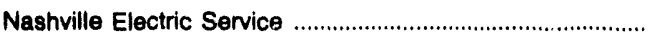 & TN & $9,851,641$ & 11.84 \\
\hline Chattanooga City of & TN & $5,090,333$ & 6.12 \\
\hline Knoxville Utilities Board & TN & $4,465,554$ & 5.37 \\
\hline Johnson City City of & TN & $1,415,614$ & 1.70 \\
\hline Decatur City of & AL & $1,348,529$ & 1.62 \\
\hline 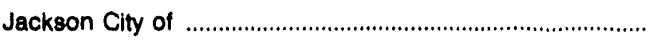 & TN & $1,065,771$ & 1.28 \\
\hline 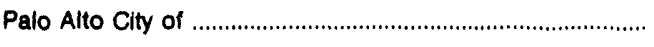 & $\mathrm{CA}$ & $1.053,790$ & 1.27 \\
\hline Greenville Utilities Comm & NC & 988,749 & 1.19 \\
\hline Lenoir City City of & TN & 936,423 & $\therefore 13$ \\
\hline Subtotal & & $37,533,826$ & 45.12 \\
\hline
\end{tabular}

Source: Energy Information Administration, Form ElA-412, "Annual Report of Public Electric Utilities."

Table C20. U.S. Publicly Owned Nongenerator Electric Utllities Ranked by Megawatthour Sales for Resale with Financial Year Ending on June 30, 1992

\begin{tabular}{|c|c|c|c|}
\hline Publlcly Owned Electric Utilitles & State & Amount & Porcent \\
\hline Colorado River Comm of Nevada & NV & 826,026 & 49.32 \\
\hline Arizona Power Authority & $A Z$ & 740,505 & 44.22 \\
\hline Wilson City of & NC & 56,166 & 3.35 \\
\hline Greenville Utilities Comm & NC & 23,700 & 1.42 \\
\hline 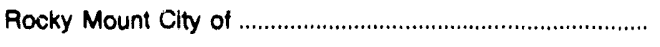 & NC & 15,873 & .95 \\
\hline 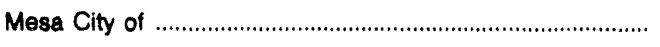 & $A Z$ & 6,542 & .39 \\
\hline Groton City of & $\mathrm{CT}$ & 5,908 & .35 \\
\hline Subtotal & & $1,674,720$ & 100.00 \\
\hline
\end{tabular}

Source: Energy Information Administration, Form ElA-412, "Annual Report of Public Electric Utilities." 
Table C21. Composite Statement of Income for Major U.S. Publicly Owned Nongenerator Electric Utilities with Financial Year Ending on June 30, 1989-1992

(Thousand Dollars)

\begin{tabular}{|c|c|c|c|c|}
\hline Item & 1992 & 1991 & 1990 & 1989 \\
\hline Electric Utility Operating Revenues ...................... & $4,265,830$ & $4,167,470$ & $4,143,051$ & $4,002,283$ \\
\hline 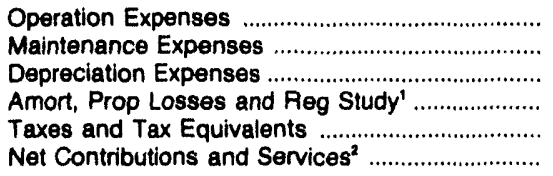 & $\begin{array}{r}3,735,743 \\
109,346 \\
126,288 \\
476 \\
85,310 \\
-\end{array}$ & $\begin{array}{r}3,646,906 \\
104,862 \\
121,975 \\
- \\
69,589 \\
106,005\end{array}$ & $\begin{array}{r}3,645,672 \\
111,773 \\
116,224 \\
- \\
64,919 \\
88,261\end{array}$ & $\begin{array}{r}3,514,644 \\
108,284 \\
107,743 \\
- \\
61,090 \\
103,436\end{array}$ \\
\hline $\begin{array}{l}\text { Total Electric Utility Operating } \\
\text { Expenses }\end{array}$ & $4,057,164$ & $4,049,336$ & $4,026,850$ & $3,895,197$ \\
\hline 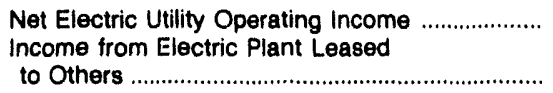 & $\begin{array}{r}208,666 \\
81\end{array}$ & $\begin{array}{r}118.134 \\
1.160\end{array}$ & $\begin{array}{r}116,201 \\
695\end{array}$ & $\begin{array}{r}107,086 \\
600\end{array}$ \\
\hline Electric UtIlity Operating Income ..................... & 208,748 & 119,293 & 116,896 & 107,685 \\
\hline Other Electric Income & 80,578 & 73,710 & 76,072 & 84,288 \\
\hline 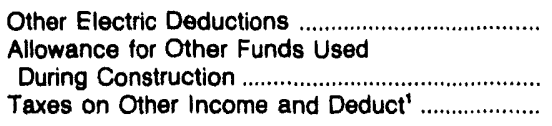 & $\begin{array}{r}44,944 \\
53\end{array}$ & $\begin{array}{r}8,220 \\
1,229 \\
-\end{array}$ & 130 & $\begin{array}{r}- \\
170 \\
-\end{array}$ \\
\hline Electric Utility Income & 244,329 & 186,012 & 193,098 & 192,143 \\
\hline 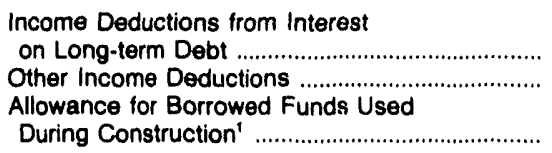 & $\begin{array}{l}42,612 \\
18,618\end{array}$ & $\begin{array}{l}43,191 \\
16,967\end{array}$ & $\begin{array}{l}44,711 \\
14,892\end{array}$ & $\begin{array}{l}45,145 \\
11,356\end{array}$ \\
\hline 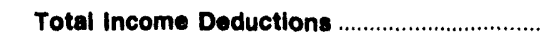 & 61,230 & 60,157 & 59,602 & 56,500 \\
\hline 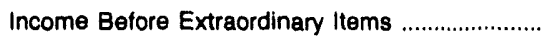 & 183,099 & 125,855 & 133,496 & 135,643 \\
\hline 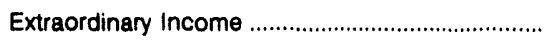 & 18,338 & 21,330 & 2,541 & 2,033 \\
\hline 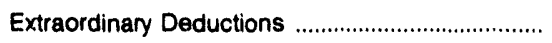 & 11,979 & 19,747 & 13,024 & 4,226 \\
\hline Net Income & 189,459 & 127,438 & 123,012 & 133,451 \\
\hline
\end{tabular}

Data reporting initiated in 1992.

- Data reporting discontinued in 1992.

- Data not available.

Note: Totals may not equal sum of components because of independent rounding. The number of nongenerating publicly owned electric utilities for end of period is 137 for June 30,1992; 135 for June 30,1991; 136 for June 30, 1990; and 135 for June 30, 1989. The City of Memphis (TN) and the City of LaFollette (TN) changed fiscal years from December 31 to June 30 in 1992. Emerald Peoples Utility Dis. trict (OR), City of Bryan (OH), and Northern Wasco County PUD (OR) were nongenerators for 1989 through 1991, but became generators in 1992. The City of Foley (AL) changed fiscal year from June 30 to December 31 in 1990. The Wisconsin Public Power incorporated System (WI) was a nongenerator in 1989 and 1990, but became a generator in 1991. The City of Marshtield (WI) was a generator in 1989 and 1990 , but became a nongenerator in 1991 .

Source: Energy Information Administration, Form EIA-412, "Annual Report of Public Electric Utilities." 
Table C22. Composite Balance Sheet for Major U.S. Publicly Owned Nongenerator Electric Utilities with Financial Year Ending on June 30 at End of Period, 1989-1992 (Thousand Dollars)

\begin{tabular}{|c|c|c|c|c|}
\hline Item & 1992 & 1991 & 1990 & 1989 \\
\hline \multicolumn{5}{|l|}{ Electric Utility Plant } \\
\hline Electric Utility Plant \& Adjust .................................... & $3,876,053$ & $3,793,405$ & $3,563,010$ & $3,364,686$ \\
\hline 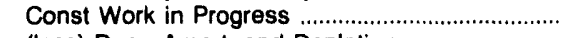 & 131,760 & - & - & - \\
\hline (less) Depr, Amort, and Depletion .......................... & $1,457,939$ & $1,356,953$ & $1,257,905$ & $1,175,271$ \\
\hline Net Electric Utility Plant' & $2,549,875$ & - & - & - \\
\hline 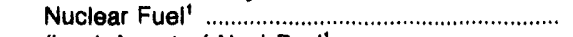 & - & - & - & - \\
\hline (less) Amort of Nucl Fuel' & - & - & - & - \\
\hline 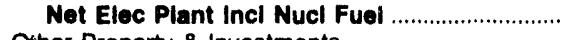 & $2,549,875$ & $2,436,453$ & $2,305,105$ & $2,189,415$ \\
\hline \multicolumn{5}{|l|}{ Other Property \& Investments } \\
\hline 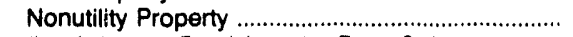 & $1,081,940$ & $1,025,569$ & $1,057,341$ & $1,011,306$ \\
\hline (less) Accum Provisions for Depr \& Amort .......... & 246,838 & 224.761 & 223,212 & 197,865 \\
\hline 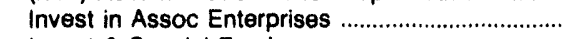 & 8,808 & 9,821 & 9,969 & 6,018 \\
\hline 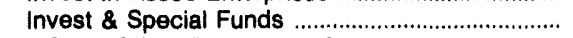 & 373,447 & 342,179 & 326,036 & 339,994 \\
\hline Total Other Property \& Investments ................ & $1,217,357$ & $1,152,807$ & $1,170,135$ & $1,159,453$ \\
\hline \multicolumn{5}{|l|}{ Current and Accrued Assets } \\
\hline 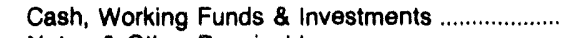 & 645,610 & 606,203 & 588,851 & 568,326 \\
\hline 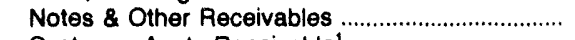 & 220,262 & 431,451 & 466,338 & 443,934 \\
\hline Customer Accts Receivable ${ }^{1}$ & 173,544 & - & - & - \\
\hline (less) Accum Prov for Uncollected Accts ........... & 10,382 & 10,519 & 8,962 & 9,480 \\
\hline 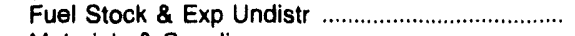 & 680 & - & - & - \\
\hline 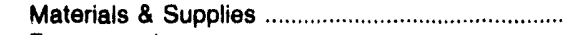 & 31,063 & 82,498 & 83,405 & 86,000 \\
\hline Prepayments & 21,100 & 20,390 & 44,432 & 39,564 \\
\hline 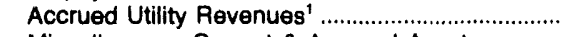 & 14,061 & - & - & - \\
\hline Miscellaneous Current \& Accrued Assets ............ & 42,405 & 33,666 & 16,127 & 30,200 \\
\hline \multicolumn{5}{|l|}{ Deferred Debits } \\
\hline 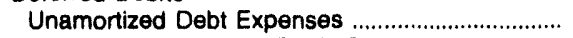 & 54,266 & 40,495 & 34,697 & 33,037 \\
\hline 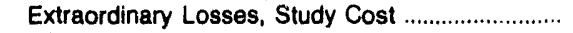 & 380 & - & - & - \\
\hline Misc Debt, A \& D Exp, Unamrt Losses ................. & 207,957 & 171,031 & 130,729 & 130,405 \\
\hline 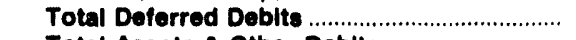 & 262,602 & 211,527 & 165,426 & 163,442 \\
\hline Total Aseots Other Deblts & $5,218,177$ & $4,984,477$ & $4,830,856$ & $4,670,855$ \\
\hline \multicolumn{5}{|l|}{ Proprietary Capital } \\
\hline 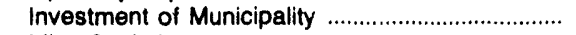 & 130,155 & 181,752 & 189,661 & 165,533 \\
\hline 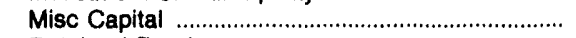 & 321,883 & 309,795 & 264,116 & 273,808 \\
\hline 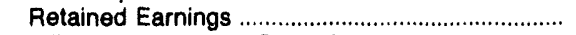 & $2,655,556$ & $2,464,326$ & $2,400,616$ & $2,262,249$ \\
\hline 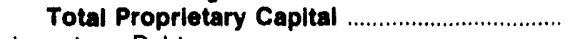 & $3,107,593$ & $2,955,873$ & $2,854,393$ & $2,701,589$ \\
\hline \multicolumn{5}{|l|}{ Long-term Debt } \\
\hline 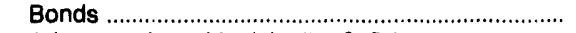 & $1,121,996$ & $1,021,581$ & $1,014,631$ & $1,044,629$ \\
\hline Advances from Municipality \& Other ........................ & 350,771 & 306,400 & 307,645 & 309,444 \\
\hline Unamort Prem on Long-term Debt ....................... & 6,144 & 1,317 & 994 & 1,076 \\
\hline (less) Unamort Discount on Long-term Debt ....... & 8,254 & 14,948 & 15,471 & 16,393 \\
\hline 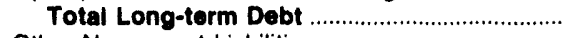 & $1,470,657$ & $1,314,349$ & $1,307,799$ & $1,338,756$ \\
\hline \multicolumn{5}{|l|}{ Other Noncurrent Liabilities } \\
\hline 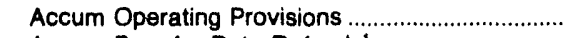 & 3,437 & 18,478 & 6,531 & 10,264 \\
\hline 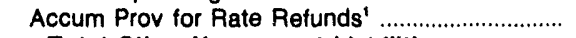 & 206 & - & - & - \\
\hline Total Other Noncurrent Llabllitles .................. & 3,643 & 18,478 & 6,531 & 10,264 \\
\hline \multicolumn{5}{|l|}{ Current and Accrued Liabilities } \\
\hline 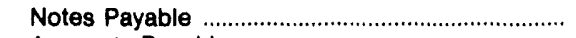 & 24,735 & 23,134 & 27,149 & 22,272 \\
\hline Accounts Payable & 353,395 & 358,975 & 359,439 & 335,341 \\
\hline 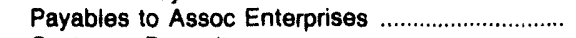 & 10,252 & 24,142 & 17,759 & 24,095 \\
\hline 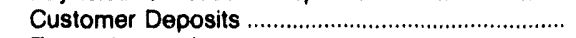 & 87,252 & 79,605 & 71,803 & 66,386 \\
\hline Taxes Accrued & 9,891 & 25,935 & 8,172 & 8,375 \\
\hline Interest Accrued & 46,566 & 27,387 & 38,542 & 26,363 \\
\hline Misc Current \& Accrued Liabilities ........................... & 50,848 & 40,828 & 45,490 & 40,422 \\
\hline Total Current Accrued Llablilties ................... & 582,938 & 580,007 & 568,354 & 523,253 \\
\hline \multicolumn{5}{|l|}{ Deferred Credits } \\
\hline Customer Advances for Construction ...................... & 3,614 & 3,597 & 3,523 & 3,268 \\
\hline 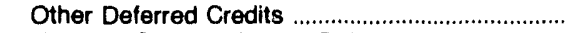 & 49,733 & 91,505 & 90,243 & 93,671 \\
\hline 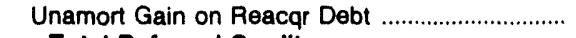 & - & 666 & 13 & 52 \\
\hline $\begin{array}{l}\text { Total Deferred Credits } \\
\text { Total Llablilties and Other Credits }\end{array}$ & $\begin{array}{r}53,346 \\
5,218,177\end{array}$ & $\begin{array}{r}95,769 \\
4,964,477\end{array}$ & $\begin{array}{r}93,778 \\
4,830,856\end{array}$ & $\begin{array}{r}96,992 \\
4,670,855\end{array}$ \\
\hline
\end{tabular}

Data reporting initiated in 1992.

Note: Totals may not equal sum of components because of independent rounding. The number of nongenerating publicly owned electric utilities for end of period is 137 for June 30, 1992; 135 for June 30, 1991; 136 for June 30, 1990; and 135 for June 30, 1989. The City of Memphis (TN) and the City of LaFollette (TN) changed fiscal years from December 31 to June 30 in 1992. Emerald Peoples Utility District (OR). City of Bryan (OH), and Northern Wasco County PUD (OR) were nongenerators for 1989 through 1991, but became generaturs in 1992. The City of Foley (AL) changed fiscal year from June 30 to December 31 in 1990 . The Wisconsin Public Power Incorporated System (WI) was a nongenerator in 1989 and 1990, but became a generator in 1991. The City of Marshfield (WI) was a generator in 1989 and 1990 , but became a nongenerator in 1991 .

Source: Energy Information Administration, Form EIA-412, "Annual Report of Public Electric Utilities." 
Table C23. Composite Financial Indicators for Major U.S. Publicly Owned Nongenerator Electric Utillties with Financial Year Ending on June 30, 1989-1992

\begin{tabular}{|c|c|c|c|c|}
\hline Item & 1982 & 1991 & 1990 & 1989 \\
\hline Total Electric Utility Plant per Dollar of Revenue & 0.9 & 0.9 & 0.8 & 0.8 \\
\hline 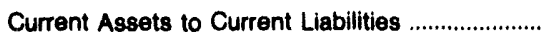 & 2.0 & 2.0 & 2.1 & 2.2 \\
\hline $\begin{array}{l}\text { Total Electric Utility Plant as a Percent of Total } \\
\text { Assets }\end{array}$ & 76.8 & 76.4 & 73.8 & 72.0 \\
\hline $\begin{array}{l}\text { Net Eloctric Utility Plant as a Percent of Total } \\
\text { Assets }\end{array}$ & 48.9 & 49.1 & 47.7 & 46.9 \\
\hline 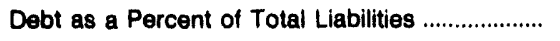 & 39.4 & 38.2 & 38.8 & 39.9 \\
\hline $\begin{array}{l}\text { Depreciation, Amortization and Depletion } \\
\text { as a Percent of Total Electric Utility Plant ........... }\end{array}$ & 36.4 & 35.8 & 35.3 & 34.9 \\
\hline $\begin{array}{l}\text { Electric Operation and Maintenance Expenses } \\
\text { as a Percent of } \\
\text { Electric Utility Operating Revenues ....................... }\end{array}$ & 90.1 & 90.0 & 90.7 & 90.5 \\
\hline $\begin{array}{l}\text { Electric Depreciation and Amortization } \\
\text { as a Percent of } \\
\text { Electric Utility Operating Revenues .......................... }\end{array}$ & 3.0 & 2.9 & 2.8 & 2.7 \\
\hline $\begin{array}{l}\text { Texes and Tax Equivalents } \\
\text { as a Percent of } \\
\text { Electric Utility Operating Revenues ......................... }\end{array}$ & 2.0 & 1.7 & 1.6 & 1.5 \\
\hline $\begin{array}{l}\text { Interest on Long-term Debt } \\
\text { as a Percent of } \\
\text { Electric Utility Operating Revenues ...................... }\end{array}$ & 1.0 & 1.0 & 1.1 & 1.1 \\
\hline $\begin{array}{l}\text { Net Income as a Percent of Electric } \\
\text { Utility Operating Revenues }\end{array}$ & 4.4 & 3.1 & 3.0 & 3.3 \\
\hline
\end{tabular}

Note: Totals may not equal sum of components because of independent rounding. The number of nongenerating publicly owned electric utilities for end of period is 137 for June 30, 1992; 135 for June 30, 1991; 136 for June 30, 1990; and 135 for June 30, 1989. The City of Memphis (TN) and the City of LaFollette (TN) changed fiscal years from December 31 to June 30 in 1992. Emerald Peoples Utility Dis. trict (OR), City of Bryan (OH), and Northern Wasco County PUD (OR) were nongenerators for 1989 through 1991, but became generators in 1992. The City of Foley (AL) changed fiscal year from June 30 to December 31 in 1990. The Wisconsin Public Power Incorporated System (WI) was a nongenerator in 1989 and 1990, but became a generator in 1891. The City of Marshfield (WI) was a generator in 1989 and 1990, but became a nongenerator in 1991.

Source: Energy Information Administration, Form ElA-412, "Annual Report of Public Electric Utilities." 
Table C24. Electric Operation and Maintenance Expenses for Major U.S. Publicly Owned Nongenerator Electric Utilities with Financial Year Ending on June 30, 1989-1992

(Thousand Dollars)

\begin{tabular}{l|l|l|l|l|l|}
\hline Item & 1992 & 1991 & 1990 & 1989 & \\
\hline
\end{tabular}

\section{Production Expenses}

Steam Power Generation

Nuclear Power Generation

Hydraulic Power Generation

Other Power Generation

Purchased Power

on.......

Other Production Expenses

Total Production Expenses

Transmission Expenses

Distribution Expenses

Customer Accounts Expenses

Customer Service and Information Expenses .....

Sales Expenses

Administrative and General Expenses

Total Electric Operation

and Maintenance Expenses

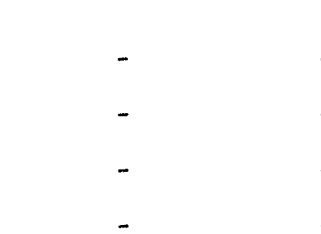

$3,410,265$

2,565

$3,412,829$

17,158

$3,339,710$

6,949

$3,346,659$

13,330

167,664

60,355

64,164

9,006

7,703

8,597

9,731

139,857

145,023

$3,845,089$

$\mathbf{3 , 7 5 1 , 7 6 7}$
1,802

$3,118,544$

4,817

$3,125,163$

10,515

241,118

55,808

8,011

3,690

178,624

$3,622,929$

\section{Fuel Expenses in Operation}

Steam Power Generation

Nuclear Power Generation

Other Power Generation

Number of Elec Dept Employees

Regular Full-time

Part-time \& Temporary'

Total Elec Dept Employees'

7,937

1 Data reporting initiated in 1992.

Note: Totals may not equal sum of components because of independent rounding. The number of nongenerating publicly owned electric utilities for end of period is 137 for June 30, 1992; 135 for June 30,1991; 136 for June 30, 1990; and 135 for June 30, 1989. The City of Memphis (TN) and the City of LaFollette (TN) changed fiscal years from December 31 to June 30 in 1992 . Emerald Peoples Utility District (OR), City of Bryan (OH), and Northern Wasco County PUD (OR) were nongenerators for 1989 through 1991, but became generators in 1992. The City of Foley (AL) changed fiscal year from June 30 to December 31 in 1990. The Wisconsin Public Power Incorporated System (WI) was a nongenerator in 1989 and 1990, but became a generator in 1991. The City of Marshfield (WI) was a generator in 1989 and 1990 , but became a nongenerator in 1991.

Source: Energy Information Administraicion, Form E!A-412, "Annual Report of Public Electric Utilities." 
Table C25. Electric Utility Plant for Major U.S. Publicly Owned Nongenerator Electric Utilities with Financlal Year Ending on June 30 at End of Period, 1989-1992 (Thousand Dollars)

\begin{tabular}{|c|c|c|c|c|}
\hline Item & 1992 & 1991 & 1990 & 1989 \\
\hline \multicolumn{5}{|l|}{ Electric Plant in Sorvice } \\
\hline 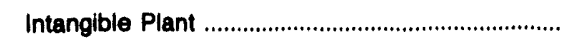 & 102 & 1 & 1 & 1 \\
\hline \multicolumn{5}{|l|}{ Production Plant } \\
\hline Steam & 41,649 & 40,412 & 286 & 39,768 \\
\hline Nuclear & - & - & - & - \\
\hline 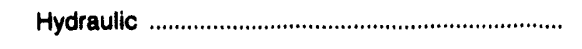 & - & - & - & - \\
\hline Other & 12,615 & 12,622 & 46,445 & 12,796 \\
\hline 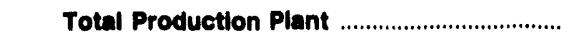 & 54,264 & 53,034 & 46,731 & 52,564 \\
\hline 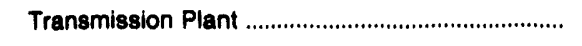 & 264,009 & 303,770 & 225,936 & 213,418 \\
\hline 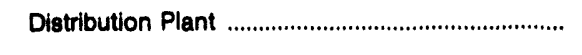 & $2,793,942$ & $2,665,391$ & $2,534,520$ & $2,393,745$ \\
\hline 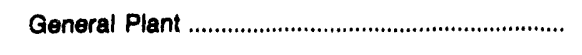 & 719,782 & 657,870 & 624,449 & 579,758 \\
\hline Total Electric Plant In Service ........................... & $3,832,090$ & $3,680,067$ & $3,431,637$ & $3,239,487$ \\
\hline 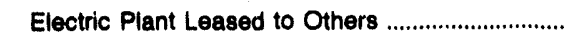 & - & - & - & - \\
\hline Construction Work in Progress - Electric ................... & 131,760 & 91,741 & 107,001 & 98,906 \\
\hline 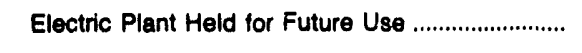 & 14,765 & 3,207 & 1,195 & 592 \\
\hline Electric Plant Misc & 29,189 & 18,391 & 23,178 & 25,702 \\
\hline Total Electric Utility Plant ................................... & $4,007,814$ & $3,793,405$ & $3,563,010$ & $3,364,686$ \\
\hline 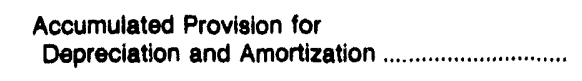 & $1,457,939$ & $1,356,953$ & $1,257,905$ & $1,175,271$ \\
\hline Not Electric Utility Plant ....................................... & $2,549,875$ & $2,436,453$ & $2,305,105$ & $2,189,415$ \\
\hline
\end{tabular}

Note: Totals may not equal sum of components because of independent rounding. The number of nongenerating publicly owned electric utilities for end of period is 137 for June 30,1992; 135 for June 30, 1991; 136 for June 30, 1990; and 135 for June 30 , 1989 . The City of Memphis (TN) and the City of LaFollette (TN) changed fiscal years from December 31 to June 30 in 1992 . Emerald Peoples Utility District (OR), City of Bryan (OH), and Northern Wasco County PUD (OR) were nongenerators for 1989 through 1991, but became generators in 1992. The City of Foley (AL) changed fiscal year from June 30 to December 31 in 1990 . The Wisconsin Public Power Incorporated System (WI) was a nongenerator in 1989 and 1990 , but became a generator in 1991. The City of Marshfield (WI) was a generator in 1989 and 1990 , but became a nongenerator in 1991.

Source: Energy Information Administration, Form ElA-412, "Annual Report of Public Electric Utilities." 
Table C26. Number of Consumers, Sales, and Operating Revenue for Major U.S. Publicly Owned Nongenerator Electric Utilities with Financlal Year Ending on June 30, 1989-1992

\begin{tabular}{|c|c|c|c|c|}
\hline Item & 1992 & 1991 & 1990 & 1988 \\
\hline \multicolumn{5}{|l|}{ Number of Coneumers } \\
\hline 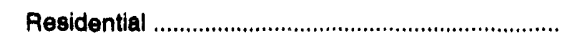 & $2,076,553$ & $2,043,331$ & $2,014,320$ & $1,994,831$ \\
\hline Commercial or Small & 302,966 & 304,983 & 299.578 & 274,657 \\
\hline Industrial or Large & 28,125 & 21,272 & 22,680 & 26,849 \\
\hline Other & 29,744 & 37,337 & 39,318 & 37,806 \\
\hline Total Ultimate Consumere ...................................... & $2,437,388$ & $2,406,923$ & $2,375,896$ & $2,334,143$ \\
\hline \multicolumn{5}{|l|}{ Salee for the Year (megawatthours) } \\
\hline 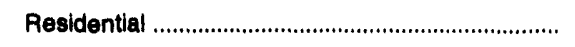 & $26,477,707$ & $26,467,624$ & $25,874,718$ & $25,712,773$ \\
\hline Commercial or Small & $11,831,242$ & $12,926,802$ & $12,284,981$ & $10,997,593$ \\
\hline Industrial or Large & $31,979,721$ & $30,010,647$ & $29,889,490$ & $28,509,416$ \\
\hline Other & $1,304,399$ & $1,335,152$ & $1,319,707$ & $1,401,838$ \\
\hline Total Sales to Uitimate Consumers ................... & $71,593,069$ & $70,740,225$ & $69,368,896$ & $67,621,620$ \\
\hline Sales for Resale & $1,601,017$ & $1,729,566$ & $4,488,088$ & $4,318,625$ \\
\hline Total Salos & $73,194,086$ & $72,469,791$ & $73,865,084$ & $71,940,245$ \\
\hline \multicolumn{5}{|l|}{$\begin{array}{l}\text { Operating Revenues for the Year } \\
\text { (thouseand dollars) }\end{array}$} \\
\hline 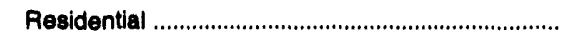 & $1,638,72{ }^{\prime}$ & $1,607,450$ & $1,569,090$ & $1,539,650$ \\
\hline Commercial or Small & 830,365 & 874,603 & 825,242 & 740,813 \\
\hline Industrial or Large & $1,634,958$ & $1,539,511$ & $1,532,962$ & $1,509,668$ \\
\hline 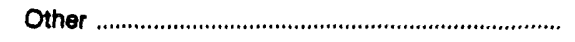 & 98,564 & 100,896 & 98,548 & 95,847 \\
\hline $\begin{array}{l}\text { Total Revenues from Sales to } \\
\text { Uitimate Coneumers }\end{array}$ & $4,202,610$ & $4,122,560$ & $4,025,842$ & $3,885,978$ \\
\hline Sales for Resale & 37,832 & 34,291 & 128,216 & 116,892 \\
\hline $\begin{array}{l}\text { Total Rovenues From sales of } \\
\text { Electrielty }\end{array}$ & $4,240,442$ & $4,156,851$ & $4,154,058$ & $4,002,870$ \\
\hline
\end{tabular}

Note: Totals may not equal sum of components because of independent rounding. The number of nongenerating publicly owned electric utilities for end of period is 137 for June 30, 1992; 135 for June 30, 1991; 136 for June 30, 1990; and 135 for June 30, 1989. The Clty of Memphis (TN) and the Clty of LaFollette (TN) changed fiscal years from December 31 to June 30 in 1982. Emerald Peoples Utility District (OR), City of Bryan (OH), and Northern Wasco County PUD (OR) were nongenerators for 1989 through 1991, but became generators in 1992. The City of Foley (AL) changed fiscal year from June 30 to December 31 in 1990. The Wisconsin Public Power Incorporated System (WI) was a nongenerator in 1989 and 1990, but became a generator in 1981. The City of Marshfield (WI) was a generator in 1989 and 1980, but became a nongenerator in 1991. sions.

Source: Energy Information Administration, Form ciA-861, "Annual Electric Utility Report." Data are based on calendar year submis- 
Table C27. Electric Energy Account for Major U.S. Publicly Owned Nongenerator Electric Utilities with Financial Year Ending on June 30, 1989-1992

(Megawatthours)

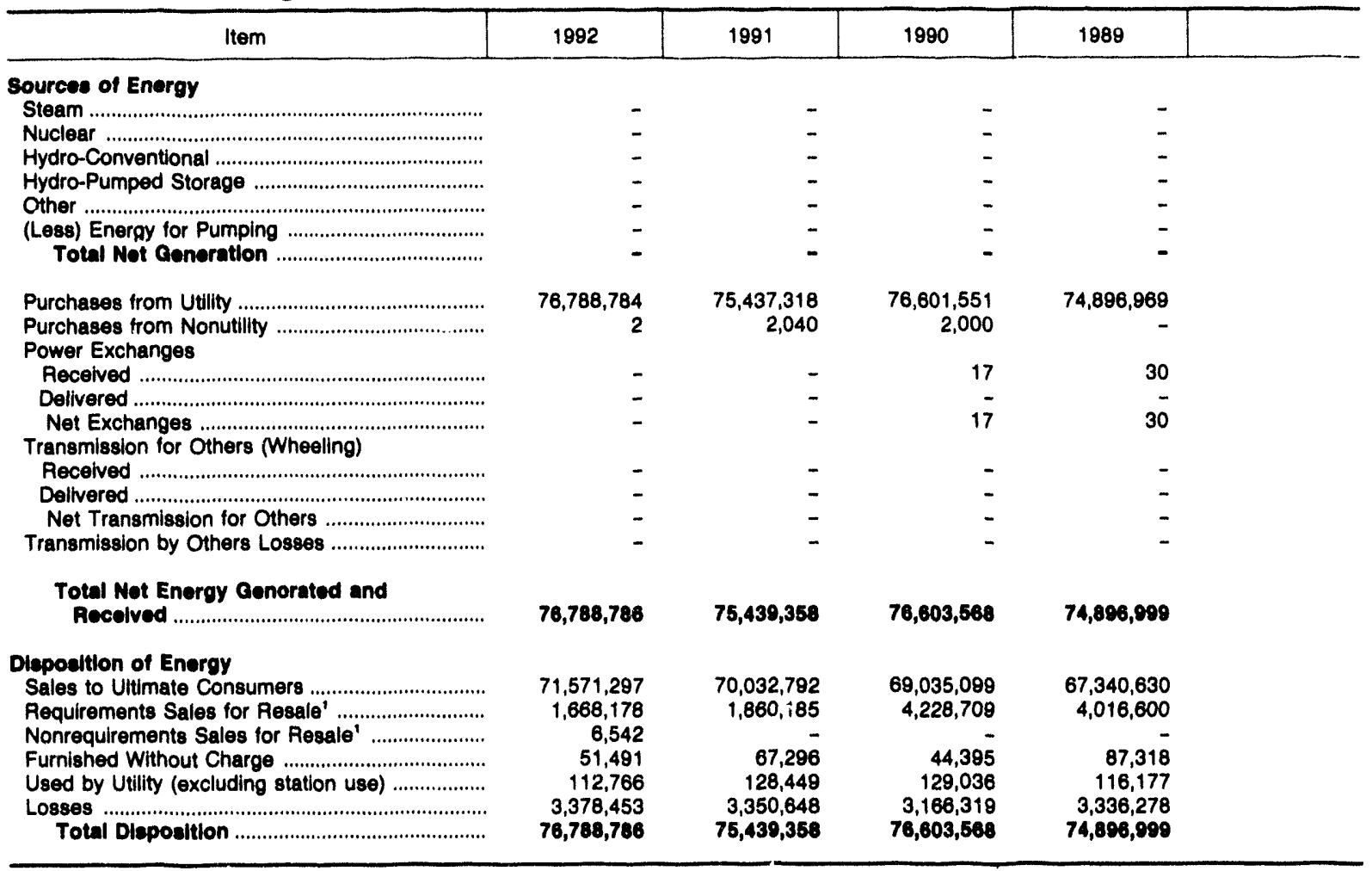

1 The 1989 data were reported as Sales for Resale (one entry) which is shown as Requirements Sales for Resale.

Note: Totals may not equal sum of components because of independent rounding. The number of nongenerating publicly owned electric utilities for end of period is 137 for June 30, 1992; 135 for June 30, 1991; 136 for June 30, 1990; and 135 for June 30, 1989. The City of Memphis (TN) and the City of LaFollette (TN) changed fiscal years from December 31 to June 30 in 1992 . Emerald Peoples Utility District (OR), City of Bryan (OH), and Northern Wasco County PUD (OR) were nongenerators for 1989 through 1991, but became generators in 1992. The City of Foley (AL) changed fiscal year from June 30 to December 31 in 1990. The Wisconsin Public Power Incorporated System (WI) was a nongenerator in 1989 and 1990, but became a generator in 1991. The City of Marshfield (WI) was a generator in 1989 and 1990 , but became a nongenerator in 1991

Source: Energy Information Administration, Form ElA-412, "Annual Report of Public Electric Utilities." 
Table C28. Ten Largest U.S. Publicly Owned Nongenerator Electric Utllities Ranked by Megawatthour Sales to Ultimate Consumers with Financial Year Ending on December 31, 1992

\begin{tabular}{|c|c|c|c|}
\hline Publlety Owned Electric Utulties & State & Amount & Percent \\
\hline 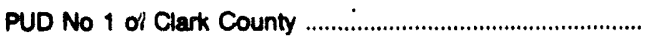 & WA & $3,097,698$ & 11.20 \\
\hline 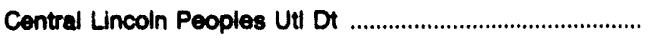 & OR & $1,329,302$ & 4.81 \\
\hline PUD No 1 of Benton County & WA & $1,295,684$ & 4.68 \\
\hline 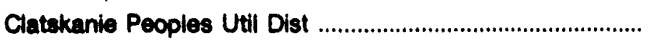 & OR & 879,449 & 3.18 \\
\hline Fort Collins City of & co & 821,008 & 2.97 \\
\hline 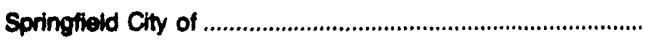 & OR & 750,570 & 2.71 \\
\hline 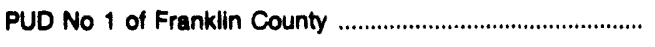 & WA & 595,482 & 2.15 \\
\hline Athens City of & AL & 591,873 & 2.14 \\
\hline Anderson City of & IN & 585,374 & 2.12 \\
\hline 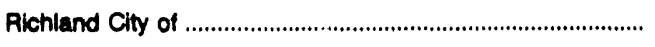 & WA & 580,580 & 2.10 \\
\hline 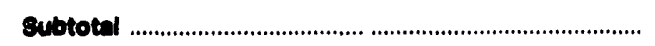 & & $10,527,030$ & 38.05 \\
\hline
\end{tabular}

Source: Energy Information Administration, Form EIA-412، "Annual Report of Public Electric Utilities."

Table C29. Ten Largest U.S. Publicly Owned Nongenerator Electric Utilities Ranked by Megawatthour Sales for Resale with Financial Year Ending on December 31, 1992

\begin{tabular}{|c|c|c|c|}
\hline Publlely Ownod Electric Utllities & State & Amount & Porcent \\
\hline 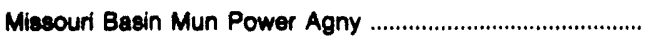 & SD & $2,003,698$ & 69.55 \\
\hline 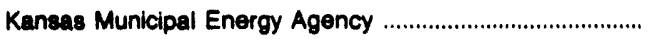 & KS & 311,554 & 10.81 \\
\hline 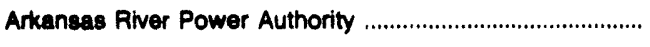 & co & 265,274 & 8.21 \\
\hline 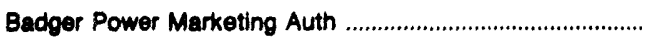 & WI & 238,700 & 8.29 \\
\hline Norris Public Power District & NE & 13,387 & .46 \\
\hline 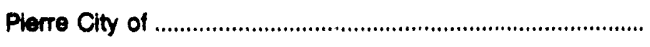 & SD & 12,182 & .42 \\
\hline 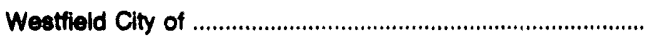 & MA & 7,202 & .25 \\
\hline Mansfield Town of & MA & 6,455 & .22 \\
\hline 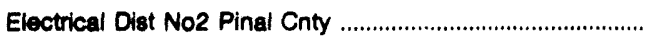 & $A Z$ & 6,425 & .22 \\
\hline 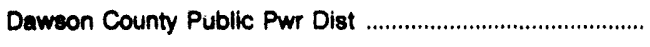 & NE & 4,900 & .17 \\
\hline 8ubtotel & & $2,869,777$ & 99.61 \\
\hline
\end{tabular}

Source: Energy Information Administration, Form EIA-412, "Annual Report of Public Electric Utilities." 
Table C30. Composite Statement of Income for Major U.S. Publicly Owned Nongenerator Electric Utilities with Financial Year Ending on December 31, 1989-1992 (Thousand Dollars)

\begin{tabular}{|c|c|c|c|c|}
\hline Item & 1992 & 1991 & 1990 & 1989 \\
\hline 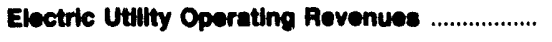 & $2,158,597$ & $2,251,181$ & $2,128,674$ & $1,801,801$ \\
\hline 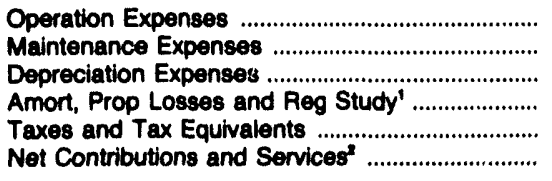 & $\begin{array}{r}1,833,153 \\
68,719 \\
87,335 \\
2,340 \\
56,344 \\
-\end{array}$ & $\begin{array}{r}1,894,483 \\
63,243 \\
83,189 \\
- \\
54,151 \\
35,714\end{array}$ & $\begin{array}{r}1,794,945 \\
63,287 \\
89,010 \\
- \\
52,609 \\
35,693\end{array}$ & $\begin{array}{r}1,640,446 \\
59,486 \\
72,264 \\
- \\
49,263 \\
30,132\end{array}$ \\
\hline $\begin{array}{l}\text { Total Electric Utilty Operating } \\
\text { Expensees }\end{array}$ & $2,047,891$ & $2,140,780$ & $2,035,543$ & $1,851,591$ \\
\hline $\begin{array}{l}\text { Net Electric Utility Operating Income } \\
\text { Income from Electric Plant Leased } \\
\text { to Others }\end{array}$ & $\begin{array}{r}110,707 \\
750\end{array}$ & $\begin{array}{r}110,401 \\
360\end{array}$ & $\begin{array}{r}93,131 \\
424\end{array}$ & $\begin{array}{r}50,210 \\
140\end{array}$ \\
\hline Electric Utility Operating Income .................... & 111,456 & 110,761 & 93,555 & 50,350 \\
\hline 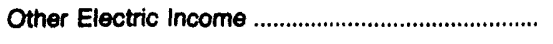 & 65,687 & 51,653 & 54,390 & 60,863 \\
\hline $\begin{array}{l}\text { Other Electric Deductions } \\
\text { Allowance for Other Funds Used }\end{array}$ & 23,319 & 4,873 & - & - \\
\hline 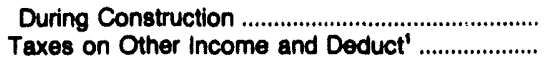 & $\begin{array}{r}21 \\
1,374\end{array}$ & $\begin{array}{r}361 \\
-\end{array}$ & 562 & 289 \\
\hline 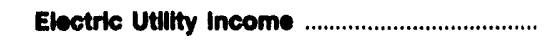 & 152,471 & 157,802 & 148,506 & 111,502 \\
\hline 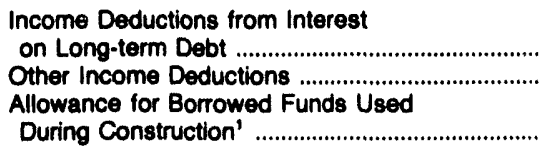 & $\begin{array}{r}46,371 \\
4,172 \\
-78\end{array}$ & $\begin{array}{r}61,140 \\
4,724\end{array}$ & $\begin{array}{r}57,925 \\
5,953\end{array}$ & $\begin{array}{r}47,579 \\
3,970\end{array}$ \\
\hline Total Income Deductions .................................... & 50,465 & 65,864 & 63,878 & 51,549 \\
\hline Income Before Extraordinary Items ........................... & 102,006 & 92,038 & 84,628 & 59,953 \\
\hline 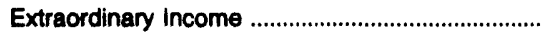 & 13,557 & 1,973 & 2,558 & 24,423 \\
\hline 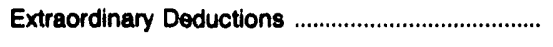 & 14,209 & 5,426 & 240 & 4,916 \\
\hline Not Income & 101,354 & 88,585 & 86,847 & 79,461 \\
\hline
\end{tabular}

Data reporting initiated in 1992.

- Data reporting discontinued in 1992.

- Data not available.

Note: Totals may not equal sum of components because of independent rounding. The number of nongenerating publicly owned electric utilities for end of period is 88 for December 31, 1992; 86 for December 31, 1991; 84 for December 31, 1990; and 77 for December 31. 1989. The City of Memphis (TN) and the City of LaFollette (TN) changed fiscal years from December 31 to June 30 in 1992 . Emerald Peoples Utility District (OA), City of Bryan (OH), and Northern Wasco County PUD (OR) were nongenerators for 1989 through 1991 , but became generators in 1992. The City of Foley (AL) changed fiscal year from june 30 to December 31 in 1990 . The Wisconsin Public Power Incorporated System (WI) was a nongenerator in 1989 and 1990, but became a generator in 1991. The City of Marshfield (WI) was a generator in 1989 and 1990, but became a nongenerator in 1991.

Source: Energy Information Administration, Form ElA-412, "Annual Report of Public Electric Utilities." 
Table C31. Composite Balance Sheet for Major U.S. Publicly Owned Nongenerator Electric Utilities with Financial Year Ending on December 31 at End of Period, 1989-1992 (Thousand Dollars)

\begin{tabular}{|c|c|c|c|c|}
\hline Item & 1992 & 1991 & 1990 & 1989 \\
\hline \multicolumn{5}{|l|}{ Electric Utility Plant } \\
\hline 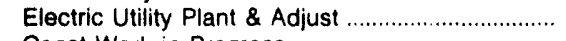 & $2,882,052$ & $2,852,226$ & $2,670,370$ & $2,432,306$ \\
\hline Const Work in Progress & 115,017 & & & - \\
\hline (less) Depr. Amort, and Depletion ........................... & $1,096,972$ & $1,035,792$ & 960,118 & 858,220 \\
\hline Net Electric Utllity Plant' .................................... & $1,900,097$ & - & - & - \\
\hline $\begin{array}{l}\text { Nuclear Fuel' } \\
\text { (less) Amort of Nucl Fuel' . }\end{array}$ & $\begin{array}{l}- \\
-\end{array}$ & - & - & $\overline{-}$ \\
\hline Net Elec Plant Incl Nucl Fuel ............................ & $1,900,097$ & $1,816,434$ & $1,710,253$ & $1,574,086$ \\
\hline \multicolumn{5}{|l|}{ Other Property \& investments } \\
\hline Nonutility Property & 203,618 & 198,098 & 159,993 & 159,012 \\
\hline $\begin{array}{l}\text { (less) Accum Provisions for Depr \& Amort .......... } \\
\text { Invest in Assoc Enterprises }\end{array}$ & $\begin{array}{r}48,346 \\
7,762\end{array}$ & $\begin{array}{r}45,858 \\
99\end{array}$ & 35,068 & 39,158 \\
\hline $\begin{array}{l}\text { Invest in Assoc Enterprises } \\
\text { Invest \& Special Funds }\end{array}$ & $\begin{array}{r}7,762 \\
304,054\end{array}$ & $\begin{array}{r}99 \\
370,683\end{array}$ & 525 & 788 \\
\hline & $\begin{array}{l}304,054 \\
467,088\end{array}$ & $\begin{array}{l}370,683 \\
523,021\end{array}$ & $\begin{array}{l}306,116 \\
\mathbf{4 3 1 , 5 6 6}\end{array}$ & $\begin{array}{l}274,650 \\
395,293\end{array}$ \\
\hline \multicolumn{5}{|l|}{ Current and Accrued Assets } \\
\hline 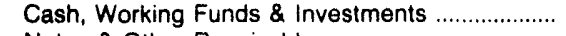 & 339,322 & 362,180 & 271,648 & 280,657 \\
\hline Notes \& Other Receivables & 71,293 & 235,845 & 215,712 & 198,098 \\
\hline Customer Accts Receivable ${ }^{\prime} \ldots \ldots \ldots \ldots \ldots \ldots \ldots \ldots \ldots$ & 147,247 & - & - & $=$ \\
\hline (less) Accum Prov for Uncollected Accts ............ & 8,016 & 7,590 & 6,807 & 6,626 \\
\hline 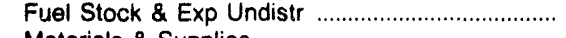 & 500 & - & - & - \\
\hline Materials \& Supplies & 69,972 & 67,872 & 67,040 & 62,867 \\
\hline Prepayments & 21,237 & 83,368 & 85,744 & 10,138 \\
\hline Accrued Utility Revenues' & 11,517 & - & - & - \\
\hline Miscellaneous Current \& Accrued Assets ........... & 15,415 & 27,160 & 24,173 & 33,421 \\
\hline Total Current \& Accrued Assets & 668,487 & 768,834 & 657,510 & 578,555 \\
\hline \multicolumn{5}{|l|}{ Deferred Debits } \\
\hline Unamortized Debt Expenses ...................................... & 18,917 & 25,875 & 26,614 & 15,817 \\
\hline Extraordinary Losses, Study Cost .............................. & 3,980 & - & - & - \\
\hline Misc Debt, R \& D Exp, Unamrt Losses .................. & 39,228 & 80,645 & 74,893 & 65,708 \\
\hline Total Deferred Debits & 62,125 & 106,520 & 101,508 & 81,524 \\
\hline Total Assets \& Other Debits & $3,097,797$ & $3,214,809$ & $2,900,836$ & $2,629,458$ \\
\hline \multicolumn{5}{|l|}{ Proprietary Capital } \\
\hline 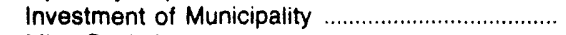 & 91,968 & 95,426 & 93,420 & 85,966 \\
\hline Misc Capital & 88,736 & 136,711 & 126,335 & 114,893 \\
\hline Retained Earnings ……………………………… & $1,702,946$ & $1,512,670$ & $1,410,735$ & $1,305,678$ \\
\hline Total Proprietary Capital ...................................... & $1,883,650$ & $1,744,806$ & $1,630,490$ & $\mathbf{1 , 5 0 6 , 5 3 7}$ \\
\hline \multicolumn{5}{|l|}{ Long-term Debt } \\
\hline 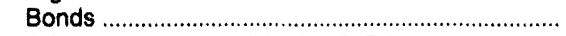 & 759,756 & $1,011,891$ & 838,541 & 698,437 \\
\hline Advances from Municipality \& Other ........................ & 70,241 & 58,600 & 50,983 & 56,599 \\
\hline Unamort Prem on Long-term Debt ........................ & 2,791 & & & 5 \\
\hline (less) Unamort Discount on Long-term Debt ....... & 1,481 & 1,283 & 1,464 & 5,312 \\
\hline Total Long-term Debt ................................. & 831,307 & $1,069,215$ & 888,064 & 749,730 \\
\hline \multicolumn{5}{|l|}{ Other Noncurrent Liabilities } \\
\hline Accum Operating Provisions.. & 6,035 & 36,590 & 31,001 & 29,484 \\
\hline Accum Prov for Rate Refunds' & & & & \\
\hline \multirow{2}{*}{\multicolumn{5}{|c|}{ Current and Accrued Liabilities }} \\
\hline & & & & \\
\hline Notes Payable & 22,041 & 24,474 & 18,660 & 13,914 \\
\hline Accounts Payable & 190,881 & 192,092 & 192,249 & 188,613 \\
\hline Payables to Assoc Enterprises & 2,998 & 1,898 & 1,914 & 2,043 \\
\hline Customer Deposits & 16,811 & 15,768 & 15,059 & 12,557 \\
\hline Taxes Accrued & 11,124 & 10,501 & 9,238 & 9,044 \\
\hline Interest Accrued & 8,666 & 10,514 & 9,736 & 8,719 \\
\hline Misc Current \& Accrued Liabilities .............................. & 40,286 & 34,968 & 34,715 & 35,723 \\
\hline Total Current \& Accrued Llabilities & 292,806 & 290,214 & 281,571 & 270,611 \\
\hline \multicolumn{5}{|l|}{ Deferred Credits } \\
\hline Customer Advances for Construction ....................... & 35,813 & 35,394 & 30,221 & 25,316 \\
\hline Other Deferred Credits & 43,212 & 37,365 & 39,404 & 43,032 \\
\hline Unamort Gain on Reacqr Debt ................................ & 4,973 & 1,224 & & 4,748 \\
\hline Total Deterred Credits & 83,998 & 73,982 & 69,710 & 73,096 \\
\hline ............... & $3,097,797$ & $3,214,809$ & $2,900,836$ & $2,629,458$ \\
\hline
\end{tabular}

Data reporting initiated in 1992.

Note: Totals may not equal sum of components because of independent rounding. The number of nongenerating publicly owned electric utilities for end of period is 88 tor December 31, 1992; 86 for December 31, 1991; 84 for December 31, 1990; and 77 for December 31. 1989. The City of Memphis (TN) and the City of LaFollette (TN) changed fiscal years from December 31 to June 30 in 1992 . Emerald Peoples Utility District (OR), City of Bryan (OH), and Northern Wasco County PUD (OR) were nongenerators for 1989 through 1991 , but became generators in 1992. The City of Foley (AL) changed fiscal year from June 30 to December 31 in 1990 . The Wisconsin Public Power Incorporated System (WI) was a nongenerator in 1989 and 1990, but became a generator in 1991. The City of Marshfield (WI) was a generator in 1989 and 1990, but became a nongenerator in 1991.

Source: Energy Information Administration, Form ElA-412, "Annual Report of Public Electric Utilities." 


\section{Table C32. Composite FInancial Indicators for Major U.S. Publicly Owned Nongenerator Electric Utilities with Financial Year Ending on December 31, 1989-1992}

\begin{tabular}{|c|c|c|c|c|}
\hline Item & 1992 & 1991 & 1990 & 1989 \\
\hline Total Electric Utility Plant per Dollar of Revenue & 1.4 & 1.3 & 1.3 & 1.3 \\
\hline 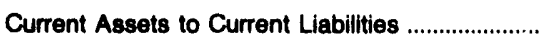 & 2.3 & 2.6 & 2.3 & 2.1 \\
\hline $\begin{array}{l}\text { Total Electric Utility Plant as a Percent of Total } \\
\text { Assets }\end{array}$ & 96.7 & 88.7 & 92.1 & 92.5 \\
\hline 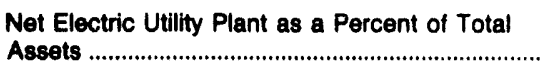 & 61.3 & 56.5 & 59.0 & 59.9 \\
\hline Debt as a P - ynt of Total Liabilities ..................... & 36.3 & 42.3 & 40.3 & 38.8 \\
\hline $\begin{array}{l}\text { Depreciation, Amortization and Depletion } \\
\text { as a Percent of Total Electric Utility Plant ........... }\end{array}$ & 36.6 & 36.3 & 36.0 & 35.3 \\
\hline $\begin{array}{l}\text { Electric Operation and Maintenance Expenses } \\
\text { as a Percent of } \\
\text { Electric Utility Operating Revenues ........................... }\end{array}$ & 88.1 & 87.0 & 87.3 & 89.4 \\
\hline $\begin{array}{l}\text { Electric Depreciation and Amortization } \\
\text { as a Percent of } \\
\text { Electric Utility Operating Revenues .......................... }\end{array}$ & 4.0 & 4.1 & 4.2 & 3.8 \\
\hline $\begin{array}{l}\text { Taxes and Tax Equivalents } \\
\text { as a Percent of } \\
\text { Electric Utility Operating Revenues ........................ }\end{array}$ & 2.6 & 2.4 & 2.5 & 2.6 \\
\hline $\begin{array}{l}\text { Interest on Long-term Debt } \\
\text { as a Percent of } \\
\text { Electric Utility Operating Revenues .......................... }\end{array}$ & 2.1 & 2.7 & 2.7 & 2.5 \\
\hline $\begin{array}{l}\text { Net Income as a Percent of Electric } \\
\text { Utility Operating Revenues }\end{array}$ & 4.7 & 3.9 & 4.1 & 4.2 \\
\hline
\end{tabular}

Note: Totals may not equal sum of components because of independent rounding. The number of nongenerating publicly owned electric utilities for end of period is 88 for December 31, 1992; 86 for December 31, 1991; 84 for December 31, 1990; and 77 for December 31, 1989. The City of Memphis (TN) and the City of LaFollette (TN) changed fiscal years from December 31 to June 30 in 1992. Emerald Peoples Utility District (OR), City of Bryan (OH), and Northern Wasco County PUD (OR) were nongenerators for 1989 through 1991, but became generators in 1992. The City of Foley (AL) changed fiscal year from June 30 to December 31 in 1990. The Wisconsin Public Power Incorporated System (WI) was a nongenerator in 1989 and 1990, but became a generator in 1991. The City of Marshfield (WI) was a generator in 1989 and 1990, but became a nongenerator in 1991.

Source: Energy information Administration, Form EIA-412, "Annual Report of Public Electric Utilities." 
Table C33. Electric Operation and Maintenance Expenses for Major U.S. Publicly Owned Nongenerator Electric Utilities with Financlal Year Ending on December 31, 1989-1992 (Thousand Dollars)

\begin{tabular}{|c|c|c|c|c|}
\hline Item & 1992 & 1991 & 1990 & 1989 \\
\hline \multicolumn{5}{|l|}{ Production Expenses } \\
\hline Steam Power Generation & 416 & 544 & 230 & 263 \\
\hline 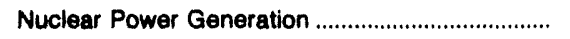 & - & - & - & - \\
\hline 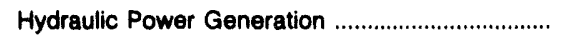 & 1 & - & - & - \\
\hline 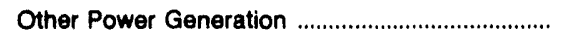 & 622 & 97 & 105 & - \\
\hline Purchased Power & $1,579,889$ & $1,648,190$ & $1,538,236$ & $1,414,003$ \\
\hline 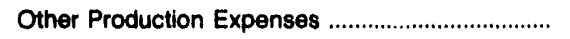 & 4,576 & 7,326 & 36,240 & 31,211 \\
\hline 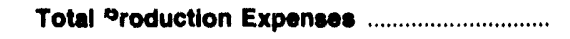 & $1,585,505$ & $1,656,156$ & $1,574,811$ & $1,445,478$ \\
\hline 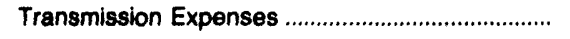 & 22,387 & 20,321 & 22,677 & 17,736 \\
\hline 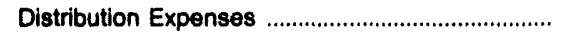 & 134,814 & 125,756 & 114,903 & 103,496 \\
\hline 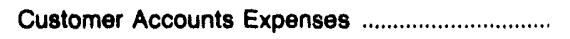 & 38,622 & 37,058 & 36,105 & 33,759 \\
\hline Customer Service and Information Expenses ..... & 6,113 & 5,280 & 4,879 & 4,695 \\
\hline Sales Expenses & 2,495 & 1,582 & 1,483 & 1,743 \\
\hline Administıative and General Expenses ..................... & 111,937 & 111,572 & 103,374 & 93,225 \\
\hline $\begin{array}{l}\text { Total Electric Operation } \\
\text { and Maintenance Expenses }\end{array}$ & $1,901,872$ & $1,957,726$ & $1,858,231$ & $1,699,932$ \\
\hline \multicolumn{5}{|l|}{ Fuel Expenses In Operation } \\
\hline 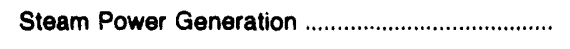 & 13 & 2 & -3 & - \\
\hline 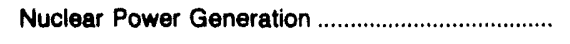 & - & - & - & - \\
\hline 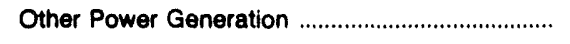 & 5 & 2 & 3 & - \\
\hline \multicolumn{5}{|l|}{ Number of Elec Dept Employees } \\
\hline Regular Full-time' & 5,493 & - & - & - \\
\hline 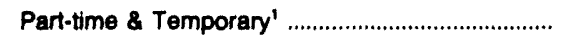 & 870 & - & - & - \\
\hline 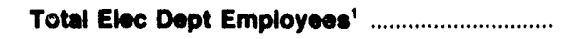 & 6,365 & - & - & - \\
\hline
\end{tabular}

1. Data reporting initiated in 1992.

Note: Totals may not equal sum of components because of independent rounding. The number of nongenerating publicly owned electric utilities for end of period is 88 for December 31, 1992; 86 for December 31, 1991; 84 for December 31, 1990; and 77 for December 31, 1989. The City of Memphis (TN) and the City of LaFollette (TN) changed fiscal years from December 31 to June 30 in 1992 . Emeraid Peoples Utility District (OR), City of Bryan (OH), and Northern Wasco County PUD (OR) were nongenerators for 1989 through 1991 , but became generators in 1992. The City of Foley (AL) changed fiscal year from June 30 to December 31 in 1990 . The Wisconsin Public Power Incorporated System (WI) was a nongenerator in 1989 and 1990, but became a generator in 1991. The City of Marshfield (WI) was a generator in 1989 and 1990, but became a nongenerator in 1991.

Source: Energy Information Administration, Form EIA-412, "Annual Report of Public Electric Utilities." 
Table C34. Electric UtIlity Plant for Major U.S. Publicly Owned Nongenerator Electric Utilities with Financial Year Ending on December 31 at End of Period, 1989-1992 (Thousand Dollars)

\begin{tabular}{|c|c|c|c|c|}
\hline Item & 1992 & 1991 & 1990 & 1989 \\
\hline \multicolumn{5}{|l|}{ Electric Plant in Service } \\
\hline 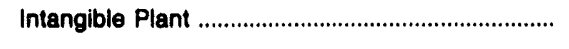 & 10,091 & 7,860 & 7,015 & 6,854 \\
\hline \multicolumn{5}{|l|}{ Production Plant } \\
\hline Steam & 28,078 & 27,651 & 26,928 & 31,281 \\
\hline Nuclear & - & - & - & - \\
\hline 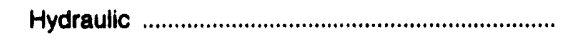 & 582 & 582 & 582 & 582 \\
\hline Other & 6,369 & 6,541 & 2,162 & 2,158 \\
\hline Total Production Plant .......................................... & 35,029 & 34,774 & 29,673 & 34,021 \\
\hline 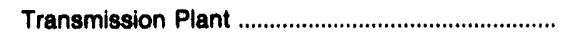 & 287,707 & 251,496 & 242,341 & 214,584 \\
\hline 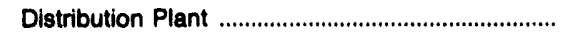 & $2,129,995$ & $2,060,843$ & $1,924,956$ & $1,753,797$ \\
\hline 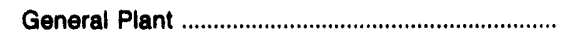 & 376,397 & 346,682 & 332,205 & 298,721 \\
\hline Total Electric Plant In Service ............................ & $2,839,219$ & $2,701,656$ & $2,536,190$ & $2,307,977$ \\
\hline 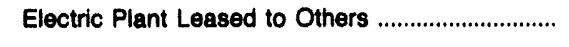 & 615 & 662 & 708 & 640 \\
\hline Construction Work in Progress - Electric ............... & 115,017 & 103,296 & 89,870 & 75,729 \\
\hline Electric Plant Held for Future Use ............................. & 1,309 & 10,653 & 10,197 & 10,046 \\
\hline Electric Plant Misc & 40,909 & 35,960 & 33,407 & 37,914 \\
\hline Total Eloctrlc Utility Plant .................................... & $2,997,069$ & $2,852,226$ & $2,670,370$ & $2,432,306$ \\
\hline 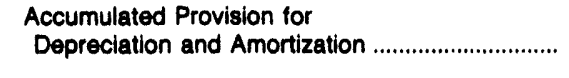 & $1,096,972$ & $1,035,792$ & 960,118 & 858,220 \\
\hline Net Electrle Utillty Plant ..................................... & $1,900,097$ & $1,816,434$ & $1,710,253$ & $1,574,086$ \\
\hline
\end{tabular}

Note: Totals may not equal aum of components because of independent rounding. The number of nongenerating publicly owned electric utilities for end of period is 88 for December 31,$1992 ; 86$ for December 31,$1991 ; 84$ for December 31,1990 ; and 77 for December 31 , 1988. The City of Memphis (TN) and the City of LaFollette (TN) changed fiscal years from December 31 to June 30 in 1992. Emerald Peoples Utility District (OR), City of Bryan (OH), and Northern Wasco County PUD (OR) were nongenerators for 1989 through 1991, but became generators in 1992. The City of Foley (AL) changed fiscal year from June 30 to December 31 in 1990. The Wisconsin Public Power incorporated System (WI) was a nongenerator in 1989 and 1990, but became a generator in 1991. The City of Marshfield (WI) was a generator in 1989 and 1990 , but became a nongenerator in 1981.

Source: Energy Information Administration, Form EIA-412, "Annual Report of Public Electric Utilities." 
Table C35. Number of Consumers, Sales, and Operating Revenue for Major U.S. Publicly Owned Nongenerator Electric Utilities with Financial Year Ending on December 31, 1989-1992

\begin{tabular}{|c|c|c|c|c|}
\hline Item & 1992 & 1991 & 1990 & 1989 \\
\hline \multicolumn{5}{|l|}{ Number of Consumers } \\
\hline 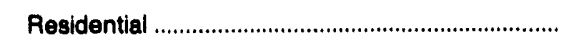 & $1,252,787$ & $1,215,874$ & $1,187,590$ & $1,131,699$ \\
\hline Commercial or Small & 143,672 & 146,187 & 143,435 & 131,239 \\
\hline Industrial or Large & 14,306 & 6,913 & 6,824 & 6,583 \\
\hline Other & 49,680 & 58,258 & 54,952 & 51,921 \\
\hline Total Uitimate Consumers ......................................... & $1,460,445$ & $1,427,232$ & $1,392,801$ & $1,321,442$ \\
\hline \multicolumn{5}{|l|}{ Sales for the Year (megawatthours) } \\
\hline 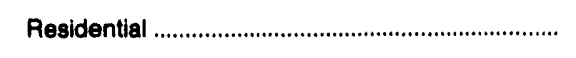 & $15,090,546$ & $15,659,505$ & $14,897,373$ & $14,093,218$ \\
\hline Commercial or Small & $7,259,565$ & $11,332,825$ & $10,868,836$ & $10,243,430$ \\
\hline Industrial or Large & $15,685,347$ & $11,090,867$ & $10,624,836$ & $10,064,758$ \\
\hline Other & $1,250,985$ & $1,432,510$ & $1,400,762$ & $1,312,076$ \\
\hline Total Sales to Ultimate Consumers .................... & $39,286,443$ & $39,515,707$ & $37,791,807$ & $35,713,482$ \\
\hline 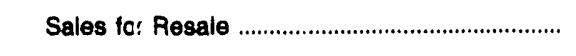 & $2,881,020$ & $4,786,485$ & $4,517,100$ & $2,070,272$ \\
\hline 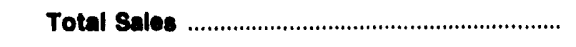 & $42,167,463$ & $44,302,192$ & $42,308,907$ & $37,783,754$ \\
\hline \multicolumn{5}{|l|}{$\begin{array}{l}\text { Operating Rovenues for the Year } \\
\text { (thousand dollars) }\end{array}$} \\
\hline 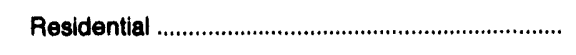 & 851,333 & 859,173 & 814,217 & 761,718 \\
\hline Commercial or Small & 399,907 & 625,575 & 596,333 & 560,246 \\
\hline Industrial or Large & 726,419 & 464,741 & 444,333 & 423,850 \\
\hline Other & 71,459 & 79,256 & 75,527 & 70,472 \\
\hline $\begin{array}{l}\text { Total Revenues from Sales to } \\
\text { Ultimate Consumers }\end{array}$ & $2,049,118$ & $2,028,745$ & $1,930,410$ & $1,816,286$ \\
\hline 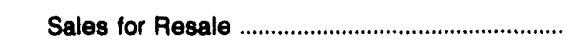 & 79,291 & 164,736 & 152,081 & 76,877 \\
\hline $\begin{array}{l}\text { Total Revenues From Sales of } \\
\text { Eloctricity }\end{array}$ & $2,128,409$ & $2,193,481$ & $2,082,491$ & $1,893,183$ \\
\hline
\end{tabular}

Note: Totals may not equal sum of components because of independent rounding. The number of nongenerating publicly owned electric utilities for end of period is 88 for December 31, 1992; 86 for December 31, 1991; 84 for December 31, 1990; and 77 for December 31 , 1989. The City of Memphis (TN) and the City of LaFollette (TN) changed fiscal years from December 31 to June 30 in 1992 . Emerald Peoples Utility District (OR), City of Bryan (OH), and Northern Wasco County PUD (OR) were nongenerators for 1989 through 1991 , but became generators in 1992. The City of Foley (AL) changed fiscal year from June 30 to December 31 in 1990 . The Wisconsin Public Power Incorporated System (WI) was a nongenerator in 1989 and 1990, but became a generator in 1991. The City of Marshfield (WI) was a gen. erator in 1989 and 1990 , but became a nongenerator in 1991. sions.

Source: Energy Information Administration, Form ElA-861, "Annual Electric Utility Report." Data are based on calendar year submis- 
Table C36. Electric Energy Account for Major U.S. Publicly Owned Nongenerator Electric Utilities with Financlal Year Ending on December 31, 1989-1992

(Megawatthours)

\begin{tabular}{|c|c|c|c|c|}
\hline Item & 1992 & 1991 & 1990 & 1989 \\
\hline \multicolumn{5}{|l|}{ Sources of Energy } \\
\hline Stoam & - & - & - & - \\
\hline Nuclear & - & - & - & - \\
\hline 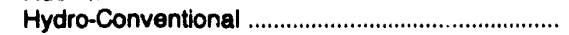 & - & - & - & - \\
\hline 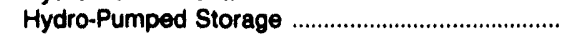 & - & - & - & - \\
\hline Other & - & - & - & - \\
\hline (Less) Energy for Pumping ............................... & - & - & - & - \\
\hline 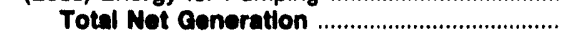 & - & - & - & - \\
\hline 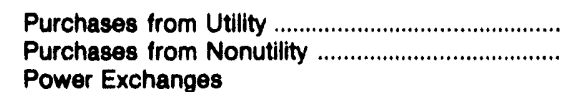 & $\begin{array}{r}43,971,877 \\
160,421\end{array}$ & $\begin{array}{r}45,754,785 \\
318,282\end{array}$ & $\begin{array}{r}44,246,921 \\
5,865\end{array}$ & $\begin{array}{r}39,792,406 \\
2,345\end{array}$ \\
\hline 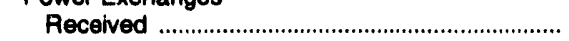 & 363,092 & 289,014 & 67,326 & 274,542 \\
\hline 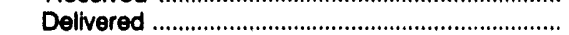 & 158,997 & 202,905 & 22,894 & 268,065 \\
\hline 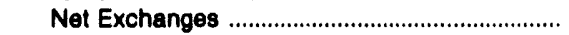 & 204,095 & 86,109 & 44,332 & 6,476 \\
\hline \multicolumn{5}{|l|}{ Transmission for Others (Wheeling) } \\
\hline 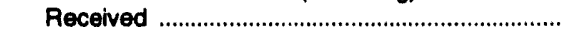 & 1,986 & 7,164 & 8,071 & 14,484 \\
\hline 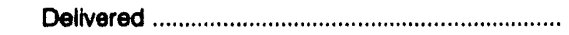 & 1,986 & 7,164 & 8,825 & 6,681 \\
\hline Net Transmission for Others ................................ & & - & -754 & 7,803 \\
\hline 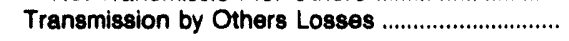 & -220 & - & - & - \\
\hline \multicolumn{5}{|l|}{ Total Net Energy Generated and } \\
\hline 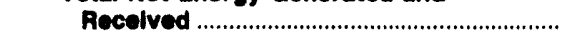 & $44,336,172$ & $46,159,176$ & $44,296,364$ & $39,800,034$ \\
\hline \multicolumn{5}{|l|}{ Dieposition of Energy } \\
\hline Sales to Ultimate Consumers & $39,282,927$ & $39,512,479$ & $37,790,731$ & $35,735,573$ \\
\hline Requirements Sales for Resale' ................................. & $1,459,980$ & $3,775,557$ & $3,517,537$ & $2,051,847$ \\
\hline Nonrequirements Sales for Resale' .......................... & $1,420,867$ & $1,010,926$ & 999,561 & \\
\hline Furnished Without Charge ………………………. & 77,698 & 78,966 & 86,114 & 83,438 \\
\hline Used by Utility (exciuding station use) ..................... & 57,199 & 54,114 & 67,227 & 67,065 \\
\hline 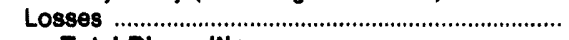 & $2,037,395$ & $1,727,132$ & $1,835,182$ & $1,871,106$ \\
\hline 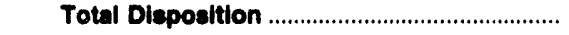 & $44,336,172$ & $46,159,176$ & $44,296,364$ & $39,809,034$ \\
\hline
\end{tabular}

1 The 1889 data were reported as Sales for Resale (one entry) which: is shown as Requirements Sales for Resale.

Note: Totals may not equal sum of components because of independent rounding. The number of nongenerating publicly owned elec. tric utilities for end of period is 88 for December 31, 1992; 86 for December 31, 1991; 84 for December 31, 1990; and 77 for December 31, 1989. The City of Memphis (TN) and the City of LaFollette (TN) changed fiscal years from December 31 to June 30 in 1992 . Emerald Peoples Utility District (OR), City of Bryan (OH), and Northern Wasco County PUD (OR) were nongenerators for 1989 through 1981, but became generators in 1992. The City of Foley (AL) changed fiscal year from June 30 to December 31 in 1990 . The Wisconsin Public Power Incorporated System (WI) was a nongenerator in 1989 and 1990, but became a generator in 1991. The City of Marshfield (WI) was a generator in 1989 and 1990 , but became a nongenerator in 1991.

Source: Energy Information Administration, Form ElA-412, "Annual Report of Public Electric Utilities." 


\section{Table C37. Twenty Largest U.S. Publicly Owned Electric Utillties Ranked by Megawatthour Sales to Ultimate Consumers for All Respondents, 1992}

\begin{tabular}{|c|c|c|c|}
\hline Publlcly Owned Electric Utilities & State & Amount & Reporting Date \\
\hline $\begin{array}{l}\text { Los Angeles City of } \\
\text { Salt River Proj Ag I \& P Dist . } \\
\text { Power Authority of State of NY } \\
\text { San Antonio City of } \\
\text { Memphis City of }\end{array}$ & $\begin{array}{l}C A \\
A Z \\
N Y \\
T X \\
T N\end{array}$ & $\begin{array}{l}21,515,437 \\
14,678,648 \\
13,242,116 \\
11,958,749 \\
11,317,322\end{array}$ & $\begin{array}{c}\text { June } 30 \\
\text { April } 30 \\
\text { December } 31 \\
\text { January } 31 \\
\text { June } 30\end{array}$ \\
\hline 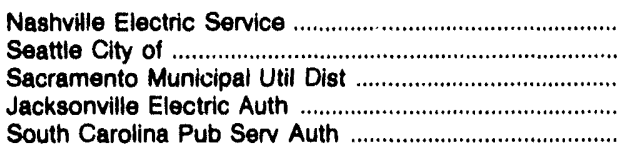 & $\begin{array}{l}\text { TN } \\
\text { WA } \\
\text { CA } \\
\text { FL } \\
\text { SC }\end{array}$ & $\begin{array}{l}9,851,641 \\
8,762,380 \\
8,471,202 \\
8,199,190 \\
7,637,583\end{array}$ & $\begin{array}{l}\text { June } 30 \\
\text { December } 31 \\
\text { December } 31 \\
\text { September } 30 \\
\text { December } 31\end{array}$ \\
\hline 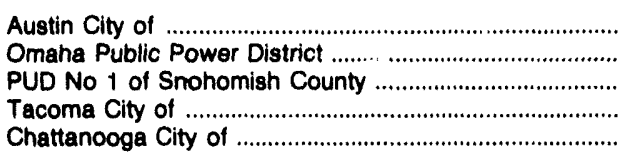 & $\begin{array}{l}\text { TX } \\
\text { NE } \\
\text { WA } \\
\text { WA } \\
\text { TN }\end{array}$ & $\begin{array}{l}6,582,788 \\
6,452,515 \\
5,421,469 \\
5,387,959 \\
5,090,333\end{array}$ & $\begin{array}{c}\text { September } 30 \\
\text { December } 31 \\
\text { December } 31 \\
\text { December } 31 \\
\text { June } 30\end{array}$ \\
\hline 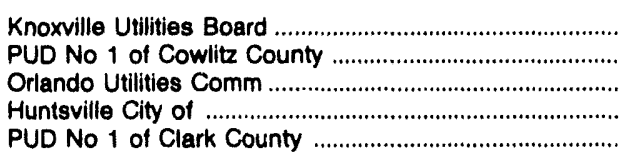 & $\begin{array}{l}\text { TN } \\
\text { WA } \\
\text { FL } \\
\text { AL } \\
\text { WA }\end{array}$ & $\begin{array}{l}4,465,554 \\
4,404,205 \\
3,543,506 \\
3,474,156 \\
3,097,698\end{array}$ & $\begin{array}{l}\text { June } 30 \\
\text { December } 31 \\
\text { September } 30 \\
\text { September } 30 \\
\text { December } 31\end{array}$ \\
\hline
\end{tabular}

Source: Energy Information Administration, Form ElA-412, "Annual Report of Public Electric Utilities." Individual electric utilities report fiscal year data. Appendix $B$ shows the fiscal year for each electric utility.

\section{Table C38. Twenty Largest U.S. Publicly Owned Electric Utilities Ranked by Megawatthour Sales for Resale for All ?espondents, 1992}

\begin{tabular}{|c|c|c|c|}
\hline Publicly Owned Electric Uillities & State & Amount & Reporting Date \\
\hline $\begin{array}{l}\text { Power Authority of State of NY } \\
\text { Intermountain Power Agency } \\
\text { Nebraska Public Power District } \\
\text { Municipal Electric Authority } \\
\text { Lower Colorado River Authority }\end{array}$ & $\begin{array}{l}\text { NY } \\
\text { UT } \\
\text { NE } \\
\text { GA } \\
\text { TX }\end{array}$ & $\begin{array}{r}20,962,342 \\
11,385,417 \\
11,309,492 \\
9,684,579 \\
8,071,364\end{array}$ & $\begin{array}{l}\text { December } 31 \\
\text { June } 30 \\
\text { December } 31 \\
\text { December } 31 \\
\text { June } 30\end{array}$ \\
\hline 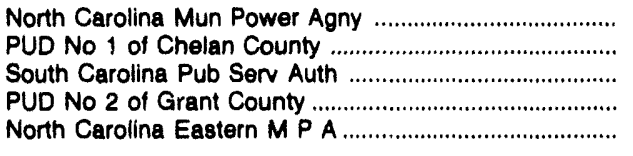 & $\begin{array}{l}\text { NC } \\
\text { WA } \\
\text { SC } \\
\text { WA } \\
\text { NC }\end{array}$ & $\begin{array}{l}7,962,505 \\
7,898,961 \\
6,395,055 \\
6,367,661 \\
5,899,408\end{array}$ & $\begin{array}{l}\text { December } 31 \\
\text { December } 31 \\
\text { December } 31 \\
\text { December } 31 \\
\text { December } 31\end{array}$ \\
\hline 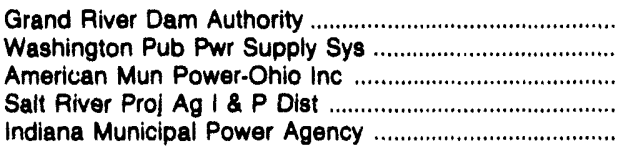 & $\begin{array}{l}\text { OK } \\
\text { WA } \\
\text { OH } \\
\text { AZ } \\
\text { IN }\end{array}$ & $\begin{array}{l}4,160,380 \\
3,882,011 \\
3,730,661 \\
3,593,342 \\
3,393,949\end{array}$ & $\begin{array}{l}\text { December } 31 \\
\text { June } 30 \\
\text { December } 31 \\
\text { April } 30 \\
\text { December } 31\end{array}$ \\
\hline 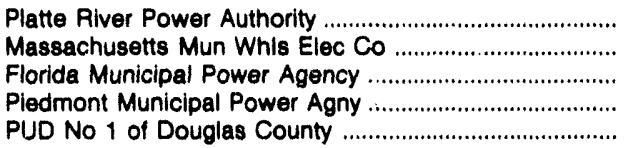 & $\begin{array}{l}\text { CO } \\
\text { MA } \\
\text { FL } \\
\text { SC } \\
\text { WA }\end{array}$ & $\begin{array}{l}3,271,591 \\
3,237,364 \\
3,142,207 \\
3,094,260 \\
3,067,097\end{array}$ & $\begin{array}{l}\text { December } 31 \\
\text { December } 31 \\
\text { September } 30 \\
\text { December } 31 \\
\text { December } 31\end{array}$ \\
\hline
\end{tabular}

Source: Energy Information Administration, Form EIA-412, "Annual Report of Public Electric Utilities." Individual electric utilities report fiscal year data. Appendix $B$ shows the fiscal year for each electric utility. 
Table C39. Twenty Largest U.S. Publicly Owned Electric Utillties Ranked by Electric Utility Revenues for All Respondents, 1992 (Thousand Dollars)

\begin{tabular}{|c|c|c|c|}
\hline Publicly Owned Electrlc Utilities & State & Amount & Reporting Date \\
\hline $\begin{array}{l}\text { Los Angeles City of } \\
\text { Power Authority of State of NY } \\
\text { Salt River Proj Ag I \& P Dist } \\
\text { Nebraska Public Power District } \\
\text { San Antonio Clity of }\end{array}$ & $\begin{array}{l}\text { CA } \\
\text { NY } \\
\text { AZ } \\
\text { NE } \\
\text { TX }\end{array}$ & $\begin{array}{r}1,829,075 \\
1,298,616 \\
1,176,736 \\
729,399 \\
706,609\end{array}$ & $\begin{array}{l}\text { June } 30 \\
\text { December } 31 \\
\text { April } 30 \\
\text { December } 31 \\
\text { January } 31\end{array}$ \\
\hline 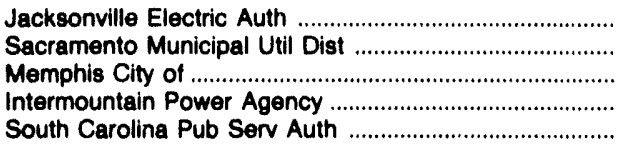 & $\begin{array}{l}\text { FL } \\
\text { CA } \\
\text { TN } \\
\text { UT } \\
\text { SC }\end{array}$ & $\begin{array}{l}662,850 \\
648,170 \\
628,316 \\
609,337 \\
546,878\end{array}$ & $\begin{array}{l}\text { September } 30 \\
\text { December } 31 \\
\text { December } 31 \\
\text { June } 30 \\
\text { December } 31\end{array}$ \\
\hline $\begin{array}{l}\text { Nashville Electric Service } \\
\text { Municipal Electric Authority } \\
\text { Washington Pub Pwr Supply Sys } \\
\text { Austin City of } \\
\text { North Carolina Mun Power Agny }\end{array}$ & $\begin{array}{l}\text { TN } \\
\text { GA } \\
\text { WA } \\
\text { TX } \\
\text { NC }\end{array}$ & $\begin{array}{l}542,392 \\
538,301 \\
439,370 \\
426,070 \\
418,234\end{array}$ & $\begin{array}{l}\text { June } 30 \\
\text { December } 31 \\
\text { June } 30 \\
\text { September } 30 \\
\text { December } 31\end{array}$ \\
\hline $\begin{array}{l}\text { North Carolina Eastern M P A } \\
\text { Omaha Public Power District } \\
\text { Lower Colorado River Authority } \\
\text { Seattle City of } \\
\text { Orlando Utilities Comm }\end{array}$ & $\begin{array}{l}\text { NC } \\
\text { NE } \\
T X \\
\text { WA } \\
\text { FL }\end{array}$ & $\begin{array}{l}398,585 \\
373,113 \\
319,810 \\
294,958 \\
286,781\end{array}$ & $\begin{array}{l}\text { December } 31 \\
\text { December } 31 \\
\text { June } 30 \\
\text { December } 31 \\
\text { September } 30\end{array}$ \\
\hline
\end{tabular}

Source: Energy Information Administration, Form EIA-412, "Annual Report of Public Electric Utilities." Individual electric utilities report fiscal year data. Appendix B shows the fiscal year for each electric utility.

\section{Table C40. Twenty Largest U.S. Publicly Owned Electric Utilities Ranked by Purchase Power Expenses for All Respondents, 1992} (Thousand Dollars)

\begin{tabular}{|c|c|c|c|}
\hline Publlely Owned Eloctric Utillties & State & Amount & Reporting Date \\
\hline $\begin{array}{l}\text { Los Angeles City of } \\
\text { Memphis City of for } \\
\text { Nashville Electric Service } \\
\text { Sacramento Municipal Util Dist } \\
\text { Chattanooga City of }\end{array}$ & $\begin{array}{l}\text { CA } \\
\text { TN } \\
\text { TN } \\
\text { CA } \\
\text { TN }\end{array}$ & $\begin{array}{l}660,345 \\
498,794 \\
445,923 \\
292,963 \\
230,178\end{array}$ & $\begin{array}{l}\text { June } 30 \\
\text { December } 31 \\
\text { June } 30 \\
\text { December } 31 \\
\text { June } 30\end{array}$ \\
\hline $\begin{array}{l}\text { Knoxville Utilities Board } \\
\text { Power Authority of State of NY } \\
\text { Huntsville City of } \\
\text { North Carolina Eastern M P A } \\
\text { Anaheim City of }\end{array}$ & $\begin{array}{l}\text { TN } \\
\text { NY } \\
\text { AL } \\
\text { NC } \\
\text { CA }\end{array}$ & $\begin{array}{l}208,085 \\
173,052 \\
163,873 \\
144,465 \\
132,962\end{array}$ & $\begin{array}{l}\text { June } 30 \\
\text { December } 31 \\
\text { September } 30 \\
\text { December } 31 \\
\text { June } 30\end{array}$ \\
\hline $\begin{array}{l}\text { PUD No } 1 \text { of Snohomish County } \\
\text { North Carolina Mun Power Agny } \\
\text { Santa Clara City of ......... } \\
\text { American Mun Power-Ohio Inc } \\
\text { PUD No } 1 \text { of Cowlitz County }\end{array}$ & $\begin{array}{l}\text { WA } \\
\text { NC } \\
\text { CA } \\
\text { OH } \\
\text { WA }\end{array}$ & $\begin{array}{r}130,971 \\
125,058 \\
115,210 \\
96,777 \\
95,512\end{array}$ & $\begin{array}{l}\text { December } 31 \\
\text { December } 31 \\
\text { June } 30 \\
\text { December } 31 \\
\text { December } 31\end{array}$ \\
\hline $\begin{array}{l}\text { Indiana Municipal Power Agency } \\
\text { Seattle City of .. } \\
\text { Wisconsin Public Power Inc Sys } \\
\text { Riverside City of ... } \\
\text { PUD No } 1 \text { of Clark County }\end{array}$ & $\begin{array}{l}\text { IN } \\
\text { WA } \\
\text { WI } \\
\text { CA } \\
\text { WA }\end{array}$ & $\begin{array}{l}87,049 \\
83,366 \\
80,141 \\
79,660 \\
77,436\end{array}$ & $\begin{array}{c}\text { December } 31 \\
\text { December } 31 \\
\text { June } 30 \\
\text { June } 30 \\
\text { December } 31\end{array}$ \\
\hline
\end{tabular}

Source: Energy Information Administration, Form EIA-412, "Annual Report of Public Electric Utilities." Individual electric utilities report fiscal year data. Appendix B shows the fiscal year for each electric utility. 
Table C41. Twenty Largest U.S. Publicly Owned Electric Utilitles Ranked by Electric Utility Plant for All Respondents, 1992 (Thousand Dollars)

\begin{tabular}{|c|c|c|c|}
\hline Publlcly Owned Electric Utillties & State & Amount & Reporting Date \\
\hline 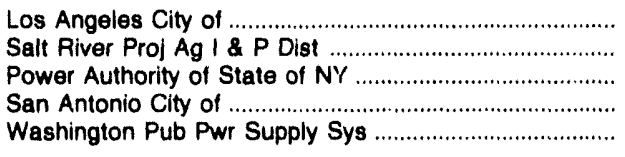 & $\begin{array}{l}\text { CA } \\
\text { AZ } \\
N Y \\
\text { TX } \\
\text { WA }\end{array}$ & $\begin{array}{l}5,716,181 \\
5,355,058 \\
4,845,235 \\
4,323,282 \\
3,320,661\end{array}$ & $\begin{array}{l}\text { June } 30 \\
\text { April } 30 \\
\text { December } 31 \\
\text { January } 31 \\
\text { June } 30\end{array}$ \\
\hline 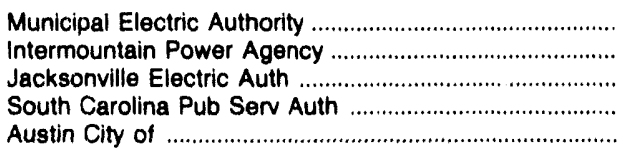 & $\begin{array}{l}\text { GA } \\
\text { UT } \\
\text { FL } \\
\text { TX }\end{array}$ & $\begin{array}{l}3,131,733 \\
2,792,463 \\
2,735,644 \\
2,475,764 \\
2,017,484\end{array}$ & $\begin{array}{l}\text { December } 31 \\
\quad \text { June } 30 \\
\text { September } 30 \\
\text { December } 31 \\
\text { September } 30\end{array}$ \\
\hline 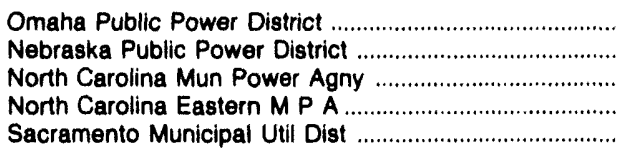 & $\begin{array}{l}\text { NE } \\
\text { NE } \\
\text { NC } \\
\text { NC } \\
\text { CA }\end{array}$ & $\begin{array}{l}1,837,126 \\
1,790,546 \\
1,413,516 \\
1,372,153 \\
1,339,617\end{array}$ & $\begin{array}{l}\text { December } 31 \\
\text { December } 31 \\
\text { December } 31 \\
\text { December } 31 \\
\text { December } 31\end{array}$ \\
\hline 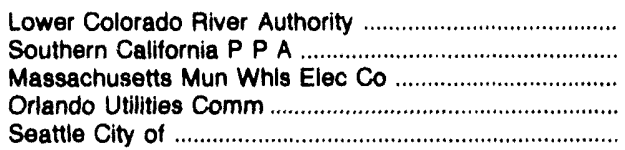 & $\begin{array}{l}\text { TX } \\
\text { CA } \\
\text { MA } \\
\text { FL } \\
\text { WA }\end{array}$ & $\begin{array}{l}1,336,514 \\
1,305,355 \\
1,229,945 \\
1,161,515 \\
1,068,586\end{array}$ & $\begin{array}{l}\text { June } 30 \\
\text { June } 30 \\
\text { December } 31 \\
\text { September } 30 \\
\text { December } 31\end{array}$ \\
\hline
\end{tabular}

Source: Energy Information Administration, Form ElA-412, "Annual Report of Public Electric Utilities." Individual electric utilities report fiscal year data. Appendix B shows the fiscal year for each electric utility.

\section{Table C42. Twenty Largest U.S. Publicly Owned Electric Utilities Ranked by Construction Work in Progress for All Respondents, 1992 (Thousand Dollars)}

\begin{tabular}{|c|c|c|c|}
\hline Publicly Owned Electric Utillites & State & Amount & Reporting Date \\
\hline 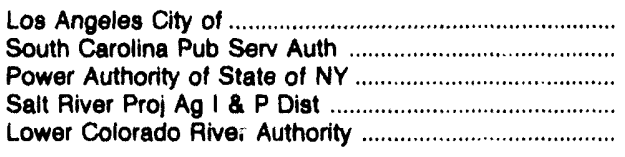 & $\begin{array}{l}\text { CA } \\
\text { SC } \\
\text { NY } \\
\text { AZ } \\
\text { TX }\end{array}$ & $\begin{array}{l}356,913 \\
267,411 \\
215,776 \\
210,090 \\
153,398\end{array}$ & $\begin{array}{c}\text { June } 30 \\
\text { December } 31 \\
\text { December } 31 \\
\text { April } 30 \\
\text { June } 30\end{array}$ \\
\hline $\begin{array}{l}\text { Nebraska Public Power District } \\
\text { Sacramento Municipal Util Dist } \\
\text { Washington Pub Pwr Supply Sys } \\
\text { Texas Municipal Power Agency } \\
\text { Austin City of }\end{array}$ & $\begin{array}{l}\text { NE } \\
\text { CA } \\
\text { WA } \\
\text { TX } \\
\text { TX }\end{array}$ & $\begin{array}{l}150,996 \\
122,893 \\
119,709 \\
113,192 \\
106,502\end{array}$ & $\begin{array}{l}\text { December } 31 \\
\text { December } 31 \\
\text { June } 30 \\
\text { September } 30 \\
\text { September } 30\end{array}$ \\
\hline $\begin{array}{l}\text { San Antonio City of ... District } \\
\text { Omaha Public Power } \\
\text { Orlando Utilities Comm } \\
\text { PUD No } 1 \text { of Lewis County } \\
\text { Tacoma City of }\end{array}$ & $\begin{array}{l}\text { TX } \\
\text { NE } \\
\text { FL } \\
\text { WA } \\
\text { WA }\end{array}$ & $\begin{array}{l}98,333 \\
92,376 \\
76,694 \\
76,219 \\
55,368\end{array}$ & $\begin{array}{l}\text { January } 31 \\
\text { December } 31 \\
\text { September } 30 \\
\text { December } 31 \\
\text { December } 31\end{array}$ \\
\hline $\begin{array}{l}\text { Seattle City of } \\
\text { Kansas City City of } \\
\text { Imperial Irrigation District } \\
\text { Vero Beach City of }\end{array}$ & $\begin{array}{l}\text { WA } \\
\text { KS } \\
\text { CA } \\
\text { FL } \\
\text { FL }\end{array}$ & $\begin{array}{l}54,866 \\
51,582 \\
49,51,7 \\
46,221 \\
44,199\end{array}$ & $\begin{array}{l}\text { December } 31 \\
\text { December } 31 \\
\text { December } 31 \\
\text { September } 30 \\
\text { September } 30\end{array}$ \\
\hline
\end{tabular}

Source: Energy Information Administration, Form EIA-412, "Annual Roport of Public Electric Utilities." Individual electric utilities report fiscal year data. Appendix B shows the fiscal year for each electric utility. 
Table C43. Composite Statement of Income for Major U.S. Publlcly Owned Electric Utilities for All Respondents, 1989-1992 (Thousand Dollars)

\begin{tabular}{|c|c|c|c|c|}
\hline Item & 1992 & 1991 & 1990 & 1989 \\
\hline Electric Utillty Operating Revenues ...................... & $28,933,766$ & $28,202,745$ & $27,449,123$ & $25,814,544$ \\
\hline 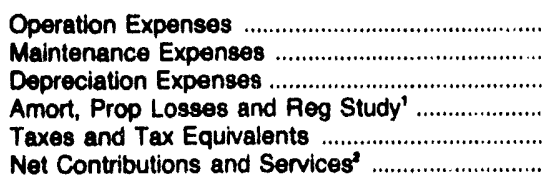 & $\begin{array}{r}18,772,266 \\
1,757,427 \\
2,533,847 \\
134,511 \\
836,134 \\
-\end{array}$ & $\begin{array}{r}18,274,460 \\
1,632,563 \\
2,547,126 \\
- \\
734,209 \\
558,182\end{array}$ & $\begin{array}{r}17,978,112 \\
1,647,407 \\
2,306,792 \\
- \\
683,167 \\
586,148\end{array}$ & $\begin{array}{r}17,003,962 \\
1,668,932 \\
2,251,638 \\
- \\
624,584 \\
526,596\end{array}$ \\
\hline $\begin{array}{l}\text { Total Electric Utility Opserating } \\
\text { Expenses }\end{array}$ & $24,034,185$ & $23,746,541$ & $23,201,626$ & $22,076,712$ \\
\hline $\begin{array}{l}\text { Net Electric Utility Operating Income } \\
\text { Income from Electric Plant Leased } \\
\text { to Others }\end{array}$ & $\begin{array}{r}4,899,571 \\
16,902\end{array}$ & $\begin{array}{r}4,456,204 \\
9,207\end{array}$ & $\begin{array}{r}4,247,497 \\
13,452\end{array}$ & $\begin{array}{r}3,738,832 \\
7,052\end{array}$ \\
\hline Electric Utility Operating Income .................... & $4,916,473$ & $4,465,411$ & $4,260,949$ & $3,745,084$ \\
\hline Other Electric Income & $2,012,422$ & $2,037,255$ & $1,889,347$ & $1,909,736$ \\
\hline 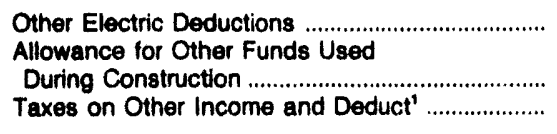 & $\begin{array}{r}324,310 \\
24,222 \\
25,807\end{array}$ & $\begin{array}{r}137,294 \\
72,632 \\
-\end{array}$ & $\begin{array}{r}- \\
123,069 \\
-\end{array}$ & $\begin{array}{r}- \\
231,694 \\
-\end{array}$ \\
\hline Electric Utility Income & $6,603,001$ & $6,438,004$ & $6,273,365$ & $5,887,314$ \\
\hline 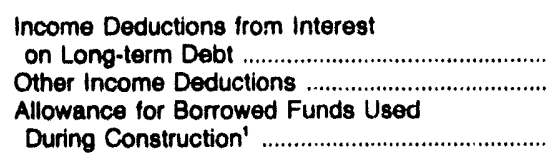 & $\begin{array}{r}4,866,961 \\
345,454 \\
-45,797\end{array}$ & $\begin{array}{r}4,887,034 \\
458,570\end{array}$ & $\begin{array}{r}4,773,086 \\
429,161 \\
-\end{array}$ & $\begin{array}{r}4,439,431 \\
423,163 \\
-\end{array}$ \\
\hline Total Income Deductions & $5,166,618$ & $5,345,605$ & $5,202,247$ & $4,862,594$ \\
\hline 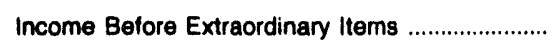 & $1,436,382$ & $1,092,399$ & $1,071,118$ & $1,024,721$ \\
\hline Extraordinary Income & 146,747 & 123,504 & 141,966 & 87,059 \\
\hline 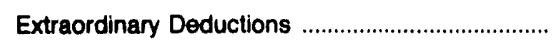 & 264,178 & 198,300 & 262.239 & 725,970 \\
\hline Not Income & $1,318,951$ & $1,017,603$ & 950,845 & 385,800 \\
\hline
\end{tabular}

Data reporting initiated in 1992.

- Data reporting discontinued in 1992.

- Net income reflects $\$ 584$ million of extraordinary deduction associated with the abandonment of the Rancho Seco Nuclear Plant reported by the Sacramento Municipal Utility District.

- Data not available.

Note: Totals may not equal sum of components because of independent rounding. The number of publicly owned electric utilities for end of period is 483 for 1992,470 for 1991,467 for 1990 , and 454 for 1989.

Source: Energy Information Administration, Form EIA-412, "Annual Report of Public Electric Utilities." Individual electric utilities report fiscal year data. Appendix $\mathbf{B}$ shows the fiscal year for each electric utility. 
Table C44. Composite Balance Sheet for Major U.S. Publlcly Owned Electric Utilities for All Respondents at End of Period, 1989-1992 (Thousand Dollars)

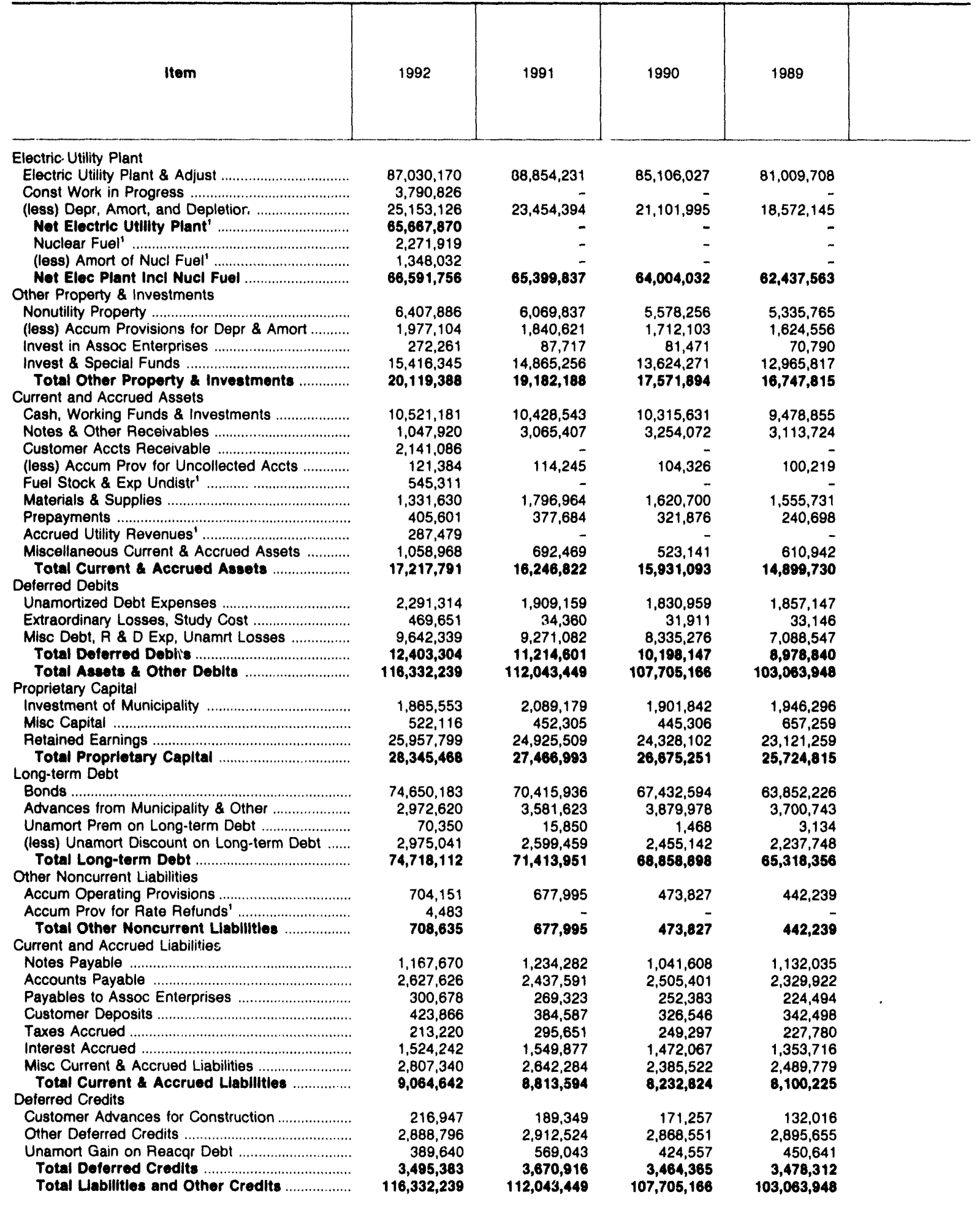

Data reporting initiated in 1992

Note: Totals may not equal sum of components because of independent rounding. The number of publicly owned electric utilities for end of period is 483 for 1992,470 for 1991,467 for 1990 , and 454 for 1989.

Source: Energy Information Administration, Form EIA-412, "Annual Report of Public Electric Utilities." Individual electric utilities report fiscal year data. Appendix $B$ shows the fiscal year for each electric utility. 


\section{Table C45. Composite Financlal Indicators for Major U.S. Publicly Owned Electric Utillties for All Respondents, 1989-1992}

\begin{tabular}{|c|c|c|c|c|}
\hline Item & 1892 & 1891 & 1980 & 1889 \\
\hline Total Electric Utility Plant per Dollar of Revenue & 3.2 & 3.2 & 3.1 & 3.1 \\
\hline Current Assets to Current Liabilities ...................... & 1.9 & 1.8 & 1.8 & 1.8 \\
\hline $\begin{array}{l}\text { Total Electric Utility Plant as a Percent of Total } \\
\text { Assets }\end{array}$ & 80.0 & 79.3 & 79.0 & 78.6 \\
\hline $\begin{array}{l}\text { Net Electric Utility Plant as a Percent of Total } \\
\text { Assets }\end{array}$ & 57.2 & 58.4 & 59.4 & 60.6 \\
\hline Debt as a Percent of Total Liabilities .................... & 72.0 & 71.6 & 71.6 & 71.2 \\
\hline $\begin{array}{l}\text { Depreciation, Amortization and Depletion } \\
\text { as a Percent of Total Electric Utility Plant .......... }\end{array}$ & 28.5 & 26.4 & 24.8 & 22.9 \\
\hline $\begin{array}{l}\text { Electric Operation and Maintenance Expenses } \\
\text { as a Percent of } \\
\text { Electric Utilty Operating Revenues ...................... }\end{array}$ & 71.0 & 70.6 & 71.5 & 72.3 \\
\hline $\begin{array}{l}\text { Electric Depreciation and Amortization } \\
\text { as a Percent of } \\
\text { Electric Utility Operating Revenues ........................ }\end{array}$ & 8.8 & 9.0 & 8.4 & 8.7 \\
\hline 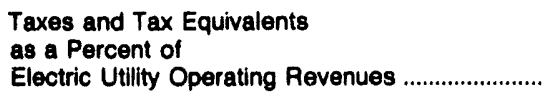 & 2.9 & 2.6 & 2.5 & 2.4 \\
\hline 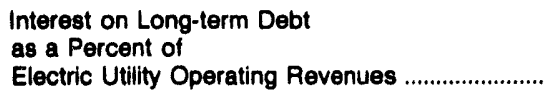 & 16.8 & 17.3 & 17.4 & 17.2 \\
\hline $\begin{array}{l}\text { Net Income as a Percent of Electric } \\
\text { Utility Operating Revenues }\end{array}$ & 4.6 & 3.6 & 3.5 & 1.5 \\
\hline
\end{tabular}

Utility Operating Revenues

Note: Totals may not equal sum of components because of independent rounding. The number of publicly owned electric utilities for end of period is 483 for 1992,470 for 1991,467 for 1990 , and 454 for 1989 .

Source: Energy Information Administration, Form EIA-412, "Annual Report of Public Electric Utilities." Individual electric utilities report fiscal year data. Appendix $B$ shows the fiscal year for each electric utility. 
Table C46. Electric Operation and Maintenance Expenses for Major U.S. Publicly Owned Electric Utilities for All Respondents, 1989-1992 (Thousand Dollars)

\begin{tabular}{|c|c|c|c|c|}
\hline Item & 1992 & 1991 & 1990 & 1989 \\
\hline \multicolumn{5}{|l|}{ Production Expenees } \\
\hline Steam Power Generation & $3,762,389$ & $3,688,872$ & $3,741,569$ & $3,437,966$ \\
\hline 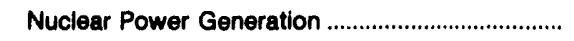 & $1,318,443$ & $1,217,567$ & $1,133,495$ & $1,179,125$ \\
\hline Hydraulic Power Generation ................................... & 244,158 & 225,699 & 204,512 & 187,182 \\
\hline Other Power Generation & 175,873 & 167,230 & 196,419 & 171,971 \\
\hline 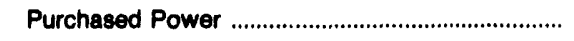 & $10,834,814$ & $10,571,167$ & $10,541,975$ & $10,000,080$ \\
\hline 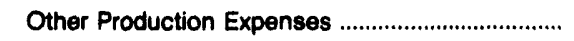 & 80,582 & 102,572 & 154,970 & 99,149 \\
\hline Total Production Expenses .................................. & $16,416,269$ & $15,973,107$ & $15,972,941$ & $15,075,473$ \\
\hline Transmission Expenses & 677,711 & 645,169 & 604,017 & 552,316 \\
\hline Distribution Expenses & $1,125,391$ & $1,027,679$ & 950,271 & 988,374 \\
\hline 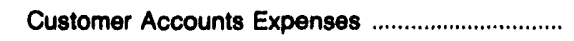 & 408,405 & 393,462 & 374,729 & 344,197 \\
\hline Customer Service and Information Expenses ...... & 98,360 & 89,656 & 74,710 & 77,971 \\
\hline Sales Expenses & 29,191 & 29,665 & 29,350 & 17,615 \\
\hline Administrative and General Expenses ...................... & $1,774,365$ & $1,748,285$ & $1,619,500$ & $1,616,947$ \\
\hline $\begin{array}{l}\text { Total Electric Operation } \\
\text { and Maintenance Expenses ............................. }\end{array}$ & $20,529,693$ & $19,907,023$ & $19,625,519$ & $18,672,894$ \\
\hline \multicolumn{5}{|l|}{ Fuel Exponses in Operation } \\
\hline 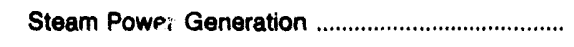 & $2,562,527$ & $2,634,842$ & $2,394,566$ & $2,142,836$ \\
\hline 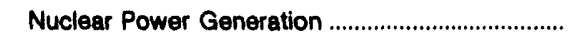 & 290,674 & 345,206 & 242,283 & 351,889 \\
\hline Other Power Generation ............................................. & 82,758 & 92,113 & 113,041 & 92,268 \\
\hline \multicolumn{5}{|l|}{ Number of Elec Dept Employees } \\
\hline 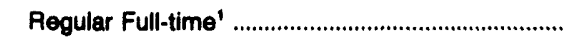 & 74,893 & - & - & - \\
\hline 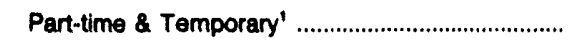 & 3,866 & - & - & - \\
\hline Total Elec Dept Employees' ………………........... & 78,758 & - & - & - \\
\hline
\end{tabular}

Data reporting initiated in 1992.

Note: Totals may not equal sum of components because of independent rounding. The number of publicly owned electric utilities for end of period is 483 for 1992,470 for 1991,467 for 1990 , and 454 for 1989.

Source: Energy Information Administration, Form EIA-412, "Annual Report of Public Electric Utilities." Individual electric utilities report fiscal year data. Appendix B shows the fiscal year for each electric utility. 
Table C47. Electric Utility Plant for Major U.S. Publicly Owned Electric Utilities for All Respondents at End of Period, 1989-1992 (Thousand Dollars)

\begin{tabular}{|c|c|c|c|c|}
\hline Item & 1992 & 1991 & 1990 & 1989 \\
\hline \multicolumn{5}{|l|}{ Electric Plant in Sorvice } \\
\hline Intangible Plant & 294,715 & 373,212 & 325,985 & 390,809 \\
\hline \multicolumn{5}{|l|}{ Production Plant } \\
\hline Steam & $23,415,826$ & $22,556,413$ & $21,246,646$ & $19,191,316$ \\
\hline Nuclear & $18,743,463$ & $19,440,482$ & $18,992,687$ & $18,313,109$ \\
\hline Hydraulic & $7,506,785$ & $6,991,010$ & $6,852,874$ & $6,348,174$ \\
\hline Other & $1,887,069$ & $1,576,299$ & $1,639,697$ & $1,485,027$ \\
\hline 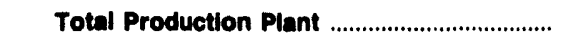 & $51,553,142$ & $50,564,203$ & $48,731,905$ & $45,337,628$ \\
\hline 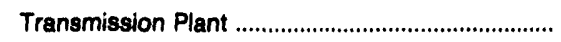 & $9,345,935$ & $9,079,912$ & $8,348,613$ & $7,936,162$ \\
\hline 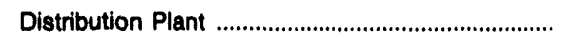 & $18,846,975$ & $17,779,290$ & $16,579,615$ & $15,686,298$ \\
\hline General Plant & $5,455,979$ & $5,221,061$ & $4,867,426$ & $4,227,270$ \\
\hline Total Electric Plant in Service .......................... & $85,496,746$ & $83,017,677$ & $78,853,544$ & $73,578,165$ \\
\hline 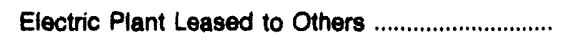 & 68,195 & 566,610 & 483,654 & 478,683 \\
\hline Construction Work in Progress - Electric ............... & $3,790,826$ & $4,119,184$ & $4,151,170$ & $5,559,795$ \\
\hline 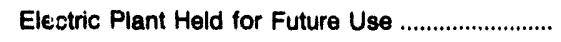 & 321,639 & 640,637 & 830,399 & 754,445 \\
\hline Eloctric Plant Misc & $1,143,590$ & 510,123 & 787,260 & 638,620 \\
\hline 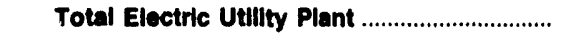 & $90,820,996$ & $88,854,231$ & $85,106,027$ & $81,009,708$ \\
\hline 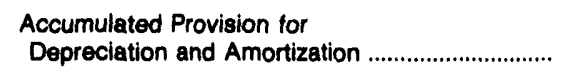 & $25,153,126$ & $23,454,394$ & $21,101,995$ & $18,572,145$ \\
\hline 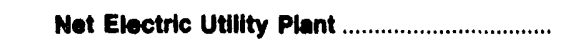 & $65,667,870$ & $65,389,837$ & $64,004,032$ & $62,437,563$ \\
\hline
\end{tabular}

Note: Totals may not equal sum of components because of independent rounding. The number of publicly owned electric utilities for end of period is 483 for 1992,470 for 1991,467 for 1990 , and 454 for 1989 .

Source: Energy Information Administration, Form EIA-412, "Annual Report of Public Electric Utilities." Individual electric utilities report fiscal year data. Appendix B shows the fiscal year for each electric utility. 
Table C48. Number of Consumers, Sales, and Operating Revenue for Major U.S. Publicly Owned Electric Utilities

for All Respondents, 1989-1992

\begin{tabular}{|c|c|c|c|c|}
\hline ltem & 1992 & 1991 & 1990 & 1989 \\
\hline \multicolumn{5}{|l|}{ Number of Consumers } \\
\hline 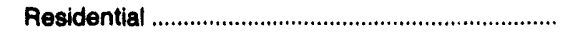 & $11,105,178$ & $10,944,056$ & $10,712,154$ & $10,481,349$ \\
\hline 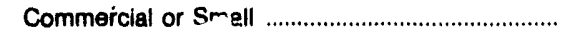 & $1,477,033$ & $1,398,521$ & $1,386,959$ & $1,381,849$ \\
\hline Industrial or Large & 96,002 & 75,831 & 82,683 & 85,548 \\
\hline Other & 245,135 & 266,248 & 264,000 & 232,389 \\
\hline Total Uitimate Co & $12,923,348$ & $12,684,656$ & $12,445,796$ & $12,181,135$ \\
\hline
\end{tabular}

\section{Sales for the Year (megawatthoure)}

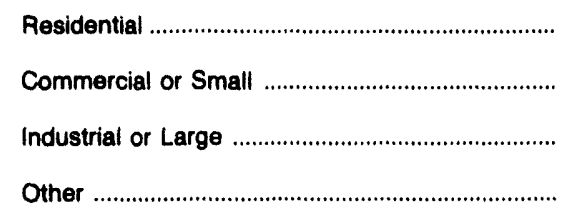

Total Sales to Uitimate Consumers

Sales for Resale

$117,620,115$

$118,476,9,42$

$115,426,617$

$112,306,344$

$88,617,000$

$92,271,342$

$91,071,107$

$86,439,072$

$122,151,852$

$113,244,276$

$111,325,058$

$107,626,843$

$20,914,175$

$20,790,016$

$20,433,764$

$18,405,584$

$349,303,142$

$344,782,576$

$338,256,546$

$324,777,843$

Total Sales

$191,766,731$

$190,797,303$

$195,603,526$

$189,649,740$

$541,069,873$

$535,579,879$

$533,860,072$

$514,427,583$

Operating Revenues for the Year (thousand dollars)

Residential ...

$7,671,053$

$7,512,382$

$7,333,324$

$7,014,301$

Commercial or Small

$5,846,417$

$5,924,545$

$5,893,278$

$5,469,714$

Industrial or Large

$5,797,866$

$5,305,256$

$5,165,253$

$5,044,231$

Other

$1,431,809$

$1,303,801$

$1,333,963$

$1,192,012$

Total Revenues from Sales to

Uitimate Consumers

$20,747,145$

$20,045,984$

$19,725,818$

$18,720,258$

Sales for Resale

$7,479,049$

$7,221,545$

$7,397,548$

$7,075,131$

Total Revenues From Sales of Electricity

$28,226,194$

$27,267,529$

$27,123,366$

$25,795,389$

Note: Totals may not equal sum of components because of independent rounding. The number of publicly owned electric utilities for end of period is 483 for 1992,470 for 1991,467 for 1990 , and 454 for 1989.

Source: Energy Information Administration, Form EIA-861, "Annual Electric Utility Report." Data are based on calender year submissions. 
Table C49. Electric Energy Account for Major U.S. Publicly Owned Electric Utilities for All Respondents, 1989-1992 (Megawatthours)

\begin{tabular}{|c|c|c|c|c|}
\hline Item & 1992 & 1991 & 1990 & 1989 \\
\hline \multicolumn{5}{|l|}{ Sources of Energy } \\
\hline 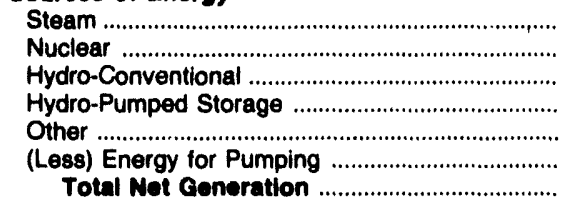 & $\begin{array}{r}169,087,041 \\
52,565,245 \\
65,807,396 \\
4,722,771 \\
2,940,656 \\
4,255,476 \\
290,867,622\end{array}$ & $\begin{array}{r}164,401,739 \\
57,756,871 \\
73,348,633 \\
3,789,638 \\
3,137,344 \\
3,904,547 \\
298,529,666\end{array}$ & $\begin{array}{r}168,806,546 \\
50,740,159 \\
75,007,682 \\
4,741,854 \\
3,990,503 \\
3,551,799 \\
299,734,947\end{array}$ & $\begin{array}{r}177,940,856 \\
53,149,705 \\
68,743,015 \\
4,059,041 \\
2,371,953 \\
3,603,646 \\
302,680,924\end{array}$ \\
\hline 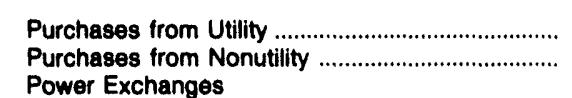 & $\begin{array}{r}276,321,959 \\
1,085,377\end{array}$ & $\begin{array}{r}269,663,812 \\
1,380,739\end{array}$ & $\begin{array}{r}268,249,437 \\
1,006,129\end{array}$ & $\begin{array}{r}244,431,395 \\
1,026,297\end{array}$ \\
\hline 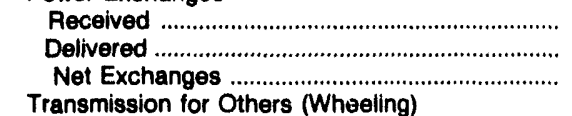 & $\begin{array}{r}18,993,247 \\
18,641,568 \\
351,686\end{array}$ & $\begin{array}{l}19,788,332 \\
22,835,269 \\
-3,046,936\end{array}$ & $\begin{array}{l}35,464,128 \\
37,525,397 \\
-2,061,270\end{array}$ & $\begin{array}{r}21,257,570 \\
21,995,791 \\
-738,223\end{array}$ \\
\hline 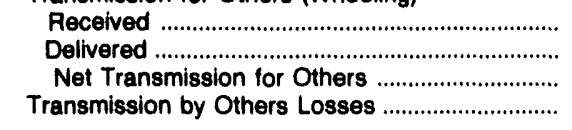 & $\begin{array}{r}22,142,579 \\
21,938,318 \\
204,261 \\
-243,202\end{array}$ & $\begin{array}{r}27,661,154 \\
27,454,743 \\
206,410 \\
-169,733\end{array}$ & $\begin{array}{r}30,857,303 \\
30,584,606 \\
272,696 \\
-81,436\end{array}$ & $\begin{array}{r}30,259,971 \\
29,732,194 \\
527,777 \\
-\end{array}$ \\
\hline 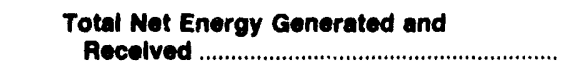 & $568,587,689$ & $566,563,961$ & $567,120,501$ & $547,908,177$ \\
\hline 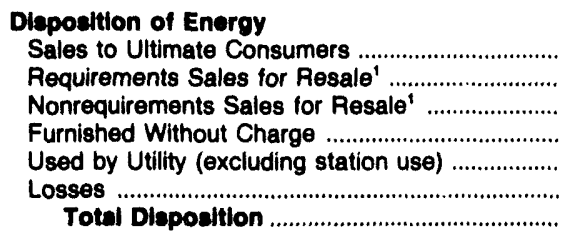 & $\begin{array}{r}347,801,781 \\
152,099,605 \\
37,818,022 \\
1,851,080 \\
6,877,310 \\
22,139,822 \\
568,587,689\end{array}$ & $\begin{array}{r}343,531,980 \\
161,294,421 \\
31,087,612 \\
1,881,389 \\
7,865,267 \\
20,903,280 \\
566,563,961\end{array}$ & $\begin{array}{r}336,588,347 \\
160,452,347 \\
34,819,786 \\
1,957,491 \\
11,843,735 \\
21,458,772 \\
567,120,501\end{array}$ & $\begin{array}{r}324,252,064 \\
188,376,475 \\
- \\
2,006,568 \\
11,633,694 \\
21,639,359 \\
547,808,177\end{array}$ \\
\hline
\end{tabular}

1 The 1989 data were reported as Sales for Resale (one entry) which is shown as Requirements Sales for Resale.

Note: Totals may not equal sum of components because of independent rounding. The number of publicly owned electric utilities for end of period is 483 for 1992,470 for 1991,467 for 1990 , and 454 for 1989 . Double counting occurs in components of both sources and disposition of energy and thus neither provides a true total. Purchases from utilities, net exchanges, and net wheeling (except for imports) are included in net generation. Sales for resale is included in sales to ultimate consumers.

Source: Energy Information Administration, Form EIA-412, "Annual Report of Public Electric Utilities." Individual electric utilities report fiscal year data. Appendix B shows the fiscal year for each electric utility. 


\section{Appendix D}

Regulation of U.S.

Publicly Owned

Electric Utilities 


\section{Regulation of U.S. Publicly Owned Electric Utilities}

Table D1. State Agency Authority to Regulate Rates of Public Owned Electric Utillities, 1992

\begin{tabular}{|c|c|c|c|c|c|c|}
\hline \multirow[b]{2}{*}{ State } & \multirow[b]{2}{*}{ State Agency Authority } & \multirow{2}{*}{$\begin{array}{l}\text { Authority } \\
\text { To Regulate } \\
\text { Rates }\end{array}$} & \multirow[b]{2}{*}{ Boundaries } & \multicolumn{3}{|c|}{ Sales Regulated } \\
\hline & & & & \begin{tabular}{c|} 
Ultimate \\
Consumer
\end{tabular} & $\begin{array}{l}\text { Public } \\
\text { Authority }\end{array}$ & $\begin{array}{c}\text { Sales for } \\
\text { Resale }\end{array}$ \\
\hline AL ... & Alabama Public Service Commission & NO & & & & \\
\hline AK ... & Alaska Public Utilities Cominission & YES & inside \& outside & $x$ & $x$ & $x$ \\
\hline$A Z \ldots$ & Arizona Corporation Commission & NO & & & & \\
\hline AR .. & Arkansas Public Service Commission & No & & & & \\
\hline CA ... & California Public Utilities Commission & NO & & & & \\
\hline $\mathrm{CO} .$. & Colorado Public Utillities Commission & LTD & outside & & & \\
\hline CT ... & Connecticut Department of Public Utility Control & LTD & & & & $x$ \\
\hline DE ... & Delaware Public Service Commission & NO & & & & \\
\hline FL ... & Florida Public Service Commision & LTD & inside \& outside & $x$ & $x$ & \\
\hline GA.. & Georgia Public Service Commission & NO & outside Home Cty & & & \\
\hline $\mathrm{HI} \ldots .$. & Hawail Public Utilities Commission & NO & & & & \\
\hline ID .... & Idaho Public Utilities Commission & NO & & & & \\
\hline $\mathbb{I L} \ldots . .$. & Illinois Commerce Commission & NO & inside \& outside & & & \\
\hline $\mathbb{N} \ldots$ & Indiana Utility Regulatory Commision & LTD & inside \& outside & $x$ & $x$ & $x$ \\
\hline IA .... & lowa Utilities Board & NO & inside \& outside & $x$ & $x$ & \\
\hline KS ... & Kansas State Corporation Commission & YES & outside & $x$ & $x$ & $x$ \\
\hline KY ... & Kentucky Public Service Commission & NO & & & & \\
\hline LA ... & Lousiana Public Service Commission & NO & & & & \\
\hline ME .. & Maine Public Utilities Commission & YES & outside & $x$ & $x$ & \\
\hline MD .. & Maryland Public Service Commission & YES & inside \& outside & $x$ & $x$ & \\
\hline MA.. & Massachusetts Department of Public Utilities & YES & inside \& outside & $x$ & $x$ & $x$ \\
\hline MI .... & Michigan Public Service Commission & NO & & & & \\
\hline MN.. & Minnesota Public Service Commission & NO & & & & \\
\hline MS .. & Mississippi Public Service Commission & LTO & safety inside,full outside & $x$ & $x$ & \\
\hline MO .. & Missouri Public Senvice Commission & NO & & $x$ & $x$ & $x$ \\
\hline MT .. & Montana Public Service Commission & YES & inside \& outside & & & \\
\hline
\end{tabular}

See endnotes at end of this table. 
Table D1. State Agency Authority to Regulate Rates of Public Owned Electric Utillities, 1992 (Continued)

\begin{tabular}{|c|c|c|c|c|c|c|}
\hline \multirow[b]{2}{*}{ State } & \multirow[b]{2}{*}{ State Agency Authority } & \multirow{2}{*}{$\begin{array}{c}\text { Authoritv } \\
\text { To Regulate } \\
\text { Pates }\end{array}$} & \multirow[b]{2}{*}{ Boundaries } & \multicolumn{3}{|c|}{ Sales Regulated } \\
\hline & & & & $\begin{array}{l}\text { Ultimate } \\
\text { Consumer }\end{array}$ & $\begin{array}{l}\text { Public } \\
\text { Authority }\end{array}$ & $\begin{array}{c}\text { Sales for } \\
\text { Resale }\end{array}$ \\
\hline NE .. & Nebraska Public Service Commission & NO & inside \& outside & & & \\
\hline NV .. & Nevada Public Service Commission & NO & & & & \\
\hline NH .. & New Hampshire Public Utilities Commission & YES & outside & $x$ & $x$ & $x$ \\
\hline NJ ... & New Jersey Board of Public Utilities & YES & outside & $x$ & & \\
\hline NM .. & New Mexico Public Service Commission & NO & & & & \\
\hline NY... & New York Public Service Commission & YES & outside & $x$ & $x$ & $x$ \\
\hline NC ... & North Carolina Utilities Commission & NO & & & & \\
\hline ND .. & North Dakota Public Service Commission & NO & & & & \\
\hline $\mathrm{OH} .$. & Ohio Public Utitities Commission & NO & & & & \\
\hline OK... & Oklahoma Corporation Commission & NO & & & & \\
\hline OR... & Oregon Public Utility Commission & LTO & & & & \\
\hline PA ... & Pennsyalvania Public Utility Commission & YES & outsive & $x$ & & \\
\hline AI .... & Rhode Island Public Utlities Commission & NO & inside $\&$ outside & $x$ & $x$ & \\
\hline sc ... & South Carolina Public Service Cornmission & LTD & inside \& outside & & & \\
\hline SD ... & South Dakota Public Utilities Commission & LTD & & & & \\
\hline TN ... & Tennessee Public Service Commission & NO & outside & & & \\
\hline$T X \ldots$ & Texas Publlc Utility Commission & YES & outside & $x$ & $x$ & $x$ \\
\hline UT ... & Utah Public Service Commission & NO & & & & \\
\hline VA ... & Virginia State Corporation Commission & NO & & & & \\
\hline WA.. & Washington Utilties \& Transportation Commission & NO & inside \& outside & & & \\
\hline WV .. & West Virginia Public Service Commission & LTD & & & & \\
\hline WI ... & Wisconsin Public Service Commission & YES & inside \& outside & $x$ & $x$ & $x$ \\
\hline WY .. & Wyoming Public Service Commission & YES & outside & $x$ & & \\
\hline
\end{tabular}

Rate Schedule.

- Rates Oniy.

- Annual revenue increase greater than 12 percent.

Note: There are no publicly owned electric utilities in the District of Columbia. The District of Columbia Public Service Commission does regulate invester-owned electric utilities.

Source: National Association of Regulatory Utility Commissioners, 1990 Annual Report on Utility and Carrier Regulation, publication. 


\section{Appendix E}

\section{Technical Notes}




\section{Appendlx E}

\section{Technical Notes}

\section{Sources of Data}

The Financial Statistics of Major U.S. Publicly Owned Electric Utilities (FSMPO) publication is prepared by the Management Survey Division; Office of Coal, Nuclear, Electric and Alternate Fuels; Energy Information Administration (EIA); U.S. Department of Energy (DOE). Detailed financial data published in this publication are from the Form EIA-412, "Annual Report of Public Electric Utilities." Other summary data are provided from the Form EIA-861, "Annual Electric Utility Report," and the Rural Electrification Administration statistics taken from the Statistical Report, Rural Electric Borrowers publication for the years 1987 through 1992. A brief summary of surveys in this publication is presented below.

\section{Form EIA-412}

The Form EIA-412 is used annually to collect accounting, financial, and operating data from major publicly owned electric utilities in the United States. For the fiscal or calendar year that ended December 31, 1992, the criteria used to select the respondents for this survey resulted in submissions by 483 publicly owned and 8 Federal electric utilities. Those publicly oivned electric utilities engaged in the generation, transmission, or distribution of electricity which had 120,000 megawatthours of sales to ultimate consumers and/or 120,000 megawatthours of sales for resale for the 2 previous years, as reported on the Form EIA-861, "Annual Electric Utility Report," must submit the Form EIA-412. Summary data are also published in the Electric Power Annual.

Federally owned electric utilities are required to file the Form EIA-412. The financial data for the U.S. Army Corps of Engineers (except for Saint Mary's Falls at Sault St. Marie, Michigan), the U.S. International Boundary and Water Commission, and the U.S. Department of Interior Bureau of Reclamation were collected on the Form EIA-412 from the Federal power marketing administrations.

Instrument and Design History. The FPC created the Form $1 \mathrm{M}$ in 1961 as a mandatory survey. It became the responsibility of the EIA in October 1977 when the FPC was merged with DOE. Since 1979, the FPC Form $1 \mathrm{M}$ has been superseded by the Economic Regulatory Administration (ERA) Form ERA-412, and in January 1980 by the Form EIA-412.

Data Processing. The processing of data reported on this survey is the responsibility of the Management Survey Division, Office of Coal, Nuclear, Electric and Alternate Fuels. The completed surveys are due on or before the last day of the third month following the close of the fiscal year. Nonresponse follow-up procedures are used to attain 100 percent response. Automated systems are used to edit data from the surveys using deterministic and statistical checks. When all data have passed the edit process, the data are aggregated into a master file used as input to the publication.

\section{Form EIA-861}

The Form EIA-861 is a mandatory census of electric utilities in the United States, its territories, and Puerto Rico. The survey is used to collect information on power production and sales data from 3,235 electric utilities in the United States. (3,239 electric utilities if U.S. territories are included.) These data collected are used to maintain and update the electric utility frame data base for the EIA. This data base supports queries from the Executive Branch, Congress, other public agencies, and the general public. Summary data from the Form EIA-861 are also contained in the Electric Power Monthly, the Electric Power Annual, the Electric Sales and Revenue, the Annual Outlook for U.S. Electric Power, the Financial Statistics of Major U.S. InvestorOwned Electric Utilities and the Financial Statistics of Major U.S. Publicly Owned Electric Utilities. These reports present aggregate totals for electric utilities on a national level by State and by ownership type.

Instrument and Design History. The Form EIA-861 was implemented in January 1985 to collect data as of year-end 1984. The Federal Administration Act of 1974 (Public Law 93-275) defines the legislative authority to collect these data.

Data Processing. The Form EIA-861 is mailed to the respondents in February to collect data for the preceding calendar year. The completed surveys are returned 
to the EIA by May 1. These data are manually edited before being entered into the interactive on-line system. Internal edit checks are performed to verify that current data total across and between schedules, and are comparable to data reported the previous year. Edit checks are also performed to compare data reported on the Form EIA-861 and similar data reported on the Form EIA-826, "Monthly Electric Utility Sales and Revenue Report with State Distributions," the FERC Form 1, "Annual Report of Major Electric Utilities, Licensees and Others," and the Form EIA-412, "Annual Report of Public Electric Utilities." These are utility-level checks. Respondents are called to clarify reported data and to obtain missing data.

\section{Rural Electrification Administration}

The Rural Electrification Administration (REA) in the U.S. Department of Agriculture is authorized to provide long-term financing and guarantee long-term loans for utilities supplying power to rural America. Borrowing electric utilities file the REA Form 7, "Financial and Statistical Report" and the REA Form 12a through 12i, "Electric Power Supply Borrowers" or the REA Form 12c through $12 \mathrm{~g}$, "Electric Distribution Borrowers with Generating Facilities." Data are provided on a yearly basis. Other revenue and expense statistics show the year's financial operations. For 1992, borrowers' operations data are based on the financial and operating statements of 916 active borrowers, of which 862 were distribution borrowers and 54 were power supply borrowers. Operations of cooperative borrowers systems are based on reports submitted by borrowers. 'The reports are subject to possible revisions from audits and adjustments. No attempt has been made to consolidate (in the technical accounting sense) the borrowers' accounts in the summary statement appearing in this publication. The combined totals represent the sum of all accounts as reported by the individual borrowers.

\section{Quality of Data}

The Office of Coal, Nuclear, Electric, and Alternate Fuels (CNEAF) is responsible for routine data improvement and quality assurance. All operations at CNEAF are done in accordance with formal standards established by EIA. Data improvement efforts include verification of data-keyed input by automatic computerized methods, editing by subject matter specialists, and follow-up on nonrespondents. CNEAF reviews the structure of information requirements and proposed designs for new and revised data collection surveys and systems. Once started, the performance of working data collection systems is also validated. Computerized respondent data files are checked to identify those respondents which fail to respond to the survey. EIA tries to obtain required information by encouraging the cooperation of nonrespondents. By law, nonrespondents may be fined or penalized for not filing a mandatory EIA data survey.

CNEAF screens submitted surveys for completeness, and keys the data onto computer tapes for storage. These data are transferred to random access databases for computer processing. The information coded on the computer tapes is manually spot-checked against the surveys to certify accuracy of the tapes. To ensure EIA quality standards, formulas using the past history of data values in the data base have been designed and implemented to automatically check data input for errors. Data values falling outside the ranges prescribed in the formulas are verified by telephoning respondents to resolve any discrepancies.

Conceptual problems affecting the quality of data are discussed in the report, An Assessment of the Quality of Selected EIA Data Series: Electric Power Data. This report is published by the Office of Statistical Standards in EIA.

\section{Data Entry System}

Manual editing of the reported data is completed prior to data entry. Additional edit checks of the data are performed through computer programs. The program edits include both deterministic checks, in which records are checked for the presence of data in required fields, and statistical checks, in which data are checked against a range of values based on historical data values and for logical or mathematical consistency with data elements reported in the survey. Discrepancies found in the data, as a result of these checks, are resolved either by the processing office or by further information obtained from a telephone call to the respondent.

\section{Confidentiality of the Data}

Data collected on the surveys for this publication are not confidential.

\section{Rounding Rules for Data}

Given a number with $r$ digits to the left of the decimal and $\mathrm{d}+\mathrm{t}$ digits in the fraction part, with $\mathrm{d}$ being the place to which the number is to be rounded and $t$ being the remaining digits which will be truncated. This number is then rounded to $r+d$ digits by adding five to the $(r+d+1)$ th digit when the number is positive or by subtracting five when the number is negative. The $t$ digits are then truncated at the $(r+d+1)$ th digit. The symbol for a rounded number truncated to zero is $\left({ }^{*}\right)$. 


\section{Data Corroction and Revislon Procedures}

The CNEAF has adopted the following policy with respect to the revision and correction of recurrent data in energy publications:

- Annual survey data collected by this office are published either as preliminary or final when first appearing in a data report. Data initially released as preliminary will be so noted in the report. These data will be revised, if necessary, and declared final in the next publication of the data.

- All monthly and quarterly survey data collected by this office are published as preliminary. These data are revised only after the completion of the 12-month cycle of the data. No revisions are made to the published data before this.

- The magnitudes of changes due to revisions experienced in the past will be included in the data reports, so that the reader can assess the accuracy of the data.

- After data are published as final, corrections will be made only in the event of a greater than one percent difference at the national level. Corrections for differences that are less than the beforementioned threshold are left to the discretion of the Office Director.

In accordance with this policy, the CNEAF has not revised any prior year summary data in this publication.

\section{Formulas and Calculations}

\section{Composite Financlal Indicators for Selected Publicly Owned Electric UtIIItles}

Total Electric Utility Plant per Dollar of Revenue =

$$
\frac{\sum_{i}\left(T E U P_{i}\right)}{\sum_{i}\left(E U O R_{i}\right)}
$$

where TEUP is the Total Electric Utility Plant for the $i^{\text {th }}$ public utility; and, EUOR is the Electric Utility Operating Revenue for the $i^{\text {th }}$ public utility.

Current Assets to Current Liabilities =

$$
\frac{\sum_{i}\left(C A_{i}\right)}{\sum_{i}\left(C L_{i}\right)}
$$

where $C \boldsymbol{A}_{i}$ are the Current and Accrued Assets for the $i^{\text {th }}$ public utility; and, $C L_{i}$ are the Current and Accrued Liabilities for the $i^{\text {th }}$ public utility.

Total Electric Utility Plant as a Percent of Total Assets $=$

$$
\frac{\sum_{i}\left(T E U P_{i}\right)}{\sum_{i}\left(T A_{i}\right)} \times 100
$$

where $T E U P_{i}$ is the Total Electric Utility Plant for the $i^{\text {th }}$ public utility; and, $T A_{i}$ are the Total Assets for the $i^{\text {th }}$ public utility.

\section{Net Electric Utility Plant as a Percent of}

Total Assets =

$$
\frac{\sum_{i}\left(N E U P_{i}\right)}{\sum_{i}\left(T A_{i}\right)} \times 100
$$

where NEUP $P_{i}$ is the Net Electric Utility Plant for the $i^{\text {th }}$ public utility; and, $T A_{i}$ is the Total Assets for the $i^{\text {th }}$ public utility.

Debt as a percent of Total Liabilities =

$$
\frac{\sum_{i}\left(D_{i}\right)}{\sum\left(T L_{i}\right)} \times 100
$$

where $D_{i}$ is the Debt for the $i^{\text {th }}$ public utility; and, $T L_{i}$ is the Total Liabilities for the $i^{t h}$ public utility.

Depreciation, Amortization and Depletion as a Percent of Total Electric Utility Plant =

$$
\frac{\sum_{i}\left(D A D_{i}\right)}{\sum_{i}\left(T E U P_{i}\right)} \times 100,
$$

where $D A D_{i}$ is the Depreciation, Amortization and Depletion for the $i^{\text {th }}$ public utility; and, $T E U P_{i}$ is the Total Electric Plant for the $i^{\text {th }}$ public utility.

Electric Operation and Maintenance Expenses as a Percent of Electric Utility Operating Revenues =

$$
\frac{\sum_{i}\left(E O M E_{i}\right)}{\sum_{i}\left(E U O R_{i}\right)} \times 100,
$$

where $E O M E_{i}$ is the Electric Operation and Maintenance Expenses for the $i^{\text {th }}$ public utility; and, $E U O R_{i}$ 
is the Electric Utility Operating Revenues for the $i^{\text {th }}$ public utility.

Electric Depreciation and Amortization as a Percent of Electric Utility Operating Revenues =

$$
\frac{\sum_{i}\left(E D A_{i}\right)}{\sum_{i}\left(E U O R_{i}\right)} \times 100
$$

where $E D A_{i}$ is Electric Depreciation and Amortization for the $i^{\text {th }}$ public utility; and, EUOR $R_{i}$ is the Electric Utility Operating Revenues for the $i^{\text {th }}$ public utility.

Taxes and Tax Equivalents as a Percent of Electric Utility Operating Revenues =

$$
\frac{\sum_{i}\left(T T E_{i}\right)}{\sum_{i}\left(E U O R_{i}\right)} \times 100,
$$

where $T T E_{i}$ are the Taxes and Tax Equivalents for the $i^{\text {th }}$ public utility; and, $E U O R_{i}$ is the Electric Utility Operating Revenues for the $i^{\text {th }}$ public utility.

Interest on Long-term Debt as a Percent of Electric Utility Operating Revenues =

$$
\frac{\sum_{i}\left(I L T D_{i}\right)}{\sum_{i}\left(E U O R_{i}\right)} \times 100
$$

where $I L T D_{i}$ is the Interest on Loulg-term Debt for the $i^{\text {th }}$ public utility; and, $E U O R_{i}$ is the Electric Utility Operating Revenues for the $i^{\text {th }}$ public utility.

Net Income as a Percent of Electric Utility Operating Revenues $=$

$$
\frac{\sum_{i}\left(N I_{i}\right)}{\sum_{i}\left(E U O R_{i}\right)} \times 100
$$

where $N I_{i}$ is the Net Income for the $i^{\text {th }}$ public utility; and, $E U O R_{i}$ is the Electric Utility Operating Revenues for the $i^{\text {th }}$ public utility.

\section{General Information}

\section{Use of the Glossary}

The terms in the glossary have been defined for general use. Restrictions on the definitions, as used in these data collection systerns, are included in each definition when necessary to define the terms as they are used in this report.

\section{Obtaining Copies of Data}

Upon EIA approval of the Financial Statistics of Major U.S. Publicly Owned Electric Utilities, these data are available for public use.

Computer listings are obtained by submitting a written request to:

Energy Information Administration

Survey Management Division, EI-523

U. S. Department of Energy

1000 Independence Avenue, S.W.

Washington, DC 20585

(202) $254-5440$

FAX (202) 254-5765

Magnetic tapes may be purchased by using Visa, Master Card, or American Express cards, as well as money orders or checks payable to the National Technical Information Service (NTIS). Purchasers may also use NTIS and Government Printing Office deposit accounts. To place an order, contact:

National Technical Information Service (NTIS)

Office of Data Base Services

U.S. Department of Commerce

5285 Port Royal Road

Springfield, Virginia 22161

(703) 487-4650

FAX (703) 321-8547

Personal computer diskettes ( $31 / 2$ "or $51 / 4$ ") may be purchased by using Visa or Master Card, as well as money orders or checks payable to the Superintendent of Documents. Purchasers may also use Government Printing Office deposit accounts. To place an order, contact:

Superintendent of Documents U.S. Government Printing Office Attn: Electronic Products Sales Coordinator P.O. Box 37080

Washington, DC 20013-7082

(202) $512-1530$

FAX (202) 512-1262 


\section{Glossary}

Accounting System: A method of recording accounting data for a utility or company or a method of supplying accounting information for controlling, evaluating, planning and decision-making.

Administrative and General Expenses: Expenses of an electric utility relating to the overall directions of its corporate offices and administrative affairs, as contrasted with expenses incurred for specialized functions. Examples include office salaries, office supplies, advertising, and other general expenses.

\begin{abstract}
Allowance for Funds Used During Construction (AFUDC): A noncash item representing the estimated composite interest costs of debt and a return on equity funds used to finance construction. The allowance is capitalized in the property accounts and included in income.
\end{abstract}

Amortization: The gradual write-off of an amount in an account by distributing such amount over a fixed period, over the life of the asset or liability to which it applies, or over the period during which it is anticipated the benefit will be realized.

Asset: An economic resource, tangible or intangible, which is expected to provide benefits to a business.

Average Stream Flow: The rate, usually expressed in cubic feet per second, at which water passes a given point in a stream over a set period of time.

Capacity: The amount of electric power delivered or required for which a generator, turbine, transformer, transmission circuit, station, or system is rated by the manufacturer.

Capacity (Purchased): The amount of energy and capacity available for purchase from outside the system.
Capital: The equity interest of the owners consisting of common stock, preferred stock, and retained earnings in the entity, that is the difference between assets and liabilities.

Capital (Financial): The line items on the right side of a balance sheet, that include debt, preferred stock, and common equity. A net increase in assets must be financed by an increase in one or more forms of capital.

Capital Intensive: A condition in which investment in plant and equipment is relatively large compared to labor and to operation and maintenance expenses.

Capitalization: The long-term sources of funds comprising an entity's total capitalization; that is, the longterm debt, preferred stock, and common equity. The short-term sources of capital are not included.

Capitalization Ratio: The percentage of debt, or preferred stock, or common stock, or other equity to the total capital structure of an entity.

Circuit: A conductor or a system of conductors through which electric current flows.

Circuit-Miles: The total length in miles of separate circuits regardless of the number of conductors used per circuit.

Classes of Service: Consumers grouped by similar characteristics in order to be identified for the purpose of setting a common rate for electric service. Usually classified into groups identified as residential, commercial, industrial and other.

Commercial: The commercial sector is generally defined as nonmanufacturing business establishments, including hotels, motels, restaurants, wholesale businesses, retail stores, and health, social, and educational 
institutions. The utility may classify commercial service as all consumers whose demand or annual use exceeds some specified limit. The limit may be set by the utility based on the rate schedule of the utility.

Commercial and Industrial: Classes of service supplied to a similar grouping of consumers. These customer groupings are usually subdivided into smaller segments by classifying such consumers as commercial or industrial using the Federal Government's Office Of Management and Budget's Standard Industrial Classification Guide and/or a scale of energy usage as yardsticks; other consumers are reclassified as commercial or industrial when their demands or annual use exceeds some specified limit. These limits are generally based on a utility's rate schedules, except for those consumers who are supplied under special contracts or agreements calling for particular services.

Common Equity, Book Value: The retained earnings and common stock earnings plus the balances in common equity reserves and all other common stock accounts. This also includes the capital surplus, the paidin surplus, the premium on common stocks, except those balances specifically related to preferred or preference stocks; less any common stocks held in the treasury.

Common Stock Equity Ratio: The net income after interest taxes and the preferred dividends divided by the average common stock equity.

Condenser Cooling Water: A source of water external to a boiler's feed system is passed through the steam leaving the turbine in order to cool and condense the steam. This reduces the steam's exit pressure and recaptures its heat, which is then used to preheat fluid entering the boiler, thereby increasing the plant's thermodynamic efficiency.

Conditionally Effective Rates: An electric rate schedule that has been put into effect by the FERC subject to refund pending final disposition or refiling.

Construction Costs (of the electric power industry): All direct and indirect costs incurred in acquiring and constructing electric utility plant and equipment and proportionate shares of common utility plant. Included are the cost of land and improvements, nuclear fuel and spare parts, allowance for funds used during construction, general overheads capitalized, less the cost of acquiring plant and equipment previously operated in utility service.

Construction Expenditures (of the electric power industry): The gross expenditures for construction costs, including the cost of replacing worn-out plants, and electric construction costs and land held for future use.

Construction Work In Progress (CWIP): The balance shown on a utility's balance sheet for construction work not yet completed but in process. This balance line item may or may not be included in the rate base.

Conventional Hydroelectric Plant: A plant in which all of the power is produced from natural streamflow as regulated by available storage.

Cooperative Electric Utility: An electric utility legally established to be owned by and operated for the benefit of those using its service. The utility company will generate, transmit, and/or distribute supplies of electric energy to a specified area not being serviced by another utility. Such ventures are generally exempt from Federal income tax laws. Most electric cooperatives have been initially financed by the Rural Electrification Administration, U.S. Department of Agriculture.

Cost: The amount paid to acquire resources, such as plant and equipment, fuel, or labor services.

Cost of Capital: The rate of return an entity must offer to obtain additional funds. The cost of capital varies with the leverage ratio, the effective income tax rate, conditions in the bond and stock markets, growth rate of the firm, its dividend strategy, stability of net income, the amount of new capital required, and other factors dealing with business and financial risks. It is a composite of the cost for debt interest, preferred stock dividends, and common stockholders' earnings that provide the facilities used in supplying utility service.

Cost of Debt: The interest rate paid on new increments of debt capital multiplied by 1 minus the tax rate.

Cost of Preferred Stock: Equals the preferred dividend divided by the net price of preferred stock. 
Cost of Retained Earnings: The residual of an entity's earnings over expenditures, including taxes and dividends, that are reinvested in its business. The cost of these funds is always lower than the cost of new equity capital, due to taxes and transactions costs. Therefore, the cost of retained earnings is the yield that retained earnings accrue upon reinvestment.

Cost of Service: A ratemaking concept used for the design and development of rate schedules to ensure that the filed rate schedules recover only the cost of providing the electric service at issue. These cos: include operating and maintenance expenses, depreciation and amortization expenses, and income and other taxes found just and reasonable by the regulatory agency for ratemaking purposes plus, in the case of privately owned electric utilities, an allowance for a return on capital (usually computed by applying a rate of return to the rate base). This concept attempts to equate the cost incurred by the utility to the revenue received for the service provided to each of the consumer classes.

Curreni: Assets: Cash and other assets that are expected to be turned into cash, sold, or exchanged within the normal operating cycle of the firm, usually one year. Current assets include cash, marketable securities, receivables, inventory and current prepayments.

Current Liabilities: A debt or other obligation that must be discharged within a short time, usually the earnings cycle or one year, normally by expending current assets.

Current Ratio: The ratio (current assets divided by current liabilities) that shows the ability of an entity to pay its current obligations from its current assets.

Debt: Money or services owed through a legal obligation to an outside party. Debt may be classified short-term which is 1 year or less or long-term which is more than 1 year.

Deferred Cost: An expenditure not recognized as a cost of operation of the period in which incurred, but carried forward to be written off in future periods.

Deferred Fuel Costs: An expenditure for fuel that is not recognized for bookkeeping practices as a cost in the operating period incurred, but carried forwar $u$ to be written off in future periods.
Deferred Income Tax: Usually, a liability in the balance sheet representing the additional Federal income taxes that would have been due if a company had not been allowed to compute tax expenses differently for income tax reporting purposes than for ratemaking reporting purposes.

Depreciation: Charges made against income for distributing the cost of a tangible asset, so as to allocate it systematically across the period in which the asset is used.

Design Head: The achieved river, pondage, or reservoir surface height (forebay elevation) that provides the water level to produce the full flow at the gate of the turbine in order to attain the manufacturer's installed nameplate rating for generation capacity.

Diesel-Electric Plant: A generating station that uses diesel engines to drive its electric generators.

Distribution System: The portion of an electric system that is dedicated to delivering electric energy to an end user.

Docket: A formal record of a Federal Energy Regulatory Commission proceeding. These records are available for inspection and copying by the public. Each individual case proceeding is identified by an assigned number.

Economy of Scale: The principle that larger production facilities have lower unit costs than smaller facilities.

Electric Expenses: The cost of labor, material, and expenses incurred in operating a facility's prime movers, generators, auxiliary apparatus, switching gear, and other electric equipment for each of the points where electricity enters the transmission or distribution grid.

Electric Operating Expenses: Summation of electric operation-related expenses, such as operation expenses, maintenance expenses, depreciation expenses, amortization, taxes other than income taxes, Federal income taxes, other income taxes, provision for deferred income taxes, provision for deferred income-credit, and investment tax credit adjustment. 
Electric Plant (Financial): Assets comprising land, building, and equipment permanently employed.

Electric Power Industry: The privately, publicly, federally and cooperatively owned electric utilities of the United States taken as a whole. This includes all electric systems serving the public: regulated investorowned electric utility companies; Federal power projects; State, municipal, and other governmentowned systems, including electric public utility districts; electric cooperatives, including generation and transmission entities. Excluded from this definition are the special purpose electric facilities or systems that do not offer service to the public.

Electric Power System: An individual electric power entity -- a company, an electric cooperative, a public electric supply corporation as the Tennessee Valley Authority, a similar Federal department or agency as the Bonneville Power Administration, the Bureau of Reclamation or the Corps of Engineers, a municipally owned, electric department offering service to the public, or an electric public utility district (a "PUD"); also a jointly owned electric supply project such as the Keystone.

Electric Rate Schedule: A statement of the electric rate and the terms and conditions governing its application, including attendant contract terms and conditions that have been accepted by a regulatory body with appropriate oversite authority.

Electric Utility: A corporation, person, agency, authority, or other legal entity or instrumentality that owns and/or operates facilities within the United States, its territories, or Puerto Rico for the generation, transmission, distribution, or sale of electric energy primarily for use by the public and files forms listed in the Code of Federal Regulations, Title 18, Part 141. Facilities that qualify as cogenerators or small power producers under the Public Utility Regulatory Policies Act (PURPA) are not considered electric utilities.

Electrical System Energy Losses: The amount of energy lost during generation, transmission, and distribution of electricity, including plant and unaccounted for use.

End User: The final consumer of electricity.
Energy: The capacity for doing work as measured by the capability of doing work (potential energy) or the conversion of this capability to motion (kinetic energy). Energy has several forms, some of which are easily convertible and can be changed to another form useful for work. Most of the world's convertible energy comes from fossil fuels that are burned to produce heat that is then used as a transfer medium to mechanical or other means in order to accomplish tasks. Electrical energy is usually measured in kilowatthours, while heat energy is usually measured in British thermal units.

Energy Deliveries: Energy generated by one electric utility system and delivered to another system through one or more transmission lines.

Energy Information Administration (EIA): An independent agency within the U.S. Department of Energy that develops surveys, collects energy data, and does analytical and modeling analyses of energy issues. The Agency must satisfy the requests of Congress, other elements within the Department of Energy, Federal Energy Regulatory Commission, the Executive Branch, its own independent needs, and assist the general public, or other interest groups, without taking a policy position.

Energy Loss: The difference between energy input and output as a result of transfer of energy between two points.

Energy Receipts: Energy generated by one electric utility system and received by another system through one or more tresismission lines.

Equity (Financial): Ownership interest of shareiolders in a corporation represented by stock.

Equity Capital: The sum of capital from retained earnings and the issuance of stocks.

Expenditure: The incurrence of a liability to obtain an asset or service.

Federal Electric Utility: A utility that is either owned or financed by the Federal Government. 
Federal Energy Regulatory Commission (FERC): A quasi-independent regulatory agency within the Department of Energy having jurisdiction over interstate electricity sales, wholesale electric rates, hydroelectric licensing, natural gas pricing, oil pipeline rates, and gas pipeline certification.

Federal Power Act: Enacted in 1920, and amended in 1935, the Act consists of three parts. The first part incorporated the Federal Water Power Act administered by the former Federal Power Commission, whose activities were confined almost entirely to licensing non-Federal hydroelectric projects. Parts II and III were added with the passage of the Public Utility Act. These parts extended the Act's jurisdiction to include regulating the interstate transmission of electrical energy and rates for its sale as wholesale in interstate commerce. The Federal Energy Regulatory Commission is now charged with the administration of this law.

Federal Power Commission: The predecessor agency of the Federal Energy Regulatory Commission. The Federal Power Commission (FPC) was created by an Act of Congress under the Federal Water Power Act on June 10,1920 . It was charged originally with regulating the electric power and natural gas industries. The FPC was abolished on September 20, 1977, when the Department of Energy was created. The functions of the FPC were divided between the Department of Energy and the Federal Energy Regulatory Commission.

FERC: The Federal Energy Regulatory Commission.

FERC Guidelines: A compilation of the Federal Energy Regulatory Commission's enabling statutes, procedural and program regulations, and orders, opinions and decisions.

Financial Accounting Standards Board (FASB): An independent board responsible, since 1973, for establishing generally accepted accounting principles. Its official pronouncement are called "Statements of Financial Accounting Standards" and "Interpretations of Financial Accounting Standards."

Fiscal Year: A financial year based on a predetermined starting date. The Federal Government's financial year runs from October 1 through September 30.
Fixed Asset Turnover: A ratio of revenue to fixed assets which is a measure of the productivity and efficiency of property, plant, and equipment in generating revenue.

Fixed Assets: Tangible property used in the operations of an entity, but not expected to be consumed or converted into cash in the ordinary course of events.

Fixed Charge Coverage: The ratio of earnings available to pay so-called fixed charges to such fixed charges. Fixed charges include interest on funded debt, including leases, plus the related amortization of debt discount, premium and expense. Earnings available for fixed charges may be computed before or after deducting income taxes. Occasionally credits for the "allowance for fund used during construction " are excluded from the earnings figures. The precise procedures followed in calculating fixed charge or interest coverages vary widely.

Fixed Cost (expense): An expenditure or expense that does not vary with volume of activity.

Fixed Operating Costs: Costs other than those associated with capital investment that do not vary with the operation, such as maintenance and payroll.

Fossil Fuel: Any naturally occurring organic fuel, such as petroleum, coal, and natural gas.

Fossil-Fuel Plant: A plant using coal, petroleum, or gas as its source of energy.

Fuel Expenses: These costs include the fuel used in the production of steam or driving another prime mover for the generation of electricity. Other associated expenses include unloading the shipped fuel and all handling of the fuel up to the point where it enters the first bunker, hopper, bucket, tank, or holder in the boiler-house structure.

Gas Turbine Plant: A plant in which the prime mover is a gas turbine. A gas turbine consists typically of an axial-flow air compressor, one or more combustion chambers, where liquid or gaseous fuel is burned and the hot gases are passed to the turbine and where the hot gases expand to drive the generator and are then used to run the compressor. 
Generally Accepted Accounting Principles (GAAP): Defined by the FASB as the conventions, rules, and procedures necessary to define accepted accounting practice at a particular time; includes both broad guidelines and relatively detailed practices and procedures.

Generating Unit: Any combination of physically connected generator(s), reactor(s), boiler(s), combustion turbine(s), or other prime mover(s) operated together to produce electric power.

Generator Nameplate Capacity: The full-load continuous rating of a generator, prime mover, or other electric power production equipment under specific conditions as designated by the manufacturer. Installed generator nameplate rating is usually indicated on a nameplate physically attached to the generator.

Geothermal Plant: A plant in which the prime mover is a steam turbine. The turbine is driven either by steam produced from hot water or by natural steam that derives its energy from heat found in rocks or fluids at various depths beneath the surface of the earth. The energy is extracted by drilling and/or pumping.

Grid: The layout of an electrical distribution system.

Gross Generation: The total amount of electric energy produced by a generating facility, as measured at the generator terminals.

Head: The product of the water's weight and a usable difference in elevation gives a measurement of the potential energy possessed by water.

Historical Plant Cost of Equipment: The charges for equipment assigned to power production include: the net purchased price thereof; sales taxes; investigation and inspection expenses necessary for such purchases, any expenses of transportation when borne by the utility; labor employed charges; materials and supplies consumed; and expenses incurred by the utility in unloading and placing the equipment in readiness to operate.

Historical Plant Cost of Land and Land Rights: The cost of land purchased or the fees paid by the utility for rights, interests, and privileges to be held by the utility in land owned by others. The types of rights acquired include leaseholds, easements, water and water power rights, rights-of-way, and other like interests.

Historical Plant Cost of Structures and Improvements (Expenses): The cost of all buildings and facilities to house, support, or safeguard property or persons, including all fixtures permanently attached to and made a part of building. Also includes the cost incurred in connection with the first clearing and grading of land and rights-of-ways.

Holding Company: A company that confines its activities to owning stock in, and supervising management of, other companies. The Securities and Exchange Commission, as administrator of the Public Utility Holding Company Act of 1935, defines a holding company as "a company which directly or indirectly owns, controls or holds 10 percent or more of the outstanding voting securities of a holding company" (15 USC 79b, par. a (7)).

Hydroelectric Energy: The production of electricity from kinetic energy in flowing water.

Hydroelectric Plant: A plant in which the turbine generators are driven by falling water.

Hydroelectric Plant Capacity: This capacity figure is a function of fluid flow losses, hydraulic turbines, head, and water flow. The minimum net head limits the firm capacity of the plant.

Hydroelectric Power: The harnessing of flowing water to produce mechanical or electrical energy.

Independent Power Producer: A corporation, person, agency, authority, or other legal entity or instrumentality that owns electric generating capacity and is a wholesale electric producer without a designated franchised service area. The entity is not a qualifying facility as defined in the Public Utility Regulatory Policies Act of 1978.

Industrial: The industrial sector is generally defined as manufacturing, construction, mining, agriculture, fishing and forestry establishments Standard Industrial Classification (SIC) codes 01-39. The utility may classify industrial service using the SIC codes, or based on demand or annual usage exceeding some specified 
limit. The limit may be set by the utility based on the rate schedule of the utility.

Instantaneous Peak Demand: The maximum demand at the instant of greatest load.

Interchange Energy: Kilowatthours delivered to or received by one electric utility or pooling system from another. Settlement may be by payment, returned in kind at a later time or accumulated as energy balances until the end of the stated period.

Interconnection: Two or more electric systems having a common transmission line that permits a flow of energy between them. The physical connection of the electric power transmission facilities allows for the sale or exchange of energy.

Interdepartmental Service (Electric): Interdepartmental service includes amounts charged by the electric department at tariff or other specified rates for electricity supplied by it to other utility departments.

Interest Coverage Ratio: The number of times that fixed interest charges were earned indicates the margin of safety of interest on fixed debt. The timesinterest-earned ratio is calculated using net income before and after income taxes; and the credits of interest charged to construction being treated as other incomes. The interest charges include interest on longterm debt, interest on debt of associated companies, and other interest expense.

Interlocking Directorates: The holding of a significant position in management or a position on the corporate board of a utility, while simultaneously holding a comparable position with another utility, or with a firm doing business with the utility.

Internal Cash Flow: Composed of funds available for common stockholders after adjustments for common stock equivalents, depreciation and depletion, amortization, deferred income taxes (net), investment tax credit (net), and other internal sources (net); less common dividends and AFUDC (total).

Internal Combustion Plant: A plant in which the prime mover is an internal combustion engine. An internal combustion engine has one or more cylinders in which the process of combustion takes place, con- verting energy released from the rapid burning of a fuel-air mixture into mechanical energy. Diesel or gasfired engines are the principal types used in electric plants. The plant is usually operated during periods of high demand for electricity.

Investor-Owned Electric Utility: A class of utility that is investor owned and organized as a tax paying business, usually financed by the sales of securities in the capital market.

Kilowatt (kW): One thousand watts.

Kilowatthour (kWh): One thousand watthours.

Leverage Ratio: A measure that indicates the financial ability to meet debt service requirements and increase the value of the investment to the stockholders. (i.e. the ratio of total debt to total assets).

Liability: An amount payable in dollars or by future services to be rendered.

Licensees: Entity that has been granted permission to engage in an activity otherwise unlawful (i.e. hydropower project).

Line Loss: Energy kilowatthours lost in transmission and distribution lines.

Load (Electric): The amount of electric power delivered or required at any specific point or points on a system. The requirement originates at the energyconsuming equipment of the consumers.

Long-term Debt: Debt securities or borrowings having a maturity of more than a year.

Maintenance Expenses: That portion of operating expenses consisting of labor, materials, and other direct and indirect expenses incurred for preserving the operating efficiency and/or physical condition of utility plants used for power production, transmission, and distribution of energy. 
Maximum Demand: The greatest of all demands of the load that has occurred within a specified period of time.

Mcf: One thousand cubic feet.

Megawatt (MW): One million watts.

Megawatthour (MWh): One million watthours.

Mill: A monetary cost and billing unit used by utilities; it is equal to $1 / 1000$ of the U.S. dollar (equivalent to $1 / 10$ of 1 cent).

Multiple Purpose Reservoir: Stored water and its usage governed by advanced water resource conservation practices to achieve more than one water control objective. Some of the objectives include flood control, hydro- electric power development, irrigation, recreation usage, and wilderness protection.

Municipality: (As defined in section 3, paragraph (7) of the Federal Power Act, P.L. 66-280 as amended) A city, county, irrigation district, drainage district, or other political subdivision or agency of a State competent under the laws thereof to carry on the business of developing, transmitting, utilizing, or distributing power (41 Stat. 1064; 49 Stat. 838; 16 U.S.C. $796(7)$ ).

Net Generation: Gross generation minus plant use from all electric utility owned plants. The energy required for pumping at a pumped-storage plant is regarded as plant use and must be deducted from the gross generation.

Net Income: The excess of all revenues and gains for a period over all expenses and losses of the period.

Nonutility Power Producer: A corporation, person, agency, authority, or other legal entity or instrumentality that owns electric generating capacity and is not an electric utility. Nonutility power producers include qualifying cogenerators, qualifying small power producers, and other nonutility generators (including independent power producers) without a designated franchised service area, and which do not file forms listed in the Code of Federal Regulations, Title 18, Part 141.
Nuclear Fuel: Fissionable materials that have been enriched to such a composition that, when placed in a nuclear reactor, will support a self-sustaining fission chain reaction, producing heat in a controlled manner for process use.

Nuclear Power Plant: A facility in which heat produced in a reactor by the fissioning of nuclear fuel is used to drive a steam turbine.

Nuclear Reactor: An apparatus in which the nuclear fission chain can be initiated, maintained, and controlled so that energy is released at a specific rate. The reactor includes fissionable material (fuel), such as uranium or plutonium; fertile material; moderating material (unless it is a fast reactor); a heavy-walled pressure vessel; shielding to protect personnel; provision for heat removal; and control elements and instrumentation.

Ohm: The unit of measurement of electrical resistance. The resistance of a circuit in which a potential difference of 1 volt produces a current of 1 ampere.

Operating Expenses: Expenses related to utility operations, which include operation and maintenance expenses, provisions for depreciation and amortization, taxes other than income taxes, income taxes, provision for deferred income taxes, income taxes deferred in prior years-- credit and investment tax credit adjustments--net.

Operating Income: Operating revenues less operating expenses.

Operation Expenses: The components of power production expenses that incur cost for operations that are directly related to producing electricity. The major item is almost always fuel that has to be burned to generate the electricity.

Operation Supervision and Engineering (Expenses): These expenses include the cost of labor and expenses incurred in the general supervision and direction of the operation of power generation stations. The supervision and engineering costs consist of the pay and expenses of staff and consultants engaged in supervising and directing the operation of each utility function. Direct supervision and engineering of activities, such as fuel handling, boiler room operations, and generator operations, are charged to the appropriate accounts. 
Original Cost: The initial amount of money spent to acquire an asset.

Other Generation: Electricity originating from these sources: biomass, fuel cells, geothermal heat, solar power, waste, wind, and wood.

Owners Equity: Interest of the owners in the assets of the business represented by capital contributions and retained earnings.

Parent Company: Company owning more than 50 percent of the voting shares of another company, called the subsidiary.

Plant: A facility at which are located prime movers, electric generators, and auxiliary equipment for converting mechanical, chemical, and/or nuclear energy into electric energy. A plant may contain more than one type of prime mover. Electric utility plants exclude facilities that satisfy the definition of a qualifying facility under the Public Utility Regulatory Policies Act of 1978.

Plant-Use Electricity: The electric energy used in the operation of a plant. This energy total is subtracted from the gross energy production of the plant; for reporting purposes the plant energy production is then reported as a net figure. The energy required for pumping at pumped-storage plants is, by definition, subtracted, and the energy production for these plants is then reported as a net figure.

Pole-Mile: A unit of measuring the simple length of a transmission line carrying electric conductors, without regard to the number of conductors carried.

Power: The rate at which energy is transferred. Electrical energy is usually measured in watts. Also used for a measurement of capacity.

Power (Electrical): An electric measurement unit of power called a voltampere is equal to the product of 1 volt and 1 ampere. This is equivalent to 1 Watt for a direct current system and a unit of apparent power is separated into real and reactive power. Real power is the work-producing part of apparent power that measures the rate of supply of energy and is denoted as Kilowatts $(\mathrm{KW})$. Reactive power is the portion of apparent power that does no work and is referred to as kilovars; this type of power must be supplied to most types of magnetic equipment, such as motors, and is supplied by generator or by electrostatic equipment. Voltamperes are usually divided by 1,000 and called kilovoltamperes (kVA). Energy is denoted by the product of real power and the length of time utilized; this product is expressed as kilowatthours.

Power Production Plant: All the land and land rights, structures and improvements, boiler or reactor vessel equipment, engines and engine-driven generator, turbogenerator units, accessory electric equipment, and miscellaneous power plant equipment are grouped together for each individual facility.

Preferred Stock: Ownership interests in a corporation which have been granted a preference, usually in the distribution of dividends before payment of dividends to common stockholders and assets in dissolution. It is usually nonvoting.

Price: The amount of money or consideration-in-kind for which a service is bought, sold, or offered for sale.

Prime Mover: The motive force that drives an electric generator (e.g., steam engine, turbine, or water wheel).

Production (Electric): Act or process of producing electric energy from other forms of energy; also, the amount of electric energy expressed in watthours (Wh).

Production Expenses: Costs incurred in the production of electric power that conform to the accounting requirements of the Operation and Maintenance Expense Accounts of the FERC Uniform System of Accounts.

Profit: The income remaining after all business expenses are paid.

Public Authority Service to Public Authorities: Public authority service includes electricity supplied and services rendered to municipalities or divisions or agencies of State or Federal governments, under special contracts or agreements or service classifications applicable only to public authorities.

Public Street and Highway Lighting: Public street and highway lighting includes electricity supplied and ser- 
vices rendered for the purposes of lighting streets, highways, parks, and other public places; or for traffic or other signal system service, for municipalities, or other divisions or agencies of State or Federal governments.

Public Utility District: Municipal corporations organized to provide electric service to both incorporated cities and towns and unincorporated rural areas. Public utility districts, sometimes called "People's Utility Districts" or "Public Power Districts," operate in six States.

Pumped-Storage Hydroelectric Plant: A plant that usually generates electric energy during peak-load periods by using water previously pumped into an elevated storage reservoir during off-peak periods when excess generating capacity is available to do so. When additional generating capacity is needed, the water can be released from the reservoir through a conduit to turbine generators located in a power plant at a lower level.

Purchased Power: Power purchased or available for purchase from a source outside the system.

Railroad and Railway Services: Railroad and railway services include electricity supplied and services rendered to railroads and interurban and street railways, for general railroad use, including the propulsion of cars or locomotives, where such electricity is supplied under separate and distinct rate schedules.

Rate Base: The value of property upon which a utility is permitted to earn a specified rate of return as established by a regulatory authority. The rate base generally represents the value of property used by the utility in providing service and may be calculated by any one or a combination of the following accounting methods: fair value, prudent investment, reproduction cost, or original cost. Depending on which method is used, the rate base includes cash, working capital, materials and supplies, and deductions for accumulated provisions for depreciation, contributions in aid of construction, customer advances for construction, accumulated deferred income taxes, and accumulated deferred investment tax credits.

Ratemaking Authority: A utility commission's legal authority to fix, modify, approve, or disapprove rates, as determined by the powers given the commission by a State or Federal legislature.
Rate of Return: The ratio of net operating income earned by a utility is calculated as a percentage of its rate base.

Rate of Return on Rate Base: The ratio of net operating income to a specified rate base, expressed as a percentage.

Rate of Return on Common Equity: Net income less preferred stock dividends divided by common stock equity.

Refunding: Retirement of one security issue with proceeds received from selling another. Refunding provides for retiring maturing debt by taking advantage of favorable money market conditions.

Regulation: The governmental function of controlling or directing economic entities through the process of rulemaking and adjudication.

Residential: The residential sector is defined as private household establishments which consume energy primarily for space heating, water heating, air conditioning, lighting, refrigeration, cooking and clothes drying. The classification of an individual consumer's account, where the use is both residential and commercial, is based on principal use. For the residential class, do not duplicate consumer accounts due to multiple metering for special services (water, heating, etc.). Apartment houses are also included.

Retail: Sales covering electrical energy supplied for residential, commercial, and industrial end-use purposes. Other small classes, such as agriculture and street lighting, also are included in this category.

Retail Wheeling: An arrangement in which a utility transmits electricity from outside its service territory to a retail customer within its customer service territory.

Retained Earnings: The balance, either debit or credit, of appropriated or unappropriated earnings of an entity that are retained in the business.

Return on Common Equity: An entity's earnings available for common stockholders calculated as a percentage of its common equity capital. 
Revenue: The total amount of money received by a firm from sales of its products and/or services, gains from the sales or exchange of assets, interest and dividends earned on investments, and other increases in the owner's equity except those arising from capital adjustments.

Revenue Requirement: The total revenue that the utility is authorized an opportunity to recover, which includes operating expenses and a reasonable return on rate base.

Rural Electrification Administration (REA): A lending agency of the U.S. Department of Agriculture, the REA makes self-liquidation loans to qualified borrowers to finance electric and telephone service to rural areas. The REA also finances the construction and operation of generating plants, electric transmission and distribution lines, or systems for the furnishing of initial and continued adequate electric services to persons in rural areas not receiving central station service.

Sales: The amount of kilowatthours sold in a given period of time; usually grouped by classes of service, such as residential, commercial, industrial, and other. Other sales include public street and highway lighting, other sales to public authorities and railways, and interdepartmental sales.

Sales for Resale: Energy supplied to other electric utilities, cooperatives, municipalities, and Federal and State electric agencies for resale to ultimate consumers.

Short-term Debt or Borrowings: Debt securities or borrowings having a maturity of less than 1 year.

Solar Energy: Energy produced from the sun's radiation.

Steam-Electric Plant (Conventional): A plant in which the prime mover is a steam turbine. The steam used to drive the turbine is produced in a boiler where fossil fuels are burned.

Steam Expenses: The cost of labor, materials, fuel, and other expenses incurred in production of steam for electric generation.
Steam from other Sources: Steam purchased, transferred from another department of the utility, or acquired from others under a joint-facility operating agreement.

Steam Transferred-Credit: The expenses of producing steam charged to others or to other utility departments under a joint operating arrangement.

Substation: Facility equipment that switches, changes, or regulates electric voltage.

Switching Station: Facility equipment used to tie together two or more electric circuits through switches. The switches are selectively arranged to permit a circuit to be disconnected, or to change the electric connection between the circuits.

System (Electric): Physically connected generation, transmission, and distribution facilities operated as an integrated unit under one central management, or operating supervision.

Transformer: An electrical device for changing the voltage of alternating current.

Transmission: The movement or transfer of electric energy over an interconnected group of lines and associated equipment between points of supply and points at which it is transformed for delivery to consumers, or is delivered to other electric systems. Transmission is considered to end when the energy is transformed for distribution to the consumer.

Transmission System (Electric): An interconnected group of electric transmission lines and associated equipment for moving or transferring electric energy in bulk between points of supply and points at which it is transformed for delivery over the distribution system lines to consumers, or is delivered to other electric systems.

Turbine: A machine for generating rotary mechanical power from the energy of a stream of fluid (such as water, steam, or hot gas). Turbines convert the kinetic energy of fluids to mechanical energy through the principles of impulse and reaction, or a mixture of the two. 
Ultimate Consumer: A consumer that purchases electricity for its own use and not for resale.

Uniform System of Accounts: Prescribed financial rules and regulations established by the Federal Energy Regulatory Commission for utilities subject to its jurisdiction under the authority granted by the Federal Power Act.

Utility Generation: Generation by electric systems engaged in selling electric energy to the public.
Watt: The electrical unit of power. The rate of energy transfer equivalent to 1 ampere flowing under a pressure of 1 volt at unity power factor.

Watthour (Wh): An electrical energy unit of measure equal to 1 watt of power supplied to, or taken from, an electric circuit steadily for 1 hour.

Wheeling Service: The movement of electricity from one system to another over transmission facilities of intervening systems. Wheeling service contracts can be established between two or more systems. 


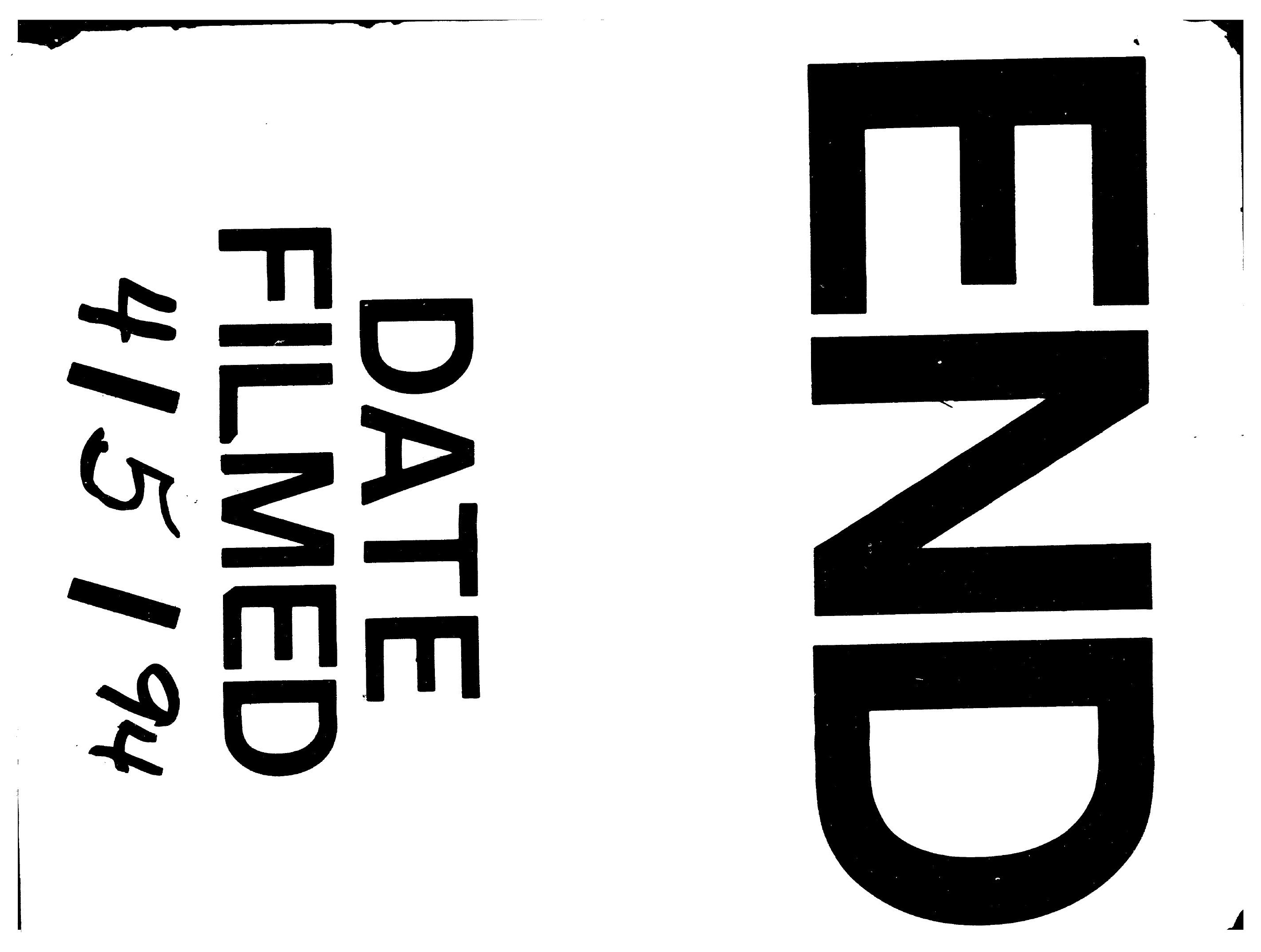


